TRW Emirormental Safoty Systems inc.

\author{
DOE/RW/00134-. T27 \\ Total System Performance Assessment - 1995:
}

\author{
An Evaluation of the Potential \\ Yucca Mountain Repository
}

B00000000-01717-2200-00136, Rev. 01 November 1995

\title{
Civilian Radioactive Waste Management System
}

\section{Management \& Operating . Contractor}

B\&W Federal Services

Duke Enginering \& Services, Inc.

E.R. Johnson Associates, inc.

Fluor Daniel, Inc.

Framatome Cogema Fuels

Integrated Resources Group

INTERA, InC.
JK Research Associates, Inc.

Kiewit/Parsons Brinkertoff

Lawrence Berkeley Laboratory

Lawrence Livermore National Laboratory

Logicon RDA

Los Alamos National Laboratory

Morrison-Knudsen Corporation
SAC

Sandia National Laboratories

TRW Environmental Safety Systems Inc.

Woodward-Clyde Federal Services

Winston \& Strawn

Cooperating Federal Agency:

U.S. Geological Survey
Prepared by:

TRW Environmental Safety

Systems inc.
Prepared for:

U.S. Department of Energy

Office of Civilian Radioactive Waste

Management

1000 hindependence Avenue, S.W.

Washington, D.C. 20565 


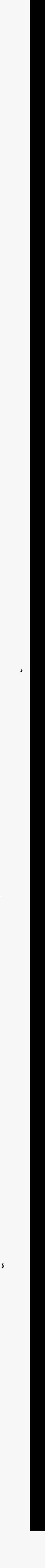




\section{DISCLAIMER}

Portions of this document may be illegible in electronic image products. Images are produced from the best available original document. 


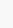


Civilian Radioactive Waste Management System Management and Operating Contractor

TOTAL SYSTEM PERFORMANCE ASSESSMENT - 1995:

AN EVALUATION OF THE POTENTIAL

YUCCA MOUNTAIN REPOSITORY

B00000000-01717-2200-00136, Rev. 01

November 1995

Prepared for:

U.S. Department of Energy

Yucca Mountain Site Characterization Project

P.O. Box 98608

Las Vegas, Nevada 89193-8608

Prepared by:

TRW

101 Convention Center Drive

Suite P-110

Las Vegas, Nevada 89109-2006

Under Contract Number DE-AC01-91RW00134 



\section{DISCLAIMER}

"This report was prepared as an account of work sponsored by an agency of the United States Government. Neither the United States Government nor any agency thereof, nor any of their employees, makes any warranty, express or implied, or assumes any legal liability or responsibility for the accuracy, completeness, or usefulness of any information, apparatus, product, or process disclosed, or represents that its use would not infringe privately owned rights. Reference herein to any specific commercial product, process, or service by trade name, trademark, manufacturer, or otherwise, does not necessarily constitute or imply its endorsement, recommendation, or favoring by the United States Government or any agency thereof. The views and opinions of authors expressed herein do not necessarily state or reflect those of the United States Government or any agency thereof." 


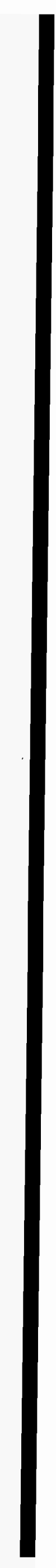




\section{ACKNOWLEDGEMENTS}

By its very nature, evaluation of the performance of the overall potential Yucca Mountain repository system requires inputs from across the gamut of the Yucca Mountain Site Characterization Project. Acknowledging all the individuals that have provided useful insights into the potential behavior of the wide range of processes and conceptual models that may potentially affect the predicted performance of the engineered and natural components of the system is not possible because we would invariably overlook someone. However, there are some individuals that warrant particular mention because they provided explicit input to the development of the parameters used in the analyses. These individuals include: Arend Meijer, Clarence Duffy and Inez Triay (M\&O/LANL); Jack Gauthier (M\&O/SNL); Bill Halsey, Alan Lamont, Dan McCright and Tom Buscheck (M\&O/LLNL); Bo Boddvarsson (M\&O/LBNL); Hugh Benton, Dave Stahl and Kevin McCoy (M\&O/BWFC); Rick Kossik, Ian Miller and Wei Li (Golder Federal Services); Kal Battacharyya (M\&O/MK; and Paul Chambre (M\&O/UCB).

The principal authors and major contributors to this document are acknowledged at the beginning of each chapter. In addition to these individuals, additional computational support was provided by Xin Yang (M\&O/INTERA). The preparation of the manuscript has been ably managed and coordinated by Lin Henderson (M\&O/TRW), with assistance from Lydia Jones, (M\&O/TRW), Jacqueline North, Racquel Grant, and Doria Volk (Manpower).

We have benefitted from reviews and suggested modifications of the draft version of the document that we received from Peter Gottlieb and Kevin McCoy (M\&O/BWFC), Albin Brandstetter (M\&O/INTERA) and Sandra Trillo (M\&O/TRW). In addition, a detailed technical review was provided by Mike Wilson (M\&O/SNL) and a programmatic review was conducted by Eric Smistad (YMSCO). These reviews greatly improved the completeness of the final document.

The work reported in this document was funded under Work Breakdown Structure 1.2.5.4.1 -Total System Performance Assessment by the U.S. Department of Energy Office of Civilian Radioactive Waste Management --Yucca Mountain Site Characterization Project Office under Contract \#DE-AC01-91RW00134 to TRW Environmental Safety Systems, Inc. The Civilian Radioactive Waste Management System Management and Operating Contractor responsible manager for this activity is Jean Younker (M\&O/TRW). The responsible manager of this WBS element is Eric Smistad (DOE/YMSCO). The responsible Technical Area Lead for this activity is Abe VanLuik (DOE/YMSCO).

The support of all of these individuals and organizations is gratefully acknowledged. 
$-$ 
EXECUTIVE SUMMARY $\ldots \ldots \ldots \ldots \ldots \ldots \ldots \ldots \ldots \ldots \ldots \ldots \ldots \ldots \ldots \ldots$

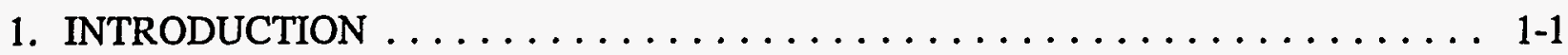

$1.1 \quad$ BACKGROUND $\ldots \ldots \ldots \ldots \ldots \ldots \ldots \ldots \ldots \ldots \ldots \ldots \ldots$ 1-1

1.2 SCOPE OF THE CURRENT TOTAL SYSTEM PERFORMANCE

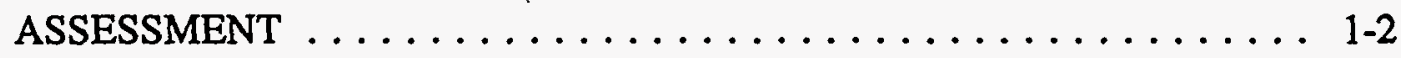

1.3 OBJECTIVES OF THE CURRENT TOTAL SYSTEM PERFORMANCE ASSESSMENT $\ldots \ldots \ldots \ldots \ldots \ldots \ldots \ldots \ldots .1-5$

1.4 ANALYSIS COMPONENTS AND INFORMATION FLOW IN THE CURRENT TOTAL SYSTEM PERFORMANCE ASSESSMENT $\ldots \ldots$ 1-8

1.4.1 System and Analysis Components $\ldots \ldots \ldots \ldots \ldots \ldots \ldots$ 1-8

1.4 .2 Analysis Hierarchy $\ldots \ldots \ldots \ldots \ldots \ldots \ldots \ldots \ldots \ldots \ldots \ldots \ldots . \ldots \ldots$

1.4.3 Information Flow $\ldots \ldots \ldots \ldots \ldots \ldots \ldots \ldots \ldots \ldots . \ldots \ldots$

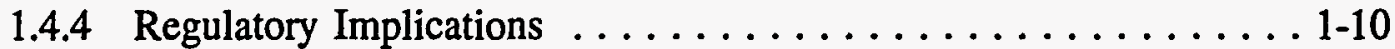

1.4.5 Waste Package Processes . . . . . . . . . . . . . . . 1-11

1.4.6 Near-Field Environment $\ldots \ldots \ldots \ldots \ldots \ldots \ldots \ldots \ldots \ldots \ldots \ldots \ldots$

1.4.7 Waste Form Processes ................... 1-14

1.4.8 Radionuclide Transport Processes $\ldots \ldots \ldots \ldots \ldots \ldots \ldots \ldots 1-15$

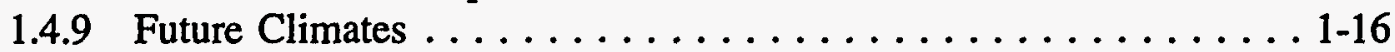

1.4.10 Radiation Dose Calculation .................. 1-16

1.5 REPOSITORY INTEGRATION PROGRAM (RIP) $\ldots \ldots \ldots \ldots \ldots \ldots 1-17$

1.6 ORGANIZATION OF THE CURRENT TOTAL SYSTEM PERFORMANCE ASSESSMENT DOCUMENT $\ldots \ldots \ldots \ldots \ldots \ldots 1-19$

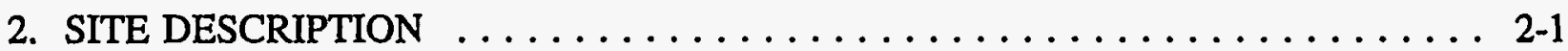

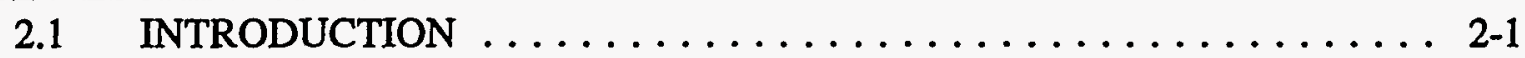

2.2 GEO-ENVIRONMENTAL FRAMEWORK $\ldots \ldots \ldots \ldots \ldots \ldots \ldots 2-1$

2.3 HYDROSTRATIGRAPHY $\ldots \ldots \ldots \ldots \ldots \ldots \ldots \ldots \ldots \ldots .2-3$

2.4 MATRIX/FRACTURE HYDROLOGIC PROPERTIES $\ldots \ldots \ldots \ldots .2-4$

2.5 REGIONAL HYDROGEOLOGY AND GROUND-WATER USE $\ldots \ldots .2-6$

2.5.1 Regional Hydrogeology $\ldots \ldots \ldots \ldots \ldots \ldots \ldots \ldots \ldots .2-6$

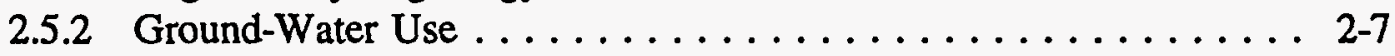

2.6 UNSATURATED ZONE HYDROLOGY $\ldots \ldots \ldots \ldots \ldots \ldots \ldots \ldots 2-8$

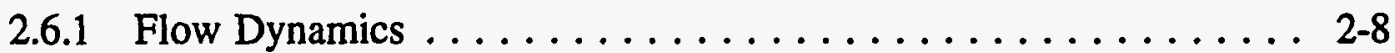

2.6.2 Infiltration Pattern and Rate $\ldots \ldots \ldots \ldots \ldots \ldots \ldots \ldots .2-8$

2.7 POTENTIAL NATURAL CHANGES TO THE AMBIENT GEO-

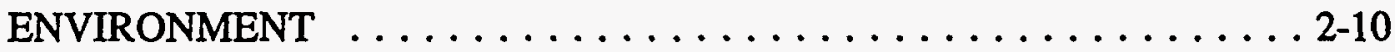

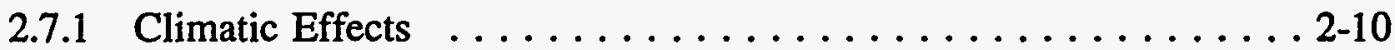

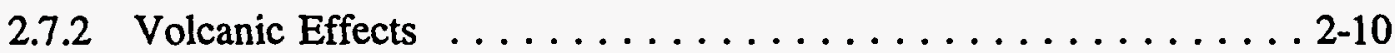

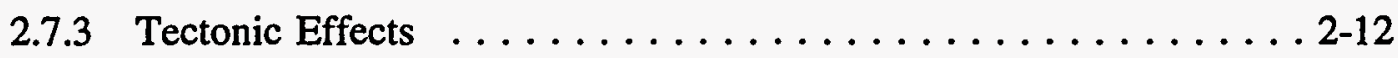


Table of Contents (Continued)

3. REPOSITORY AND WASTE PACKAGE DESCRIPTION $\ldots \ldots \ldots \ldots \ldots$ 3-1

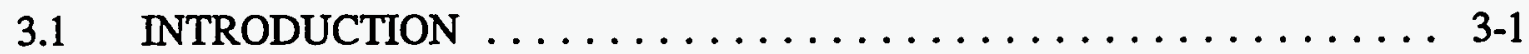

3.2 GENERAL LAYOUT CONSIDERATIONS $\ldots \ldots \ldots \ldots \ldots \ldots \ldots$ 3-1

3.3 THERMAL LOADING ISSUES $\ldots \ldots \ldots \ldots \ldots \ldots \ldots \ldots \ldots \ldots . \ldots \ldots \ldots$

3.4 LAYOUTS FOR 25 AND 83 MTU/ACRE $\ldots \ldots \ldots \ldots \ldots \ldots \ldots . \ldots \ldots$

3.5 WASTE PACKAGE DESIGN $\ldots \ldots \ldots \ldots \ldots \ldots \ldots \ldots \ldots \ldots . .4$

3.6 WASTE PACKAGE EMPLACEMENT $\ldots \ldots \ldots \ldots \ldots \ldots \ldots .3-5$

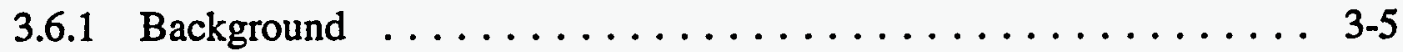

3.6.2 Emplacement Mode Selection ................ 3-6

3.6.3 Drift Design for TSPA-1995 Analyses . . . . . . . . . 3-6

3.7 RADIONUCLIDE INVENTORY $\ldots \ldots \ldots \ldots \ldots \ldots \ldots \ldots \ldots \ldots$ 3-7

3.8 UZ PATHWAY STRATIGRAPHY $\ldots \ldots \ldots \ldots \ldots \ldots \ldots \ldots \ldots . . \ldots \ldots$

3.8.1 Pathways in Primary and Optional Areas . . . . . . . . . 3-9

3.8.2 Comparative Statistics ................... 3-10

4. NEAR-FIELD ENVIRONMENT $\ldots \ldots \ldots \ldots \ldots \ldots \ldots \ldots \ldots \ldots \ldots$ 4-1

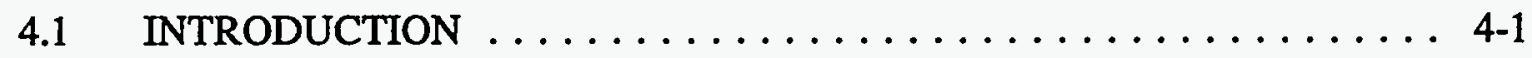

4.2 DRIFT-SCALE THERMAL-HYDROLOGY $\ldots \ldots \ldots \ldots \ldots \ldots$ 4-1

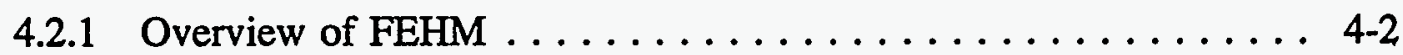

4.2.2 Model Geometry .................... 4-2

4.2 .3 Model Assumptions ................... 4-3

4.2.4 Stratigraphy and Hydrogeologic Properties . . . . . . . . 4-4

4.2.5 Thermal Properties . . . . . . . . . . . . . . . . . 4-4

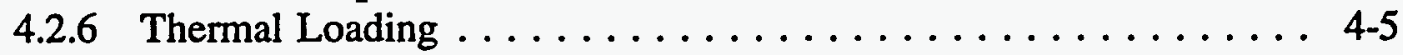

4.2.7 Initial and Boundary Conditions $\ldots \ldots \ldots \ldots \ldots \ldots \ldots .4-5$

4.2.8 Determination of Relative Humidity ............. 4-6

4.2.9 Drift-Scale Thermohydrologic Results . . . . . . . . . . 4-7

4.2.10 An Alternate Drift-Scale Thermal-hydrology Model . . . . . . . . 4 4-10

4.3 REPOSITORY-EDGE THERMOHYDROLOGIC CALCULATIONS . . 4-12

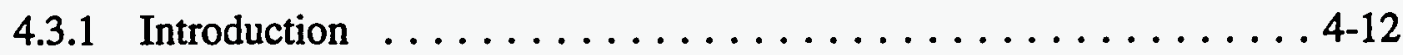

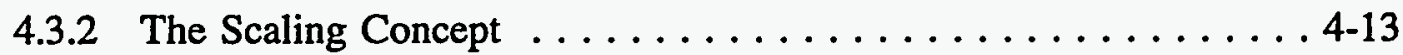

4.3.3 Model Description ..................... 4-13

4.3 .4 Results ....................... 4-14

4.3.5 Implications $\ldots \ldots \ldots \ldots \ldots \ldots \ldots \ldots \ldots \ldots .4 .15$

4.4 NEAR-FIELD THERMAL-MECHANICAL CONSIDERATIONS $\ldots \ldots$ 4-15

4.5 THERMAL-CHEMICAL EFFECTS IN THE NEAR-FIELD

ENVIRONMENT $\ldots \ldots \ldots \ldots \ldots \ldots \ldots \ldots \ldots \ldots \ldots \ldots$. 4 .15

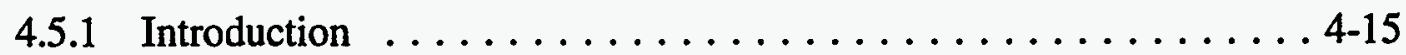

4.5.2 Perturbations from Introduced Materials $\ldots \ldots \ldots \ldots \ldots \ldots$ 4-16

4.5.3 Perturbations from Thermal Effects $\ldots \ldots \ldots \ldots \ldots \ldots \ldots$ 4-17 
Table of Contents (Continued)

5. WASTE PACKAGE DEGRADATION ABSTRACTION $\ldots \ldots \ldots \ldots \ldots \ldots \ldots$. . $\ldots$.

5.1 INTRODUCTION ...................... $5-1$

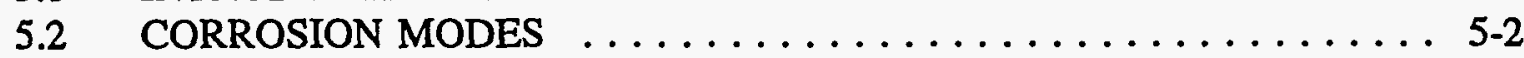

5.3 HUMID-AIR CORROSION MODELS FOR CORROSION-

ALLOWANCE MATERIALS . . . . . . . . . . . . . . 5-3

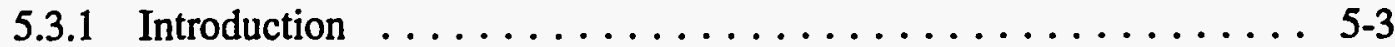

5.3 .2 Corrosion Data Compilation $\ldots \ldots \ldots \ldots \ldots \ldots \ldots \ldots$. . . . . .

5.3.3 Exposure Parameter Transformation ............... 5-5

5.3.4 Development of General Corrosion Model ............ 5-6

5.3.5 Results of the General Corrosion Model . . . . . . . . . . . . 5-8

5.3.6 Development of Pitting Corrosion Model ............ 5-9

5.3.7 Results of the Pitting Corrosion Model . . . . . . . . . . . . . . . 5-10

5.3.8 Comparison with the McCoy Model . . . . . . . . . . . 5-10

5.4 AQUEOUS CORROSION MODELS FOR CORROSION-

ALLOWANCE MATERIALS . . . . . . . . . . . . . . . . 5-13

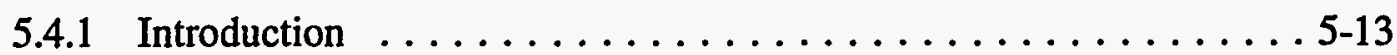

5.4 .2 Development of General Corrosion Model . . . . . . . . . . . . 5-14

5.4.3 Results of the General Corrosion Modeling . . . . . . . . . . . . 5-15

5.4.4 Development of Pitting Corrosion Model . . . . . . . . . . . 5-16

5.4.5 Results of Pitting Corrosion Modeling . . . . . . . . . . . . . 5-16

5.5 CORROSION MODELING OF CORROSION RESISTANT

MATERIALS ........................ 5-16

5.6 CLADDING DEGRADATION $\ldots \ldots \ldots \ldots \ldots \ldots \ldots \ldots \ldots \ldots \ldots \ldots$

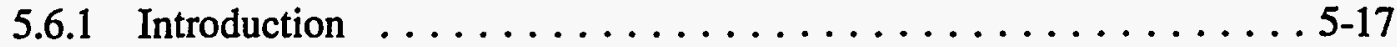

5.6.2 Cladding Degradation Associated with Defective or Intact Fuel

Rods ............................ . . . . . . . .

5.6.3 Conceptual Model and Approach for Cladding Degradation

Modeling ......................... 5-19

5.6.4 Cladding Degradation Models . . . . . . . . . . . . . . . 5-20

5.7 WASTE PACKAGE DEGRADATION HISTORY . . . . . . . . . . . 5-22

5.7 .1 Introduction ....................... 5-22

5.7.2 Major Assumptions in Waste Package Degradation Simulation . . 5-23

5.7.3 Stochastic Simulation of Waste Package Degradation . . . . . . . 5 5-25

5.7.4 General Descriptions for Waste Package Degradation Simulation . . 5-28

5.7.5 Corrosion Initiation with Humidity and Temperature . . . . . 5-28

5.7 .6 Corrosion Initiation with Humidity $\ldots \ldots \ldots \ldots \ldots \ldots$. . . . . . . . . . . . .

5.7 .7 Alternative Thermal Load . . . . . . . . . . . . . 5 5-31

5.7 .8 Cathodic Protection ... . . . . . . . . . . . . . . . . 5-33

5.7.9 Time-Dependent Pit Growth Rate in Alloy 825 Inner Barrier . . . 5-34

5.7.10 Alternative Thermal-Hydrologic Model . . . . . . . . . . . . 5-35

5.7.11 Alternative Interpretation of the Elicitation for the Inner Barrier

Pit Growth Rate ................... . . 5-37

vii 
Table of Contents (Continued)

5.8 SUMMARY AND RECOMMENDATION

6. ENGINEERED BARRIER SYSTEM ABSTRACTTON $\ldots \ldots \ldots \ldots \ldots \ldots$ 6-1

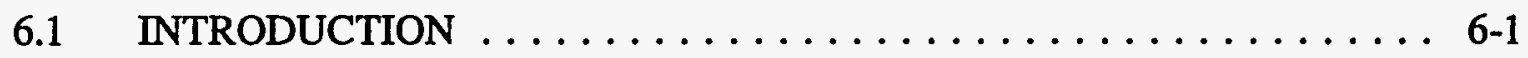

6.2 WASTE FORM ALTERATION MODELING ............. 6-1

6.2.1 Alteration/Dissolution of Spent Fuel Waste Form ......... 6-1

6.2.2 Alteration/Dissolution of DHLW Glass Waste Form ....... . 6-4

6.3 SOLUBILITY-LIMITED AQUEOUS RADIONUCLIDE

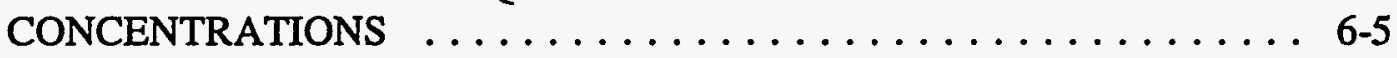

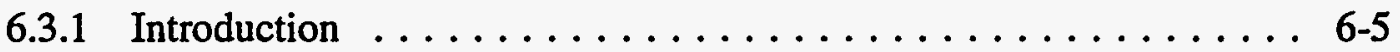

6.3.2 Nominal-Case Distributions . . . . . . . . . . . . 6-6

6.3.3 Sensitivity Cases for Solubility-Limited Aqueous Radionuclide

Concentrations . ................... 6-11

6.4 COLLOID CONTRIBUTIONS TO MOBILE MASS OF

RADIONUCLIDES $\ldots \ldots \ldots \ldots \ldots \ldots \ldots \ldots \ldots \ldots \ldots \ldots \ldots \ldots$

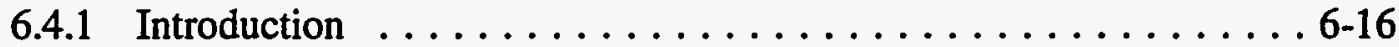

6.4.2 Assessment of Colloid Constraints . . . . . . . . . . 6-16

6.4.3 Incorporation of Colloids into Total System Performance

Assessments . . . . . . . . . . . . . . . . . 6-18

6.5 RADIONUCLIDE RELEASE MODELING $\ldots \ldots \ldots \ldots \ldots \ldots \ldots 6-19$

6.5.1 Approaches for Radionuclide Release Modeling . . . . . . . 6-19

6.5.2 Conceptual Models for Radionuclide Release . . . . . . . . . 6 6-19

6.5.3 Diffusive Release from Waste Package and EBS . . . . . . 6-20

6.5.4 Diffusion Coefficient in Unsaturated Porous Media . . . . . . . 6-24

6.5.5 Advective Release from Waste Package and EBS ... . . . . 6-25

7. UNSATURATED- AND SATURATED-ZONE FLOW AND TRANSPORT $\ldots \ldots$ 7-1

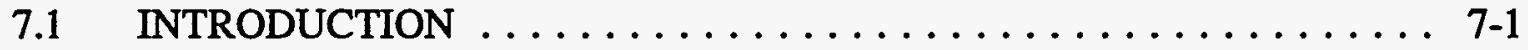

7.2 UNSATURATED-ZONE AMBIENT HYDROLOGY $\ldots \ldots \ldots \ldots \ldots 7-1$

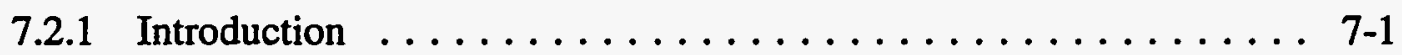

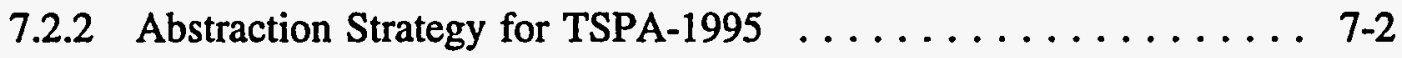

7.2.3 Testing of the Proposed Abstraction Methodology ........ 7-3

7.2.4 Process-level Model Description ................ 7-4

7.2.5 Abstraction Results and Sensitivity Analyses ........... 7-8

7.2.6 Abstraction Caveats . . . . . . . . . . . . . . . . .

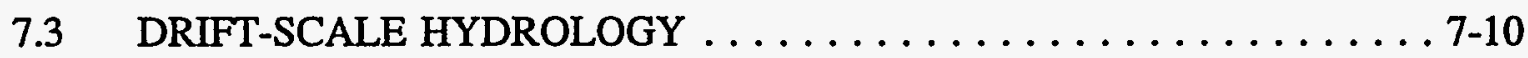

7.4 UNSATURATED-ZONE TRANSPORT $\ldots \ldots \ldots \ldots \ldots \ldots \ldots \ldots 7-12$

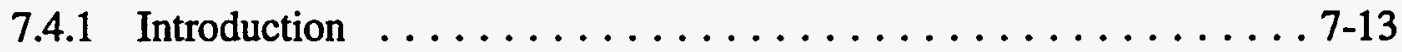

7.4.2 Unsaturated-Zone Transport Stratigraphy and Model Dimensionality 7-13

7.4.3 RIP Geosphere Pathways . . . . . . . . . . . . .

7.4.4 Fracture/Matrix Interaction in the Geosphere ......... 7-14 
Table of Contents (Continued)

7.4.5 Comparison of UZ Transport Models in RIP and FEHM ..... 7-17

7.4.6 Radionuclide Retardation .................. 7-18

7.5 TRANSPORT OF GASEOUS-PHASE RADIONUCLIDES $\ldots \ldots \ldots .7-20$

7.6 SATURATED-ZONE TRANSPORT $\ldots \ldots \ldots \ldots \ldots \ldots \ldots \ldots \ldots 7-21$

7.6.1 Saturated-Zone Flux Distribution ............... 7-21

7.6.2 Dilution and Dose at the Accessible Environment ........ 7-22

7.6.3 Dilution in the Regional Aquifer ............... $7-23$

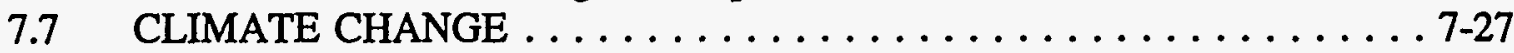

8. WASTE PACKAGE/ENGINEERED BARRIER SYSTEM RESULTS $\ldots \ldots \ldots$ 8-1

$8.1 \quad$ INTRODUCTION $\ldots \ldots \ldots \ldots \ldots \ldots \ldots \ldots \ldots \ldots \ldots . \ldots \ldots$. 1

8.2 MAJOR ASSUMPTIONS AND KEY PARAMETER VALUES . . . . 8 8-1

8.2.1 Major Assumptions in Waste Package/Engineered Barrier System

Performance Analyses . . . . . . . . . . . . . . 8-1

8.2.2 Key Parameter Values $\ldots \ldots \ldots \ldots \ldots \ldots \ldots \ldots \ldots$ 8-2

8.3 EBS PEAK RELEASE RATE $\ldots \ldots \ldots \ldots \ldots \ldots \ldots \ldots \ldots \ldots, 8-3$

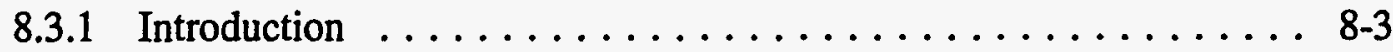

8.3.2 Selection of Radionuclides of Concern . . . . . . . . . 8-4

8.3.3 Effects of Alternative Waste Container Corrosion Initiation

Conceptual Models ..................... 8-5

8.3.4 Effects of Alternative Thermal Loading and Repository Level

Percolation Rate .................... 8-6

8.3.5 Alternative EBS Release Conceptual Models: Effects of Backfill

and Capillary Barrier ................... 8-7

8.3.6 Effects of Cladding Failure $\ldots \ldots \ldots \ldots \ldots \ldots \ldots \ldots$ 8 $8-9$

8.3.7 Effects of Alternative Thermal-Hydrologic Model . . . . . . . 8-10

8.3.8 Sensitivity of ${ }^{129} \mathrm{I}$ Release Rate to Its Release Mode $\ldots \ldots \ldots$. 8-10

8.3.9 Most Important Model Parameters . . . . . . . . . . 8-11

8.4 CUMULATIVE EBS RELEASE AT 10,000 YEARS $\ldots \ldots \ldots \ldots \ldots .8-11$

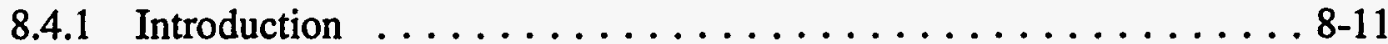

8.4.2 Effects of Alternative Thermal Load ............ 8-12

8.4.3 Effects of Infiltration on EBS Release .......... 8-12

8.5 SUMMARY AND CONCLUSIONS FROM EBS PERFORMANCE

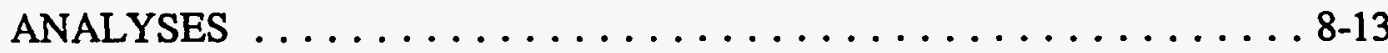

9. NATURAL-BARRIER RELEASE AND DOSE $\ldots \ldots \ldots \ldots \ldots \ldots \ldots \ldots$ 9-1

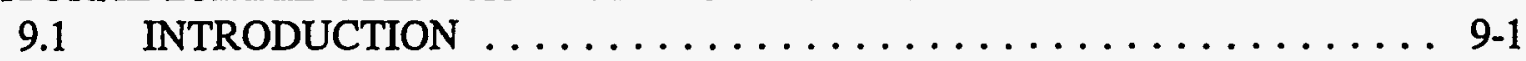

$9.210,000$-YEAR REPOSITORY PERFORMANCE ........... 9-2

9.2.1 Alternative Thermal Loads, Thermohydrologic Models, and

Infiltration Scenarios . . . . . . . . . . . . . . . 9-2

9.2.2 Alternative Waste-Package Degradation Models . . . . . . . . 9-6

9.2.3 Alternative Conceptual Models for EBS Transport ........ 9-7 
9.2.4 Fracture/Matrix Interaction in the Geosphere . . . . . . . . 9-10

9.2.5 Most Important Model Parameters . . . . . . . . . . . 9-11

9.2.6 Summary of 10,000 -year Performance $\ldots \ldots \ldots \ldots \ldots \ldots .9 .13$

$9.3 \quad 1,000,000$-YEAR REPOSITORY PERFORMANCE . . . . . . . . 9-13

9.3.1 Alternative Thermal Loads, Thermohydrologic Models, and Infiltration Scenarios . . . . . . . . . . . . . . . 9-13

9.3.2 Alternative Waste Package Degradation Models . . . . . . . . 9-20

9.3.3 Alternative Conceptual Models for EBS Transport ......... 9-20

9.3.4 Fracture/Matrix Interaction in the Geosphere . . . . . . . 9-22

9.3.5. Climate Change .................... 9-23

9.3.6 Alternative Solubility Models for $\mathrm{Np}, \mathrm{Pu}$, and $\mathrm{Am} \ldots \ldots \ldots \ldots$. . . . .

9.3.7 Most Important Model Parameters . . . . . . . . . . . 9-25

9.3.8 Summary of $1,000,000$-year Performance . . . . . . . . . 9-27

9.4 SUBSYSTEM PERFORMANCE $\ldots \ldots \ldots \ldots \ldots \ldots \ldots \ldots \ldots . . \ldots 9.27$

10. CONCLUSIONS AND RECOMMENDATIONS $\ldots \ldots \ldots \ldots \ldots \ldots \ldots \ldots$ 10-1

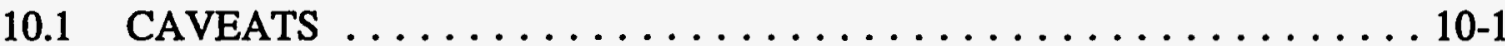

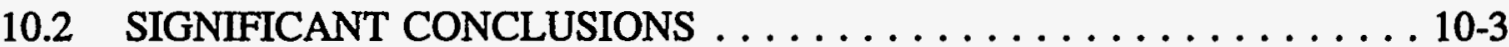

10.2.1 Substantially Complete Containment $\ldots \ldots \ldots \ldots \ldots \ldots \ldots$ 10-3

10.2.2 Peak Release Rate from the Engineered Barrier System . . . . . 10-5

10.2.3 Cumulative Release of Radionuclides at the Accessible Environment $-10,000$ Years . . . . . . . . . . . . . . 10-6

10.2.4 Peak Radiation Dose to Maximally Exposed Individual at the Accessible Environment - 10,000 Years . . . . . . . 10-7

10.2.5 Peak Radiation Dose to Maximally Exposed Individual at the Accessible Environment - 1,000,000 Years . . . . . . . . 10-8

10.3 PRIORITIZATION OF SITE CHARACTERIZATION AND DESIGN

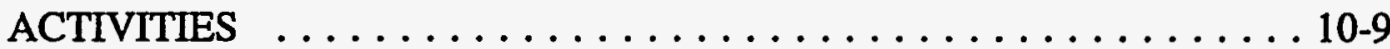

10.4 SUMMARY OF CONCEPTUAL ASSUMPTIONS NOT

EVALUATED . . . . . . . . . . . . . . . . . . . . . 10-12

10.5 POTENTIAL IMPACTS OF ALTERNATIVE ENVIRONMENTAL

STANDARDS . . . . . . . . . . . . . . . . . . 10-13

10.6 RECOMMENDED DEVELOPMENT, SUBSTANTIATION, DOCUMENTATION AND TESTING OF PROCESS LEVEL MODELS

TO BE USED IN FUTURE TOTAL SYSTEIM PERFORMANCE

ASSESSMENTS . ....................... 10-16

10.7 CONSERVATIVE AND NONCONSERVATIVE FACTORS

INFLUENCING THE PREDICTED RESULTS $\ldots \ldots \ldots \ldots \ldots \ldots$ 10-23

10.7.1 Significance of Nonconservative Assumptions . . . . . . . . 10-23

10.7.2 Significance of Conservative Assumptions . . . . . . . 10-25

10.8 FUTURE TSPA ACTIVITIES $\ldots \ldots \ldots \ldots \ldots \ldots \ldots \ldots \ldots \ldots \ldots$ 
Table of Contents (Continued)

11. REFERENCES AND ACRONYM LIST 


\section{List of Tables}

Table 2.4-1. Summary Statistics for Matrix Bulk Density $\left(\rho_{b}\right) \ldots \ldots \ldots \ldots$. . . . . 2-13

Table 2.4-2. Summary Statistics for Matrix Porosity $(\phi) \ldots \ldots \ldots \ldots \ldots \ldots$. . . . . . . . 2-13

Table 2.4-3. Summary Statistics for Matrix Saturated Conductivity $\left(K_{\text {sal }}\right) \quad \ldots \ldots$. . . . 2-14

Table 2.4-4. Summary Statistics for Matrix VG Air-Entry Parameter $(\alpha) \quad \ldots \ldots$. . . . 2-14

Table 2.4-5. Summary Statistics for Matrix VG Pore-Size Distribution Parameter $(\beta)$. . 2-15

Table 2.4-6. Bulk Permeability and Fracture Hydrologic Properties . . . . . . . . . 2-15

Table 2.5-1. Summary Estimates of Annual Ground-Water Inflow, Recharge, and Outflow in thousands of acre-feet per year ............. 2-16

Table 2.5-2. Public Water Suppliers in the Community of Amargosa Valley, for wells located in the southern portion of the Alkali Flat/Furnace Creek Ranch sub-basin and in the southwestern portion of the Ash Meadows

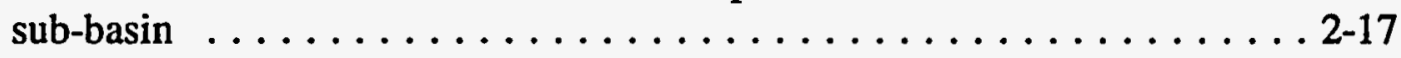

Table 3.2-1 Available Area for Potential Emplacement Panels . . . . . . . . . . . . . 3-12

Table 3.5-1 Dimensions of Waste Disposal Containers for A Typical Large MPC and DHLW . . . . . . . . . . . . . . . . . . . 3-13

Table $3.7-1$ Spent Fuel Waste Inventory $\ldots \ldots \ldots \ldots \ldots \ldots \ldots \ldots \ldots \ldots$. . . . . . . . . . . . . . . . . . . . . . . .

Table 3.7-2 DHLW Waste Inventory . . . . . . . . . . . . . . . . . 3-16

Table 3.8-1 Pathway Thicknesses and Relative Areas . . . . . . . . . . . 3-18

Table 4.2-1 Matrix Hydraulic Properties ... . . . . . . . . . . . . . 4-18

Table 4.2-2 Fracture Hydraulic Properties $\ldots \ldots \ldots \ldots \ldots \ldots \ldots \ldots \ldots$. . . . . . . . . . . . . . . . . . . .

Table 4.2-3 Matrix Thermal Properties . . . . . . . . . . . . . . . . . 4-19

Table 5.3-1 Corrosion Current Density of Iron at Different Humidities at $25{ }^{\circ} \mathrm{C}$ in Static and Dynamic Air Conditions and General Corrosion Rates Calculated from the Corrosion Current Density Data . . . . . . . . . . 5-40

Table 5.5-1 Elicitation of 'Constant' Pit Growth Rate Distribution for the Alloy 825

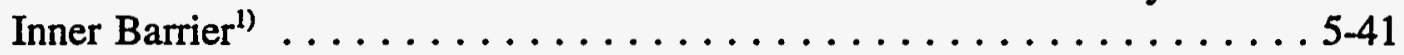

Table 6.2-1 Fractional Distribution of Gap Inventory Species Used in TSPA-1995 . . 6-27

Table 6.3-1 Distributions of Solubility-Limited Aqueous Radionuclide Concentrations for Nominal Case in TSPA-1995

Table 6.3-2 Averages and Standard Deviations for $\log ($ Neptunium Steady-State Concentrations) Calculated Using the Measurements of Nitsche et al., (1993)

Table 6.3-3 Averages and Standard Deviations for $\log$ (Plutonium Steady-State Concentrations) Calculated Using the Measurements of Nitsche et al., 
(1993)

Table 6.3-4 Averages and Standard Deviations for $\log$ (Americium Steady-State

Concentrations) Calculated Using the Measurements of Nitsche et al., (1993)

Table 7-2.1 TOUGH2 Results Used in the Testing of the Abstraction Methodology . . 7-29

Table 7.2-2 Comparison of TOUGH2 and RIP Travel Times ........... 7-30

Table 7.2-3 TOUGH2 Abstractions for the Low-Infiltration Case . . . . . . . . . 7-31

Table 7.2-4 TOUGH2 Abstractions for the High-Infiltration Case $\ldots \ldots \ldots \ldots \ldots$. 7-32 $^{2}$

Table 7.4-1 Stratigraphy for TSPA-1995 . . . . . . . . . . . . . . 7-33

Table 7.4-2 TSPA-1995 Sorption-Coefficient Distributions $\left(\mathrm{K}_{\mathrm{d}}\right.$ in $\left.\mathrm{ml} / \mathrm{g}\right)$ for

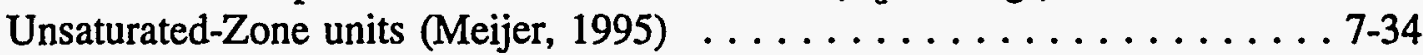

Table 7.4-3 TSPA-1995 Sorption Coefficient Distributions $\left(\mathrm{K}_{\mathrm{d}}\right.$ in $\left.\mathrm{ml} / \mathrm{g}\right)$ for Saturated-

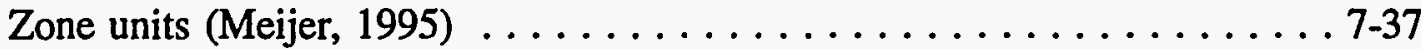

Table 7.6-1. Dose Conversion Factors $\ldots \ldots \ldots \ldots \ldots \ldots \ldots \ldots \ldots \ldots .40 \ldots \ldots$

Table 8.2-1. Comparison of TSPA-1995 Container Parameters with TSPA-1993

Container Parameters . . . . . . . . . . . . . . . . . 8 8-15

Table 8.2-2. Comparison of Selected Radionuclide Inventory in TSPA-1995 with TSPA-

1993 Inventory . . . . . . . . . . . . . . . . . . 8-16

Table 8.2-3. Comparison of TSPA-1995 Gap Fraction with TSPA-1993 Gap

Fraction ......................... 8-17

Table 8.2-4. Comparison of TSPA-1995 Exposure Parameters with TSPA-1993

Exposure Parameters . ..................... 8-18

Table 8.2-5. Comparison of TSPA-1995 Transport Parameters with TSPA-1993

Transport Parameters ....................... 8-20

Table 8.3-1. Calculation of the NRC Release Limit ............... 8-21

Table 8.3-2. Summary of Analysis Variations for Major Cases Evaluated in TSPA1995 ... . . . . . . . . . . . . . . . . . . . . . 8 8-23

Table 8.3-3. Waste Package Degradation Information for Major Cases as

Implemented in RIP Simulations . . . . . . . . . . . . . . . 8-24

Table 8.3-4. Comparison of NRC Release Rate Limit with an Expected Value Case for up to 100,000 years $(83 \mathrm{MTU} / \mathrm{acre}$, no backfill, and high infiltration rate. RH criteria for corrosion initiation ${ }^{1)} \ldots \ldots \ldots \ldots \ldots \ldots \ldots$. 8 -25

Table 8.3-5. Radionuclides Considered for the Comparison with the NRC EBS

Release Rate Limit in TSPA-1995 ${ }^{1)}$ and TSPA-19932) . . . . . . . . . . 8-27

Table 8.3-6. Regression Statistics for 10,000 Year EBS Peak Release Rate for the Case of 25 MTU/acre, no Backfill, High Infiltration Rate . . . . . 8-28

Table 8.3-7. Regression Statistics for 10,000 Year EBS Peak Release Rate for the Case of 83MTU/acre, no Backfill, High Infiltration Rate . . . . . . . 8-29 
Table 9.2-1 Regression statistics for 10,000-year normalized cumulative release, 83 MTU/acre, high- $\mathrm{q}_{\text {inf }}$ range $(0.5-2.0 \mathrm{~mm} / \mathrm{year})$, with backfill and climate change (no water-table rise) . . . . . . . . . . . . . . . . . . 9-29

Table 9.2-2 Regression statistics for 10,000-year total peak dose, 83 MTU/acre, high- $\mathrm{q}_{\text {inf }}$ range $(0.5-2.0 \mathrm{~mm} / \mathrm{year})$, with backfill and climate change (no water-table rise) . . . . . . . . . . . . . . . . . . 9-30

Table 9.3-1. Regression statistics for 1,000,000-year total peak dose, 83 MTU/acre, high- $\mathrm{q}_{\mathrm{inf}}$ range $(0.5-2.0 \mathrm{~mm} / \mathrm{yr})$, with backfill and climate change (no water-table rise) . . . . . . . . . . . . . . . . . 9-31

Table 9.3-2 Regression statistics for 1,000,000-year total peak dose, $83 \mathrm{MTU} / \mathrm{acre}$, low- $q_{\text {inf }}$ range $(0.01-0.05 \mathrm{~mm} / \mathrm{yr}$ ), with backfill and climate change (no water-table rise) . . . . . . . . . . . . . . . . . . 9-32

Table 9.3-3 Regression statistics for 1,000,000-year total peak dose, 83 MTU/acre, entire- $q_{\text {inf }}$ range $(0.01-2.0 \mathrm{~mm} / \mathrm{yr}$ ), with backfill and climate change (no water-table rise) . . . . . . . . . . . . . . . . . 9-33

Table 9.4-1 Cumulative releases from various subsystems: Expected-value releases at various times for $83 \mathrm{MTU} /$ acre thermal load, with backfill, $\mathrm{q}_{\text {inf }}=1.25$ $\mathrm{mm} / \mathrm{yr}$, and climate change (no water-table rise) $\ldots \ldots \ldots . \ldots . . \ldots 94$

Table 10.6-1 List of Process Level Models Required by Ferformance Assessment for Development of Future TSPA Abstractions . . . . . . . . . . . . . . 10 10-27

Table 10.6-2 Example Observations Used to Evaluate Representativeness of Process Models . . . . . . . . . . . . . . . . . . . . . . . . 10-28

Table 10.6-3. Example Evaluation Measures Used to Determine Significance of Process Models . . . . . . . . . . . . . . . . . . . . . . . . . . . . . 10-29 


\section{List of Figures}

Figure 1.4-1 Process Model Influence Diagram Used in Total System Performance Assessment . . . . . . . . . . . . . . . . . . . . . . 1-21

Figure 1.4-2 Schematic of Information Transfer Between Domains. . . . . . . . . . . 1-22 Figure 1.4-3 Schematic Depiction of the Barriers to Radionuclide Migration at the Potential Yucca Mountain Repository. . . . . . . . . . . . . . 1-22

Figure 1.4-4 Engineered Barrier System Components . . . . . . . . . . . . . . . . 1-23

Figure 1.4-5 Levels of Models Used to Evaluate MGDS Performance . . . . . . . . . . 1-24 Figure 1.4-6 Information Flow Diagram for TSPA-1995. . . . . . . . . . . . 1-25

Figure 1.5-1 RIP Total System Performance Assessment Model Components. . . . . . . 1-26

Figure 2.1-1 Relationship of Chapter 2 to the Overall Information Flow Diagram for TSPA 1995 (Figure 1.4-6) . . . . . . . . . . . . . . . . 2-18

Figure 2.2-1 Location of the Yucca Mountain Area . . . . . . . . . . . . . . . . . . . 2-19

Figure 2.2-2 Geologic map of Yucca Mountain . . . . . . . . . . . . . . . . . 2-20

Figure 2.2-3 Lithology of Major Stratigraphic Units at Yucca Mountain . . . . . . . . 2-21

Figure 2.3-1 Borehole Locations in the Yucca Mountain Region . . . . . . . . . . . 2-22

Figure 2.3-2 Isopach Map for Tiva Canyon Welded (TCw) Unit . . . . . . . . . . . 2-23

Figure 2.3-3 Isopach Map of Paintbrush Nonwelded (PTn) Unit . . . . . . . . . . . . . 2-23

Figure 2.3-4 Isopach Map of Topopah Spring Welded (TSW) unit (Contours in

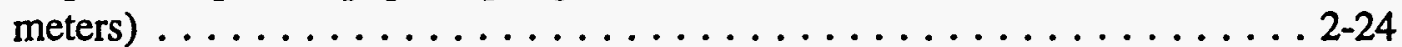

Figure 2.3-5 Isopach Map for Calico Hills Nonwelded (CHn) unit . . . . . . . . . . . . 2-24

Figure 2.3-6 Contour Map of Water Table at Yucca Mountain . . . . . . . . . . . . . 2-25

Figure 2.3-7 Geologic Cross-Section through the Potential Repository at Yucca

Mountain Mountain . . . . . . . . . . . . . . . . . 2-26

Figure 2.5-1 State of Nevada Hydrographic Areas Within the Yucca Mountain Hydrogeologic Study Area . . . . . . . . . . . . . . . . . . . . 2-27

Figure 2.5-2 Hydrogeologic Study Area Showing Major Inflows and Outflows Across

Subbasin Boundaries. Modified by Dudley from Rush (1970), Blankennagel and Weir (1973), Winograd and Thordarson (1975), Dudley and Larson (1976), Waddell (1982), and Waddell et al., (1984) . . 2-27

Figure 2.5-3 Potentiometric Surface of the Ground-Water Table Down Gradient from Yucca Mountain (modified from Claassen, 1985) . . . . . . . . . . . 2-28

Figure 2.5-4 Idealized Geohydrologic Cross Section from Yucca Mountain to Eagle Mountain (After Czarnecki, 1989) . . . . . . . . . . . . . . . . . 2-29

Figure 2.5-5 Map Showing Areas of Heavy Ground-Water Withdrawal Down Gradient FromYucca Mountain (modified from French et al., 1984) . . . . 2-30

Figure 2.6-1 Generalized Section Across Yucca Mountain Showing Flow Regime Under Baseline Conditions . . . . . . . . . . . . . . 2-31 
Figure 2.6-2 Spatial Distribution of Ambient Matrix Driven Infiltration Rates (derived from Flint and Flint, 1994) . . . . . . . . . . . . 2-31

Figure 3.1-1 Relationship of Chapter 3 to the Overall Information Flow Diagram for TSPA 1995 (Figure 1.4-6) . . . . . . . . . . . . . . . . . 3-19

Figure 3.2-1 SCP-CDR repository layout (after DOE, 1988) . . . . . . . . . 3-20

Figure 3.2-2 Potential Emplacement Panels (after M\&O, 1994) . . . . . . . . . . 3-21

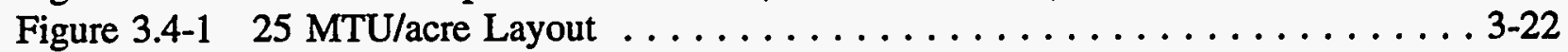

Figure $3.4-283$ MTU/acre Layout $\ldots \ldots \ldots \ldots \ldots \ldots \ldots \ldots \ldots \ldots . \ldots \ldots \ldots .23$

Figure 3.6-1 Borehole and in-drift emplacement concepts from SCP-CDR (DOE, 1988) . . . . . . . . . . . . . . . . . . . . . 3-24

Figure 3.6-2 Emplacement drift design for the CIDP option (after M\&O, 1995f) . . . . 3-24

Figure 3.8-1 Subdivision of Primary Area (Upper Block) into six (6) pathways . . . . 3-25

Figure 3.8-2 Pathway definition for 25 MTU/acre Case $\ldots \ldots \ldots \ldots \ldots \ldots \ldots . . \ldots \ldots$

Figure 3.8-3 Pathway definition of 83 MTU/acre Case . . . . . . . . . . . . 3-26

Figure 3.8-4 Relative thickness of pathways and their components . . . . . . . . . 3-27

Figure 3.8-5 Comparison of thickness ranges predicted by Wittwer et al., (1995)

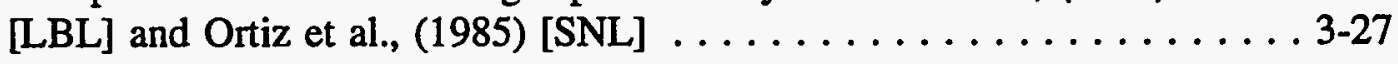

Figure 4.1-1 Relationship of Chapter 4 to the Overall Information Flow Diagram for

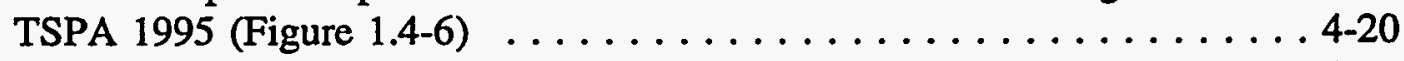

Figure 4.2-1 Near-Field Thermal-Hydrologic Conceptual Model . . . . . . . . . . . 4-21

Figure 4.2-2 Finite-Element Mesh Used for Drift Scale Thermal-Hydrologic

Simulations ......................... 4-22

Figure 4.2-3 Heat Generation Rates of an Average Waste Package . . . . . . . . . 4-23

Figure 4.2-4 Conceptual View of Relative Humidity Determination Module . . . . . . 4-23

Figure 4.2-5 Waste Package Surface Temperature Predictions for 83 MTU/acre . . . . . 4-24

Figure 4.2-6 Relative Humidity Predictions for 83 MTU/acre Case . . . . . . . . . . 4 4-24

Figure 4.2-7 Predictions of Liquid Saturation within Drift for 83 MTU/acre Case . . . 4-25

Figure 4.2-8 Abstractions of Temperatures and Relative Humidities for 10,000 years (83 MTU/acre Case . . . . . . . . . . . . . . . . . .

Figure 4.2-9 Waste Package Surface Temperature Predictions for 25 MTU/acre . . . . . 4-26

Figure 4.2-10 Relative Humidity Predictions for 25 MTU/acre Case . . . . . . . . . . 4-26

Figure 4.2-11 Predictions of Liquid Saturation within Backfill for 25 MTU/acre Case . . 4-27

Figure 4.2-12 Abstractions of Temperatures and Relative Humidities for 10,000 years

(25 MTU/acre Case) . . . . . . . . . . . . . . . . 4-27

Figure 4.2-13 Predicted Temperature Distribution for 83 MTU/acre, with Backfill, Infiltration $=0.05 \mathrm{~mm} /$ year . . . . . . . . . . . . . . . . . . 4-28

Figure 4.2-14 Predicted Saturation Distribution for 83 MTU/acre, with Backfill, Infiltration $=0.05 \mathrm{~mm} /$ year $\ldots \ldots \ldots \ldots \ldots \ldots \ldots \ldots .4 .29$

Figure 4.2-15 Predicted Temperature Distribution for 83 MTU/acre, with Backfill, Infiltration $=0.3 \mathrm{~mm} /$ year $\ldots \ldots \ldots \ldots \ldots \ldots \ldots \ldots \ldots \ldots \ldots \ldots$ 
Figure 4.2-16 Predicted Saturation Distribution for 83 MTU/acre, with Backfill, Infiltration $=0.3 \mathrm{~mm} /$ year $\ldots \ldots \ldots \ldots \ldots \ldots \ldots \ldots .4 .31$

Figure 4.2-17 Predicted Temperature Distribution for 83 MTU/acre, No Backfill, Infiltration $=0.3 \mathrm{~mm} /$ year $\ldots \ldots \ldots \ldots \ldots \ldots \ldots \ldots \ldots \ldots \ldots .4 .32$

Figure 4.2-18 Predicted Saturation Distribution for 83 MTU/acre, No Backfill, Infiltration $=0.3 \mathrm{~mm} /$ year $\ldots \ldots \ldots \ldots \ldots \ldots \ldots \ldots . . \ldots \ldots$

Figure 4.2-19 Predicted Temperature Distribution for 25 MTU/acre, with Backfill,

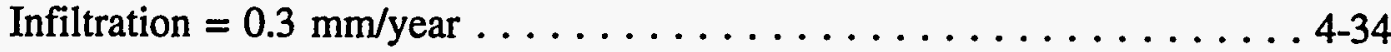

Figure 4.2-20 Predicted Saturation Distribution for 25 MTU/acre, with Backfill,

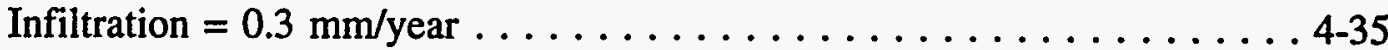

Figure 4.2-21 Comparison of $\mathrm{RH}$ and temperature predictions from Buscheck et al. (24 MTU/acre) and this study (25 MTU/acre). . . . . . . . . . 4-36

Figure 4.2-22 Comparison of RH and temperature predictions from Buscheck et al. (80 MTU/acre) and this study ( $83 \mathrm{MTU} / \mathrm{acre}) . \ldots \ldots \ldots \ldots \ldots \ldots .4 .37$

Figure 4.3-1 Temperature Contours at 1,000 Years for an Infiltration Rate of 0.1 $\mathrm{mm} /$ year and Enhanced Vapor Diffusivity . . . . . . . . . . . 4-38

Figure 4.3-2 Liquid Saturation contours at 1,000 years for an Infiltration Rate of 0.1 $\mathrm{mm} /$ year and Enhanced Vapor Diffusivity . . . . . . . . . . 4-38

Figure 4.3-3 One- and Two-Dimensional Results at 1,000 years for Column 6 with a One-Dimensional Heat Loading of $92 \mathrm{MTU} / \mathrm{acre}$, an Infiltration Rate of $0.1 \mathrm{~mm} / \mathrm{year}$, and Enhanced Vapor Diffusivity . . . . . . . . 4-39

Figure 4.3-4 One- and Two-Dimensional Results at 1,000 Years for Column 11 with a One-Dimensional Heat Loading of $58 \mathrm{MTU} / \mathrm{acre}$ an Infiltration Rate of $0.1 \mathrm{~mm} /$ year and Enhanced Vapor Diffusity . . . . . . . . . 4-39

Figure 5.1-1 Relationship of Chapter 5 to the Overall Information Flow Diagram for TSPA 1995 (Figure 1.4-6) . . . . . . . . . . . . . . . . . . . 5-42

Figure 5.3-1 Weather data and model predictions of the fraction of time for $\mathrm{RH}^{3} 70$ $\%$ as a function of average relative humidity. . . . . . . . . . 5-43

Figure 5.3-2 Atmospheric general corrosion data and the model prediction for corrosion allowance materials. . . . . . . . . . . . . . . 5-43

Figure 5.3-3a Model prediction of general corrosion rates of CAM in humid-air as a function of exposure time in humid-air at different humidities at $60^{\circ} \mathrm{C} . \ldots 5-44$

Figure 5.3-3b Model prediction of general corrosion rates of CAM in humid-air as a function of exposure time in humid-air at different humidities at $90{ }^{\circ} \mathrm{C} . \ldots 5-44$

Figure 5.3-4a Model prediction of general corrosion rates of CAM in humid-air as a function of relative humidity at $30^{\circ} \mathrm{C}$ and different exposure times. No

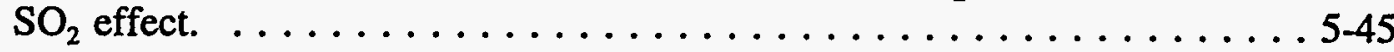

Figure 5.3-4b Model prediction of general corrosion rates of CAM in humid-air as a function of relative humidity at $90^{\circ} \mathrm{C}$ and different exposure times. No $\mathrm{SO}_{2}$ effect. . ...................... 5-45

Figure 5.3-5 Model prediction of general corrosion rate of CAM in humid-air as a function of relative humidity at different exposure temperatures after 
- one year exposure. ...................... 5-46

Figure 5.3-6 Model prediction of general corrosion rates of CAM in humid-air as a function of relative humidity at different $\mathrm{SO}_{2}$ levels in the air after one

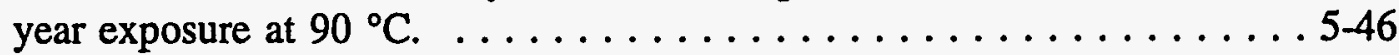

Figure 5.3-7a Comparison of model prediction of general corrosion rates of CAM in humid-air at different humidities and in water at $30^{\circ} \mathrm{C} . \ldots \ldots \ldots .47$

Figure 5.3-7b Comparison of model prediction of general corrosion rates of CAM in humid-air at different humidities and in water at $60^{\circ} \mathrm{C} \ldots \ldots \ldots \ldots 5-47$

Figure 5.3-7c Comparison of model prediction of general corrosion rates of CAM in humid-air at different humidities and in water at $90^{\circ} \mathrm{C} . \ldots \ldots \ldots .548$

Figure 5.3-8a Model prediction of probability density functions (PDFs) of pit depth distribution of CAM in humid-air after different exposure times at 60 ${ }^{\circ} \mathrm{C}$ and $80 \%$ RH. . . . . . . . . . . . . . . . . . 5-49

Figure 5.3-8b Model prediction of probability density functions (PDFs) of pit depth distribution of CAM in humid-air after different exposure times at 60

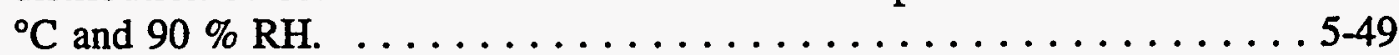

Figure 5.3-9a Model prediction of probability density functions (PDFs) of pit depth distribution of CAM in humid-air after different exposure times at 90

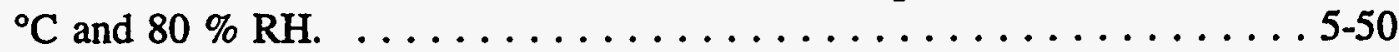

Figure 5.3-9b Model prediction of probability density functions (PDFs) of pit depth distribution of CAM in humid-air after different exposure times at 90

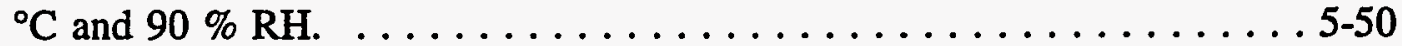

Fig. 5.3-10a Model prediction of cumulative density functions (CDFs) of pit depth distribution of CAM in humid-air at different: temperatures and humidities after 1,000 -year exposure. . . . . . . . . . . 5-51

Fig. 5.3-10b Model prediction of cumulative density functions (CDFs) of pit depth distribution of CAM in humid-air at different temperatures and humidities after 3,000 -year exposure. . . . . . . . . . . 51

'Figure 5.3-11 Sensitivity of constant $k$ of the McCoy model in humid-air at $25{ }^{\circ} \mathrm{C} . \ldots$ 5-52

Figure 5.3-12 Comparison of the McCoy model prediction of general corrosion depth of CAM in humid-air with the atmospheric corrosion data from

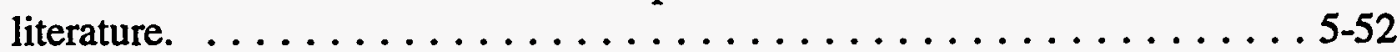

Figure 5.3-13 Comparison of the current model prediction for long-term general corrosion depth of CAM in humid-air with those of the McCoy model. . . 5-53

Figure 5.4-1 General corrosion data of CAM in tropical lake water and polluted river water, and the model prediction with the uncertainty. ......... 5-53

Figure 5.4-2 Temperature-dependent general corrosion data of mild steel in distilled water, and the model prediction with the uncertainty. . . . . . . 5-54

Figure 5.4-3 Model prediction of aqueous general corrosion rates as a function of exposure time at different temperatures. . . . . . . . . . . . 5-54

Figure 5.4-4 Model prediction of aqueous general corrosion rates as a function of temperature at different exposure times. . . . . . . . . . . . 5-55 
Figure 5.4-5. Comparison of model prediction of aqueous general corrosion of CAM at different temperatures with the data in J-13 water. The J-13 water data are from McCright and Weiss (1985). . . . . . . . . . . . . 5-55

Figure 5.4-6 Comparison of the current model prediction of aqueous general corrosion of CAM with the Westinghouse model at different temperatures. . . . . . . . . . . . . . . . . . . 5-56

Figure 5.4-7a Model prediction of probability density function (PDF's) of pit depth distribution of $C A M$ in aqueous condition after different exposure times

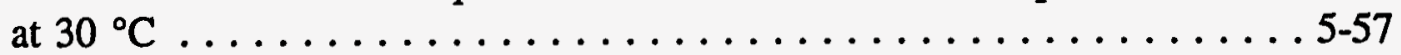

Figure 5.4-7b Model prediction of probability density function (PDF's) of pit depth distribution of CAM in aqueous condition after different exposure times

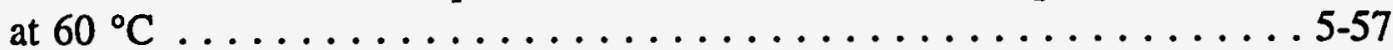

Figure 5.4-7c Model prediction of probability density function (PDF's) of pit depth distribution of CAM in aqueous condition after different exposure times

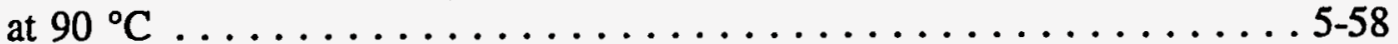

Figure 5.5-1 Elicitation for the distribution of 'constant' pit growth rate in Alloy 825 inner barrier as a function of temperature ............ 5-58

Figure 5.7-1 An overview of the stochastic waste package performance simulation model developed for TSPA-1995. . . . . . . . . . . . . . . . . 5-59

Figure 5.7-2a Flowchart of the stochastic waste package performance simulation model developed for TSPA-1995. . . . . . . . . . . . . . . . . 5-60

Figure 5.7-2b Flowchart of the stochastic waste package performance simulation model developed for TSPA-1995 (continued). . . . . . . . . . . . . . 5-61

Figure 5.7-3a Waste package failure history for the case of $83 \mathrm{MTU} / \mathrm{acre}$, low infiltration, and without backfill, using RH and temperature switch for corrosion initiation. . . . . . . . . . . . . . . . . . 5-62

Figure 5.7-3b Representative pitting histories for 25 waste packages for the case of 83 MTU/acre, low infiltration, and without backfill, using $\mathrm{RH}$ and temperature switch for corrosion initiation. . . . . . . . . . . . . 5-62

Figure 5.7-3c Abstractions for the RIP implementation for the case of 83 MTU/acre, low infiltration, and without backfill, using $\mathrm{RH}$ and temperature switch for corrosion initiation. . . . . . . . . . . . . . . 5-63

Figure 5.7-4a Waste package failure history for the case of $83 \mathrm{MTU} / \mathrm{acre}$, high infiltration, and without backfill, using RH and temperature switch for corrosion initiation. . . . . . . . . . . . . . . . . 5-63

Figure 5.7-4b Representative pitting histories for 25 waste packages for the case of 83 MTU/acre, high infiltration, and without backfill, using $\mathrm{RH}$ and temperature switch for corrosion initiation. . . . . . . . . . . . 5-64

Figure 5.7-4c Abstractions for the RIP implementation for the case of 83 MTU/acre, high infiltration, and without backfill, using RH and temperature switch for corrosion initiation. . . . . . . . . . . . . . . . . . 5-64

Figure 5.7-5a Waste package failure history for the case of $83 \mathrm{MTU} / \mathrm{acre}$, low infiltration, and with backfill, using $\mathrm{RH}$ and temperature switch for corrosion initiation. 
Figure 5.7-5b Representative pitting histories for 25 waste packages for the case of 83 MTU/acre, low infiltration, and with backfill, using RH and temperature switch for corrosion initiation. . . . . . . . . . . . . . . 5-65

Figure 5.7-5c Abstractions for the RIP implementation for the case of 83 MTU/acre, low infiltration, and with backfill, using $\mathrm{RH}$ and temperature switch for corrosion initiation. . . . . . . . . . . . . . . . . . 5-66

Figure 5.7-6a Waste package failure history for the case of 83 MTU/acre, high infiltration, and with backfill, using $\mathrm{RH}$ and temperature switch for corrosion initiation.

Figure 5.7-6b Representative pitting histories for 25 waste packages for the case of 83 MTU/acre, high infiltration, and with backfill, using $\mathrm{RH}$ and temperature switch for corrosion initiation. . . . . . . . . . . . . 5-67

Figure 5.7-6c Abstractions for the RIP implementation for the case of 83 MTU/acre, high infiltration, and with backfill, using $\mathrm{RH}$ and temperature switch for corrosion initiation. . . . . . . . . . . . . . . . . . . 5-67

Figure 5.7-7a Waste package failure history for the case of 83 MTU/acre, low infiltration, and without backfill, using RH switch for corrosion initiation. . . . . . . . . . . . . . . . . . . . . . 5-68

Figure 5.7-7b Representative pitting histories for 25 waste packages for the case of 83 MTU/acre, low infiltration, and without backfill, using $\mathrm{RH}$ switch for corrosion initiation. . . . . . . . . . . . . . . . . . 5-68

Figure 5.7-7c Abstractions for the RIP implementation for the case of 83 MTU/acre, low infiltration, and without backfill, using RH switch for corrosion initiation. . . . . . . . . . . . . . . . . . . . . . 5-69

Figure 5.7-8a Waste package failure history for the case of 83 MTU/acre, high infiltration, and without backfill, using $\mathrm{RH}$ switch for corrosion initiation. . . . . . . . . . . . . . . . . . . . . . . . . . . . . . . 5-69

Figure 5.7-8b Representative pitting histories for 25 waste packages for the case of 83 MTU/acre, high infiltration, and without backfill, using $\mathrm{RH}$ switch for corrosion initiation. . . . . . . . . . . . 5 . . . . . .

Figure 5.7-8c Abstractions for the RIP implementation for the case of $83 \mathrm{MTU} / \mathrm{acre}$, high infiltration, and without backfill, using $\mathrm{RH}$ switch for corrosion initiation. . . . . . . . . . . . . . . . . . . . . .

Figure 5.7-9a Waste package failure history for the case of 83 MTU/acre, low infiltration, and with backfill, using $\mathrm{RH}$ switch for corrosion initiation. . . 5-71

Figure 5.7-9b Representative pitting histories for 25 waste packages for the case of 83 MTU/acre, low infiltration, and with backfill, using RH switch for corrosion initiation. . . . . . . . . . . . . . . . 5-71

Figure 5.7-9c Abstractions for the RIP implementation for the case of 83 MTU/acre, low infiltration, and with backfill, using RH switch for corrosion initiation. . . . . . . . . . . . . . . . . . . . . . 5-72

Fig. 5.7-10a Waste package failure history for the case of $83 \mathrm{MTU} / \mathrm{acre}$, high infiltration, and with backfill, using RH switch for corrosion initiation. . . 5-72 
Fig. 5.7-10b Representative pitting histories for 25 waste packages for the case of 83 MTU/acre, high infiltration, and with backfill, using RH switch for corrosion initiation. . ...................... 5-73

Fig. 5.7-10c Abstractions for the RIP implementation for the case of 83 MTU/acre, high infiltration, and with backfill, using RH switch for corrosion initiation. ......................... 5-73

Fig. 5.7-11a Waste package failure history for the case of $25 \mathrm{MTU} / \mathrm{acre}$, low infiltration, and without backfill, using RH switch for corrosion initiation. . . ....................... 5-74

Fig. 5.7-11b Representative pitting histories for 25 waste packages for the case of 25 MTU/acre, low infiltration, and without backfill, using RH switch for corrosion initiation. ..................... 5-74

Fig. 5.7-11c Abstractions for the RIP implementation for the case of 25 MTU/acre, low infiltration, and without backfill, using RH switch for corrosion initiation. 5-75

Fig. 5.7-12a Waste package failure history for the case of 25 MTU/acre, high infiltration, and without backfill, using RH switch for corrosion initiation. ........................... 5-75

Fig. 5.7-12b Representative pitting histories for 25 waste packages for the case of 25 MTU/acre, high infiltration, and without backfill, using RH switch for corrosion initiation. ..................... 5-76

Fig. 5.7-12c Abstractions for the RIP implementation for the case of 25 MTU/acre, high infiltration, and without backfill, using RH switch for corrosion initiation. ........................... 5-76

Fig. 5.7-13a Waste package failure history for the case of 25 MTU/acre, low infiltration, and with backfill, using RH switch for corrosion initiation. . . 5-77

Fig. 5.7-13b Representative pitting histories for 25 waste packages for the case of 25 MTU/acre, low infiltration, and with backfill, using RH switch for corrosion initiation. . .................... 5-77

Fig. 5.7-13c Abstractions for the RIP implementation for the case of 25 MTU/acre, low infiltration, and with backfill, using RH switch for corrosion initiation. ........................ 5.78

Fig. 5.7-14a Waste package failure history for the case of 83 MTU/acre, high infiltration, and without backfill, with cathodic protection of the inner barrier and using RH and temperature switch for corrosion initiation. . . . 5-78

Fig. 5.7-14b Representative pitting histories for 25 waste packages for the case of 83 MTU/acre, high infiltration, and without backfill, with cathodic protection of the inner barrier and using $\mathrm{RH}$ and temperature switch for corrosion initiation. . . . . . . . . . . . . . . . . . . 5-79

Fig. 5.7-14c Abstractions for the RIP implementation for the case of 83 MTU/acre, high infiltration, and without backfill, with cathodic protection of the inner barrier and using RH and temperature switch for corrosion initiation. ......................... . . . . . . 
Figure 5.7-15 Waste package failure history for the case of 25 MTU/acre, high infiltration, and without backfill, with cathodic protection of the inner barrier and using $\mathrm{RH}$ switch for corrosion initiation. . . . . . . . . 5-80

Figure 5.7-16 Waste package failure history for the case of $83 \mathrm{MTU} / \mathrm{acre}$, high infiltration, and without backfill, with time-dependent pit growth rate in the inner barrier and using $\mathrm{RH}$ and temperature switch for corrosion initiation. . . . . . . . . . . . . . . . . . . . . .

Fig. 5.7-17a Waste package failure history for the case of 24 MTU/acre, no infiltration, and without backfill, with the results from the Buscheck's model and using RH switch for corrosion initiation. . . . . . . . . 5-81

Fig. 5.7-17b Representative pitting histories for 25 waste packages for the case of 24 MTU/acre, no infiltration, and without backfill, with the results from the Buscheck's model and using RH switch for corrosion initiation. . . . . . . 5-81

Fig. 5.7-17c Abstractions for the RIP implementation for the case of $24 \mathrm{MTU} / \mathrm{acre}$, no infiltration, and without backfill, with the results from the Buscheck's model and using RH switch for corrosion initiation. . . . . . . . . . 5-82

Fig. 5.7-18a Waste package failure history for the case of $24 \mathrm{MTU} / \mathrm{acre}$, no infiltration, and with backfill, with the results from the Buscheck's model and using RH switch for corrosion initiation. . . . . . . . . . . 5-82

Fig. 5.7-18b Representative pitting histories for 25 waste packages for the case of 24 MTU/acre, no infiltration, and with backfill, with the results from the Buscheck's model and using RH switch for corrosion initiation. . . . . . . 5-83

Fig. 5.7-19a Waste package failure history for the case of 80 MTU/acre, no infiltration, and without backfill, with the results from the Buscheck's model and using RH and temperature switch for corrosion initiation. . . . 5-83

Fig. 5.7-19b Representative pitting histories for 25 waste packages for the case of 80 MTU/acre, no infiltration, and without backfill, with the results from the Buscheck's model and using RH and temperature switch for corrosion initiation. . . . . . . . . . . . . . . . . . . . . 5-84

Fig. 5.7-20a Waste package failure history for the case of $80 \mathrm{MTU} / \mathrm{acre}$, no infiltration, and with backfill, with the results from the Buscheck's model and using $\mathrm{RH}$ and temperature switch for corrosion initiation. . . . 5-84

Fig. 5.7-20b Representative pitting histories for 25 waste packages for the case of 80 MTU/acre, no infiltration, and with backfill, with the results from the Buscheck's model and using $\mathrm{RH}$ and temperature switch for corrosion initiation.

Figure 5.7-21 Waste package failure history for the case of $25 \mathrm{MTU} / \mathrm{acre}$, high infiltration, and without backfill, with alternative interpretation of the elicitation for the inner barrier pit growth rate and using $\mathrm{RH}$ switch for corrosion initiation. . . . . . . . . . . . . . . . . . 5-85

Figure 5.7-22 Waste package failure history for the case of 83 MTU/acre, high infiltration, and without backfill, with alternative interpretation of the elicitation for the inner barrier pit growth rate and using $\mathrm{RH}$ switch for corrosion initiation. . . . . . . . . . . . . . . . . 5-86 
Figure 6.1-1. Relation of Chapter 6 to the Overall Information Flow Diagram for TSPA 1995 (Figure 1.4-6) . . . . . . . . . . . . . . . . 6-34

Figure 6.2-1 Model Prediction with the Uncertainty and Relevant Data of the Intrinsic Dissolution Rate of Spent Fuel Matrix as a Function of Temperature at a Total Carbonate Concentration of $0.002 \mathrm{M} \ldots \ldots$. . . 6-35

Figure 6.2-2 Model Prediction with the Uncertainty and Relevant Data of the Intrinsic Dissolution Rate of Spent Fuel Matrix as a Function of Temperature at a Total Carbonate Concentration of $0.02 \mathrm{M} \ldots \ldots .66-35$

Figure 6.2-3 Model Prediction with the Uncertainty and Relevant Data of the Intrinsic Dissolution Rate of Spent Fuel Matrix as a Function of Total Carbonate Concentration at $296.15 \mathrm{~K} . \ldots \ldots \ldots \ldots \ldots \ldots \ldots$. . . . . . . . . .

Figure 6.2-4 Comparison of Spent Fuel Dissolution Rates Calculated by the Current Model with the Model Used in TSPA-1993. . . . . . . . . . . . 6-36

Figure 6.2-5 Prediction and the Data of the Intrinsic Dissolution Rates of DHLW Glass Waste Form as a Function of $\mathrm{pH}$ and Temperature ........ 6-37

Figure 6.2-6 Comparison of the Prediction of the Intrinsic Glass Dissolution Rate as a Function of Temperature at $\mathrm{pH}$ of 7 Calculated with the Current Model and the Model Used in TSPA-1993 . . . . . . . . . . 6 6-37

Figure 6.3-1 Plot of the Distribution Function for Solubility-Limited Concentrations of Ac, Am, and Sm. .................... 6-38

Figure 6.3-2 Plot of the Distribution Function for Solubility-Limited Concentrations

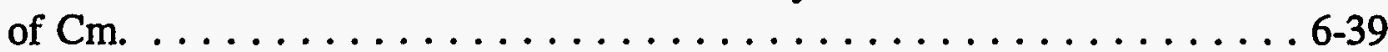

Figure 6.3-3 Plot of the Distribution Function for Solubility-Limited Concentrations

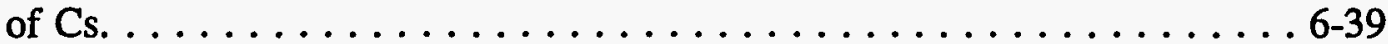

Figure 6.3-4 Plot of the Distribution Function for Solubility-Limited Concentrations

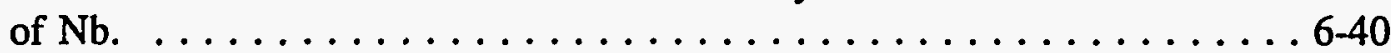

Figure 6.3-5 Plot of the Distribution Function for Solubility-Limited Concentrations

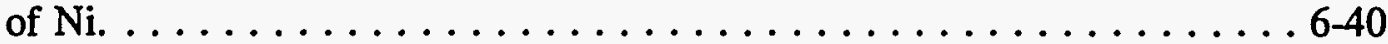

Figure 6.3-6 Plot of the Distribution Function for Solubility-Limited Concentrations

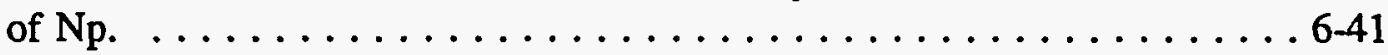

Figure 6.3-7 Plot of the Distribution Function for Solubility-Limited Concentrations

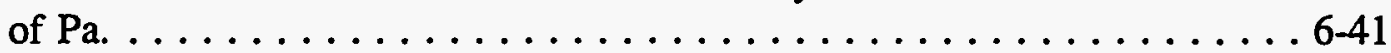

Figure 6.3-8 Plot of the Distribution Function for Solubility-Limited Concentrations

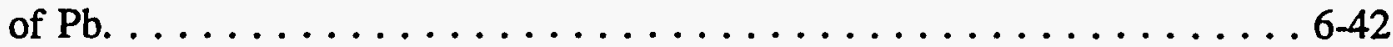

Figure 6.3-9 Plot of the Distribution Function for Solubility-Limited Concentrations

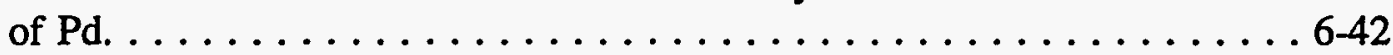

Fig. 6.3-10 Plot of the Distribution Function for Solubility-Limited Concentrations

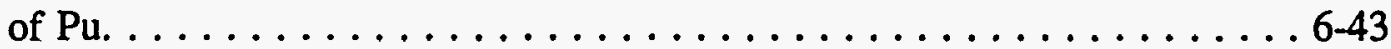

Fig. 6.3-11 Plot of the Distribution Function for Solubility-Limited Concentrations of Ra. . . . . . . . . . . . . . . . . . . . . 6 6-44

Fig. 6.3-12 Plot of the Distribution Function for Solubility-Limited Concentrations of Se. . . . . . . . . . . . . . . . . . . . . 6-44

Fig. 6.3-13 Plot of the Distribution Function for Solubility-Limited Concentrations

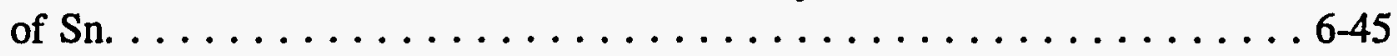


Fig. 6.3-14. Plot of the Distribution Function for Solubility-Limited Concentrations of

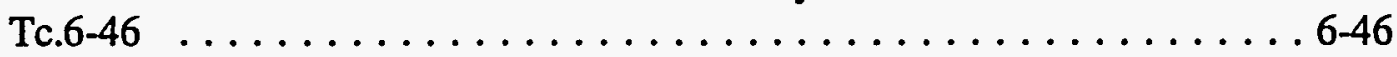

Fig. 6.3-15 Plot of the Distribution Function for Solubility-Limited Concentrations

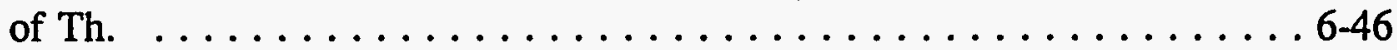

Fig. 6.3-16 Plot of the Distribution Function for Solubility-Limited Concentrations

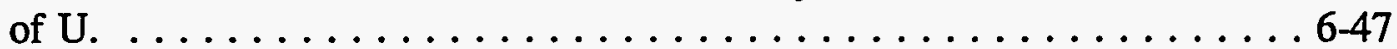

Fig. 6.3-17 Plot of the Distribution Function for Solubility-Limited Concentrations of Zr. . . . . . . . . . . . . . . . . . . . . 6 6-47

Fig. 6.3-18 Temperature- and pH-Dependent Functional Fit to Nitsche et al. (1993) measurements of $\log$ (Steady-State Np Concentration) in J-13 Initial Water (Curves) Compared to Empirical Determinations Used (SymbolsTable 6.3-2). . . . . . . . . . . . . . . . . . . . 6-48

Fig. 6.3-19 Temperature- and pH-Dependent Functional Fit to Nitsche et al. (1993) measurements of $\log$ (Steady-State Pu Concentration) in J-13 Initial Water (Curves) Compared to Empirical Determinations Used (SymbolsTable 6.3-3). . . . . . . . . . . . . . . . . . . 6-48

Fig. 6.3-20 Temperature- and pH-Dependent Functional Fit to Nitsche et al. (1993) measurements of $\log$ (Steady-State Am Concentration) in J-13 Initial Water (Curves) Compared to Empirical Determinations Used (SymbolsTable 6.3-4). . . . . . . . . . . . . . . . . . . . . . 6 6-49

Fig. 6.3-21 Comparison of Solubility-Limited $\log$ (Concentration) for Np as Function of Temperature and $\mathrm{pH}$ in J-13 Initial Water with $\mathrm{Np}$ Distribution Function Range.

Fig. 6.3-22 Comparison of Solubility-Limited $\log$ (Concentration) for Pu as Function of Temperature and $\mathrm{pH}$ in J-13 Initial Water to Pu Distribution Function Range. ............................66-50

Fig. 6.3-23 Comparison of Solubility-Limited $\log$ (Concentration) for Am as Function of Temperature and $\mathrm{pH}$ in J-13 Initial Water to Am Distribution Function Range. ..................... 6-50

Figure 6.4-1 Incorporation of the Effects of Natural Colloids on the Source Term into TSPA ......................... 6-51

Figure 6.5-1 Schematic Drawing of Waste Disposal Container Placed on the Invert in an Emplacement Drift (side view) ................ 6-52

Figure 6.5-2 Schematic Drawing of Waste Disposal Container Placed on the Invert in an Emplacement Drift (front view) . . . . . . . . . . . . 6 6-52

Figure 6.5-3 Schematic of Radionuclide Release Through Multiple Cylindrical Holes on the Waste Disposal Container for the Equivalent Spherical Configuration Approximation.

Figure 6.5-4 Conceptualization of Radionuclide Release Through a Cylindrical Hole in the Waste Disposal Container, the Invert, and the Host Rock. . . . . . 6-53

Figure 6.5-5 Comparison of Steady-State Diffusive Release at the EBS Boundary from A Waste Container with Multiple Pits to the Release from the Bare Waste Form. . . . . . . . . . . . . . . . . . . . .

Figure 6.5-6 A Representative Pitting Profile of a Waste Container. . . . . . . . . . 6-54 
Figure 6.5-7. Transient and Steady-State Diffusive Releases at the EBS Boundary from A Waste Container with Multiple Pits. . . . . . . . . . . . 6-55

Figure 6.5-8 Model Estimation and the Uncertainty for the Diffusion Coefficient in Porous Geologic Media as a Function of the Volumetric Water Content. . 6-55

Figure 6.5-9 Conceptual Model for Diffusive Release and Advective Release from Both Waste Package and Other EBS Components. . . . . . . . . . 6-56

Figure 6.5-10 Conceptual Model for Diffusive Release from Waste Package and Diffusive Plus Advective Release from Other EBS Components. . . . . . . 6-56

Figure 6.5-11 Conceptual Model for Only Diffusive Release from Both Waste Package and Other EBS Components (Capillary Barrier Effect). . . . . . . 6-57

Figure 7.1-1 Information flow schematic for unsaturated zone flow model. . . . . . 7-42

Figure 7.2-1 Illustration of Proposed Testing of Process Model Abstractions/Responses Used in Total System Simulators (after Nelson, 1995). . . . . . . . . . . . . . . . . . . . . . . . . 7-43

Figure 7.2-2 Schematic Depiction of Distribution of Infiltration into Fracture and Matrix Percolation Flux Components (TSPA-1995). . . . . . . . . . . . . 7-44

Figure 7.2-3 Schematic of proposed abstraction methodology for determining velocity and fraction of fracture flow as a function of infiltration flux, $q_{\mathrm{inf}} \ldots \ldots 7-45$

Figure 7.2-4 LBL/USGS Site Scale Model, 2-dimensional cross section. . . . . . . . . 7 7-46 Figure 7.2-5 Comparison of single-point arrival times for TOUGH2 and RIP. . . . . . 7-46 Figure 7.2-6 Plan view of the LBL/USGS Site-Scale Model of the Unsaturated Zone at Yucca Mountain (from Wittwer et al., 1995). . . . . . . . . . . . 7-47

Figure 7.2-7 Range of matrix hydrologic property values sampled randomly from parameter distributions presented in Schenker et al., (1995). . . . . . . 7-48

Figure 7.2-8 Ranges of pore velocity and fractional fracture flow for TSw. . . . . . . 7-49

Figure 7.2-9 Ranges of pore velocity and fractional fracture flow for TSv. . . . . . . 7-50 Figure 7.2-10 Ranges of pore velocity and fractional fracture flow for CHnv. . . . . 7-51

Figure 7.2-11 Ranges of pore velocity and fractional fracture flow for $\mathrm{CHnz}$. . . . . . 7-52 Figure 7.2-12 Liquid saturation distributions along Column 153 of the LBL/USGS site-scale model, for (A) matrix, and (B) fracture. . . . . . . . . 7-53

Figure 7.2-13 Liquid flow distribution along Column 153 of the LBL/USGS site-scale model, showing (A) fracture of liquid flow rate in fracture, and (B) pore velocity in matrix. ...................... 7-54

Figure 7.2-14 Comparison of matrix pore velocities for columns 153 and 157 with infiltration of: (i) $0.01 \mathrm{~mm} / \mathrm{yr}$ and (ii) $1.0 \mathrm{~mm} / \mathrm{yr} . \ldots \ldots \ldots \ldots \ldots 7-55$

Figure 7.3-1 $\mathrm{CDF}$ for $\mathrm{K}_{\mathrm{sat}}$ (in the $\mathrm{TSw}$ ) when $\mathrm{q}_{\mathrm{inf}}$ is $2 \mathrm{~mm} / \mathrm{yr} . \ldots \ldots \ldots \ldots .7-56$ Figure 7.3-2 CDF for dripping flux, $\mathrm{q}_{\text {drip }}$, on waste packages when $\mathrm{q}_{\mathrm{inf}}$ is $2 \mathrm{~mm} / \mathrm{yr}$. . . 7-56 Figure 7.3-3 CDF for $\mathrm{K}_{\text {sat }}$ (in the TSw) when $\mathrm{q}_{\mathrm{inf}}$ is $0.05 \mathrm{~mm} / \mathrm{yr} . \ldots \ldots \ldots .7 .57$ Figure 7.3-4 CDF for dripping flux, $\mathrm{q}_{\text {drip }}$, on waste packages when $\mathrm{q}_{\mathrm{inf}}$ is $0.05 \mathrm{~mm} / \mathrm{yr}$. . 7-57 Figure 7.3-5 Average dripping flux (Darcy velocity), $q_{\text {drip }}$, on waste packages for low unsaturated-zone infiltration rates. $\ldots \ldots \ldots \ldots \ldots \ldots \ldots \ldots \ldots .7-58$ 
Figure 7.3-6 Average dripping flux (Darcy velocity), $\mathrm{q}_{\text {drip }}$, on waste packages for high unsaturated-zone infiltration rates. . . . . . . . . . .

Figure 7.3-7 Average fraction of waste packages with drips, $\mathrm{f}_{\text {drip }}$, for low unsaturatedzone infiltration rates. . . . . . . . . . . . . . . . . . .

Figure 7.3-8 Average fraction of waste packages with drips, $\mathrm{f}_{\text {drip }}$, for high unsaturated-zone infiltration rates. . . . . . . . . . . .

Figure 7.3-9 100,000 -yr expected-value releases for ${ }^{239} \mathrm{Pu}$ from all waste packages, for various values of the dripping flow rate, $Q_{\text {drip }} \ldots \ldots \ldots \ldots \ldots$ 7-60

Figure 7.3-10 100,000-yr expected-value releases for ${ }^{99} \mathrm{Tc}$ from all waste packages, for various values of the dripping flow rate, $Q_{\text {drip }} \ldots \ldots \ldots \ldots \ldots \ldots$ 7-60

Figure 7.4-1 Schematic of UZ and SZ pathway geometry in RIP TSPA model. . . . . 7-61

Figure 7.4-2 Schematic of fracture/matrix interaction in RIP: Markovian-particletransitioning process to represent intra-unit fracture connectivity. . . . 7-62

Figure 7.4-3 Schematic of inter-unit fracture and pathway connectivity in RIP. . . . . 7-62 Figure 7.4-4 Comparisons between RIP simulations with different fracture/matrix transition rates and the FEHM simulation for an infiltration rate of 4.0 $\mathrm{mm} / \mathrm{yr}$ and no matrix diffusion (from $\mathrm{Li}$ et al., 1995). . . . . . . 7-63

Figure 7.7-1 Effect of climate change on infiltration rate, $q_{\text {inf }} \ldots \ldots \ldots \ldots \ldots \ldots$ 7-64 Figure 7.7-2 Effect of climate change on water-table elevation. . . . . . . . .

Figure 8.1-1 Relationship of Chapter 8 to the Overall Information Flow Diagram for TSPA 1995 (Figure 1.4-6) . . . . . . . . . . . . . . 8-30

Figure 8.3-1a Sensitivity of the EBS release rate for ${ }^{14} \mathrm{C}$ to the initiation of the carbon steel outer barrier corrosion (NRC limit $=0.796 \mathrm{Ci} / \mathrm{yr}) \ldots \ldots \ldots \ldots$ 8-31

Figure 8.3-1b Sensitivity of the EBS release rate for ${ }^{99} \mathrm{Tc}$ to the initiation of the carbon steel outer barrier corrosion $(\mathrm{NRC}$ limit $=9.03 \mathrm{Ci} / \mathrm{yr}) . \ldots \ldots$ 8-31

Figure 8.3-1c Sensitivity of the EBS release rate for ${ }^{79} \mathrm{Se}$ to the initiation of the carbon steel outer barrier corrosion (NRC linit $=0.282 \mathrm{Ci} / \mathrm{yr}$ ). . . . 8-32

Figure 8.3-1d Sensitivity of the EBS release rate for ${ }^{135} \mathrm{Cs}$ to the initiation of the carbon steel outer barrier corrosion (NRC limit $=0.331 \mathrm{Ci} / \mathrm{yr}$ ). . . 8 8-32

Figure 8.3-1e Sensitivity of the EBS release rate for ${ }^{59} \mathrm{Ni}$ to the initiation of the carbon steel outer barrier corrosion (NRC limit $=1.51 \mathrm{Ci} / \mathrm{yr}) \ldots \ldots .8 \mathrm{8}-33$

Figure 8.3-1f Sensitivity of the EBS release rate for ${ }^{237} \mathrm{~Np}$ to the initiation of the carbon steel outer barrier corrosion (NRC limit $=0.782 \mathrm{Ci} / \mathrm{yr}) \ldots \ldots .833$

Figure 8.3-1g Sensitivity of the EBS release rate for ${ }^{210} \mathrm{~Pb}$ to the initiation of the carbon steel outer barrier corrosion (NRC limit $=0.00236 \mathrm{Ci} / \mathrm{yr}$ ). . . 8 8-34

Figure 8.3-1h Sensitivity of the EBS release rate for ${ }^{226} \mathrm{Ra}$ to the initiation of the carbon steel outer barrier corrosion (NRC linit $=0.00237 \mathrm{Ci} / \mathrm{yr}$ ). . . . . 8-34

Figure 8.3-2a Sensitivity of the EBS release rate for ${ }^{14} \mathrm{C}$ to cathodic protection (NRC limit $=0.796 \mathrm{Ci} / \mathrm{yr}) \ldots \ldots \ldots \ldots \ldots \ldots \ldots \ldots \ldots \ldots \ldots \ldots \ldots \ldots \ldots \ldots \ldots . .35$

Figure 8.3-2b Sensitivity of the EBS release rate for ${ }^{99} \mathrm{Tc}$ to cathodic protection (NRC $\operatorname{limit}=9.03 \mathrm{Ci} / \mathrm{yr}) . \ldots \ldots \ldots \ldots \ldots \ldots \ldots \ldots \ldots \ldots \ldots \ldots \ldots \ldots \ldots .35$ 
Figure 8.3-2c Sensitivity of the EBS release rate for ${ }^{79} \mathrm{Se}$ to cathodic protection (NRC limit $=0.282 \mathrm{Ci} / \mathrm{yr}) \ldots \ldots \ldots \ldots \ldots \ldots \ldots \ldots \ldots \ldots \ldots \ldots \ldots \ldots \ldots \ldots .36$

Figure 8.3-2d Sensitivity of the EBS release rate for ${ }^{135} \mathrm{Cs}$ to cathodic protection (NRC limit $=0.331 \mathrm{Ci} / \mathrm{yr}) \ldots \ldots \ldots \ldots \ldots \ldots \ldots \ldots \ldots \ldots \ldots . .36$

Figure 8.3-2e Sensitivity of the EBS release rate for ${ }^{59} \mathrm{Ni}$ to cathodic protection (NRC

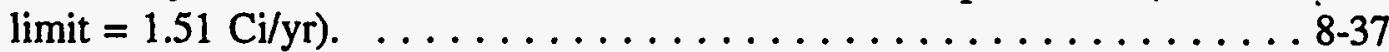

Figure 8.3-2f Sensitivity of the EBS release rate for ${ }^{237} \mathrm{~Np}$ to cathodic protection $(\mathrm{NRC}$ limit $=0.782 \mathrm{Ci} / \mathrm{yr}) \ldots \ldots \ldots \ldots \ldots \ldots \ldots \ldots . \ldots \ldots .37$

Figure 8.3-2g Sensitivity of the EBS release rate for ${ }^{210} \mathrm{~Pb}$ to cathodic protection (NRC

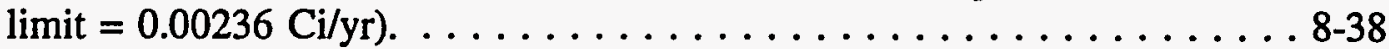

Figure 8.3-2h Sensitivity of the EBS release rate for ${ }^{226} \mathrm{Ra}$ to cathodic protection (NRC limit $=0.00237 \mathrm{Ci} / \mathrm{yr}) \ldots \ldots \ldots \ldots \ldots \ldots \ldots \ldots \ldots \ldots \ldots \ldots \ldots \ldots .38$

Figure 8.3-3a Sensitivity of the EBS release rate for ${ }^{14} \mathrm{C}$ to thermal loading and infiltration rate (NRC limit $=0.796 \mathrm{Ci} / \mathrm{yr}) . \ldots \ldots \ldots \ldots \ldots . . \ldots .39$

Figure 8.3-3b Sensitivity of the EBS release rate for ${ }^{99} \mathrm{Tc}$ to thermal loading and infiltration rate $(\mathrm{NRC}$ limit $=9.03 \mathrm{Ci} / \mathrm{yr}) \ldots \ldots \ldots \ldots \ldots . . \ldots .39$

Figure 8.3-3c Sensitivity of the EBS release rate for ${ }^{79} \mathrm{Se}$ to thermal loading and infiltration rate (NRC limit $=0.282 \mathrm{Ci} / \mathrm{yr}) . \ldots \ldots \ldots \ldots \ldots . . .48$

Figure 8.3-3d Sensitivity of the EBS release rate for ${ }^{135} \mathrm{Cs}$ to thermal loading and infiltration rate $(\mathrm{NRC}$ limit $=0.331 \mathrm{Ci} / \mathrm{yr}) \ldots \ldots \ldots \ldots \ldots \ldots .4 .40$

Figure 8.3-3e Sensitivity of the EBS release rate for ${ }^{59} \mathrm{Ni}$ to thermal loading and infiltration rate $(\mathrm{NRC}$ limit $=1.51 \mathrm{Ci} / \mathrm{yr}) \ldots \ldots \ldots \ldots \ldots \ldots .4 .41$

Figure 8.3-3f Sensitivity of the EBS release rate for ${ }^{237} \mathrm{~Np}$ to thermal loading and infiltration rate (NRC limit $=0.782 \mathrm{Ci} / \mathrm{yr}) . \ldots \ldots \ldots \ldots \ldots . . .48$

Figure 8.3-3g Sensitivity of the EBS release rate for ${ }^{210} \mathrm{~Pb}$ to thermal loading and infiltration rate (NRC limit $=0.00236 \mathrm{Ci} / \mathrm{yr}$ ).

Figure 8.3-3h Sensitivity of the EBS release rate for ${ }^{226} \mathrm{Ra}$ to thermal loading and infiltration rate (NRC limit $=0.00237 \mathrm{Ci} / \mathrm{yr}) . \ldots \ldots \ldots \ldots \ldots .42$

Figure 8.3-4a Sensitivity of the EBS release rate for ${ }^{14} \mathrm{C}$ to the presence of backfill (NRC limit $=0.796 \mathrm{Ci} / \mathrm{yr}) \ldots \ldots \ldots \ldots \ldots \ldots \ldots \ldots \ldots \ldots \ldots \ldots \ldots \ldots \ldots \ldots .43$

Figure 8.3-4b Sensitivity of the EBS release rate for ${ }^{99} \mathrm{Tc}$ to the presence of backfill $($ NRC limit $=9.03 \mathrm{Ci} / \mathrm{yr}) . \ldots \ldots \ldots \ldots \ldots \ldots \ldots \ldots .4 \ldots \ldots \ldots$

Figure 8.3-4c Sensitivity of the EBS release rate for ${ }^{79} \mathrm{Se}$ to the presence of backfill $(\mathrm{NRC}$ limit $=0.282 \mathrm{Ci} / \mathrm{yr}) \ldots \ldots \ldots \ldots \ldots \ldots \ldots \ldots \ldots .4 \ldots \ldots \ldots$

Figure 8.3-4d Sensitivity of the EBS release rate for ${ }^{135} \mathrm{Cs}$ to the presence of backfill $(\mathrm{NRC}$ limit $=0.331 \mathrm{Ci} / \mathrm{yr}) \ldots \ldots \ldots \ldots \ldots \ldots \ldots \ldots \ldots \ldots \ldots \ldots .44$

Figure 8.3-4e Sensitivity of the EBS release rate for ${ }^{59} \mathrm{Ni}$ to the presence of backfill (NRC limit $=1.51 \mathrm{Ci} / \mathrm{yr}) . \ldots \ldots \ldots \ldots \ldots \ldots \ldots \ldots \ldots \ldots \ldots .45$

Figure 8.3-4f Sensitivity of the EBS release rate for ${ }^{237} \mathrm{~Np}$ to the presence of backfill

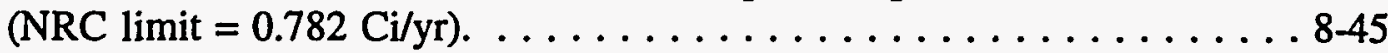

Figure $8.3-4 \mathrm{~g}$ Sensitivity of the EBS release rate for ${ }^{210} \mathrm{~Pb}$ to the presence of backfill $(\mathrm{NRC}$ limit $=0.00236 \mathrm{Ci} / \mathrm{yr}) . \ldots \ldots \ldots \ldots \ldots \ldots \ldots \ldots \ldots \ldots \ldots .46$

Figure 8.3-4h Sensitivity of the EBS release rate for ${ }^{226} \mathrm{Ra}$ to the presence of backfill $(\mathrm{NRC}$ limit $=0.00237 \mathrm{Ci} / \mathrm{yr}), \ldots \ldots \ldots \ldots \ldots \ldots \ldots \ldots .4 \ldots \ldots \ldots$ 
Figure 8.3-5a Sensitivity of the EBS release rate for ${ }^{14} \mathrm{C}$ to the alternative advective release model $(\mathrm{NRC}$ limit $=0.796 \mathrm{Ci} / \mathrm{yr}) . \ldots \ldots \ldots \ldots$. . . . . 47

Figure 8.3-5b Sensitivity of the EBS release rate for ${ }^{99} \mathrm{Tc}$ to the alternative advective release model $(\mathrm{NRC}$ limit $=9.03 \mathrm{Ci} / \mathrm{yr}) \ldots \ldots \ldots \ldots$. . . . . . . . 47

Figure 8.3-5c Sensitivity of the EBS release rate for ${ }^{79} \mathrm{Se}$ to the alternative advective release model (NRC limit $=0.282 \mathrm{Ci} / \mathrm{yr}) \ldots \ldots \ldots \ldots$. . . . 48

Figure 8.3-5d Sensitivity of the EBS release rate for ${ }^{135} \mathrm{Cs}$ to the alternative advective release model (NRC limit $=0.331 \mathrm{Ci} / \mathrm{yr}) \ldots \ldots \ldots \ldots$. . . . . 48

Figure 8.3-5e Sensitivity of the EBS release rate for ${ }^{59} \mathrm{Ni}$ to the alternative advective release model $(\mathrm{NRC}$ limit $=1.51 \mathrm{Ci} / \mathrm{yr}) \ldots \ldots \ldots \ldots$. . . . . . 8 - 49

Figure 8.3-5f Sensitivity of the EBS release rate for ${ }^{237} \mathrm{~Np}$ to the alternative advective release model (NRC limit $=0.782 \mathrm{Ci} / \mathrm{yr}) \ldots \ldots \ldots \ldots$. . . . . . 8 - 49

Figure 8.3-5g Sensitivity of the EBS release rate for ${ }^{210} \mathrm{~Pb}$ to the alternative advective release model $(\mathrm{NRC}$ limit $=0.00236 \mathrm{Ci} / \mathrm{yr}) . \ldots \ldots \ldots$. . . . 50

Figure 8.3-5h Sensitivity of the EBS release rate for ${ }^{226} \mathrm{Ra}$ to the alternative advective release model $(\mathrm{NRC}$ limit $=0.00237 \mathrm{Ci} / \mathrm{yr}) \ldots \ldots \ldots$. . . . . . 8 50

Figure 8.3-6a Sensitivity of the EBS release rate for ${ }^{14} \mathrm{C}$ to the presence of a capillary

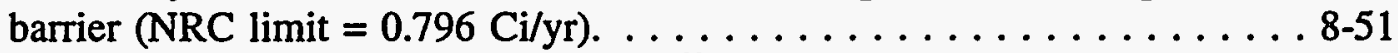

Figure 8.3-6b Sensitivity of the EBS release rate for ${ }^{99} \mathrm{Tc}$ to the presence of a capillary barrier (NRC limit $=9.03 \mathrm{Ci} / \mathrm{yr}) . \ldots \ldots \ldots \ldots \ldots \ldots . \ldots \ldots$. . . . . . . . . .

Figure 8.3-6c Sensitivity of the EBS release rate for ${ }^{79} \mathrm{Se}$ to the presence of a capillary barrier (NRC limit $=0.282 \mathrm{Ci} / \mathrm{yr}) . \ldots \ldots \ldots \ldots \ldots \ldots$. . . . . . . . . . . . .

Figure 8.3-6d Sensitivity of the EBS release rate for ${ }^{135} \mathrm{Cs}$ to the presence of a capillary barrier (NRC limit $=0.331 \mathrm{Ci} / \mathrm{yr}$ ).

Figure 8.3-6e Sensitivity of the EBS release rate for ${ }^{59} \mathrm{Ni}$ to the presence of a capillary barrier $(\mathrm{NRC}$ limit $=1.51 \mathrm{Ci} / \mathrm{yr}) \ldots \ldots \ldots \ldots \ldots \ldots . \ldots \ldots$. . . . . . . . . . .

Figure 8.3-6f Sensitivity of the EBS release rate for ${ }^{237} \mathrm{~Np}$ to the presence of capillary barrier $(\mathrm{NRC}$ limit $=0.782 \mathrm{Ci} / \mathrm{yr}) . \ldots \ldots \ldots \ldots \ldots \ldots . \ldots \ldots$. . . . . . . . . .

Figure 8.3-6g Sensitivity of the EBS release rate for ${ }^{210} \mathrm{~Pb}$ to the presence of a capillary barrier $(\mathrm{NRC}$ limit $=0.00236 \mathrm{Ci} / \mathrm{yr}) \ldots \ldots \ldots \ldots$. . . . . . . . . . .

Figure 8.3-6h Sensitivity of the EBS release rate for ${ }^{226} \mathrm{Ra}$ to the presence of a capillary barrier $(\mathrm{NRC}$ limit $=0.00237 \mathrm{Ci} / \mathrm{yr}) \ldots \ldots \ldots \ldots \ldots$. . . . . . . . . . .

Figure 8.3-7a Sensitivity of the EBS release rate for ${ }^{14} \mathrm{C}$ to cladding failure (NRC limit $=$

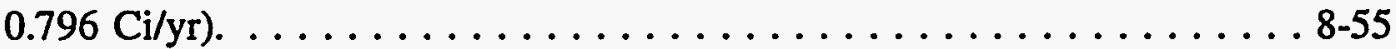

Figure 8.3-7b Sensitivity of the EBS release rate for ${ }^{99} \mathrm{Tc}$ to cladding failure (NRC

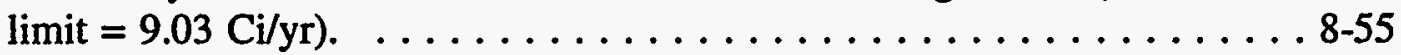

Figure 8.3-7c Sensitivity of the EBS release rate for ${ }^{79} \mathrm{Se}$ to cladding failure (NRC $\operatorname{limit}=0.282 \mathrm{Ci} / \mathrm{yr}) \ldots \ldots \ldots \ldots \ldots \ldots \ldots \ldots \ldots$. . . . . . . . . . . . . . . . .

Figure 8.3-7d Sensitivity of the EBS release rate for ${ }^{135} \mathrm{Cs}$ to cladding failure (NRC limit $=0.331 \mathrm{Ci} / \mathrm{yr}) \ldots \ldots \ldots \ldots \ldots \ldots \ldots \ldots \ldots \ldots . \ldots \ldots \ldots$

Figure 8.3-7e Sensitivity of the EBS release rate for ${ }^{59} \mathrm{Ni}$ to cladding failure (NRC limit $=1.51 \mathrm{Ci} / \mathrm{yr}$ ).

Figure 8.3-7f Sensitivity of the EBS release rate for ${ }^{237} \mathrm{~Np}$ to cladding failure (NRC limit $=0.782 \mathrm{Ci} / \mathrm{yr}$ ) 
Figure $8.3-7 \mathrm{~g}$ Sensitivity of the EBS release rate for ${ }^{210} \mathrm{~Pb}$ to cladding failure (NRC limit $=0.00236 \mathrm{Ci} / \mathrm{yr}) . \ldots \ldots \ldots \ldots \ldots \ldots \ldots \ldots \ldots$ 8.5. . . . . . . . .

Figure 8.3-7h Sensitivity of the EBS release rate for ${ }^{226} \mathrm{Ra}$ to cladding failure (NRC limit $=0.00237 \mathrm{Ci} / \mathrm{yr}) . \ldots \ldots \ldots \ldots \ldots \ldots \ldots \ldots \ldots \ldots . \ldots \ldots$

Figure 8.3-8a Sensitivity of the EBS release rate for ${ }^{14} \mathrm{C}$ to cladding failure with the spent fuel surface area increased by a factor of 100 (NRC limit $=0.796$

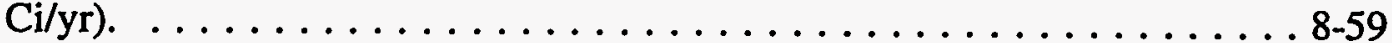

Figure 8.3-8b Sensitivity of the EBS release rate for ${ }^{99} \mathrm{Tc}$ to cladding failure with the spent fuel surface area increased by a factor of 100 (NRC limit $=9.03$ $\mathrm{Ci} / \mathrm{yr}$ ).

Figure 8.3-8c Sensitivity of the EBS release rate for ${ }^{79} \mathrm{Se}$ to cladding failure with the spent fuel surface area increased by a factor of 100 (NRC limit $=0.282$ $\mathrm{Ci} / \mathrm{yr}$ ).

Figure 8.3-8d Sensitivity of the EBS release rate for ${ }^{135} \mathrm{Cs}$ to cladding failure with the spent fuel surface area increased by a factor of 100 (NRC limit $=0.331$ $\mathrm{Ci} / \mathrm{yr}) . \ldots \ldots \ldots \ldots \ldots \ldots \ldots \ldots \ldots \ldots \ldots . \ldots \ldots$. . . . . . . . . . . . . . . . . .

Figure $8.3-8 \mathrm{e}$ Sensitivity of the EBS release rate for ${ }^{59} \mathrm{Ni}$ to cladding failure with the spent fuel surface area increased by a factor of 100 (NRC limit $=1.51$

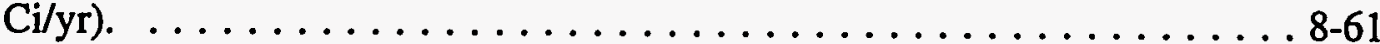

Figure 8.3-8f Sensitivity of the EBS release rate for ${ }^{237} \mathrm{~Np}$ to cladding failure with the spent fuel surface area increased by a factor of 100 (NRC limit $=0.782$ $\mathrm{Ci} / \mathrm{yr}$ ).

Figure $8.3-8 \mathrm{~g}$ Sensitivity of the EBS release rate for ${ }^{210} \mathrm{~Pb}$ to cladding failure with the spent fuel surface area increased by a factor of 100 (NRC limit $=$ $0.00236 \mathrm{Ci} / \mathrm{yr}$ ).

Figure 8.3-8h Sensitivity of the EBS release rate for ${ }^{226} \mathrm{Ra}$ to cladding failure with the spent fuel surface area increased by a factor of 100 (NRC limit $=$

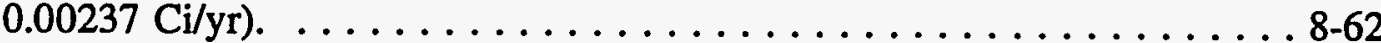

Figure 8.3-9a Sensitivity of the EBS release rate for ${ }^{14} \mathrm{C}$ to the thermal-hydrologic model $(\mathrm{NRC}$ limit $=0.796 \mathrm{Ci} / \mathrm{yr}$ ).

Figure 8.3-9b Sensitivity of the EBS release rate for ${ }^{99} \mathrm{Tc}$ to the thermal-hydrologic

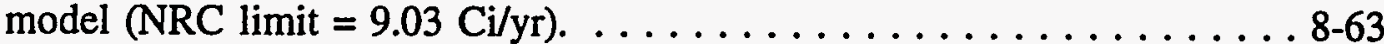

Figure $8.3-9 \mathrm{c}$ Sensitivity of the EBS release rate for ${ }^{79} \mathrm{Se}$ to the thermal-hydrologic model $(\mathrm{NRC}$ limit $=0.282 \mathrm{Ci} / \mathrm{yr}) . \ldots \ldots \ldots$. . . . . . . . . . 8-64

Figure 8.3-9d Sensitivity of the EBS release rate for ${ }^{135} \mathrm{Cs}$ to the thermal-hydrologic model $(\mathrm{NRC}$ limit $=0.331 \mathrm{Ci} / \mathrm{yr}) . \ldots \ldots \ldots \ldots \ldots$. . . . . . . . . . . . . . .

Figure 8.3-9e Sensitivity of the EBS release rate for ${ }^{59} \mathrm{Ni}$ to the thermal-hydrologic model $(\mathrm{NRC}$ limit $=1.51 \mathrm{Ci} / \mathrm{yr}) . \ldots \ldots \ldots \ldots \ldots \ldots \ldots$ 8-65

Figure 8.3-9f Sensitivity of the EBS release rate for ${ }^{237} \mathrm{~Np}$ to the thermal-hydrologic model $(\mathrm{NRC}$ limit $=0.782 \mathrm{Ci} / \mathrm{yr}) . \ldots \ldots \ldots \ldots \ldots \ldots \ldots$ 8.6. . . . . . .

Figure $8.3-9 \mathrm{~g}$ Sensitivity of the EBS release rate for ${ }^{210} \mathrm{~Pb}$ to the thermal-hydrologic model $(\mathrm{NRC}$ limit $=0.00236 \mathrm{Ci} / \mathrm{yr}) . \ldots \ldots \ldots \ldots \ldots$. . . . . . . . . . . . . . .

Figure 8.3-9h Sensitivity of the EBS release rate for ${ }^{226} \mathrm{Ra}$ to the thermal-hydrologic model $(\mathrm{NRC}$ limit $=0.00237 \mathrm{Ci} / \mathrm{yr})$. 
Figure 8.3-10 Sensitivity of the EBS release rate for ${ }^{129} \mathrm{I}$ to its release mode from the EBS (NRC limit $=0.022 \mathrm{Ci} / \mathrm{yr}) . \ldots \ldots \ldots \ldots$. . . . . . . . . . . . . . . .

Figure 8.4-1 CCDF's of normalized cumulative release from the EBS (normalized to the 10 CFR 191.13 limit): 83 MTU/acre, no backfill, high infiltration rate, R.H. switch for the corrosion initiation. . . . . . . . . . . . . . . . 8-67

Figure 8.4-2 CCDF's of normalized cumulative release from the EBS (normalized to the 10 CFR 191.13 limit): 25 MTU/acre, no backfill, high infiltration rate, R.H. switch for the corrosion initiation. . . . . . . . . . . 8-68

Figure 8.4-3 CCDF's of normalized cumulative release for all the radionuclides from the EBS (normalized to the 10 CFR 191.13 limit): 25 or $83 \mathrm{MTU} / \mathrm{acre}$, no backfill, high or low infiltration rate, R.H. switch for corrosion

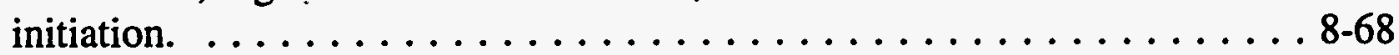

Figure 8.4-4 CCDF's of normalized cumulative release for ${ }^{14} \mathrm{C}$ from the EBS (normalized to the $10 \mathrm{CFR} 191.13$ limit): 25 or $83 \mathrm{MTU} / a c r e$, no backfill, high or low infiltration rate, R.H. switch for the corrosion initiation. . . . . . . . . . . . . . . . . . . . . . 8-69

Figure 8.4-5 CCDF's of normalized cumulative release for ${ }^{99} \mathrm{Tc}$ from the EBS (normalized to the $10 \mathrm{CFR} 191.13$ limit): $25 \mathrm{MTU} / \mathrm{acre}$ or 83 MTU/acre, no backfill, high or low infiltration rate, R.H. switch for the corrosion initiation. . . . . . . . . . . . . . . . . . . . 8-69

Figure 8.4-6 CCDF's of normalized cumulative release for ${ }^{129} \mathrm{I}$ from the EBS (normalized to the $10 \mathrm{CFR} 191.13$ limit): 25 or $83 \mathrm{MTU} / \mathrm{acre}$, no backfill, high or low infiltration rate, R.H. switch for the corrosion initiation. $8-70$

Figure 8.4-7 CCDF's of normalized cumulative release for ${ }^{237} \mathrm{~Np}$ from the EBS (normalized to the $10 \mathrm{CFR} 191.13$ limit): 25 or $83 \mathrm{MTU} / \mathrm{acre}$, no backfill, high or low infiltration rate, R.H. switch for the corrosion initiation. $8-70$

Figure 8.4-8 CCDF's of normalized cumulative release for ${ }^{59} \mathrm{Ni}$ from the EBS (normalized to the 10 CFR 191.13 limit): $25 \mathrm{MTU} /$ acre or 83 MTU/acre, no backfill, high or low infiltration rate, R.H. switch for the corrosion initiation. . . . . . . . . . . . . . . 8-71

Figure 9.1-1 Relationship of Chapter 9 to the Overall Information Flow Diagram for TSPA 1995 (Figure 1.4-6). . . . . . . . . . . . . . . . . 9-35

Figure 9.2-1 Expected-value release-rate history: 10,000 years, 83 MTU/acre, no backfill, high infiltration $\left(\mathrm{q}_{\mathrm{inf}}=1.25 \mathrm{~mm} / \mathrm{yr}\right) . \ldots \ldots \ldots$. . . . . . . . . .

Figure 9.2-2 Expected-value release-rate history: 10,000 years, 25 MTU/acre, no backfill, high infiltration $\left(\mathrm{q}_{\mathrm{inf}}=1.25 \mathrm{~mm} / \mathrm{yr}\right) . \ldots \ldots \ldots \ldots$. . . . . . . . .

Figure 9.2-3 Expected-value release-rate history: 10,000 years, 83 MTU/acre, backfill ("yes"), high infiltration $\left(\mathrm{q}_{\mathrm{inf}}=1.25 \mathrm{~mm} / \mathrm{yr}\right) . \ldots \ldots \ldots$. . . . 9-37

Figure 9.2-4 Expected-value release-rate history: 10,000 years, 25 MTU/acre, backfill ("yes"), high infiltration $\left(q_{\mathrm{inf}}=1.25 \mathrm{~mm} / \mathrm{yr}\right)$. 
Figure 9.2-5 CCDF of Total Normalized Cumulative Release: 10,000 years, 83 MTU/acre and 25 MTU/acre, no backfill, high infiltration range. . . . . 9-38

Figure 9.2-6 CCDF of Total Normalized Cumulative Release: 10,000 years, 83 MTU/acre and $25 \mathrm{MTU} / \mathrm{acre}$, backfill, high infiltration range. . . . . . 9-38

Figure 9.2-7 CCDF of Total Normalized Cumulative Release: 10,000 years, 83 MTU/acre, with and without backfill, high infiltration range. . . . . . . 9-39

Figure 9.2-8 CCDF of Total Normalized Cumulative Release: 10,000 years, 25 MTU/acre, with and without backfill, high infiltration range. . . . . . 9-39

Figure 9.2-9 Expected-value dose history: 10,000 years, 83 MTU/acre, no backfill, high infiltration $\left(\mathrm{q}_{\mathrm{inf}}=1.25 \mathrm{~mm} / \mathrm{yr}\right) \ldots \ldots \ldots \ldots \ldots \ldots \ldots . .40$

Figure 9.2-10 Expected-value dose history: 10,000 years, 25 MTU/acre, no backfill, high infiltration $\left(\mathrm{q}_{\mathrm{inf}}=1.25 \mathrm{~mm} / \mathrm{yr}\right) \ldots \ldots \ldots \ldots \ldots \ldots \ldots .40$

Figure 9.2-11 Expected-value dose history: 10,000 years, 83 MTU/acre, backfill ("yes"), high infiltration $\left(\mathrm{q}_{\mathrm{inf}}=1.25 \mathrm{~mm} / \mathrm{yr}\right) \ldots \ldots \ldots \ldots \ldots \ldots .41$

Figure 9.2-12 Expected-value dose history: 10,000 years, 25 MTU/acre, backfill ("yes"), high infiltration $\left(\mathrm{q}_{\mathrm{inf}}=1.25 \mathrm{~mm} / \mathrm{yr}\right) \ldots \ldots \ldots \ldots \ldots \ldots .41$

Figure 9.2-13 CCDF of Total Peak Dose: 10,000 years, 83 MTU/acre and 25 MTU/acre, no backfill, high infiltration range. . . . . . . . . 9-42

Figure 9.2-14 CCDF of Total Peak Dose: 10,000 years, 83 MTU/acre and 25 MTU/acre, backfill, high infiltration range. . . . . . . . . . 9-42

Figure 9.2-15 CCDF of Total Peak Dose: 10,000 years, $83 \mathrm{MTU} / \mathrm{acre}$, with and without backfill, high infiltration range. . . . . . . . . . . 9-43

Figure 9.2-16 CCDF of Total Peak Dose: 10,000 years, 25 MTU/acre, with and without backfill, high infiltration range. . . . . . . . . . . 9-43

Figure 9.2-17 CCDF of Total Normalized Cumulative Release: 10,000 years, Buscheck $24 \mathrm{MTU} / \mathrm{acre}$ and Lingineni $25 \mathrm{MTU} / \mathrm{acre}$, no backfill, high infiltration range. . . . . . . . . . . . . . . . . . 9-44

Figure 9.2-18 CCDF of Total Peak Dose: 10,000 years, Buscheck 24 MTU/acre and Lingineni 25 MTU/acre, no backfill, high infiltration range. . . . . . . 9-44

Figure 9.2-19 Expected-value release-rate history: 10,000 years, Buscheck 24 MTU/acre, no backfill, high infiltration $\left(\mathrm{q}_{\mathrm{inf}}=1.25 \mathrm{~mm} / \mathrm{yr}\right) . \ldots \ldots .99$

Figure 9.2-20 Expected-value dose history: 10,000 years, Buscheck 24 MTU/acre, no backfill, high infiltration $\left(\mathrm{q}_{\mathrm{inf}}=1.25 \mathrm{~mm} / \mathrm{yr}\right) . \ldots \ldots \ldots \ldots \ldots .45$

Figure 9.2-21 Effect of alternative corrosion initiation models: Relative humidity only vs. temperature and relative humidity. CCDF of Total Peak Dose: 10,000 years, 83 MTU/acre, no backfill, high infiltration range. . . . . . 9-46

Figure 9.2-22 Effect of alternative corrosion initiation models: Relative humidity only vs. temperature and relative humidity. CCDF of Total Normalized Cumulative Release: 10,000 years, 83 MTU/acre, no backfill, high infiltration range. . . . . . . . . . . . . . . . . 9-46

Figure 9.2-23 Expected-value dose history: 10,000 years, "drips-on-waste-container" EBS transport model, 83 MTU/acre, backfill, high infiltration $\left(\mathrm{q}_{\text {inf }}=\right.$ $1.25 \mathrm{~mm} / \mathrm{yr}) \ldots \ldots \ldots \ldots \ldots \ldots \ldots \ldots \ldots \ldots \ldots \ldots . .47$ 
Figure 9.2-24 Expected-value dose history: 10,000 years, capillary-barrier-effect ("no drips") EBS transport model, $83 \mathrm{MTU} / \mathrm{acre}$, backfill, high infiltration $\left(\mathrm{q}_{\mathrm{inf}}=1.25\right.$

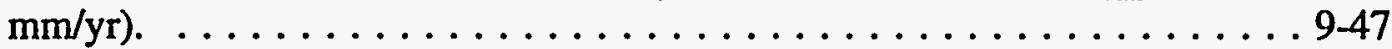

Figure 9.2-25 Expected-value dose history: 10,000 years, capillary-barrier-effect ("no drips") EBS transport model with ${ }^{129} \mathrm{~T}$ and ${ }^{36} \mathrm{Cl}$ transported through EBS in the aqueous phase, $83 \mathrm{MTU} / \mathrm{acre}$, backfill, high infiltration $\left(\mathrm{q}_{\mathrm{inf}}=\right.$

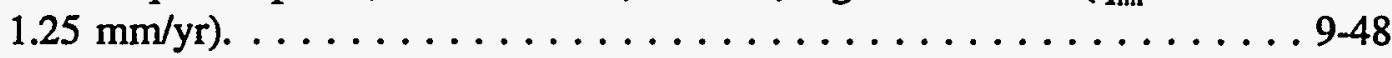

Figure 9.2-26 Comparison of EBS transport models. CCDF of Total Peak Dose: 10,000 years, 83 MTU/acre, backfill, high infiltration range. . . . . . . . 9-48

Figure 9.2-27 Comparison of EBS transport models. CCDF of Total Normalized Cumulative Release: 10,000 years, 83 MTU/acre, backfill, high infiltration range. . . . . . . . . . . . . . . . . . . . . 9-49

Figure 9.2-28 Comparison of intra-unit fracture connectivity parameter: $\lambda=1 /(0.1 \mathrm{~h})$ vs. $\lambda=1 / \mathrm{h}$ vs. $\lambda=1 /(100 \mathrm{~h})$, where $\mathrm{h}=$ pathway length in each unit. CCDF of Total Peak Dose: 10,000 years, 83 MTU/acre, backfill, high infiltration range. . . . . . . . . . . . . . . . . . . 9-49

Figure 9.2-29 Comparison of intra-unit fracture connectivity parameter: $\lambda=1 /(0.1 \mathrm{~h})$ vs. $\lambda=1 / \mathrm{h}$ vs. $\lambda=1 /(100 \mathrm{~h})$, where $h=$ pathway length in each unit. CCDF of Total Normalized Cumulative Release: 10,000 years, 83 MTU/acre, backfill, high infiltration range. . . . . . . . . . 9-50

Figure 9.2-30 Scatter plot of 10,000-year total normalized cumulative release versus matrix velocity $(\mathrm{m} / \mathrm{yr})$ in the $\mathrm{CHnv}$ for $83 \mathrm{MTU} / \mathrm{acre}$, backfill, high infiltration $\left(\mathrm{q}_{\mathrm{inf}}=1.25 \mathrm{~mm} / \mathrm{yr}\right) . \ldots \ldots \ldots \ldots \ldots \ldots . \ldots \ldots$. . . . . . . . .

Figure 9.2-31 Scatter plot of 10,000-year total normalized cumulative release versus $\mathrm{UZ}$ percolation flux (mm/yr) for $83 \mathrm{MTU} / \mathrm{acre}$, backfill, high infiltration

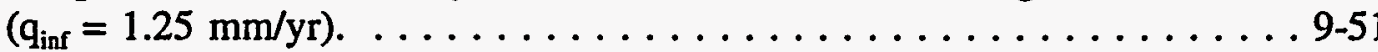

Figure 9.2-32 Scatter plot of 10,000-year total normalized cumulative release versus fraction of fracture flow in the CHnv for $83 \mathrm{MTU} / \mathrm{acre}$, backfill, high infiltration $\left(\mathrm{q}_{\mathrm{inf}}=1.25 \mathrm{~mm} / \mathrm{yr}\right) . \ldots \ldots \ldots \ldots \ldots \ldots . \ldots \ldots$. $\ldots \ldots \ldots$

Figure 9.2-33 Scatter plot of 10,000-year total normalized cumulative release versus climate-change modifier for $83 \mathrm{MTU} / \mathrm{acre}$, backfill, high infiltration $\left(\mathrm{q}_{\mathrm{inf}}\right.$

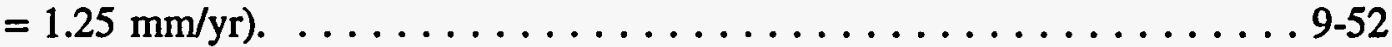

Figure 9.2-34 Scatter plot of 10,000-year total normalized cumulative release versus saturated-zone Darcy velocity (m/yr) for $83 \mathrm{MTU} / \mathrm{acre}$, backfill, high infiltration $\left(\mathrm{q}_{\mathrm{inf}}=1.25 \mathrm{~mm} / \mathrm{yr}\right)$.

Figure 9.2-35 Scatter plot of 10,000-year total normalized cumulative release versus fraction of fracture flow in the CHnz for $83 \mathrm{MTU} /$ acre, backfill, high infiltration $\left(\mathrm{q}_{\mathrm{inf}}=1.25 \mathrm{~mm} / \mathrm{yr}\right)$.

Figure 9.2-36 Scatter plot of 10,000-year total normalized cumulative release versus $\mathrm{Np}$ sorption coefficient in the vitric tuff for $83 \mathrm{MTU} / \mathrm{acre}$, backfill, high infiltration $\left(\mathrm{q}_{\mathrm{inf}}=1.25 \mathrm{~mm} / \mathrm{yr}\right)$. 
Figure 9.2-37 Scatter plot of 10,000-year total peak dose versus matrix velocity $(\mathrm{m} / \mathrm{yr})$ in the CHnv for 83 MTU/acre, backfill, high infiltration ( $q_{\text {inf }}=1.25$

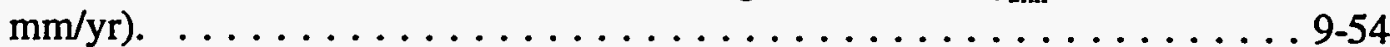

Figure 9.2-38 Scatter plot of 10,000-year total peak dose versus UZ percolation flux $(\mathrm{mm} / \mathrm{yr})$ for $83 \mathrm{MTU} / \mathrm{acre}$, backfill, high infiltration $\left(\mathrm{q}_{\mathrm{inf}}=1.25 \mathrm{~mm} / \mathrm{yr}\right)$. . 9-55

Figure 9.2-39 Scatter plot of 10,000-year total peak dose versus fraction of fracture flow in the CHnv for $83 \mathrm{MTU} / \mathrm{acre}$, backfill, high infiltration $\left(\mathrm{q}_{\text {inf }}=\right.$ $1.25 \mathrm{~mm} / \mathrm{yr}) . \ldots \ldots \ldots \ldots \ldots \ldots \ldots \ldots \ldots \ldots . . \ldots .55$

Figure 9.2-40 Scatter plot of 10,000-year total peak dose versus climate-change modifier for $83 \mathrm{MTU} / \mathrm{acre}$, backfill, high infiltration $\left(\mathrm{q}_{\mathrm{inf}}=1.25 \mathrm{~mm} / \mathrm{yr}\right)$. . 9-56

Figure 9.2-41 Scatter plot of 10,000-year total peak dose versus fraction of fracture flow in the CHnz for $83 \mathrm{MTU} / \mathrm{acre}$, backfill, high infiltration $\left(\mathrm{q}_{\text {inf }}=1.25\right.$ $\mathrm{mm} / \mathrm{yr}) . \ldots \ldots \ldots \ldots \ldots \ldots \ldots \ldots \ldots \ldots . \ldots \ldots .6 .56$

Figure 9.2-42 Scatter plot of 10,000-year total peak dose versus fraction of fracture flow in the TSv for $83 \mathrm{MTU} / \mathrm{acre}$, backfill, high infiltration $\left(\mathrm{q}_{\mathrm{inf}}=1.25\right.$ $\mathrm{mm} / \mathrm{yr}) . \ldots \ldots \ldots \ldots \ldots \ldots \ldots \ldots \ldots \ldots . \ldots \ldots$. 57

Figure 9.2-43 Scatter plot of 10,000-year total peak dose versus matrix velocity (m/yr) in the TSv for $83 \mathrm{MTU} / \mathrm{acre}$, backfill, high infiltration $\left(\mathrm{q}_{\mathrm{inf}}=1.25\right.$ $\mathrm{mm} / \mathrm{yr}) . \ldots \ldots \ldots \ldots \ldots \ldots \ldots \ldots \ldots \ldots \ldots . \ldots \ldots .6 \ldots \ldots$

Figure 9.3-1a Expected-value dose history: 1,000,000 years, 83 MTU/acre, no backfill, high infiltration (initial $\mathrm{q}_{\mathrm{inf}}=1.25 \mathrm{~mm} / \mathrm{yr}$ ), cyclical- $\mathrm{q}_{\mathrm{inf}}$ climate model. . . 9-58

Figure 9.3-1b Expected-value dose history: 100,000 years, 83 MTU/acre, no backfill, high infiltration (initial $\mathrm{q}_{\mathrm{inf}}=1.25 \mathrm{~mm} / \mathrm{yr}$ ), cyclical- $\mathrm{q}_{\mathrm{inf}}$ climate model. . . 9-58

Figure 9.3-2a Expected-value dose history: 1,000,000 years, 25 MTU/acre, no backfill, high infiltration (initial $\mathrm{q}_{\mathrm{inf}}=1.25 \mathrm{~mm} / \mathrm{yr}$ ), cyclical- $\mathrm{q}_{\mathrm{inf}}$ climate model. . . 9-59

Figure 9.3-2b Expected-value dose history: 100,000 years, 25 MTU/acre, no backfill, high infiltration (initial $\mathrm{q}_{\mathrm{inf}}=1.25 \mathrm{~mm} / \mathrm{yr}$ ), cyclical- $\mathrm{q}_{\text {inf }}$ climate model. . . 9 9-59

Figure 9.3-3a Expected-value dose history: 1,000,000 years, 83 MTU/acre, backfill, high infiltration (initial $\mathrm{q}_{\mathrm{inf}}=1.25 \mathrm{~mm} / \mathrm{yr}$ ), cyclical- $\mathrm{q}_{\mathrm{inf}}$ climate model. . . 9-60

Figure 9.3-3b Expected-value dose history: 100,000 years, 83 MTU/acre, backfill, high infiltration (initial $\mathrm{q}_{\mathrm{inf}}=1.25 \mathrm{~mm} / \mathrm{yr}$ ), cyclical- $\mathrm{q}_{\mathrm{inf}}$ climate model. . . . . 9-60

Figure 9.3-4a Expected-value dose history: 1,000,000 years, 25 MTU/acre, backfill, high infiltration (initial $\mathrm{q}_{\mathrm{inf}}=1.25 \mathrm{~mm} / \mathrm{yr}$ ), cyclical- $\mathrm{q}_{\mathrm{inf}}$ climate model. . . 9-61

Figure 9.3-4b Expected-value dose history: 100,000 years, 25 MTU/acre, backfill, high infiltration (initial $\mathrm{q}_{\mathrm{inf}}=1.25 \mathrm{~mm} / \mathrm{yr}$ ), cyclical- $\mathrm{q}_{\mathrm{inf}}$ climate model. . . . . 9-61

Figure 9.3-5 Expected-value total dose history: 1,000,000 years, 83 MTU/acre versus $25 \mathrm{MTU} / \mathrm{acre}$, no backfill, high infiltration (initial $\mathrm{q}_{\mathrm{inf}}=1.25 \mathrm{~mm} / \mathrm{yr}$ ), cyclical- $\mathrm{q}_{\text {inf }}$ climate model. . ................... 9-62

Figure 9.3-6 Expected-value dose history: 1,000,000 years, 83 MTU/acre, no backfill, low infiltration (initial $\mathrm{q}_{\text {inf }}=0.03 \mathrm{~mm} / \mathrm{yr}$ ), cyclical- $\mathrm{q}_{\text {inf }}$ climate model. $\ldots$ 9-62

Figure 9.3-7a Expected-value dose history: 1,000,000 years, 25 MTU/acre, no backfill, low infiltration (initial $\mathrm{q}_{\mathrm{inf}}=0.03 \mathrm{~mm} / \mathrm{yr}$ ), cyclical- $\mathrm{q}_{\mathrm{inf}}$ climate model. . . 9-63 


\section{List of Figures (Continued)}

Figure 9.3-7b Expected-value dose history: 100,000 years, 25 MTU/acre, no backfill, low infiltration (initial $q_{\mathrm{inf}}=0.03 \mathrm{~mm} / \mathrm{yr}$ ), cyclical $-\mathrm{q}_{\mathrm{inf}}$ climate model. . . 9-63

Figure 9.3-8 Expected-value dose history: 1,000,000 years, 83 MTU/acre, backfill, low infiltration (initial $q_{\mathrm{inf}}=0.03 \mathrm{~mm} / \mathrm{yr}$ ), cyclical- $\mathrm{q}_{\mathrm{inf}}$ climate model. $\ldots$ 9-64

Figure 9.3-9a Expected-value dose history: 1,000,000 years, 25 MTU/acre, backfill, low infiltration (initial $\mathrm{q}_{\mathrm{inf}}=0.03 \mathrm{~mm} / \mathrm{yr}$ ), cyclical- $\mathrm{q}_{\mathrm{inf}}$ climate model. $\ldots$ 9-65

Figure 9.3-9b Expected-value dose history: 100,000 years, 25 MTU/acre, backfill, low infiltration (initial $\mathrm{q}_{\mathrm{inf}}=0.03 \mathrm{~mm} / \mathrm{yr}$ ), cyclical- $\mathrm{q}_{\mathrm{inf}}$ climate model. . . . . . 9-65

Figure 9.3-10 Expected-value dose history for ${ }^{99} \mathrm{Tc}$. 1,000,000 years, infiltration rate comparison: "high" ( $\left.\mathrm{q}_{\mathrm{inf}}=1.25 \mathrm{~mm} / \mathrm{yr}\right)$ versus "low" $\left(\mathrm{q}_{\mathrm{inf}}=0.03\right.$ $\mathrm{mm} / \mathrm{yr}$ ) infiltration, $83 \mathrm{MTU} / \mathrm{acre}$, backfill, cyclical- $\mathrm{q}_{\text {inf }}$ climate model. . . . 9-66

Figure 9.3-11 Expected-value dose history for ${ }^{129} \mathrm{~T}$. 1,000,000 years, infiltration rate comparison: "high" ( $\left.\mathrm{q}_{\text {inf }}=1.25 \mathrm{~mm} / \mathrm{yr}\right)$ versus "low" $\left(\mathrm{q}_{\mathrm{inf}}=0.03\right.$ $\mathrm{mm} / \mathrm{yr}$ ) infiltration, $83 \mathrm{MTU} / \mathrm{acre}$, backfill, cyclical- $\mathrm{q}_{\mathrm{inf}}$ climate model. . . 9-66

Figure 9.3-12 Expected-value dose history for ${ }^{237} \mathrm{~Np}$. 1,000,000 years, infiltration rate comparison: "high" $\left(\mathrm{q}_{\mathrm{inf}}=1.25 \mathrm{~mm} / \mathrm{yr}\right)$ versus "low" $\left(\mathrm{q}_{\mathrm{inf}}=0.03\right.$ $\mathrm{mm} / \mathrm{yr}$ ) infiltration, $83 \mathrm{MTU} / \mathrm{acre}$, backfill, cyclical- $\mathrm{q}_{\mathrm{inf}}$ climate model. . . . 9-67

Figure 9.3-13 CCDF of Total Peak Dose: 1,000,000 years, 83 MTU/acre, with ("yes") and without ("no") backfill, high and low infiltration $\left(\mathrm{q}_{\mathrm{inf}}\right)$ ranges, cyclical- $q_{\text {inf }}$ climate model. . . . . . . . . . . . . . . . . . 9-67

Figure 9.3-14 CCDF of Total Peak Dose: 1,000,000 years, 25 MTU/acre, with ("yes") and without ("no") backfill, high and low infiltration $\left(\mathrm{q}_{\mathrm{inf}}\right)$ ranges,

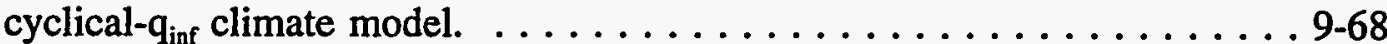

Figure 9.3-15 CCDF of Total Peak Dose: 1,000,000 years, 83 MTU/acre and 25 MTU/acre, with ("yes") backfill, high and low infiltration $\left(\mathrm{q}_{\mathrm{inf}}\right)$ ranges, cyclical- $\mathrm{q}_{\mathrm{inf}}$ climate model. . . . . . . . . . . . . . . . 9-68

Figure 9.3-16 CCDF of Total Normalized Cumulative Release: $1,000,000$ years, 83 MTU/acre and 25 MTU/acre, with ("yes") backfill, high and low infiltration $\left(\mathrm{q}_{\mathrm{inf}}\right)$ ranges, cyclical- $\mathrm{q}_{\mathrm{inf}}$ climate model.

Figure 9.3-17 Expected-value release-rate history: 1,000,000 years, 83 MTU/acre, backfill, high infiltration (initial $\mathrm{q}_{\mathrm{inf}}=1.25 \mathrm{~mm} / \mathrm{yr}$ ), cyclical- $\mathrm{q}_{\mathrm{inf}}$ climate

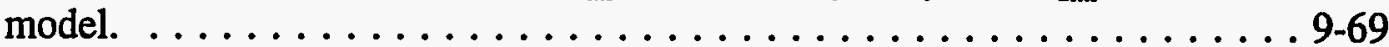

Figure 9.3-18 Expected-value release-rate history: 1,000,000 years, 25 MTU/acre, backfill, high infiltration (initial $\mathrm{q}_{\mathrm{inf}}=1.25 \mathrm{~mm} / \mathrm{yr}$ ), cyclical- $\mathrm{q}_{\mathrm{inf}}$ climate

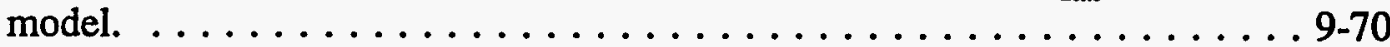

Figure 9.3-19 Expected-value release-rate history: 1,000,000 years, 83 MTU/acre, backfill, low infiltration (initial $\mathrm{q}_{\mathrm{inf}}=0.03 \mathrm{~mm} / \mathrm{yr}$ ), cyclical- $\mathrm{q}_{\mathrm{inf}}$ climate model.

Figure 9.3-20 Expected-value release-rate history: 1,000,000 years, $25 \mathrm{MTU} / \mathrm{acre}$, backfill, low infiltration (initial $\mathrm{q}_{\text {inf }}=0.03 \mathrm{~mm} / \mathrm{yr}$ ), cyclical- $\mathrm{q}_{\mathrm{inf}}$ climate model. ...........................9-71 
Figure 9.3-21 Expected-value dose history: 1,000,000 years, Buscheck 80 MTU/acre, no backfill, high infiltration (initial $\mathrm{q}_{\mathrm{inf}}=1.25 \mathrm{~mm} / \mathrm{yr}$ ), cyclical- $\mathrm{q}_{\mathrm{inf}}$ climate model. . . . . . . . . . . . . . . . . . . . . . 9-71

Figure 9.3-22 Expected-value dose history: 1,000,000 years, Buscheck 24 MTU/acre, no backfill, high infiltration (initial $\mathrm{q}_{\text {inf }}=1.25 \mathrm{~mm} / \mathrm{yr}$ ), cyclical- $\mathrm{q}_{\mathrm{inf}}$ climate model. . . . . . . . . . . . . . . . . . . . . . . . . 9-72

Figure 9.3-23 Expected-value dose history: 1,000,000 years, Buscheck 80 MTU/acre, backfill, high infiltration (initial $\mathrm{q}_{\mathrm{inf}}=1.25 \mathrm{~mm} / \mathrm{yr}$ ), cyclical- $\mathrm{q}_{\mathrm{inf}}$ climate model. . . . . . . . . . . . . . . . . . . . . . . 9-72

Figure 9.3-34 CCDF of Total Peak Dose: 1,000,000 years, Lingineni 25 MTU/acre and Buscheck $24 \mathrm{MTU} / \mathrm{acre}$, no backfill, high and low infiltration $\left(\mathrm{q}_{\mathrm{inf}}\right)$ ranges, cyclical- $\mathrm{q}_{\mathrm{inf}}$ climate model. . . . . . . . . . . . 9-78

Figure 9.3-35 CCDF of Total Peak Dose: 1,000,000 years, Lingineni 25 MTU/acre and Buscheck $24 \mathrm{MTU} / \mathrm{acre}$, backfill, high and low infiltration $\left(\mathrm{q}_{\mathrm{inf}}\right)$ ranges, cyclical- $\mathrm{q}_{\mathrm{inf}}$ climate model. . . . . . . . . . . . . . . . 9-78

Fig. 9.3-36a Expected-value dose history: 1,000,000 years, 83 MTU/acre, backfill, intermediate infiltration rate (initial $\mathrm{q}_{\mathrm{inf}}=0.376 \mathrm{~mm} / \mathrm{yr}$ ), cyclical $-\mathrm{q}_{\mathrm{inf}}$ climate model. . . . . . . . . . . . . . . . . . . . . . . 9-79

Fig. 9.3-36b Expected-value dose history: 100,000 years, 83 MTU/acre, backfill, intermediate infiltration rate (initial $\mathrm{q}_{\mathrm{inf}}=0.376 \mathrm{~mm} / \mathrm{yr}$ ), cyclical- $\mathrm{q}_{\mathrm{inf}}$ climate model. . . . . . . . . . . . . . . . . . . . . . . . . . . . . . . 9 9-79

Figure 9.3-37 CCDF of Total Peak Dose: 1,000,000 years, 83 MTU/acre, backfill, high infiltration range $\left(\mathrm{q}_{\mathrm{inf}}=0.5-2.0 \mathrm{~mm} / \mathrm{yr}\right)$, low infiltration range $\left(\mathrm{q}_{\mathrm{inf}}\right.$ $=0.01-0.05 \mathrm{~mm} / \mathrm{yr})$, and entire infiltration range $\left(\mathrm{q}_{\mathrm{inf}}=0.01-2.0\right.$ $\mathrm{mm} / \mathrm{yr})$, cyclical- $\mathrm{q}_{\mathrm{inf}}$ climate model. . . . . . . . . . . . . 9-80

Figure 9.3-38 Effect of alternative corrosion-initiation models: Relative humidity only vs. temperature and relative humidity vs. temperature, relative humidity, and cathodic protection. CCDF of Total Peak Dose: 1,000,000 years, 83 MTU/acre, no backfill, high infiltration range, cyclical- $\mathrm{q}_{\mathrm{inf}}$ climate model. . . . . . . . . . . . . . . . . . . . . . . . . . . . . . . 99-80

Figure 9.3-39 Expected-value dose history: 1,000,000 years, cathodic protection (with temperature and relative humidity corrosion-initiation), $83 \mathrm{MTU} / \mathrm{acre}$, no backfill, high infiltration (initial $\mathrm{q}_{\text {inf }}=1.25 \mathrm{~mm} / \mathrm{yr}$ ), cyclical- $\mathrm{q}_{\text {inf }}$ climate model. . . . . . . . . . . . . . . . . . . . . . . . . . 9-81

Figure 9.3-40 Expected-value dose history: 1,000,000 years, "drips-on-wastecontainer" EBS transport model, 83 MTU/acre, backfill, high infiltration (initial $\mathrm{q}_{\mathrm{inf}}=1.25 \mathrm{~mm} / \mathrm{yr}$ ), cyclical- $\mathrm{q}_{\mathrm{inf}}$ climate model. . . . . . . . . 9-81

Figure 9.3-41 Expected-value dose history: 1,000,000 years, capillary-barrier-effect ("no drips") EBS transport model, 83 MTU/acre, backfill, high infiltration (initial $\mathrm{q}_{\mathrm{inf}}=1.25 \mathrm{~mm} / \mathrm{yr}$ ), cyclical- $\mathrm{q}_{\mathrm{inf}}$ climate model. . . . . . 9-82 
Figure 9.3-42 Expected-value dose history: 1,000,000 years, capillary-barrier-effect ("no drips") EBS transport model with ${ }^{129} \mathrm{I}$ and ${ }^{36} \mathrm{Cl}$ transported through EBS in the aqueous phase, $83 \mathrm{MTU} / \mathrm{acre}$, backfill, high infiltration (initial $\mathrm{q}_{\mathrm{inf}}=1.25 \mathrm{~mm} / \mathrm{yr}$ ), cyclical- $\mathrm{q}_{\mathrm{inf}}$ climate model. . . . . . . . 9-82

Figure 9.3-43 Expected-value dose history: 1,000,000 years, "diffusion-only" EBS transport model, 83 MTU/acre, backfill, high infiltration (initial $q_{\text {inf }}=$ $1.25 \mathrm{~mm} / \mathrm{yr})$, cyclical- $\mathrm{q}_{\mathrm{inf}}$ climate model. . . . . . . . . . . . 9-83

Figure 9.3-44 Comparison of EBS transport models. Expected-value dose history for ${ }^{99}$ Tc: 1,000,000 years, "drips-on-waste-form" model vs. "drips-on-wastecontainer" model vs. "no-drip" model, $83 \mathrm{MTU} / \mathrm{Tcre}$, high infiltration (initial $\mathrm{q}_{\mathrm{inf}}=1.25 \mathrm{~mm} / \mathrm{yr}$ ), cyclical- $\mathrm{q}_{\mathrm{inf}}$ climate model. . . . . . . . 9-83

Figure 9.3-45 Comparison of EBS transport models. Expected-value dose history for ${ }^{237} \mathrm{~Np}: 1,000,000$ years, "drips-on-waste-form" model vs. "drips-onwaste-container" model vs. "no-drip" model, $83 \mathrm{MTU} / \mathrm{acre}$, high infiltration (initial $\mathrm{q}_{\mathrm{inf}}=1.25 \mathrm{~mm} / \mathrm{yr}$ ), cyclical- $\mathrm{q}_{\mathrm{inf}}$ climate model. . . . . . 9 9-84

Fig. 9.3-46a Comparison of EBS transport models. CCDF of Total Peak Dose: $1,000,000$ years, $83 \mathrm{MTU} / a c r e$, high infiltration range, cyclical- $\mathrm{q}_{\mathrm{inf}}$ climate model. . . . . . . . . . . . . . . . . . . . . 9-85

Fig. 9.3-46b Comparison of EBS transport models. CCDF of Total Peak Dose: $1,000,000$ years, $83 \mathrm{MTU} / \mathrm{acre}$, high infiltration range, cyclical- $\mathrm{q}_{\mathrm{inf}}$ climate model. . . . . . . . . . . . . . . . . . . . . 9-85

Fig. 9.3-47a Effect of intra-unit fracture connectivity parameter: $\lambda=1 /(100 \mathrm{~h})$, where $\mathrm{h}=$ pathway length in each unit. Expected-value dose history: $1,000,000$ years, $83 \mathrm{MTU} / \mathrm{acre}$, backfill, high infiltration (initial $\mathrm{q}_{\mathrm{inf}}=$ $1.25 \mathrm{~mm} / \mathrm{yr})$, cyclical $-\mathrm{q}_{\mathrm{inf}}$ climate model. . . . . . . . . . . . 9-86

Fig. 9.3-47b Effect of intra-unit fracture connectivity parameter: $\lambda=1 /(100 \mathrm{~h})$, where $\mathrm{h}=$ pathway length in each unit. Expected-value dose history: 100,000 years, $83 \mathrm{MTU} / \mathrm{acre}$, backfill, high infiltration (initial $\mathrm{q}_{\text {inf }}=1.25 \mathrm{~mm} / \mathrm{yr}$ ), cyclical- $\mathrm{q}_{\mathrm{inf}}$ climate model. . . . . . . . . . . . . . . 9-86

Fig. 9.3-48a Effect of intra-unit fracture connectivity parameter: $\lambda=1 /(0.1 \mathrm{~h})$, where $\mathrm{h}=$ pathway length in each unit. Expected-value dose history: 1,000,000 years, $83 \mathrm{MTU} / \mathrm{acre}$, backfill, high infiltration (initial $\mathrm{q}_{\mathrm{inf}}=$ $1.25 \mathrm{~mm} / \mathrm{yr})$, cyclical- $\mathrm{q}_{\mathrm{inf}}$ climate model. . . . . . . . . . . 9-87

Fig. 9.3-48b Effect of intra-unit fracture connectivity parameter: $\lambda=1 /(0.1 \mathrm{~h})$, where $h=$ pathway length in each unit. Expected-value dose history: 100,000 years, $83 \mathrm{MTU} / \mathrm{acre}$, backfill, high infiltration (initial $\mathrm{q}_{\mathrm{inf}}=1.25 \mathrm{~mm} / \mathrm{yr}$ ), cyclical- $\mathrm{q}_{\mathrm{inf}}$ climate model. . . . . . . . . . . . . . . . . . 9 9-87

Figure 9.3-49 Effect of matrix-only flow (no fracture flow). Expected-value dose history: 1,000,000 years, $83 \mathrm{MTU} /$ acre, backfill, high infiltration (initial $\left.\mathrm{q}_{\mathrm{inf}}=1.25 \mathrm{~mm} / \mathrm{yr}\right)$, cyclical- $\mathrm{q}_{\mathrm{inf}}$ climate model. . . . . . . . . . 9-88 


\section{List of Figures (Continued)}

Figure 9.3-50 Comparison of intra-unit fracture connectivity parameter: $\lambda=1 /(100 \mathrm{~h})$ vs. $\lambda=1 / \mathrm{h}$ vs. $\lambda=1 /(0.1 \mathrm{~h})$ vs. matrix-flow-only, where $\mathrm{h}=$ pathway length in each unit. Expected-value dose history for ${ }^{99} \mathrm{Tc}: 1,000,000$ years, $83 \mathrm{MTU} / \mathrm{acre}$, backfill, high infiltration (initial $\mathrm{q}_{\mathrm{inf}}=1.25 \mathrm{~mm} / \mathrm{yr}$ ), cyclical- $\mathrm{q}_{\text {inf }}$ climate model. . . . . . . . . . . . . . 9-88

Figure 9.3-51 Comparison of intra-unit fracture connectivity parameter: $\lambda=1 /(100 \mathrm{~h})$ vs. $\lambda=1 / \mathrm{h}$ vs. $\lambda=1 /(0.1 \mathrm{~h})$ vs. matrix-flow-only, where $h=$ pathway length in each unit. Expected-value dose history for ${ }^{237} \mathrm{~Np}: 1,000,000$ years, $83 \mathrm{MTU} / \mathrm{acre}$, backfill, high infiltration (initial $\mathrm{q}_{\mathrm{inf}}=1.25 \mathrm{~mm} / \mathrm{yr}$ ), cyclical- $\mathrm{q}_{\mathrm{inf}}$ climate model. . . . . . . . . . . . . . . . . . 9-89

Figure 9.3-52 Comparison of intra-unit fracture connectivity parameter: $\lambda=1 /(100 \mathrm{~h})$ vs. $\lambda=1 / \mathrm{h}$ vs. $\lambda=1 /(0.1 \mathrm{~h})$ vs. matrix-flow-only (no fractures), where $\mathrm{h}=$ pathway length in each unit. CCDF of Total Peak Dose: $1,000,000$ years, $83 \mathrm{MTU} / \mathrm{acre}$, backfill, high infiltration range, cyclical- $\mathrm{q}_{\text {inf }}$ climate model. . . . . . . . . . . . . . . . . . . . . . . . . . 9-89

Fig. 9.3-53a No climate-change model. Expected-value dose history: 1,000,000 years, $83 \mathrm{MTU} / \mathrm{acre}$, backfill, high infiltration $\left(\mathrm{q}_{\mathrm{inf}}=1.25 \mathrm{~mm} / \mathrm{yr}\right) \ldots . .9-90$

Fig. 9.3-53b No climate-change model. Expected-value dose history: 100,000 years, $83 \mathrm{MTU} / \mathrm{acre}$, backfill, high infiltration $\left(\mathrm{q}_{\mathrm{inf}}=1.25 \mathrm{~mm} / \mathrm{yr}\right) . \ldots \ldots . .990$

Fig. 9.3-54a Climate-change model with cyclical $q_{\text {inf }}$ and cyclical water table rise. Expected-value dose history: 1,000,000 years, 83 MTU/acre, backfill, high infiltration (initial $\mathrm{q}_{\mathrm{inf}}=1.25 \mathrm{~mm} / \mathrm{yr}$ ). . . . . . . . . . 9-91

Fig. 9.3-54b Climate-change model with cyclical $\mathrm{q}_{\text {inf }}$ and cyclical water table rise. Expected-value dose history: 100,000 years, 83 MTU/acre, backfill, high infiltration (initial $\mathrm{q}_{\mathrm{inf}}=1.25 \mathrm{~mm} / \mathrm{yr}$ ). . . . . . . . . . . . 9-91

Fig. 9.3-55a Effect of climate on ${ }^{99} \mathrm{Tc}$ dose: Climate change with and without water table rise vs. no climate change. Expected-value dose history: $1,000,000$ years, $83 \mathrm{MTU} / \mathrm{acre}$, backfill, high infiltration (initial $\mathrm{q}_{\mathrm{inf}}=$

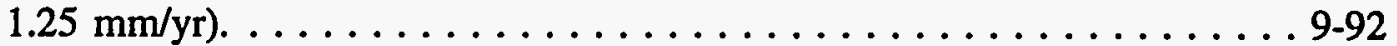

Fig. 9.3-55b Effect of climate on ${ }^{99} \mathrm{Tc}$ dose: Climate change with and without water table rise vs. no climate change. Expected-value dose history: 100,000 years, $83 \mathrm{MTU} / \mathrm{acre}$, backfill, high infiltration (initial $\mathrm{q}_{\mathrm{inf}}=1.25 \mathrm{~mm} / \mathrm{yr}$ ). $.9-92$

Fig. 9.3-56a Effect of climate on ${ }^{237} \mathrm{~Np}$ dose: Climate change with and without water table rise vs. no climate change. Expected-value dose history: 1,000,000 years, 83 MTU/acre, backfill, high infiltration (initial $\mathrm{q}_{\text {inf }}=$ $1.25 \mathrm{~mm} / \mathrm{yr}) . \ldots \ldots \ldots \ldots \ldots \ldots \ldots \ldots \ldots \ldots . \ldots . . \ldots .93$

Fig. 9.3-56b Effect of climate on ${ }^{237} \mathrm{~Np}$ dose: Climate change with and without water table rise vs. no climate change. Expected-value dose history: 100,000 years, $83 \mathrm{MTU} / \mathrm{acre}$, backfill, high infiltration (initial $\mathrm{q}_{\mathrm{inf}}=1.25 \mathrm{~mm} / \mathrm{yr}$ ). . 9-93

Fig. 9.3-57 No climate-change model. Expected-value dose history: 1,000,000 years, 83 MTU/acre, no backfill, low infiltration $\left(\mathrm{q}_{\text {inf }}=0.03 \mathrm{~mm} / \mathrm{yr}\right) \ldots \ldots . .994$ 
Fig. 9.3-58 Climate-change model with cyclical $\mathrm{q}_{\mathrm{inf}}$ and cyclical water table rise.

Expected-value dose history: 1,000,000 years, 83 MTU/acre, no backfill, low infiltration (initial $\mathrm{q}_{\mathrm{inf}}=0.03 \mathrm{~mm} / \mathrm{yr}$ ). . . . . . . . . . . . 9 9-94

Figure 9.3-59 Effect of climate on ${ }^{99} \mathrm{Tc}$ dose: Climate change with and without water table rise vs. no climate change. Expected-value dose history:

1,000,000 years, $83 \mathrm{MTU} / \mathrm{acre}$, no backfill, low infiltration (initial $\mathrm{q}_{\mathrm{inf}}=$ $0.03 \mathrm{~mm} / \mathrm{yr}) . \ldots \ldots \ldots \ldots \ldots \ldots \ldots \ldots \ldots \ldots . \ldots \ldots$. . . . . . . . . . . . . . . . .

Figure 9.3-60 Effect of climate on ${ }^{237} \mathrm{~Np}$ dose: Climate change with and without water table rise vs. no climate change. Expected-value dose history: $1,000,000$ years, $83 \mathrm{MTU} / \mathrm{acre}$, no backfill, low infiltration (initial $\mathrm{q}_{\mathrm{inf}}=$

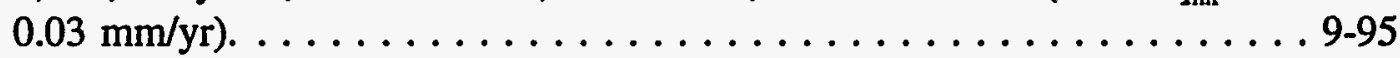

Figure 9.3-61 Effect of climate on total dose: Climate change with and without water table rise ("w.t.r.") vs. no climate change. CCDF of Total Peak Dose: $1,000,000$ years, 83 MTU/acre, with and without backfill, high and low infiltration ranges . . . . . . . . . . . . . . . . . . 9-96

Figure 9.3-62 Effect of alternative models for $\mathrm{Np}, \mathrm{Pu}$, and Am solubility: LANL expert-elicited model vs. Sassani temperature-dependent model. CCDF of Total Peak Dose: 1,000,000 years, 83 MTU/acre, backfill, high infiltration range. . . . . . . . . . . . . . . . . . . 9-96

Figure 9.3-63 Scatter plot of 1,000,000-yr total peak dose versus saturated zone Darcy velocity (m/yr) for $83 \mathrm{MTU} / \mathrm{acre}$, backfill, high infiltration (initial $\mathrm{q}_{\mathrm{inf}}=$ $1.25 \mathrm{~mm} / \mathrm{yr})$, cyclical $-\mathrm{q}_{\mathrm{inf}}$ climate model. . . . . . . . . . . . . 9-97

Figure 9.3-64 Scatter plot of 1,000,000-yr total peak dose versus UZ percolation flux (mm/yr) for $83 \mathrm{MTU} / \mathrm{acre}$, backfill, high infiltration (initial $\mathrm{q}_{\mathrm{inf}}=1.25$ $\mathrm{mm} / \mathrm{yr}$ ), cyclical- $\mathrm{q}_{\mathrm{inf}}$ climate model. . . . . . . . . . . . . . . . . 9 9-97

Figure 9.3-65 Scatter plot of 1,000,000-yr total peak dose versus climate change modifier for $83 \mathrm{MTU} / \mathrm{acre}$, backfill, high infiltration (initial $\mathrm{q}_{\mathrm{inf}}=1.25$ $\mathrm{mm} / \mathrm{yr}$ ), cyclical- $\mathrm{q}_{\mathrm{inf}}$ climate model. . . . . . . . . . . . . . . . . 9 9-98

Figure 9.3-66 Scatter plot of 1,000,000-yr total peak dose versus matrix velocity $\left(\mathrm{m} / \mathrm{yr}\right.$ ) in the TSw for $83 \mathrm{MTU} / \mathrm{acre}$, backfill, high infiltration (initial $\mathrm{q}_{\mathrm{inf}}$ $=1.25 \mathrm{~mm} / \mathrm{yr})$, cyclical- $\mathrm{q}_{\mathrm{inf}}$ climate model. . . . . . . . . . . 9-98

Figure 9.3-67 Scatter plot of 1,000,000-yr total peak dose versus fraction of flow in fractures in the TSw for 83 MTU/acre, backfill, high infiltration (initial $\left.\mathrm{q}_{\mathrm{inf}}=1.25 \mathrm{~mm} / \mathrm{yr}\right)$, cyclical- $\mathrm{q}_{\mathrm{inf}}$ climate model. . . . . . . . . . . . . 9-99

Figure 9.3-68 Scatter plot of 1,000,000-yr total peak dose versus matrix velocity $(\mathrm{m} / \mathrm{yr})$ in the TSv for $83 \mathrm{MTU} / \mathrm{acre}$, backfill, high infiltration (initial $\mathrm{q}_{\text {inf }}$ $=1.25 \mathrm{~mm} / \mathrm{yr})$, cyclical- $\mathrm{q}_{\mathrm{inf}}$ climate model. . . . . . . . . . . 9-99

Figure 9.3-69 Scatter plot of 1,000,000-yr total peak dose versus fraction of flow in fractures in the TSv for $83 \mathrm{MTU} / \mathrm{acre}$, backfill, high infiltration (initial $\left.\mathrm{q}_{\mathrm{inf}}=1.25 \mathrm{~mm} / \mathrm{yr}\right)$, cyclical- $\mathrm{q}_{\mathrm{inf}}$ climate model. . . . . . . . . 9 9-100 


\section{- $\quad$ List of Figures (Continued)}

Figure 9.3-70 Scatter plot of 1,000,000-yr total peak dose versus saturated zone Darcy velocity (m/yr) for $83 \mathrm{MTU} / \mathrm{acre}$, backfill, low infiltration (initial $\mathrm{q}_{\mathrm{inf}}=$ $0.03 \mathrm{~mm} / \mathrm{yr})$, cyclical- $\mathrm{q}_{\mathrm{inf}}$ climate model. . . . . . . . . . . 9-100

Figure 9.3-71 Scatter plot of 1,000,000-yr total peak dose versus UZ percolation flux $\left(\mathrm{mm} / \mathrm{yr}\right.$ ) for $83 \mathrm{MTU} / \mathrm{acre}$, backfill, low infiltration (initial $\mathrm{q}_{\mathrm{inf}}=\mathbf{0 . 0 3}$ $\mathrm{mm} / \mathrm{yr})$, cyclical- $\mathrm{q}_{\mathrm{inf}}$ climate model. . . . . . . . . . . . . 9-101

Figure 9.3-72 Scatter plot of 1,000,000-yr total peak dose versus matrix velocity $(\mathrm{m} / \mathrm{yr})$ in the $\mathrm{CHnz}$ for $83 \mathrm{MTU} / \mathrm{acre}$, backfill, low infiltration (initial $\left.\mathrm{q}_{\mathrm{inf}}=0.03 \mathrm{~mm} / \mathrm{yr}\right)$, cyclical- $\mathrm{q}_{\mathrm{inf}}$ climate model. . .......... 9-101

Figure 9.3-73 Scatter plot of 1,000,000-yr total peak dose versus fraction of flow in fractures in the $\mathrm{CHnz}$ for 83 MTU/acre, backfill, low infiltration (initial $\left.\mathrm{q}_{\mathrm{inf}}=0.03 \mathrm{~mm} / \mathrm{yr}\right)$, cyclical- $\mathrm{q}_{\mathrm{inf}}$ climate model. . . . . . . . . 9-102

Figure 9.3-74 Scatter plot of 1,000,000-yr total peak dose versus matrix velocity $(\mathrm{m} / \mathrm{yr})$ in the TSw for $83 \mathrm{MTU} / \mathrm{acre}$, backfill, low . . . . . . . . 9-102

Figure 9.3-75 Scatter plot of 1,000,000-yr total peak dose versus climate change

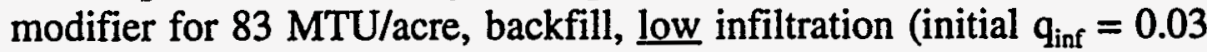
$\mathrm{mm} / \mathrm{yr})$, cyclical- $\mathrm{q}_{\mathrm{inf}}$ climate model. ............... 9-103

Figure 9.3-76 Scatter plot of 1,000,000-yr total peak dose versus Np sorption coefficient in the vitric tuff for $83 \mathrm{MTU} / \mathrm{acre}$, backfill, low infiltration (initial $\mathrm{q}_{\mathrm{inf}}=0.03 \mathrm{~mm} / \mathrm{yr}$ ), cyclical- $\mathrm{q}_{\mathrm{inf}}$ climate model. . . . . . . 9-103

Figure 9.4-1. Subsystem Total Release. Expected-value release at 10,000, 100,000 and 1,000,000 years for 83 MTU/acre, backfill, high infiltration $\left(\mathrm{q}_{\mathrm{inf}}=\right.$ $1.25 \mathrm{~mm} / \mathrm{yr}$ ), no climate change, with decay. . . . . . . . . 9-104

Figure 9.4-2. Subsystem ${ }^{99}$ Tc Release. Expected-value release at 10,000, 100,000 and $1,000,000$ years for $83 \mathrm{MTU} / \mathrm{acre}$, backfill, high infiltration $\left(\mathrm{q}_{\mathrm{inf}}=1.25\right.$ $\mathrm{mm} / \mathrm{yr}$ ), no climate change, with decay. . ............ 9-104

Figure 9.4-3. Subsystem ${ }^{129}$ I. Expected-value release at $10,000,100,000$ and $1,000,000$ years for $83 \mathrm{MTU} / \mathrm{acre}$, backfill, high infiltration $\left(\mathrm{q}_{\mathrm{inf}}=1.25\right.$ $\mathrm{mm} / \mathrm{yr}$ ), no climate change, with decay. . . . . . . . . .

Figure 9.4-4. Subsystem ${ }^{237} \mathrm{~Np}$. Expected-value release at 10,000, 100,000 and $1,000,000$ years for 83 MTU/acre, backfill, high infiltration $\left(\mathrm{q}_{\mathrm{inf}}=1.25\right.$ $\mathrm{mm} / \mathrm{yr}$ ), no climate change, with decay. . ............ 9-105

Figure 9.4-5. Subsystem ${ }^{229} \mathrm{Th}$. Expected-value release at 10,000, 100,000 and $1,000,000$ years for $83 \mathrm{MTU} / \mathrm{acre}$, backfill, high infiltration $\left(\mathrm{q}_{\mathrm{inf}}=1.25\right.$ $\mathrm{mm} / \mathrm{yr}$ ), no climate change, with decay. ............ 9-106

Figure 9.4-6. Subsystem ${ }^{229} \mathrm{Th}$. Expected-value release at 10,000, 100,000 and $1,000,000$ years for 83 MTU/acre, backfill, high infiltration $\left(\mathrm{q}_{\text {inf }}=1.25\right.$ $\mathrm{mm} / \mathrm{yr})$, no climate change, no decay. .............. 9-106 
. 


\section{EXECUTIVE SUMMARY}

\section{Robert W. Andrews, S. David Sevougian, Joon H. Lee, Srikanta Mishra and Jerry A. McNeish}

\section{ES.1 INTRODUCTION}

The U.S. Department of Energy (DOE) is currently investigating the feasibility of permanently disposing the nation's commercial high-level radioactive wastes (in the form of spent fuel from the over 100 electric power-generating nuclear reactors across the U.S.) and a portion of the defense high-level radioactive wastes (currently stored at federal facilities around the country) in the unsaturated tuffaceous rocks at Yucca Mountain, Nevada. Quantitative predictions based on the most current understanding of the processes and parameters potentially affecting the longterm behavior of the disposal system are used to assess the ability of the site and its associated engineered designs to meet regulatory objectives set forward by the U.S. Nuclear Regulatory Commission (NRC) and the U.S. Environmental Protection Agency (EPA).

The evaluation of the ability of the overall system to meet the performance objectives specified in the applicable regulatory standards has been termed total system performance assessment (TSPA). Total system performance assessments require the explicit quantification of the relevant processes and process interactions. In addition to providing a quantitative basis for evaluating the suitability of the site to meet regulatory objectives, such assessments are useful to help define the most significant processes, the information gaps and uncertainties regarding these processes and the corresponding parameters, and therefore the additional information required in order to have a more robust and defensible assessment of the overall performance.

Total system performance assessments explicitly acknowledge the uncertainty in the process models and parameters and strive to evaluate the impact of this uncertainty on the overall performance. The aim of any total system performance assessment is to be as complete and reasonably conservative as possible and to assure that the descriptions of the predictive models and parameters are sufficient to ascertain their accuracy.

Total system performance assessments evolve with time. As additional site and design information is generated, performance assessment analyses can be revised to become more representative of the expected conditions and remove some of the conservative assumptions necessitated by the incompleteness of site and design data. Previous iterations of total system performance assessment of the Yucca Mountain site and associated engineered barriers have been conducted in 1991 and 1993. These analyses have been documented in Barnard et al. (1992), Eslinger et al. (1992), Wilson et al. (1994) and Andrews et al. (1994).

\section{ES.2 OBJECTIVES}

The overall philosophy of any assessment of total system performance is (1) to use models and parameters which are as representative as current information allows for those processes that may affect the predicted behavior of the system and (2) to predict the responses of the natural and engineered components of the system that are expected to result from the emplacement of wastes in the potential repository. In those cases where representative information is not available or 
is very uncertain, bounding or conservative assumptions must be made, in order that the predicted performance is demonstrably worse than would be the case if more optimistic assumptions were included in the analyses. The performance assessment process requires the explicit treatment of uncertainty and variability of natural phenomena. The impact of the uncertainty is directly evaluated in the assessments themselves due to the stochastic nature of the analyses. In addition to evaluating the overall performance of the total system of engineered and natural barriers working in concert, an important objective of any predictive performance assessment modeling is to identify the significance of the current uncertainty in processes, models, and parameters on the performance. Those components that are most significant and which are uncertain are therefore identified as warranting additional information. This provides direct input to the site characterization and design programs to assist in prioritizing the necessary testing to develop more robust and defensible performance assessments.

The specific goals of the current iteration of total system performance assessment are to (1) utilize what are believed to be more representative conceptual models that build upon the assumptions employed in TSPA-1993, in particular for the treatment of the engineered barrier system including the waste package, (2) incorporate more recent design information since the completion of TSPA-1993, (3) utilize the most recent site information and models (where available) acknowledging their uncertainty and variability, and (4) evaluate the engineered barrier system release performance measure as well as alternative measures of total system performance (cumulative release and peak dose over different time periods).

Given the universe of potential issues that may be incorporated in any TSPA, it is necessary to limit the analyses to those components and processes that have been determined from previous analyses to be most significant or address particular concerns that may be raised by regulatory or technical oversight groups. In the present TSPA iteration, advantage has been made of the recommendations made in the most recent TSPA analyses clocumented in Wilson et al. (1994) and Andrews et al. (1994), namely, the need to develop and apply more representative models of (1) drift-scale thermal-hydrologic environment to provide more reasonable estimates of relative humidity and temperature adjacent to the waste packages, since these control the initiation and rate of humid-air and aqueous corrosion processes; (2) waste-package degradation, including the effects of variable near-field environments and the temporal degradation history of the waste packages, since this controls the time period during which the radionuclides are contained; (3) near-field unsaturated-zone aqueous flux, since this controls the percentage of waste packages potentially subjected to advective-flux release from the EBS; and (4) unsaturated-zone flow and transport, including the potential effects of fracture-matrix interaction, since this controls the advective travel time from the repository horizon to the water table. In addition to identifying the most significant issues, the earlier iterations of TSPA have also been used to eliminate some processes from consideration in the current analyses, including (1) disruptive events such as volcanism and human intrusion due to their insignificant effect on post-closure performance, and (2) gaseous-phase transport in the unsaturated zone because the gaseous-phase transport rate to the atmosphere is so much faster than the degradation rate of the waste package.

Where appropriate, the current TSPA iteration has incorporated revised design and site information, new since completion of TSPA-1993, to enhance the representativeness of the analyses. Design information that has been revised includes the thermal load, possible alternative backfills, the degradation model for corrosion of the mild-steel corrosion-allowance material, and 
the effects of cathodic protection of the corrosion-resistant material. Site information that has been revised since the completion of TSPA-1993 includes estimates of the spatial variability of surficial infiltration, alternative conceptual representations of the distribution of surficial infiltration at the depth of the potential repository horizon, alternative conceptual representations of fracture/matrix flow and radionuclide transport, and modified geochemical information such as radionuclide solubilities and retardation potential.

Although several alternative measures of performance could be evaluated to quantify the ability of the site and associated engineering barriers to isolate radioactive wastes from the biosphere over the extended periods of time that pose the greatest environmental and health risks, the present analyses focus on two measures of total system performance, namely, the cumulative release of radionuclides at the accessible environment boundary normalized to the limits presented in Table 1 of 40 CFR Part 191, and the maximum dose to an individual using groundwater from a well in the tuff aquifer at the accessible-environment boundary. For consistency, the definition of the "accessible environment" in both instances is assumed to correspond to a location 5 kilometers down the saturated zone hydraulic gradient from the edge of the potential repository.

While integrated release or peak dose are accepted as being appropriate total system performance measures of long-term safety associated with the containment and isolation of radioactive wastes, the NRC has promulgated additional requirements on three subsystems. These subsystems include the waste package itself, the engineered barrier system, and the geosphere. The first two of these subsystems are directly quantified in the definition of the source term used in the total system performance assessment analyses. Therefore, predictions of the performance of these engineered barrier components are also addressed in this TSPA iteration.

\section{ES.3 INFORMATION FLOW IN THE CURRENT TSPA}

Total system performance assessments bring together all relevant components of the waste containment and isolation system that potentially affect the release of radionuclides to the accessible environment and the corresponding concentration and dose associated with the release. The individual components of the analyses are indicated on the schematic flow diagram illustrated in Figure ES.3-1. Each of the bubbles of the influence diagram corresponds to a process-level model which in turn is based on direct laboratory or field data that have been synthesized using either empirical relationships or a numerical relationship describing the process of interest. The key attributes of the multiple barriers associated with waste disposal in the unsaturated zone at Yucca Mountain are presented in Figure ES.3-2.

The flow of information in any assessment of total system performance goes from (1) the test data and corresponding interpretation and documentation of these data, to (2) the use of processlevel models to synthesize the available test data and other soft information into a consistent representation of the relevant processes affecting waste isolation and containment, to (3) the abstraction of results from these process-level models in the form of response surfaces, table look-ups or other functional relationships for use in the total system performance assessment software, and finally, to (4) the total system performance assessments themselves. The information flow used in TSPA-1995 is depicted in Figure ES.3-3. 
In many cases the information derived from laboratory or in-situ testing is used directly in the analyses rather than going through the process-level model and abstraction steps. Examples of this include the alteration/dissolution rate of the waste form, the solubility of individual radionuclides, and radionuclide sorption values all of which are derived from laboratory experiments. In many other instances, however, predictive models are required to provide results that can be abstracted for input to the TSPA analysis. Examples of these include unsaturated and saturated-zone flow, drift-scale thermal hydrology, and waste-package degradation. In these instances, the results from the process-level model simulations are used to define the relationship between the "known" parameters, including their corresponding uncertainty and spatial variability, and the required results used as input to the TSPA calculations. The abstraction process is required for these analyses because it is not possible to efficiently imbed the process model itself into the total system performance predictions and make the repetitive simulations required of the probabilistic analyses.

The abstracted models and parameter distributions derived from process-level models or other information sources are input to the total system performance assessment model RIP (Repository Integration Program). RIP was developed by Golder Associates Inc. (GAI) in order to evaluate the performance of a potential radioactive waste disposal facility at Yucca Mountain (Miller et al., 1992) and has subsequently been applied to a wide variety of proposed radioactive waste disposal facilities both in the U.S. and internationally. RIP allows for the stochastic prediction of total system or subsystem performance caused by the uncertainty and variability in the input distributions.

\section{ES.4 SUMMARY OF SITE AND DESIGN DESCRIPTIONS}

Yucca Mountain is located in the Southern Great Basin, about $140 \mathrm{~km}$ northwest of Las Vegas in the state of Nevada (Figure ES.4-1). The Great Basin is characterized topographically by north-trending mountain ranges separated by alluvium-filled valleys. Structurally, Yucca Mountain is a complex of north- to northwest-trending fault-delineated ridges. The potential repository is proposed to be constructed within Yucca Crest which is bounded to the west by the Solitario Canyon Fault and to the east by the Bow Ridge Fault and is transected by the Ghost Dance Fault (Figure ES.4-2).

Hydrologically, the Great Basin is characterized as an arid to semi-arid region. Precipitation in the vicinity of Yucca Mountain is approximately $170 \mathrm{~mm} / \mathrm{yr}$, with an estimated potential evapotranspiration of about $1000 \mathrm{~mm} / \mathrm{yr}$. Consequently, most of the precipitation is returned to the atmosphere and only a small residual remains to infiltrate into the unsaturated zone. Net infiltration is believed to be extremely variable over Yucca Mountain due to variations in soil cover, topographic controls and vegetation patterns (Flint and Flint, 1994).

Stratigraphically, the unsaturated zone beneath Yucca Crest consists of a layered sequence of tuffs deposited from volcanic eruptions which occurred about 10 million years ago. The tuffs range from porous, nonwelded ash-flow, ash-fall and reworked/bedded tuff deposits to massive, welded ash-flow and ash-fall rocks. The four major hydrogeologic units from the surface to the water table consist of the following: 
- Tiva_Canyon welded (TCW) unit: consisting of moderately- to densely-welded tuffs characterized by low matrix porosity, low matrix saturated hydraulic conductivity, and high fracture density.

- $\quad$ Paintbrush nonwelded (PTn) unit: consisting of partially-welded to nonwelded tuffs characterized by high matrix porosity, high matrix saturated hydraulic conductivity, and low fracture density.

- Topopah Spring welded (TSw) unit: consisting of welded tuffs characterized by low matrix porosity, low matrix saturated hydraulic conductivity, and high fracture density. The basal vitrophyre of the Topopah Spring member (TSv) is generally identified as a subunit because of its lower porosity compared to TSw.

Calico Hills nonwelded ( $\mathrm{CHn}$ ) unit: consisting of moderately-welded to nonwelded tuffs of the Topopah Spring member underlying the basal vitrophyre and other partially-welded to nonwelded tuffs located below the Calico Hills formation (i.e., Prow Pass, Bullfrog and Tram members of the Crater Flat Unit). Portions of the lower Topopah Spring member are vitrified, and zeolitic alteration appears in both the lower part of the Topopah Spring member and in the tuffaceous beds of the Calico Hills, leading to a further division of this unit into vitric (CHnv) and zeolitic (CHnz) subunits. The fracture density is similar in both zones, and the porosity of the vitric tuffs is marginally higher than that of the zeolitic tuffs. However, the matrix saturated hydraulic conductivity of the CHnv is roughly two orders of magnitude higher than that of the $\mathrm{CHnz}$.

A conceptual design of the potential repository at Yucca Mountain has been described in the Site Characterization Plan (DOE, 1988) and has been revised to take into account the possibility of alternative areal mass loads as well as the decision to use a tunnel boring machine for the excavation of the emplacement drifts (M\&O, 1994c). Two alternative areal mass-load ranges have been proposed for the potential repository, a "low" thermal load of between 20 and 40 metric tons of uranium (MTU) per acre and a "high" thermal load of between 80 and $100 \mathrm{MTU} / \mathrm{acre}$. Two areal mass loads have been investigated in TSPA-1995, 25 MTU/acre and $83 \mathrm{MTU} / \mathrm{acre}$. The total amount of radioactive waste to be emplaced in the potential repository consists of 63,000 MTU of spent nuclear fuel and 7,000 MTU of defense high-level waste.

In the current design concept of waste disposal containers for the potential repository at Yucca Mountain, two or three layers of different metals, depending on thermal load, have been proposed for the containment of spent nuclear fuel (SF) and vitrified defense high-level waste (DHLW). For spent fuel in the high thermal load case, a corrosion-allowance material (CAM) such as mild steel has been proposed as the outer containment barrier, and a corrosion-resistant material (CRM) such as Inconel 825 (Alloy 825) has been proposed as the inner containment barrier. For the low thermal load case, a moderately corrosion resistant material (MCRM) such as Monel 400 has been added as an additional containment barrier on top of the two-layer containment barrier design used for the high thermal load case. Since adequate models for predicting the performance of the moderately corrosion resistant materials (Monel 400 and 70/30 copper-nickel alloy) are not available, it has been recommended that this potential containment barrier not be included in any waste package performance analysis (Doering, 1995). Thus, in TSPA-1995, all waste containers for spent fuel and defense high-level waste are assumed to have the same 
design, viz.,- a corrosion-resistant inner barrier of Alloy 82.5 and a corrosion-allowance outer barrier of carbon steel. The stainless-steel shell of the multi-purpose canister (MPC) and the DHLW pour canister are not considered as barriers to waste-package degradation in the current TSPA iteration.

For a typical large MPC, containing 21 pressurized-water-reactor (PWR), or 40 boiling-waterreactor (BWR), fuel assemblies, the dimensions of the waste container are about $5.7 \mathrm{~m}$ long and about $1.8 \mathrm{~m}$ in diameter. The thickness of the inner barrier for both the large MPC and DHLW waste containers is $20 \mathrm{~mm}$; the thickness of the outer barrier for the large MPC waste container is $100 \mathrm{~mm}$, and for the DHLW waste container $50 \mathrm{~mm}$.

The adoption of the MPC waste package concept has necessitated the use of in-drift emplacement as the preferred emplacement option based a number of factors including operational considerations, ease of retrieval, safety, and flexibility. A schematic cross section of a centered in-drift package (CIDP) is illustrated in Figure ES.4-3.

The potential use of backfill as a capillary barrier and thermal management tool has been advocated in recent studies of near-field thermohydrologic environments (Buscheck et al., 1995). This iteration of TSPA therefore considers both backfill and no backfill options in evaluating waste package/EBS and total system performance.

\section{ES.5 AMBIENT AND THERMALLY-PERTURBED FLOW MODELS AND ABSTRACTIONS}

The total system simulator employed for TSPA-1995 does not explicitly include hydrologic and thermohydrologic process models describing the redistribution of moisture and heat following waste emplacement. However, information concerning the velocity and flux through the unsaturated zone is required for EBS and geosphere transport calculations. In addition, information concerning near-field temperature, saturation and relative humidity is required for waste package degradation and EBS release calculations. TSPA-1995 assumes that thermal effects have dissipated prior to the onset of EBS/geosphere transport, thus facilitating the use of ambient models of unsaturated flow for post-closure performance predictions.

\section{ES.5.1 Conceptual Hydrologic Model}

The conceptual model of unsaturated zone hydrology at Yucca Mountain utilized in the present TSPA analyses is shown schematically in Figure ES.5-1. This model provides a qualitative description of how moisture is assumed to be distributed within the unsaturated zone. A part of the precipitation received at the ground surface $\left(\mathrm{q}_{\mathrm{ppt}}\right)$ enters the unsaturated zone as infiltration flux, $q_{\text {inf }}$. After moving vertically and/or laterally through the Tiva Canyon welded (TCw) and the Paintbrush nonwelded (PTn) units, this flux is modified to a percolation flux, $\mathrm{q}_{\text {perc }}$, at the proposed repository horizon within the Topopah Springs welded (TSw) unit. At the scale of the repository block $(\sim 1 \mathrm{~km})$, the "average" percolation flux is distributed (for each hydrostratigraphic unit) between the fractures and matrix blocks as $q_{\text {frac }}$ and $q_{\text {mat }}$, respectively, depending on the hydrologic properties of the unit. At the scale of individual drifts $(\sim 10 \mathrm{~m})$, the "average" percolation flux over the repository horizon is re-distributed across each drift as $\mathrm{q}_{\text {perc,i }}$, reflecting the underlying local spatial variability in material properties. Each local percolation flux is 
further partitioned into a component entering the drifts via dripping fractures $\left(\mathrm{q}_{\mathrm{drip}, \mathrm{i}}\right)$ and a component retained by the intact rock matrix surrounding the drift $\left(\mathrm{q}_{\mathrm{mat}, \mathrm{i}}\right)$.

\section{ES.5.2 Site-Scale Unsaturated Flow Model and Abstractions}

A suite of simulations was performed with the LBL-USGS site-scale unsaturated flow model (Wittwer et al., 1995) to incorporate the effects of: (i) uncertainty in the assumed infiltration scenarios, (ii) the impact of uncertain and/or spatially variable matrix hydrologic properties, and (iii) conceptualizations of fracture-matrix flow using both equilibrium and non-equilibrium assumptions. The simulations were also used to develop abstractions of unsaturated hydrology in the form of functional relationships between the key dependent variables (i.e., pore velocity and percent of total flux in fractures/matrix for each hydrogeologic unit) and the primary independent variable (i.e., infiltration rate). A NW-SE cross-section (Figure ES.5-2) extracted from the LBL-USGS model was used as the basis for these simulations. Detailed calculations were carried out using the one-dimensional column denoted as Column 153 (located in the center of the proposed repository block) assuming the pervasiveness of vertical flow.

Two infiltration scenarios were postulated based on the infiltration map of Flint and Flint (1994). For the "low" infiltration scenario, the surficial infiltration over the footprint of the potential repository $(\sim 0.02 \mathrm{~mm} / \mathrm{yr})$ was assumed to be invariant with depth due to predominantly 1-D vertical flow. For the "high" infiltration scenario, the areally-weighted average flux $(\sim 1.2 \mathrm{~mm} / \mathrm{yr})$ over the site-scale model domain was assumed to be uniformly distributed over the potential repository horizon due to significant lateral diversion. Hydrologic simulations were carried out for six discrete cases consistent with the above scenarios, i.e., at $0.01,0.02,0.05 \mathrm{~mm} / \mathrm{yr}$ for the "low" range, and at $0.5,1.0$ and $2.0 \mathrm{~mm} / \mathrm{yr}$ for the "high" range.

The hydrogeologic database developed by Schenker et al. (1995) was used as the source for matrix and fracture properties. In order to account for the uncertainty/variability in matrix hydrologic properties, ten random sets of values for porosity, saturated conductivity and the two van Genuchten parameters were generated. The properties for the hydrogeologic units above the potential repository horizon (TCw, PTn) were kept fixed at their expected values, and fracture properties were treated as constants for all the units.

The LBL-USGS model conceptualizes the fractured units as equivalent continua with specified threshold saturations for triggering liquid flow in fractures. A key assumption of the equivalent continuum model (ECM) is that liquid flow in the fractures is initiated only after bulk-liquid saturation exceeds a threshold value corresponding to full saturation of the matrix. A relaxation of this assumption, as proposed by Xiang et al. (1995), allows fracture flow to commence whenever the matrix liquid saturation is greater than or equal to a "satiated" matrix saturation.

Steady-state simulations were carried out to develop hydrologic abstractions for: the cases described above (i.e., six infiltration rates, ten sets of material properties, and two fracture-flow initiation rules) by treating matrix pore velocity, $v_{\text {mat }}$, and fractional fracture flux, $f_{\text {frac }}$, along Column 153 as the two performance measures. For each of the four hydrostratigraphic units below the potential repository horizon (TSw, TSv, CHnv, CHnz), ranges for $\mathrm{v}_{\text {mat }}$ and $\mathrm{f}_{\text {frac }}$ were tabulated as a function of the infiltration rate-an example for the TSw unit being shown in Figure ES.5-3. The ranges in this figure reflect the effects of uncertainty in material properties 
and the fracture-flow initiation rule, and provide a simple approach for propagating uncertainty from the detailed process model to the RIP TSPA model.

Within RIP, infiltration rate is treated as a stochastic parameter. For a given sampled value of infiltration rate, the information such as that presented in Figure ES.5-3 is used to determine the appropriate minimum and maximum values for $v_{\text {mat }}\left(\right.$ or $f_{\text {frac }}$ ). Treating these as the lower and upper bounds for a uniform distribution, a second sampling would then provide the corresponding value for $v_{\text {mat }}$ (or $f_{\text {frac }}$ ) for input into the geosphere transport module of RIP.

\section{ES.5.3 Stochastic Drift-Scale Fracture Flow Model and Abstractions}

As discussed previously, the dynamics of flow at the drift scale are influenced by the spatial variability in percolation flux and in material properties (e.g., saturated hydraulic conductivity). The stochastic fracture flow model developed for TSPA-1995 assumes that the infiltration flux (or "average" percolation flux at the repository horizon) is distributed log-normally into a series of local percolation fluxes, corresponding to each waste package "catchment area". This local percolation flux, denoted as $\mathrm{q}_{\text {perc,i }}$ in Figure ES.5-1, is then partitioned between a "dripping" fracture intercepting the drift, and the rock matrix surrounding the drift, depending on the local spatially variable saturated matrix conductivity, also sampled from a log-normal distribution.

This methodology allows the development of functional relationships between the number of (and flux through) dripping fractures and the imposed infiltration rate, as shown in Figure ES.5-4. Such information is then used in RIP to predict advective release from the EBS.

\section{ES.5.4 Drift-Scale Thermohydrologic Model and Abstractions}

A drift-scale thermohydrologic model was developed to provide descriptions of the thermallyperturbed near-field environment (e.g., temperature, saturation, relative humidity). These variables are required inputs for waste-package degradation modeling and analyses of diffusive release from the EBS. The model assumes a two-dimensional geometry in a plane orthogonal to the emplacement drift and extending from the ground surface to the water table. The modeled domain represents a "unit cell" between adjacent waste packages and adjacent drifts. The model geometry is discretized into a two-dimensional mesh near the waste package which gradually transitions into essentially one-dimensional elements in the far-field. The unsaturated zone stratigraphy is taken to be identical to that of Column 153 shown in Figure ES.5-2.

Thermohydrologic simulations were carried out for areal mass loadings of 25 and 83 MTU/acre, using waste stream characteristics typical of a 21-PWR waste package containing 30-year fuel with an initial heat output of $0.98 \mathrm{~kW} / \mathrm{MTU}$. Simulations included cases with and without a "gravel"-type backfill, and for infiltration rates of 0.05 and $0.3 \mathrm{~mm} / \mathrm{yr}$. Abstracted results consisted of temporal variations in: (i) waste package surface temperature, (ii) average liquid saturation within drift, and (iii) relative humidity at the surface of the waste package. The latter was calculated by equating the absolute humidity at the waste package surface to that at the dryout front. These attributes of the perturbed near-field environment were also abstracted from another drift-scale model developed by Buscheck et al. (1995) to provide a range of expected post-emplacement conditions for the waste package and the engineered barrier system. This was done in view of the uncertainty in backfill thermohydrologic characteristics and the conceptual 
uncertainty associated with quantifying heat-driven liquid and vapor flow at sub-residual saturation (and the corresponding calculation of relative humidities).

Figure ES.5-5 shows an example comparison of temperature and relative humidities for the $83 \mathrm{MTU} /$ acre case with $0.05 \mathrm{~mm} / \mathrm{yr}$ infiltration (this study), and for the $80 \mathrm{MTU} / \mathrm{acre}$ case with $0 \mathrm{~mm} / \mathrm{yr}$ infiltration (Buscheck et al.). Note that the two alternative models yield considerably different results, especially for the case with backfill. The impact of these differences on radionuclide release and dose at the accessible environment are discussed in Section ES.8.

\section{ES.6 SUMMARY OF WASTE-PACKAGE DEGRADATION MODELS AND PREDICTED RESULTS}

Given that the waste packages must "fail" (i.e., be breached to an extent that the mobile water present in the near field environment can enter the package and any dissolved radionuclides can be transported out of the package) before any dissolution of the waste form can occur, an important first step in total system performance assessment is the prediction of waste package degradation. The degradation rate of the waste package is dependent on (1) the waste package design (in particular the material(s) used in the waste package fabrication and the thickness of these material(s)), (2) the repository design (in particular the thermal load, the presence of backfill, and the size of the emplacement drifts), (3) the near-field thermohydrologic regime in the drifts adjacent to the waste package surface (in particular the temperature and relative humidity), and (4) the degradation characteristics of the waste package materials (including the criteria for corrosion initiation and the rate of corrosion as a function of the near field thermohydrologic environment). Information from each of these topics is required as input to the waste package degradation model to predict the time-rate of "failure" of the waste packages.

\section{ES.6.1 Waste-Package Degradation Models}

A detailed stochastic waste-package performance simulation model has been developed for TSPA1995. The stochastic simulation model incorporates the following five individual corrosion models: (1) humid-air general corrosion model (including uncertainty) for the carbon steel corrosion-allowance outer barrier; (2) stochastic humid-air pitting corrosion model for the carbon steel outer barrier; (3) aqueous general corrosion model (including uncertainty) for the carbon steel outer barrier; (4) stochastic aqueous pitting corrosion model for the carbon steel outer barrier; and (5) aqueous pitting corrosion model (including pit growth rate distribution) for the Alloy 825 corrosion-resistant inner barrier. The uncertainties in the individual corrosion models were incorporated to capture the variability in the corrosion degradation among waste packages and among pits in the same waste package.

\section{Humid-Air Corrosion Models for the Corrosion-Allowance Outer Barrier}

Humid-air general corrosion and pitting corrosion models (including their uncertainties) for the corrosion-allowance (carbon steel) outer barrier were developed using a total of 166 atmospheric corrosion data points (up to 16 years of exposure time) for a suite of cast iron and carbon steel which are known to have corrosion behaviors similar to the candidate carbon steel. The collected data are from various exposure conditions in tropical, rural, urban, and industrial testing sites. The atmospheric corrosion data incorporate the effects of pollutants such as $\mathrm{SO}_{2}$ and other 
chemicals in the atmosphere that interact with test specimens. The data also embed any effects of salts that may form on the surface of the corroding specimen due to cyclic wetting and drying.

The humid-air general corrosion model for the outer barrier was developed as a function of exposure time, relative humidity, temperature, and sulfur-dioxide content in air. The corrosion data used, and the model prediction with its uncertainties ( $\forall 2$ standard deviations), are shown in Figure ES.6-1. The input parameters $\left(15{ }^{\circ} \mathrm{C}, 84 \%\right.$ R.H., and $\left.90 \mu \mathrm{g} \mathrm{SO}{ }_{2} / \mathrm{m}^{3}\right)$ for the modelprediction in the figure are the averages of the data set. In the waste-package degradation simulation, sulfur-dioxide content in the potential repository is assumed to be negligible.

Pitting corrosion of corrosion-allowance material is commonly represented with a pitting factor that is defined as the ratio of the maximum pit depth to the general corrosion depth at a given exposure time. Accordingly, the pitting factor has been utilized in the development of the stochastic pitting corrosion model for the corrosion-allowance barrier in a humid-air condition. The pitting factor was assumed to be normally distributed. with a mean at 4 and a standard deviation of 1 . In addition, the pitting factor was constrained to be greater than or equal to 1 , i.e. with the pitting factor equal to 1 , the pit depth is equal to the general corrosion depth. The pitting factor was sampled randomly and used as a multiplier to the general corrosion depth.

\section{Aqueous Corrosion Models for the Corrosion-Allowance Outer Barrier}

The aqueous general corrosion model for the corrosion-allowance outer barrier was developed as a function of exposure time and temperature. In the model development, "long-term" corrosion data (up to 16 years) in polluted river water and in tropical lake water were used to determine parameter values for the corrosion reaction term and time-dependence term. The data include the potential effects of various chemical species dissolved and of microbial activity in the waters. Parameter values for the temperature-dependence terms were determined from a set of short-term corrosion data for temperatures from 5 to $90{ }^{\circ} \mathrm{C}$. The current model has an improved representation for the temperature dependence of aqueous corrosion of the corrosionallowance outer-barrier material compared to the aqueous corrosion model used in TSPA-1993 (Andrews, et al., 1994). The aqueous pitting corrosion of the outer barrier was modeled using the same approach as in the humid-air pitting corrosion of the outer barrier.

\section{Aqueous Pitting Corrosion Model for the Corrosion-Resistant Inner Barrier}

Since there has been no new development or improvement over the pitting corrosion model for the Alloy 825 inner barrier used in TSPA-1993 (Andrews, et al., 1994), the same pitting model was utilized in the development of the stochastic waste-package degradation model in TSPA1995. The elicitation provides a range of time-independent pit growth rates in aqueous conditions at 70 and $100{ }^{\circ} \mathrm{C}$, and the pit-growth-rate ranges are presented as median, 95th-percentile, and 5 th-percentile growth rates. For the pit-growth-rate ranges at other temperatures, these values were extrapolated as a function of temperature in an Arrhenius-type functional form. In the stochastic waste-package degradation simulation model, pit growth rates for the Alloy 825 inner barrier were sampled randomly within the 95 th and 5th percentile pit-growth-rate ranges given in the elicitation. 


\section{ES.6.2 Approach to Stochastic Waste-Package Degradation Simulation}

A flowchart that illustrates the approach to stochastic waste-package degradation simulation is shown in Figure ES.6-2. The approaches and assumptions made for the waste-package degradation modeling are discussed below. The temperature and relative-humidity profiles at the waste-package surface are incorporated into the stochastic waste-package degradation simulation model as a lookup table.

The initial post-closure near-field environment of the potential repository will be hot and dry, and following the peak temperature period, the near-field environment would cool down gradually. Thus, the waste containers are expected to undergo humid-air corrosion initially at elevated temperatures, but the corrosion mode would gradually shift to aqueous corrosion as the near-field environment continues to cool down to lower temperature and more humid conditions. It was assumed that both humid-air general corrosion and humid-air pitting corrosion of the carbon-steel outer barrier initiate at a threshold relative humidity (R.H.) that is uniformly distributed between $65 \%$ and $75 \%$, and that both aqueous general corrosion and aqueous pitting corrosion of the outer barrier initiate at a threshold R.H. that is uniformly distributed between $85 \%$ and $95 \%$. The Alloy 825 corrosion-resistant inner-barrier material was assumed to be subjected to aqueous pitting corrosion only (not to general corrosion). When pits reach the inner barrier through the outer barrier, aqueous conditions are assumed.

In the post-closure repository, about 10,000 waste packages will be spread over the repository area, and a local corrosion environment in one part of the repository may be different from that in another part. This variability of the local corrosion environment is referred to here as wastepackage-to-waste-package variability. Also, since a waste container has a relatively large surface area $\left(37.26 \mathrm{~m}^{2}\right)$, the general corrosion rate on one part of the waste package may be different from that on another part of the waste package. This variability in corrosion rate on a waste package is referred to here as pit-to-pit variability. The uncertainties in the humid-air and aqueous general corrosion models for the outer barrier and those in the aqueous pitting corrosion model for the inner barrier were utilized to account for the variability among waste packages and the variability among pits.

It is generally agreed that in the current waste-package design, some degree of cathodic protection of the Alloy 825 corrosion-resistant inner barrier will be provided by the carbon-steel outer barrier. An expert elicitation was provided to account for the cathodic protection of the corrosion-resistant inner barrier in the waste package (McCright, 1995). The elicitation suggests the pitting corrosion of the inner barrier be delayed until the thickness of the carbon-steel outer barrier is reduced by $75 \%$.

The simulation module provides as output the "failure" time for each waste package, which corresponds to the time for the initiation of waste-form alteration (or radionuclide mobilization) inside the waste package. "Failure" of a waste package is defined as having at least one pit completely penetrated through all package barriers. The simulation module also provides the pitting history of a "failed" waste package in terms of the number of pit penetrations as a function of time. The total number of pit penetrations at a given time gives the area on the waste package that is available for transport of mobilized radionuclides through the waste package. The waste package "failure" time and subsequent pitting history are fed into the EBS transport model. 


\section{ES.6.3 Summary of Major Waste-Package Degradation Results}

Within the scope of assumptions employed in the simulations, the corrosion modes considered, and the near-field conditions from the drift-scale thermohydrologic model, the results of the waste package performance analyses show that the current waste-package design appears to meet the "controlled design assumption" requirement on waste-package performance, which is currently defined as having less than $1 \%$ of waste packages breached at 1,000 years (M\&O, 1995c). Breach of a waste package is defined here as having at least one pit penetration. Since a quantitative definition of the substantially complete containment requirement, as referred to in the NRC subsystem requirement (10 CFR 60.113), has not been decided, the (tentative) "controlled design assumption" requirement has been employed throughout the analyses of the waste-package degradation simulations in this study.

Another important finding is the significant impact on waste-package performance of cathodic protection of the corrosion-resistant Alloy 825 inner barrier by the corrosion-allowance carbonsteel outer barrier. The impacts of cathodic protection on waste-package performance are shown in Figure ES.6-3, in which the simulation results for the case of 83 MTU/acre, no backfill, high infiltration rate $(0.3 \mathrm{~mm} / \mathrm{yr})$, and cathodic protection are compared to the corresponding case without cathodic protection. The time for the initiation of waste-package failure is delayed significantly from about 2,200 years without cathodic protection to about 8,000 years with cathodic protection. The waste-package failure rate is also significantly lowered. Also shown in the figure is the fraction of waste packages with their outer barrier thickness reduced by $75 \%$.

Currently, alternative thermohydrologic models are being used by M\&O Performance Assessment Group and Lawrence Livermore National Laboratory (Buscheck, et al., 1995; hereafter referred to as Buscheck's model). Using the temperature and humidity profiles at the waste-package surface from Buscheck's model, a series of simulations were conducted for waste-package performance in the different near-field environments for the four cases, and the results were compared to those from a "similar" case in this study. The near-field conditions calculated with Buscheck's model are generally hotter and drier than those for "similar" cases in this study, and these resulted in fewer waste package failures and slower degradation.

In Figure ES.6-4, the simulation results for the case of $24 \mathrm{MTU} / \mathrm{acre}$, without backfill and no infiltration (from Buscheck's model) are compared to those for the case of $25 \mathrm{MTU} / \mathrm{acre}$, without backfill and high infiltration (from this study). The time for the initiation of waste-package failure for the two cases are comparable, both cases being at about 2,000 years. However, the waste-package failure rate for the case with Buscheck's model is significantly lower than for the case based on this study. Differences of the predicted waste-package performance between the two thermohydrologic models are more significant in the corresponding thermal loading cases with backfill.

The differences caused by alternative thermohydrologic models are even more pronounced in the high thermal loading cases (i.e., 83 MTU/acre cases with and without backfill in this study vs 80 MTU/acre cases with and without backfill from Buscheck's model). Shown in Figure ES.6-5 is the comparison of the waste-package failure results for the case of $80 \mathrm{MTU} / \mathrm{acre}$, without backfill and no infiltration (from Buscheck's model) to those for the case of $83 \mathrm{MTU} / \mathrm{acre}$, without backfill and high infiltration rate (from this study). There is a significant difference in 
the time for the initiation of waste-package failures between the two cases. The initiation time for the case from Buscheck's model is about 50,000 years, whereas it is about 2,000 years for the case from this study. Also, the waste-package failure rates from Buscheck's model are significantly lower than those from this study. The impacts of these differences on peak dose at the accessible environment are discussed in Section ES.8.

\section{ES.7 SUMMARY OF EBS RELEASE MODELS AND PREDICTED RESULTS}

\section{ES.7.1 EBS Release Models}

Figure ES.7-1 shows a sketch of the major EBS processes and parameters leading to release from the EBS. The thermohydrologic drift-scale modeling analyses provide waste-package surface temperature and relative humidity (which are used in the waste-package degradation modeling), and liquid saturation of the gravel invert (which is used in calculation of the diffusion coefficient for diffusive release of radionuclides). The waste-package degradation modeling results provide the time to first pit penetration of the waste container, and subsequent degradation or pitting of the waste container. The waste form in the nominal case was assumed to be exposed upon first pit penetration, due to immediate cladding failure. No detailed cladding failure modeling was conducted in TSPA-1995, although limited sensitivity analyses were conducted using a simple cladding model.

The near-field environmental conditions affect such processes as the waste-form dissolution, the solubility of the radionuclides in the aqueous phase in contact with the waste form, and the magnitude of both the advective and diffusive components of transport from the waste-form surface through the degraded waste package and the in-drift materials into the host rock. Wasteform dissolution rates have been derived from empirical fits to data obtained from laboratory experiments under a range of environmental conditions. Radionuclide solubilities have also been derived from empirical fits to data obtained from laboratory experiments under a range of thermal and chemical conditions. The advective flux component of radionuclide transport is derived from the distribution of local percolation flux in excess of the saturated hydraulic conductivity of the host rock. The diffusive flux component of radionuclide transport is derived from the hydrologic conditions in the drift materials as calculated in thermohydrologic modeling for TSPA-1995.

Three alternative EBS-release conceptual models were evaluated (Figure ES.7-2). First, for the conceptual model of advective and diffusive release from both the waste package and EBS (the "drips-on-waste-form" model), after a waste package has "failed" (i.e., the initial pit has penetrated the inner corrosion-resistant layer), it is assumed that the near-field environmental conditions (i.e., the temperature, humidity, liquid saturation, and the presence of drips) occurring outside of the waste package are immediately transferred to the inside of the waste package. These environmental conditions, combined with information on the behavior of the waste form and other engineered barriers under these environmental conditions, are required in the prediction of radionuclide releases from the engineered barriers to the host rock. In this model, advective release occurs at a rate proportional to the flow of dripping water in the drift, and diffusive release occurs at a rate proportional to the number of pits penetrating the waste container.

A second EBS-release conceptual model (the "drips-on-waste-container" model) is presumed to be more realistic than the first model, and takes more credit for a partially intact waste container. 
This model assumes only diffusive releases through the waste container, because of corrosion products filling the corrosion pits and blocking advective flow into the waste container. Nearfield environmental conditions (except for dripping flow) were assumed present inside the waste container immediately' after the first pit. The model still assumes both advective and diffusive release from the EBS.

A third EBS release conceptual model was developed to evaluate the potential benefits associated with the emplacement of a so-called Richards' or capillary barrier, in which the backfill is designed to conduct any advective flux (i.e., drips) away from the waste package and underlying invert materials due to the capillary-pressure differences across unconsolidated materials of different grain size. Only diffusive releases from both the waste package and EBS were allowed to occur in this model.

\section{ES.7.2 EBS Release Results}

The analyses of the waste-package/EBS performance evaluated the release of radionuclides from the EBS for several scenarios with the NRC peak-release-rate standard in mind. The analyses considered the effects on the EBS peak release rate of three alternative corrosion-initiation models, two alternative thermal loads, two different infiltration-rate ranges, various backfill conditions, alternative cladding-performance models, alternative thermohydrologic models, and alternative EBS-release models. Eight radionuclides were selected for the analyses-those with a maximum release rate that exceeded $0.1 \%$ of the NRC total-release-rate limit. These radionuclides, ${ }^{14} \mathrm{C},{ }^{135} \mathrm{Cs},{ }^{59} \mathrm{Ni},{ }^{237} \mathrm{~Np},{ }^{210} \mathrm{~Pb},{ }^{226} \mathrm{Ra},{ }^{79} \mathrm{Se}$, and ${ }^{99} \mathrm{Tc}$, were all considered in the analyses that evaluated the importance of the various paraneters and conceptual models listed above. EBS release rates were calculated as a function of time for simulations that used the expected values of the stochastic distributions of the various model parameters.

The analyses demonstrate the significance of the rate of percolation or dripping on the waste containers to the predicted release (Figure ES.7-3). Generally, the influence of infiltration was more significant than the alternate corrosion-initiation criteria (i.e., temperature and R.H. vs. R.H. only) in terms of causing radionuclides to exceed the NRC total-release-rate limit. However, when cathodic protection was considered in the corrosion-degradation model, the initial release from the EBS to the host rock was delayed until after 10,000 years and the peak release rate at that time was predicted to be reduced by about a factor of 10 . As expected, using a simple cladding failure model, the EBS release was correspondingly decreased when the percent of cladding failure decreased. The Buscheck thermohydrologic conceptual model produced significantly less EBS release than the thermohydrologic model used in this study, due to lower waste-package failure rates caused by higher temperatures and lower relative humidities. The higher thermal load cases produced higher releases than the corresponding lower thermal load cases for all simulations performed.

The effects of alternative EBS-release models on the EBS release rate was significant (Figure ES.7-4). Comparing the "drips-on-waste-container" EBS-release model, which assumed only diffusive release through the perforations in "failed" waste containers, to the more conservative "drips-on-waste-form" EBS-release model, which allows advective flow through the perforations, the former yielded release rates for most nuclides that are within their NRC limit. The implication is that the "partially failed" waste containers by pitting corrosion should still be able 
to perform as a potentially important barrier to radionuclide release, and EBS transport models that incorporate more realism need to be considered. Assuming a capillary-barrier effect (i.e., no advective flux through the EBS), the EBS peak release rate showed an additional decrease of several orders of magnitude.

The key model parameters contributing to EBS peak release were identified using regression analysis for the 25 and 83 MTU/acre, no backfill, and high infiltration cases. ${ }^{99} \mathrm{Tc}$ solubility, infiltration or percolation rate, and spent fuel dissolution rate were identified as the three most important parameters contributing to EBS peak release.

\section{ES.8 SUMMARY OF GEOSPHERE TRANSPORT MODELS AND PREDICTED RELEASES AND DOSES AT THE ACCESSIBLE ENVIRONMENT}

\section{ES.8.1 Geosphere Transport Models}

\section{Unsaturated-Zone Transport}

Those radionuclides released from the engineered barrier system are available for transport through the geosphere to the accessible environment. The travel time of radionuclides in the geosphere is a function of both physical and chemical processes between the fluid and the rock, and in the best possible scenario, this time delay between release from the EBS and arrival at the accessible environment would be long enough to allow the bulk of the radionuclide mass to decay to insignificant levels of radioactivity.

Travel time to the accessible environment is a function of the percolation flux distribution in the unsaturated zone and the advective flux distribution in the saturated zone, as well as the conceptual representation of hydrostratigraphy along the along the likely ground-water flow paths between the repository and the accessible environment (Figure ES.8-1). The percolation flux distribution within the Topopah Spring hydrostratigraphic unit (and other UZ units below it) is a function of the infiltration rate and the conceptual model for ground-water flow in the unsaturated zone. In particular, the key conceptual uncertainty in the transport of radionuclides through the geosphere at Yucca Mountain is the possible presence of fracture flow and transport which might, if fracture pathways existed and were continuous and interconnected, lead to the formation of so-called "fast" paths. However, "fast paths" per se are more of a concern with regard to the groundwater travel-time requirement than the peak dose at the accessible environment. This is because the latter is caused by the arrival of the bulk of the radionuclide mass, which is a result of combined fracture/matrix flow, whereas the former is due to the arrival of the initial part of the breakthrough curve through the fast paths.

At the time of the TSPA-1995 simulations, the Yucca Mountain process-level aqueous-transport model (Robinson et al., 1995) had not been completed. Thus, unlike the TSPA-1995 UZ flow model (discussed above), which is based on abstracted process-level model results, the TSPA transport model is incorporated directly into the RIP TSPA model. It is partly based on the abstractions from the process-level flow model (i.e., the matrix and fracture velocity fields and the partitioning of volumetric flow between fractures and matrix), but also includes a fracturematrix interaction model (to represent intra-unit fracture connectivity and matrix imbibition) and a radionuclide retardation model (to represent chemical interaction between the matrix and pore 
water), neither of which is based on process-level transport modeling (although the chemical retardation model is based on LANL experiments on whole tuff samples).

To simulate particle transport in the RIP TSPA model, velocity fields for both fracture and matrix transport are required. These steady-state fields come from simulations with process-level models. From these simulations, which use the equivalent continuum model (ECM), two families of curves ( $v_{\text {mat }} v s . q_{\text {inf }}$ and $f_{\text {frac }} v s . q_{\text {inf }}$ ) were generated for each hydrogeologic unit (where $v_{\text {mat }}$ is the matrix velocity and $f_{\text {frac }}$ is the fraction of the total percolation flux within the fractures). The range in uncertainty of $v_{\text {mat }}$ or $f_{\text {frac }}$ for any given $q_{\text {inf }}$ was determined by a range in material properties, fracture/matrix coupling, and vertical spatial variability. According to this method, the infiltration rate, $\mathrm{q}_{\mathrm{inf}}$, is the primary independent variable for geosphere transport in the aqueous phase. In particular, during a stochastic simulation, RIP will sample from a $q_{\text {inf }}$ distribution (either over the "high" infiltration range, $0.5-2.0 \mathrm{~mm} / \mathrm{yr}$, or over the "low" infiltration range, $0.01-0.05 \mathrm{~mm} / \mathrm{yr}$ ) to determine the $\mathrm{q}_{\mathrm{inf}}$ at repository closure (i.e., the initial $\mathrm{q}_{\mathrm{inf}}$ ). For this value of $q_{i n f}$, there will be stochastic distributions of $v_{\text {mat }}$ and $f_{\text {frac }}$ (as functions of depth or pathway), which are described by the minimum and maximum values of the given parameter at that $\mathrm{q}_{\text {inf }}$. Random uniform sampling between these minimum and maximum values is used to determine a stochastic initial $v_{\text {mat }}$ and $\mathrm{f}_{\text {frac }}$ for a given realization, as illustrated in Figure ES.8-2. During any given simulation (realization), $\mathrm{q}_{\mathrm{inf}}$ may change due to climatic variations, and thus, $f_{\text {frac }}$ and $v_{\text {mat }}$ will be time dependent.

Because of the lack of an appropriate process-level model, fracture/matrix interaction in the geosphere, for example, fracture connectivity, imbibition, and matrix diffusion, is simulated directly in the TSPA model by a Markovian process algorithm that randomly transitions particles between fracture and matrix modes. The magnitude of this transition "rate" (which is not really a rate, but rather the inverse of the random travel length in a fracture or in the matrix), $\lambda$, determines the strength of the fracture/matrix coupling. For TSPA-1995, the "default" particletransition rate for the Markovian dispersion process between fracture and matrix is set equal to the inverse of the pathway length, $h$. This means that on average a radionuclide particle will travel the length of the pathway (e.g., through the TSw) within a fracture, before transitioning to the matrix-flow mode or vice-versa. For a slug input through a single pathway (i.e., one hydrogeologic unit), this will result in some smearing of the two peaks (fracture and matrix) in the breakthrough curve, but will retain much of the bimodal character of the breakthrough curve. Two sensitivity cases for fracture/matrix coupling were considered: $\lambda=1 /(0.1 \mathrm{~h})$, which represents strong fracture/matrix coupling, i.e., a reduction of transport through fractures, and $\lambda=1 /(100 \mathrm{~h})$, which represents weak fracture/matrix coupling, i.e., much weaker than the $\lambda=1 / \mathrm{h}$ "default" case (see Figure ES.8-3).

In TSPA-1995, all rock/water interactions that can serve to retard the transport of radionuclides are modeled with a simple, equilibrium (infinite capacity), distribution-coefficient $\left(\mathrm{K}_{\mathrm{d}}\right)$ model. Whole rock distribution functions $\left(\mathrm{K}_{\mathrm{d}} \mathrm{s}\right)$ have been used based on laboratory-derived data and the "minimum $\mathrm{K}_{\mathrm{d}}$ concept" (Meijer, 1992). These distribution coefficients are related to the chemical nature of the individual hydrostratigraphic unit, and are classified according to vitric, devitrified, and zeolitic (Meijer, 1995). In addition, for TSPA-1995, $\mathrm{K}_{\mathrm{d}}$ distributions in the saturated zone are different from those in the unsaturated zone, with the main difference due to the effect of ionic strength of the groundwater in the different domains. 


\section{Saturated-Zone Transport}

The saturated-zone flux affects the arrival time of radionuclides at the accessible-environment boundary as well as the degree of mixing and dilution in the ground water of the tuff aquifer prior to its extraction and use. Since process-level modeling of saturated-zone flow and transport has not changed appreciably since the completion of TSPA-1993, the same abstraction and basis thereof used in the previous TSPA iteration (Andrews et al., 1994) is also used in the current analyses. The entire flux distribution incorporates the effects of large-scale spatial heterogeneity of aquifer properties. Small-scale heterogeneity is included through the use of dispersion in the solution of the one-dimensional advection-dispersion equation. Because of the one-dimensional nature of the solution algorithm, only longitudinal dispersion is simulated, i.e., there is no transverse dispersion. This is conservative when considering predictions of peak concentration or peak dose.

The actual distribution for $\mathrm{q}_{\mathrm{SZ}}$ (Darcy velocity in the saturated zone) used in TSPA-1995 is a lognormal distribution with a mean of $2.0 \mathrm{~m} / \mathrm{yr}$, a median of $1.1 \mathrm{~m} / \mathrm{yr}$, and a standard deviation of 0.4859. Based on this distribution, both TSPA-1993 and TSPA-1995 indicate that the saturated zone is not a significant geosphere barrier compared to the unsaturated zone, as far as time delay of the breakthrough to the accessible environment. The saturated zone's greatest importance lies in its dilution effect.

\section{Climate Change}

Given the long time frames of potential interest in total system performance assessment (up to $1,000,000$ years), it is likely that the atmospheric conditions will change with a resulting change in climate, especially precipitation and net evapotranspiration. Therefore, the potential effects of climate change are important to consider. Climate-change effects are abstracted directly into the current total system performance assessment. It is reasonable to postulate that increased precipitation would result in an increase in percolation flux and a rise in the water table, although the degree of correlation and the time lag between changes in surficial processes and the subsurface effects are uncertain. Both of these effects are included in TSPA-1995, although the water-table rise is only considered as a sensitivity case.

\section{Biosphere/Dose Modeling}

Although only engineered barrier and natural barrier (i.e., geosphere) models and parameters are required in the prediction of cumulative releases of radionuclides at the accessible-environment boundary, the calculation of dose requires the definition of the potentially exposed population(s) and the potential biosphere pathways by which individuals may be exposed to any radionuclides released. In the current total system performance assessment it is assumed that the peak individual dose corresponds to an individual taking drinking water from the tuff aquifer (2 liters/day). It is also assumed that this "maximally-exposed" individual is located at the point on the accessible-environment boundary that corresponds to the peak of the radionuclide concentration within the tuff aquifer. Mixing volumes are based on a fixed cross-sectional area of flow in the saturated zone, with the horizontal mixing being given by the width of the potential repository and the vertical mixing by a well with a $50 \mathrm{~m}$ saturated-zone interval. Dose 
conversion factors, which convert radionuclide concentrations to doses, have been derived from published values used by the U.S. Environmental Protection Agency (EPA, 1988).

\section{Treatment of Gaseous-Phase Radionuclides. ${ }^{14} \mathrm{C}$}

For TSPA-1995, geosphere transport of radionuclides in the gaseous phase of the unsaturated zone is not considered (except in one limiting sensitivity case). The primary radionuclide to be transported in the gas (air) phase in the geosphere would be ${ }^{14} \mathrm{C}$. However, given the recent recommendations of the NAS (National Research Council, 1995) on protection of the global population, the risk from gaseous release of ${ }^{14} \mathrm{C}$ is negligible. Therefore, TSPA-1995 assumes that the ${ }^{14} \mathrm{C}$ released from the inventory is dissolved in the aqueous phase once it reaches the geosphere (i.e., the top of the TSw), and is then transported by the aqueous phase to the accessible environment. Since this is a conservative assumption with respect to computing dose at the accessible environment (although it has little effect, since ${ }^{237} \mathrm{~Np},{ }^{99} \mathrm{Tc}$, and ${ }^{129} \mathrm{I}$ doses are much higher than those from ${ }^{14} \mathrm{C}$ ), there is one sensitivity analysis that computes aqueous dose at the accessible environment assuming ${ }^{14} \mathrm{C}$ is directly released to the atmosphere, i.e., it never enters the aqueous phase and therefore does not contribute to dose exposure in a water well at the accessible environment.

\section{ES.8.2 Predicted Radionuclide Release and Dose at the Accessible Environment}

This section of the executive summary discusses predicted radionuclide release and radiation dose at the accessible-environment boundary, $5 \mathrm{~km}$ from the repository footprint boundary (Figure ES.8-1). Inherent in the nature of any such prediction is its uncertain or stochastic nature. This statistical behavior is captured by plots of the complementary cumulative distribution function (CCDF) of a particular performance measure over the time period of interest, either 10,000 or $1,000,000$ years. (Note: $\mathrm{CCDF}=1-\mathrm{CDF}$, where $\mathrm{CDF}$ is the cumulative distribution function.) The performance measure for radionuclide release (in Curies) is the total (i.e., the sum of all radionuclides) cumulative release over 10,000 years, normalized to the Table 1 values in 40 CFR Part 191. The performance measure for radiation dose (in rem/yr) is the total (i.e., the sum of all radionuclides) peak dose to a person (the "maximally exposed individual") at the accessible environment using the tuff aquifer for his or her drinking water (2 liters/day), calculated over both 10,000 years and 1,000,000 years. The 1,000,000-year time frame for peak dose is the one suggested in the recent report by the National Research Council (1995). These peak doses should not be compared to the average dose a member of the "critical" population may be exposed to over the time period of interest. The average dose is expected to be more than an order of magnitude less than the peak dose to the maximally-exposed individual.

The expected value of a statistical distribution is one of the most important parameters used to characterize the behavior of the distribution. Thus, besides showing CCDFs that represent the entire range of the various parameter distributions, expected-value time histories ("breakthrough curves") are also shown for the radionuclides with the highest release rates or doses at the accessible environment. An expected-value release-rate history is the breakthrough curve for rate-of-release of radioactivity $(\mathrm{Ci} / \mathrm{yr})$ at the accessible environment for a single realization that uses the expected values for all stochastic parameters. Similarly, an expected-value dose history is the breakthrough curve for dose exposure (rem/yr) at the accessible environment for a single realization that uses the expected values for all stochastic parameters. 
The effect of model and parameter uncertainty on predicted results is evaluated by a number of sensitivity analyses. Alternative repository designs and alternative scenarios for natural-system behavior are considered, including (1) low and high water-infiltration rates through the unsaturated zone $(0.01-0.05 \mathrm{~mm} / \mathrm{yr}$ and $0.5-2.0 \mathrm{~mm} / \mathrm{yr})$; (2) low and high thermal load (25 MTU/acre and $83 \mathrm{MTU} / \mathrm{acre}$ ); (3) alternative thermohydrologic models for the near-field environment (one developed in this study, referred to as the Lingineni model vs. one developed by LLNL, referred to as the Buscheck model); (4) three waste-package-degradation (corrosioninitiation) models (relative-humidity controlled, temperature and relative-humidity controlled, and temperature and relative-humidity controlled with cathodic protection); (5) five conceptual models of EBS transport and water movement (drips directly on waste form, drips on waste package but not on waste form, no drips or capillary-barrier effect, no drips and aqueous EBS transport of ${ }^{129} \mathrm{I}$ and ${ }^{36} \mathrm{Cl}$, and no drips and aqueous EBS transport of ${ }^{129} \mathrm{I}$ and ${ }^{36} \mathrm{Cl}$ plus ${ }^{14} \mathrm{C}$ transport directly to atmosphere-the "diffusion-only" model); (6) fracture/matrix interaction in the geosphere (the effect of intra-unit fracture connectivity within a given hydrogeologic unit); and (7) climate change (with and without water table rise).

In addition to CCDFs and expected-value time histories, evaluation of repository performance using linear regression analysis provides an explanation for the degree of the variance in the performance measures (total peak dose or cumulative release) that can be explained by one or more of the model parameters. This type of analysis can indicate where to focus future efforts in gathering more data to substantiate physical models. It can also indicate what repository design elements are most important, e.g., waste-package design or backfill design.

\subsection{0-year Cumulative Releases}

Although all of the sensitivity analyses mentioned above were carried out for the 10,000 -year time frame, a number of combinations of repository design and natural system behavior resulted in no releases at the accessible environment up to 10,000 years postclosure. These included the following: (i) low infiltration range $(0.01-0.05 \mathrm{~mm} / \mathrm{yr})$, (ii) cathodic protection of the wastepackage, (iii) Buscheck $80 \mathrm{MTU} / \mathrm{acre}$ thermal load with and without backfill and Buscheck $24 \mathrm{MTU} /$ acre thermal load with backfill, and (iv) matrix-flow-only (zero fracture flow) in the unsaturated zone. Thus for these cases, there are no CCDFs or expected-value breakthrough curves to be shown.

Two cases that do result in releases to the accessible environment are the two thermal loads modeled with the Lingineni thermohydrologic model, $83 \mathrm{MTU} / \mathrm{acre}$ and $25 \mathrm{MTU} / \mathrm{acre}$, with a gravel backfill, at the high infiltration range $(0.5-2.0 \mathrm{~mm} / \mathrm{yr})$. Normalized total cumulative releases for these two thermal loads are shown in Figure ES.8-4, where the shaded area in the figure represents the Table-1 release limits in 40 CFR Part 191. Although not specifically indicated in this figure, the radionuclides with greatest releases to the accessible environment during the 10,000 -year time frame are ${ }^{99} \mathrm{Tc},{ }^{14} \mathrm{C},{ }^{129} \mathrm{I}$, and ${ }^{36} \mathrm{Cl}$. All of these are nonsorbing nuclides, i.e., $\mathrm{K}_{\mathrm{d}}=0$ in the geosphere.

As indicated by Figure ES.8-4, and because of the fact that the two thermal loads generate similar temperature and relative humidities in the near field, the release at the accessible environment is about the same for $83 \mathrm{MTU} / \mathrm{acre}$ compared to $25 \mathrm{MTU} / \mathrm{acre}$. However, as discussed above, this conclusion is not valid when using the Buscheck thermohydrologic model, 
which produces very different releases over the 10,000-year time period at high versus low thermal load. This points to the need to better substantiate and test the thermohydrologic process-level models used for TSPA predictions.

\subsection{0-year Total Peak Dose}

Figure ES.8-5 shows 100-realization CCDFs of predicted total peak dose at the accessible environment during the first 10,000 years. All of these cases were modeled using the thermohydrologic results (temperatures, humidities, and saturations) for the Lingineni 83 MTU/acre case with gravel backfill. The particular curves shown in this plot represent a comparison of alternative conceptual models of water movement and radionuclide transport in the EBS. These models are (1) fractures dripping directly onto the waste-form, i.e., directly on the spent fuel and DHLW glass; (2) fractures dripping on the corroding metal waste containers, but not directly on the waste form; (3) no dripping fractures (the so-called capillary-barrier effect); (4) no dripping fractures and also aqueous (rather than gaseous) transport of ${ }^{129} \mathrm{I}$ and ${ }^{36} \mathrm{Cl}$; and (5) no dripping fractures and also aqueous transport of ${ }^{129} \mathrm{I}$ and ${ }^{36} \mathrm{Cl}$ plus direct shunting of ${ }^{14} \mathrm{C}$ to the atmosphere (i.e., ${ }^{14} \mathrm{C}$ does not travel to the accessible environment in the aqueous phase, so it has no effect on aqueous dose). The last model is also called the "diffusion-only" model, since in this model any radionuclide transport to the accessible environment must result from pure diffusive transport through the aqueous phase in the EBS. This mode of transport is so slow that no radionuclides reach the accessible environment in 10,000 years, so no curve is present on the plot. The basis for the fourth model is that, although the first three models conservatively assume that ${ }^{129} \mathrm{I}$ and ${ }^{36} \mathrm{Cl}$ traverse the EBS in the gas phase, it is quite possible, due to the high reactivity of $\mathrm{I}_{2}$ and $\mathrm{Cl}_{2}$, that they may dissolve in the aqueous phase before being transported across the EBS.

These various transport models are listed above in order of conservatism, with the first model (i.e., the "drips-on-waste-form") being the most conservative (i.e., most pessimistic) regarding repository performance. The dose curve for this model in Figure ES.8-5 corresponds to the cumulative release curve labeled "83 MTU/acre, backfill" in Figure ES.8-4. The CCDFs in Figure ES.8-5 indicate that over 10,000 years, different models of EBS transport yield somewhat different peak doses. For example, the capillary barrier model reduces doses by about $50 \%$, while the capillary barrier combined with aqueous transport of ${ }^{129} \mathrm{I}$ and ${ }^{36} \mathrm{Cl}$ reduces peak doses by about a factor of 20 . However, since the ultimate peak of the radionuclide breakthrough curves is far from reaching the accessible environment after 10,000 years (i.e., only the leading edge of the curve has broken through), the effect of these various models is much less than it is at $1,000,000$ years (see next section).

Linear regression analysis was used to determine the most influential model parameters. Over the 10,000-year time frame the top two parameters are the matrix velocity in the CHnv and the mean percolation flux in the unsaturated zone (which is assumed to be equal to the infiltration rate, $\mathrm{q}_{\text {inf }}$ ). This ranking is not unexpected. In particular, the peak concentrations of the radionuclides never reach the accessible environment during 10,000 years and variability in $q_{\text {inf }}$ translates directly to a shifting in time of the initial portion of the breakthrough curve. However, since this is the steeply rising portion of the breakthrough curve(s) regardless of the value of $q_{\text {inf }}$ (for $\mathrm{q}_{\mathrm{inf}}=0.5-2.0 \mathrm{~mm} / \mathrm{yr}$ ), there is a very strong dependence on $\mathrm{q}_{\mathrm{inf}}$. The strong dependence on 
matrix velocity in the CHnv is also not unexpected because the CHnv is the formation with the highest value of saturated matrix conductivity, $\mathrm{K}_{\text {sat }}$, and therefore the lowest value of flow in fractures. Therefore, it tends to control connected fracture flow throughout the mountain, as noted in the Calico Hills System Study (M\&O, 1995d); and without fracture flow, no releases can reach the accessible environment in 10,000 years.

\subsection{0,000-year Total Peak Dose}

In their recent report to Congress, the National Research Council (1995) has concluded that "...there is no scientific basis for limiting the time period of the individual-risk standard to 10,000 years... (and) that compliance assessment be conducted for the time when the greatest risk occurs, within the limits imposed by long-term predictability of both the geologic environment and the distribution of local and global populations." Based on geologic considerations, they also state that "the ultimate restriction on time scale ... is on the order of 1,000,000 years at Yucca Mountain." For these reasons, we have conducted performance assessments to predict dose and peak dose over a 1,000,000-year time frame. These are presented here as various sensitivity analyses that examine the effect of various natural system parameters and various repository designs.

Alternative Infiltration Rates. Figure ES.8-6 shows the history of dose exposure from ${ }^{129} \mathrm{I}$ and ${ }^{237} \mathrm{~Np}$ to the maximally exposed individual at the accessible environment $(5 \mathrm{~km}$ from the repository boundary) over the 1,000,000 year time frame for the $83 \mathrm{MTU} /$ acre thermal load, with backfill, and using a climate-change model that is based on a cyclical variation of the infiltration rate, $q_{i n f}{ }^{129} I$ is one of the two highest-dose radionuclides that is nonsorbing in the geosphere (the other is ${ }^{99} \mathrm{Tc}$ ), while ${ }^{237} \mathrm{~Np}$ is the highest-dose nonsorbing nuclide (and also the highest-dose nuclide, period). The dose histories for these two radionuclides are for the two different infiltration-rate scenarios, i.e., $0.03 \mathrm{~mm} / \mathrm{yr}$ versus $1.25 \mathrm{~mm} / \mathrm{yr}$. For the high infiltration case, ${ }^{237} \mathrm{~Np}$ at late times, and ${ }^{99} \mathrm{Tc}$ and ${ }^{129} \mathrm{I}$ at early times, produce the highest dose exposure at the accessible environment. (The same is true for a $25 \mathrm{MTU} / \mathrm{acre}$ thermal load). For the low infiltration case ${ }^{129} \mathrm{I}$ dominates the dose exposure at all times.

One major point of Figure ES.8-6 is to examine the differences between the high and low infiltration scenarios. First of all, the long-lived, sorbing nuclides, such as ${ }^{237} \mathrm{~Np}$, do not have significant releases for low UZ infiltration fluxes over the 1,000,000-year time frame. Second, the periods of highest releases (and doses) for nonsorbing nuclides, such as ${ }^{129} \mathrm{I}$ and ${ }^{99} \mathrm{Tc}$, are spread out over a much broader time interval for the low- $\mathrm{q}_{\mathrm{inf}}$ case compared to the high- $\mathrm{q}_{\text {inf }}$ case, and have a much lower peak.

Alternative Thermohydrologic Models. 100-realization CCDFs of the 1,000,000-year total peak dose to the maximally exposed individual are presented in Figure ES.8-7 for the two alternative near-field thermohydrologic models, at the low and high infiltration ranges. Within the RIP TSPA simulator, the relative humidities, temperatures, and water saturations for these two thermohydrologic models are coupled to the dripping-fracture EBS transport model and the farfield geosphere transport model. The Buscheck model has much later and more spread-out package failure times than the Lingineni model, which are a result of a considerably lower relative-humidity history. However, Figure ES.8-7 demonstrates that even large changes in 
relative humidity and temperature in the near field do not greatly affect the ultimate peak dose during the 1,000,000-year time frame. In particular, the high-thermal-load Lingineni model only gives about 2 to 3 times greater peak doses over the entire sampled range of stochastic variables than the Buscheck model. So, although the Buscheck model delays the appearance of the peak dose at the accessible environment by tens- to hundreds-of-thousands of years (not shown on these plots), it does not reduce the peak very much over the long time span of $1,000,000$ years. Another result was that backfill in either thermohydrologic model (and the resulting changes in humidity, temperature, and saturation) had a negligible effect on 1,000,000-year total peak dose (although it could serve to significantly delay initial arrivals at the accessible environment). However, this conclusion is predicated on the assumption that backfill does not alter the EBS transport model. If EBS transport were assumed to be different for backfill versus no-backfill (e.g., if drips on the waste-package were assumed for the no-backfill scenario, but not assumed for the backfill scenario), then the results are significantly different, as discussed below.

Alternative Conceptual Models for EBS Transport. Similarly to Figure ES.8-5 for 10,000-year total peak dose, Figure ES.8-8 examines the effect of alternative EBS transport models on 1,000,000-year total peak dose at the accessible environment. These five models manifest much larger differences in peak dose over $1,000,000$ years than 10,000 years because the peak of the breakthrough curve for ${ }^{237} \mathrm{~Np}$ reaches the accessible environment over that long time frame. The 100-realization, total-peak-dose CCDFs in Figure ES.8-8 are for the case of 83 MTU/acre, with backfill, over the high infiltration range, with a cyclical- $q_{\text {inf }}$ climate model. The total peak dose is reduced by about a factor of about 25 for the "drips-on-waste-container" compared to the "drips-on-waste-form" model, because of a large reduction in ${ }^{237} \mathrm{~Np}$ dose, resulting from its slow diffusion through the corrosion pits in the waste container before it is able to interact with dripping flow in the EBS. The no-drip (or capillary-barrier-effect) model does not show much additional reduction in dose compared to the "drips-on-waste-container" model because of the contribution from gaseous ${ }^{129} \mathrm{I}$. The fourth model, which combines the "capillary barrier" with aqueous EBS transport of ${ }^{129} \mathrm{I}$ and ${ }^{36} \mathrm{Cl}$, reduces the peak doses by about an additional factor of about 200 for the entire range of the CCDF. In this case, the only nuclide that is able to traverse the EBS rapidly is ${ }^{14} \mathrm{C}$ in the gaseous phase, which is then assumed to enter the aqueous phase in the geosphere, from whence it is transported through the unsaturated and saturated zones to the accessible environment. The final model, which eliminates ${ }^{14} \mathrm{C}$ as a contributor to peak dose at the accessible environment (by assuming it is transported in the gaseous phase to the atmosphere), leaves only diffusively transported aqueous-phase nuclides across the EBS. This results in an additional reduction by a factor of more than $10^{4}$ in peak dose over the $1,000,000$ year time frame, compared to the fourth model. In summary, these various EBS transport models point to the importance of estimating the amount of dripping flow in the EBS, and to the advantages of constructing a barrier to such flow.

Fracture/Matrix Interaction in the Geosphere, Figure ES.8-9 shows the effect of fracture/matrix interaction on the ultimate peak dose at the accessible environment during the first $1,000,000$ years. At one extreme is matrix flow only, i.e., no water flow in fractures. At the other extreme is highly connected intra-unit fracture flow $[\lambda=1 /(100 \mathrm{~h})]$, such that radionuclides remain within the fractures of each unit for the entire time spent traveling through the unit (and similarly for nuclides traveling within the matrix), i.e., there is very little interaction between fractures and matrix. The only interaction between fractures and matrix is at the hydrogeologic-unit boundaries, where matrix flow leaving the base of a given unit can enter the fractures of the next 
lower unit and fracture flow from the base of the unit can enter the matrix of the next lower unit. Figure ES.8-9 indicates that fracture/matrix interaction does not significantly affect peak doses over the long time frame of $1,000,000$ years. Although strong fracture/matrix coupling (such as in matrix diffusion) can significantly delay initial breakthrough (not shown by the CCDFs), it does not delay it enough to affect the peak dose very much over the 1,000,000-year time span.

Most Important Model Parameters During 1,000,000-Year Time Frame

One important difference between repository performance over the 1,000,000-year time frame compared to the 10,000-year time frame is which physical parameters are most influential. For 10,000 years it is mainly percolation rate in the unsaturated zone (or, equivalently, infiltration rate, $\mathrm{q}_{\text {inf }}$ ) and fracture/matrix flow in the CHnv, but for the 1,000,000-year time frame, dilution in the saturated zone (i.e., the saturated-zone fluid flux, $\mathrm{q}_{\mathrm{Sz}}$ ) is apparently the most important parameter. This is demonstrated by Figures ES.8-10 and ES.8-11. Figure ES.8-10 shows scatter plots of 1,000,000-year peak dose vs. $\mathrm{q}_{\mathrm{SZ}}$ over the high and low $\mathrm{q}_{\text {inf }}$ ranges. Clear linear trends are apparent. Figure ES.8-11 shows the result of two linear regression analyses for the high $\mathrm{q}_{\text {inf }}$ case: (1) $\ln ($ dose $)$ vs. $\ln (x)$ and (2) $\ln ($ dose $)$ vs. $x$, where $x$ is a subset of the stochastic parameters that were expected to be the most important. For each analysis, the five most important independent parameters are shown in Figure ES.8-11, as well as the amount of the variability they explain. For example, consider the $\ln ($ dose) vs. $\ln (x)$ transformation, which explains the results much better than the $\ln \left(\right.$ dose) $v s . x$ transformation. In particular, $\mathrm{q}_{\mathrm{SZ}}$ is the most important parameter, and by itself explains $48 \%$ of the variance in the results, assuming a ln-ln relationship (whereas, it only explains $23 \%$ of the variance by itself for the ln-linear relationship). The second most important parameter is $\mathrm{q}_{\mathrm{inf}}$, and in combination with $\mathrm{q}_{\mathrm{SZ}}$, they explain $65 \%$ of the variability when using a $\ln -\ln$ fit.

An explanation of the different rankings for $1,000,000$ years versus 10,000 years is that the breakthrough of the dose peak has generally occurred within the 1,000,000-year time period, so that the only model parameter of importance is how much the waste mass has been diluted (or how much it has decayed); whereas, for 10,000 years only the leading edge of the breakthrough curve has arrived at the accessible environment, so a change in an important UZ parameter can significantly shift this steeply rising portion of the breakthrough curve.

In TSPA-1995 some of the stochastic distributions for parameters have been eliminated and replaced with sensitivity analyses, which are conducted for only three or four values of the given parameter. Thus, the linear regression analysis does not include such parameters in the importance rankings, even though they could be more important than the ranked parameters. An example is the fracture/matrix particle transition parameter, $\lambda$. A more important example is $q_{\text {inf }}$, which is equivalent in TSPA-1995 to the mean UZ percolation flux at repository depth. In particular, $\mathrm{q}_{\text {inf }}$ has been separated into two ranges, or sensitivity cases. Within each range, we have included $\mathrm{q}_{\text {inf }}$ in the stepwise linear regression, but its importance has been much reduced compared to if we had constructed 100-realization CCDFs over the entire $q_{\text {inf }}$ range from 0.01-2.0 mm/yr. Thus, $\mathrm{q}_{\mathrm{sz}}$ is the \#1 ranked parameter. However, if stepwise linear regression is performed over the entire range, then $\mathrm{q}_{\text {inf }}$ becomes the \#1 ranked parameter and $\mathrm{q}_{\mathrm{SZ}}$ becomes the \#2 ranked parameter. This is shown in Figure ES.8-12, which is a scatter plot of 1,000,000year peak dose versus $\mathrm{q}_{\mathrm{inf}}$, over the entire range 0.01-2.0 mm/yr, and also in Figure ES.8-13, which show the importance rankings for a linear regression analysis over this entire $\mathrm{q}_{\mathrm{inf}}$ range. 
It should be-noted that it is actually the ratio of $\mathrm{q}_{\text {inf }}$ (i.e., $\mathrm{q}_{\mathrm{UZ}}$ ) to $\mathrm{q}_{\mathrm{SZ}}$ that determines dilution in the saturated zone, so this again points out that over the 1,000,000-year time frame, it is primarily dilution that controls peak dose at the accessible environment-at least according to the current models and data incorporated into TSPA-1995.

\section{Subsystem Performance}

Another important aspect of the TSPA analysis is to determine the ability of various parts of the system, both engineered and natural, to contain or retard the transport of the waste. To evaluate the containment capability of these various subsystems, cumulative (but not normalized) expected-value releases were calculated for a particular case (83 MTU/acre, with backfill, "high" $\mathrm{q}_{\mathrm{inf}}=1.25 \mathrm{~mm} / \mathrm{yr}$ initially, and cyclical $\mathrm{q}_{\text {inf }}$ due to climate change) at various times $(10,000$, 100,000 , and 1,000,000 years) at the following locations:

1. From the engineered barrier system (EBS),

2. From the base of the repository-level formation (TSw),

3. From the base of the unsaturated zone (PPn), and

4. At the accessible environment (AE).

Results are presented in Figure ES.8-14 for ${ }^{237} \mathrm{~Np}$ release. Generally, the saturated zone does not act as a significant containment barrier as evidenced by the releases being similar at the base of the unsaturated zone and at the AE. However, the individual natural barriers, and combinations thereof, in the unsaturated zone provide additional reduction of radioactivity compared to the EBS, up to and slightly beyond $1,000,000$ years. The natural barriers have a much greater effect at earlier times because the bulk of the ${ }^{237} \mathrm{~Np}$ is still in the unsaturated zone; however, by $1,000,000$ years, the natural barrier system only reduces ${ }^{237} \mathrm{~Np}$ releases by about a factor of 1.5 compared to the EBS, since a large portion of the ${ }^{237} \mathrm{~Np}$ has traveled to the accessible environment.

This comparison of subsystem performance demonstrates that the natural barriers are less effectual as time increases, and one must rely on dilution or effective EBS containment to reduce doses at the accessible environment. However, given the many conservative assumptions in TSPA-1995, neither of these may be necessary, since doses may already be at a very low level.

\section{ES.8.3 Summary of Predicted Repository Performance}

\subsection{0-year Predicted Performance}

The following are general conclusions concerning 10,000-year repository performance, based on the sensitivity analyses completed in TSPA-1995:

(1) 10,000-year total peak dose, due mainly to ${ }^{99} \mathrm{Tc}$ and ${ }^{129} \mathrm{I}$, is most sensitive to the following model parameters: matrix velocity in the CHnv and percolation flux in the unsaturated zone;

(2) Over 10,000 years there are zero releases to the accessible environment for the following cases: (i) low infiltration range $(0.01-0.05 \mathrm{~mm} / \mathrm{yr})$, (ii) cathodic protection of the waste- 
package, (iii) Buscheck $80 \mathrm{MTU} / \mathrm{acre}$ thermal load with and without backfill and Buscheck $24 \mathrm{MTU} / a c r e$ thermal load with backfill, and (iv) matrix-flow-only (zero fracture flow) in the unsaturated zone;

(3) Depending on the conceptual model of intra-unit fracture connectivity, fracture/matrix interaction can significantly affect peak dose and cumulative release during the first 10,000 years after repository closure;

(4) Depending on the conceptual model for radionuclide transport across the EBS (viz., if ${ }^{129} \mathrm{I}$ and ${ }^{36} \mathrm{Cl}$ are assumed to be in the aqueous phase and/or ${ }^{14} \mathrm{C}$ is supposed not to contribute to peak dose since it is dispersed in the atmosphere), a "capillary barrier" that prevents drips (i.e., advective flow) from contacting the waste packages can reduce 10,000-year peak doses at the accessible environment by at least a factor of 20 or more (and up to many orders-of-magnitude if only diffusive releases are possible through the EBS).

\subsubsection{0-year Predicted Performance}

The following general conclusions can be drawn about 1,000,000-year repository performance from the sensitivity analyses completed in TSPA-1995:

(1) 1,000,000-year total peak dose, due mainly to ${ }^{129} \mathrm{I}$ over the low infiltration range $\left(\mathrm{q}_{\text {inf }}=\right.$ $0.01-0.05 \mathrm{~mm} / \mathrm{yr})$ and to ${ }^{237} \mathrm{~Np}$ over the high infiltration range $\left(\mathrm{q}_{\mathrm{inf}}=0.5-2.0 \mathrm{~mm} / \mathrm{yr}\right)$, is most sensitive to the following model parameters: (i) dilution in the saturated zone (or equivalently, the saturated-zone bulk Darcy flux, $\mathrm{q}_{\mathrm{sz}}$ ), and (ii) percolation flux in the unsaturated zone (where the mean UZ percolation flux equals the average infiltration flux, $\mathrm{q}_{\text {inf }}$-both averaged over the repository area);

(2) 1,000,000-year total peak dose may be greatly reduced by a barrier that intercepts dripping water on the waste packages (the capillary-barrier effect), i.e., for aqueous-phase radionuclides, pure diffusion (no advection) through the WP/EBS produces extremely low doses at the accessible environment (reduced by a factor of $10^{8}$ compared to dripping flow on the waste form);

(3) Low intra-unit fracture connectivity in the unsaturated zone (i.e., high transition rate between the fracture and matrix in the RIP model) can significantly delay the breakthrough of peak doses to the accessible environment, but only slightly reduces the ultimate peak dose that occurs during the entire 1,000,000-year time frame after repository closure (a similar conclusion applies to matrix diffusion);

(4) Alternative thermal loads, alternative thermohydrologic models for the near-field, and alternative corrosion-initiation models (including cathodic protection) do not have a very large effect on the total peak dose that occurs during the 1,000,000-year time span (a factor of three is about the largest effect);

(5) Over 1,000,000 years, climate change with water table rise can increase peak dose at the accessible environment by a factor of about 2 to 10 compared to no change in climate; 
climate change without water table rise (varying infiltration rate only) falls in between these two extremes.

\section{ES.9 EFFECT OF CONSERVATISM ON PREDICTED RESULTS}

A large number of sensitivity and uncertainty analyses have been performed during the course of this iteration of total system performance assessment. Such analyses are always an important component of any performance assessment. They provide an important means to gain insights into those components, processes, models, and parameters which most significantly affect the predicted waste containment and isolation over the time periods of interest.

While many useful insights have been reached on the basis of the sensitivity analyses performed, it is also instructive to step back and examine in a more qualitative fashion the implications of some of the assumptions made in the development of the total system performance assessment. The implications may be in the direction of improving the predicted performance (when the conservative assumptions are relaxed) or in the direction of degrading the predicted performance (when the nonconservative assumptions are tightened).

The question of the significance of nonconservative assumptions may be posed as follows: What components, processes, models, or parameters could, with some reasonable likelihood, be sufficiently different from the assumptions made in the current TSPA iteration, such that the predicted releases or doses could be greater than those presented? The primary factor which could cause a significant increase in the predicted releases or doses at the accessible environment is the unsaturated-zone percolation flux. Significantly greater percolation flux values (on the order of $10 \mathrm{~mm} / \mathrm{yr}$ ) would be expected to increase the percentage of waste packages experiencing advective release from the EBS and the magnitude of that advective release if no hydraulicallyengineered barrier (such as a capillary barrier or drip shield) were emplaced in the drifts. At some percolation flux, the limiting factor on the predicted release from the EBS would be the dissolution rate of the waste form itself, which in the present analyses is quite conservative. Although increasing the percolation flux also decreases the advective travel time in the unsaturated zone and therefore increases the possible release of key radionuclides to the accessible environment, the travel time factor does not appreciably affect the peak dose because the dominant dose contributor is always ${ }^{237} \mathrm{~Np}$ (at the higher percolation flux values) and it is released eventually anyway.

An additional factor that may increase the dose above the values predicted is the assumed value for the dose conversion factor. This factor, which converts from mass concentration to radiation dose, has been derived from an EPA reference, but it is possible that revised biosphere modeling of ingestion pathways and bio-concentration factors may affect the conversion factor. It is recommended that the EPA delineate this conversion ratio as part of their rulemaking process, assuming they accept the notion of dose- or risk-based total system performance.

Given that it is neptunium which generally controls the predicted peak dose at the higher percolation flux values (it may be iodine or technetium at lower percolation flux values), the solubility of this radionuclide plays a significant role. The assumed solubility value of this nuclide is already considered to be at the conservative end of the expected range. Therefore increasing this value substantially is not believed reasonable. In addition, even if the value were 
increased, one would quickly reach a point where the dissolution rate would control the release of this radionuclide (assuming a significant advective release component through the EBS).

Finally, colloidal transport of radionuclides has not been considered in the present TSPA analyses. Although natural- and/or radio-colloids may be formed in the waste package environment, their stability and mobility is uncertain. For those nuclides that may exist as a colloidal phase and that are also stable and mobile, their transport to the accessible environment may be significantly enhanced if the colloidal matter does not sorb onto the rock. In such a scenario, albeit unlikely, the peak concentration of some key dose-producing radionuclides (especially plutonium) may be significantly increased, which would correspondingly increase the predicted total peak dose.

The question of the significance of conservative assumptions may be posed as follows: What components, processes, models, or parameters could, with some reasonable likelihood, be sufficiently different from the assumptions made in the current TSPA iteration, such that the predicted releases or doses could be less than those presented? In answering this question, virtually every element of the total system is a candidate for discussion. A large number of conservative assumptions have been made that would tend to significantly impact the predicted long-term release or dose if the assumptions were relaxed or if the nonconservative end of the parameter space was considered. For example, when considering the lowest percolation fluxes, the peak dose is reduced by a factor of about 100 , even when the release of ${ }^{129}$ I from the EBS is assumed to be in the gaseous phase. Assuming that the ${ }^{129} \mathrm{I}$ is released in the aqueous phase would reduce the peak dose by an additional factor of about 100 . Low average percolation fluxes have two very positive effects, namely reducing the EBS release rate (because the advective component of the release is reduced) and increasing the travel time (because the propensity for fracture flow and transport is reduced and the matrix velocities are lower).

Limiting the available inventory by either extending the lifetime of a certain fraction of the waste packages or incorporating the potential contribution of cladding has a positive effect on the predicted performance. Therefore, although the time of waste-package failure may not be so important in peak dose calculations (even in the most optimal degradation model some packages have failed by 100,000 years), the fact that only a small fraction of the packages have failed for certain assumptions is still important.

An important conservatism that significantly affects the predicted peak dose is the determination of the amount of mixing due to dilution and dispersion in the saturated zone. For the present analyses, the only dispersive mixing assumed to occur is in the vertical plane to a depth of $50 \mathrm{~m}$ below the top of the water table. Transverse dispersion would not be considered significant over the $5 \mathrm{~km}$ distance to the accessible environment. Also, longitudinal dispersion has a minimal effect when considering essentially a constant source term. However, if one considers the mixing possible between the repository and the ultimate point of ground-water discharge (whether $30 \mathrm{~km}$ down-gradient in the Amargosa Valley or $80 \mathrm{~km}$ down-gradient at Franklin Lake Playa), then significant reductions in the peak concentrations and doses would result.

In those cases where the neptunium release dominates the peak dose, the neptunium solubility plays a key role. It has been suggested that the neptunium solubilities used in the TSPA analyses are based on experiments that represent metastable equilibrium concentrations and that the actual 
equilibrium concentration may be several orders of magnitude lower. If this were the case, neptunium would be replaced by either technetium or iodine as the peak dose contributor and would result in a lower predicted peak dose by about an order of magnitude.

\section{ES.10 CONCLUSIONS AND RECOMMENDATIONS}

When considering a 10,000-year total system performance measure, there are many EBS and natural-barrier system factors that affect the predicted results. Under certain conceptual assumptions, the engineered barriers by themselves can provide complete containment of the radionuclides for the entire 10,000-year time period. Similarly, for cases when the percolation flux distribution is at the lower end of the possible range of likely values, the natural barrier by itself can provide complete isolation of the radionuclides from the accessible environment for the entire 10,000-year time period. This is the definition of reclundant barriers.

For cases when the most conservative estimates of both EBS and natural barrier performance are considered, i.e., those cases which produce some non-zero integrated release to the accessible environment over 10,000 years, several factors are important. The predominant factor is the percolation flux distribution. This distribution not only affects the likelihood of there being advective flux (i.e., dripping) through the EBS, but it also affects the magnitude of the advective release from the EBS, the distribution of radionuclide transport between the fractures and matrix in the unsaturated zone and the average matrix velocity through the unsaturated zone. That is, for given conservative assumptions regarding the waste-package degradation model, the percolation flux distribution controls the 10,000-year cumulative release. This is the same conclusion reached in TSPA-1991 (Barnard et al., 1992) and TSPA-1993 (Wilson et al., 1994 and Andrews et al., 1994). It is worthwhile to point out that the radionuclides of interest over the 10,000-year time period are highly soluble nuclides with little or no sorption such as ${ }^{99} \mathrm{Tc},{ }^{129} \mathrm{I}$, and ${ }^{14} \mathrm{C}$. Slightly sorbed nuclides such as ${ }^{237} \mathrm{~Np}$ can be released in small quantities over 10,000 years in cases of high percolation flux. For the parameter distributions used in the present analyses (which may be subject to change upon evaluation of the controlling phase of the nuclide), highly sorbed and low-solubility nuclides, such as plutonium, americium, and curium, are not transported appreciable distances through the EBS or host rock in 10,000 years.

While the predicted peak dose over a 10,000-year time period is dependent on numerous factors, in extending the time to $1,000,000$ years only a few factors dominate the predicted response. In general, factors which tend to delay the arrival of the peak concentration at the accessible environment are found to be less significant. This is a direct result of the extremely long time period considered and the long half-lives of some of the key radionuclides that always contribute to the predicted peak dose (notably ${ }^{99} \mathrm{Tc}$ with a 200,000 -year half-life, ${ }^{237} \mathrm{~Np}$ with a 2,000,000year half-life, and ${ }^{129}$ I with a 20,000,000-year half-life). Even for the low end of the assumed percolation flux distribution and even assuming the optimal conceptual representation of fracturematrix flow and transport, the above radionuclides are either not sorbed at all $\left({ }^{99} \mathrm{Tc}\right.$ and $\left.{ }^{129} \mathrm{I}\right)$ or are only slightly sorbed $\left({ }^{237} \mathrm{~Np}\right)$, and they generally tend to break through to the accessibleenvironment boundary within $1,000,000$ years. In addition, even with the most optimal wastepackage degradation model assumptions, a certain fraction of waste packages would be degraded within the 1,000,000-year period. In sum, although a combination of waste package and site performance can contribute to containing and isolating radioactive wastes within the Yucca Mountain area for some tens to even hundreds of thousands of years, it is unlikely that such 
barriers can be reasonably shown to delay the above radionuclides sufficiently to preclude their release over a 1,000,000-year time period.

While delay itself does not contribute appreciably to the prediction of long term doses, dispersion and dilution are still significant processes. Dispersion in this case is the result of both geosphere and EBS processes. Dispersion tends to spread out the release of the radionuclides over time and therefore reduce the peak concentration and peak dose. Geosphere dispersion is enhanced by increasing the matrix diffusion or decreasing the mean fracture-flow length (in cases where fracture transport is active) or increasing the vertical, lateral, and/or longitudinal dispersion in the saturated zone. The dispersive effects in the saturated zone are enhanced as the distance between the repository and the assumed user of the tuff aquifer increases. This effect has significant ramifications with respect to the definition of where the average member of the critical population proposed in the recent NAS recommendations resides. If the critical group is located in the Amargosa Valley, some $25 \mathrm{~km}$ down gradient from the present "accessible environment" as defined in 40 CFR Part 191, the increased geosphere dispersion may be expected to reduce the peak concentration and peak dose by more than one order of magnitude.

Dispersive-type effects within the engineered barrier system are extremely important in reducing the predicted peak concentration and dose in the geosphere. Spreading of releases from the EBS can occur as a result of (1) a wide distribution of waste-package failure times, (2) an extremely low alteration/dissolution rate or (3) diffusion-dominated releases through the package and EBS. The first two factors are generally insufficient to significantly decrease the peak release rate over the range of values considered in this TSPA iteration. However, diffusion-dominated releases from the EBS can significantly reduce the peak release rate. Such diffusion-dominated releases occur when either a low percolation flux distribution is assumed (in which case only a small percent of the packages experience advective release) or a very efficient capillary barrier in the backfill is considered. In both cases, the diffusion through the waste package and other EBS materials is a highly nonlinear function of the in-drift liquid saturation (generally very low for all thermal loads except when advective flow into the drift occurs), as well as the effective surface area through which diffusion occurs (which in turn is controlled by the waste-package degradation model).

Confidently demonstrating that diffusive release is the dominant transport mechanism in the EBS is key to reducing the predicted long term dose to individuals or critical groups. It is not at all coincidental that virtually every other high-level radioactive waste disposal program around the world that has published results of total system performance has incorporated a diffusive barrier in their engineered barrier design (see Neall et al., 1995). In other countries the diffusive barrier is a bentonite or bentonite-sand mixture, because these programs have focussed on crystalline host rocks within the saturated zone. An equivalent barrier (in the sense of maximizing the possibility of diffusive only releases from the EBS) in an unsaturated hydrologic environment such as Yucca Mountain is a crushed rock with low capillary suction.

In addition to spreading out the release of radionuclides from the source term, dilution in the saturated zone also significantly affects the predicted peak dose at the accessible environment boundary over the 1,000,000-year time period. This dilution can occur by the mixing of different ground-water sources either naturally along the flow path between the repository and the user of the tuff aquifer (or other ground-water sources that are supplied by the tuff aquifer) or by the 
user tapping alternative sources of water for consumption (i.e., by slotting the well over different isolated hydrostratigraphic units). Although alternative dilution scenarios are likely, quantitative descriptions of these scenarios are beyond the scope of the present document. Assuming that the EPA accepts the NAS recommendations of protecting individuals of critical groups as an appropriate environmental standard that should be applied to Yucca Mountain, additional analyses of regional ground-water flow patterns should be conducted. It is relevant to point out that saturated-zone mixing issues are not important for the cumulative release performance measure and are less significant at shorter distances between the potential repository and the defined location of the critical group.

Throughout the assessment of the individual components included in the overall TSPA analyses, an over-arching theme comes back again and again as being the driving factor impacting the predicted results. Simply stated, it is the amount of water present in the natural and engineered systems and the magnitude of aqueous flux through these systems that controls the overall predicted performance. The following discussion details the significance of water to the overall performance of the system. First, the degradation of the waste package is controlled by the relative humidity of the near field environment-at low relative humidities there is virtually no corrosion of the corrosion-allowance material. Second, once the waste packages have failed, the rate of dissolution of the waste form is dependent on the presence of liquid water in direct contact with the spent fuel. Third, the concentration of the radionuclides dissolved in this liquid water is dependent on the volume of water in contact with the spent fuel and the solubility of the radionuclides in that water. Fourth, transport of any dissolved radionuclides through the failed waste packages and other materials in the engineered barrier system (such as the invert upon which the packages are placed or any backfill or packing placed around the waste packages) is controlled by the presence of liquid water on the grain boundaries, which affects the diffusive transport component, and by the presence of dripping water through the drifts, which control the advective transport component. Fifth, those radionuclides which are transported through the drifts to the host rock may be advectively transported through the unsaturated zone to the water table, with the rate of transport being directly related to the aqueous percolation flux distribution. Sixth, those radionuclides which reach the water table are expected to be transported laterally through the saturated zone to the ultimate discharge of the ground water or to a potential user of the water between the potential repository and the ultimate discharge location. Seventh, within the saturated zone, the dissolved radionuclides would be diluted and dispersed due to small scale velocity heterogeneity of the ground-water flow regime. Finally, if an individual does extract ground water from the tuff aquifer, the particular use of that water will affect the pathways by which any dissolved radionuclides in the ground water may by consumed by that individual. In summary, the amount of water present at all points along the system, from the drift to the saturated zone, controls the ultimate release of radionuclides to the accessible environment and the corresponding dose attributed to those radionuclides. Therefore, information on the distribution of the amount and rate of water movement through the various scales relevant to the prediction of post-closure performance, remains the key need to enhance the representativeness of future iterations of TSPA. 


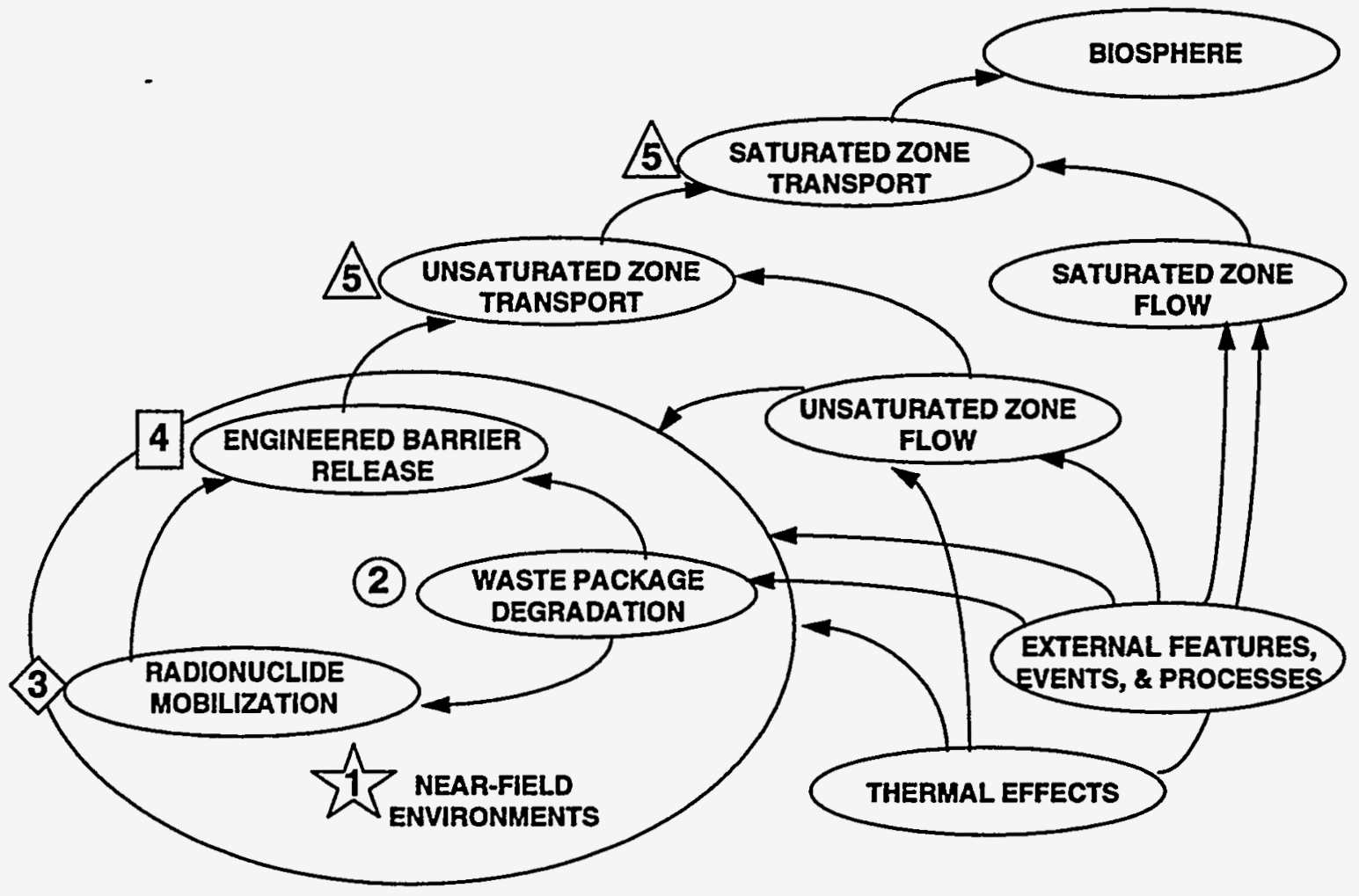

Figure ES.3-1 Process Model Influence Diagram Used in Total System Performance Assessment

\section{Top-Level Strategy for Waste Isolation}

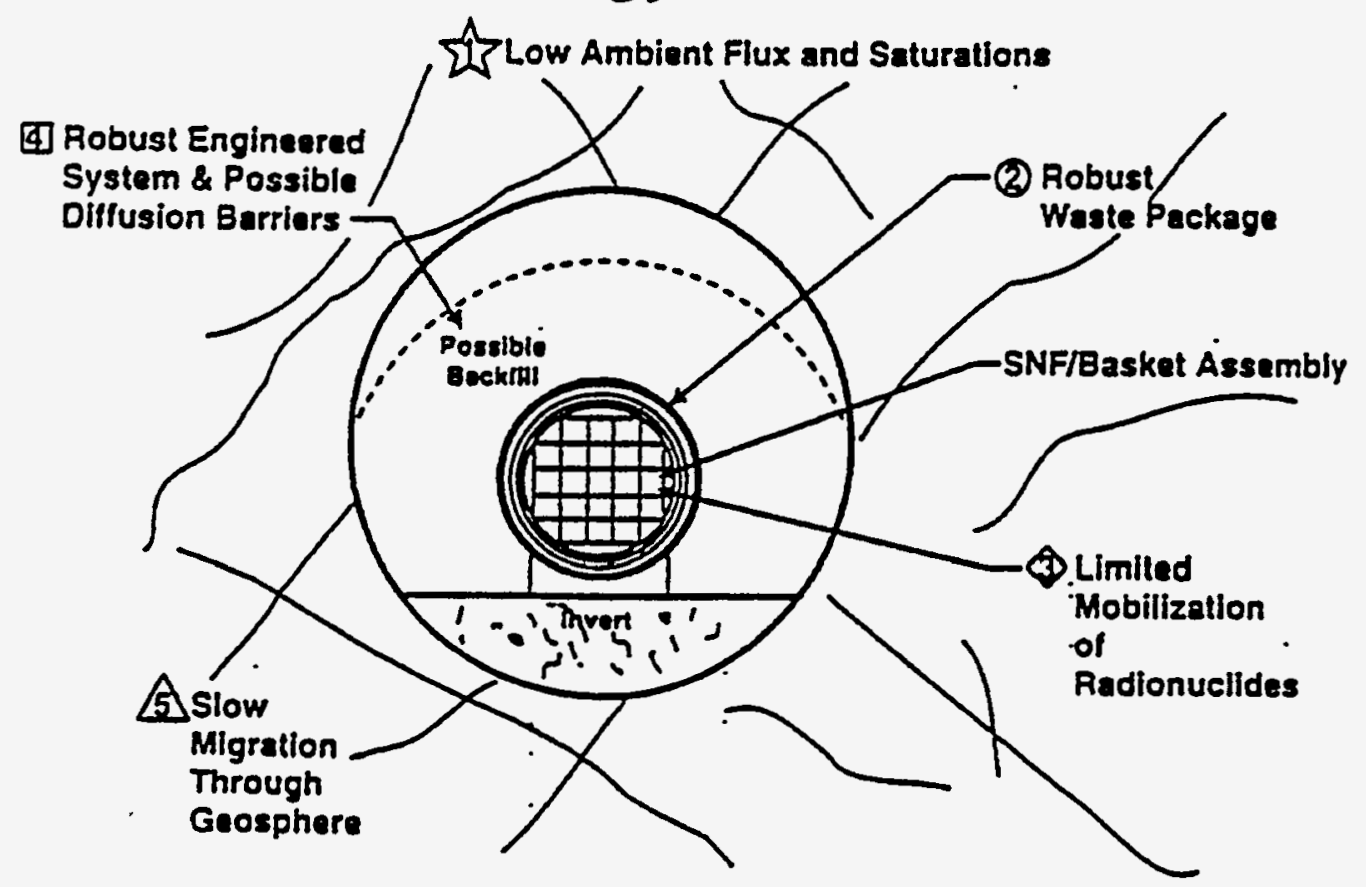

Figure ES.3-2 Engineered Barrier System Components 


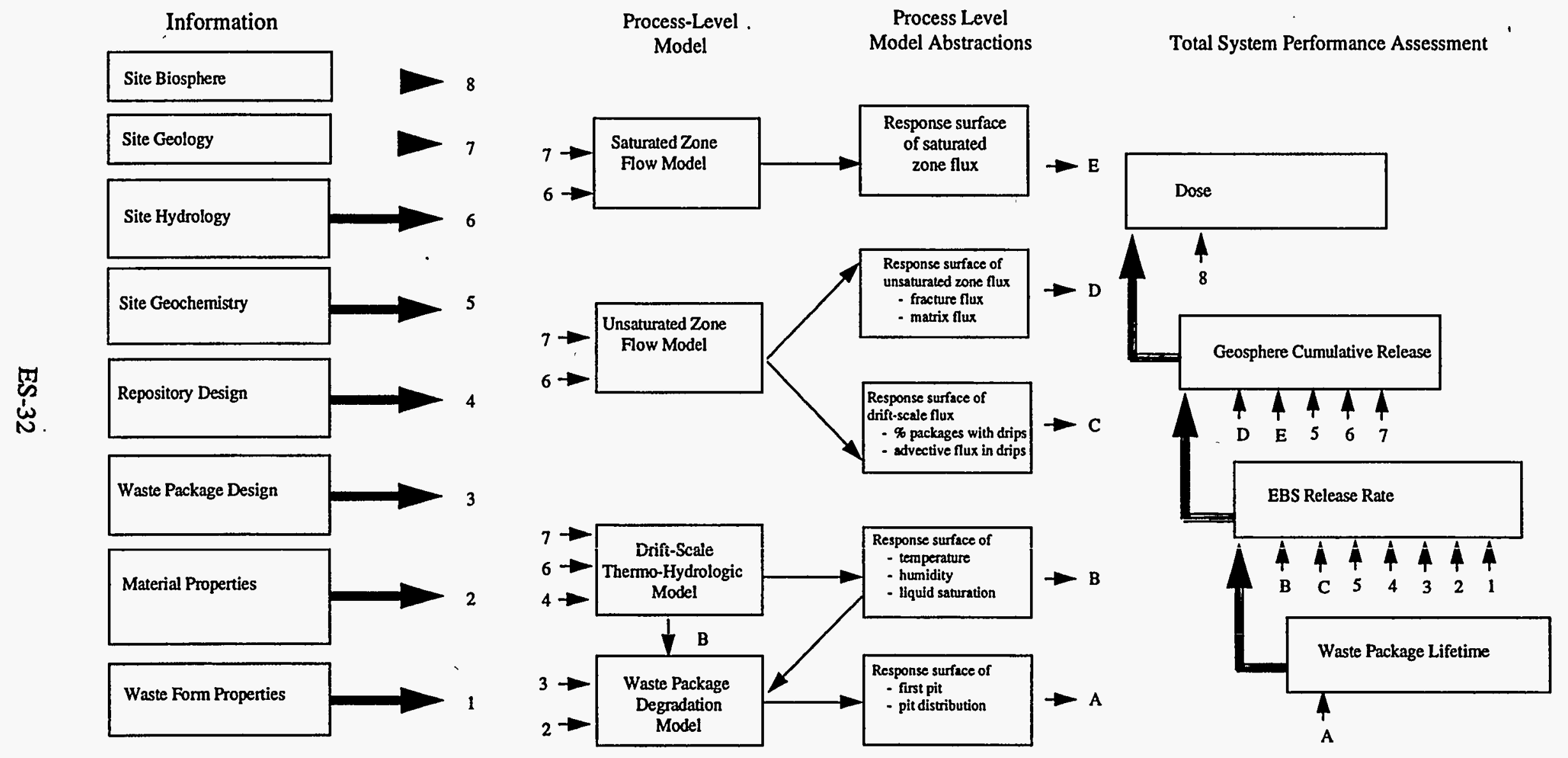

Figure ES.3-3 Information Flow Diagram for TSPA-1995 


\section{EE-S马}

( $\$ 86$ I 'Uos!!M

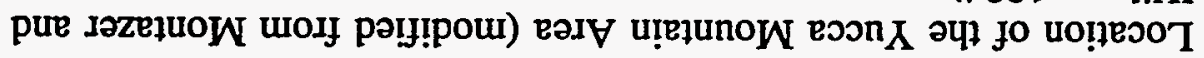
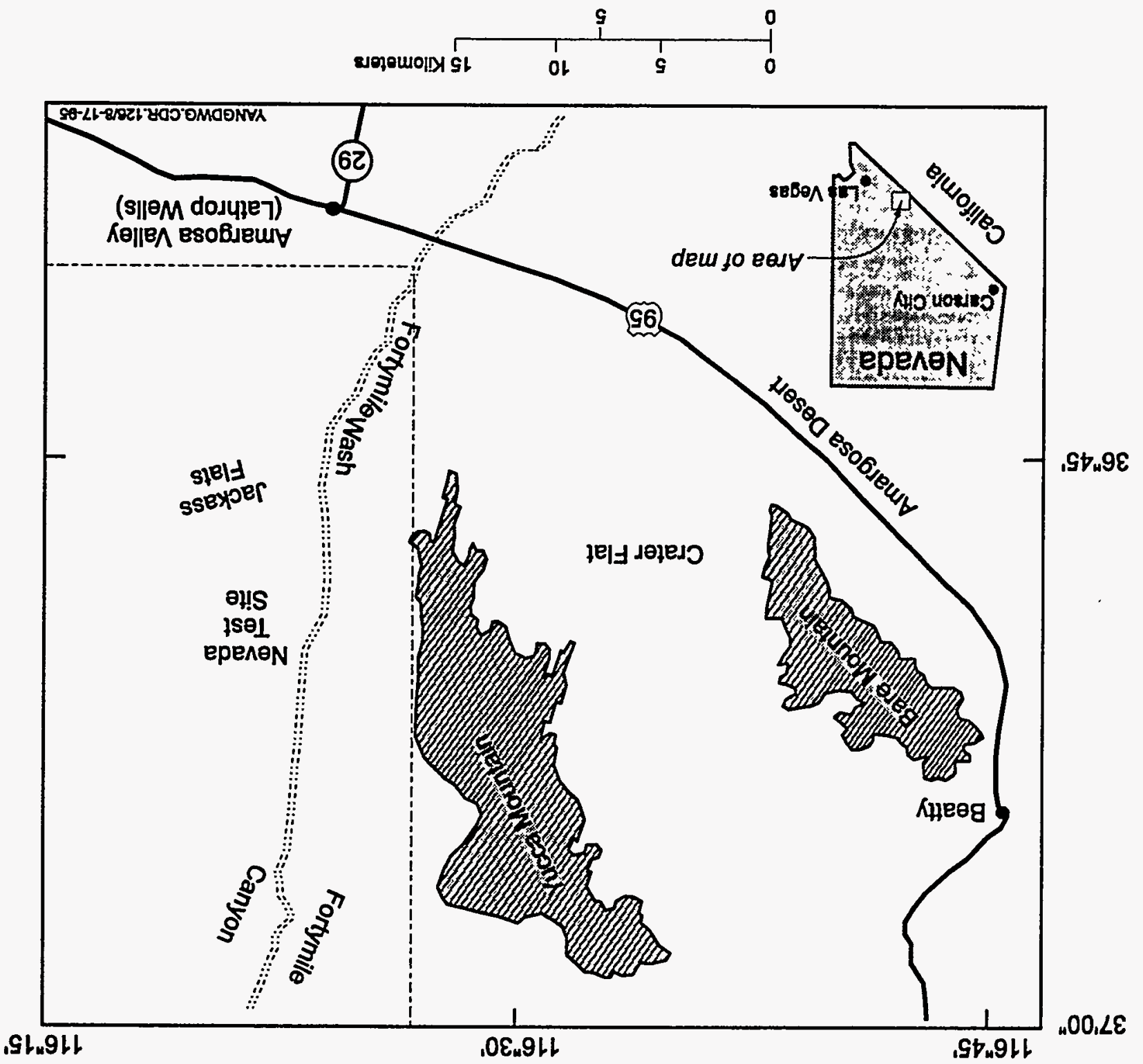


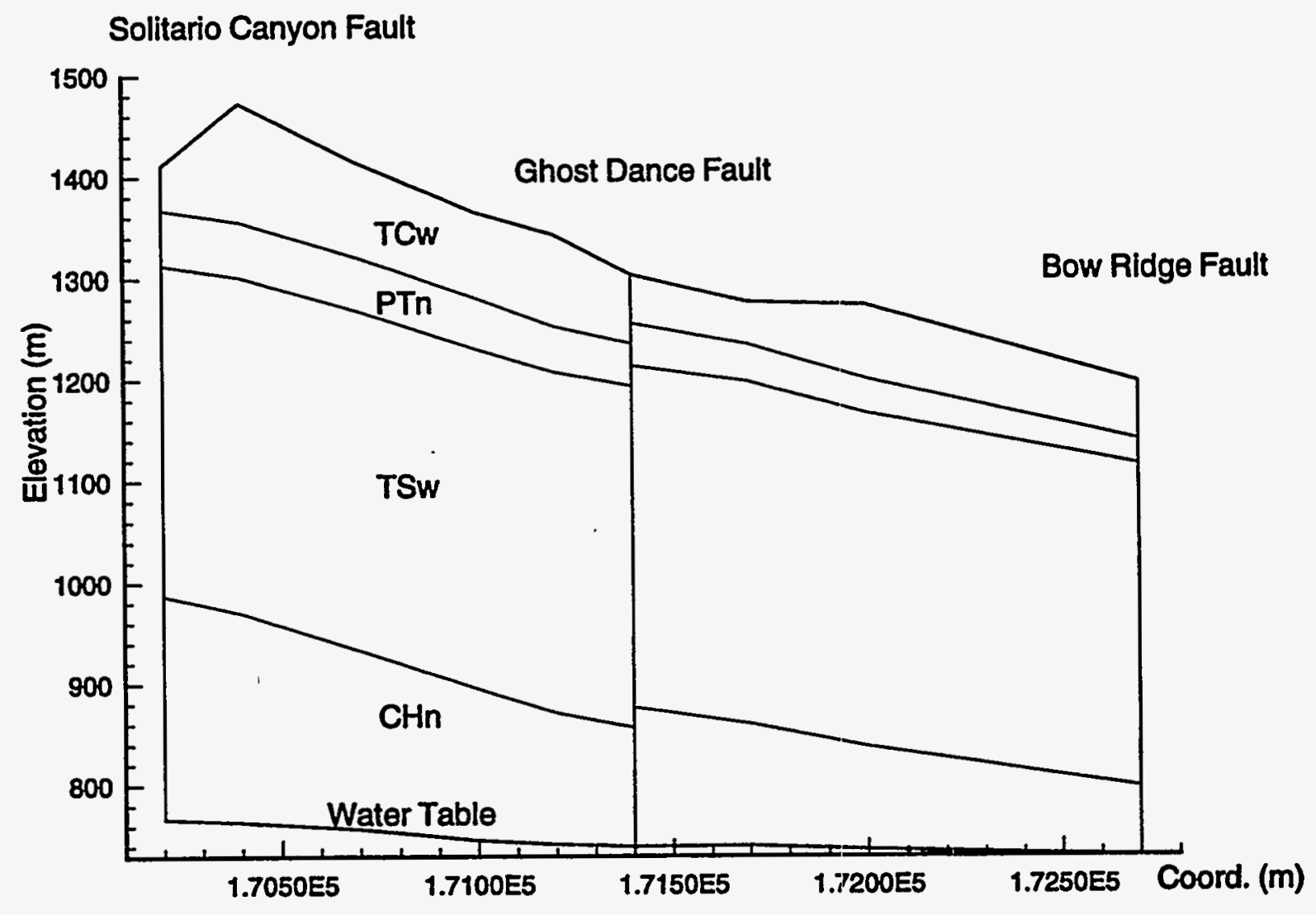

Figure ES.4-2 Geologic Cross-Section through the Potential Repository at Yucca Mountain (from Wittwer et al., 1995) 


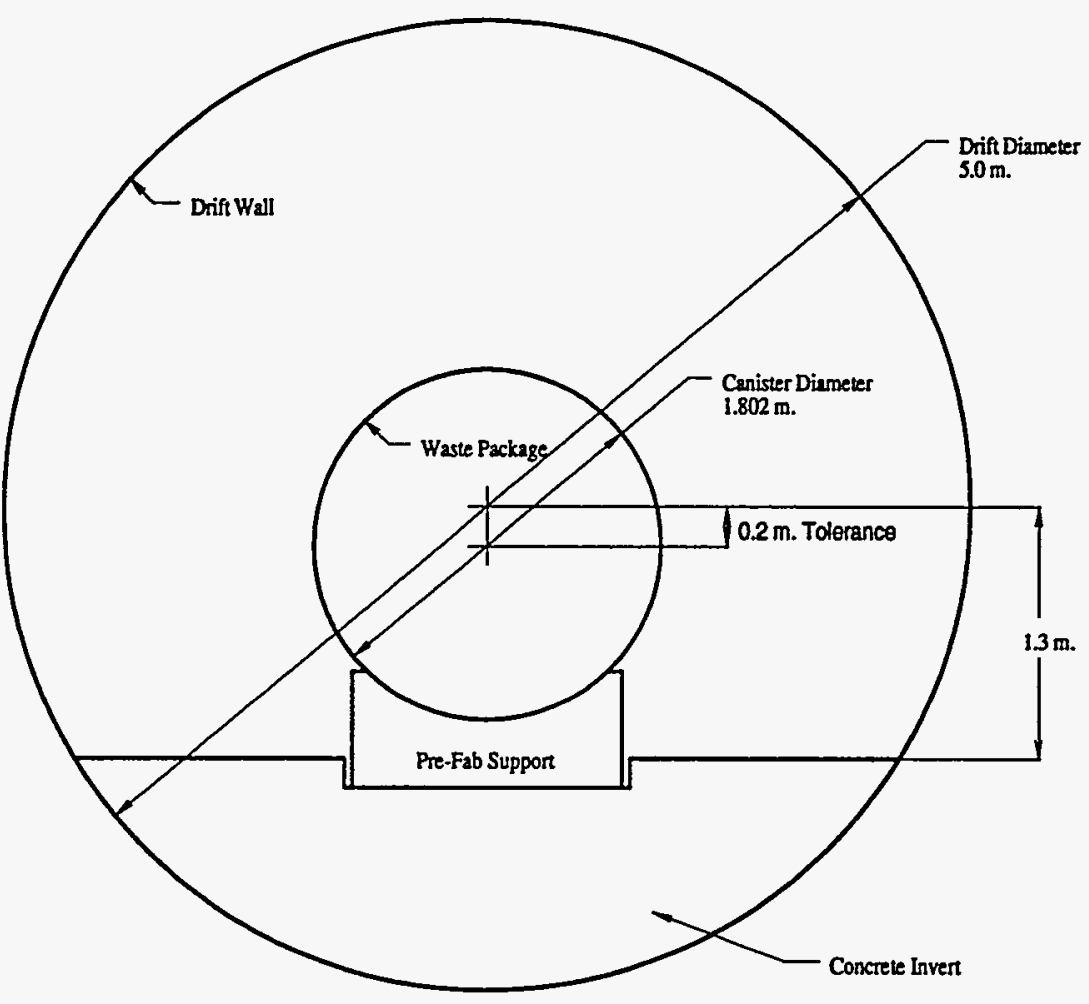

Figure ES.4-3 Emplacement drift design for the CIDP option (after M\&O, 1995f)

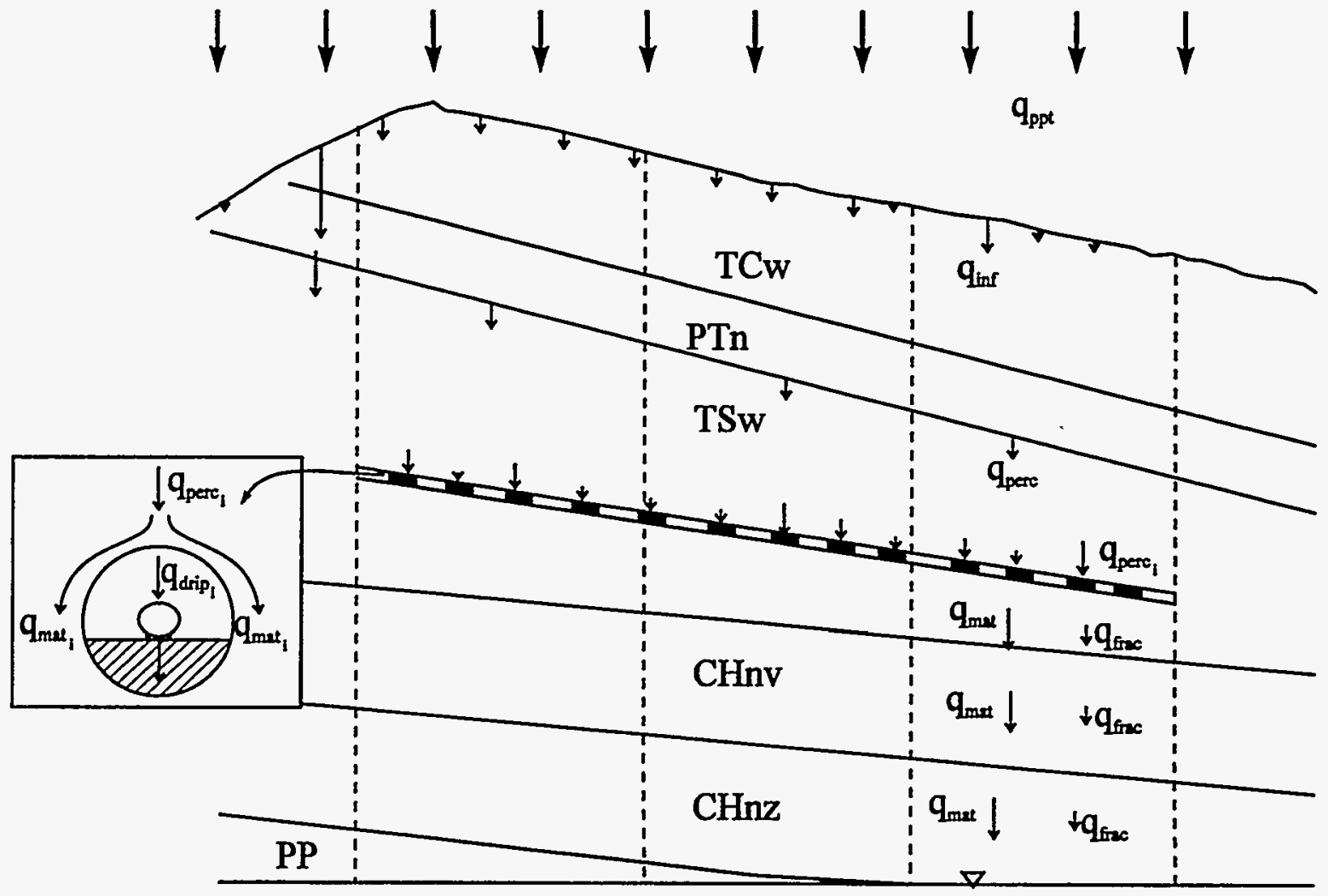

Figure ES.5-1 Conceptual model of unsaturated zone hydrology at Yucca Mountain as utilized in TSPA-1995. 


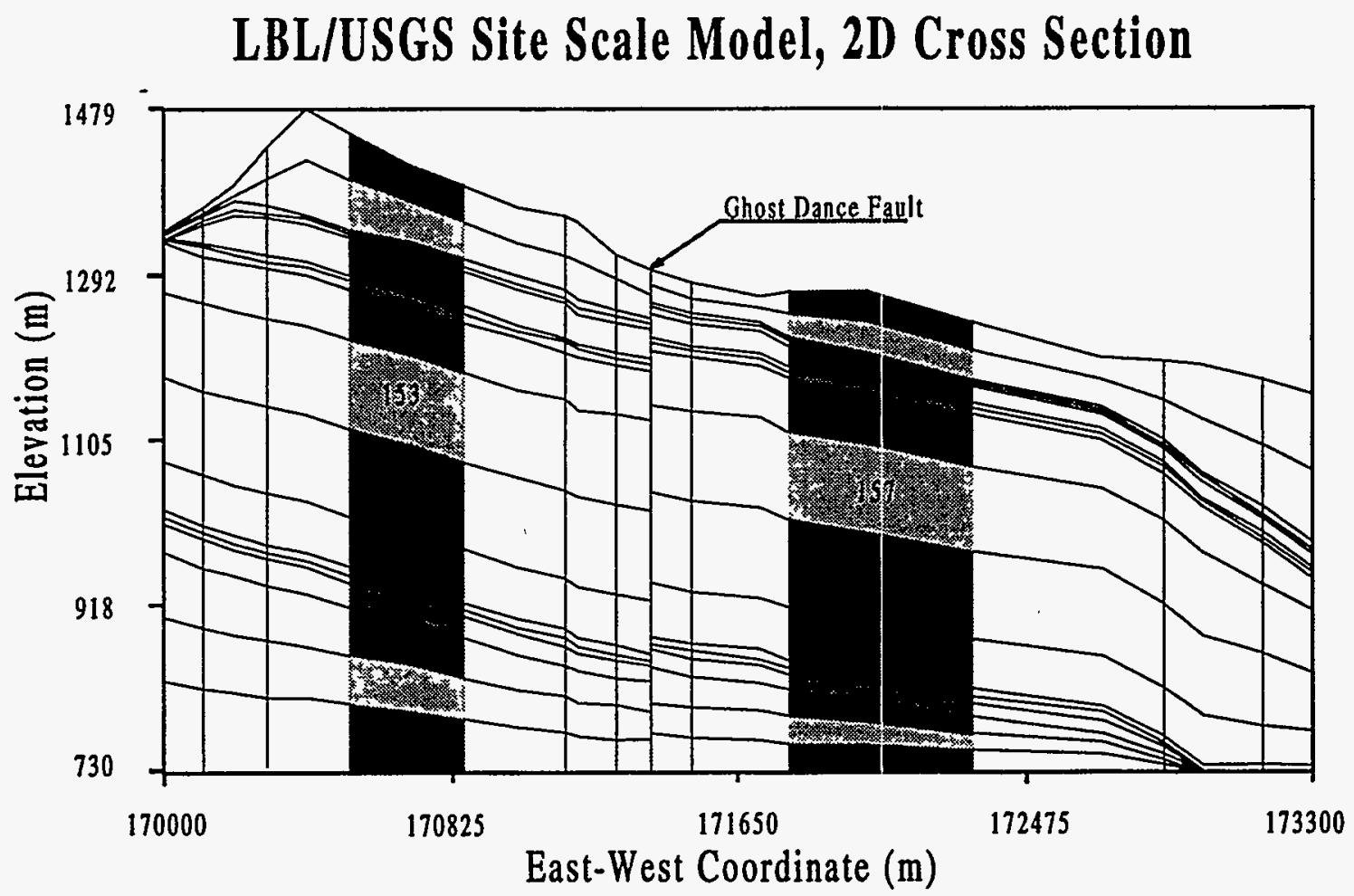

Figure ES.5-2

NW-SE cross-section extracted from the LBL-USGS site-scale model and used for hydrologic abstractions.
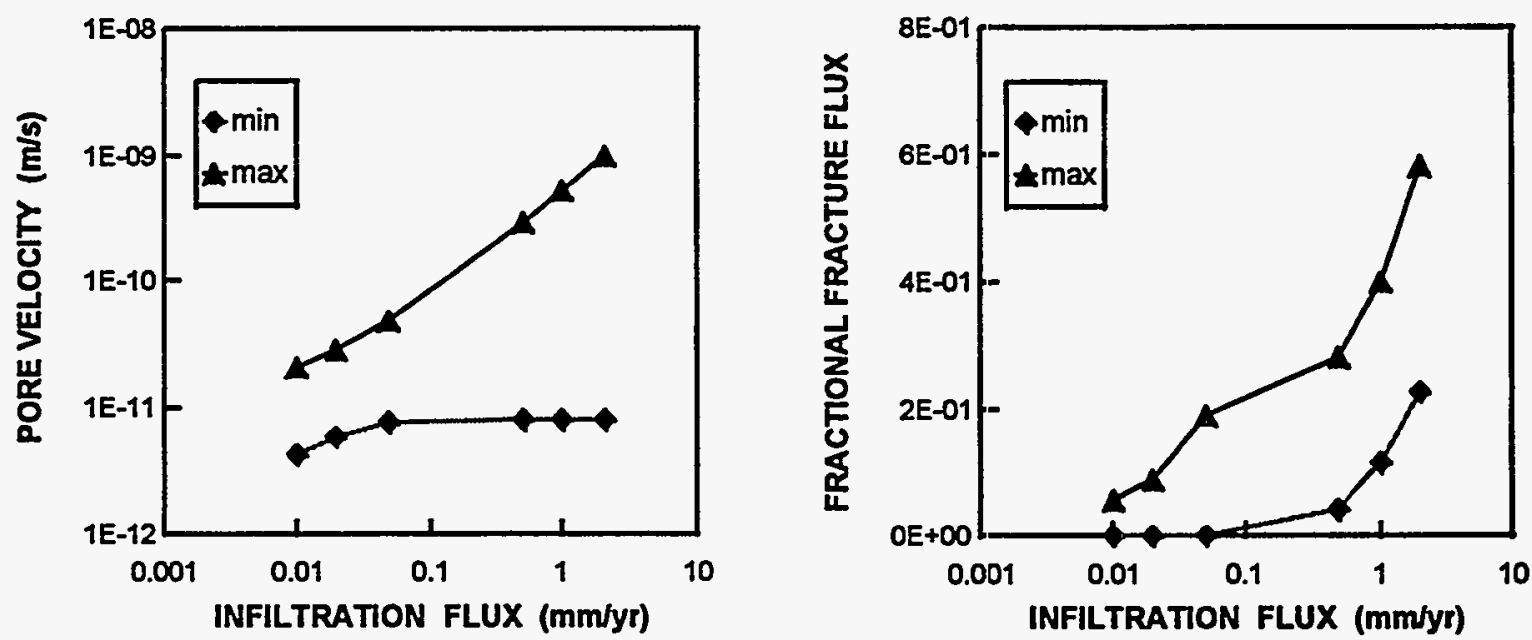

Figure ES.5-3

Abstractions of matrix pore velocity and fractional fracture flow as a function of infiltration rate for TSw. 


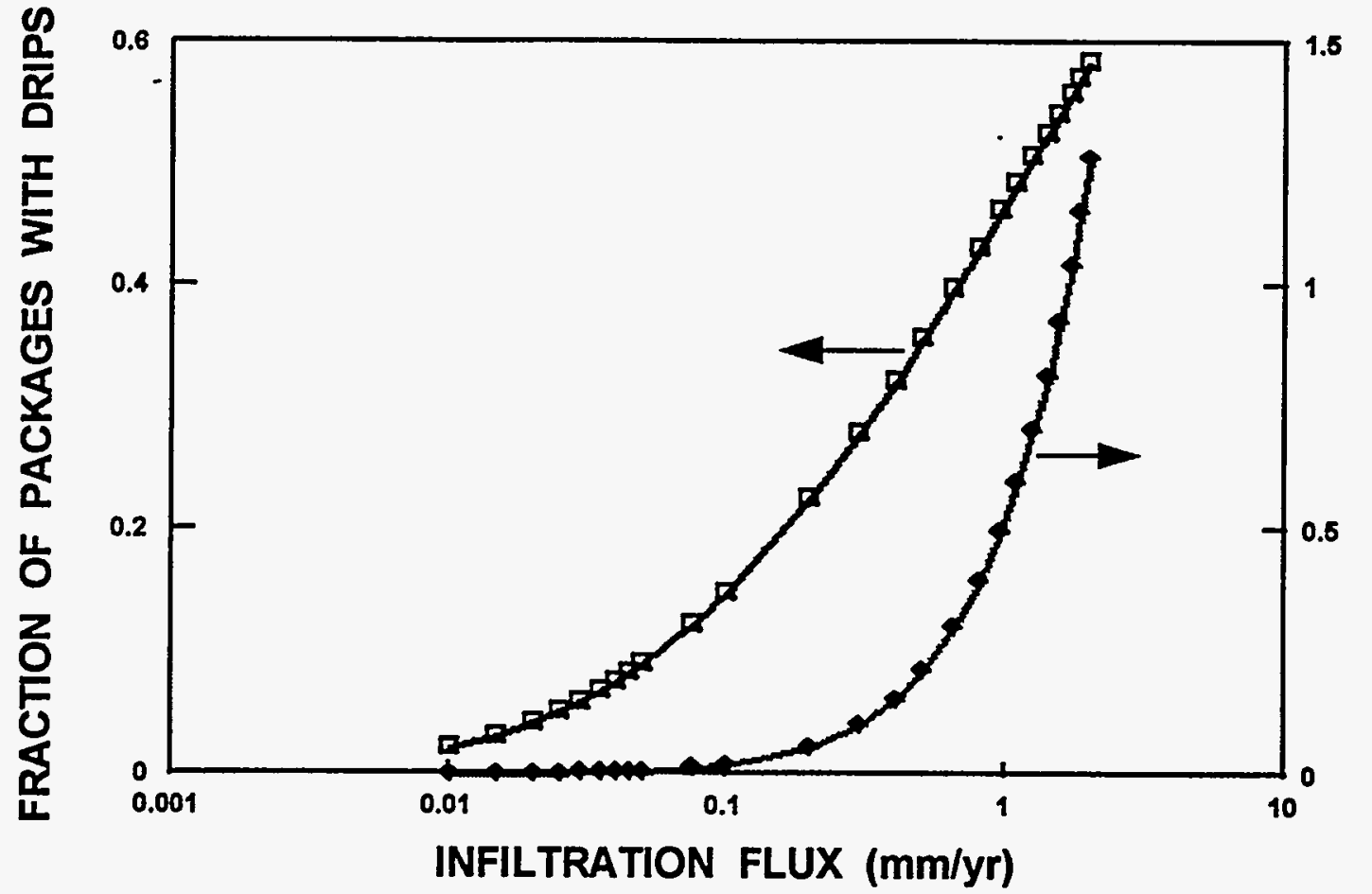

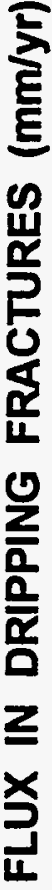

Figure ES.5-4

Drift-scale abstractions of the number of (and flux through) dripping fractures as a function of infiltration rate
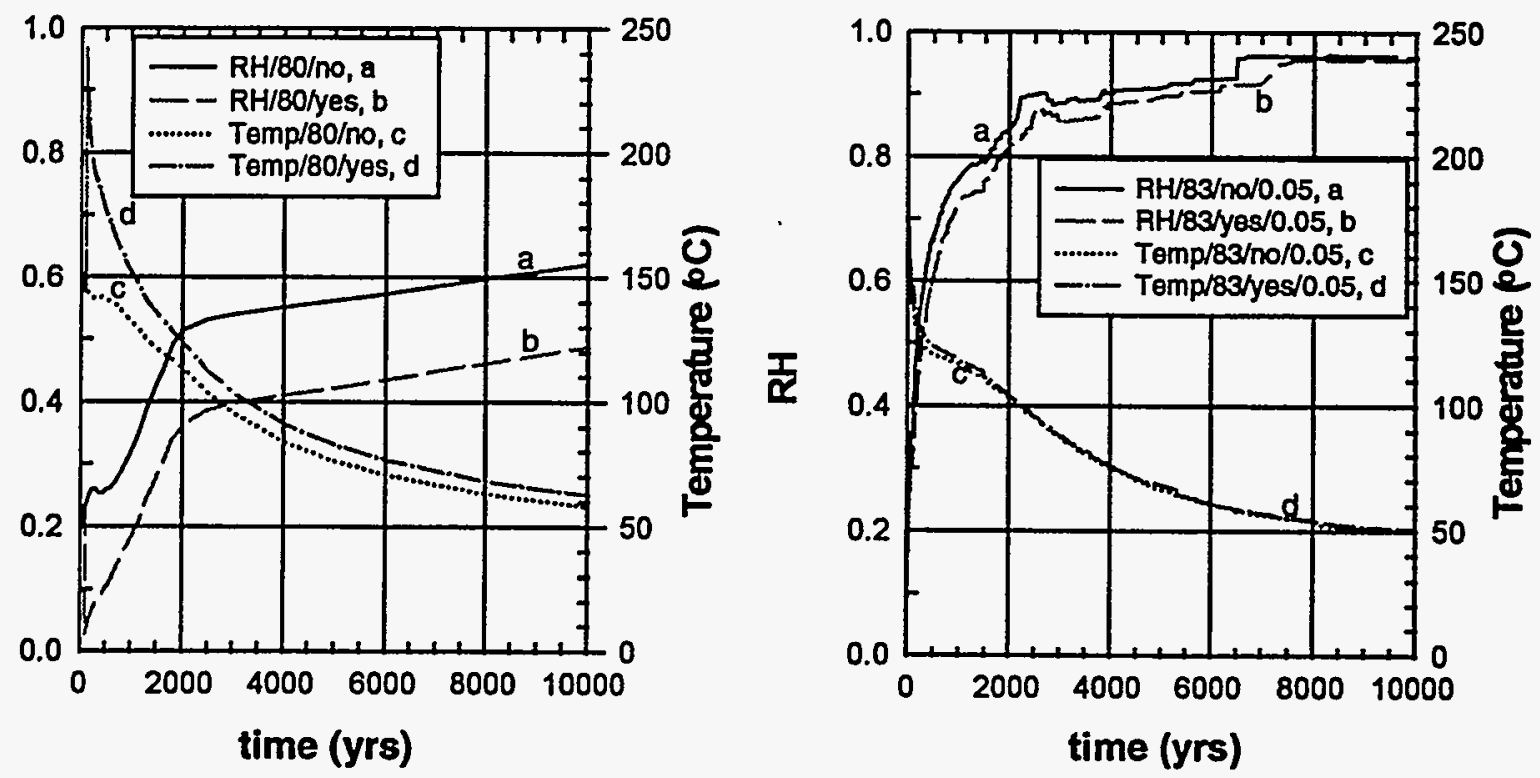

Figure ES.5-5 Comparison of temperature and relative humidities for the $83 \mathrm{MTU} / \mathrm{acre}$, $0.05 \mathrm{~mm} / \mathrm{yr}$ infiltration (this study), and for the $80 \mathrm{MTU} / \mathrm{acre}, 0 \mathrm{~mm} / \mathrm{yr}$ infiltration (Buscheck et al., 1995). 


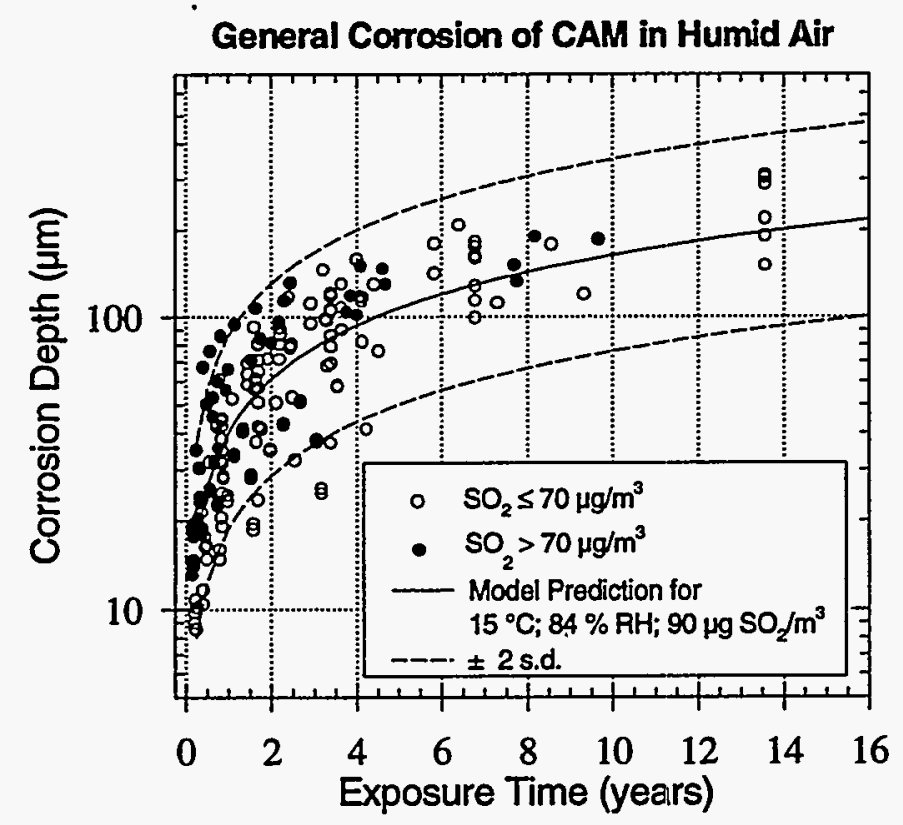

Figure ES.6-1 Atmospheric general corrosion data used and the model estimate with its uncertainty for corrosion-allowance barrier material.

\section{Approach to Stochastic Waste Package Degradation Simulation}

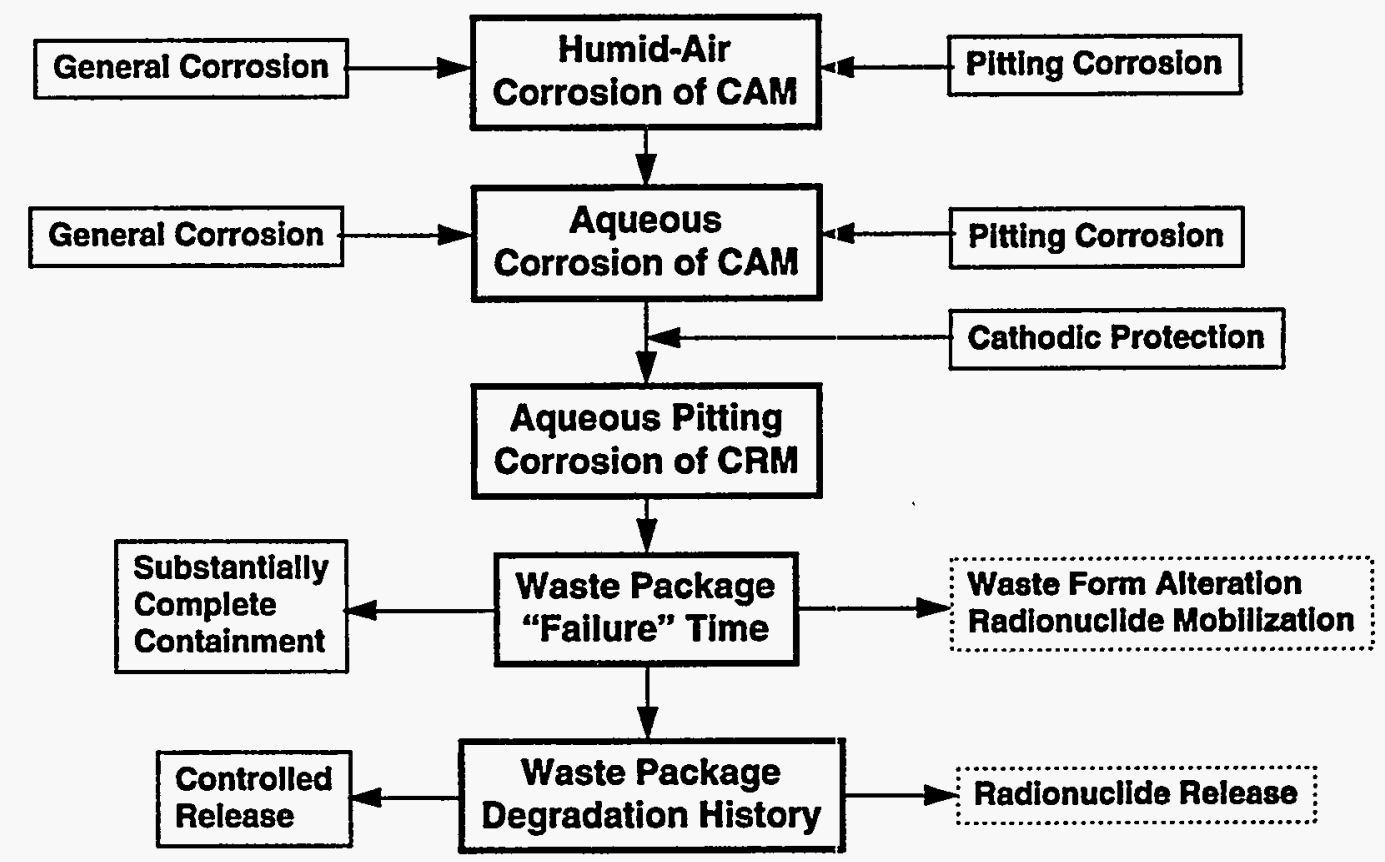

Figure ES.6-2 Flowchart illustrating the approach to stochastic waste package degradation simulation. 


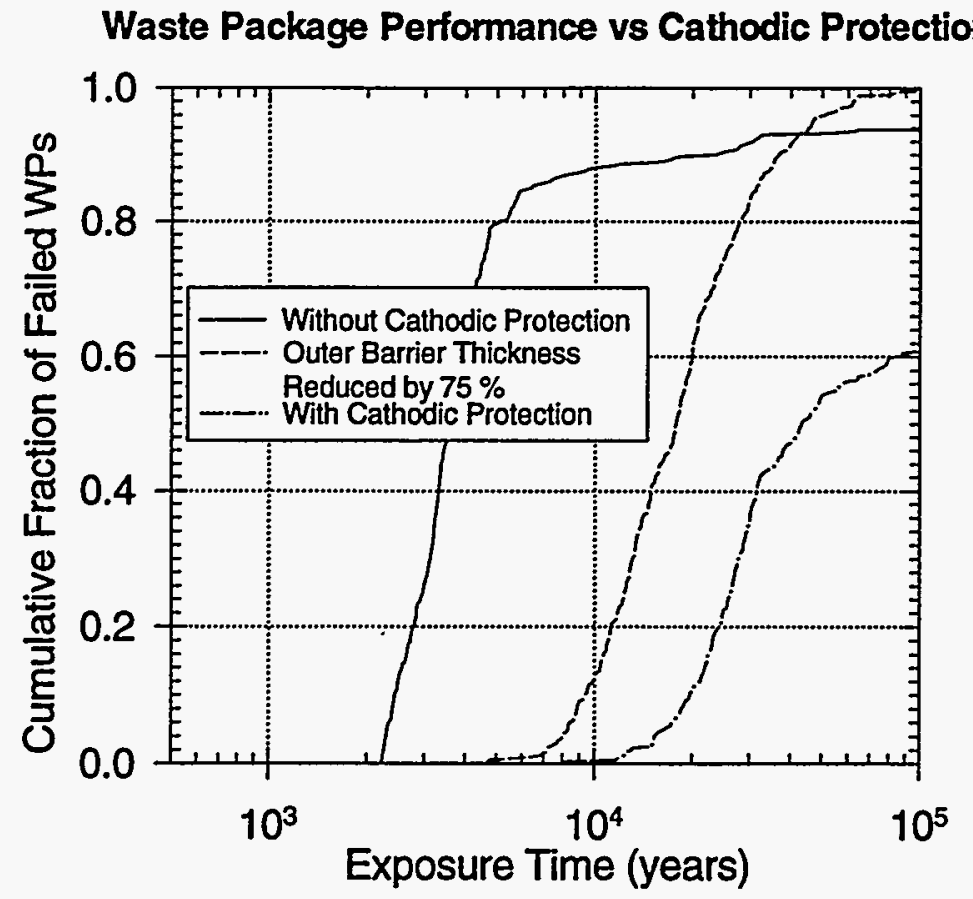

Figure ES.6-3

Comparison of waste package failure history with cathodic protection to that without cathodic protection for the case of $83 \mathrm{MTU} / \mathrm{acre}$, without backfill and high infiltration rate.

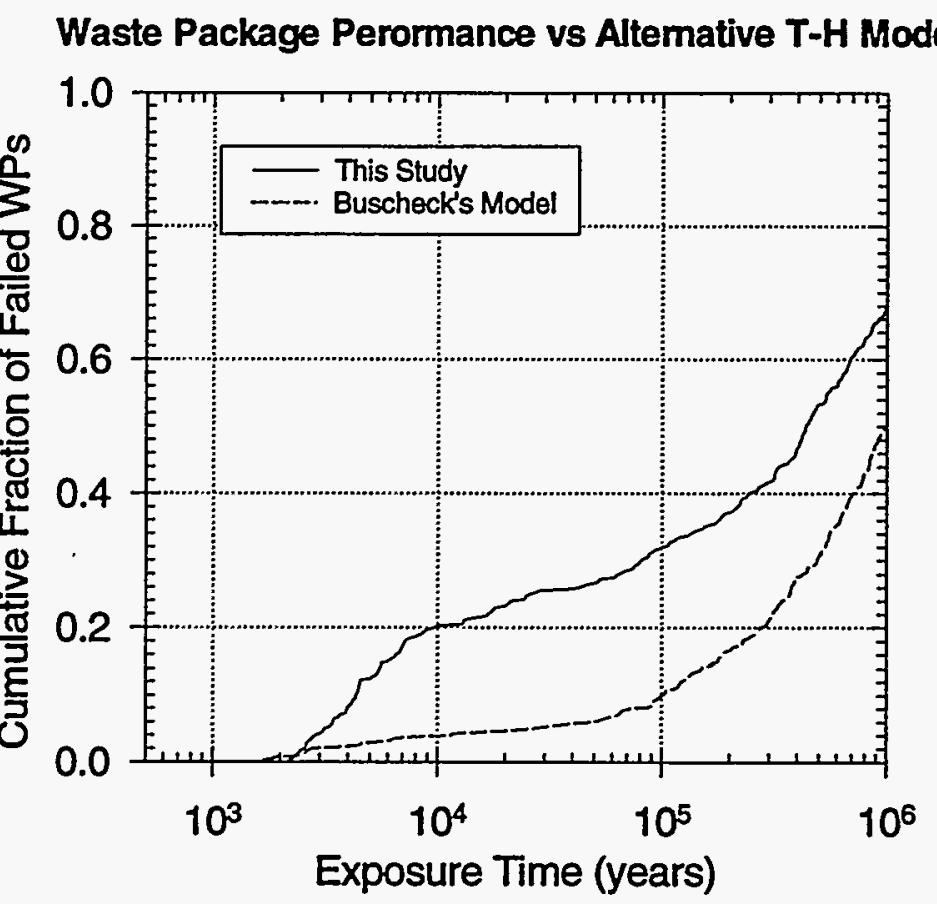

Figure ES.6-4 Comparison of waste package failure history for the case from Buscheck's model (24 MTU/acre, without backfill and no infiltration) to that for the case from this study (25 MTU/acre, without backfill and high infiltration rate). 
Waste Package Performance vs Alternative T-H Models

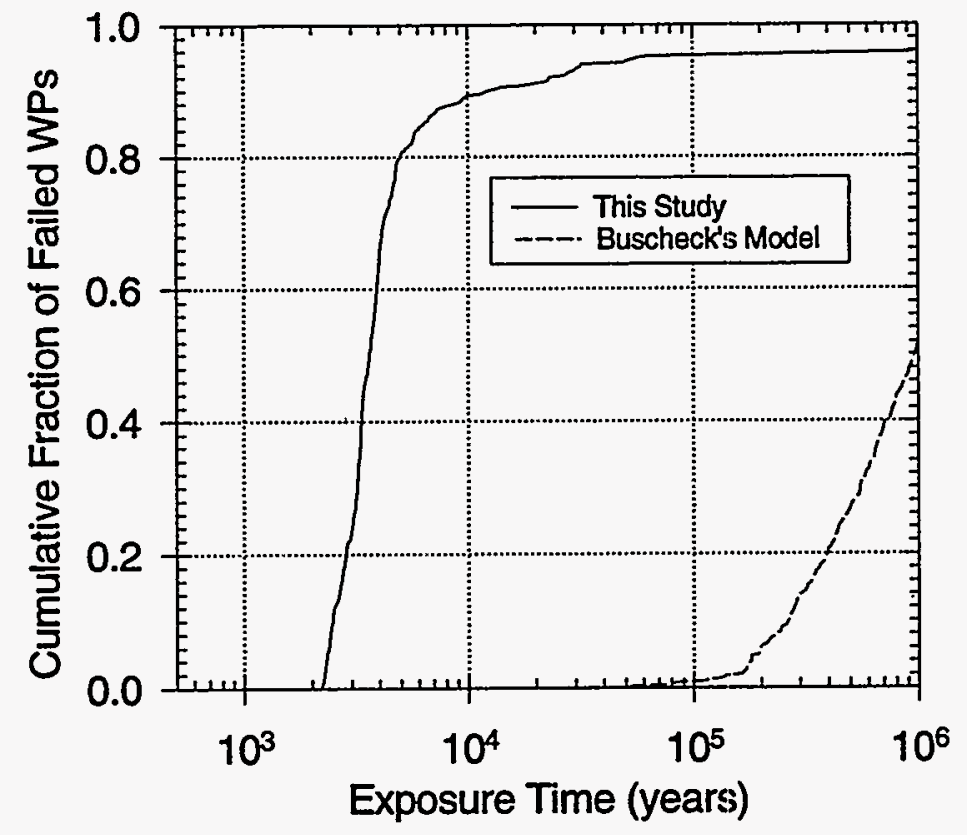

Figure ES.6-5 Comparison of waste package failure history for the case from Buscheck's model (80 MTU/acre, without backfill and no infiltration) to that for the case from this study ( $83 \mathrm{MTU} / \mathrm{acre}$, without backfill and high infiltration rate). 


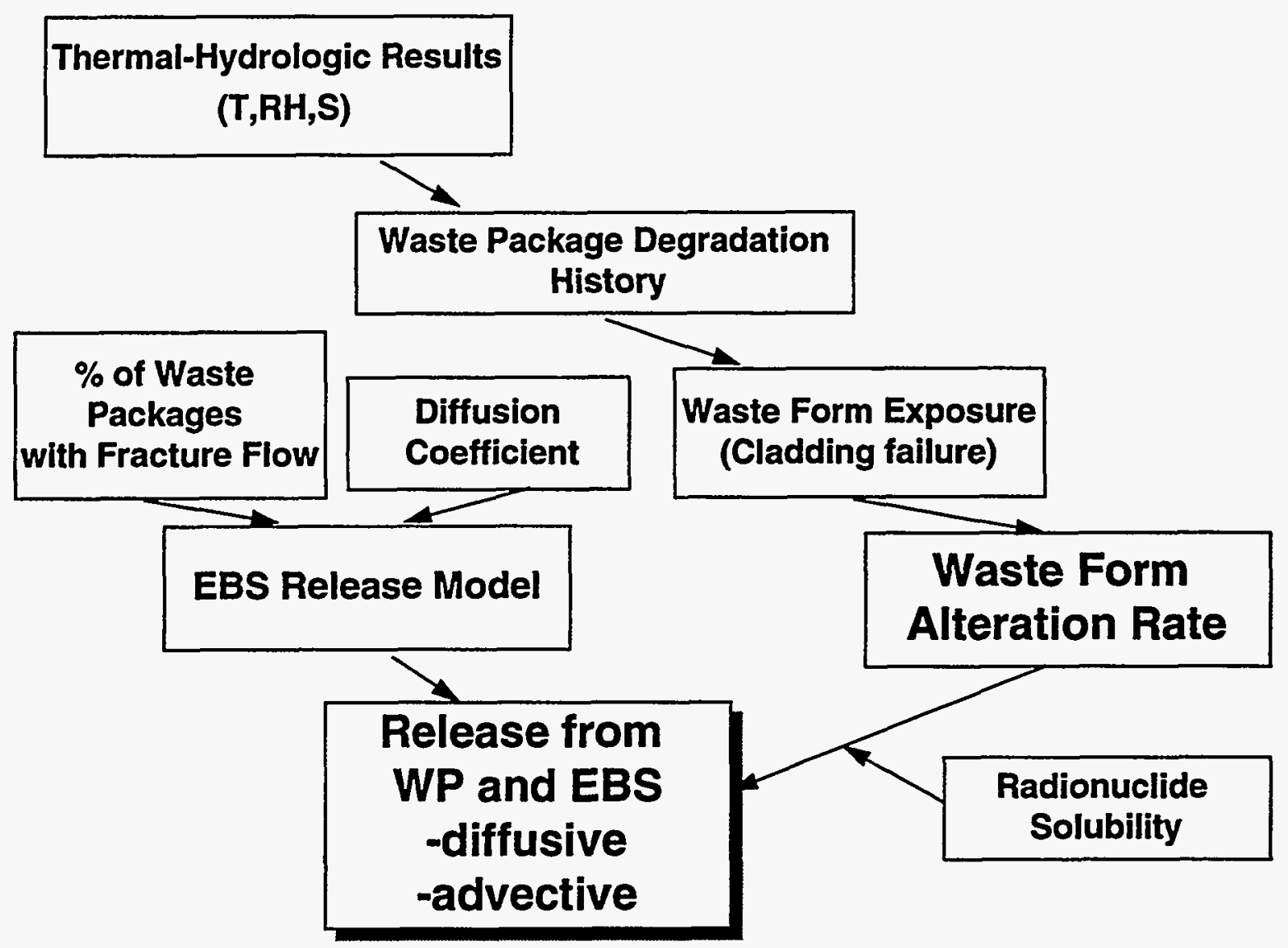

Figure ES.7-1 Engineered Barrier System Processes 


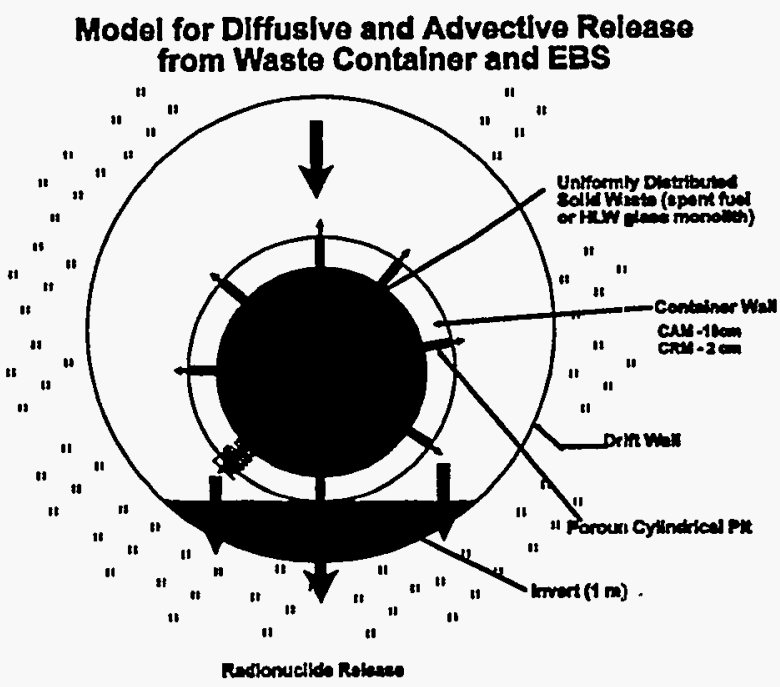

Model for Diffusive Release from Waste Contalner and DIffusive/Advective Release from EBS

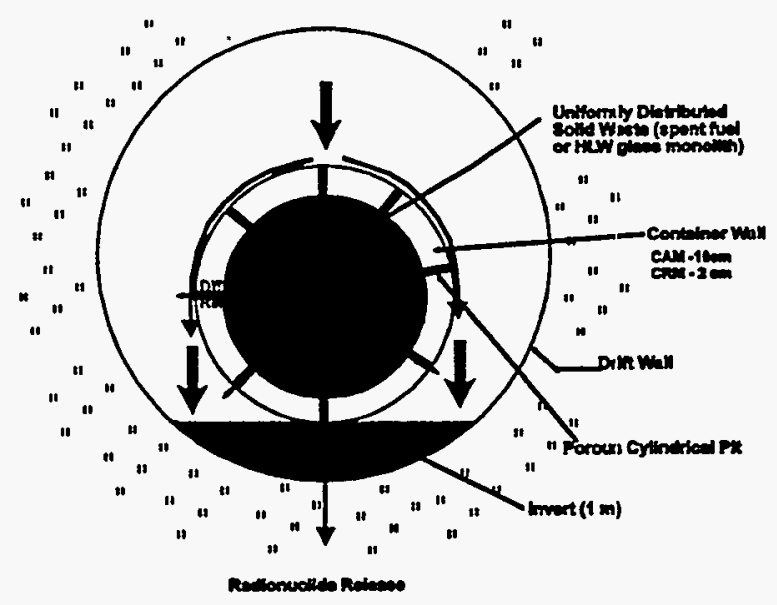

Model for Only Diffusive Release trom Wasto Container and EBS (capillary barrier effect)

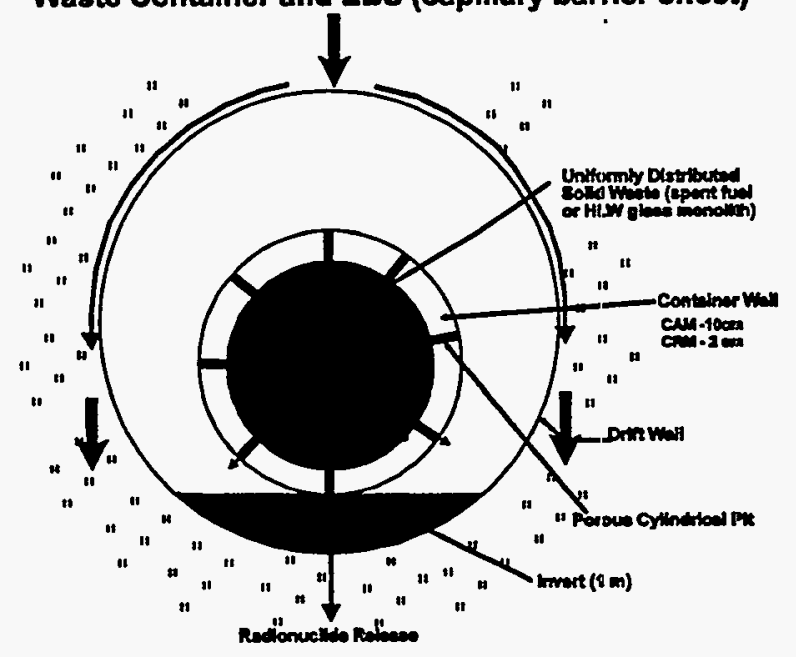

Figure ES.7-2

EBS Release Conceptual Models. 


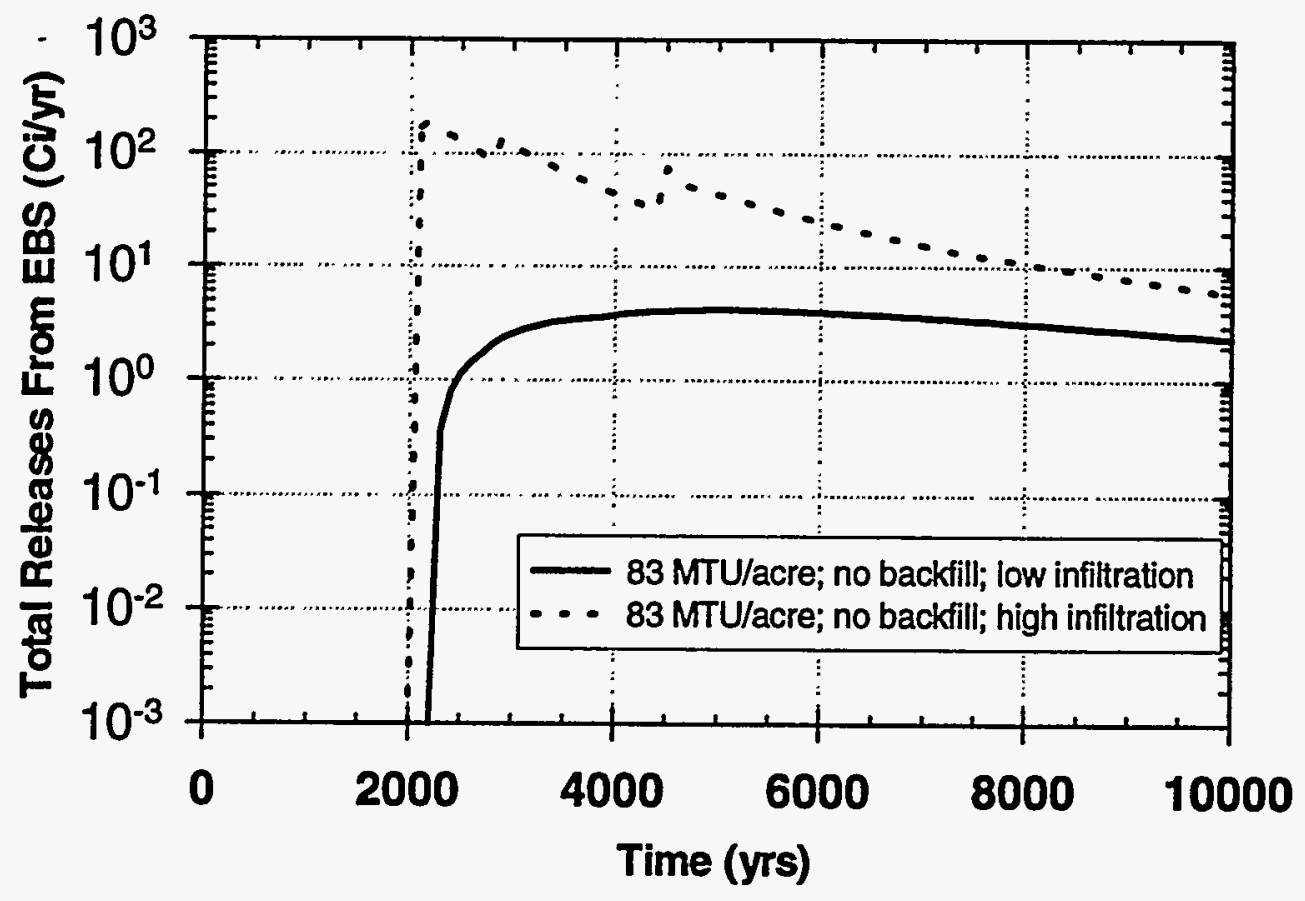

Figure ES.7-3 Predicted EBS ${ }^{99}$ Tc Release Rate History: Sensitivity to Infiltration

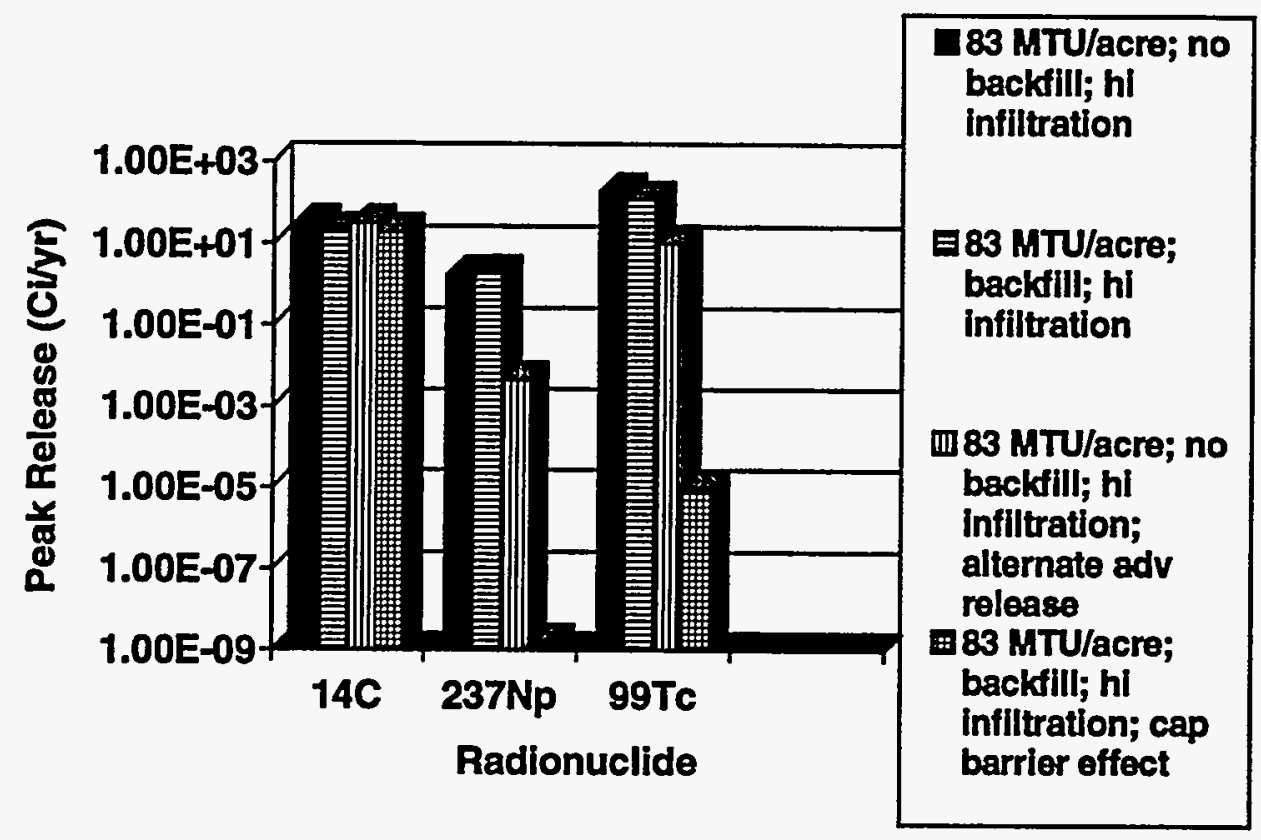

Figure ES.7-4 Predicted EBS Peak Release Rate: EBS Release Model Comparison. 


\section{Schematic of Natural Barriers}

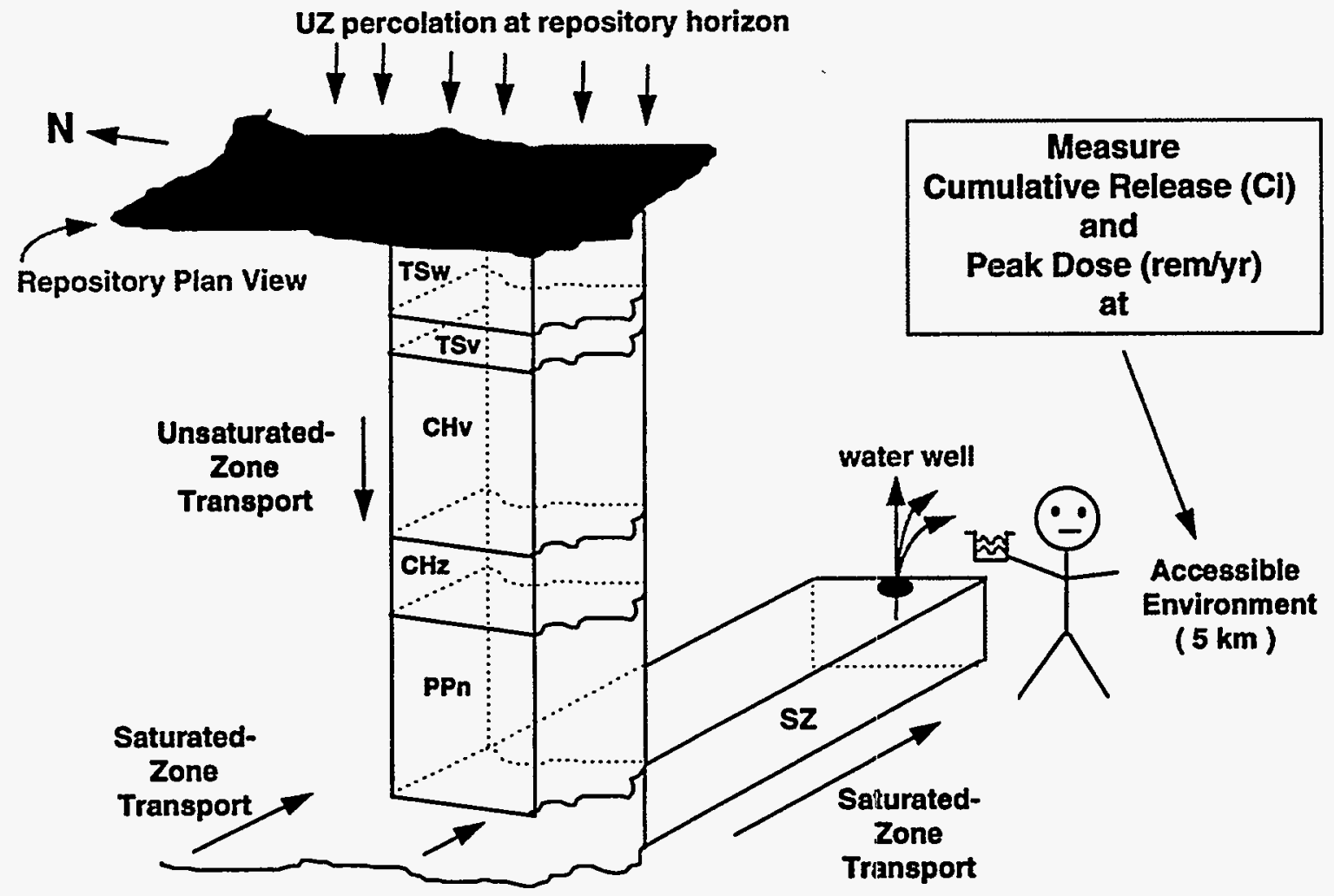

Figure ES.8-1 Schematic of Natural Barriers. 
(Fractional-Fracture-Flow Process-Level Abstraction)

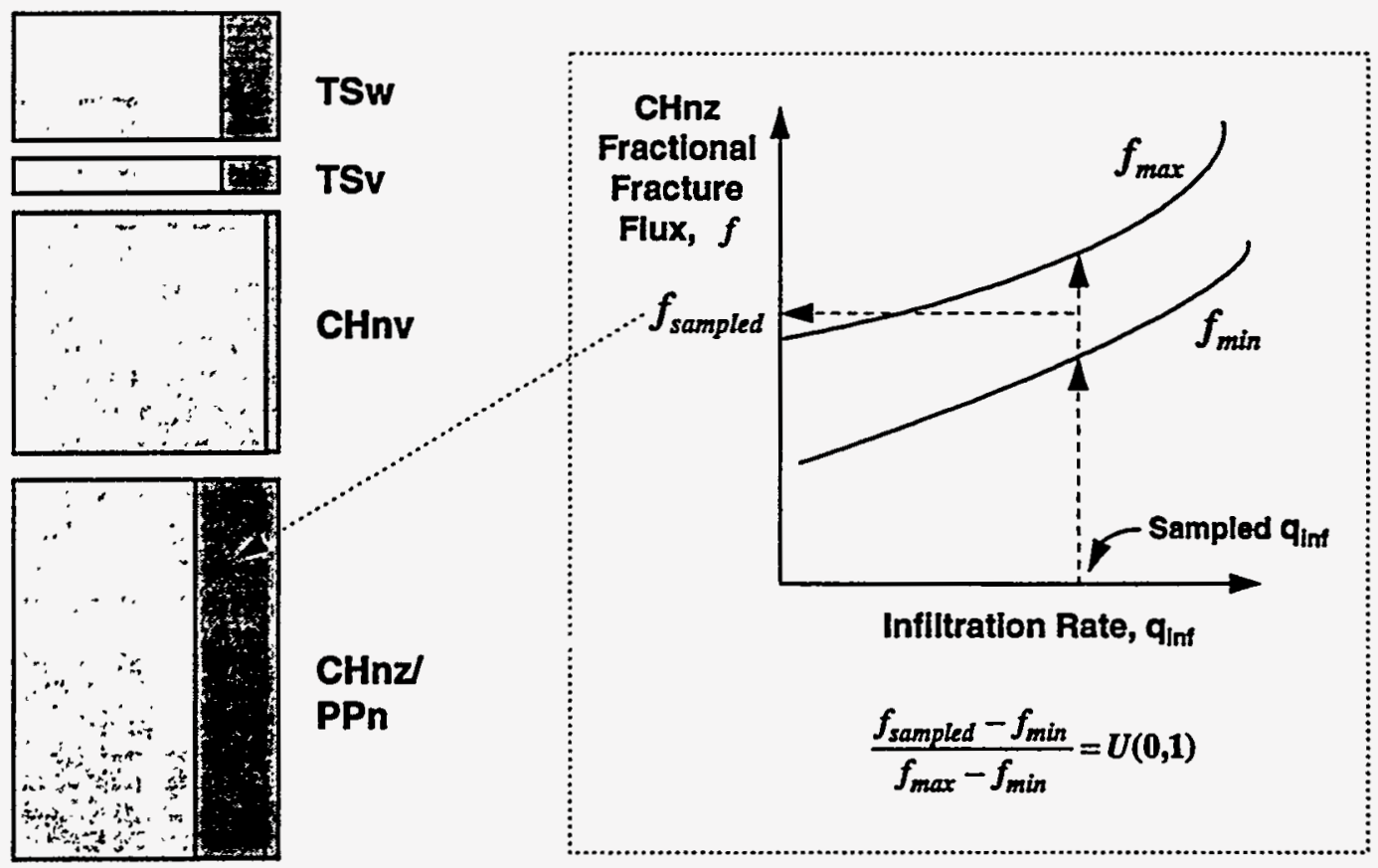

\section{How Fast?}

(Matrix-Velocity-Field Process-Level Abstraction)
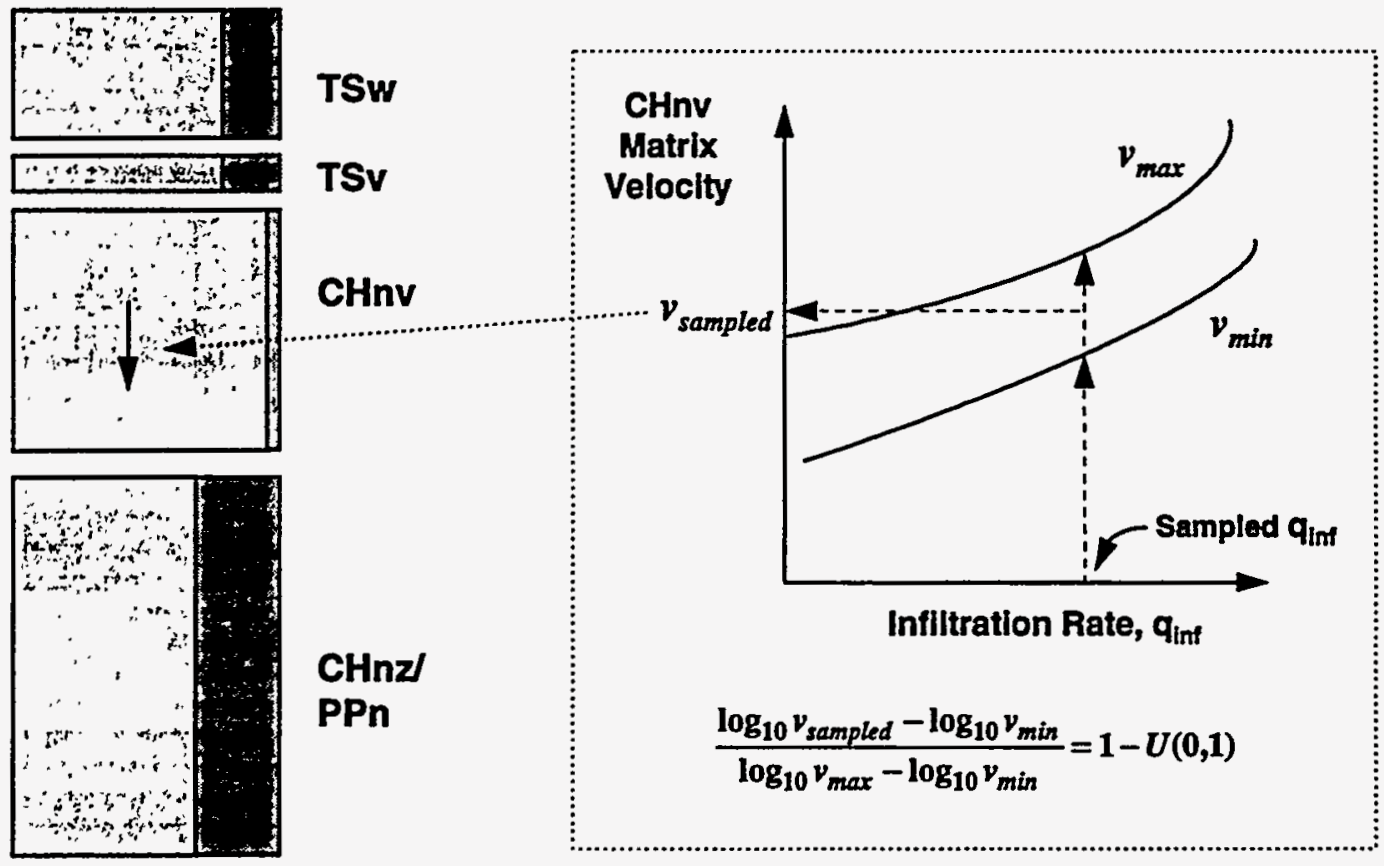

Figure ES.8-2

Schematic of proposed abstraction methodology for determining velocity and fraction of fracture flow as a function of infiltration flux, $\mathrm{q}_{\mathrm{inf}}$. 


\section{(Intra-unit Fracture Connectivity: TSPA Abstraction)}

- Average path length in fracture or in matrix before transitioning is equal $1 / \lambda$, where $\lambda$ is the transition rate:

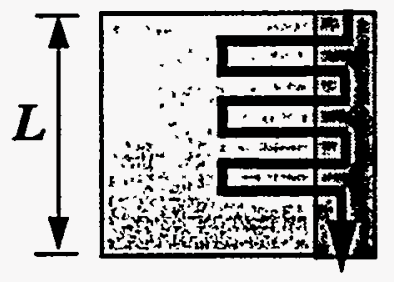

$\lambda=\frac{1}{(0.1) L}$

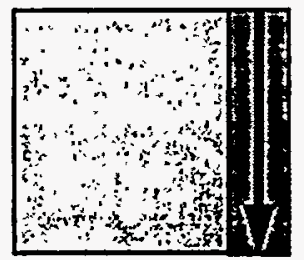

$\lambda=\frac{1}{L}$

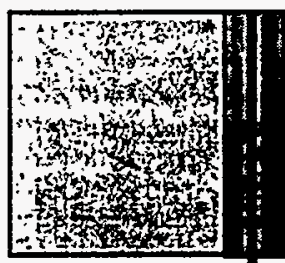

$\lambda=\frac{1}{(100) L}$

random travel length in fracture, $l=-\frac{1}{\lambda} \ln [U(0,1)]$

particle transition rate, $\lambda=\frac{1}{l_{\text {avg }}}$

Figure ES.8-3

Schematic of fracture/matrix interaction in RIP: Markovian-particletransitioning process to represent intra-unit fracture connectivity. 


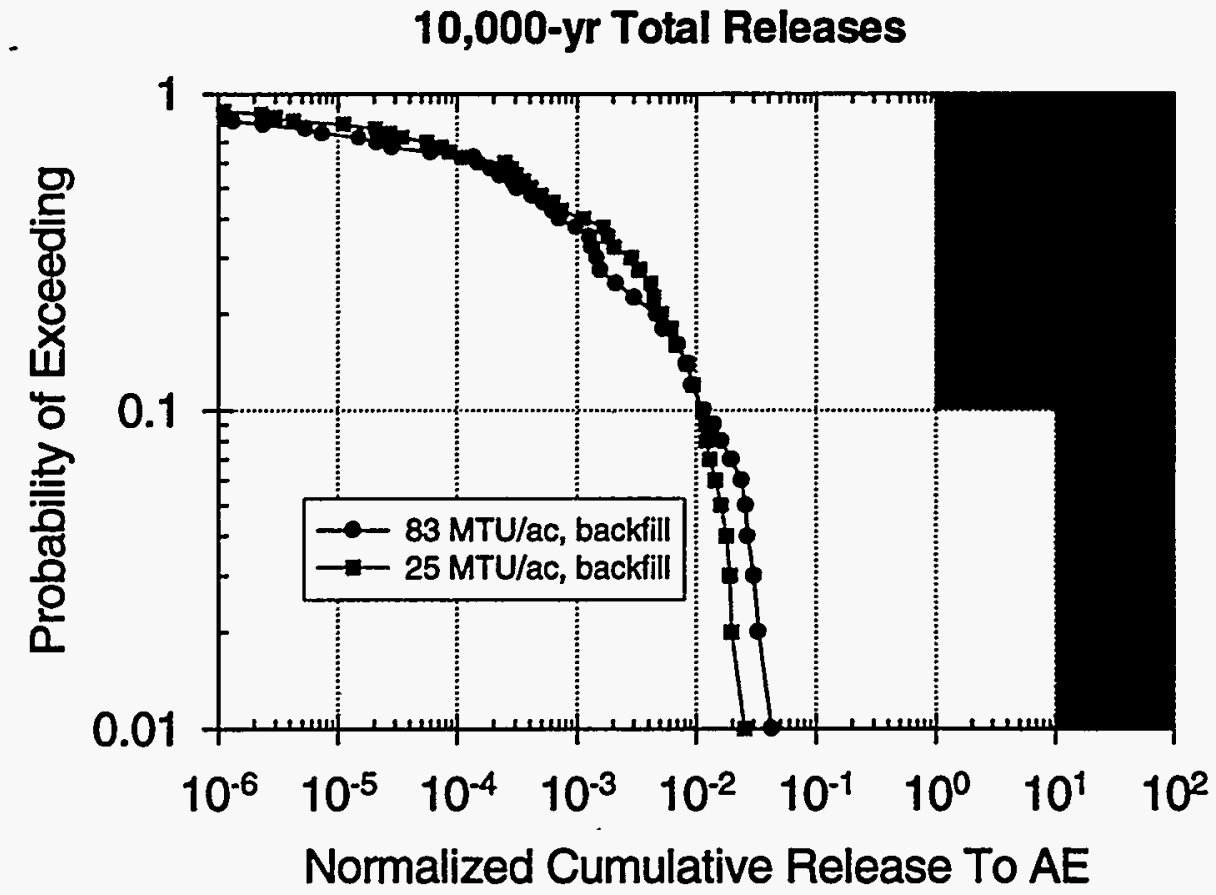

Figure ES.8-4

CCDF of Total Normalized Cumulative Release: 10,000 years, 83 MTU/acre and $25 \mathrm{MTU} / \mathrm{acre}$, backfill, high infiltration range.

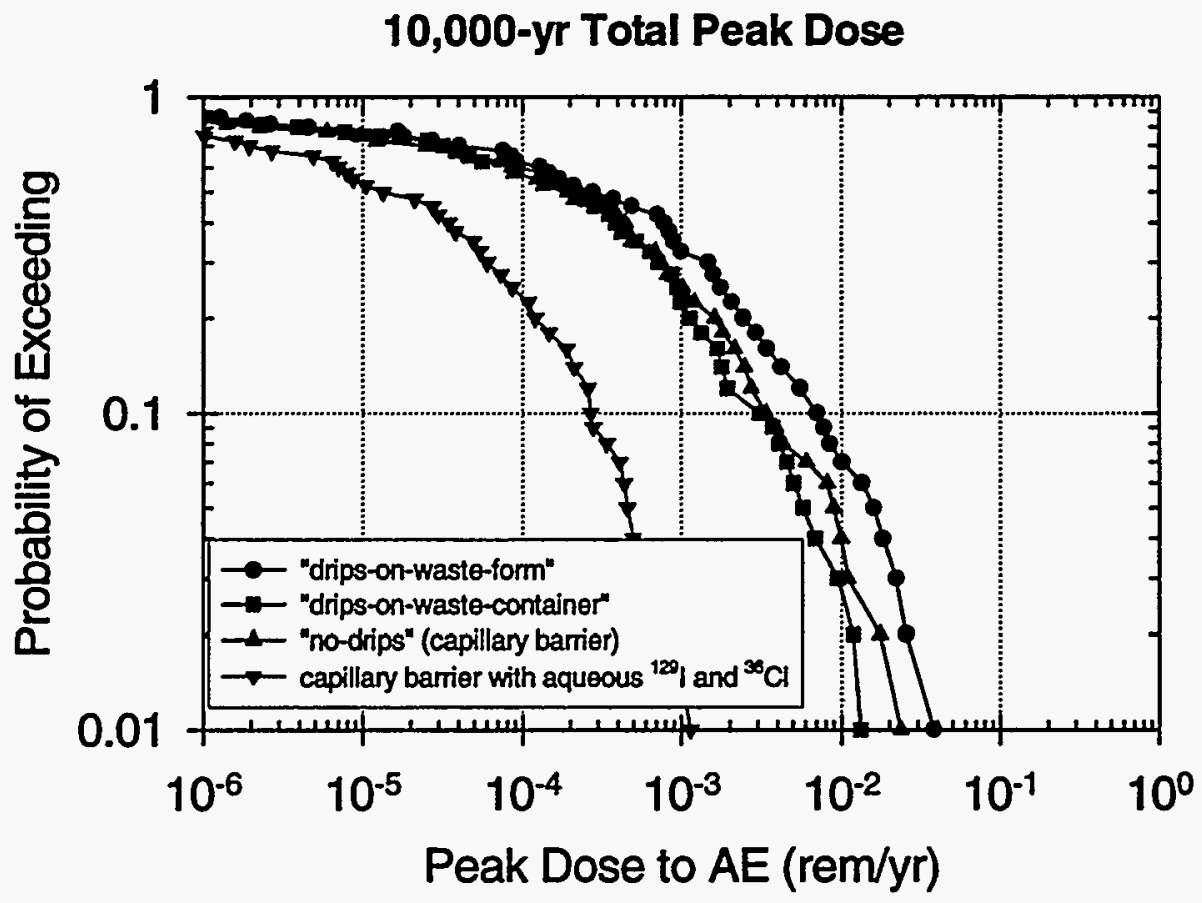

Figure ES.8-5 Comparison of EBS transport models. CCDF of Total Peak Dose: 10,000 years, 83 MTU/acre, backfill, high infiltration range. 


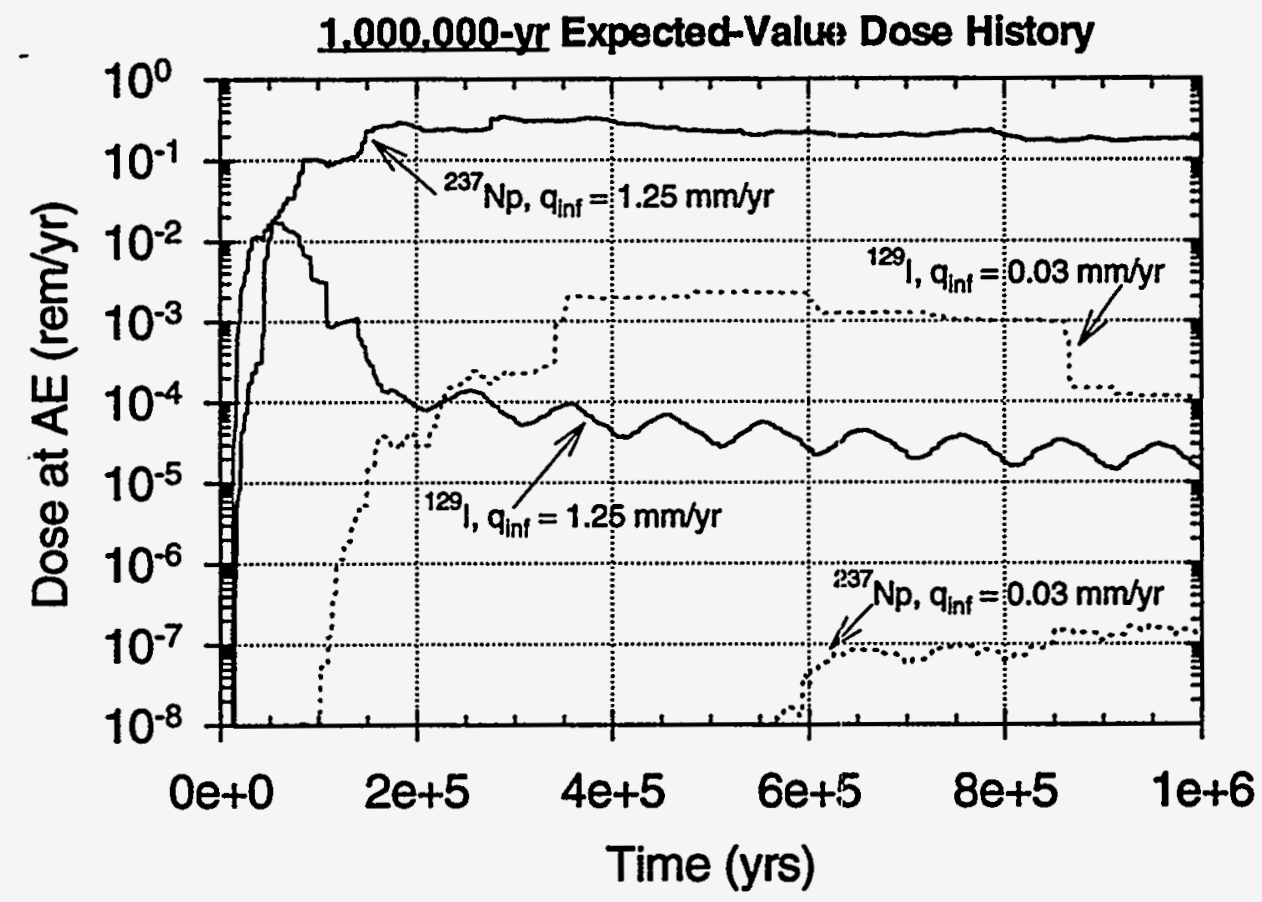

Figure ES.8-6

Expected-value dose history for ${ }^{99} \mathrm{Tc}$ and ${ }^{237} \mathrm{~Np} .1,000,000$ years, Infiltration Rate Comparison: "high" $\left(\mathrm{q}_{\text {inf }}=1.25 \mathrm{~mm} / \mathrm{yr}\right)$ versus "low" $\left(\mathrm{q}_{\text {inf }}=0.03 \mathrm{~mm} / \mathrm{yr}\right)$ infiltration, $83 \mathrm{M}$ TU/acre, backfill, cyclical $-\mathrm{q}_{\text {inf }}$ climate model.

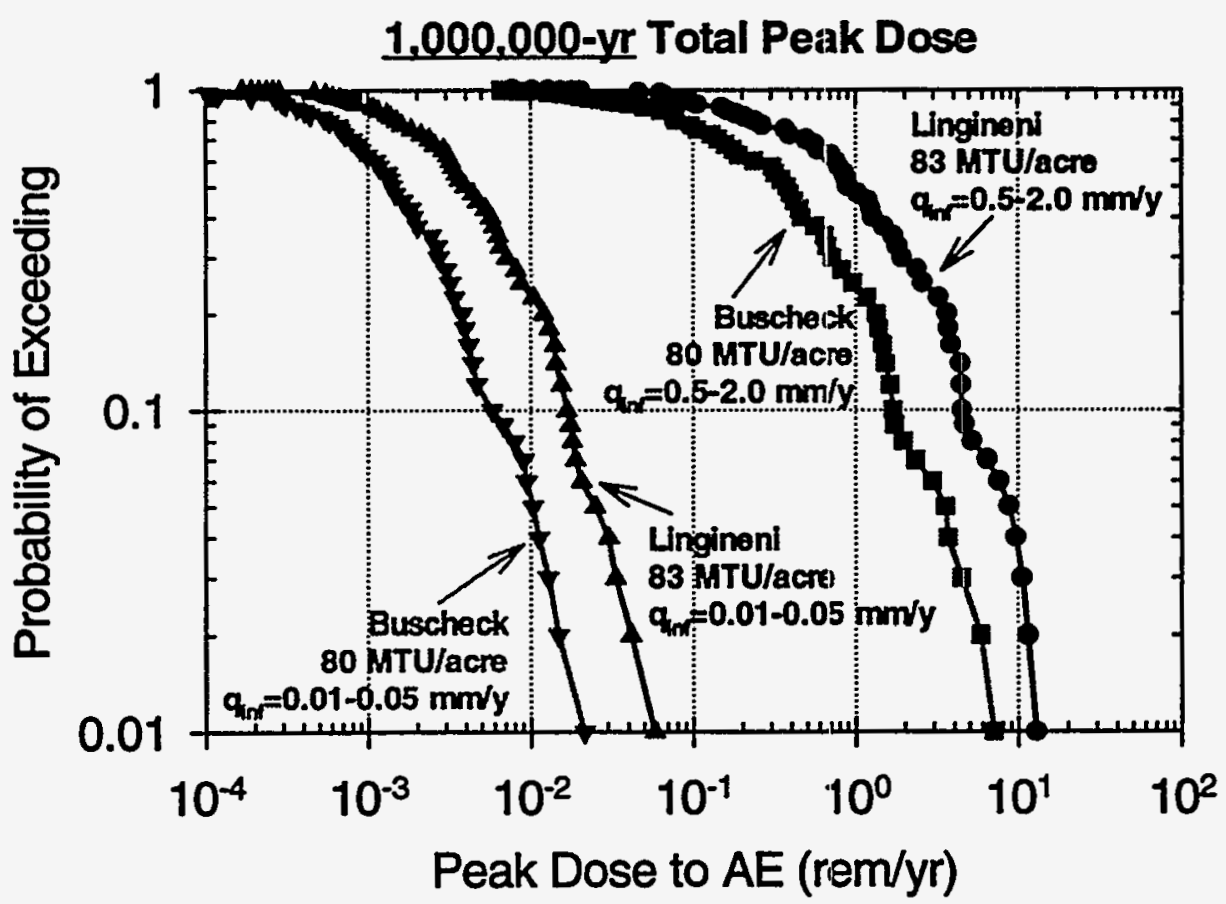

Figure ES.8-7

CCDF of Total Peak Dose: 1,000,000 years, Lingineni 83 MTU/acre and Buscheck $80 \mathrm{MTU} /$ acre thermohydrologic models, backfill, high and low infiltration $\left(\mathrm{q}_{\text {inf }}\right)$ ranges, cyclical- $\mathrm{q}_{\text {inf }}$ climate model. 


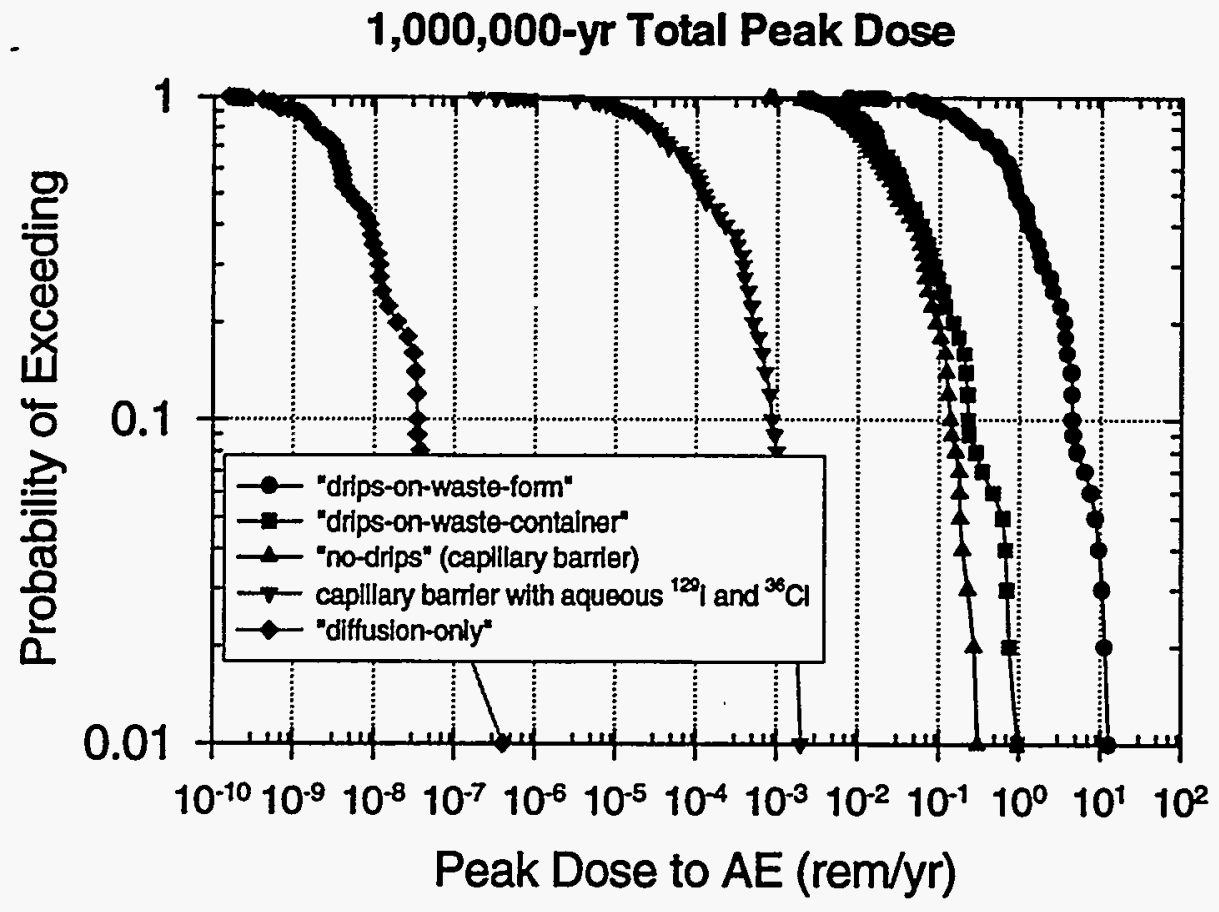

Figure ES.8-8 Comparison of EBS transport models. CCDF of Total Peak Dose: $1,000,000$ years, $83 \mathrm{MTU} / \mathrm{acre}$, high infiltration range, cyclical- $\mathrm{q}_{\text {inf }}$ climate model.

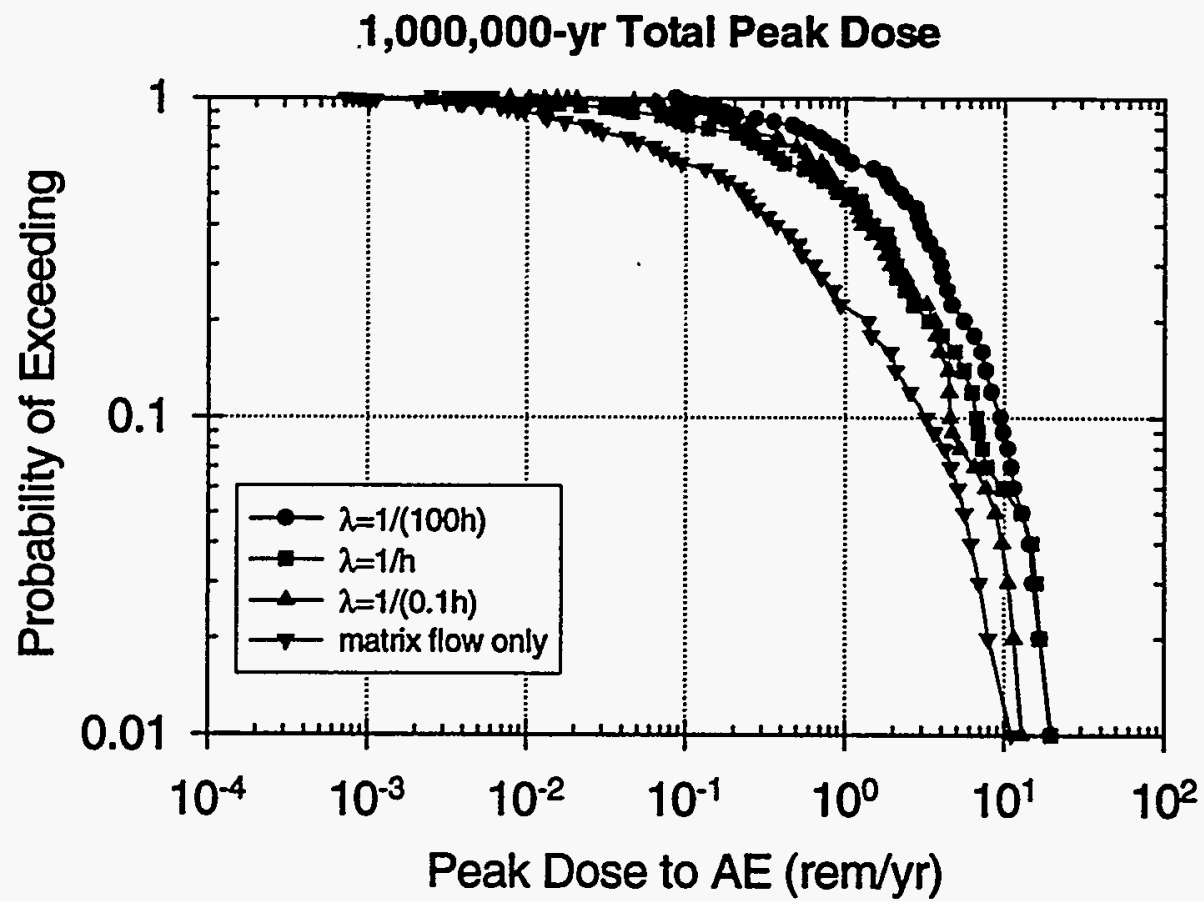

Figure ES.8-9

Comparison of intra-unit fracture connectivity parameter: $\lambda=1 /(100 \mathrm{~h})$ vs. $\lambda=1 / \mathrm{h}$ vs. $\lambda=1 /(0.1 \mathrm{~h})$ vs. matrix-flow-only (no fractures), where $\mathrm{h}=$ pathway length in each unit. CCDF of Total Peak Dose: 1,000,000 years, $83 \mathrm{MTU} / \mathrm{acre}$, backfill, high infiltration range, cyclical- $\mathrm{q}_{\text {inf }}$ climate model. 
high $\mathrm{q}_{\text {inf }}$ range $(0.5-2.0 \mathrm{~mm} / \mathrm{yr})$

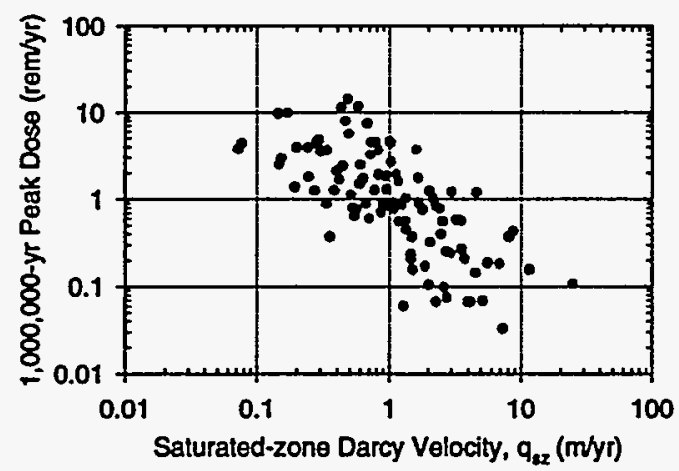

low $q_{\text {lift }}$ range $(0.01-0.05 \mathrm{~mm} / \mathrm{yr})$

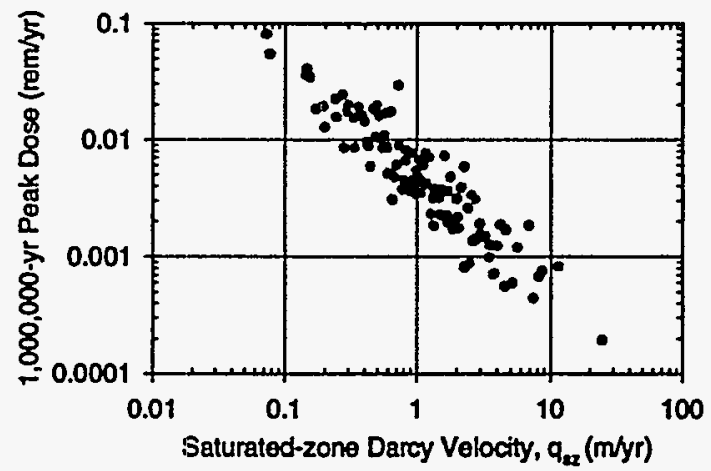

Figure ES.8-10 Sensitivity of 1,000,000-year Total Peak Dose to saturated-zone flux distribution, $q_{\mathrm{sz}}$, for $83 \mathrm{MTU} / \mathrm{acre}$, gravel backfill, climatic variation of $\mathrm{q}_{\text {inf }}$.

high $\mathrm{q}_{\mathrm{inf}}$ range (0.5 - $\left.2.0 \mathrm{~mm} / \mathrm{yr}\right)$

\begin{tabular}{|c|c|c|c|c|}
\hline \multirow{2}{*}{$\begin{array}{c}\text { Performance } \\
\text { Measure }\end{array}$} & \multicolumn{2}{|c|}{ In (P.M.) vs. $x$} & \multicolumn{2}{|c|}{$\ln$ (P.M.) v8. In (x) } \\
\hline & $\begin{array}{c}\text { Rank } \\
\text { Importance }\end{array}$ & $\begin{array}{c}\% \text { of } \\
\text { variance } \\
\text { explained }\end{array}$ & $\begin{array}{c}\text { Rank } \\
\text { Impiortance }\end{array}$ & $\begin{array}{c}\% \text { of } \\
\text { variance } \\
\text { explained }\end{array}$ \\
\hline$U_{\text {cli }}(1,3)$ & 3 & 53 & 4 & 81 \\
\hline \multicolumn{5}{|c|}{ Np Kd (TSv, CHnv) } \\
\hline $9 s z$ & 1 & 23 & 1 & 48 \\
\hline \multicolumn{5}{|l|}{$f_{\text {frac }}$ CHnz } \\
\hline \multicolumn{5}{|l|}{$\mathrm{v}_{\text {mat }} \mathrm{CHnz}$} \\
\hline$a_{\text {Ine }}(U Z)$ & 2 & 45 & 2 & 65 \\
\hline
\end{tabular}




\section{CHAPTER 1}

INTRODUCTION 


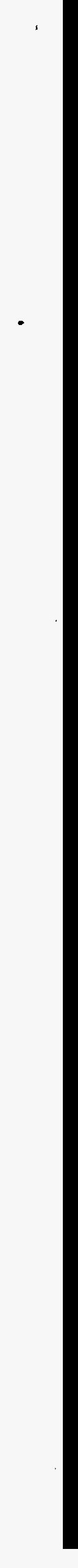




\title{
1. INTRODUCTION
}

\author{
Robert W. Andrews
}

\subsection{BACKGROUND}

As required by the Nuclear Waste Policy Act, as amended, the U.S. Department of Energy (DOE) is investigating the feasibility of permanently disposing the nation's commercial high-level radioactive wastes (currently in the form of spent fuel at over 100 electric power-generating nuclear reactors) and a portion of the defense high-level radioactive wastes (currently stored at federal facilities) in the unsaturated tuffaceous rocks at Yucca Mountain, Nevada. Over the past decade, detailed investigations of the site and preliminary designs of the facility and waste packages have been undertaken by DOE contractors. These activities are aimed at evaluating the suitability of the site and the adequacy of the engineered barriers to meet regulatory standards set by the U.S. Environmental Protection Agency (EPA) and the U.S. Nuclear Regulatory Commission $(\mathrm{NRC})$ to protect the public from the potentially harmful effects of ionizing radiation.

Quantitative predictions based on the most current understanding of the processes and parameters potentially affecting the long-term behavior of the disposal system are used to assess the ability of the site and engineered barriers to meet the regulatory standards. These predictions are termed performance assessments. It is the goal of performance assessment to evaluate all relevant features, events and processes that may affect the ability of the site and engineered barriers to meet the regulatory standards for containing and isolating the wastes from the biosphere.

The evaluation of the ability of the overall system to meet the regulatory standards has been termed total system performance assessment (TSPA). These analyses are distinct from the evaluation of individual components of the system (such as the period of containment associated with waste package "lifetime", the release of radionuclides from the engineered barrier system, or the isolation ability of the geologic barrier as embodied in the ground-water travel time requirement). Total system performance assessments require the explicit quantification of the relevant features, events and processes and their interactions. In addition to providing a quantitative basis for evaluating the suitability of the site to meet regulatory standards for the overall system, such assessments are useful at early stages of an investigation program to help identify the most significant processes and the information gaps and uncertainties regarding these processes and their parameters. This is essential for defining the additional information required assuring a defensible assessment of the overall system performance.

Total system performance assessment relies largely on simulations with a computer code that links mathematical models of the important features, events and processes for computing overall system performance. Because of the uncertainty in the processes and parameters, the computer code is run repeatedly with different model assumptions and parameter values in order to estimate the range of possible model outputs for the expected ranges of process and parameter uncertainty. Because of the many processes to be simulated, the many parameters involved, and the need for repeated simulations, the individual process models in a total system performance assessment code have to be simplified mathematically in order to be executed in a reasonable amount of time 
and at a reasonable cost. These simplifications (also called abstractions), however, are based on more detailed models for each process that have their basis in field and laboratory tests and that can be validated with field and laboratory measurements. In total system performance assessments, both detailed process-level codes and the overall total system performance assessment code are run. The outputs of the individual process-level codes provide inputs to the total system performance assessment code, while the latter predicts overall system performance with the associated uncertainties.

Total system performance assessments explicitly acknowledge the uncertainty in the processes, models and parameters and strive to evaluate the impact of this uncertainty on meeting the overall system performance standards. A significant portion of this uncertainty is a result of the variability in site properties over the domain being considered. The effect of this uncertainty on total system performance is evaluated with a variety of sensitivity analysis techniques depending on the nature of the uncertainty in the process or parameter. In some cases, discrete sensitivity analyses are conducted, while in other cases, the sensitivity analyses are embodied directly in the stochastic simulation. In either instance, the sensitivity analyses provide useful insights that may assist managers in the prioritization of testing and design activities.

Total system performance assessments are one component of the suitability evaluation (and ultimately, licensing, if the site is found suitable) of the Yucca Mountain site and associated engineered barriers. Another component is the fundamental scientific and engineering basis for the models and parameters used in the TSPA analyses. In the overall framework, the technical underpinnings of the abstracted models used in performance assessment are based on field and laboratory tests that are interpreted, synthesized and incorporated into detailed process-level models. With respect to meeting regulatory standards, the importance of a particular model or parameter can only be evaluated quantitatively within the context of performance assessment; i.e., significance is defined with respect to the impact on performance. Conversely, the reliability or confidence in a particular model of a site or engineered component can only be ascertained with respect to the ability of the process-level model to adequately reproduce the observed conditions. Therefore, the performance assessment and site characterization/engineering-design functions progress in an iterative fashion. In each iteration, performance assessment (1) uses the most representative (and/or demonstrably conservative ${ }^{1}$ ) process level models or abstractions in order to define the most significant processes and components, and (2) site-characterization/engineeringdesign conducts, interprets and synthesizes test information into process-level models to increase the confidence in those models and parameters that are most significant to performance.

\subsection{SCOPE OF THE CURRENT TOTAL SYSTEM PERFORMANCE ASSESSMENT}

Prior to initiating an iteration of total system performance assessment, it is important to place the effort into the context of the rest of the Project's understanding of the important issues affecting the suitability of the potential site and the range of possible engineering designs. A goal of any performance assessment is to be as complete and reasonably conservative as possible, with the

${ }^{1}$ Conservative as used in this report implies that the particular model or parameter, when used in a quantitative performance assessment, leads to a prediction of poorer overall performance. 
descriptions of the predictive models and parameters being sufficient for the reader to easily ascertain their technical basis. The descriptions should point to the need for additional interpretation and/or synthesis so that the basis for the model can be demonstrably shown to be conservative.

Each set of analyses of total system performance is associated with some basic objectives that define the scope of the work performed. These objectives may be broadly stated as (1) attempting to incorporate reasonably conservative representations of the relevant processes and parameters affecting total system performance, (2) evaluating a range of alternative conceptual models and parameters to explicitly address the uncertainty and variability in the current understanding and the significance of this uncertainty on the predicted performance, (3) focussing the analyses on those components of the waste containment and isolation system that are most sensitive (i.e., small changes in the model or parameter have a relatively large affect on the predicted response of the overall system) and/or most transparent (i.e., those models or parameters which are easiest to confidently demonstrate their validity for the intended purpose of predicting long term performance), and (4) evaluating the long-term performance of the engineered and site barriers using a range of possible measures of "safety" (including cumulative radionuclide releases, peak concentrations or doses, or other measures of risk to the public). Each of these general objectives is relevant to the analyses performed as part of the current iteration of total system performance.

The focus of the current total system performance assessment is on those components of the system that have been determined by previous analyses (e.g., TSPA-1993: see Wilson et al., 1994; Andrews et al., 1994) to be most significant in the predicted containment and isolation of radioactive wastes from the biosphere. Therefore, the current focus is on the engineered components of the system and on the near-field environment in which these engineered components reside. Consequently, this assessment includes (1) drift-scale thermohydrologic analyses to predict the temperature and humidity environments in the vicinity of the waste package (as these control the initiation and rate of humid air and aqueous corrosion processes) and the liquid saturation within the materials placed in the drift (as this controls the diffusive release through these materials), (2) degradation analyses of waste package localized corrosion (as this controls the time period during which the radionuclides are contained within the waste package and the effective diffusion through partially "failed" waste packages), and (3) analyses of near-field unsaturated-zone aqueous flux (as this defines the magnitude of the advective flux and controls the percentage of waste packages potentially exposed to advective flux releases).

An underlying premise in the current total system performance assessment is to be as realistic as possible, acknowledging that in many instances conservative and/or bounding assumptions are required. These bounding assessments are required when process-level models are absent or are unsubstantiated by site- or design-specific relevant observations. Increased realism is incorporated in TSPA-1995 in the drift-scale thermohydrologic analyses and the container degradation analyses for corrosion-allowance materials in a humid air environment, among others. Bounding assessments are employed to describe the cathodic protection provided by corrosion allowance material, the model for corrosion-resistant material degradation, the degradation of cladding, and the relationship between fracture and matrix flow. In each bounding assessment, sensitivity analyses are conducted to evaluate the significance of the uncertainty in the model and 
the associated parameters (i.e, the potential benefit to overall performance if it could be confidently demonstrated that the conservative/bounding assumption could be replaced by a more realistic approximation).

An important issue in any performance assessment is the issue of how to best represent the uncertainty in the existing understanding of the processes affecting overall performance, as well as distinguishing between uncertainty and variability in individual parameters within the models used to describe these processes. Approximately 10,000 waste packages are currently planned for disposal in the potential repository at Yucca Mountain. These waste packages would be spread over an area of about $10,000,000 \mathrm{~m}^{2}$. Over the spatial scale of interest, the geologic and hydrogeologic properties of significance are expected to be highly variable and it is assumed that the observed distribution in properties is representative of what might be expected at any particular location (e.g., at any of the 10,000 waste package emplacement locations). Given the large number of waste packages and the variability in material properties and local-scale environmental conditions different waste package degradation rates are expected from package to package. Additionally, given the size of each waste package, on the order of 25 to $40 \mathrm{~m}^{2}$ the micro-environment and material property is expected to vary from location to location on each package, with the range in this variability being determined by the range in observed degradation rates on similar materials under a range of undetermined micro-environmental conditions. Whether, and how, a model or parameter is treated as uncertain or variable (or both) is discussed in the technical details of the model implementation.

All total system performance assessments strive to be as complete as reasonably possible and to include all relevant processes and parameters that may conceivably affect the overall performance of the site and engineered barriers. In the current assessments, the focus is on the engineered components and the near-field environmental conditions (in particular the thermohydrologic conditions) that affect the performance of the engineered components. Less emphasis is placed on the externally-initiated natural phenomena (such as seismic and volcanic events and tectonic processes) that may disrupt the repository if they occur. Such scenario analyses have been considered in several earlier analyses, including those conducted by Sandia National Laboratories (Barnard et al., 1992; Wilson et al., 1994), as well as those conducted by Risk Engineering, Inc. for the Electric Power Research Institute (McGuire et al., 1990 and 1992), and by the Nuclear Regulatory Commission (NRC, 1995). In all of these instances, the probability-weighted releases associated with externally-initiated natural events and processes have been insignificant in comparison to the range of releases caused by repository-induced processes. When a complete total system performance assessment is submitted for regulatory review, however, the performance-related consequences of all significant features, events and processes (collectively referred to as FEPs) will have to be addressed either quantitatively or screened based on conservative estimates of the probability or potential effects of such FEPs on components of the waste isolation and disposal system.

Many processes that may affect repository performance are complexly coupled to one another. Examples of these couplings include (1) the thermo-mechanical response of the rock mass adjacent to emplacement drifts caused by the transfer of heat away from the waste packages and the coupling of this response through a change in bulk permeability with the near-field hydrology, (2) the thermo-chemical response of the rock mass and the coupling of the resultant dissolution/precipitation reactions with the bulk permeability and therefore the near-field 
hydrology, and (3) the chemical response caused by the interaction of the ambient mineralogy and aqueous geochemistry with the introduced anthropogenic materials placed in the drifts. Although these couplings could be incorporated into predictions of system performance, their effects are probably insignificant, primarily because the variability in ambient (i.e., unperturbed by the presence of the drifts) hydrogeologic and geochemical properties accounted for in the analyses already encompasses the changes induced by the coupled processes. As a result, these complex process couplings are not included explicitly in this iteration of total system performance assessment.

\subsection{OBJECTIVES OF THE CURRENT TOTAL SYSTEM PERFORMANCE ASSESSMENT}

Several analyses of the overall system performance of the Yucca Mountain site and associated engineered barriers have been conducted by DOE contractors over the past several years. The most recently completed iteration of total system performance assessments is documented in Wilson et al., (1994) and Andrews et al., (1994). Other studies have built upon these documents by conducting sensitivity analyses addressing particular technical issues associated with the earlier analyses. For example, M\&O (1994a) evaluated the effect of drift-scale thermohydrologic conditions on the degradation of waste packages, the release of radionuclides from the engineered barrier system to the host rock, the radionuclide release to the accessible environment, and the radiation doses to maximally-exposed individual. M\&O (1994a) also examined the peak release rate from the engineered barrier system for a range of alternative thermal loads. In addition, analyses were performed with alternative unsaturated- zone flow and transport conceptual models and parameter values in support of the systems study that evaluated options for characterizing the Calico Hills hydrogeologic unit (M\&O, 1995d).

The specific goals of the current iteration of total system performance assessment are to (1) utilize what are believed to be more representative conceptual models that build upon the assumptions employed in TSPA-1993, in particular for the treatment of the engineered barrier system including the waste package, (2) incorporate more recent design information since the completion of TSPA-1993, (3) utilize the most recent site information and models (where available) acknowledging their uncertainty and variability, and (4) evaluate the engineered barrier system release performance measure as well as alternative measures of total system performance (cumulative release and peak dose over different time periods) ${ }^{2}$, and the correlation between these measures of performance. Each of these goals is discussed in the following paragraphs.

In the concluding comments of TSPA-1993 (Andrews et al., 1994), the need to use more representative process-level models and to incorporate their corresponding abstractions into the total system code was noted in order to increase the realism of the analyses. In particular, the

\footnotetext{
${ }^{2}$ Alternative time periods have been proposed by various regulatory bodies in different countries concerned with the ultimate disposal of high-level radioactive wastes containing very long-lived radionuclides. A recently completed study commissioned by the National Academy of Sciences (NAS, 1995) has recommended a time corresponding to the arrival of the peak dose to average members of a critical group, where this time may be several tens to hundreds of thousands of years.
} 
definition of the very near field (drift-scale) thermohydrologic environment and the effect of this environment on the initiation and rate of aqueous corrosion was identified as a key uncertainty warranting additional predictive ability. Towards this end, the present TSPA iteration includes drift-scale thermohydrologic analyses with response surfaces that were fit to the temperature, relative humidity and liquid saturations in the drift materials. In addition, TSPA-1993 identified the degradation models of both the corrosion-allowance and corrosion-resistant waste package materials as requiring more technical substantiation from either direct laboratory measurements or analog observations. Although TSPA-1995 revises the model of localized corrosion of the corrosion-allowance material substantially (with the bases being developed from empirical fits to observations of corrosion of similar materials under similar environments), it employs the same model used in TSPA-1993 for the corrosion-resistant layer due to a lack of any specific information on this material since then. Finally, it was noted in TSPA-1993 that the processmodel understanding of localized advective flow in the unsaturated zone needed to be substantiated. Although there is no better indication of the potential for localized advective flux than existed then, TSPA-1995 includes additional process model analyses in order to try to quantify the likelihood and amount of localized advective flux.

Both the repository and waste package designs have evolved since the completion of TSPA-1993. The bases for repository and waste package designs used in this iteration of total system performance assessment have been derived from the conceptual design information documented in the Conceptual Design Assumption Report (M\&O, 1995c). Alternative designs continue to be developed and evaluated by the design organizations of the M\&O with respect to their cost and schedule impacts. One of the purposes of performance assessment in general, and this iteration of total system performance assessment in particular, is to evaluate the performance implications of some representative subset of the alternative designs that are being explored. For example, the current TSPA iteration uses both a high and a low thermal load, evaluates the implications of using backfill or not (with or without the use of the backfill as a capillary barrier). The previous iteration of TSPA documented in Andrews et al., (1994) examined the effects of alternative waste package material thicknesses for both the outer corrosion allowance layer and the inner corrosion resistant layer. Many factors go into the decision of the final design of any waste repository and the associated waste packages that are independent of their consequences on performance. Trade-off studies between cost, constructability, and performance are required to define the optimum design. The design decisions of significance to post-closure performance include the thermal load, the presence or absence of backfill, the use of ventilation during the pre-closure performance monitoring period, the drift size, the number of fuel assemblies within each waste package, and the thickness and materials selected for the waste package corrosion-allowance and corrosion-resistant layers. In TSPA-1995, only the first two of these issues were directly evaluated in the analyses.

Significant advances have been made in the site characterization program since the completion of TSPA-1993. In particular, preliminary estimates of surficial infiltration rates based on observed steady-state matrix water contents, assumed matrix characteristic curves, and assumed hydraulic gradients have been generated by Flint and Flint (1994). Also, analyses incorporating the potential effect of fracture-initiated infiltration have recently been presented by Flint (1995). 
In addition, the preliminary site-scale unsaturated zone flow model $^{3}$ which aims to synthesize all available hydrogeologic information into a self-consistent representation of the average unsaturated-zone flow regime, has recently been published by Wittwer et al., (1995). Additional characterization efforts have been focused on reducing the uncertainty in some of the key geochemical parameters, including the solubility of neptunium, as well as providing more representative estimates of radionuclide retardation. These new site data are considered in the current TSPA.

The unsaturated-zone aqueous flow system is a critical component of any assessment of system performance. Two aspects of the flow system are important: on one hand, the distribution of volumetric flux through the unsaturated zone in general, and the magnitude of the localized percolation flux in the vicinity of the potential repository drifts in particular, are important as they significantly affect the near-field hydrologic environment and ultimately the releases from the engineered barrier system; on the other hand, the distribution of advective velocities (along with other transport processes such as matrix diffusion and retardation) significantly affects the rate of release of radionuclides to the saturated zone. Therefore the distribution of localized unsaturated-zone flow pathways that might have high advective velocities (i.e., be "fast" paths) is a significant consideration in the overall performance assessment. Recently interpreted isotopic evidence for ground-water residence times in the unsaturated zone at Yucca Mountain (Kwicklis, 1994; Fabryka-Martin, 1995) indicate the potential for "fast" paths through the unsaturated zone. Although these data and interpretations are ambiguous (i.e., alternative interpretations of the same information yield the possibility that there are no "fast" paths in the aqueous phase in the unsaturated zone), the potential for "fast" advective paths caused by, among other aspects, localized increases in the percolation flux, needs to be accommodated in the total system performance assessment. The approach taken in the current TSPA iteration to address the issue of localized percolation fluxes and "fast" paths is discussed in Chapter 7.

A number of different measures of system and subsystem performance have been postulated by various regulatory agencies. The degree to which any of these performance measures, if they were met, would ensure adequate protection of human health and the environment over the time period the radioactive wastes could pose the most severe hazard, is a societal issue beyond the scope of the present document. An important aspect of performance assessment is to quantify the expected performance using different measures of "safety" (and the corresponding uncertainty in the expected performance) and to determine the relationship, if any, between the different measures. It is not inconceivable, for example, to have a "poor" predicted performance of a particular subsystem, such as defined by the peak release rate from the engineered barrier system, while the total system performance as defined by the peak dose to a maximally-exposed individual is well below the levels of concern to society. In the present performance assessment, the waste package lifetime (as defined by the time the first localized pit penetrates the multi-layer waste package), the peak EBS release rate, the cumulative release at the edge of the accessible environment (assumed to be $5 \mathrm{~km}$ down gradient from the potential repository), and the peak dose to the maximally exposed individual located at the accessible environment boundary are all evaluated.

3 The preliminary site-scale unsaturated-zone transport model has been documented concurrently with the completion of this TSPA-1995 report (Robinson et al, 1995). 


\subsection{ANALYSIS COMPONENTS AND INFORMATION FLOW IN THE CURRENT TOTAL SYSTEM PERFORMANCE ASSESSME'NT}

\subsubsection{System and Analysis Components}

Total system performance assessments bring together all relevant components of the waste containment and isolation system that potentially affect the release of radionuclides to the accessible environment and the corresponding radionuclide concentration and radiation dose associated with the release. The individual components of the analyses are indicated on the schematic flow diagram illustrated in Figure 1.4-1. Each of the bubbles of the influence diagram corresponds to a process-level model, which in turn is based on direct laboratory or field data that have been synthesized using either an empirical relationship (as in the case of observations of generalized corrosion rates of corrosion allowance materials, waste form alteration/dissolution rates, and radionuclide solubilities among others) or a numerical relationship describing the process of interest. The general flow of information between the different model domains is illustrated in Figure 1.4-2. In this depiction, the boundary conditions of one domain are provided by the output from the preceding domain. For example, the repository-scale percolation flux (q) is derived from the results of the site-scale unsaturated-zone flow model. Similarly, the source term for radionuclide transport in the unsaturated zone is provided by the calculated release from the engineered barrier system. Other parameters that are transferred between domains include the temperature $(\mathrm{T})$, liquid water saturation (Sw), chemical composition $(\mathrm{C})$, and mechanical stress $(\sigma)$.

A sketch of the multiple barriers associated with waste disposal in the unsaturated zone at Yucca Mountain is presented in Figure 1.4-3. The engineered barrier components contributing to waste isolation and containment are illustrated in Figure 1.4-4. All of the above figures serve to orient the reader towards the many components and the corresponding processes, models and parameters required to construct a comprehensive total system performance assessment that aims to capture the relevant aspects that influence the predicted performance.

\subsubsection{Analysis Hierarchy}

Performance assessments for underground repository systems typically consist of several levels of analyses, ranging from the detailed representation of individual processes to analyses of the entire waste disposal system. This model hierarchy is shown in Figure 1.4-5. The base of the pyramid corresponds to independent phenomenological modeling of processes acting within the engineered or the geologic components of the system. The top of the pyramid corresponds to the abstracted representation of processes that are used to evaluate the effects of various scenarios on total system performance.

For each detailed process/conceptual model, there exists a corresponding, albeit abstracted, version for the purposes of total system performance assessment. The need for abstracted (i.e., simplified) models originates from the complexities inherent in total system assessments due to the coupling between various processes/sub-systems, parameter and model uncertainties, spatial and temporal variabilities, and multiplicity of designs and future scenarios. The use of probabilistic performance assessments to evaluate regulatory compliance of complex systems within current computational capabilities also necessitates some degree of simplification within 
the abstracted models. Codell and Sagar (1995) discuss various approaches for model abstraction currently being used by the performance assessment community, viz., (1) intuitive simplification, (2) equivalent parameters, (3) direct propagation of variability and uncertainty, (4) integration, (5) dimensional analysis, and (6) empirical models based on full models.

For the purposes of TSPA-1995, the word abstraction is used to connote the development of a simplified/idealized process model (with appropriately defined inputs) that reproduces/bounds the results of an underlying detailed process model. The inputs for the abstracted model can be a subset of those required for the detailed process model. Alternatively, intermediate results from the detailed process model can be analyzed to develop "response functions" which can then be used as inputs to the abstracted model. In either case, it is necessary to demonstrate that predictions of both the detailed process model and the abstracted model are reasonably similar.

The assessment of total system performance is based on results derived from process-level models which in turn are based on direct observations or interpretations of laboratory and/or field tests. The flow of information used in the current TSPA iteration from "data" to processlevel models (where applicable), to abstractions of process-level models (where applicable), and finally to the total system performance assessment itself, is illustrated in Figure 1.4-6. This figure will be revisited at the beginning of each chapter to orient the reader as to the topics of the particular chapter.

\subsubsection{Information Flow}

The flow of information in any assessment of total system performance starts from test data and the corresponding interpretation and documentation of these data, the use of process-level models to synthesize the available test data and other information into a consistent representation of the relevant processes affecting waste isolation and containment, the abstraction of results from these process-level models in the form of response surfaces, table look-ups or other functional relationships for use in the total system performance assessment software, and finally, the total system performance assessments themselves. In many cases the information derived from field and laboratory testing is used directly in the analyses rather than going through the process-level model and abstraction steps. Examples of information derived from laboratory experiments include alteration/dissolution rates of the waste form, solubility of individual radionuclides, and radionuclide sorption values. Examples of information derived directly or indirectly from field measurements include hydrogeologic unit thicknesses and surficial infiltration rates. In many other instances, however, predictive models are required to provide results that can become input to the TSPA analysis. Examples of these include unsaturated- and saturated-zone flow, drift-scale thermal hydrology, and waste package degradation. In these instances, the results from the process-level model simulations are used to define the relationship between the "known" parameters, including their corresponding uncertainty and spatial variability, and the required results used as input to the TSPA calculations. The detailed process modeling is required for these analyses because it is not possible to either (1) simplify the process model sufficiently for meaningful predictions in the total system code or (2) efficiently imbed the coupled process model itself into the total system performance code and make the repetitive simulations required of the probabilistic analyses. 
It is important to bear in mind that the TSPA calculations are conducted in a probabilistic or stochastic fashion in order to attempt to capture the uncertainty and variability in the processes and the corresponding parameters so that the significance of this uncertainty on the predicted performance can be evaluated. Performance assessments attempt to explicitly include uncertainty and variability in the analyses through the use of parameter distributions covering the range of observed or inferred conditions.

\subsubsection{Regulatory Implications}

Although several alternative measures of performance could be evaluated to quantify the ability of the site and associated engineered barriers to isolate radioactive wastes from the biosphere over the extended periods of time that the wastes pose the greatest environmental and health risks, the present analyses focus on two measures of total system performance. These performance measures are (1) the cumulative release of radionuclides at the accessible environment boundary normalized to the limits presented in Table 1 of 40 CFR Part 191, and (2) the maximum radiation dose to an individual ${ }^{4}$ using groundwater derived from a well into the tuff

4 It is important to point out that the potentially exposed population defined by the "critical group" mentioned in the National Academy of Sciences (NAS) recommended standard for high-level radioactive waste disposal at Yucca Mountain, is based on existing land and water use patterns in the vicinity of the Yucca Mountain potential repository site. At present the closest members of the public are about 20 kilometers from the potential repository. Individuals that are downgradient from the site rely on water primarily derived from the alluvial aquifer, not the tuff aquifer. The correlation between the calculated peak individual doses evaluated in this total system performance assessment, the peak individual doses presented previously in TSPA-1993 (Wilson et al., 1994; Andrews et al., 1994), and the analyses conducted in support of the Calico Hills Systems Study (M\&O, 1995d)) should not be construed to represent the peak dose associated with the average individual of a "critical" population. The NAS committee has recommended that the definition of the "critical" population be developed as part of the EPA rulemaking process in repromulgating the environmental standards applicable to the Yucca Mountain potential repository site. Although performance assessment could be used to evaluate the effect of alternative definitions of this "critical" population, such analyses are beyond the scope of the present document due to the short time available between the release of the NAS recommendations on August 1, 1995, and the due date of the draft TSPA-1995 documentation of August 31, 1995. It is recommended that (1) alternative biospheres utilizing the concept of a "critical" population be defined, (2) alternative saturated-zone travel paths and associated mixing, dilution, and lateral and transverse dispersion be analyzed and (3) the assumptions and results be compared with the present analyses. When this comparison is completed, the reader should have a better understanding of how different definitions of the biosphere affect the absolute value of the predicted peak dose. Until such time, great care should be used in interpreting the peak dose of the maximally-exposed individual of the current analyses. They should not be interpreted on the basis of the NAS recommended biosphere. Additional comments regarding the potential significance of the NAS recommendations are presented in the concluding remarks of this document (Chapter 10). 
aquifer at the accessible environment boundary. For consistency, the definition of the "accessible environment" in both instances is assumed to correspond to a location in the saturated zone, five kilometers downgradient from the edge of the potential repository.

In addition to the analysis of alternative measures of total system performance, these predictions can be made over a range of times following closure of the repository. In order to provide a comparison to the remanded EPA standard presented in 40 CFR Part 191, the normalized cumulative release is calculated over the first 10,000 years after waste emplacement. Given the EPA direction to evaluate the cumulative release over 10,000 years, this same time period has been chosen to evaluate the peak individual dose (this is consistent with the revised EPA standard in 40 CFR Part 191 that is only applicable to the Waste Isolation Pilot Plant). Also in this study, analyses of peak individual dose have been extended to $1,000,000$ years to predict the time of occurrence of the maximum dose. This time period was mentioned in the NAS recommendations on applicable Yucca Mountain environmental standards. NAS based this time period on earlier performance assessment calculations (Wilson et al., 1994; Andrews et al., 1994), which showed that the predicted peak doses occurred several tens to hundreds of thousands of years following waste emplacement (with the predicted time of occurrence of the peak depending primarily on the advective flux within the unsaturated zone). Because this time period is generally sufficient to ensure the arrival of the most significant radionuclide peaks given virtually all reasonable estimates of advective flux except for the lowest possible values, it appears to be adequate for the relative comparison of peak dose or risk.

While integrated release or peak dose (or other surrogates of these performance measures such as cumulative population dose, peak concentration, peak individual risk or health effects) are generally accepted as being appropriate total system performance measures of long-term safety associated with the containment and isolation of radioactive wastes, the NRC has promulgated additional requirements on three subsystems. These subsystems include (1) the waste package itself [substantially complete containment, 10 CFR 60.113(a)(1)(ii)(A)], (2) the engineered barrier system [maximum release rate, 10 CFR 60.113(a)(1)(ii)(B)], and (3) the geosphere [ground-water travel time, 10 CFR 60.113(a)(2)]. The first two of these subsystems are directly quantified in the definition of the source term used in the total system performance assessment. In fact, they are prerequisites to the calculation of releases and doses at the accessible environment, with the waste package containment having to be breached and radionuclides released from the engineered barrier (the cladding, the waste form, the waste package itself and the materials placed under or around the waste package) before any transport in the geosphere occurs. Therefore, predictions of the performance of these engineered barrier components are also addressed in this document (Chapter 5 for substantially complete containment and Chapter 8 for peak release rate from the EBS). The ground-water travel time performance measure could be evaluated as a component of the total system performance assessment, but separate analyses of this geosphere subsystem requirement precluded the need to include these in this document. The interested reader is referred to Arnold et al., (1995) for a discussion of preliminary analyses of ground-water travel time.

\subsubsection{Waste Package Processes}

Given that the waste packages must "fail" (i.e., be breached to an extent that the mobile water present in the near field environment can ingress into the package and any dissolved 
radionuclides can be transported out of the package) before any dissolution of the waste form can occur, an important first step in total system performance assessment is the prediction of waste package degradation. The degradation rate of the waste package is dependent on (1) the waste package design (in particular, the material(s) used in the waste package fabrication and the thickness of these material(s)), (2) the repository design (in particular, the thermal load, the presence and nature of backfill, and the size of the emplacement drifts), (3) the near-field thermohydrologic regime in the drifts adjacent to the waste package surface (in particular, the temperature and relative humidity), and (4) the degradation characteristics of the waste package materials (including the criteria for corrosion initiation and the rate of corrosion as a function of the near-field thermohydrologic environment). Information from each of these topics is required as input to the waste package degradation model to predict the time-rate of "failure" of the waste packages. Brief descriptions of the current repository and waste package designs are presented in Chapter 3. The predicted near-field thermohydrologic response using a drift-scale model is presented in Chapter 4. The bases for the material properties used in the prediction of waste package degradation, as well as the results associated with this prediction, are presented in Chapter 5.

As with every process that affects the total performance of the repository system (including both the engineered and natural components), the prediction of waste package degradation uses a stochastic representation. Employing such an assumption acknowledges that each of the approximately 10,000 waste packages is not exactly the same. It would be unreasonable to expect that they would be the same given, among other things, that the waste packages would be fabricated over approximately a 30 -year time period. However, the stochastic assumption is made that the range of predicted material behavior of all waste packages is encompassed by the range in observed material characteristics. Similarly, it is unreasonable to assume that all environments encountered by the 10,000 waste packages are identical, either initially or as the system evolves under the applied thermal load. Again, the stochastic approximation attempts to capture this package to package variability due to the heterogeneity of the natural system as well as the heterogeneity of the local thermohydrologic perturbation. Also, for the waste package degradation model described in Chapter 5, localized corrosion of the surface of the waste package is considered to be the dominant degradation mechanism. Observations of corrosion over a range of materials indicate that localized corrosion is highly variable, i.e., it may be more rapid in some locations than others along the surface of the metal. This variability is again treated in the analysis presented in Chapter 5 as a stochastic process. Combining all these stochastic representations causes a distribution of waste package "failures" as well as a distribution of the amount of each waste package that is degraded as a function of time. It is worthwhile to point out that if these processes were not treated as being stochastic, then all waste packages would "fail" at exactly the same time and the radionuclide release rate over time would be exactly the same from all waste packages. Treating the processes as stochastic leads to a fraction of the waste packages "failing" earlier while another fraction will "fail" later and to radionuclide release rates that vary between waste package groups.

Once the waste packages have "failed" (i.e., the initial pit has penetrated the inner corrosionresistant layer), it is assumed that the environmental conditions (in particular the temperature, humidity, liquid saturation (if any) and the presence of drips (if any)) occurring outside of the waste package are immediately transferred to the inside of the waste package. It is these 
environmental conditions, combined with information on the behavior of the waste form and other engineered barriers under these environmental conditions, that are required in the prediction of radionuclide releases from the engineered barriers to the host rock.

\subsubsection{Near-Field Environment}

The thermohydrologic conditions inside the package and within the materials placed in the drift are derived from response surface fits to the results from the drift-scale thermohydrologic process model. The predicted thermohydrologic response in the vicinity of the drift-emplaced waste packages is dependent on a number of repository and waste package design issues, notably the areal mass loading of the waste packages in the repository, the line loading of the waste packages along the drift, the size of the drift, the use of backfill around the waste package, the use of ventilation prior to closure of the repository, the number of waste packages (or equivalently, the mass loading of each waste package), the age of waste at emplacement, and the average burn-up of the fuel. It is not possible to incorporate this many degrees of freedom in the current TSPA iteration. With the exception of the thermal load emplaced in the repository (both average areal mass loading and line loading of the drift) and the use of backfill within the drift, the other design related parameters are fixed at their best-estimate values from the Controlled Design Assumptions Report (M\&O, 1995c). These assumptions are discussed in Chapter 4. Two areal mass loads are used in the present total system performance assessment, a "high" value corresponding to $83 \mathrm{MTU} / \mathrm{acre}$ and a "low" value corresponding to $25 \mathrm{MTU} / \mathrm{acre}$.

In addition to the design-related factors affecting the predicted drift-scale thermohydrologic response, a number of hydrogeologic conceptual model and parameter uncertainties also exist. These include the conceptual representation of fracture-matrix flow, the hydrologic characteristic curves for the Topopah Spring Tuff host rock, the characteristic curves for the emplaced backfill (if present) and invert materials, the thermal characteristics of the backfill (if present) and invert materials, the amount of percolation flux (which also affects the liquid saturation in the host rock prior to emplacement of the heat-generating waste), and finally the magnitude of the bulk permeability of the host rock. In addition to being uncertain, each of these factors is likely to be variable from location to location within the potential repository block due to the heterogeneity of the hydrogeologic environment and the engineered emplacement of any driftemplaced materials. To account for this uncertainty and/or variability, a number of process-level model realizations are conducted to evaluate the range in the thermohydrologic response; the key model parameters are the applied percolation flux and the thermal properties of the in-drift materials. The sensitivity of the predicted waste package degradation times and engineered barrier system releases to this uncertainty is evaluated in the results that are presented in Chapters 5 and 8 , respectively.

The geochemical environment inside the waste package is assumed to be analogous to the ambient aqueous geochemistry inferred to exist in the Topopah Spring Tuff host rock. This neglects any geochemical perturbation likely to occur as a result of the varying thermohydrologic regime, as well as the interaction of the pore fluids with the introduced materials placed in the drift (not the least of which is the thick iron-based corrosion-allowance outer layer of the waste package). The likelihood and magnitude of localized advective flux (i.e., drips) into and through the in-drift materials is predicted by a stochastic representation of the distribution of percolation flux and saturated hydraulic conductivity of the host rock (both of which are assumed to be log- 
normally distributed) in the vicinity of the in-drift emplaced waste packages . The localized advective flux is then represented by a response surface.

\subsubsection{Waste Form Processes}

The near-field environmental conditions affect such processes as the waste form dissolution, the solubility of the radionuclides in the aqueous phase in contact with the waste form, and the magnitude of both the advective and diffusive components of transport from the waste form surface through the degraded waste package and the in-drift materials into the host rock. Waste form dissolution rates are derived from empirical fits to data collected in laboratory experiments conducted under a range of environmental conditions (primarily different temperature and geochemistry environments although hydrologic conditions are also being investigated). The empirical fits include the uncertainty in the fitting parameters but do not include any stochastic effects (i.e., variability associated with different waste form samples). Radionuclide solubilities are also derived from empirical fits to data obtained from laboratory experiments for a range of thermal and chemical conditions. Uncertainty in the fitting parameters reflects the uncertainty in the experimental data only and does not account for uncertainty in the stability of the controlling phase (i.e., conceptual uncertainty) or the variability associated with a range of local geochemical environments.

The advective flux component of radionuclide transport is derived from the distribution of local percolation flux in excess of the saturated hydraulic conductivity of the host rock. This is a stochastic parameter that is directly correlated with the average percolation flux. The diffusive flux component of radionuclide transport is derived from the hydrologic conditions in the drift materials. For cases with an advective flux component, the diffusion coefficient is derived from laboratory-observed values of diffusion through coarse-grained materials. For cases with no advective flux, the diffusion coefficient is derived from an empirical fit of laboratory observed values as a function of liquid saturation. This empirical fit includes the uncertainty in the fit to the laboratory values, but does not include potential stochastic effects associated with material heterogeneity. Sensitivity analyses are conducted to evaluate the potential benefits associated with the emplacement of a so-called Richard's or capillary barrier, in which the backfill is designed to conduct (or "wick") any advective flux (i.e., drips) away from the waste package and underlying invert materials due to the capillary pressure (or matric potential) differences across unconsolidated materials of different grain-size.

An important component in the determination of radionuclide releases from the engineered barrier system to the host rock is the percent of the waste form surface that is exposed to the environmental conditions inside the waste package and the percent of the exposed waste form surface that is in contact with liquid water. The first component is related to the degradation of the cladding and any expansion of the waste form caused by thermal-chemical alteration. The second component is related to the amount and distribution of liquid water present in the waste package as a function of time. Both of these issues are difficult to predict rigorously. Sensitivity analyses are conducted to evaluate the potential contribution to total system performance associated with cladding performance. 


\subsubsection{Radionuclide Transport Processes}

The radionuclides released from the engineered barrier system are available for transport in the geosphere to the accessible environment. The geosphere provides for both a physical and chemical delay for radionuclides to reach the accessible environment. This delay is a function of (1) the percolation flux distribution in the unsaturated zone, (2) the advective flux distribution in the saturated zone, and (3) the conceptual representation of transport in the hydrogeologic layers along the likely ground-water travel path between the repository and the accessible environment. The percolation flux distribution within the Topopah Spring hydrogeologic unit is a function of the surficial infiltration rate and the conceptual model for ground-water flow in the unsaturated zone. The infiltration rate is a complex function of many near- surface hydrologic factors including (1) precipitation timing, intensity, and duration (including snowmelt), (2) surficial slope orientation and angle, (3) surficial geology, and (4) surficial vegetation.

For the present total system performance assessment, an infiltration distribution based on inferences made by Flint and Flint (1994) is employed. Two conceptual representations of the distribution of these infiltration rates to the percolation flux within the Topopah Spring hydrogeologic unit are considered. In one instance, the surficial infiltration over the footprint of the repository is assumed to be invariant with depth, i.e., there is an insignificant amount of lateral diversion of areally distributed infiltration. This assumption is consistent with the existing version of the unsaturated-zone hydrology model (Wittwer et al., 1995). An alternative conceptual representation is that the areally variable infiltration rate (which ranges from about $0.02 \mathrm{~mm} / \mathrm{yr}$ to over $10 \mathrm{~mm} / \mathrm{yr}$ ) is uniformly distributed across the Topopah Spring hydrogeologic unit due to significant lateral diversion within the basal vitrophyre of the Tiva Canyon hydrogeologic unit or within the Paintbrush hydrogeologic unit. In this case, the areally-weighted average infiltration rate is used to define the percolation flux. This model is consistent with small-scale flow models tested by Kwicklis (1994).

The key conceptual uncertainty in the transport of radionuclides through the geosphere at Yucca Mountain is the possible presence of fracture flow and transport which might, if fracture pathways existed and were continuous and interconnected, lead to the formation of so-called "fast" paths. Although the magnitude and distribution of percolation flux may also be considered a conceptual uncertainty, in the present analyses this flux is treated as a parameter. Therefore the conceptual uncertainty is embodied in the two parameter distributions. The likelihood and magnitude of any fracture flow is a function of the average percolation flux and the spatial distribution of hydrologic characteristics of the unsaturated media. In order to develop a representative distribution of fracture flow, a series of one- and two-dimensional process-level analyses are conducted over a range of possible unsaturated zone hydrologic characteristics. The results are then abstracted for use in the total system performance assessment by fitting a response surface through the results, with each hydrogeologic layer having different distributions because of their differing hydrologic properties. Because the resulting probability and magnitude of fracture flow are highly dependent on the average percolation flux, the principal dependency used in the TSPA analyses is a correlation with percolation flux.

The conceptual model for fracture transport is dependent on the mean travel path length through fractures before the dissolved constituents can transition into the matrix. This length corresponds physically to the average fracture length combined with the degree of interconnectedness of the 
fracture network. A range of mean flow path lengths is studied in the sensitivity analyses of this total system performance assessment. In addition, alternative conceptual representations, including the effects of radionuclide retardation along fracture walls and matrix diffusion from the fractures into the rock matrix, are investigated.

Geosphere transport is also affected by the potential for radionuclide sorption on the mineral grains in the rock matrix. Whole rock distribution functions $\left(k_{d} ' s\right)$ are used based on laboratoryderived data and the "minimum $k_{d}$ concept" (Meijer, 1992) for the highly-sorbed radionuclides. These distribution coefficients are related to the individual hydrogeologic unit. Although the actual retardation within any particular unit is expected to be spatially variable due to mineralogic heterogeneity and perhaps local geochemical variability, this stochastic effect is not considered in the current total system performance assessment. The use of the "minimum" $k_{d}$ value (i..e, most conservative from a release or peak dose perspective) obviates the need to account for the spatial variability explicitly.

The advective flux distribution in the saturated zone used in TSPA-1995 is the same as that employed in TSPA-1993. The entire flux distribution incorporates the effects of the considered large-scale spatial heterogeneity of aquifer properties. Small-scale heterogeneity is included through the use of dispersion in the solution of the one-dimensional advective-dispersive equation. Because of the one-dimensional nature of the solution algorithm, only longitudinal dispersion is simulated, i.e., there is no transverse dispersion. This is conservative when considering predictions of peak concentration or peak dose.

\subsubsection{Future Climates}

Given the long time frames of potential interest in total system performance (up to $1,000,000$ years), it is likely that the atmospheric conditions will change with a resulting change in climate, especially precipitation and net evapotranspiration. Therefore, the potential effects of climate change are important to consider. Although a range of estimates exist on the possible changes in precipitation in the Yucca Mountain region over the next 10,000 years, at present no process model results of the potential effects of precipitation changes on (1) net infiltration and percolation flux in the unsaturated zone or on (2) the elevation of the water table and advective flux in the saturated zone are available. It is rational to postulate that increased precipitation would result in an increase in percolation flux and a rise in the water table, although the degree of correlation and the time lag between changes in surficial processes and the subsurface effects are uncertain. For simplicity it is assumed in the current total system performance assessment that changes in precipitation are immediately transferred through the unsaturated zone to the water table and that there is a linear relationship between precipitation and infiltration rate (and therefore percolation flux) and the magnitude of the water table rise.

\subsubsection{Radiation Dose Calculation}

Although only engineered barrier and natural barrier (i.e., geosphere) models and parameters are required in the prediction of cumulative releases of radionuclides at the accessible environment boundary, the calculation of radiation dose requires the definition of the potentially exposed population(s) and the potential biosphere pathways by which individuals may be exposed to any radionuclides released. In the current total system performance assessment it is assumed that an 
individual receives the peak dose by taking all his or her drinking water from the tuff aquifer. It is also assumed that this individual is located at the point on the accessible environment boundary which corresponds to the peak of the radionuclide concentration within the tuff aquifer. Mixing volumes are based on a fixed cross-sectional area of flow in the saturated zone, with the horizontal mixing being given by the width of the potential repository and the vertical mixing assuming a well with a 50-m saturated-zone interval. Dose conversion factors, which convert radionuclide concentrations to radiation doses, are derived from published values of the U.S. Environmental Protection Agency (EPA, 1988).

\subsection{REPOSITORY INTEGRATION PROGRAM (RIP)}

The total system performance of a potential radioactive waste repository at the Yucca Mountain site is computed with the computer program RIP (Repository Integration Program) in conjunction with detailed process-level models. This subsection describes RIP, while the detailed process models are identified and described in later chapters of this document. RIP was specifically developed by Golder Associates Inc. (GAI) in order to evaluate the performance of a potential radioactive waste disposal facility at Yucca Mountain (Miller et al., 1992; Golder Associates, 1993) and has subsequently been applied to a wide variety of proposed radioactive waste disposal facilities both in the U.S. and abroad. Most recently, RIP has been applied to the WIPP site in New Mexico (Golder Associates, 1994a; Golder Associates, 1995a) and to evaluating alternative disposal options for low-level waste for the State of New York (Golder Associates, 1995b). RIP is fully documented in a Theory Manual and User's Guide (Golder Associates, 1994) and has a context-sensitive online help utility. The program has recently been formally verified consistent with ASME NQA-1 and ISO-9000 standards (Golder Associates, 1995c).

The major features of the four component models of RIP (see Figure 1.5-1) that comprise the performance assessment model are (1) waste package behavior and radionuclide release component model, (2) radionuclide transport pathways component model, (3) disruptive events model, and (4) biosphere dose/risk model. These models are summarized briefly below.

The waste package behavior and radionuclide release component model input requirements are descriptions of the radionuclide inventories in the waste packages, a description of near field environmental conditions (which may be defined as temporally and spatially variable), and subjective estimates of high-level parameters describing container failure, matrix alteration/dissolution, and radionuclide mass transfer. The waste package component model can simulate two layers of containment (e.g., outer package and zircalloy cladding). Waste package failure rates, along with matrix alteration/dissolution rates, are used to compute the rate at which radionuclides are exposed. Once exposed, RIP computes the rate of mass transfer out of and away from the waste package. Parameters describing waste package failure and radionuclide exposure and mass transfer can be described as a function of near-field environmental conditions. The output from this component (for each system realization) consists of time histories of release for each radionuclide from the waste packages, and acts as the input for the transport pathways component.

The radionuclide transport pathways component model simulates radionuclide transport through the near and far field in a probabilistic mode. The RIP model uses a phenomenological approach that attempts to describe rather than explain the transport system. The resulting transport 
algorithm is based on a network of user defined pathways. The geosphere and biocell pathways reflect the major features of the hydrologic system and the biosphere, and are conduits through which transport occurs. The pathways may be used for both flow balance and radionuclide transport purposes, and may account for either gas or liquid phase transport. The purpose of a pathway is to represent large-scale heterogeneity of the hydrologic system, such as geologic structures and formation-scale hydrostratigraphy.

Geosphere pathways may be subdivided into flow modes, which address heterogeneity at the local scale (e.g., flow in rock matrix, flow in fractures). The flow modes are primarily distinguished from one another based on flow velocity in the mode, although retardation parameters may also differ between flow modes.

The transport of radionuclides along a geosphere pathway is based on a breakthrough curve, which is calculated as a cumulative probability distribution for radionuclide travel times along the pathway. The breakthrough curve combines the effects of all flow modes and retardation on the radionuclide travel time, and determines the expected proportion of mass that has traversed the pathway by any specified time. The breakthrough curve is computed based on a Markov process algorithm for exchange between different flow modes.

The third performance assessment component model represents disruptive events. Disruptive events are defined as discrete occurrences that have some quantifiable effect on the processes described by the other two component models. Examples of disruptive events include volcanism, faulting, and human intrusion. The user first identifies all significant events (i.e., events that are both credible and consequential). Having done so, each event is assigned a rate of occurrence and, if desired, one or more descriptor parameters, which define the characteristics and magnitude of the event (e.g., length of a volcanic dike). Descriptor parameters may be described stochastically. Event occurrences are simulated as Poisson processes.

The user defines probability distributions for the event consequences (which may be functions of event descriptors). A consequence may take the form of a number of discrete responses (e.g., disrupting a number of waste packages, moving radionuclides from some waste packages directly to the accessible environment). It is also possible for an event to directly modify parameters defined in the other two component models, and this capability can be used to specify long-term consequences (e.g., raising the water table or opening a new pathway).

The fourth performance assessment component model describes the fate and effect of radionuclides in the biosphere. The biosphere dose/risk model allows the user to define dose receptors in the system. Receptors receive radiation doses from specified geosphere (e.g., a water supply aquifer) or biosphere (e.g., a pond, or flora and fauna) pathways. Concentrations in these pathways are converted to radiation doses (or cancer risks) based on user-defined conversion factors. 


\subsection{ORGANIZATION OF THE CURRENT TOTAL SYSTEM PERFORMANCE ASSESSMENT DOCUMENT}

Following this introductory chapter, Chapter 2 describes the Yucca Mountain site in general and the geohydrologic and geochemical attributes of the site that are significant with respect to the prediction of total system performance. The information presented in Chapter 2 is used as input to the development and substantiation of the process-level models that simulate the aqueous flow and transport in the unsaturated zone. Information on the saturated zone is only briefly presented because little additional analyses have been conducted since TSPA-1993 to better define this component of geosphere. Chapter 2 summarizes the current conceptual representation of flow in the unsaturated zone and describes the basis for the infiltration rates used in the current iteration of TSPA. In addition, this chapter describes the potential natural changes that may occur and their possible effects on the repository system.

Chapter 3 describes the current repository and waste package designs which have been used in the current total system performance assessment. The emphasis is on changes in understanding or designs since the last TSPA iteration in 1993. Within this chapter, the general layout of the potential repository is described, including the proposed alternative thermal loading cases. This chapter also describes the alternative waste package emplacement and backfill options proposed for the repository drifts. The radionuclide inventory associated with both the spent fuel containers and the high-level waste canisters within each waste package are also presented in this chapter.

Chapter 4 presents the conceptual representation used to predict the drift-scale thermal hydrology resulting from a range of alternative repository designs. In particular, two thermal loads, with and without the presence of backfill above and around the waste packages have been considered. In addition, due to the uncertainty in the ambient percolation flux, the thermohydrologic analyses have considered both a "low" percolation flux $(0.05 \mathrm{~mm} / \mathrm{yr})$ and a "high" percolation flux $(0.3 \mathrm{~mm} / \mathrm{yr})$. Although higher percolation fluxes are conceivable, the numerical algorithm used in the prediction of the thermohydrologic response had numerical convergence problems at higher percolation fluxes. In order to address some conceptual uncertainties, alternative drift-scale thermohydrologic analyses are also presented in Chapter 4.

Chapter 5 presents the conceptual representation and the associated parameters used for the evaluation of waste package degradation. A range of predictions of waste package "failures", based on a range of alternative conceptual assumptions, is presented in this chapter. These predictions use the thermohydrologic results described in Chapter 4.

Chapter 6 presents the abstraction of models and other parameters required in the prediction of engineered barrier system releases. The processes that are described in this chapter include waste form alteration/dissolution, solubility constraints on the concentration of dissolved radionuclide species, the potential existence of colloids to increase the mobile component of radionuclides in the aqueous phase, the effective diffusion of radionuclides through the degraded waste package and other engineered materials, and the potential for advective transport in the presence of localized flow intersecting the drift. This chapter presents the abstraction of laboratory-derived information for use in the prediction of releases from the engineered barrier system. 
Chapter 7 presents the technical basis for the abstraction of unsaturated- and saturated-zone advective fluxes for the different hydrostratigraphic layers at Yucca Mountain. The response surface fits to the process-model results are presented in this chapter. Both site-scale and repository-scale unsaturated zone hydrology abstractions are presented in this chapter.

Chapter 8 presents the predicted results of radionuclide releases from the engineered barrier system to the host rock for a range of alternative conceptual representations and sampled parameter distributions. These results provide the source term for geosphere transport. The results are presented as both cumulative releases and peak release rates, with the latter being compared to the NRC release rate limits specified in 10 CFR 60.113(a)(1)(ii)(B).

Chapter 9 presents the predicted results of radionuclide releases at the accessible environment boundary and the peak individual doses attributed to these releases. The cumulative releases are normalized to the Table 1 values in 40 CFR Part 191 (the remanded environmental standard). The peak individual doses presented in this chapter are attributed to an individual at the accessible environment using the tuff aquifer for all of his or her drinking water and are calculated over a 10,000-yr and 1,000,000-yr time period. [Note, these peak doses should not be compared to the average dose to which a member of the "critical" population may be exposed over the time periods of interest. The average dose is expected to be some orders of magnitude less than the peak dose to the maximally-exposed individual.] In order to evaluate the significance of the predicted results to uncertainties in models and parameters, a number of sensitivity analyses are described in this chapter.

Chapter 10 presents a summary of the major results of this iteration of total system performance assessment and the potential implications of these results to current site characterization and design activities. In addition, the need to substantiate process-level model assumptions and the requirements of process-level models are discussed in this chapter. 


\section{Important Components of}

TSPA-1995 Analyses

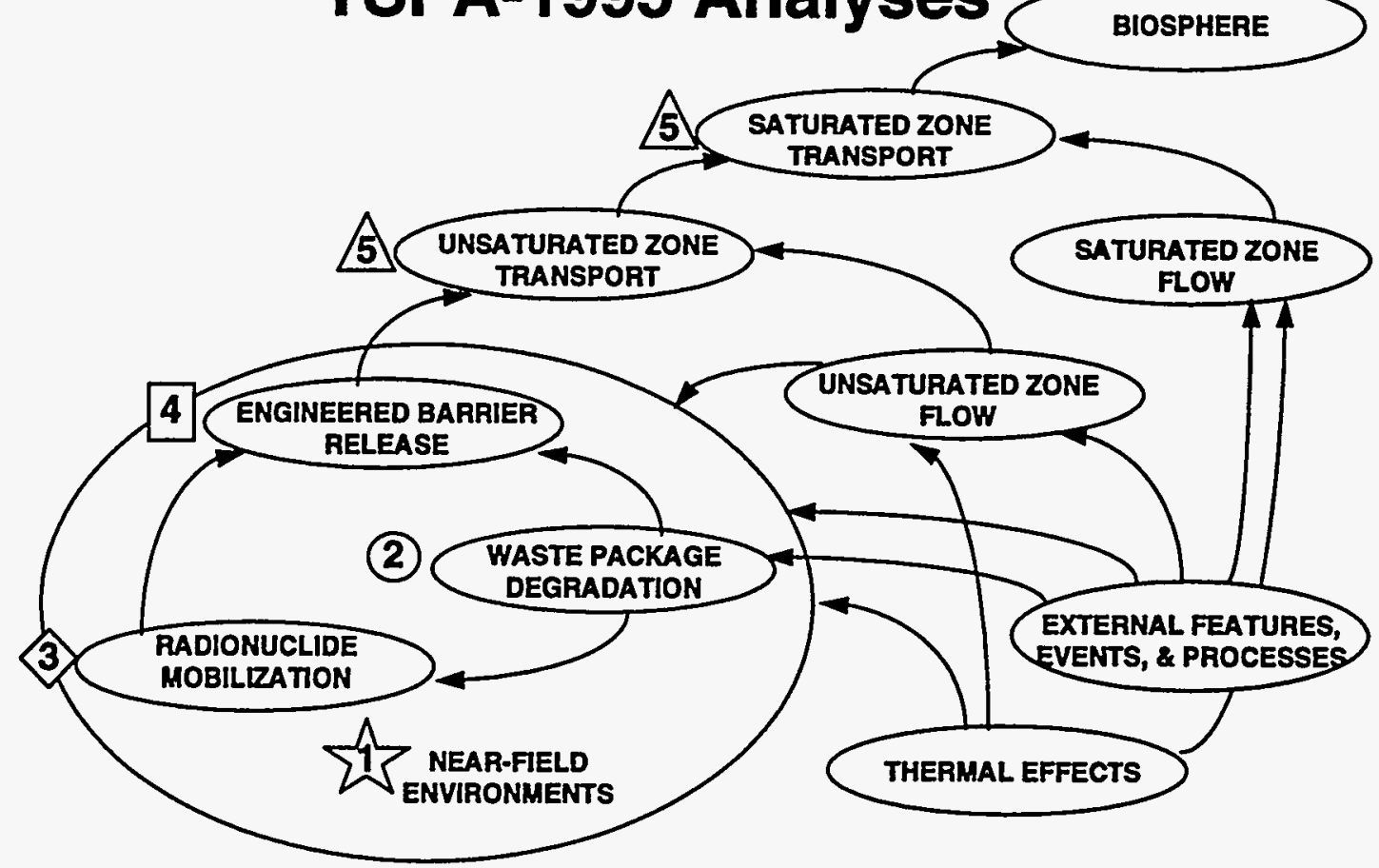

Figure 1.4-1 Process Model Influence Diagram Used in Total System Performance Assessment. 


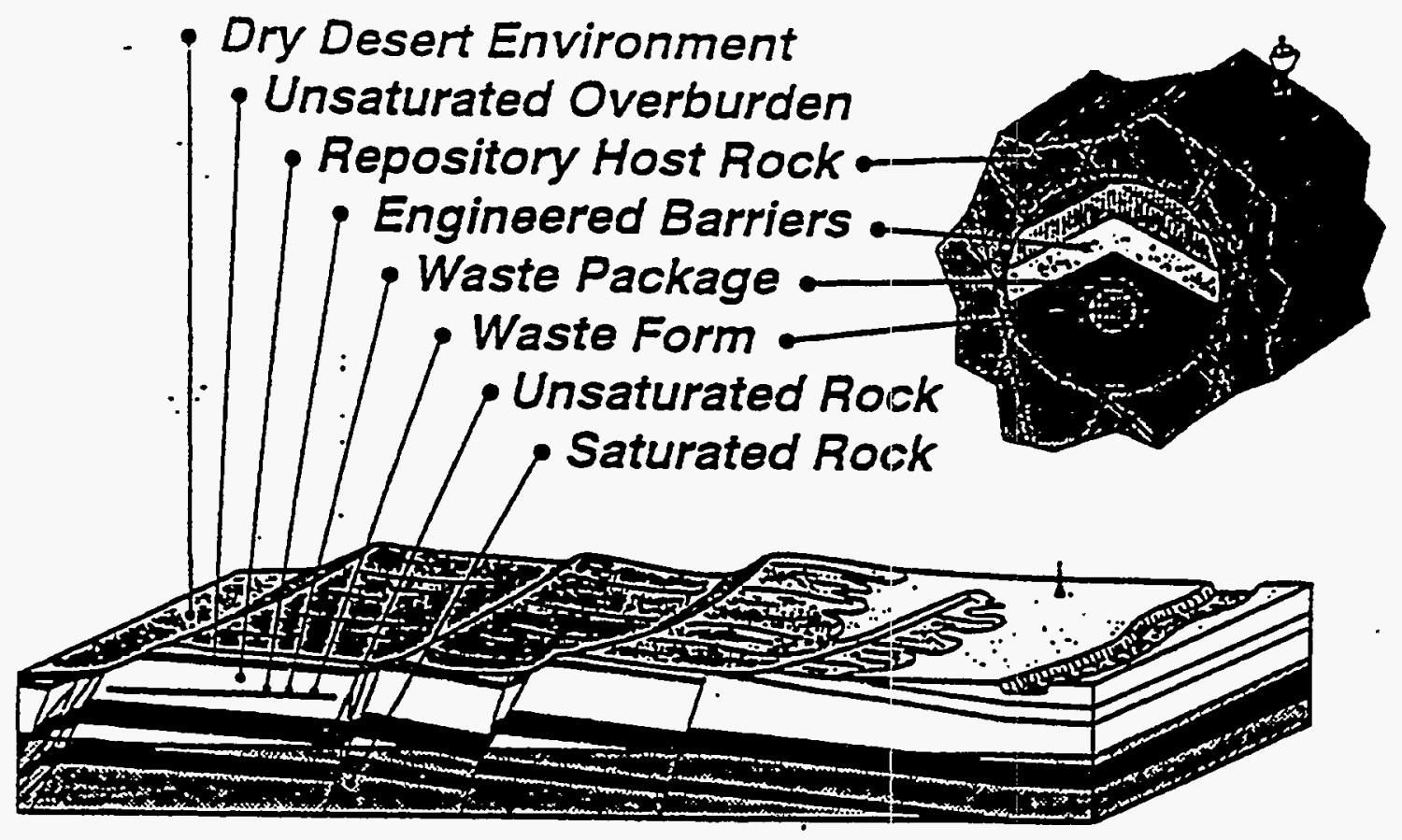

Figure 1.4-2 Schematic of Information Transfer Between Domains.

\section{Information Transfer Between Domains}

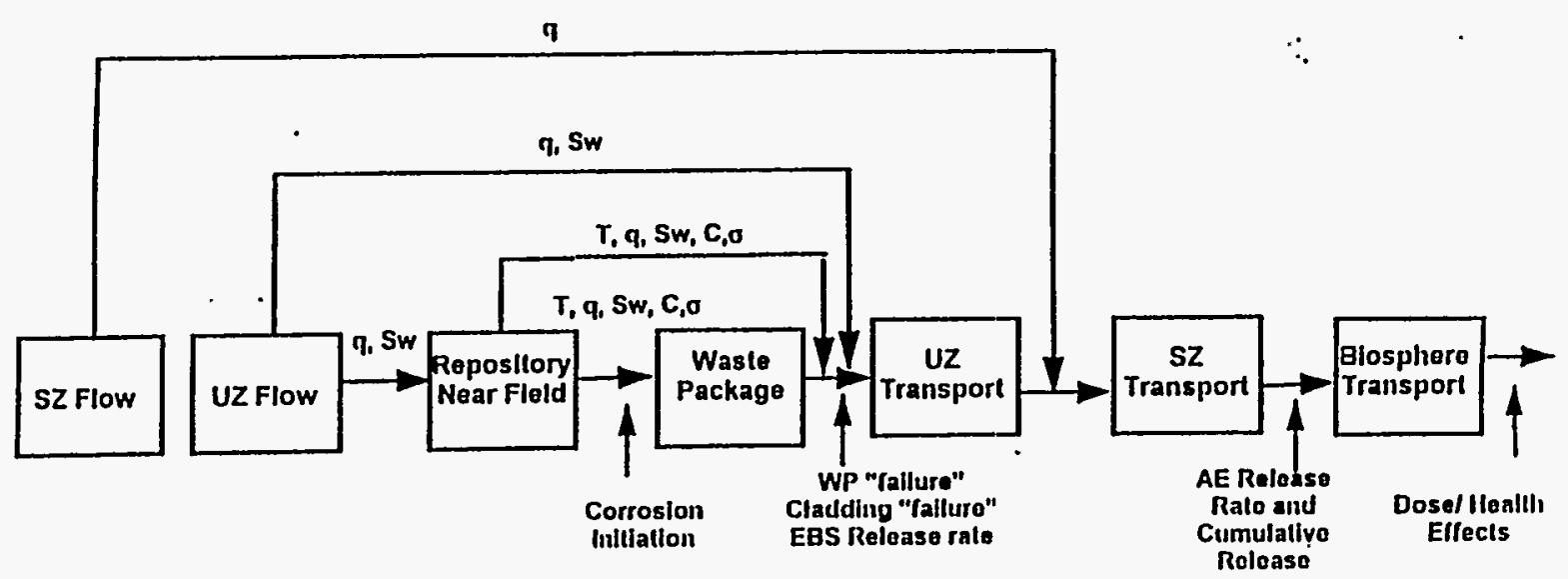

Figure 1.4-3 Schematic Depiction of the Barriers to Radionuclide Migration at the Potential Yucca Mountain Repository. 


\section{Top-Level Strategy for Waste Isolation}

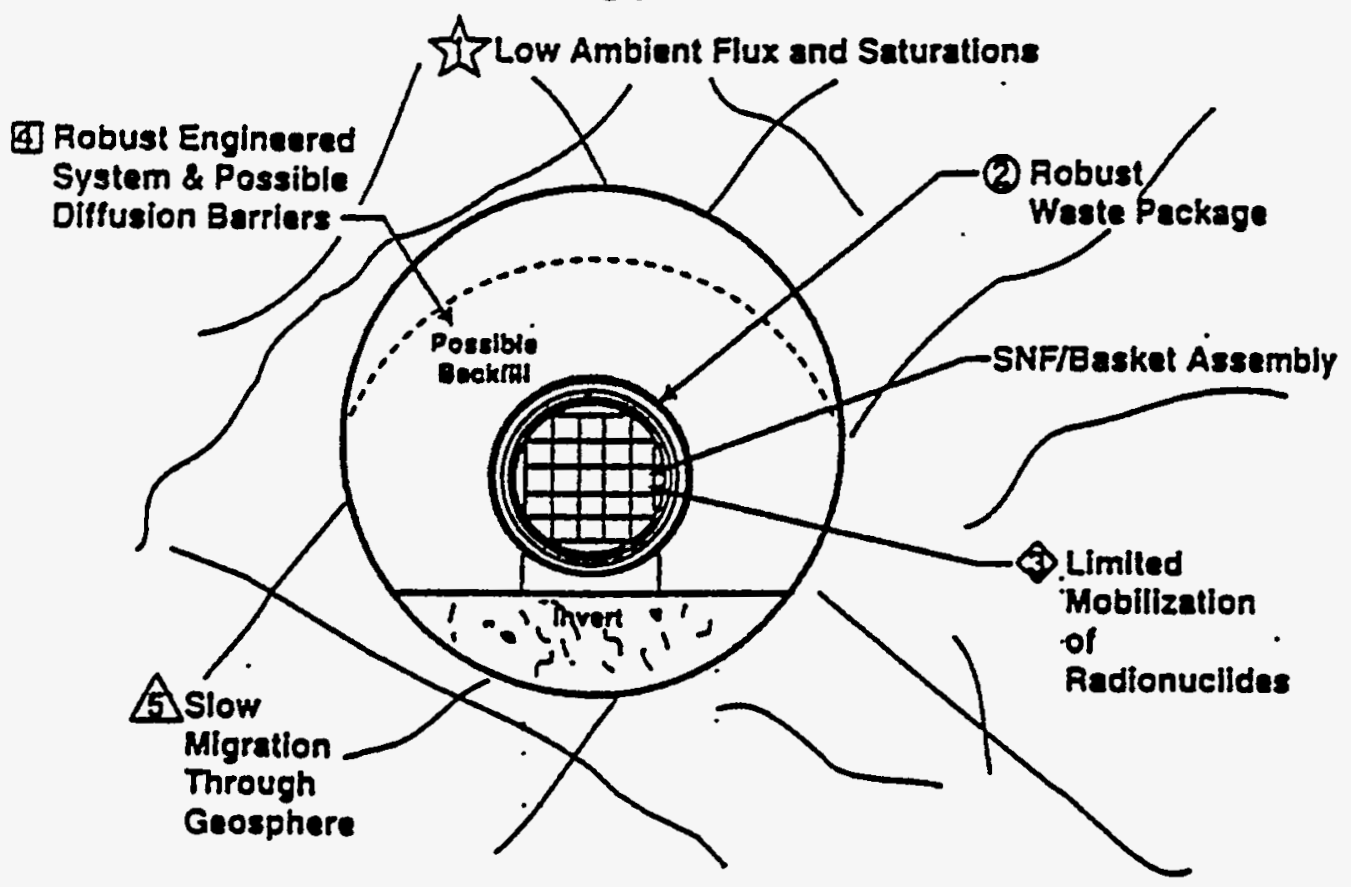

Figure 1.4-4 Engineered Barrier System Components. 


\section{MODEL HIERARCHY}

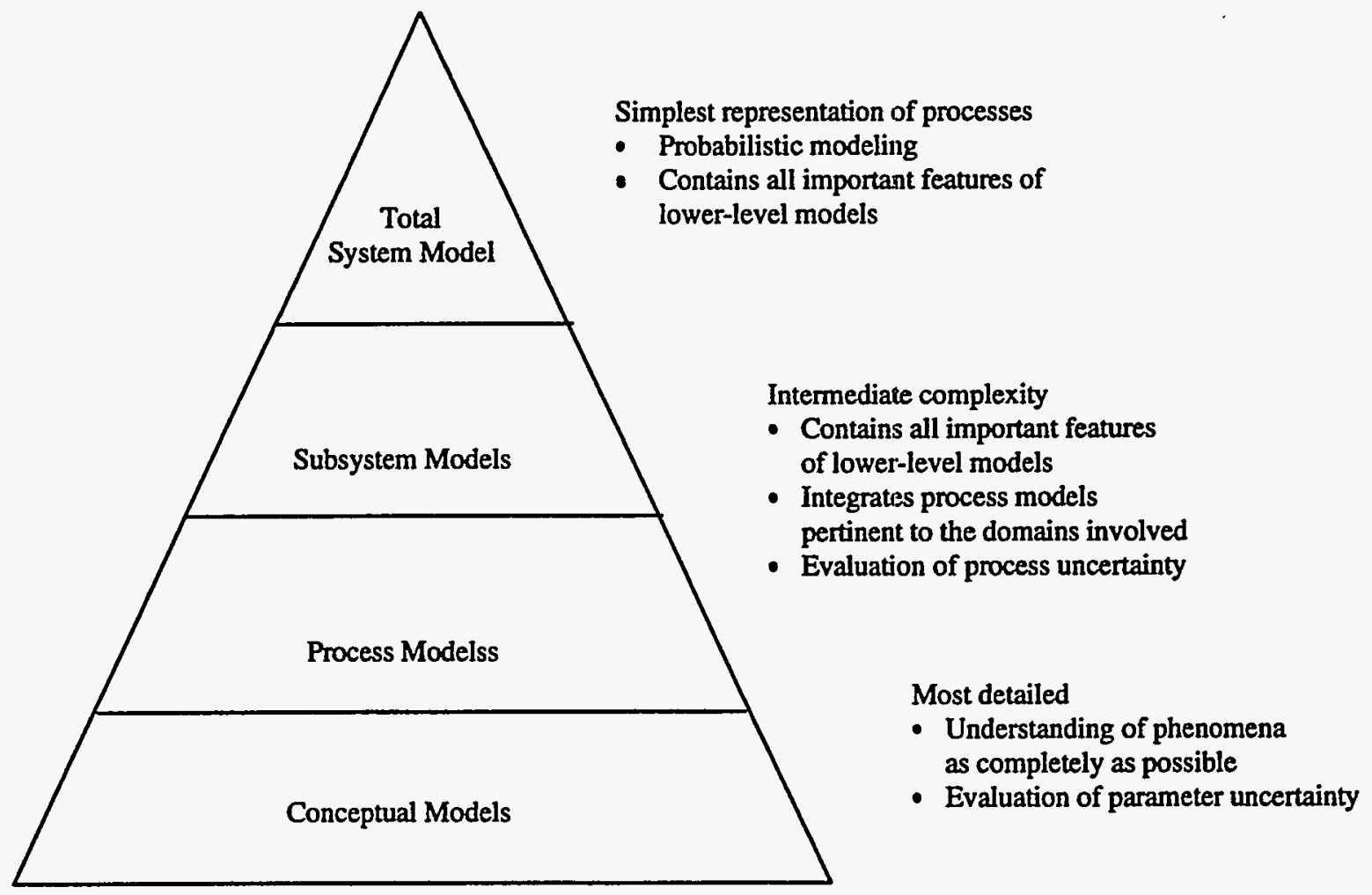

Figure 1.4-5 Levels of Models Used to Evaluate MGDS P'erformance. 


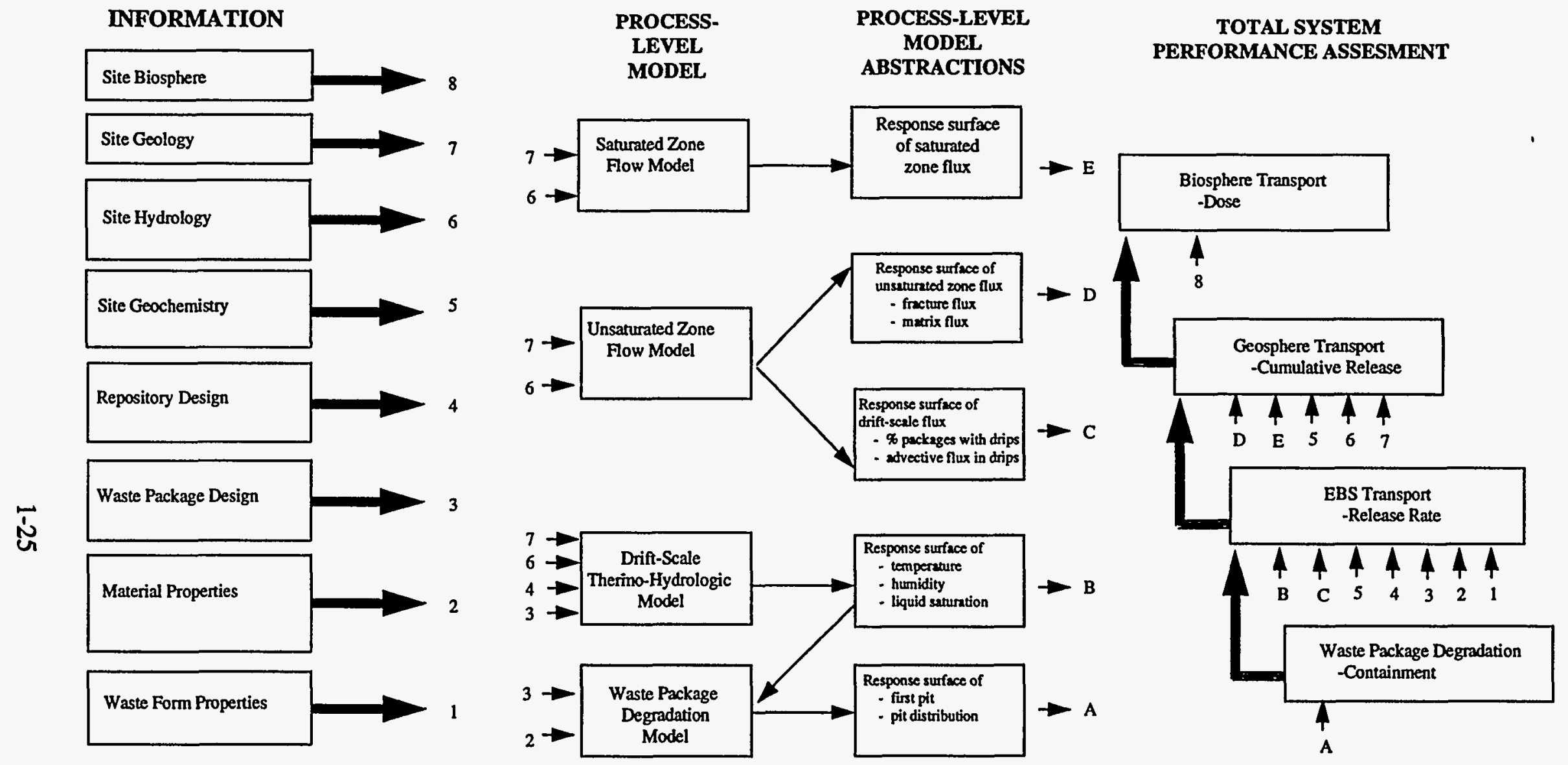

Figure 1.4-6 Information Flow Diagram for TSPA-1995. 


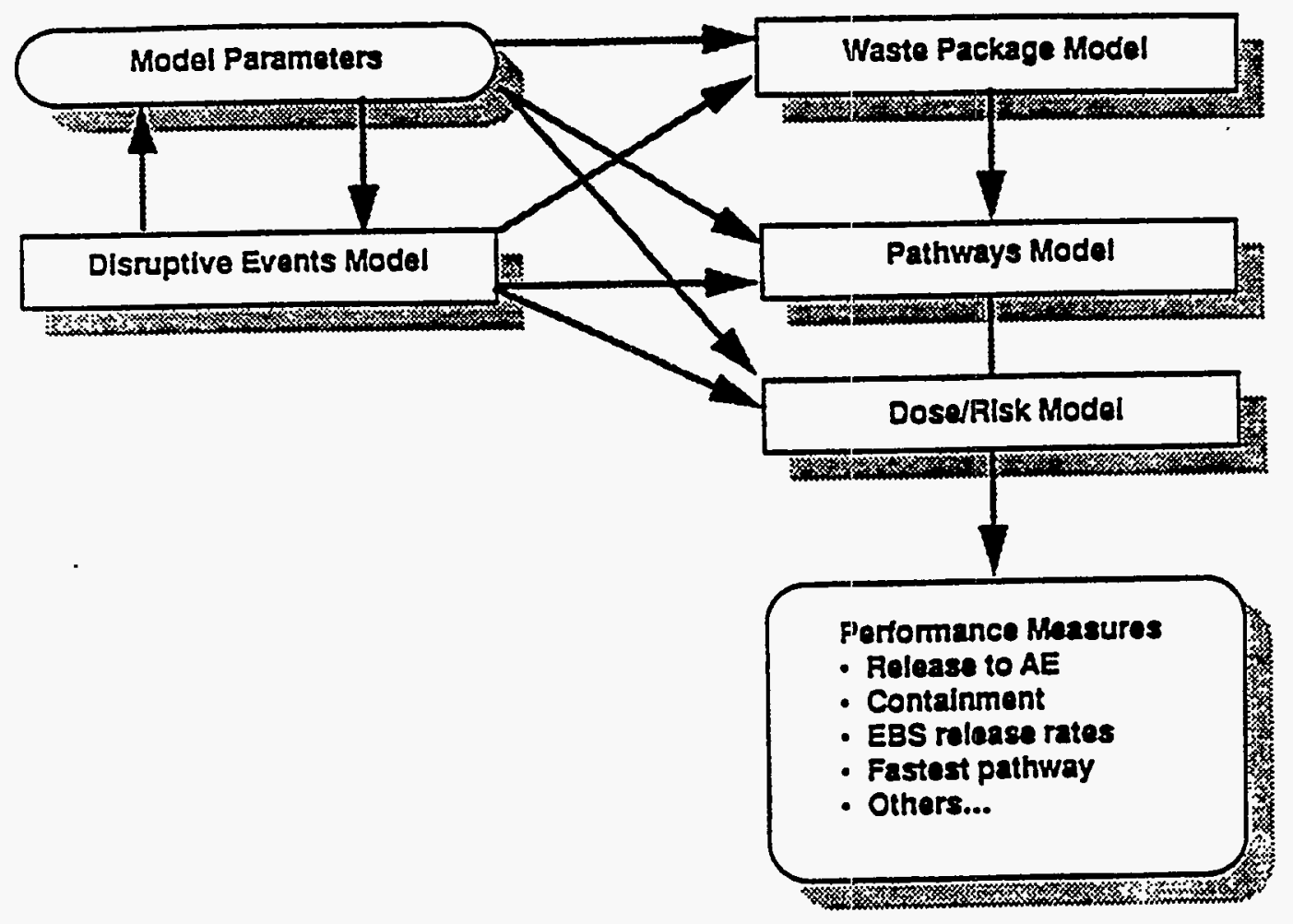

Figure 1.5-1 RIP Total System Performance Assessment Model Components. 
CHAPTER 2

SITE DESCRIPTION 


\section{SITE DESCRIPTION}

\section{Srikanta Mishra, James O. Duguid}

\subsection{INTRODUCTION}

The geologic setting at Yucca Mountain provides the framework within which all relevant processes affecting the long-term containment and isolation of radioactive wastes are active. It provides the boundary conditions for the engineered components of the system and defines those aspects of the geosphere barrier which retard and spread the arrival of dissolved nuclides at the accessible environment boundary. Although several excellent summaries of the natural environment exist for the interested reader to gain an understanding of the Yucca Mountain area and its surroundings (most notably the Early Site Suitability Evaluation (Younker et al., 1992) and the License Application Annotated Outline (DOE, 1995)), the salient aspects of the geosphere affecting long-term performance are briefly described in the present chapter.

The information in the present chapter is used as input to the development and substantiation of the process-level models describing aqueous flow and transport in the unsaturated zone, as illustrated in Figure 2.1-1. Information on the saturated zone is presented only briefly because few additional analyses have been conducted since TSPA-1993 to better define this component of the waste isolation system. Section 2.2 discusses the basic geologic framework of the Yucca Mountain area. Section 2.3 presents the hydrostratigraphy of the unsaturated zone. Section 2.4 summarizes the available information regarding matrix and fracture hydrologic characteristics for the unsaturated media at Yucca Mountain. Section 2.5 briefly summarizes the conceptual model for saturated-zone flow. Section 2.6 summarizes the current conceptual representation of flow in the unsaturated zone and describes the basis for the infiltration rates used in the current iteration of TSPA. Finally, Section 2.7 describes the potential natural changes that may occur and their possible effect on the repository system.

The geo-hydrologic descriptions in Sections $2.2-2.4$ are based primarily on the works of Montazer and Wilson (1984), Schenker et al., (1995) and Wittwer et al., (1995), as well as the review by Hoxie (1989). In addition to providing a geologic frame-of-reference for the proposed repository site, this information is used to develop the one-dimensional stratigraphy for radionuclide transport calculations implemented in RIP and to provide the parametric bases for the supporting thermo-hydrologic simulations presented in Chapter 7.

\subsection{GEO-ENVIRONMENTAL FRAMEWORK}

Yucca Mountain is located in the Southern Great Basin, about $140 \mathrm{~km}$ northwest of Las Vegas in the state of Nevada (Figure 2.2-1). The Great Basin of Nevada and Utah is a broad, arid-tosemiarid region characterized topographically by linear, usually north-trending mountain ranges separated by deep alluvium-filled valleys. The mountain ranges are typically tilted fault blocks that are delineated by mountain-front normal faults on which considerable vertical displacement has occurred.

Precipitation in the vicinity of Yucca Mountain is approximately $170 \mathrm{~mm} / \mathrm{yr}$, whereas potential evapotranspiration is estimated to be about $1000 \mathrm{~mm} / \mathrm{yr}$ (Hevesi et al., 1993). Consequently, 
most of the precipitation received at the surface is returned to the atmosphere, leaving only a small residual to infiltrate into the unsaturated zone. Net infiltration into Yucca Mountain is believed to be extremely variable spatially due to variations in soil cover, and associated differences in the impact of evapotranspiration rates, retention time, topographic controls, and fracture exposure on the infiltration process (Flint and Flint, 1994).

Structurally, Yucca Mountain is a complex of north- to northwest-trending, parallel to subparallel, generally fault-delineated ridges (Figure 2.2-2). The potential repository is proposed to be constructed within Yucca Crest, a major ridge that attains an elevation of more than $1,500 \mathrm{~m}$ above sea level and more than $300 \mathrm{~m}$ above the adjacent valley floors. Yucca Crest is bounded on the west by a steep escarpment defined by the trace of the Solitario Canyon fault, which is a west-dipping normal fault with vertical displacements ranging between $70 \mathrm{~m}$ and $300 \mathrm{~m}$. To the west and north, Yucca Crest is bounded by a plexus of west-dipping normal faults and, possibly, a few northwest-trending strike-slip faults. Although the block is transected by the Ghost Dance Fault, a west-dipping, north-trending normal fault on which about $25 \mathrm{~m}$ of vertical displacement has occurred, Yucca Crest is a relatively undisturbed structural block that is tilted $5^{\circ}$ to $8^{\circ}$ to the east.

Stratigraphically, the unsaturated zone beneath Yucca Crest consists of a layered sequence of tuffs deposited from volcanic eruptions which occurred about 10 million years ago. Tuff is a siliceous rock composed of compacted, indurated volcanic ash. The compaction depends upon the temperature and pressure within the original deposit and, in general, is described by the degree of "welding" of the resultant tuff. The tuffs range from porous, nonwelded ash-flow, ashfall, and reworked/bedded tuff deposit to massive, highly brittle, welded ash-flow and ash-fall rocks depending on their depositional mechanisms and cooling history.

The formal geologic stratigraphy for Yucca Mountain is shown in Figure 2.2-3 (Scott and Bonk, 1984; Montazer and Wilson, 1984). The basis for this lithostratigraphic subdivision is genetic. Specifically, the first-order nomenclature (e.g., Paintbrush group) is used for deposits interpreted to be of common petrogenetic character, perhaps indicating eruption from the same magma chamber. Secondary sub-divisions (e.g., Tiva Canyon member), commonly designated as cooling units for the welded ash-flow tuffs, are used for rocks procluced by single/multi-stage eruptive cycles. The boundaries between the deposits of these major eruptive events possibly represent extended periods of relative quiescence, which may have produced relatively thin intervals of reworked (bedded) deposits or unreworked ash-fall tuffs.

Measurements of ground-water compositions from the saturated zone indicate that the fluids within the tuffaceous units (as represented by samples from well J-13) are predominantly dilute sodium-bicarbonate fluids with high concentrations of aqueous silica (Benson et al., 1983; Ogard and Kerrisk, 1984; Kerrisk, 1987). Generally, the saturated-zone fluids have pHs in the range of 7-8 (but have been measured as low as 6.7 or as high as 9.4), and contain the cations $\mathrm{Ca}^{2+}$, $\mathrm{K}^{+}$, and $\mathrm{Mg}^{2+}$, and the anions $\mathrm{SO}_{4}{ }^{2-}, \mathrm{Cl}^{-}, \mathrm{F}^{-}$, and $\mathrm{NO}_{3}{ }^{-}$in order of decreasing concentration. The ground water from the deep Paleozoic carbonate aquifer (sampled from well UE-25p\#1) is more highly concentrated with respect to all these constituents except aqueous silica and is characterized by pH values slightly lower than 7 (Ogard and Kerrisk, 1984; Kerrisk, 1987). The saturated-zone water analyses suggest that these fluids are, in general, relatively oxidized, but a few samples may indicate reducing conditions at depth (Ogard and Kerrisk, 1984). 
Measurements of the organic content of the saturated-zone fluids are below $1 \mathrm{ppm}$ (Means et al., 1983).

Analysis of water compositions from the unsaturated-zone tuffaceous rocks (Yang et al., 1988, 1990; Peters et al., 1992) indicates that the water samples have $\mathrm{pH}$ values in the range of 6.4 to 7.5 and that some constituents (i.e., $\mathrm{Ca}^{2+}, \mathrm{K}^{+}, \mathrm{Mg}^{2+}, \mathrm{SO}_{4}{ }^{2-}, \mathrm{Cl}^{-}$, and dissolved silica) are more concentrated than found in samples from the saturated-zone tuffaceous aquifer. However, the average $\mathrm{HCO}_{3}^{-}$content measured in 83 water samples extracted from unsaturated-zone, nonwelded tuff was lower than that for the saturated-zone samples (Peters et al., 1992). Some of this variability may be caused by the extraction techniques used to remove water from unsaturated samples (Peters et al., 1992). No analyses of the dissolved organic content have been given in the studies of the unsaturated-zone fluid compositions. Because of the intimate contact between the unsaturated-zone fluids and the pore gases in the rock, these ground waters are relatively oxidizing.

\subsection{HYDROSTRATIGRAPHY}

As shown in Figure 2.2-3, the lithostratigraphic units may be regrouped into four major hydrogeologic units based largely on the degree of welding (Montazer and Wilson, 1984). This delineation results in a sequence of welded, fractured and low matrix porosity/permeability rocks alternating with nonwelded, poorly fractured, high matrix porosity/permeability rocks, viz.:

- Tiva Canyon welded (TCw) unit: consisting of the moderately- to densely-welded zones of the Tiva Canyon geologic member. This unit is characterized by low matrix porosity $(-10 \%)$, low matrix saturated hydraulic conductivity $\left(-10^{-11} \mathrm{~m} / \mathrm{s}\right)$, and high fracture density $\left(10-20\right.$ fractures $\left./ \mathrm{m}^{3}\right)$.

- Paintbrush nonwelded (PTn) unit: consisting of the lower partially-welded to nonwelded zones of the Tiva Canyon geologic member, partially-welded to nonwelded Yucca Mountain and Pah Canyon members, the porous interlayers of bedded tuffs, and the upper partially-welded to nonwelded part of the Topopah Spring member. This unit is characterized by high matrix porosity $(\sim 40 \%)$, high matrix saturated hydraulic conductivity $\left(\sim 10^{-7} \mathrm{~m} / \mathrm{s}\right)$, and low fracture density $\left(\sim 1\right.$ fracture $\left./ \mathrm{m}^{3}\right)$.

- Topopah Spring welded (TSw) unit: consisting of the welded zones of the Topopah Spring member. This unit is characterized by low matrix porosity $(\sim 10 \%)$, low matrix saturated hydraulic conductivity $\left(\sim 10^{-11} \mathrm{~m} / \mathrm{s}\right)$, and high fracture density $\left(8-40\right.$ fractures $\left./ \mathrm{m}^{3}\right)$. The basal vitrophyre of the Topopah Spring member (TSv) is generally identified as a subunit because of its lower porosity compared to TSw.

- Calico Hills nonwelded (CHn) unit: consisting of the moderately-welded to nonwelded zones of the Topopah Spring member underlying the basal vitrophyre, the partially-welded to nonwelded tuffs of the Calico Hills formation, and other partially-welded to nonwelded tuffs located below the Calico Hills formation (i.e., Prow Pass, Bullfrog and Tram members of the Crater Flat Unit). Portions of the lower Topopah Spring member are vitrified, and zeolitic alteration appears in both the lower part of the Topopah Spring member and in the tuffaceous beds of the Calico Hills, leading to a further division of this 
unit _ into vitric (CHnv) and zeolitic ( $\mathrm{CHnz}$ ) subunits. The fracture density (2-3 fractures $\left./ \mathrm{m}^{3}\right)$ is similar in both zones, and the porosity of the vitric tuffs $(\sim 30 \%)$ is marginally higher than that of the zeolitic tuffs. However, matrix saturated hydraulic conductivity of $\mathrm{CHnv}\left(\sim 10^{-9} \mathrm{~m} / \mathrm{s}\right)$ is roughly two orders of magnitude higher than that of CHnz.

A 3-D hydrostratigraphic model was developed by Wittwer et al., (1995) to provide the framework for the LBL-USGS site-scale model of the unsaturated hydrologic system at Yucca Mountain. Lithologic logs from 34 boreholes, as identified in Figure 2.3-1, were used to define the spatial distribution of the four major hydrogeologic units. Figures 2.3-2 through 2.3-6 show: (i) an isopach map for TCw, (ii) an isopach map for PTn, (iii) an isopach map for TSw, (iv) an isopach map for CHn, and (v) a contour map for the water table. Based on the above information, a northwest-southeast cross-section through the potential repository at Yucca Mountain is shown in Figure 2.3-7.

Although stratigraphic information is also available from such sources as (i) the USGS lithostratigraphic model (Buesch et al., 1995), (ii) a stochastic lithologic model developed in support of SNL's TSPA-1993 activities (Schenker et al., 1995), and (iii) the thermo-mechanical stratigraphic model of Ortiz et al., (1985), the hydrostratigraphic model from Wittwer et al., (1995) was chosen for this study because of the following reasons:

- The latest lithostratigraphic information from the USGS geologic framework model (Buesch et al., 1995) has already been incorporated into the LBL-USGS model.

- A preliminary version of the LBL-USGS site-scale model has been used for performing hydrologic sensitivity analyses and developing hydrologic abstractions in support of this study (Xiang et al., 1995).

- The LBL-USGS model also provides the framework for the site-scale unsaturated-zone transport model being developed at LANL, which will be used as the basis for abstractions of coupled flow and transport in subsequent TSPAs.

\subsection{MATRIX/FRACTURE HYDROLOGIC PROPERTIES}

The LBL-USGS site-scale model uses a 'best-guess' hydrologic parameter set (Wittwer et al., 1995). An alternative, and more comprehensive, set of material properties has been developed by Schenker et al., (1995) in support of Sandia National Laboratory's total system performance assessments (TSPA-1993) for the potential repository at Yucca Mountain (Wilson et al., 1994). This database, which includes the latest available information from ongoing site-characterization activities, consists of ranges and summary statistics associated with matrix and fracture properties for the hydrogeologic units at Yucca Mountain, and is more amenable to uncertainty propagation studies. Therefore, this more comprehensive data set is used as the basis for the unsaturated-flow calculations carried out in support of TSPA-1995. The following paragraphs briefly summarize the information available for the various parameters.

- Matrix bulk density $\left(\rho_{b}\right)$ : Rock bulk-density data are derived from core samples taken from various boreholes, i.e., UE-25a-4/5/6/7, UE-25p\#1, USW UZ-13, USW GU-3, USW 
G-4, UZN-54, UZN-55, USW H-1, UE-25b\#1, J-13, USW G-2, UE-25a\#1, USW GU-3/G3, USW G-1, UE-25a\#3, USW UZ-7; as well as from samples taken from surface transects. Summary statistics of these data for each hydrogeologic unit are presented in Table 2.4-1. These statistics include measurements over the entire range of water saturation, from 0 to 1 .

- Matrix porosity $(\phi)$ : Porosity data are derived from core samples taken from various boreholes, i.e., UE-25a-4/5/6/7, UE-25a\#1, UE-25p\#1, USW GU-3, USW G-4, UZN-54, UZN-55, USW H-1, UE-25b\#1, USW GU-3/G-3, USW UZ-7; as well as from samples taken from surface transects. Summary statistics of these data for each hydrogeologic unit are presented in Table 2.4-2.

- Matrix saturated hydraulic conductivity $\left(\mathrm{K}_{\mathrm{sat}}\right)$ : Saturated hydraulic conductivity data are derived from core samples taken from boreholes USW G-1, UE-25c\#1, UE-25a\#1, UE25a\#6, USW G-4,USW H-1, and UE-25b\#1. Because saturated conductivity is commonly found to be log-normally distributed (Gelhar, 1993), summary statistics of the logtransformed data for each hydrogeologic unit are presented in Table 2.4-3.

- Matrix capillary retention properties: The functional form of van Genuchten (1980) is used to describe the retention function, i.e., the relationship between capillary-pressure head $(\mathrm{h})$ and liquid saturation (S). The van Genuchten (VG) model has the form:

$$
S=S_{r}+\left(1-S_{r}\right)\left[1+\mid \alpha h^{\beta}\right]^{1 / \beta-1}
$$

where $\alpha$ is the VG air-entry parameter, $\beta$ is the VG pore-size distribution parameter, and $S_{\mathrm{r}}$ is the residual liquid saturation. These parameters have been determined by fitting the VG equation to retention functions measured in core samples taken from boreholes USW G-1, USW GU-3, UE-25a\#1, UE-25a\#6, USW G-4, and other samples taken from surface transects. Because $\alpha$ and $\beta$ are commonly found to be log-normally distributed (e.g., Wang and Narasimhan, 1993), summary statistics of the log-transformed data for $\alpha$ and $\beta$, for each hydrogeologic unit, are presented in Table 2.4-4 and Table 2.4-5, respectively.

The residual saturation, $S_{r}$, is known to be an ill-determined fitting parameter (van Genuchten and Nielsen, 1985), and hence, the arithmetic average for each hydrogeologic unit is used as a surrogate representative value. Following Schenker et al., (1995), these values have been determined to be as follows: TCw $-0.021, \mathrm{PTn}-0.154$, TSw -0.045 , TSv - 0.118, CHnv - 0.097 and CHnz - 0.121.

- Bulk rock permeability $\left(\mathrm{K}_{\text {bulk }}\right)$ : Bulk saturated hydraulic-conductivity and air-permeability data are derived from pump tests and/or barometric-pumping data in boreholes USW G-4, USW H-1, USW H-3, USW H-4, UE-25b\#1, UE-25p\#1, J-13, USW UZ-1, UE-25a\#4 and UZ-16. In some cases, permeability values for units with sparse measurements have been inferred from measured permeability values of lithologically similar units (Schenker et al., 1995). The bulk permeability represents the transmissive potential of the combined matrixfracture system in general, and the permeability to vapor migration through the fracture network, in particular. However, given the paucity of bulk-permeability data it was decided to use only the geometric-mean value, rather than a statistical distribution, for 
characterizing bulk permeability of various hydrogeologic units. These values are tabulated in Table 2.4-6.

- Fracture hydrologic properties: Based on fracture-density frequency data available from boreholes USW G-1, USW GU-3, USW G-4, UE-25a\#1, as well as the bulk-rock permeability information described above, Schenker et al., (1995) derived such fracture properties as spacing, porosity, VG air-entry parameter, aperture, angle/orientation, and saturated hydraulic conductivity for each hydrogeologic unit. Given the uncertainty associated with such derived parameters (in as much as geometric fracture density is commonly found to be weakly correlated with hydraulic properties), it was decided to use a single set of values to characterize fracture properties for all units. These values, which are similar to the ones recommended for the fractures by Klavetter and Peters (1986), are also presented in Table 2.4-6.

\subsection{REGIONAL HYDROGEOLOGY AND GROUND-WATER USE}

\subsubsection{Regional Hydrogeology}

The regional ground-water flow system in the vicinity of the Yucca Mountain site encompasses several topographic basins and ground-water basins. Interbasin flow is common and important with respect to the total volume of water transferred within the system boundaries. The lengths of regional ground-water flow paths are relatively large when compared to those of "local" flow systems (Mifflin and Hess, 1979). The Hydrologic Study Area is defined as that portion of the regional-flow system that is of interest in defining the potential transport path to ground-water users downgradient from a repository at Yucca Mountain (Figure 2.5-1). The study area consists of three ground-water sub-basins; Oasis Valley, Alkali Flat/Furnace Creek Ranch, and Ash Meadows (Figure 2.5-1). Also shown on Figure 2.5-1 are the State-of-Nevada hydrographic areas used by the State Engineer as a basis for estimation of perennial ground-water yield. A summary for estimates of annual ground-water inflow, recharge, and outflow of these hydrographic areas is given in Table 2.5-1.

Figure 2.5-2 shows the major inflows and outflows of the three ground-water sub-basins in the hydrogeologic study area. The flow southward from Yucca Mountain in the Alkali Flat/Furnace Creek Ranch sub-basin is about 8 acre-ft/yr $\left(10,000 \mathrm{~m}^{3} / \mathrm{yr}\right)$ based on the outflow from the Jackass Flat and Buckboard Mesa hydrographic areas (Table 2.5-1). The northwestward flow from the Amargosa Desert sub-basin is about 20 acre-ft/yr $\left(25,000 \mathrm{~m}^{3} / \mathrm{yr}\right.$ ) (Table $\left.2.5-1\right)$. These two components of flow are strongly influenced by ground-water withdrawal, and both flows are toward the location of heavy withdrawal to the south and west of the town of Amargosa Valley.

The ground-water flow from Yucca Mountain is generally south to southeast as indicated by the potentiometric surface of the ground-water table of the Amargosa Desert (Figure 2.5-3). A schematic cross section of the flow system between Yucca Mountain and Eagle Mountain is presented in Figure 2.5-4. The flow system can be generalized to consist of recharge at the higher elevations just north of Yucca Mountain, flow through the hydrogeologic units to the south and southeast, and discharge through both evapotranspiration at: Franklin Lake Playa and flow into other ground-water sub-basins (i.e., Death Valley). 


\subsubsection{Ground-Water Use}

The Yucca Mountain Site is located within the Alkali Flat/Furnace Creek Ranch sub-basin between Crater Flat and Jackass Flat and to the north of the Amargosa Desert (Figure 2.5-1). Very little ground water is withdrawn in the northern and central parts of this sub-basin. In addition, very little ground water has been appropriated to the north of Yucca Mountain (upgradient) according to information filed with the Nevada State Engineer's Office.

The major ground-water users in the area, the town of Amargosa Valley and small rural communities of the northeastern Amargosa Desert, are located in the southwestern portion of the Alkali Flat/Furnace Creek Ranch sub-basin (Figure 2.5-5). Figure 2.5-5 indicates the location of major ground-water users as areas of heavy withdrawal. Most of the water is supplied by wells; however, there has been development of some springs. Most residences rely on individual wells, while some trailer parks, public facilities, and commercial establishments are served by small, private water companies. Table 2.5-2 summarizes the public water suppliers in the area, the type of well used, and the population served. All of these wells are completed in, and produce from, the valley-fill aquifer.

Two mineral production operations are located in the Amargosa Desert. One operation, owned by the American Borate Corporation, located between Amargosa Valley, Nevada, and Death Valley Junction, California, was decommissioned in July, 1986. The facility consisted of a large mineral processing plant and a housing development for its employees (French et al., 1984). The other operation is owned by IMV Division of Floridin, Inc. and is also located between Amargosa Valley, Nevada and Death Valley Junction, California. This operation employs approximately 53 people to mine specialty clays (Nevada Bureau of Mines and Geology, 1993).

In addition to well production, a number of springs supply water to the region. The main concentration of springs is in Death Valley in the vicinity of Furnace Creek Ranch, approximately 50 to $60 \mathrm{~km}$ southwest of the Yucca Mountain Site (Figure 2.5-5). Many points of ground-water discharge have been identified in the Death Valley National Park in California (Winograd and Thordarson, 1975). The water supply for the National Park Service facilities is derived principally from three groups of springs: Travertine Springs, Texas Springs, and Nevares Springs (French et al., 1984). The population served by this water supply varies during the year. From October through April, approximately 800 persons live in the area on a semipermanent basis, and an additional 2,000 persons live in the area as visitors. From May through September, the number of semipermanent residents decreases, and there are few visitors (French et al., 1984).

Water use within the Alkali Flat/Furnace Creek Ranch sub-basin occurs primarily in the Amargosa Desert (shown as hydrographic area 230 in Figure 2.5-1). The perennial yield to this hydrographic area is estimated to be $2.96 \times 10^{7} \mathrm{~m}^{3} / \mathrm{yr}$ (French et al., 1984). An estimated $2.10 \times 10^{7} \mathrm{~m}^{3} / \mathrm{yr}$ of this total is naturally discharged from springs and seeps in the Ash Meadows area (French et al., 1984), and nearly 10,000 acre-ft/yr $\left(1.23 \times 10^{7} \mathrm{~m}^{3} / \mathrm{yr}\right)$ is artificially discharged from wells in the Amargosa Valley (Coache, 1986). Thus, an overdraft of $3.70 \times 10^{6} \mathrm{~m}^{3} / \mathrm{yr}$ currently exists. Water levels in wells drilled in the valley-fill aquifer declined an average of $3.75 \mathrm{~m}$ between 1963 and 1984 (Nichols and Akers, 1985). Total appropriations in 1985 were over $8.64 \times 10^{7} \mathrm{~m}^{3} / \mathrm{yr}$. If these rights to appropriate water were exercised, rapid depletion of the valley-fill aquifer would result. 
Crater Flat (hydrographic area 229 in Figure 2.5-1) is currently overdrawn because of an appropriation made to Saga Exploration, Inc. for the development of the Sterling Mine, a gold deposit, located on the east side of Bare Mountain. The mine uses its own well for its heap-leach operation and relies on municipal water for its potable water. The mine employs approximately 40 individuals, and is expected to be in operation until 1997 or 1998 . Although an overdraft exists, no protective measures will be taken because the water has been appropriated for mining, which is considered a preferred use under the Nevada Revised Statutes. Under these Nevada statutes, overdrafts for mining are allowable for periods not to exceed five years.

\subsection{UNSATURATED ZONE HYDROLOGY}

\subsubsection{Flow Dynamics}

The ground-water-flow regime through the partially-saturated tuffaceous rocks at Yucca Mountain is controlled by the hydrologic characteristics, including the heterogeneity and spatial variability, of the hydrostratigraphic units identified in Section 2.3. Because of the large disparity in capillary suction between fracture and matrix, pore water in the unsaturated zone is bound mostly in the matrix. Average annual precipitation at Yucca Mountain is estimated to be approximately 170 millimeters per year, of which only a very small fraction becomes net infiltration. Precipitation occurs during a few intense storms. Surface runoff is infrequent and of short duration, and no perennial streams exist in the area. Water infiltrates principally into the Tiva Canyon welded (TCw) unit, but also into the Paintbrush nonwelded (PTn) unit and Topopah Spring welded (TSw) unit where they are exposed at the land surface.

The qualitative description of the unsaturated-zone flow dynamics presented here is based on the conceptual hydrologic flow model of Montazer and Wilson (1984), and is shown schematically in Figure 2.6-1. Eastward lateral flow occurs within the P'Tn unit and above its upper contact. The lateral flow is intercepted by structural features, which transmit most of the infiltrated water vertically to the water table. Percolation through the matrix occurs principally vertically in the welded units and both laterally and vertically in the nonwelded units. Fracture flow is predominant in the $\mathrm{TCw}$ unit during intense pulses of infiltration and is insignificant in the TSw unit except near the upper contact and near structural features. Temporary development of perched water bodies is possible within and above the nonwelded units near structural features. This water drains into the structural flow paths and much of it travels directly to the water table.

\subsubsection{Infiltration Pattern and Rate}

The overall flow regime and the distribution of percolation flux (i.e., the flux that passes the root zone and is no longer susceptible to evapotranspiration processes) is controlled by the infiltration rate through the surficial layers. Quantification of the infiltration rate at arid sites has been the focus of numerous scientific investigations over the past decade. An excellent review of infiltration studies associated with arid hydrology is found in Scanlon (1995). Such investigations have intensified due to both the desire to develop ground-water resources in these environments and the effort to evaluate these environments for the potential disposal of wastes. In the United States potential waste-disposal sites in arid environments have been investigated in Texas (the potential West Texas low-level radioactive waste-disposal facility at Eagle Flat), California (the potential Ward Valley low-level radioactive waste-disposal facility), and Nevada (the Greater 
Confinement Area in Beatty and the potential repository for high-level radioactive waste at Yucca Mountain). In each of these instances, understanding and bounding the possible infiltration rate has been a key component of the scientific investigations into the suitability of the planned facility.

Because no direct observations of infiltration are possible, infiltration rate is always a derived parameter. In general, infiltration rate is obtained from other observations or inferred from process-level models which attempt to capture the relevant factors and quantify the effect of these factors on the net infiltration. An analogous situation exists in saturated-zone investigations where the advective flux is not directly measured (with the possible exception of point measurement of borehole dilution), but is inferred from potentiometric observations and hydrogeologic properties. Numerous variables affect the prediction of the net infiltration rate of water in arid climates. These variables include (1) surficial soil texture, including the possible existence of preferential pathways such as fractures or root tubules, (2) vegetation, (3) topography, and (4) climate, including the timing, intensity and duration of precipitation events (Scanlon, 1995). Greater infiltration rates are associated with coarse-grained surficial soils, areas with bare soil instead of vegetated soil (with the exception that preferential flow may occur along plant-root systems), topographic lows where water may pond intermittently, and precipitation events in the winter (due to a lower potential for evapotranspiration) (Scanlon, 1995).

The general factors identified above are directly applicable to the quantification of net infiltration over the surface of the Yucca Mountain area and are the focus of ongoing scientific investigations. The recent status of the Yucca Mountain Site Characterization Project Office studies on shallow infiltration measurements and their interpretations have been summarized by Flint (1995). The key variables noted by Flint in the estimation of total infiltration include: (1) the depth of the alluvial cover overlying the bedrock, (2) the hydrologic characteristics of the bedrock including matrix porosity and fracture intensity and connectivity, (3) the topographic position providing differences in radiation load, slope, runoff and run-on, and (4) the time of the precipitation events.

Although revised estimates of the spatial distribution of infiltration over the Yucca Mountain area and the associated uncertainty and variability in these estimates are expected to be provided to the Project early in Fiscal Year 1996, the existing interpretations are based on assumed matrix-driven flow processes. The present interpretations (documented in Flint and Flint, 1994) utilize quasisteady-state soil-moisture profiles developed from neutron logs in approximately 100 shallow boreholes combined with laboratory-derived moisture retention curves. These characteristics curves relate moisture content to effective permeability using an assumed unit hydraulic gradient. By combining these observations and assumptions, it is possible to infer the magnitude of infiltration.

Due to the highly nonlinear nature of the characteristic curves at low liquid saturations, extrapolation of effective permeability is very uncertain in this region. This uncertainty is compounded by the large spatial variability and/or uncertainty in the properties of the tested samples (see Section 2.4). Based on the above approximations, Flint and Flint (1994) generated a matrix infiltration map (reproduced as Figure 2.6-2) defining the spatial distribution of estimated infiltration rates primarily based on the outcropping lithologic unit. This map only partially includes the potential effects of slope and soil cover, which would be expected to modify substantially this distribution (especially in areas of steep slope such as along the western 
escarpment of Yucca Crest to the east of the Solitario Canyon fault). This distribution of infiltration rates has been incorporated in the site-scale model of the unsaturated zone recently documented in Wittwer et al (1995). Revisions to this moclel based on revised estimates of the infiltration rate are expected in Fiscal Year 1996 and should be available in time for inclusion in the next iteration of total system performance assessment.

In order to test the sensitivity of the total system performance to uncertainties in the ambient infiltration rate (and the resulting percolation flux) a series of process-level calculations have been conducted covering a range of values. The process-model results and corresponding abstractions are presented in Chapter 7.

\subsection{POTENTIAL NATURAL CHANGES TO THE AMBIENT GEO-ENVIRONMENT}

\subsubsection{Climatic Effects}

The ambient hydrologic conditions in the Yucca Mountain region are characterized by extremely low precipitation (generally concentrated in the winter months) and very high potential evapotranspiration rates (concentrated in the summer months). Numerous ongoing studies sponsored by the DOE and NRC have indicated that the climate has remained essentially uniform over the past several thousand years and may change to a slightly wetter and cooler period over the next 10,000 years. The general effects of such a potential climate change on the net infiltration amount are uncertain because of the complex interrelation between precipitation and vegetation (e.g, increased precipitation yields the potential for increased infiltration, but the presumed increase in transpiration due to the presence of more vegetation may offset that increase). However, observations at Rainier Mesa suggest that for increased precipitation levels, there is a significant increase in net infiltration (this observation does not account for the fact that the topography at Rainier Mesa is much flatter than at Yucca Mountain). In summary, there is little quantitative information on the direct (i.e, infiltration-rate change) or indirect (i.e., watertable rise) effects potentially associated with climate change. [Note: A major deliverable on this topic is expected to be completed by the end of Fiscal Year 1996.]

\subsubsection{Volcanic Effects}

Two tasks are planned to support the inclusion of volcanism effects into TSPA-1995. The first includes: (1) simulation modeling of the probability of magmatic intersection of specified areas (area of the potential repository, controlled area, and surrounding areas of the Yucca Mountain region), (2) assessment of spatial models of the distribution of basaltic volcanic centers, and (3) review of published volcanism probability models by the State of Nevada. The second task is modeling, using the RIP code, the radiological releases associated with direct penetration of a repository by basalt magma that subsequently erupts at the surface. The scope and objectives of these tasks are described below.

As part of the first task described above, spatial simulation modeling has been conducted using the FRACMAN computer code to estimate the probability of magmatic disruption for specific areas associated with the Yucca Mountain site. The simulation uses the set of alternative spatial and structural models described in the volcanism status report (Crowe et al., 1995). For each spatial and structural model, simulations have been run using three sets of feeder systems for 
basaltic volcanic centers. These sets are: (1) simple linear feeder dikes, (2) linear feeder dikes with associated plug-like intrusive masses (conduit plug, radial and concentric dikes), and (3) linear feeder dikes with associated plugs and sill-like intrusions. The dimensions of the basalt feeder systems have been developed from literature references and from analog studies of eroded basalt centers. The orientations of the basalt feeder systems have been established using constraints from the local stress field, orientation of basalt centers and cone alignments, and predictions/observations of the spatial geometry imposed by individual spatial or structural models. The simulations record the number of penetrations of specified areas, the probability of penetration, the projected area of penetration, and the projected volume of penetration. Data from these simulations have been used to refine the disruption ratio of the variable E2 in estimating the occurrence probability of magmatic disruption of the repository and associated areas. These data will be used to revise the probabilistic-volcanic-hazard assessments of Crowe et al. (1995). A second application of the results from simulation modeling would be as input for studies of the subsurface effects of magmatic disruption of the potential repository.

A review of published models for the spatial distribution of volcanic centers in the Yucca Mountain region has been conducted (Crowe et al., 1995). This review assesses the strengths and weaknesses of existing models, emphasizing stationary and nonstationary distribution models, and also evaluate ranges of alternative distribution models that could be applied to the record of PlioQuaternary volcanic centers in the Yucca Mountain region. The review is emphasizes the impact of different spatial distribution models on probabilistic volcanic hazard assessment.

A brief review by the State of Nevada of published probability models has been completed, emphasizing assessment of homogeneous and nonhomogeneous models and the application of methods of Bayesian statistics to probabilistic volcanic hazard assessment.

If the occurrence probability of direct disruption of a repository by future volcanic activity is $<10^{-8} \mathrm{yr}^{-1}$, the risk of future volcanism would be judged not to be a disqualifying issue. The most current estimates of the occurrence probability for direct disruption of the potential repository are about 1-3 x 10 $0^{-8} \mathrm{yr}^{-1}$ (Crowe et al., 1995). After the conclusion of the Los Alamos volcanism task, DOE was advised that release calculations will need to include estimates for eruptive releases from direct magmatic penetration of the potential repository (pending possible changes in $40 \mathrm{CFR}$ Part 191). The purpose of this task is to initiate that work, building on volcanism studies completed as part of performance assessments.

Volcanic scenarios have been developed for: (1) the geometry of basaltic feeder systems, (2) the induced changes in the rocks immediately surrounding basaltic feeder systems, (3) the incorporation of radioactive waste in magma, and (4) the dispersal of that waste in basaltic eruptions. Parameters identified from these scenarios are used as inputs into the RIP computer code to assess the changes in the nominal-case releases for a potential repository system at Yucca Mountain. The eruption simulations have been used to identify the most critical input parameters. These parameters will be reassessed through ongoing scientific investigations and the refined parameters will be used in future computer simulations of cumulative releases. The goal of this iterative work is to assess the significance of future volcanic events on the long-term performance of a repository. If eruptive releases are insignificant with respect to the base case repository performance, studies of the eruptive effects will be terminated and future work will focus on the subsurface effects of future volcanism (perturbation of the repository system). If the eruptive 
releases are significant with respect to nominal-case performance, enhanced studies of eruption dynamics will be conducted to constrain more carefully the predictions of total radiological releases and to clarify the mechanisms of dispersal of radioactive waste in basaltic eruptions.

\subsubsection{Tectonic Effects}

Gauthier et al. (1995) recently presented an evaluation of the effects of potential seismic activity on the release of radionuclides from a potential repository at Yucca Mountain. Future seismic events were predicted using data from seismic hazard analysis conducted for the Exploratory Studies Facility (ESF). Several phenomenological models were developed, including rockfall in unbackfilled emplacement drifts, container damage caused by fault displacement within the repository, and flow-path change caused by changes in strain. Total system release over a 10,000 year period was evaluated using the total system simulator TSA (Wilson et al., 1994) with a composite-porosity flow model (relatively large-scale, regular percolation), as well as the weeps model (episodic pulses of flow in locally saturated fractures). For the composite-porosity model, seismic events showed little effect on total-system release, whereas for the weeps model, container damage and flow-path changes cause over an order of magnitude increase in releases. In separate calculations using more realistic representations of faulting, water-table rise caused by seismically induced changes was found to be insufficient to reach a potential repository.

These calculations suggest that the consequences of potential seismic activity on total-system performance (i.e., release to accessible environment) are negligible. 
Table 2.4-1. Summary Statistics for Matrix Bulk Density $\left(\rho_{b}\right)$

\begin{tabular}{||c|c|c|c|c|c||}
\hline \multirow{2}{*}{ UNIT } & \multirow{2}{*}{$\begin{array}{c}\text { Number of } \\
\text { samples }\end{array}$} & $\mathbf{E}(\mathbf{x})$ & \multirow{2}{*}{$\mathbf{S D}(\mathbf{x})$} & Minimum & Maximum \\
\cline { 3 - 3 } & & $\left(\mathbf{k g} / \mathbf{m}^{3}\right)$ & & $\left(\mathbf{k g} / \mathbf{m}^{3}\right)$ & $\left(\mathbf{k g} / \mathbf{m}^{3}\right)$ \\
\hline \hline TCW & 380 & 2285 & 114.2 & 1410 & 2420 \\
\hline PTn & 268 & 1419 & 279.5 & 850 & 2420 \\
\hline TSw & 750 & 2247 & 134.8 & 1360 & 2710 \\
\hline TSv & 59 & 2308 & 60.0 & 2090 & 2400 \\
\hline CHnv & 199 & 1737 & 290.1 & 1050 & 2280 \\
\hline CHnz & 198 & 1746 & 192.1 & 1300 & 2230 \\
\hline
\end{tabular}

Table 2.4-2. Summary Statistics for Matrix Porosity $(\phi)$

\begin{tabular}{|c|c|c|c|c|c||}
\hline \hline Unit & $\begin{array}{c}\text { Number of } \\
\text { samples }\end{array}$ & $\mathbf{E}(\mathbf{x})$ & $\mathbf{S D}(\mathbf{x})$ & Minimum & Maximum \\
\hline \hline TCw & 290 & 0.087 & 0.055 & 0.033 & 0.450 \\
\hline PTn & 205 & 0.421 & 0.104 & 0.132 & 0.650 \\
\hline TSw & 300 & 0.139 & 0.057 & 0.004 & 0.480 \\
\hline TSv & 26 & 0.065 & 0.043 & 0.014 & 0.177 \\
\hline CHnv & 117 & 0.331 & 0.090 & 0.097 & 0.510 \\
\hline CHnz & 127 & 0.306 & 0.064 & 0.141 & 0.470 \\
\hline
\end{tabular}


Table 2.4-3. Summary Statistics for Matrix Saturated Conductivity $\left(\mathrm{K}_{\text {sat }}\right)$

\begin{tabular}{|c|c|c|c|c|c||}
\hline \multirow{2}{*}{ UNIT } & \multirow{2}{*}{$\begin{array}{c}\text { Number of } \\
\text { samples }\end{array}$} & $\mathbf{E}(\mathbf{x})^{\mathbf{1}}$ & \multirow{2}{*}{$\mathbf{S D}(\mathbf{x})^{2}$} & Minimum & Maximum \\
\cline { 3 - 3 } \cline { 5 - 6 } & & $(\mathrm{m} / \mathbf{s})$ & & $(\mathrm{m} / \mathbf{s})$ & $(\mathbf{m} / \mathbf{s})$ \\
\hline \hline TCw & 14 & $1.3 \mathrm{E}-11$ & 1.07 & $7.0 \mathrm{E}-13$ & $4.8 \mathrm{E}-09$ \\
\hline $\mathrm{PTn}$ & 12 & $1.1 \mathrm{E}-08$ & 2.40 & $2.9 \mathrm{E}-12$ & $2.4 \mathrm{E}-06$ \\
\hline $\mathrm{TSw}$ & 66 & $2.0 \mathrm{E}-11$ & 0.90 & $3.1 \mathrm{E}-13$ & $5.2 \mathrm{E}-09$ \\
\hline $\mathrm{TSv}$ & 7 & $1.0 \mathrm{E}-11$ & 0.68 & $1.5 \mathrm{E}-12$ & $6.9 \mathrm{E}-11$ \\
\hline $\mathrm{CHnv}$ & 44 & $1.0 \mathrm{E}-09$ & 1.03 & $5.1 \mathrm{E}-13$ & $2.9 \mathrm{E}-07$ \\
\hline $\mathrm{CHnz}$ & 51 & $1.6 \mathrm{E}-11$ & 1.00 & $2.4 \mathrm{E}-14$ & $3.1 \mathrm{E}-09$ \\
\hline
\end{tabular}

1 Geometric Mean

2 Standard deviation of $\log _{10}\left(\mathrm{~K}_{\mathrm{sat}}\right)$

Table 2.4-4. Summary Statistics for Matrix VG Air-Entry Parameter ( $\alpha$ )

\begin{tabular}{|c|c|c|c|c|c||}
\hline \multirow{2}{*}{ UNIT } & \multirow{2}{*}{$\begin{array}{c}\text { Number of } \\
\text { samples }\end{array}$} & $\mathbf{E}(\mathbf{x})^{\mathbf{1}}$ & \multirow{2}{*}{$\mathbf{S D}(\mathbf{x})^{\mathbf{2}}$} & Minimum & Maximum \\
& & $(\mathbf{1} / \mathbf{m})$ & & $(\mathbf{1} / \mathbf{m})$ & $(\mathbf{1} / \mathbf{m})$ \\
\hline \hline TCw & 19 & 0.0081 & 0.68 & 0.0003 & 0.1338 \\
\hline $\mathrm{PTn}$ & 43 & 0.0735 & 0.72 & 0.0104 & 1.6690 \\
\hline TSw & 51 & 0.0130 & 0.50 & 0.0021 & 0.4224 \\
\hline TSv & 10 & 0.0024 & 0.44 & 0.0002 & 0.0077 \\
\hline CHnv & 24 & 0.0227 & 0.50 & 0.0054 & 0.3752 \\
\hline CHnz & 50 & 0.0054 & 0.62 & 0.0004 & 0.2355 \\
\hline
\end{tabular}

1 Geometric mean

2 Standard deviation of $\log _{10}(\alpha)$ 
Table 2.4-5. Summary Statistics for Matrix VG Pore-Size Distribution Parameter ( $\beta$ )

\begin{tabular}{||c|c|c|c|c|c||}
\hline UNIT & $\begin{array}{c}\text { Number of } \\
\text { samples }\end{array}$ & $\mathbf{E}(\mathbf{x})^{1}$ & $\mathbf{S D}(\mathbf{x})^{\mathbf{2}}$ & Minimum & Maximum \\
\hline \hline $\mathrm{TCw}$ & 19 & 1.607 & 0.053 & 1.349 & 2.085 \\
\hline $\mathrm{PTn}$ & 43 & 2.223 & 0.225 & 1.187 & 11.80 \\
\hline $\mathrm{TSw}$ & 51 & 1.710 & 0.122 & 1.155 & 5.363 \\
\hline $\mathrm{TSv}$ & 10 & 2.234 & 0.188 & 1.377 & 4.473 \\
\hline $\mathrm{CHnv}$ & 24 & 2.361 & 0.229 & 1.249 & 9.888 \\
\hline $\mathrm{CHnz}$ & 50 & 1.671 & 0.120 & 1.184 & 5.914 \\
\hline
\end{tabular}

1 Geometric mean

2 Standard deviation of $\log _{10}(\beta)$

Table 2.4-6. Bulk Permeability and Fracture Hydrologic Properties

\begin{tabular}{||l|l|}
\hline \multicolumn{1}{|c|}{ Parameter } & \multicolumn{1}{|c|}{ Value } \\
\hline \hline Bulk permeability, $\mathrm{K}_{\text {bulk }}(\mathrm{m} / \mathrm{s})$ & $\begin{array}{l}1.8 \mathrm{E}-5 \quad \text { (TCw, TSw, TSv) } \\
\text { (PTn, CHnv) } \\
\text { (CHnz) }\end{array}$ \\
\hline Porosity, $\phi(-)$ & $1.2 \mathrm{E}-6 \quad$ (.00E-3 \\
\hline VG air-entry parameter, $\alpha(1 / \mathrm{m})$ & 10 \\
\hline VG pore-size distribution parameter, $\beta(-)$ & 5 \\
\hline Residual saturation, $\mathrm{S}_{\mathrm{r}}(-)$ & 0 \\
\hline
\end{tabular}


Table 2.5-1. Summary Estimates of Annual Ground-Water Inflow, Recharge, and Outflow in thousands of acre-feet per year

\begin{tabular}{||l|c|c|c|l||}
\hline \multicolumn{1}{|c|}{ Unit } & $\begin{array}{c}\text { Sub- } \\
\text { surface } \\
\text { Inflow }\end{array}$ & $\begin{array}{c}\text { Local } \\
\text { Recharge }\end{array}$ & $\begin{array}{c}\text { Sub- } \\
\text { Surface } \\
\text { Outflow }\end{array}$ & \multicolumn{1}{|c|}{ Source of Estimates } \\
\hline \hline Amargosa Desert & 20 & 2 & 20 & Walker and Eakin, 1963 \\
\hline Crater Flat & 2 & 0 & 2 & Rush, 1970; Rush et al., 1971 \\
\hline Emigrant & 0 & 3 & 3 & Rush, 1970; Rush et al., 1971 \\
\hline Indian Springs & 22 & 10 & 32 & Rush, 1970; Rush et al., 1971 \\
\hline $\begin{array}{l}\text { Jackass Flat and } \\
\text { Buckboard Mesa }\end{array}$ & 6 & 2 & 8 & Rush, 1970; Rush et al., 1971 \\
\hline Mercury and Rock & 33 & 0 & 33 & Rush, 1970; Rush et al., 1971 \\
\hline Pahrump & 0 & 42 & 18 & Harrill, 1986 \\
\hline Three Lakes & 5 & 8 & 13 & Rush, 1970; Rush et al., 1971 \\
\hline Tikaboo & 6 & 6 & 12 & $\begin{array}{l}\text { Rush, 1970; Winograd and } \\
\text { Friedman, 1972 }\end{array}$ \\
\hline $\begin{array}{l}\text { Yucca and } \\
\text { Frenchman Flats }\end{array}$ & 32 & 1 & 33 & Rush, 1970; Rush et al., 1971 \\
\hline
\end{tabular}


Table 2.5-2. Public Water Suppliers in the Community of Amargosa Valley, for wells located in the southern portion of the Alkali Flat/Furnace Creek Ranch sub-basin and in the southwestern portion of the Ash Meadows sub-basin

\begin{tabular}{||l|l|c|}
\hline \multicolumn{1}{|c|}{ Supplier } & \multicolumn{1}{|c|}{ Type } & Population Served \\
\hline \hline American Borate Trailer Park & Community & 300 \\
Amargosa Water Company (IMV) & Community & 45 \\
Embrey's Trailer Park & Community & 45 \\
Mountain View Apartments and & Community & 75 \\
Shopping Center & & \\
Amargosa Elementary School & Single User & a \\
Amargosa Senior Citizen's Center & Single User & a \\
Coach House Bar & Single User & a \\
Roadside Park 801NY & Single User & a \\
Water-N-Hole & Single User & a \\
\hline
\end{tabular}

${ }^{a}$ In general these systems serve a transient population of at least 25 persons per day. 

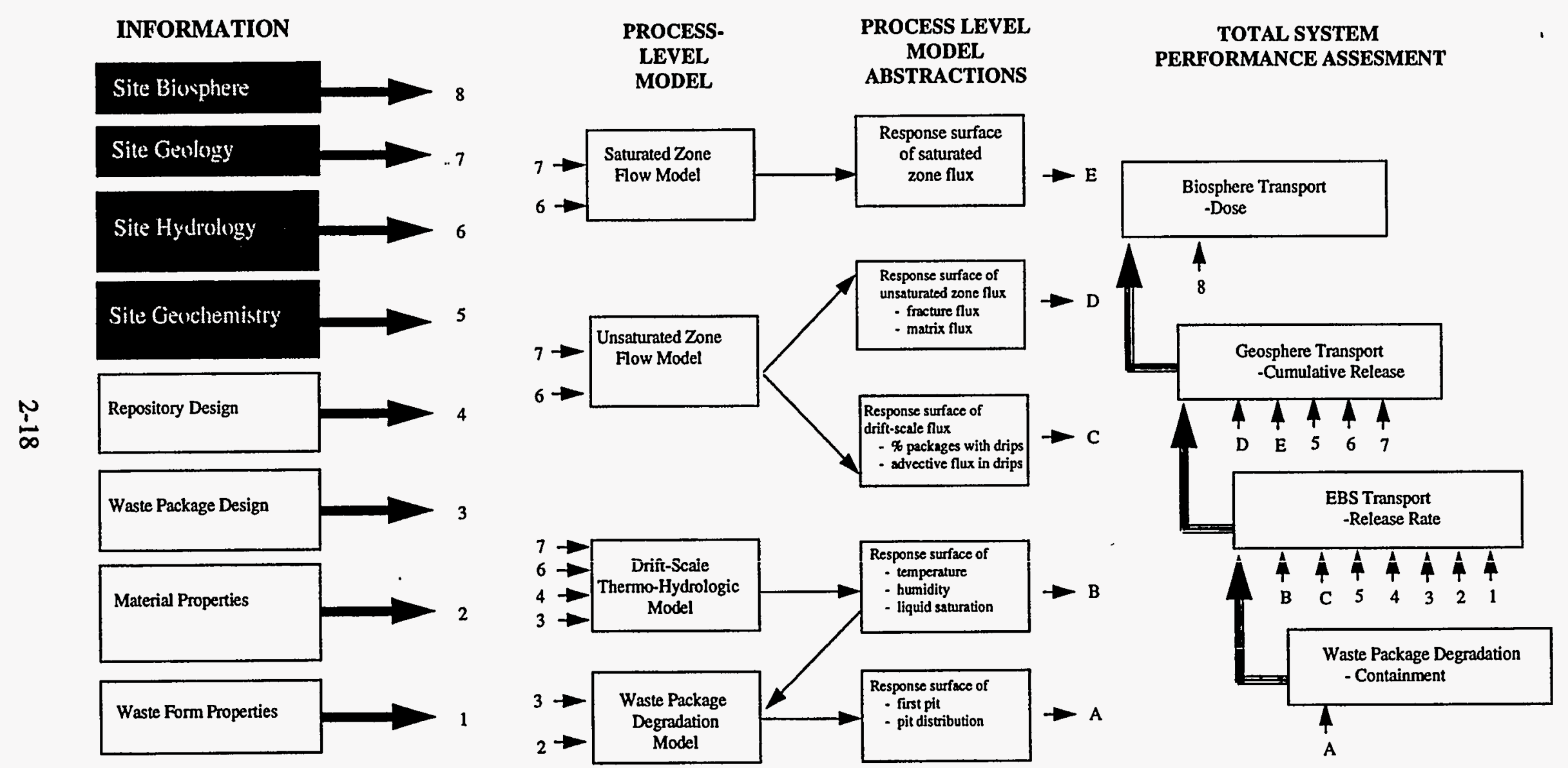

Figure 2.1-1 Relationship of Chapter 2 to the Overall Information Flow Diagram for TSPA 1995 (Figure 1.4-6) 


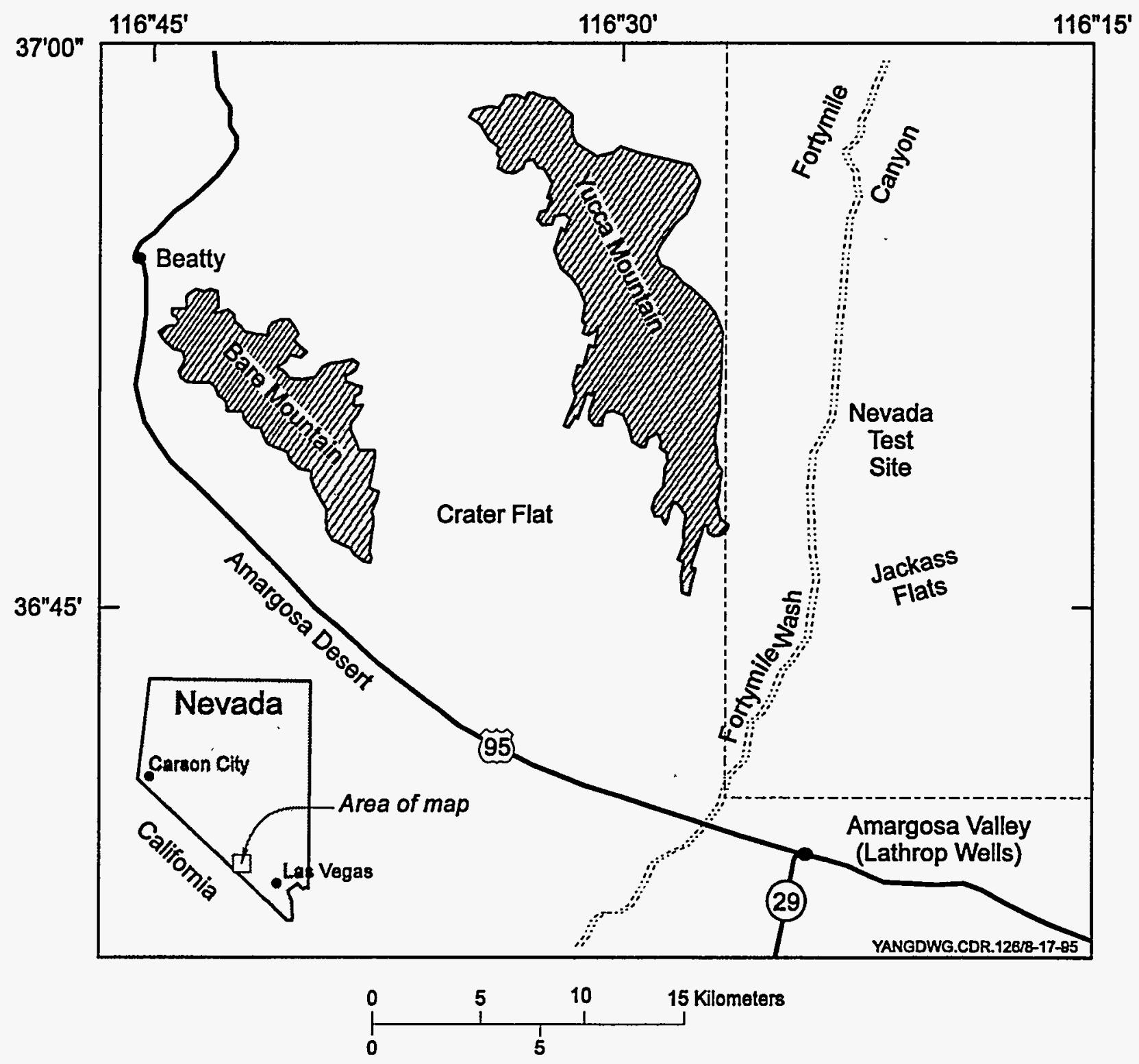

Figure 2.2-1 Location of the Yucca Mountain Area (modified from Montazer and Wilson, 1984) 


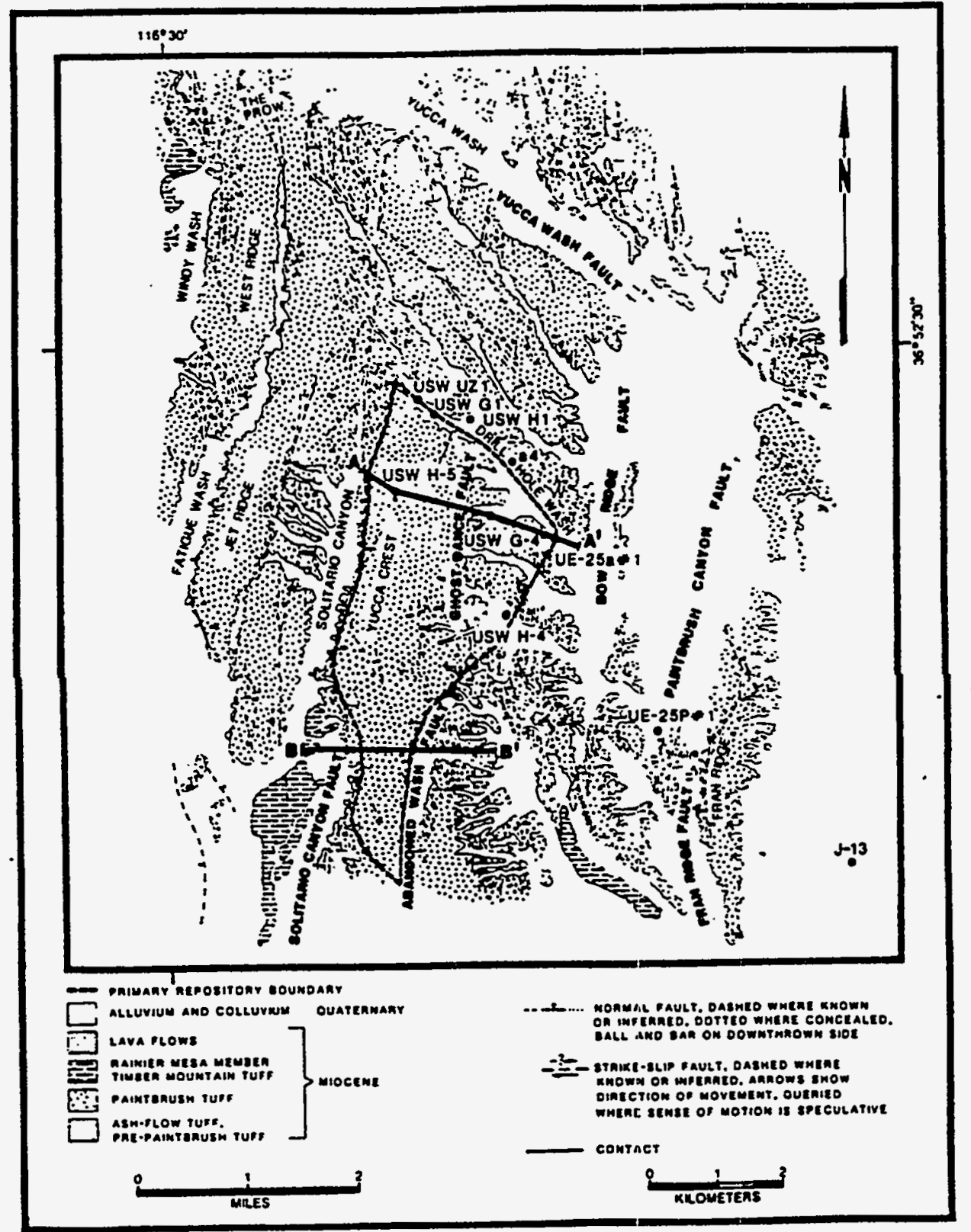

Figure 2.2-2 Geologic map of Yucca Mountain (from Hoxie, 1989) 


\begin{tabular}{|c|c|c|c|}
\hline & $\begin{array}{l}\text { GEOLOGICAL } \\
\text { UNIT }\end{array}$ & LITHOLOGY & $\begin{array}{l}\text { HYDRO- } \\
\text { GEOLOGICAL } \\
\text { UNIT }\end{array}$ \\
\hline & $\begin{array}{l}\text { Tiva Canyon } \\
\text { Member }\end{array}$ & $\begin{array}{l}\text { densely welded tuff } \\
\text { moderately welded tuff }\end{array}$ & TIVA CANYON \\
\hline & & $\begin{array}{l}\text { partially welded tuff } \\
\text { nonwelded tuff } \\
\text { bedded tuff }\end{array}$ & \\
\hline 官 & $\begin{array}{l}\text { Yucca Mountain } \\
\text { Member }\end{array}$ & $\begin{array}{l}\text { non- to moder. welded tuff } \\
\text { bedded tuff }\end{array}$ & PAINTBRUSH \\
\hline 爱 & $\begin{array}{l}\text { Pah Canyon } \\
\text { Member }\end{array}$ & $\begin{array}{l}\text { non- to moder. welded tuff } \\
\text { bedded tuff }\end{array}$ & \\
\hline 学 & Topopah Spring & non- to partially welded tuff & \\
\hline & & $\begin{array}{l}\text { moder. to densely welded tuff } \\
\text { densely welded tuff } \\
\text { basal vitrophyre }\end{array}$ & $\begin{array}{l}\text { TOPOPAH } \\
\text { SPRING }\end{array}$ \\
\hline & & moder. to partially welded tuff & \\
\hline & ICO HILLS FORMATION & $\begin{array}{l}\text { bedded tuff } \\
\text { non- to partially welded tuff }\end{array}$ & \\
\hline 过 & $\begin{array}{l}\text { Prow Pass } \\
\text { Member }\end{array}$ & $\begin{array}{l}\text { non-to partially welded tuff } \\
\text { bedded tuff }\end{array}$ & CALICO HILLS \\
\hline 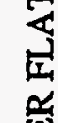 & Bullfrog Member & $\begin{array}{l}\text { non- to densely welded tuff } \\
\text { bedded tuff }\end{array}$ & \\
\hline శ્ય & Tram Member & non- moder. to welded tuff & \\
\hline
\end{tabular}

Figure 2.2-3 Lithology of Major Stratigraphic Units at Yucca Mountain (after Montazer and Wilson, 1984) 


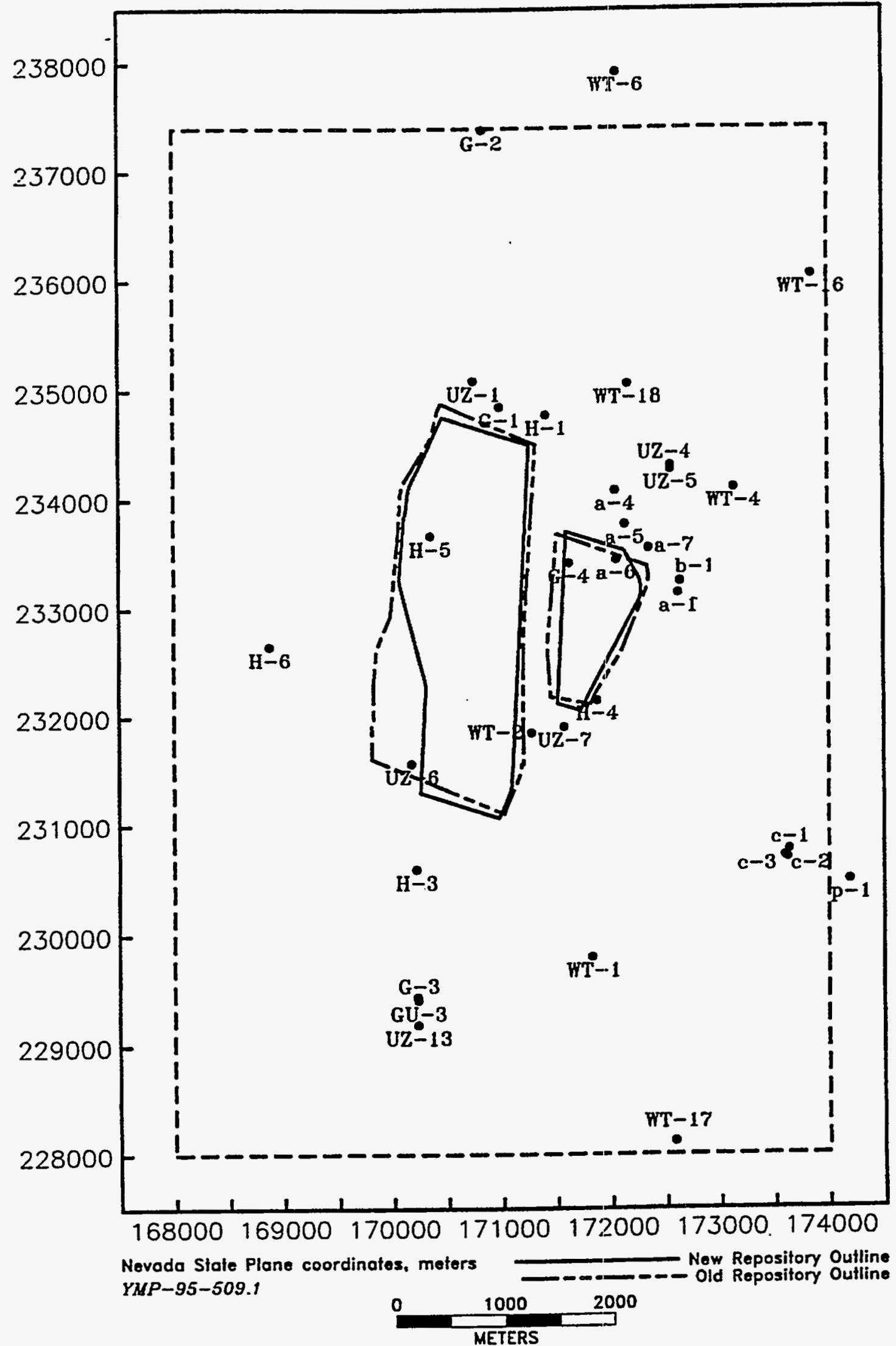

Figure 2.3-1 Borehole Locations in the Yucca Mountain Region 


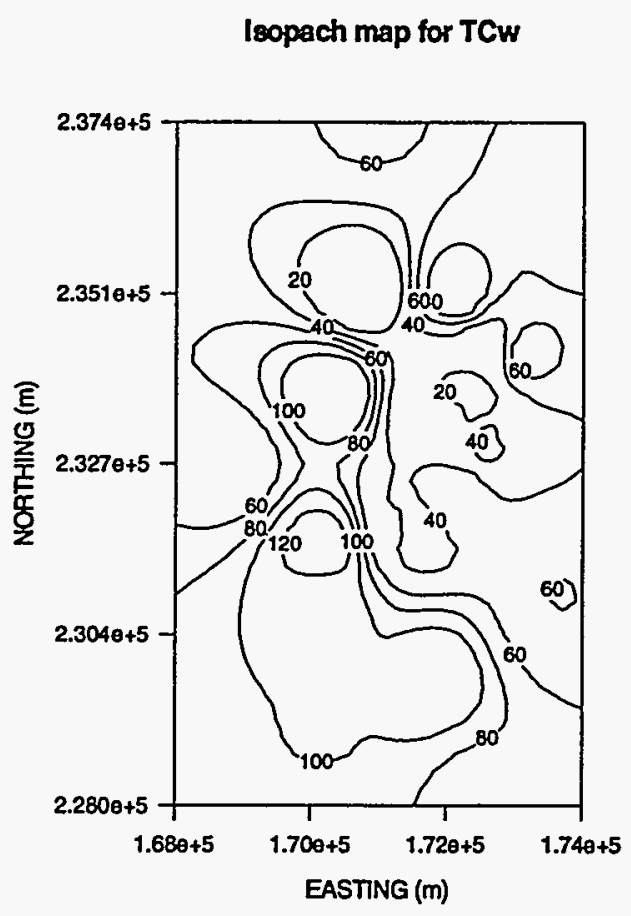

Figure 2.3-2 Isopach Map for Tiva Canyon welded (TCw) Unit (Contours in meters)

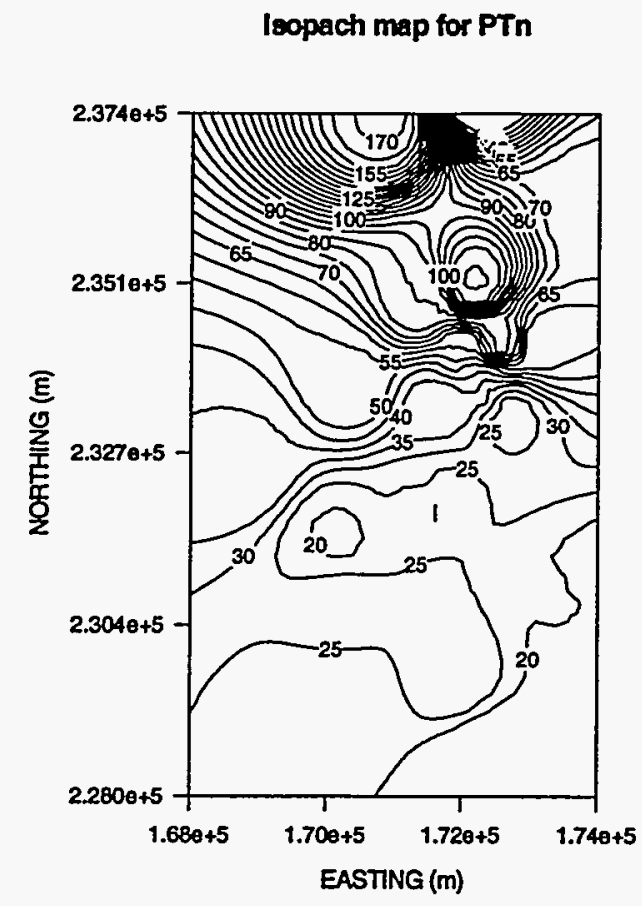

Figure 2.3-3 Isopach Map of Paintbrush nonwelded (PTn) Unit (Contours in meters) 


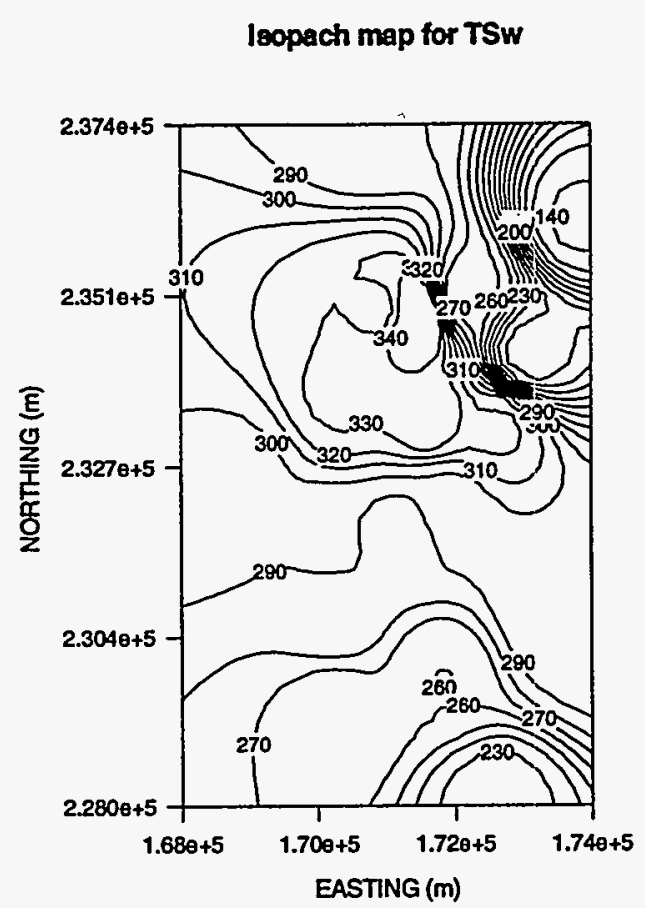

Figure 2.3-4 Isopach Map of Topopah Spring welded (TSw) unit (Contours in meters)

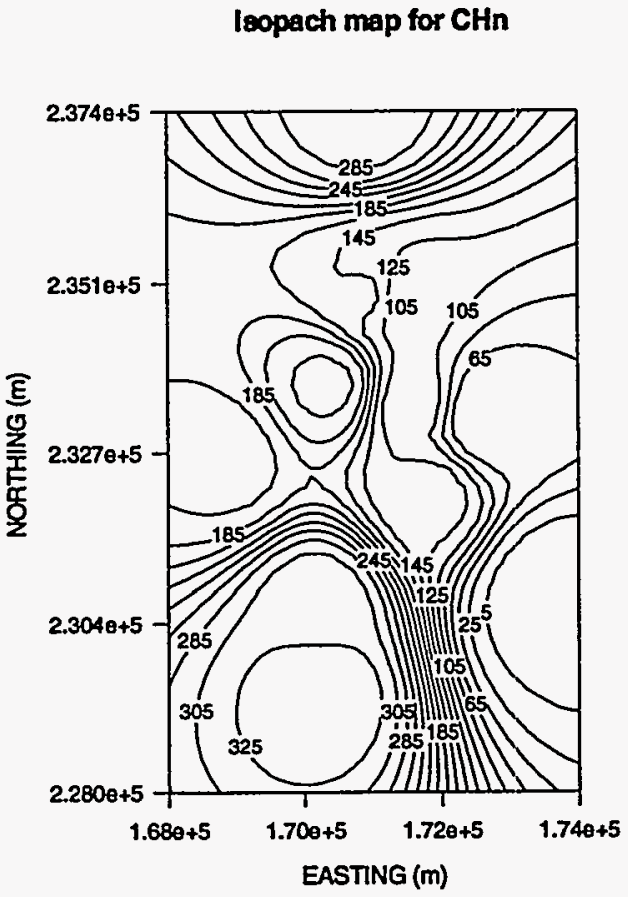

Figure 2.3-5 Isopach Map for Calico Hills nonwelded ( $\mathrm{CHn}$ ) unit (Contours in meters) 

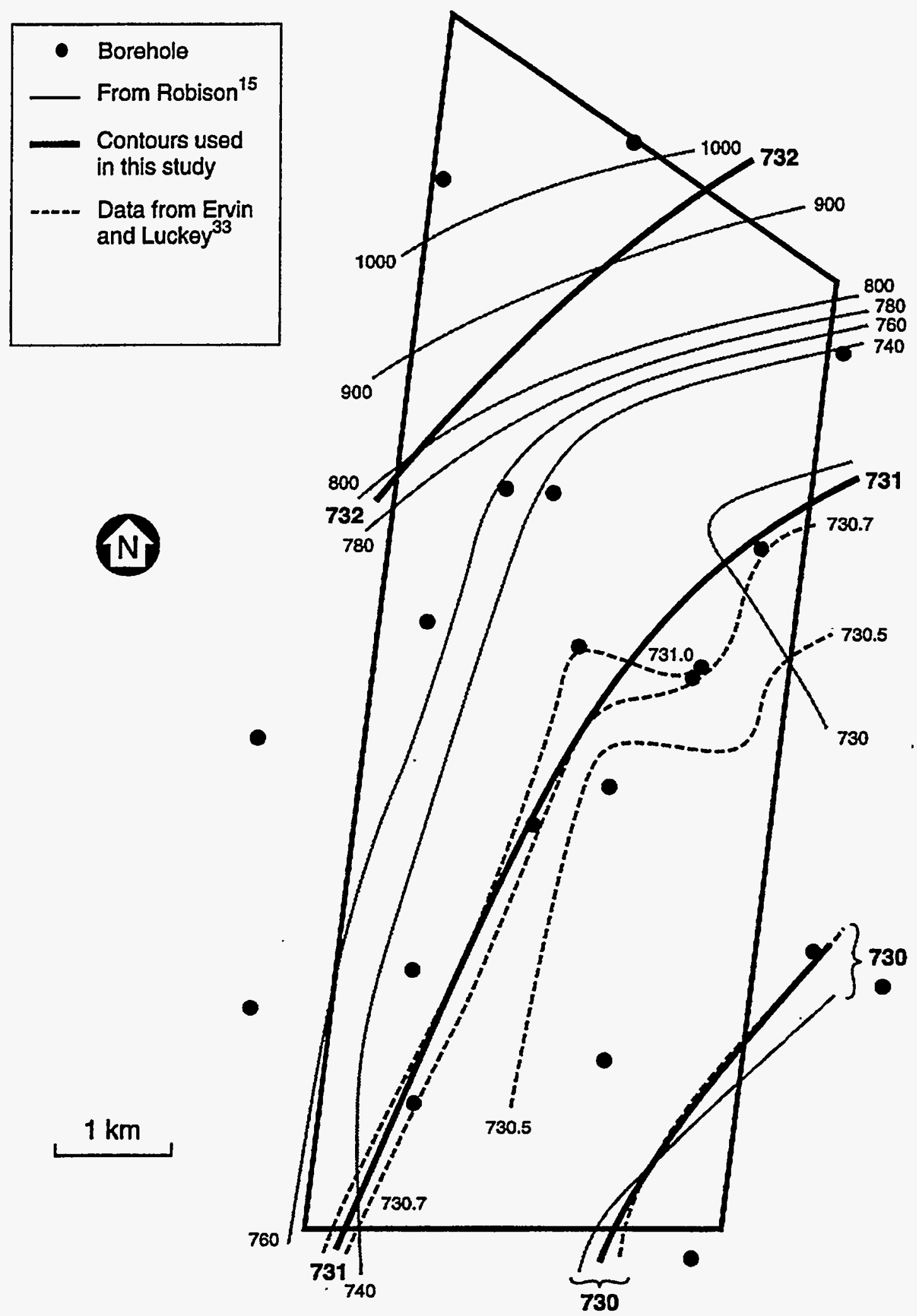

Figure 2.3-6 Contour Map of Water Table at Yucca Mountain (from Wittwer et al., 1995) 


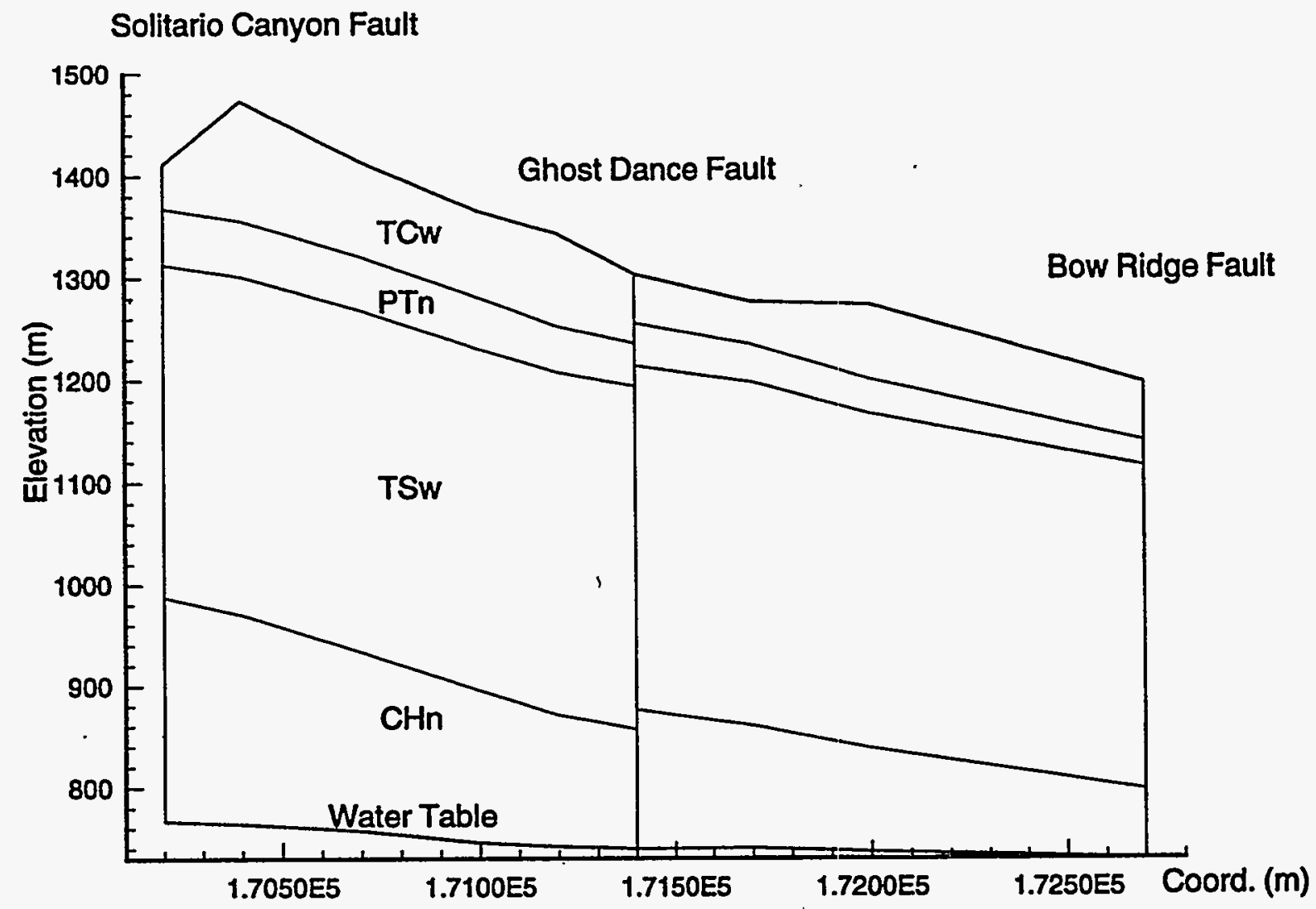

Figure 2.3-7 Geologic Cross-Section through the Potential Repository at Yucca Mountain (from Wittwer et al., 1995) 


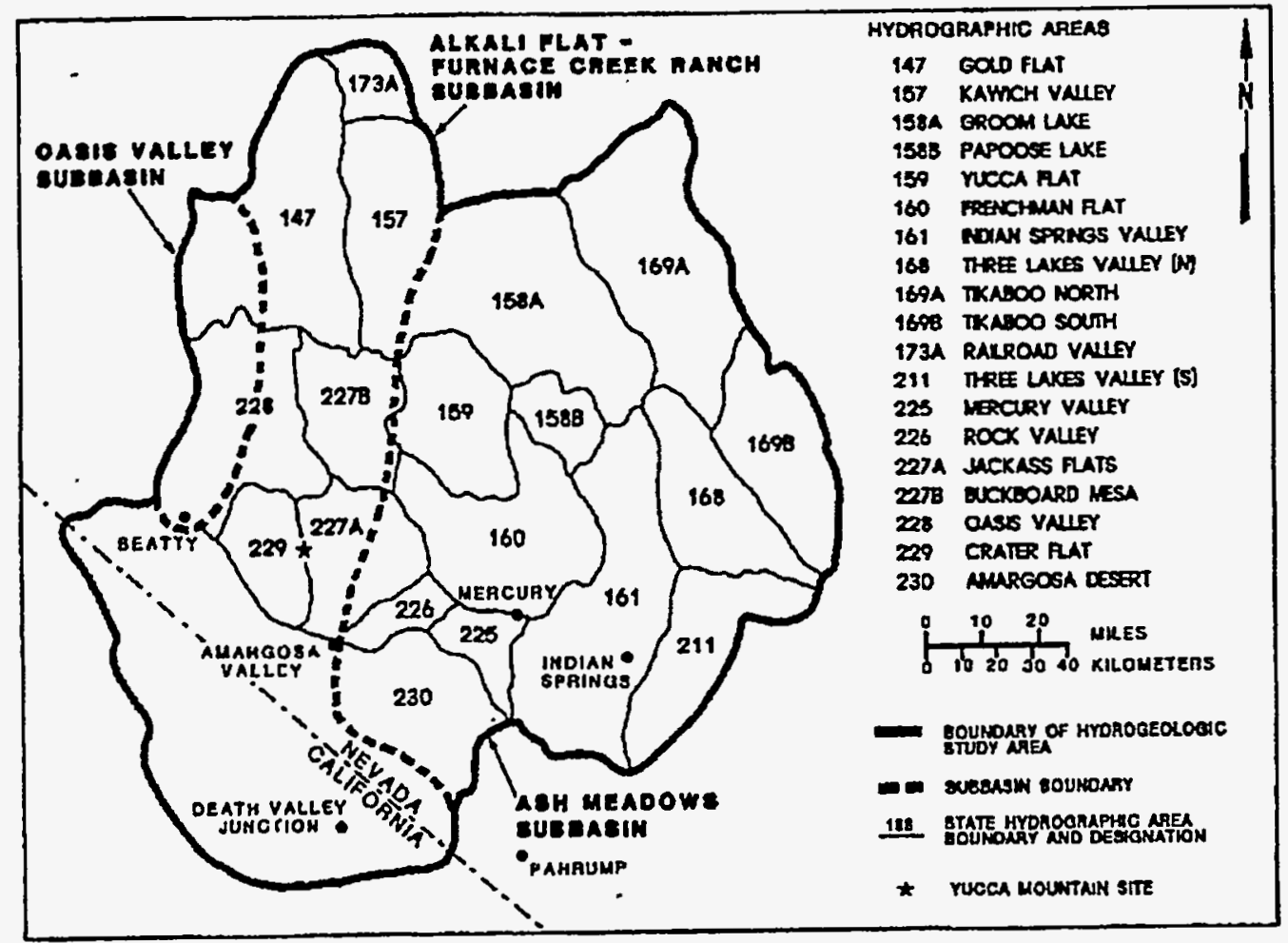

Figure 2.5-1 State of Nevada Hydrographic Areas Within the Yucca Mountain Hydrogeologic Study Area

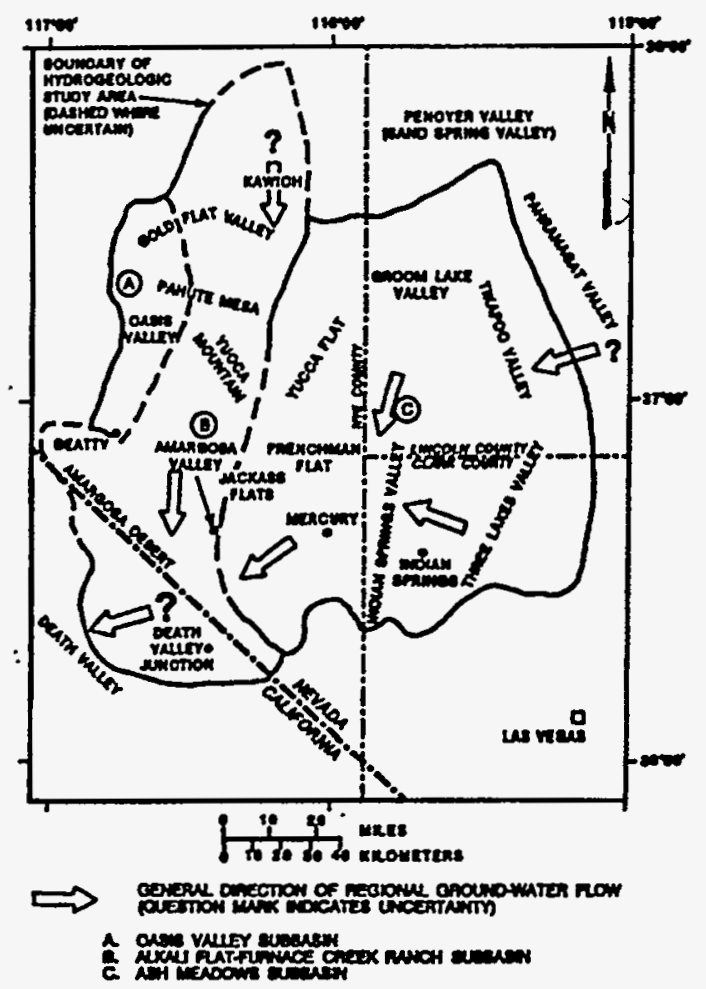

Figure 2.5-2 Hydrogeologic Study Area Showing Major Inflows and Outflows Across Subbasin Boundaries. Modified from Rush (1970), Blankennagel and Weir (1973), Winograd and Thordarson (1975), Dudley and Larson (1976), Waddell (1982), and Waddell et al., (1984) 


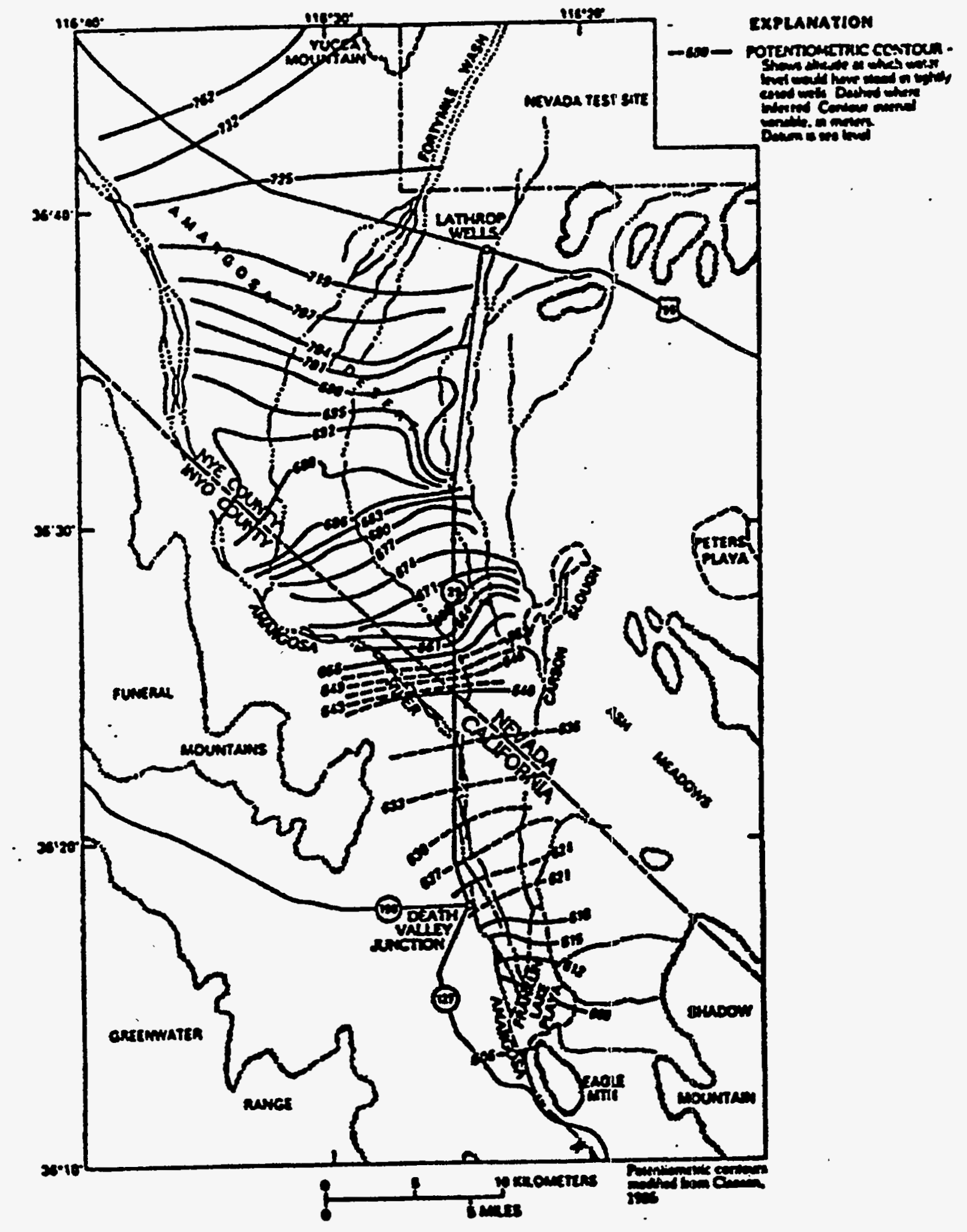

Figure 2.5-3 Potentiometric Surface of the Ground-Water Table Down Gradient from Yucca Mountain (modified from Claassen, 1985) 


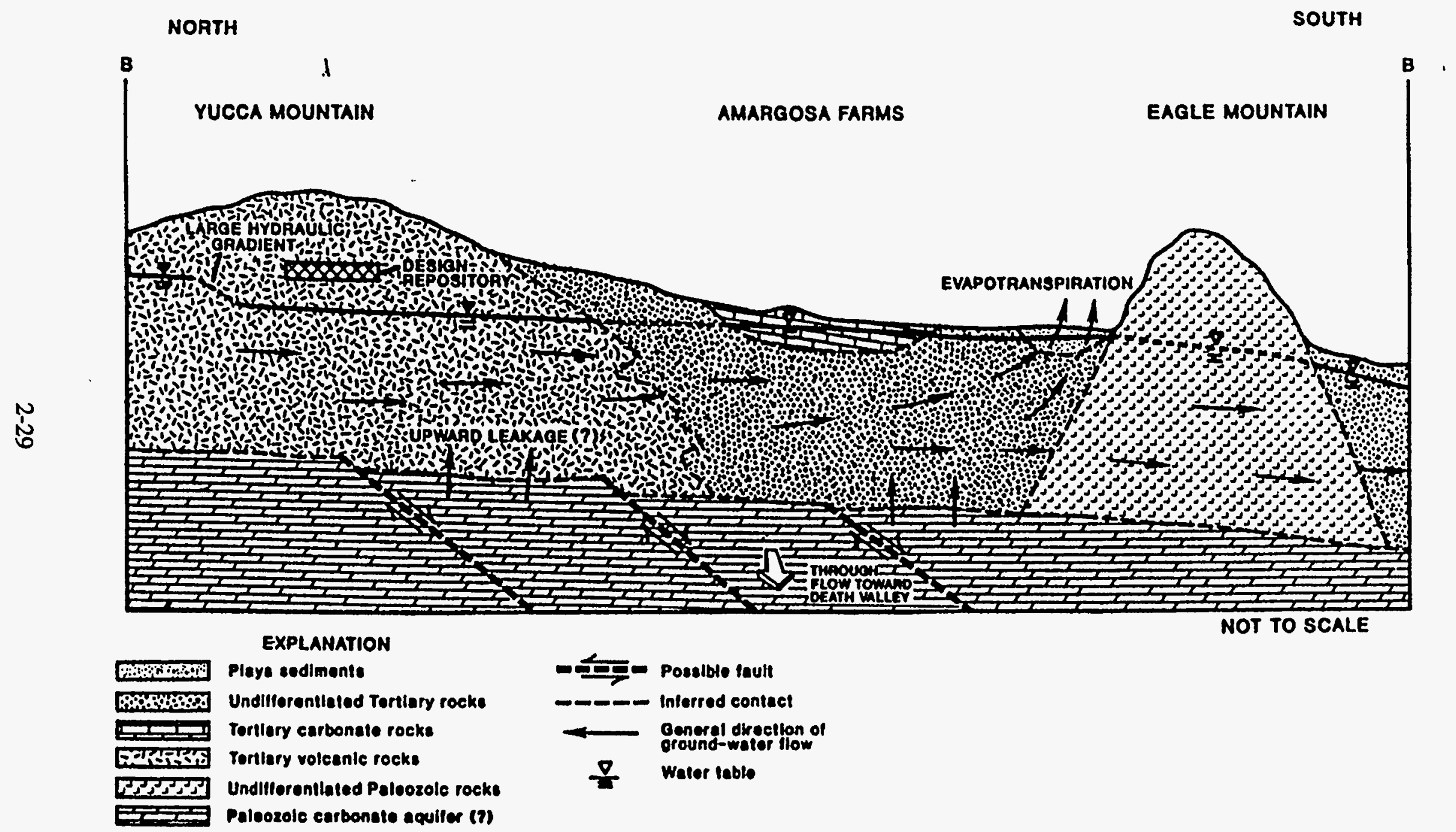

Figure 2.5-4 Idealized Geohydrologic Cross Section from Yucca Mountain to Eagle Mountain (After Czarnecki, 1989) 


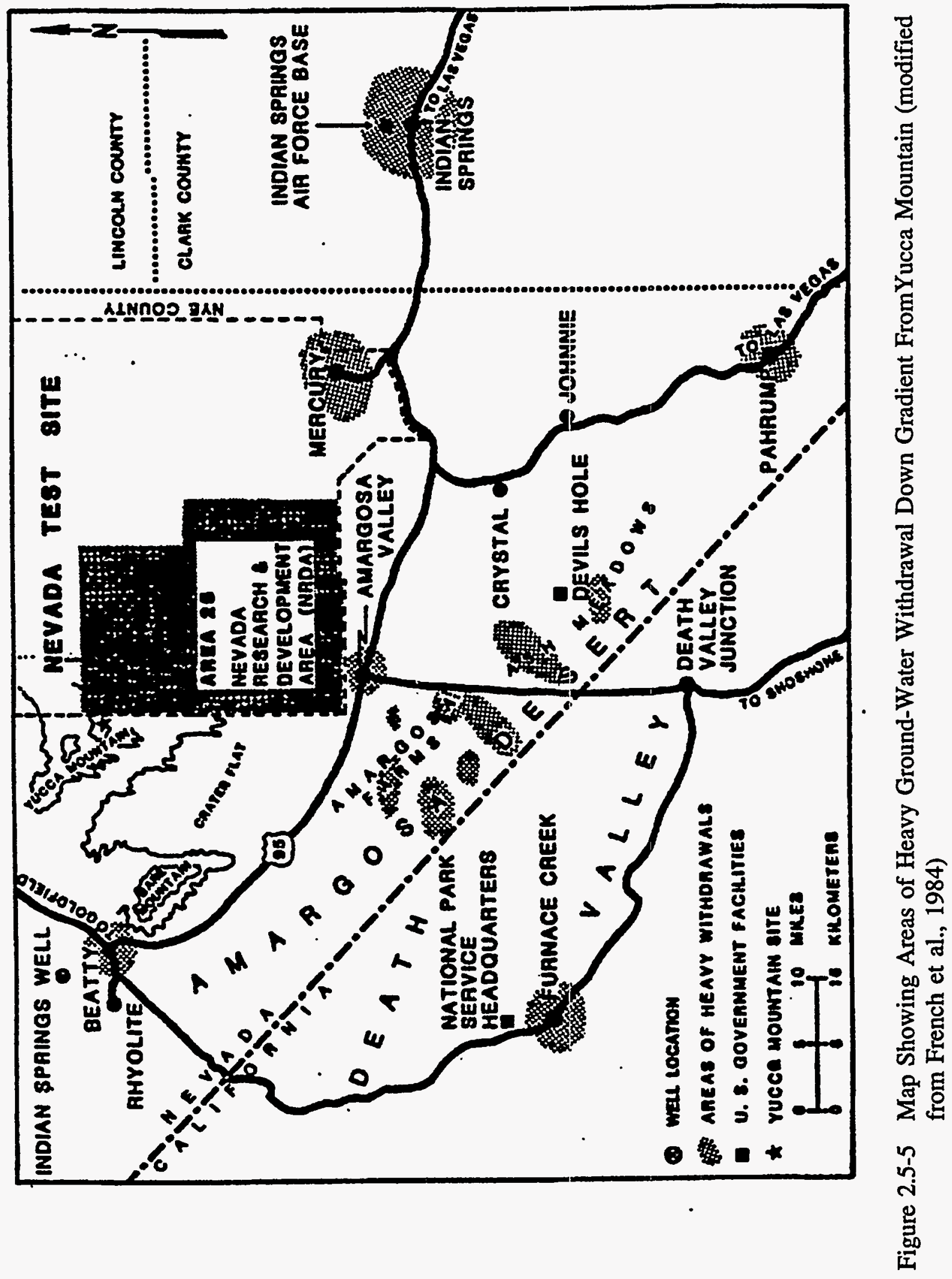



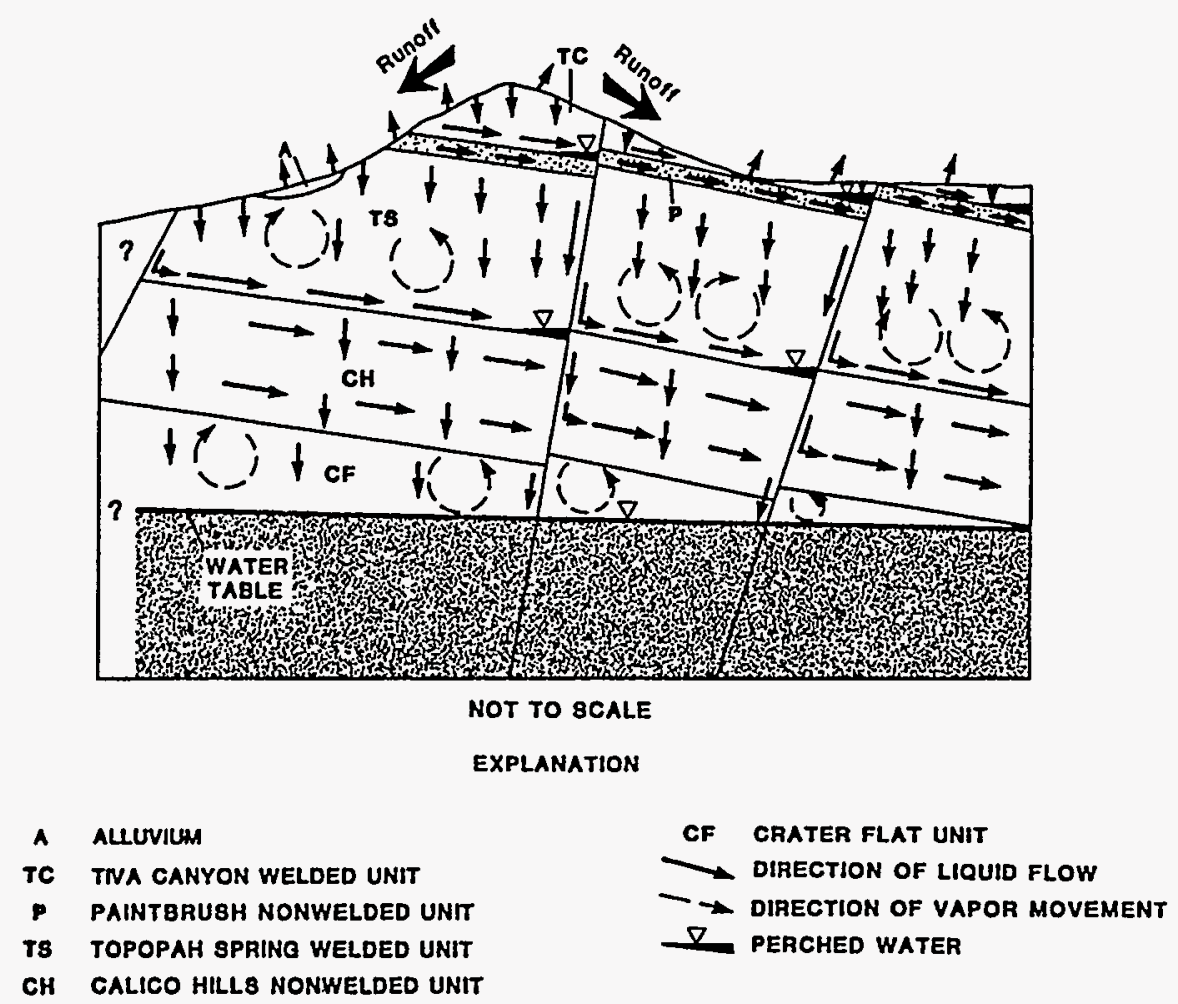

Figure 2.6-1 Generalized Section Across Yucca Mountain Showing Flow Regime Under Baseline Conditions

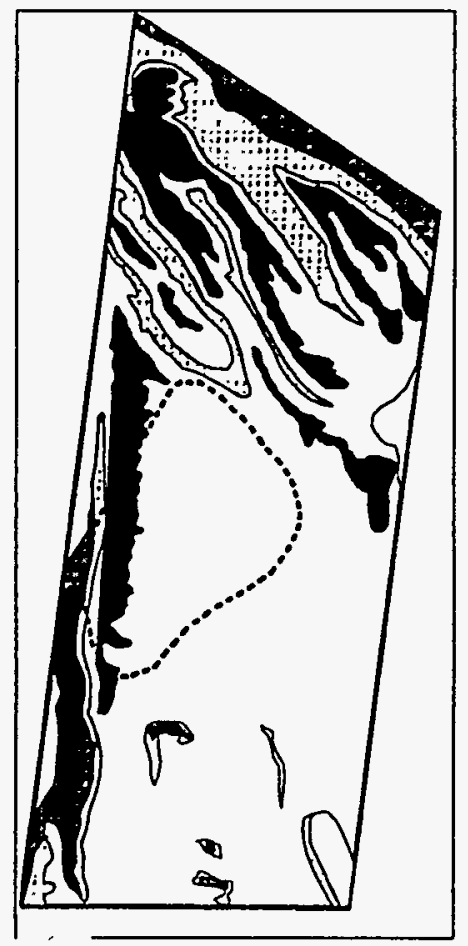

\section{Flux in $\mathrm{mm} /$ year}

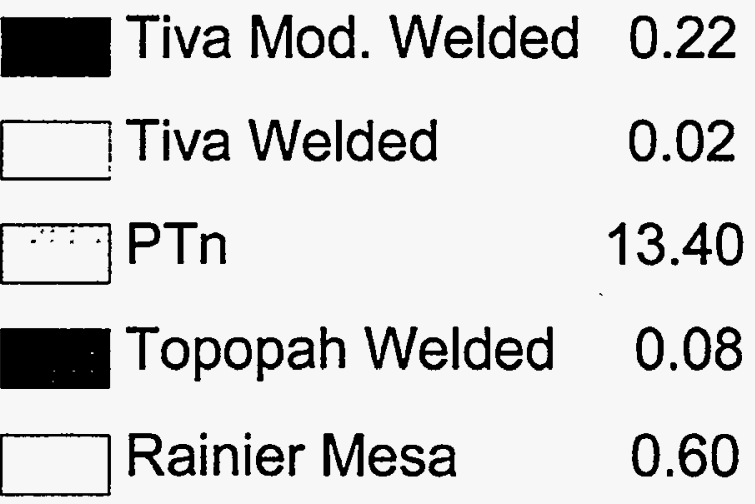

Figure 2.6-2 Spatial Distribution of Ambient Matrix Driven Infiltration Rates (derived from Flint and Flint, 1994) 


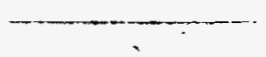


CHAPTER 3

REPOSITORY AND WASTE PACKAGE DESCRIPTION 



\title{
- 3. REPOSITORY AND WASTE PACKAGE DESCRIPTION
}

\author{
Srikanta Mishra, Joon H. Lee, Jerry A. McNeish
}

\subsection{INTRODUCTION}

Determination of total system performance requires definition of the planned engineered components of the system that are proposed to be constructed for the disposal of the radioactive wastes. Complete definition of all the engineered components is not possible at this time as many factors, including cost and constructability, must be factored into the final design. However, in order to provide a consistent basis for design, analysis (including performance assessment) and cost/schedule evaluations, a Controlled Design Assumption document has been compiled (M\&O, 1995c).

The information presented in the current chapter describes the repository and drift design options used to evaluate drift-scale thermal hydrology, and the waste package design options used to evaluate waste package degradation (Figure 3.1-1). Section 3.2 describes the general layout of the potential repository. Section 3.3 presents alternative thermal loading designs that have been proposed. Section 3.4 presents the repository layouts proposed to accommodate the different thermal loads. Section 3.5 presents the current waste package design options consistent with the Multi-Purpose Container (MPC) concept. Section 3.6 presents alternative waste package emplacement and backfill options proposed for the repository drifts. Section 3.7 presents the radionuclide inventory associated with both the spent fuel containers and the high-level waste canisters within each waste package. Finally, Section 3.8 describes the hydrostratigraphy associated with repository layouts for the two different thermal loads examined in this TSPA.

\subsection{GENERAL LAYOUT CONSIDERATIONS}

A conceptual design of a potential, high-level nuclear waste repository at Yucca Mountain is described in Chapter 6 of the Site Characterization Plan (SCP) (DOE, 1988) and is based on evaluations presented in the Site Characterization Plan - Conceptual Design Report (SCP-CDR) (SNL, 1987). This conceptual design consists of a series of emplacement panels approximately rectangular in shape and extending from the outer main drift to the perimeter of the repository (Figure 3.2-1). Three main drifts traversing the length of the repository provide access to the emplacement panels, with panel-access drifts leading from the main drifts to the emplacement drifts within the panels.

Subsequently, several programmatic decisions have necessitated modifications to the SCP-CDR emplacement concept. These include: (i) the construction of the Exploratory Studies Facility (ESF) and the need to develop an ESF-repository interface, (ii) the decision to use a Tunnel Boring Machine (TBM) for constructing the repository in lieu of the primarily drill-and-blast method proposed in the SCP-CDR, and (iii) the possibility of emplacing waste packages at a lower (or higher) areal mass loading than the SCP-CDR design. Motivated by such concerns, new conceptual layouts were developed using the following key criteria (M\&O, 1993b):

- Provide a layout that provides for logical development and waste emplacement schemes, and is compatible with the TBM-based repository concept. 
- Locate the emplacement horizon within the unsaturated zone and at least $200 \mathrm{~m}$ below the ground surface.

- Locate the waste emplacement horizon within the lithophysae-poor section of the Topopah Spring welded (TSw) unit.

- Locate and orient emplacement areas, to the extent practicable, to avoid major identifiable faults and fracture systems, consistent with achieving relatively continuous disposal areas and a workable layout.

Six potential emplacement areas were identified using these and other operational (i.e., ventilation, drainage, etc.) criteria, and are shown in Figure 3.2-2. The general characteristics as well as bounding conditions which formed the bases for the configurations shown in this figure are discussed elsewhere (M\&O, 1994c). The individual emplacement area available for each of the potential emplacement areas is given in Table 3.2-1.

\subsection{THERMAL LOADING ISSUES}

Thermal loading refers to the spatial density at which waste packages (WP) are emplaced within the repository, and is typically characterized by two common measures: (i) the areal power density (APD), which relates the average initial heat generated by WPs at the time of emplacement to the two-dimensional area occupied by WPs in the subsurface, and (ii) the areal mass loading (AML), which relates the amount of waste expressed in metric tons of uranium (MTU) to the emplacement area. The SCP designs, as well as subsequent analyses of thermal/thermohydrologic/thermo-mechanical behavior, have used the APD concept, with the thermal loading expressed in $\mathrm{kW} / \mathrm{acre}$. A major shortcoming of this approach is that it cannot address the wide variability in the thermal characteristics of the waste stream. Using a constant emplacement drift spacing and spacing the WPs within the drift according to their initial heat output (APD) would result in non-uniform thermal conditions within the repository after a relatively short period of time because of the variability in waste stream characteristics. These considerations have led recent work to use the AML concept, with the thermal loading expressed in MTU/acre. The AML approach recognizes that WP heat output will be nearly the same after several hundred years for packages containing the same amount of waste. Thus, package spacings based on MTU content will provide more uniform thermal conditions over the long-term performance period.

The original thermal loading strategy for the potential repository at Yucca Mountain, as described in the SCP (DOE, 1988), involved emplacement of 63,000 MTU of spent nuclear fuel (SNF) and 7,000 MTU of defense high-level waste within the primary area - resulting in an areal power density of $57 \mathrm{~kW} / \mathrm{acre}$. Small waste packages, containing only a few SNF assemblies with low thermal output (1-3 kW), were designed for emplacement in boreholes in the floors or walls of the emplacement drifts. Since that time, a wide range of thermal loadings and thermal designs have been investigated with a view to maximizing thermohydrologic performance and/or minimizing thermohydrologic disturbance to the repository system (e.g., Buscheck and Nitao, 1992, 1993; Pruess and Tsang, 1993, 1994). Such studies led to the inclusion of thermal loads of $28 \mathrm{~kW} /$ acre and $114 \mathrm{~kW} / \mathrm{acre}$, in addition to the SCP value of $57 \mathrm{~kW} / \mathrm{acre}$, in previous evaluations of total system performance for Yucca Mountain (Andrews et al., 1994). 
No decisions have been made as yet regarding the final thermal loading for the proposed repository at Yucca Mountain. These decisions have been deferred until such time as results from laboratory and in-situ thermal tests (and performance confirmation testing) are available to provide greater confidence to the understanding of thermohydrologic phenomena and more defensible bases to their predictions using numerical models (M\&O, 1995e). In the interim, engineering design is proceeding under the assumption that "Surface, subsurface and waste package/EBS designs will be robust and flexible and will accommodate a range of thermal loads from about 20 to about 100 MTU/acre" (M\&O, 1995c, Key Assumption 019). Within the framework of this general guideline, design/analyses are being carried out for two cases:

- 'Low' Thermal Load ( $20-40$ MTU/acre): For these conditions, it is postulated that the hydrology of the host rock will not be significantly disturbed from its ambient state. A low loading can be achieved using either wide spacing of WPs with moderately spaced drifts (the minimal disturbance, MD, concept), or with WPs spaced close together in widely-spaced drifts (the localized disturbance, LD, concept). The MD option minimizes near-field temperatures, while the LD option minimizes thermal influences on the overall hydrologic system. The low thermal loading option requires emplacement of wastes beyond the primary emplacement area (in optional areas $A$ through $D$ as shown in Figure 3.2-2) to meet the statutory capacity requirements as specified in the Nuclear Waste Policy Act Amendment of 1987.

- 'High' Thermal Load ( 80-100 MTU/acre): At a sufficiently high thermal load, it is hypothesized that water will be vaporized and driven away from the vicinity of the waste packages, resulting in dry conditions for extended periods of time (the extended dry, ED, concept), and hence, improved waste containment and isolation. This option would allow the statutory capacity requirements to be met by emplacing wastes in the upper block of the primary emplacement area alone (Figure 3.2-2).

TSPA-1995 focusses on these two thermal loading scenarios, i.e., the low thermal loading case ( 20-40 MTU acre) and the high thermal loading case ( $80-100 \mathrm{MTU} / \mathrm{acre})$. In order to integrate the various design, performance assessment and systems analysis calculations related to thermal loading, it has been suggested that the values of $25 \mathrm{MTU} / \mathrm{acre}$ and $83 \mathrm{MTU} / \mathrm{acre}$ be taken as common points of reference (Saterlie, 1994). These two values have therefore been used as representative 'point designs' for low and high thermal loading, respectively, in this study.

Note that for the reference waste stream used in TSPA-1995 (Section 4.2.5), the conversion factor between areal mass loading (MTU/acre) and areal power density (kW/acre) is $\sim 1 \mathrm{~kW} / \mathrm{MTU}$.

\subsection{LAYOUTS FOR 25 AND 83 MTU/ACRE}

The layouts for waste emplacement are developed for 63,000 MTU of spent nuclear fuel, assuming that the heat generation from defense high-level wastes is negligible. For the 25 MTU/acre case, this requires an area of approximately 2520 acres - which is $7 \%$ less than the cumulative area of the six emplacement panels identified in Table 3.2-1. A further examination of the emplacement panels reveals that Optional Area $A$ is located over the region of potentially large hydraulic gradient (Ervin et al., 1994) and also has a relatively short travel distance to the water table. Eliminating Optional Area A from consideration reduces the cumulative area to 
2535 acres --which satisfies the areal requirements for the 25 MTU/acre case, and also minimizes the potential for any adverse impact of the large hydraulic gradient on waste isolation. Figure 3.4-1 shows the corresponding spatial distribution of wastes over the five emplacement areas.

The high thermal loading ( $83 \mathrm{MTU} / \mathrm{acre}$ ) case requires an area of approximately $760 \mathrm{acres}$, and can be accommodated within the upper emplacement block of the Primary Area. The corresponding spatial distribution of wastes is shown in Figure 3.4-2. Note that both of these layouts (25 and $83 \mathrm{MTU} / \mathrm{acre}$ ) are essentially similar to those presented in M\&O (1994c), with the exception that Optional Area A has been excluded for the low thermal loading case because of the reasons described above.

\subsection{WASTE PACKAGE DESIGN}

The waste package (WP) as defined in 10 CFR Part 60.2 includes the waste form and any containers, shielding, packing and other absorbent materials immediately surrounding an individual waste container (NRC, 1993). The NRC regulations define the engineered barrier system (EBS) as the waste packages and the underground facility. The waste package and engineered barrier system components have been discussed briefly in Section 1.4 with the schematic diagram for the components shown in Figure 1.4-4. Except for the waste disposal container and the invert, specifics of the design of other Waste Package and EBS components are in their early stages (Stahl, 1995).

In the current design concept of waste disposal containers for the potential repository at Yucca Mountain, two or three layers of different metals, depending on thermal load, have been proposed for the disposal containment barriers for spent nuclear fuel (SF) and vitrified defense high-level waste (DHLW). According to the recent Controlled Design Assumption (CDA) Document (M\&O, 1995c), a corrosion-allowance material (CAM) such as mild steel has been proposed as the outer containment barrier, and a corrosion-resistant material (CRM) such as Inconel 825 (Alloy 825) has been proposed as the inner containment barier for the spent fuel waste disposal container and for a high thermal load case. For the low thermal load case, a moderately corrosion resistant material (MCRM) such as Monel 400 has been added as an additional containment barrier on top of the two-layer containment barrier design for a high thermal load case. Addition of MCRM in a low thermal load case was prompted by the possibility of microbiologically influenced corrosion (MIC). For the DHLW waste container design for both thermal load cases, CAM is replaced with another candidate MCRM (70/30 copper-nickel alloy).

Additional details on the dimensions of the waste disposal containers were provided in a recent M\&O document (Doering, 1995). The dimensions of the waste container for a typical large multi-purpose canister (MPC) for 21 pressurized water reactor (PWR) or 40 boiling water reactor (BWR) fuel assemblies are given in Table 3.5-1 along with those of the waste container for four DHLW pour canisters. The thickness of the inner barrier for the large MPC and DHLW waste container is $20 \mathrm{~mm}$, the thickness of the outer barrier for the large MPC waste container is $100 \mathrm{~mm}$, and that for DHLW waste container is $50 \mathrm{~mm}$. The M\&O document did not provide the specifications of the potential third (or outermost) containment barrier (Monel 400) specified in the CDA for a low thermal load case. 
In the current design concept, Alloy 825 was chosen because it is highly resistant to uniform corrosion and in many environments is resistant to localized corrosion such as pitting, crevice, and stress corrosion. Carbon steel has relatively low corrosion resistance in nearly all environments; but, its corrosion rates are predictable, and its cost is low. A thick layer of carbon steel is intended to allow for the higher corrosion rate and to provide structural integrity of the waste package and radiation shielding to the outer surface of the waste package. Once penetrated, carbon steel would serve as a sacrificial anode which cathodically protects the Alloy 825 inner barrier. Moderately corrosion resistant materials have properties between corrosion resistant and corrosion allowance materials, but their corrosion behavior is largely unknown (Van Konynenburg et al., 1994).

Since adequate models for predicting the performance of the moderately corrosion resistant materials (Monel 400 and 70/30 copper-nickel alloy) are not available, it has been recommended that this potential containment barrier not be included in any waste package performance analysis (Doering, 1995). Thus, in TSPA-1995, all waste containers for spent fuel and defense high-level waste are assumed to have the same design, viz., a $20 \mathrm{~mm}$ thick corrosion-resistant inner barrier of Alloy 825, and a $100 \mathrm{~mm}$ thick corrosion-allowance outer barrier of carbon steel. Also, the stainless steel MPC shell and DHLW pour canister are not considered in this TSPA iteration.

\subsection{WASTE PACKAGE EMPLACEMENT}

\subsubsection{Background}

Three major waste emplacement concepts have been considered in previous conceptual repository design studies, i.e., vertical borehole emplacement, horizontal borehole emplacement, and in-drift emplacement. Schematic diagrams illustrating the emplacement concepts are shown in Figure 3.6-1 (DOE, 1988). The two borehole emplacement methods were developed as part of the SCPCDR (SNL, 1987). The primary emplacement mode called for placement of waste packages in vertical boreholes drilled into the floor of emplacement drifts. The alternative consisted of placing waste packages in long horizontal boreholes drilled between adjacent drifts. In-drift emplacement was also proposed as an alternative to horizontal borehole emplacement in order to accommodate large waste packages.

The adoption of the Multi-Purpose Canister (MPC) waste package concept has lead to a rethinking of repository emplacement modes for the following reasons:

- A typical 21 pressurized water reactor (PWR) MPC-based waste package would be $5.6 \mathrm{~m}$ long and $1.8 \mathrm{~m}$ in diameter, weigh 66 tons, contain $9 \mathrm{MTU}$ and produce an average of $10 \mathrm{~kW}$ heat at emplacement. The SCP-based consolidated 3 PWR / 4 BWR waste package, on the other hand, would be $4.6 \mathrm{~m}$ long and $0.7 \mathrm{~m}$ in diameter, weigh 5.3 tons, contain 2.6 MTU and produce an average of $2-3 \mathrm{~kW}$ heat at emplacement. Emplacement of the large-diameter, high heat output MPC-based waste packages would not be appropriate in boreholes because thermal design goals associated with canister centerline temperatures $\left(<350^{\circ} \mathrm{C}\right)$ would be violated $(\mathrm{M} \& \mathrm{O}, 1994 \mathrm{~b})$.

- The Controlled Design Assumption document (M\&O, 1995c) calls for a flexible subsurface repository design to accommodate a range of thermal loads from about 20 to 
about $100 \mathrm{MTU} / \mathrm{acre}$. The need for maintaining such design flexibility must be taken into account in developing and selecting an emplacement: mode.

\subsubsection{Emplacement Mode Selection}

A recent $M \& O$ study (M\&O, 1995f) provides a basis for the selection of a waste package emplacement mode with which to complete current repository advanced conceptual design activities. Six different modes of emplacement were described and evaluated against ten different criteria, as summarized below.

The emplacement modes evaluated included:

- Center In-Drift - WPs emplaced along the centerline of a TBM-excavated emplacement drift.

- Off-Center In-Drift - WPs emplaced off-center within the envelope of primary TBMexcavated emplacement drifts.

- Short Parallel Alcove - WPs emplaced in alcoves with the long axis of the alcove parallel to a primary TBM-excavated drift.

- Short Perpendicular Alcove - WPs emplaced in alcoves with the long axis of the alcove perpendicular to a primary TBM-excavated drift.

- Short Angled Alcove - WPs emplaced in alcoves excavated at a $45^{\circ} \mathrm{C}$ angle from the primary TBM-excavated drift.

- Short Cross Drift - WPs emplaced in short cross drifts between pairs of primary TBMexcavated drifts.

The criteria used to evaluate these emplacement modes included: (1) operational complexity during emplacement, (2) ease of retrieval, (3) safety, (4) flexibility to accommodate a range of thermal loads, and to adjust thermal loading, (5) potential for thermal management via ventilation, (6) constructability, (7) ability to emplace backfill, (8) inherent stability of resulting excavation, (9) relative cost, and (10) long-term performance.

The results of these evaluations showed a clear preference for in-drift modes over alcove-based modes, with little distinction between center in-drift and off-center in-drift emplacement modes (M\&O, 1995f).

\subsubsection{Drift Design for TSPA-1995 Analyses}

This sub-section provides a brief review of the drift design used in TSPA-1995, along with related information on the issues of backfill and ventilation.

Information regarding the exact nature of emplacement (i.e., drift size, location of waste package within drift, dimensions of invert and other supporting material, etc.) is needed to develop the 
geometry for the near-field thermo-hydrologic calculations described in Chapter 4. This information is also utilized in the assessment of radionuclide transfer through the engineered barrier system (EBS). In order to simplify the emplacement geometry in such model representations, the Center In-Drift On Pedestal (CIDP) option has been chosen as the basis for the analyses reported in this document.

The CIDP option, as shown schematically in Figure 3.6-2, involves placement of waste packages by a remote controlled rail-mounted gantry crane on permanent pedestals that are prepositioned in the drift. The waste package dimensions shown in the figure are typical of a 21-PWR MPCbased waste package. The drift diameter of $5 \mathrm{~m}$ is determined by the need to provide a reasonable operating clearance, and to provide additional space for ground support and excavation misalignment tolerance. The materials to be used in the fabrication of the emplacement pedestal have not been determined as yet. For the purposes of this study, the tunnel invert fill, as well as the support pedestal, are taken to be made of a gravel-type material similar to the backfill.

The current version of the Controlled Design Assumption document states that "Means for retarding the escape of radionuclides from the disposal container and/or for physical protection of the waste package (e.g., backfill) will be evaluated for implementation in Waste Package and Subsurface designs" (M\&O, 1995c, Key Assumption 046). The use of a granular backfill material as a capillary barrier and a thermal management tool has also been advocated in recent studies of near-field thermohydrologic performance (Buscheck et al., 1995). On the other hand, practical considerations render the emplacement of backfill in long drifts $(\sim 1000 \mathrm{~m})$, under hot conditions $\left(\sim 100^{\circ} \mathrm{C}\right)$, and with unshielded waste packages, a difficult proposition. No final decision has been made with respect to the backfill issue, and the selection of likely candidates for use as backfill. This study therefore considers both backfilling and no backfilling options in evaluating Waste Package/EBS and total system performance. The characteristics of the backfill are taken to represent a gravel type material, with suitable modifications to incorporate enhancements in porosity and thermal conductivity.

Plans have been developed for ventilating the repository during the construction and waste emplacement operations (M\&O, 1994b). Waste emplacement management could potentially involve continuous ventilation to maintain a constant wall rock temperature of $50{ }^{\circ} \mathrm{C}$. This represents an extreme case that is not likely to be a realistic design option because of air flow requirements. An alternative is to focus air flow so as to minimize localized heat spikes next to emplaced waste packages, resulting in lower air quantity requirements. A third alternative is to provide ventilation only on an "as needed" basis during retrieval operations. From the perspective of near-field performance, the cumulative effects of heat removal due to ventilation is expected to be marginal for the third (and perhaps the most likely) option described above. Therefore, the effects of ventilation are not included in this analysis.

\subsection{RADIONUCLIDE INVENTORY}

The radionuclide inventory used in the TSPA-1995 analyses is divided into two basic components: spent fuel (PWR and BWR) and DHLW. The inventory used in the analyses is based on inventories for the PWR and BWR in the Characteristics Database (M\&O, 1993c). The DHLW inventory was obtained from DOE (1987). A weighted average spent fuel inventory was determined. Screening was conducted based on contribution of the radionuclide to: (1) potential 
release normalized to 40 CFR 191 Table 1 values over time periods from 1,000 to $1,000,000$ years, and (2) potential average annual whole body dose over time periods from 1,000 to $1,000,000$ years. This screening is explained in more detail later in the section. Spent fuel (both PWR and BWR) and DHLW are included in the inventory. Thirty-nine radionuclides for spent fuel and thirty two radionuclides for HLW are included in the analyses.

Spent Fuel: The spent fuel is composed of PWR and BWR fuel with tonnages of 40,785 MTHM and 22,210 MTHM respectively to reach a total of $63,000 \mathrm{MTHM}$. The average burnup rate for the TSPA-1995 analyses is based on a content of 64.68 percent PWR fuel and 35.32 percent BWR fuel with burnups of 39,651 MWd/MTHM and 31,186 MWd/MTHM respectively for an average burnup of $36,666 \mathrm{MWd} / \mathrm{MTHM}$. Thirty-year-old fuel is assumed. The spent fuel inventory assumes the PWR and BWR fuel are mixed (Table 3.7-1). The metric tons of uranium (MTU) (for practical purposes the equivalent of MTHM) is calculated from the number of PWR spent fuel assemblies per container and the mass of a PWR assembly.

Defense High-Level Waste: The DHLW inventory presented in Table 3.7-2 is directly from DOE (1987). The thermal output of the DHLW is small in comparison to the spent fuel. The burnup value for DHLW is assumed to be 10,000 MWd/MTU after Golder Associates Inc. (1993). This is used only for purposes of normalization to the EPA standard. The assumption is 7,000 MTHM of DHLW in 14,000 containers. The waste is assumed to be derived from West Valley, Idaho National Energy Laboratory, Savannah River Laboratory, and Hanford Facilities.

Screening: The screening of radionuclides for inclusion in the analyses was done in two steps. The first step used the ratio of the inventory to EPA Table 1 release limits. The ratio of the weighted average spent fuel inventories of specific radionuclides to corresponding EPA Table 1 values were determined for $1,000,10,000,100,000$, and 1,000,000 years. The fractional contribution of each isotope to release at a time of 1,000,10,000,100,000, and 1,000,000 years was calculated assuming a combination of delay due to waste package lifetime and retarded transport of 1,000 to $1,000,000$ years. Isotopes which contributed at least a fraction of the EPA limit at any of the selected times passed this screening. The entire decay chain for daughters which contributed greater than $10^{-5}$ of the EPA limit at any time were also included.

The second step of the screening used dose and was based on inventories from the Characteristics Database at the same time periods. The waste form was assumed to be altered at a rate of $10^{-5}$ of the total inventory per year ( $\mathrm{Ci} / \mathrm{yr})$. The isotopes were assumed to dissolve, as they were made available by the assumed waste form alteration rate, at the maximum solubilities according to NAS (1983), EPRI (1992), and Barnard et al., (1992). The advective, downward flux in ground water moving through the unsaturated zone was assumed to occur at $0.1 \mathrm{~mm} / \mathrm{yr}$ over a cross sectional area of $33,000 \mathrm{~m}^{2}$. On arrival at the saturated zone, the isotopes were assumed to mix in the saturated zone with a flow rate of $10,000 \mathrm{~m}^{3} / \mathrm{yr}$. Ingestion of 700 liters/year by a person using this ground water was assumed. The ingested dose was calculated using the maximum effective (whole body) dose conversion factor from DOE (1988), NRC (1981), or EPA (1988). The fractional contribution of each isotope to total dose at times of $1,000,10,000,100,000$, and 1,000,000 years was determined. For radionuclides with two or more isotopes present in the waste, the solubility limit was set for the element (i.e., all isotopes) and then proportioned between the individual isotopes by the mass fraction present at the corresponding time. All isotopes contributing less than $10^{-5}$ of total dose at any time period were eliminated from the inventory unless they were in the 
decay chain for daughters which contributed $10^{-5}$ of total dose at any time. The two screening steps produced the radionuclide inventory for the spent fuel shown in Table 3.7-1.

\subsection{UZ PATHWAY STRATIGRAPHY}

The unsaturated zone is treated as a series of vertical one-dimensional pathways in RIP. Preliminary simulations of ambient unsaturated hydrology, which indicate the pervasiveness of vertical one-dimensional flow, at least in the vicinity of the proposed repository block, are described in Chapter 7. In this section, the pathways are identified and their hydrostratigraphic descriptions presented. These pathways are overlain on the footprint of the proposed waste emplacement panels (Figure 3.2-2) and are the origination point for radionuclide transport out of the EBS and through the geosphere.

\subsubsection{Pathways in Primary and Optional Areas}

As noted in Section 2.3, data from 34 boreholes were used to develop the three-dimensional hydrostratigraphy for the site-scale unsaturated flow model (Wittwer et al., 1995). The region covered by this model includes the two emplacement panels in the Primary Area, i.e., the Upper Block and the Lower Block, as shown in Figure 3.2-2. Information from Wittwer et al., (1995) was thus used to define pathway stratigraphies for these two panels. Limited borehole data are available in the regions corresponding to the Optional Areas. Some preliminary stratigraphic information, based on the thermo-mechanical stratigraphic model of Ortiz et al., (1985), was developed in support of the FY/94 Thermal Loading Systems Study (M\&O, 1994c). This information has been used as the basis for the pathway stratigraphies of the other three panels.

\section{Primary Area (Upper Block)}

A preliminary examination of the isopach maps of the various hydrogeologic units described in Section 2.3 revealed that there is sufficient spatial variation in formation thicknesses to warrant the subdivision of the Upper Block of the Primary Area into multiple pathways. As a first step in this process, one-dimensional stratigraphic information was extracted for the 25 vertical columns of the Wittwer et al., (1995) model falling within the Upper Block. The data consisted of the thickness of TSw, TSv, CHnv and CHnz units between the proposed repository horizon and the water table. These were then reorganized in terms of three variables: (i) depth to the water table, (ii) absolute thickness of $\mathrm{CHn}$ (including both vitric and zeolitic units), and (iii) percent of the pathway in $\mathrm{CHn}$. Use of the two latter variables for pathway demarcation allows a grouping of areas with similar percentages of welded (or nonwelded) rocks along a vertical column between the repository and the water table.

Figure 3.8-1 shows scatter plots of: (a) the percent of the pathway in CHn vs. depth to water table, and (b) thickness of CHn vs. depth to water table. Based on these scatter plots, the columns from the Wittwer et al., (1995) model were grouped into six pathways, shown as pathways 1 to 6 in Figure 3.8-2. The boundary between pathways was established by drawing a line midway between the columns in adjacent pathways. The stratigraphy for each of these pathways was determined by averaging the thicknesses of the various units for all the columns within the pathway. 
The footprint of the pathways shown in Figure 3.8-2 represents part of the required area for the low thermal loading (25 MTU/acre) layout. However, as discussed in Section 3.4, this area is adequate for the high thermal loading (83 MTU/acre) layout. The corresponding areal distribution of the pathways for the 83 MTU/acre case is shown in Figure 3.8-3.

\section{Primary Area (Lower Block)}

This emplacement area includes three columns from the Wittwer et al., (1995) model, with only modest changes in hydrogeologic unit thicknesses. A single pathway was therefore chosen to represent this region, shown as pathway 7 in Figure 3.8-2. 'The stratigraphy was determined, as before, by averaging the thicknesses of the various units for the three columns within this pathway. Note that this pathway is used only in the analysis of the 25 MTU/acre case.

\section{Optional Areas}

Because of limited stratigraphic information in the regions corresponding to the Optional Areas, it was decided to treat each emplacement panel as a single pathway. These are shown as pathways 8, 9, and 10 in Figure 3.8-2. Stratigraphic information for these panels has been tabulated in M\&O (1994c) in terms of minimum and maximum thickness for each hydrogeologic unit. This description has been simplified to provide an average thickness for each hydrogeologic unit in the present study. Note that these pathways are used only in the analysis of the $25 \mathrm{MTU} /$ acre case.

\subsubsection{Comparative Statistics}

The thickness of TSw, TSv, CHnv and CHnz units for each of the 10 pathways is given in Table 3.8-1. Also provided therein is the relative area occupied by the footprint of each pathway (as a percentage of the total emplacement area) for the $25 \mathrm{MTU} / a c r e$ and the $83 \mathrm{MTU} /$ acre cases. Note that the total area utilized for the $25 \mathrm{MTU} / \mathrm{acre}$ layout is $2535 \mathrm{acres}$, and for the 83 MTU/acre layout is 760 acres - assuming that 63,000 MTU are emplaced. A bar graph showing a visual comparison of the relative thickness of each pathway and its components for the 10 pathways is displayed in Figure 3.8-4.

The hydrostratigraphic division employed by Wittwer et al., (1995), as shown in Figure 3.8-4, lumps the nonwelded Prow Pass, Bullfrog and Tram Members of the Crater Flat Group hereafter referred to as the Prow Pass nonwelded (PPn) unit - into the Calico Hills nonwelded $(\mathrm{CHn})$ hydrogeologic unit. The rationale for this simplification is the similarity in the degree of welding (and hence in hydrologic properties) between these units and the overlying nonwelded vitric/zeolitic rocks of the Calico Hills formation. Although adequate for modeling water flow under ambient conditions, this strategy is inappropriate for modeling nuclide transport because of the difference in sorption properties between CHnz and PPn. Thus, a further partitioning of the CHnz unit as described in Wittwer et al., (1995) into CHnz and PPn is needed for transport modeling purposes. The relative proportion of $\mathrm{PPn}$ in the CHnz-PPn sequence is obtained from the 3-D thermo-mechanical stratigraphic model of Ortiz et al., (1985), and interpolated onto the pathway map shown in Figure 3.8-2. This information is also tabulated in Table 3.8-1. 
Note that two complementary sources of information are used to develop the hydrostratigraphy of the pathways - the hydrogeologic model of Wittwer et al., (1995) and the thermo-mechanical model of Ortiz et al., (1985). In order to compare the consistency between the two, the ranges of thickness for the four hydrogeologic units (TSw, TSv, CHnv and CHnz) in the Primary Area (pathways 1-7) as predicted by the two models have been compared. As shown in the bar graph of Figure 3.8-5, there is good agreement between the predictions of Wittwer et al., (1995), denoted as LBL, and those of Ortiz et al., (1985), denoted as SNL. 
Table 3.2-1 Available Area for Potential Emplacement Panels

\begin{tabular}{|l|c|c|}
\hline \multirow{2}{*}{$\begin{array}{c}\text { Potential } \\
\text { Emplacement Panel }\end{array}$} & \multicolumn{2}{|c|}{ Available Area } \\
\cline { 2 - 3 } & $\left(\mathbf{m}^{\mathbf{2}}\right)$ & (acres) \\
\hline \hline Primary Area (Upper Block) & $3,766,000$ & 930.6 \\
\hline Primary Area (Lower Block) & 883,000 & 218.2 \\
\hline Optional Area A & 634,000 & 156.7 \\
\hline Optional Area B & $1,777,000$ & 439.1 \\
\hline Optional Area C & $1,467,000$ & 362.5 \\
\hline Optional Area D & $2,369,000$ & 585.4 \\
\hline
\end{tabular}


Table 3.5-1 . Dimensions of Waste Disposal Containers for A Typical Large MPC and DHLW $^{1}$

\begin{tabular}{|c|c|c|}
\hline Parameters & Large MPC & DHLW \\
\hline Capacity & $\begin{array}{c}\text { 21 PWR or 40 BWR } \\
\text { Spent Fuel Assemblies }\end{array}$ & 4 Pour Canisters \\
\hline WP Number & 6323 & 3259 \\
\hline First Layer Inner Length & 4932.2 & 3040.0 \\
\hline First Layer Outer Length & 5012.2 & 3120.0 \\
\hline Second Layer Inner Length & 5012.2 & 3120.0 \\
\hline Second Layer Outer Length & 5682.2 & 3680.0 \\
\hline First Layer Inner Diameter & 1561.6 & 1569.0 \\
\hline First Layer Outer Diameter & 1601.6 & 1609.0 \\
\hline Second Layer Inner Diameter & 1601.6 & 1609.0 \\
\hline Second Layer Outer Diameter & 1801.2 & 1709.0 \\
\hline
\end{tabular}

1 Dimensions are in millimeters. 
Table 3.7-1 Spent Fuel Waste Inventory

\begin{tabular}{|c|c|}
\hline Isotope & $\begin{array}{c}\text { Multi-Barrier Waste } \\
\text { Package Design - 21 PWR } \\
\text { (Ci/pkg) }\end{array}$ \\
\hline${ }^{227} \mathrm{Ac}$ & $1.79 e-4$ \\
\hline${ }^{241} \mathrm{Am}$ & $3.73 \mathrm{e} 4$ \\
\hline${ }^{242 \mathrm{M}} \mathrm{Am}$ & $2.16 \mathrm{e} 2$ \\
\hline${ }^{243} \mathrm{Am}$ & $2.48 \mathrm{e} 2$ \\
\hline${ }^{14} \mathrm{C}$ & $1.38 \mathrm{e} 1$ \\
\hline${ }^{36} \mathrm{Cl}^{3}$ & $1.11 \mathrm{e}-1$ \\
\hline${ }^{244} \mathrm{Cm}$ & $1.16 \mathrm{e} 4$ \\
\hline${ }^{245} \mathrm{Cm}$ & $3.36 \mathrm{e} 0$ \\
\hline${ }^{246} \mathrm{Cm}$ & $6.95 e-1$ \\
\hline${ }^{135} \mathrm{Cs}$ & $5.13 \mathrm{e} 0$ \\
\hline${ }^{129} \mathrm{I}^{3}$ & $3.43 \mathrm{e}-1$ \\
\hline${ }^{93 \mathrm{M}} \mathrm{Nb}$ & $1.82 \mathrm{e} 1$ \\
\hline${ }^{94} \mathrm{Nb}$ & $8.24 \mathrm{e} 0$ \\
\hline${ }^{59} \mathrm{Ni}$ & $2.36 \mathrm{e} 1$ \\
\hline${ }^{63} \mathrm{Ni}$ & $3.10 \mathrm{e} 3$ \\
\hline${ }^{237} \mathrm{~Np}$ & $4.35 \mathrm{e} 0$ \\
\hline${ }^{231} \mathrm{~Pa}$ & $3.30 \mathrm{e} 04$ \\
\hline${ }^{210} \mathrm{~Pb}$ & $6.75 e-6$ \\
\hline${ }^{107} \mathrm{Pd}$ & $1.26 \mathrm{e} 0$ \\
\hline${ }^{238} \mathrm{Pu}$ & $3.05 \mathrm{e} 4$ \\
\hline${ }^{239} \mathrm{Pu}$ & $3.56 \mathrm{e} 3$ \\
\hline${ }^{240} \mathrm{Pu}$ & $5.26 \mathrm{e} 3$ \\
\hline${ }^{241} \mathrm{Pu}$ & $3.39 \mathrm{e} 5$ \\
\hline${ }^{242} \mathrm{Pu}$ & $2.01 \mathrm{e} 1$ \\
\hline${ }^{226} \mathrm{Ra}$ & $2.50 \mathrm{e}-5$ \\
\hline
\end{tabular}


Table 3.7-1. Spent Fuel Waste Inventory (Continued)

\begin{tabular}{|c|c|}
\hline Isotope & $\begin{array}{c}\text { Multi-Barrier Waste } \\
\text { Package Design - 21 PWR } \\
\text { (Ci/pkg) }\end{array}$ \\
\hline${ }^{228} \mathrm{Ra}$ & $3.10 \mathrm{e}-9$ \\
\hline${ }^{79} \mathrm{Se}$ & $4.41 \mathrm{e} 0$ \\
\hline${ }^{151} \mathrm{Sm}$ & $3.53 \mathrm{e} 3$ \\
\hline${ }^{126} \mathrm{Sn}$ & $8.50 \mathrm{e} 0$ \\
\hline${ }^{99} \mathrm{Tc}$ & $1.40 \mathrm{e} 2$ \\
\hline${ }^{229} \mathrm{Th}$ & $3.54 \mathrm{e}-6$ \\
\hline${ }^{230} \mathrm{Th}$ & $3.59 \mathrm{e}-3$ \\
\hline${ }^{232} \mathrm{Th}$ & $4.35 \mathrm{e}-9$ \\
\hline${ }^{233} \mathrm{U}$ & $7.01 \mathrm{e}-4$ \\
\hline${ }^{234} \mathrm{U}$ & $1.34 \mathrm{e} 1$ \\
\hline${ }^{235} \mathrm{U}$ & $1.68 \mathrm{e}-1$ \\
\hline${ }^{236} \mathrm{U}$ & $2.72 \mathrm{e} 0$ \\
\hline${ }^{238} \mathrm{U}$ & $3.07 \mathrm{e} 0$ \\
\hline${ }^{93} \mathrm{Zr}$ & $2.38 \mathrm{e} 1$ \\
\hline
\end{tabular}

'Assumes 40,785 MTU PWR with a burnup of 39,651 MWd/MTU, and 22,211 MTU BWR with a burnup of $31,186 \mathrm{MWd} / \mathrm{MTU}$

${ }^{2} 9.74 \mathrm{MTHM} /$ container, 21 PWR case

${ }^{3}$ Carbon, Chlorine, and Iodine inventory assumed to be gaseous release 
Table 3.7-2 DHLW Waste Inventory

\begin{tabular}{|c|c|}
\hline Isotope & $\begin{array}{c}\text { DHLW Inventory } \\
\text { (Ci/pkg) }^{1}\end{array}$ \\
\hline${ }^{227} \mathrm{Ac}$ & $6.02 \mathrm{E}-4$ \\
\hline${ }^{241} \mathrm{Am}$ & 8.65E1 \\
\hline${ }^{242 \mathrm{M}} \mathrm{Am}$ & $2.06 \mathrm{E}-2$ \\
\hline${ }^{243} \mathrm{Am}$ & 3.67E-2 \\
\hline${ }^{14} \mathrm{C}$ & 0 \\
\hline${ }^{36} \mathrm{Cl}$ & 0 \\
\hline${ }^{244} \mathrm{Cm}$ & $1.14 \mathrm{E} 1$ \\
\hline${ }^{245} \mathrm{Cm}$ & $5.64 \mathrm{E}-5$ \\
\hline${ }^{246} \mathrm{Cm}$ & $6.39 \mathrm{E}-6$ \\
\hline${ }^{135} \mathrm{Cs}$ & $1.15 \mathrm{E}-1$ \\
\hline${ }^{129} \mathrm{~T}$ & $1.90 \mathrm{E}-6$ \\
\hline${ }^{93 \mathrm{M}} \mathrm{Nb}$ & $5.48 \mathrm{E}-1$ \\
\hline${ }^{94} \mathrm{Nb}$ & 3.02E-5 \\
\hline${ }^{59} \mathrm{Ni}$ & $2.70 \mathrm{E}-2$ \\
\hline${ }^{63} \mathrm{Ni}$ & 0 \\
\hline${ }^{237} \mathrm{~Np}$ & 2.83E-2 \\
\hline${ }^{231} \mathrm{~Pa}$ & 9.74E-4 \\
\hline${ }^{210} \mathrm{~Pb}$ & $2.72 \mathrm{E}-8$ \\
\hline${ }^{107} \mathrm{Pd}$ & 0 \\
\hline${ }^{238} \mathrm{Pu}$ & $4.00 \mathrm{E} 2$ \\
\hline${ }^{239} \mathrm{Pu}$ & $4.73 \mathrm{E} 0$ \\
\hline${ }^{240} \mathrm{Pu}$ & $3.30 \mathrm{E} 0$ \\
\hline${ }^{241} \mathrm{Pu}$ & $1.48 \mathrm{E} 2$ \\
\hline${ }^{242} \mathrm{Pu}$ & $5.02 \mathrm{E}-3$ \\
\hline${ }^{226} \mathrm{Ra}$ & 9.37E-8 \\
\hline${ }^{228} \mathrm{Ra}$ & 0 \\
\hline
\end{tabular}


Table 3.7-2. DHLW Waste Inventory (Continued)

\begin{tabular}{|c|c|}
\hline Isotope & $\begin{array}{c}\text { DHLW Inventory } \\
\text { (Ci/pkg) }{ }^{1}\end{array}$ \\
\hline${ }^{79} \mathrm{Se}$ & $9.18 \mathrm{E}-2$ \\
\hline${ }^{151} \mathrm{Sm}$ & 0 \\
\hline${ }^{126} \mathrm{Sn}$ & 0 \\
\hline${ }^{99} \mathrm{Tc}$ & $3.30 \mathrm{E} 0$ \\
\hline${ }^{229} \mathrm{Th}$ & $1.51 \mathrm{E}-5$ \\
\hline${ }^{230} \mathrm{Th}$ & $1.24 \mathrm{E}-5$ \\
\hline${ }^{232} \mathrm{Th}$ & $1.05 \mathrm{E}-4$ \\
\hline${ }^{233} \mathrm{U}$ & $5.84 \mathrm{E}-4$ \\
\hline${ }^{234} \mathrm{U}$ & $5.00 \mathrm{E}-2$ \\
\hline${ }^{235} \mathrm{U}$ & $7.93 \mathrm{E}-5$ \\
\hline${ }^{236} \mathrm{U}$ & $4.35 \mathrm{E}-4$ \\
\hline${ }^{238} \mathrm{U}$ & $3.78 \mathrm{E}-3$ \\
\hline${ }^{93} \mathrm{Zr}$ & $7.01 \mathrm{E}-1$ \\
\hline
\end{tabular}

'Assumed 4 canisters per container.

Source: DOE (1987). Same inventory as DHLW inventory in TSPA-1993. 
Table 3.8-1 Pathway Thicknesses and Relative Areas

\begin{tabular}{|c|c|c|c|c|c|c|c|c|}
\hline \multirow[b]{2}{*}{ Pathway } & \multicolumn{4}{|c|}{ Thickness (m) } & \multirow{2}{*}{$\begin{array}{c}\text { Total } \\
\text { Thickness (m) }\end{array}$} & \multirow{2}{*}{$\begin{array}{c}\text { \% PPn in } \\
\text { CHnz }\end{array}$} & \multirow{2}{*}{$\begin{array}{l}\text { \% total area } \\
\text { (25 MTU/ac) }\end{array}$} & \multirow{2}{*}{$\begin{array}{l}\% \text { total } \\
\text { area }(83 \\
\mathrm{MTU} / \mathrm{ac})\end{array}$} \\
\hline & TSw & TSv & CHnv & CHnz & & & & \\
\hline 1 & 105 & 8 & 92 & 139 & 345 & 83 & 7.2 & 14.8 \\
\hline 2 & 176 & 8 & 72 & 88 & 344 & 43 & 6.1 & 8.0 \\
\hline 3 & 87 & 8 & 105 & 158 & 358 & 80 & 4.9 & 16.4 \\
\hline 4 & 147 & 8 & 87 & 118 & 359 & 52 & 3.4 & 11.1 \\
\hline 5 & .35 & 7 & 132 & 198 & 372 & 80 & 6.3 & 20.7 \\
\hline 6 & 113 & 7 & 102 & 148 & 370 & 71 & 8.9 & 29.0 \\
\hline 7 & 151 & 8 & 55 & 68 & 282 & 0 & 9.2 & - \\
\hline 8 & 105 & 15 & 54 & 66 & 240 & 73 & 17.7 & - \\
\hline 9 & 80 & 15 & 63 & 77 & 235 & 73 & 14.7 & - \\
\hline 10 & 85 & 15 & 47 & 58 & 205 & 73 & 21.6 & - \\
\hline
\end{tabular}




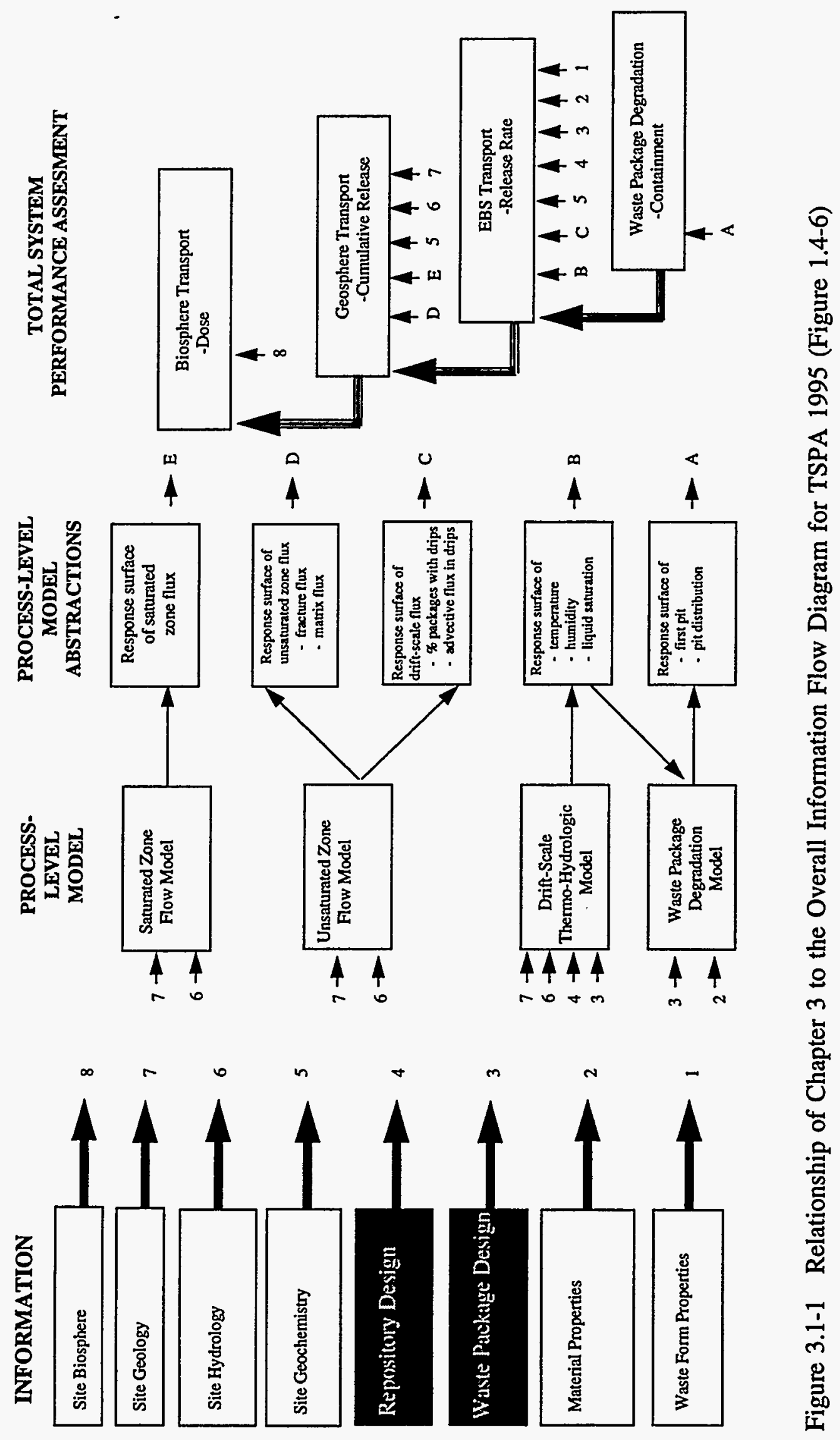




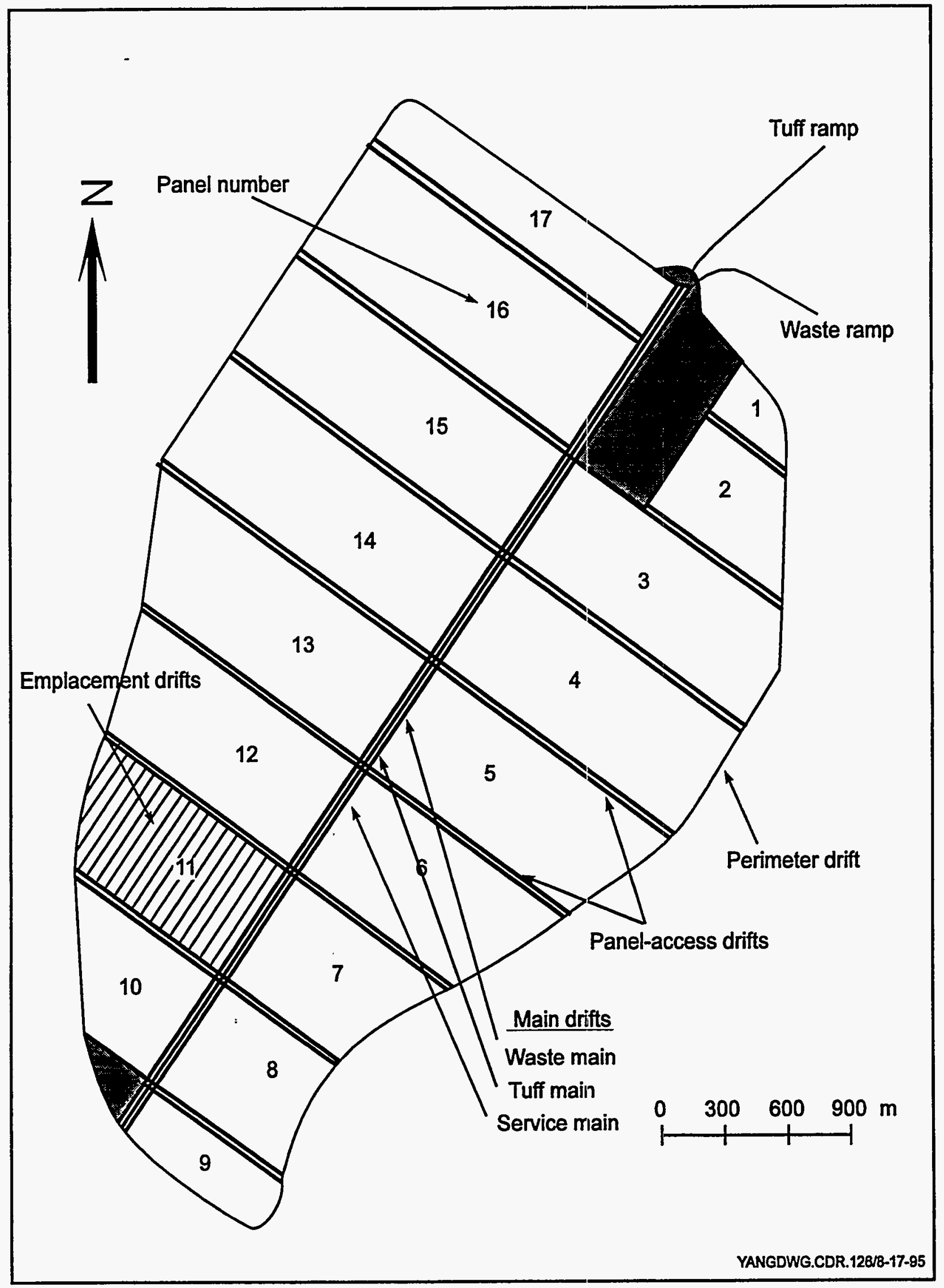

Figure 3.2-1 SCP-CDR repository layout (after DOE, 1988) 


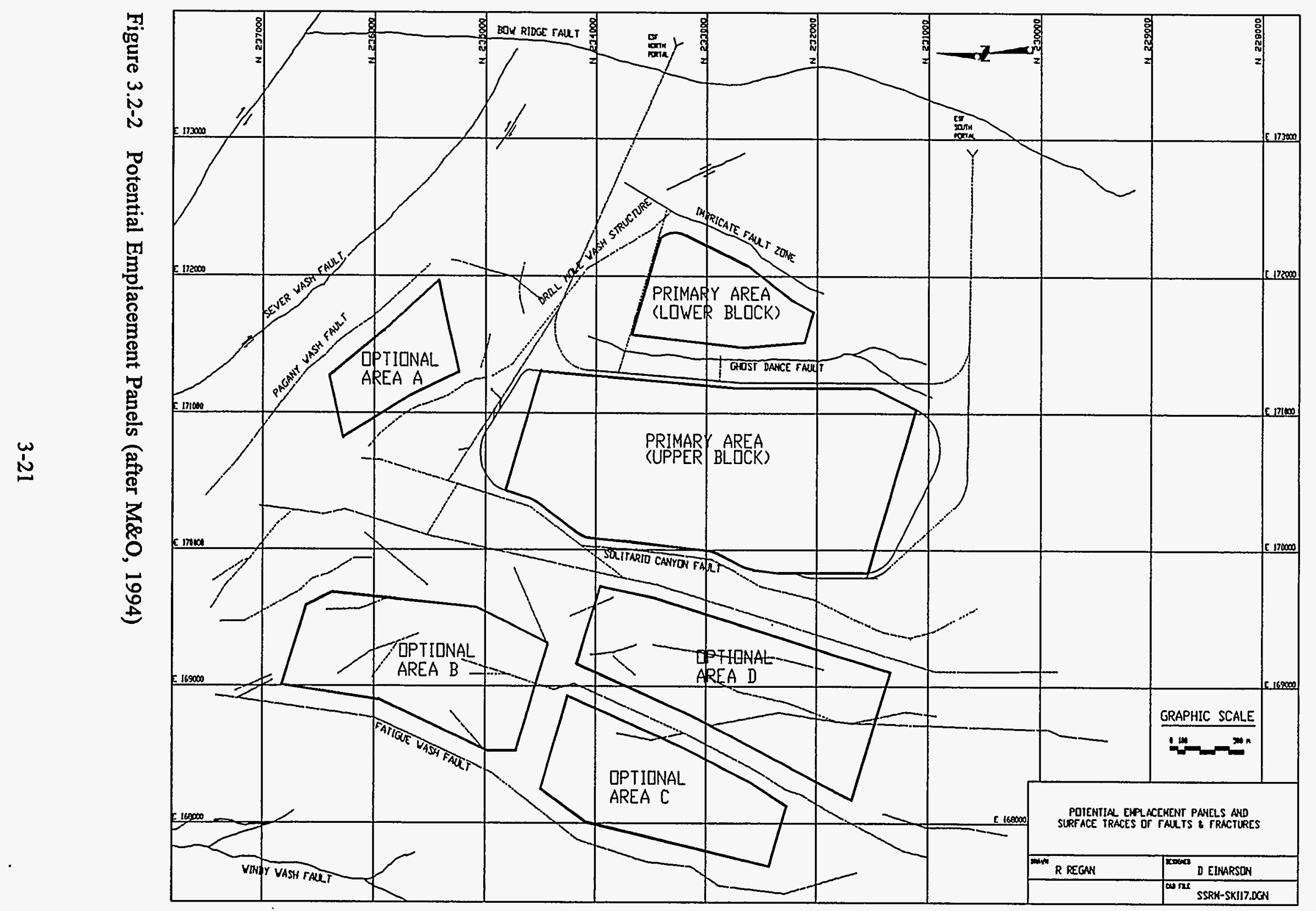




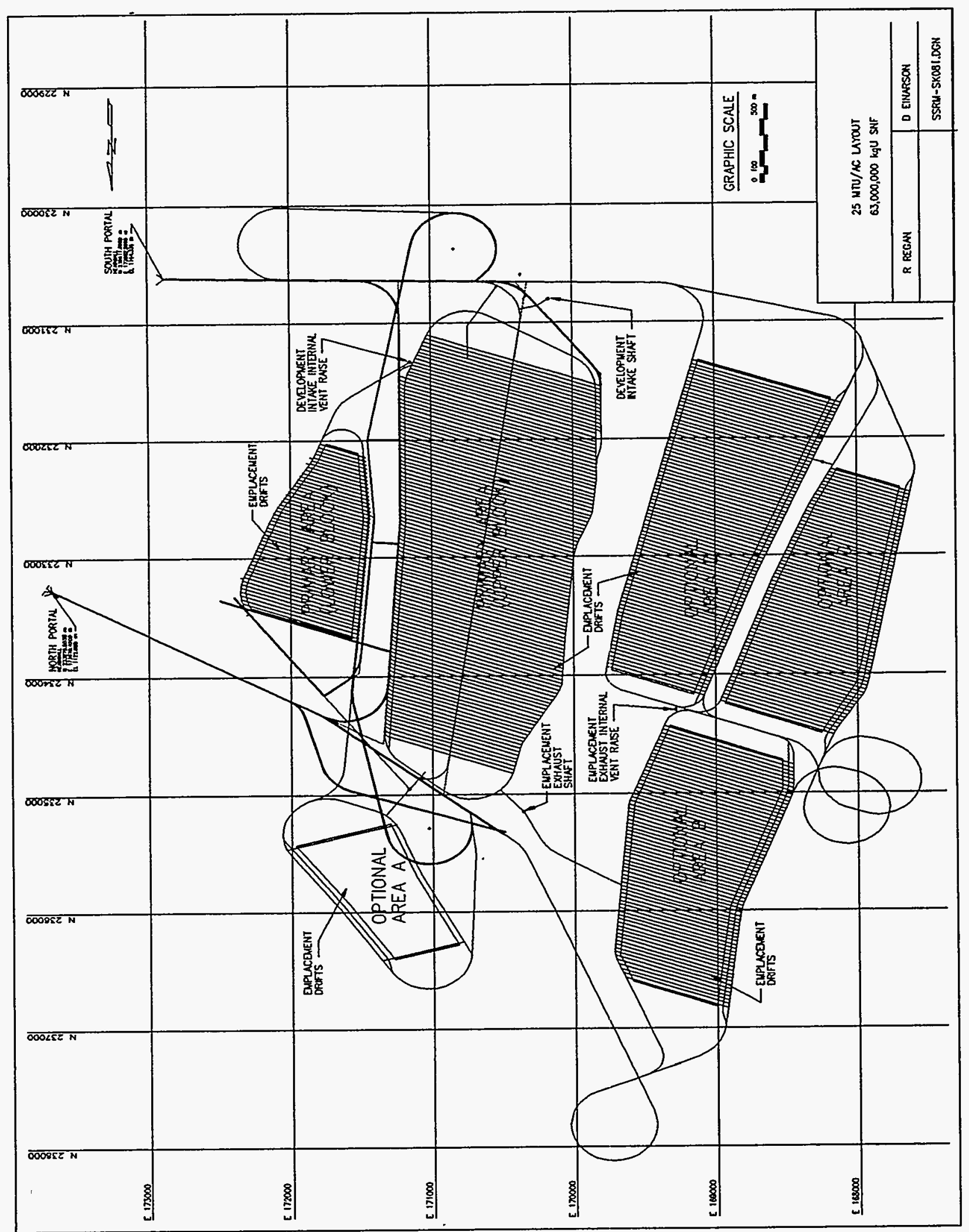

Figure 3.4-1 25 MTU/acre Layout 


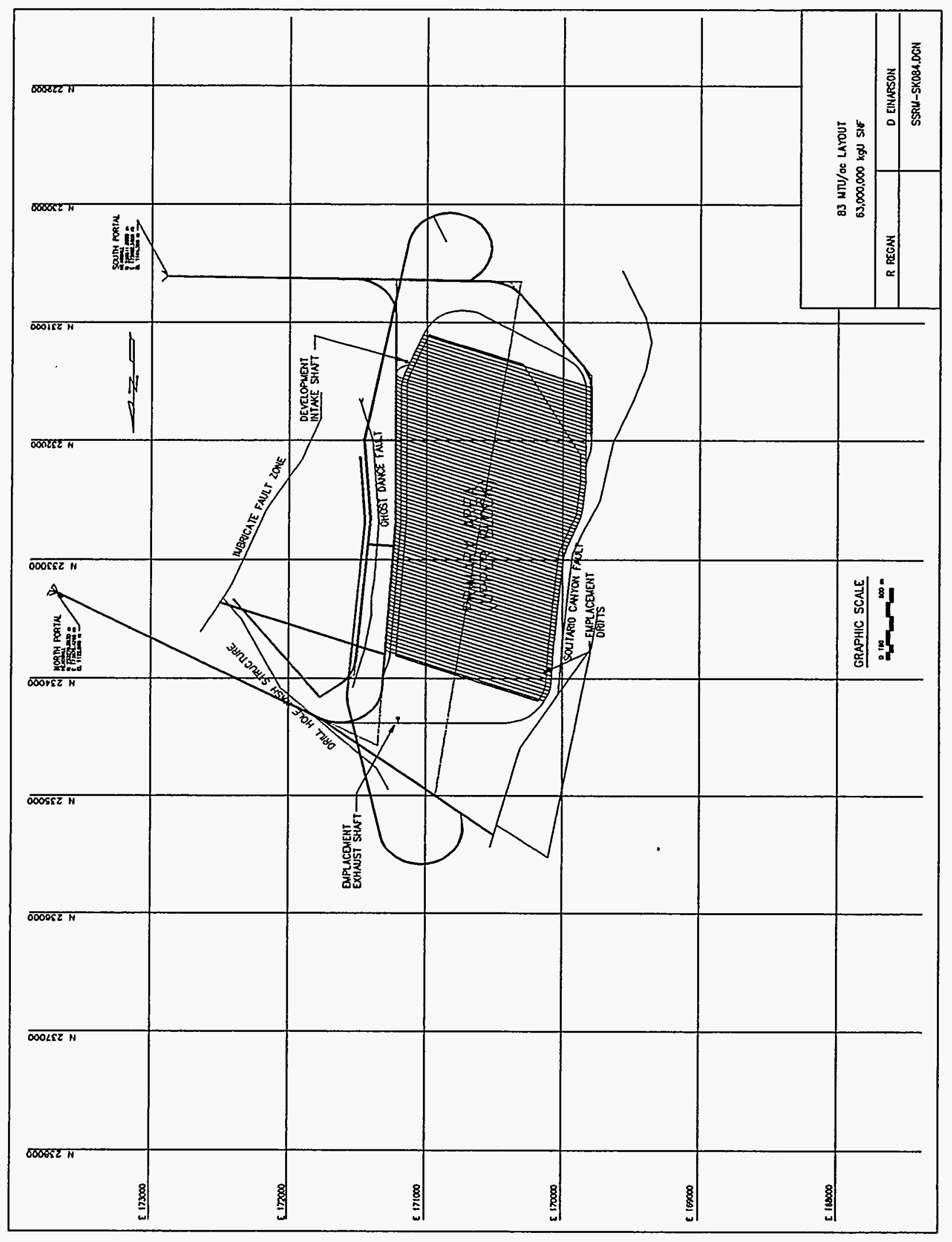

Figure 3.4-2 83 MTU/acre Layout 

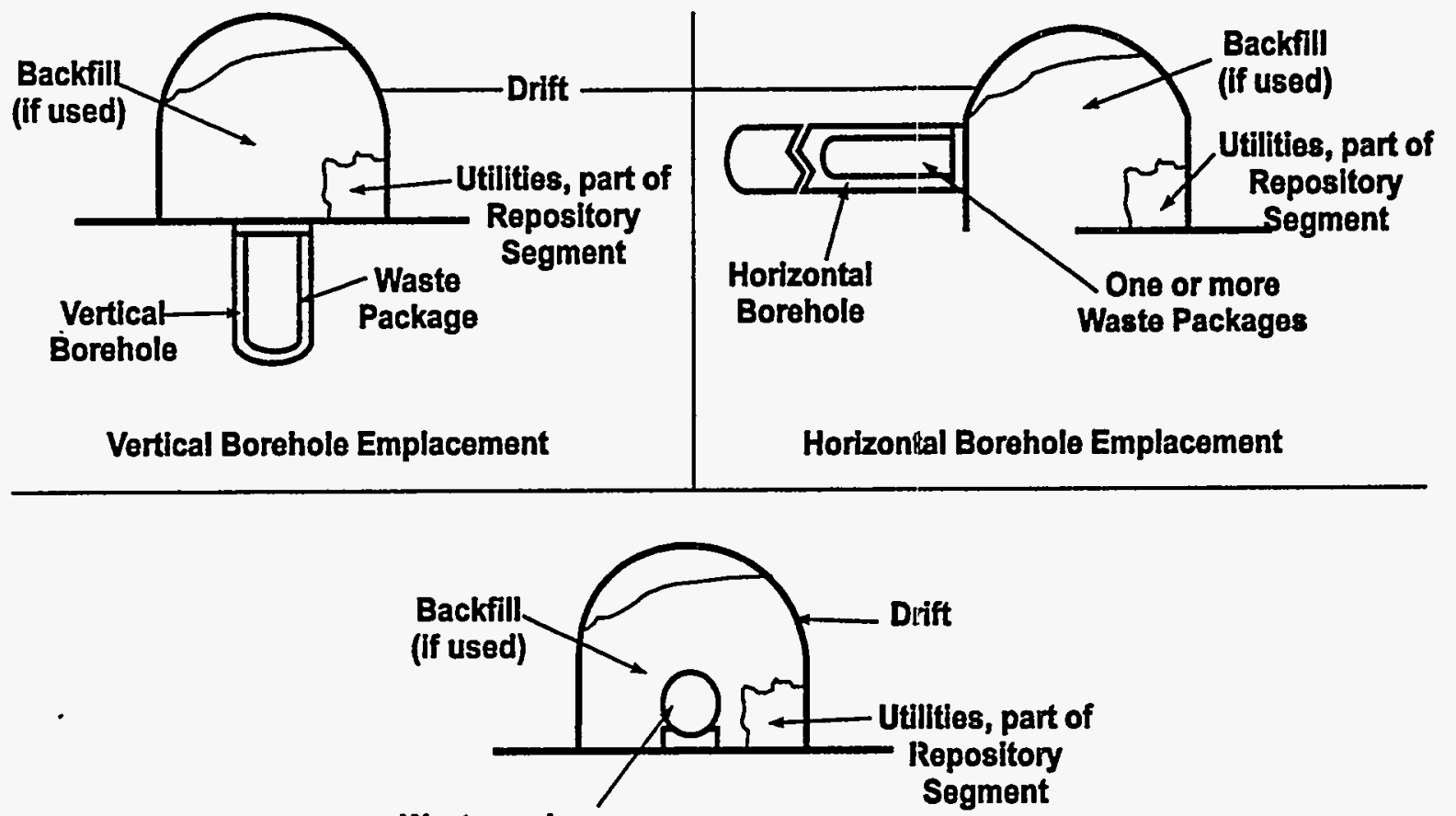

Waste package

with supporting structure

\section{In-Drift Emplacement}

Figure 3.6-1 Borehole and in-drift emplacement concepts from SCP-CDR (DOE, 1988)

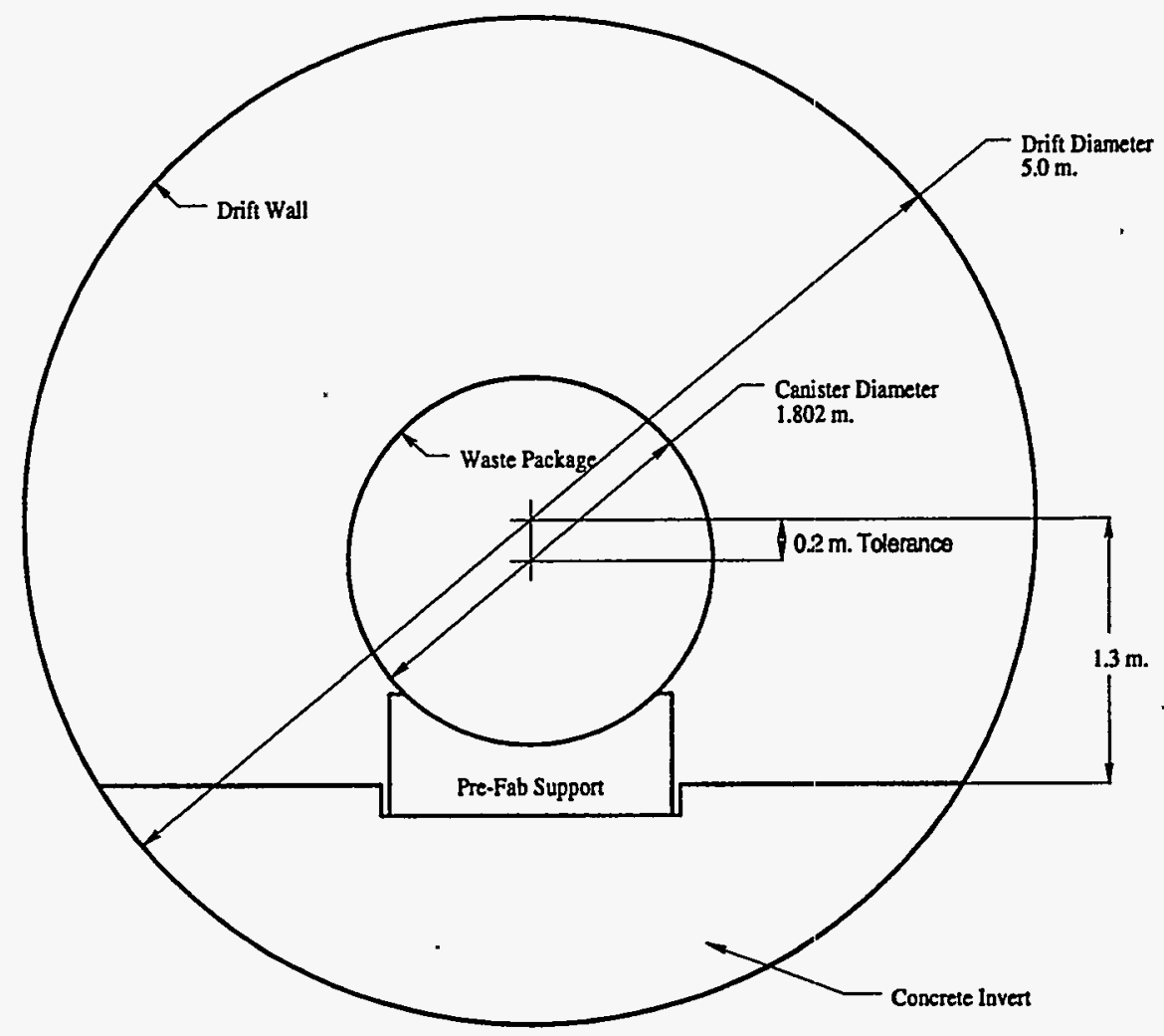

Figure 3.6-2 Emplacement drift design for the CIDP option (after M\&O, 1995f) 

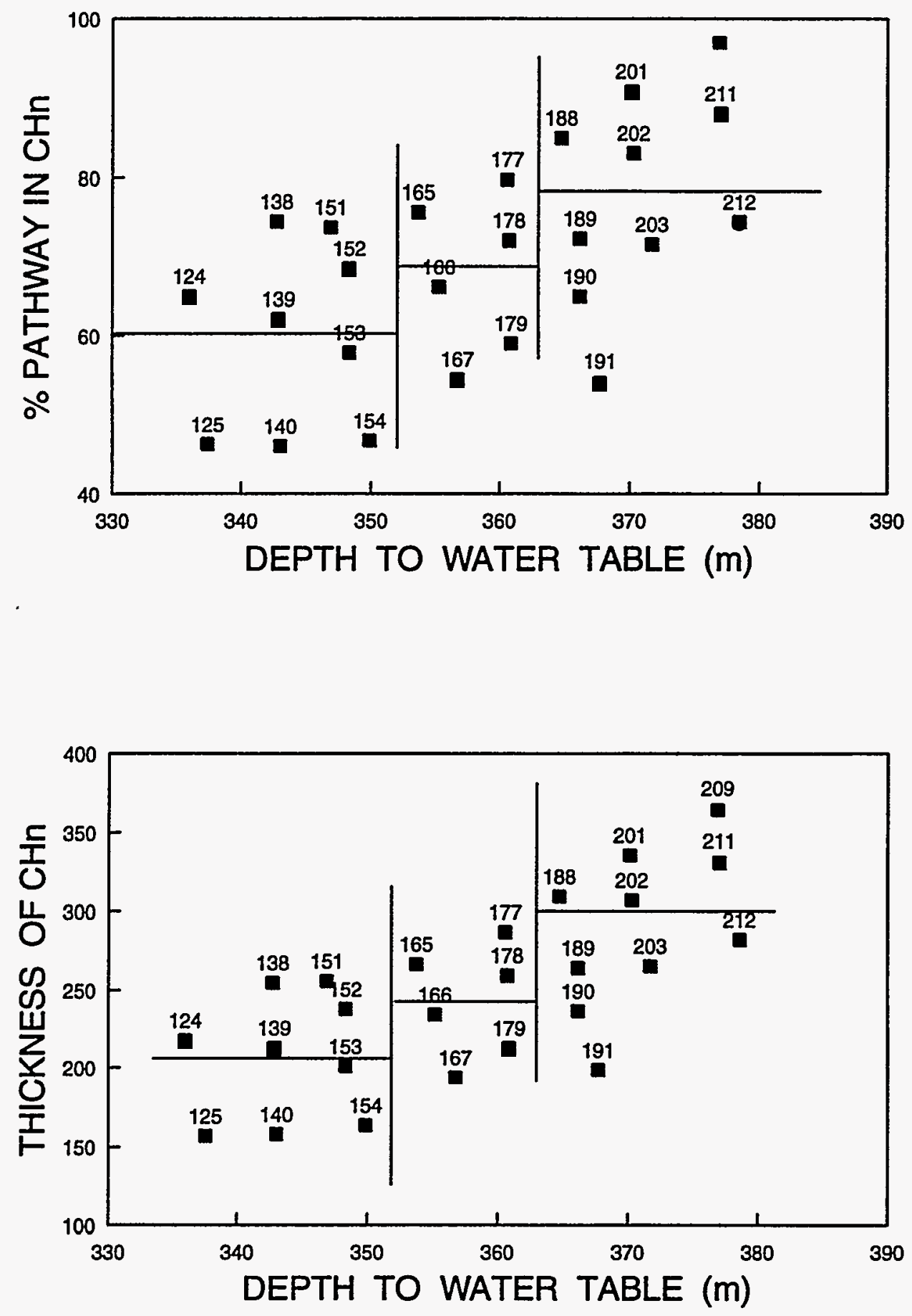

Figure 3.8-1 Subdivision of Primary Area (Upper Block) into six (6) pathways 


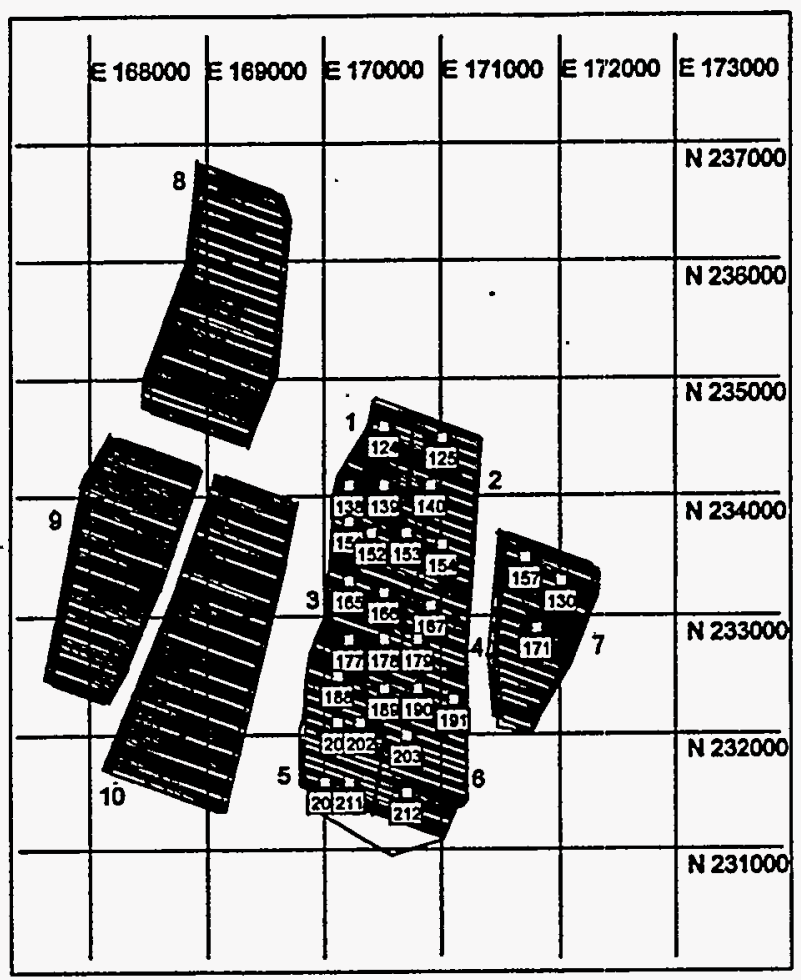

Figure 3.8-2 Pathway definition for 25 MTU/acre Case

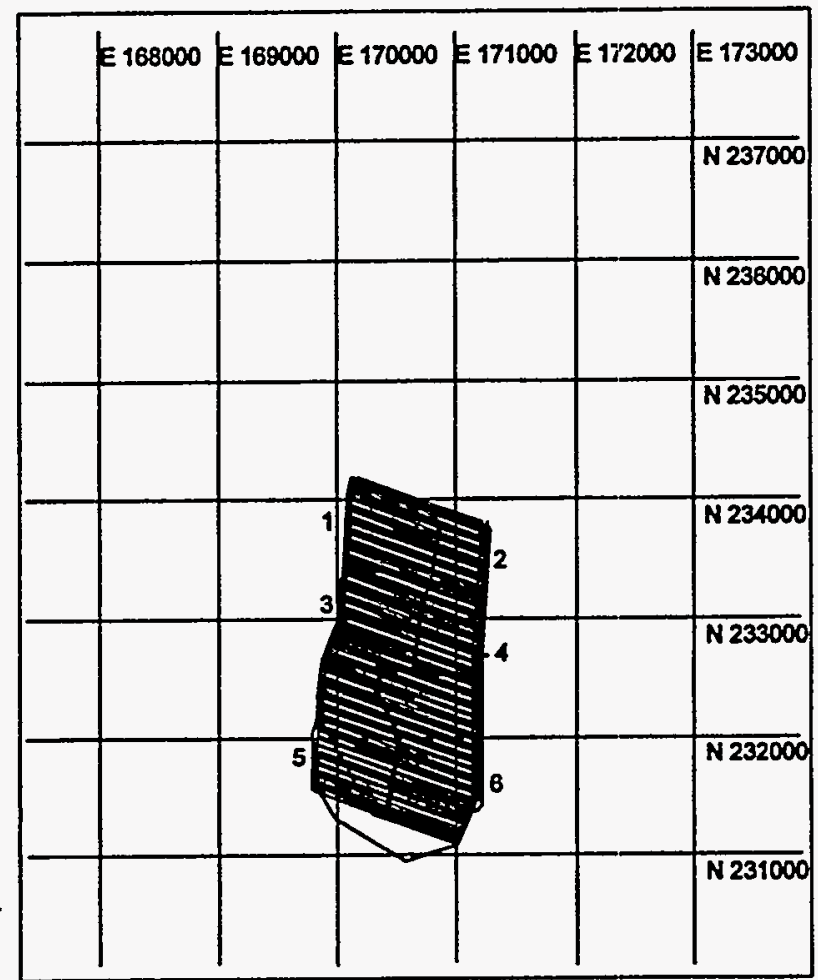

Figure 3.8-3 Pathway definition of 83 MTU/acre Case 


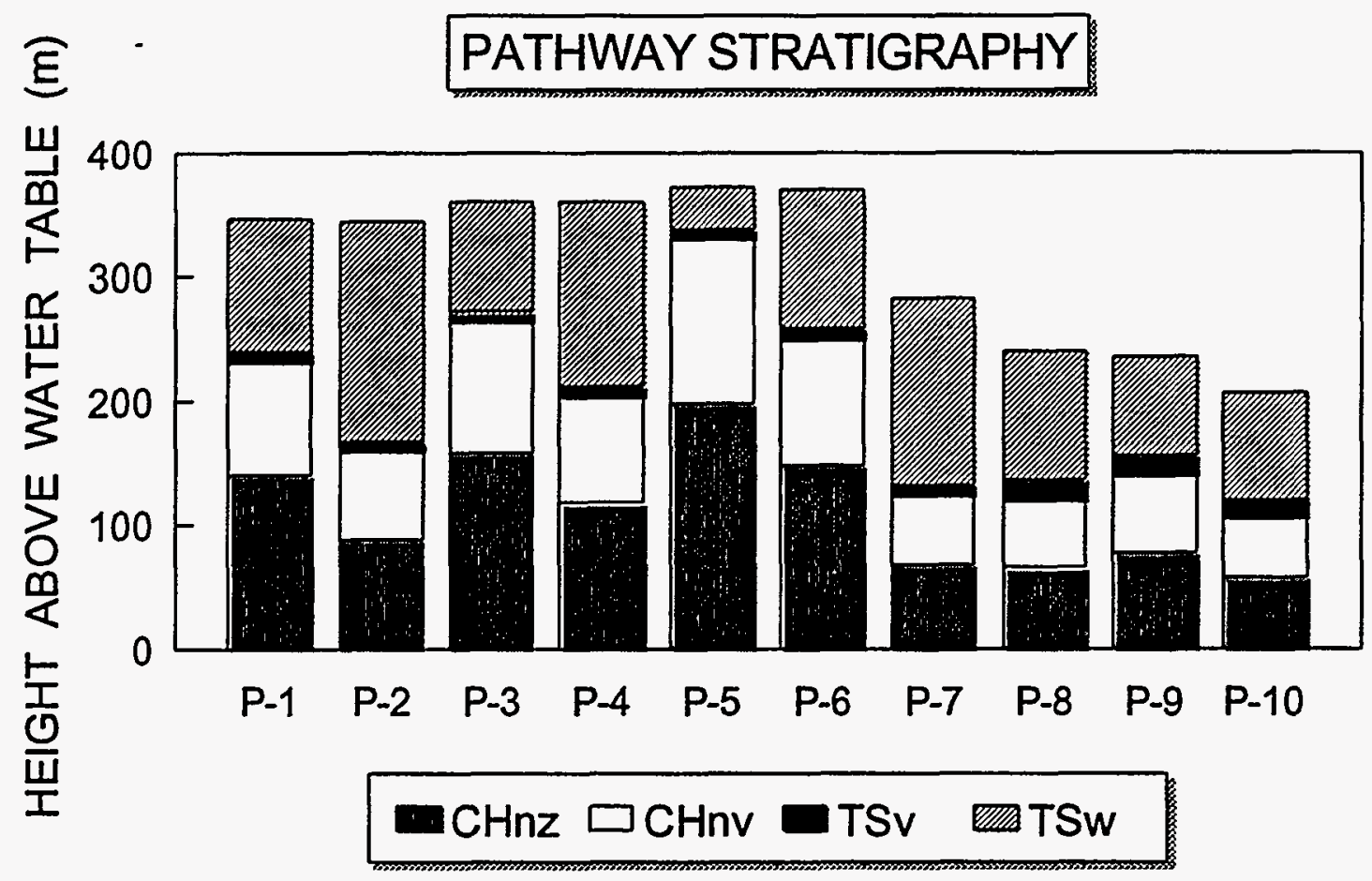

Figure 3.8-4 Relative thickness of pathways and their components

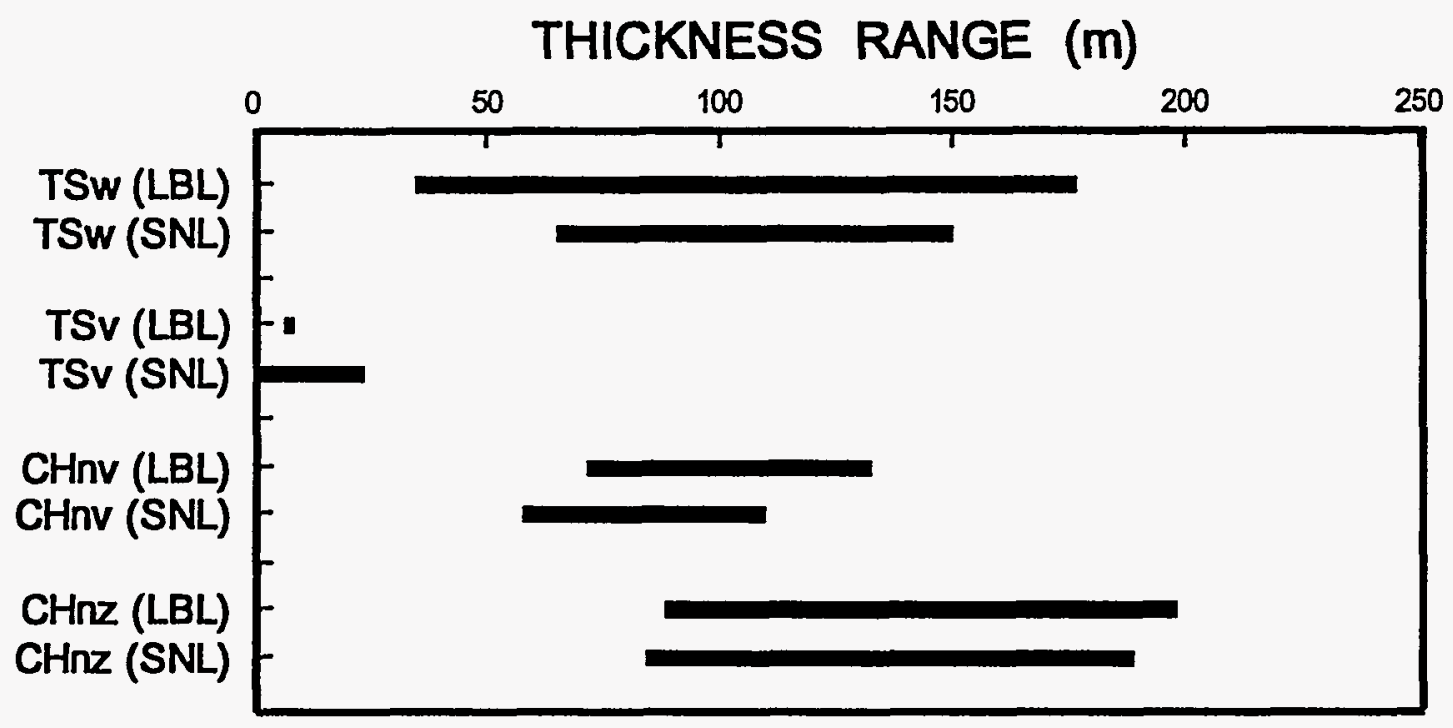

Figure 3.8-5 Comparison of thickness ranges predicted by Wittwer et al., (1995) [LBL] and Ortiz et al., (1985) [SNL] 
CHAPTER 4

NEAR-FIELD ENVIRONMENT 


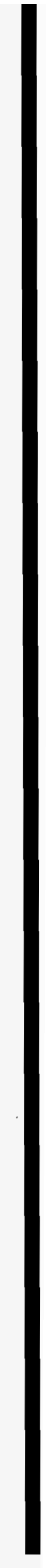




\title{
4. NEAR-FIELD ENVIRONMENT
}

\author{
Suresh Lingineni, Srikanta Mishra, Laureen R. Kennedy, Mark Reeves, \\ Frank Tsai, David C. Sassani
}

\subsection{INTRODUCTION}

The performance of the waste package and other components of the engineered system is affected by the environment in the vicinity of the waste packages. This environment is determined by the ambient hydrogeologic and hydrochemical conditions and the perturbation of these conditions by the emplacement of materials introduced into the drifts during construction and operation of the facility. A perturbation of central interest is the increase in temperature caused by the generation of heat from the radioactive waste itself.

Thermohydrologic perturbations to the near-field environment have a significant effect on total system performance. This is a result of: (a) the dependence of the initiation and rate of humid air and aqueous corrosion on the humidity and temperature within the drift, and (b) the effect of liquid saturation on the diffusive release of radionuclides through the waste package and driftemplaced materials. Consequently, the primary near-field environment process-level model considered in this TSPA is the drift-scale thermal hydrology (Figure 4.1-1).

A detailed drift-scale thermohydrologic model was developed to simulate the heat transport and fluid flow caused by two different thermal loading scenarios (25 and 83 MTU/acre). Results from the drift-scale thermohydrologic analyses presented in Section 4.2 are used in subsequent corrosion modeling (Chapter 5) and repository-scale release analyses (Chapters 8 and 9).

An evaluation of the thermal effects at the edge of the repository is presented in Section 4.3. Although not used explicitly in TSPA-1995, these calculations are important in determining the cooling that may occur at the repository edge and the overall impact on the hydrologic conditions in the outer portion of the repository. Two other potential thermal couplings, mechanical and chemical, are discussed briefly in Sections 4.4 and 4.5 , respectively. The thermal-mechanical effects are not explicitly included in TSPA-1995, but include such factors as rock fabric alterations that may affect repository performance. The thermal-chemical effects are included in TSPA-1995 through temperature-dependent solubilities and waste form dissolution rates.

\subsection{DRIFT-SCALE THERMAL-HYDROLOGY}

The near-field thermohydrologic model developed to evaluate the heat transport and fluid flow occurring in the vicinity of heat-generating waste packages is described in this section. The model simulates various processes initiated as a result of the emplacement of heat-generating waste, including: conductive and convective heat transfer; boiling and condensation; capillary adsorption and vapor pressure lowering; and thermal buoyancy driven vapor flow. All of these processes can alter the distribution and movement of heat and/or water in the vicinity of the repository and thus have a significant effect on waste package degradation, waste package failure rates and transport of radionuclides from the breached waste packages through the EBS/geosphere to the accessible environment. 
The major objectives of the drift-scale thermohydrologic analyses were as follows:

- To develop a drift scale thermohydrologic model that can simulate the near-field fluid flow and heat transport processes.

- To predict temperatures and liquid saturations in the vicinity of the waste packages, for various infiltration rates, thermal loadings, and backfill scenarios.

- To provide abstractions of waste package temperatures and relative humidities near the waste packages for use in corrosion models and TSPA analyses using RIP.

The computational model chosen for performing near-field thermohydrologic simulations is the FEHM (Finite Element Heat and Mass Transfer) code developed at Los Alamos National Laboratory (Zyvoloski et al., 1995). This code is one of the multiphase, non-isothermal flow and transport codes shortlisted through a careful review of existing models from those currently used in the DOE waste management programs and those used in the recent past (Reeves et al., 1994).

\subsubsection{Overview of FEHM}

FEHM is a multi-dimensional heat and mass transfer code developed to simulate non-isothermal multiphase flow in porous media under saturated and unsaturated conditions (Zyvoloski, et al., 1995). The code simulates fluid flow in both gas and liquid phases under pressure, viscous, and gravity forces according to Darcy's equation. FEHM also accounts for the capillarity between liquid and gas phases as well as phase interference (relative permeability) effects. Fracture-matrix coupling can be simulated in FEHM via dual-porosity, dual-permeability or the equivalent continuum model (ECM) formulations.

Within FEHM, Kelvin's law is used to represent vapor pressure lowering due to capillary effects. Interphase equilibrium of the condensing gas component is described with standard steam tables. FEHM uses finite-element spatial discretization for both flow and transport. A Newton-Raphson technique is employed to linearize the coupled set of non-linear difference equations. FEHM solves the linearized equations for liquid pressure, temperature, and gas saturation using the minimum-residual technique, a variant of conjugate-gradient approach which is suitable for nonsymmetric elements.

The original version of FEHM can simulate heat flow by conduction and convection of sensible and latent heat. During the preclosure period and/or in the case of non-backfilled drifts, the waste package will lie on a pedestal surrounded by an air-gap between the drift wall and the waste package. Under such conditions heat transfer due to radiation is expected to be the dominant mechanism of heat flow from the waste package to the drift wall. The current version of FEHM used to perform these thermohydrologic simulations has therefore been modified to account for radiative heat transfer.

\subsubsection{Model Geometry}

The near-field thermohydrologic model developed in this work assumes a two-dimensional geometry in a plane orthogonal to the drift and extending from ground surface to the top of the 
water table (Figure 4.2-1). The modeled domain represents a unit cell within the drift, which consists of a single waste package placed inside a horizontal drift. Waste packages are assumed to be placed on pedestals lying atop an invert. The lateral width of the domain extends to the symmetry boundary between two adjacent drifts. The modeled geometry is discretized into a fine two-dimensional mesh near the waste package which gradually transitions into essentially onedimensional grid blocks (coarse discretization in the horizontal direction) in the far-field (Figure 4.2-2). As shown in Figure 3.6-2, the diameter of the drift is $5 \mathrm{~m}$ and the diameter of the waste package is $1.8 \mathrm{~m}$. For a given drift spacing and waste package capacity, the waste package spacing is determined from the choice of areal mass loading. Thus, the width of the model domain along the drift depends on the areal mass loading being used in a simulation.

The area inside the drift is discretized into four cylindrical layers of elements with the innermost two layers representing the waste package itself. To simplify the analysis and to reduce the total number of elements required for the discretization of model geometry, the waste package outer boundary is approximated by a dodecagon. The heat generated from the waste package is smeared over elements within the two innermost layers, and the total heat generated is distributed to each element in proportion to its area.

\subsubsection{Model Assumptions}

Axial Smearing of Thermal Load: As the model geometry used in this study is two-dimensional, it cannot be used to discretely represent the waste package along the drift. Thus, the heat generated from the waste package has to be smeared across the entire length of the unit cell (which is the symmetry element between adjacent drifts and adjacent waste packages). This length is usually taken to be equal to the waste package spacing. However, as the WP spacing increases, the heat smearing occurs over longer lengths, which results in underprediction of waste package temperatures. These underpredictions are greater for the lower areal mass loading case for which the waste package spacing is much greater compared to its length. The details of heat smearing effects and measures taken to minimize (or to quantify the sensitivity of) these uncertainties are discussed in Section 4.2.6.

Ventilation; The near-field thermohydrologic simulations performed for this TSPA do not account for ventilation. The heat removal from a waste package and drift wall due to ventilation depends upon the axial location of the package along the drift and also upon the design of ventilation pathways. Due to the two-dimensional nature of this model, it is not possible to accurately represent the effects of ventilation on heat and fluid flow in the near-field environment. Also, it is beyond the current capabilities of available thermohydrologic codes to simulate water or moisture transfer from the host rock into the air gap through which ventilation air is flowing. Considering these uncertainties/limitations, and realizing that neglecting ventilation would provide higher waste package surface temperatures and higher relative humidities (conservative estimates in terms of waste package performance predictions in as much as both heat and moisture removal by ventilation are not considered), ventilation effects are not included in this model.

Saturated Zone: The saturated zone is not included in the model domain. This assumption is made primarily to avoid numerical instabilities caused by oscillations in gas pressures at nodes in the neighborhood of the water table. Previous studies (Lingineni et al., 1994, Buscheck et al., 1994) have shown that the effect of including the water table is significant at late time periods 
(after about 1000 years) after the thermal front reaches the water table. In the absence of the saturated zone in the model, the thermal boundary condition at the lower boundary plays an important role. This model assumes a constant prescribed temperature at the lower boundary, which is expected to remove heat from the repository at a faster rate at late time periods, thus giving rise to lower waste package temperatures at late times.

Relative Humidity: Predictions of relative humidity in the near field are performed assuming that local phase equilibrium exists at each location, and diffusional resistance and time scales for moisture transport in the rock as well as backfill are negligible. The details of these assumptions and their implications are explained in Section 4.2.7.

Fracture-Matrix Interaction: Fracture-matrix interaction is simulated using the equivalent continuum assumption. The paucity of data on geometric/hydraulic characteristics of fractures at Yucca Mountain, as well as the computational complexity associated with modeling hydrothermal behavior in a discrete fracture network, necessitates the use of such an assumption. The ECM formulation (Pruess et al., 1985) assumes capillary pressure and thermal equilibrium between the fractures and the matrix, which allows equivalent continuum properties to be derived by volume averaging of fracture and matrix characteristics. The assumption of capillary pressure continuity implies that for most cases of fracture density and permeability, the fractures will be dry so long as the matrix is not close to full liquid saturation. In other words, the ECM forces liquid movement to occur primarily within the matrix and to be controlled by the matrix permeability, whereas air/vapor movement takes place primarily in the fractures and is controlled by the fracture permeability.

\subsubsection{Stratigraphy and Hydrogeologic Properties}

The unsaturated zone consists of a series of variably fractured and variably welded tuffaceous rock units, with the stratigraphy taken to be that corresponding to Column 153 in the model of Wittwer et al., (1995). From the land surface down to the water table, the sequence of hydrostratigraphic units, and their corresponding thicknesses, are as follows: Tiva Canyon welded (TCw) - 94.7 m, Paintbrush nonwelded (PTn) - $52.9 \mathrm{~m}$, Topopah Spring welded (TSw) - $326 \mathrm{~m}$, Topopah Spring basal vitrophyre (TSv) $-8.4 \mathrm{~m}$, Calico Hills non-welded vitric (CHnv) - $80.7 \mathrm{~m}$, and Calico Hills non-welded zeolitic (CHnz) - $121.2 \mathrm{~m}$ (Figure 4.2-1). The water table is located at a depth of $683.9 \mathrm{~m}$ below the ground surface. The center of the potential repository horizon is located at a depth of $340.2 \mathrm{~m}$ below the ground surface within the TSw unit. Matrix and fracture hydraulic properties are based on data from Klavetter and Peters (1986), and are given in Tables 4.2-1 and 4.2-2. Also included therein are the hydrologic characteristics of the backfill, assuming it to be a 'gravel'-type material.

\subsubsection{Thermal Properties}

Thermal rock properties (shown in Table 4.2-3) correspond to those given in version 4 of the Reference Information Base (DOE, 1990). The backfill properties are assumed to be similar to that of TSw, with the thermal conductivity modified for the higher porosity of the backfill. The matrix thermal conductivity is assumed to vary with local liquid saturation with a square root dependence. The rock density, specific heat and thermal conductivity are assumed to be independent of temperature. A previous study carried out by Longenbaugh et al. (1994) 
illustrated the effect of temperature dependent thermal properties on thermal predictions of a conduction based model. Their results showed that temperature-dependent thermal property models predict lower temperatures in the near-field when compared to temperature independent thermal property models. However, the major contributing factor to these differences is the term arising due to energy absorption during water evaporation. As FEHM explicitly accounts for the latent heat of vaporization of water, neglecting other temperature dependencies of thermal properties is not expected to have a major impact on the near-field thermohydrologic predictions.

\subsubsection{Thermal Loading and Waste Stream Characteristics}

Thermal characteristics of the emplaced spent fuel assemblies are computed assuming "Oldest Fuel First (OFF)" for a 21-PWR assembly PWR package, with an average age of 26 years, a burnup of $39 \mathrm{GWd} / \mathrm{MTU}$ and an initial heat output of $0.98 \mathrm{~kW} / \mathrm{MTU}$. The heat generated from a representative waste package is shown in Figure 4.2-3. This information, together with the drift spacing and areal mass loading, is used to determine the waste package spacing, which corresponds to the depth of the unit cell along the drift axis. Thus, for an areal mass loading of $83 \mathrm{MTU} /$ acre and a nominal drift spacing of $22.5 \mathrm{~m}$, the waste package spacing becomes $19 \mathrm{~m}$, and for the $25 \mathrm{MTU} / \mathrm{acre}$ case with a $45 \mathrm{~m}$ drift spacing, it becomes $32 \mathrm{~m}$.

As mentioned earlier, the two-dimensional model used in this study cannot be used to represent discretely the waste package along the drift. However, smearing the heat generated from the waste package across the entire length of the unit cell would result in an underprediction of temperatures because the unit cell is larger than the waste package. On the other hand, assuming the heat output to be concentrated only along the length of the waste package would result in overprediction of temperatures because the heat loss to the rest of the unit cell would not be taken into account. In the absence of detailed three-dimensional simulations to resolve this issue, our preliminary solution has been to use a smearing length which is larger than the waste package length, but smaller than the length of the unit cell. Thus, for the $83 \mathrm{MTU} / \mathrm{acre}$ case, a smearing length of $15 \mathrm{~m}$ is used for a $19 \mathrm{~m}$-long unit cell, and for the $25 \mathrm{MTU} / \mathrm{acre}$ case, a smearing length of $30 \mathrm{~m}$ is used for the $32 \mathrm{~m}$-long unit cell.

\subsubsection{Initial and Boundary Conditions}

Initial conditions for the model are calculated assuming an average ground surface temperature of $13^{\circ} \mathrm{C}$ and a water-table temperature of $27^{\circ} \mathrm{C}$. Taking these two temperatures as boundary conditions, and assuming surface recharge rates of 0.05 and $0.3 \mathrm{~mm} / \mathrm{yr}$ for the two alternative infiltration scenarios, a steady-state solution of the full two-phase, non-isothermal flow problem yields initial conditions for the transient simulations with repository heating.

For the steady-state calculations of initial conditions described above (as well as for the subsequent transient simulations under thermal loading) the boundary conditions are set as follows. The lateral boundaries are taken to be of the no-flow type for both heat and fluid flow. Such an assumption is representative of unit cells in the middle of the repository due to symmetry, but not very realistic for drifts close to the edges of the repository. The upper boundary is assigned a constant pressure $(0.86 \mathrm{~atm})$ representative of atmospheric contact. The lower boundary (water table) is taken to be at a constant (hydrostatic) pressure of $1.0 \mathrm{~atm}$. 
As discussed in sections 2.6 and 7.2, two infiltration scenarios were considered in TSPA-1995, i.e., a "low" infiltration rate sampled uniformly between 0.01 and $0.05 \mathrm{~mm} / \mathrm{yr}$, and a "high" infiltration rate sampled between 0.5 and $2.0 \mathrm{~mm} / \mathrm{yr}$. However, for the thermohydrologic calculations described in this section, only two discrete values of the infiltration rate were considered for computational expediency. At one extreme, the value of $0.05 \mathrm{~mm} / \mathrm{yr}$ was taken to represent the low-infiltration rate scenario. At the other extreme, the value of $0.3 \mathrm{~mm} / \mathrm{yr}$ was used for the high-infiltration rate scenario. Numerical difficulties prevented the use of an infiltration rate higher than $0.3 \mathrm{~mm} / \mathrm{yr}$.

\subsubsection{Determination of Relative Humidity}

Relative humidity near the waste package surface is an important factor in the initiation of pitting of waste package surface as well as the corrosion rates of the waste package. In the current iteration of TSPA, a direct dependence of waste package performance on the relative humidity values in the near-field environment is incorporated. However, the multi-phase flow and transport models being used in support of thermohydrologic analyses being carried out at Yucca Mountain (i.e. TOUGH2, FEHM) do not have a rigorous way of calculating relative humidities. This limitation arises due to the fact that these codes do not solve for the transport of water vapor as a species, but assume local equilibrium conditions to calculate spatial and temporal variations in water vapor concentrations. Given these limitations in the code capabilities, the methodology described below was used in calculating relative humidities in the near-field environment.

Relative humidity $(\mathrm{RH})$ can be defined as the ratio of vapor pressure of water vapor $\left(\mathrm{P}_{\mathrm{v}}\right)$ at a particular location to the saturation water vapor pressure $\left(\mathrm{P}_{\mathrm{sat}}\right)$ at the temperature corresponding to that particular location (see Figure 4.2-4).

$$
R H=\frac{P_{v}}{P_{s a t}(T)}
$$

Thus, determination of relative humidity at a particular location requires information on both the temperature and local water vapor pressure. In the absence of explicit tracking of water vapor transport, it is a common practice to assume that local water vapor concentrations can be determined from Kelvin's law of vapor pressure lowering (lPruess, 1987). Kelvin's law relates the reduction in gas pressures due to gas-liquid interface effects, which then indirectly provides a relationship between water vapor pressure and local liquid saturation. Thus, Kelvin's law of vapor pressure lowering relates the local water vapor pressure to capillary pressure in the following functional form

$$
P_{v}=P_{s a s}(T) \exp \left[\frac{P_{c}}{\rho_{w} T R}\right]
$$

where $P_{c}$ is the local capillary pressure, $R$ is the gas constant, $\rho_{w}$ is the molar density of water and $T$ is the local temperature. 
Using the above relationship to determine relative humidity requires underlying assumptions that relate capillary pressure to the gas-liquid interface curvature. For example, to ensure that liquid flow ceases to exist at very low liquid saturations, it is customary to increase the capillary pressure to very high values. The exact magnitude of these high capillary pressure values is not very critical in flow calculations so long as numerical problems are avoided. However, in relative humidity calculations, unreasonably high values of capillary pressures imply that local humidity values are very low or zero, even though there is no physical basis for such result. This assumption plays an important role in the determination of relative humidity in the backfill area, because the liquid saturation levels are below or near residual saturations. The following discussion provides the methodology used in the determination of relative humidity in the nearfield thermohydrologic simulations.

The main assumption in determining water vapor pressure at the waste package surface is to equate the absolute water vapor pressures at the waste package surface and at the dry-out front (Figure 4.2-4). The dry-out front can be visualized as a loci of points where non-zero liquid saturations can be encountered as one moves away from the waste package into the host rock. The validity of this assumption is based upon relative magnitudes of the characteristic time for the diffusion of water vapor from the dry-out front to the waste package surface in comparison to the time scales of simulation. Simple calculations using diffusivity of water vapor in air show that the characteristic time for diffusion is of the order of days, which justifies the above approximation. However, it still neglects the effects of any near-field thermal or pressure gradients on water vapor transport away from the package. This approach provides conservative results in terms of relative humidity predictions and waste package degradation rates, because the relative humidity values are higher than might be calculated using actual thermal or pressure gradients in the near field.

\subsubsection{Drift-Scale Thermohydrologic Results}

For TSPA-1995, multiple thermohydrologic simulations were conducted in order to: (a) determine transient waste package surface temperatures, water content within drift material, and relative humidity in the vicinity of waste package surface, and (b) evaluate different design options. Two thermal loads were considered, 25 and $83 \mathrm{MTU} / \mathrm{acre}$. Also, cases with and without backfill material were considered. Simulations were carried out at two separate infiltration rates, viz. 0.05 and $0.3 \mathrm{~mm} / \mathrm{yr}$.

\section{Temperature and Relative Humidity at Waste Package Surface}

For each of the eight simulations performed with parametric variations in areal mass loading, infiltration rate and presence or absence of backfill, abstractions of waste package surface temperature and relative humidity in the vicinity of the waste package are provided as input to subsequent corrosion modeling and repository scale release analyses. Waste package surface temperatures are calculated as the average of all of the six nodal temperatures lying on the waste package surface. Relative humidity is calculated for each of the elements just outside the waste package and an average value is calculated to represent the abstracted relative humidity in the vicinity of the waste package. 
Figures 4.2-5 and 4.2-6 (and 4.2-8) show the time-dependent temperatures and relative humidities predicted at the waste package surface for an areal mass loading of $83 \mathrm{MTU} /$ acre, infiltration rates of $0.05 \mathrm{~mm} / \mathrm{yr}$ and $0.3 \mathrm{~mm} / \mathrm{yr}$, and with and without backfill. For each of these simulations, the following general trends can be observed. Peak waste package surface temperatures are predicted to occur within 10 to 20 years after waste emplacement. In the case of backfilled drifts, there is a small increase in the waste package temperatures due to the placement of lowthermal conductivity backfill material at 100 years. Waste package surface temperatures gradually decrease to about $60^{\circ} \mathrm{C}$ at 10,000 years. It should be noted that these waste package surface temperatures at longer time periods (i.e. after 1,000 years) are possibly underpredicted because of the constant temperature boundary condition prescribed at the water table interface. In reality, saturated-zone temperatures increase due to heat transfer from the repository to bottom surface and further heat removal from the host rock may occur at a lower rate. At higher infiltration rates, the predicted waste package surface temperatures are lower. This is due to the fact that the ambient saturations in the host rock increase with increasing infiltration rates, and a larger amount of heat has to be utilized in the form of latent heat of vaporization during the drying out periods. Thus the surrounding rock provides a better heat sink for waste package heat removal at high infiltration rates.

Similarly, relative humidity predictions for 83 MTU/acre show the following trends. The predicted relative humidities near the waste package surface are in the range of 0.20 to 0.40 in the preclosure period and gradually increase to approximately 0.90 to 0.95 within the 10,000 year period. The relative humidities in the near-field are implicitly related to the near-field temperatures and saturations in the following manner. The relative humidity at the waste package surface is inversely proportional to its surface temperature and directly proportional to the temperature in the host rock or backfill where the dry-out front exists. Thus at later time periods, when the waste package surface temperatures are decreasing and the dry-out front is moving closer to the waste package, the relative humidities in the near-field keep increasing. For a given infiltration rate, the presence of backfill tends to reduce the relative humidities near the waste package by increasing waste package temperatures and by acting as a capillary barrier to delay the rewetting process of waste package. With an increase in infiltration rates, the dry-out region does not progress far into the host rock and thus provides a nearer source for water vapor. This effect together with lower waste package surface temperatures results in higher relative humidity predictions in the near-field.

Corresponding saturation variations in the near-field for 83 MTU/acre are shown in Figure 4.2-7. These show that at lower infiltration rates, the water within the near-field is instantly evaporated, and even at longer time levels (within 10,000 years) water is predicted to not come back into the drift. However, at higher infiltration rates, due to the high ambient saturation levels in the host rock, condensation of water is found to be significant thus allowing water to move relatively quickly toward the drift. Rewetting of the waste packages is predicted to occur within about 8,000 years. The abstractions of temperature and relative humidity predictions for 83 MTU/acre for the period of 0 to 10,000 years are shown in Figure 4.2-8.

Similar abstractions of waste package surface temperatures, saturations within the drift and relative humidities near the waste package surface for design scenarios with $25 \mathrm{MTU} / \mathrm{acre}$ areal mass loading are shown in Figures 4.2-9, 4.2-10 and 4.2-11. The general behavior of these predictions are similar to the predictions of 83 MTU/acre. However, for the case of 
$25 \mathrm{MTU} / a c r e$, a wider drift spacing is chosen so that the waste package spacing can be smaller such that the uncertainty due to heat smearing in the direction of the drift axis can be minimized. The following predictions are thus based on a drift spacing of $45 \mathrm{~m}$ and a waste package spacing of $32 \mathrm{~m}$. A peak temperature of about $160^{\circ} \mathrm{C}$ is observed in the case of $25 \mathrm{MTU} / \mathrm{acre}, 0.05$ $\mathrm{mm} / \mathrm{yr}$ infiltration rate and with backfill. In the case of $25 \mathrm{MTU} / \mathrm{acre}$, the relative humidities in the near field increased at a faster rate than that observed in $83 \mathrm{MTU} / \mathrm{acre}$ cases. This is due to the fact that for $83 \mathrm{MTU} / \mathrm{acre}$, the waste packages remain at higher temperatures for longer period and extended dry-out forces the liquid water to move farther away from the waste package surface. However, the maximum relative humidities observed within the 10,000 year period still remain in the range of 0.90 to 0.95 . Saturation variations in the near field also indicate that rewetting of waste packages only occurs in scenarios with high infiltration rates. However, due to the low thermal loading, the amount of dry-out (or reduction in liquid saturations below ambient levels) is quite small, and rewetting of the waste package occurs at very early periods. The overall abstractions of temperature and relative humidity predictions for $25 \mathrm{MTU} / \mathrm{acre}$ for the period of 0 to 10,000 years are shown in Figure 4.2-12.

\section{Predicted drift-scale temperature and saturation distributions}

The temperature and saturation distributions in the near field of the waste package at various time levels are useful in understanding the temperature gradients away from the waste package surface and movement of dry-out front in the near field. Figures $4.2-13$ to $4.2-20$ show two-dimensional interpolated images of temperature and liquid saturation distributions in the vicinity of the waste packages. These figures are plotted at four different time levels (10, 100, 1000 and 10000 years) and time levels are chosen on a logarithmic scale to capture both temperatures near the waste package at earlier time levels as well as dry-out front movement at late time levels. These figures correspond to four different scenarios in which areal mass loading ( 25 and 83 MTU/acre), infiltration rate $(0.05$ and $0.3 \mathrm{~mm} / \mathrm{yr}$ ) and backfill status (with and without backfill) are parametrically varied. Each of these figures is plotted in a half-symmetry plane, extending laterally from the centerline of the waste package to the mid-line between two adjacent drifts and extending to a distance of about $24 \mathrm{~m}$ above and below the waste package center.

The following general trends can be noticed from the two-dimensional images presented in Figure 4.2-13 to 4.2-20. The temperature distributions for the case of $83 \mathrm{MTU} / \mathrm{acre}$ and $0.05 \mathrm{~mm} / \mathrm{yr}$ infiltration rate with backfill (Figure 4.2-13) show that at 10 years high temperatures occur near the waste package and within the drift, but thermal effects have not progressed far into the host rock. With time, the thermal front progresses into the rock, but the heat being released from the waste package is decreasing. Thus, after about 10 years, while temperatures are decreasing near the waste package, distal temperatures are rising. At very late times (after 1,000 years), the temperature distribution looks nearly uniform, and only gradual cooling continues with time.

For this case (i.e., $83 \mathrm{MTU} / \mathrm{acre}$, backfill, and infiltration rate of $0.05 \mathrm{~mm} / \mathrm{yr}$ ), the ambient liquid saturations (Figure 4.2-14) are about 0.75 in the host rock and close to residual saturation levels of 0.01 within the drift. The saturation distribution at 10 years does not show much variation from the ambient levels except for a thin area around the drift where liquid saturation is slightly reduced. However, the distribution at 100 years shows that a distinct dry-out front has progressed outward from the waste package. In Figure $4.2-14$, it can be seen that a region of zero liquid saturation extends about $4 \mathrm{~m}$ into the host rock with significant water condensation 
and moisture redistribution evident outside this dry-out front. Saturation levels at 1,000 years indicate that the dry-out region has progressed further into the host rock (approximately $14 \mathrm{~m}$ from the drift wall). Saturation levels below and above the waste package show that dry-out is asymmetric with more dry-out below the waste package. The predicted saturation distribution at 10,000 years indicates that recondensed water has started to move back towards the drift and most of the dry-out regions have been rewetted. Average liquid saturation levels in the host rock are about 0.50 , implying that hydrologic conditions have not yet returned to ambient levels.

The effect of infiltration rate variation can be noticed by comparison of Figures $4.2-13$ and 4.2-14 with Figures 4.2-15 and 4.2-16. For the higher infiltration rate of $0.3 \mathrm{~mm} / \mathrm{yr}$, the ambient saturations in the host rock for are approximately 0.90 and the saturations within the backfill remain around residual saturation levels of 0.01 . The general trend of a progressive dry-out front is evident for this higher infiltration case also. However, both the rate at which the dry-out front progresses into the rock and the radial extent to which complete dry-out is achieved, are much lower. This is due to the higher ambient saturations (cf. Figures 4.2-16 and 4.2-14) and lower waste package temperatures (cf. Figures 4.2-15 and 4.2-13) that are calculated for higher infiltration rates. Thus, for the $0.3 \mathrm{~mm} / \mathrm{yr}$ infiltration case at the 100 years, the dry-out zone has progressed only about $3 \mathrm{~m}$ into the rock, and at 1,000 years, it has advanced about $8 \mathrm{~m}$ outward. In this case, the dry-out zone is completely gone at 10,000 years and saturations within the host rock have come back to nearly uniform values of about 0.70 .

Temperature and saturation distributions shown in Figures 4.2-17 and 4.2-18 are for the case of $83 \mathrm{MTU} / \mathrm{acre}, 0.3 \mathrm{~mm} / \mathrm{yr}$ infiltration rate and no backfill. These distributions show similar general trends as explained above for the backfilled scenario (Figures 4.2-15 and 4.2-16). The waste package surface temperatures are lower, however, the far-field values are not influenced, significantly, by the lack of backfill. The temporal variations in saturation and as position of the dry-out front, are also not significantly different from the case with backfill. Figures 4.2-19 and 4.2-20 show the temperature and saturation distributions for the case of $25 \mathrm{MTU} / \mathrm{acre}$ areal mass loading, $0.3 \mathrm{~mm} / \mathrm{yr}$ infiltration rate, and backfill. Temperature gradients for this case are much lower than for the $83 \mathrm{MTU} / \mathrm{acre}$ cases and produce only minor changes to the ambient conditions. Because of this, the distributions do not show much variation in regions far from the waste package and most of the dry-out is constrained to within the drift.

\subsubsection{An Alternate Drift-Scale Thermal-hydrology Model}

Drift-scale models of heat and fluid flow for the proposed repository at Yucca Mountain are also being developed at Lawrence Livermore National Laboratory (LLNL) in support of waste package (WP) design related activities. Buscheck et al. (1995) describe a suite of calculations for a variety of WP-spacing and drift-spacing scenarios in their evaluation of near-field thermohydrologic performance. A selected set of simulations from that study is described in order to provide a comparison with the thermohydrologic calculations reported previously.

\section{Model Description}

The drift-scale model is based on a two-dimensional cross-section which assumes an infinite repository with uniformly spaced drifts. The model represents a symmetry element from the symmetry plane down the center of the waste package to the symmetry plane in the pillar 
between neighboring drifts. The waste package has a cross-section of $1.6 \mathrm{~m} \times 1.6 \mathrm{~m}$ and is located within an emplacement drift that is $6.0 \mathrm{~m}$ high and $6.0 \mathrm{~m}$ wide. The waste package is emplaced on a $1.2 \mathrm{~m}$ thick "gravel" invert within the emplacement drift. The gravel invert is also taken to be the material for backfilling the drift. Note that such a square drift/waste package model is a simplification adopted for computational convenience.

The stratigraphy and parametrization used to characterize this drift-scale model are described in Buscheck and Nitao (1993). Briefly, the $\sim 530 \mathrm{~m}$ thick unsaturated zone is taken to consist of six major hydrogeologic units, viz. TCw, PTn, TSw, TSv, CHnv and CHnz. A $1000 \mathrm{~m}$ thick section of the saturated zone is also included in the model. Hydrologic and thermal properties of the unsaturated zone are taken from version 4 of the Reference Information Base (DOE, 1990). The saturated zone is assumed to have the properties of the welded Prow Pass (PPw) unit. Properties of the gravel invert (and of the backfill) are assumed to be similar to that of the PTn unit, albeit with a higher porosity, and correspondingly, a lower thermal conductivity.

Thermal decay characteristics are calculated by blending the heat output from the first 161 40-BWR WPs and 239 21-PWR WPs received during the first two years of repository operation, assuming an "Oldest Fuel First" scenario. This results in a typical WP containing 7.5 MTU with an average age of 26 years, a burnup of $38 \mathrm{GWd} / \mathrm{MTU}$ and an initial heat output of $0.96 \mathrm{~kW} / \mathrm{MTU}$. Simulations are carried out for thermal loads of 24 and $80 \mathrm{MTU} / \mathrm{acre}$. For the $24 \mathrm{MTU} /$ acre case, assuming a $50 \mathrm{~m}$ drift spacing yields a waste package spacing of $24 \mathrm{~m}$. For the $80 \mathrm{MTU} /$ acre case, assuming a $25 \mathrm{~m}$ drift spacing yields a waste package spacing of $14 \mathrm{~m}$.

\section{Results and Discussion}

All calculations were performed using the V-TOUGH code (Nitao, 1989), which is LLNL's enhanced version of the TOUGH code (Pruess, 1987). V-TOUGH is a multidimensional numerical simulator capable of modeling the coupled transport of water, water vapor, air and heat in porous and fractured media. In previous benchmarking studies (Reeves et al., 1994; Lingineni et al., 1994), the TOUGH family of codes has been shown to provide essentially similar results to those obtained by the FEHM code - which is used in the thermohydrologic modeling studies described earlier. Results from four V-TOUGH simulations will be described in this section. The simulations correspond to two thermal loads (24 and $80 \mathrm{MTU} / \mathrm{acre}$ ) and two backfill options (with and without backfill). These cases are similar to the FEHM calculations presented earlier, albeit for slightly different thermal loads (25 and $83 \mathrm{MTU} / \mathrm{acre}$ ). Note that the LLNL calculations do not include the effects of any surficial infiltration, whereas the FEHM simulations consider infiltration rates of 0.05 and $0.3 \mathrm{~mm} / \mathrm{yr}$. For reasons of consistency, the V-TOUGH calculations are compared with the FEHM calculations corresponding to the low infiltration rate $(0.05 \mathrm{~mm} / \mathrm{yr})$ case. The performance measures of interest here are the temperature and relative humidity $(\mathrm{RH})$ at the surface of the waste package.

Figure 4.2-21 shows a comparison between temperature and $\mathrm{RH}$ predictions for the $24 \mathrm{MTU} / \mathrm{acre}$ case (Buscheck et al., 1995) and the 25 MTU/acre case (this study). The temperature predictions are in general agreement, as are the RH predictions for the no backfill case. For the case of backfill emplaced at 100 years after waste emplacement, the RH predictions of Buscheck et al. (1995) are lower than those resulting from this study. A comparison between the results of the $80 \mathrm{MTU} / \mathrm{acre}$ case (Buscheck et al., 1995) and the $83 \mathrm{MTU} / \mathrm{acre}$ case (this study) is shown in 
Figure 4.2-22. As before, predictions of temperature for the no-backfill case are essentially similar for both sets of calculations. However, the results of Buscheck et al. (1995) show a significant thermal spike at the time of waste emplacement - leading to persistent higher temperatures as compared to this study. This discrepancy may be attributed to the following: (i) the use of lower value for the dry thermal conductivity of the backfill $\left(\sim 0.3 \mathrm{~W} / \mathrm{m}-{ }^{\circ} \mathrm{K}\right)$ by Buscheck et al. compared to the value used in this study $\left(\sim 0.6 \mathrm{~W} / \mathrm{m}-{ }^{\circ} \mathrm{K}\right)$, and (ii) the differences in model geometry in the two analyses. The model geometry used by Buscheck et al. ( $6 \mathrm{~m}$ square drift, $1.6 \mathrm{~m}$ square waste package, $1.2 \mathrm{~m}$ thick invert) results in a $3.2 \mathrm{~m}$ separation between the top of the waste package and the drift wall, as compared to a $1.6 \mathrm{~m}$ separation for the model used in this study ( $5 \mathrm{~m}$ diameter drift, $1.8 \mathrm{~m}$ diameter waste package). The combination of a larger volume of backfilled drift and a lower conductivity material results in higher temperatures predicted by Buscheck et al. (1995).

As in the case of the low-thermal loading scenario, $\mathrm{RH}$ predictions by Buscheck et al. (1995) for the high-thermal loading option are significantly lower than those of this study. Figure 4.2-22 shows RH values approaching a plateau of $\sim 0.95$ based on the results of this study, whereas the simulations of Buscheck et al. yield a plateau of $\sim 0.6$ and $\sim 0.5$ at 10,000 years for the no-backfill and the backfill cases, respectively. These differences are believed to be due predominantly to the methodology employed for RH calculations, as discussed below. Buscheck et al. (1995) assume that the absolute humidity at the drift wall is equal to that at the surface of the waste package. Thus, the $\mathrm{RH}$ at the waste package is obtained as the ratio of the vapor pressure at the drift wall to the saturation pressure at the waste package surface. As explained in Section 4.2.7, this study assumes that the absolute humidity at the dry-out front is the corresponding quantity to be equated to that at the waste package surface. Typically, the dry-out front will be located further away into the rock as compared to the drift wall, and will also have a lower temperature. Its vapor pressure will thus be lower than that prevailing at the drift-wall. Furthermore, as discussed earlier, the WP surface temperature predictions of this study are typically lower than those by Buscheck et al., with a correspondingly lower saturation pressure. The combined effect results in higher relative humidity (ratio of vapor pressure to saturation pressure) at the surface of the waste package.

The above discussion underscores the need for better definition of backfill thermohydrologic properties, as well as improvements in the methodology used to estimate relative humidity. Detailed sensitivity studies are planned to further examine the impact of various assumptions regarding backfill parameters on near-field thermohydrologic performance. In any case, the combination of various simplifying assumptions in the thermohydrologic models of this study and Buscheck et al. (1995) and the conceptual/parametric uncertainties described above, point to the need to use caution when using relative humidity to predict the initiation of corrosion in WP/EBS performance assessments.

\subsection{REPOSITORY-EDGE THERMOHYDROLOGIC CALCULATIONS}

\subsubsection{Introduction}

The near-field (drift-scale) calculations described in the previous section are based on a 2-D $x-z$ model. In the vertical $(\mathrm{z})$ direction, the model extends from the ground surface to $1000 \mathrm{~m}$ below the water table. Along the horizontal $(x)$ direction, the model is centered around a typical 
emplacement drift and extends to the middle of the two adjoining pillars, where symmetry boundary conditions are invoked for computational convenience. As stated above, this simplified model is more applicable at the center of the repository than at the edge, where heat transfer to the surrounding rock might produce significant edge-cooling effects (e.g., Ryder, 1993).

One approach to account for these edge effects requires embedding a locally refined mesh within a generally coarse mesh to simultaneously simulate both near- and far-field conditions. To date, however, limited software/hardware efficiency has precluded the modeling of transient heat and fluid flow in such hybrid domains. An alternative approach, which is based on the concept of scaling, is presented below. By decoupling of the drift- and repository-scale simulations, this scaling methodology seeks to enforce internal consistency in far- and near-field results and provides an efficient tool for incorporating edge effects.

\subsubsection{The Scaling Concept}

Consider a subdomain of the repository, which we assume can be partitioned into a 'center' and an 'edge', each with its characteristic thermohydrologic response. This implies that every point within the 'center', or the 'edge', has the same $\mathrm{T}$ (temperature) and/or $\mathrm{S}_{\text {liq }}$ (liquid saturation) vs. $t$ (time) behavior. It is further assumed that the response of the 'edge' region is equivalent to that of the 'center' region, but for a different (lower) thermal load. In other words, the thermohydrologic response of the 'edge' region can be obtained by simulating the behavior of the 'center' region at a reduced thermal load. Because the response of the 'center' is typically obtained using a simple model with symmetry boundary conditions, this approach eliminates the need for performing detailed calculations to explicitly characterize edge effects. Note that the partitioning of the model domain into 'center' and 'edge' is for illustration purposes only, and does not preclude the use of additional zones in actual simulations.

The proposed scaling methodology consists of the following steps. Step 1 calls for far-field, twodimensional simulations with an average heat load uniformly distributed over the repository area. Step 2 calls for one-dimensional simulations of vertical columns passing through the repository. Here the heat loading would be adjusted (scaled to an effective heat loading) by trial and error so that one-dimensional results (temperature, saturation, relative humidity) for the column optimally reproduce predictions of the two-dimensional model for the same column. Step 3 calls for detailed near-field simulations employing the effective heat loading determined in step 2 and a localized two-dimensional mesh focused around a single waste package in an emplacement drift. In what follows, we present some preliminary results related to the development of scale factors using far-field simulations are presented.

\subsubsection{Model Description}

A two-dimensional cross-section, adapted from the site-scale model of Wittwer et al. (1995) is shown in Figure 4.3-1. This cross-section, bounded by the Solitario Canyon Fault and the Ghost Dance Fault, includes the proposed repository horizon in the Upper Block of the Primary Emplacement Area. The model contains six major hydrostratigraphic intervals in the unsaturated zone (i.e., TCw, PTn, TSw, TSv, CHnv and CHnz), as well as $1,000 \mathrm{~m}$ of the saturated Prow Pass unit below the water table. 
As indicated by the dots (block centers) in Figure 4.3-1, the discretization consisted of 12 vertical columns with column heights varying in accord with the surface topography. Model boundaries were characterized by atmospheric conditions at the top and deep-saturated conditions at the bottom. Although the vertical boundaries permitted no liquid or gas flows, they allowed a free exchange of heat with the external system via the method of Vinsome and Westerveld (1980). As implemented in TOUGH2 (Pruess, 1991), this method attaches a semi-infinite, onedimensional thermal field to each edge block, and a semi-analytical determination of an external field employs the thermal properties of the edge block. The temperature contours of Figure 4.3-1 indicate that the method yielded realistic results, even for vertical boundaries located only 100 meters from the repository edges.

For this implementation, the heat input curve was determined for a mix of 21PWR/40BWR assemblies emplaced at an areal mass loading of $85 \mathrm{MTU} /$ acre. Thermal parameters were taken from Lingineni et al. (1994), and hydrologic properties were based on data of Schenker et al. (1995) as summarized in Section 2.2. For implementation in the equivalent continuum option, fracture capillary pressures were linearized using the prescription of Tsang and Pruess (1989).

The analyses considered two different rates of infiltration $(0.0$ and $0.1 \mathrm{~mm} / \mathrm{yr})$ and two levels of vapor diffusion, yielding four sets of calculations. With vapor diffusivity varying in direct proportion to the factor $\beta$, one level (enhanced) assumed $\beta=1$. The other (unenhanced) assumed $\beta=\tau \phi S_{g}$ where $\tau$ is the tortuosity, $\phi$ the porosity, and $S_{g}$ is the gas saturation. Citing references from soil physics literature, Tsang and Pruess (1990) discuss the basis for assuming an enhanced level of vapor diffusion. The specification of initial conditions was based on results of transient analyses representing 400,000 years. Including no heat source, four separate calculations considered both rates of infiltration and both levels of vapor diffusion.

\subsubsection{Results}

The combination of $0.1 \mathrm{~mm} / \mathrm{yr}$ and enhanced vapor diffusivity $(\beta=1)$ produced the most rapid resaturation of the dry-out zone. For brevity, the discussion presented here will be confined to this case. Figures 4.3-1 and 4.3-2 present contour plots of the two-dimensional distributions of temperature and liquid saturation at 1,000 years. Figures 4.3-3 and 4.3-4 give results for columns 6 and 11, which approximately pass through the center and edge of the repository horizon, respectively. These results indicate that at 1,000 years, resaturation of the dry-out zone is considerably more advanced at the edge than at the center of the repository. In fact, results for 10,000 years (not shown) reveal that, by this time, a small downward flow has been established in column 2 and 11 (the edges), while convergent flow toward the repository is still occurring in all interior columns.

Figures 4.3-3 and 4.3-4 present the scaled one-dimensional fits alongside two-dimensional results. Figures 4.3-4 indicates that, for the edges of the repository, the two-dimensional results were reasonably matched by the scaled one-dimensional simulations. For Column 11, the optimal (scaled) one-dimensional heat loading was found to be $58 \mathrm{MTU} / \mathrm{acre}$. Figure 4.3-3 indicates that, within the interior, one-dimensional fits to the two-dimensional results were of lower quality. Interestingly, at the center of the repository, i.e. for Columns 6 and 7, the scaled one-dimensional heat loading had to be increased to values greater than the prescribed values of $85 \mathrm{MTU} / \mathrm{acre}$. For Column 6, this value was found to be $92 \mathrm{MTU} / \mathrm{acre}$. 


\subsubsection{Implications}

As discussed earlier, the use of the 2-D drift-scale model with symmetry boundary conditions (Section 4.2) would result in optimistic predictions of the near-field thermohydrologic environment. Neglecting edge-cooling effects would mean that the waste packages emplaced near the edge of the repository would be predicted to stay hotter, and drier, for a longer period of time than might actually be the case. A separate set of calculations for the 'edge' region of the repository, using the lower (scaled) thermal loads described in the previous section, would provide more representative predictions of waste package performance.

\subsection{NEAR-FIELD THERMAL-MECHANICAL CONSIDERATIONS}

Thermal-mechanical response of the rock mass in the vicinity of emplacement drifts may alter the near-field hydrology. In turn, the potential changes in near-field hydrologic properties caused by thermal loading may impact repository performance. Rock fabric may be modified due to fracture creation, closure, or widening caused by temperatures above ambient geothermal conditions. Thermal-mechanical analyses may be used to assess the degree of disturbance (changes in permeability) and the extent of the thermally- and mechanically-disturbed zone for the ground-water travel time analyses.

Results of M\&O (1995b) show that vertical joint apertures above and below the drifts may close due to the induced horizontal compressive stress induced by the application of thermal load to the rock mass. The M\&O study also shows that horizontal joint apertures may open up to $0.2 \mathrm{~mm}$ in the near field due to the motion of rock blocks caused by a $111 \mathrm{MTU} / \mathrm{acre}$ thermal load. Such a disturbance may change the horizontal components of bulk permeability of the rock mass in the near field. In addition, the M\&O study shows that the thermally induced stress in the near-field rock mass may exceed the rock mass strength if an 111 MTU/acre thermal load is applied. This suggests that there may be continuous joint slip in the near-field rock mass at such a thermal load.

Although no thermal-mechanical coupling has been considered in this iteration of TSPA, such processes may need to be included in subsequent TSPA iterations if significant changes in rockmass properties (i.e., changes outside of the natural variability in rock-mass properties), are anticipated due to the emplacement of heat-generating wastes.

\subsection{THERMAL-CHEMICAL EFFECTS IN THE NEAR-FIELD ENVIRONMENT}

\subsubsection{Introduction}

In addition to the potential changes to hydrology and mechanical response of the near-field environment induced by thermal perturbations to the ambient system, the chemical evolution of the near-field geochemical environment will be impacted by these temperature changes, as well as by the masses of introduced materials which remain over geologic time in the vicinity of the potential repository horizon (West, 1988; Murphy, 1991; Glassley, 1993; Meike and Wittwer, 1993). Although the ambient geochemical system has a large capacity to moderate system geochemistry, changes to the near-field environment have the potential to affect waste-package corrosion, waste-form dissolution, radionuclide solubility limits, and transport characteristics, and 
may ultimately impact the performance of a potential repository. Inclusion of such effects into Performance Assessment models relies on process-level models which quantify the detailed geochemical interactions in the near-field. The following discussion presents an overview of some of the potential effects on near-field geochemistry from introduced materials and from thermal perturbations.

\subsubsection{Perturbations from Introduced Materials}

During both site characterization activities and construction of a potential repository, a number of substances, which are likely to remain in the system over geologic time, will be introduced into the site. These may include a wide variety of compounds but there are three main categories that, as part of the waste package or as structural components, potentially will be abundant postclosure: steels, cementitious materials, and organic substances. -Steel, containing abundant Fe, may stabilize Fe-oxide or Fe-hydroxide solids in the near field which would provide effective sorption sites for many dissolved species, and may be particularly effective in sorbing some unretarded elements such as Tc (Meijer, 1990). The dissolution of steels will liberate metal cations to the aqueous phase and the increased concentration of $\mathrm{Fe}$ in the fluids (which are naturally very poor in $\mathrm{Fe}$ ), may stabilize more complex Fe-silicates. In addition, as the $\mathrm{Fe}$ in steel will oxidize, it will provide a sink for oxygen in the system and may generate locally reducing conditions dependent upon the rate of oxygen supply in the gas phase. Locally reducing conditions would lower solubility-limits on dissolved concentrations of many metal ions. Finally, colloids generated from steel may strongly sorb radionuclides and provide additional transport capabilities (Meike and Wittwer, 1993).

The pH of groundwater equilibrated with cement will; in general, be shifted to the extremely alkaline range of about 12-13. This $\mathrm{pH}$ range may not constitute a concern for accelerated waste package corrosion because of the formation of passivation films (Pourbaix, 1966). At these high $\mathrm{pH}$ conditions, however, dissolved elements controlled by hydroxide complexing will have increased aqueous concentrations (e.g., Aluminum-Castet et al., 1992), as may many actinides because of enhanced formation of very stable carbonate complexes (Clark et al., 1995). In addition, at such high-pH conditions, there is a large ( 3 to 6 orders of magnitude) increase in the capacity to dissolve silica, and thus in the potential to change the porosity and permeability of the system (Baes and Mesmer, 1976; Eikenberg, 1990; Eikenberg and Lichtner, 1992; Glassley, 1993). Because of microbial colonies feeding on organic admixtures used within concretes, acidic $\mathrm{pH}$ values have also been observed (Meike, 1995). As with steel, cements may generate colloids which enhance radionuclide mobility, but may also sorb dissolved species onto the immobile solids (Meike and Wittwer, 1993). Cementitious materials can provide a large source of $\mathrm{Ca}$ to the system phase, and therefore may effect the distribution of calcite in the near field.

The introduction of organic substances into the near field may have an impact on performance through changes in the concentrations of organic acids and organic colloids which can increase waste package corrosion, increase radionuclide solubility-limits, enhance radionuclide transport properties, and enhance silicate mineral dissolution (Choppin, 1992; Minai et al., 1992; Bennett et al., 1993; Meike and Wittwer, 1993). Such organics may also promote microbial activity which could detrimentally effect waste package corrosion (Meike 1995). In addition, organic substances can take part in oxidation/reduction reactions and, therefore, may contribute to the generation of locally reducing conditions. 


\subsubsection{Perturbations from Thermal Effects}

As temperature increases, a number of changes may impact the geochemical behavior of the nearfield environment. Mineral stabilities and phase equilibria are temperature dependent, and the rates at which reactions occur will generally increase at higher temperatures. Both continuous reactions such as the progressive dehydration or shift in cation composition of a solid phase, and discontinuous reactions such as the disappearance of a phase outside of its stability range, will occur as temperature increases (Glassley, 1993; Murphy, 1993). The higher temperatures in the near field, may result in regions where attainment of thermochemical equilibrium can be assumed (Glassley, 1993). Mineral transformation reactions, as well as precipitation/dissolution reactions will cause changes in porosity and permeability of the system as temperature increases and will result in a change in both the type and distribution of minerals in the near field (Glassley, 1993). This has ramifications for the hydrologic properties of the system as well as the near-field transport properties.

In addition to changes in the natural phases, introduced substances such as cementitious materials will undergo phase transformations which will include dehydration reactions as fluids are expelled from pores and from mineral structures (Bruton et al., 1993a, 1993b; Meike et al., 1994). Model results suggest that calcite precipitation will occur at higher temperatures and will be limited only by the Ca supply (Murphy, 1993), this could mean that Ca supplied from near-field cementitious materials may enhance the abundance of calcite precipitated (and retardation of $\mathrm{CO}_{2}$ ) in close proximity to the potential repository. The increased temperatures will vaporize much of the water in the near field as an above-boiling zone forms in the very near field (Glassley, 1993). This transition will increase the capacity of the system to transport moisture as volatiles and will result in precipitation of all dissolved solids from boiling fluids in the near field. Reprecipitation of water in cooler regions above the potential repository horizon will dissolve new material which could be transported through fractures back down into the boiling zone with subsequent boiling and phase precipitation. This refluxing could result in the presence of soluble salts in the Nearfield environment and could produce porosity and permeability changes that may impact the nearfield hydrology (Glassley, 1993). 
Table 4.2-1 Matrix Hydraulic Properties

\begin{tabular}{|c|c|c|c|c|c|c|}
\hline \multirow{2}{*}{$\begin{array}{l}\text { Rock } \\
\text { Unit } \\
\text { Type }\end{array}$} & \multirow{2}{*}{ Porosity } & \multirow{2}{*}{$\begin{array}{l}\text { Permeability } \\
\left(\mathrm{m}^{2}\right)\end{array}$} & \multirow{2}{*}{$\begin{array}{c}\text { Residual } \\
\text { Saturation }\end{array}$} & \multicolumn{3}{|c|}{ Van Genuchten Parameters } \\
\hline & & & & $\begin{array}{c}1 / \alpha \\
(\mathbf{P a})\end{array}$ & $\beta$ & $\lambda=1-1 / \beta$ \\
\hline $\mathrm{TCW}$ & 0.0870 & $9.7 e-19$ & 0.002 & $1.19 \mathrm{e} 6$ & 1.558 & 0.36 \\
\hline PTN & 0.4210 & $3.9 e-14$ & 0.100 & $6.54 \mathrm{e} 5$ & 6.872 & 0.85 \\
\hline TSw & 0.1390 & $1.9 e-18$ & 0.080 & $1.73 \mathrm{e} 6$ & 1.798 & 0.44 \\
\hline TSV & 0.0650 & $1.9 \mathrm{e}-18$ & 0.080 & $1.73 \mathrm{e} 6$ & 1.798 & 0.44 \\
\hline CHnv & 0.3310 & $2.7 e-14$ & 0.041 & $6.13 e 5$ & 3.861 & 0.74 \\
\hline $\mathrm{CHnz}$ & 0.3060 & $2.0 \mathrm{e}-18$ & 0.110 & $3.19 \mathrm{e} 6$ & 1.602 & 0.38 \\
\hline Backfill & 0.5000 & $3.9 e-14$ & 0.010 & $9.04 \mathrm{e} 4$ & 3.333 & 0.70 \\
\hline
\end{tabular}

Table 4.2-2 Fracture Hydraulic Properties

\begin{tabular}{|c|c|c|c|c|c|}
\hline \multirow{2}{*}{$\begin{array}{c}\text { Rock } \\
\text { Unit } \\
\text { Type }\end{array}$} & \multirow{2}{*}{$\begin{array}{c}\text { Permeability } \\
\left(\mathrm{m}^{2}\right)\end{array}$} & \multirow{2}{*}{$\begin{array}{c}\text { Residual } \\
\text { Saturation }\end{array}$} & \multicolumn{3}{|c|}{ Van Genuchten Parameters } \\
\hline & & & $\begin{array}{c}1 / \alpha \\
(\mathbf{P a})\end{array}$ & $\beta$ & $\lambda=1-1 / \beta$ \\
\hline $\mathrm{TCw}$ & $3.9 e-12$ & 0.04 & $7.66 \mathrm{e} 4$ & 4.230 & 0.7636 \\
\hline PTn & $3.9 e-13$ & 0.04 & $7.66 \mathrm{e} 4$ & 4.230 & 0.7636 \\
\hline TSw & $3.9 e-12$ & 0.04 & $7.66 \mathrm{e} 4$ & 4.230 & 0.7636 \\
\hline TSv & $3.9 e-12$ & 0.04 & $7.66 \mathrm{e} 4$ & 4.230 & 0.7636 \\
\hline CHnv & $3.9 e-13$ & 0.04 & $7.66 \mathrm{e} 4$ & 4.230 & 0.7636 \\
\hline CHnz & $3.9 e-12$ & 0.04 & $7.66 \mathrm{e} 4$ & 4.230 & 0.7636 \\
\hline Backfill & $3.9 e-12$ & 0.04 & $7.66 \mathrm{e} 4$ & 4.230 & 0.7636 \\
\hline
\end{tabular}


Table 4.2-3 Matrix Thermal Properties

\begin{tabular}{||c|c|c|c||}
\hline $\begin{array}{c}\text { Thermohydrologic } \\
\text { Unit }\end{array}$ & $\begin{array}{c}\text { Thermal } \\
\text { Conductivity (dry) } \\
(\mathbf{W} / \mathbf{m}-\mathbf{K})\end{array}$ & $\begin{array}{c}\text { Density (dry) } \\
\left(\mathbf{k g} / \mathbf{m}^{3}\right)\end{array}$ & $\begin{array}{c}\text { Specific Heat (dry) } \\
(\mathbf{J} / \mathbf{k g}-\mathbf{K})\end{array}$ \\
\hline \hline TCw & 1.69 & 2580 & 728 \\
\hline PTn & 0.61 & 2580 & 422 \\
\hline TSw & 2.10 & 2580 & 840 \\
\hline TSv & 1.28 & 2580 & 948 \\
\hline CHnv & 0.84 & 2580 & 488 \\
\hline CHnz & 1.42 & 2580 & 526 \\
\hline Backfill & 0.6 & 2580 & 840 \\
\hline
\end{tabular}




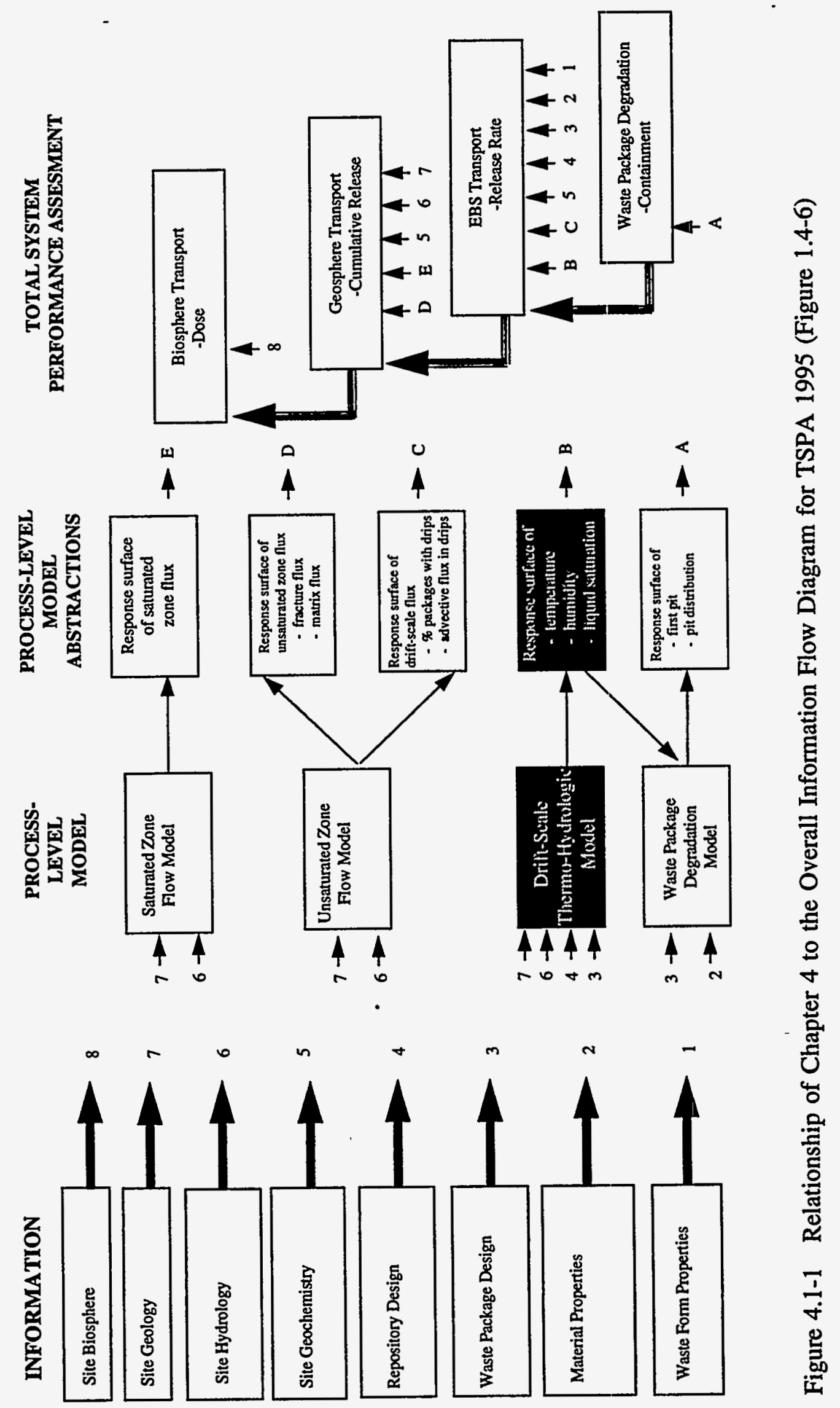




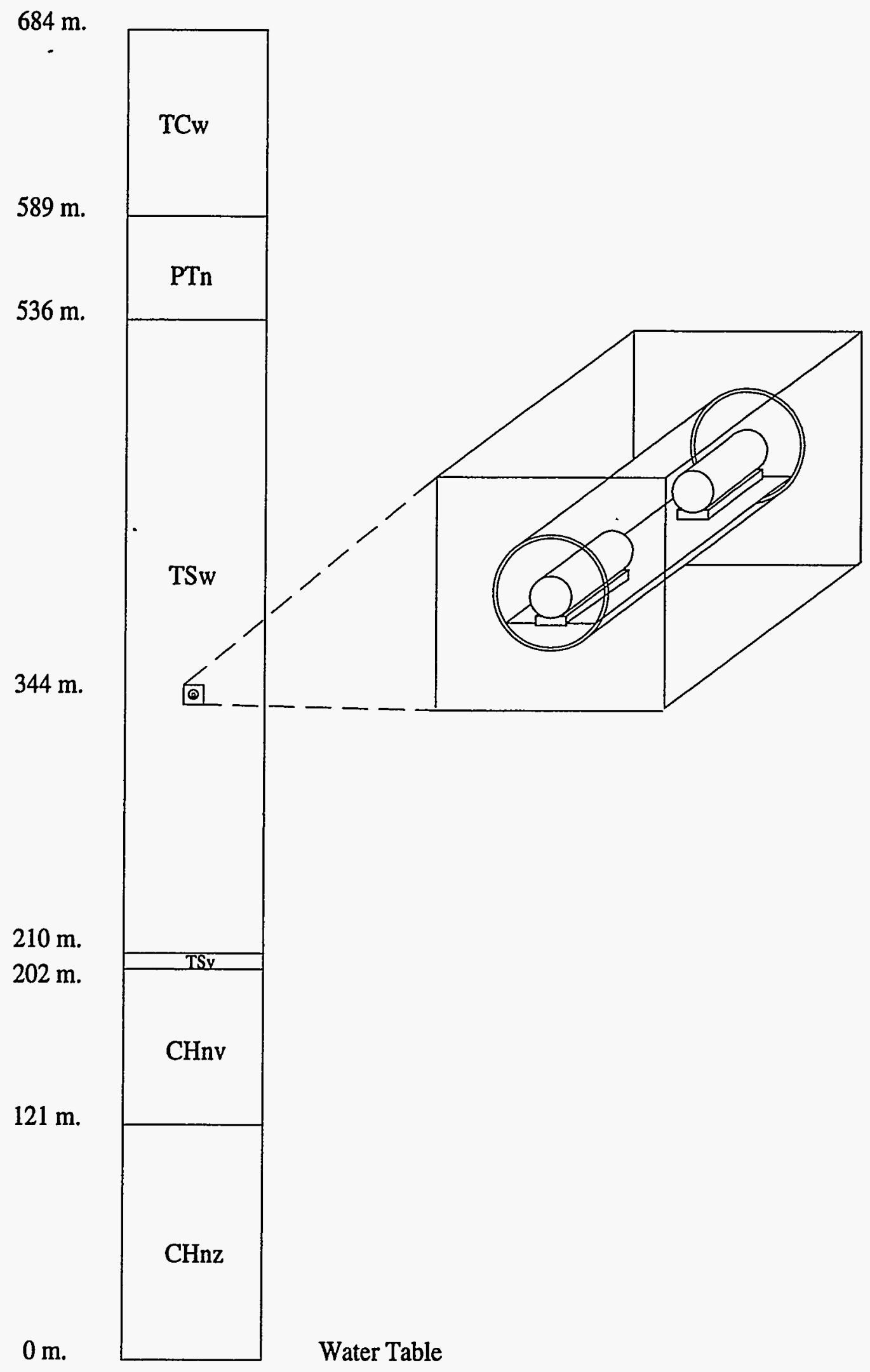

Figure 4.2-1 Near-Field Thermal-Hydrologic Conceptual Model

$4-21$ 


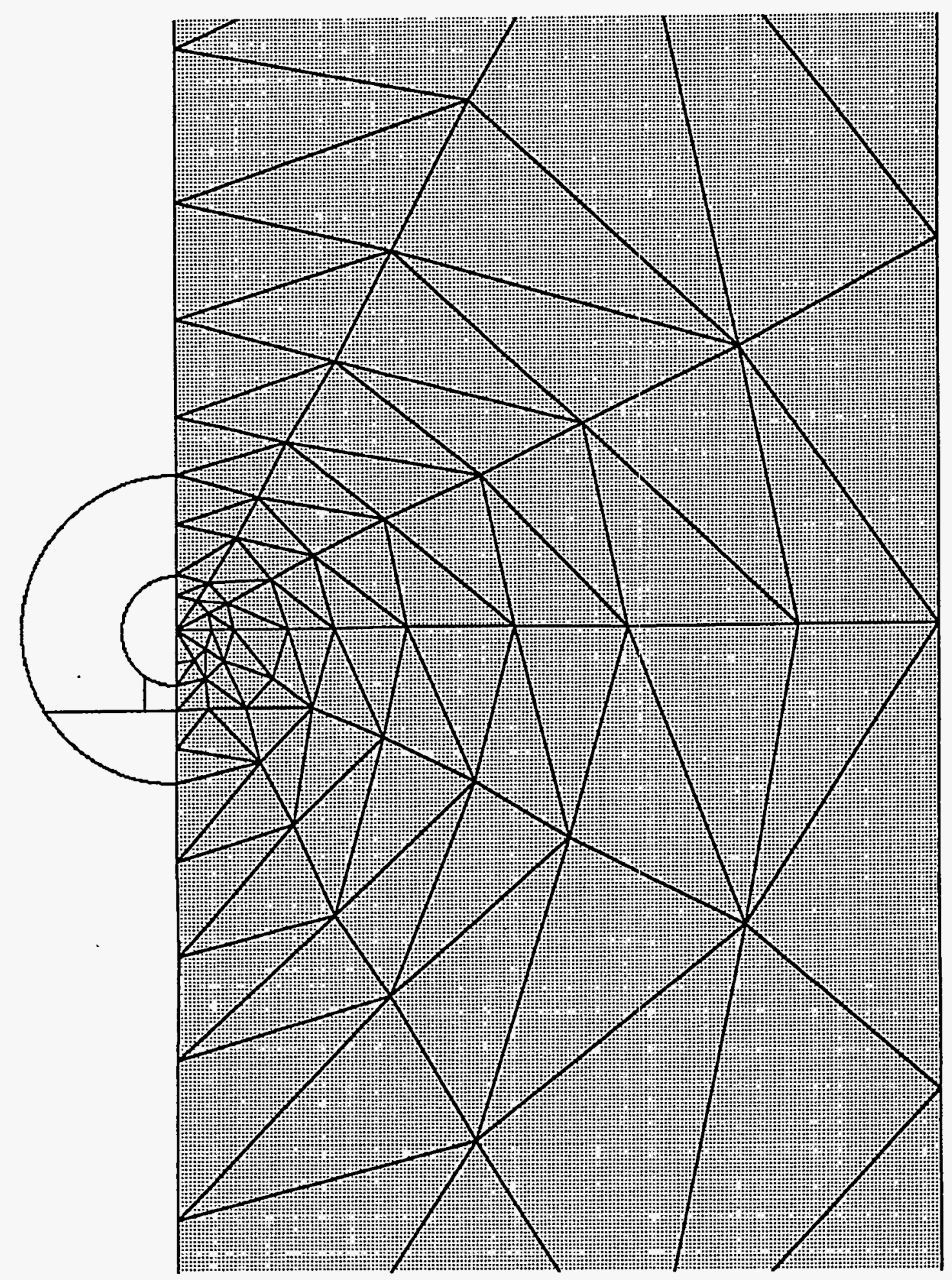

Figure 4.2-2 Finite-Element Mesh Used for Drift Scale Thermal-Hydrologic Simulations 


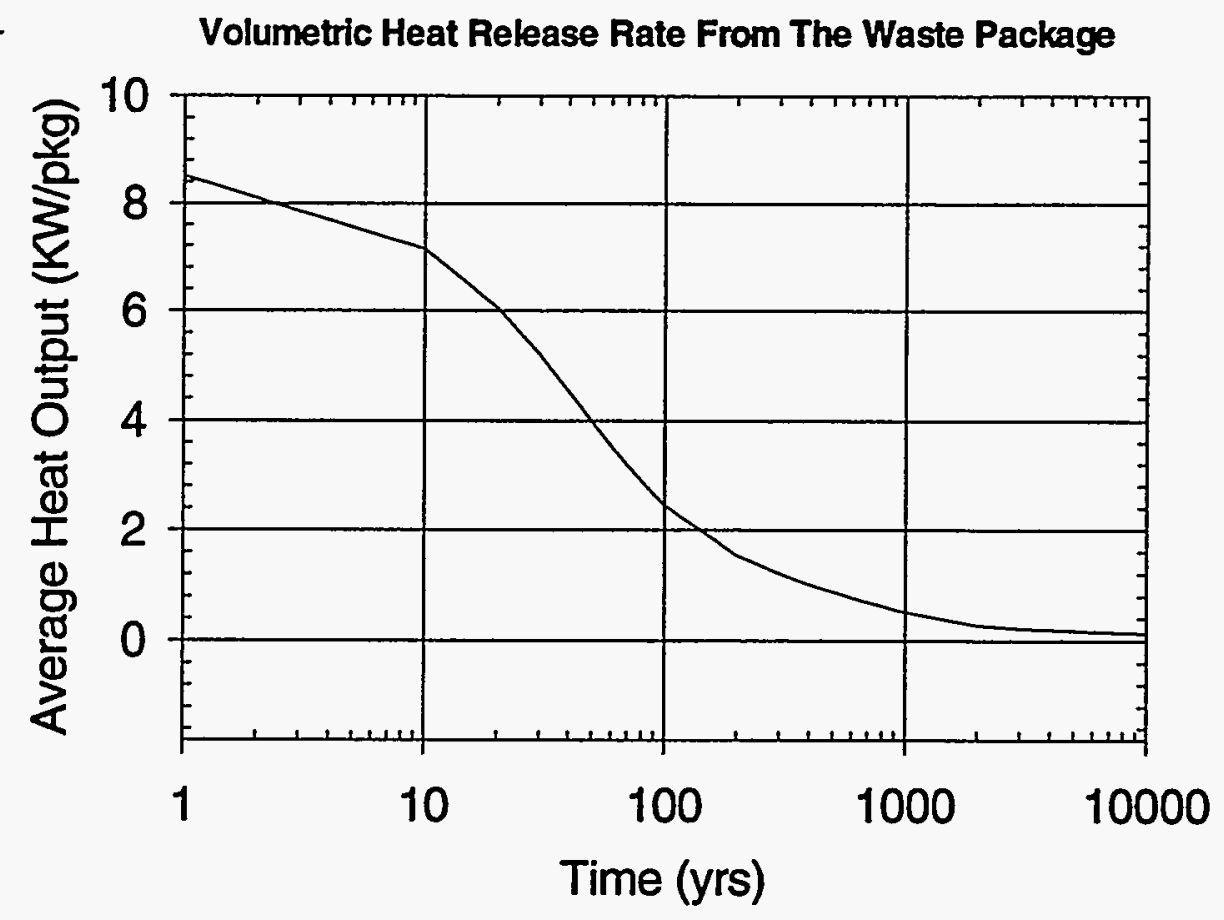

Figure 4.2-3 Heat Generation Rates of an Average Waste Package

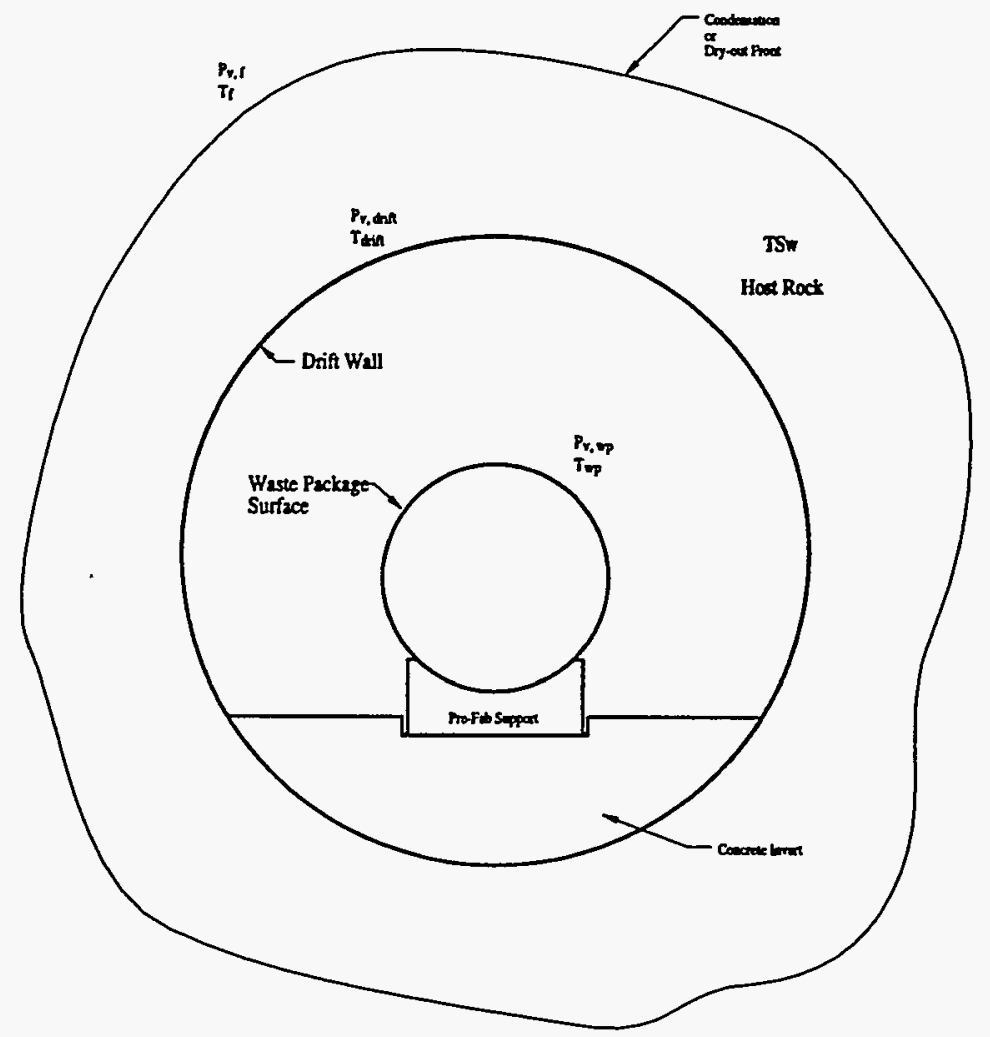

Figure 4.2-4 Conceptual View of Relative Humidity Determination Module 


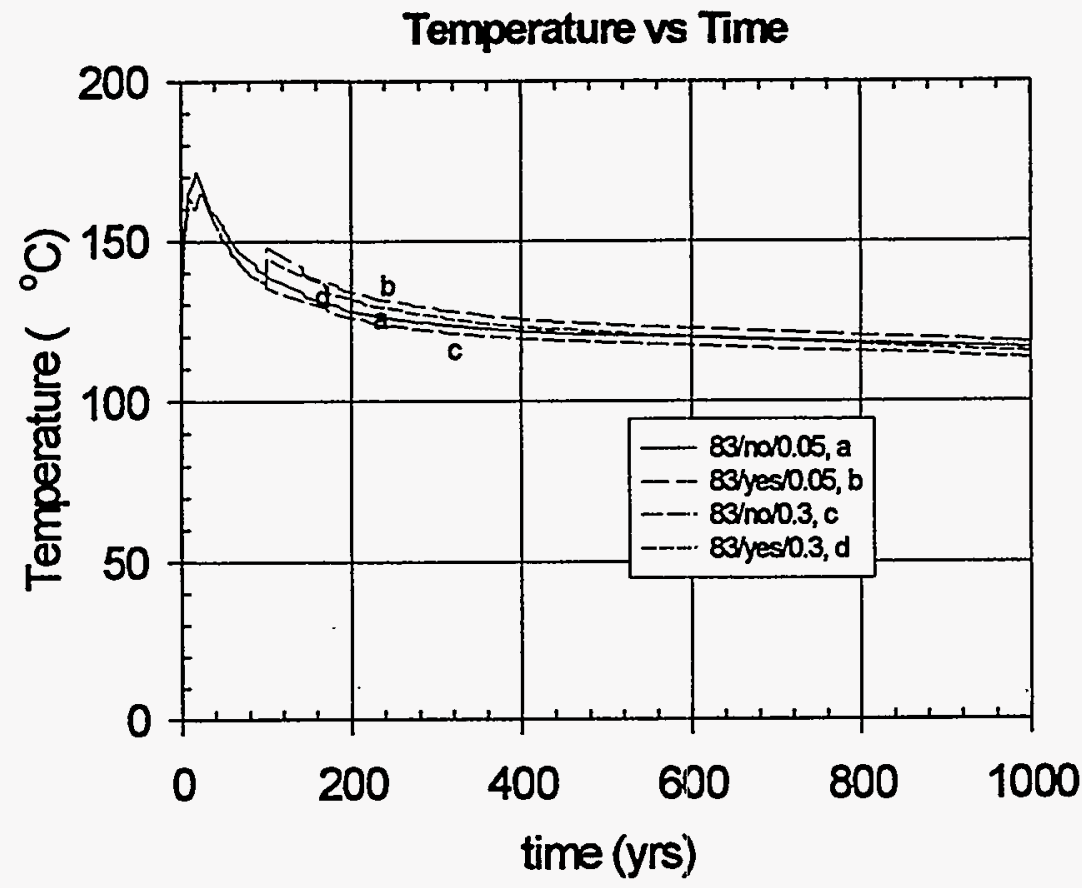

Figure 4.2-5 Waste Package Surface Temperature Predictions for 83 MTU/acre

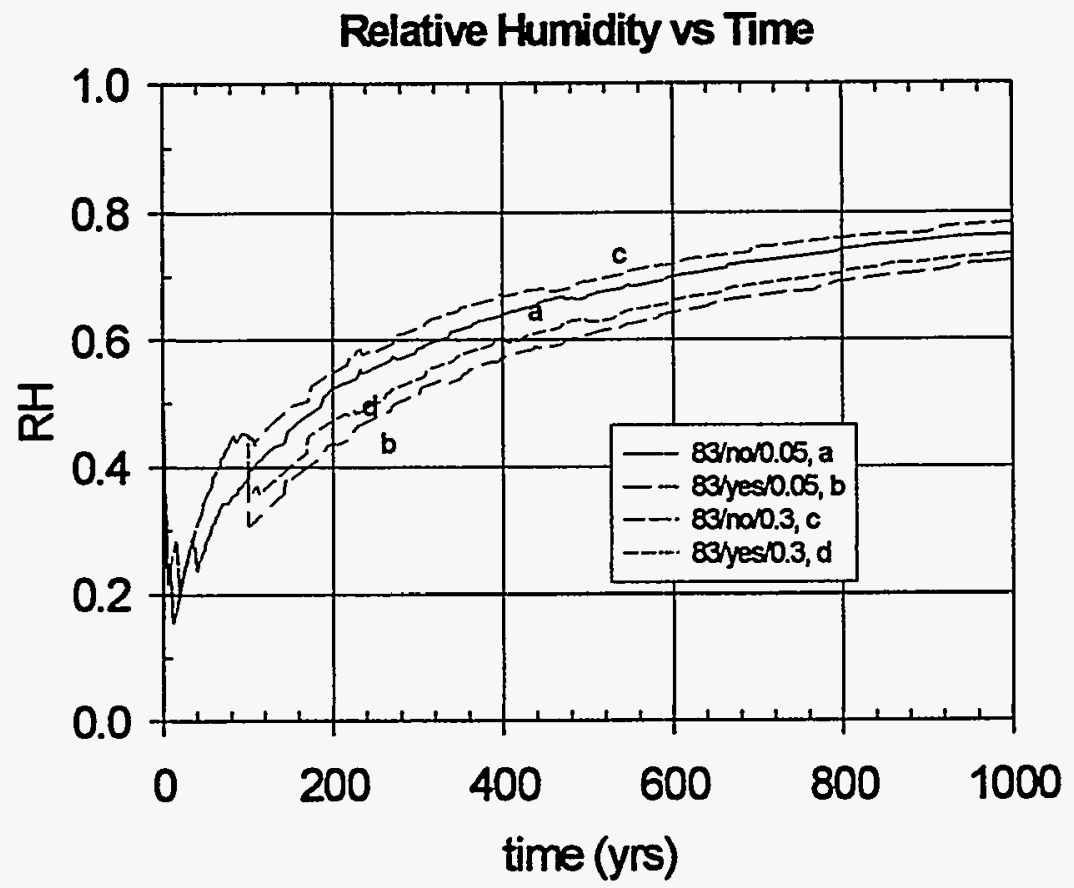

Figure 4.2-6 Relative Humidity Predictions for 83 MTU/acre Case 


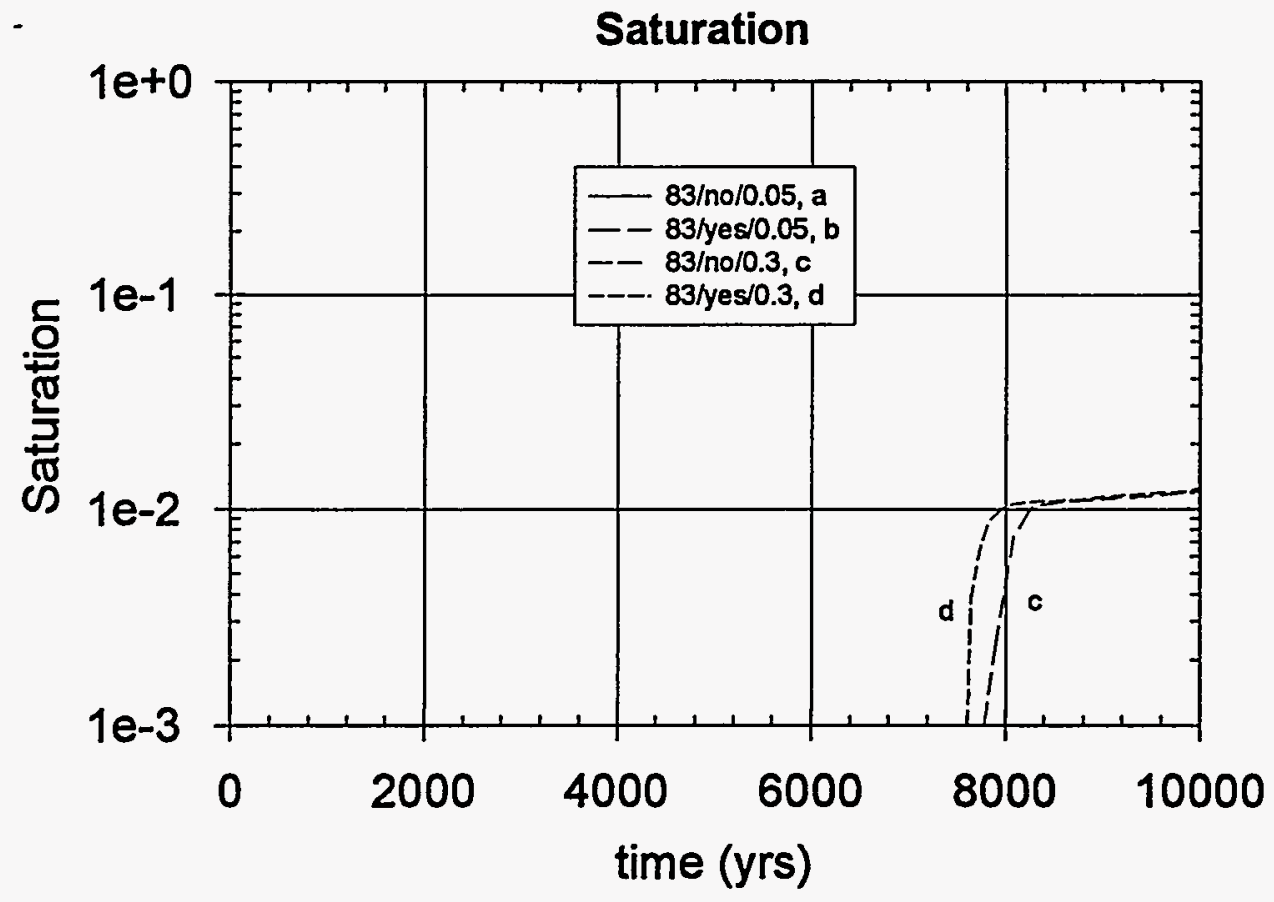

Figure 4.2-7 Predictions of Liquid Saturation within Drift for 83 MTU/acre Case

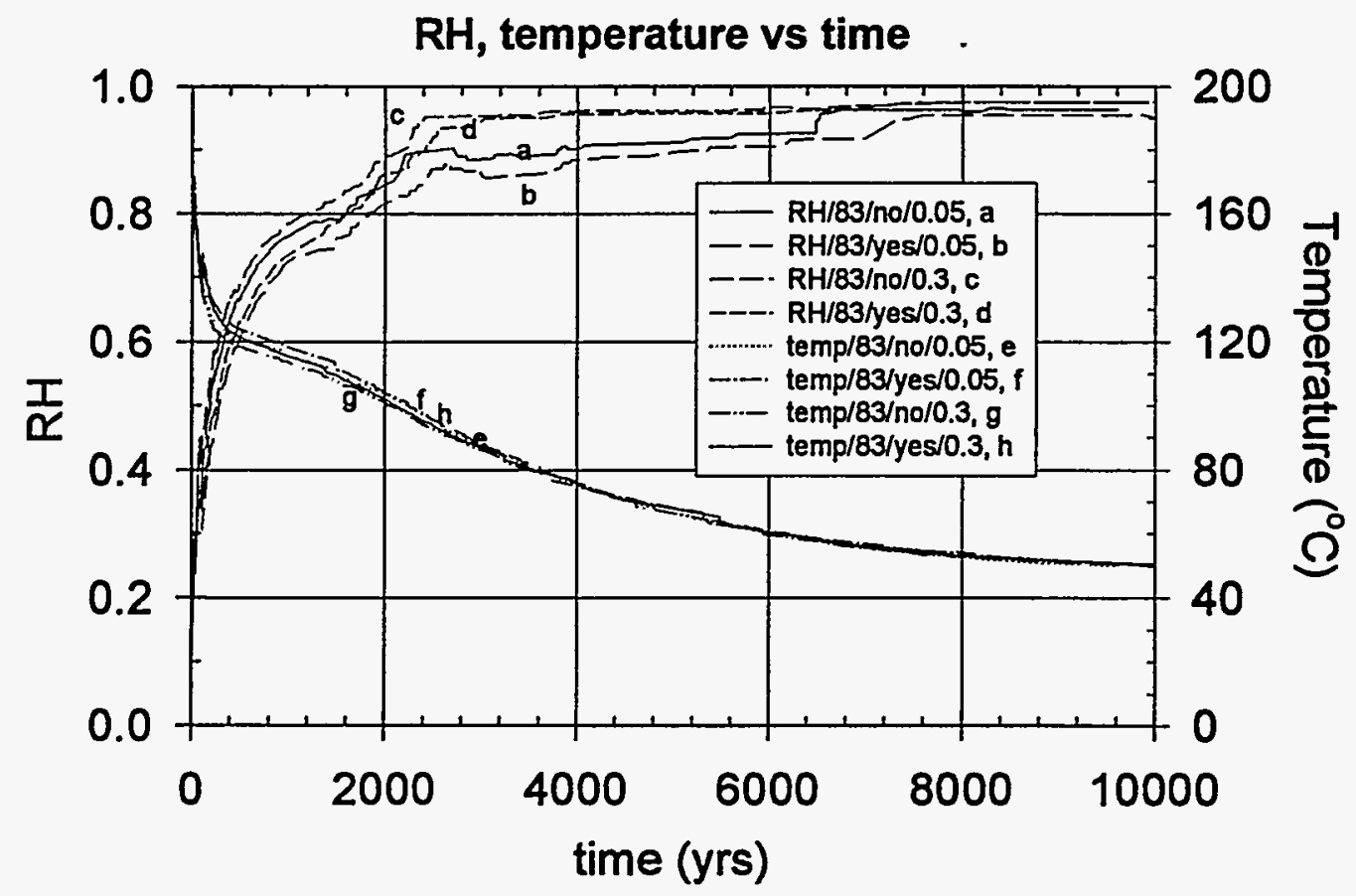

Figure 4.2-8 Abstractions of Temperatures and Relative Humidities for 10,000 years (83 MTU/acre Case) 


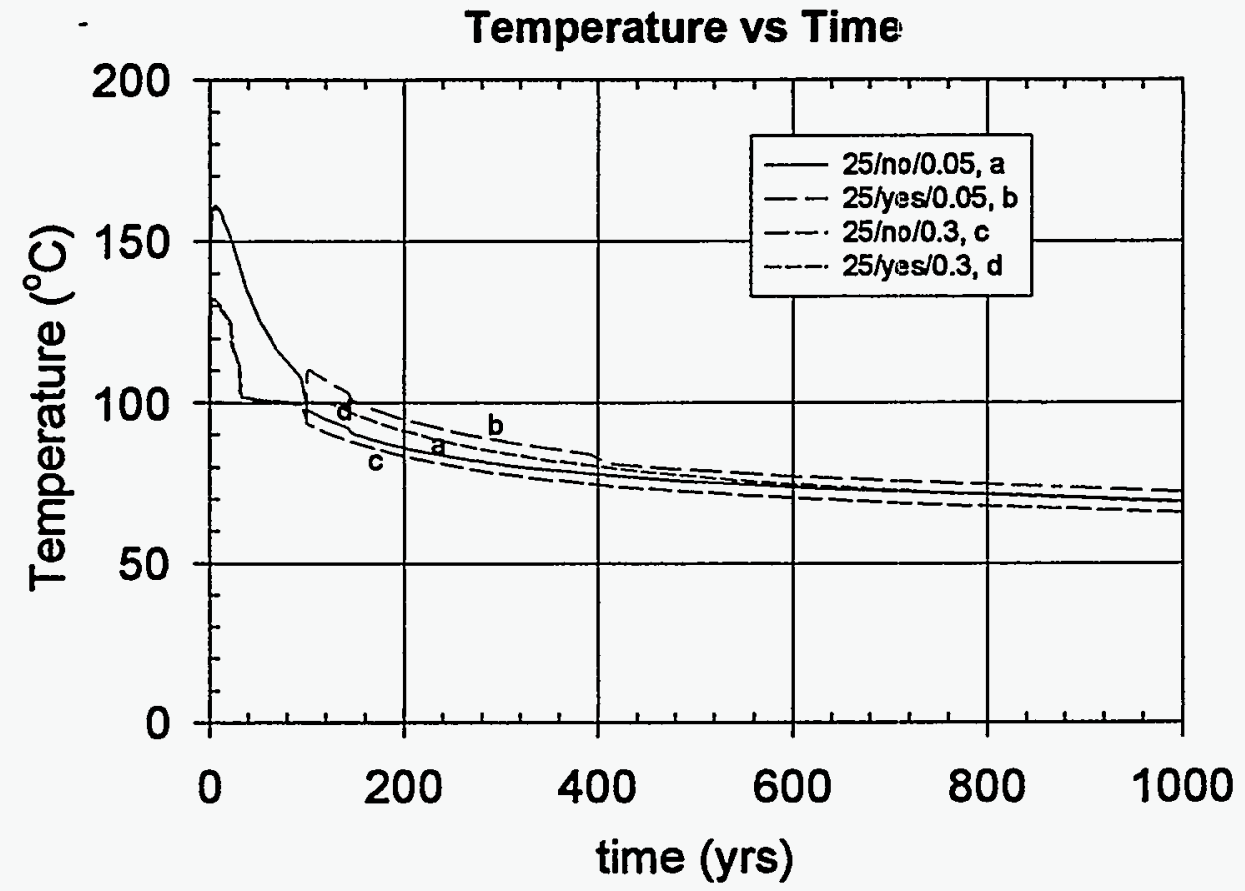

Figure 4.2-9 Waste Package Surface Temperature Predictions for 25 MTU/acre Case

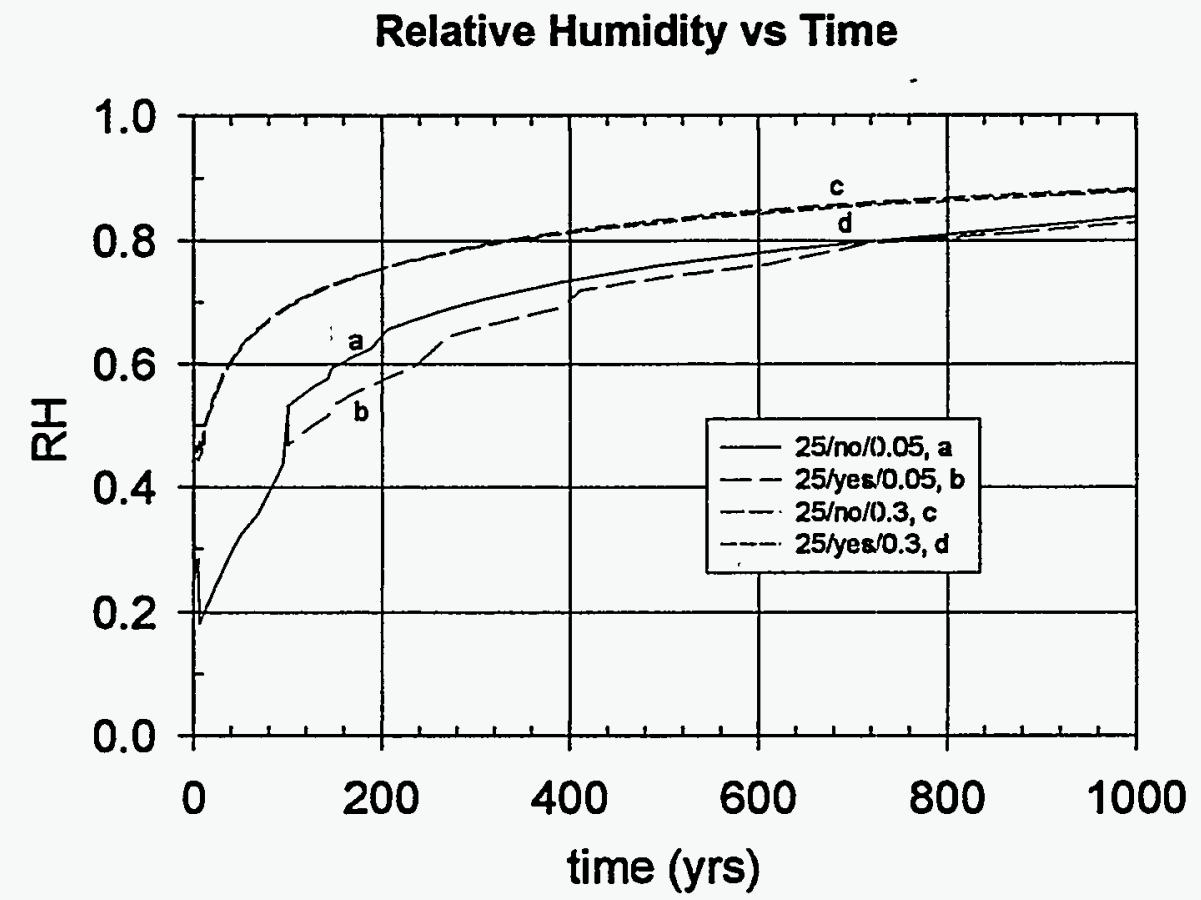

Figure 4.2-10 Relative Humidity Predictions for 25 MTU/acre Case 


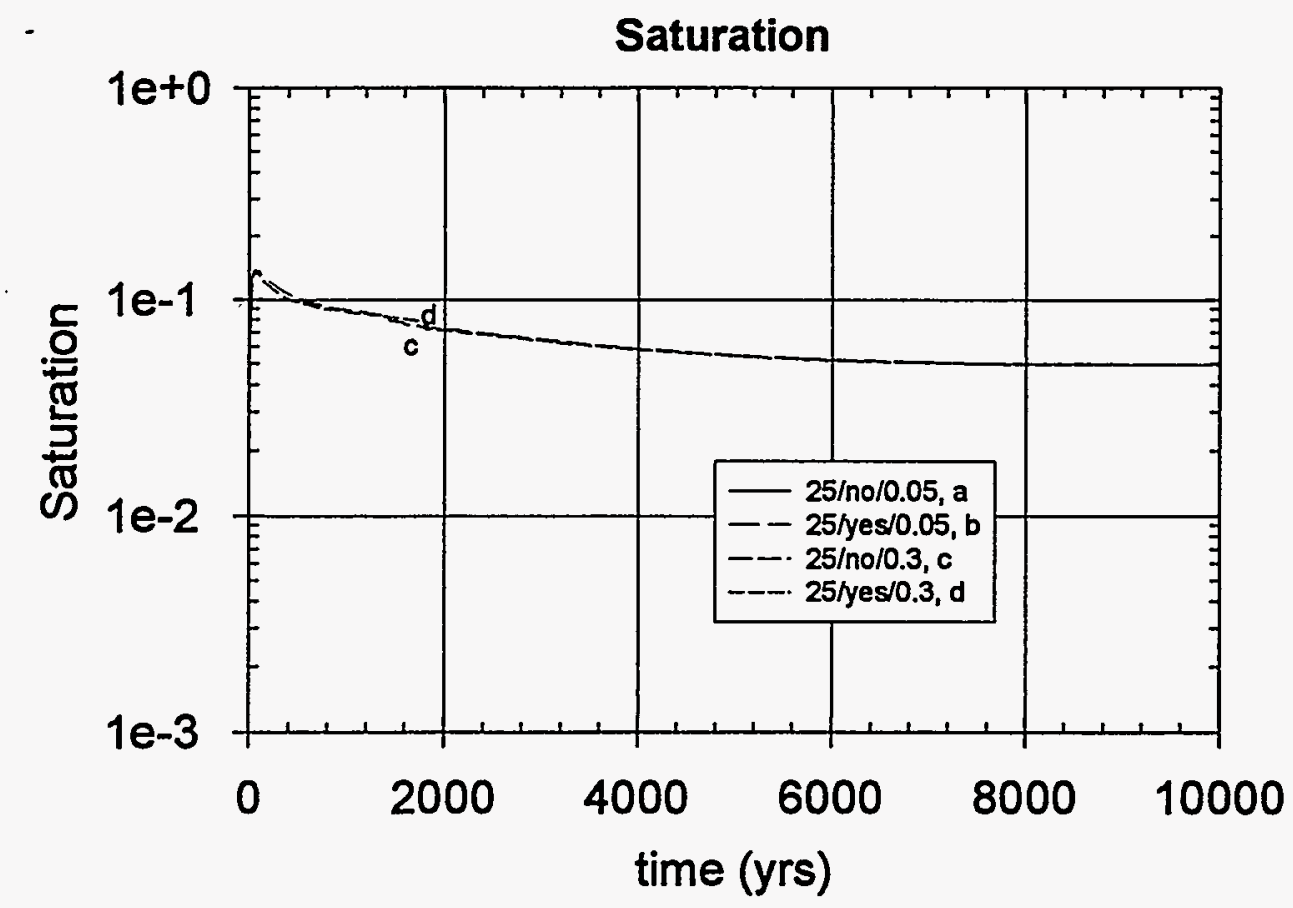

Figure 4.2-11 Predictions of Liquid Saturation within Backfill for 25 MTU/acre Case

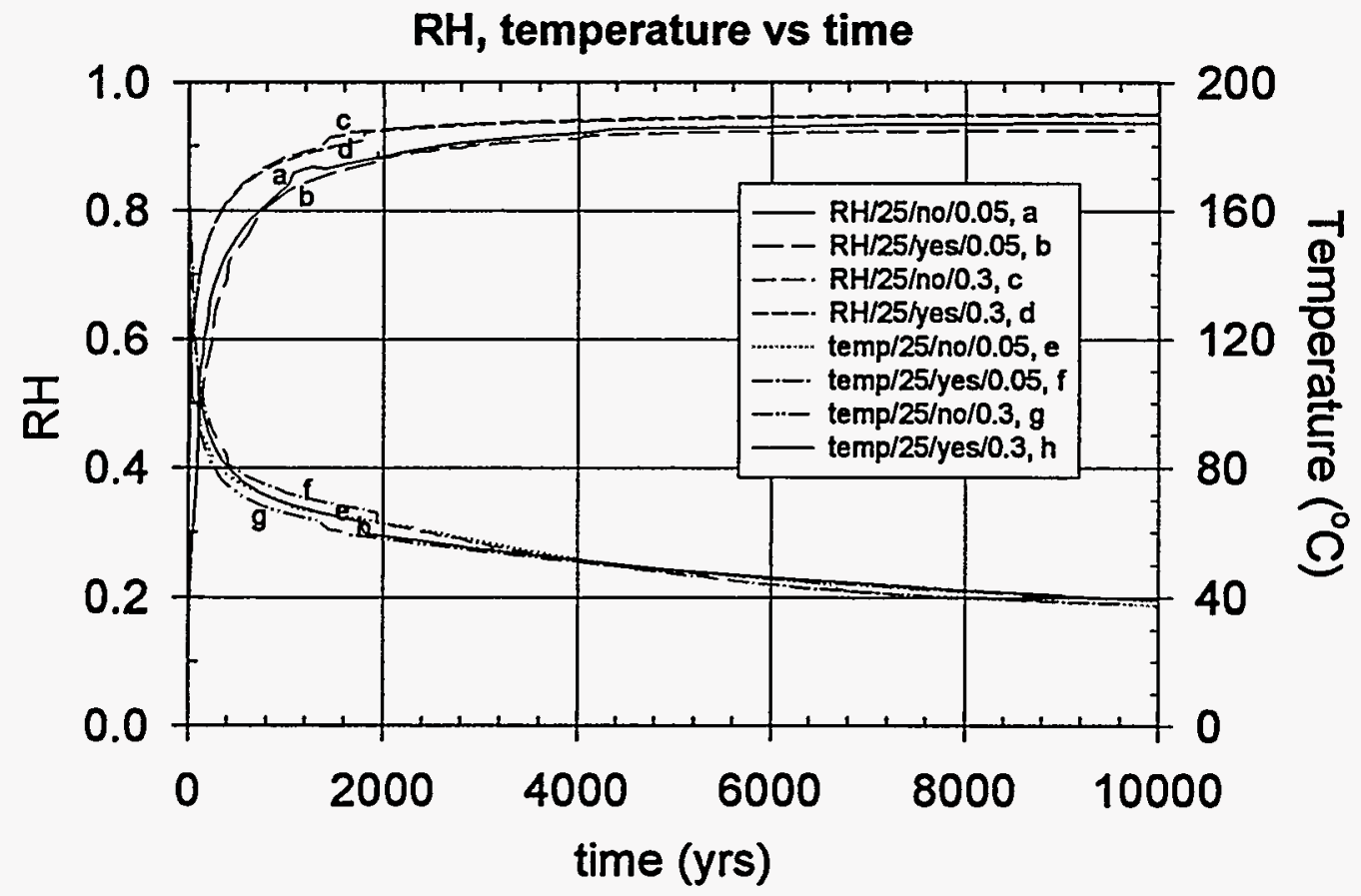

Figure 4.2-12 Abstractions of Temperatures and Relative Humidities for 10,000 years (25 MTU/acre Case) 

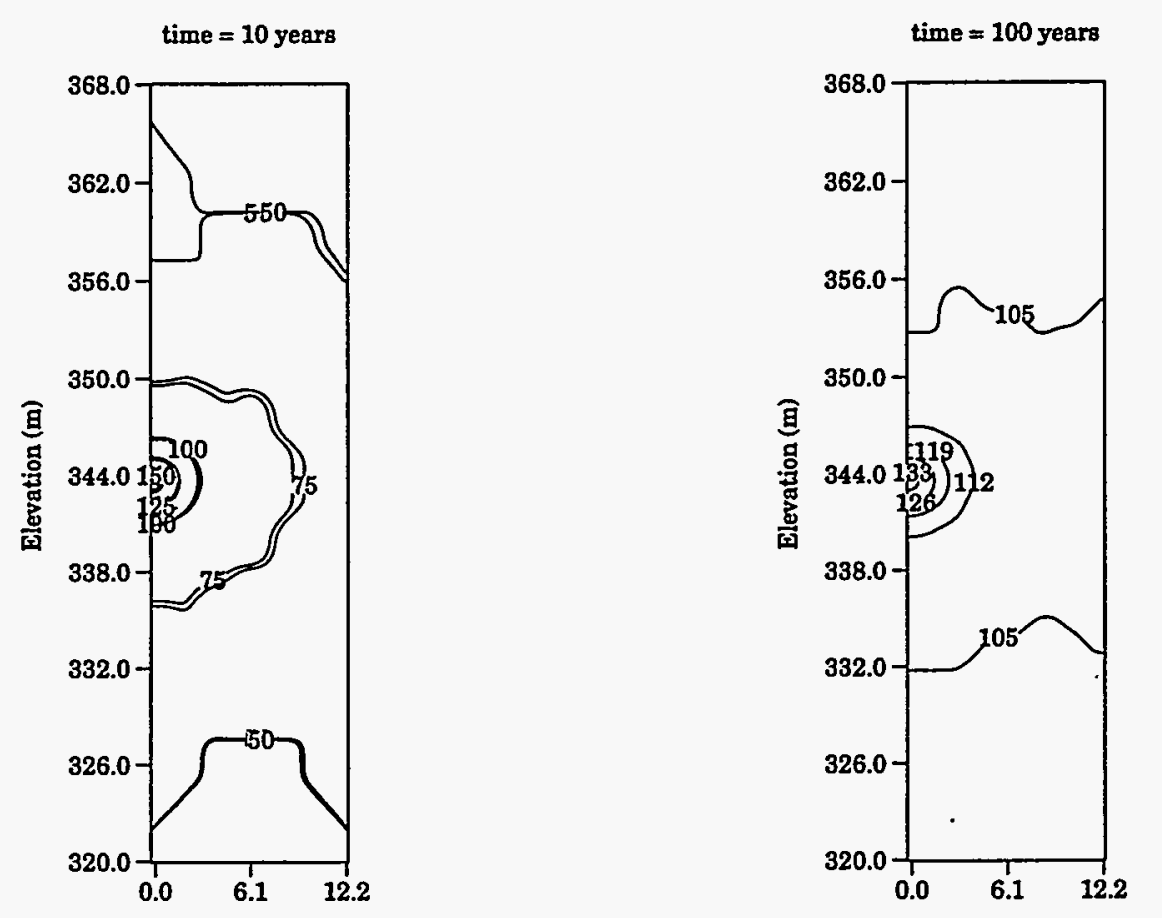

Distance From Centerline (m)

Distance From Centerline (m)
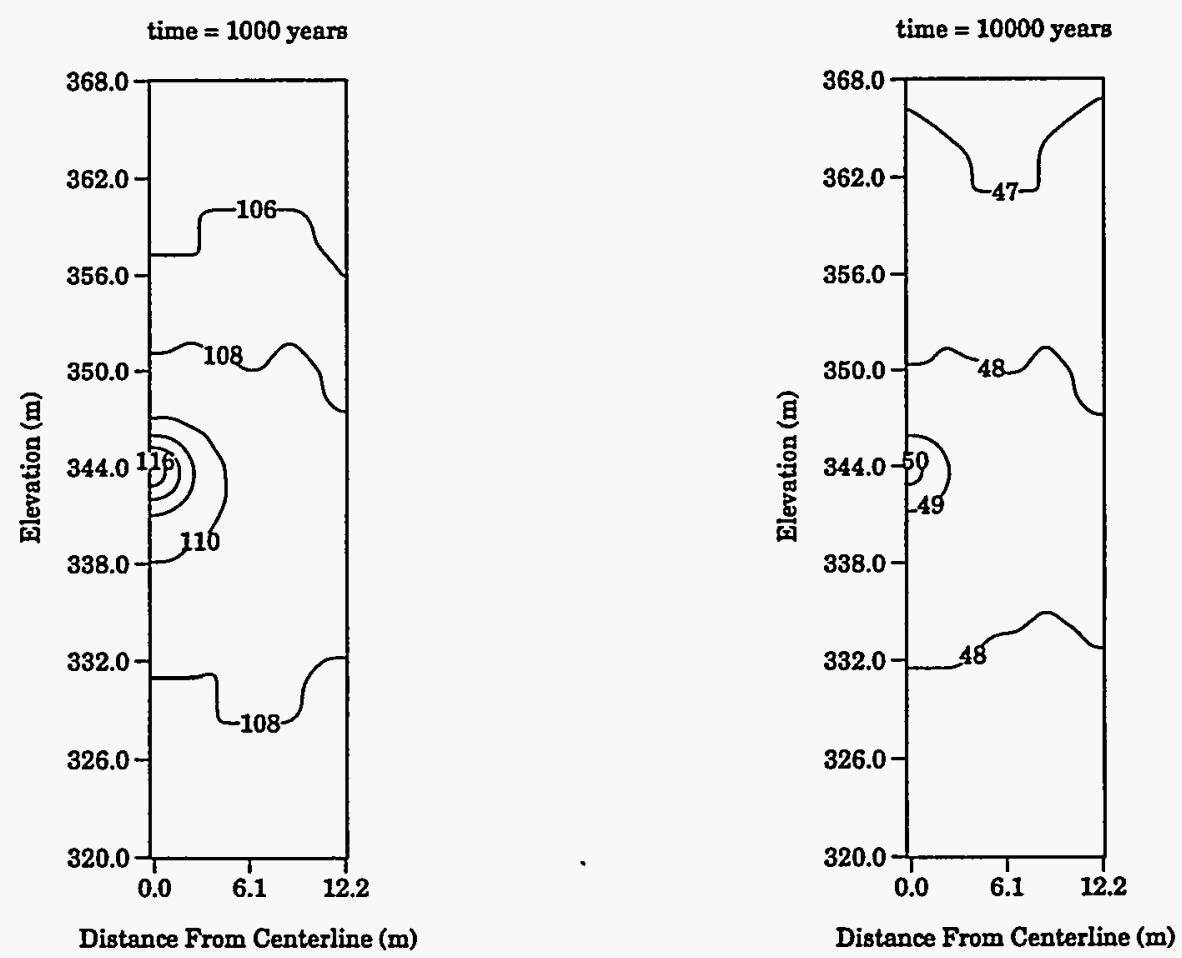

Figure 4.2-13 Predicted Temperature Distribution for 83 MTU/acre, with Backfill, Infiltration $=0.05 \mathrm{~mm} /$ year 

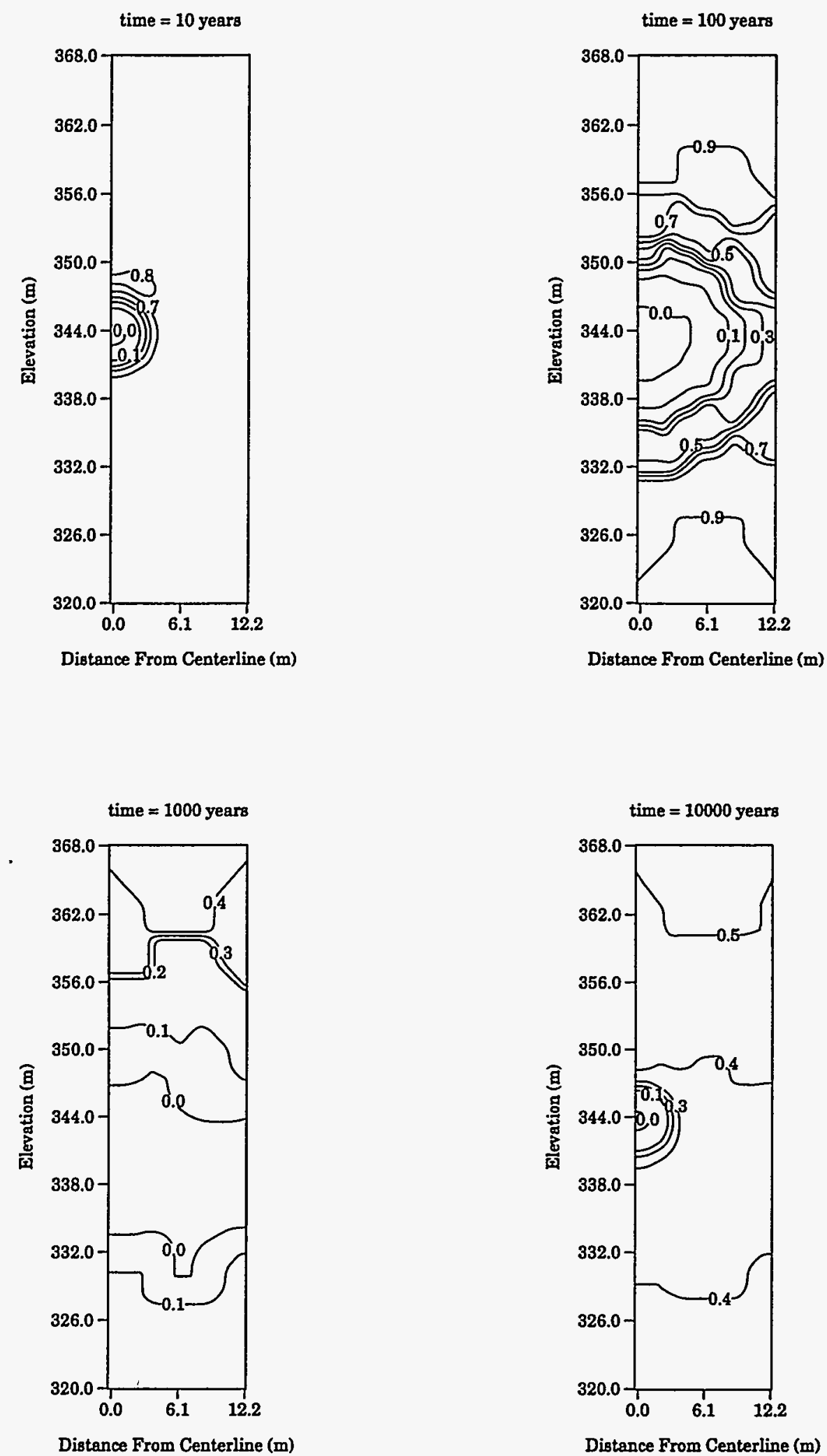

Figure 4.2-14 Predicted Saturation Distribution for 83 MTU/acre, with Backfill, Infiltration $=0.05 \mathrm{~mm} /$ year 

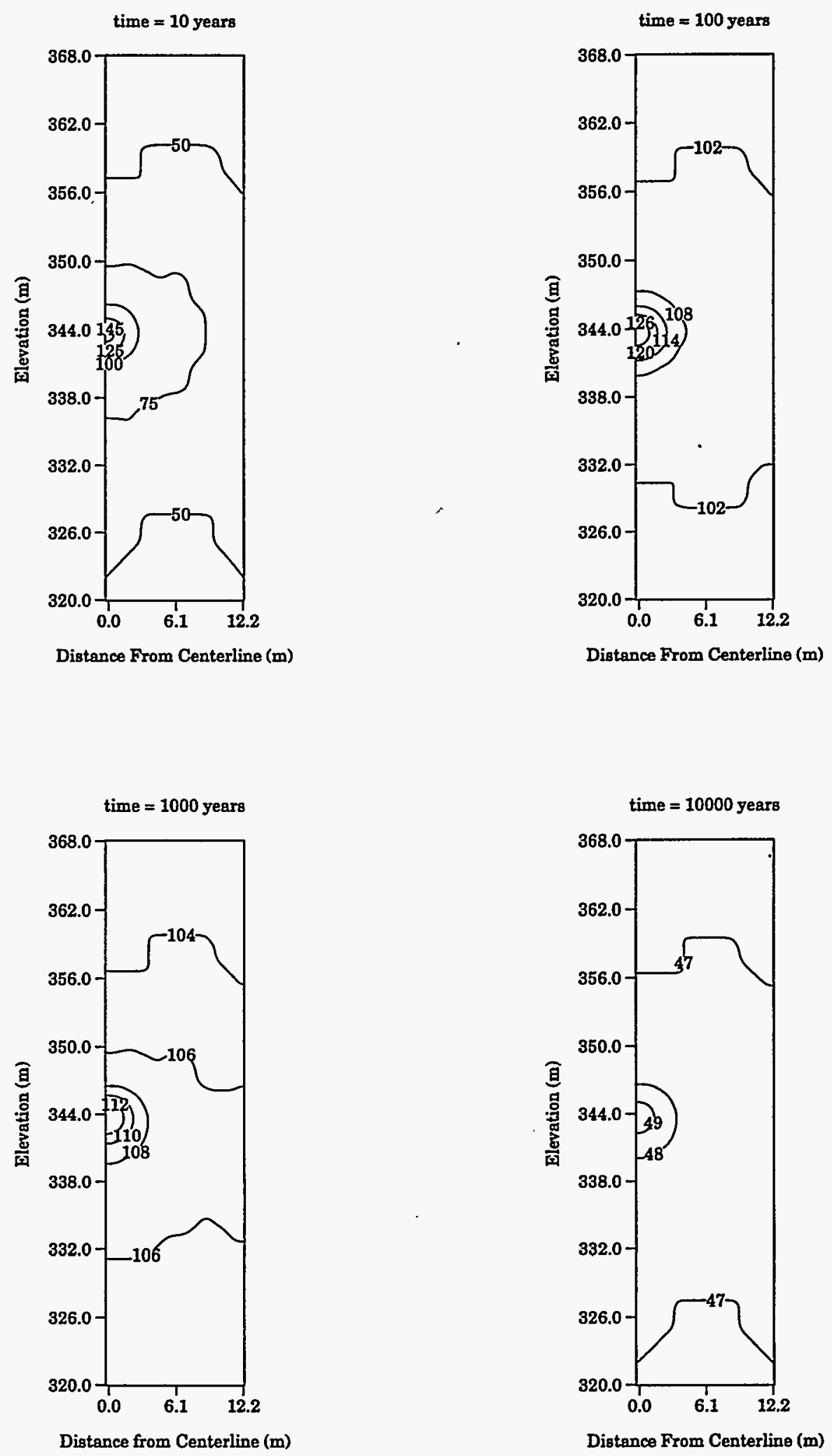

Figure 4.2-15 Predicted Temperature Distribution for 83 MTU/acre, with Backfill, Infiltration $=0.3 \mathrm{~mm} / \mathrm{year}$ 

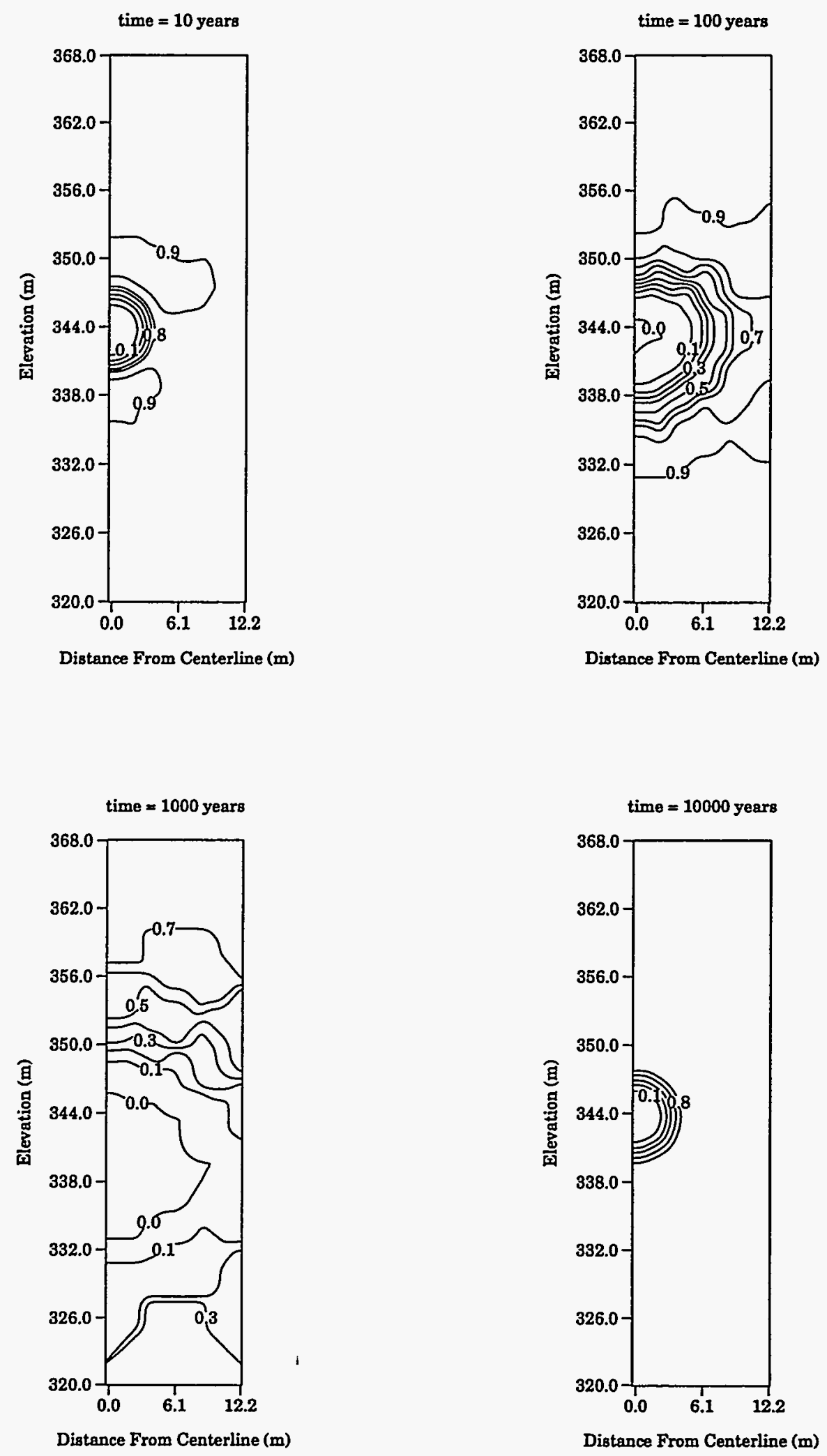

Figure 4.2-16 Predicted Saturation Distribution for 83 MTU/acre, with Backfill, Infiltration $=0.3 \mathrm{~mm} / \mathrm{year}$ 

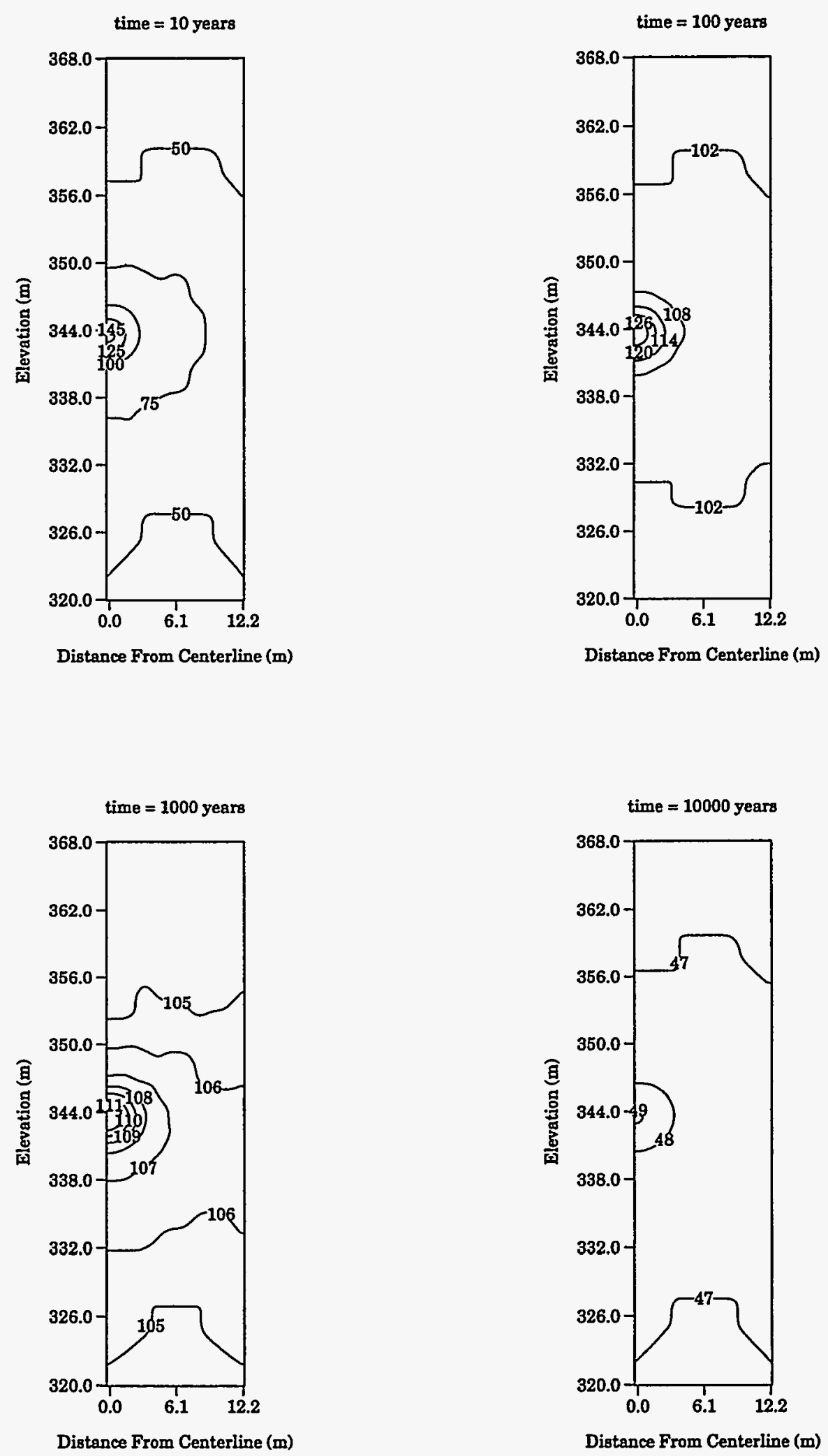

Figure 4.2-17 Predicted Temperature Distribution for 83 MTU/acre, No Backfill, Infiltration $=0.3 \mathrm{~mm} /$ year 

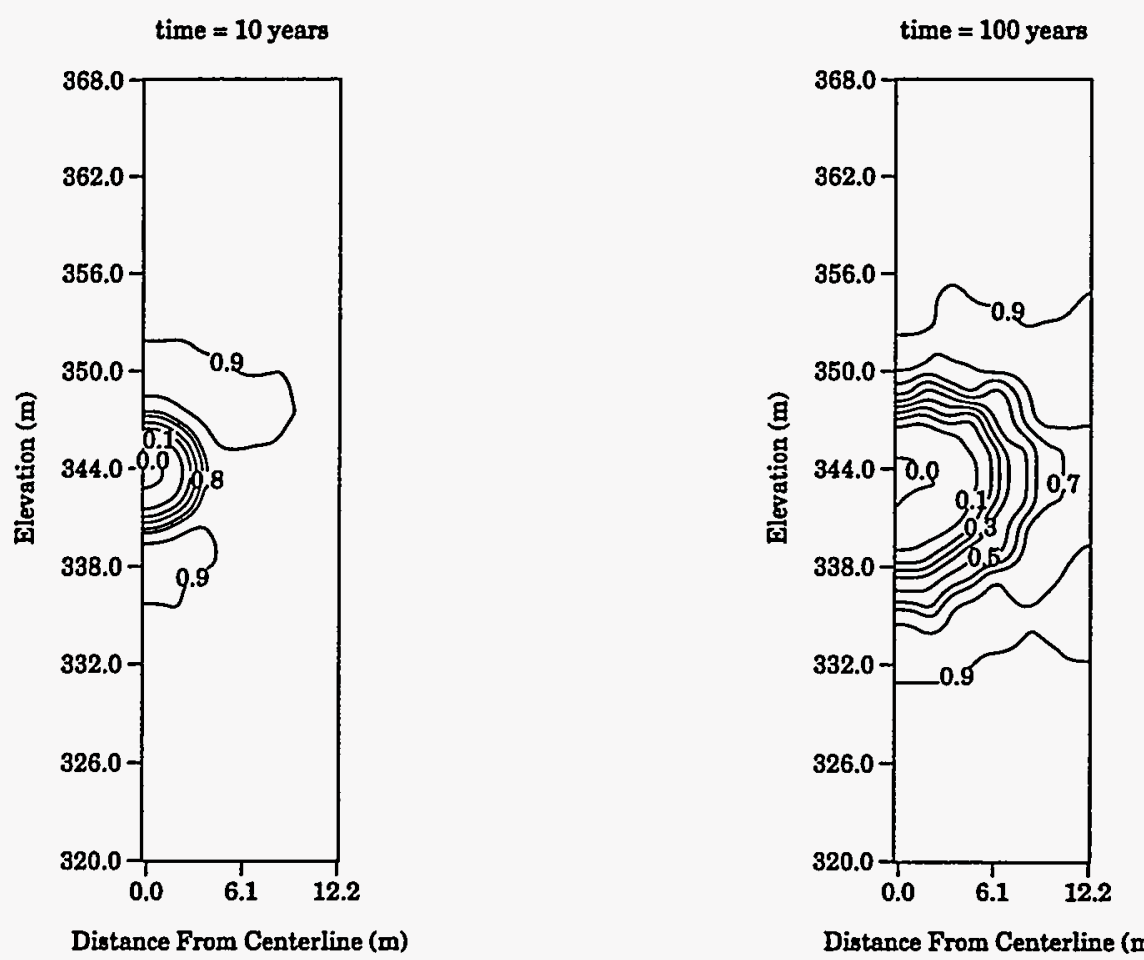

Distance From Centerline (m)
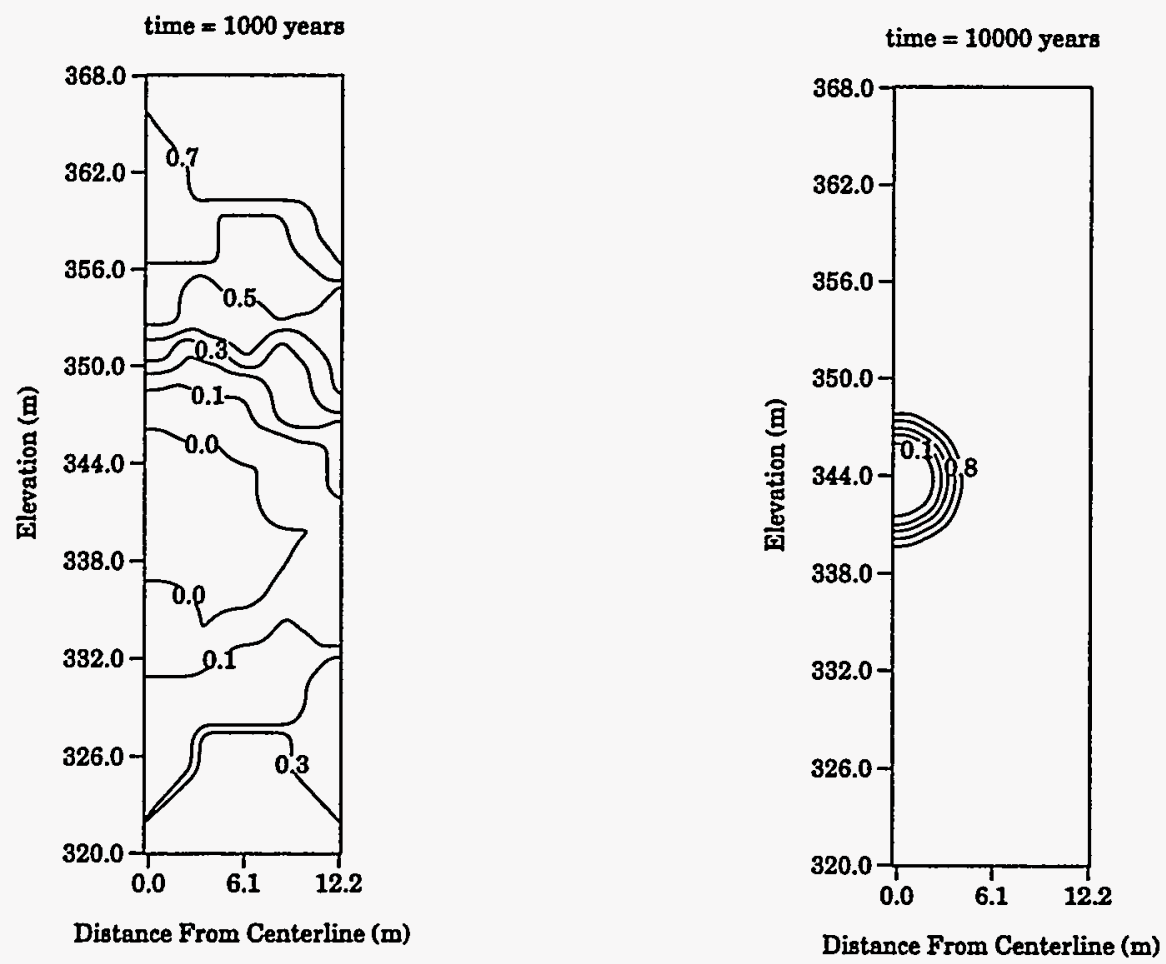

Figure 4.2-18 Predicted Saturation Distribution for 83 MTU/acre, No Backfill, Infiltration $=0.3 \mathrm{~mm} /$ year 

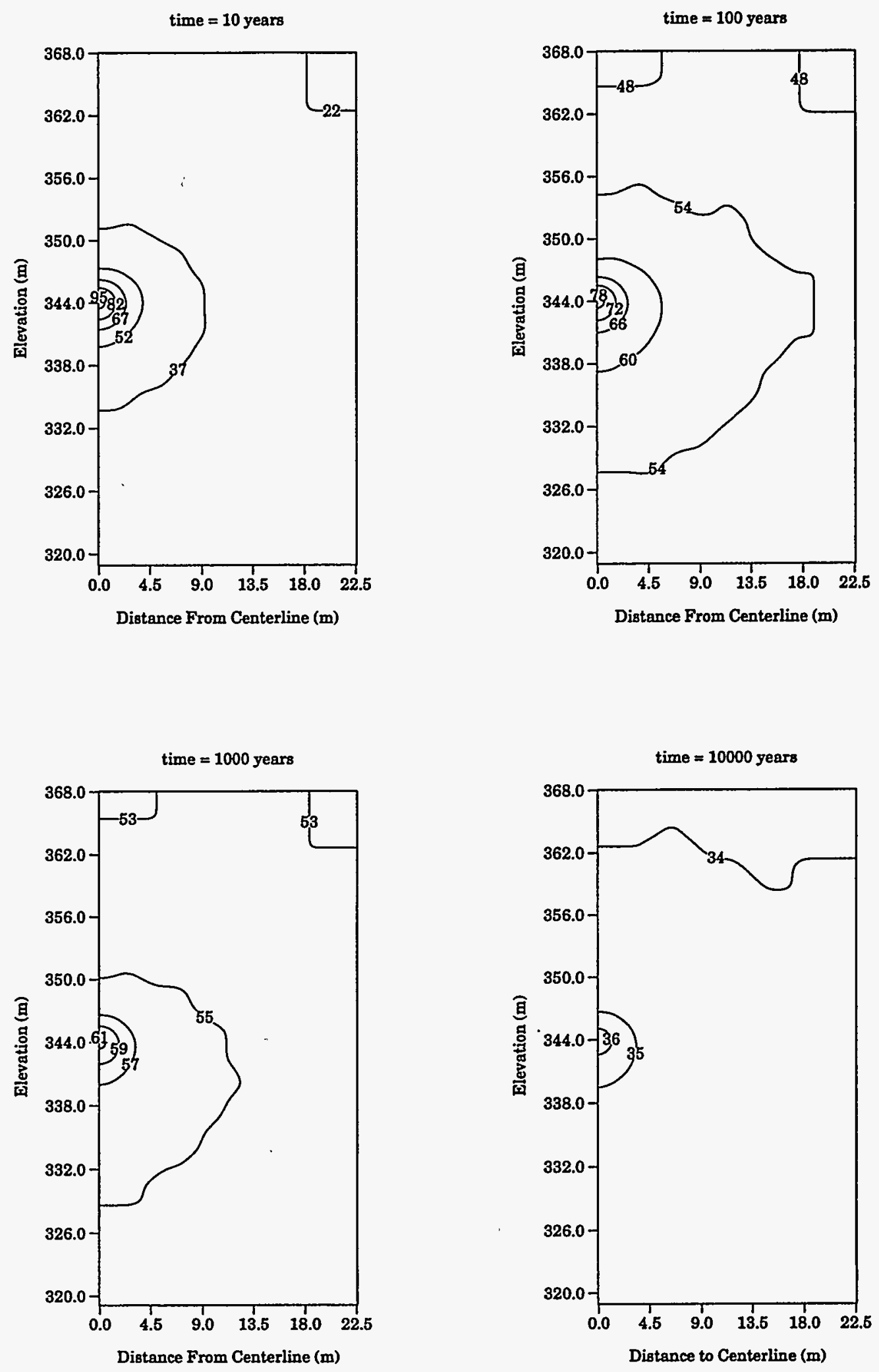

Figure 4.2-19 Predicted Temperature Distribution for 25 MTU/acre, with Backfill, Infiltration $=0.3 \mathrm{~mm} /$ year 

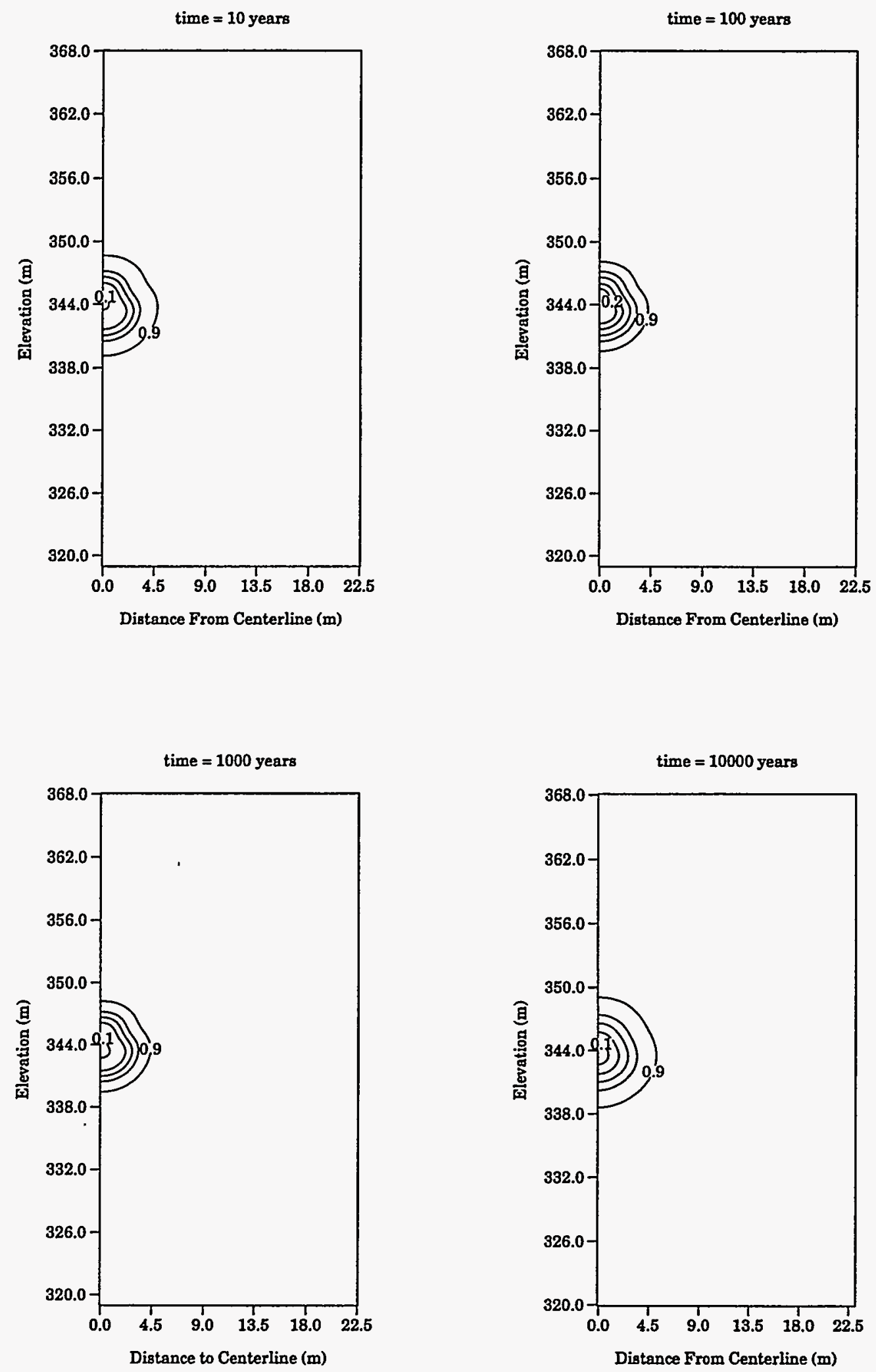

Figure 4.2-20 Predicted Saturation Distribution for 25 MTU/acre, with Backfill, Infiltration $=0.3 \mathrm{~mm} /$ year 

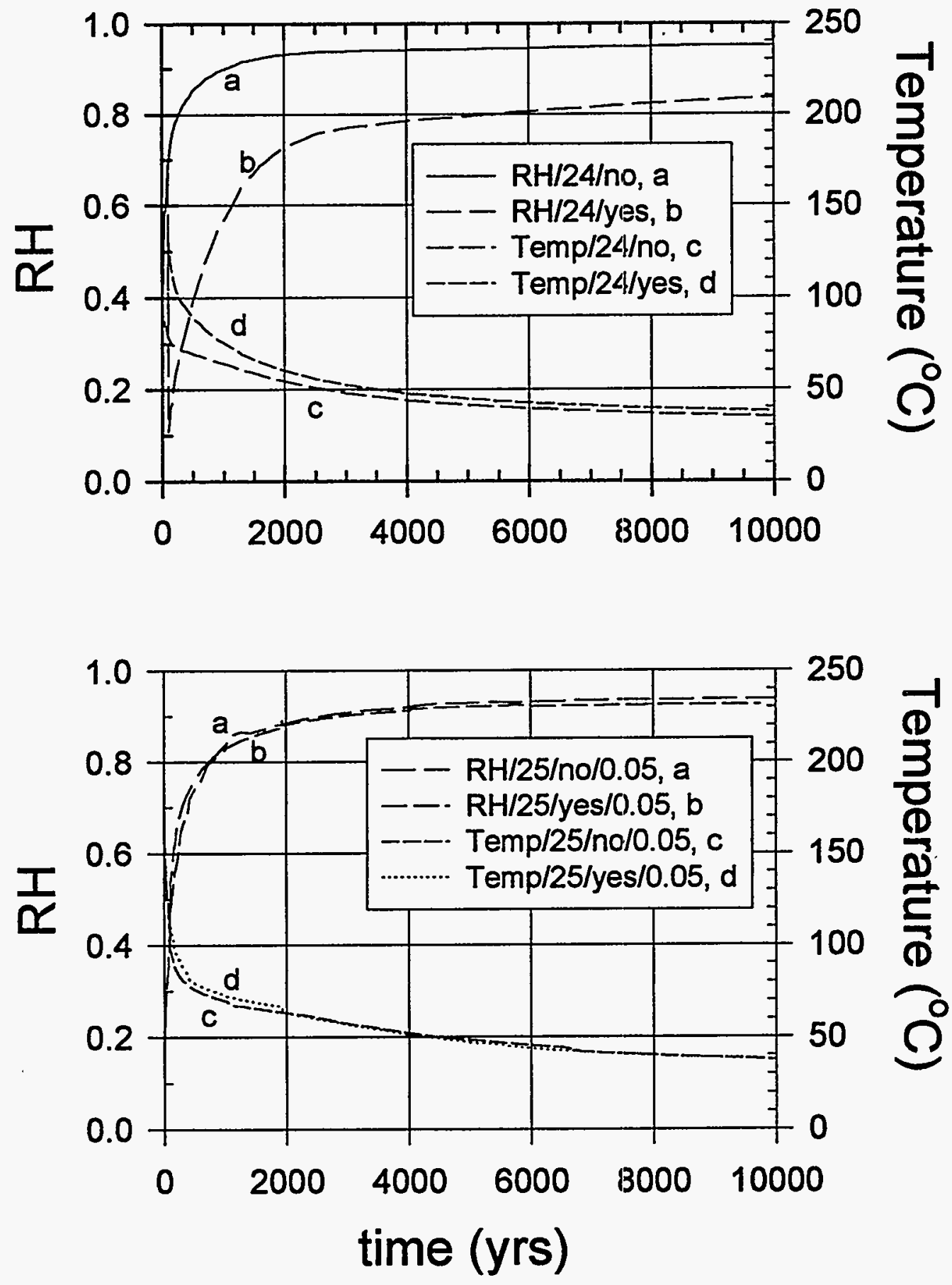

Figure 4.2-21 Comparison of $\mathrm{RH}$ and temperature predictions from Buscheck et al. (24 MTU/acre) and this study (25 MTU/acre). 

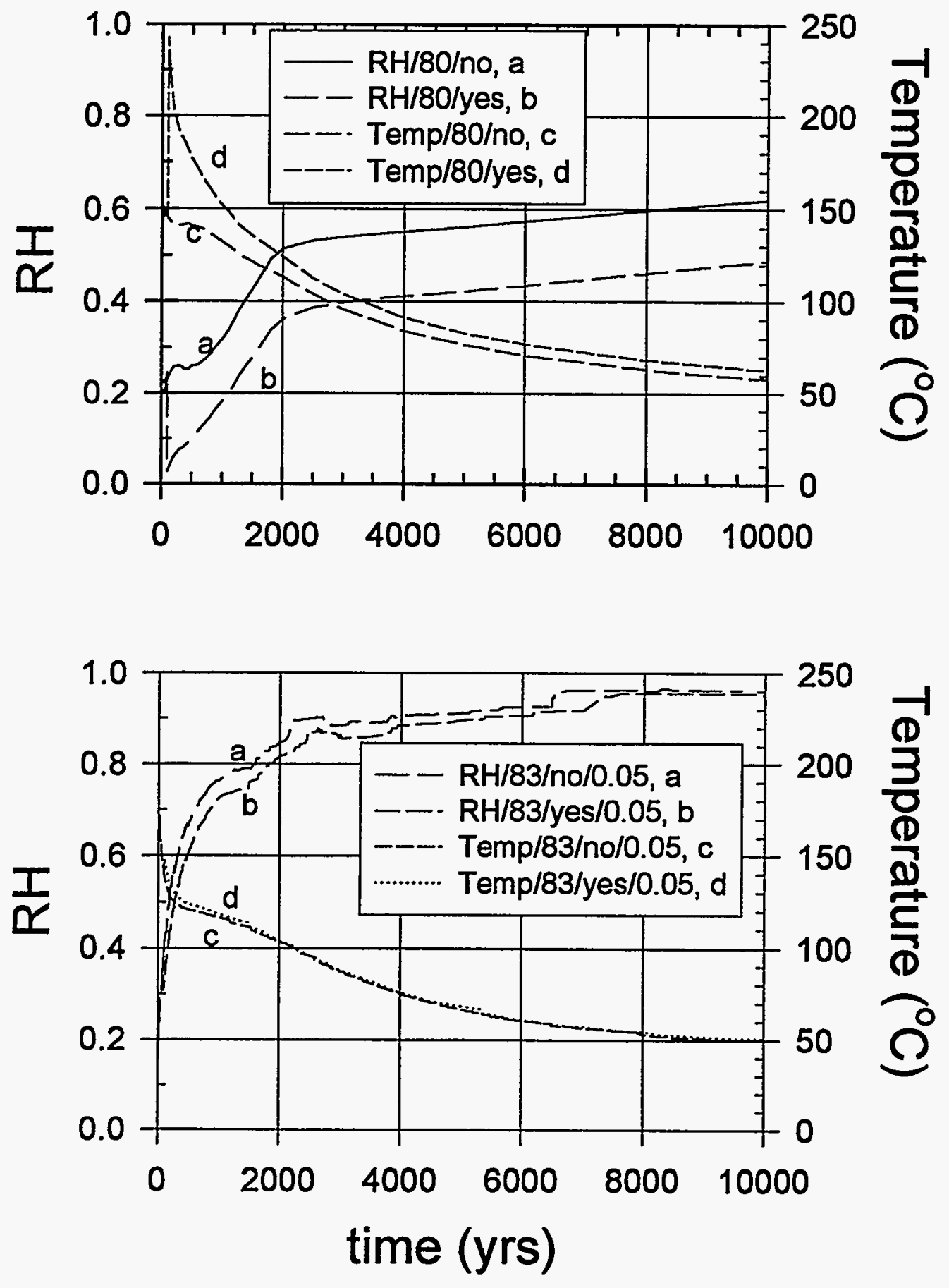

Figure 4.2-22 Comparison of $\mathrm{RH}$ and temperature predictions from Buscheck et al. (80 MTU/acre) and this study (83 MTU/acre). 


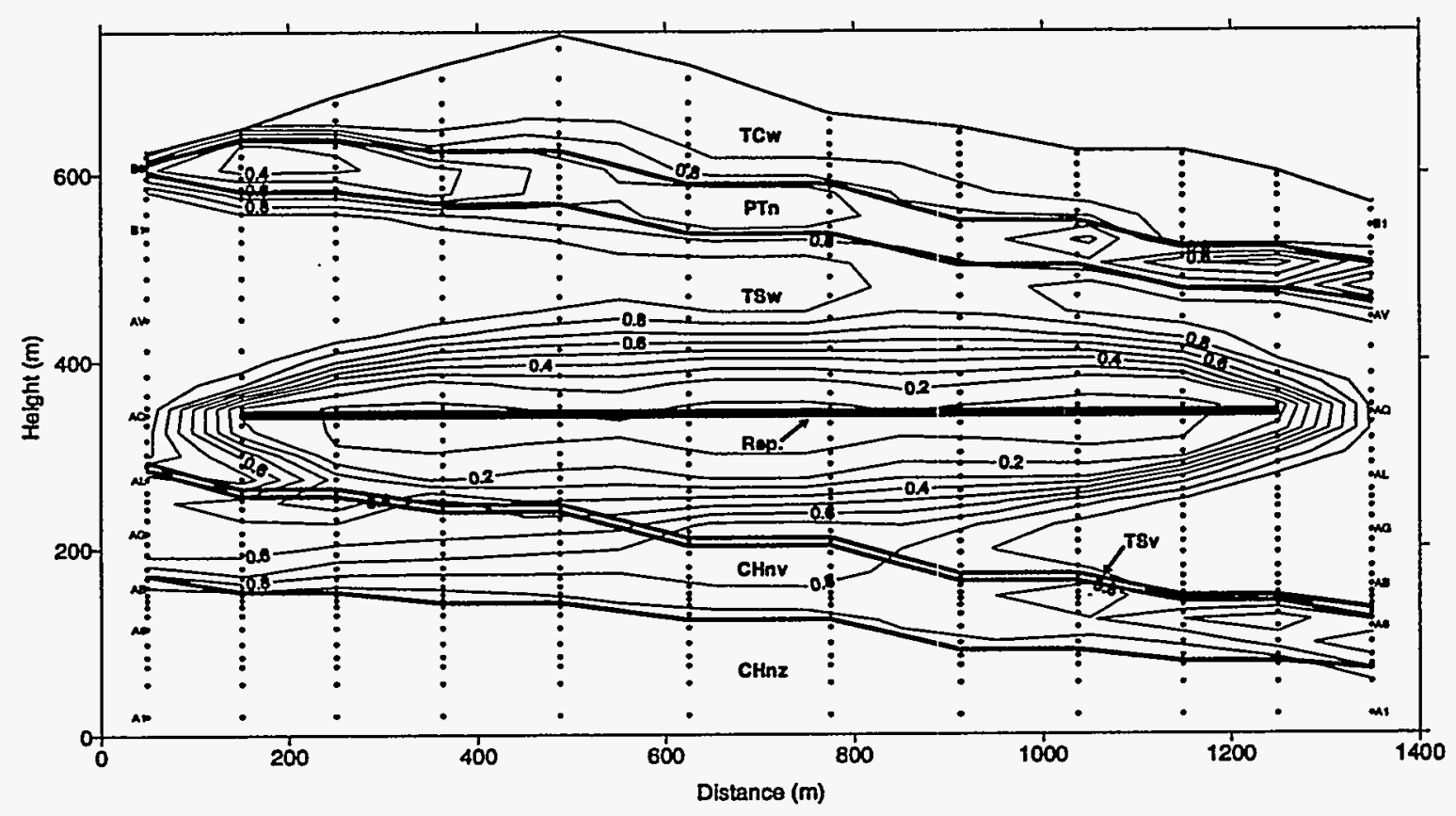

Figure 4.3-1 Temperature Contours at 1,000 Years for an Infiltration Rate of 0.1 $\mathrm{mm} / \mathrm{year}$ and Enhanced Vapor Diffusivity

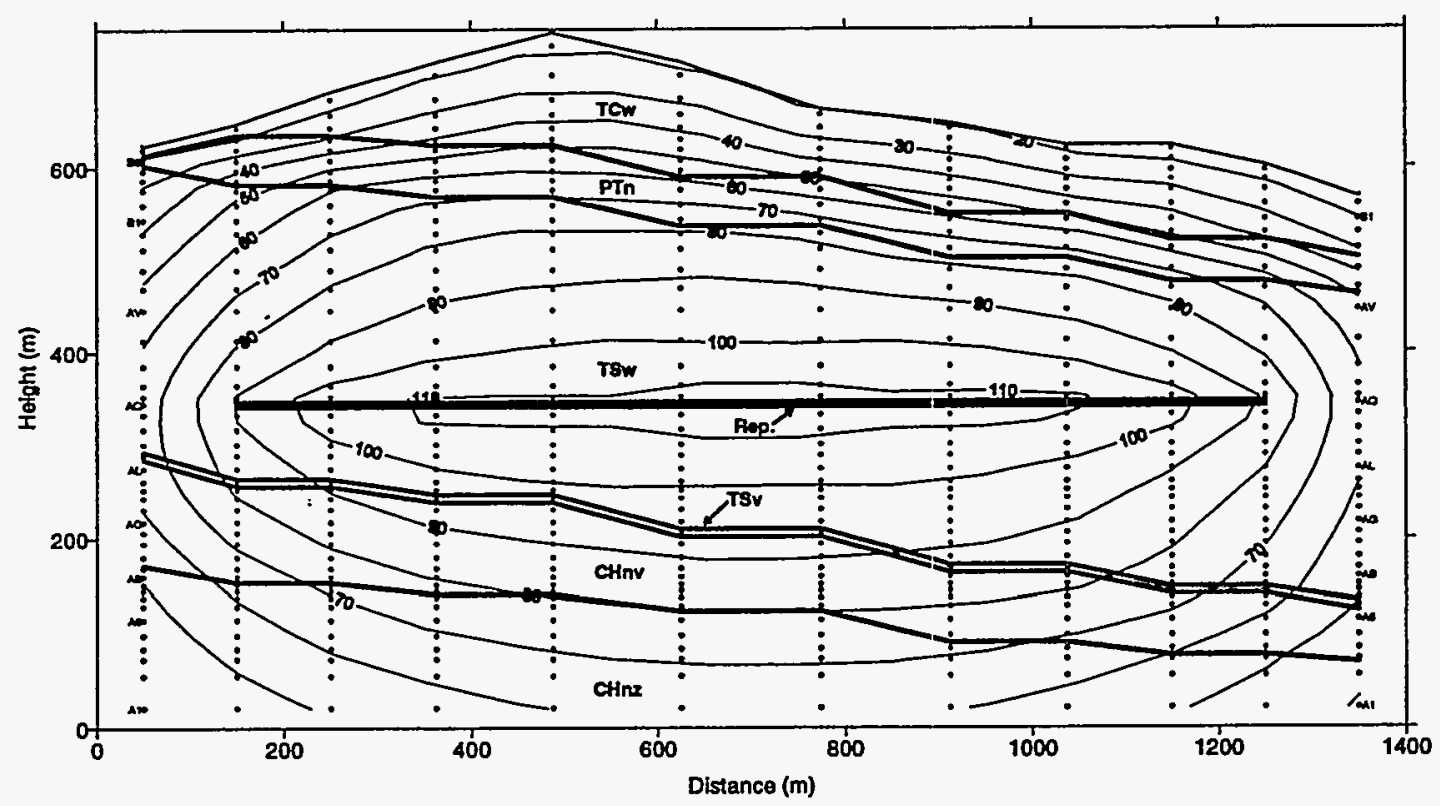

Figure 4.3-2 Liquid Saturation contours at 1,000 years for an Infiltration Rate of 0.1 $\mathrm{mm} / \mathrm{year}$ and Enhanced Vapor Diffusivity 


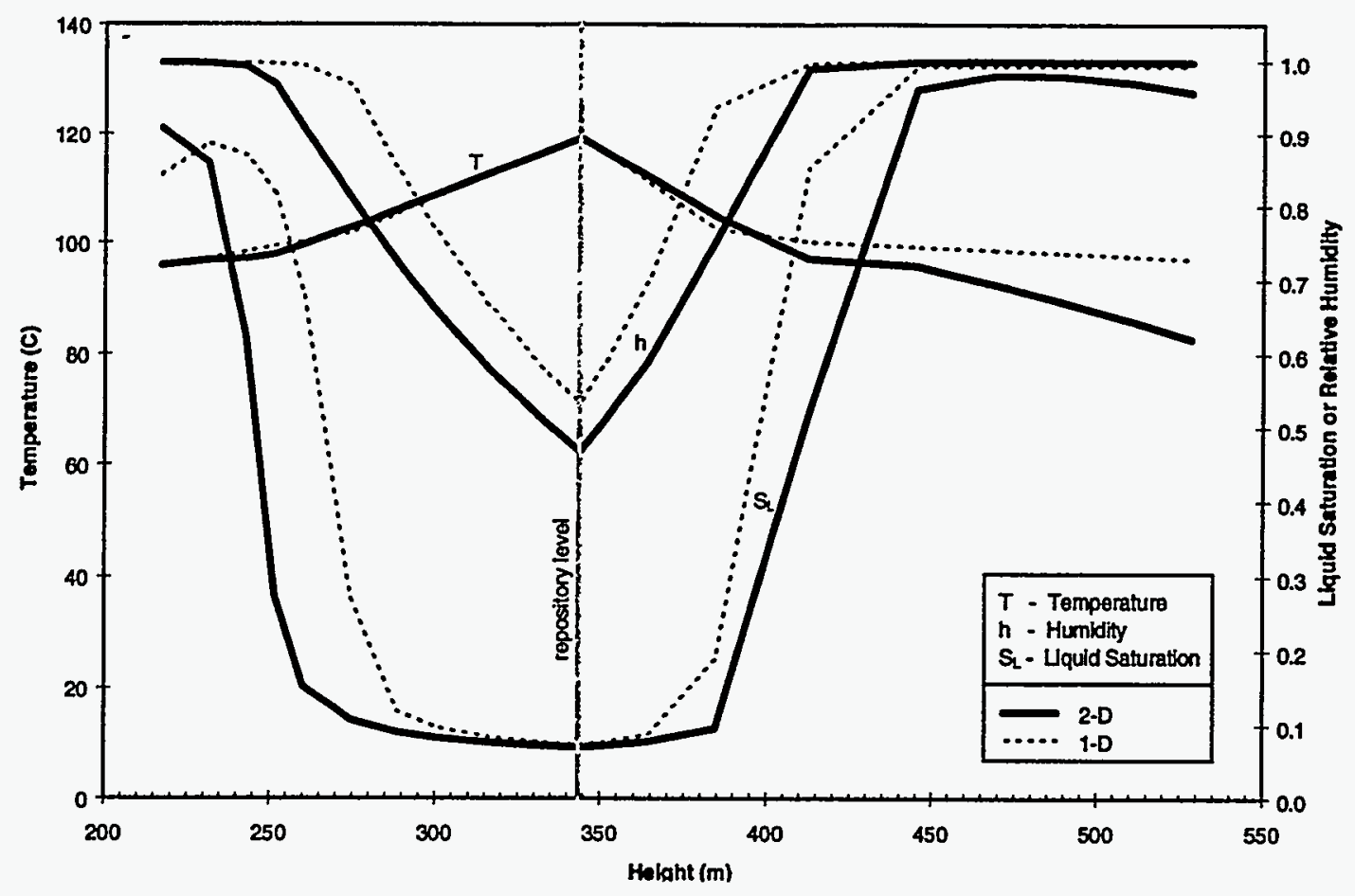

Figure 4.3-3 One- and Two-Dimensional Results at 1,000 years for Column 6 with a One-Dimensional Heat Loading of $92 \mathrm{MTU} / \mathrm{acre}$, an Infiltration Rate of $0.1 \mathrm{~mm} / \mathrm{year}$, and Enhanced Vapor Diffusivity

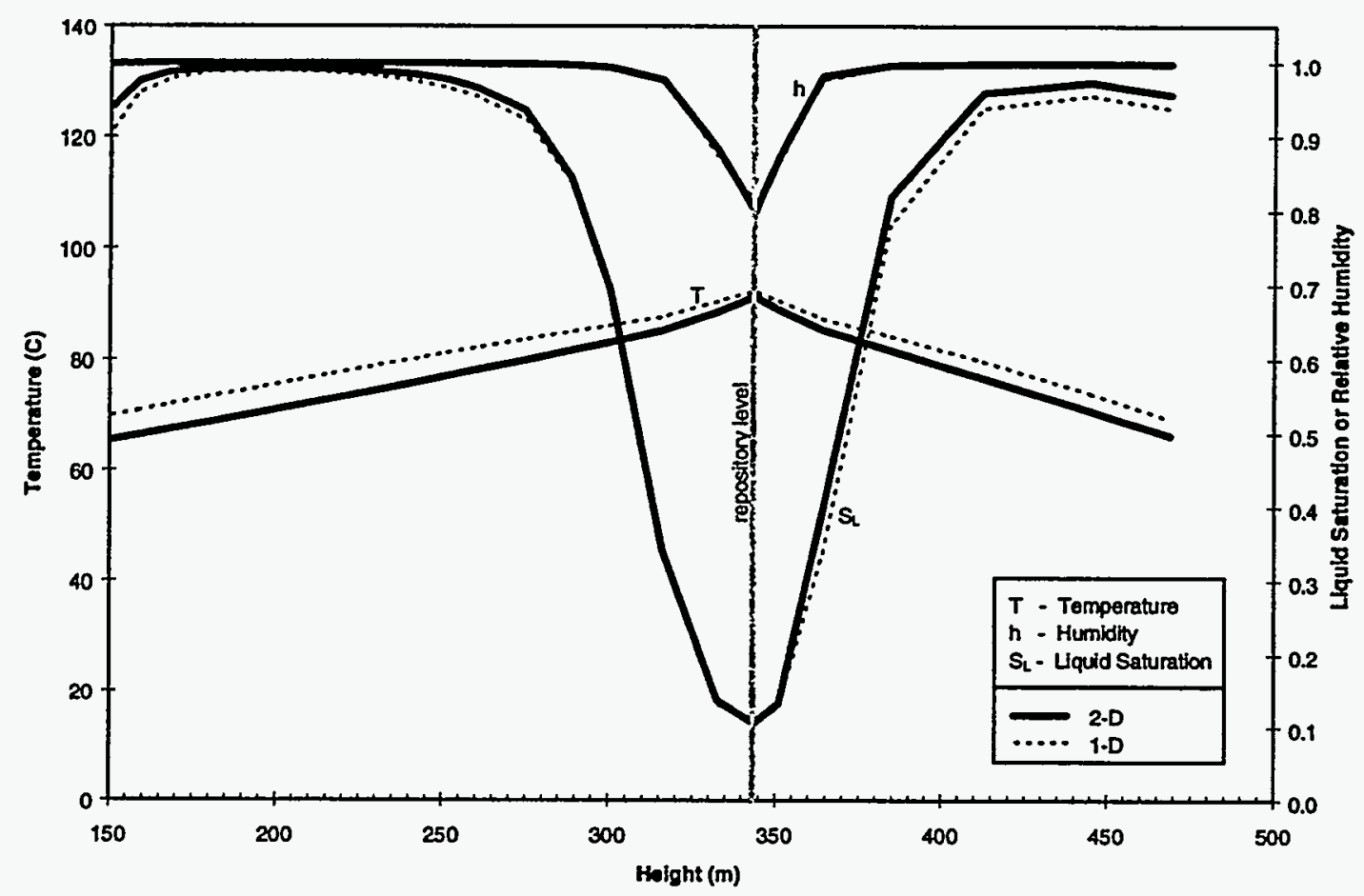

Figure 4.3-4 One- and Two-Dimensional Results at 1,000 Years for Column 11 with a One-Dimensional Heat Loading of 58 MTU/acre an Infiltration Rate of $0.1 \mathrm{~mm} / \mathrm{year}$ and Enhanced Vapor Diffusity 


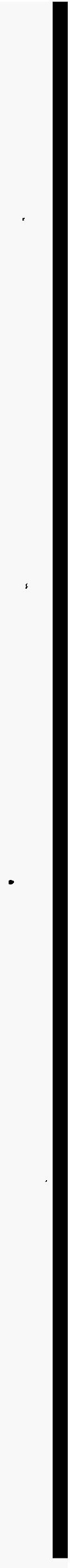


CHAPTER 5

WASTE PACKAGE DEGRADATION ABSTRACTION 


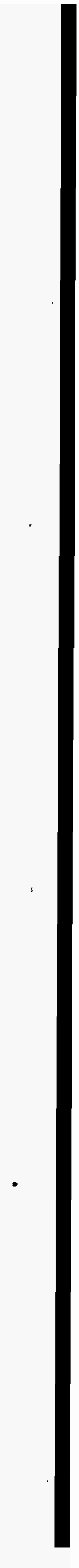




\title{
- 5. WASTE PACKAGE DEGRADATION ABSTRACTION
}

\author{
Joon H. Lee and Joel E. Atkins
}

\subsection{INTRODUCTION}

The current design concept for a multi-barrier waste container provides the primary component of the engineered barrier system (EBS) for containment and isolation of spent fuel and vitrified defense high-level waste (DHLW) in the potential repository at Yucca Mountain. Fulfillment of the requirements for substantially complete containment and subsequent controlled release of radionuclides into the geosphere will rely upon a robust waste container design, among other EBS components. Failure of the waste container will most likely occur in the form of 'holes' created by localized corrosion of the container materials. An additional 'small' fraction of waste containers may fail prematurely due to material and/or manufacturing defects or damage during handling. Even if perforated with holes and cracks, the waste container should still be able to provide a substantial barrier to release (Pigford, 1993). Additional means to suppress and retard radionuclide release into the geosphere may be provided by introducing other engineered components in the immediate vicinity of the waste container. Such measures include placement of backfill around the waste container and/or absorbent materials underneath the waste container (DOE, 1995a).

Prior to any release of radionuclides from the waste packages, the waste package must be breached. Under the near-field environmental conditions expected in the unsaturated media at Yucca Mountain, the primary modes of waste package degradation are humid air and aqueous corrosion. As illustrated in Figure 5.1-1, this chapter presents the container material properties, their corrosion degradation models and the data on which they are based, and the model results which provide the waste package degradation histories to be abstracted into TSPA- 1995 .

Section 5.2 discusses the corrosion modes relevant to the candidate waste container barrier materials in the expected near-field environment. The technical basis for the humid-air corrosion models of the candidate corrosion-allowance material (CAM) is discussed in Section 5.3, and that for its aqueous corrosion models is discussed in Section 5.4. Section 5.5 describes the pitting corrosion model for the candidate corrosion-resistant material (CRM). Although for the nominal case, the potential positive attributes of cladding are not included in this TSPA iteration, Section 5.6 presents a conceptual basis for the incorporation of cladding performance in future TSPA analyses. Section 5.7 presents the predicted waste package degradation history resulting from the combination of the thermo-hydrologic modeling results presented in Chapter 4 and the corrosion degradation models presented in Sections 5.3 to 5.5.

The corrosion models presented in this chapter result from synthesis and analysis of literature data to capture and represent the major parameters in the corrosion degradation processes. The site-relevant corrosion testing and model development programs currently underway in this program should enable incorporation of detailed electrochemical and other physicochemical processes associated with waste container corrosion (Henshall, et al., 1993; McCright, 1994) for use in future TSPA analyses. 


\subsection{CORROSION MODES}

This section discusses the corrosion modes expected for the candidate containment barrier materials (described in Section 3.5) in the near-field environment of the potential repository. The candidate barrier materials fall into two major categories: corrosion-resistant material (CRM) (Alloy 825) and corrosion-allowance material (CAM) (carbon steel). A third category of moderately corrosion resistant material (MCRM) (Monel 400 and $70 \mathrm{Cu} / 30 \mathrm{Ni}$ alloy) has performance features between the two categories. Many factors influence the potential corrosion modes on the candidate materials. These include: 1) metallurgical factors (alloy composition and alloy microstructure);2) physical factors (temperature); 3) chemical factors ( $\mathrm{pH}$ and concentration of aggressive species such as chloride, sulfate, nitrate and carbonate); and 4) mechanical factors (stress) (McCright, 1994).

In general, the corrosion modes can be classified into five groups: 1) general corrosion; 2) localized corrosion (pitting and crevice corrosion); 3 ) environmentally induced cracking (stress corrosion cracking); 4) metallurgically influenced corrosion (intergranular corrosion); and 5) mechanically assisted degradation (erosion and corrosion fatigue) (Craig and Pohlman, 1987). A recent report discussed potentially important degradation modes for the candidate barrier materials in the potential repository near-field environment at Yucca Mountain (Van Konynenburg, et al., 1995). The potentially important degradation modes identified in the report include: 1) general corrosion; 2) pitting corrosion; 3) crevice corrosion; 4) stress corrosion cracking; 5) galvanic effects (galvanic corrosion and cathodic protection); 6) microbiologically influenced corrosion (MIC); 7) radiation induced corrosion; 8) corrosion in welded materials; and 9) low temperature oxidation. Each of these specific degradation modes is discussed below.

General corrosion normally results in a 'relatively' uniform thinning of materials without significant localized attack. The corrosion-allowance material would be affected mostly by this corrosion mode. Localized corrosion (pitting and crevice corrosion) is induced by local variations in electrochemical potential on a micro-scale over small regions. The variations in electrochemical potential may result from the local perturbations in the structure and composition of usually protective, passive films on metal surfaces and also in the electrolyte composition of the solution that contacts the metal (McCright, 1994; Henshall, et al., 1993).

Microbiologically influenced corrosion (MIC) results from the metabolic activity of microorganisms. MIC may operate throughout the life of the repository, especially after the near-field temperature of the potential repository cools down. Microbial metabolism produces corrosive chemicals. For example, sulfate-reducing bacteria reduce sulfate $\left(\mathrm{SO}_{4}{ }^{2-}\right)$ to sulfide $\left(\mathrm{S}^{2-}\right)$ which forms HS', a highly corrosive species (Van Konynenburg, et al., 1995). Because of the localized nature of MIC and associated electrochemical perturbations, the overall effects can be modeled probabilistically. Additionally, the biochemical variations surrounding microbial activity is expected to introduce a further probabilistic consideration (McCright, 1994). Although 300 -series stainless steels are known to be susceptible to MIC, the nickel-based alloys such as Alloy 825 seem to be immune to MIC (Farmer, et al., 1988).

Stress corrosion cracking is a crack propagation process that results from the combined and synergistic interaction of mechanical stress and corrosion reactions. The distribution of mechanical strain is subject to local (micro-scale) perturbations in metals because of structural 
inhomogeneities from one location to another on a similar scale to the electrochemical potential variations. Stress corrosion cracking can be represented probabilistically with a non-uniform electrochemical potential distribution and a non-uniform strain distribution (McCright, 1994). In many alloy systems, localized corrosion and stress corrosion cracking are interrelated because the sites of localized corrosion attack become the sources of initiation of stress corrosion (Farmer and McCright, 1989; Farmer, et al., 1988).

Radiation induced corrosion is another potentially important degradation process of waste packages in the repository. In the presence of a liquid phase irradiated under gamma radiation, the fixed nitrogen may exist in the liquid phase as nitrite and nitrate ions that are corrosive to metals. The total amount of nitrite and nitrate that can be formed in a liquid phase is limited by the gamma radiation dose rate and the volume of air irradiated. If a thin film of water on the waste package container is irradiated in the contact with a relatively thicker air space, it is possible to achieve a significant concentration of nitrate in the relatively small amount of water in the film (Van Konynenburg, et al., 1995).

Alloy microstructure, which can be thought of as the alloy composition at a very local level, may be an important parameter in many degradation modes. Since the alloy microstructure is most likely to vary in and around welds, differences in the behaviors are most likely to be with the welded materials (Strum, et al., 1988). The impact of oxidation of the candidate barrier materials in the potential repository condition is considered insignificant (Gdowski and Bullen, 1988).

Among the degradation modes discussed above, pitting corrosion is considered the primary degradation mode to impact waste container performance. In the simulation of the waste container degradation presented in this chapter, only general corrosion and pitting corrosion are considered.

\subsection{HUMID-AIR CORROSION MODELS FOR CORROSION-ALLOWANCE MATERIALS}

\subsubsection{Introduction}

Carbon steel, the candidate corrosion-allowance barrier material, undergoes active corrosion both in humid-air and aqueous environments (refer to Section 3.5 for the waste container barrier materials). In the potential repository, it is expected that the waste container will be exposed to humid-air and aqueous conditions at elevated temperatures for extended periods of time. In this report, the term "humid-air corrosion" is used to refer to corrosion which takes place under a 'thin' film of water that forms on the container surface above a certain critical humidity threshold. Such a water film is not thick enough to behave as bulk water. The term "aqueous corrosion" is used to refer to corrosion of metal in contact with bulk water.

This section outlines the development and abstraction of general and pitting corrosion models of the candidate corrosion-allowance barrier materials in humid-air, and presents results of these newly developed models. This section includes a comparison of the new model results with those from the existing McCoy model (McCoy, 1994). 


\subsubsection{Corrosion Data Compilation}

A considerable amount of data for atmospheric general and pitting corrosion of commercial iron and steel has been accumulated by numerous testing programs over the past few decades in the U.S. and other countries. An average general corrosion depth at a given exposure time is determined from a weight loss measurement (after removing the corrosion products) of a specimen under testing. The pit depths are determined directly by measuring the depth of each pit with a device equipped with a microscope and a fine, measuring needle. A literature survey was conducted to collect data for atmospheric general and pitting corrosion for a suite of cast iron and carbon steel which are known to have corrosion behaviors similar to the candidate carbon steel. The atmospheric corrosion data include the effects of pollutants such as $\mathrm{SO}_{2}$ and other chemicals in the atmosphere that interact with test specimens. The data also embed any effects of salts that may form on the surface of the corroding specimen due to cyclic wetting and drying. Data from marine sites were excluded because marine environments are much more corrosive (due mostly to the presence of chloride salts in a marine atmosphere) than the potential repository near-field environment considered in TSPA-1995. Future TSPA analyses may incorporate the effects of such corrosive environments for different conceptual models of nearfield water chemistry, such as those that may result from salt precipitation in a moisture refluxing condition at elevated temperatures.

Important testing parameters that were considered in the data compilation included test duration, average exposure temperature and relative humidity, and average sulfur dioxide content in the test atmosphere. From the general corrosion data collected, a total of 166 data points that have the testing (exposure) parameters documented were included in the model abstraction. The test environments included rural, urban, and industrial sites. The following is the list of the data sources used in the model development.

1. Haynie, F.H., and J.B. Upham (1971)

2. Knotkova, D., P. Holler, and J. Vickova (1981)

3. Knotkova-Cermakova, D., J. Vickova, and J. Honzak (1982)

4. Komp, M.E. (1987)

5. Pereira D., O. Nobre, and E. Almeida (1993)

6. Southwell, C.R., and J.D. Bultman (1982)

7. Southwell, C.R., J.D. Bultman, and A.L. Alexander (1976)

8. Townsend, H.E., and J.C. Zoccola (1982)

9. Tri, N.Q., V.D. Huy, L.V. Cuong, P.Th. San (1993)

10. Wei, F.-I. (1991)

The longest-term data were from the 16-year corrosion test program conducted by the Naval Research Laboratory in a tropical environment in Panama (Southwell and Bultman, 1982; Southwell, et al., 1976). The exposure conditions for the entire set of data range from 5 to $27^{\circ} \mathrm{C}$ average temperature, 63 to $85 \%$ average relative humidity $(\mathrm{RH})$, and an average $\mathrm{SO}_{2}$ level of 2 to $406 \mu \mathrm{g} \mathrm{SO} / \mathrm{m}^{3}$. 


\subsubsection{Exposure Parameter Transformation}

After the initial waste emplacement and subsequent heating to a peak temperature, the near-field environment of the potential repository is expected to be relatively steady-state (or quasi-steady state) during the gradual cooling periods in terms of temperature and relative humidity. However, the exposure conditions of the atmospheric corrosion data fluctuated over periods as short as a day. Therefore, in order to develop a model that is applicable to the potential repository environment, it was necessary to transform the collected corrosion data to testing periods, for which corrosion was active and also the exposure conditions were relatively steady.

In the data transformation, three generalized relationships were needed to transform the exposure conditions and corrosion data: (1) a relationship to estimate the fraction of the exposure time during which corrosion was active; (2) a relationship to estimate the average relative humidity during that fraction of the time; and (3) a relationship to estimate the average temperature during that fraction of the time. In an effort to develop the generalized relationships, hourly weather data for a 10-year period from 9 geographical areas were received from the Western Climatic Center in Reno, Nevada (Prowell, 1994). The areas were selected to cover a wide range of weather conditions from hot and dry (Las Vegas, NV, Albuquerque, NM, and Tucson, AZ) to warm and humid (Honolulu, HI, and Arcata, CA) to cold and humid (Great Falls, MT, Denver, $\mathrm{CO}$, Cheyenne, WY, and Anchorage, AK).

\section{Time Fraction for Relative Humidity Greater than $70 \%$}

Numerous experimental results of iron specimens exposed to controlled humidity conditions have shown that at around $70 \% \mathrm{RH}$ their surfaces become covered with a 'thin' water film and 'active' corrosion initiates (Vernon, 1933; Phipps and Rice, 1979). Accordingly, $70 \% \mathrm{RH}$ was chosen as the threshold level at which 'active' humid-air corrosion initiates. Using the weather data, a relationship for estimating the fraction of time during which relative humidity is greater than or equal to $70 \%$ was developed as a function of the average relative humidity and average temperature. For each year's hourly weather data, the time fraction with $\mathrm{RH} \geq 70 \%$ was calculated, and fitted as a function of the annual average relative humidity and temperature. The resulting functional form is expressed as:

$$
f_{70}=\frac{1}{1+\exp \left[1.0362+\frac{27.8249\left(55.3159-R H_{\text {avg }}\right)}{T_{\text {avg }}}\right]}
$$

where $f_{70}$ is the fraction of time during which $\mathrm{RH} \geq 70 \%, \mathrm{RH}_{\text {avg }}$ is the annual average relative humidity (\%), and $\mathrm{T}_{\text {avg }}$ is the annual average temperature $\left({ }^{\circ} \mathrm{C}\right) . \mathrm{RH}_{\text {avg }}$ and $\mathrm{T}_{\text {avg }}$ are provided with the corrosion data. Estimates made with Equation (5.3-1) are compared with the weather data in Figure 5.3-1. 


\section{$\underline{\text { Reduction of Relative Humidity and Temperature }}$}

As discussed in Section 5.3.4, a 'new' exposure time of each corrosion data point was estimated by multiplying the actual exposure time with the time fraction during which $\mathrm{RH} \geq 70 \%$, calculated with Equation (5.3-2), and it corresponds to the time fraction during which corrosion was active. The new exposure time is shorter than the actual exposure time because a portion of the actual exposure time during which the exposure condition was 'dry' or $\mathrm{RH}<70 \%$ is excluded. Accordingly, it was necessary to estimate a 'new' average relative humidity and 'new' average temperature of each corrosion data for that period of time during which $\mathrm{RH} \geq 70 \%$. The weather data were utilized to develop relationships for estimating the 'new' average relative humidity and 'new' average temperature as follows: for each year's hourly weather data, the average relative humidity and average temperature were calculated for the periods with $\mathrm{RH} \geq 70$ $\%$, and fitted as a function of the annual average relative humidity and average temperature. The relationship developed for the new average relative humidity is:

$$
R H_{\text {new }}=83.16-0.1383 R H_{\text {avg }}-0.1057 T_{\text {avg }}+0.002337 R H_{\text {avg }}^{2}
$$

where $\mathrm{RH}_{\text {new }}$ is the new average relative humidity (\%). The new average temperature was estimated with the following equation:

$$
T_{\text {new }}=-13.34+0.1514 R H_{\text {avg }}+1.017 T_{\text {avg }}
$$

where $T_{\text {new }}$ is the new average temperature $(K)$. The new average relative humidity and temperature are assumed to be the representative exposure conditions for the transformed corrosion data discussed in the following section.

\subsubsection{Development of General Corrosion Model}

\section{Corrosion Data Transformation}

The corrosion data collected were transformed using Equations (5.3-1) to (5.3-3) as such: (1) the fraction of the exposure time, for each observation, during which $\mathrm{RH} \geq 70 \%$ (i.e. duration of active corrosion), was calculated with Equation (5.3-1), then a new exposure time was estimated by multiplying this time fraction and the actual exposure time; (2) a new average relative humidity for that time period ( $\mathrm{RH} \geq 70 \%$ ) was estimated with Equation (5.3-2); and (3) a new average temperature for that time period $(\mathrm{RH} \geq 70 \%)$ was estimated with Equation (5.3-3).

\section{Conceptual Models}

The following corrosion dependencies on exposure conditions in humid-air were incorporated into the model development.

$$
D_{8} \propto A_{1} t^{A_{2}}
$$




$$
\begin{aligned}
& \frac{d D_{8}}{d t} \propto B_{1} e^{\frac{B_{2}}{R H}} \\
& \frac{d D_{8}}{d t} \propto C_{1} e^{\frac{C_{2}}{T}} \\
& \frac{d D_{8}}{d t} \propto D_{1} e^{D_{2}\left[s O_{2}\right]}
\end{aligned}
$$

$D_{g}$ is general corrosion depth $(\mu \mathrm{m}), d D_{g} / d t$ is general corrosion rate $(\mu \mathrm{m} / \mathrm{yr}), t$ is exposure time (years), $\mathrm{RH}$ is relative humidity (\%), $\mathrm{T}$ is temperature $(\mathrm{K})$, and $\left[\mathrm{SO}_{2}\right]$ is sulfur dioxide content in the testing atmosphere $\left(\mu \mathrm{g} / \mathrm{m}^{3}\right)$. A's, B's, C's, and D's are constants.

\section{General Corrosion Model}

Combining the conceptual relationships (Equations (5.3-4) to (5.3-7)), the corrosion model can be expressed as follows:

$$
\ln D_{8}=a_{0}+a_{1} \ln t+\frac{a_{2}}{R H}+\frac{a_{3}}{T}+a_{4}\left[S O_{2}\right]+\varepsilon,
$$

where $a_{0}, a_{1}, a_{2}, a_{3}$ and $a_{4}$ are constants to be determined from fitting Equation (5.3-8) to the transformed corrosion data, and $\varepsilon$ is a term representing uncertainty not explained by the model. The variance of the model estimate was calculated as follows:

$$
\operatorname{Var}\left(\ln D_{8}\right)=\left[\begin{array}{lllll}
1 & \ln t & \frac{1}{R H} & \frac{1}{T} & {\left[S O_{2}\right.}
\end{array}\right] V\left[\begin{array}{c}
1 \\
\ln t \\
\frac{1}{R H} \\
\frac{1}{T} \\
{\left[S O_{2}\right]}
\end{array}\right]+\frac{R S S}{D F},
$$

where $\operatorname{Var}\left(\ln D_{g}\right)$ is the variance of the model estimate, $V$ is the covariance matrix ( $5 \times 5$ ), RSS is the residual sum of squares of the model fit, and DF is the degrees of freedom in the model fitting.

Linear regression was used to fit the model in Equation (5.3-8), giving the following parameter values: $\mathrm{a}_{0}=16.9865 \pm 2.8736, \mathrm{a}_{1}=0.6113 \pm 0.0295, \mathrm{a}_{2}=-893.76 \pm 231.04, \mathrm{a}_{3}=-833.53 \pm$ 381.97, and $\mathrm{a}_{4}=0.002637 \pm 0.000377$. 
The corrosion data used and the model estimate with its uncertainties ( \pm 2 standard deviations) are shown in Figure 5.3-2. The input parameters $\left(15^{\circ} \mathrm{C}, 84 \%\right.$ R.H., and $\left.90 \mu \mathrm{g} \mathrm{SO} / \mathrm{m}^{3}\right)$ for the estimate in the figure are the averages of the data set. The atmospheric pollution level of $70 \mu \mathrm{g} \mathrm{SO} / \mathrm{m}^{3}$ was chosen arbitrarily to differentiate corrosion behaviors in heavily polluted areas from that in relatively clean atmospheric environments.

\subsubsection{Results of the General Corrosion Model}

Model predictions of the general corrosion rate as a function of exposure time at different humidities $(80,90$ and $95 \% \mathrm{RH})$ are shown in Figures 5.3-3a and 5.3-3b for exposure temperatures of $60^{\circ} \mathrm{C}$ and $90^{\circ} \mathrm{C}$, respectively. The figures show that the general corrosion rate decreases rapidly with the exposure time. The rate reduction is due primarily to corrosion products formed on the bare metal, which act as a barrier to the transport of reacting species.

The model predictions for the effects of relative humidity on the general corrosion rate for different exposure times are shown in Figures 5.3-4a and 5.3-4b for exposure temperature of $30{ }^{\circ} \mathrm{C}$ and $90^{\circ} \mathrm{C}$, respectively. As discussed in Section 5.3.3, the figures show that the general corrosion rate of CAM is negligible at RH values less than about $60 \%$. The general corrosion rate starts to increase with humidity at about $65 \% \mathrm{RH}$, and the rate of increase becomes greater with increasing relative humidity. However, the relative humidity effects on the general corrosion rate decrease with exposure time. The model predictions are consistent with the literature data discussed in Section 5.3.3.

Similar model predictions at different exposure temperatures showing the effects of relative humidity on the general corrosion rate are shown in Figure 5.3-5 for an exposure time of 1 year. It is shown in the figure that relative humidity has a greater effect on general corrosion than temperature. The model predictions for the effects of $\mathrm{SO}_{2}$ levels in humid-air on the general corrosion of CAM are shown in Figure 5.3-6 for an exposure time of 1 year. The general corrosion rate at $200 \mu \mathrm{g} \mathrm{SO}_{2} / \mathrm{m}^{3}, 90 \% \mathrm{RH}$ and $90{ }^{\circ} \mathrm{C}$ is about twice that of the general corrosion rate predicted at $90 \% \mathrm{RH}, 90^{\circ} \mathrm{C}$ and no $\mathrm{SO}_{2}$ pollution (shown in Figure 5.3-5). These corrosion behaviors predicted with the current model are consistent with numerous literature data (see Duncan and Spedding, 1973; Guttman, 1968; Guttman and Sereda, 1968; Haynie and Upham, 1974; Kucera and Mattson, 1974).

In Figures 5.3-7a to 5.3-7c, the predicted general corrosion of CAM as a function of exposure time in humid-air at different exposure conditions (i.e., humidity and temperature) is compared with that predicted by the aqueous general corrosion model (noted as "water" on the figures) which was developed for TSPA-1995 (discussed in Section 5.4). As shown in the figures, when humidity is in the range of 85 to $100 \% \mathrm{RH}$, the humid-air general corrosion rates are close to the aqueous corrosion rates at the corresponding temperatures. These model predictions are consistent with an observation that the surface of a steel panel tested in a controlled humidity chamber was covered with moisture at about $85 \%$ RH (visually detected) (Haynie, et al., 1978). 


\subsubsection{Development of Pitting Corrosion Model}

In pitting corrosion models, pit initiation and pit growth rate are two major parameters that need to be quantified. However, these parameters are influenced by many factors including materials characteristics, exposure conditions, and aggressive species present. Additionally, complex electrochemical processes associated with the factors also strongly influence pit initiation and pit growth processes. In general, pitting of metal results from complicated interactions among many. factors and appears to be random. As a result, stochastic approaches have been applied to represent and quantify pitting processes.

Pitting of CAM is commonly represented with a pitting factor that is defined as the ratio of the maximum pit depth to the general corrosion depth at a given exposure time. Accordingly, the pitting factor has been utilized in developing a stochastic pitting corrosion model for the corrosion-allowance barrier in a humid-air condition. The range and distribution of the pitting factor were obtained from the literature.

The results from the extensive corrosion testing programs in inland tropical environments in Panama indicate that the pitting factor for carbon steels and cast irons exposed to 'normal' atmospheric conditions (i.e. in the absence of highly aggressive conditions such as in acidic or concentrated salt conditions) ranged from 2 to 6 (Southwell and Bultman, 1982; Southwell et al, 1976). The distribution may be considered as a normal distribution that is skewed to the right (or with a long tail to the right) (Marsh and Taylor, 1988; Marsh et al, 1988; Strutt et al, 1985). In the current stochastic pitting modeling, the pitting factor was assumed to be normally distributed with a mean at 4 and a standard deviation of 1 . In addition, the pitting factor was constrained to be greater than or equal to 1 , i.e. with the pitting factor equal to 1 , the pit depth is equal to the general corrosion depth. The pitting factor was sampled randomly and used as a multiplier to the general corrosion depth. Thus, the pitting corrosion model of CAM in humidair is expressed as follows:

$$
D_{p}=f_{p} \cdot D_{g}=\left\{\begin{array}{cl}
\operatorname{normal}(4,1) \cdot D_{8} & \text { if } \operatorname{normal}(4,1) \geq 1 \\
D_{g} & \text { if } \operatorname{normal}(4,1)<1
\end{array}\right.
$$

$D_{p}$ is pit depth $(\mu \mathrm{m})$ in humid-air, $D_{g}$ is general corrosion depth $(\mu \mathrm{m})$ in humid-air, and $f_{p}$ is the pitting factor.

In the stochastic pitting modeling, pit initiation was not explicitly considered. Instead, all the pits that can form on the waste container were assumed to start growing at the same time. The total number of pits that can form on the waste container was calculated from the pit density (about 10 pits $/ \mathrm{cm}^{2}$ ) obtained from literature (Marsh and Taylor, 1988; Marsh et al, 1988; Strutt et al, 1985 ) and the nominal surface area of the container discussed in Section 3.5. 


\subsubsection{Results of the Pitting Corrosion Model}

The pitting corrosion model results for CAM in humid-air presented in this section are calculated using the expected values of the parameters in the humid-air general corrosion model in Equation (5.3-8). The predicted probability density functions (PDFs) of pit depth distribution for CAM at $60{ }^{\circ} \mathrm{C}$ and 80 and $90 \% \mathrm{RH}$ are shown in Figures 5.3-8a and 5.3-8b, respectively, for up to 3,000-year exposure times. Considering a CAM that is continuously exposed to the corresponding constant humid-air conditions, the deepest pit penetrates the CAM thickness within 3,000 years at $90 \% \mathrm{RH}$ and $60{ }^{\circ} \mathrm{C}$, whereas it is only about $30-\mathrm{mm}$ deep at $80 \% \mathrm{RH}$ and at the same temperature. Similar modeling results at $90^{\circ} \mathrm{C}$ are given in Figure 5.3-9a for $80 \% \mathrm{RH}$ and Figure 5.3-8b for $90 \% \mathrm{RH}$. For CAM exposed continuously to a humid-air at $90 \% \mathrm{RH}$ and $90^{\circ} \mathrm{C}$ (Figure 5.3-9b), the deepest pit reaches about 70-mm after 1,000-year exposure and would penetrate up to about $130-\mathrm{mm}$ deep after 3,000-year exposure. The corresponding cumulative probability density functions (CDFs) are shown in Figure 5.3-10a for the 1,000-year exposure case and in Figure 5.3-10b for the 3,000-year exposure case. As in general corrosion of CAM in humid-air discussed in Section 5.3.5, relative humidity has a greater effect in pitting corrosion of CAM than temperature.

\subsubsection{Comparison with the McCoy Model}

Recently, a model for general corrosion of CAM in humid-air environment has been suggested by McCoy (1994). The McCoy model was developed by combining the general corrosion model of CAM in brine and salt water developed by Westinghouse (1982; later recommended by Stahl (1993) for M\&O TSPA-1993 (Andrews, et al., 1994)) with short-term corrosion current density data of pure iron foils exposed to controlled humid-air conditions $(52,64,76$ and $86 \% \mathrm{RH})$ at $25^{\circ} \mathrm{C}$ (Jones and Howryla, 1993). In the McCoy model the parameter value for the humid-air corrosion term was determined from only four data points of corrosion current density data, and the experimental technique employed to measure the data was semi-quantitative in nature. Inaccuracy of the electrochemical measurement technique used by Jones and Howryla (1993) was reported previously, and was attributed to the accumulation of corrosion products between electrodes, short-circuiting the corrosion current measurements (Kucera and Mattsson, 1974). Additionally, the data developed by Jones and Howryla (1993) do not account for potential uncertainties and variabilities of the humid-air corrosion rates anticipated in the potential repository environment.

Significant uncertainties also arise when extrapolating the McCoy model to a steam environment (humid-air at elevated temperatures), because the McCoy model uses the same value for the temperature-dependency parameter as the Westinghouse model, which was estimated from four data points collected from corrosion tests in brine and sea water. The temperature dependency of general corrosion in steam would be different from that in brine and sea water. Since the McCoy model is the only one currently available for CAM corrosion in humid air, it is desirable to compare the McCoy model to the current model.

\section{Review of the McCoy Model}

As discussed previously, the McCoy model is based on an aqueous general corrosion model for low carbon steels and cast irons, developed by Westinghouse (1982), and short-term corrosion 
current density data of pure iron foils exposed to controlled humidity environments of 'static' and 'dynamic' air conditions at $25^{\circ} \mathrm{C}$ (Jones and Howryla, 1993). The Westinghouse model is expressed as

$$
D_{g}=2525 t^{0.47} e^{\frac{-2850}{T}}
$$

where $D_{g}$ is general corrosion depth (mm), $t$ is exposure time (year), and $T$ is exposure temperature $(K)$. The temperature dependency term of the model $(\exp (-2850 / T))$ was evaluated from four corrosion data points in brine and sea water at temperatures up to $523 \mathrm{~K}\left(250^{\circ} \mathrm{C}\right.$ ) (this was essentially two points as they were two data points at $298 \mathrm{~K}$ and another two data points at $523 \mathrm{~K}$. The time dependency term was derived from the 16-year corrosion data in tropical lake water in Panama, developed by the Naval Research Laboratory (Southwell and Alexander, 1970; Southwell et al, 1976). This Westinghouse model was later suggested for the M\&O TSPA-1993 (Stahl, 1993).

In the development of the McCoy model, Equation (5.3-11), expressed as $D_{g}=A t^{c} \exp (-B / T)$, was differentiated with respect to time to obtain the corrosion rate equation, and the explicit time dependence term was removed from the rate equation. The resulting equation is

$$
\frac{d D_{8}}{d t}=c A^{\frac{1}{c}} D_{g}^{\frac{c-1}{c}} e^{\frac{-B}{c T}}+\frac{D_{8} B}{T^{2}} \frac{d T}{d t}
$$

The temperature-derivative term may be assumed to be negligible within a time step in which temperature is in a relatively steady-state or "quasi" steady-state. Dropping the temperature derivative term, Equation (5.3-12) becomes the corrosion rate expression of the McCoy model as follows

$$
\frac{d D_{g}}{d t}=c A^{\frac{1}{c}} D_{g}^{\frac{c-1}{c}} e^{\frac{-B}{c T}}
$$

A humidity dependency term was added into Equation (5.3-13), giving:

$$
\frac{d D_{8}}{d t}=c A^{\frac{1}{c}} D_{g}^{\frac{c-1}{c}} e^{\left(\frac{k h}{c}-\frac{B}{c T}\right)}
$$

where $\mathrm{h}$ is defined as ( $\mathrm{RH}-100)$ where $\mathrm{RH}$ is relative humidity (\%). The corrosion current density data of iron foils from Jones and Howryla (1993) were used to determine the constant $\mathrm{k}$ in Equation (5.3-14). 
The corrosion current density data given in Table 5.3-1 were read directly from the graphs given by Jones and Howryla (1993). The data show that at the humidity conditions greater than $52 \%$ $\mathrm{RH}$, the corrosion current density in dynamic air-flow conditions is about two orders of magnitude larger than those in static air condition. From the data, McCoy obtained $\mathrm{k}=0.1908$ for the static air condition, and $k=0.2$ for the dynamic air condition (McCoy, 1994). However, because smaller $\mathbf{k}$ values give higher corrosion rates, it is assumed in the following discussions that $k=0.1908$ for the dynamic air condition, and $k=0.20$ for the static air condition.

Being consistent with the Westinghouse aqueous corrosion model upon which it is based, the McCoy model can be rewritten as follows:

$$
D_{g}=2525000 t^{0.47} e^{\left(0.1908 h-\frac{2830}{T}\right)}
$$

where $D_{g}$ has units of $\mu \mathrm{m}$. A smaller value for constant $\mathrm{k}$ is used in the following discussions.

\section{Evaluation of the McCoy Model}

Using the electrochemical couple for dissolution reaction of iron (Equation (5.3-16)) which is applicable for general corrosion, and applying Faraday's law (Equation (5.3-17), the corrosion current density data in Table 5.3-1 can be converted to general corrosion rates.

$$
\begin{gathered}
F e(m)=F e^{2+}(a q)+2 e^{-} \\
I_{c}=\frac{z_{F e} F \rho_{F e} R}{M_{F e}}
\end{gathered}
$$

where $\mathrm{I}_{\mathrm{c}}=$ corrosion current density $\left(\mathrm{amp} / \mathrm{cm}^{2}\right.$ or coulombs $\left./ \mathrm{cm}^{2} \cdot \mathrm{sec}\right)$,

$\mathrm{z}_{\mathrm{Fe}}=$ number of electrons involved in the dissolution reaction $\left(\mathrm{z}_{\mathrm{Fe}}=2\right)$,

$\rho_{\mathrm{Fe}}=$ density of iron $\left(7.86 \mathrm{~g} / \mathrm{cm}^{3}\right)$,

$\mathrm{M}_{\mathrm{Fe}}=$ molecular weight of iron $(55.85 \mathrm{~g} / \mathrm{mol})$,

$\mathrm{F}=$ Faraday constant $(96,485$ coulombs/mole $)$, and

$\mathrm{R}=$ general corrosion rate $(\mathrm{cm} / \mathrm{sec})$.

The calculated general corrosion rates at the corresponding humidities at $25{ }^{\circ} \mathrm{C}$ are shown in Table 5.3-1. Their range at humidities between 64 and $86 \% \mathrm{RH}$ is from 3 to $7 \mu \mathrm{m} / \mathrm{yr}$. The data in the table indicate that the corrosion rate becomes negligible at humidities below about $60 \%$ RH. In addition, the data agree qualitatively with the current model predictions (see Figures 5.3-4 to 5.3-6).

There is approximately two orders of magnitude difference in the corrosion rate between static and dynamic air conditions (Table 5.3-1). This difference was examined by varying the constant, 
$\mathrm{k}$, in the $\mathrm{McCoy}$ model within the range from $\mathrm{k}=0.18$ to $\mathrm{k}=0.22$. As shown in Figure 5.3-11, the McCoy model does not predict the corrosion rate changes indicated in Table 5.3-1.

The general corrosion depths calculated using the McCoy model are compared in Figure 5.3-12 with the atmospheric corrosion data used for the current model and also with the current model estimate (Equation (5.3-8)). The general corrosion depths calculated with the $\mathrm{McCoy}$ model and the current model are for the average exposure conditions (humidity and temperature) of the atmospheric corrosion data. As shown in the figure, the McCoy model underestimates general corrosion depth of CAM in humid air by a factor of about 10. Samples in atmospheric corrosion testing are likely to be exposed to cyclic wetting and drying conditions, which may cause a higher corrosion rate compared to testing in a constant condition. As such, the atmospheric corrosion data used in the current model development provide higher corrosion rates, which may be better representative of the humid-air corrosion environment expected in the potential repository (i.e., waste packages may be exposed to localized dripping fractures and consequent wetting and drying cycles).

Long-term general corrosion depths of CAM in humid-air calculated by the current model (Equation (5.3-8)) are compared with those by the McCoy model in Figure 5.3-13. As shown in the figure, the effect of the exposure temperature on the general corrosion depths predicted by the current model is less than those by the McCoy model. The differences between the two model predictions are smaller at higher humidities. When projected to 3,000-year exposure time at $70 \% \mathrm{RH}$ and $90{ }^{\circ} \mathrm{C}$, the general corrosion depth predicted by the McCoy model is smaller than that by the current model by a factor of 7 . This difference is reduced to a factor of 3 at 90 $\% \mathrm{RH}$ and $90^{\circ} \mathrm{C}$.

\subsection{AQUEOUS CORROSION MODELS FOR CORROSION-ALLOWANCE MATERIALS}

\subsubsection{Introduction}

In addition to the effect on corrosion rate caused by the presence of corrosive species, the material characteristics, and other exposure conditions, corrosion rates of CAM in water are also strongly affected by temperature, exhibiting maximum corrosion rates at temperatures around 60 to $80^{\circ} \mathrm{C}$. Such corrosion behavior is commonly observed in corrosion processes governed by the reduction of dissolved oxygen. An increase in temperature enhances the diffusivity of oxygen molecules and reaction rates, but at the same time decreases the solubility of oxygen gas. The net mass transport of oxygen increases with temperature until a maximum is reached where the oxygen concentration begins to decrease approaching the boiling point. Thus, the corrosion rate attains a maximum and then decreases with further increase in temperature (Boden, 1994).

The Westinghouse aqueous general corrosion model (Equation 5.3-11) (Westinghouse, 1982) used in TSPA-1993 (Andrews et al, 1994) does not dictate properly the temperature-dependence. Thus, efforts to develop a more representative aqueous corrosion model for CAM take into account the temperature-dependent corrosion behavior. 


\subsubsection{Development of General Corrosion Model}

\section{Conceptual Models}

The improved aqueous general corrosion model was developed using long-term corrosion data for a suite of carbon steel and cast iron, which were obtained from literature. The following aqueous general corrosion dependencies on exposure conditions were incorporated into the model development:

$$
\begin{gathered}
D_{8} \propto A_{3} t^{A_{4}} \\
\frac{d D_{g}}{d t} \propto C_{3} e^{\left(\frac{C_{4}}{T}+C_{5} T^{2}\right)}
\end{gathered}
$$

where $D_{g}$ is general corrosion depth $(\mu \mathrm{m}), d D_{g} / d t$ is general corrosion rate $(\mu \mathrm{m} / \mathrm{yr}), t$ is exposure time (years), $\mathrm{T}$ is temperature $(\mathrm{K})$, and A's and C's are constants.

\section{General Corrosion Model}

By combining the above conceptual models (Equations (5.4-1) and (5.4-2)), the new aqueous general corrosion model is expressed as follows:

$$
\ln D_{8}=b_{0}+b_{1} \ln t+\frac{b_{2}}{T}+b_{3} T^{2}+\varepsilon
$$

where $b_{0}, b_{1}, b_{2}$ and $b_{3}$ are constants to be determined from fitting Equation (5.4-3) to the aqueous general corrosion data, and $\varepsilon$ is a term representing uncertainties not accounted for in the model. The variance of the model was calculated as follows:

$$
\operatorname{Var}\left(\ln D_{g}\right)=\left[\begin{array}{llll}
1 & \ln t & \frac{1}{T} & T^{2}
\end{array}\right] V\left[\begin{array}{c}
1 \\
\ln t \\
\frac{1}{T} \\
T^{2}
\end{array}\right]+\frac{R S S}{D F}
$$

where $\operatorname{Var}\left(\ln D_{g}\right)$ is the variance of the model estimate, $V$ is the covariance matrix (4 $x 4$ ), RSS is the residual sum of squares of the model fitting, and DF is the degrees of freedom in the model fitting. 
Parameter values for the corrosion rate constant $\left(b_{0}\right)$ and the time-dependence term $\left(b_{1}\right)$ were determined from long-term corrosion data (up to 16 years) in polluted river water (Larrabee, 1953; Coburn, 1978) and in tropical lake water (Southwell et al, 1970). The data include the potential effects of various chemical species dissolved and of microbial activity in the waters. Parameter values for the temperature dependence terms $\left(b_{2}\right.$ and $\left.b_{3}\right)$ were determined from a set of short-term (100 days) corrosion data of mild steel in distilled water at temperatures from 5 to $90{ }^{\circ} \mathrm{C}$ (Brasher and Mercer, 1968; Mercer et al, 1968). The parameter values determined are: $b_{0}=111.506 \pm 10.804, b_{1}=0.532 \pm 0.0272, b_{2}=-23303.2 \pm 2296.2$, and $b_{3}=-3.193 \times 10^{-4} \pm$ $3.526 \times 10^{-5}$.

\subsubsection{Results of the General Corrosion Modeling}

Shown in Figure 5.4-1 are the long-term aqueous general corrosion data in lake water and (polluted) river water that were used for the model development, and the model estimate with its uncertainty envelope of two standard deviations. The temperature-dependent general corrosion data of mild steel in distilled water are shown in Figure 5.4-2 along with the model estimate with its uncertainty envelope of two standard deviations. The aqueous general corrosion rate of CAM is shown to have a maximum at temperatures between 60 and $70^{\circ} \mathrm{C}$.

Predictions of the aqueous general corrosion rate of CAM as a function of exposure time are shown in Figure 5.4-3 at three exposure temperatures $\left(30,60\right.$ and $\left.90^{\circ} \mathrm{C}\right)$. The calculations were made using the expected values of the model parameters of Equation (5.4-3). As shown in Figure 5.4-2, the general corrosion rates are about the same at 30 and $90^{\circ} \mathrm{C}$, and higher at $60{ }^{\circ} \mathrm{C}$. Predictions of the temperature dependence of general corrosion rates at various exposure times shown in Figure 5.4-4 indicate the temperature dependence decreases with increasing exposure time. This is due to the increased thickness of the corrosion products forming on the bare metal over time.

The current model estimate is compared in Figure 5.4-5 with the general corrosion data of carbon steel and cast iron which were tested in a simulated (and possibly concentrated) J-13 water (McCright and Weiss, 1985). Even though the model was developed from a different set of data, the J-13 water corrosion depths are generally within two standard deviations of the model estimates. Compared to the greater temperature-dependence of mild steel corrosion in distilled water (Brasher and Mercer, 1968; Mercer, et al., 1968), the corrosion data in J-13 water given in the figure show a smaller temperature dependence.

In the corrosion of mild steel in distilled water, dissolved oxygen $\left(\mathrm{O}_{2}(\mathrm{aq})\right)$ and, to a lesser extent, hydrogen ion $\left(\mathrm{H}^{+}(\mathrm{aq})\right)$ in the water may have been the major species that participated in the corrosion reduction reactions (Mercer, et al., 1968). For the corrosion in the simulated (or possibly concentrated) J-13 water, other species (mostly carbonate ions and nitrate ions) in addition to dissolved oxygen and hydrogen ion may also have participated in the corrosion reduction reactions. This difference in the reduction reaction mechanisms would reduce the temperature dependence of the aqueous general corrosion (Beckmann and Mayne, 1960; Brasher and Mercer, 1968; Hersch, et al., 1961a and 1961b; Masamura and Matsushima, 1983; Mercer et al, 1968; Pryor and Cohen, 1953; Pyke and Cohen, 1948).

Aqueous general corrosion depths of CAM predicted with the current model for up to 3,000-year exposure time at three constant temperatures $\left(30,60\right.$ and $\left.90^{\circ} \mathrm{C}\right)$ are compared in Figure 5.4-6 
with those from the Westinghouse model, Equation (5.3-11). The calculations were made using the expected values of the model parameters. As expected, the Westinghouse model predicts increased corrosion with increasing temperature, whereas the current model predicts the largest corrosion depth at $60^{\circ} \mathrm{C}$. From the simulation results shown in the figure, the mean general corrosion depth of CAM at $60{ }^{\circ} \mathrm{C}$ is about $30-\mathrm{mm}$ after 3,000 years. This indicates that the 100 -mm thick corrosion-allowance barrier should not fail by aqueous general corrosion at 3,000 years.

\subsubsection{Development of Pitting Corrosion Model}

As in humid-air pitting corrosion of CAM discussed in Section 5.3.6, aqueous pitting corrosion of CAM was modeled stochastically by assuming the pitting factor is normally distributed with a mean of 4 and a standard deviation of 1. The same approach discussed in Section 5.3.6 was taken in developing an aqueous pitting corrosion model of CAM, and the same equation (Equation (5.3-10)) is also employed to model aqueous pitting corrosion of CAM as follows

$$
D_{p}=f_{p} \cdot D_{s}=\left\{\begin{array}{ccc}
\operatorname{normal}(4,1) \cdot D_{8} & \text { if } & \operatorname{normal}(4,1) \geq 1 \\
D_{8} & \text { if } & \operatorname{normal}(4,1)<1
\end{array}\right.
$$

\subsubsection{Results of Pitting Corrosion Modeling}

Probability density functions (PDFs) of pit depths for CAM exposed to aqueous condition at three temperatures are shown in Figures 5.4-7a, 5.4-7b and 5.4-7c. The simulations were performed using the expected values of the parameters of the aqueous general corrosion model (Equation (5.4-3)). As for general corrosion, the simulation results show that aqueous pitting corrosion of CAM is most severe at temperatures around $60{ }^{\circ} \mathrm{C}$. At the exposure temperatures of 30 and $90{ }^{\circ} \mathrm{C}$, the deepest pit penetrates 100 -mm thick CAM at about 3,000 years, whereas it takes only about 500 years at $60^{\circ} \mathrm{C}$. The modeling results indicate the $100-\mathrm{mm}$ thick outer containment barrier may have the first pit penetration as early as $\mathbf{5 0 0}$ years if the near-field environment maintains aqueous conditions at about $60^{\circ} \mathrm{C}$.

\subsection{CORROSION MODELING OF CORROSION R]ESISTANT MATERIALS}

It has been shown that corrosion-resistant material (CRM) such as Alloy 825 (proposed as the inner barrier corrosion-resistant material) rarely corrodes under humid air conditions (Beavers and Durr, 1991). Thus, it was assumed CRM is not subjected to corrosion in humid-air conditions. Also, because general corrosion rates of CRM in 'normal' aqueous conditions are insignificant, only pitting corrosion was assumed to be active on CRM in aqueous conditions. Currently, no long-term pitting corrosion data for CRM are available, which may be utilized to develop a robust CRM pitting model. Although a limited number of short-term laboratory pitting data were reported previously (Beavers and Durr, 1991), only a few pits were observed on CRM in the short-term (about 90 days) tests, and those pits that formed were very shallow. Hence, the CRM 
Since there has been no new development or improvement over the pitting corrosion model for Alloy 825 inner barrier which was developed from an expert elicitation and used in TSPA-1993 (Andrews, et al., 1994), the same pitting model (or expert elicitation) was utilized in TSPA-1995.

The elicitation (Table 5.5-1) provides a range of time-independent pit growth rates in aqueous conditions at 70 and $100{ }^{\circ} \mathrm{C}$. In the elicitation, the pit growth rate ranges are presented as a median, a 95th percentile and a 5th percentile growth rates. For the pit growth rate ranges at other temperatures, these values were extrapolated as a function of temperature in an Arrheniustype functional form. The resulting functional form for the median pit growth rate is given as follows:

$$
\ln R_{p}=50.373-\frac{19655.85}{T}
$$

where $R_{p}$ is the time-independent pit growth rate $(\mathrm{mm} / \mathrm{yr})$, and $T$ is temperature $(\mathrm{K})$. The median pit growth rates as a function of temperature are presented graphically in Figure 5.5-1 along with the 95th and 5th percentile growth ranges. As shown in the figure, the pit growth rate decreases exponentially with decreasing temperature, and the rate at room temperature is about 6 orders of magnitude less than the rate at $100^{\circ} \mathrm{C}(373 \mathrm{~K})$. The time-independent pit growth rates given in the elicitation are conservative because, in reality, the pit growth rate decreases with exposure time.

In TSPA-1995, pit growth rates for the Alloy 825 inner barrier were sampled randomly within the 95th and 5th percentile pit growth rate ranges given in the elicitation. For the 95th percentile value to be one order of magnitude larger than the mean value would require a very skewed distribution. Thus, the pit growth rate distribution in the mean growth rate column was used to generate the distribution of pitting rates. In the expert elicitation, the low and high growth rates were given as the 5th and 95th percentiles respectively. Thus, one order of magnitude, or 2.30 natural log units, is 1.645 standard deviations implying that a standard deviation is 1.40 natural $\log$ units. This was split equally between waste package to waste package variability and pit to pit variability. More details are discussed in Section 5.7.3.

Development of a defensible corrosion model for moderately corrosion resistant materials (MCRM) (Monel 400 and $70 \mathrm{Cu} / 30 \mathrm{Ni}$ alloy) has been also hindered by the lack of long-term corrosion data. Since there are no adequate models available for the performance of these materials, it has been recommended that these materials not be included in any waste package performance analyses (Doering, 1995). Therefore, MCRM was not considered in TSPA-1995.

\subsection{CLADDING DEGRADATION}

\subsubsection{Introduction}

Previous iterations of total system performance assessment (Andrews, et al., 1994; M\&O, 1993a; M\&O, 1994a; Wilson, et al., 1994) did not take credit for spent fuel (SF) cladding as a potential barrier to radionuclide release after failure of the waste disposal container. In an additional 
sensitivity study to TSPA-1993 (Andrews, et al., 1994), effects of cladding performance were simulated by progressively reducing SF wetted surface areas from $100 \%$ to $0.01 \%$ (M\&O, 1994a). In addition, a preliminary analysis for cladding performance was recently reported (McCoy, 1995).

In an attempt to include more realism in studying the effects of cladding performance, initial efforts have been made to collect information and data for the dominant cladding failure modes expected during the containment period in the potential repository. In the following sections, brief descriptions are given for expected cladding degradation modes, conceptual models and approaches for cladding degradation modeling, and mechanistic models for the degradation modes. Additional data will be added as it becomes available. Utilizing the information and data available, continued efforts will be given to develop abstractions for cladding degradation that are suitable to be included into a TSPA code. In TSPA-1995, cladding performance was evaluated using approaches similar to those used in the additional sensitivity study to TSPA-1993 (M\&O, 1994a).

\subsubsection{Cladding Degradation Associated with Defective or Intact Fuel Rods}

In view of the different types of cladding degradation modes, spent fuel rods placed in the waste package can be divided into two groups: 1) defective rods that have developed defects (or failures) on the cladding during the reactor operation and interim storage prior to permanent disposal; and 2) intact rods with intact cladding at the time of emplacement in the potential repository. Clads associated with the different fuel rods and their implications to cladding performance are discussed in the following subsections.

\section{Defective Fuel Rods}

A defective fuel rod is one that suffers cladding failure or becomes flawed through some physical or chemical damage. Fuel cladding can develop defects during service in reactor and/or interim (wet or dry) storage. Possible cladding failure modes leading to a defective fuel rod are listed below (DOE, 1987):

1. Pellet-clad interaction (PCI) is the differential movement of the fuel pellets and cladding following a rapid power transient during operation and can cause cladding breach;

2. Hydride embrittlement of cladding is caused by the reaction of zircaloy cladding with water vapor released from fuel pellets cluring service;

3. Gaseous fission products released into the gap between the fuel pellet and the cladding cause a decrease in the thermal conductivity of the initially helium-filled gap and generate stresses on the cladding by increasing the internal pressure;

4. Corrosion of cladding is caused by reactor water and the impurities it carries;

5. Deformation and bowing of fuel rods because of differential changes in dimension from nonuniform neutron fluxes; 
6. - Other mechanical effects in service such as rubbing of metallic parts due to flowinduced vibrations, debris lodging in the fuel channels, or water jetting due to certain flow imbalances or blockages; and

7. Welding defects, dropping, and excessive stress in handling.

The estimated fractional ranges of defective fuel rods for boiling water reactors (BWRs) and pressurized water reactors (PWRs) are summarized in the following table (DOE, 1987).

\begin{tabular}{|c|c|c|}
\hline \multirow{2}{*}{$\begin{array}{c}\text { Reactor } \\
\text { Type }\end{array}$} & \multicolumn{2}{|c|}{ Fraction of Defective Fuel Rods } \\
\cline { 2 - 3 } & Prior to 1981 & $\mathbf{1 9 8 1}$ to 1985 \\
\hline \hline BWR & $0.06-1.13 \%$ & $0.03-0.55 \%$ \\
\hline PWR & $0.02-0.28 \%$ & $0.02-0.17 \%$ \\
\hline
\end{tabular}

In some extreme cases, $2.86 \%$ of defective fuel cladding was reported for stainless steel clad fuels used in PWRs (Was, et al., 1985). The data may be used as a bounding estimate of defective fuel cladding prior to permanent emplacement in the repository.

Intact Fuel Rods

For intact fuel rods, an inert environment such as helium is maintained inside the cladding. Once spent fuel assemblies are placed inside the waste disposal container, the container is also filled with a similar inert environment before it is sealed off. Among various degradation modes of zircaloy cladding in an inert environment during storage and/or permanent disposal periods, creep rupture is the most dominant mechanism (Chin and Gilbert, 1989). Therefore, creep rupture of zircaloy cladding is considered the dominant degradation mode of intact fuel rods.

\subsubsection{Conceptual Model and Approach for Cladding Degradation Modeling}

In TSPA-1995, the waste container is assumed to undergo degradation by general and pitting corrosion. The current corrosion models predict general and pitting corrosion of the containment barriers as functions of emplacement time and the near-field environments (relative humidity and temperature). The models discussed in Sections 5.3 to 5.5 indicated failure of the waste container is likely to result from pitting corrosion, rather than by general corrosion. When the first pit penetrates the entire thickness of the waste container wall, the inert environment inside the waste container would be released immediately and replaced with the near-field moisture conditions. Following the waste container failure, the intact cladding and the spent fuel inside the "pre-failed" (relative to container failure time) cladding would begin degradation subject to the near-field environments.

In the simulation of degradation of cladding, fuel rods in a waste package are divided into two groups, fuel rods with intact cladding and those with "pre-failed" (relative to container failure 
time) and defective cladding. The dominant degradation mechanism for intact cladding during disposal in the repository is creep rupture. Such failure is driven by stress caused by gas pressure buildup inside the cladding due to heating of the inert helium and fission gas released into the gap. Creep rupture is active during the entire disposal time span until cladding fails. Creep rupture is likely to produce "pin-hole"-type breaches, and, when cladding fails, the stress is relieved by releasing the gases from inside the fuel rod, and creep of the cladding will stop.

"Pre-failed" cladding at the time of waste container failure includes the cladding failed in reactor operation and interim storage (collectively referred to as defective cladding) and the cladding that fails during emplacement but prior to waste container failure. Cladding failure rates during emplacement are calculated from creep rupture models, and the fraction of defective cladding is given in the literature discussed previously. As soon as the first pit penetrates the waste container and the inert environment inside the waste container is lost, the spent fuel inside the breached cladding undergoes oxidation at a rate depending on the near-field environment (mostly temperature). Spent fuel oxidation results in volume expansion and surface area increase of the fuel matrix. The consequence is the splitting (or "unzipping") of cladding, which exposes a progressively greater amount of spent fuel to the near-field environment, making the spent fuel inside available for alteration and subsequent radionuclide release. After failure of the waste container, creep rupture still remains active on the intact cladding, and the cladding breaches continue. However, the failure rate by creep rupture will be reduced significantly as the cladding temperature decreases.

Another cladding degradation mode expected in a failed waste container is oxidation of cladding, which results in a gradual thinning of cladding. However, the oxidation rates are minimal at the near-field temperatures anticipated at the time of waste container failure, so cladding oxidation is not included in the cladding degradation models described below.

\subsubsection{Cladding Degradation Models}

As discussed above, failure of intact cladding by creep rupture, and splitting of the breached cladding due to oxidation of spent fuel inside are the dominant cladding degradation modes. Mechanistic models for these degradation modes are available from the literature, and are discussed in this section.

\section{Creep Rupture Models}

Zircaloy cladding creep rupture models developed by Santanam and others (1992) are considered to calculate failure of intact zircaloy cladding. The models for the different creep rupture modes are given as follows:

Transgranular Fracture:

$$
\ln t_{f}^{t g}=-1.797-\ln \varepsilon
$$


Triple-Point .Cracking:

$$
\ln t_{f}^{t p}=-5.655-\ln \dot{\varepsilon}-\ln \frac{\sigma}{E}-\ln \frac{E}{10^{4}}
$$

Cavitation-Diffusional Growth:

$$
\ln t_{f}^{c d}=4.15-\ln \dot{\varepsilon}_{g b s}+\ln \frac{\sigma}{E}
$$

Cavitation-Power Law Growth:

$$
\ln t_{f}^{c p}=-1.587-\ln \varepsilon
$$

where $\mathrm{t}_{f}$ is time to fracture (years), $\dot{\varepsilon}$ is strain rate, $\sigma$ is stress (MPa), and $\mathrm{E}$ is Young's modulus (MPa). Young's modulus is calculated as a function of temperature by

$$
\begin{aligned}
& E=\left(11.81-13.0434577 \frac{T}{T_{m}}\right) \times 10^{4} \text { for } \frac{T_{m}}{T} \geq 3.63 \\
& E=\left(11.09-10.3793382 \frac{T}{T_{m}}\right) \times 10^{4} \text { for } \quad \frac{T_{m}}{T}<3.63
\end{aligned}
$$

where $T_{m}$ is zircaloy melting temperature $(1900 \mathrm{~K})$. Zircaloy cladding strain rates $(\dot{\varepsilon})$ used in Equations (5.6-1) to (5.6-4) are calculated using the following equations for different strain modes:

High-Temperature Climb:

$$
\ln \varepsilon_{H T}=5 \ln \frac{\sigma}{E}+55.862-15.828 \frac{T_{m}}{T}+\ln \frac{T_{m}}{T}+\ln \frac{E}{10^{4}}
$$

Low-Temperature Climb:

$$
\ln \varepsilon_{L T}=7 \ln \frac{\sigma}{E}+55.292-11.398 \frac{T_{m}}{T}+\ln \frac{T_{m}}{T}+\ln \frac{E}{10^{4}}
$$

Grain Boundary Sliding:

$$
\ln \varepsilon_{G B S}=2 \ln \frac{\sigma}{E}+20.852-11.078 \frac{T_{m}}{T}+\ln \frac{T_{m}}{T}+\ln \frac{E}{10^{4}}
$$

Nabarro-Herring:

$$
\ln \varepsilon_{N H}=\ln \frac{\sigma}{E}+18.362-15.828 \frac{T_{m}}{T}+\ln \frac{T_{m}}{T}+\ln \frac{E}{10^{4}}
$$


Coble:

$$
\ln \varepsilon_{c o}=\ln \frac{\sigma}{E}+11.142-11.078 \frac{T_{m}}{T}+\ln \frac{T_{m}}{T}+\ln \frac{E}{10^{4}}
$$

All the strain modes given in Equations (5.6-7) to (5.6-11) are considered at a given time period and cladding temperature, and the mode which gives the largest strain rate is taken as the dominant strain mode for that time period. Then, the dominant strain rate is used to calculate the time to fracture from the different fracture modes given in Equations (5.6-1) to (5.6-4), and the fracture mode giving the earliest fracture time is taken as the dominant fracture mode. The above equations are assumed to be applicable also to cladding of other materials such as stainless steel.

\section{Cladding Splitting}

All the cladding that fails prior to and following the container failure is subjected to another cladding degradation mechanism, i.e. cladding splitting resulting from oxidation of the spent fuel inside the clad. Cladding splitting grossly exposes the spent fuel, making it available for alteration and subsequent radionuclide release. Cladding splitting rate is largely dependent on the near-field temperature, and is divided into two stages: splitting initiation and propagation. The models for splitting initiation and splitting propagation developed by Einziger (1994) are:

$$
\begin{gathered}
t_{S I}=9.8 \times 10^{-21} \exp \left(\frac{47.4 \mathrm{Kcal}}{R T}\right) \\
t_{S P}=1.14 \times 10^{-9} d \exp \left(\frac{18.4 \mathrm{Kcal}}{R T}\right)
\end{gathered}
$$

where $t_{\mathrm{SI}}$ is splitting initiation time (years) (i.e., time required to initiate cladding splitting relative to the time of waste container failure), $t_{\mathrm{sp}}$ is time required to split cladding a distance $\mathrm{d}$ (inches) relative to $t_{S I}, R$ is the universal gas constant, and $T$ is temperature $(K)$. The models are also assumed to be applicable to cladding of other materials such as stainless steel.

The peak cladding temperature as a function of time after permanent disposal is available (Bahney, 1995). The peak cladding temperature may be used to conservatively represent the fuel clads in the waste package.

\subsection{WASTE PACKAGE DEGRADATION HISTORY}

\subsubsection{Introduction}

Incorporating the corrosion models discussed in Sections 5.3 to 5.5, and the temperature and humidity profiles at the waste package surface, which are provided from drift-scale thermalhydrologic modeling (described in Section 4.2), a series of stochastic simulations for waste package degradation were performed. 
The objectives of the simulations were to evaluate the effects of 1) repository designs, 2) scenarios for the near-field conditions, 3) corrosion initiation thresholds, and 4) corrosion mechanisms on the performance of the current design of the multi-barrier waste container (refer to Section 3.5). Different repository designs included alternative thermal loadings (25 MTU/acre and $83 \mathrm{MTU} / \mathrm{acre}$ ) and the use of backfill. Different scenarios for the near-field conditions included the effects of alternative infiltration rates $(0.05 \mathrm{~mm} / \mathrm{yr}$ and $0.3 \mathrm{~mm} / \mathrm{yr})$ at the surface of the mountain for the potential repository. Corrosion initiation thresholds included using relative humidity $(\mathrm{RH})$ only for the initiation of the outer barrier corrosion and using both temperature and relative humidity $(\mathrm{RH})$ criteria. Different corrosion mechanisms included cases with and without cathodic protection of the Alloy 825 inner barrier by the carbon steel outer barrier.

General assumptions embedded in the stochastic waste package degradation simulations are discussed in the following section. A detailed description of the computing algorithms for the simulations is provided in Section 5.7.3. Analyses of the simulation results are presented in the following sections.

\subsubsection{Major Assumptions in Waste Package Degradation Simulation}

This section discusses the major assumptions made in the stochastic waste package degradation simulations. If not specifically indicated in each subsection, the assumptions are implicitly included.

1) Humid-air general and pitting corrosion of the carbon steel outer barrier initiate at a threshold RH which is uniformly distributed between 65 and $75 \%$. This threshold is independently chosen for each waste package. This assumption is based on numerous data found in the literature (see Haynie, et al, 1978; Phipps and Rice, 1979; Vernon, 1933).

2) Aqueous general and pitting corrosion of the carbon steel outer barrier initiate at a threshold $\mathrm{RH}$ which is uniformly distributed between 85 and $95 \% \mathrm{RH}$. Visual observations indicating that steel coupon surfaces were covered with a thin film of water at about $85 \% \mathrm{RH}$ in a controlled environment chamber have been reported (Haynie, et al., 1978).

3) For each waste package, complete and positive correlation of the humid-air corrosion initiation threshold and the transition threshold from humid-air corrosion to aqueous corrosion is assumed. That is, if humid-air corrosion initiates at $65 \% \mathrm{RH}$, aqueous corrosion initiates at $85 \% \mathrm{RH}$.

4) Corrosion-allowance outer barrier material (carbon steel) is subjected to general and pitting corrosion both in humid-air and aqueous conditions. The uncertainties in the humid-air and aqueous general corrosion models (Equations (5.3-8) and (5.4-3)) were utilized to account for pit to pit variability and waste package to waste package variability. In the post-closure repository, about 10,000 waste packages will be spread over the repository area, and a local corrosion environment in one part of the repository may be different from that in another part. This variability of the local corrosion environment is referred to here as waste package to waste package variability. Also, 
since. a waste container has a relatively large surface area $\left(37.26 \mathrm{~m}^{2}\right)$, the general corrosion rate on one part of the waste package may be different from that on another part of the waste package. This variability in corrosion rate on a waste package is referred to here as pit to pit variability. Because information on the degree of the variability among waste packages and among pits is not available currently, the variabilities are accounted for in TSPA-1995 by equally splitting the uncertainties in the humid-air and aqueous general corrosion models into the variability among waste packages and the variability among pits.

5) Corrosion resistant inner barrier material (Alloy 825) is subjected to aqueous pitting corrosion only (not to general corrosion). The time-independent pit growth rate distributions discussed in Section 5.5 (Equation (5.5-1)) were utilized to represent pit to pit variability and waste package to waste package variability. The same reasoning given in item (4) is applied also to account for the variability among waste packages and among pits.

6) When pits reach the inner barrier through the outer barrier, aqueous conditions are assumed there. This assumption is based on the observations that the capillary condensation of moisture by gel-like porous corrosion products of the outer barrier covering the inner barrier surface (Vernon, 1933) and the hygroscopic nature of many corrosion products (Fyfe, 1994; Haynie et al, 1978) would provide an aqueous corrosion condition at the surface of the inner barrier.

7) Pits form uniformly over the entire waste container surface. It is known that pits are most stable when growing in the direction of gravity because the dense, concentrated solution within a pit is necessary for its continuing activity (Fontana, 1986, pp. 64-69). Elongation of pits growing in the direction of gravity has been observed (Ruijini, et al, 1989). However, there is an uncertainty regarding crevice corrosion at the bottom of the waste container contacting the invert. Additionally, over the containment and isolation periods, rock may fall on the waste container, or backfill may be introduced. In these cases, there may be crevice corrosion occurring at the contact points between the rocks and waste container surface. Because of the uncertainty of the possibility of crevice corrosion at the side and bottom of waste containers, we assumed that pits form uniformly over the entire waste container surface.

8) All pits have a uniform area of $1 \mathrm{~mm}^{2}$ which corresponds to a pit radius of $0.56 \mathrm{~mm}$. This may be large for the pits forming in Alloy 825, which tend to be much narrower (Szklarska-Smialowska, 1986, pp. 127-141).

9) The waste container surface has a pit density of $10 \mathrm{pits} / \mathrm{cm}^{2}$ (Marsh, and Taylor, 1988; Marsh, Taylor, and Sooi, 1988; Strutt, Nichols and Barbier, 1985), and the same pit density is also assumed for the inner barrier.

10) Taking the pit density $\left(10\right.$ pits $\left./ \mathrm{cm}^{2}\right)$, the uniform pit area $\left(1 \mathrm{~mm}^{2}\right)$ and the nominal surface area $\left(37.26 \mathrm{~m}^{2}\right)$ of the waste container for a typical Jarge MPC, the total number of pits that can form on the waste container is about 4 million. This corresponds to about $10 \%$ of the total surface area. 
11) All the pits on a waste package start to grow at the same time when the threshold humidity discussed in items (1) and (2) is reached. That is, pit initiation is not explicitly considered in TSPA-1995.

As discussed in Section 3.5, different moderately corrosion resistant materials (MCRM) were specified as candidate waste container barrier materials for spent fuel in a low-thermal load case (Monel 400 as the third layer) and for vitrified defense high-level waste in both a high-thermal load case (70/30 $\mathrm{Cu}-\mathrm{Ni}$ alloy as the second layer) and a low-thermal load case (70/30 Cu-Ni alloy as the second layer and Monel 400 as the third layer). Since adequate corrosion models or data are not available for MCRM, it has been recommended that these materials not be included in any waste package performance analysis (Doering, 1995). Thus, in TSPA-1995, the waste containers for both spent fuel and defense high-level waste were treated equally as having two layers of containment barrier, i.e. Alloy 825 inner barrier and carbon steel outer barrier with the thicknesses given in Section 3.5.

\subsubsection{Stochastic Simulation of Waste Package Degradation}

Corrosion Models for the Containment Barriers

Since the sulfur dioxide level in the air of the potential repository is expected to be insignificant, the humid-air general corrosion model given in Equation (5.3-8) for the carbon steel outer barrier reduces to

$$
\ln D_{8}=a_{0}+a_{1} \ln t+\frac{a_{2}}{R H}+\frac{a_{3}}{T}+\varepsilon
$$

The estimates of the model parameters are

$$
E(C A M)_{a i r}\left[\begin{array}{l}
a_{0} \\
a_{1} \\
a_{2} \\
a_{3}
\end{array}\right]=\left[\begin{array}{c}
16.984 \\
0.6113 \\
-893.55 \\
-833.27
\end{array}\right]
$$

and the covariance matrix of the model parameters is

$$
V(C A M)_{\text {air }}=\left[\begin{array}{cccc}
8.257 & -0.03 & -591.0 & -365.0 \\
-0.03 & 8.68 E-4 & 1.827 & 2.775 \\
-591.0 & 1.827 & 5.338 E+4 & -1.173 E+4 \\
-365.0 & 2.775 & -1.173 E+4 & 1.459 E+5
\end{array}\right]
$$


The aqueous general corrosion model given in Equation (5.4-3) for the carbon steel outer barrier is re-written as

$$
\ln D_{g}=b_{0}+b_{1} \ln t+\frac{b_{2}}{T}+b_{3} T^{2}+\varepsilon
$$

The estimates of the model parameters are

$$
E(C A M)_{a q}\left[\begin{array}{l}
b_{0} \\
b_{1} \\
b_{2} \\
b_{3}
\end{array}\right]=\left[\begin{array}{c}
111.5 \\
0.5320 \\
-2.330 E+4 \\
-3.193 E-4
\end{array}\right]
$$

and the covariance matrix of the model parameters is

$$
V(C A M)_{a q}=\left[\begin{array}{cccc}
116.7 & -9.504 E-4 & -2.480 E+4 & -3.798 E-4 \\
-9.504 E-4 & 7.413 E-4 & 1.777 E-3 & 2.661 E-11 \\
-2.480 E+4 & 1.777 E-3 & 5.272 E+6 & 8.046 E-2 \\
-3.798 E-4 & 2.661 E-11 & 8.046 E-2 & 1.243 E-9
\end{array}\right]
$$

Pitting corrosion of the corrosion resistant Alloy 825 inner barrier is modeled with the time independent pit growth rate model given by Equation (5.5-1) which is re-written here as

$$
\left\ulcorner\quad \ln R_{p}=c_{0}-\frac{c_{1}}{T}\right.
$$

The elicitation for the time independent pit growth rate distributions (Table 5.5-1) used in TSPA1993 (Andrews, et al., 1994) gave median pit growth rates of $0.001 \mathrm{~mm} / \mathrm{yr}$ at $70^{\circ} \mathrm{C}$ and $0.1 \mathrm{~m} / \mathrm{yr}$ at $100{ }^{\circ} \mathrm{C}$. Using these values, $c_{0}$ in Equation (5.7-7) was estimated to be 50.37 , and $c_{1}$ was estimated to be $-19,656$. The elicitation also suggested that for a given temperature, the pit growth rate would have a log-normal distribution with the given median and a standard deviation of 1.39975 in natural $\log$ space. To incorporate this variability, $c_{1}$ is set equal to $-19,656$ for every pit, and $c_{0}$ is allowed to vary among pits with a mean of 50.37 and a standard deviation of 1.39975. Therefore, the estimate of the model parameters is

$$
E(C R M)_{a q}\left[\begin{array}{l}
c_{0} \\
c_{1}
\end{array}\right]=\left[\begin{array}{c}
50.37 \\
-19656
\end{array}\right]
$$


and the covariance matrix of the model parameters is

$$
V(C R M)_{a q}=\left[\begin{array}{cc}
1.95929 & 0.0 \\
0.0 & 0.0
\end{array}\right]
$$

The uncertainty in the parameters was equally divided between waste package to waste package variability and pit to pit variability, based on the reasoning discussed in Section 5.7.2. To do this, the covariance matrix, $\mathrm{V}$, was divided by 2 to obtain a new covariance matrix, $\mathrm{V}_{\mathrm{N}}$. Then, $V_{N}$ was used to select average values of the parameters for each waste package. These average values were used, again with $V_{N}$, to select parameters for each pit on that waste package. Thus, the average value of $c_{0}$ on a given waste package would be normally distributed with a mean of 50.43 and a standard deviation of 0.98977 . For each pit on this waste package, $c_{0}$ would be normally distributed with the mean chosen above and a standard deviation of 0.98977 . For example, 52.22 might be selected as the average value of $c_{0}$ for one waste package. In this case, the value of $c_{0}$ for each pit on this waste package would be chosen from a normal distribution with a mean of 52.22 and a standard deviation of 0.98977. Similarly, for each waste package, average values would be chosen for each of the parameters in the humid-air general corrosion model for the carbon steel outer barrier and each of the parameters in the aqueous general corrosion model for the outer barrier: These average values would be subsequently used to choose values for these parameters for each pit.

\section{Waste Package Degradation Model Implementation}

An overview of the stochastic waste package performance simulation model is shown in Figure 5.7-1. The humid-air and aqueous general and pitting corrosion models (with the uncertainties) for the carbon steel outer barrier, and the aqueous pitting corrosion model (with the uncertainties) for the Alloy 825 inner barrier are fed into the stochastic waste package degradation simulation module. The drift-scale temperature and humidity profiles at the waste package surface are incorporated into the waste package degradation simulation module as a lookup table. The waste package degradation simulation module calls on appropriate corrosion model(s) depending on the near-field environment and the waste package degradation at a given time step. The simulation module provides as output the "failure" time for each waste package, which corresponds to the time for the initiation of waste form alteration (or radionuclide mobilization) inside the waste package. "Failure" of waste package is defined as having at least one pit penetration. The simulation module also provides the pitting history of a "failed" waste package in terms of the number of pit penetrations as a function of time. A total number of pit penetrations at a given time gives an area on the waste package that is available for transport of mobilized radionuclides through the waste package. The waste package "failure" time and subsequent pitting history are fed into the EBS transport model.

The simulations were performed for up to 100,000 years, and the time steps were discretized such that within any time step, both the relative humidity and the temperature are relatively constant. The algorithm for the waste package degradation simulations is described in the flow chart shown in Figure 5.7-2. A total of 400 waste packages were simulated in each case. For each simulated waste package, random values were selected to represent the mean values on that particular waste 
package of each of the parameters in the corrosion models. This selection process is represented by the second box in the flow chart in Figure 5.7-2.

A total of 250,000 pits per waste package were used in the simulations. The choice of this number is discussed in Section 5.7.4. Based on the mean values already selected for each waste package, random values were sampled for each pit to represent the parameters in the corrosion models. This is represented by the third box in the flow chart in Figure 5.7-2.

Once the parameter values for the corresponding corrosion model are known for a given pit, the depth of that pit is tracked through each time step. Within each time step, the average relative humidity and temperature are calculated. These are used to determine whether humid-air or aqueous corrosion is occurring, and at what rate corrosion is occurring. Based on this information, the model calculates how much corrosion occurs during that time step, and check if the pit penetrates the waste package. If the pit penetrates the waste package during that time step, the time when the pit penetrates the waste package is also calculated. This is illustrated in the fourth through seventh boxes of the flow chart in Figure 5.7-2.

\subsubsection{General Descriptions for Waste Package Degradation Simulation}

All the simulations discussed in the following sections were conducted for a total of 400 waste packages and 250,000 pits per waste package. Results for each case are presented with a sequence of three figures: 1) cumulative fraction of waste packages that have a first pit penetrated through the container wall; 2) representative pitting history as a function of time for each of 25 waste packages; and 3) abstraction of the pitting histories (based on 400 waste packages) into 6 groups of waste packages for implementation into the RIP code.

The simulations were conducted with a reduced number of waste packages (400 waste packages) and pits (250,000 pits per waste package) primarily because of constraints in computing resources. Considering various sources of uncertainties embedded in conceptual models and process-level models (thermal-hydrologic model, corrosion model, etc.), the results based on the smaller number of waste packages and pits should not be significant in light of the overall uncertainty range of the analyses. Also, test simulations were conducted with waste package numbers from 50 to 500 and pit numbers per waste package from 100,000 to $4,000,000$ to evaluate the effect of using smaller values to represent the larger system. It was generally found that the number of waste packages used did not influence the results noticeably. For example, in the $83 \mathrm{MTU} / \mathrm{acre}$ case, when the number of pits was increased from 100,000 to 4,000,000 per waste package, the time for the first pit penetration was earlier by as much as 100 to 200 years than that for the runs with 100,000 pits. However, the differences are smeared out during the abstraction process in which the waste packages are divided into 6 groups. For each waste package group, an average of the first pit penetration times of individual waste packages in that group is used as the first pit penetration time for that group, and all the waste packages in the same group are assumed to have the same pitting history.

\subsubsection{Corrosion Initiation with Humidity and Temperature}

A set of simulations for a thermal loading of 83 MTU/acre was performed assuming that corrosion of the carbon steel outer barrier initiates only when the temperature at the waste 
container surface becomes less than $100{ }^{\circ} \mathrm{C}$ and the relative humidity is above the threshold values defined in Section 5.7.2. Impacts of different infiltration rates (low infiltration rate with $0.05 \mathrm{~mm} / \mathrm{yr}$ and high infiltration rate with $0.3 \mathrm{~mm} / \mathrm{yr}$ ) and backfill were also studied.

\section{Effect of Infiltration Rate}

The results for the case with low infiltration rate $(0.05 \mathrm{~mm} / \mathrm{yr})$ and without backfill are shown in Figures 5.7-3a to 5.7-3c. As previously discussed for this case in Section 4.2, at about 2,000 years the waste container temperature cools to $100^{\circ} \mathrm{C}$, and $\mathrm{RH}$ is approaching about $85 \%$. Thus, some portion of the waste packages in the repository are exposed to an aqueous corrosion condition. The effects of this aqueous corrosion environment at elevated temperatures are illustrated in Figure 5.7-3a which presents the "failure" history (or "empirical" cumulative density function) for 400 waste packages. "Failure" of a waste package has been defined in Section 5.7.3 as having at least one pit penetration through the container. Waste packages start to fail (first pit penetration) at about 2200 years, and the number of failed waste packages increases rapidly before flattening out at about 6,000 years.

This result is expected from the temperature and humidity profiles at the waste container surface (refer to Section 4.2). After corrosion initiates at about 2,000 years, temperature steadily decreases from about $100{ }^{\circ} \mathrm{C}$ to about $70^{\circ} \mathrm{C}$ at about 5,000 years, and $\mathrm{RH}$ is between 85 and 90 $\%$ during the time period. This indicates that the carbon steel outer barrier of a large portion of waste packages undergo aqueous corrosion at high corrosion rates. Additionally, at these temperature conditions, the time-independent pit growth rate for the inner barrier (Figure 5.5-1) is also high. It is also shown in the figure that about $8 \%$ of the waste packages do not have a first pit penetration by 100,000 years.

Representative pitting histories for 25 waste packages, randomly selected from the waste packages that fail before 100,000 years, are shown in Figure 5.7-3b. The waste package with the 'highest pitting penetrations' has about $10 \%$ of the total of 4 million pits penetrated at 10,000 years, and then the number of pit penetrations levels off. This is caused mainly by a very low pit growth rate for the inner barrier beyond 10,000 years, i.e. the waste container surface temperature is about $50^{\circ} \mathrm{C}$ at 10,000 years. Other waste packages follow similar pitting histories. Shown in Figure 5.7-3c is the abstraction for implementation of the RIP of the six waste package groups.

As shown in Section 4.2 , infiltration rate (high at $0.3 \mathrm{~mm} / \mathrm{yr}$ or low at $0.05 \mathrm{~mm} / \mathrm{yr}$ ) does not have a significant effect on the temperature and humidity profiles at the waste container surface. The waste package degradation results for the high infiltration rate case are presented in Figures 5.7-4a to 5.7-4c, and are similar to those for the low infiltration rate case. In Figures 5.7-4b and $5.7-4 \mathrm{c} 4$, the number of pit penetrations steadily increase even after 10,000 years, and this contrasts with the low infiltration rate case for which the number of pit penetrations is virtually flat after about 10,000 years. This is mainly due to higher humidity for the high infiltration rate case. 


\section{Effect of Backfill}

As described in the thermal-hydrologic modeling in Section 4.2, backfill is assumed to be emplaced after 100 years when most of the intense decay heat has dissipated from the waste package. The thermal-hydrologic modeling results showed that temperature and humidity profiles at the waste container surface are not affected greatly by the backfill emplacement.

Consequently, the waste package degradation histories (Figures 5.7-5a to 5.7-5c) for the case with backfill at the low infiltration rate are not much different from those without backfill at the same infiltration rate, except that the fraction of waste packages without a pit penetration at 10,000 years is about $20 \%$ (Figure 5.7-5a) compared to about $10 \%$ (Figure 5.7-3a). Similarly, in Figures 5.7-5b and 5.7-5c, the number of the pits penetrating the waste containers is lower, i.e. the maximum fraction is about 0.01 at 10,000 years compared to 0.1 at 10,000 years in the case without backfill. This was caused mainly by a lower humidity with the backfill case.

The simulation results for the case with backfill and at high infiltration rate are shown in Figures 5.7-6a to 5.7-6c. They are similar to those for the corresponding case at low infiltration rate, except the maximum fraction of pit penetrations is about 0.05 (Figures 5.7-6b and 5.7-6c) at 10,000 years compared to 0.01 at 10,000 years.

\subsubsection{Corrosion Initiation with Humidity}

It has been shown in the current drift-scale thermal-hydrologic modeling (see Section 4.2) that the waste container surface in a high thermal load case ( $83 \mathrm{MTU} / \mathrm{acre}$ ) is predicted to have relatively high humidity profiles (above $60 \% \mathrm{RH}$ for most of time) while the temperature is predicted to be higher than $100^{\circ} \mathrm{C}$. Most of the uncertainties of the model prediction come from the assumptions in the humidity calculation, the uncertainty of the conceptual model of the driftscale thermal-hydrology, and the uncertainty and variability of the thermal-hydrologic properties of the geologic materials. The simulations discussed in this subsection apply only to the highthermal load case (83 MTU/acre); for a low-thermal load case (25 MTU/acre), the temperature profile at the waste package surface is below $100{ }^{\circ} \mathrm{C}$ almost all the time. A set of simulations in this subsection were performed to evaluate the impacts on the waste package performance by initiating the carbon steel outer barrier corrosion whenever humidity is greater than the threshold value (see Section 5.7.2) regardless of the temperature.

\section{Effect of Infiltration Rate}

The simulation results for the case with low infiltration rate and without backfill are shown in Figures 5.7-7a to 5.7-7c. As shown in Figure 5.7-7a, "failure" (first pit penetration) of waste packages begins at about 1,000 years, which is about 1,200 years earlier than the corresponding case using the RH and temperature switch for the corrosion initiation (Figure 5.7-3a). This earlier waste package penetration is caused mainly by an earlier initiation of corrosion (starting at about 400 years) while temperature is still high (about $120^{\circ} \mathrm{C}$ ). However, the rate of waste package failures (from the "slope" of the curve) is lower than the case using the $\mathrm{RH}$ and temperature switch. This is due mostly to the long duration of humid-air corrosion of the carbon steel outer barrier, which initiates at about 400 years and continues to about 2,000 years before it switches to an aqueous corrosion condition. As described in Sections 5.3 and 5.4, the humid- 
air corrosion rate of the carbon steel outer barrier is lower than the aqueous corrosion rate. The pitting histories for 25 waste packages (Figure 5.7-7b) are similar to those using the RH and temperature switch, which are shown in Figure 5.7-3b.

The simulation results for the high infiltration rate $(0.3 \mathrm{~mm} / \mathrm{yr})$ case are shown in Figures $5.7-8 \mathrm{a}$ to 5.7-8c. In this case, waste packages begin to fail at about 850 years (Figure 5.7-8a) compared to about 1,000 years in the low infiltration rate case shown in Figure $5.7-7 \mathrm{a}$, and the waste package failure rate is about the same as in the low infiltration rate case. The number of pit penetrations steadily increase even after 10,000 years (Figure 5.7-8b), compared to the relatively steady-state at 10,000 years in the low infiltration rate case. A similar observation was made in the case with $83 \mathrm{MTU} / a c r e$, high infiltration, without backfill, and using RH and temperature switch (Figure 5.7-4a), and a similar explanation is offered, i.e. higher humidity in the high infiltration rate case.

\section{Effect of Backfill}

The simulation results for the case with backfill and low infiltration rate are presented in Figures 5.7-9a to 5.7-9c. Compared to the case without backfill (Figure 5.7-7a), the first waste package failure occurs at about 200 years later (Figure 5.7-9a), and the cumulative fraction of waste packages that have failed at 10,000 years is lower, i.e. about $75 \%$ of waste packages failed compared to about $85 \%$ for the case without backfill. Similar observations are made for the representative pitting histories of 25 waste packages shown in Figure 5.7-9b when compared to the case without backfill shown in Figure 5.7-7b.

The simulation results for the case with backfill and the high infiltration rate are shown in Figures 5.7-10a to 5.7-10c. As shown in Figure 5.7-10a, the time for the initiation of waste package failure is about the same as in the corresponding case without backfill (Figure 5.7-8a). However, the cumulative fraction of waste packages that have failed at 10,000 years is somewhat lower than the case without backfill. Additionally, for the backfill case, the number of failed waste packages is leveling off at 10,000 years (Figure 5.7-10a), and the number of pit penetrations in those waste packages beyond 10,000 years are relatively steady, i.e. fewer additional pit penetrations beyond 10,000 years (Figure 5.7-10b). These results contrast with those for the corresponding case without backfill, in which waste package failure continues beyond 10,000 years but at a significantly low rate (Figure 5.7-8a), and some waste packages have steadily increasing number of pit penetrations beyond 10,000 years (Figure 5.7-8b).

\subsubsection{Alternative Thermal Load}

A series of simulations were conducted for the low thermal load case (25 MTU/acre) to evaluate the effects of alternative thermal loadings (25 MTU/acre vs $83 \mathrm{MTU} /$ acre) on waste package performance. These simulations were made using only the $\mathrm{RH}$ switch for the corrosion initiation of the carbon steel outer barrier because temperature at the waste container surface is below $100{ }^{\circ} \mathrm{C}$ all times except for the very early period during which humidity at the surface is below the threshold humidity (see Section 5.7.2). The effects of infiltration rate (low infiltration rate at $0.05 \mathrm{~mm} / \mathrm{yr}$ or high infiltration rate at $0.3 \mathrm{~mm} / \mathrm{yr}$ ) and the presence of backfill were evaluated for the low thermal load case. The simulation results are compared with those of the 
corresponding high thermal load cases using RH and temperature switch for the outer barrier corrosion initiation.

\section{Effect of Infiltration Rate}

The simulation results for the case of low infiltration rate and without backfill are shown in Figures 5.7-11a to 5.7-11c. As shown in Figure 5.7-11a, the time to the first waste package failure is about 2,000 years which is close to that (about 2,200 years) for the corresponding high thermal load case (Figure 5.7-3a). However, the waste package failure rate (or number of waste packages that fail at a given time) is substantially lower than the corresponding high-thermal load case, i.e. failure of about $10 \%$ of the waste packages for this case compared to about $90 \%$ for the corresponding high-thermal load case by 10,000 years, and failure of about $18 \%$ of the waste packages for this case compared to about $92 \%$ for the corresponding high-thermal load case by 100,000 years. The explanation below is offered for this marked difference in the waste package degradation histories.

In the low-thermal load case, the carbon steel outer barrier of the waste packages begins humidair corrosion at very early time (starting at about 80 years), when humidity and temperature at the waste container surface reach about 65 to $75 \% \mathrm{RH}$ and 90 to $100{ }^{\circ} \mathrm{C}$, respectively (refer to Section 4.2). At these conditions, the corrosion rates are very low (see Section 5.3.5), and the humid-air corrosion lasts about 700 years before switching to an aqueous corrosion condition (at between 85 and $95 \% \mathrm{RH})$. Another important factor that contributes to the much reduced waste package failure rate in the low-thermal loading case is the lower pit growth rate of the corrosionresistant inner barrier because of the lower waste container surface temperature. The waste container surface temperature cools to about $60^{\circ} \mathrm{C}$ at 2,000 years to about $50{ }^{\circ} \mathrm{C}$ at 4,000 years and to about $40^{\circ} \mathrm{C}$ at 6,000 years. In this temperature range, pit growth rates of the inner barrier are low (see Section 5.5).

Shown in Figures 5.7-12a to 5.7-12c are the simulation results for the case with the high infiltration rate and without backfill. Compared to the results for the low infiltration rate and without backfill case in the low-thermal loading (Figure 5.7-11a), the time for the first waste package failure is about the same (2,000 years as shown in Figure 5.7-12a). However, the waste package failure rate for the high infiltration rate case is about twice that of the failure rate for the low infiltration case, i.e. failure of about $20 \%$ of the waste packages for the high infiltration rate case compared to about $10 \%$ for the low infiltration rate case at 10,000 years, and failure of about $34 \%$ of the waste packages for the high infiltration rate case compared to about $18 \%$ for the low infiltration rate at 100,000 years. Also, the representative pitting histories for 25 waste packages presented in Figure 5.7-12b show higher pitting rate (greater number of pit penetrations) for the high infiltration rate case than that for the low infiltration rate case (Figure 5.7-11b). As in the low infiltration rate case, the waste package failure in the high infiltration rate case is significantly lower than the corresponding high-thermal loading case (Figures 5.7-4a to 5.7-4c), and explanations similar to those given above for the low infiltration rate case apply.

\section{Effect of Backfill}

The simulation results for the low thermal loading case with backfill and the low infiltration rate are shown in Figures 5.7-13a to 5.7-13c. Since there is no noticeable difference between the low 
and high infiltration rate cases, only the results for the low infiltration rate case are discussed. As shown in Figure 5.7-13a, the time for the first waste package failure is the same as in the corresponding case without backfill (Figure 5.7-11a). The waste package failure rate for the case with backfill is somewhat lower than the corresponding case without backfill, i.e. failure of about $6 \%$ of the waste packages for the case with the backfill compared to $10 \%$ for the case without backfill by 10,000 years, and failure of about $13 \%$ of the waste packages for the case with the backfill compared to about $18 \%$ for the case without backfill by 100,000 years. The representative pitting histories for 25 waste packages for the case with backfill (Figure 5.7-13b) are very close to those for the case without backfill (Figure 5.7-11b).

\subsubsection{Cathodic Protection}

It is generally agreed that in the current waste package design, some degree of cathodic protection of the Alloy 825 corrosion-resistant inner barrier will be provided by the carbon steel outer barrier. The cathodic protection mechanism will become active when the outer barrier is breached and a galvanic couple is formed between the outer barrier and the inner barrier. Proper cathodic protection is ensured if the two metals maintain an intimate contact. However, no published data are available that are readily applicable to the current stochastic waste package degradation simulation. An elicitation was provided to account for the cathodic protection of the corrosion-resistant inner barrier in the waste package (McCright, 1995). The elicitation indicates the inner barrier would be protected cathodically by the outer barrier, and suggests the pitting corrosion of the inner barrier be delayed until the thickness of the carbon steel outer barrier is reduced by $75 \%$. Simulations were conducted to evaluate the effects of cathodic protection on the waste package performance by incorporating the elicitated cathodic protection measure.

\section{High-Thermal Loading Case}

A set of simulations were conducted for the case of high-thermal loading without backfill and at high infiltration rate, and the results are presented in Figures 5.7-14a to 5.7-14c. Compared to the simulation results for the corresponding case without cathodic protection (83 MTU/acre without backfill and with the high infiltration rate) shown in Figure 5.7-3a, the time for the initiation of waste package failure is delayed significantly from about 2,200 years to about 8,000 years (Figure 5.7-14a). With the current measure of cathodic protection, the fraction of failed waste packages (at least one pit penetration) is negligible at 10,000 years, compared to about $90 \%$ without cathodic protection (Figure 5.7-4a). The waste package failure fraction is about $60 \%$ by 100,000 years with cathodic protection compared to about $92 \%$ without cathodic protection. Also shown in Figure 5.7-14a is the fraction of waste packages with their outer barrier thickness reduced by $75 \%$. Note that in the figure, the 'n-th' waste package to have its outer barrier thickness reduced by $75 \%$ is not necessarily the same 'n-th' waste package to have its first pit penetrated. The representative pitting histories for 25 waste packages (shown in Figure 5.7-14b) are also reduced significantly, compared to those without cathodic protection (Figure 5.7-4b).

The waste package performance analyses indicate that the cathodic protection of the corrosionresistant inner barrier by the carbon steel outer barrier may significantly improve the waste package performance and could be one most important mechanism that should be considered in developing a strategy for the waste isolation and containment in the potential repository. 
However, the measure for cathodic protection provided by the elicitation, i.e. delaying the inner barrier pitting corrosion until the outer barrier thickness reduced by $75 \%$, was not developed from experimental data or detailed analysis, rather it is semi-quantitative in nature (McCright, 1995). To quantify better the cathodic protection effects in future waste package performance analysis, the current cathodic protection model should be improved and substantiated.

An additional uncertainty is the possibility of crevice corrosion that may occur by incomplete contacts between the corrosion-resistant inner barrier and the corrosion-allowance outer barrier materials. Crevice corrosion has an adverse effect to cathodic protection and is possible if there is a poor or incomplete contact between two metals with different corrosion potentials (such as between the inner barrier and outer barrier materials). In manufacturing the multi-barrier waste container which weighs about 70 tons with a dimension of $1.8 \mathrm{~m}$ diameter and $5.7 \mathrm{~m}$ length (M\&O, 1995c), it may not be straightforward technically to maintain a complete contact between two barrier materials. A poor or incomplete contact between the barrier materials would make the cathodic protection of the inner barrier less effective and may introduce a large crevice region between the two metals that is detrimental to the performance (McCright, 1995). The effects of potential crevice corrosion should be addressed in future waste package performance analysis (Lee, 1995).

\section{Low-Thermal Load Case}

A similar set of simulations with the same cathodic protection measure implemented were run for the low-thermal loading case (25 MTU/acre) with the high infiltration rate and without backfill.

The number of waste package failures, i.e. waste packages with their first pit penetrated, is extremely low at 100,000 years (Figure 5.7-15). Also shown in the figure is the fraction of waste packages with their outer barrier thickness reduced by $75 \%$. Combined effects of the current measure of cathodic protection and the low pit growth rate in the inner barrier, caused by the low waste container surface temperature at the time for initiation of the inner barrier pitting, result in the very small number of waste package failures. Pitting rates of the waste packages are also very low. Other simulation results are not presented because of the insignificant waste package degradation for this case.

\subsubsection{Time-Dependent Pit Growth Rate in Alloy 825 Inner Barrier}

It is generally known that, like general corrosion rate (Sections 5.3 and 5.4), pitting corrosion rate decreases with exposure time. The time-independent pit growth rate for the corrosion-resistant inner barrier in the current stochastic waste package performance simulation (discussed in Section 5.5) may be conservative in light of the time-dependent pitting rate. To account for the timedependency of pit growth rate, a sensitivity case study was performed which included the incorporation of a square root of exposure time term into Equation (5.5-1) as follows (Halsey, 1995). 


$$
\ln R_{p}=50.373-0.5 \ln t-\frac{19655.85}{T}
$$

Since it would be more appropriate to use a distribution for the power of the time term instead of a single number (0.5), a set of simulations were conducted with the time power term being uniformly distributed between 0.3 and 0.5 (Lee, 1995). The simulations were run for the case of high-thermal loading ( $83 \mathrm{MTU} / \mathrm{acre}$ ) with high infiltration rate, without backfill, and using the $\mathrm{RH}$ and temperature switch for the initiation of the outer barrier corrosion.

The simulation results for the fraction of waste packages with their first pit penetration are presented in Figure 5.7-16 which shows that only about $5 \%$ of the waste packages have been penetrated by 100,000 years. Currently, no information is available for the validity of the time power term for the inner barrier pitting corrosion. This sensitivity study suggests that the inner barrier pitting corrosion model from the elicitation be improved and substantiated for future waste package performance analysis. Other simulation results are not presented because of negligible waste package degradation.

\subsubsection{Alternative Thermal-Hydrologic Model}

Alternate thermal-hydrologic models have been used for performance assessment calculations for the near-field (drift-scale) and far-field thermal hydrology for the potential repository: one by the M\&O Performance Assessment (PA) Group which is being used in this study, and the other by Buscheck and coworkers at Lawrence Livermore National Laboratory (LLNL) (Buscheck, et al., 1995). Details of the alternative models are discussed in Section 4.2. Recently, selected simulation results for the temperature, humidity and saturation profiles in the drift, calculated with the alternative drift-scale thermal-hydrologic model by Buscheck and coworkers (hereafter referred to as Buscheck's model) were provided for comparison with the results from the M\&O PA group (Buscheck, 1995). The results from Buscheck's model are for

1) $80 \mathrm{MTU} / \mathrm{acre}$, no backfill, no infiltration;

2) $80 \mathrm{MTU} / \mathrm{acre}$, backfill, no infiltration;

3) $24 \mathrm{MTU} / \mathrm{acre}$, no backfill, no infiltration; and

4) $24 \mathrm{MTU} / \mathrm{acre}$, backfill, no infiltration.

As noticed from the above list, all the results from Buscheck's model do not include the effects from the infiltration rate at the repository. Although this may not be a major factor, modeling results would indicate drier and hotter conditions than the case including the infiltration effects. Detailed comparisons of the drift-scale thermal-hydrologic modeling results (in terms of temperature, humidity and saturation) are discussed in Section 4.2. Using the temperature and humidity profiles at the waste package surface from Buscheck's model, a series of simulations were conducted for waste package performance in the different near-field environments. It may not be appropriate to compare directly the simulation results using the near-field conditions from Buscheck's model with those from this study, mainly because of the differences in the conceptual models and in the thermal and hydraulic properties of the materials employed in the two models. However, whenever reasonable, the results are compared with those from a similar case in this 
study. As -discussed below, the near-field conditions for the four cases calculated from Buscheck's model are hotter and drier than the results from this study, resulting in much lower waste package failure and degradation. Therefore, the waste package performance simulations for all the cases from Buscheck's model were run for up to 1,000,000 years, instead of 100,00 years as in the other cases in this study, assuming the waste packages maintain their structural integrity.

\section{MTU/acre Case}

Simulation results for the case of 24 MTU/acre without backfill and using the RH switch for the outer barrier corrosion initiation are presented in Figures 5.7-17a to 5.7-17c. Compared to the waste package failure rate results in this study for the low-thermal loading (25 MTU/acre) case at low infiltration rate and without backfill (Figure 5.7-11a), the time for the initiation of waste package failure at about 1,800 years (Figure 5.7-17a) is comparable. However, the waste package failure rates (about $4 \%$ at 10,000 years and about $10 \%$ at 100,000 years) are lower than the rate in this study (about $10 \%$ at 10,000 years and about $18 \%$ at 100,000 years). The pitting histories of the waste packages from Buscheck's model (Figure 5.7-17b) are also lower than the similar case in this study (Figure 5.7-11b).

The simulation results for the 24 MTU/acre case with backfill are shown in Figures 5.7-18a and 5.7-18b. As shown in Figure 5.7-18a, there is no waste package failure until about 50,000 years, and a very small number of waste package have failed at 100,000 years. The results are significantly different from those of the similar case in this study (25 MTU/acre at low infiltration rate and without backfill, shown in Figure 5.7-13a). Also, degradation of the waste packages by pitting corrosion with the Buscheck's model (Figure 5.7-18b) becomes significant only after about 200,000 years (compare to Figure $5.7-13 \mathrm{~b}$ ).

\section{$80 \mathrm{MTU} / \mathrm{acre}$ Case}

The simulation results for the $80 \mathrm{MTU} / \mathrm{acre}$ case without backfill and using the RH and temperature switch for the outer barrier corrosion initiation are presented in Figures 5.7-19a and 5.7-19b. It is shown in Figure 5.7-19a that there is no waste package failure until 50,000 years, and only about $1 \%$ of waste packages have their first pit penetration by 100,000 years. Also, pitting degradation of the waste packages becomes significant only after 100,000 years.

Figures 5.7-20a and 5.7-20b show the simulation results for the 80 MTU/acre case with backfill and using the RH and temperature switch for the outer barrier corrosion initiation. As shown in Figure 5.7-20a, the backfill further delays the time for the initiation of waste package failure to just beyond 100,000 years. As for the case without backfill, waste package degradation from pitting corrosion becomes significant only after about 200,000 years.

The alternative thermal-hydrologic models from the M\&O PA Group and Buscheck provide very different (drift-scale) near-field environments in terms of temperature and relative humidity. Depending on the choice between the two models, the current stochastic waste package performance simulation predicts very different waste package performance. These comparative study results indicate there is a need to resolve the differences between the two thermalhydrologic models in order to provide a consistent, more reliable and better representative 
information .of the near-field environment. Such reliability in the near-field environment is crucial to improve confidence in modeling the waste package and EBS performance and conducting a total system performance assessment for the potential repository.

\subsubsection{Alternative Interpretation of the Elicitation for the Inner Barrier Pit Growth Rate}

An alternative interpretation of the elicitation for the pit growth rate ranges given in Table 5.5-1 is that the pit growth rate given in the mean growth rate column should have been the median growth rate. If this were the case, it would be possible to assume that within each of the three rows, the growth rate follows a log-normal distribution. Then, it is possible to treat the variability between the rows as waste package to waste package variability, and the variability between the columns as pit to pit variability among the pits on the same waste package. This would provide a standard deviation of 1.40 natural log units for both the waste package to waste package variability and the pit to pit variability, thus effectively doubling the variability in the pit growth rate. Using this alternative interpretation, a set of simulations were run for the case of low thermal loading (25MTU/acre) without backfill, at high infiltration rate, and using the $\mathrm{RH}$ switch for the initiation of the outer barrier corrosion. Another set of simulations were run for the case of high thermal loading (83MTU/acre) without backfill, at high infiltration rate, and using the RH switch for the corrosion initiation.

The simulation results for the waste package failure rate (waste packages with at least one pit penetration) are presented in Figure 5.7-21 for the 25 MTU/acre case and in Figure 5.7-22 for the $83 \mathrm{MTU} /$ acre case. Compared to the results for the corresponding low thermal loading cases using the earlier interpretation (Figure 5.7-12a), the time to initiation of waste package failure is about 1,000 years with this alternative interpretation (Figure 5.7-21), whereas the initiation time is about 2,000 years with the earlier interpretation. Also, although the cumulative fraction of waste packages with their first pit penetration is about $20 \%$ at 10,000 years and about $34 \%$ at 100,000 years with the earlier interpretation, these are about $70 \%$ at 10,000 years and about $80 \%$ at 100,000 years respectively with the alternate interpretation.

For the $83 \mathrm{MTU} /$ acre case shown in Figure 5.7-22, the impact of the alternate interpretation is much less than the $25 \mathrm{MTU} / \mathrm{acre}$ case. The time for the initiation of waste package failure (first pit penetration) is about 900 years with the earlier interpretation (Figure 5.7-8a), whereas it is about 700 years with the alternative interpretation. The cumulative fraction of the failed waste packages is about $95 \%$ at 10,000 years and about $98 \%$ at 100,000 years with the alternate interpretation, and the fraction is about $85 \%$ at 10,000 years and about $93 \%$ at 100,000 years with the earlier interpretation.

\subsection{SUMMARY AND RECOMMENDATION}

Current design concept for the potential repository employs a robust waste package design and other defense-in-depth EBS components. The waste package is the primary EBS component and one of the major components in the current waste isolation and containment strategy (Younker, 1995). A detailed stochastic waste package performance simulation model has been developed for TSPA-1995, and the stochastic simulation model incorporates the following five individual corrosion models: 1) humid-air general corrosion model (including uncertainty) for the carbon steel corrosion-allowance outer barrier; 2) stochastic humid-air pitting corrosion model for the 
carbon steel-outer barrier; 3) aqueous general corrosion model (including uncertainty) for the carbon steel outer barrier; 4) stochastic aqueous pitting corrosion model for the carbon steel outer barrier; and 5) aqueous pitting corrosion model (including pit growth rate distribution) for the Alloy 825 corrosion-resistant inner barrier. The humid-air and aqueous corrosion models for the carbon steel outer barrier were developed for TSPA-1995 from the literature data. The same elicitation for time-independent pit growth rates for Alloy 825 as used in TSPA-1993 was utilized to model aqueous pitting corrosion of the corrosion-resistant inner barrier. The uncertainties in the individual corrosion models were incorporated to capture the variability in the corrosion degradation among waste packages and among pits in the same waste package.

Within the scope of assumptions employed in the simulations, the corrosion modes considered, and the near-field conditions from the drift-scale thermal-hydrologic model, the results of the waste package performance analyses show that the current waste package design appears to meet the 'controlled design assumption' requirement on waste package performance, which is currently defined as having less than $1 \%$ of waste packages breached at 1,000 years (M\&O, 1995c). Breach of waste package is defined here as having at least one pit penetration. Since a quantitative definition of the substantially complete containment requirement, as referred in the NRC subsystem requirement (10 CFR 60.113) has not been decided, the (tentative) 'controlled design assumption' requirement has been employed throughout the analyses of the waste package degradation simulations in this study.

Another important finding is the significant impact on waste package performance of cathodic protection of the corrosion-resistant Alloy 825 inner barrier by the corrosion-allowance carbon steel outer barrier. One reservation in interpreting the simulation results is that the measure used to account for the inner barrier cathodic protection in the current simulation model is semiquantitative in nature. With the cathodic protection measure incorporated, it has been shown cathodic protection may be able to provide additional several thousand years in waste package performance, compared to the case without cathodic protection. The cathodic protection measure should be further improved and substantiated for future waste package performance analysis.

It has been pointed out throughout the analyses of the simulation results that pitting corrosion of the corrosion-resistant inner barrier is the major mechanism that controls the failure of waste packages and their subsequent degradation. The current aqueous pitting corrosion model for the inner barrier is from an expert elicitation, not based on a reasonably complete set of experimental data or detailed systematic analyses, and the model is expressed as a function of exposure temperature only. The inner barrier pitting corrosion model should be improved and substantiated in future waste package performance analyses. Other important parameters that need to be included in the inner barrier pitting corrosion model would be the effects of near-field chemical environments and exposure time. It has been reported that localized corrosion such as pitting and stress corrosion cracking are interrelated because the sites of localized corrosion attack become the sources of initiation of stress corrosion cracking (Farmer and McCright, 1989; Farmer, et al., 1989). Thus, synergistic effects of pitting and other localized corrosion combined with stress corrosion cracking need to be included in future waste package performance analyses. Additionally, the effects of microbiologically influenced corrosion on waste package performance should also be included. 
Currently, alternative thermal-hydrologic models are being used by M\&O Performance Assessment Group and Lawrence Livermore National Laboratory. It has been stressed that very different predictions of waste package performance are obtained depending on which drift-scale thermal-hydrologic model is chosen to calculate the near-field (drift-scale) conditions. Also, the two currently available thermal-hydrologic models have significant uncertainties in their conceptual models and the thermal-hydraulic properties of the geologic materials. Differences between the two models should be resolved, and the uncertainties in the thermal-hydraulic properties should be reduced, so that a more consistent representation on the near-field environments is provided for future waste package performance assessment. 
Table 5.3-1 - Corrosion Current Density of Iron at Different Humidities at $25^{\circ} \mathrm{C}$ in Static and Dynamic Air Conditions and General Corrosion Rates Calculated from the Corrosion Current Density Data.

\begin{tabular}{|c|c|c|c|c||}
\hline \multirow{2}{*}{$\begin{array}{c}\text { Relative } \\
\text { Humidity } \\
(\%)\end{array}$} & \multicolumn{2}{c|}{$\begin{array}{c}\text { Corrosion Current Density } \\
\left(\mathrm{amp} / \mathrm{cm}^{2}\right)\end{array}$} & \multicolumn{2}{c|}{$\begin{array}{c}\text { General Corrosion Rate } \\
\left(\times 10^{-6} \mathrm{~m} / \mathrm{yr} \text { or } \mu \mathrm{m} / \mathrm{yr}\right)\end{array}$} \\
\cline { 2 - 5 } & Static Air & Dynamic Air & Static Air & Dynamic Air \\
\hline \hline 52 & $3.0 \times 10^{-10}$ & $3.0 \times 10^{-10}$ & 0.0035 & 0.0035 \\
\hline 64 & $1.3 \times 10^{-9}$ & $2.7 \times 10^{-7}$ & 0.0151 & 3.1350 \\
\hline 76 & $3.4 \times 10^{-9}$ & $3.3 \times 10^{-7}$ & 0.0395 & 3.8320 \\
\hline 86 & $6.7 \times 10^{-9}$ & $6.1 \times 10^{-7}$ & 0.0778 & 7.0840 \\
\hline 100 & $8.7 \times 10^{-6}$ & $2.7 \times 10^{-5}$ & 101.0260 & 313.5300 \\
\hline
\end{tabular}

1) Read from graphs (Jones and Howryla, 1993).

2) Calculated using Equation (5.3-16). 
Table 5.5-1 . Elicitation of 'Constant' Pit Growth Rate Distribution for the Alloy 825 Inner Barrier ${ }^{1)}$

\begin{tabular}{||c|c|c|c|c||}
\hline \multirow{2}{*}{$\begin{array}{c}\text { Growth } \\
\text { Condition }\end{array}$} & \multicolumn{2}{|c|}{ Temperature = 70 ${ }^{\circ} \mathbf{C}$} & \multicolumn{2}{|c|}{ Temperature = 100 ${ }^{\circ} \mathbf{C}$} \\
\cline { 2 - 5 } & $\begin{array}{c}\text { Mean Growth } \\
\text { Rate } \\
(\mathbf{m m} / \mathbf{y r})\end{array}$ & $\begin{array}{c}\text { 95th Percentile } \\
\text { Growth Rate } \\
(\mathbf{m m} / \mathbf{y r})\end{array}$ & $\begin{array}{c}\text { Mean Growth } \\
\text { Rate } \\
(\mathbf{m m} / \mathbf{y r})\end{array}$ & $\begin{array}{c}\text { 95th Percentile } \\
\text { Growth Rate } \\
\text { (mm/yr) }\end{array}$ \\
\hline \hline $\begin{array}{c}\text { Low Growth } \\
\text { Rate }\end{array}$ & 0.0001 & 0.001 & 0.01 & 0.1 \\
\hline $\begin{array}{c}\text { Median } \\
\text { Growth Rate }\end{array}$ & 0.001 & 0.01 & 0.1 & 1.0 \\
\hline $\begin{array}{c}\text { High Growth } \\
\text { Rate }\end{array}$ & 0.01 & 0.1 & 1.0 & 10.0 \\
\hline
\end{tabular}

1) Source: Andrews, et al (1994). 

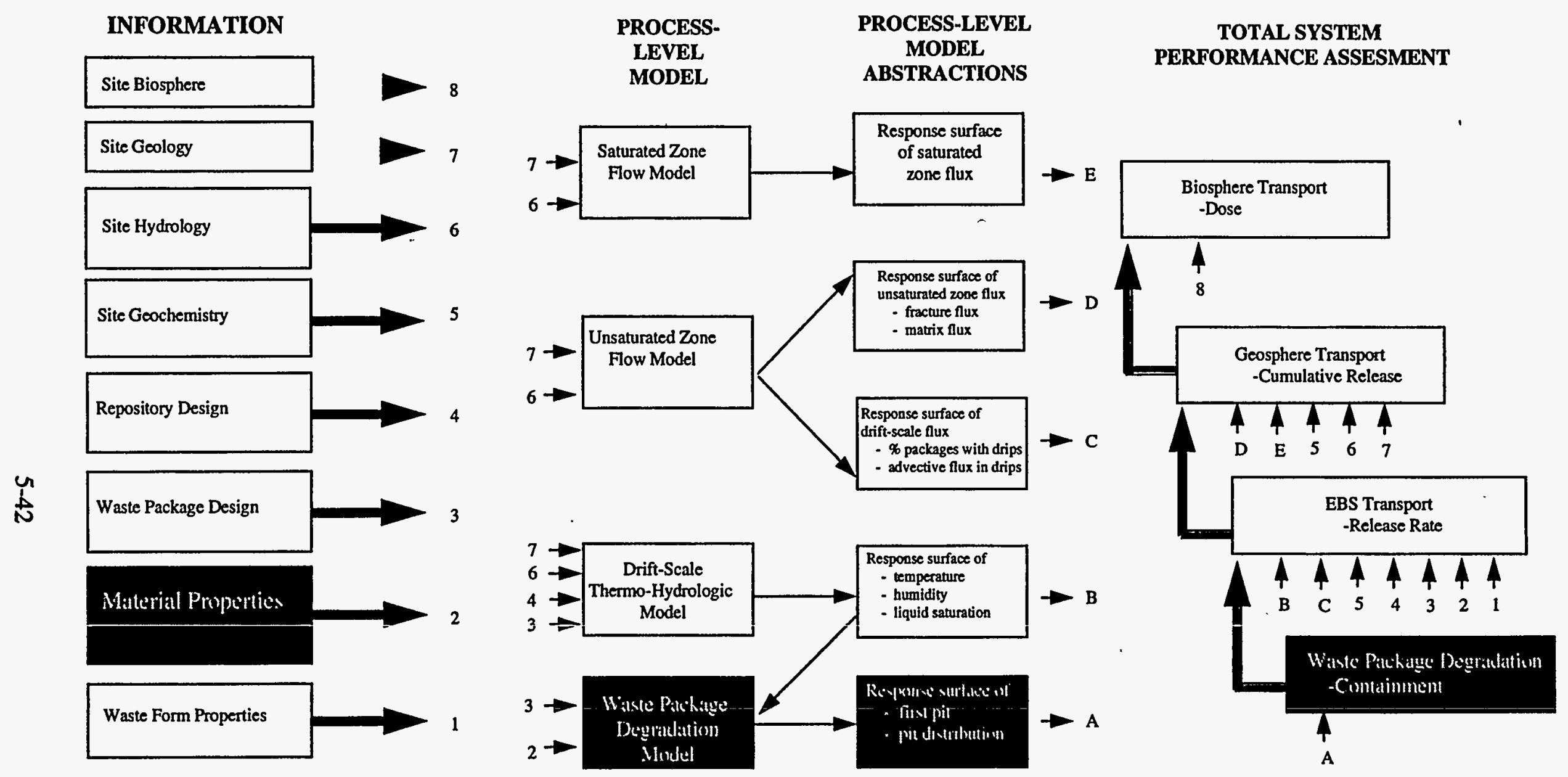

Figure 5.1-1 Relationship of Chapter 5 to the Overall Information Flow Diagram for TSPA 1995 (Figure 1.4-6) 
Fraction Time for $\mathrm{RH} \geq 70 \%$ vs Average $\mathrm{RH}$

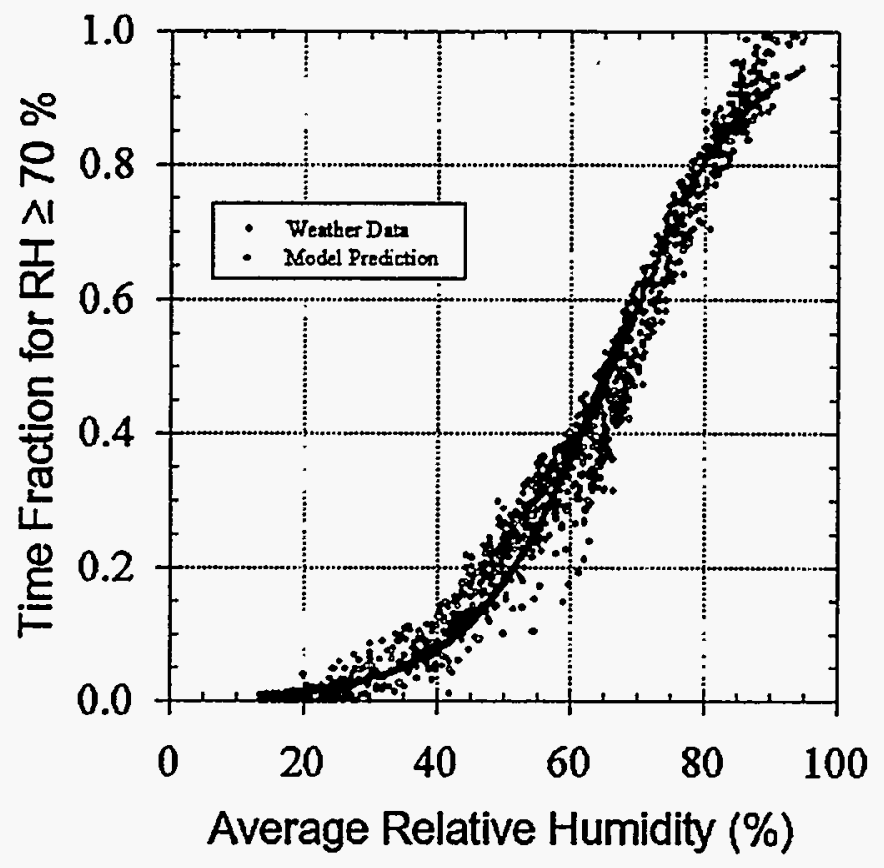

Figure 5.3-1 Weather data and model predictions of the fraction of time for $\mathrm{RH}^{3} 70 \%$ as a function of average relative humidity.

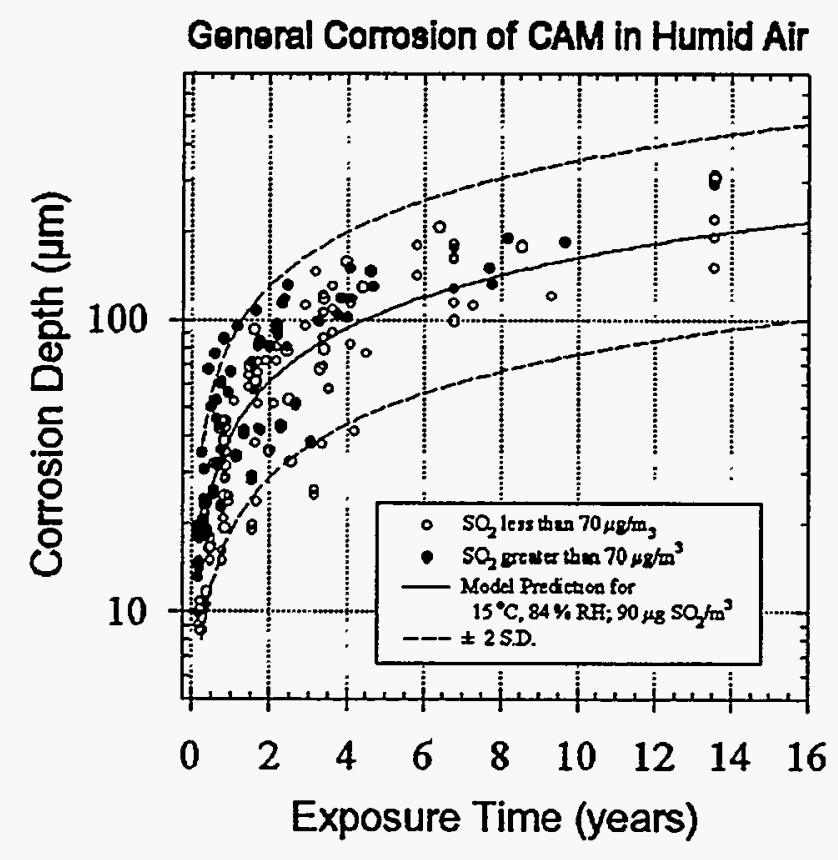

Figure 5.3-2 Atmospheric general corrosion data and the model prediction for corrosion allowance materials. 


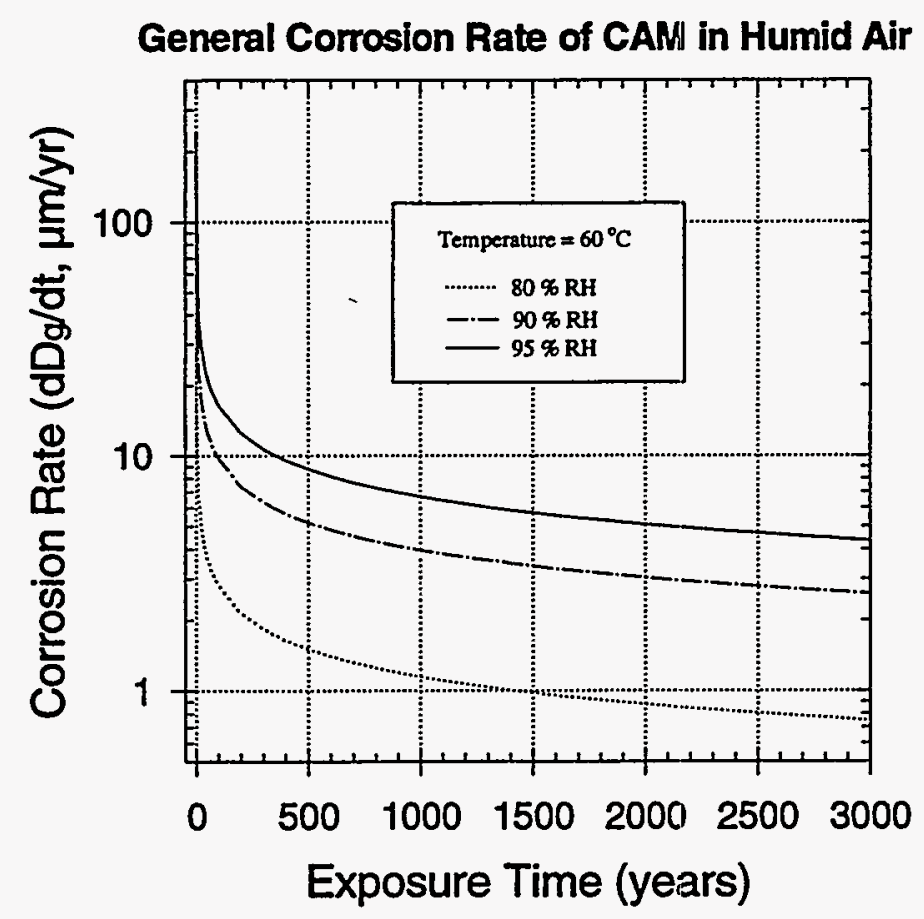

Figure 5.3-3a Model prediction of general corrosion rates of CAM in humid-air as a function of exposure time in humid-air at different humidities at $60^{\circ} \mathrm{C}$.

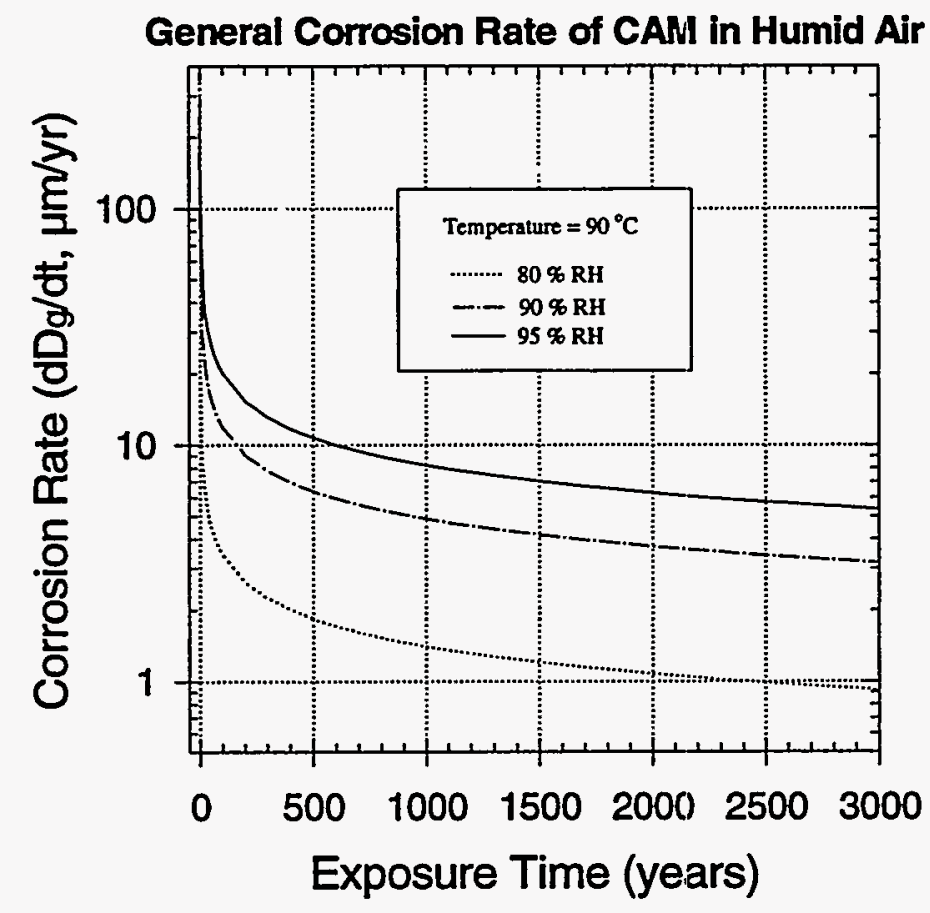

Figure 5.3-3b Model prediction of general corrosion rates of CAM in humid-air as a function of exposure time in humid-air at different humidities at $90^{\circ} \mathrm{C}$. 


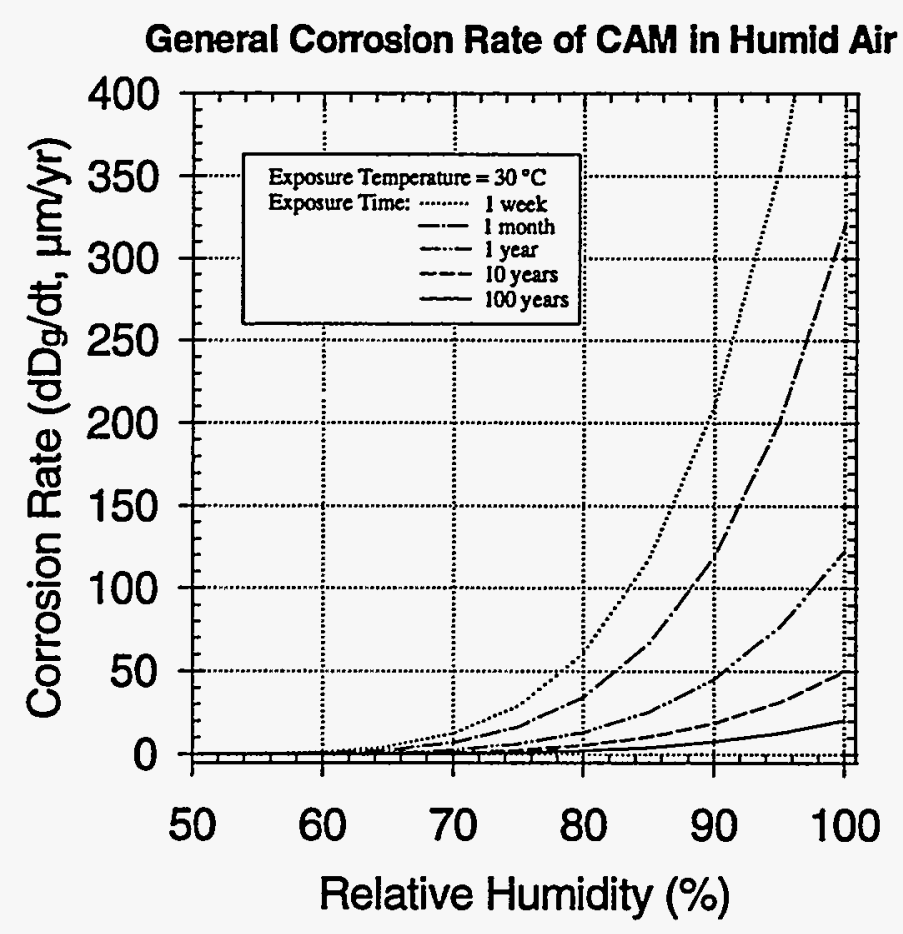

Figure 5.3-4a Model prediction of general corrosion rates of CAM in humid-air as a function of relative humidity at $30^{\circ} \mathrm{C}$ and different exposure times. No $\mathrm{SO}_{2}$ effect.

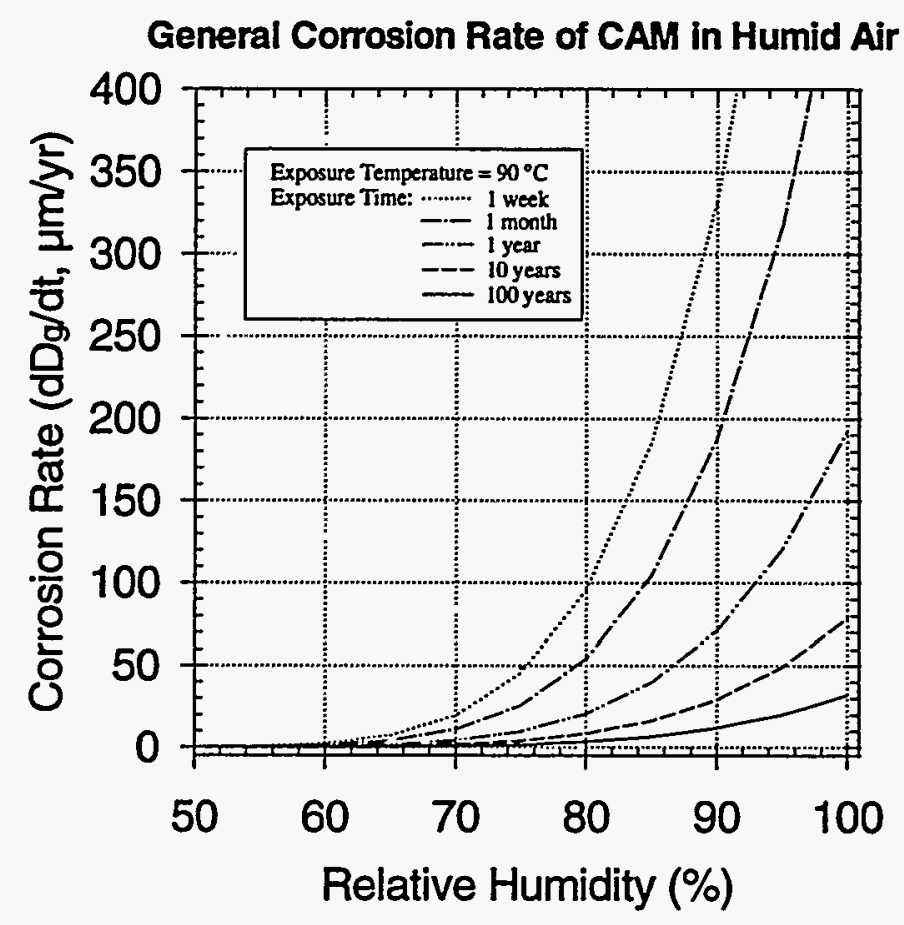

Figure 5.3-4b Model prediction of general corrosion rates of CAM in humid-air as a function of relative humidity at $90{ }^{\circ} \mathrm{C}$ and different exposure times. No $\mathrm{SO}_{2}$ effect. 


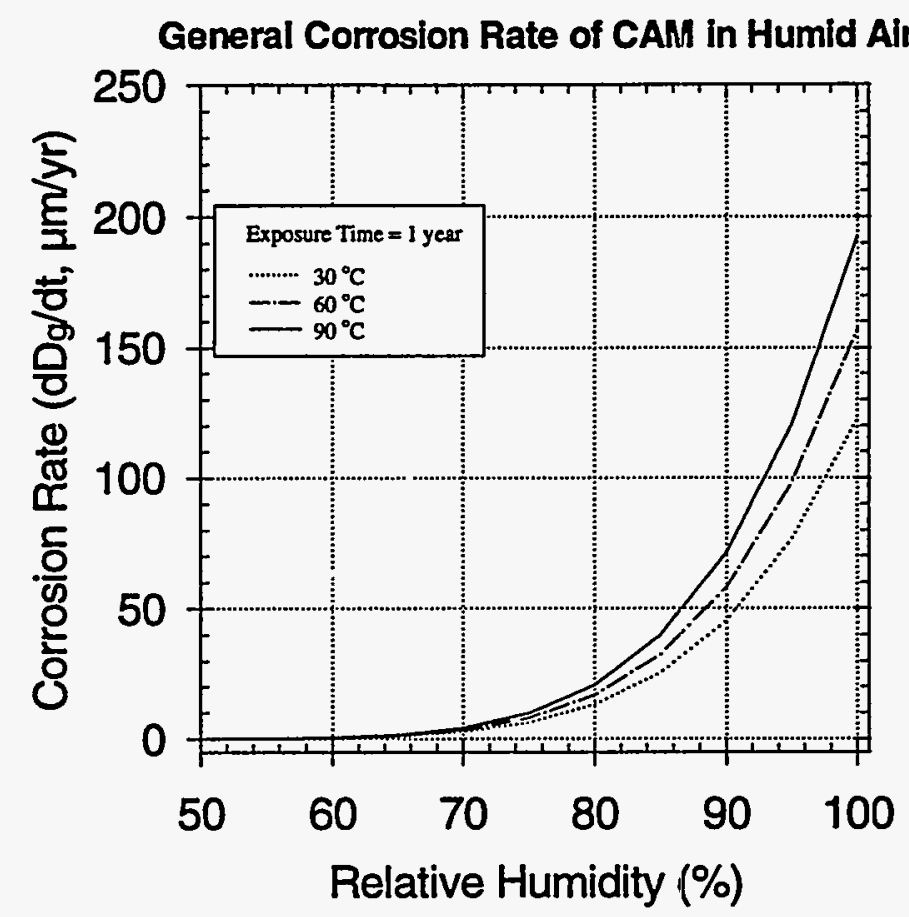

Figure 5.3-5 Model prediction of general corrosion rate of CAM in humid-air as a function of relative humidity at different exposure temperatures after one year exposure.

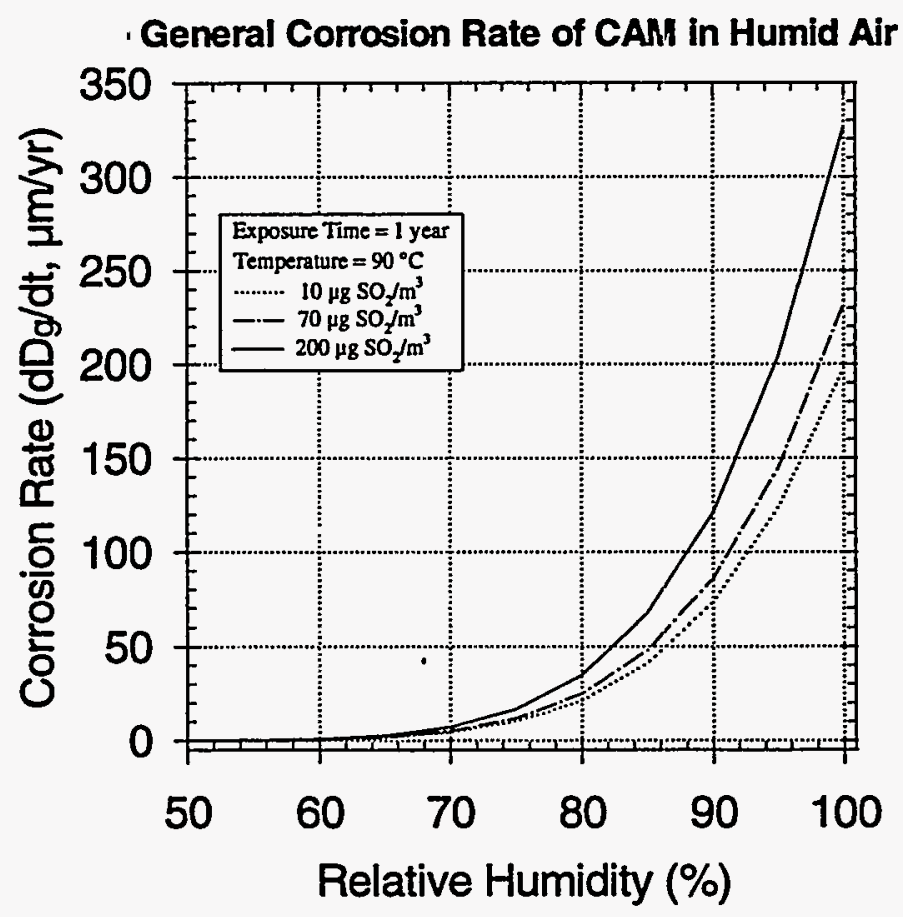

Figure 5.3-6 Model prediction of general corrosion rates of CAM in humid-air as a function of relative humidity at different $\mathrm{SO}_{2}$ levels in the air after one year exposure at $90^{\circ} \mathrm{C}$. 


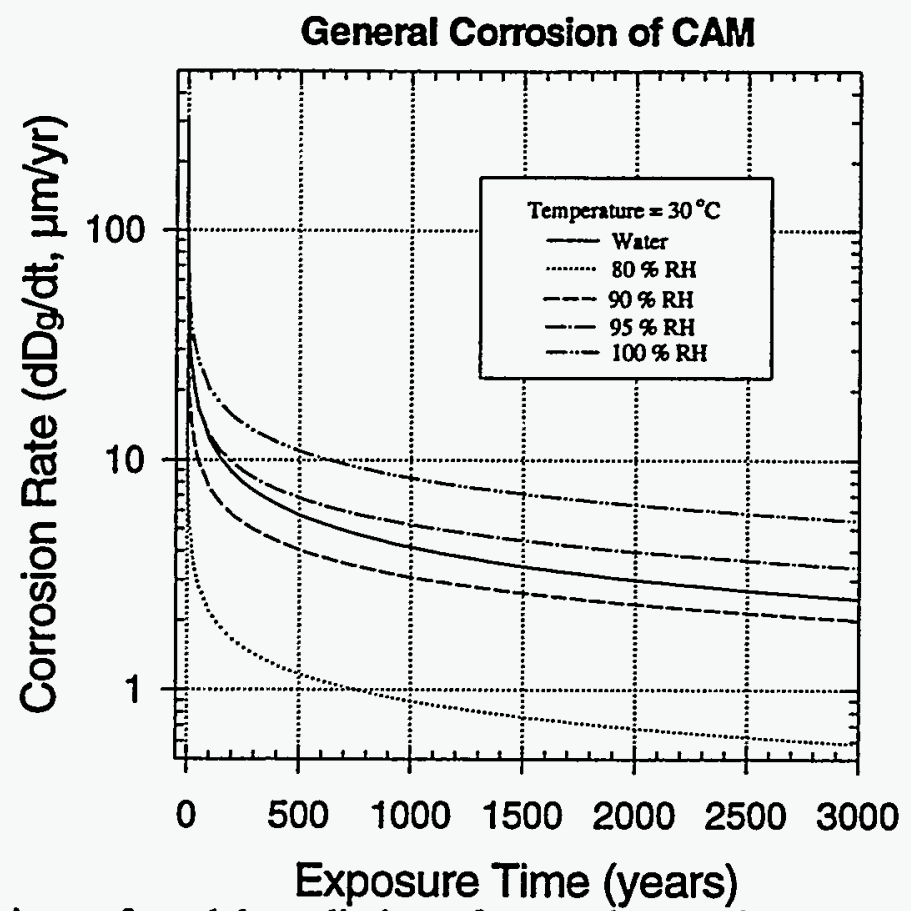

Figure 5.3-7a Comparison of model prediction of general corrosion rates of CAM in humidair at different humidities and in water at $30^{\circ} \mathrm{C}$.

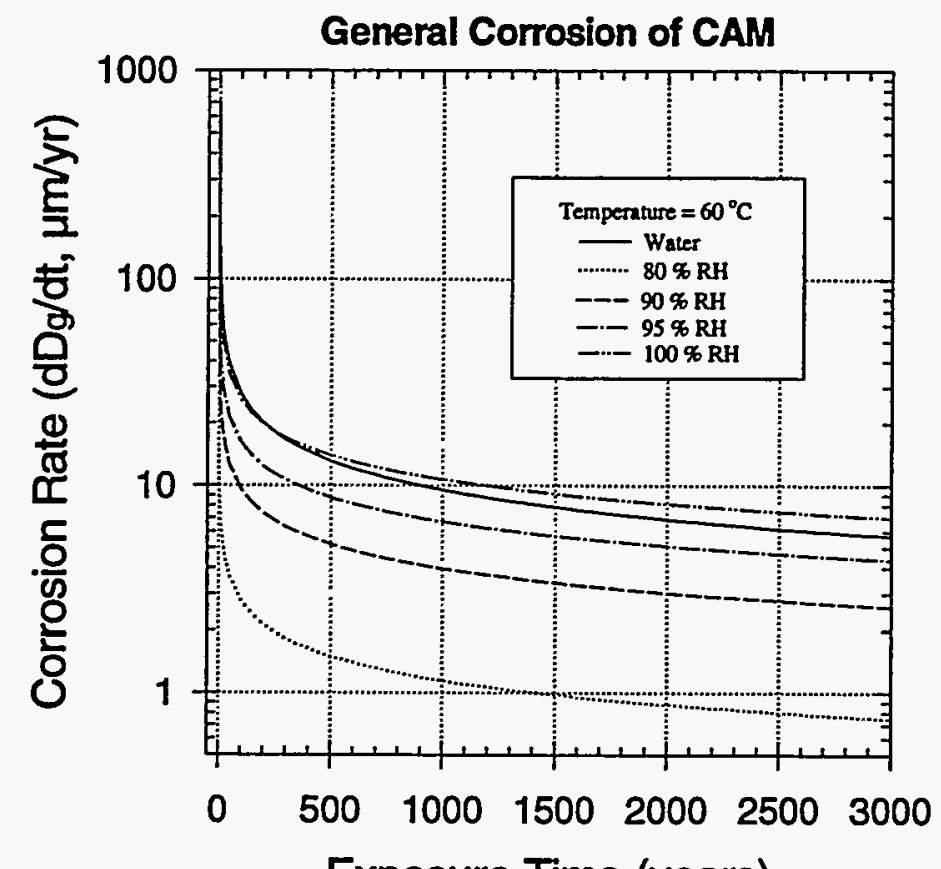

Figure 5.3-7b Comparison of model prediction of general corrosion rates of CAM in humidair at different humidities and in water at $60^{\circ} \mathrm{C}$. 


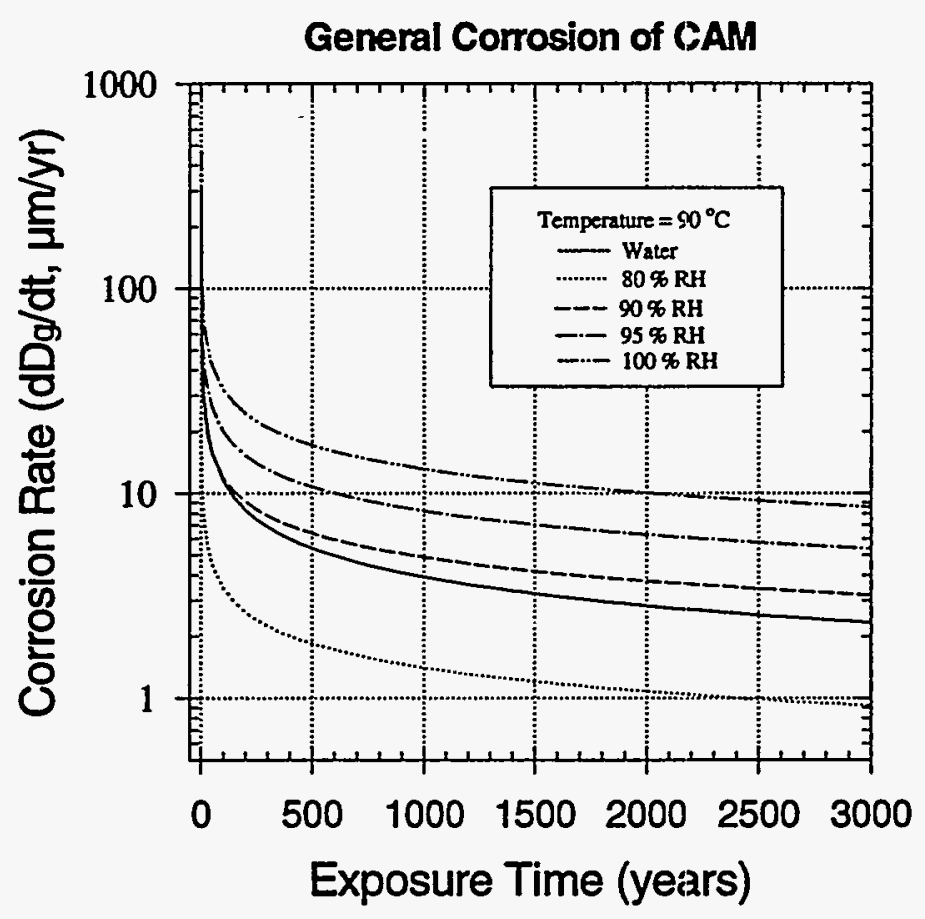

Figure 5.3-7c Comparison of model prediction of general corrosion rates of CAM in humidair at different humidities and in water at $90^{\circ} \mathrm{C}$. 


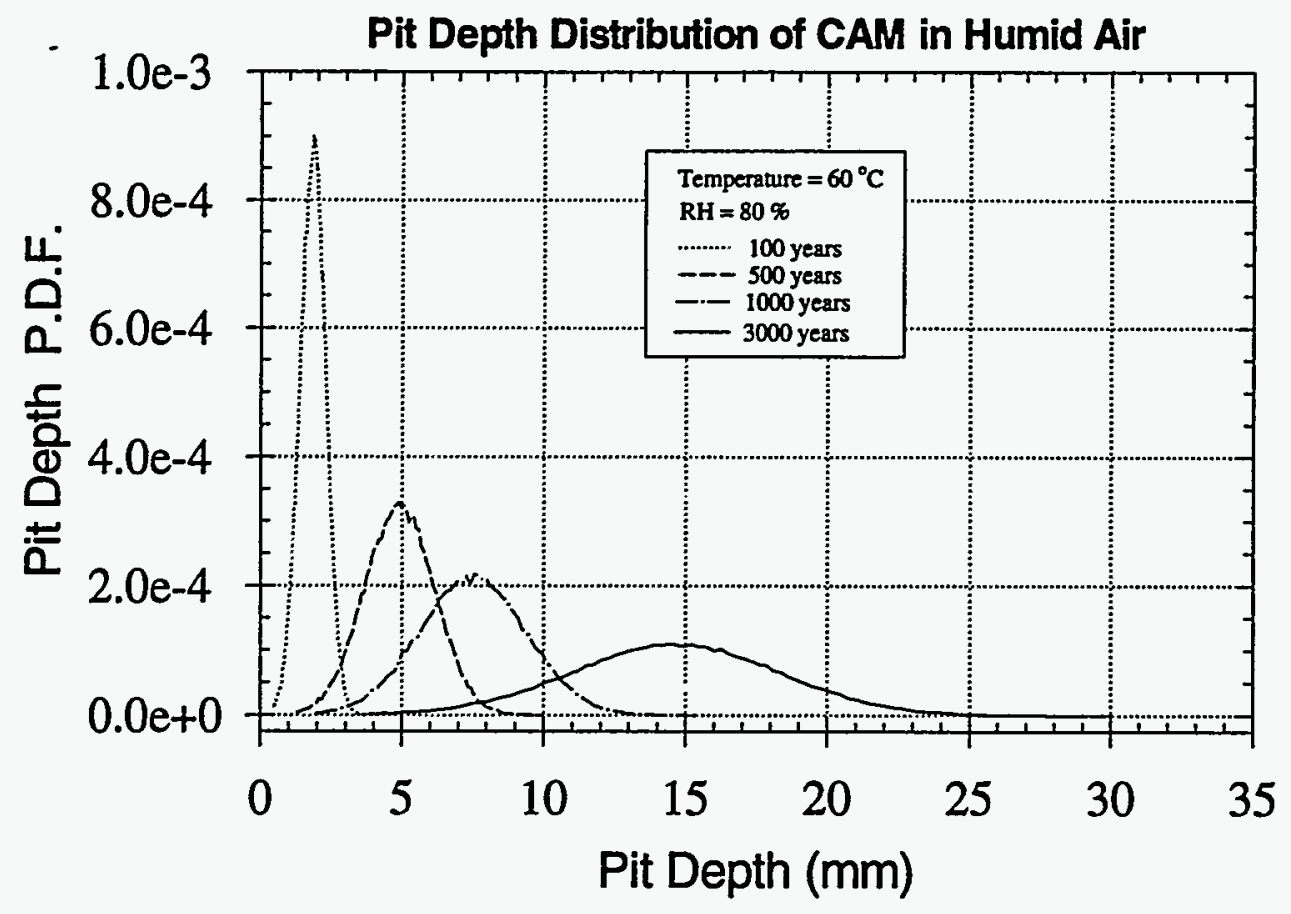

Figure 5.3-8a Model prediction of probability density functions (PDFs) of pit depth distribution of CAM in humid-air after different exposure times at $60^{\circ} \mathrm{C}$ and $80 \% \mathrm{RH}$.

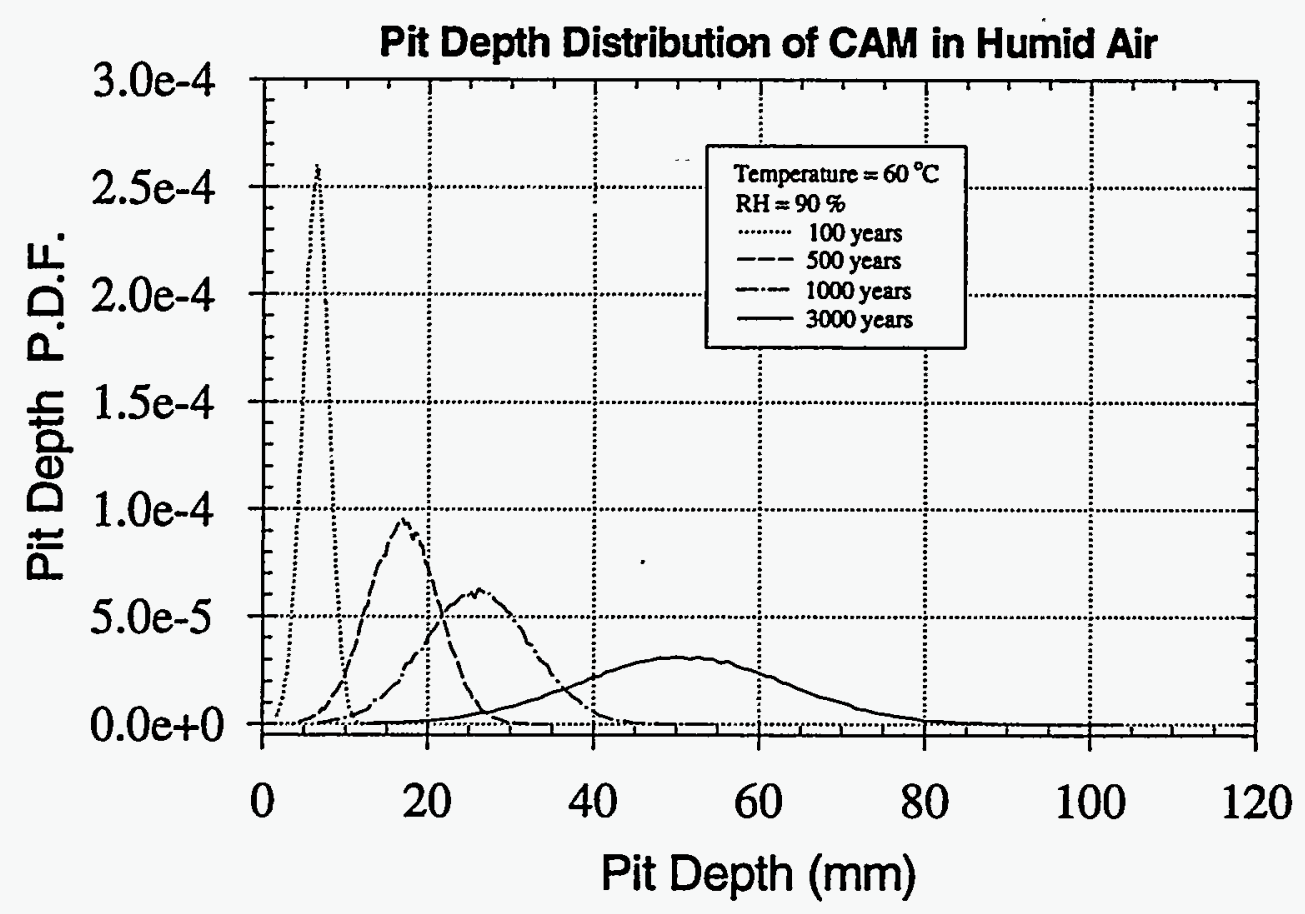

Figure 5.3-8b Model prediction of probability density functions (PDFs) of pit depth distribution of CAM in humid-air after different exposure times at $60^{\circ} \mathrm{C}$ and $90 \% \mathrm{RH}$. 


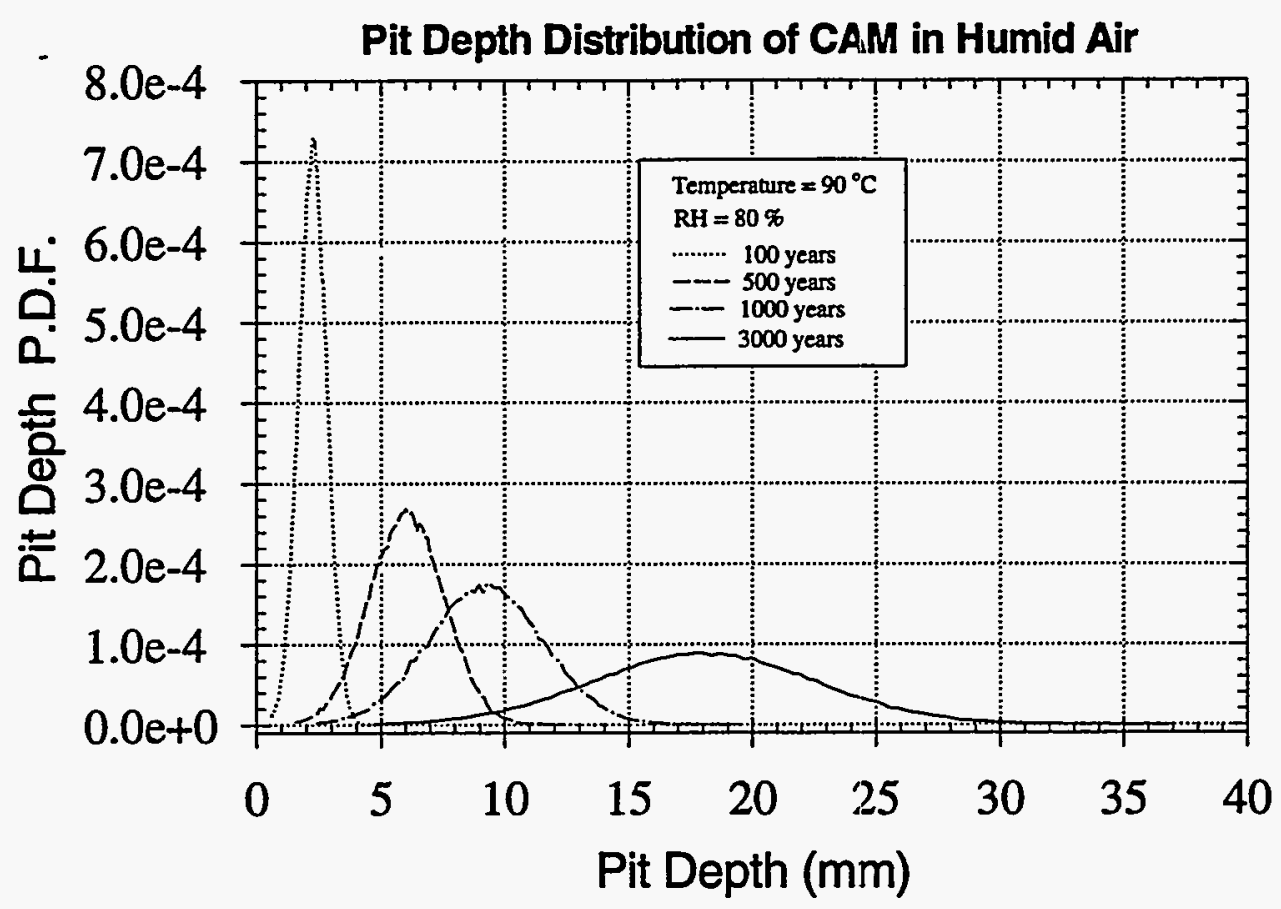

Figure 5.3-9a Model prediction of probability density functions (PDFs) of pit depth distribution of CAM in humid-air after different exposure times at $90{ }^{\circ} \mathrm{C}$ and $80 \%$ RH.

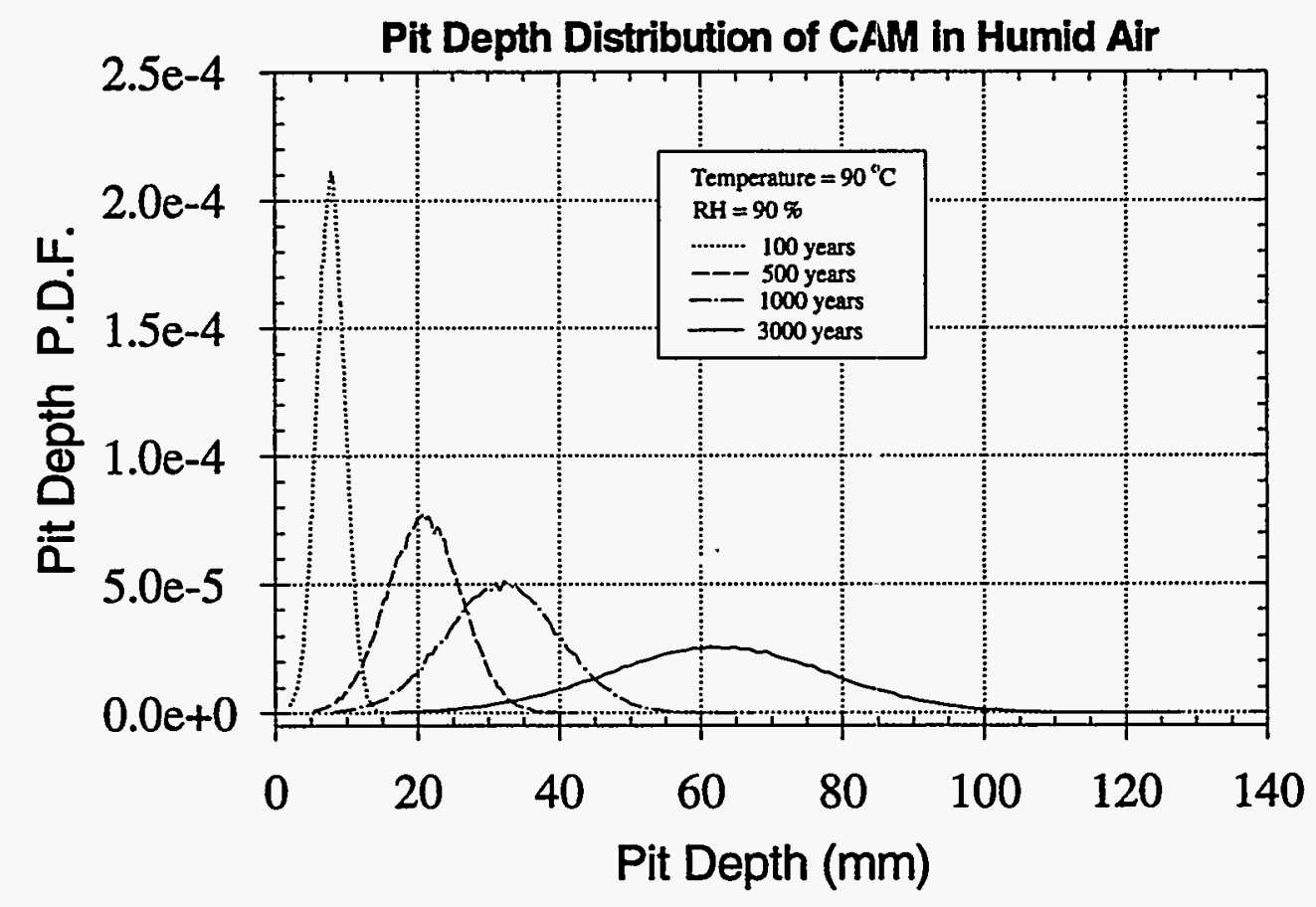

Figure 5.3-9b Model prediction of probability density functions (PDFs) of pit depth distribution of CAM in humid-air after different exposure times at $90^{\circ} \mathrm{C}$ and $90 \% \mathrm{RH}$. 


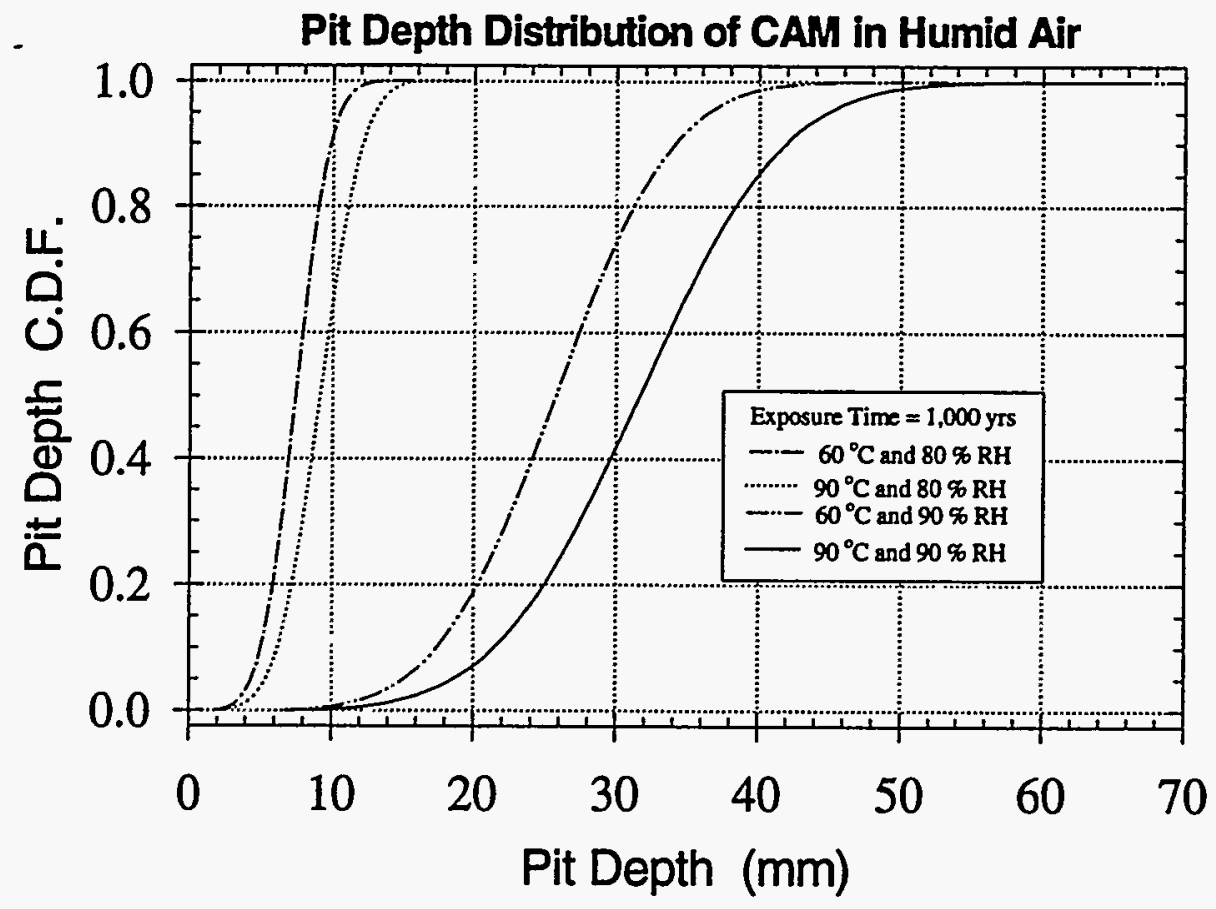

Figure 5.3-10a Model prediction of cumulative density functions (CDFs) of pit depth distribution of CAM in humid-air at different temperatures and humidities after 1,000-year exposure.

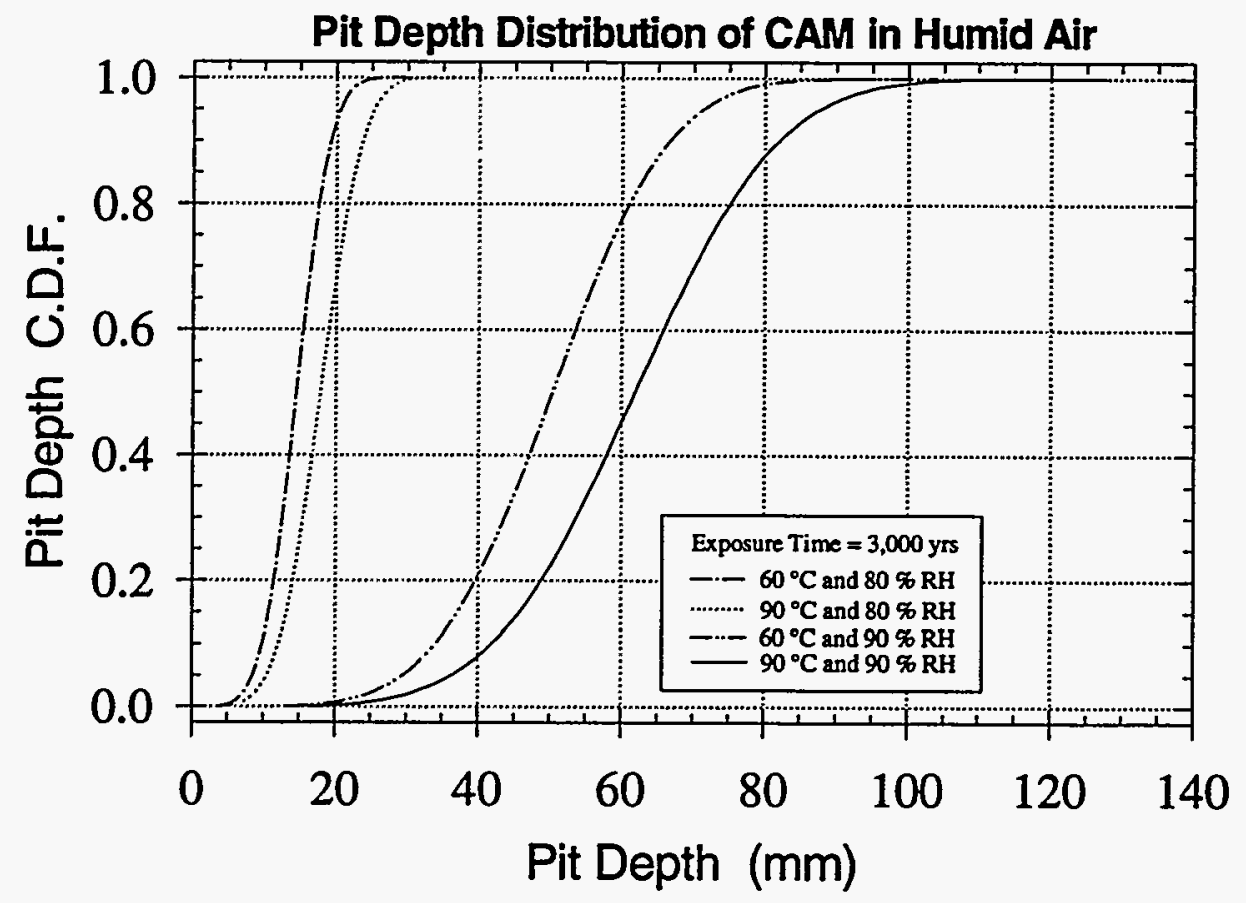

Figure 5.3-10b Model prediction of cumulative density functions (CDFs) of pit depth distribution of CAM in humid-air at different temperatures and humidities after 3,000-year exposure. 


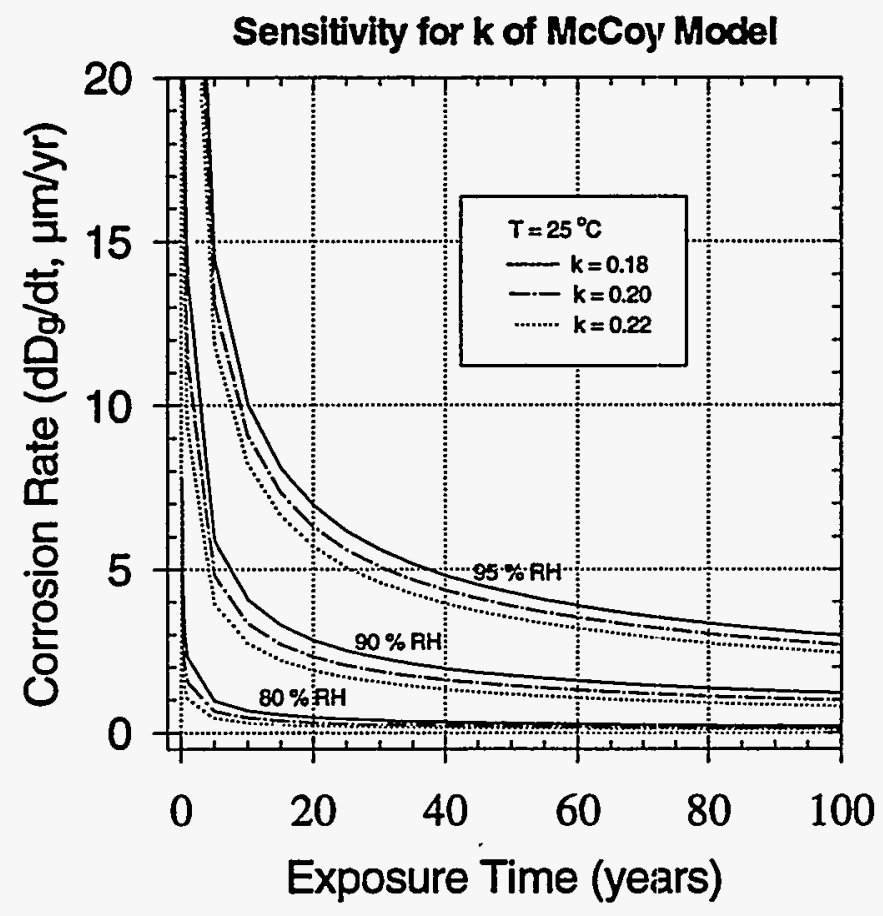

Figure 5.3-11 Sensitivity of constant $\mathrm{k}$ of the McCoy model in humid-air at $25^{\circ} \mathrm{C}$.

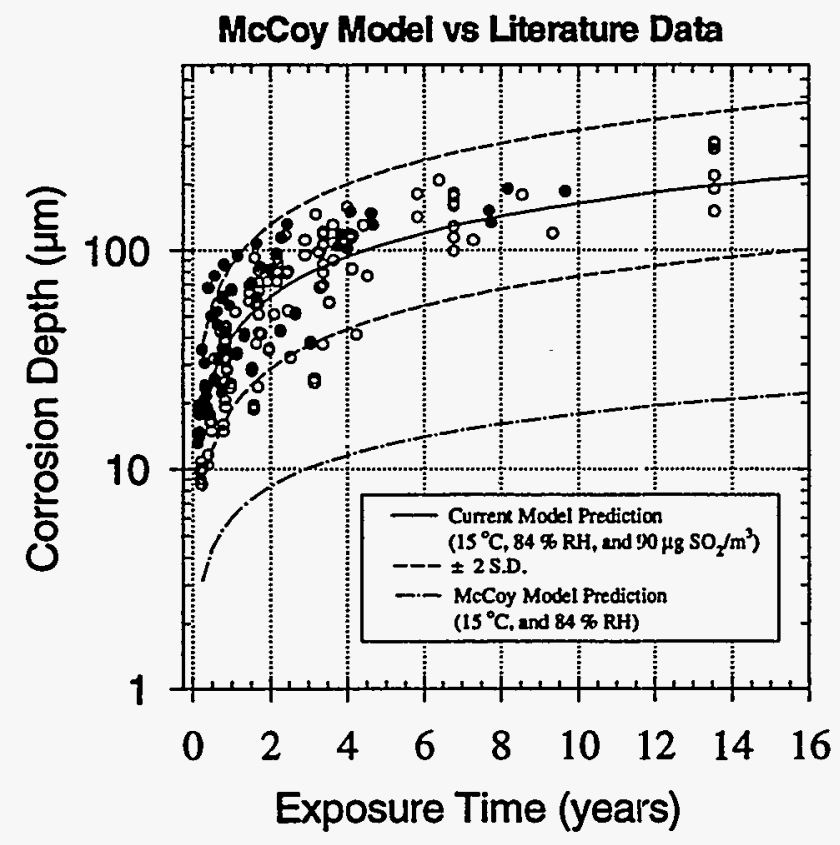

Figure 5.3-12 Comparison of the McCoy model prediction of general corrosion depth of CAM in humid-air with the atmospheric corrosion data from literature. 


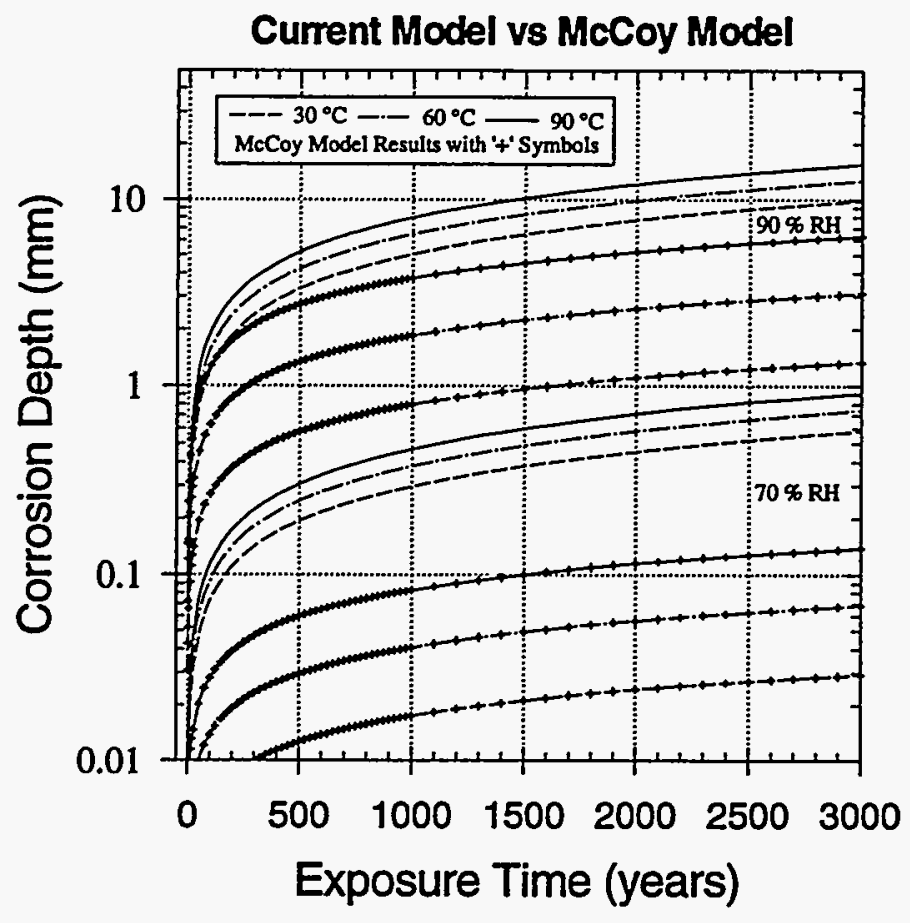

Figure 5.3-13 Comparison of the current model predictions for long-term general corrosion depth of CAM in humid-air with those of the McCoy model.

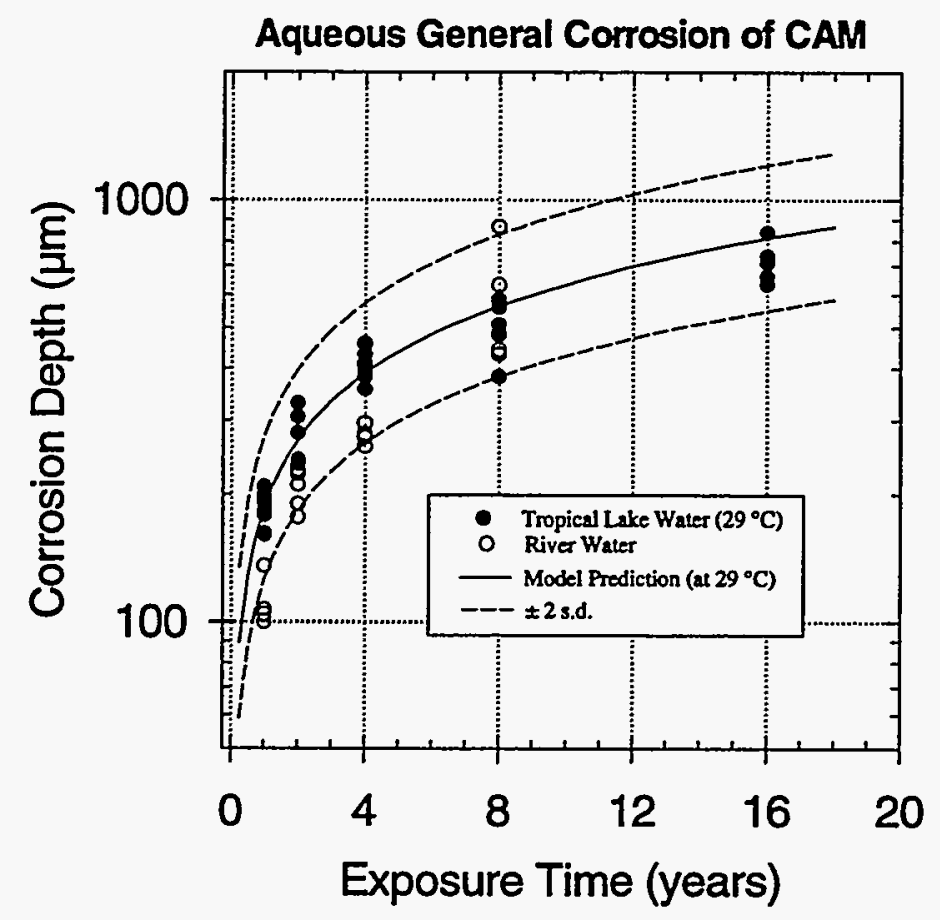

Figure 5.4-1 General corrosion data of CAM in tropical lake water and polluted river water, and the model prediction with the uncertainty. 


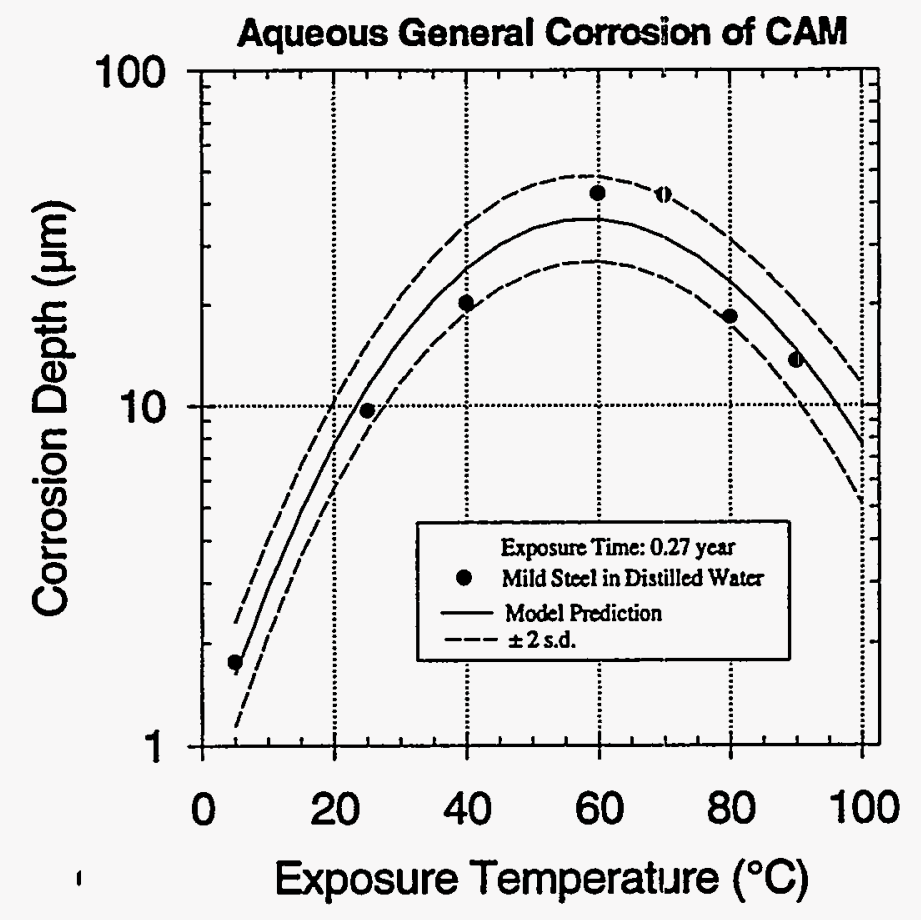

Figure 5.4-2 Temperature-dependent general corrosion data of mild steel in distilled water, and the model prediction with the uncertainty.

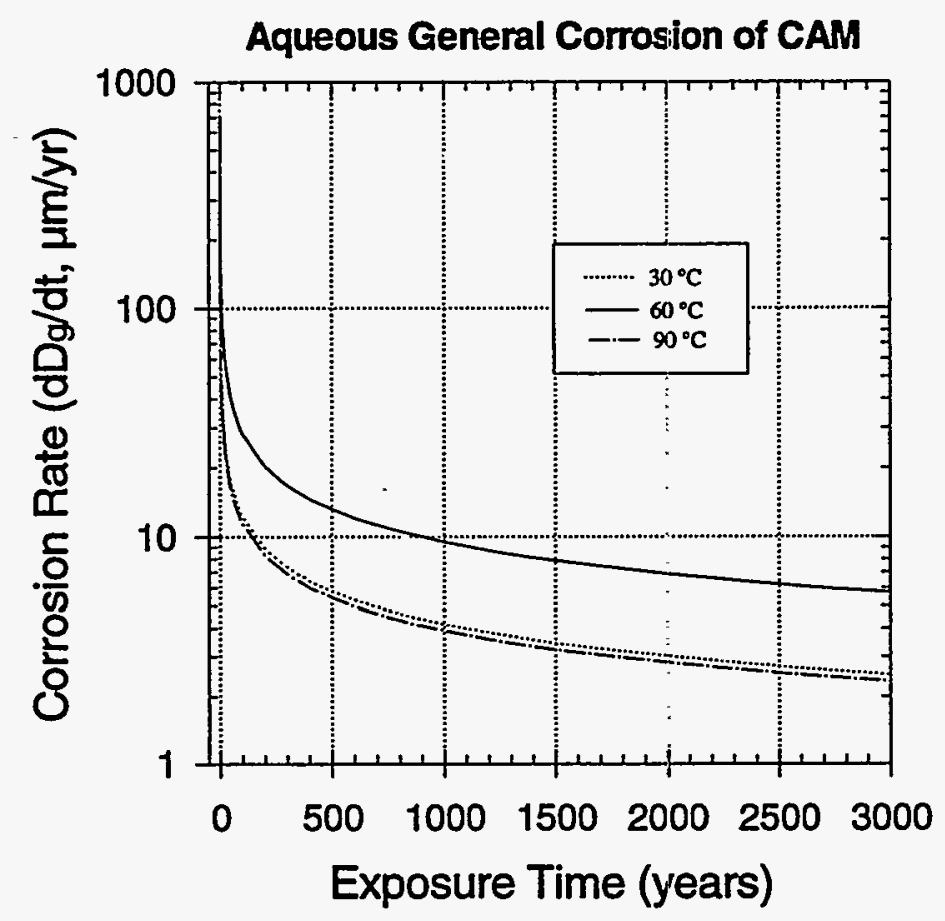

Figure 5.4-3 Model prediction of aqueous general corrosion rates as a function of exposure time at different temperatures. 


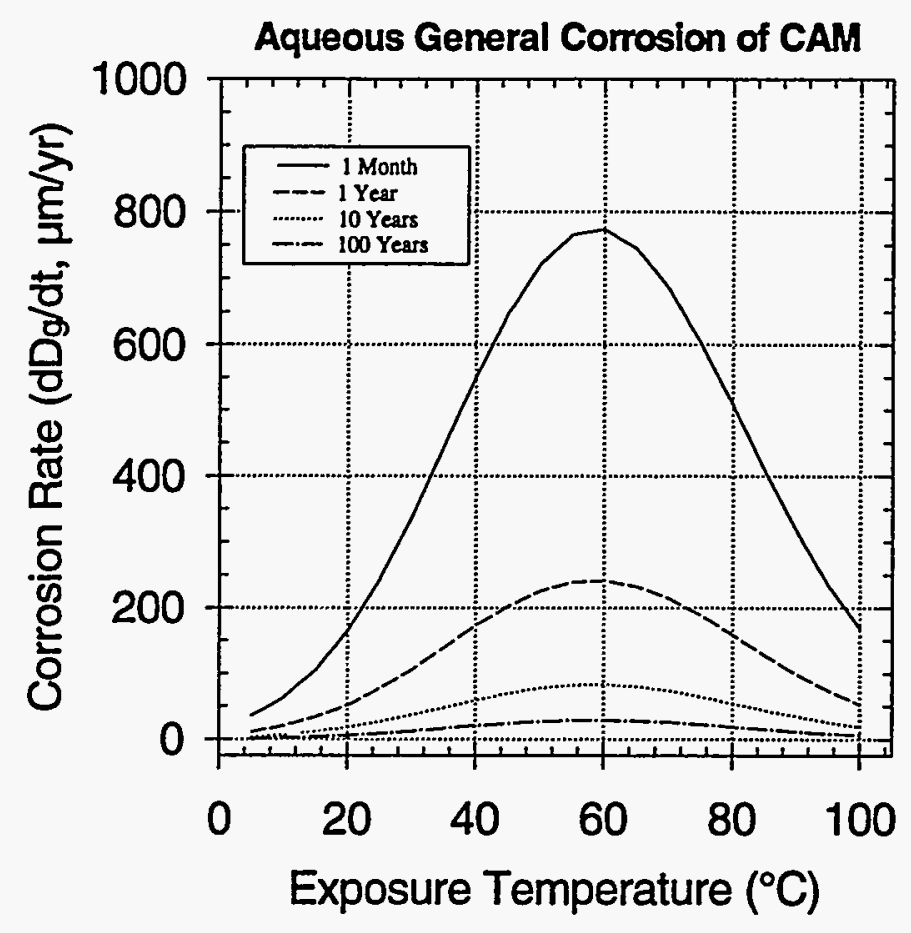

Figure 5.4-4 Model prediction of aqueous general corrosion rates as a function of temperature at different exposure times.

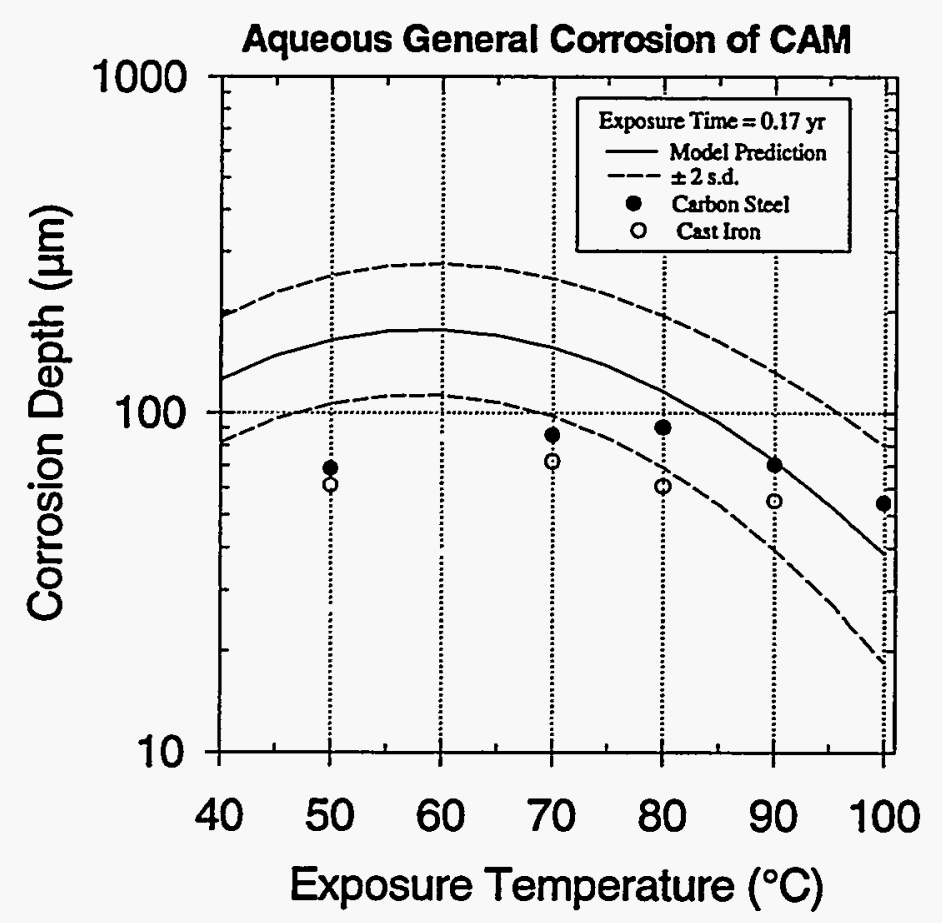

Figure 5.4-5 Comparison of model prediction of aqueous general corrosion of CAM at different temperatures with the data in J-13 water. The J-13 water data are from McCright and Weiss (1985). 


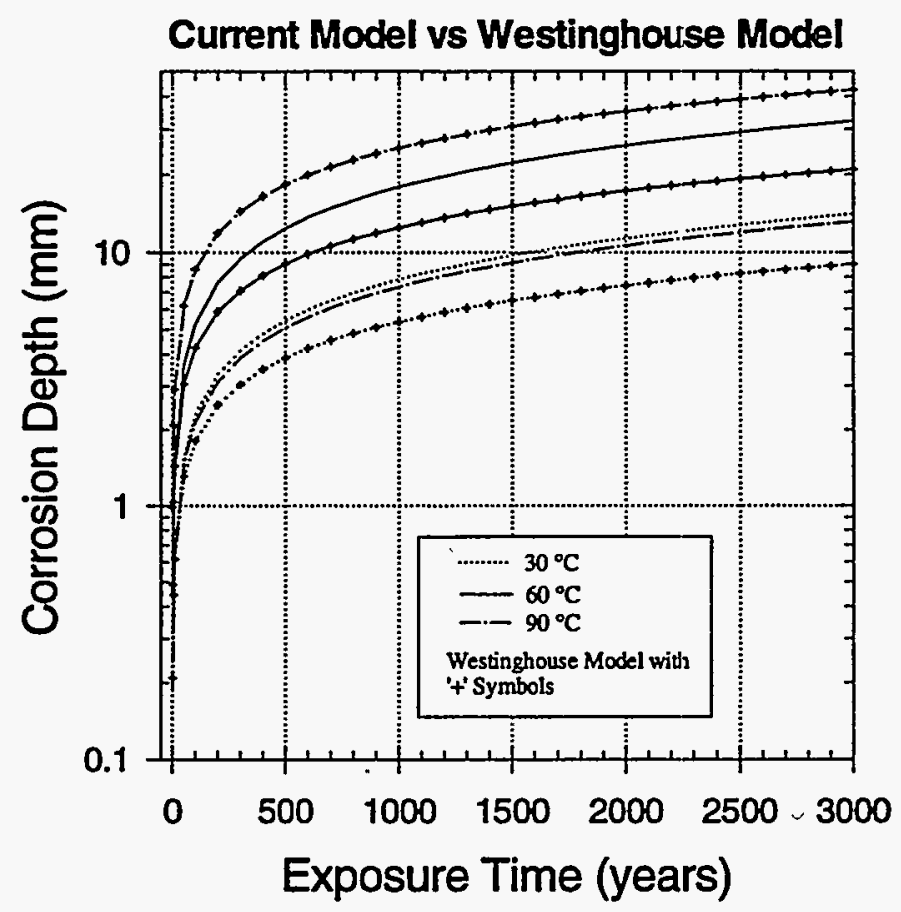

Figure 5.4-6 Comparison of the current model prediction of aqueous general corrosion of CAM with the Westinghouse model at different temperatures 


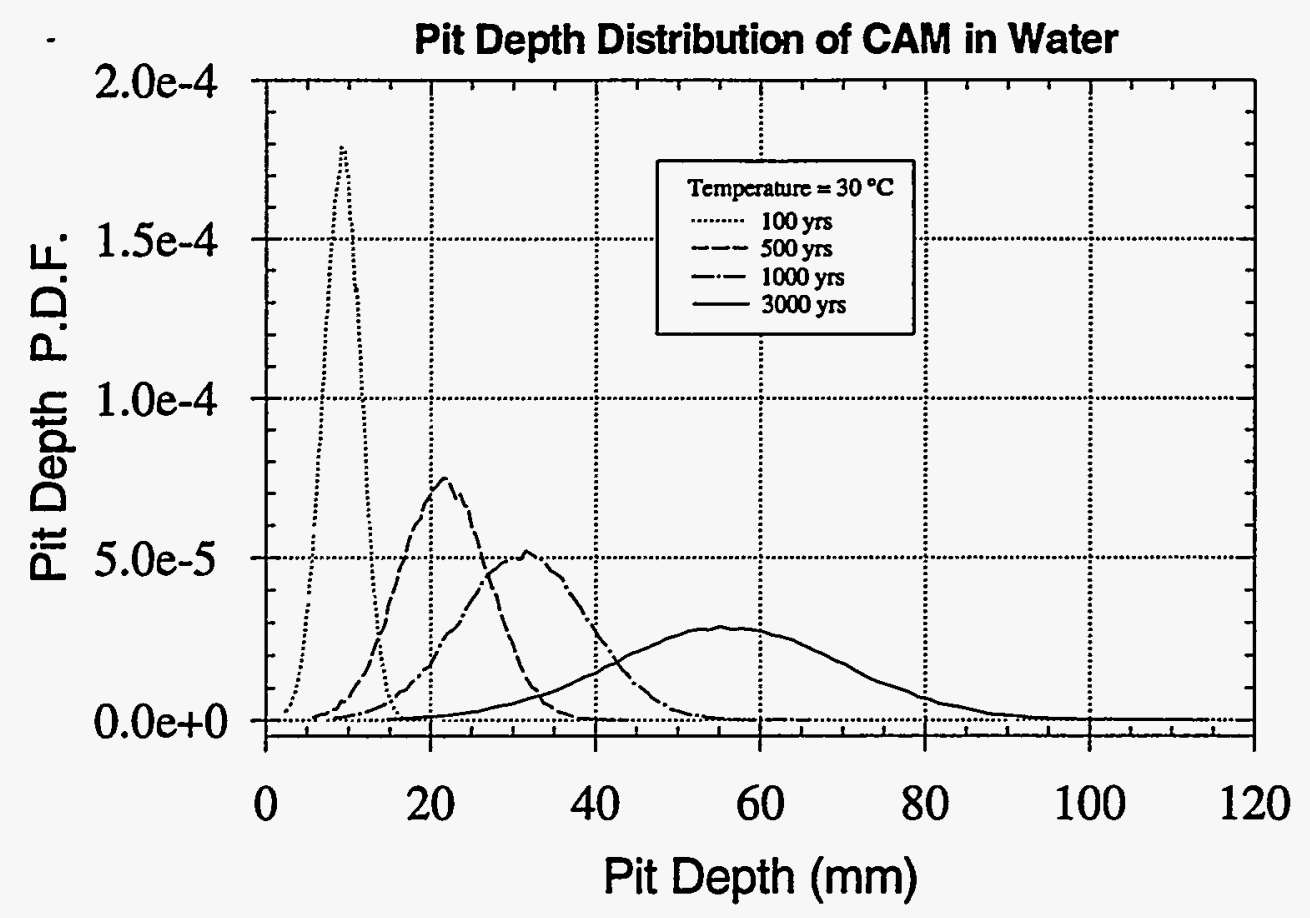

Figure 5.4-7a Model prediction of probability density functions (PDFs) of pit depth distribution of CAM in aqueous condition after different exposure times at 30 ${ }^{\circ} \mathrm{C}$.

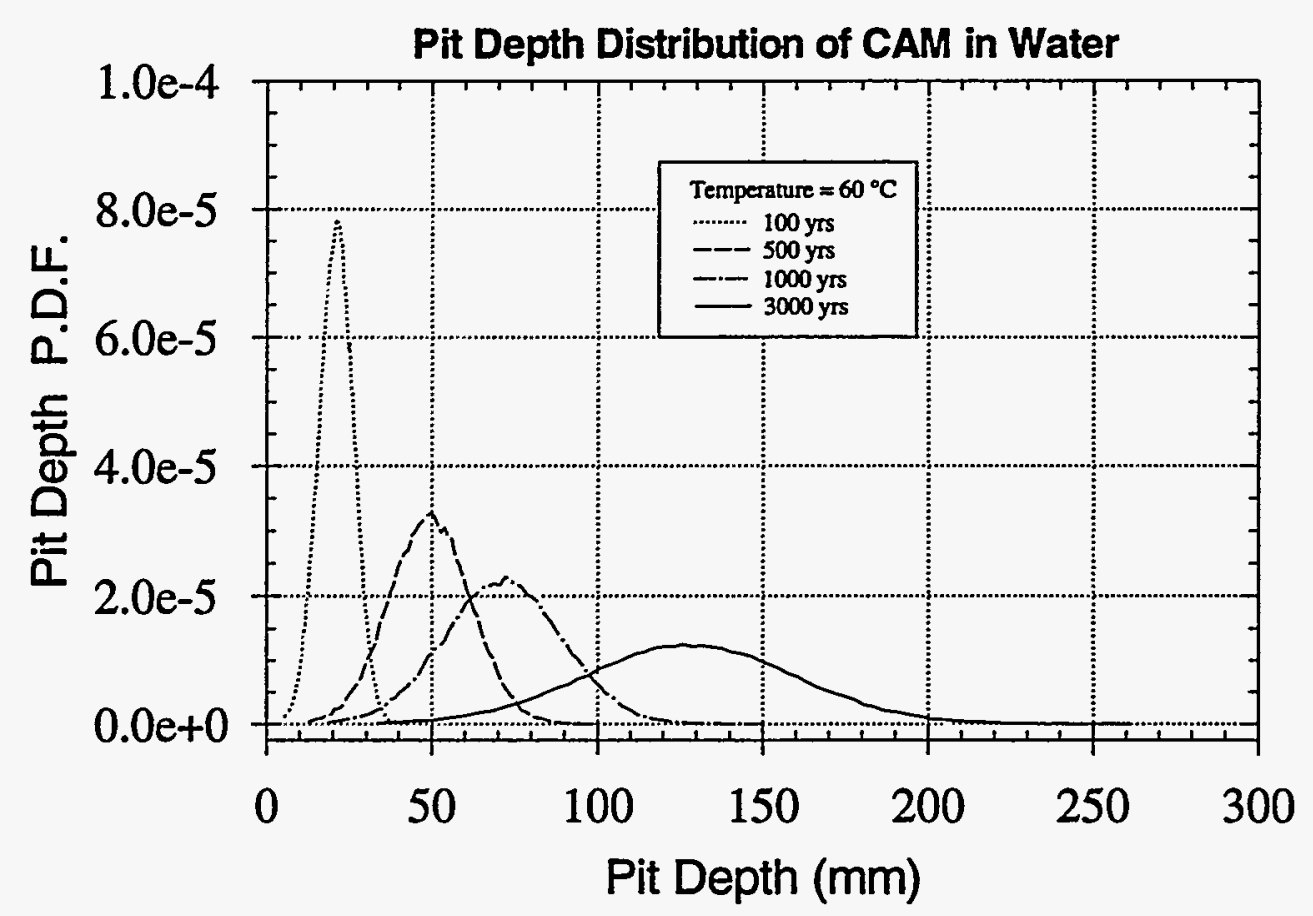

Figure 5.4-7b Model prediction of probability density functions (PDFs) of pit depth distribution of CAM in aqueous condition after different exposure times at 60 ${ }^{\circ} \mathrm{C}$. 


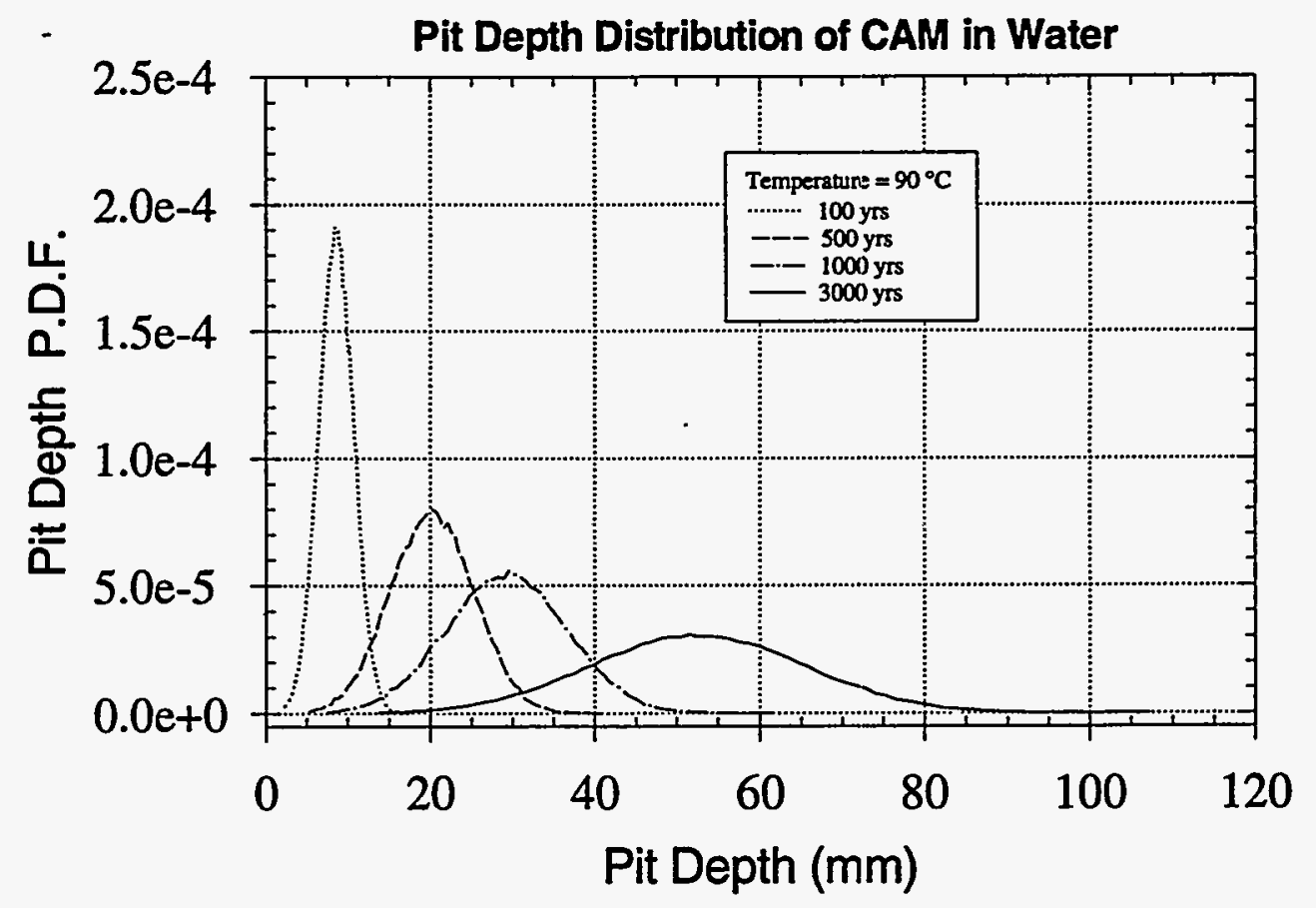

Figure 5.4-7c Model prediction of probability density functions (PDFs) of pit depth distribution of CAM in aqueous condition after different exposure times at 90 ${ }^{\circ} \mathrm{C}$.

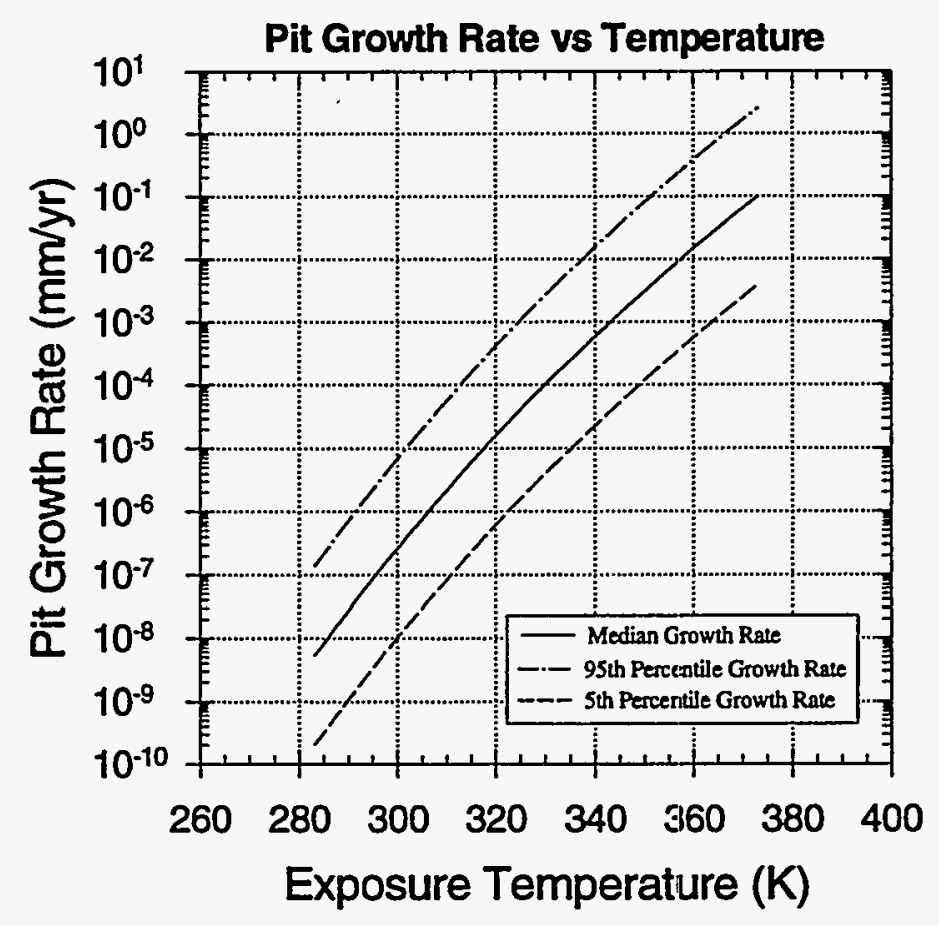

Figure 5.5-1 Elicitation for the distribution of 'constant' pit growth rate in Alloy 825 inner barrier as a function of temperature. 


\section{Stochastic Waste Package Performance Simulation Model}

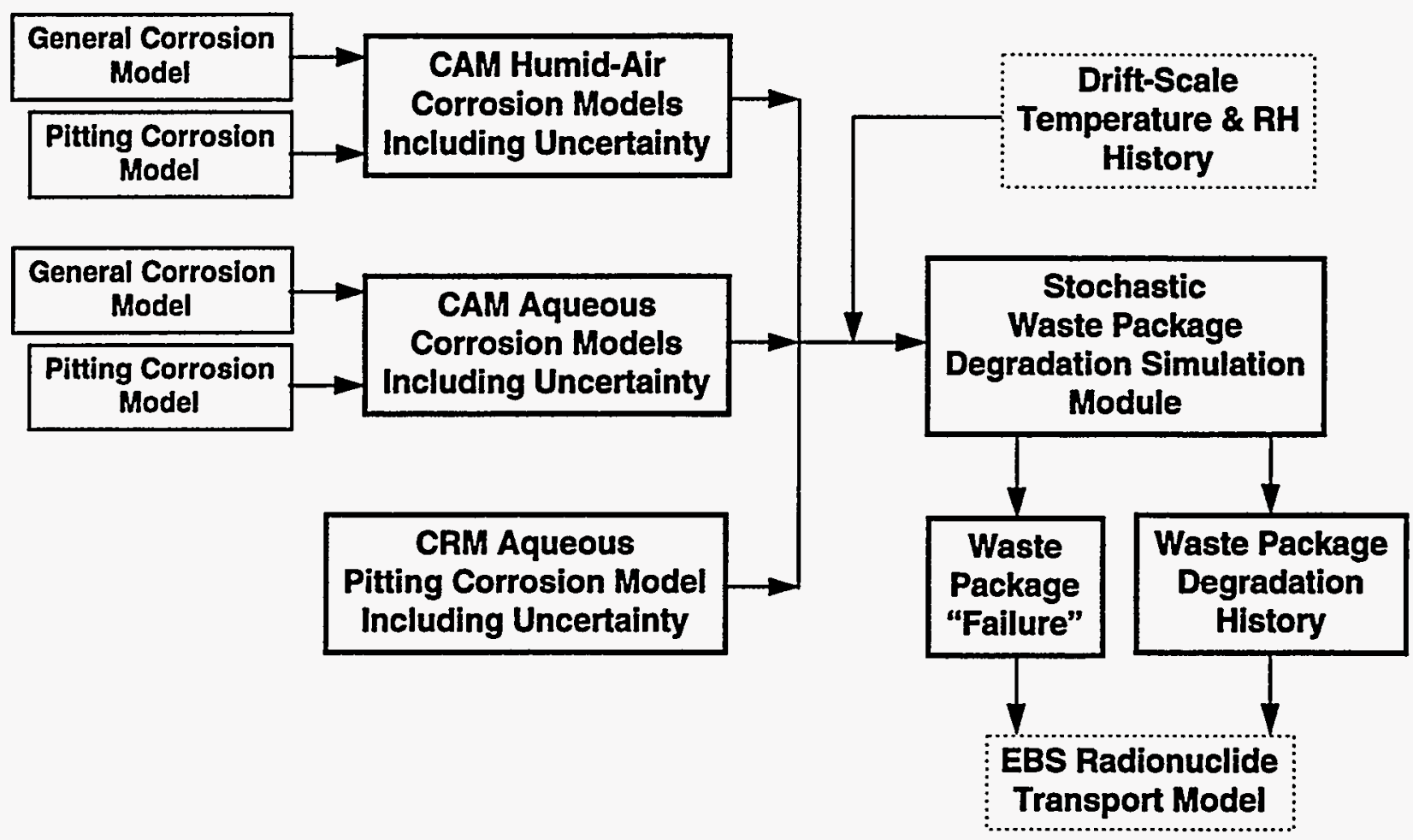

Figure 5.7-1 An overview of the stochastic waste package performance simulation model developed for TSPA-1995. 


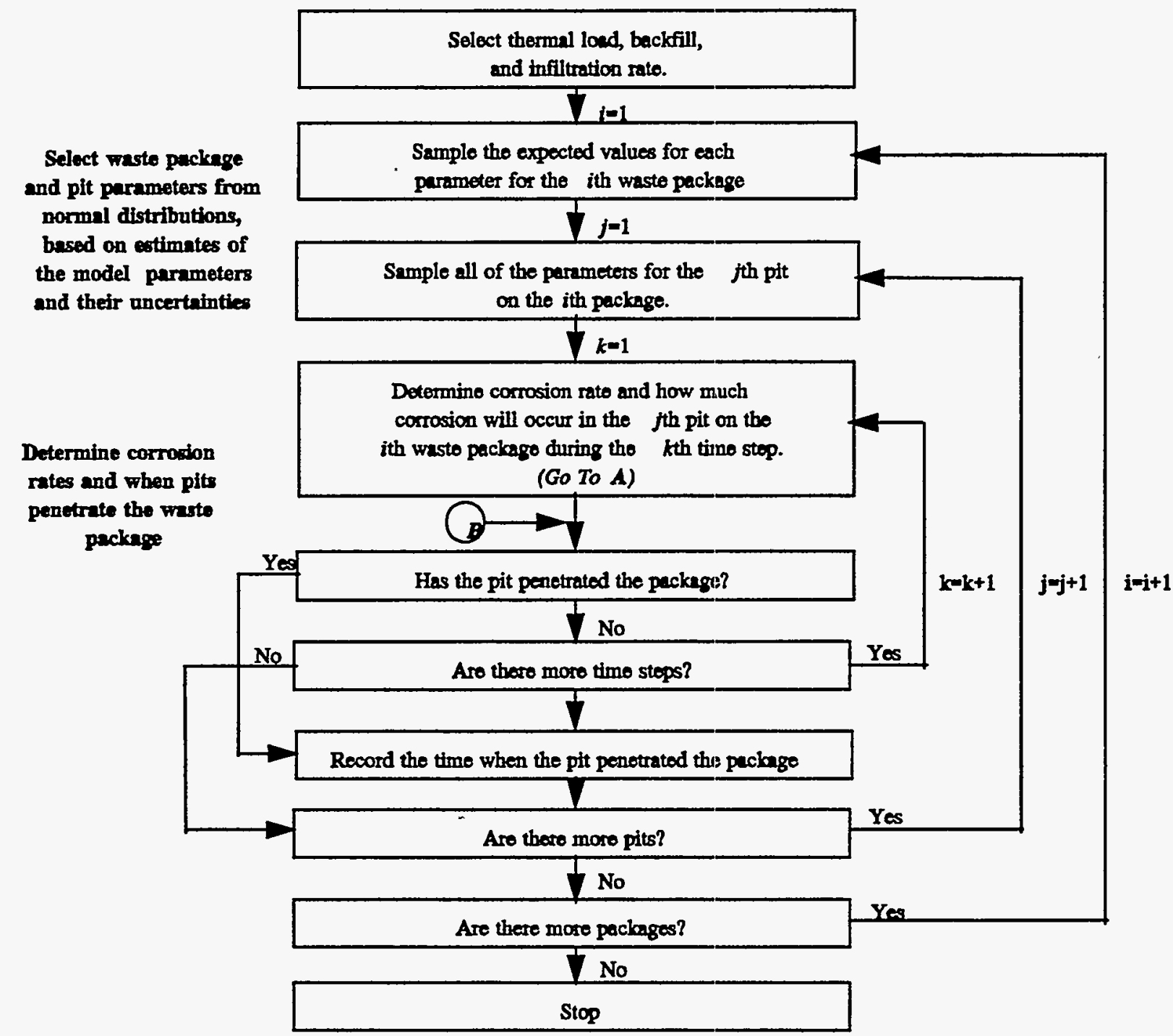

Figure 5.7-2a Flowchart of the stochastic waste package performance simulation model developed for TSPA-1995. 


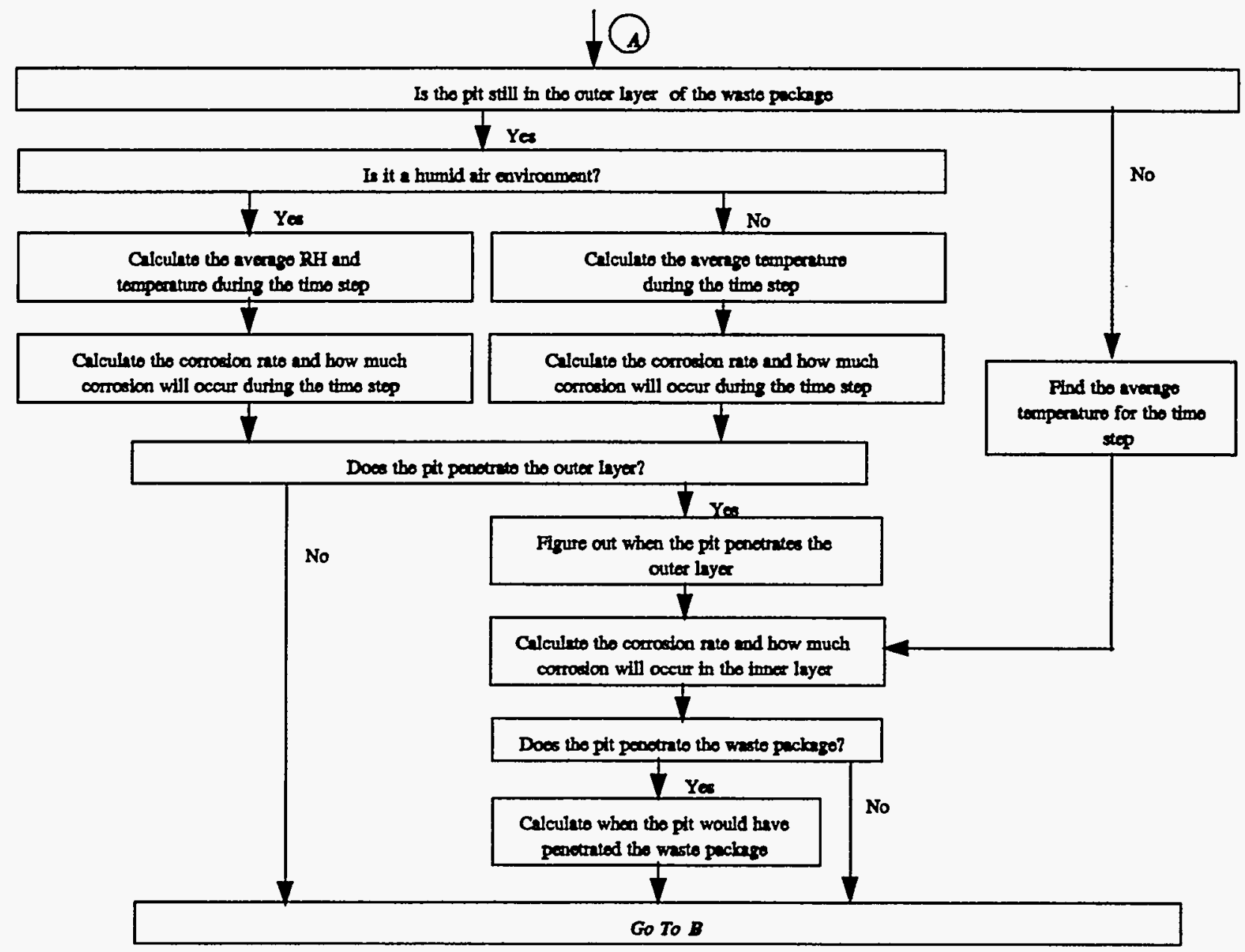

Figure 5.7-2b Flowchart of the stochastic waste package performansimulation model developed for TSPA-1995 (continued). 
RH \& T Switch; 83 MTU/acre; No Backfill; Low Infiltration

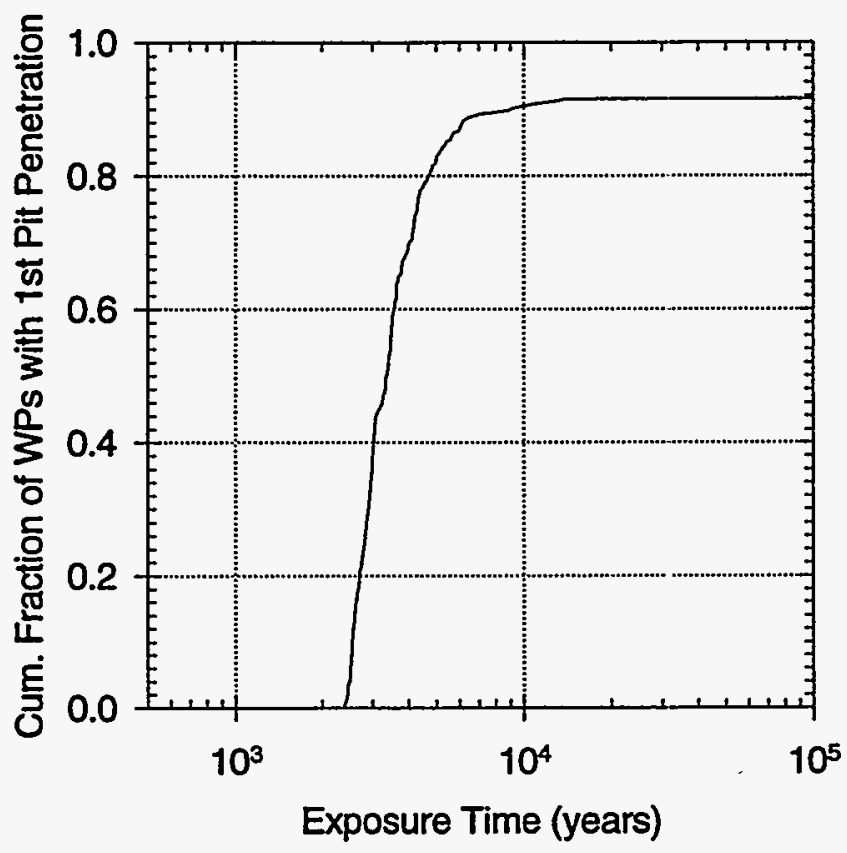

Figure 5.7-3a Waste package failure history for the case of $83 \mathrm{MTU} / \mathrm{acre}$, low infiltration, and without backfill, using RH and temperature switch for corrosion initiation.

RH \& T Switch; 83 MTU/acre; No Backfill; Low Infiltration

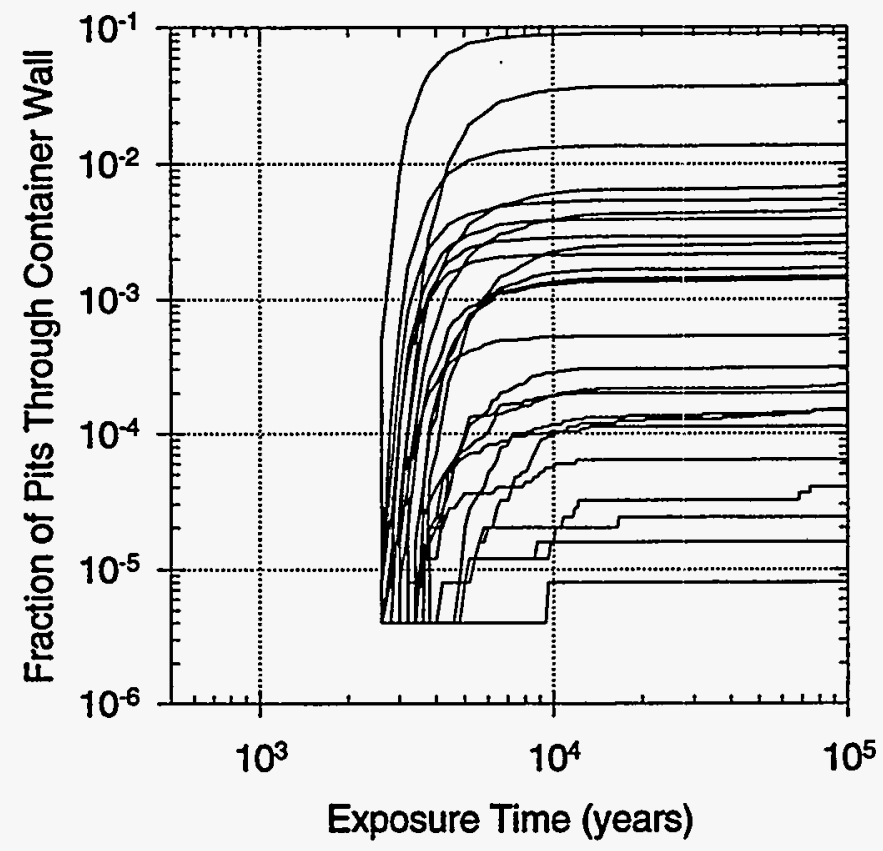

Figure 5.7-3b Representative pitting histories for 25 waste packages for the case of 83 MTU/acre, low infiltration, and without backfill, using $\mathrm{RH}$ and temperature switch for corrosion initiation. 
RH \& T Switch; 83 MTU/acre; No Backfill; Low Infiltration

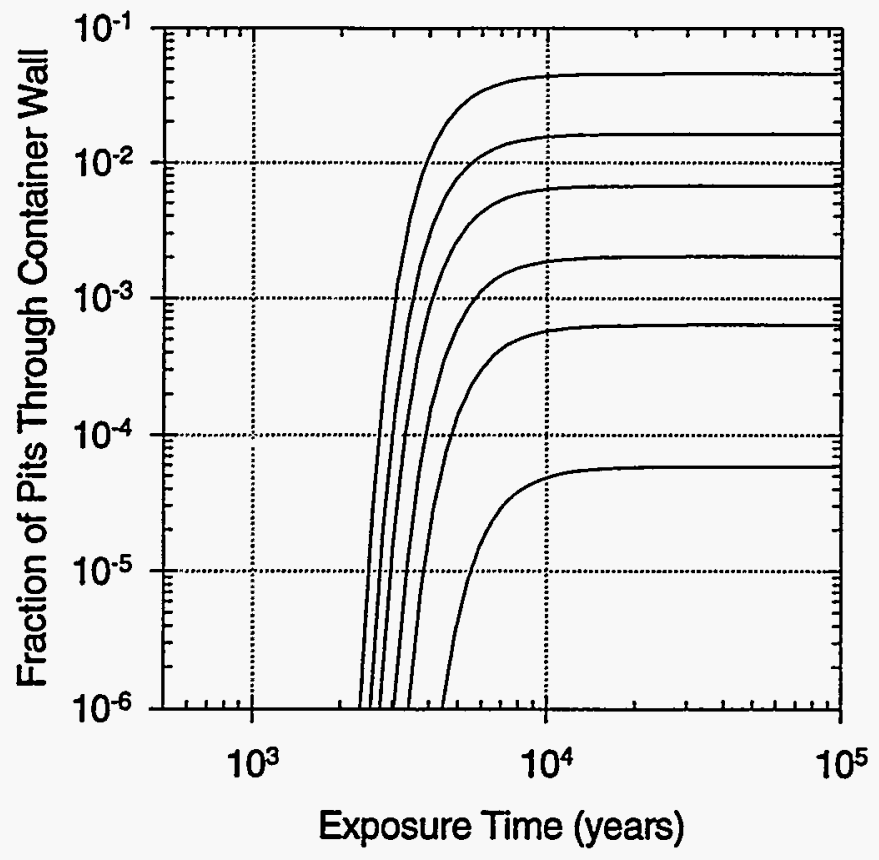

Figure 5.7-3c Abstractions for the RIP implementation for the case of 83 MTU/acre, low infiltration, and without backfill, using RH and temperature switch for corrosion initiation.

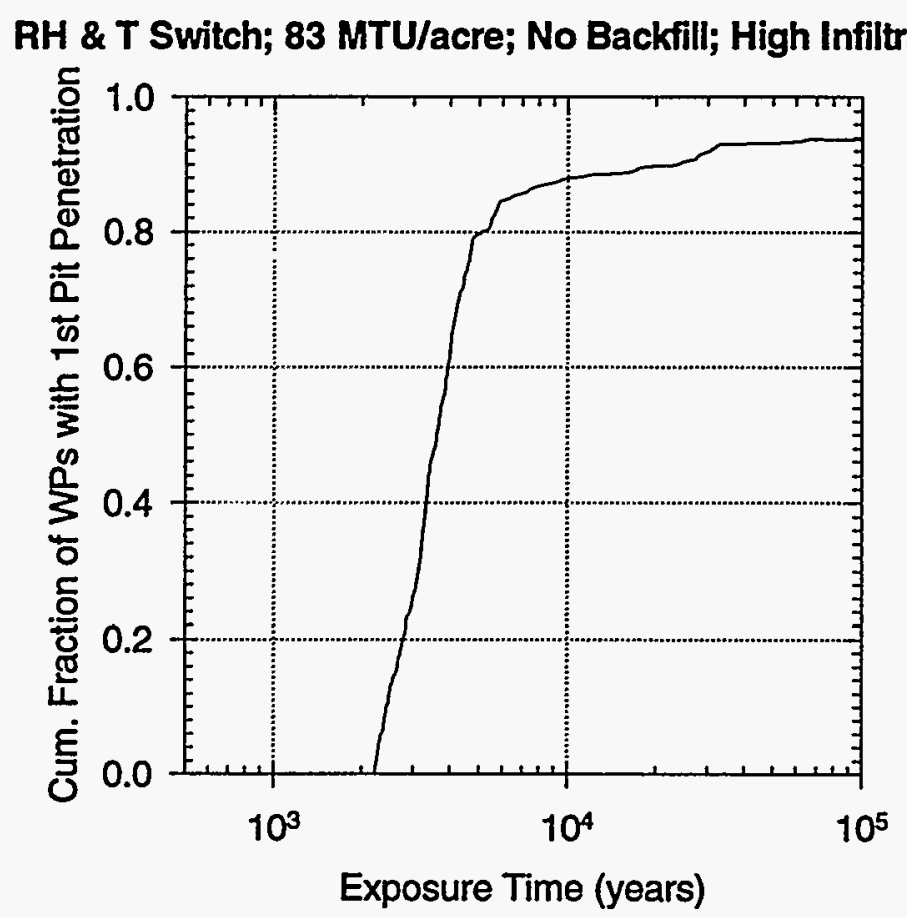

Figure 5.7-4a Waste package failure history for the case of $83 \mathrm{MTU} / \mathrm{acre}$, high infiltration, and without backfill, using $\mathrm{RH}$ and temperature switch for corrosion initiation. 
RH \& T Switch; 83 MTU/acre; No Backfill; High Infiltration

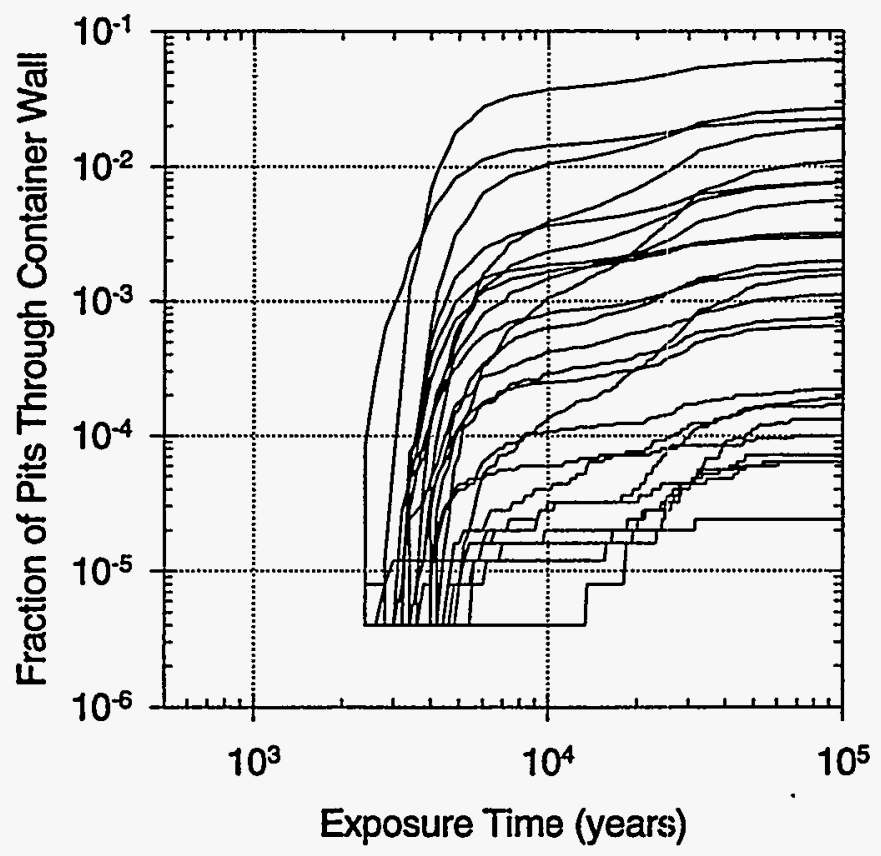

Figure 5.7-4b Representative pitting histories for 25 waste packages for the case of 83 MTU/acre, high infiltration, and without backfill, using RH and temperature switch for corrosion initiation.

RH and T Switch; 83 MTU/acre; No Backfill; High Infiltration

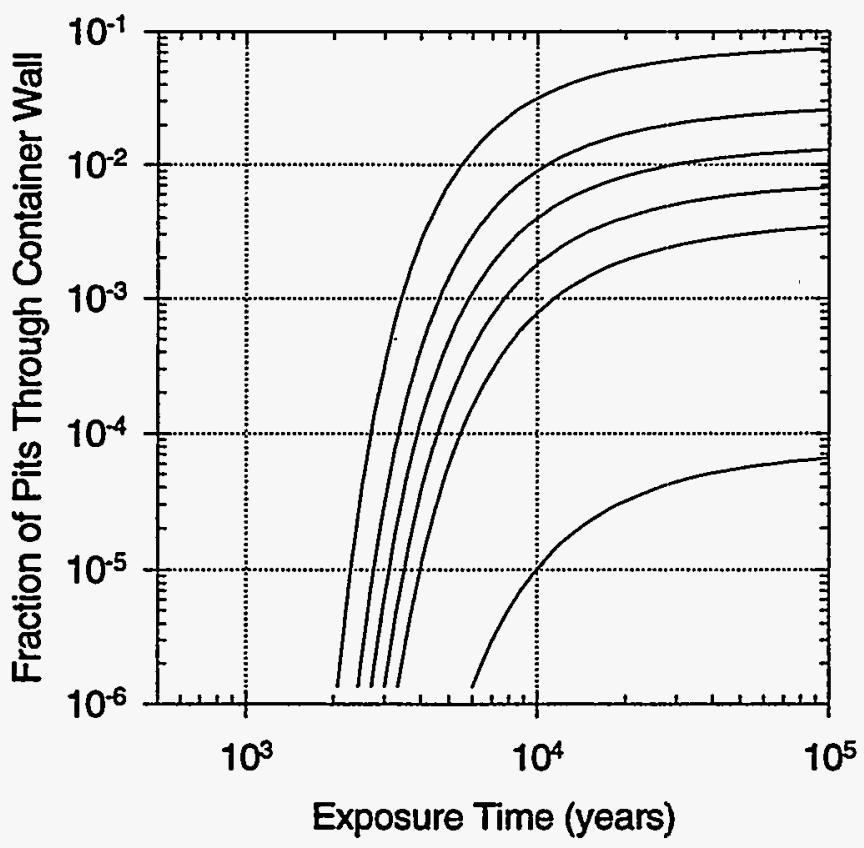

Figure 5.7-4c Abstractions for the RIP implementation for the case of $83 \mathrm{MTU} / \mathrm{acre}$, high infiltration, and without backfill, using RH and temperature switch for corrosion initiation. 
RH \& T Switch; 83 MTU/acre; Backfill; Low Infiltration

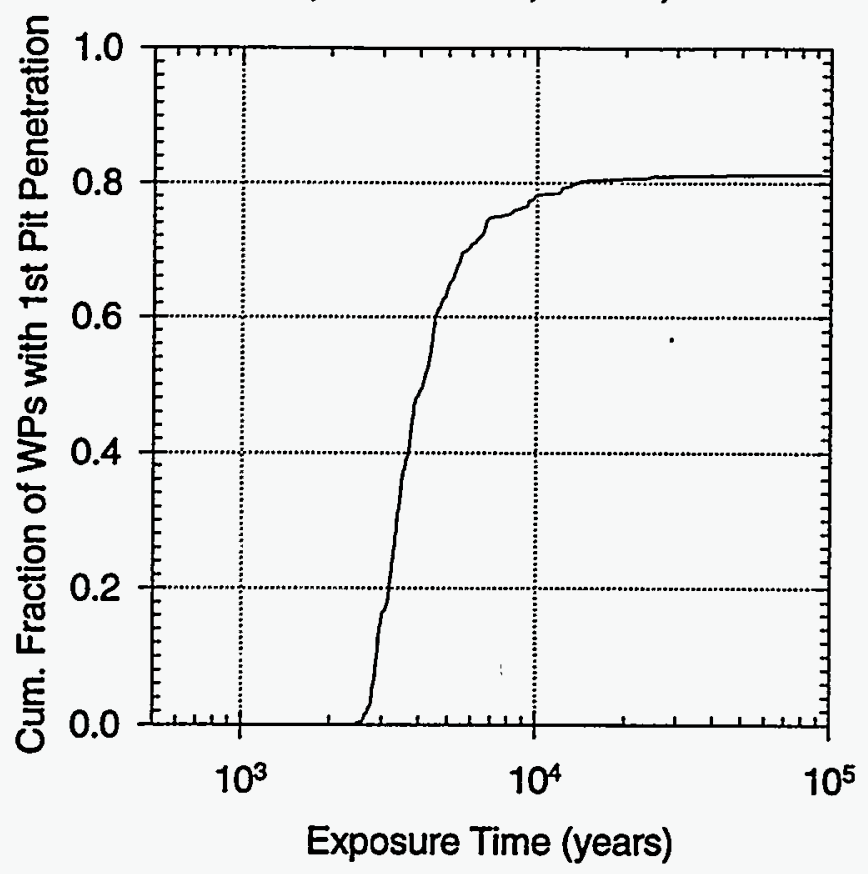

Figure 5.7-5a Waste package failure history for the case of $83 \mathrm{MTU} / \mathrm{acre}$, low infiltration, and with backfill, using RH and temperature switch for corrosion initiation.

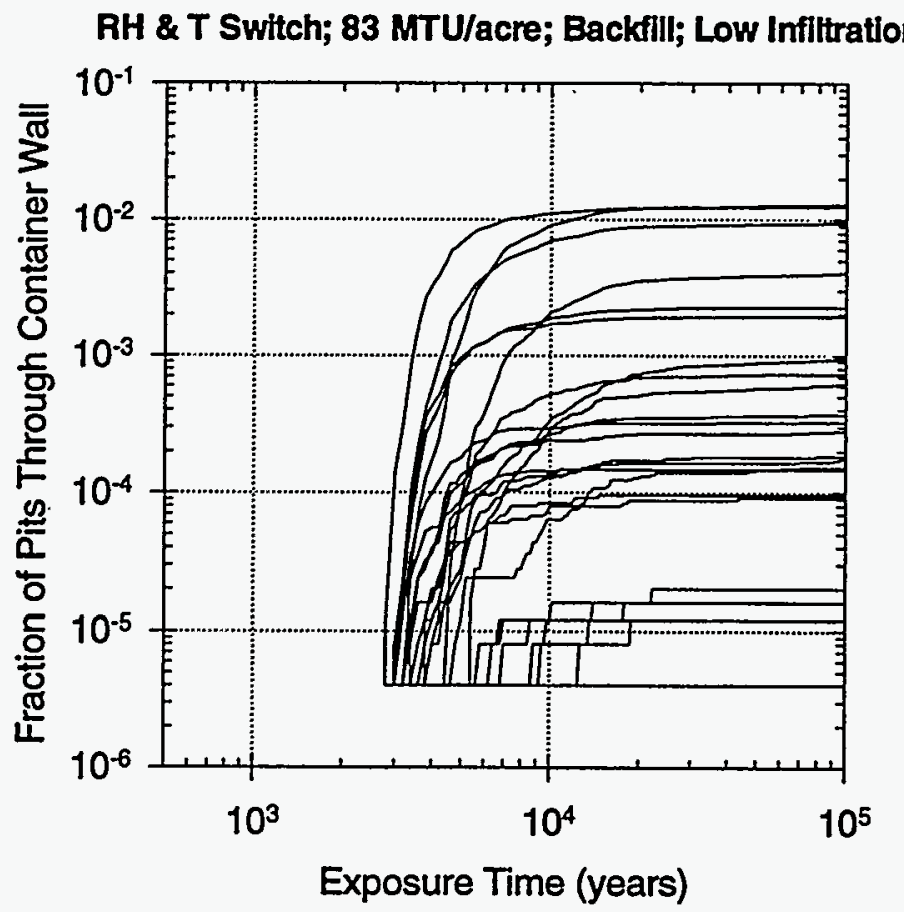

Figure 5.7-5b Representative pitting histories for 25 waste packages for the case of 83 MTU/acre, low infiltration, and with backfill, using RH and temperature switch for corrosion initiation. 


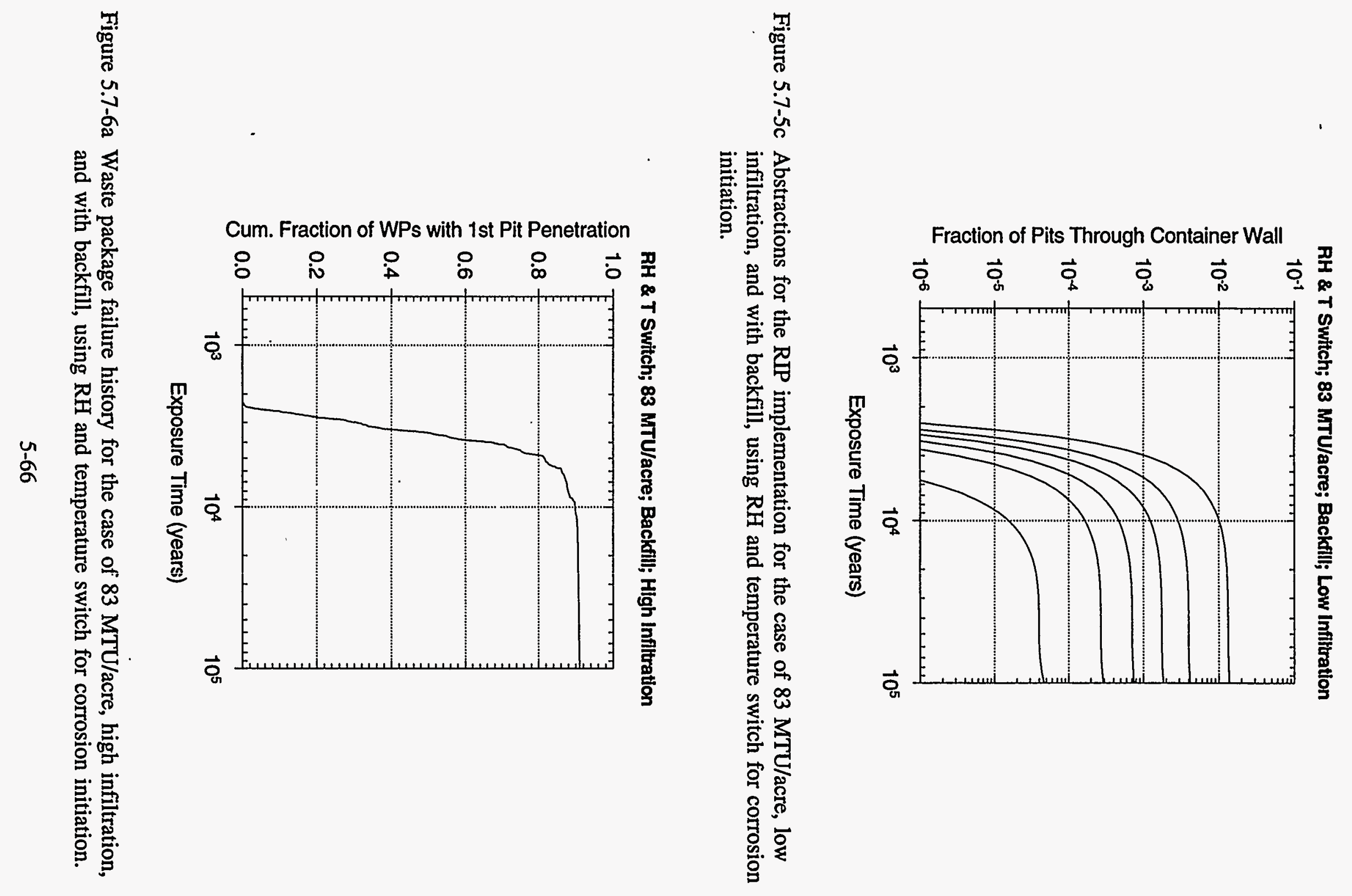


RH \& T Switch; 83 MTU/acre; Backflli; High Infiltration

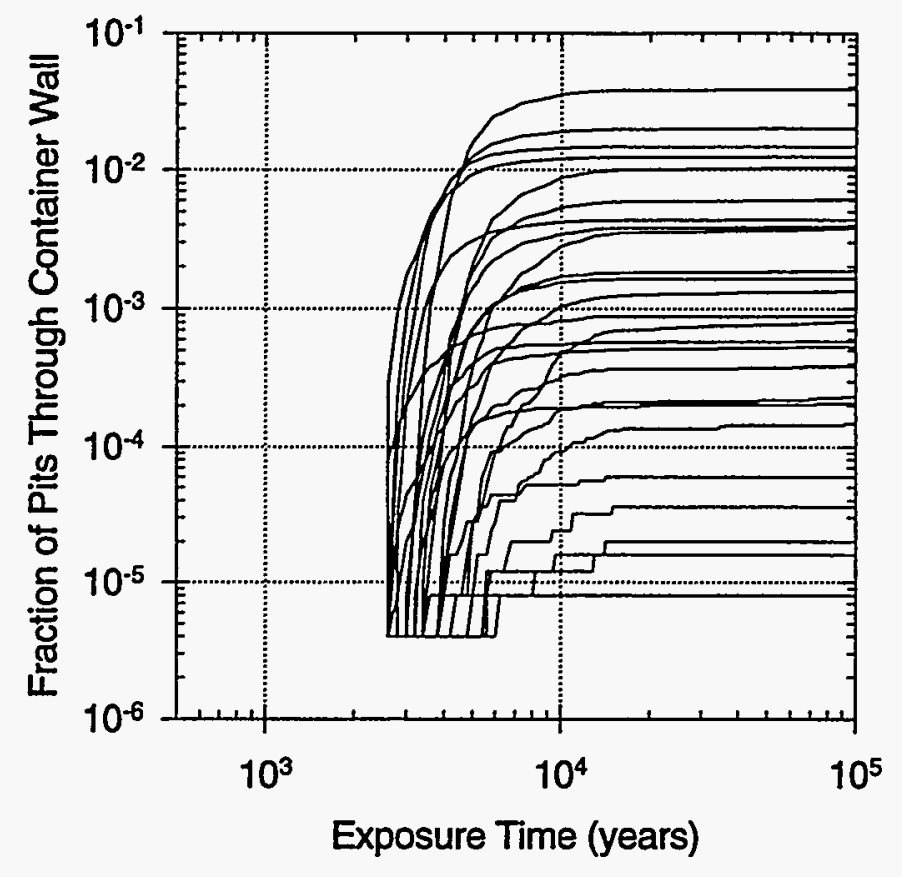

Figure 5.7-6b Representative pitting histories for 25 waste packages for the case of 83 MTU/acre, high infiltration, and with backfill, using RH and temperature switch for corrocion initiation

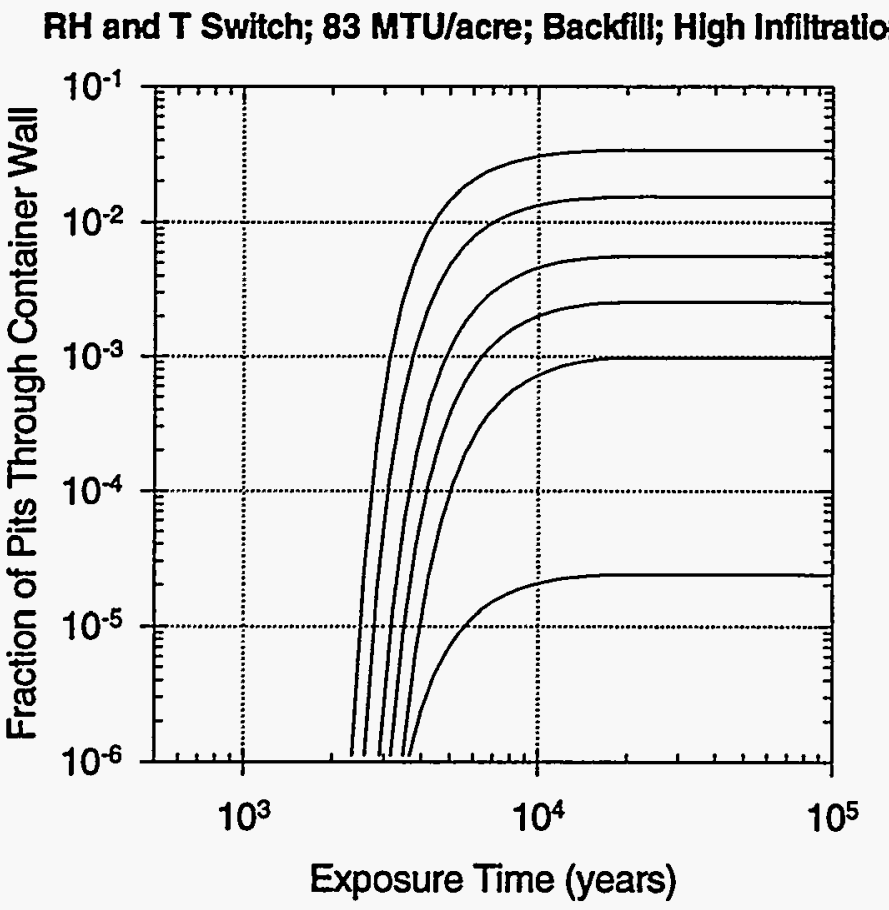

Figure 5.7-6c Abstractions for the RIP implementation for the case of 83 MTU/acre, high infiltration, and with backfill, using $\mathrm{RH}$ and temperature switch for corrosion initiation. 


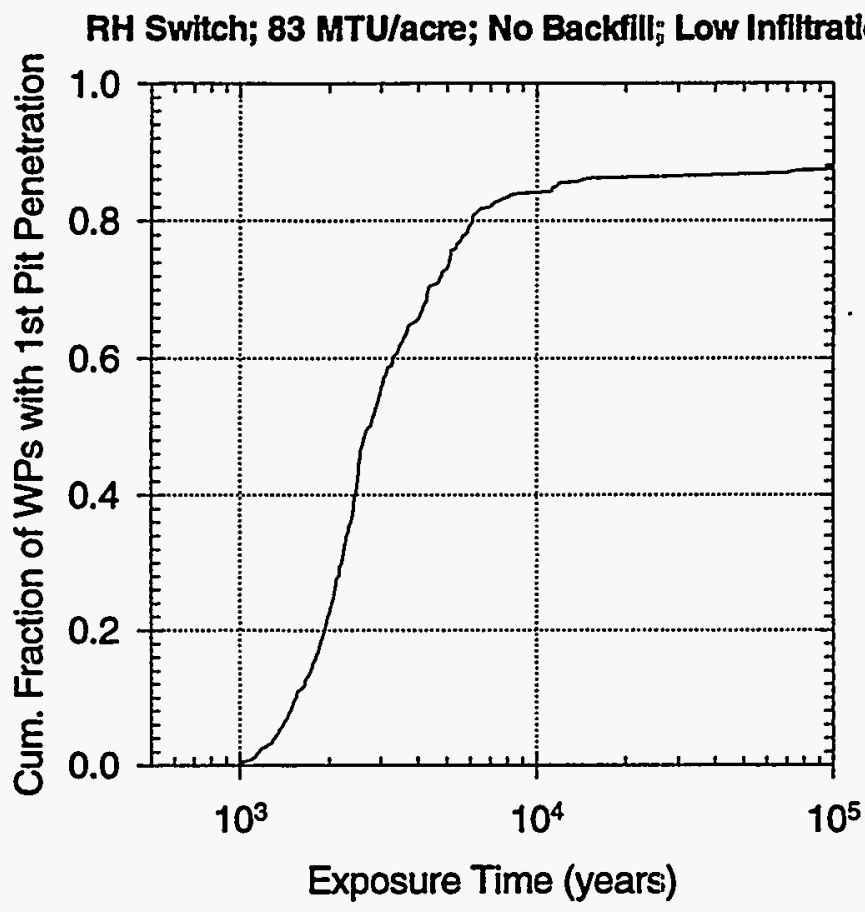

Figure 5.7-7a Waste package failure history for the case of $83 \mathrm{MTU} / \mathrm{acre}$, low infiltration, and without backfill, using RH switch for corrosion initiation.

\section{RH Switch; 83 MTU/acre; No Backfill; Low Infiltration}

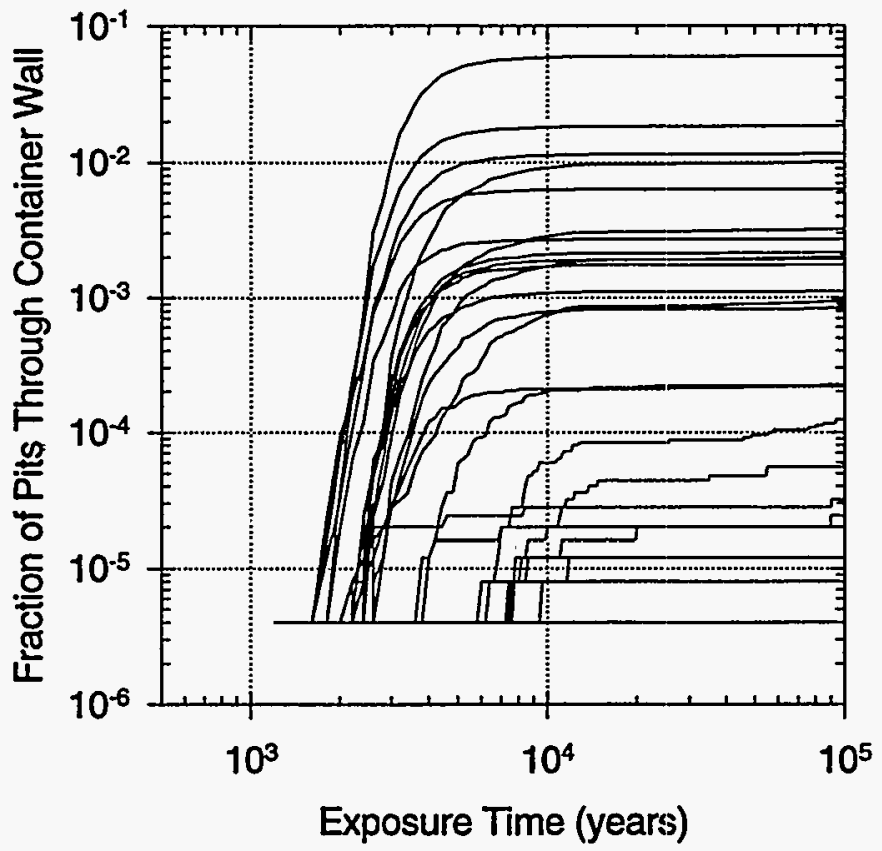

Figure 5.7-7b Representative pitting histories for 25 waste packages for the case of 83 MTU/acre, low infiltration, and without backfill, using RH switch for corrosion initiation. 
RH Switch; 83 MTU/acre; No Backfill; Low Infiltration

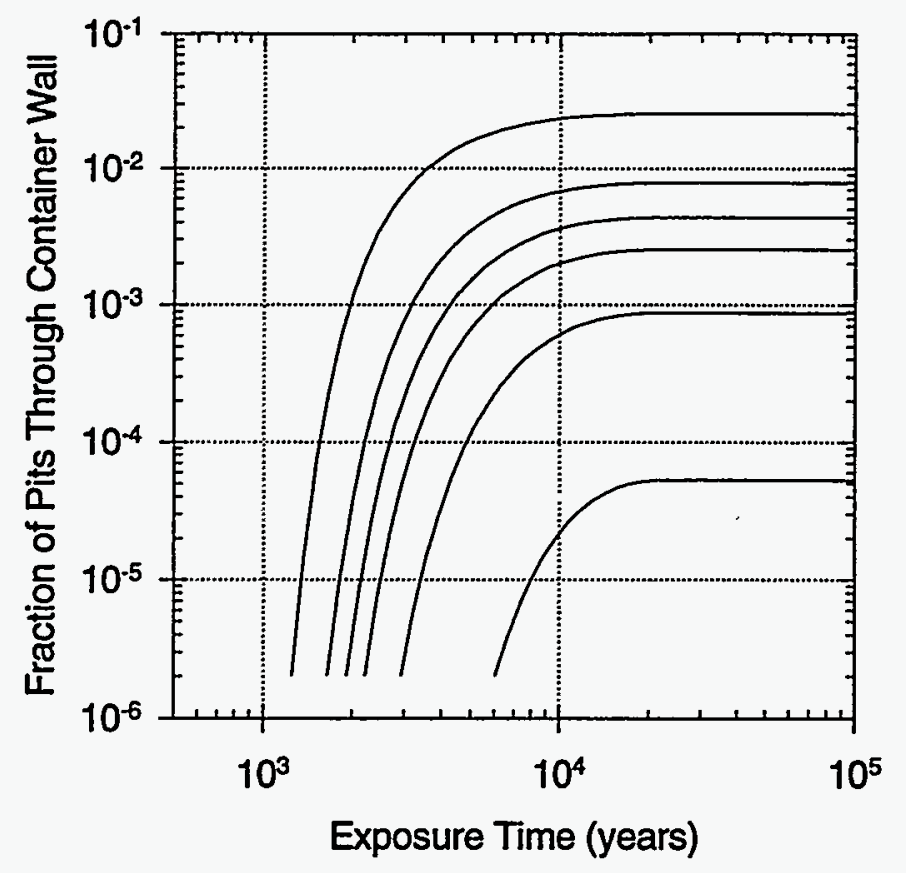

Figure 5.7-7c Abstractions for the RIP implementation for the case of 83 MTU/acre, low infiltration, and without backfill, using RH switch for corrosion initiation.

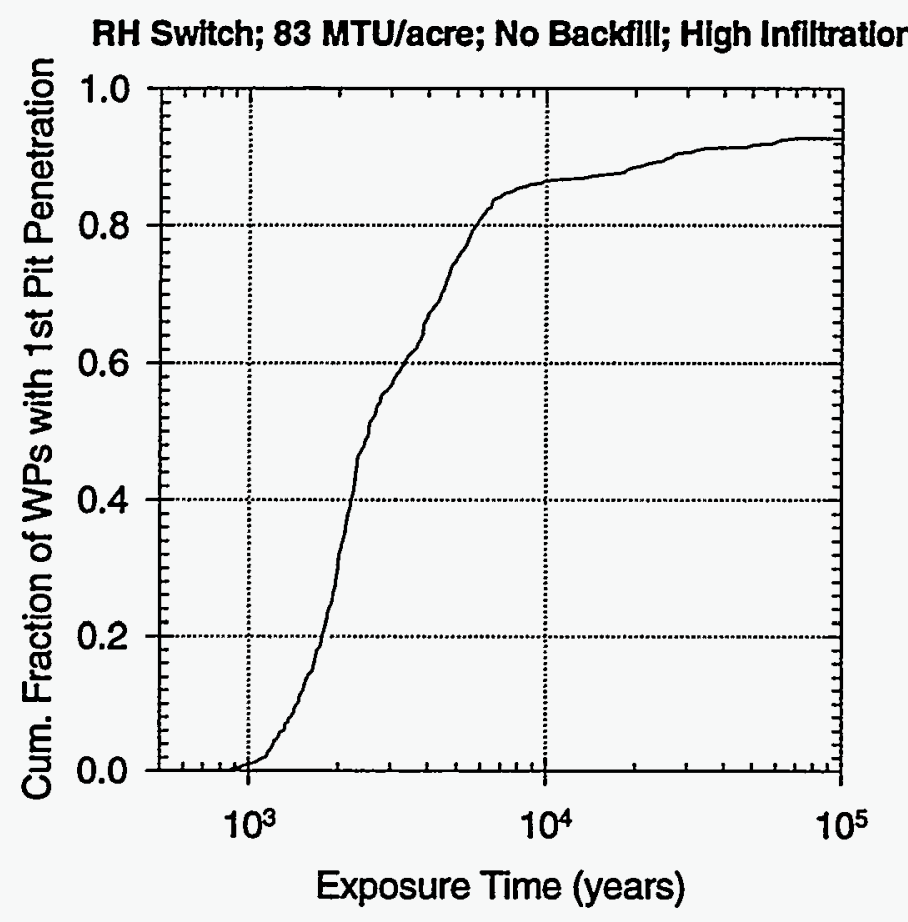

Figure 5.7-8a Waste package failure history for the case of 83 MTU/acre, high infiltration, and without backfill, using RH switch for corrosion initiation. 
RH Switch; 83 MTU/acre; No Backfll; High Infiltration

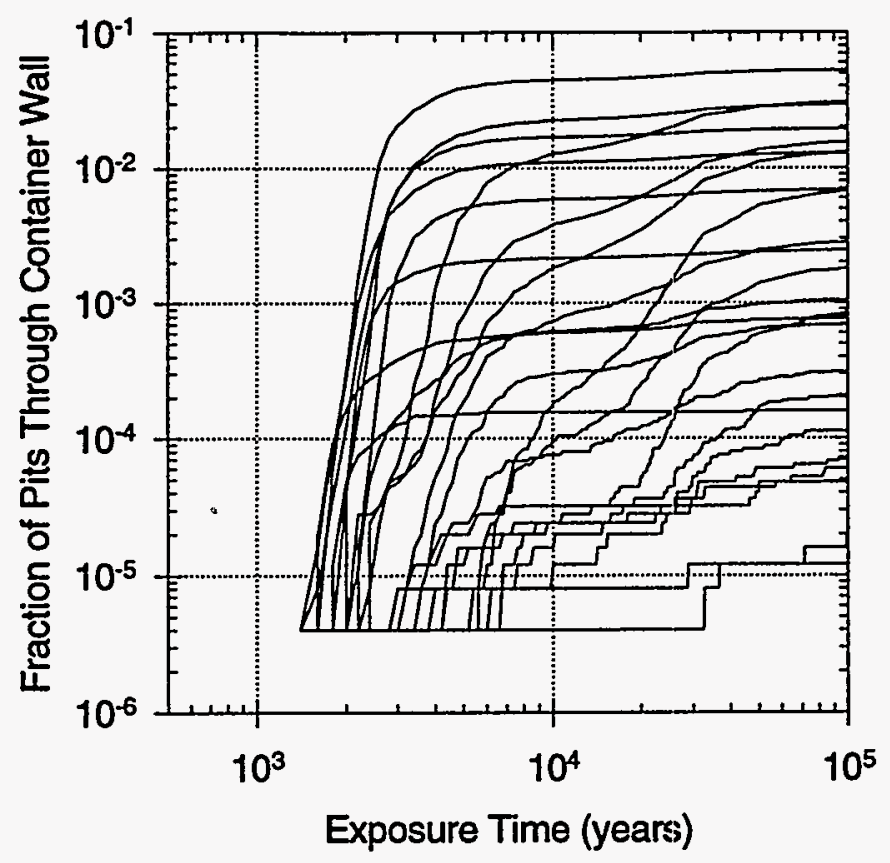

Figure 5.7-8b Representative pitting histories for 25 waste packages for the case of 83 MTU/acre, high infiltration, and without backfill, using RH switch for corrosion initiation.

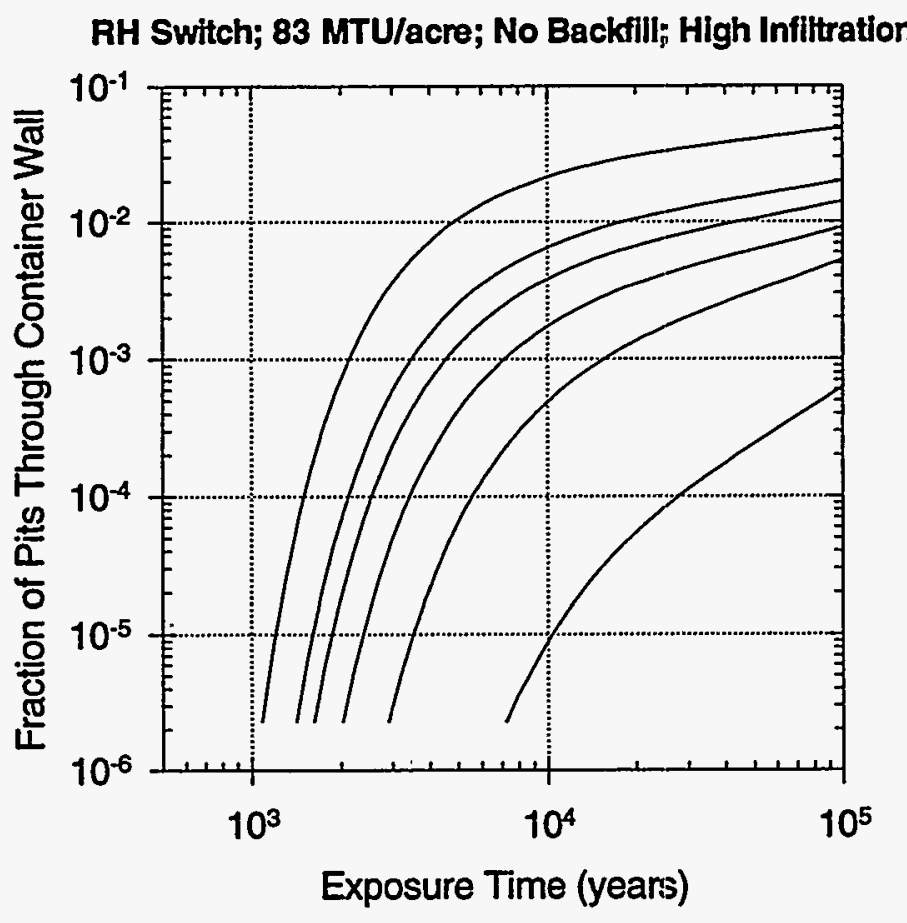

Figure 5.7-8c Abstractions for the RIP implementation for the case of 83 MTU/acre, high infiltration, and without backfill, using RH switch for corrosion initiation. 


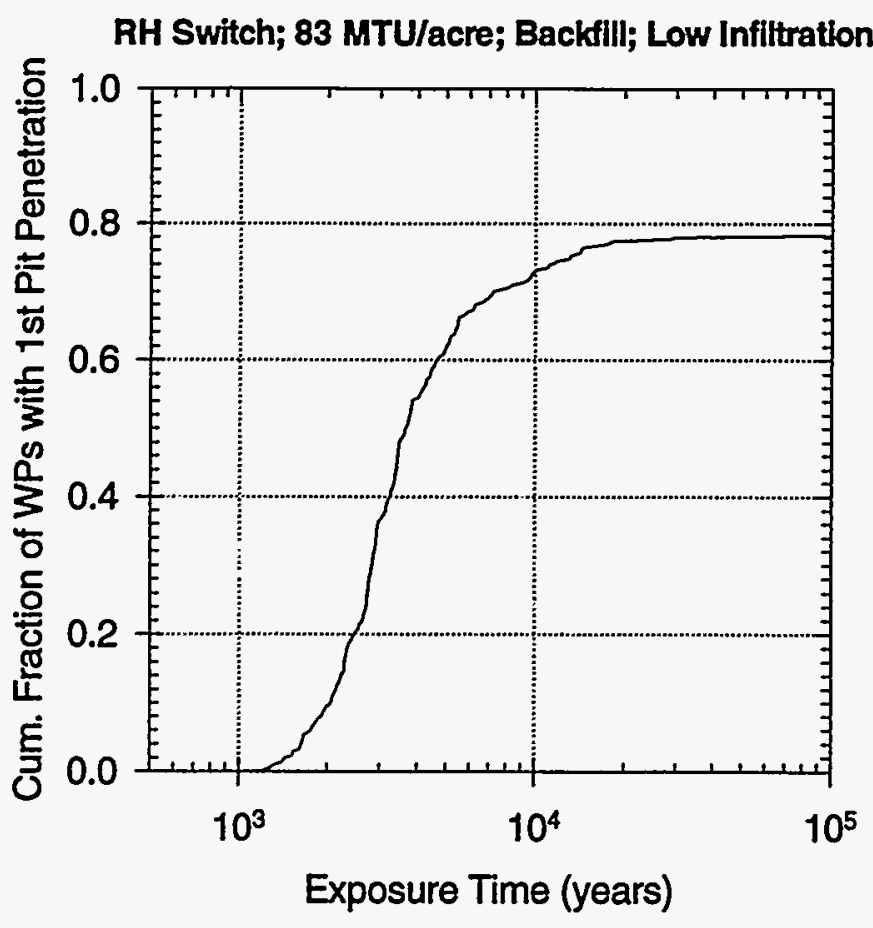

Figure 5.7-9a Waste package failure history for the case of 83 MTU/acre, low infiltration, and with backfill, using RH switch for corrosion initiation.

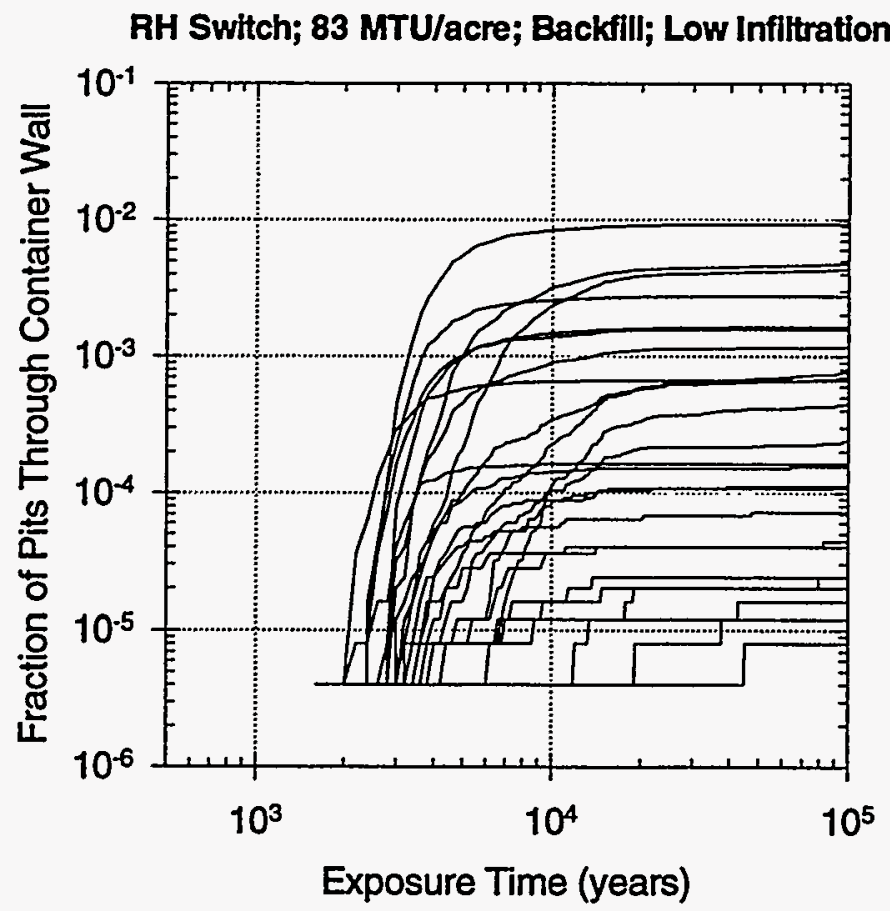

Figure 5.7-9b Representative pitting histories for 25 waste packages for the case of 83 MTU/acre, low infiltration, and with backfill, using RH switch for corrosion initiation. 


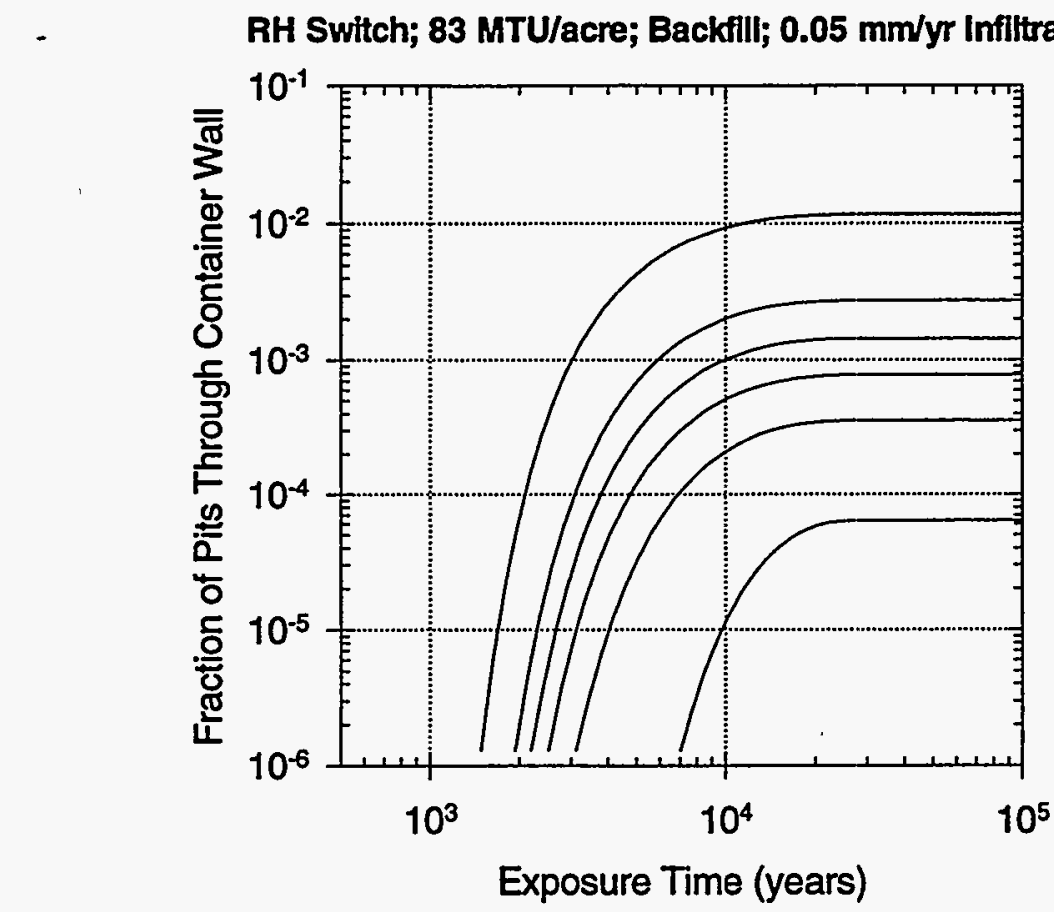

Figure 5.7-9c Abstractions for the RIP implementation for the case of 83 MTU/acre, low infiltration, and with backfill, using $\mathrm{RH}$ switch for corrosion initiation.

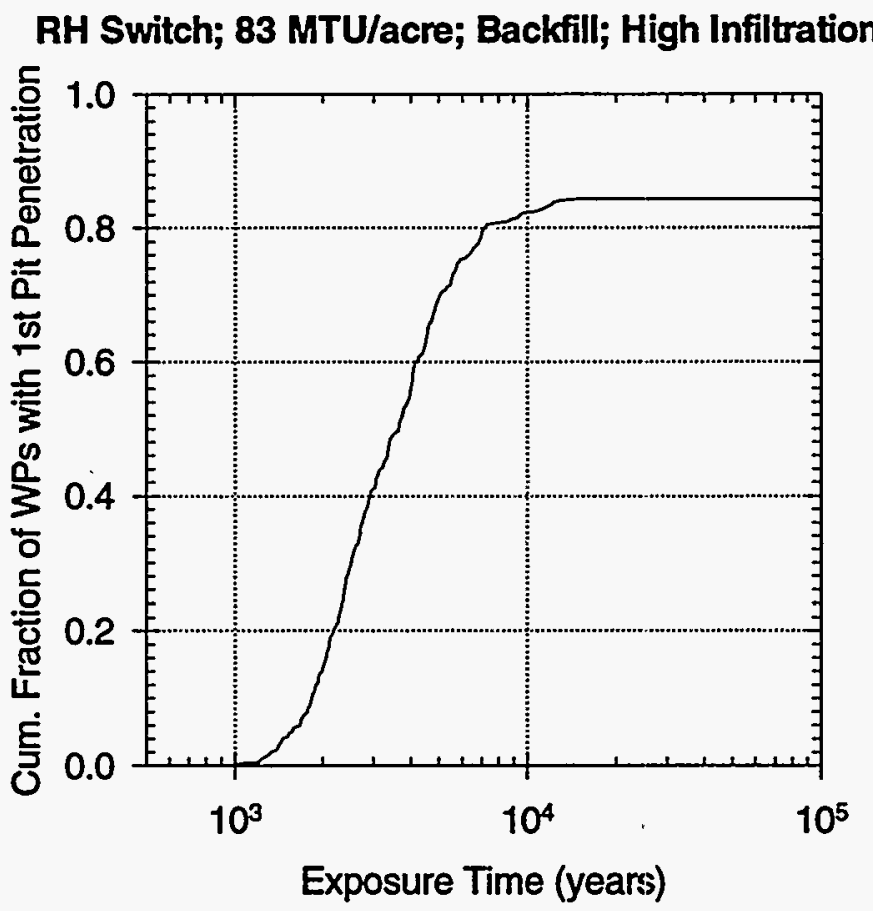

Figure 5.7-10a Waste package failure history for the case of $83 \mathrm{MTU} / \mathrm{acre}$, high infiltration, and with backfill, using RH switch for corrosion initiation. 


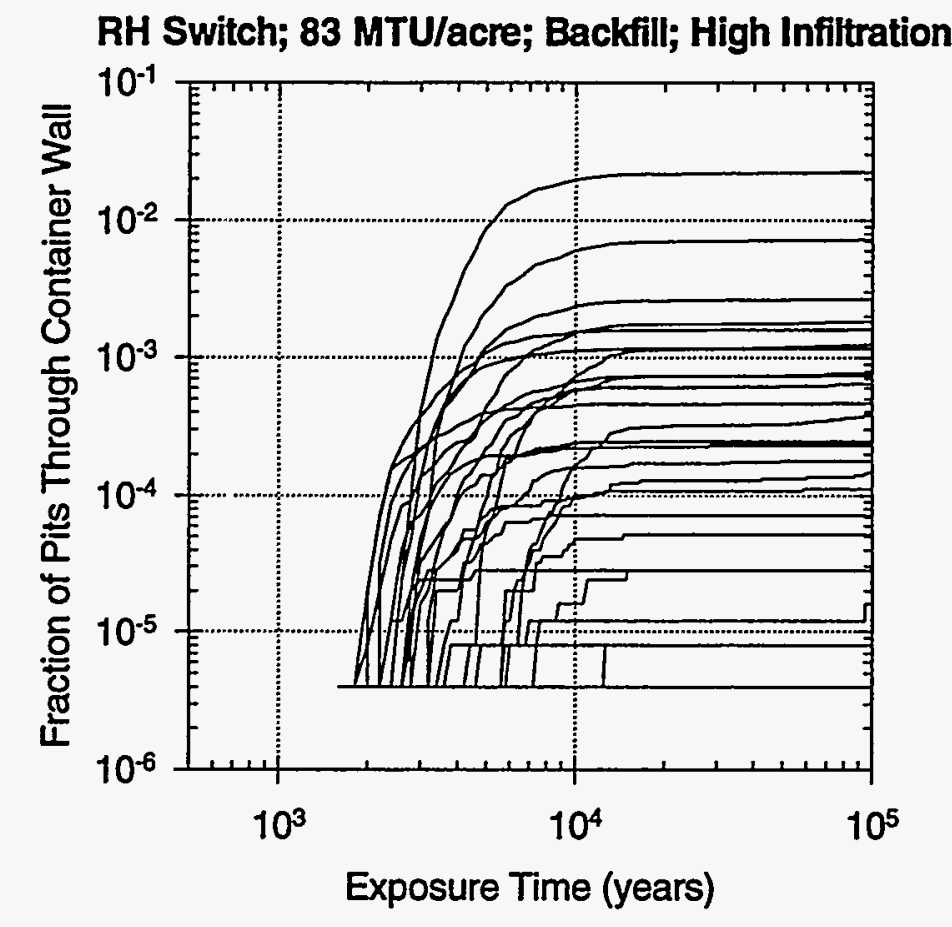

Figure 5.7-10b Representative pitting histories for 25 waste packages for the case of 83 MTU/acre, high infiltration, and with backfill, using $\mathrm{RH}$ switch for corrosion initiation.

\section{RH Switch; 83 MTU/acre; Backfill; High Infiltration}

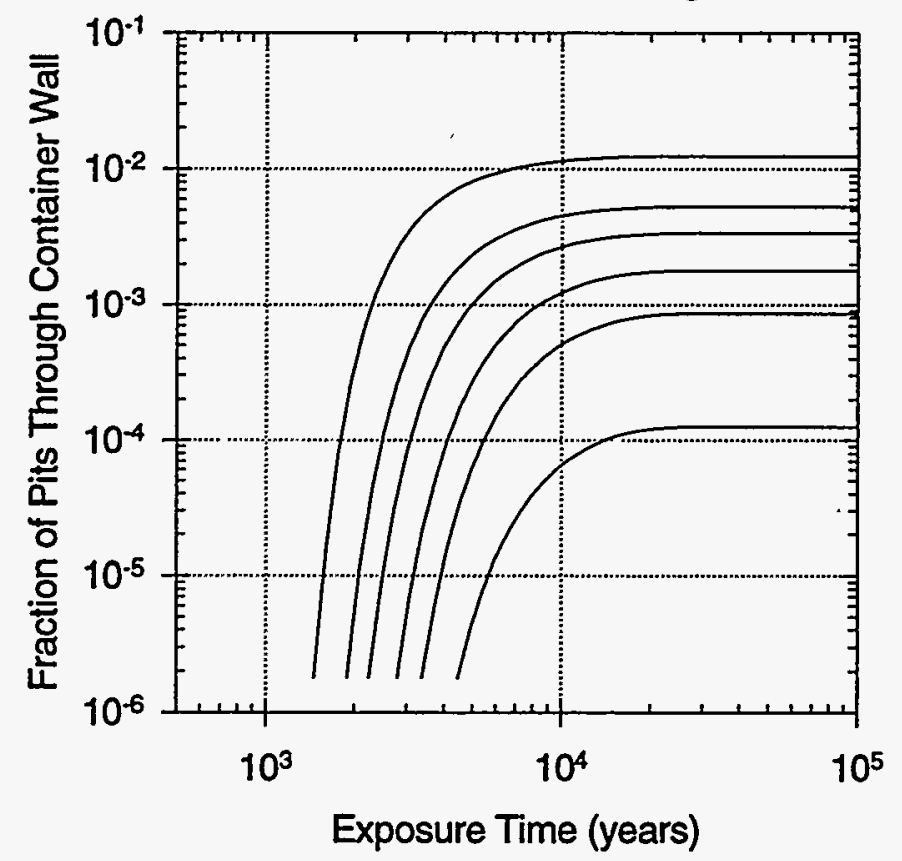

Figure 5.7-10c Abstractions for the RIP implementation for the case of $83 \mathrm{MTU} / \mathrm{acre}$, high infiltration, and with backfill, using RH switch for corrosion initiation. 
RH Switch; 25 MTU/acre; No Backfill; Low Infiltration

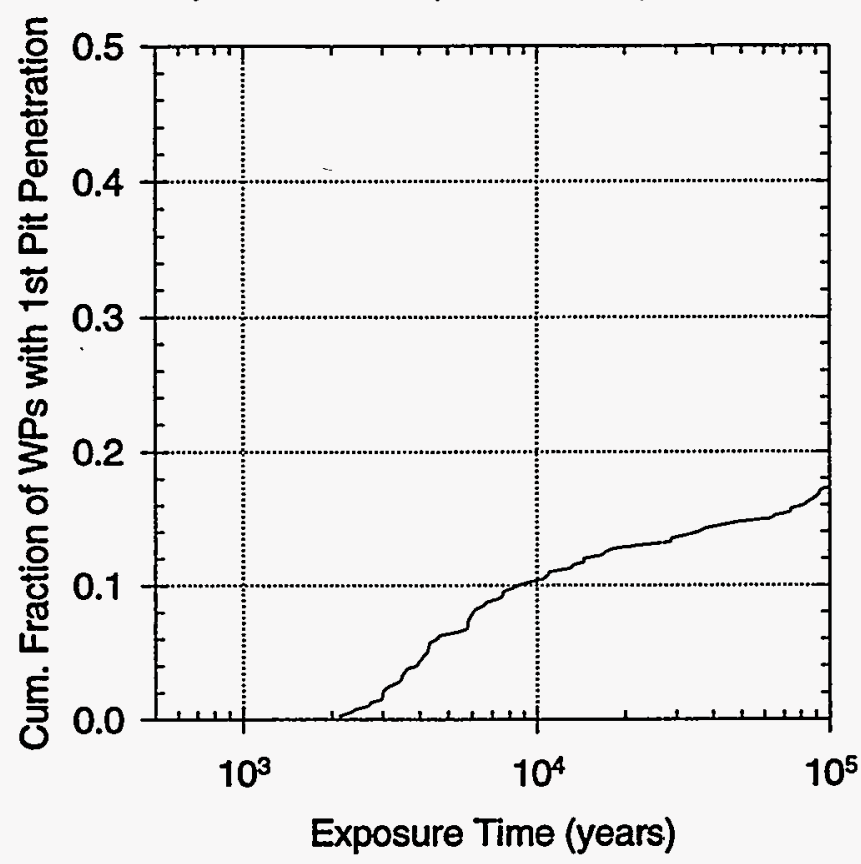

Figure 5.7-11a Waste package failure history for the case of 25 MTU/acre, low infiltration, and without backfill, using RH switch for corrosion initiation.

RH Switch; 25 MTU/acre; No Backfill; Low Infiltration

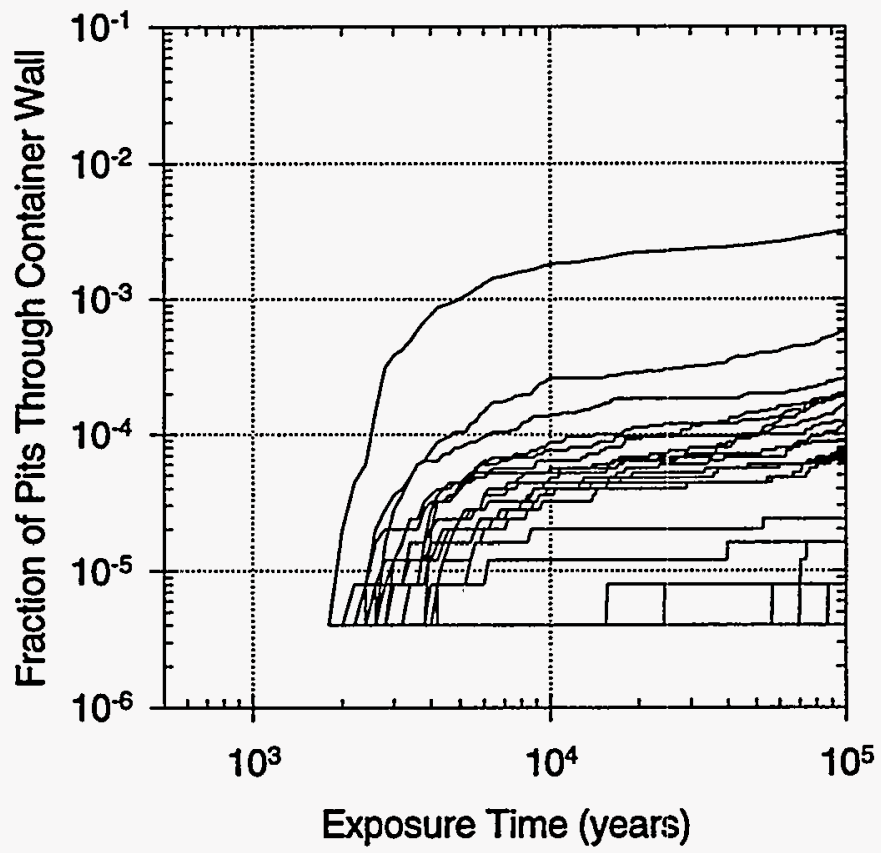

Figure 5.7-11b Representative pitting histories for 25 waste packages for the case of 25 MTU/acre, low infiltration, and without backfill, using RH switch for corrosion initiation. 
RH Switch; 25 MTU/acre; No Backfill; Low Infiltration

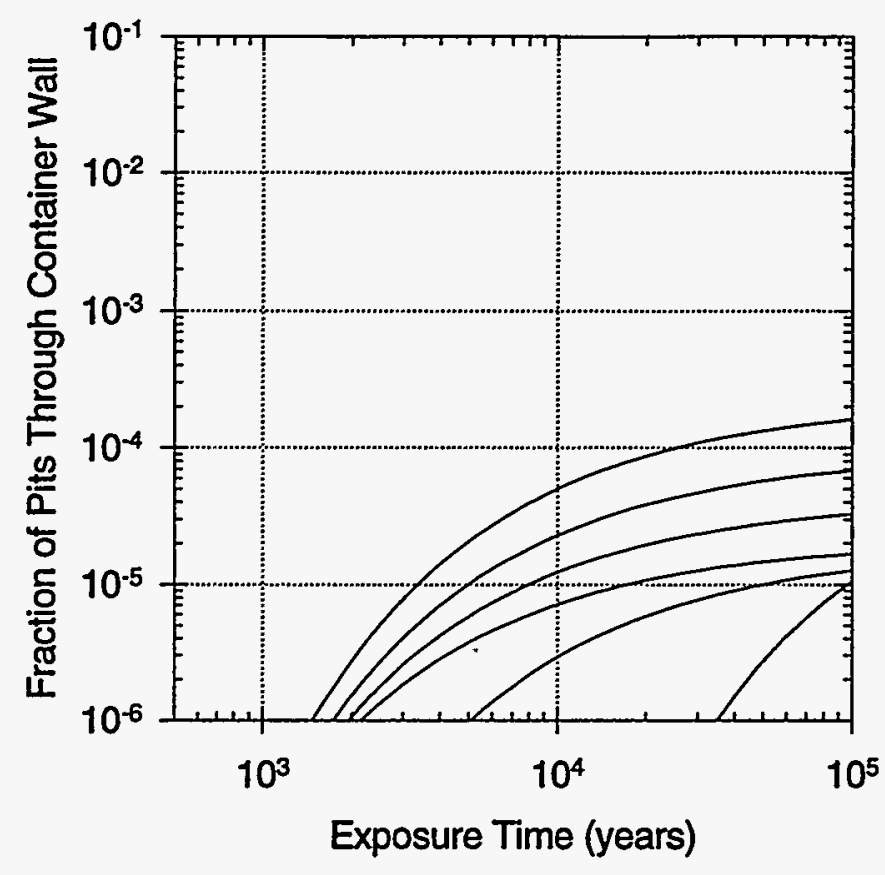

Figure 5.7-11c Abstractions for the RIP implementation for the case of 25 MTU/acre, low infiltration, and without backfill, using RH switch for corrosion initiation.

RH Switch; 25 MTU/acre; No Backfill; High Infiltration

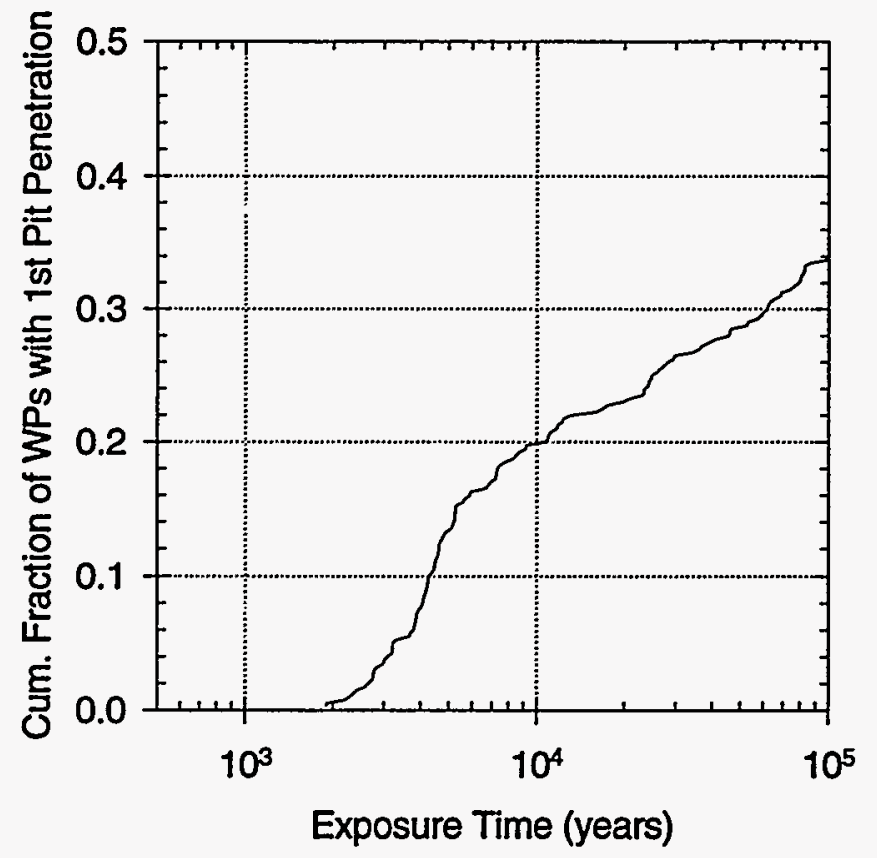

Figure 5.7-12a Waste package failure history for the case of 25 MTU/acre, high infiltration, and without backfill, using $\mathrm{RH}$ switch for corrosion initiation. 
RH Switch; 25 MTU/acre; No Backfill; High Infiltration

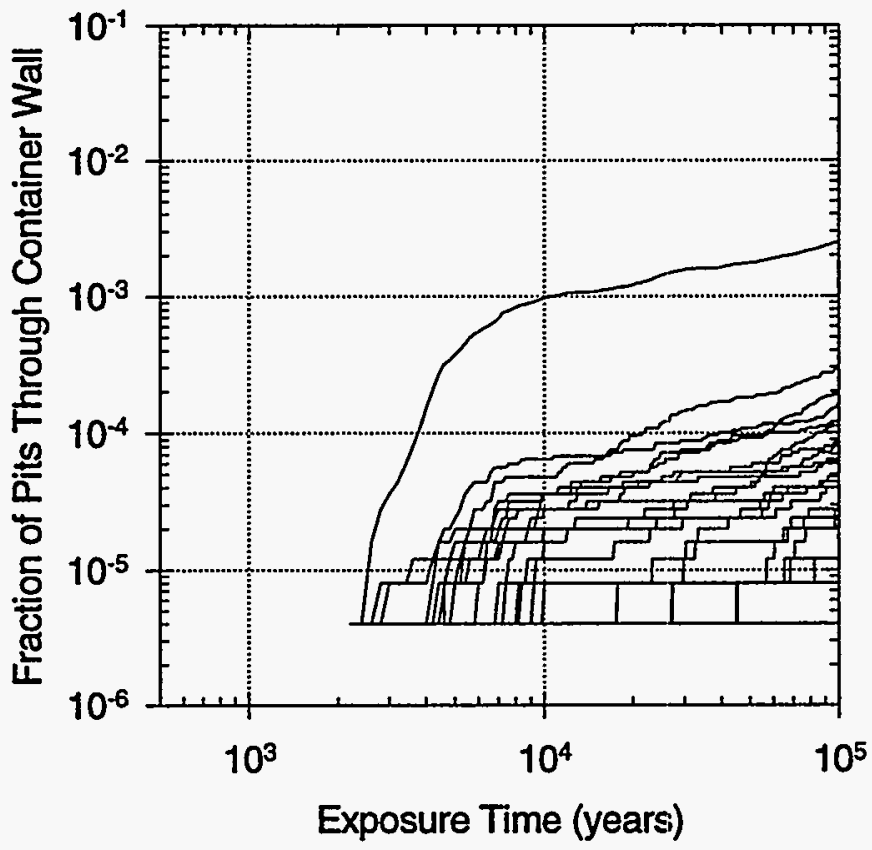

Figure 5.7-12b

Representative pitting histories for 25 waste packages for the case of 25 MTU/acre, high infiltration, and without backfill, using RH switch for corrosion initiation.

RH Switch; 25 MTU/acre; No Backill; High Infiltration

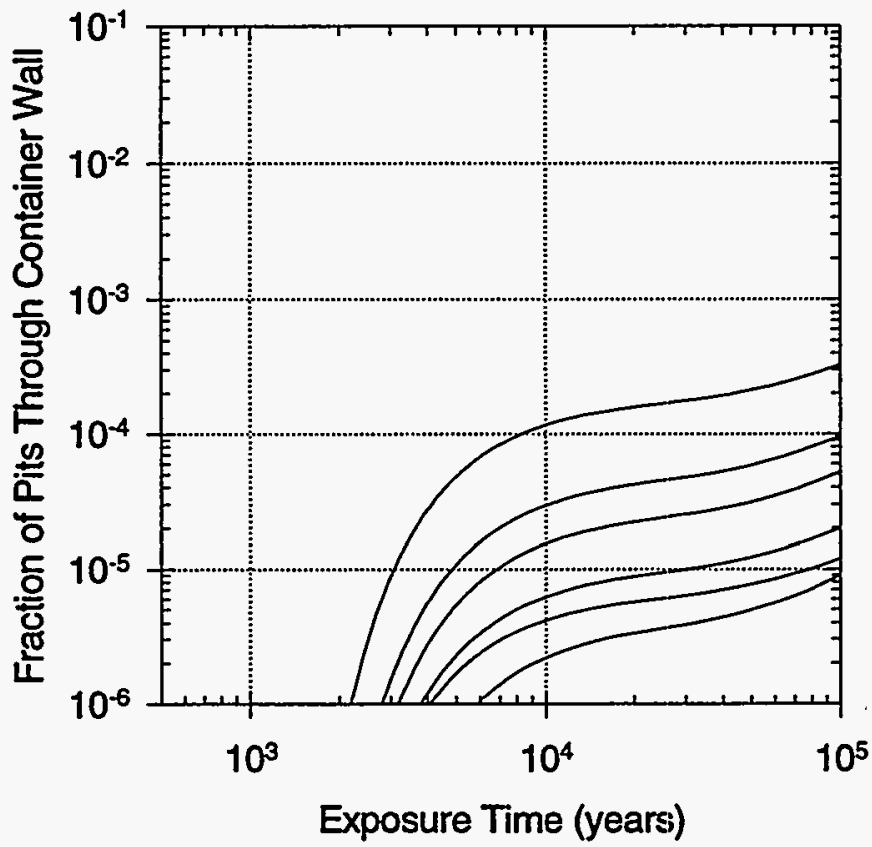

Figure 5.7-12c Abstractions for the RIP implementation for the case of $25 \mathrm{MTU} / \mathrm{c}$ (ace, high infiltration, and without backfill, using RH switch for corrosion initiation. 


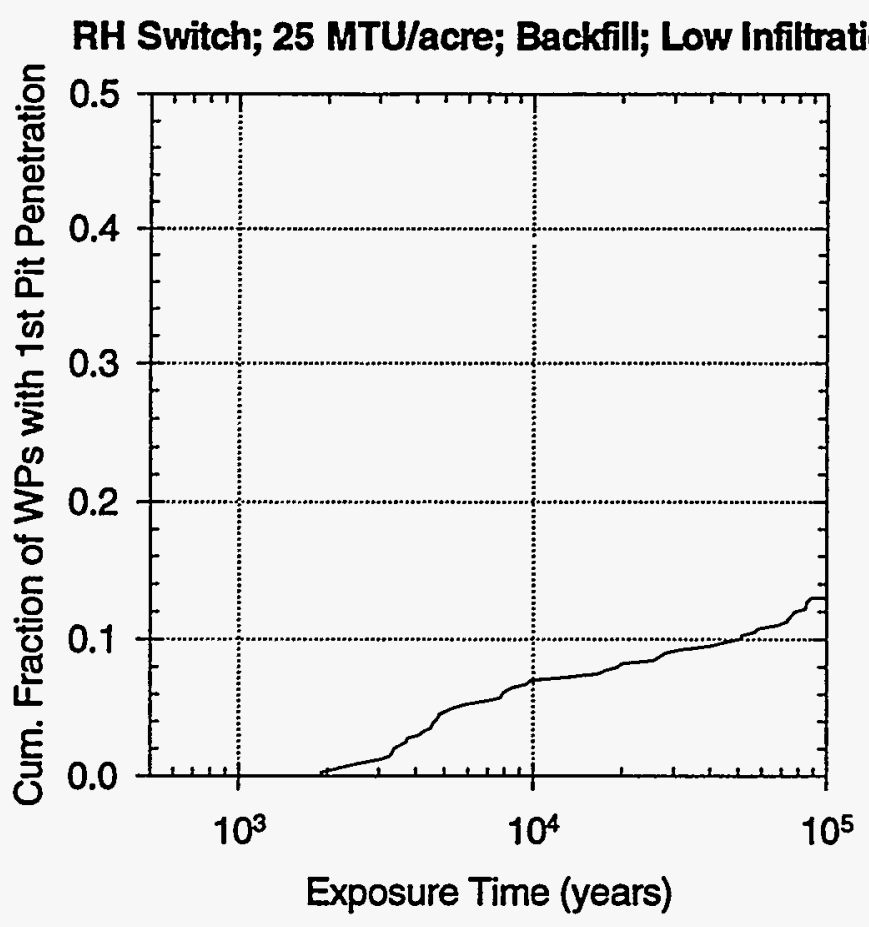

Figure 5.7-13a Waste package failure history for the case of 25 MTU/acre, low infiltration, and with backfill, using RH switch for corrosion initiation.

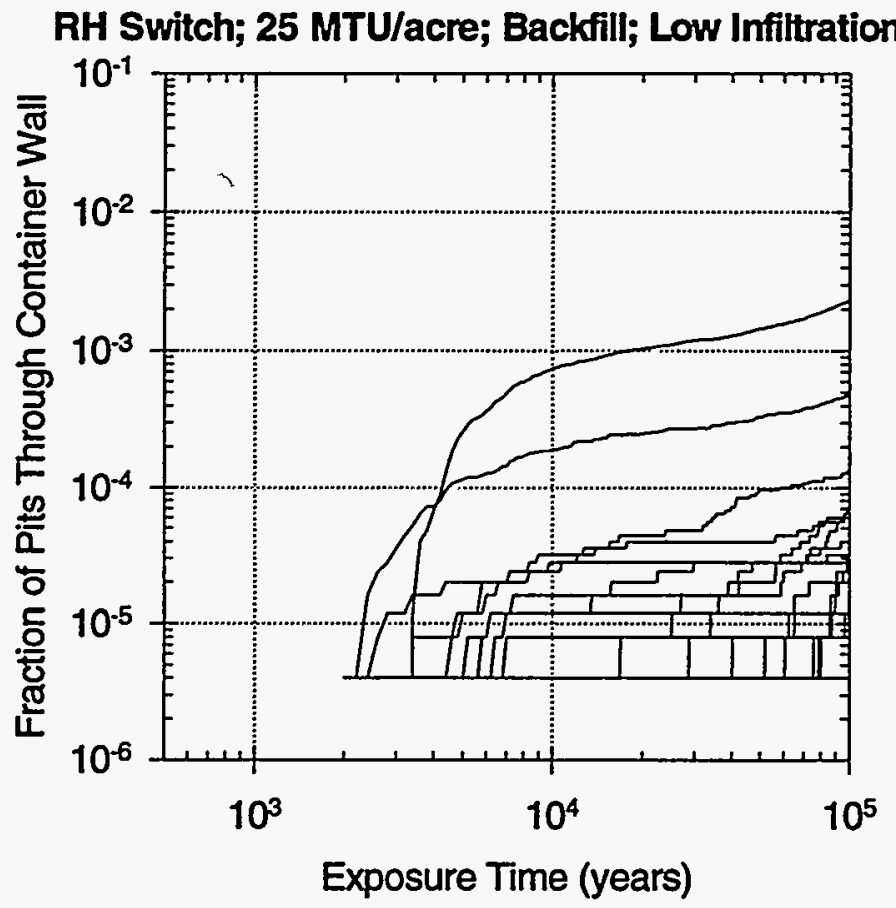

Figure 5.7-13b Representative pitting histories for 25 waste packages for the case of 25 MTU/acre, low infiltration, and with backfill, using RH switch for corrosion initiation. 
RH Switch; 25 MTU/acre; Backfill; I_ow Infiltration

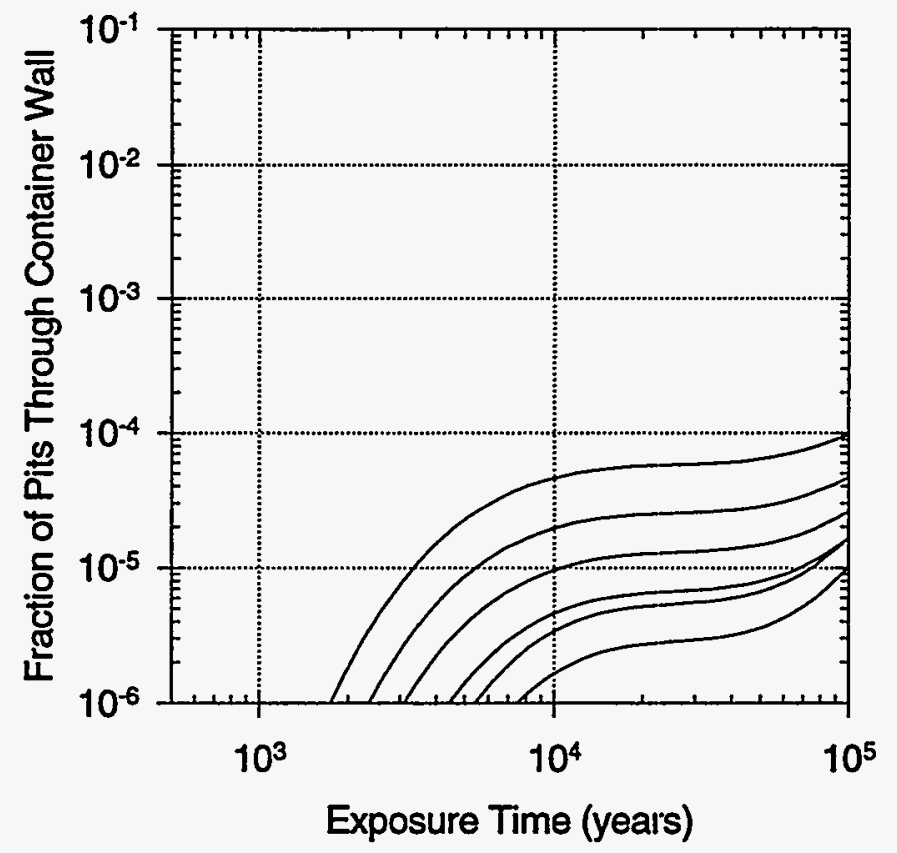

Figure 5.7-13c

Abstractions for the RIP implementation for the case of 25 MTU/acre, low infiltration, and with backfill, using RH switch for corrosion initiation.

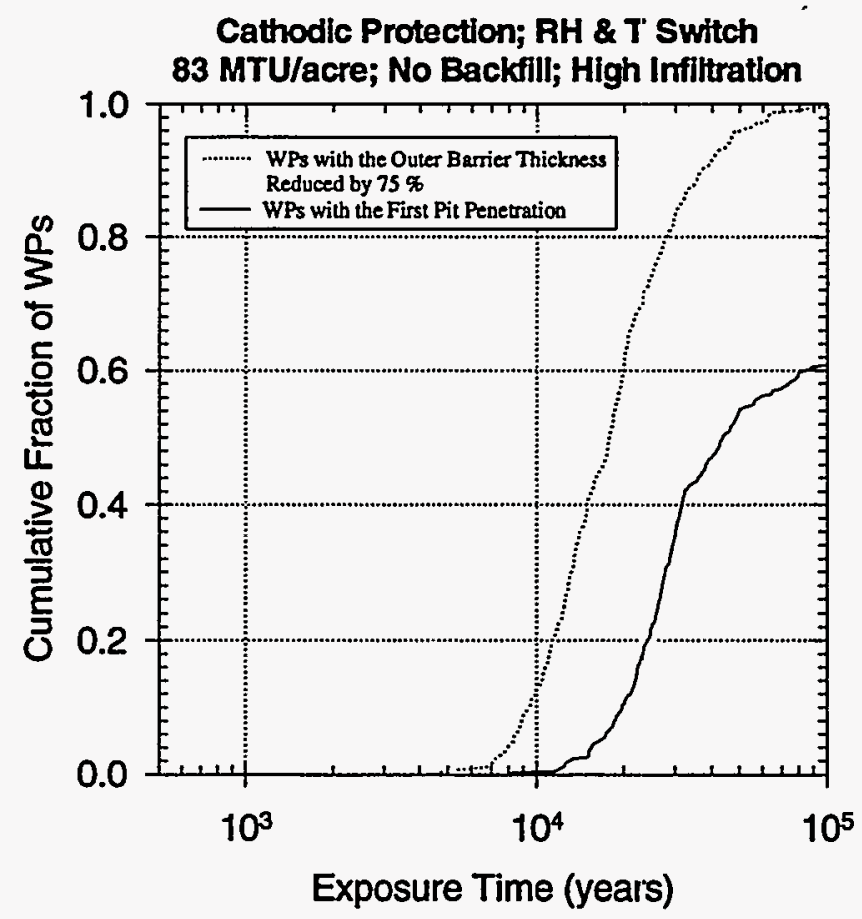

Figure 5.7-14a Waste package failure history for the case of $83 \mathrm{MTU} / \mathrm{acre}$, high infiltration, and without backfill, with cathodic protection of the inner barrier and using RH and temperature switch for corrosion initiation. 


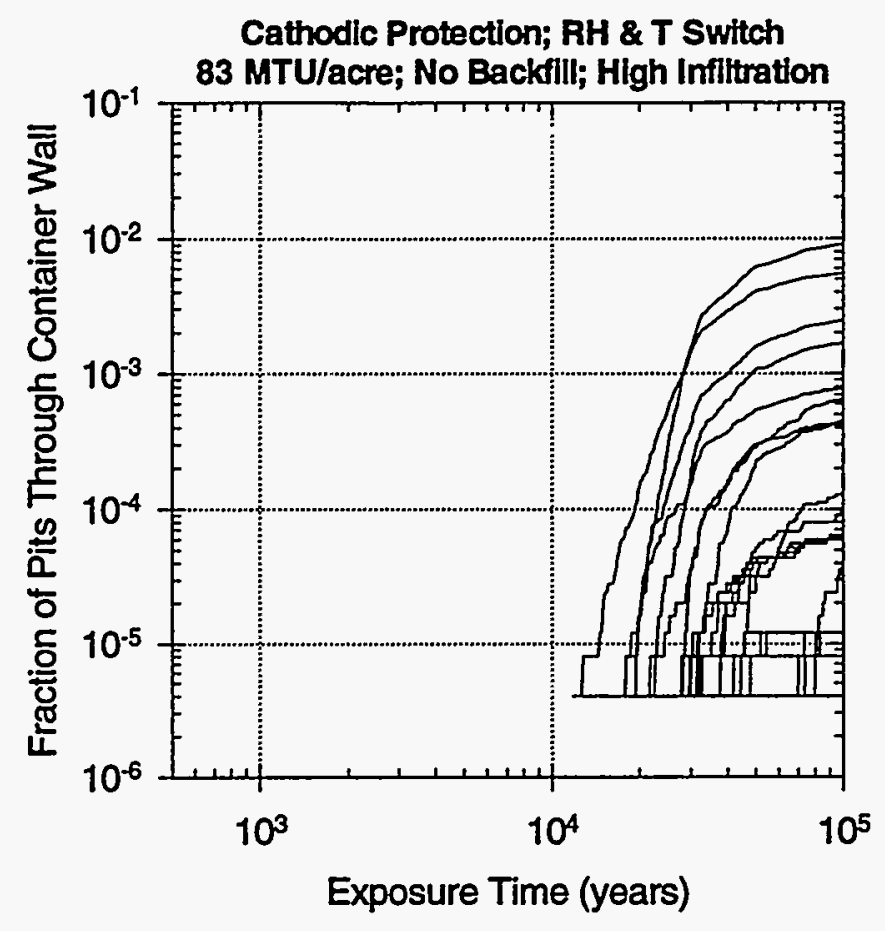

Figure 5.7-14b Representative pitting histories for 25 waste packages for the case of 83 MTU/acre, high infiltration, and without backfill, with cathodic protection of the inner barrier and using RH and temperature switch for corrosion initiation.

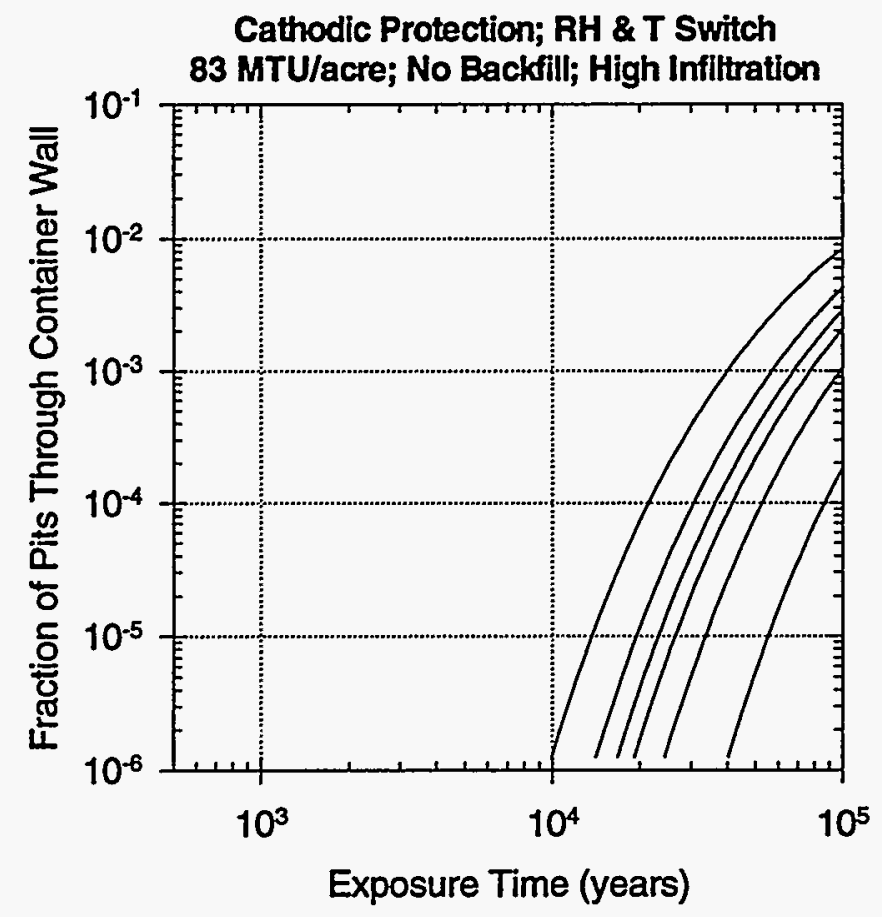

Figure 5.7-14c Abstractions for the RIP implementation for the case of 83 MTU/acre, high infiltration, and without backfill, with cathodic protection of the inner barrier and using RH and temperature switch for corrosion initiation. 


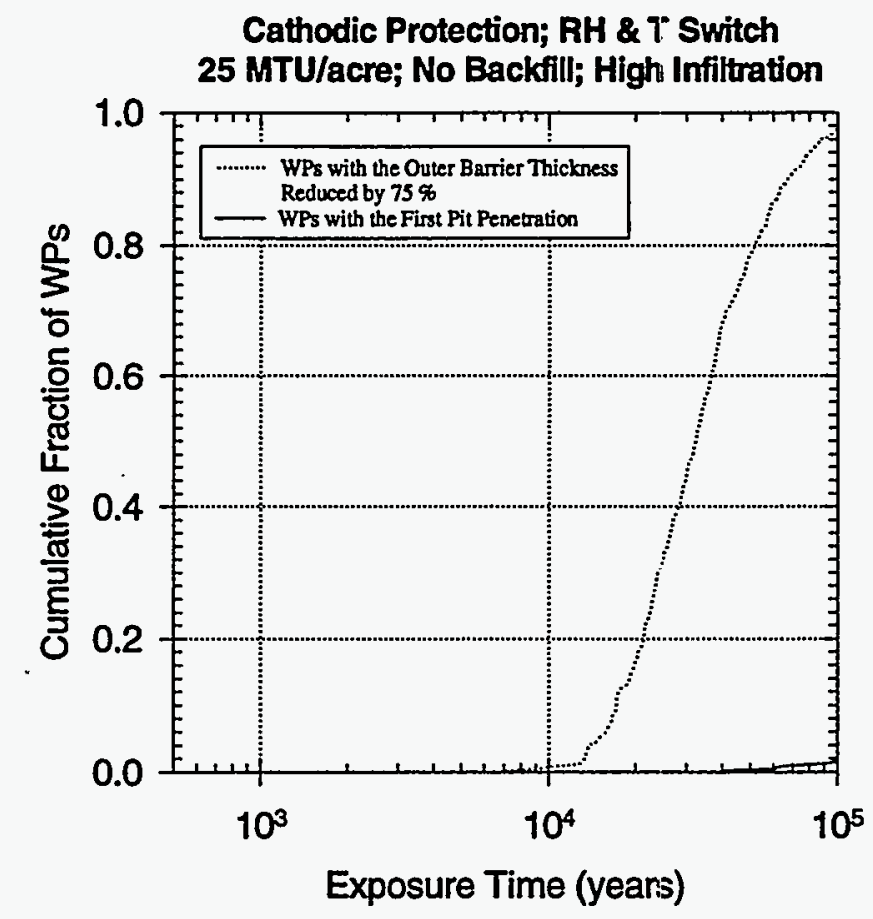

Figure 5.7-15 Waste package failure history for the case of 25 MTU/acre, high infiltration, and without backfill, with cathodic protection of the inner barrier and using RH switch for corrosion initiation.

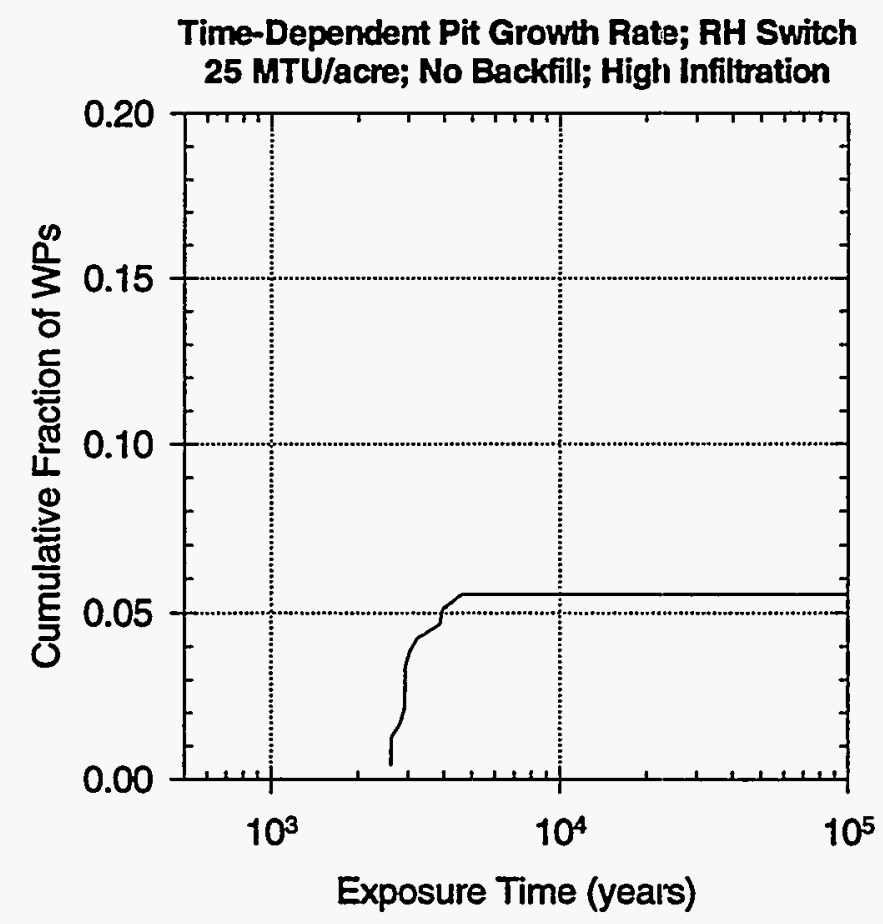

Figure 5.7-16 Waste package failure history for the case of 83 MTU/acre, high infiltration, and without backfill, with time-dependent pit growth rate in the inner barrier and using $\mathrm{RH}$ and temperature switch for corrosion initiation. 


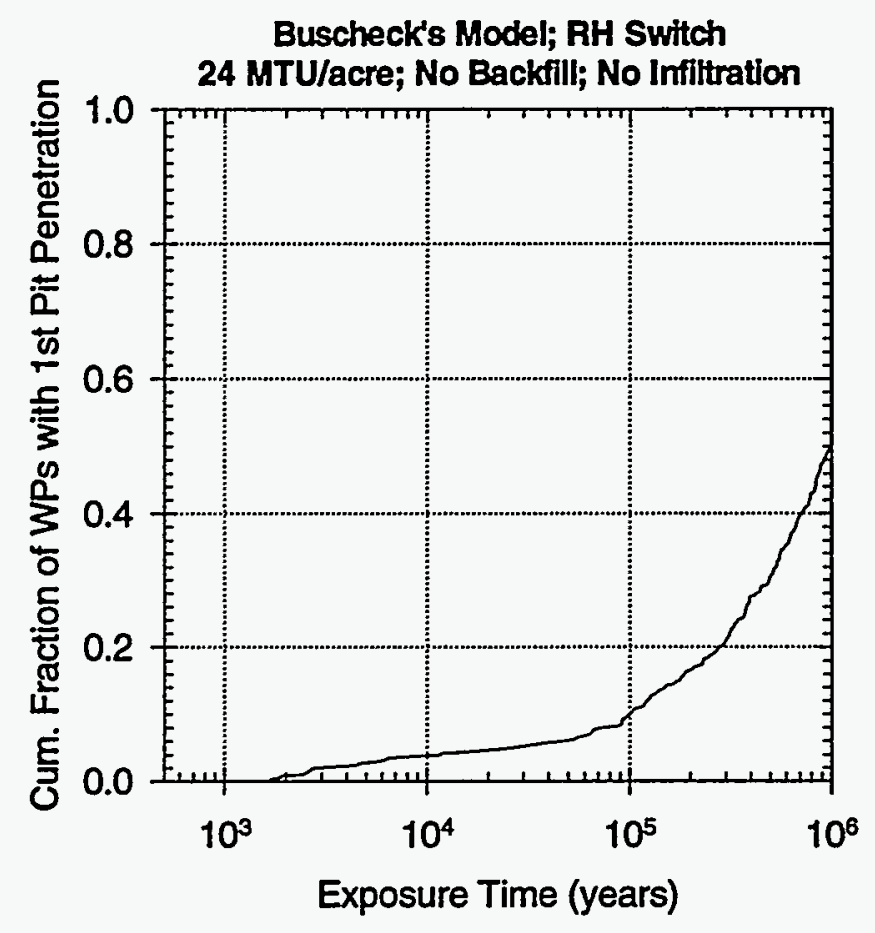

Figure 5.7-17a Waste package failure history for the case of 24 MTU/acre, no infiltration, and without backfill, with the results from the Buscheck's model and using RH switch for corrosion initiation.

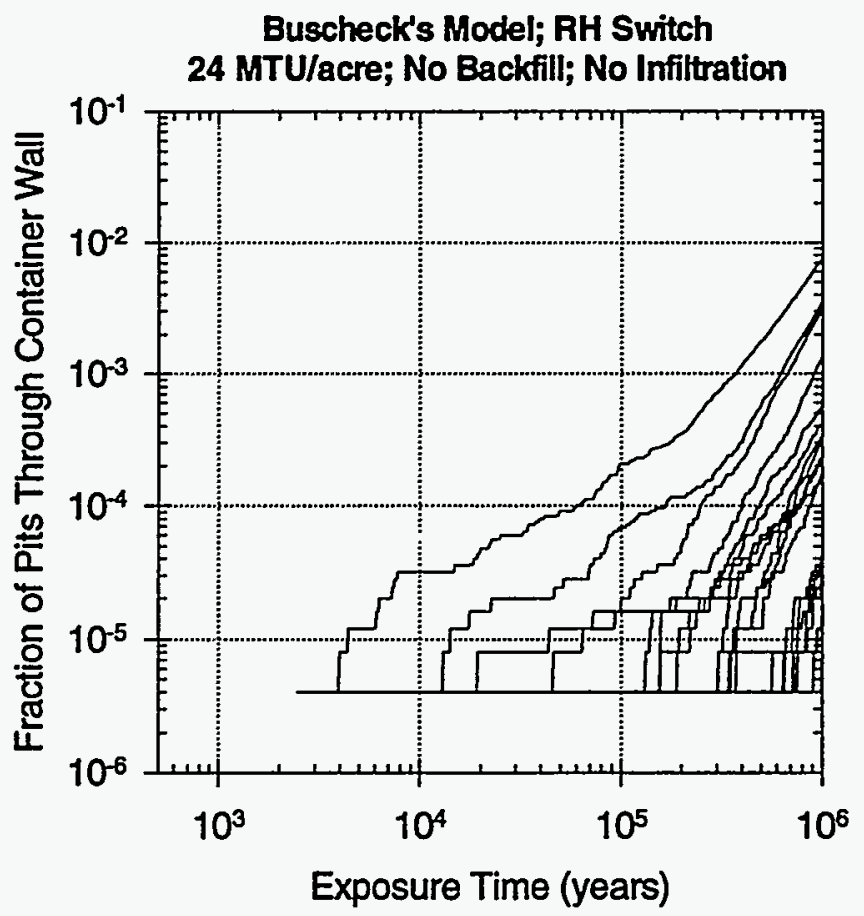

Figure 5.7-17b Representative pitting histories for 25 waste packages for the case of 24 MTU/acre, no infiltration, and without backfill, with the results from the Buscheck's model and using RH switch for corrosion initiation. 


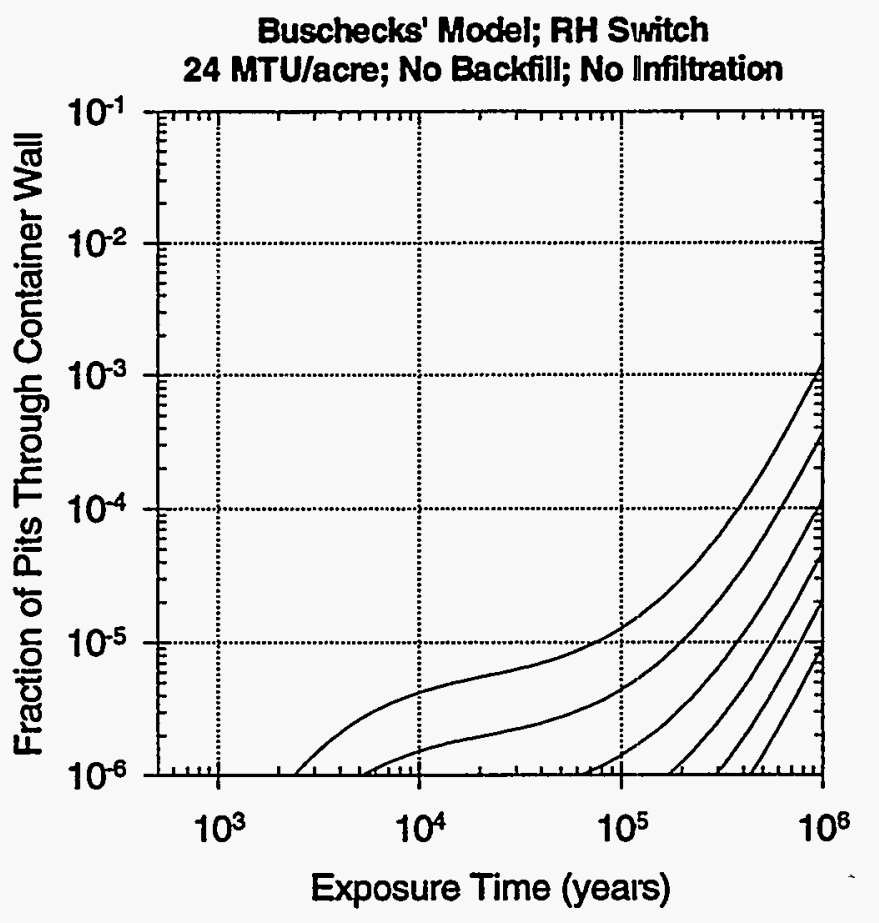

Figure 5.7-17c

Abstractions for the RIP implementation for the case of 24 MTU/acre, no infiltration, and without backfill, with the results from the Buscheck's model and using RH switch for corrosion initiation.

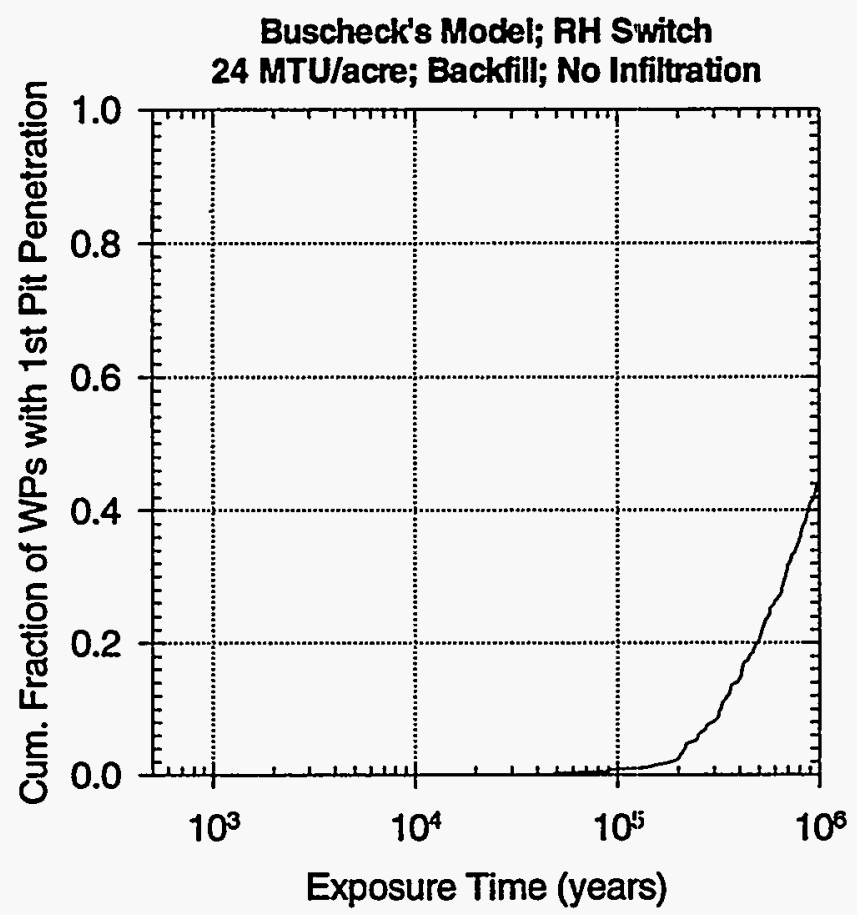

Figure 5.7-18a

Waste package failure history for the case of $24 \mathrm{MTU} / \mathrm{acre}$, no infiltration, and with backfill, with the results from the Buscheck's model and using RH switch for corrosion initiation. 


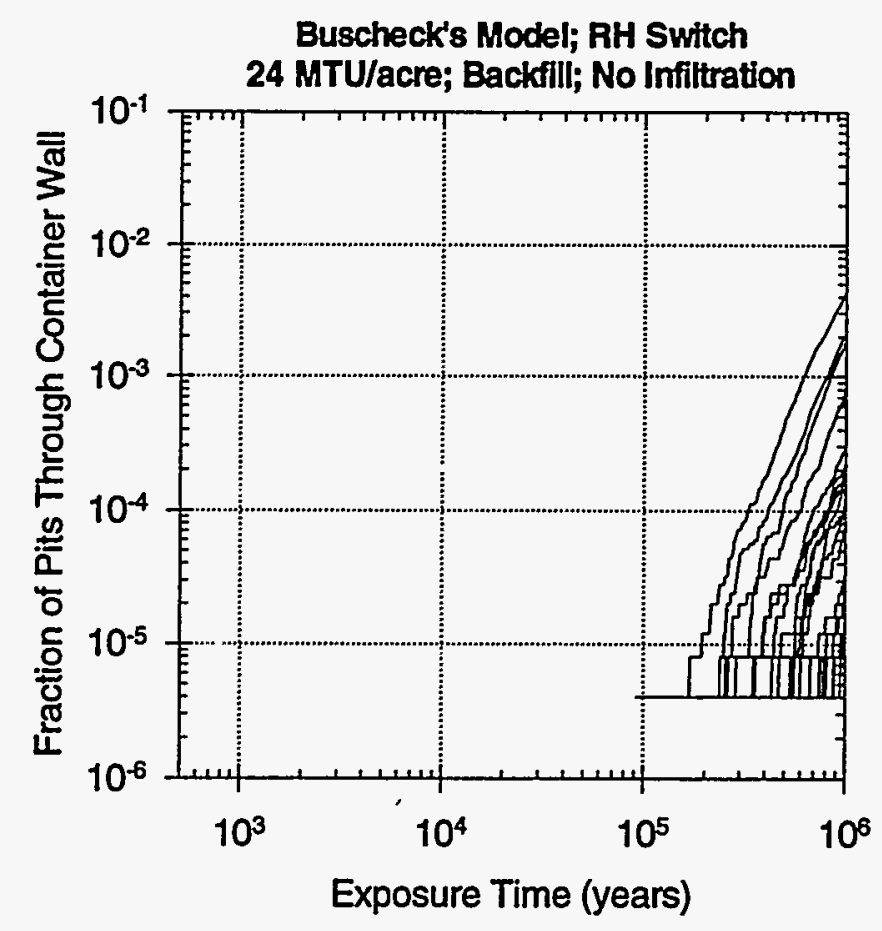

Figure 5.7-18b Representative pitting histories for 25 waste packages for the case of 24 MTU/acre, no infiltration, and with backfill, with the results from the Buscheck's model and using RH switch for corrosion initiation.

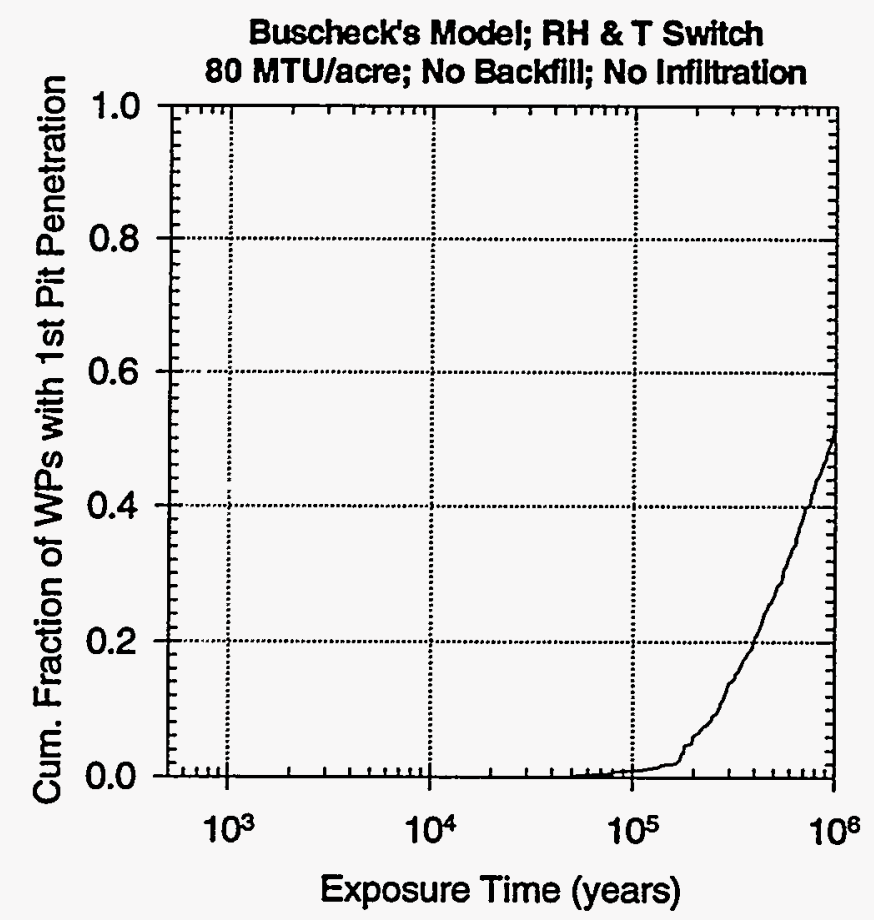

Figure 5.7-19a Waste package failure history for the case of $80 \mathrm{MTU} / \mathrm{acre}$, no infiltration, and without backfill, with the results from the Buscheck's model and using RH and temperature switch for corrosion initiation. 

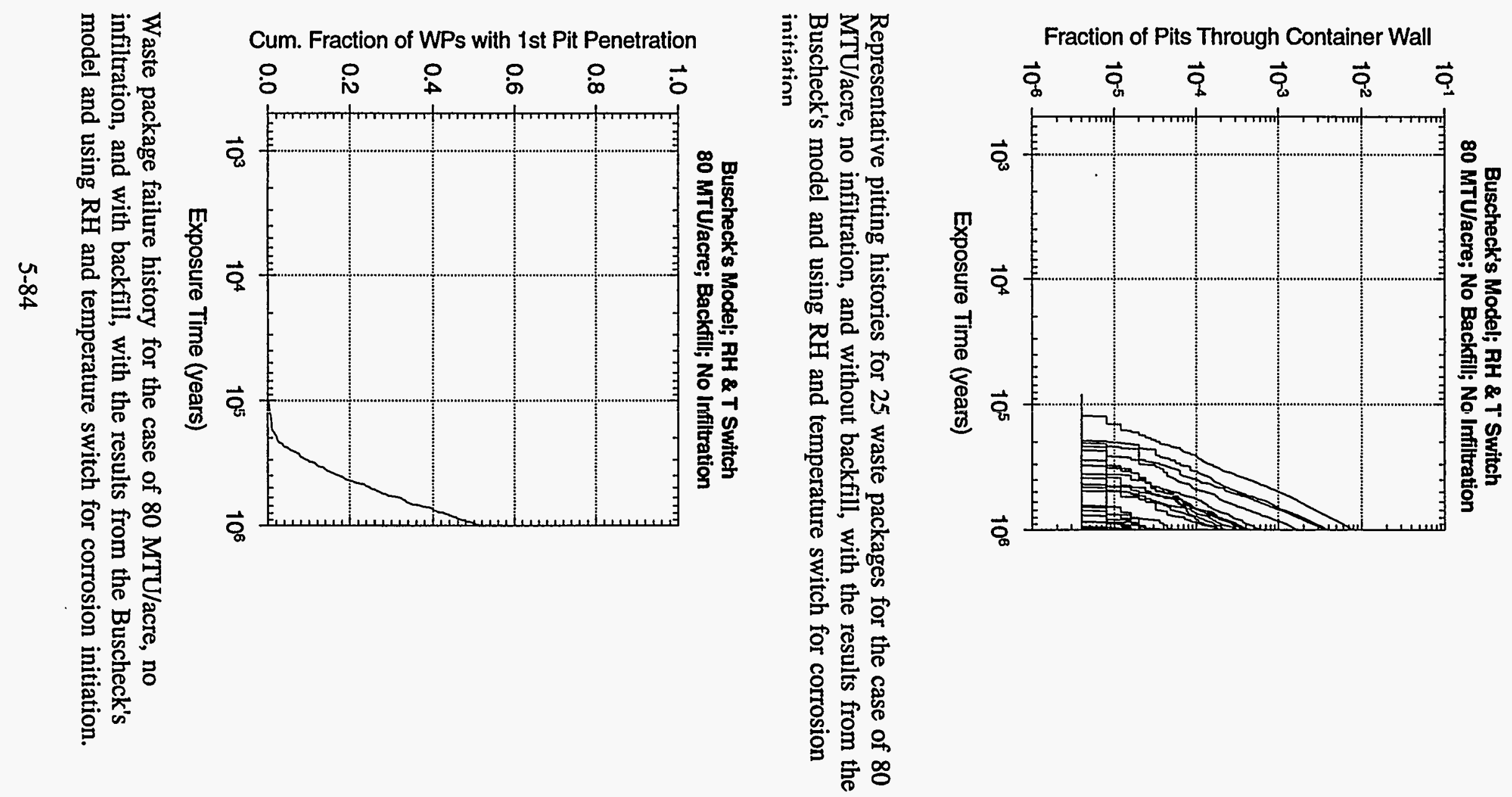


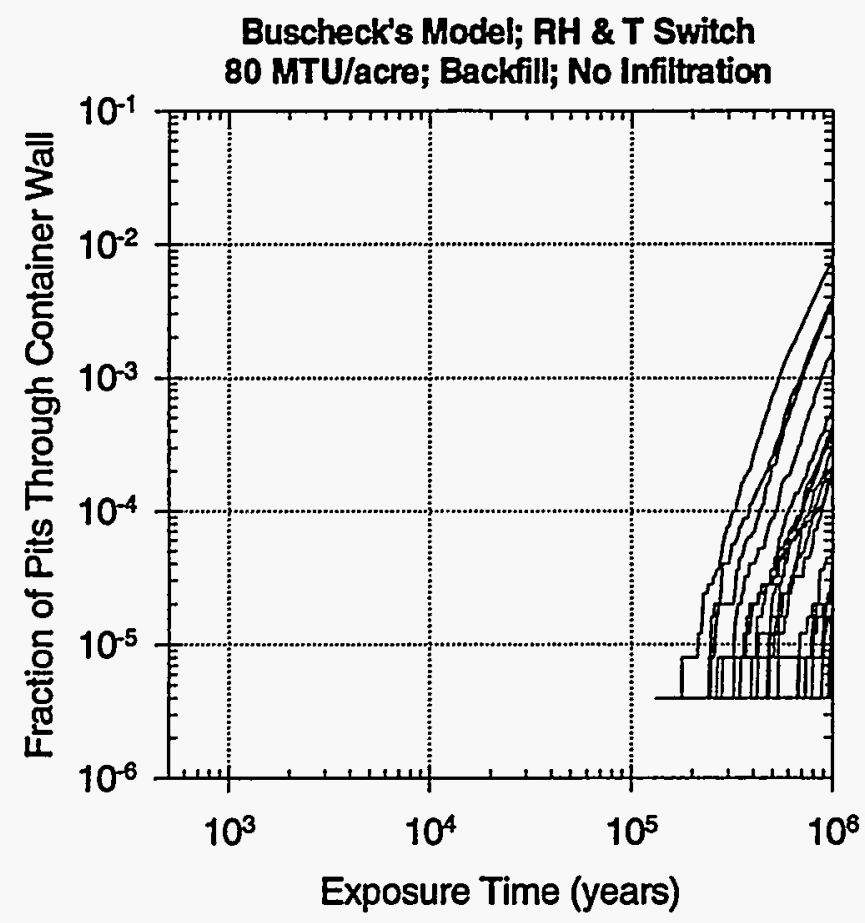

Figure 5.7-20b

Representative pitting histories for 25 waste packages for the case of 80 MTU/acre, no infiltration, and with backfill, with the results from the Buscheck's model and using RH and temperature switch for corrosion initiation

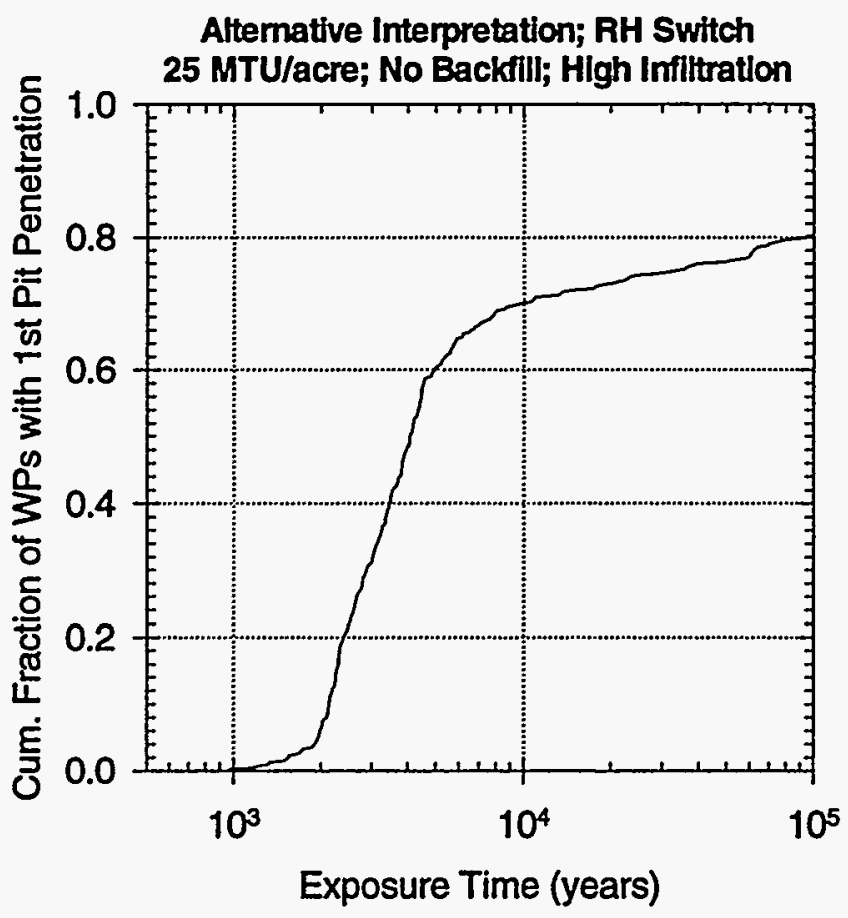

Figure 5.7-21 Waste package failure history for the case of $25 \mathrm{MTU} / \mathrm{acre}$, high infiltration, and without backfill, with alternative interpretation of the elicitation for the inner barrier pit growth rate and using RH switch for corrosion initiation. 


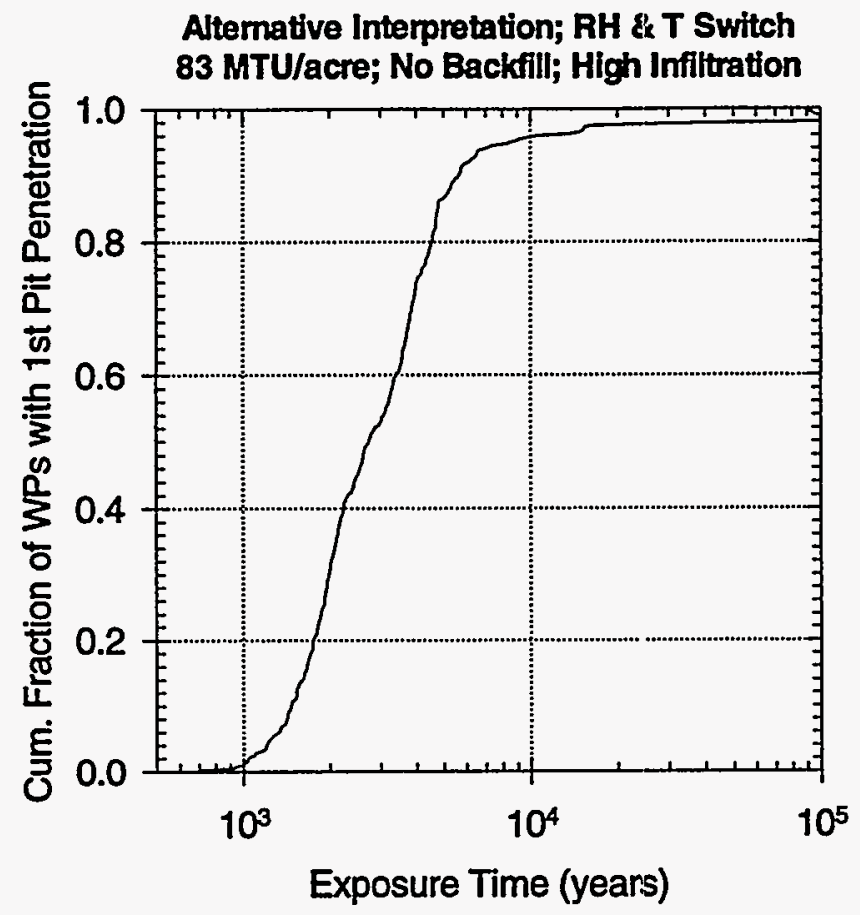

Figure 5.7-22 Waste package failure history for the case of 83 MTU/acre, high infiltration, and without backfill, with alternative interpretation of the elicitation for the inner barrier pit growth rate and using RH switch for corrosion initiation. 
CHAPTER 6

ENGINEERED BARRIER SYSTEM ABSTRACTION 



\title{
6. ENGINEERED BARRIER SYSTEM ABSTRACTION
}

\author{
David C. Sassani, Joon H. Lee, Joel E. Atkins
}

\subsection{INTRODUCTION}

For the engineered barrier system (EBS) analyses, it is assumed that the near-field environmental conditions exterior to a waste package are immediately transferred to the interior of the package after it is penetrated or "failed" by pitting corrosion. In calculating the release of radionuclides to the host rock from the engineered components of the system, the processes to be modeled include: waste form alteration/dissolution; solubility constraints on the concentration of dissolved radionuclide species; the potential for colloids to increase the source term and transport of radionuclides in the mobile phase; the effective diffusion of radionuclides through the degraded waste package and other engineered components; and the potential for advective transport in the localized flow intersecting the drift.

This chapter presents the abstraction of laboratory-derived information for use in the prediction of releases from the EBS. This information is used directly in the TSPA analyses as indicated in Figure 6.1-1. Section 6.2 presents information and its abstraction for the development of waste form alteration/dissolution model. Section 6.3 presents information on the solubility limits of radionuclides analyzed in TSPA-1995. Section 6.4 describes the potential effects of colloid formation and mobility, although colloid formation/transport is not included in TSPA-1995 analyses. Section 6.5 presents the EBS release models (diffusive and advective) used in TSPA1995. In addition, the model abstractions constraining the percent of the waste package surface through which diffusive release can occur are presented. Also covered in Section 6.5 is the relation between the effective diffusion coefficient and the liquid saturation of drift materials.

\subsection{WASTE FORM ALTERATION MODELING}

After the modeled waste package container and cladding (for spent fuel) are calculated to fail (i.e., they are breached), the waste forms (spent fuel and vitrified defense high-level waste (DHLW) glass monolith) are assumed to be exposed to the near-field environment and to undergo alteration/dissolution before the radionuclides are released. It has been pointed out that a locally reducing environment may be possible in the vicinity of a corroding waste container and within a failed one, resulting in lower alteration/dissolution rates of the waste forms and lower solubility limits of species (Pigford, 1993). The baseline assumptions in this TSPA iteration are that the post-closure repository maintains a total pressure of one atmosphere (1 atm) and an oxygen partial pressure of $0.2 \mathrm{~atm}$. These assumptions provide a conservatively oxidizing model environment for waste container corrosion and waste form degradation. This section outlines the TSPA-1995 approach for modeling spent fuel and glass waste form alteration/dissolution.

\subsubsection{Alteration/Dissolution of Spent Fuel Waste Form}

\section{Conceptual Models and Approach}

For radionuclide release from the spent fuel waste form (fuel pellets), two distinct release modes are considered: 1) instantaneous release; and 2) matrix release. The instantaneous release mode 
consists of species in the gap between fuel pellets and cladding, and species on fuel grain boundaries. These species are referred to here as "gap-inventory species" and include ${ }^{14} \mathrm{C},{ }^{135} \mathrm{Cs}$, ${ }^{137} \mathrm{Cs},{ }^{129} \mathrm{I},{ }^{99} \mathrm{Tc}$, and ${ }^{79} \mathrm{Se}$. The species are characteristically mobile and highly soluble in water. Typically, 1 to $2 \%$ of their inventories are present in these regions of instantaneous release (Apted et al., 1989). The gap-inventory species and their gap fractions used in TSPA-1995 are given in Table 6.2-1. All other radionuclides listed in Table 3.7-1 are assumed to be located in the spent fuel matrix. The gap fractions of gap-inventory species are assumed to be available for immediate release as soon as both waste package container and cladding fail.

The distribution of the ${ }^{14} \mathrm{C}$ gap inventory in Table $6.2-1$ represents the uncertainty of ${ }^{14} \mathrm{C}$ inventory in the gap and the oxidation layer on the cladding surface, and is the same as used in TSPA-1993 (Andrews et al., 1994). Van Konynenburg, et al., (1986) reported that about $65 \%$ of the total ${ }^{14} \mathrm{C}$ inventory is present in cladding, crud and other fuel assembly hardware. However, only the ${ }^{14} \mathrm{C}$ in the gap and the grain boundary of the spent fuel matrix (about $1 \%$ ), and in an oxidation layer on the surface of the cladding is available for instantaneous release. The release rate for the rest of the ${ }^{14} \mathrm{C}$ is considerably slower (Barnard, et al., 1992). The release of ${ }^{14} \mathrm{C}$ is calculated assuming that all the ${ }^{14} \mathrm{C}$ available at a given simulation period migrates out of the EBS as a gas and then dissolves in the aqueous phase, i.e. no gaseous transport in the geosphere is considered.

The second release mode is matrix release in which the release rates of radionuclides are proportional to fuel matrix alteration/dissolution rate. Radionuclides released in this mode are referred to here as "matrix-release species", and may be grouped by their solubility limits into alteration/dissolution-limited species for highly soluble species and solubility-limited species for relatively insoluble species.

\section{Spent Fuel Dissolution Model}

A semi-empirical model for intrinsic dissolution (alteration) rate of the spent fuel matrix was developed from the experimental data reported by Gray, et al., (1992) and Steward and Gray (1994). In this TSPA, the post-closure environment inside the potential repository is assumed to maintain the atmospheric oxygen partial pressure of 0.2 atm. The model is expressed as a function of temperature, total carbonate concentration and $\mathrm{pH}$ of contacting water as follows

$$
\log k_{S F}=a_{0}+\frac{a_{1}}{T}+a_{2} \log \left[\mathrm{CO}_{3}\right]+a_{3} p H+\varepsilon
$$

where $\mathrm{k}_{\mathrm{SF}}$ is the intrinsic dissolution rate of spent fuel $\left(\mathrm{mg} / \mathrm{m}^{2} \cdot\right.$ day $), \mathrm{T}$ is temperature $(\mathrm{K}),\left[\mathrm{CO}_{3}\right]$ is the total carbonate concentration of the contacting groundwater (in molarity units), and $\varepsilon$ is a term representing uncertainty not included in the model. The parameter values determined for

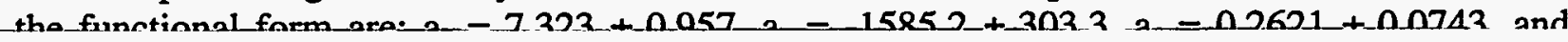

effects, sensitivity analyses on cladding failure include a factor of 100 for the spent fuel surface area of those fuel rods which are exposed due to cladding rupture.

\subsubsection{Alteration/Dissolution of DHLW Glass Waste Form}

As in the spent fuel alteration/dissolution modeling discussed above, the entire surface area of DHLW glass waste form is assumed to be exposed to the near-field environment as soon as the 
used in TSPA-1993 which was derived from Bourcier's temperature dependent estimates of Q and $\mathrm{K}$ and is given as

$$
\frac{Q}{K}=0.1425+0.001878 T
$$

where $\mathrm{T}$ is in ${ }^{\circ} \mathrm{C}$.

The intrinsic glass dissolution rate model as a function of temperature and $\mathrm{pH}$ is presented in Figure 6.2-5 along with the rate data from Bourcier (1993). In Figure 6.2-6 the glass dissolution rate calculated using Equation 6.2-3 and the previous relation from TSPA-1993 are shown as functions of temperature at $\mathrm{pH}$ of 7 . The figure shows that the current dissolution rate model predicts monotonically increasing dissolution rate with temperature.

The dissolution conceptualization presented here embodies several assumptions and limitations. The radionuclides are assumed to be released as fast as the glass structure breaks down, which is conservative because it does not account for solubility-limited radionuclides. No credit is taken for the fact that "experiments have shown that the actinides more commonly are included in alteration phases at the surface of the glass either as minor components of other phases or as phases made up predominantly of actinides" (Bourcier, 1993). The model does not include any solution chemistry other than $\mathrm{pH}$ and dissolved silica concentration. However, a variety of experiments show that species such as dissolved $\mathrm{Mg}$ and $\mathrm{Fe}$ can change glass dissolution rates by up to several orders of magnitude, with $\mathrm{Mg}$ decreasing the rate and $\mathrm{Fe}$ increasing the rate (Bourcier, 1993). The model also does not include vapor-phase alteration of the glass. Glass has been observed to undergo hydration in a humid-air environment and, upon subsequent contact with water, radionuclide releases from a hydrated glass layer were several orders of magnitude higher than those from an unhydrated (fresh) glass waste form (Bates, et al, 1990; Bourcier, 1993; Ebert and Bates, 1995; Bates, et al, 1995). These observations should be considered in future glass waste form performance modeling.

\section{DHLW Glass Surface Area}

Nominal surface area of a DHLW glass monolith (or $\log$ ) is $5 \mathrm{~m}^{2}$ per canister, and the surface area is increased by a factor of 10 to 30 per canister to account for the cracks that form during cooling following the glass pouring, leading to a glass surface area of 50 to $150 \mathrm{~m}^{2}$ per canister (Bourcier, 1993). The current design concept calls for a DHLW disposal container with fourpour canisters; thus, the total surface area of DHLW glass waste form per waste-disposal container is from 200 to $600 \mathrm{~m}^{2}$. As in TSPA-1993, the surface area range is assumed to be distributed uniformly.

\subsection{SOLUBILITY-LIMITED AQUEOUS RADIONUCLIDE CONCENTRATIONS}

\subsubsection{Introduction}

The term solubility refers to the equilibrium concentration of a solute (phase A) dissolved into a solvent (phase B) which produces a saturated solution of that solute at a fixed set of system conditions (e.g., temperature, pressure). The relation between solubility of a solute phase and 
its constituent elemental concentrations in the saturated solution is given by the stoichiometry of the solute phase. At the solubility limit, the solution concentration of any particular solute element is dependent upon the solvent composition including $\mathrm{pH}$, the initial concentration(s) of any other solute constituent(s), and complexing agents. The elemental solubility refers to the solution concentration of an element that is controlled by the equilibrium solubility of a saturated phase containing that element.

In TSPA-1995, calculated bounds on the aqueous concentration of radionuclides in ground water that has reacted with the waste form are derived initially from the waste form dissolution model. Subsequently another filter is applied which compares the dissolution-based aqueous radionuclide concentration with a solubility-limited value that is sampled from either a distribution of solubility limits for radionuclide-bearing minerals, or a functional form for the solubility limit for each radionuclide considered. If the sampled solubility-limited value is lower for a given radionuclide than its concentration derived from the waste form dissolution, then the aqueous concentration is set to the solubility-limited value and the difference in mass is calculated to "precipitate" out of solution. These solubility-limited values place constraints upon the aqueous concentration of the particular radionuclide element considered, with each isotope of that element present in proportion to its isotopic abundance.

This analysis does not include solubility limits with all their functional dependencies explicitly represented. These dependencies include temperature (and to a lesser extent pressure) and compositional parameters of both the concentration-limiting solid phase and the aqueous solution (e.g., $\mathrm{pH}$, oxygen fugacity, concentrations of other metals and ligands). However, for some of the radionuclides ( $\mathrm{Np}, \mathrm{Pu}$, and $\mathrm{Am}$ ), experimental studies of their steady-state concentration limits in modified J-13 water compositions have been used to derive empirical relations describing the temperature and $\mathrm{pH}$ dependence for their aqueous concentrations. These results are used to evaluate the release of these radionuclides based on explicit dependence for both $\mathrm{pH}$ and temperature (based on thermal loading etc.), and to evaluate the sensitivities relative to using sampled distributions included in the nominal-case calculations. Both the nominal-case distributions and functional forms used in this analysis for radionuclide solubility limits are discussed below in detail.

\subsubsection{Nominal-Case Distributions}

The concentration of aqueous radionuclides in groundwater reacting with spent fuel or glass waste has a complex dependence on the composition and phase assemblage of the waste form, the composition of the aqueous phase (e.g., pH, dissolved carbonate, oxygen fugacity), and the conditions at which reaction occurs (e.g., temperature, pressure). For many of the radionuclides considered in this analysis, explicit representation of these dependencies is not currently possible in a comprehensive manner. In addition, constraints on the system conditions which would effect aqueous radionuclide concentrations are not currently fully defined/quantified. In order to account for these uncertainties, the ranges of possible radionuclide concentrations that would be controlled by radionuclide-bearing mineral equilibration with ground water (solubility-limited concentrations) are represented as probability distributions, in general. By randomly sampling these distributions of solubility-limited aqueous radionuclide concentrations in each realization, Performance Assessment can implicitly encompass a range of possible system conditions and assess the potential consequences of this variability. For the nominal-case analyses presented 
below, distributions of solubility-limited concentrations for the radionuclides of Ac, $\mathrm{Am}, \mathrm{Cm}, \mathrm{Cs}$, $\mathrm{Nb}, \mathrm{Ni}, \mathrm{Np}, \mathrm{Pa}, \mathrm{Pb}, \mathrm{Pd}, \mathrm{Pu}, \mathrm{Ra}, \mathrm{Se}, \mathrm{Sm}, \mathrm{Sn}, \mathrm{Tc}, \mathrm{Th}, \mathrm{U}$, and $\mathrm{Zr}$ are given in Table 6.3-1 and discussed in this section. Table 6.3-1 provides the radionuclide, the type of distribution used, the variable of the distribution as either concentration or $\log$ (concentration), the parameters for the distribution in units of $\mathrm{g} / \mathrm{m}^{3}$ and molarity, and the source of the information.

The distributions of concentration limits are based primarily on an elicitation of chemical/geochemical experts held at Sandia National Laboratories on April 13, 1993 (Elicitation-Gauthier, 1993). Judgement of the expert panel was based on both empirical studies and modeling results, but did not include consideration of distributions used in the 1991 TSPA (Barnard et al., 1992). The results of the expert elicitation were reviewed in 1993 by the Solubility Working Group (SolWoG is composed primarily of project scientists conducting actinide solubility/speciation studies) which recommended only two modifications to the distributions of $\mathrm{Np}$ and $\mathrm{Pu}$ as discussed below. The assumptions behind the Elicitation's development of the distributions are: (1) the unsaturated zone water composition is between the composition of J-13 well water and that of $\mathrm{UE}-25 \mathrm{p \# 1}$; (2) the solubility-limits will be determined by the far-field ground-water environment; (3) the environment is oxidizing; and (4) future climate changes will cause ground-water compositional changes. As discussed below and shown in Table 6.3-1, a number of additional sources were used to further constrain distributions of solubility limits for the radionuclides used in this analysis.

\section{$\mathrm{C}, \mathrm{Cl}$, and I}

The Elicitation results (Gauthier, 1993) indicate that the solubility-limits on aqueous concentrations for these elements were all very high and would probably result in high dissolved concentrations. A reasonable value to use was given as 1 mole per liter (1 molar) for each of these which would place them into the dissolution-controlled regime. Each of these elements may form volatile species (e.g., Van Konynenberg, et al., 1987; Bullen, 1992). In the base case of this analysis, these elements are treated as gaseous, and hence their releases from waste packages are controlled by their presence in the gap-fraction and/or by waste form dissolution, not by solubility limits. The released "gases" are allowed to migrate uninhibited through the EBS, whereupon they are transferred into the aqueous phase. These radionuclides $\left({ }^{14} \mathrm{C},{ }^{36} \mathrm{Cl}\right.$, and $\left.{ }^{129} \mathrm{I}\right)$ are then treated as unretarded dissolved species throughout the rest of the transport calculation and ultimately contribute to the calculated dose. The release of ${ }^{14} \mathrm{C}$ along gaseous pathways was evaluated in TSPA-1993 (Andrews et al., 1994), but because dose calculations were based on drinking of well water, that radionuclide did not contribute to those calculated doses. In a sensitivity study of the effects of a diffusive barrier on transport of $\mathrm{Cl}$ and I out of the EBS as dissolved components, the solubility-limiting values of 1 molar were applied. The results are discussed in Chapter 8.

\section{Ac, Am, and Sm}

A single uniform distribution is used for each of these elements as a result of the 1993 Elicitation (Gauthier, 1993). In the Elicitation, it was indicated that both Ac and Sm should be taken as analogous to Am. The distribution chosen was based on the range of values from the recent measurements of steady-state Am concentrations in both J-13 and UE-25p\#1 ground waters (Nitsche et al., 1993; 1994). The distribution is shown in Figure $6.3-1$ and the parameters are 
given in Table 6.3-1. This uniform distribution of concentrations is shown in two ways. A linear representation (Figure 6.3-1A) emphasizes the uniform nature of the distribution, and a logarithmic representation (Figure 6.3-1B) emphasizes the range of values. Both of the views in Figure $6.3-1$ indicate that $\sim 90 \%$ of values sampled from this distribution would come from between concentrations of $1 \times 10^{-7}$ and $1 \times 10^{-6}$ molar.

\section{$\underline{\mathrm{Cm}}$}

As was done for $\mathrm{Cm}$ in TSPA-1993 (Andrews et al., 1994), the measured concentrations of $\mathrm{Cm}$ in $\mathrm{J}-13$ ground water from Wilson's dissolution experiments $\left(1.2 \times 10^{-5} \mathrm{gm} / \mathrm{m}^{3}\right.$ at $25^{\circ} \mathrm{C}$, and $1.5 \times 10^{-9} \mathrm{gm} / \mathrm{m}^{3}$ at $85^{\circ} \mathrm{C}$ - Jardine, 1991) were used in TSPA-1995. In the absence of any estimate of the error, a log-triangular distribution was assumed that extended one order of magnitude in each direction from each measured value. The temperature at which the solubility limit was switched from one distribution to the other was selected to be $55^{\circ} \mathrm{C}$, the mid-point of the two temperatures. The parameters for these distributions are given in Table 6.3-1 and the distributions are shown in Figure 6.3-2.

\section{$\mathrm{Cs}, \mathrm{Se}$, and Tc}

For Cs, Se, and Tc, the solubility-limits were constrained by the Elicitation (Gauthier, 1993) to be large such that release of these radionuclides would probably be controlled by dissolution of the waste form. Therefore, $\log$-triangular distributions for these elements (see Table $6.3-1$ and Figures 6.3-3, 6.3-12, and 6.3-14 for $\mathrm{Cs}$, Se, and Tc, respectively) were taken from the previous compilation of Golder (1993), which was based in part on the literature evaluation done by the Electric Power Research Institute (EPRI, 1992). These ranges of values allow this analysis to encompass implicitly a variety of possible conditions. Because these distributions encompass elemental concentrations controlled by highly soluble salts, they result in dissolution limited release for these radionuclides in general. It should be noted that very soluble salts have uncertain application to constraining dissolved elemental concentrations in natural systems, unless there is a large source of such salts, and it may therefore be possible in the future to constrain further the distributions of solubility-limits for these elements.

$\underline{\mathrm{Nb}}$

The Elicitation (Gauthier, 1993) based the log-uniform distribution for solubility-limited $\mathrm{Nb}$ concentration on the data given in Andersson (1988). This distribution is shown in Figure 6.3-4 and the parameters are given in Table 6.3-1.

\section{$\underline{\mathrm{Ni}}$}

The Elicitation (Gauthier, 1993) based the log-beta distribution for solubility-limited $\mathrm{Ni}$ concentrations on the data given in Andersson (1988) and clata from the caisson experiment at Los Alamos National Laboratory (Siegel et al., 1993). The parameters for this distribution are given in Table 6.3-1. In TSPA-1993 (Andrews et al., 1994) this distribution was approximated by a log-normal distribution which has been replaced with the log-beta distribution for this analysis. As shown in Figure 6.3-5, the TSPA-1993 approximation is similar to the TSPA-1995 distribution. 
The distribution for solubility-limited $\mathrm{Np}$ concentrations used in this study represents a minor modification (as recommended by the Solubility Working Group-SolWoG) of the original distribution given by the Elicitation. The Elicitation (Gauthier, 1993) based the original log beta distribution on the range of values from the recent measurements of steady-state Np concentrations in both J-13 and UE-25p\#1 ground waters (Nitsche et al., 1993; 1994) together with ongoing research at Los Alamos National Laboratory. In reviewing the proposed distributions, the SolWoG suggested that the minimum value be changed from $1 \times 10^{-8}$ to $5 \times 10^{-6}$ molar, but did not indicate how to adjust the coefficient of variation or the expected value (Dyer, 1993). It was decided for this study that a reasonable procedure was to adjust these values so that the shape of the modified distribution was similar to that of the original distribution, except for the lack of a tail at low values of $\log (\mathrm{Np}$ concentrations). The original and modified log-beta distributions are shown in Figure 6.3-6 where it can be seen that the change makes the moderate values more probable at the expense of the probability of very low values of $\log (\mathrm{Np}$ concentration). The parameters for the modified distribution are given in Table 6.3-1.

Pa

The Elicitation (Gauthier, 1993) based the range of the log-uniform distribution for solubilitylimited $\mathrm{Pa}$ concentrations on the data given in Andersson (1988). A log-uniform distribution was assigned because the panel agreed that $\mathrm{Pa}$ should be less soluble than suggested by the range of values, and that the distribution should have a large variance and be skewed to low values. This distribution is shown in Figure 6.3-7 and the parameters are given in Table 6.3-1.

$\underline{\mathrm{Pb}}$

The Elicitation (Gauthier, 1993) based the log-beta distribution for solubility-limited $\mathrm{Pb}$ concentrations on the data range given in Andersson (1988) and other previous work on this element (Pei-Lin et al., 1985). It was noted also that the concentration of dissolved $\mathrm{Pb}$ is sensitive to the amount of dissolved carbonate. The parameters for this distribution are given in Table 6.3-1. In TSPA-1993 (Andrews et al., 1994) this distribution was approximated by a log normal distribution which has been replaced with the log beta distribution for this analysis. As shown in Figure 6.3-8, the TSPA-1993 approximation is similar to the TSPA-1995 distribution.

$\underline{P d}$

The distribution of solubility-limits for Pd given by Golder (1993) is a log-uniform distribution with a minimum of $1 \mathrm{~g} / \mathrm{m}^{3}$ and a maximum of $1 \times 10^{5} \mathrm{~g} / \mathrm{m}^{3}$. This was given as an estimated distribution to cover a large range of concentrations because there was a lack of readily available data. Because Pd is one of the noble metals and belongs to the platinum-group elements (PGE) (which as a group tend to have limits on their aqueous concentrations which are in general lower than many other metals- see Sassani, (1992) and references therein), this range of values appears to be extremely high. For this analysis, the maximum value for the Pd-distribution has been reduced to $1 \times 10^{4} \mathrm{~g} / \mathrm{m}^{3}\left(9.4 \times 10^{-2}\right.$ molar), a value which is still viewed as conservative. Additional justification that this lowered maximum is conservative comes from comparison 
between the.other estimated distributions given by Golder (1993) for $\mathrm{Nb}, \mathrm{Pa}$, and $\mathrm{Pb}$, and the corresponding distributions given by the Elicitation (Gauthier, 1993) which are from 5 to 8 orders of magnitude lower. The modified distribution for $\mathrm{Pd}$ is shown in Figure 6.3-9 and the parameters are given in Table 6.3-1. Further refinement of the distribution of solubility-limits for Pd will probably lead to much lower values in future total system performance assessments.

$\underline{\mathrm{Pu}}$

The distribution for solubility-limited Pu concentrations used in this study represents a minor modification (as recommended by the Solubility Working Group-SolWoG) of the original distribution given by the Elicitation. The Elicitation (Gauthier, 1993) assigned the original uniform distribution as identical to that for Am and this was used in TSPA-1993 (Andrews et al., 1994). In reviewing the proposed distributions, the SolWoG suggested that the minimum value be changed from $1 \times 10^{-10}$ to $1 \times 10^{-8}$ molar (Dyer, 1993; Wilson et al., 1994), based on the range of values from the recent measurements of steady-state $\mathrm{Pu}$ concentrations in both $\mathrm{J}-13$ and UE-25p\#1 ground waters (Nitsche et al., 1993; 1994). Because the values below $1 \times 10^{-8}$ molar would have represented only about $1 \%$ of the samples for the unmodified distribution, this change is not expected to substantially impact the results of this study. The modified distribution is shown in Figure 6.3-10 and the parameters are given in Table 6.3-1. This uniform distribution of $\mathrm{Pu}$ concentration is shown in two ways in Figure 6.3-10. A linear representation (Figure 6.3-10A) emphasizes the uniform nature of the distribution, and a logarithmic representation (Figure 6.3-10B) emphasizes the range of values. Both of the views in Figure 6.3-10 indicate that $90 \%$ of values sampled from this distribution would come from between concentrations of $1 \times 10^{-7}$ and $1 \times 10^{-6}$ molar.

$\underline{\mathbf{R a}}$

The Elicitation (Gauthier, 1993) based the log-beta distribution for solubility-limited $\mathbf{R a}$ concentrations on the calculations done by Kerrisk (1984) noting that these limits should be similar to those for barium $(\mathrm{Ba})$ and dependent upon the presence of sulfate in the ground water. It was noted in the Elicitation that $\mathrm{Ra}$ should only form a single cation and that the solubility limits should be relatively unaffected by compositional variations in the ground water. The elicited distribution is shown in Figure 6.3-11 and the parameters are given in Table 6.3-1.

$\underline{\text { Sn }}$

The Elicitation (Gauthier, 1993) noted that the elemental solubility of $\mathrm{Sn}$ is very low and based the uniform distribution for solubility-limited Sn concentrations on the data range given in Andersson (1988) and the consensus that any value was equally likely. The elicited distribution is shown in Figure 6.3-13 and the parameters are given in Table 6.3-1. This uniform distribution of $\mathrm{Sn}$ concentration is shown in two ways in Figure 6.3-13. A linear representation (Figure 6.3-13A) emphasizes the uniform nature of the distribution, and a logarithmic representation (Figure 6.3-13B) emphasizes the range of values. Both of the views in Figure 6.3-13 indicate that $\sim 90 \%$ of values sampled from this distribution would come from between concentrations of $1 \times 10^{-8}$ and $1 \times 10^{-7}$ molar. 
The Elicitation (Gauthier, 1993) noted that the elemental solubility of Th should be less in general than either Am or Pu making it relatively unimportant and that the range of values were well defined, similar to Am. The Elicitation also indicated that the distribution should make the lower values more probable and derived a log-uniform distribution for solubility-limited $\mathrm{Th}$ concentration. The elicited log uniform distribution is shown in Figure 6.3-15 and the parameters are given in Table 6.3-1.

$\underline{\mathrm{U}}$

The Elicitation (Gauthier, 1993) noted that the elemental solubility of U should be higher in general than either Am or Pu but also that it was not expected that solubility-limits for U would be a factor in release of $U$ in Yucca Mountain even though the ground water contains dissolved silica which could cause uranium silicates to precipitate. The Elicitation panel indicated that the data for $U$ (Wanner and Forest, 1992) have a wide range with a central tendency between $1 \times 10^{-5}$ and $1 \times 10^{-4}$ molar and about 1 order-of-magnitude spread (Gauthier, 1993; Wilson et al., 1994). Based on this information, the Elicitation resulted in a log-beta (skewed log-normal) distribution for solubility-limited $U$ concentrations which is shown in Figure 6.3-16. The parameters for this distribution are given in Table 6.3-1.

\section{$\underline{\mathrm{Zr}}$}

The Elicitation (Gauthier, 1993) noted that the elemental solubility of $\mathrm{Zr}$ is very low and based the log-uniform distribution for solubility-limited $\mathrm{Zr}$ concentration on the data range given in Andersson (1988). The Elicitation panel selected a logarithmic distribution to emphasize the probability of the lower values which they concluded were more likely. The elicited log-uniform distribution is shown in Figure 6.3-17 and the parameters are given in Table 6.3-1.

\subsubsection{Sensitivity Cases for Solubility-Limited Aqueous Radionuclide Concentrations}

Although the distributions listed in Table 6.3-1 encompass implicitly a range of potential variation in system parameters, explicit incorporation of the major variables affecting the aqueous concentrations of radionuclides allows for more direct examination of parameters which impact the performance of the potential repository system. In addition, the distributions discussed above do not incorporate potential effects of near-field compositional variations which could result in fluids reacting with the waste form which are very different from those in the natural system. Such changes in the near-field fluid compositions should lead to changes in the constraints on the phases controlling the concentrations of dissolved radionuclides. Because the actual changes to the near-field environment are not yet well-defined, incorporation of such effects either into distributions such as those discussed above or into models for predicting the solubility-controlling phases for each radionuclide is not currently possible.

\section{Experimental Studies of Steady-State $\mathrm{Np}, \mathrm{Pu}$, and Am Concentrations}

A more-limited sensitivity study of the explicit temperature and $\mathrm{pH}$ dependencies of dissolved $\mathrm{Np}, \mathrm{Pu}$, and $\mathrm{Am}$ is developed in this analysis using the empirical measurements of Nitsche et al. 
(1993) for the dissolved concentrations of these radionuclides in J-13 initial water. The experiments were conducted from oversaturation with temporal measurements of dissolved radionuclide concentrations to derive steady-state concentrations for $\mathrm{Np}, \mathrm{Pu}$, and $\mathrm{Am}$ as functions of both $\mathrm{pH}(\sim 6,7$, and 8.5$)$ and temperature $\left(25^{\circ}, 60^{\circ}\right.$, and $\left.90^{\circ} \mathrm{C}\right)$. As discussed below, these data are used here to derive empirical relations for the $\log$ (concentrations) of $\mathrm{Np}, \mathrm{Pu}$, and $\mathrm{Am}$ as functions of temperature and $\mathrm{pH}$. Although there are a number of caveats as discussed below, these functions allow more explicit consideration of the effects of the variations in temperature and $\mathrm{pH}$ which is a first step in building a higher level of realism into the way Total System Performance Assessments constrain the aqueous concentrations of radionuclides.

An additional study which analyzed temperature and $\mathrm{pH}$ dependencies of dissolved $\mathrm{Np}, \mathrm{Pu}$, and Am in UE-25p\#1 initial water (higher carbonate concentration than J-13 water) from oversaturation (Nitsche et al., 1994) indicates that, compared to the results for J-13 initial water, the steady-state concentrations for $\mathrm{Np}$ are lower, and for $\mathrm{Pu}$ are within one order of magnitude in all cases ( $\mathrm{pH} \sim 6,7,8.5$ and temperature $25^{\circ}, 60^{\circ} \mathrm{C}$ ). Measured steady-state concentrations of Am in UE-25p\#1 initial water are 2 to 3 orders of magnitucle as large as the $\mathrm{J}-13$ study values at $25^{\circ} \mathrm{C}$ and all $\mathrm{pH}$ values, but are lower than those determined in $\mathrm{J}-13$ initial water at $60^{\circ} \mathrm{C}$. As a test of whether the experiments in these studies were approaching an equilibrium (metastable or stable) situation at the steady state, a set of experiments were conducted using the solid products of the previous oversaturation studies to approach the steady-state concentrations from undersaturation in UE-25p\#1 initial water at $60^{\circ} \mathrm{C}$ (Nitsche et al., 1995). In general, the results of Nitsche et al. (1995) are similar to the oversaturation studies for $\mathrm{Np}$ at all $\mathrm{pH}$ values, but show some disagreement for $\mathrm{Pu}$ and $\mathrm{Am}$ oversaturation results, generally at high $\mathrm{pH}$.

The measurements in $\mathrm{J}-13$ initial water were fit empirically as functions of temperature and $\mathrm{pH}$ and used in an analysis of sensitivity for the following reasons: (1) the water from $J-13$ (tuff aquifer) is more likely to be representative of the water that will occur within the proposed repository horizon than the water from UE-25p\#1 (deeper Paleozoic carbonate aquifer); (2) most of the previous solubility-limited studies assumed J-13 water (e.g., PNL's TSPA-91-Eslinger et al., 1993); (3) data are determined at more, and to higher, temperatures for J-13 water compared to UE-25p\#1 water (Nitsche et al. 1993; 1994); and (4) the steady-state concentrations of $\mathrm{Np}$ and $\mathrm{Pu}$ vary by only about an order of magnitude between the two waters.

\section{Functional Fits to the Steady-State Concentration Determinations}

In TSPA-1993 (Andrews et al., 1994), the empirical data were fit with functions representing the temperature dependence for equilibrium thermochemical relations for a single solid-phase solubility reaction. However, the empirical determinations (Nitsche et al., 1993) do not meet all the criteria required to accurately apply such relations (e.g., demonstration of attainment of (stable or metastable) equilibrium between a single solid with the aqueous solution). Therefore this treatment is not used in TSPA-1995 and is replaced with an empirical fit of the data in order to reproduce the temperature and $\mathrm{pH}$ dependence of the measurements. Because it was decided to derive temperature- and $\mathrm{pH}$-dependent functional forms for values of the $\log _{10}$ (radionuclide concentration) (i.e., $\log \left(\mathrm{C}_{\mathrm{RN}}\right)$ ), the original raw determinations reported in the Appendices of Nitsche et al. (1993) were reexamined in order to recast the observations as log-normal distributions. 
The derived averages and standard deviations of $\log \left(\mathrm{C}_{\mathrm{Np}}\right), \log \left(\mathrm{C}_{\mathrm{Pu}}\right)$, and $\log \left(\mathrm{C}_{\mathrm{Am}}\right)$ are listed in Tables $6.3-2,6.3-3$, and $6.3-4$, respectively, with the conditions and the range of samples (Nitsche et al., 1993) used to calculate the tabulated values for each determination. In addition, the last column of Tables 6.3-2, 6.3-3, and 6.3-4 contains the radionuclide concentration corresponding to the average $\log \left(\mathrm{C}_{\mathrm{RN}}\right)$ (note that this value should always be smaller than the average of the concentration). Comparison of the these values with those reported in Nitsche et al. (1993) indicates that there is not a substantial difference introduced by this treatment. However, this treatment allows for direct inclusion of the uncertainties on the empirical values in the comparison of the functional fits for $\log \left(C_{\mathrm{Rn}}\right)$. During reexamination of the empirical determinations of the steady-state concentration measurements for $\mathrm{Np}, \mathrm{Pu}$, and $\mathrm{Am}$ (Nitsche et al., 1993) three of the determinations were not used. Because they appear to be increasing with time, the temporal measurements of $\mathrm{Np}$ concentration at $60^{\circ} \mathrm{C}$ and $\mathrm{pH}$ of $\sim 7$ were interpreted as not representative of an approach to steady-state. This was also the conclusion for the measurements of Am concentration at $60^{\circ} \mathrm{C}$ and $\mathrm{pH}$ of $\sim 7$ which show a general increase over the last half of the determinations. Also not used in this analysis was the determination of steadystate Am concentration at $60^{\circ} \mathrm{C}$ and $\mathrm{pH}$ of $\sim 6$ which, as discussed by Nitsche et al. (1993), appears to be controlled by metastable persistence of the orthorhombic solid causing grossly higher values relative to the rest of the Am determinations.

The empirical results for steady-state concentrations of $\mathrm{Np}, \mathrm{Pu}$, and $\mathrm{Am}$ (Nitsche et al., 1993) indicate that either different phases developed at different conditions in the experimental studies, each of which may or may not have been at equilibrium with the aqueous phase, or that there were mixtures of phases. Therefore, there are not many theoretical thermochemical constraints which can be readily used to guide the functional form to use for fitting the results. The two external guides for fitting the data that we applied were: (1) the $\mathrm{pH}$ dependence was represented as the difference between the $\mathrm{pH}$ of the determination and neutral $\mathrm{pH}$ at that temperature $(\Delta \mathrm{pH})$; and (2) the fits were constrained such that the isothermal sections of the functions were concave upwards along the $\Delta \mathrm{pH}$ axis. The values used for neutral $\mathrm{pH}$ at temperatures from 10 to $100^{\circ} \mathrm{C}$ were calculated using SUPCRT92 (Johnson et al., 1992).

In order to obtain useful functional fits for the purpose of this analysis, least-squares regression was applied to the data in Tables 6.3-2, 6.3-3, and 6.3-4 using numerous polynomial functions constructed from combinations of inverse, linear, and quadratic temperature (T) terms, linear and quadratic $\Delta \mathrm{pH}$ terms, and their interaction terms. A combination of goodness-of-fit and minimization of terms was used to guide the selection of the final fit functions without regard to obtaining the same form for each radionuclide. The temperature- and $\mathrm{pH}$-dependent functions obtained to calculate the expected values are:

(1) for Neptunium

$$
\log _{10} C_{\mathrm{Np}}=-39.7+0.374(\Delta \mathrm{pH})^{2}+0.212 \mathrm{~T}-3.41 \times 10^{-3} \mathrm{~T}(\Delta \mathrm{pH})-3.06 \times 10^{-4} \mathrm{~T}^{2}
$$


(2) for Plutonium

$$
\log _{10} C_{\mathrm{Pu}}=0.124-0.876(\Delta \mathrm{pH})^{2}-0.0229 \mathrm{~T}+329.9 \frac{(\Delta \mathrm{pH})^{2}}{\mathrm{~T}}
$$

and; (3) for Americium

$$
\log _{10} C_{A m}=-9.02+0.0118 \mathrm{~T}(\Delta \mathrm{pH})+8.54 \times 10^{-4} \mathrm{~T}(\Delta \mathrm{pH})^{2}-3.96 \times 10^{-5} \mathrm{~T}^{2}(\Delta \mathrm{pH})
$$

where

$$
(\Delta \mathrm{pH})=\mathrm{pH}-\mathrm{pH}_{\mathrm{N}}
$$

and $\mathrm{pH}_{\mathrm{N}}$ represents neutral $\mathrm{pH}$ and temperature is in Kelvin.

The temperature-dependent, iso-pH sections of these functions are shown as solid curves in Figures 6.3-18, 6.3-19, and 6.3-20 for $\mathrm{Np}, \mathrm{Pu}$, and $\mathrm{Am}$, respectively, with their one standard deviation uncertainty envelopes shown by the dashed curves (note: for purposes of clarity, only the uncertainty envelope for the lowest $\mathrm{pH}$ curve is shown in Figures 6.3-19, and 6.3-20). Also shown in these figures are the corresponding empirical data points with error bars of two standard deviations (from Tables 6.3-2, 6.3-3, and 6.3-4, respectively) which are generally within the uncertainty envelopes of the fitted functions.

Comparisons of these functional fits with the concentration ranges of their corresponding TSPA1995 distributions are shown in Figures 6.3-21, 6.3-22, and 6.3-23 for $\mathrm{Np}, \mathrm{Pu}$, and $\mathrm{Am}$, respectively. The ranges of values given by the functional fits for $\mathrm{Np}$ and $\mathrm{Pu}$ are essentially equivalent to their distribution ranges. However, Figure 6.3-23 shows that the maximum of the Am distribution is about 2.5 orders of magnitude higher than the maximum for the corresponding functional fit. Because the distribution for Am is based on the empirical studies (Nitsche et al., 1993 ; 1994), this discrepancy reflects in part the metastable, high concentration in J-13 initial water measured for Am at $60^{\circ} \mathrm{C}$ and $\mathrm{pH}$ of 6 , and the high $A . \mathrm{m}$ concentrations measured at $25^{\circ} \mathrm{C}$ in UE-25p\#1 initial water.

The functions represented by Equations 6.3-1, 6.3-2, and 6.3-3, and their uncertainties, are sampled for solubility-limits for $\mathrm{Np}, \mathrm{Pu}$, and $\mathrm{Am}$, respectively, in order to conduct sensitivity analyses of explicit parameter dependencies versus random sampling of the distributions used in the base case (Table 6.3-1). The estimates of $\log \left(C_{R_{n}}\right)$ provided by these fits incorporate two sources of uncertainty. The first contribution to the uncertainty is that associated with each of the regressed parameters which results from fitting to a finite data set. As such, the parameters are represented as multivariate normal distributions which are based on the means and covariance matrix from the regression. The second source of uncertainty stems from the discrepancy between the form of the fit and the actual structure of the $\mathrm{pH}$ and temperature dependence, as well as the fact that other variables contribute to the observations of $\log \left(C_{R n}\right)$ but have been 
ignored in the regression. This uncertainty is represented as an additional error term $(\varepsilon)$ to each of the functional relations given above. This term is sampled from a normal distribution with a mean of zero ( 0 ) and a standard deviation determined from the sum of the squares of the residuals of the fit. Within the sensitivity analysis, sets of fit parameters and values of $\varepsilon$ are sampled for each realization to generate the three relations used to estimate $\log \left(C_{R n}\right)$ during the realization based on its temperature profile and $\mathrm{pH}$.

There are a number of caveats for using the above functional fits to represent bounding estimates of the $\mathrm{pH}$ and temperature dependencies of solubility limits in $\mathrm{J}-13$ water because the empirical studies may not reflect the actual solubility-controlling reactions over the range of conditions because of phase metastability and do not obtain the same solid phase at each condition. First, it cannot be demonstrated directly that the systems attained any equilibrium state, because the experiments were not conducted from both over- and undersaturation. Although attainment of equilibrium was not directly demonstrated (Nitsche et al., 1993), the approach from oversaturation makes it likely that any kinetic constraints on the system provide concentrations that are higher that one would expect had equilibrium be achieved.

Second, even if equilibrium (stable or metastable) had been achieved in the experiments, there are different solid phases at different conditions. This allows the possibility in the studies that metastable phases controlled dissolved concentrations at low temperatures, whereas at higher temperatures stable phases set concentrations to lower values. Fitting such data with a temperature-dependent function may lead to an empirical fit which is decreasing at high temperature, whereas the solubility of the stable phase could be actually increasing with temperature. Such a situation would lead to underestimation of the dissolved concentration of radionuclides at temperatures higher than the empirical data. This would be the most pronounced for estimating the $\mathrm{Pu}$ and $\mathrm{Am}$ concentrations from their functional fits because they are decreasing steeply at higher temperatures. Because the functional fits are extrapolated only $10^{\circ} \mathrm{C}$ (to $100^{\circ} \mathrm{C}$ ), any underestimate of these values should be within the uncertainties of the functional fits.

Third, during the course of the experiments $\mathrm{HClO}_{4}$ and $\mathrm{NaOH}$ added to the $\mathrm{J}-13$ initial water to control pH (Nitsche et al., 1993) changed the composition from that of J-13 ground water. Initial process-level geochemical modeling of these experiments conducted at Los Alamos National Laboratory (Janecky et al., 1994) indicates that the added Na may have impacted (lowered) the measured dissolved $\mathrm{Np}$ concentration by changing the saturation state of the Na-neptunylcarbonate-hydrate phase present in the system. Therefore using the above derived functional fits as representative of solubility constraints in J-13 water may not be bounding. However, the model calculations also indicate that the $\mathrm{Na}$-neptunyl-carbonate-hydrate phase is approximately at metastable equilibrium, and that the stable equilibrium phase in this compositional system may be $\mathrm{NpO}_{2}$, which would control dissolved $\mathrm{Np}$ concentrations to much lower values (at least a few orders of magnitude). This result, combined with consideration of the uncertainties on the above derived functional fits, allows that these fits can be used to represent a nearly J-13 fluid composition as a bounding sensitivity case. However, progress in thermochemical modeling of solubility-limited concentrations of these and other radionuclides may provide additional constraints on dissolved radionuclide concentrations and more explicit compositional dependencies to be incorporated into future total system performance analyses. 


\subsection{COLLOID CONTRIBUTIONS TO MOBILE MASS OF RADIONUCLIDES}

\subsubsection{Introduction}

In addition to radionuclides dissolved in the aqueous phase, another potentially significant contribution to the mobile mass of radionuclides could come from colloids. Suspended in the aqueous phase, colloids are minute particles ranging in size from about $10^{-8} \mathrm{~m}(100 \AA)$ up to about $10^{-5} \mathrm{~m}\left(10^{5} \AA\right)$; a range which includes viruses at the low end and bacteria at the high end (Stumm and Morgan, 1981). Field studies of saturated-system radionuclide migration associated with underground nuclear tests (Buddemeier and Hunt, 1988) or with actinide contaminant plumes (Penrose et al., 1990) indicate that those systems possess a highly mobile colloidal component. The degree to which colloids will impact the performance of a potential repository at Yucca Mountain is currently uncertain. The state of knowledge concerning this issue is summarized by Triay et al. (1995a), who propose a strategy to assess the importance of colloids for a potential repository by focussing on three aspects: (a) the presence of colloids at the potential repository; (b) the stability of the colloids in the ground-water system; and (3) the ability of the colloids to migrate through the unsaturated and saturated hydrogeologic system. Although it is not currently possible to constrain quantitatively these aspects comprehensively, a summary of how these issues may be incorporated into total system performance assessment calculations is presented below.

In a potential repository environment there are two general types of colloids: (a) waste-form colloids which contain radionuclides as part of their structural mass; and (b) pseudocolloids which are comprised of small particles of other materials which adsorb radionuclides and may act as a mobilizing agent. Waste-form colloids include radiocolloids ("true" or real colloids) produced by agglomeration of hydrolysed actinides (e.g., Hobart et al., 1989) which form during initial precipitation from supersaturated solutions, and degradation colloids formed by physical deterioration of the waste material (or alteration products) itself (e.g., Bates et al., 1992). Pseudocolloids generated from the natural system minerals or natural organic matter are natural colloids, and those generated from substances introduced to study the site or produce a potential repository are introduced colloids. For this discussion, the various colloids are sufficiently distinguished by their sources as waste-form colloids, natural colloids, and introduced colloids.

\subsubsection{Assessment of Colloid Constraints}

As pointed out by Triay et al., (1995a), the abundance, stability, and ability to migrate should determine the relative impact to the performance of a potential repository for each of these groups of colloids. In general, the detailed quantitative constraints and models for each of these aspects are not available, and it is therefore difficult to eliminate any of the potential colloid types from consideration or to develop a comprehensive Performance Assessment model of the effects of colloids (Ramsay, 1988; McCarthy and Zachara, 1989; Manaktala et al., 1995; Gauthier, 1995; Triay et al., 1995b).

Waste Form Colloids

For waste form colloids, it has been shown that degradation colloids form from high-level waste glass and can comprise over $99 \%$ of the mobile Am and Pu (Bates et al., 1992), but their long- 
term stability is poorly understood. Studies by Feng et al. (1993) indicate that these types of colloids will agglomerate readily at high ionic strengths or low temperatures and settle out of the aqueous phase, but may resuspend if contacted by dilute fluids. Under acidic conditions stable $\mathrm{Pu}(\mathrm{IV})$ radiocolloids can form, but these may not be stable at higher $\mathrm{pH}$ (Hobart et al., 1989; Triay et al., 1991). Small-scale laboratory experiments on the transport of radiocolloids of both $\mathrm{Pu}(\mathrm{IV})$ and $\mathrm{Am}(\mathrm{III})$ through tuff columns indicate that most of the material was retained in the rock, but a minor portion moved through the system faster than a conservative tracer (Thompson, 1989).

\section{Introduced Colloids}

The major introduced substances in the potential repository environment that will be potential sources of introduced colloids include organic substances, steels, and cements leading to organic colloids, iron-oxy(hydroxy) colloids, and alumino-silicate colloids, respectively (Meike and Wittwer, 1993). Meike and Wittwer (1993) indicate that the ability of these colloids to migrate is dependent on a complex interrelation of many system variables including ionic strength, organic content, flow velocity, $\mathrm{pH}$, temperature, and oxidation state. However, because the distribution and abundance of the these introduced materials is uncertain and the ability to quantify the generation and stability of colloids resulting from these materials is lacking, incorporation of the quantitative details of their effects into performance assessment models is not currently possible.

\section{$\underline{\text { Natural Colloids }}$}

Natural colloids occurring at Yucca Mountain include inorganic colloids consisting essentially of clays, silica, and iron oxyhydroxides (Ogard 1987; Levy, 1992; Triay et al., 1995b) and organic colloids such as humic and fulvic acids (Minai et al., 1992). Such colloids may be able to enhance the transport of highly sorbing radionuclides such as $\mathrm{Pu}$ and $\mathrm{Am}$. The abundance and stability of the inorganic colloids have been characterized in a manner which could facilitate incorporation into Performance Assessment models (Triay et al., 1995b). The mass concentration of natural colloids of size greater than $200 \mathrm{~nm}$ in J-13 water was measured to be about $23 \mathrm{ng} / \mathrm{ml}$ (Triay et al., 1995b), which was similar to the value of $27 \mathrm{ng} / \mathrm{ml}$ measured by Ogard (1987) for natural colloids greater than $400 \mathrm{~nm}$. In order for these concentrations of natural colloids to account for $10 \%$ of a particular mobile radionuclide, Ogard (1987) calculated that a sorption distribution coefficient of greater than $4 \times 10^{6} \mathrm{ml} / \mathrm{g}$ was necessary for that radionuclide. This is much higher in general than the measured values or the values recommended to assess the effect of these colloids on trivalent and tetravalent actinides using an irreversible sorption assumption (Triay et al., 1995b).

Transport of natural colloids through the unsaturated zone may be affected by a number of processes including size/surface charge exclusion from matrix pores, agglomeration and sedimentation, and attachment of colloids to the rock wall, and is not well-modeled using filtration theory, particularly in systems with fractures (Triay et al., 1995a). The model calculations of unsaturated media effects on colloid transport by Nuttall et al. (1991) indicate that the hydrophobic colloids concentrate at the air/water interface and should move rapidly through the system at the highest flow velocity. In contrast, experimental work in unsaturated media by Wan and Wilson (1994) indicates that the hydrophobic colloids will be retarded and become 
irreversibly immobilized at the air/water interfaces in the unsaturated system. Hydrophobic colloid transport is greatly reduced under these conditions unless the interface itself is moving. This reduced transport was observed even for continuous interfaces through the system and was less pronounced but still present for hydrophyllic colloids (Wan and Wilson, 1994).

Because these natural colloids are similar in composition to the host rock in the system, a simplified model for transport of natural colloids was presented by Gauthier (1995) assuming reversible sorption onto the colloids. The simplified model based on the work of Vilks (1994) accounts for the transport effects of natural colloids simply by reduction of the retardation factor which is justified because the colloids sorb radionuclides in the same manner that the rock itself does. In this model, the radionuclide retardation factor $(R)$ is redefined by

$$
R=1+\frac{\rho_{b} K_{d}}{\theta\left(1+C_{c} F_{A} K_{d}\right)}
$$

where $\theta$ represents the fractional water content, $\rho_{b}$ signifies the bulk rock density, $K_{d}$ denotes the radionuclide distribution coefficient, $C_{c}$ refers to the colloid concentration, and $F_{A}$ indicates the adjustment factor for the $K_{d}$ to account for the colloid surface area. In this treatment, the total mobile mass of radionuclides cannot be resolved into its component parts corresponding to those radionuclides dissolved in the aqueous phase and those radionuclides which are sorbed onto the colloids. In addition, Gauthier (1995) outlines a second model to consider irreversible sorption onto colloids which requires incorporation of an entire additional set of transport equations for the colloid component of the mobile mass of radionuclides. Although this second model is a more flexible representation of the system, it effectively doubles the amount of calculation required.

\subsubsection{Incorporation of Colloids into Total System Performance Assessments}

All of the uncertainties outlined above in both the colloid component source terms, and in the stability and transport of colloids make it difficult to assess quantitatively the colloid contribution to the mobile radionuclide mass in a Total System Performance Analysis. However, from the above discussion it also appears that a first step can be made in the construction of a performance assessment model for the effects of the natural colloids on highly-sorbing radionuclides that have solubility-limited releases (such as Pu and Am). Such a model would account for the effects of natural colloids on both the source term for the mobile mass of radionuclides and for the effects on transport of that mobile mass.

The conceptual representation of how the effects of natural colloids on the source term would be incorporated into current performance assessment models is shown in Figure 6.4-1. Figure 6.4-1 shows that for a mass of spent fuel $\left(M_{s f}\right)$ the initial dissolved radionuclide mass $\left(M_{\text {dis }}\right)$ is controlled by the dissolution rate $\left(R_{\text {dis }}\right)$, the exposed area of spent fuel $(A)$, and the length of the time step $(t)$. This constrains the initial dissolved aqueous radionuclide concentration $\left(C_{\text {dis }}\right)$ given the volume of water in contact with the waste form $\left(\mathrm{V}_{\mathrm{w}}\right)$. At this point, a filter based on the sampled phase solubility-limit $\left(S_{i}\right)$ is applied. If $C_{\text {dis }}$ is less than $S_{i}$, then the mobile radionuclide concentration ( $C_{\text {mobile }}$ ) is set equal to $C_{\text {dis }}$; otherwise the aqueous radionuclide concentration $C_{a q}$ is set equal to $S_{i}$ and the extra radionuclide mass is allowed to "precipitate" $\left(M_{p}\right)$. At this point 
the concentration of radionuclide on the natural colloids $\left(\mathrm{C}_{\mathrm{col}}\right)$ can be calculated based on $\mathrm{C}_{\mathrm{gq}}$, the sorption distribution coefficient for the radionuclide on the natural colloid $\left(\mathrm{K}_{\mathrm{p}}\right)$, and the mass concentration of the natural colloid ([CoII $\left.]_{\mathrm{m}}\right)$. In this case the $\mathrm{C}_{\text {mobile }}$ is equal to the summation of the two mobile components of $\mathrm{C}_{\mathrm{aq}}$ and $\mathrm{C}_{\mathrm{col}}$. This would allow for calculation of the change in source term for actinides which have low solubility-limits and high sorption coefficients (e.g., $\mathrm{Am}$ and $\mathrm{Pu}$ ). Constraints on the abundance of the natural colloids and values of $\mathrm{K}_{\mathrm{P}}$ for trivalent and tetravalent actinides are presented in Triay et al. (1995b). For the first step in addressing the total mobile mass of $\mathrm{Am}$ and $\mathrm{Pu}$ in this system, the transport equations could be modified as recommended by Gauthier (1995) (Equation 6.4-1) to assess the sensitivity of Am and Pu releases to the natural colloid component in the system. In addition, future adaptations of more detailed approaches will be facilitated because the aqueous and colloidal radionuclide masses are kept explicitly separate in the source term.

\subsection{RADIONUCLIDE RELEASE MODELING}

\subsubsection{Approaches for Radionuclide Release Modeling}

Dominant cladding degradation mechanisms anticipated for given repository conditions (creep rupture and cladding splitting) were discussed in Section 5.6. The potential cladding degradation mechanisms and their effects on the performance of cladding as a barrier to radionuclide release have not been implemented in a detailed model in TSPA-1995. Thus, in the nominal case in TSPA-1995, performance credit for cladding is not included in the waste package and EBS release calculations discussed in Chapter 8 . Additionally, potential performance credit for the stainless steel MPC shell as an additional barrier is not included in the nominal case in TSPA1995. Similarly, for waste packages containing vitrified defense high-level waste (DHLW), the potential performance of the stainless steel pour canister as a barrier is not considered.

Accordingly, after a waste-disposal container failure, the waste forms contained inside (spent fuel pellets or monolithic glass $\log$ ) are assumed to be exposed immediately to the near-field environment, making them available for alteration/dissolution. Then, radionuclides may be released and transported through the failed waste package and underlying gravel invert to the edge of the engineered barrier system (EBS).

\subsubsection{Conceptual Models for Radionuclide Release}

Depending on ground-water flux around or through the waste package and EBS, radionuclide release mechanisms are characterized as diffusive release, advective release, or a combination of both. As discussed in Chapter 5 for the waste-disposal container degradation modeling, waste containers are assumed to fail by pitting corrosion, not by general corrosion. The waste container degradation models developed for TSPA-1995 predict the number of pits penetrating the container wall as a function of the emplacement time, relative humidity and temperature. Therefore, release of radionuclides by diffusion, advection, or both is restricted by the number of perforations on the "partially failed" waste container, i.e. by the area available for the release. Discussed below are the conceptual models and model development approaches for diffusive and advective releases. 
Figures 6.5-1 and 6.5-2 are the schematic diagrams for the cylindrical waste-disposal container in an emplacement drift viewed from the side and front respectively. The spent fuel assemblies and DHLW glass monolith are assumed to be distributed uniformly inside the waste container. To simplify the release calculation, the cylindrical waste container and the underlying invert are represented by an equivalent spherical configuration. Figure 6.5-3 shows the equivalent spherical configuration of the waste container with multiple perforations. The perforations are formed from pitting corrosion (see Chapter 5) and filled with fine, gel-like porous corrosion products. The perforations are assumed to be cylindrical holes of uniform radius. The perforations are also assumed to form uniformly over the entire surface. It is assumed conservatively that both downward and upward perforations are equally available for radionuclide release, and, once outside the waste container, all the radionuclides are immediately released into the underlying porous (crushed gravel or concrete) invert, and allowed to migrate toward the host rock.

Shown in Figure 6.5-4 is a cross-sectional view of the geometry of the cylindrical perforation, invert, and host rock in the equivalent $1-\mathrm{D}$ conceptual release model. The contribution of each perforation to the radionuclide release is assumed to be independent of other near-by perforations, i.e. the release rates from each perforation are all the same. This assumption may be conservative in that the concentration gradients just inside adjacent perforations may be less than for the case in an isolated perforation. This assumption is supported by the finding that the concentration gradients near an aperture in a "thin" wall are very large (Chambre, et al, 1986). Although it is expected that the container wall becomes thinner with time due to wastage from general corrosion, the wall thickness is assumed to remain constant.

Because no data for the transport properties of radionuclides in the porous corrosion products filling the perforations (or pits) are currently available, it was assumed that the corrosion products have the same porosity and maintain the same water content (liquid saturation) at a given time as the invert material (either crushed gravel or concrete). In addition, whenever a waste package is under dripping water, the diffusion coefficient in the pits and the invert is assumed to be $10^{-7} \mathrm{~cm}^{2} / \mathrm{sec}$ (Conca, 1990; Conca and Wright, 1992). In reality, the corrosion products normally have a "gel-like" structure which is much finer and has a higher surface area than the invert material, thus they would have a greater capacity for holding moisture. However, the uncertainty associated with the assumptions is small relative to the overall uncertainties associated with the conceptual models and assumptions given in this section and in the mathematical models discussed in the following sections.

\subsubsection{Diffusive Release from Waste Package and EBS}

Taking into account the approaches and the conceptual models for the release from the "partially failed" waste container discussed in the previous section, both steady-state and "quasi-transient" diffusive mass transport models were developed. In the simulations using the RIP code, the "quasi-transient" diffusive mass transfer model was used to calculate diffusive release of radionuclides at the EBS edge. Because steady-state diffusive mass transfer through the "failed" waste package is utilized in developing the "quasi-transient" diffusion model, derivation of the steady-state diffusive mass transfer relation is also discussed in detail. 
The following is the derivation of an analytical solution for the radial steady-state diffusive mass transfer rate at the edge of EBS through the "partially failed" waste container and the underlying invert. The derivation is based on the equivalent spherical configuration of the waste package and other EBS components (Figure 6.5-3). Assuming that there are $\mathrm{N}$ uniformly distributed perforations on the surface of the spherical waste container (Figure 6.5-3), which represent noninteracting emitting sources, the steady-state diffusive mass transfer rate $\left(M_{\mathrm{WP}}\right)$ through the waste package perforations can be expressed as follows (Chambre, 1995):

$$
\dot{M}_{\mathrm{WP}}=\frac{C_{o}-C_{1}^{\prime}}{\frac{1}{N \pi \alpha^{2}}\left[\frac{\pi \alpha}{4}\left(\frac{1}{\sigma_{0} D_{0}}+\frac{1}{\theta_{2} D_{2}}\right)+\frac{l}{\theta_{1} D_{1}}\right]}
$$

where $C_{o}=$ concentration of radionuclide at the surface of waste form;

$\mathrm{C}_{1}{ }^{\prime}=$ concentration of radionuclide just outside a perforation at the surface of the"failed" waste container;

$\sigma_{0}=$ porosity just inside the waste container $(=1.0)$;

$\theta_{1}=$ fractional water content of the corrosion products filling the perforations;

$\theta_{2}=$ fractional water content of the invert;

$D_{0}=$ diffusion coefficient just inside the waste container $\left(=10^{-5} \mathrm{~cm}^{2} / \mathrm{sec}\right)$;

$\mathrm{D}_{1}=$ diffusion coefficient in the corrosion products-filled perforations (function of liquid saturation);

$\mathrm{D}_{2}=$ diffusion coefficient in the invert (function of liquid saturation);

$1=$ thickness of the waste container wall;

$\alpha=$ radius of the perforation; and

$\mathrm{N}=$ number of perforations at a given exposure time.

The number of perforations $(\mathrm{N})$ at a given exposure time is derived from the waste container degradation models (see Chapter 5). Assuming a spherical shell geometry for the invert surrounding the spherical waste container (Figure 6.5-3), the solution given by Crank (1975, pp. 89-90) was used to solve for the steady-state radial diffusive mass transfer rate from the surface of the waste package to the edge of EBS for a given set of boundary conditions. The boundary conditions used for the solution are

$$
\begin{aligned}
C=C_{1} & \text { at } & r=a \\
C=0 & \text { at } & r=b
\end{aligned}
$$

where $a$ is the distance from the center of the sphere to the edge of the waste container, and $b$ is the distance from the center of the sphere to the edge of the EBS. The concentration at the boundary of the EBS (i.e., the edge of the invert) was conservatively set to zero (Equation 6.5-3) to yield the highest diffusive flux at the EBS boundary. The resulting equation for the steady- 
state radial diffusive mass transfer rate from the surface of the waste package to the edge of EBS is

$$
\dot{M}_{E B S}=\frac{4 \pi a \theta_{2} D_{2} C_{1}}{1-\frac{a}{b}}
$$

Using arguments essentially equivalent to the method of matched asymptotic expansion, $C_{1}$ in Equation 6.5-4 can be equated to $C_{1}{ }^{\prime}$ in Equation 6.5-1 (Chambre, 1995). Thus, equating $M_{W P}$ (Equation 6.5-1) to $\mathrm{M}_{\mathrm{EBS}}$ (Equation 6.5-4) and solving for $\mathrm{C}_{1}$, an equation for the steady-state radial diffusive mass transfer at the edge of EBS is expressed as

$$
\dot{M}_{E B S}^{s s}=\frac{4 \pi \theta_{2} D_{2} a C_{o}}{\frac{4}{N} \frac{a}{\alpha}\left[\frac{\pi}{4}\left(\frac{\theta_{2} D_{2}}{\sigma_{o} D_{o}}+1\right)+\frac{\theta_{2} D_{2}}{\theta_{1} D_{1}} \frac{l}{r}\right]+\left(1-\frac{a}{b}\right)} .
$$

Equation 6.5-5 shows that the diffusive mass transfer rate depends on the number of perforations $(\mathrm{N})$ in the waste container, the container wall thickness (l), and the geometry of the waste container and invert ( $a$ and $b$ ). An equation for the steady-state radial diffusive mass transfer rate at the EBS edge from a bare spherical waste form can be obtained by setting $\mathrm{N} \rightarrow \infty$, resulting in

$$
\dot{M}_{E B S}^{W F}=\frac{4 \pi \theta_{2} D_{2} a C_{o}}{1-\frac{a}{b}}
$$

which lacks a dependence on the number of perforations. Figure 6.5-5 shows the steady-state diffusive release rate from the bare waste form (Equation 6.5-6) compared to the steady-state diffusive release rate at the EBS boundary from a perforated waste package as a function of the number of perforations. In the calculations, a volumetric water content of 0.1 was assumed for the crushed-tuff gravel invert. As shown in the figure, the steady-state diffusive release rate is strongly dependent on the number of perforations.

\section{Transient Diffusive Transport}

Using a similar approach to deriving the analytical solution. for the steady-state diffusive mass transfer rate (Equation 6.5-5), an analytical solution for a "quasi-transient" diffusive mass-transfer rate at the EBS boundary (i.e., the edge of the invert) through the "partially failed" waste container was developed. This "quasi-transient" diffusive mass transfer rate equation was implemented into the RIP code to calculate the EBS diffusive release of radionuclides.

The term "quasi-transient" is used because the solution incorporates steady-state diffusive transfer through the perforations of the "failed" waste container (Equation 6.5-1) combined with transient diffusive mass transfer through the spherical shell of the invert (other EBS components) surrounding the waste container (see Figure 6.5-3). The approximation for steady-state diffusion 
through the waste package should not result in a significant error because of the much shorter distance for diffusion $(12 \mathrm{~cm})$ through the waste container compared that for the invert $(100 \mathrm{~cm})$.

In developing an analytical solution for transient diffusive mass transfer through the spherical shell of the invert, the following boundary and initial conditions were considered:

$$
\begin{gathered}
C=C_{1} \quad \text { at } r=a, t>0 \\
C=0 \quad \text { at } r=b, t>0 \\
C=0 \quad \text { for } a \leq r \leq b, t=0
\end{gathered}
$$

As in the steady-state diffusion case, the concentration at the EBS boundary was conservatively set to zero (Equation 6.5-8). Utilizing a solution given by Crank (1975, p. 98), the transient mass transfer rate at the EBS (or invert) edge is expressed as

where

$$
\dot{M}_{E B S}=\frac{4 \pi a \theta_{2} D_{2} C_{1}}{b-a}\left[b+2 \sum_{n=1}^{\infty} n \exp \left(-\frac{D_{2} n^{2} \pi^{2} t}{R_{2}(b-a)^{2}}\right)\right]
$$

$$
R_{2}=1+\frac{k_{d, 2} \rho_{2}}{\theta_{2}}
$$

where $t$ is time (years), $R_{2}$ is the retardation coefficient in the invert, $k_{d, 2}$ is the distribution coefficient $\left(\mathrm{cm}^{3} / \mathrm{g}\right)$ in the invert, and $\rho_{2}$ is the bulk density $\left(\mathrm{g} / \mathrm{cm}^{3}\right)$ of the invert material. Other symbols are defined above. Following the same arguments as in the steady-state diffusive mass transfer case, equating $M_{W P}$ (Equation 6.5-1) to $M_{\text {EBS }}$ (Equation 6.5-10) and solving for $C_{1}$, the resulting equation for the "quasi-transient" diffusive mass transfer rate at the edge of EBS is expressed as follows:

where

$$
\dot{M}_{E B S}^{t r}=\frac{P_{3} C_{0}}{P_{1} P_{2}+1}
$$

$$
\begin{gathered}
P_{1}=\frac{1}{N \pi \alpha^{2}}\left[\frac{\pi \alpha}{4}\left(\frac{1}{\sigma_{o} D_{o}}+\frac{1}{\theta_{2} D_{2}}\right)+\frac{l}{\theta_{1} D_{1}}\right] \\
P_{2}=\frac{4 \pi a \theta_{2} D_{2}}{b-a}\left[b+2 \sum_{n=1}^{\infty} n \exp \left(-\frac{D_{2} n^{2} \pi^{2} t}{R_{2}(b-a)^{2}}\right)\right]
\end{gathered}
$$

and

$$
P_{3}=\frac{4 \pi a \theta_{2} D_{2}}{b-a}\left[b+2 \sum_{n=1}^{\infty}(-1)^{n} n \exp \left(-\frac{D_{2} n^{2} \pi^{2} t}{R_{2}(b-a)^{2}}\right)\right] \text {. }
$$


Shown in Figure 6.5-6 is a representative pitting history (or the change in number of pits with time) of a waste container which has the first pit penetration at about 800 years. Using this pitting history, the transient diffusive release rates at the EBS boundary calculated using (Equations $6.5-12$ through 6.5-15) with the distribution coefficients of 20,200 and $1000\left(\mathrm{~cm}^{3} / \mathrm{g}\right.$ ) are compared with the steady-state release rate in Figure 6.5-7. A volumetric water content of 0.1 was assumed for the invert. As shown in the figure, the difference between the steady-state and the transient diffusive release rates at any time is greater: for larger values of the distribution coefficient, and the difference decreases with time.

\subsubsection{Diffusion Coefficient in Unsaturated Porous Media}

Using an unsaturated flow apparatus based on open-flow centrifugation, Conca and coworkers (Conca, 1990; Conca and Wright, 1990; Conca and Wright, 1992) measured aqueous diffusion coefficients in a wide spectrum of geologic materials at varying degrees of water saturation. It was suggested from their study that parameters such as diffusion coefficient and hydraulic conductivity are functions primarily of water content and not materials characteristics. The diffusion coefficient data for a wide variety of geologic materials were received from Conca (Engel, 1995) and were used to develop a relation for the diffusion coefficient in unsaturated porous media as a function of the volumetric water content. The functional form is expressed as

$$
\log D_{p, i}=-8.255( \pm 0.0499)+1.898( \pm 0.0464) \log \phi
$$

where $D_{p, i}$ is the diffusion coefficient $\left(\mathrm{cm}^{2} / \mathrm{sec}\right.$ ) (or "pore diffusivity") of diffusing species $i$ within the pore-liquid phase (this parameter takes into account the tortuosity and constrictivity of the porous medium; Atkins and Nickerson, 1984; Brakel and Heertjes, 1974); and $\phi$ is the volumetric water content (in percent, i.e., $\phi=100 \times \theta$ ). The data used and the model estimation with its uncertainty are shown in Figure 6.5-8. Equation 6.5-16 was implemented in the RIP code to calculate the diffusion coefficients used in the simulations of waste package and EBS diffusive releases.

As a point of clarification, the pore diffusivity can be related to the diffusion coefficient in bulk water $\left(D_{o, i}\right)$ and the effective diffusion coefficient $\left(D_{e f f, i}\right)$ in a porous medium as follows (Brakel and Heertjes, 1974; Atkins and Nickerson, 1984)

$$
D_{p, i}=D_{o, i}\left(\frac{\delta}{\tau^{2}}\right)=\frac{D_{e f f, i}}{\theta}
$$

where $\tau$ is the tortuosity, $\delta$ is the constrictivity, and $\varepsilon$ is the fractional volumetric water content of the material (which is equivalent to the porosity in saturated systems). The diffusion coefficient in aqueous solution decreases as ionic strength increases, and increases as temperature increases (Miller, 1982). However, these effects are minor compared to those from the degree of saturation in an unsaturated porous medium. 


\subsubsection{Advective Release from Waste Package and EBS}

Advective releases from the waste package and EBS are analyzed using three different advective transport scenarios in TSPA-1995:

- Scenario 1: advective transport through both waste package and other EBS components;

- Scenario 2: no advective transport through the waste package, only through other EBS components;

- Scenario 3: no advective transport (capillary barrier effect).

In addition, diffusive transport through the waste package and other EBS components is active for each of these scenarios.

Advective flux into a drift $\left(\mathrm{q}_{\text {drip }}\right.$ derived in Chapter 7 ) may result in advective flow across/through waste packages within the drift. In order to address the uncertainty concerning how fracture flow will distribute once it intersects the drift, an area larger than the waste package cross-section is defined as the region from which advective flux is "focussed" onto the waste package (i.e., the effective catchment area). In TSPA-1995, the effective catchment area is assumed (arbitrarily) to be four times the length times the diameter of the waste package (i.e., four times the waste-package maximum cross-sectional area perpendicular to flow). The product of the advective flux $\left(\mathrm{q}_{\text {drip }}\right)$ and the effective catchment area referred to in Chapter 7 as the total volumetric flow rate per package $\left(Q_{\text {drip }}\right)$ and represents the advective flow for a given waste package.

Scenario 1. Advective Transport Through Both Waste Package and Other EBS Components

When there is ground water dripping onto a failed waste package, radionuclides from the waste package may be released by advection. In this scenario, once the waste package fails by pitting corrosion (i.e., at least one pit penetration) the dripping water is assumed to directly contact the waste form and the dissolved radionuclides may be released by advection. The advective release rate is calculated using the following conventional advective release rate equation

$$
\dot{M}_{a d}=Q_{\text {drip }} C_{o}
$$

where $M_{a d}$ is the advective mass transfer rate of species $i$ (moles/yr), $Q_{\text {drip }}$ is the total volumetric flow rate on the package $\left(\mathrm{m}^{3} / \mathrm{yr}\right.$-discussed above and derived in Chapter 7 ), and $C_{0}$ is the radionuclide concentration at the waste form surface $\left(\mathrm{moles} / \mathrm{m}^{3}\right)$. Figure $6.5-9$ presents a schematic of this conceptual model.

Scenario 2: No Advective Transport Through the Waste Package, Only Through Other EBS Components

The conceptual model for the advective release discussed in the previous section is conservative in that it does not include any potential performance credit for the "partially" failed (i.e., perforated) waste container as a barrier. The perforations in failed waste containers are filled with fine, gel-like porous corrosion products which may keep percolating ground water from flowing through the waste package and directly contacting the waste form. Therefore, in this 
second scenario, percolating groundwater is assumed to be diverted around the waste container and the radionuclides are assumed to transport to the edge of the waste container solely by diffusion through the corrosion-product filled perforations. The diffusive release is calculated with Equation 6.5-1, assuming steady-state diffusion through the perforations.

From that point, the radionuclides transport advectively through the underlying invert and to the edge of the EBS. The advective release from the outside of the waste package and through the other EBS components is calculated with Equation 6.5-18. Thus, the release rate at the EBS boundary is controlled by the diffusive transport rate through the perforations and the rate of water dripping onto the waste package. This advective release scenario brings more realism to the performance of the waste container which, although perforated, may still providing waste isolation benefits through controlled release of radionuclides. A schematic of this conceptual model is presented in Figure 6.5-10. The sensitivity of the EBS release rate to this transport scenario is discussed in Chapter 8.

\section{Scenario 3: No Advective Transport (Capillary Barrier Effect)}

In addition to the backfill distributing any aqueous flux which may "drip" into the drifts above the waste package, it may be possible to design and implement a capillary barrier which diverts all inflowing water away from the waste package. The effectiveness of such barriers (which are commonly referred to as diversion barriers, capillary barriers, or Richard's barriers) in diverting water flow has been demonstrated under a wide range of conditions anticipated in different waste-disposal concepts as described in Conca (1990) and Conca and Wright (1992). The design of such a barrier requires at least two materials of different grain-size distributions (and therefore capillary characteristics). The finer-grained material (e.g., sand) is placed above the coarsergrained material (e.g., gravel), and the interface between the two is sloped slightly to allow the drainage of any water which seeps into the sand layer. Although a number of questions remain regarding the long-term stability and performance of such a barrier, as well as the issue of how such a barrier might be emplaced, sensitivity analyses have been conducted in Chapters 8 and 9 to evaluate the potential performance benefits of a capillary barrier. In this scenario, radionuclides are released only by diffusive transport through the entire EBS, and the release rate is calculated with Equation 6.5-12. A schematic of this scenario for waste package and EBS release is presented in Figure 6.5-11. 
Table 6.2-1 - Fractional Distribution of Gap Inventory Species Used in TSPA-1995

\begin{tabular}{|c|c|c|}
\hline Nuclide & Spent Fuel Matrix & Gap Inventory $^{1}$ \\
\hline${ }^{14} \mathrm{C}$ & $\mathrm{U}(0.94,0.99)^{2}$ & $\mathrm{U}(0.01,0.06)^{2}$ \\
\hline${ }^{135} \mathrm{Cs}$ & 0.98 & 0.02 \\
\hline${ }^{129} \mathrm{I}$ & 0.98 & 0.02 \\
\hline${ }^{79} \mathrm{Se}$ & 0.98 & 0.02 \\
\hline${ }^{99} \mathrm{Tc}$ & 0.98 & 0.02 \\
\hline
\end{tabular}

1 Includes the inventory in grain boundary.

2 Uniformly distributed with the minimum and maximum given. 
Table 6.3-1 Distributions of Solubility-Limited Aqueous Radionuclide Concentrations for Nominal Case in TSPA-1995

\begin{tabular}{|c|c|c|c|c|c|c|c|}
\hline $\mathbf{R N}$ & $\begin{array}{l}\text { Distribution } \\
\text { Type }\end{array}$ & $\begin{array}{l}\text { Distribution } \\
\text { Variable }\end{array}$ & $\begin{array}{l}\text { Minimum Value } \\
\mathrm{g} / \mathrm{m}^{3} \&[\mathrm{~mol} / \mathrm{l}]\end{array}$ & $\begin{array}{l}\text { Maximum Value } \\
\mathrm{g} / \mathrm{m}^{3} \&[\mathrm{~mol} / \mathrm{l}]\end{array}$ & $\begin{array}{l}\text { Mean or Peak } \\
\mathrm{g} / \mathrm{m}^{3} \&[\mathrm{~mol} / 1]\end{array}$ & C.V. & Source \\
\hline Ac & uniform & Concentration & $\begin{array}{l}2.3 e-5 \\
{[1.0 e-10]}\end{array}$ & $\begin{array}{l}2.3 e-1 \\
{[1.0 e-6]}\end{array}$ & $\begin{array}{l}1.2 \mathrm{e}-1 \\
{[5 \mathrm{e}-7]}\end{array}$ & --- & Elicitation \\
\hline $\mathrm{Am}$ & uniform & Concentration & $\begin{array}{l}2.4 e-5 \\
{[1.0 e-10]}\end{array}$ & $\begin{array}{l}2.4 e-1 \\
{[1.0 e-6]}\end{array}$ & $\begin{array}{l}1.2 e-1 \\
{[5 e-7]}\end{array}$ & --- & Elicitation \\
\hline $\mathrm{Cm}$ & $\begin{array}{l}\text { triangular } \\
\text { (two } \\
\text { temperature } \\
\text { ranges) }\end{array}$ & $\log ($ Concen. $)$ & $\begin{array}{l}T \leq 55^{\circ} \mathrm{C}: \\
\log (1.2 \mathrm{e}-6) \\
{[\log (4.9 \mathrm{e}-12)]} \\
T>55^{\circ} \mathrm{C}: \\
\log (1.5 \mathrm{e}-10) \\
{[\log (6.1 \mathrm{e}-16)]}\end{array}$ & $\begin{array}{l}T \leq 55^{\circ} C \\
\log (1.2 \mathrm{e}-4) \\
{[\log (4.9 \mathrm{e}-10)]} \\
T>55^{\circ} \mathrm{C} \\
\log (1.5 \mathrm{e}-8) \\
{[\log (6.1 \mathrm{e}-14)]}\end{array}$ & $\begin{array}{l}T \leq 55^{\circ} C: \\
\log (1.2 \mathrm{e}-5) \\
{[\log (4.9 \mathrm{e}-11)]} \\
T>55^{\circ} \mathrm{C} \\
\log (1.5 \mathrm{e}-9) \\
{[\log (6.1 \mathrm{e}-15)]}\end{array}$ & -- & $\begin{array}{l}\text { Jardine (1991- } \\
\text { from Wilson, } \\
1987 ; 1990)\end{array}$ \\
\hline Cs & triangular & $\log ($ Concen. $)$ & $\begin{array}{l}\log (1.2) \\
{[\log (9.0 \mathrm{e}-6)]}\end{array}$ & $\begin{array}{l}\log (2.1 e+3) \\
{[\log (1.6 e-2)]}\end{array}$ & $\begin{array}{l}\log (3.9 e+2) \\
{[\log (2.9 e-3)]}\end{array}$ & --- & $\begin{array}{l}\text { Golder (1993), } \\
\text { EPRI (1992) }\end{array}$ \\
\hline $\mathrm{Nb}$ & uniform & $\log ($ Concen. $)$ & $\begin{array}{l}\log (9.3 e-5) \\
{[\log (1.0 e-9)]}\end{array}$ & $\begin{array}{l}\log (9.3 e-3) \\
{[\log (1.0 e-7)]}\end{array}$ & $\begin{array}{l}\log (9.3 e-4) \\
{[\log (1.0 e-8)]}\end{array}$ & --- & Elicitation \\
\hline $\mathrm{Ni}$ & beta & $\log ($ Concen. $)$ & $\begin{array}{l}\log (5.9 e-2) \\
{[\log (1.0 e-6)]}\end{array}$ & $\begin{array}{l}\log (5.9 e+3) \\
{[\log (1.0 e-1)]}\end{array}$ & $\begin{array}{l}\log (1.1 e+2) \\
{[\log (1.8 e-3)]}\end{array}$ & $\begin{array}{l}0.34 \\
{[0.25]}\end{array}$ & Elicitation \\
\hline $\mathrm{Np}$ & beta & $\log ($ Concen. $)$ & $\begin{array}{l}\log (1.2) \\
{[\log (5 e-6)]}\end{array}$ & $\begin{array}{l}\log (2.4 e+3) \\
{[\log (1.0 e-2)]} \\
\end{array}$ & $\begin{array}{l}\log (3.4 e+1) \\
{[\log (1.4 e-4)]}\end{array}$ & $\begin{array}{l}0.37 \\
{[0.15]} \\
\end{array}$ & Elicitation* \\
\hline $\mathbf{P a}$ & uniform & $\log ($ Concen. $)$ & $\begin{array}{l}\log (2.3 e-5) \\
{[\log (1.0 e-10)]}\end{array}$ & $\begin{array}{l}\log (2.3) \\
{[\log (1.0 \mathrm{e}-5)]}\end{array}$ & $\begin{array}{l}\log (7.3 e-3) \\
{[\log (3.2 e-8)]}\end{array}$ & --- & Elicitation \\
\hline
\end{tabular}


Table 6.3-1. Distributions of Solubility-Limited Aqueous Radionuclide Concentrations for Nominal Case in TSPA-1995

(Continued)

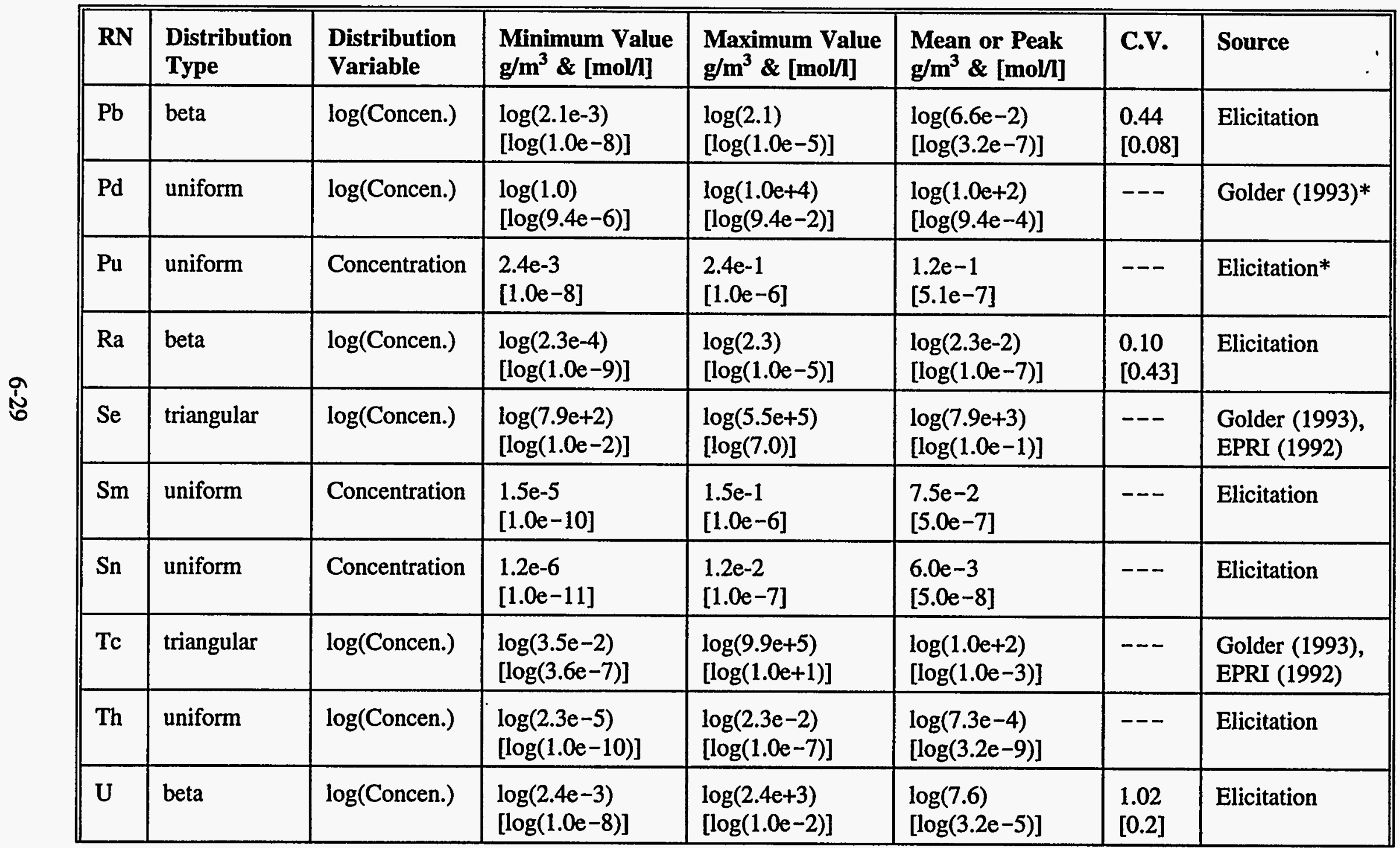


Table 6.3-1. Distributions of Solubility-Limited Aqueous Radionuclide Concentrations for Nominal Case in TSPA-1995 (Continued)

\begin{tabular}{|c|c|c|c|c|c|c|c|}
\hline $\mathbf{R N}$ & $\begin{array}{l}\text { Distribution } \\
\text { Type }\end{array}$ & $\begin{array}{l}\text { Distribution } \\
\text { Variable }\end{array}$ & $\begin{array}{l}\text { Minimum Value } \\
\mathrm{g} / \mathrm{m}^{3} \&[\mathrm{~mol} / \mathrm{l}]\end{array}$ & $\begin{array}{l}\text { Maximum Value } \\
\mathrm{g} / \mathrm{m}^{3} \&[\mathrm{~mol} / \mathrm{l}]\end{array}$ & $\begin{array}{l}\text { Mean or Peak } \\
\mathrm{g} / \mathrm{m}^{3} \&[\mathrm{~mol} / \mathrm{l}]\end{array}$ & C.v. & Source \\
\hline $\mathrm{Zr}$ & uniform & $\log ($ Concen. $)$ & $\begin{array}{l}\log (9.1 e-8) \\
{[\log (1.0 e-12)]}\end{array}$ & $\begin{array}{l}\log (9.1 e-3) \\
{[\log (1.0 e-7)]}\end{array}$ & $\begin{array}{l}\log (2.9 e-5) \\
{[\log (3.2 e-10)]}\end{array}$ & -- & Elicitation \\
\hline
\end{tabular}

Table 6.3-1 Explanation:

log: refers everywhere in the table to the base 10 logarithm.

RN: stands for radionuclide.

Mean or Peak: The values listed are the Arithmetic Mean for all distributions except log triangular distributions where the values listed correspond to the Peak of the distributions. NOTE: For any Distribution of $\log ($ Concen.), the value of the Mean is not equivalent to the $\log ($ Mean) for the corresponding Distribution of Concentration.

C.V.: stands for Coefficient of Variation which equals the absolute value of the ratio of the Standard Deviation to the Mean.

Values given only for log beta distributions.

e+: represents positive power(s) of ten.

e-: represents negative power(s) of ten.

Elicitation: Conducted at Sandia National Laboratory on April 13, 1993. Documented in draft report titled "Expert Elicitation of the Solubility Distributions to be used in TSPA\#2 Calculations", June 1, 1993, from Jack Gauthier (SPECTRA Research).

*: indicates modifications to original source information-see text for discussion. 
Table 6.3-2 Averages and Standard Deviations for $\log$ (Neptunium Steady-State Concentrations) Calculated Using the Measurements of Nitsche et al., (1993)

\begin{tabular}{|c|c|c|c|c|}
\hline $\begin{array}{l}\text { Conditions: } \\
\mathrm{T}\left({ }^{\circ} \mathrm{C}\right) ; \mathrm{pH}^{*}\end{array}$ & $\begin{array}{l}\text { Data Points from Nitsche et al. } \\
\text { (1993) Used in Derivation }\end{array}$ & $\begin{array}{c}\text { Calculated } \\
\text { Average of } \\
\log _{10}(\text { Conc. })\end{array}$ & $\begin{array}{c}\text { Calculated } \\
\text { Stnd. Deviation of } \\
\log _{10}(\text { Conc. })\end{array}$ & $10^{[\text {Avg. } \log (\operatorname{Conc})]}$ \\
\hline $25 ; 7.04$ & last 5 of Appendix AII & -3.9194 & $0.4839 E-01$ & $0.1204 E-03$ \\
\hline $60 ; 8.47$ & last 3 of Appendix AVI & -4.0518 & $0.2514 \mathrm{E}-01$ & $0.8876 E-04$ \\
\hline $90 ; 5.93$ & last 3 of Appendix AVII & -2.9307 & $0.1603 E-01$ & $0.1173 E-02$ \\
\hline $90 ; 7.02$ & last 5 of Appendix AVII & -3.8256 & $0.5351 \mathrm{E}-01$ & $0.1494 \mathrm{E}-03$ \\
\hline
\end{tabular}

* $\mathrm{pH}$ values are averages for measurements used to calculate values in the table. 
Table 6.3-3 Averages and Standard Deviations for $\log ($ Plutonium Steady-State Concentrations) Calculated Using the Measurements of Nitsche et al., (1993)

\begin{tabular}{|c|c|c|c|c|}
\hline $\begin{array}{l}\text { Conditions: } \\
\left.\text { T( }{ }^{\circ} \mathbf{C}\right) ; \mathbf{p H}^{*}\end{array}$ & $\begin{array}{l}\text { Data Points from Nitsche et al. } \\
\text { (1993) Used in Derivation }\end{array}$ & $\begin{array}{c}\text { Calculated } \\
\text { Average of } \\
\log _{10} \text { (Conc.) }\end{array}$ & $\begin{array}{c}\text { Calculated } \\
\text { Stnd. Deviation of } \\
\log _{10}(\text { Conc. })\end{array}$ & $10^{[\text {Avg. } \log (\text { Conc.) }]}$ \\
\hline $25 ; 5.88$ & last 3 of Appendix BI & -6.2234 & $0.6596 \mathrm{E}-01$ & $0.5978 \mathrm{E}-06$ \\
\hline $25 ; 6.9$ & last 13 of Appendix BII & -6.6756 & $0.1708 \mathrm{E}+00$ & $0.2111 \mathrm{E}-06$ \\
\hline $25 ; 8.41$ & last 10 of Appendix BIII & -6.5138 & $0.1197 \mathrm{E}+00$ & $0.3064 \mathrm{E}-06$ \\
\hline $60 ; 5.97$ & last 8 of Appendix BIV & -7.6786 & $0.9622 \mathrm{E}-01$ & $0.2096 \mathrm{E}-07$ \\
\hline $60 ; 6.96$ & last 10 of Appendix BV & -7.4402 & $0.1210 \mathrm{E}+00$ & $0.3629 \mathrm{E}-07$ \\
\hline $60 ; 8.46$ & last 5 of Appendix BVI & -6.9094 & $0.4434 \mathrm{E}-01$ & $0.1232 \mathrm{E}-06$ \\
\hline $90 ; 5.96$ & last 4 of Appendix BVII & -8.2809 & $0.1220 \mathrm{E}+00$ & $0.5237 \mathrm{E}-08$ \\
\hline $90 ; 7.00$ & last 4 of Appendix BVIII & -8.0382 & $0.1454 \mathrm{E}-01$ & $0.9158 \mathrm{E}-08$ \\
\hline $90 ; 8.44$ & last 7 of Appendix BIX & -8.1363 & $0.2289 \mathrm{E}-01$ & $0.7306 \mathrm{E}-08$ \\
\hline
\end{tabular}

* $\mathrm{pH}$ values are averages for measurements used to calculate values in the table. 
Table 6.3-4 Averages and Standard Deviations for $\log$ (Americium Steady-State Concentrations) Calculated Using the Measurements of Nitsche et al., (1993)

\begin{tabular}{|c|c|c|c|c|}
\hline $\begin{array}{l}\text { Conditions: } \\
\mathbf{T}\left({ }^{\circ} \mathrm{C}\right) ; \mathbf{p H}^{*}\end{array}$ & $\begin{array}{l}\text { Data Points from Nitsche et al. } \\
\text { (1993) Used in Derivation }\end{array}$ & $\begin{array}{c}\text { Calculated } \\
\text { Average of } \\
\log _{10}(\text { Conc. })\end{array}$ & $\begin{array}{c}\text { Calculated } \\
\text { Stnd. Deviation of } \\
\log _{10}(\text { Conc. })\end{array}$ & $10^{[\text {Avg. } \log (\operatorname{Conc})]}$ \\
\hline $25 ; 6.97$ & last 3 of Appendix CII & -8.9290 & $0.1496 \mathrm{E}+00$ & $0.1200 \mathrm{E}-08$ \\
\hline $25 ; 8.47$ & last $12^{\dagger}$ of Appendix CIII & -8.6777 & $0.1705 E+00$ & $0.2754 \mathrm{E}-08$ \\
\hline $90 ; 6.05$ & last 12 of Appendix CX & -8.8267 & $0.2273 \mathrm{E}+00$ & $0.1679 E-08$ \\
\hline $90 ; 7.03$ & last 13 of Appendix CXI & -9.5950 & $0.3139 E+00$ & $0.3142 E-09$ \\
\hline $90 ; 8.44$ & last 9 of Appendix CXII & -9.6369 & $0.2762 E+00$ & $0.3367 E-09$ \\
\hline
\end{tabular}

* $\mathrm{pH}$ values are averages for measurements used to calculate values in the table.

† Note: $\quad$ Sample I.D. 9-11A1J2 was not used as it appears to be an incorrect entry from the data for Appendix CII; the pH for Sample I.D. 9-12A1J2 is listed as 7.63 but was taken to be 8.63 as $\mathrm{pH}$ variations for samples are only about \pm 0.1 . 

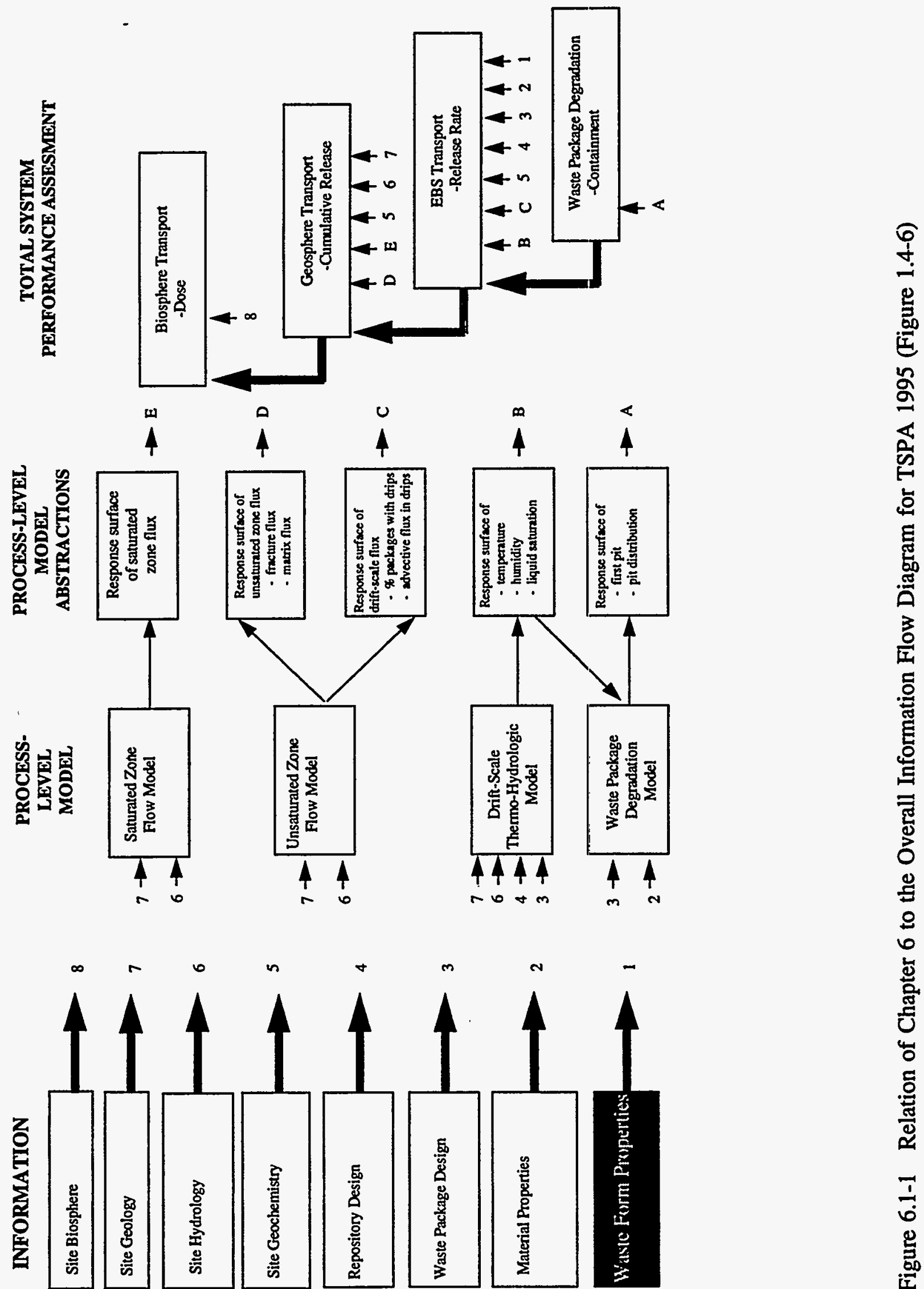

7
0
0
0
00
01 


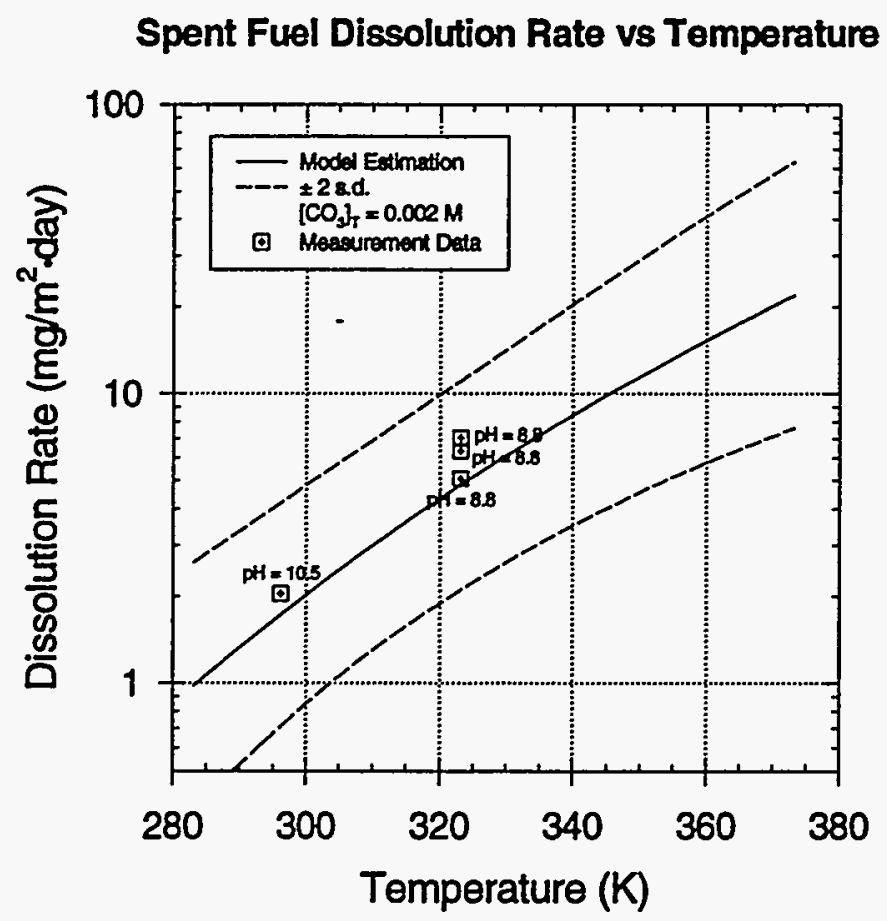

Figure 6.2-1 Model Prediction with the Uncertainty and Relevant Data of the Intrinsic Dissolution Rate of Spent Fuel Matrix as a Function of Temperature at a Total Carbonate Concentration of $0.002 \mathrm{M}$

Spent Fuel Dissolution Rate vs. Temperature

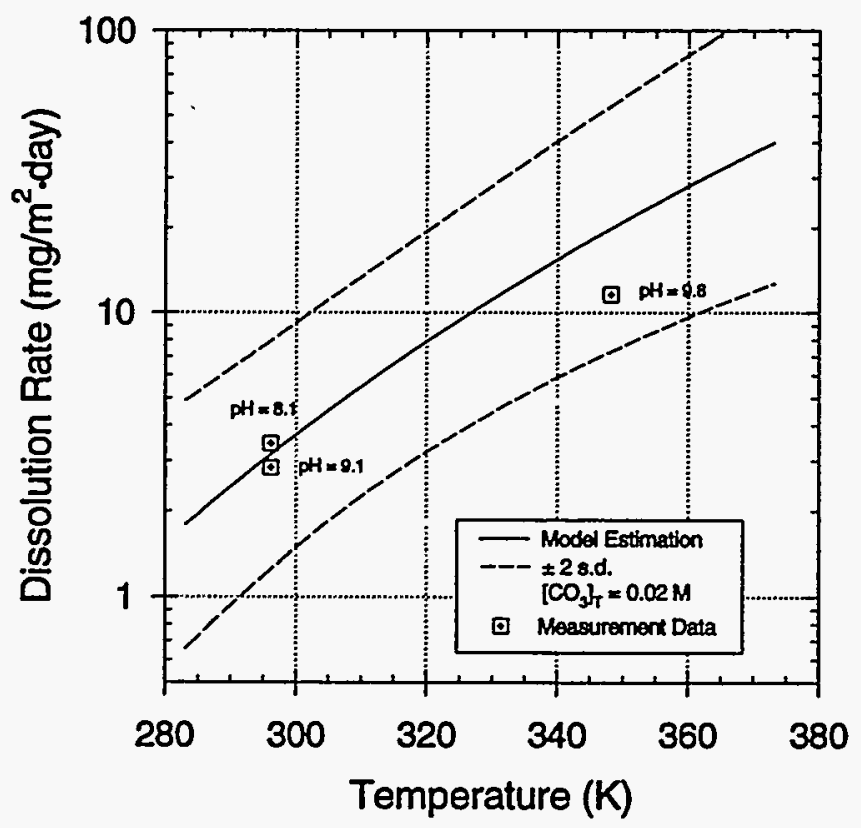

Figure 6.2-2 Model Prediction with the Uncertainty and Relevant Data of the Intrinsic Dissolution Rate of Spent Fuel Matrix as a Function of Temperature at a Total Carbonate Concentration of $0.02 \mathrm{M}$ 

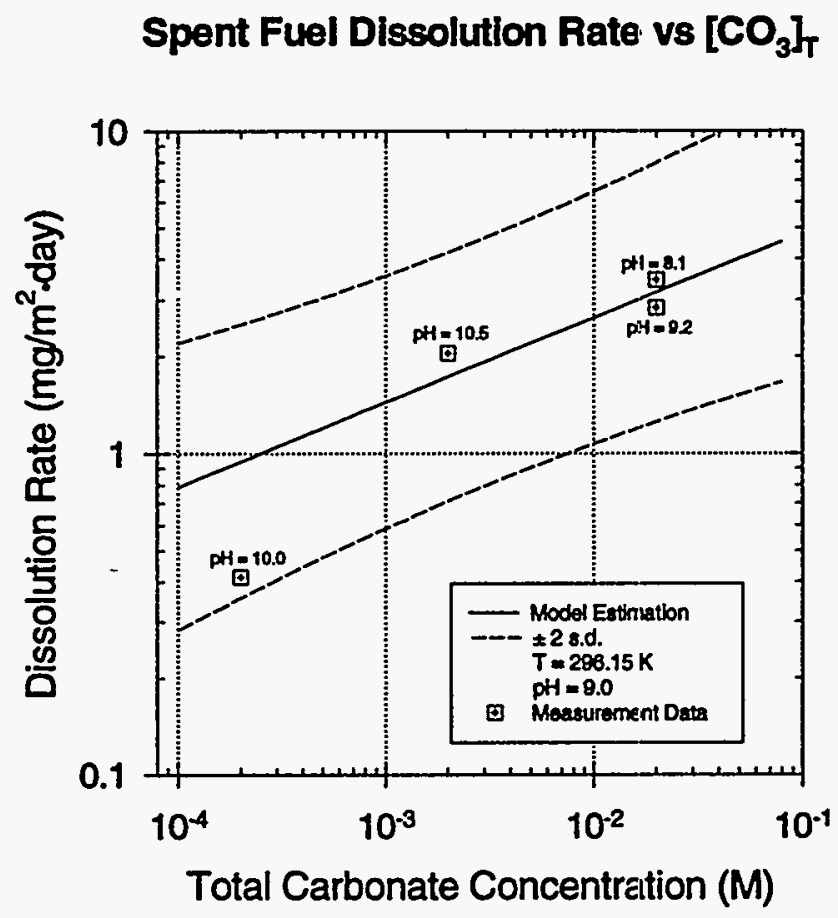

Figure 6.2-3 Model Prediction with the Uncertainty and Relevant Data of the Intrinsic Dissolution Rate of Spent Fuel Matrix as a Function of Total Carbonate Concentration at $296.15 \mathrm{~K}$.

\section{Spent Fuel Dissolution vs Temperature and $\left[\mathrm{CO}_{3}\right]_{T}$}

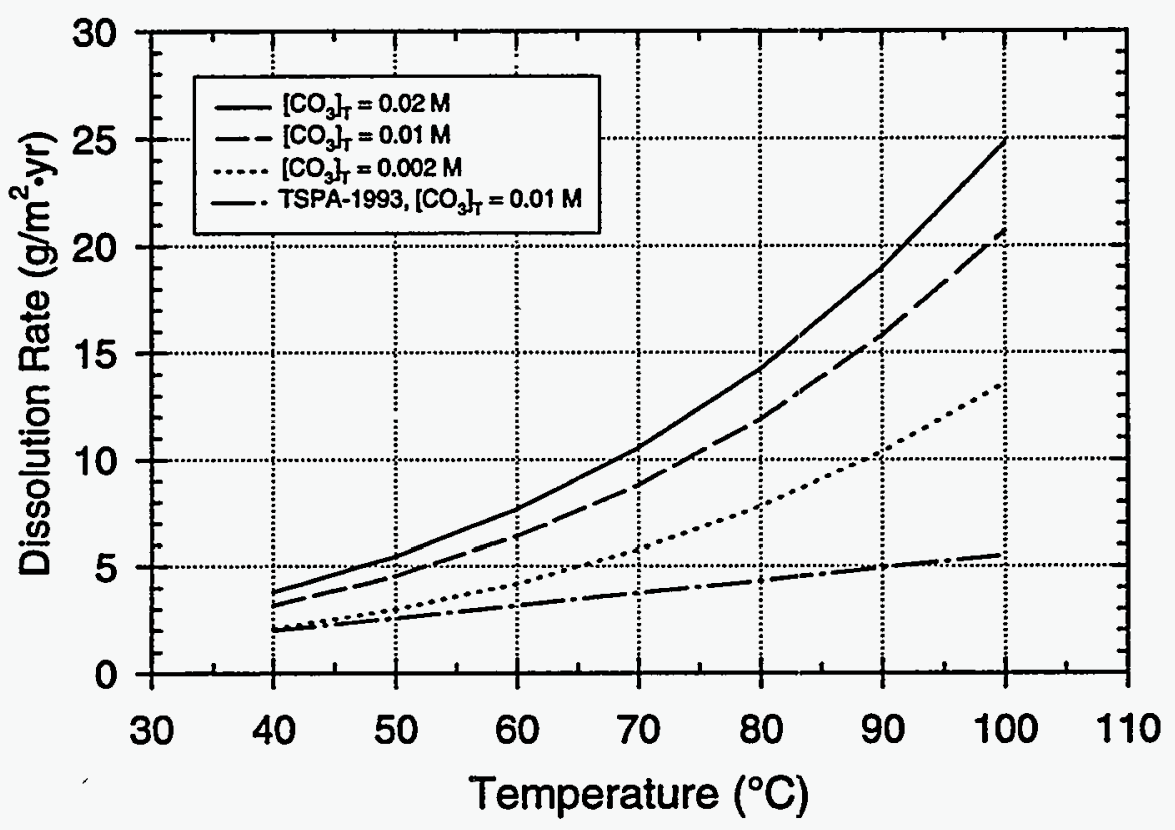

Figure 6.2-4 Comparison of Spent Fuel Dissolution Rates Calculated by the Current Model with the Model Used in TSPA-1993. 


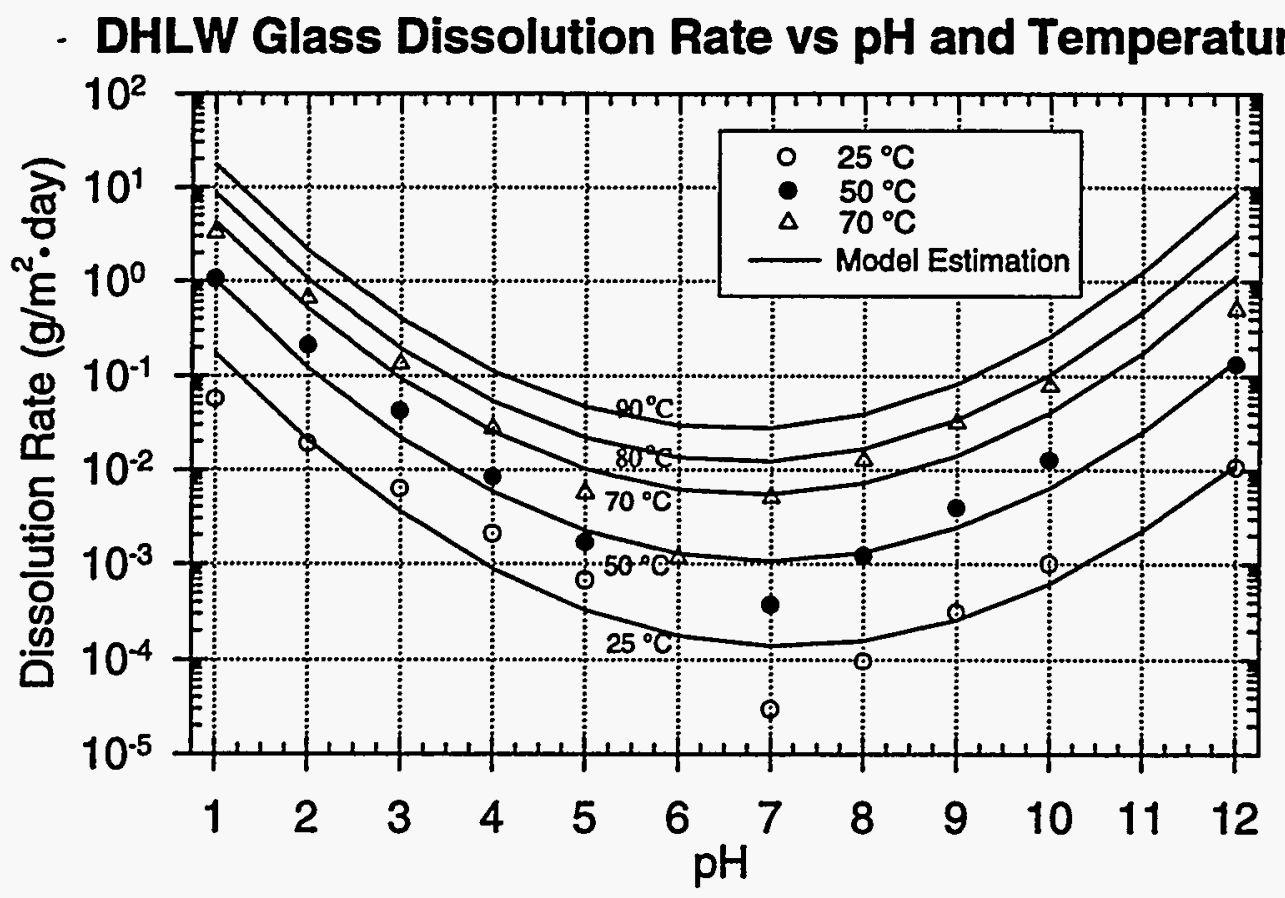

Figure 6.2-5 Prediction and the Data of the Intrinsic Dissolution Rates of DHLW Glass Waste Form as a Function of $\mathrm{pH}$ and Temperature

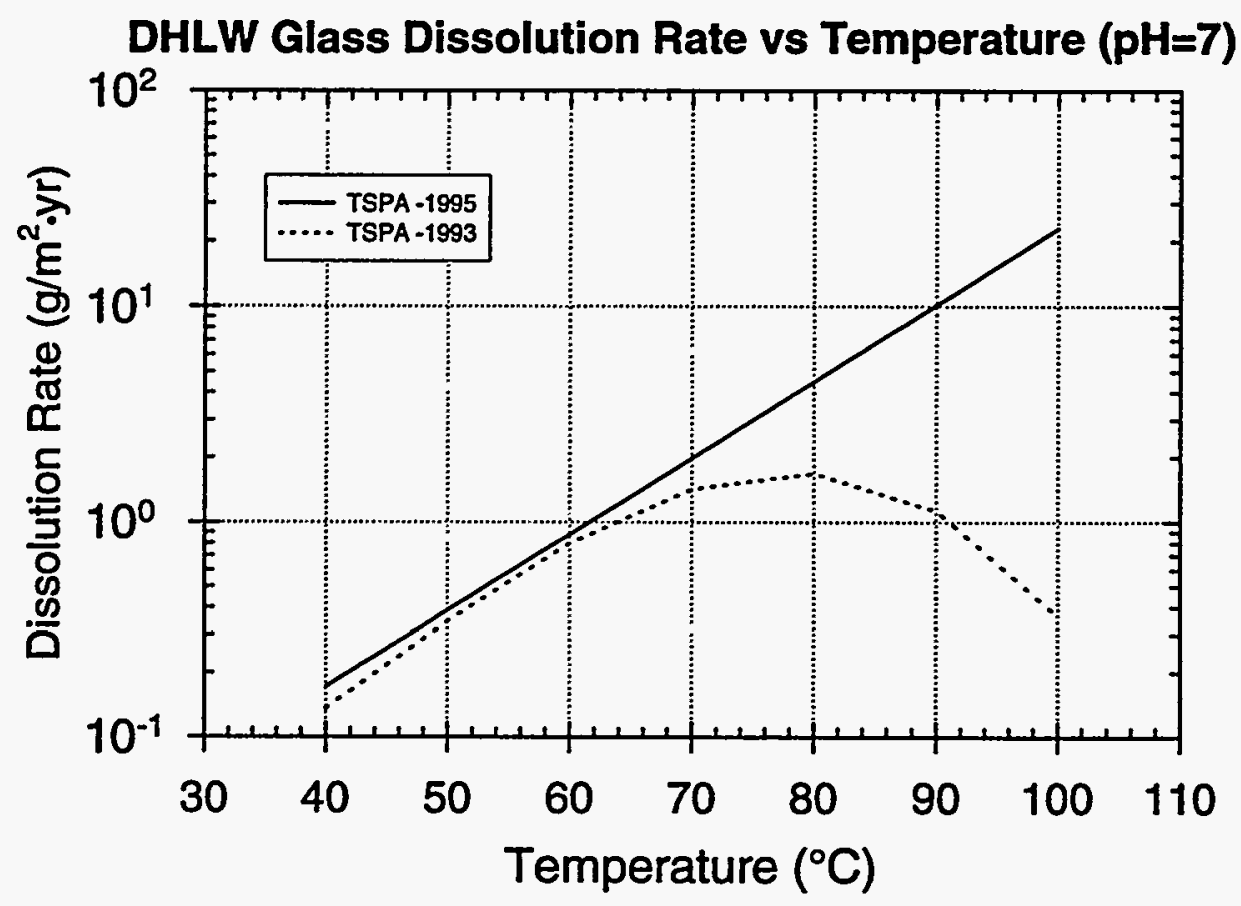

Figure 6.2-6 Comparison of the Prediction of the Intrinsic Glass Dissolution Rate as a Function of Temperature at $\mathrm{pH}$ of 7 Calculated with the Current Model and the Model Used in TSPA-1993 


\section{Probability Distribution Used to Represent Solubility-Limited Ac, Am, and Sm Concentrations}
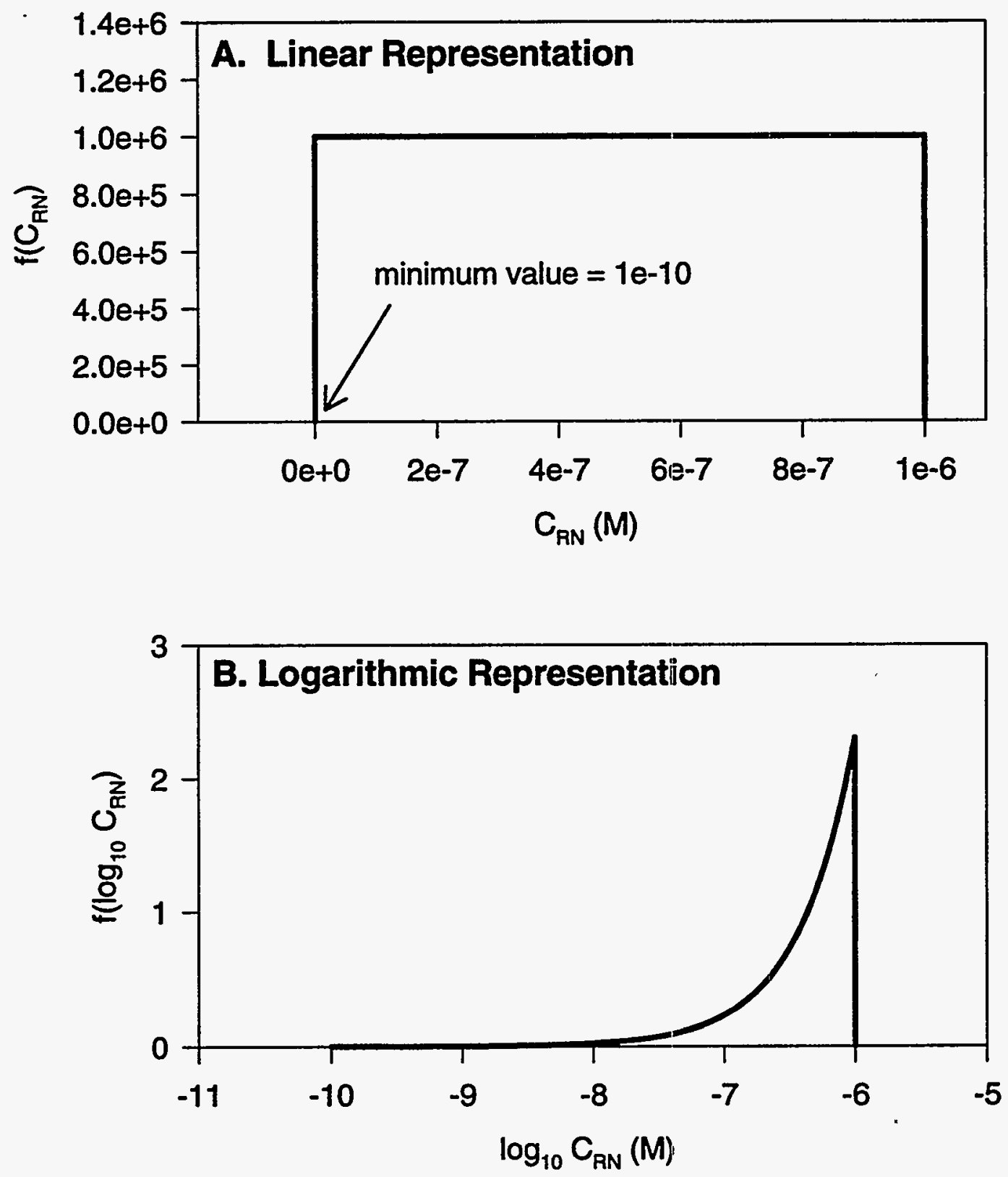

Figure 6.3-1 Plot of the Distribution Function for Solubility-Limited Concentrations of Ac, $\mathrm{Am}$, and Sm. A. Linear representation. B. Logarithmic representation. 


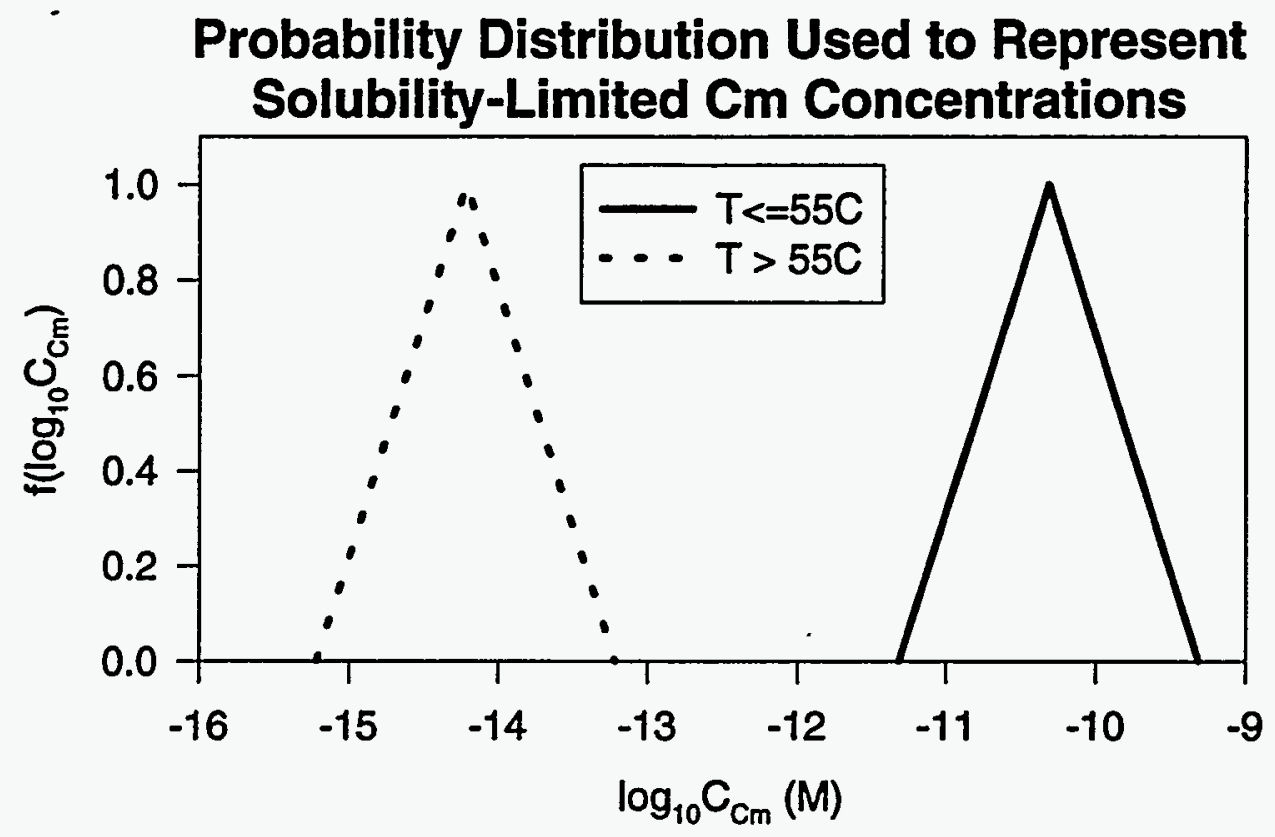

Figure 6.3-2 Plot of the Distribution Function for Solubility-Limited Concentrations of Cm.

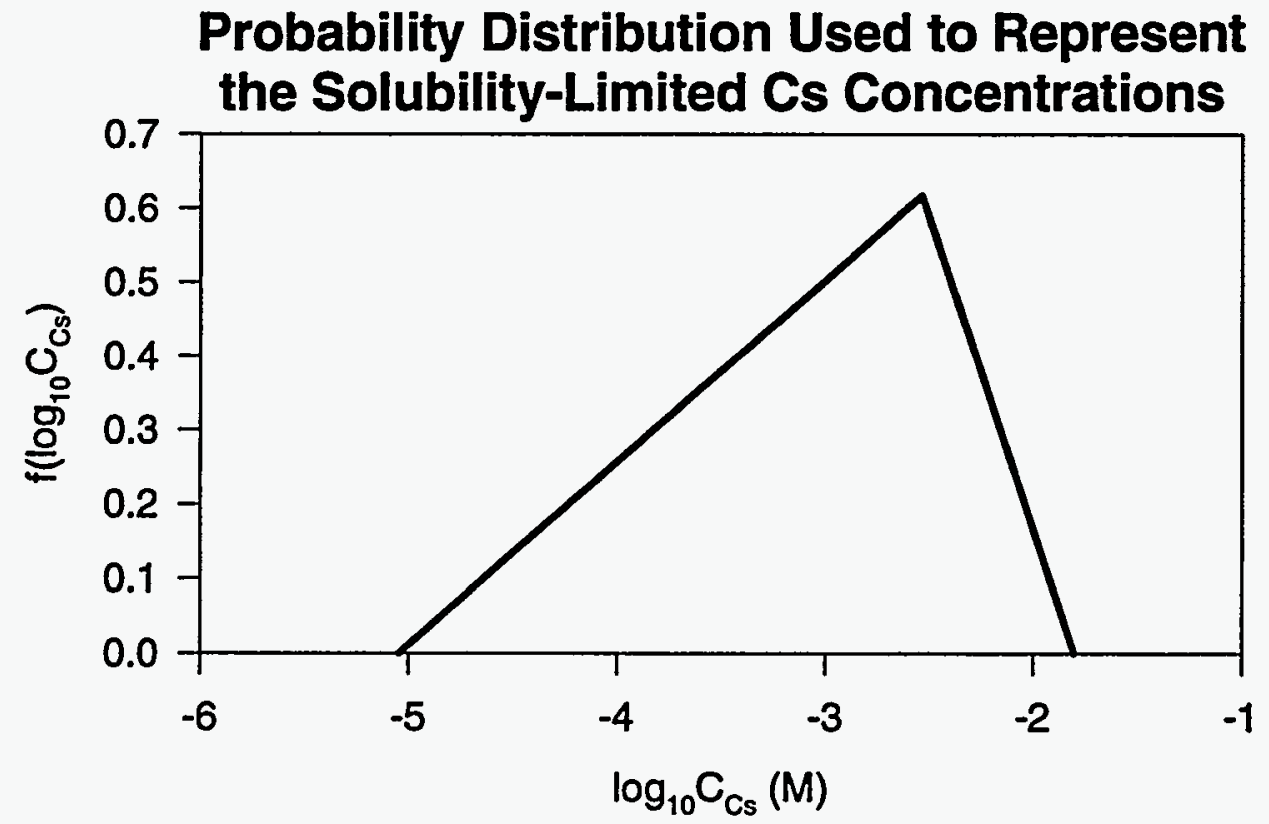

Figure 6.3-3 Plot of the Distribution Function for Solubility-Limited Concentrations of Cs. 


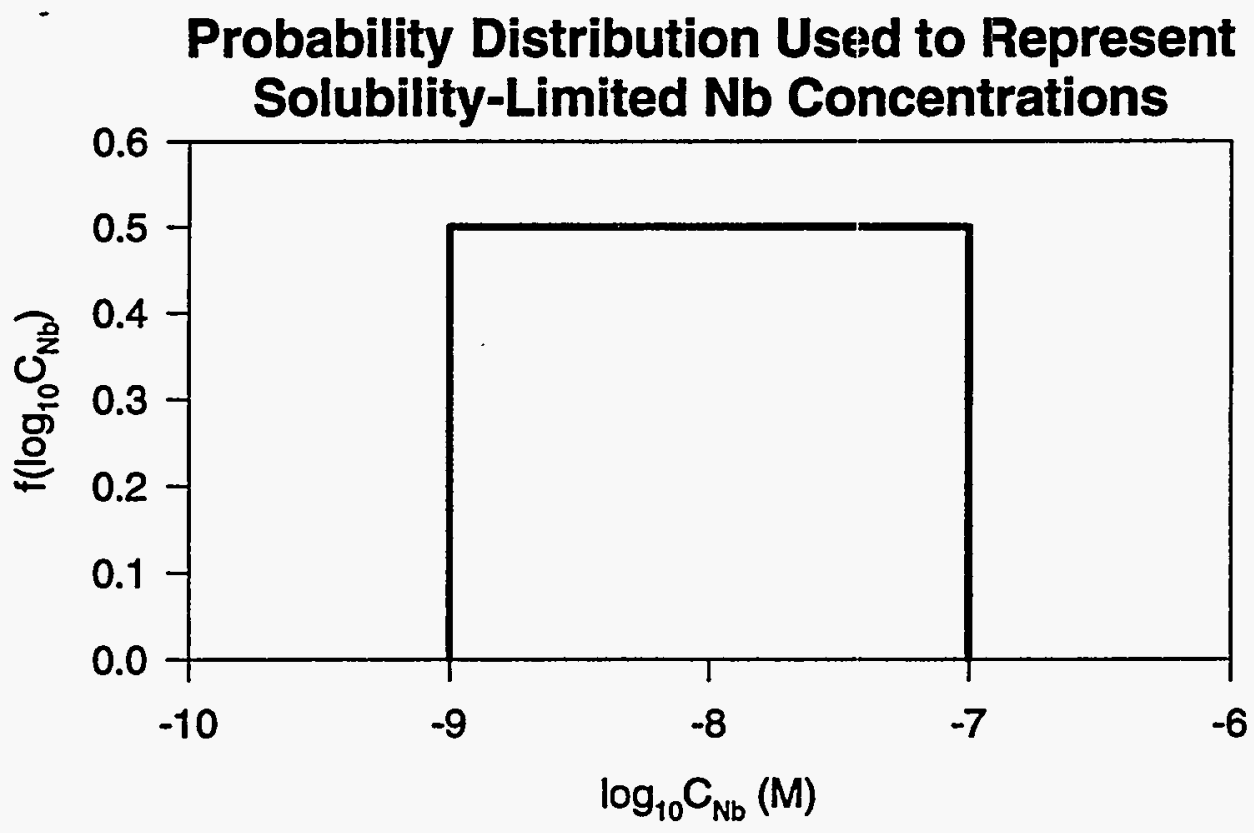

Figure 6.3-4 Plot of the Distribution Function for Solubility-Limited Concentrations of $\mathrm{Nb}$.

Probability Distributions Used to Represent Solubility-Limited Ni Concentrations

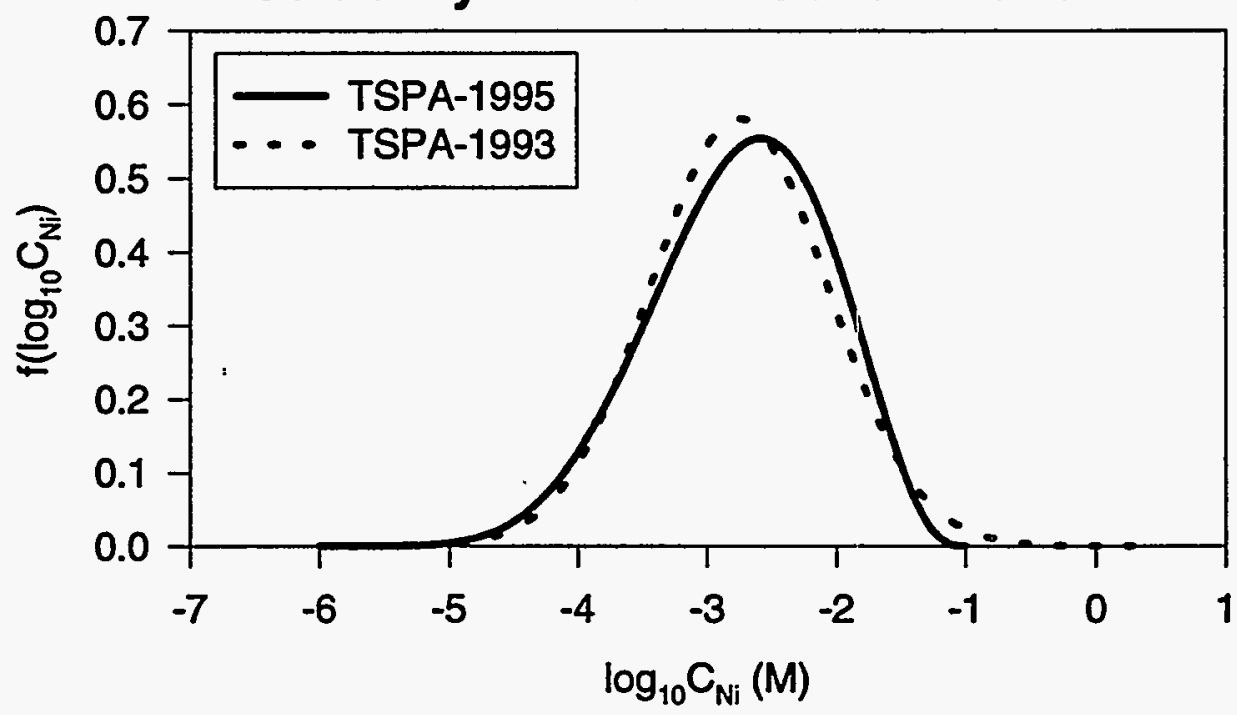

Figure 6.3-5 Plot of the Distribution Function for Solubility-Limited Concentrations of Ni. 


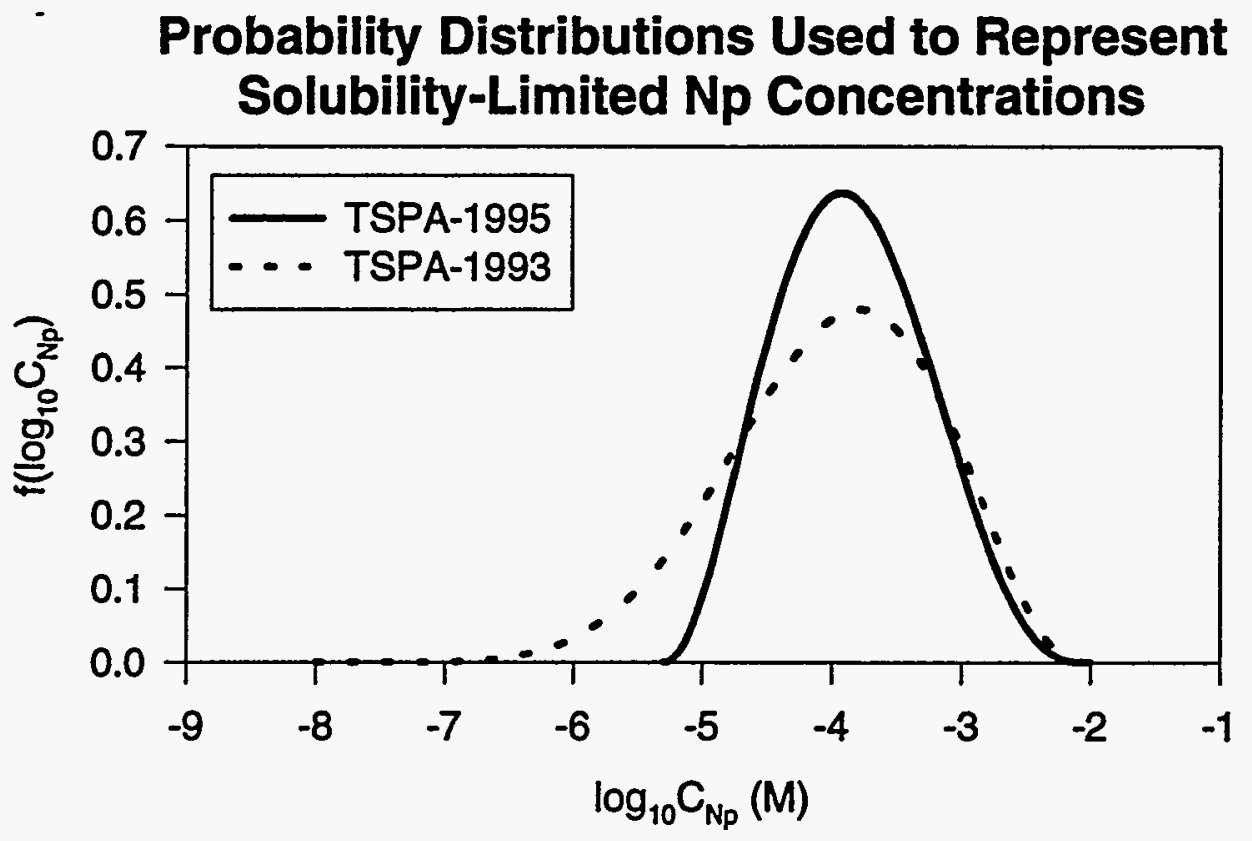

Figure 6.3-6 Plot of the Distribution Function for Solubility-Limited Concentrations of Np.

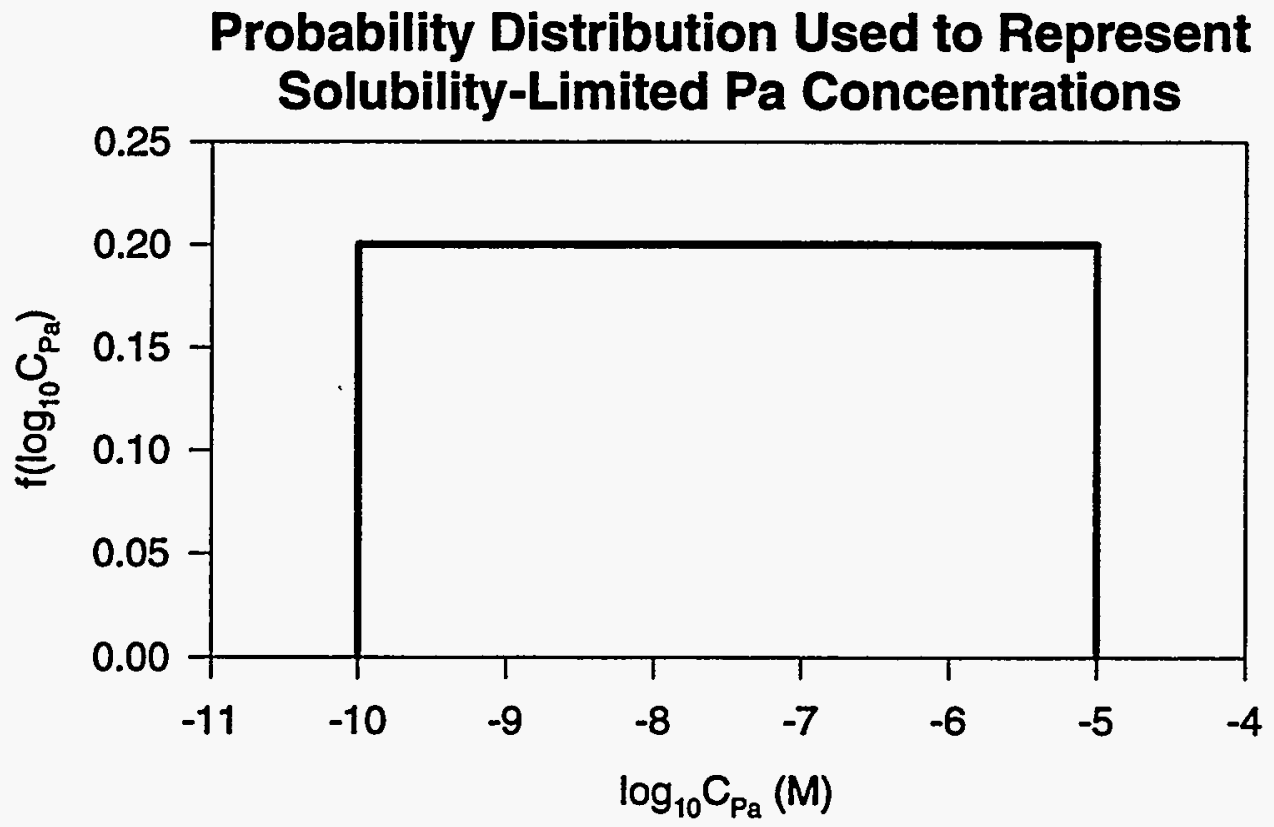

Figure 6.3-7 Plot of the Distribution Function for Solubility-Limited Concentrations of Pa. 


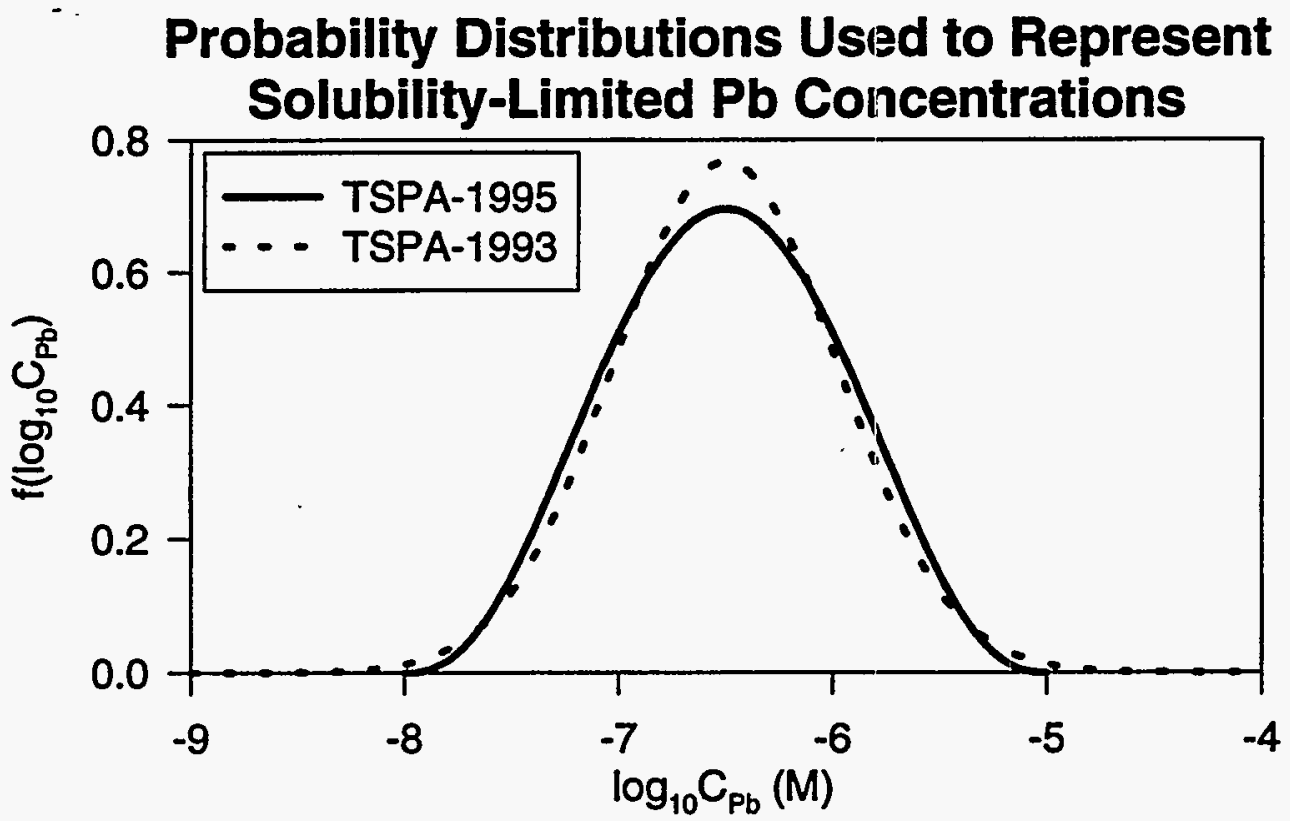

Figure 6.3-8 Plot of the Distribution Function for Solubility-Limited Concentrations of $\mathrm{Pb}$.

\section{Probability Distribution Used to Represent Solubility-Limited Pd Concentrations}

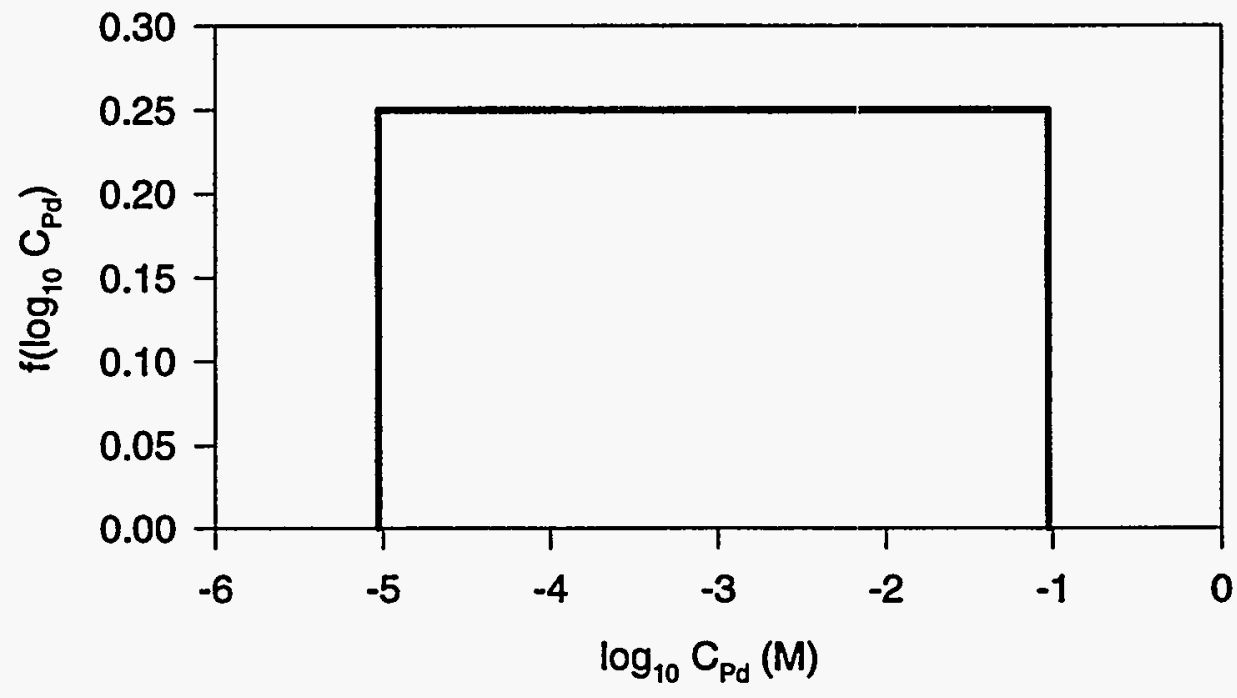

Figure 6.3-9 Plot of the Distribution Function for Solubility-Limited Concentrations of Pd. 


\section{Probability Distribution Used to Represent Solubility-Limited Pu Concentrations}
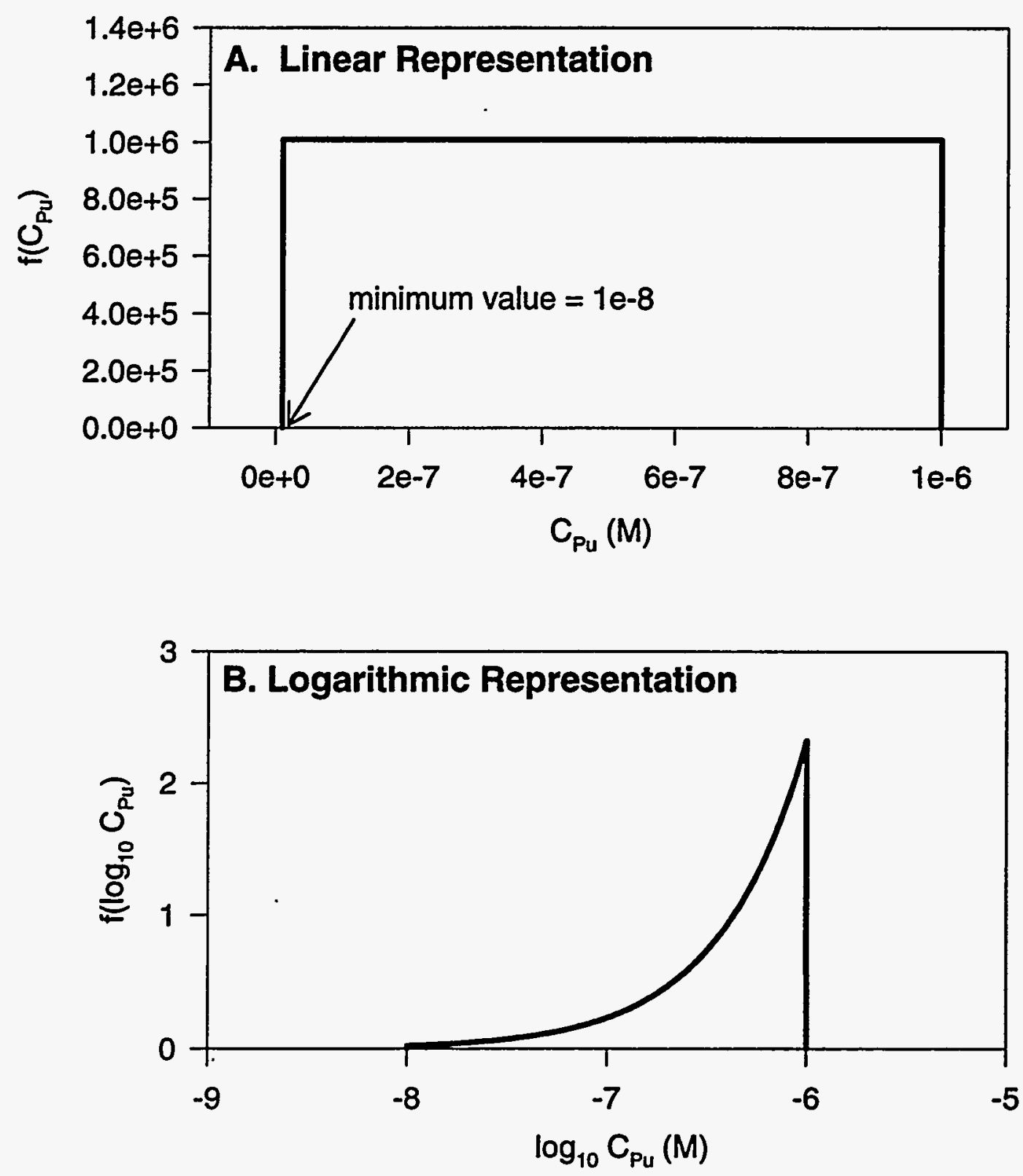

Figure 6.3-10 Plot of the Distribution Function for Solubility-Limited Concentrations of Pu. A. Linear representation. B. Logarithmic representation. 


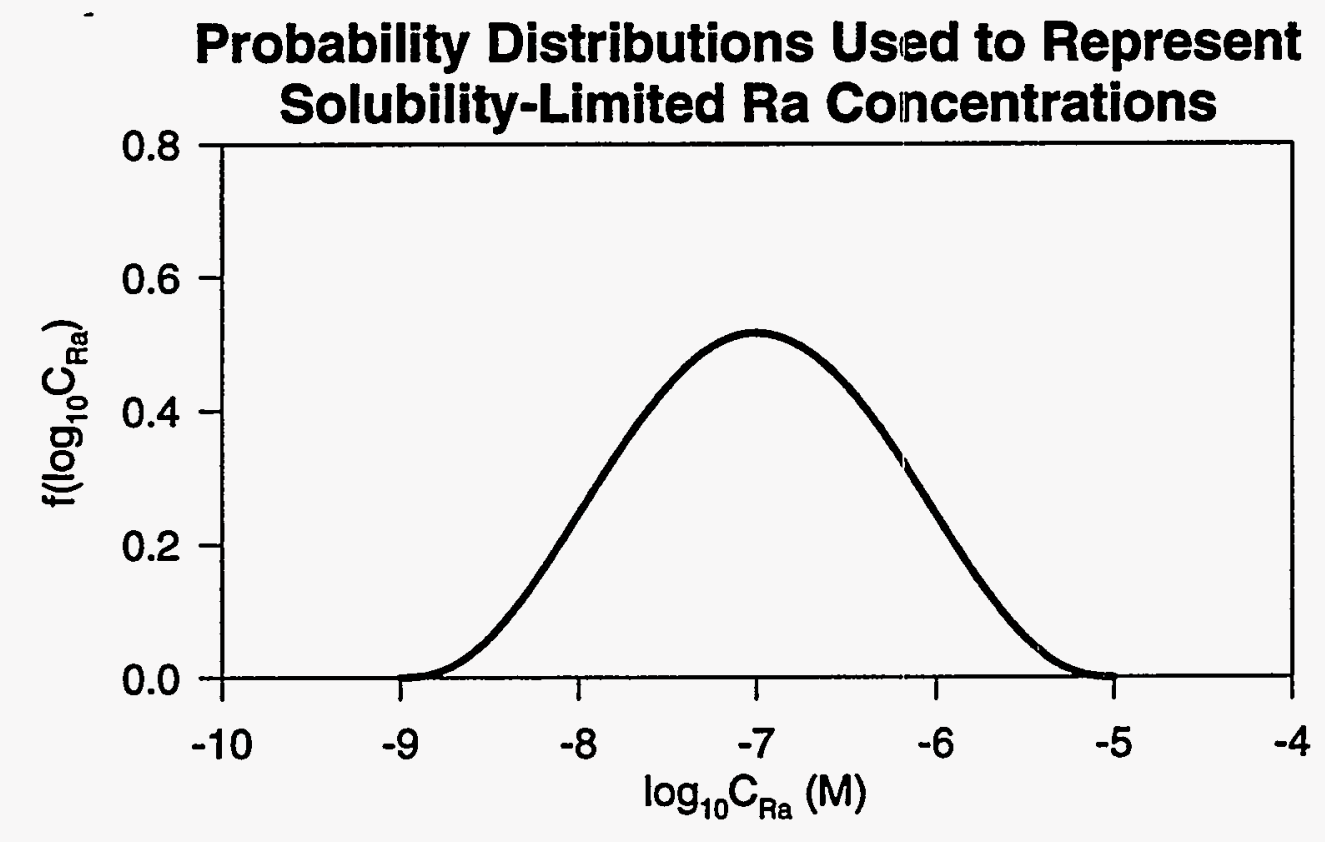

Figure 6.3-11 Plot of the Distribution Function for Solubility-Limited Concentrations of Ra.

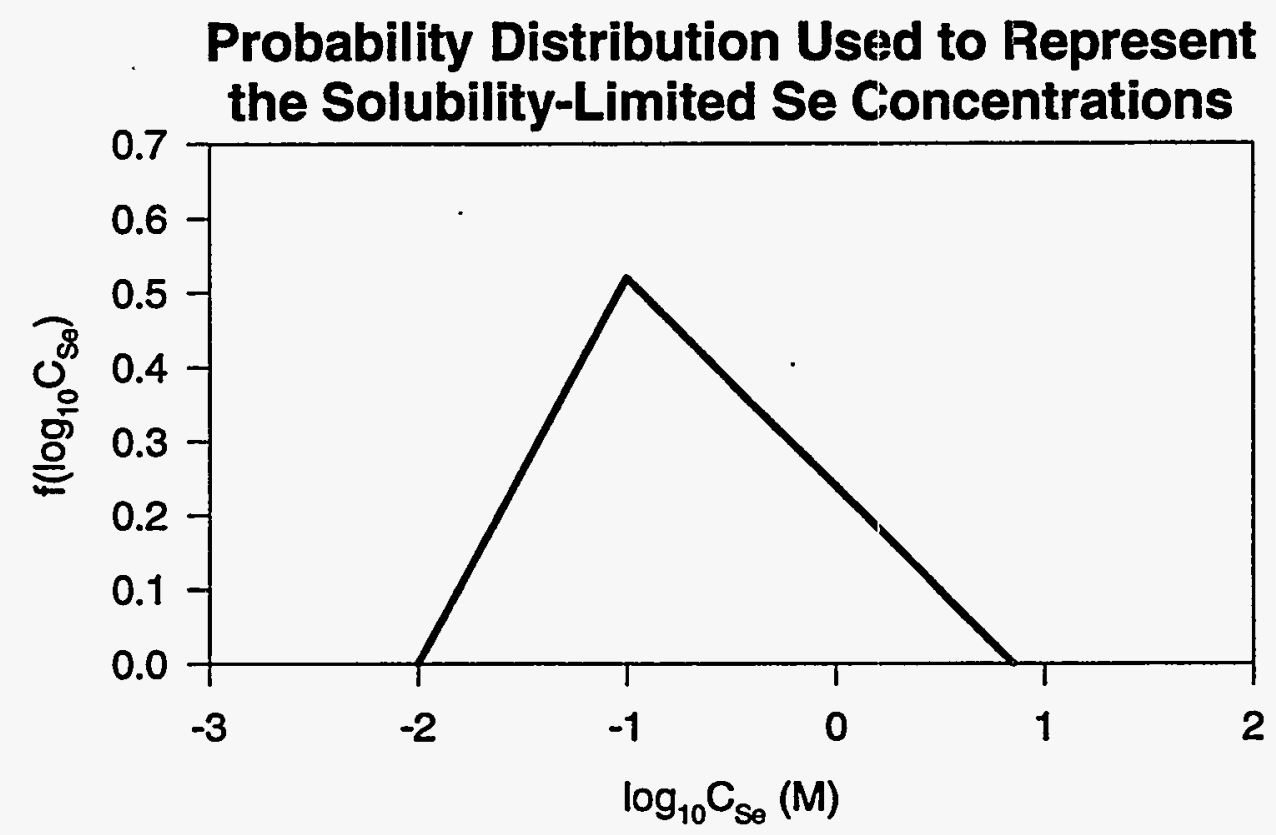

Figure 6.3-12 Plot of the Distribution Function for Solubility-Limited Concentrations of Se. 


\section{Probability Distribution Used to Represent Solubility-Limited Sn Concentrations}
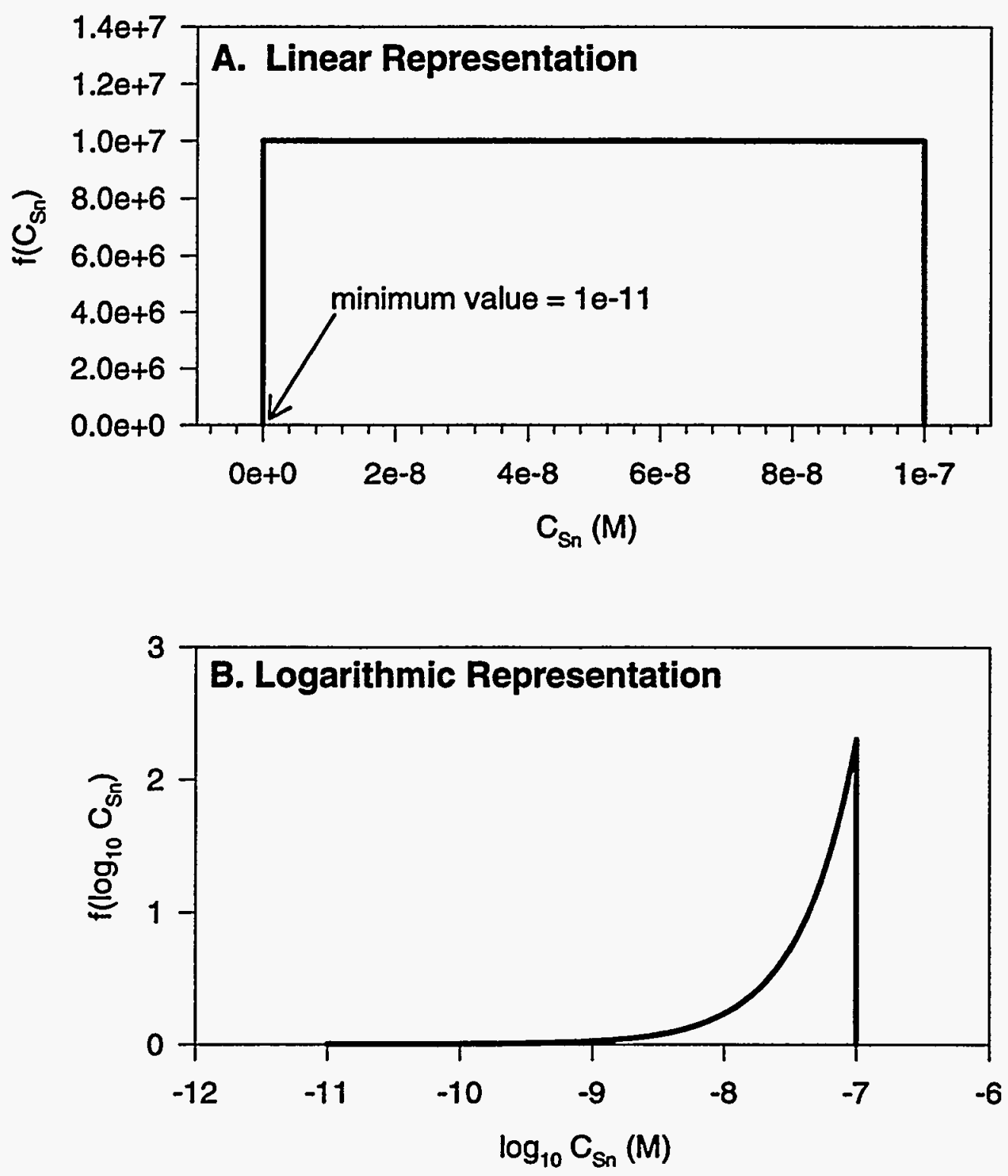

Figure 6.3-13 Plot of the Distribution Function for Solubility-Limited Concentrations of Sn. A. Linear representation. B. Logarithmic representation. 


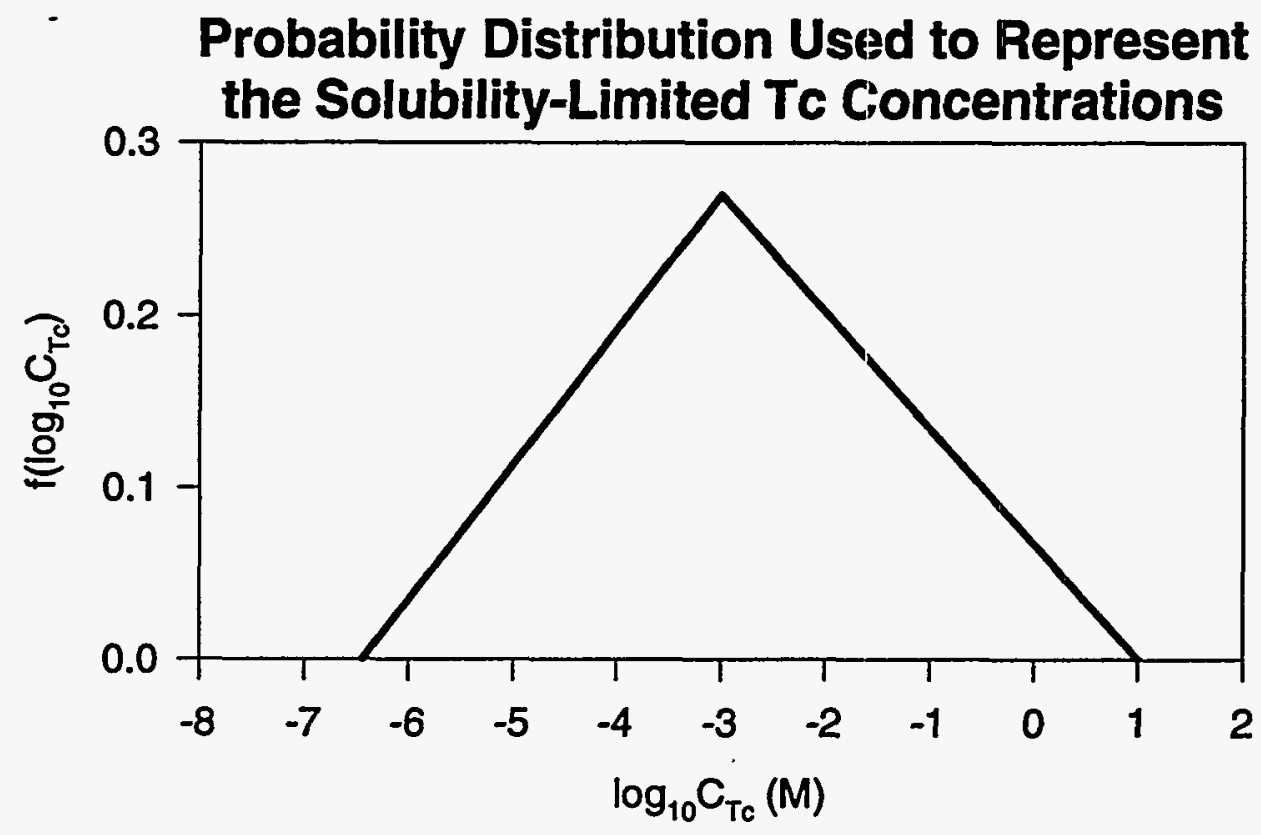

Figure 6.3-14 Plot of the Distribution Function for Solubility-Limited Concentrations of Tc.

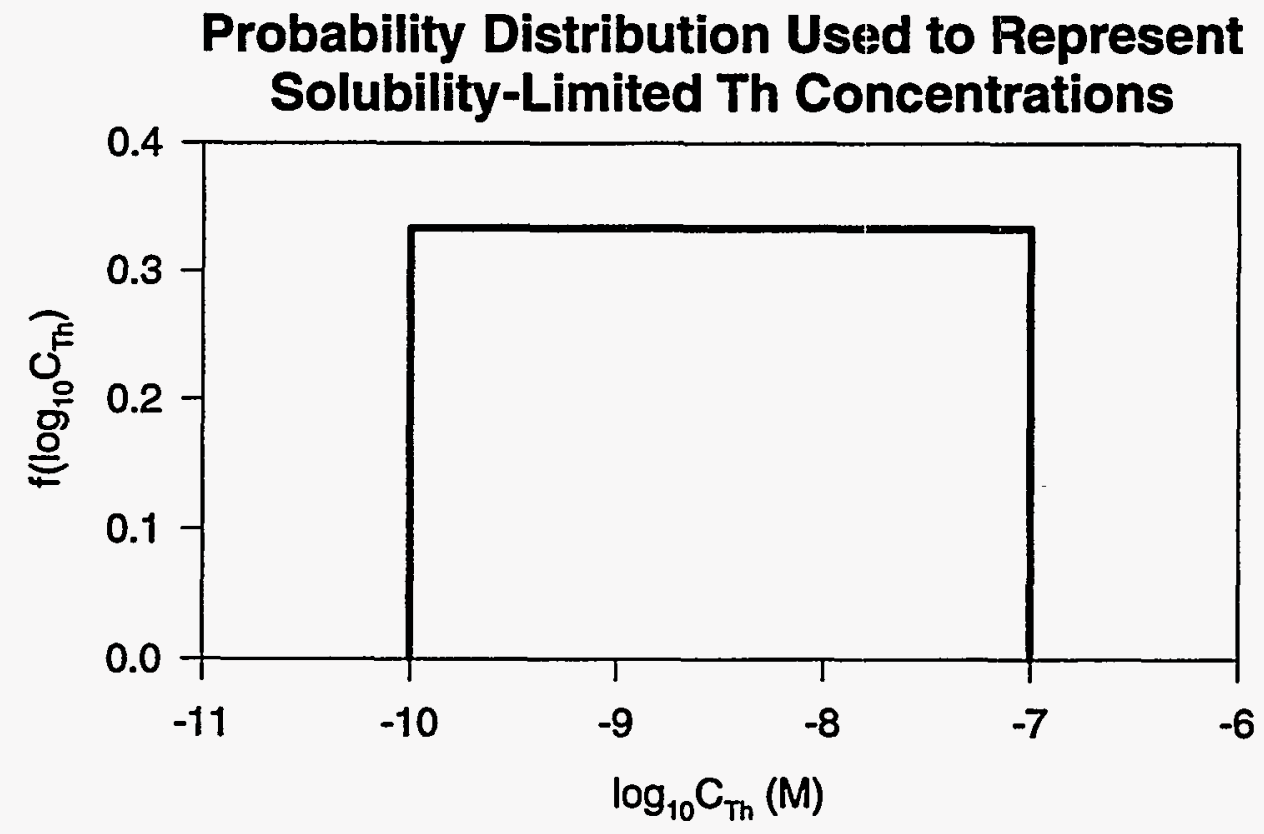

Figure 6.3-15 Plot of the Distribution Function for Solubility-Limited Concentrations of Th. 


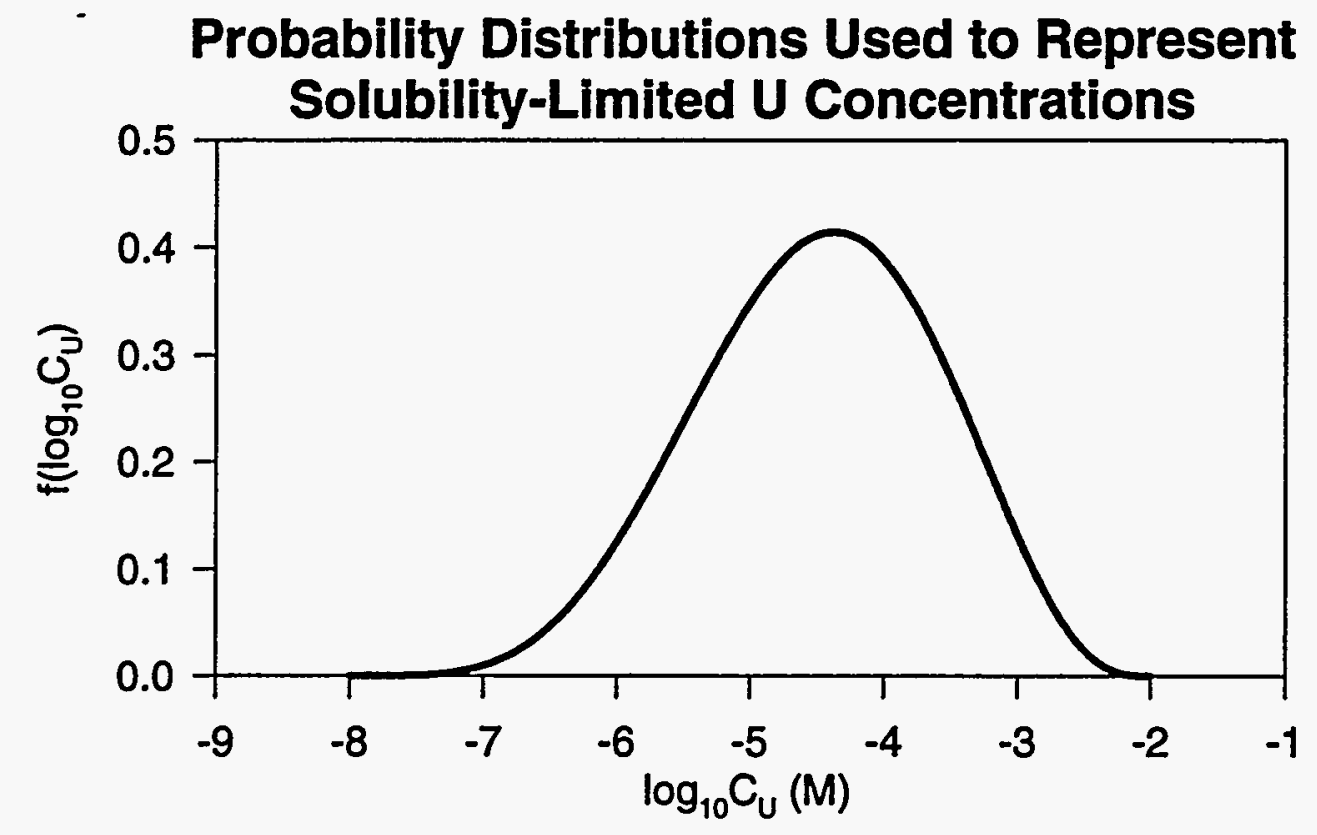

Figure 6.3-16 Plot of the Distribution Function for Solubility-Limited Concentrations of U.

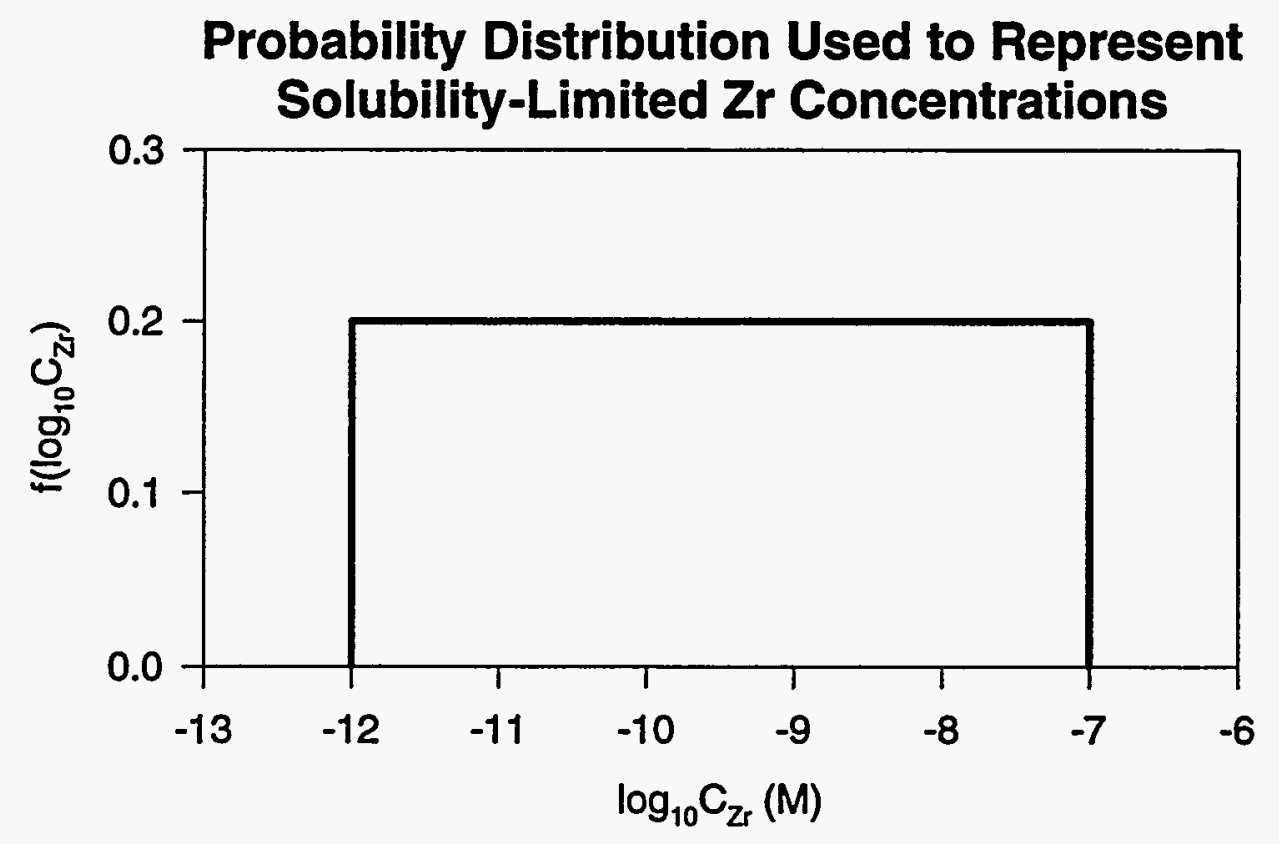

Figure 6.3-17 Plot of the Distribution Function for Solubility-Limited Concentrations of $\mathrm{Zr}$. 
Neptunium (Nitsche et al., 1993)

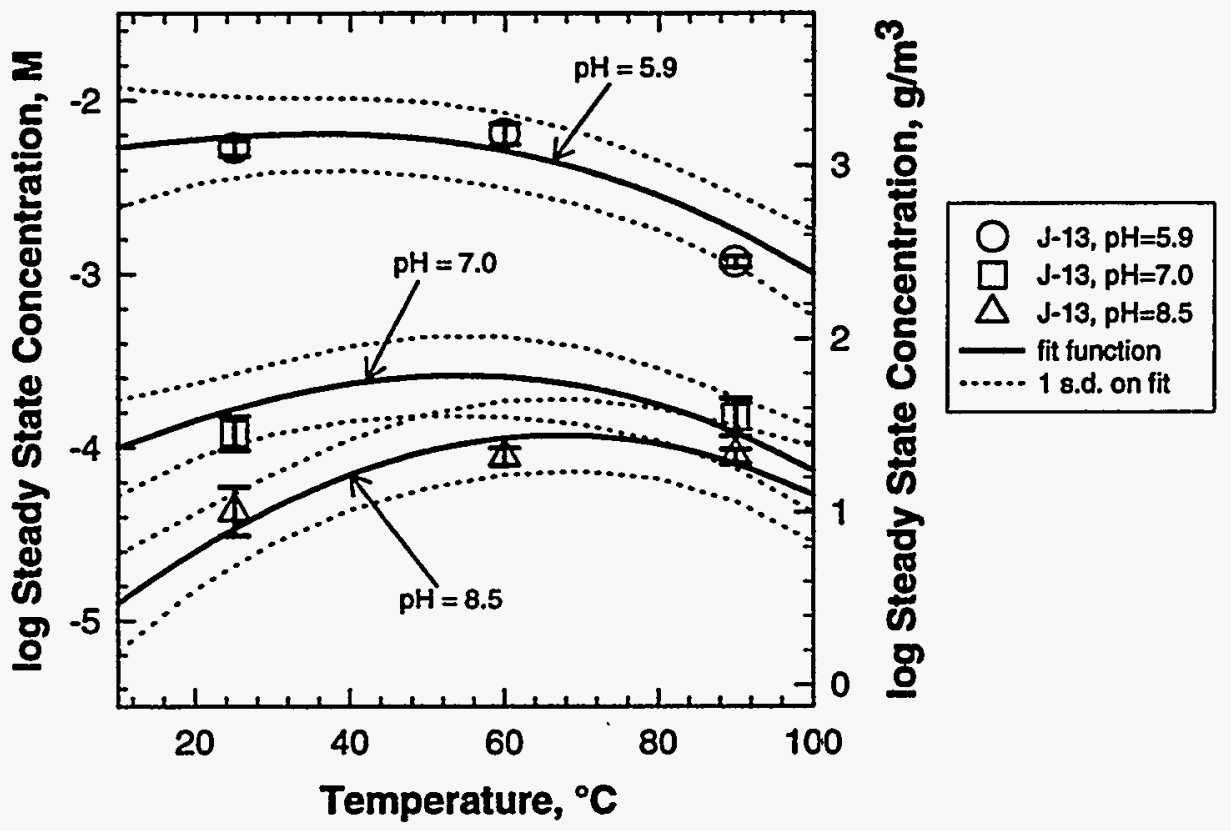

Figure 6.3-18 Temperature- and pH-Dependent Functional Fit to Nitsche et al. (1993) measurements of $\log$ (Steady-State Np Concentration) in J-13 Initial Water (Curves) Compared to Empirical Determinations Used (Symbols-Table 6.3-2). Two Standard Deviations from Analytical Uncertainties Shown on Data Points.

\section{Plutonium (Nitsche et al., 1993)}

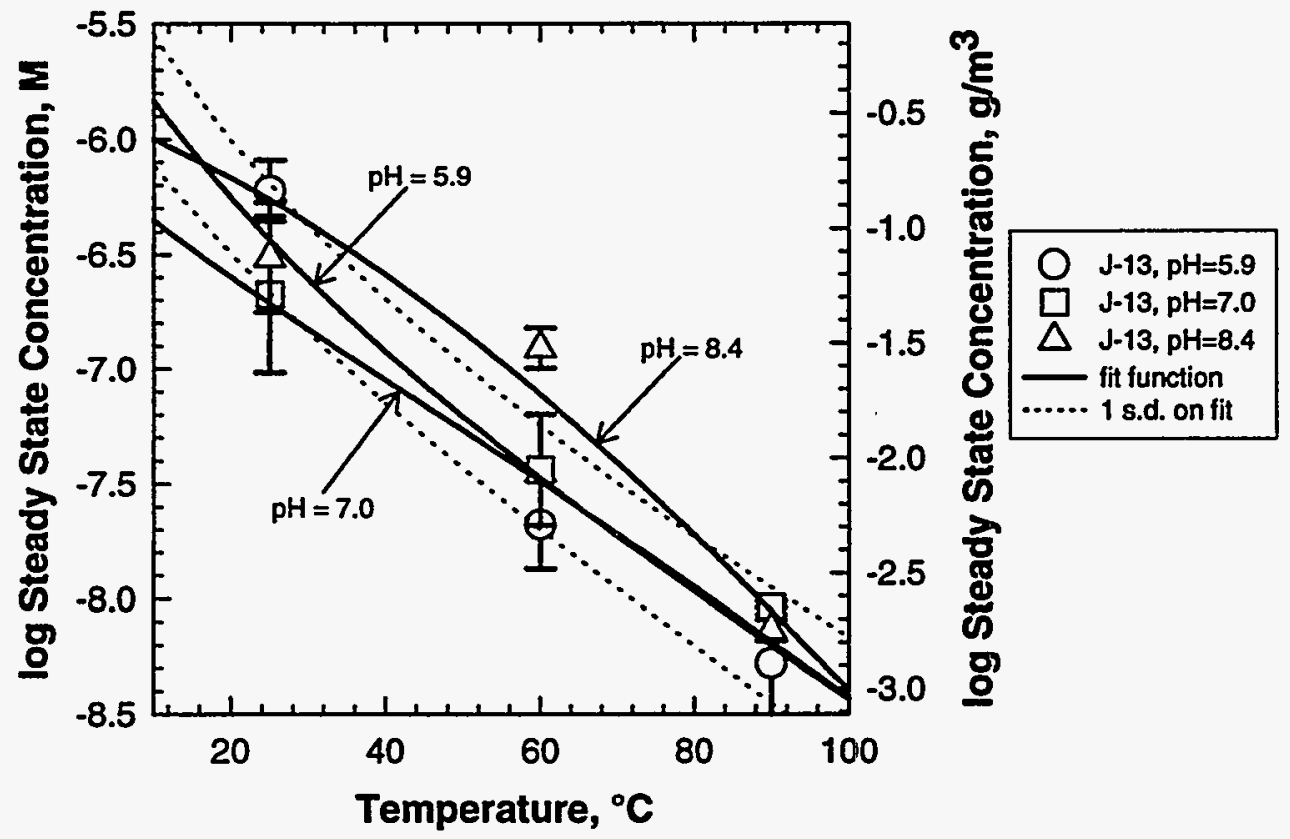

Figure 6.3-19 Temperature- and pH-Dependent Functional Fit to Nitsche et al. (1993) measurements of $\log$ (Steady-State Pu Concentration) in J-13 Initial Water (Curves) Compared to Empirical Determinations Used (Symbols-Table 6.3-3). Two Standard Deviations from Analytical Uncertainties Shown on Data Points. 

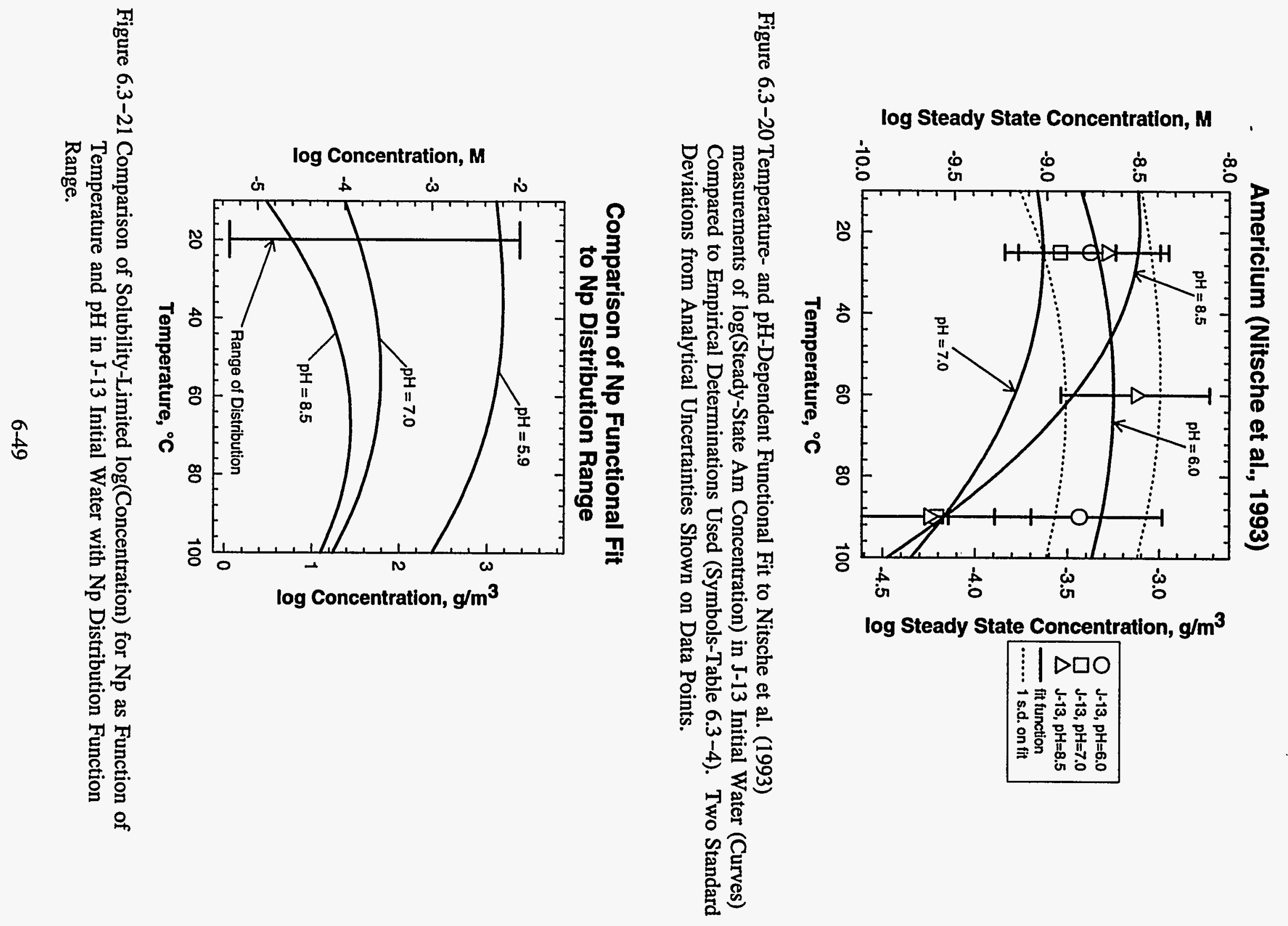


\section{Comparison of Pu Functional Fit}

to Pu Distribution Range

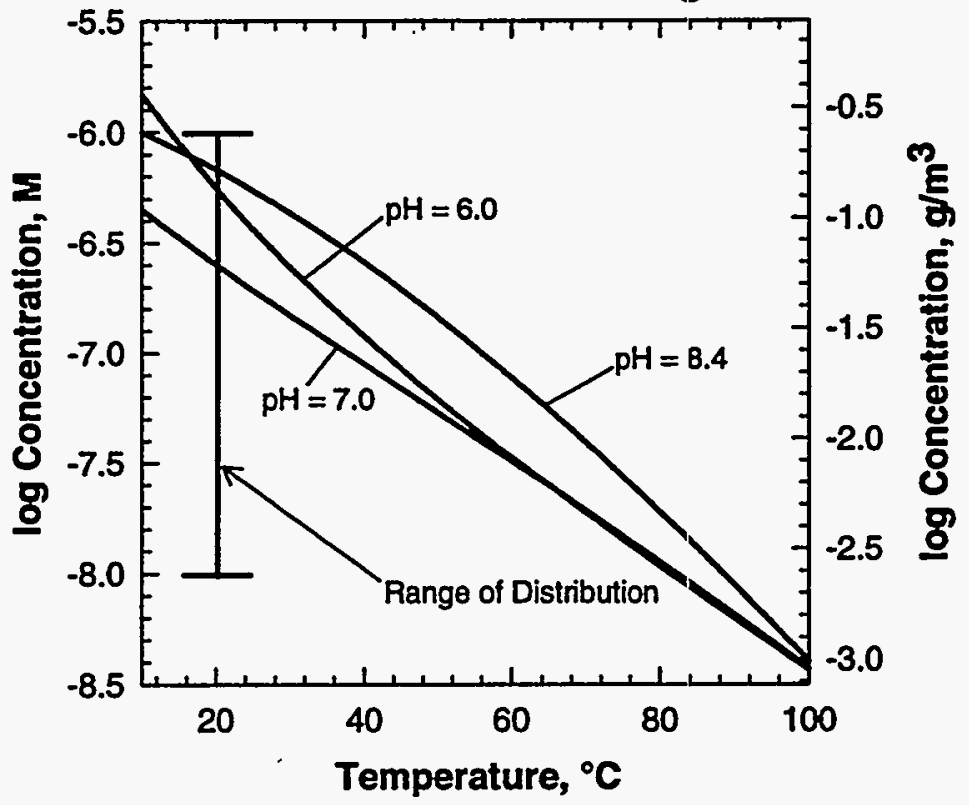

Figure 6.3-22 Comparison of Solubility-Limited $\log$ (Concentration) for Pu as Function of Temperature and $\mathrm{pH}$ in J-13 Initial Water to Pu Distribution Function Range.

\section{Comparison of Am Functional Fit} to Am Distribution Rarige

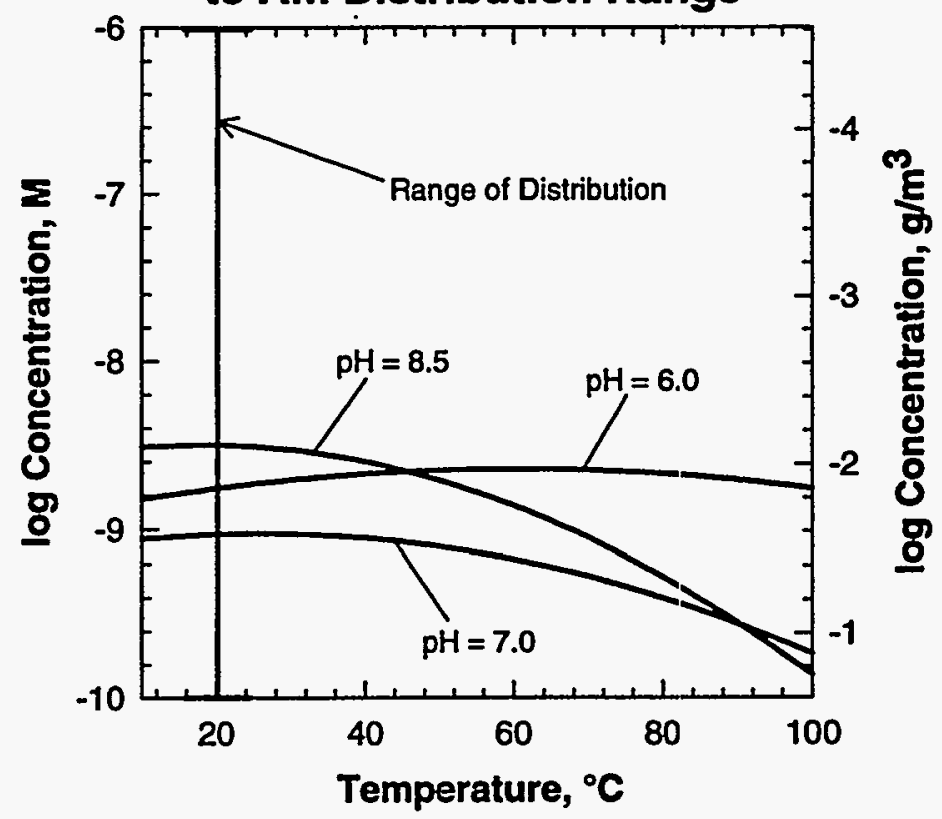

Figure 6.3-23 Comparison of Solubility-Limited $\log$ (Concentration) for Am as Function of Temperature and $\mathrm{pH}$ in $\mathrm{J}-13$ Initial Water to Am Distribution Function Range. 


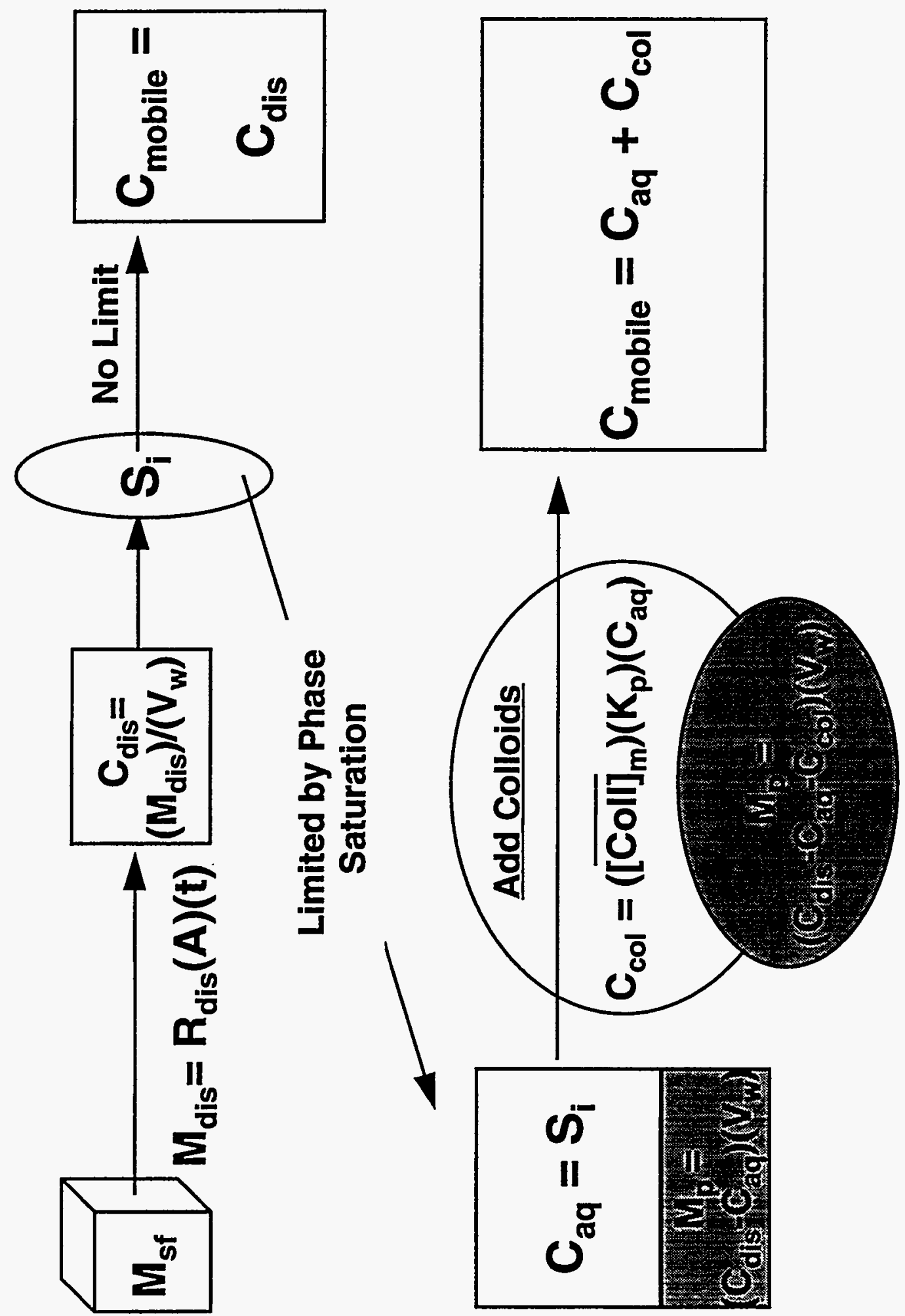

ค

E

造

을

5

응

预

廿

岁

옹

4

옳

'ं

照 


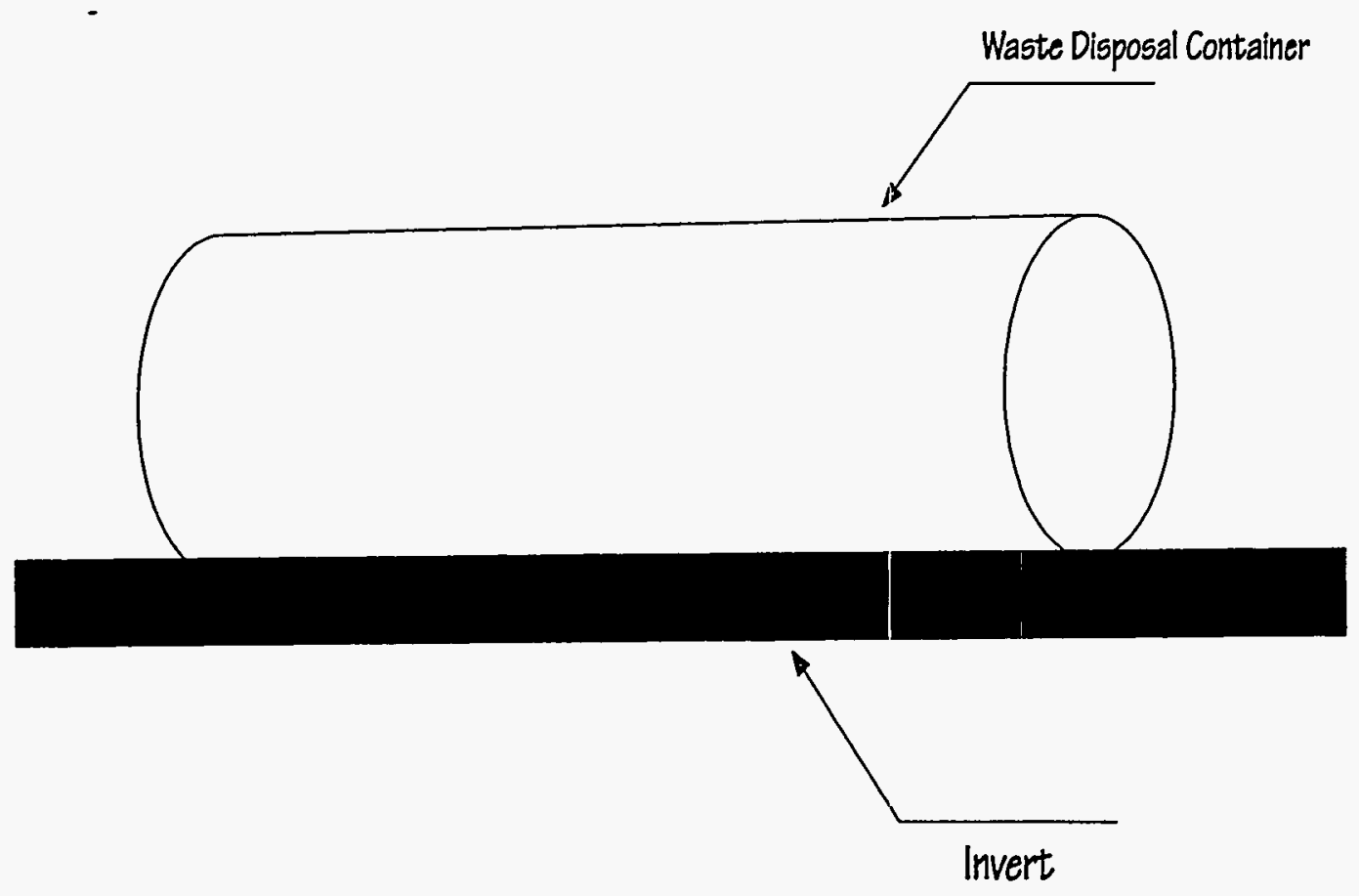

Figure 6.5-1 Schematic Drawing of Waste Disposal Container Placed on the Invert in an Emplacement Drift (side view)

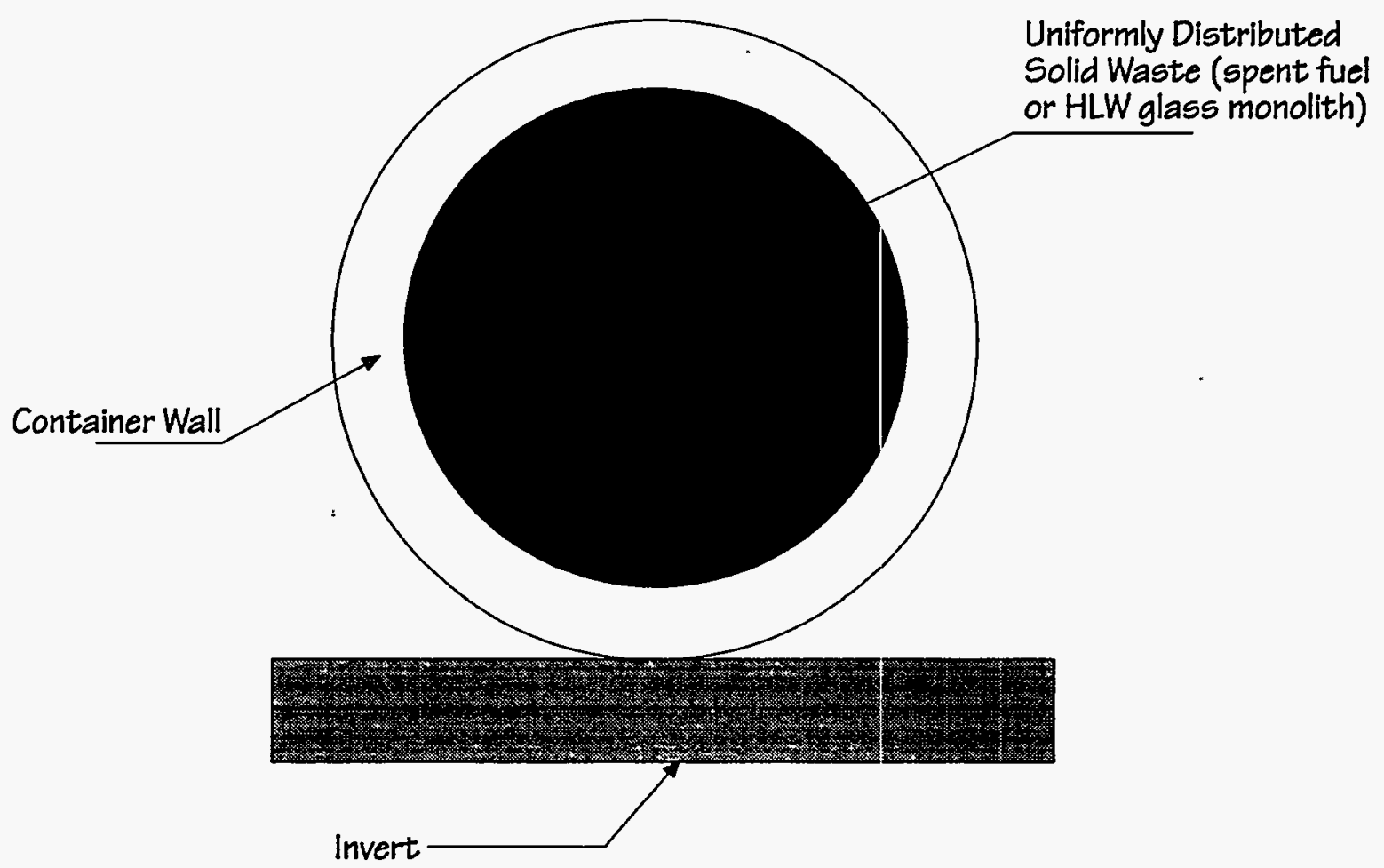

Figure 6.5-2 Schematic Drawing of Waste Disposal Container Placed on the Invert in an Emplacement Drift (front view) 


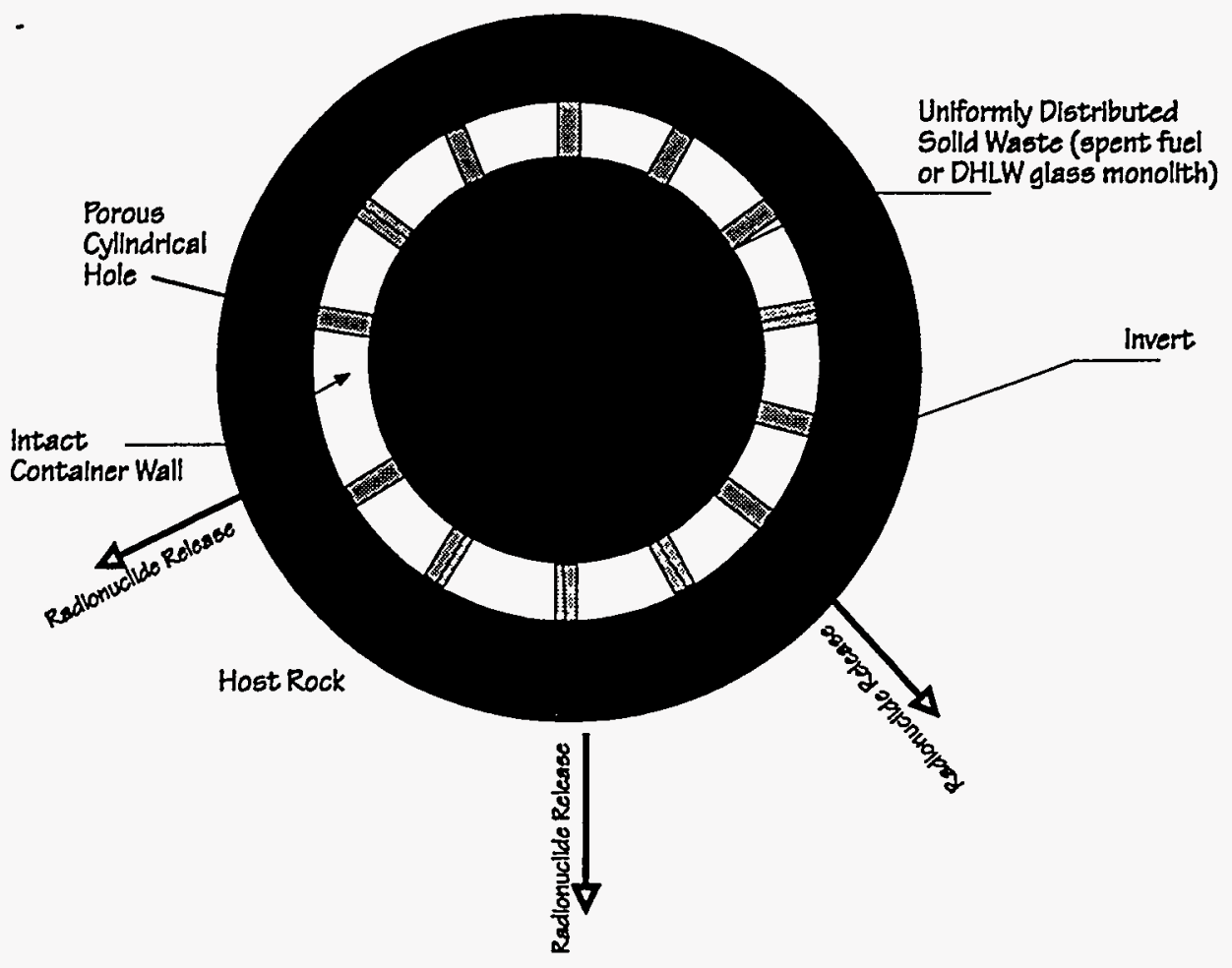

Figure 6.5-3 Schematic of Radionuclide Release Through Multiple Cylindrical Holes on the Waste Disposal Container for the Equivalent Spherical Configuration Approximation.

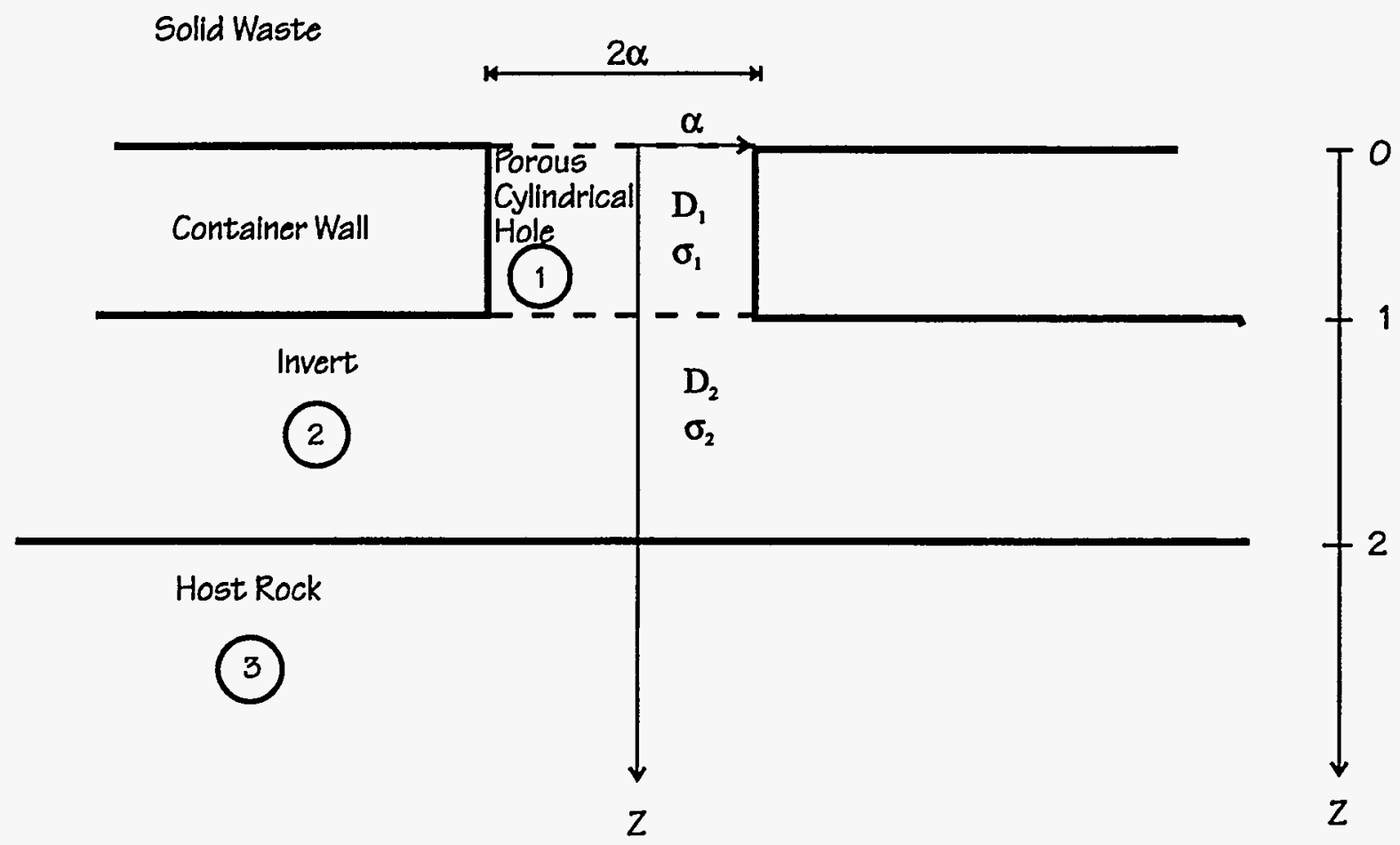

Figure 6.5-4 Conceptualization of Radionuclide Release Through a Cylindrical Hole in the Waste Disposal Container, the Invert, and the Host Rock. 


\section{Steady-State Diffusive Flelease at the Invert Boundary}

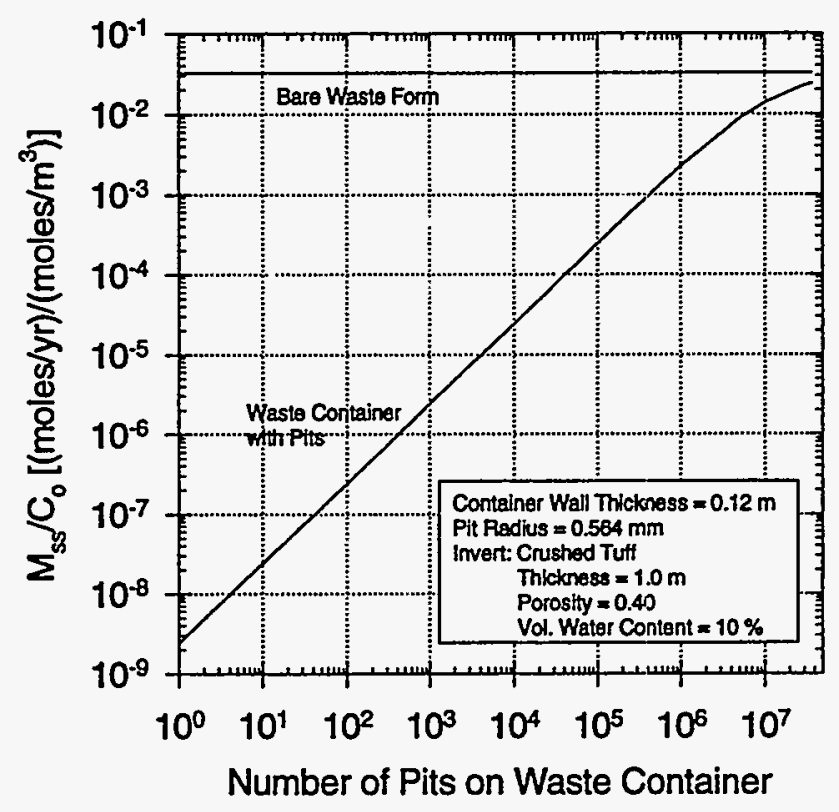

Figure 6.5-5 Comparison of Steady-State Diffusive Release at the EBS Boundary from A Waste Container with Multiple Pits to the Release from the Bare Waste Form.

A Representative Pitting Profile for A Waste Container

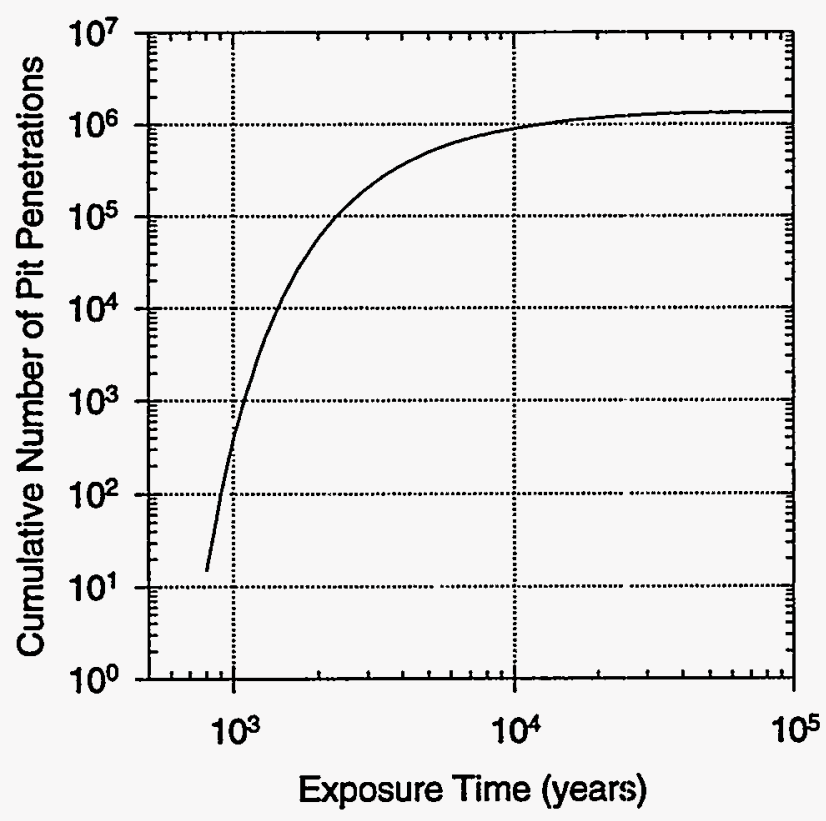

Figure 6.5-6 A Representative Pitting Profile of a Waste Container. 


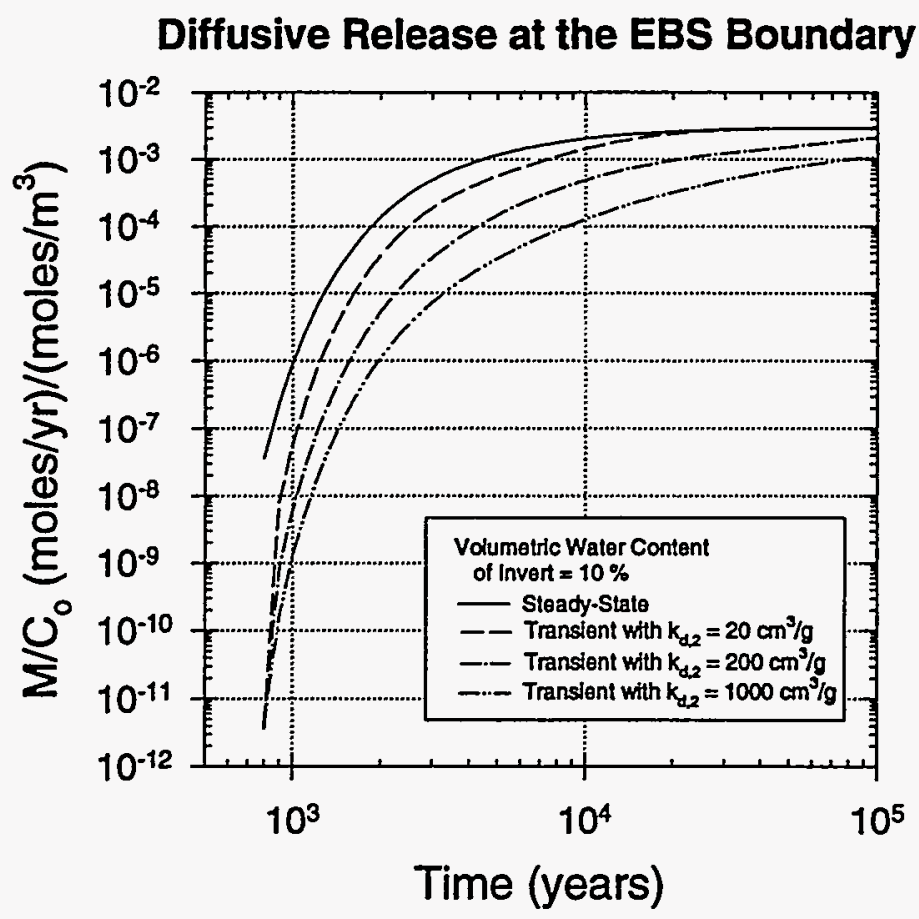

Figure 6.5-7 Transient and Steady-State Diffusive Releases at the EBS Boundary from A Waste Container with Multiple Pits.

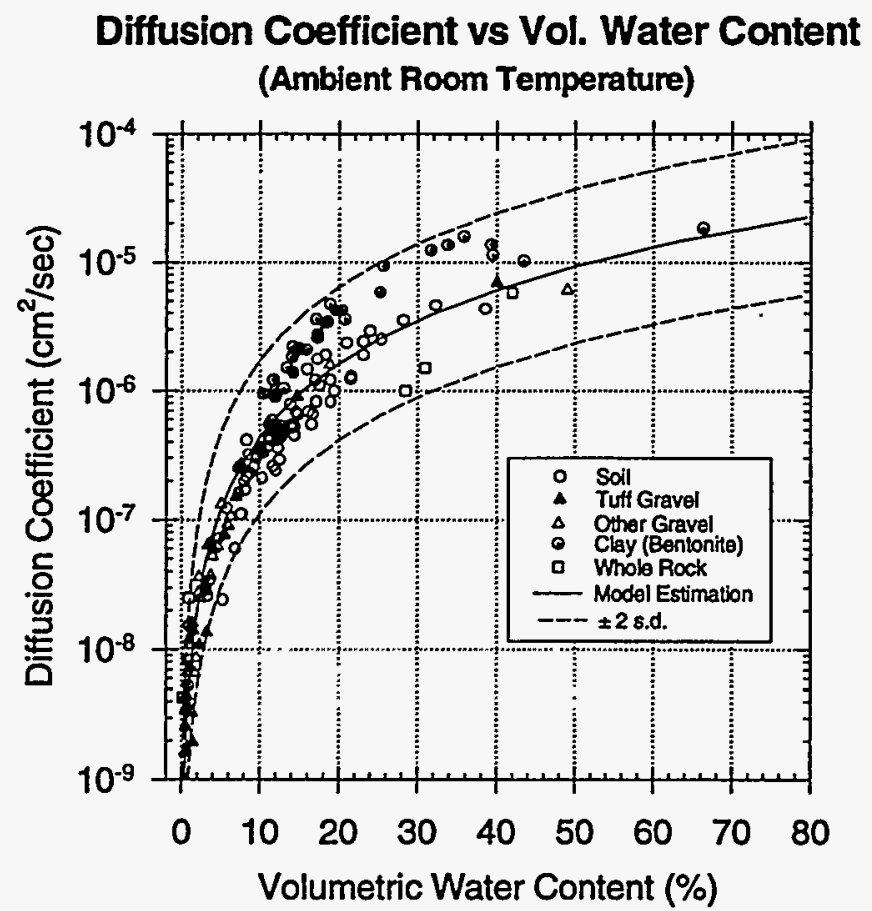

Figure 6.5-8 Model Estimation and the Uncertainty for the Diffusion Coefficient in Porous Geologic Media as a Function of the Volumetric Water Content. The raw data for a suite of geological materials were kindly provided by Jim Conca through David Engel at PNL (Engel, 1995). 


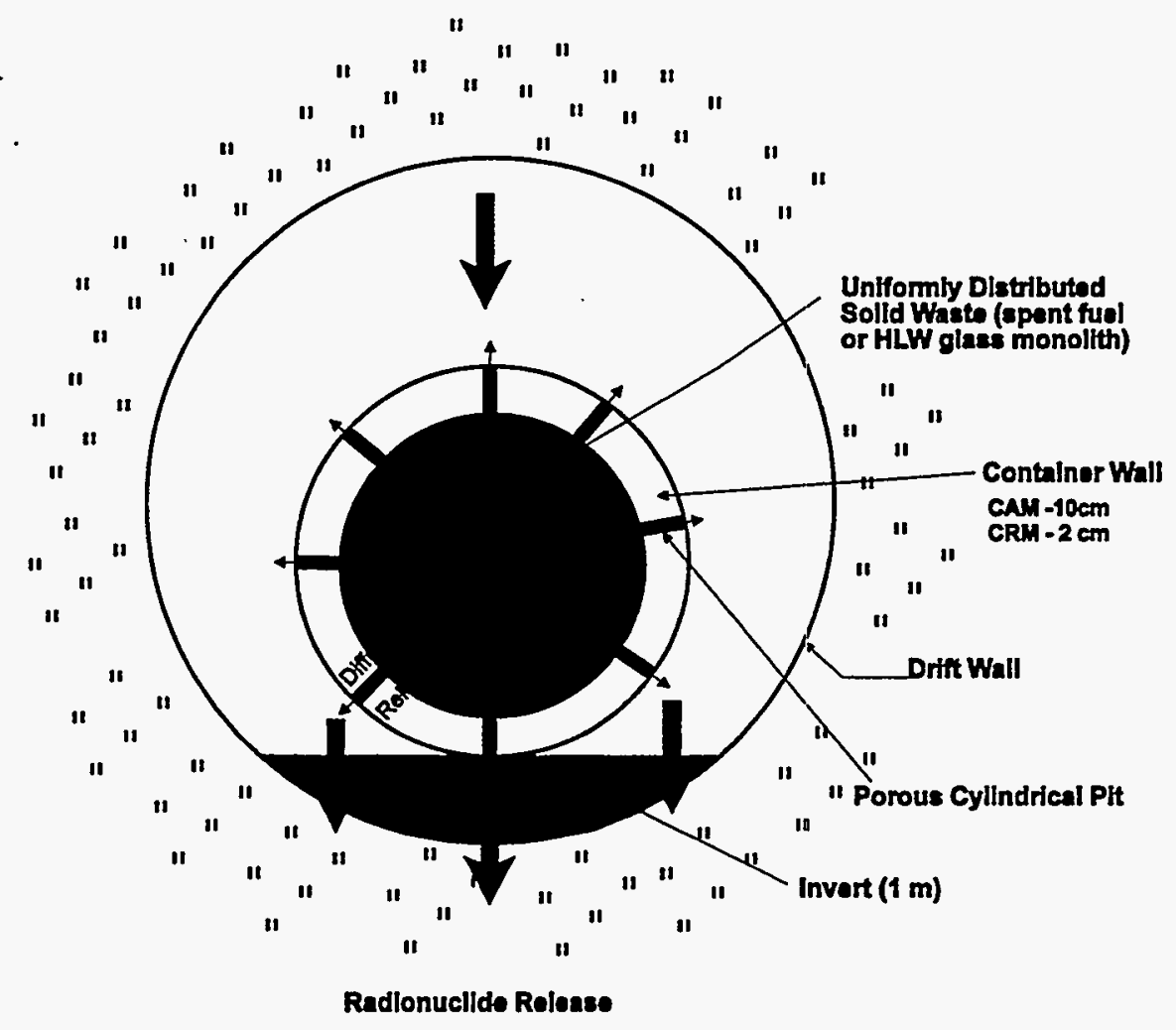

Figure 6.5-9 Conceptual Model for Diffusive Release and Advective Release from Both Waste Package and Other EBS Components.

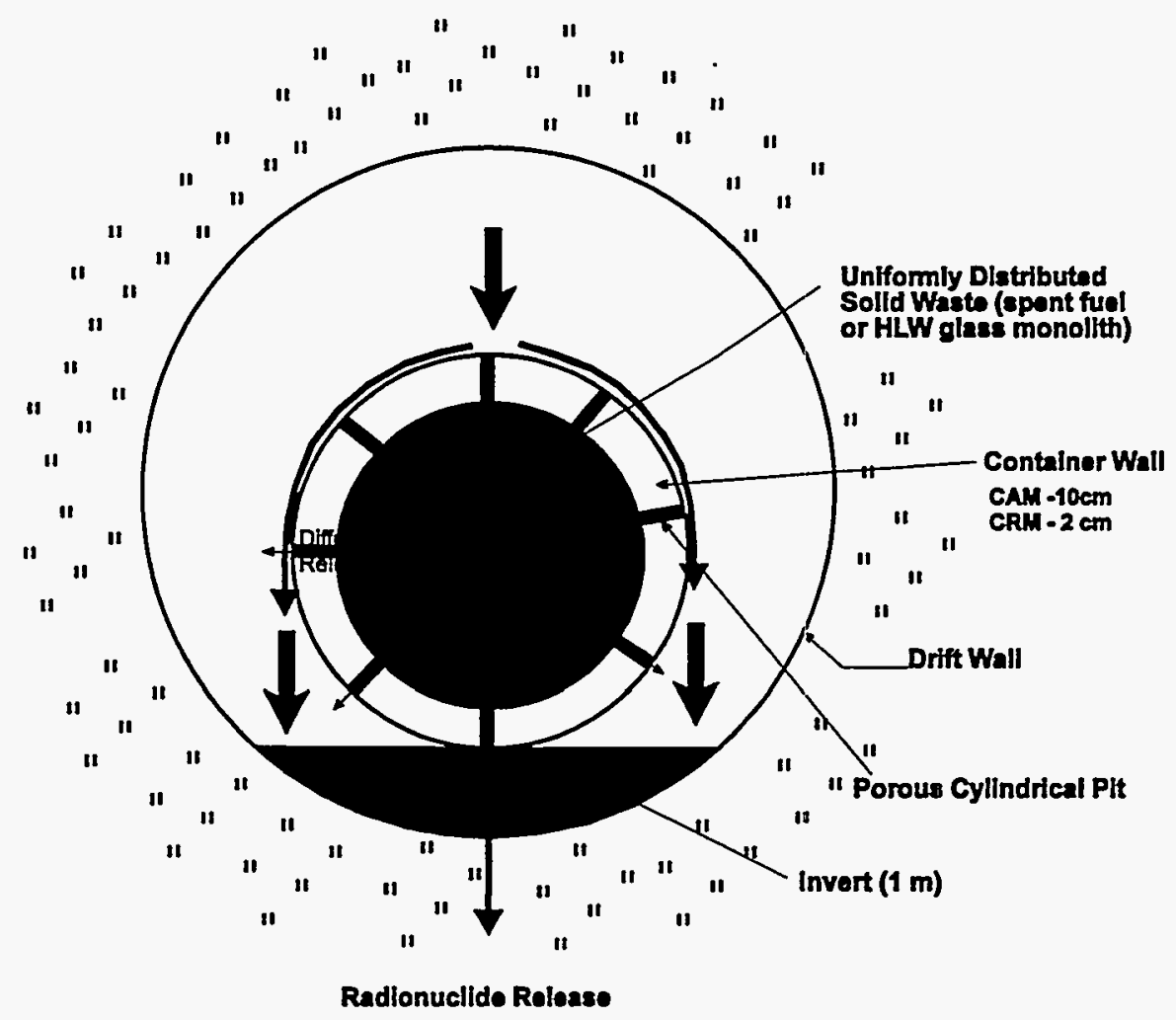

Figure 6.5-10 Conceptual Model for Diffusive Release from Waste Package and Diffusive Plus Advective Release from Other EBS Components. 


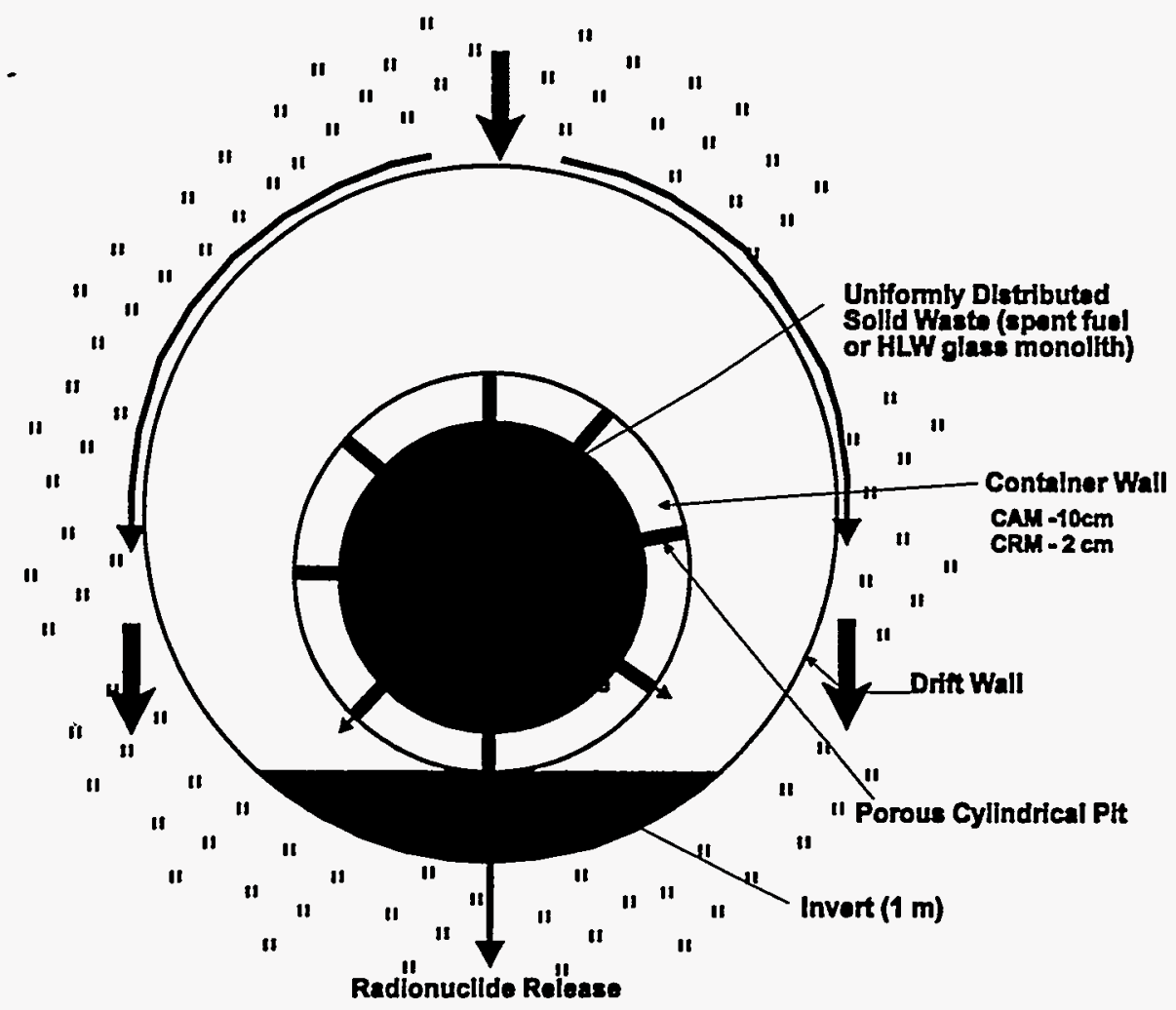

Figure 6.5-11 Conceptual Model for Only Diffusive Release from Both Waste Package and Other EBS Components (Capillary Barrier Effect). 



\section{CHAPTER 7}

UNSATURATED- AND SATURATED-ZONE FLOW AND TRANSPORTATION 



\title{
7. UNSATURATED- AND SATURATED-ZONE FLOW AND TRANSPORT
}

\author{
S. David Sevougian, Srikanta Mishra, Yanyong Xiang, Bryan E. Dunlap, \\ James O. Duguid, James E. Houseworth
}

\subsection{INTRODUCTION}

The unsaturated- and saturated-zone flow and transport models used in TSPA-1995 are described in this chapter. Results from detailed process-level models were used to develop abstractions (response surfaces) for implementation in RIP. Section 7.2 presents the process-level modeling and abstraction of those results for the mountain-scale, unsaturated-zone flow system. Details of the drift-scale, unsaturated-zone hydrologic modeling of "dripping fractures" at the repository level are presented in Section 7.3, including a discussion of how this is incorporated into the RIP TSPA model. In Section 7.4, the unsaturated-zone transport model for TSPA-1995 is presented. Because the process-level transport model for Yucca Mountain was incomplete at the time TSPA1995 simulations were conducted, the TSPA- 1995 transport model is implemented directly in the RIP simulator. The TSPA-1995 transport model includes some abstractions based on the processlevel flow model (e.g., the matrix and fracture steady-state velocity fields and the partitioning of total flow between fractures and matrix). It also includes a fracture/matrix interaction model to represent matrix imbibition and intra-unit fracture connectivity, and retardation models to represent chemical interactions between matrix and pore water. A brief comparative study of the TSPA RIP transport model with the FEHM process-level transport model is included at the end of Section 7.4. Transport of gas-phase radionuclides is discussed in Section 7.5. A brief discussion of the saturated-zone model is included in Section 7.6, though this has not changed substantially since TSPA-1993. Finally, a climate change model implemented in TSPA-1995 is described in Section 7.7.

As indicated in Figure 7.1-1, the results of the response surfaces described in the present chapter feed into the determination of engineered-barrier-system releases as well as the determination of cumulative releases and peak doses at the accessible-environment boundary.

\subsection{UNSATURATED-ZONE AMBIENT HYDROLOGY}

\subsubsection{Introduction}

If radionuclides are released from the engineered barrier system, they may be advectively transported first through the unsaturated zone and then the saturated zone to the accessible environment. Section 7.2 describes the process-level model used to simulate the flow of ground water in the unsaturated zone (UZ) at Yucca Mountain. The results from this model of UZ flow are abstracted to provide response surfaces of the aqueous flux in the unsaturated zone as a function of infiltration, and the distribution of this flux between fractures and matrix.

As indicated in Figure 7.1-1, the fundamental sources of information used to construct the unsaturated-zone flow model are derived from the results of site investigations that have been summarized in Chapter 2. The quantitative analyses presented in this section are carried out 
using 1-D and 2-D submodels extracted from the 3-D site-scale model of the unsaturated zone at Yucca Mountain (Wittwer et al., 1995).

\subsubsection{Abstraction Strategy for TSPA-1995}

Within the context of TSPA-1995, it is not possible to directly incorporate process-level models, in general, and unsaturated- and saturated-zone flow and transport models, in particular, explicitly in the analyses. Although this is possible conceptually by using "call" statements to the processlevel model, in practice this is prohibited by the tremendous increase in computational requirements when conducting multiple stochastic realizations. As a result, a limited set of process-model representations are constructed and the resulting predictions of flow are abstracted for input to the total-system simulation software, RIP. These abstractions are presented in the form of response surfaces describing the relation between the key dependent variables (whether flux or velocity or percent of total flux in different flow regimes) and the primary independent variables (infiltration rate or hydrogeologic properties). In using abstracted model results as input to the total-system model, it is important to demonstrate that the results of the detailed process model and the abstracted model are reasonably similar. A paradigm for the testing of processmodel abstractions is illustrated in Figure 7.2-1 (Nelson, 1995).

Figure 7.2-2 presents a schematic representation of the distribution of the applied infiltration over Yucca Mountain which is the basis for the abstraction strategy used in TSPA-1995. This figure identifies those components of flux that may impact the total system performance. Starting with the average annual-precipitation value $\left(\mathrm{q}_{\mathrm{ppt}}\right)$, the spatially variable infiltration rate $\left(\mathrm{q}_{\mathrm{inf}}\right)$ is derived from the distributions presented by Flint and Flint (1994). The infiltration rate is redistributed across each major hydrostratigraphic interface into the percolation flux $\left(\mathrm{q}_{\text {perc }}\right)$. The percolation flux is considered to be spatially variable across the repository area and may be uncertain because of anisotropy and heterogeneity within the unsaturated hydrostratigraphic units between the surface and the repository horizon [in particular within the basal vitrophyre of the Tiva Canyon welded unit (TCw) and the Paintbrush nonwelded unit (PTn)]. As described in Section 7.3, this uncertainty is evaluated in TSPA-1995 by using two separate percolation-flux distributions: one representing a spatially integrated average percolation flux (caused by significant lateral spreading of the infiltrating ground water); and the other representing a local percolation flux equivalent to the local infiltration rate (caused by a predominantly vertical flow).

The percolation flux is used to define the distribution between the fracture and matrix components of flow in: the unsaturated zone beneath the repository; shown as $\mathrm{q}_{\text {frac }}$ and $\mathrm{q}_{\text {mats }}$, respectively, on Figure 7.2-2. This distribution is based on process-model results described in this section. Additionally, the distribution of percolation flux at the repository horizon has been used to define the likelihood and magnitude of localized flow which might intersect the drifts; termed $\mathrm{q}_{\text {drip }}$ on Figure 7.2-2. The determination of the $\mathrm{q}_{\text {drip }}$ distribution is based on stochastic representations of both $\mathrm{q}_{\mathrm{perc}}$ and the saturated hydraulic conductivity, $\mathrm{K}_{\mathrm{sat}}$, of the Topopah Spring welded unit (TSw), as described in Section 7.3.

The abstraction strategy employed in the previous iteration of TSPA (TSPA-1993: Andrews et al., 1994) is briefly reiterated here to provide a framework for changes made in the current iteration. The percolation flux through the unsaturated zone, $q_{p e r c}$, was sampled in TSPA-1993 
from an exponential distribution with a mean value of $0.5 \mathrm{~mm} / \mathrm{yr}$. Assuming an equivalent continuum model for flow and transport, the matrix pore velocity $\left(v_{\text {mat }}\right)$ was then determined as:

$$
v_{\text {mat }}=q_{p e r c} /\left[A \phi S_{\text {liq }}\right]
$$

where $A$ is the cross-sectional area of the pathway of interest, $\phi$ is porosity and $S_{\text {liq }}$ is liquid saturation. For each hydrostratigraphic interval, porosity was sampled from a normal distribution with prescribed mean and variance, while an "average" liquid saturation was calculated from the late-time ( $t>10,000 \mathrm{yr}$ ) results of a far-field thermohydrologic model. The main limitation of this approach is that the physical relationships between the key variables are not rigorously honored, in as much as $\mathrm{q}_{\text {perc }}$ and $\phi$ are sampled independently, and $\mathrm{S}_{\mathrm{liq}}$ is obtained from another set of calculations. Furthermore, parametric uncertainties (e.g., saturated conductivity, van Genuchten parameters), as well as conceptual uncertainties (e.g., alternative conceptual models of fracture-matrix flow), cannot be taken into account when using Equation 7.2-1.

The abstraction strategy for TSPA-1995 is designed to overcome the shortcomings identified in TSPA-1993 via the application of detailed process-level modeling to develop a functional relationship between $v_{\text {mat }}$ and $q_{\text {inf }}$. Also developed in this strategy is a partitioning of the imposed flux between the fracture and matrix, characterized by the fractional fracture flux, $f_{\text {frac }}$. Multiple unsaturated-flow simulations are conducted to account for: (i) a range of infiltration scenarios, (ii) uncertain/variable matrix hydrologic properties, and (iii) variable fracture-flow initiation rules. The abstracted results are shown in terms of "bands" for $v_{\text {mat }}$ and $f_{\text {frac }}$ as functions of the imposed infiltration flux, $\mathrm{q}_{\mathrm{inf}}$.

The application of this abstraction strategy is shown in Figure 7.2-3. Within RIP, infiltration rate, $\mathrm{q}_{\mathrm{inf}}$ is treated as a stochastic parameter with a prescribed statistical distribution and its moments. For a given sampled value of $\mathrm{q}_{\mathrm{inf}}$, the types of relationships shown in Figure 7.2-3 are used to determine the corresponding minimum and maximum values for $v_{\text {mat }}$ (or $f_{\text {frac }}$ ). Treating these as the lower and upper bounds for a uniform distribution, a second random sampling between the minimum and maximum provides the value for $v_{\text {mat }}$ (or $f_{\text {frac }}$ ). (A more detailed explanation of the implementation in RIP is given in Section 7.4.4).

Implicit in this strategy is the assumption that descriptions of ambient hydrology are adequate for modeling geosphere flow and transport. This implies that thermohydrologic perturbations due to waste emplacement have dissipated before the arrival of radionuclides from breached waste packages at the EBS/geosphere boundary. Consequently, functional relationships between $v_{\text {mat }}$ (or $f_{\text {frac }}$ ) and $\mathrm{q}_{\text {inf }}$ derived from ambient-state simulations, with appropriate modifications for climate change, can be used to simulate the flow of water in the unsaturated zone, and can be incorporated into models of the migration of radionuclide from breached waste packages.

\subsubsection{Testing of the Proposed Abstraction Methodology}

In order to demonstrate that the abstraction methodology as outlined in the previous section provides reasonable bounds on system behavior, it is necessary to "test" the methodology by comparing the abstracted model results against a more detailed representation. As an initial step in this testing, the results of a two-dimensional (2-D) flow model for the unsaturated zone are compared against the one-dimensional (1-D) simplification used in RIP. The performance 
measure for comparison will be the travel time of an unretarded species from the repository to the base of the unsaturated zone (water table).

The detailed process model is a 2-D cross-section extracted from the LBL-USGS site-scale model of the unsaturated zone (Wittwer et al., 1995), described in detail in Section 7.2.4. Deterministic steady-state simulations were carried out for three different infiltration rates $(0.1,0.5$ and $1.0 \mathrm{~mm} / \mathrm{yr}$ ) using the expected values of the material properties given in Section 2.4. Column 153 was then picked as a representative one-dimensional pathway from the 2-D cross-section (Figure 7.2-4). For each hydrostratigraphic unit below the proposed repository horizon, the simulated ranges in the matrix pore velocity, $\mathrm{v}_{\text {mar }}$ and fractional fracture flux, $\mathrm{f}_{\text {frac }}$ were extracted (Table 7.2-1). Also calculated, based on the velocity information, was the advective travel time from the proposed repository horizon to the water table.

A 1-D pathway, consistent with that section of Column 153 between the proposed repository horizon and the water table, was setup within RIP. This pathway was broken up into four layers as follows: TSw $-111.2 \mathrm{~m}, \mathrm{TSv}-8.4 \mathrm{~m}, \mathrm{CHnv}-80.7 \mathrm{~m}$, and $\mathrm{CHnz}-121.2 \mathrm{~m}$. The advective transport of a tracer pulse was simulated for each of the three chosen infiltration rates using the abstracted information ( $v_{\text {mat }}$ and $f_{\text {frac }}$ ) for each hydrostratigraphic unit. The choice of a finite pulse (with $\Delta t=100 \mathrm{yr}$ ) was dictated by the need to start with a finite time-step size which could then be progressively increased so as to efficiently simulate transport over extremely long time periods $\left(\sim 10^{5}\right.$ years). The minimum and maximum arrival times of the pulse were determined by examining its breakthrough curve at the water table.

A comparison between the single-point arrival time calculated by TOUGH 2 and the minimum and maximum arrival times calculated by RIP is tabulated in Table 7.2-2, and also shown graphically in Figure 7.2-5. In all cases, the RIP results bracket the arrival times calculated by TOUGH2, and the agreement was found to be better for higher infiltration rates. These calculations indicate that using TOUGH2-derived functional relationships of $v_{\text {mat }}$ and $f_{\text {frac }} v s$. $q_{\text {inf }}$ to simulate solute transport within RIP is an expedient way of retaining the essential features of the unsaturated-flow process. The calculations also provide a verification for the proposed abstraction methodology.

\subsubsection{Process-level Model Description}

\section{Background}

A three-dimensional site-scale model of the unsaturated zone is currently under development by Lawrence Berkeley Laboratory (LBL) and the United States Geological Survey (USGS) (Wittwer et al., 1995). The model covers an area of about $30 \mathrm{~km}^{2}$ (Figure 7.2-6), and is composed vertically of four hydrogeologic units: TCw (Tiva Canyon welded), PTn (Paintbrush nonwelded), TSw (Topopah Spring welded), and CHn (Calico Hills nonwelded). These four layers have been further subdivided into seventeen layers to represent additional lithologic detail (Figure 7.2-4). Based on the work of Klavetter and Peters (1986), the fractured units TCw and TSw are treated as equivalent continua with specified threshold saturations for triggering liquid flow in fractures. Using a "best-guess" set of hydrologic properties for the matrix and fractures, Wittwer et al. (1995) have investigated the impact of uniform/non-uniform surface infiltration patterns and the 
role of major faults on the distribution and movement of moisture at Yucca Mountain in one, two, and three dimensions.

As pointed out by Andrews et al. (1994), some of the major uncertainties associated with the description of the hydrologic system in total system performance assessments include: (i) uncertainty in the assumed infiltration scenarios for both current and future climatic conditions, (ii) the impact of uncertain and/or spatially variable matrix hydrologic properties, and (iii) conceptualizations of fracture-matrix flow using both equilibrium and non-equilibrium assumptions. These uncertainties have not been explicitly addressed in the ongoing studies of ambient UZ hydrology being carried out by the LBL-USGS scientists. A suite of simulations has therefore been carried out with the LBL-USGS model to incorporate the effects of these uncertainties on the ambient unsaturated-flow regime, and to provide the abstractions of unsaturated hydrology needed by the geosphere-transport module of RIP.

\section{Geometry and Boundary Conditions}

A series of simulations will be discussed, based on one- and two-dimensional models. The onedimensional model is a vertical column, and the two-dimensional model is a vertical crosssection, extracted from the LBL-USGS three-dimensional site-scale model (Wittwer et al., 1995). The cross-sectional model, as shown in Figure 7.2-4, passes through the potential repository area and the Ghost Dance Fault. The left and right boundaries represent the Solitario Canyon fault and the Bow Ridge fault, and are assumed to be of the no-flow type. The one-dimensional model is chosen as Column 153 shown in Figure 7.2-4.

The top boundary (ground surface) is treated as a single-phase air surface at constant pressure and temperature. The bottom boundary (water table) is treated as a single-phase liquid surface also at constant pressure and temperature. Note that the constant pure-air condition at the ground surface precludes any possibility of moisture flow above the mountain, which may induce errors that are negligible for moderate infiltration rates but can become significant for very small infiltration rates. The water-table boundary condition implies that the saturated zone acts as a sink of infinite capacity, which may be inconsistent for relatively high infiltration rates depending on the transmissive properties of the saturated zone.

\section{Infiltration Scenarios}

As noted in Section 2.6, developing a reasonably representative estimate of the average infiltration rate in any particular area of an arid environment is uncertain. At present, a range of estimates exists depending primarily on the hydrogeologic characteristics of the outcropping hydrostratigraphic units. The uncertainty in these estimates has, to date, not been quantified, nor has the effect of other surficial characteristics (including slope, vegetation, and soil cover to name a few) been quantified. Several methods are being used to better represent the spatial-infiltration distribution, including (1) development of a map of current net infiltration based on ten-year average field observations, (2) development of a numerical model based on both deterministic and stochastic processes that can best reproduce that map, and (3) using this model to predict the effects of past and future climate scenarios with changeable soil, vegetation and atmospheric conditions (Flint, 1995). The results of these methods are expected to be completed and documented in the coming fiscal year. 
In the absence of definitive estimates of spatial infiltration rates, preliminary estimates documented in Flint and Flint (1994) have been used. As shown in Figure 2.6-2, these inferred infiltration rates range from $0.02 \mathrm{~mm} / \mathrm{yr}$, where the welded Tiva Canyon (TCW) unit outcrops, to $13.4 \mathrm{~mm} / \mathrm{yr}$ in areas where the Paintbrush nonwelded (PTn) unit outcrops. Neglecting the Paintbrush outcrop along the escarpment of the Yucca Crest, the bulk of the area above the repository block is dominated by the outcrop of the Tiva Canyon. If the predominant flow direction is vertical, then the average percolation flux through the repository block, assuming the inferred infiltration rates presented in Flint and Flint (1994), would be $0.02 \mathrm{~mm} / \mathrm{yr}$-a value quite consistent with liquid saturations predicted using one-dimensional flow models and representative hydrogeologic properties. If, on the other hand, the predominant flow direction is not vertical but has a significant lateral component due to hydrogeologic property heterogeneity and/or anisotropy and the sloping nature of the hydrostratigraphic unit contacts, then the average net infiltration rate over the repository block could be as high as some weighted average of the infiltration rates inferred from Flint and Flint (1994). Again, neglecting the area of Paintbrush outcrop along the Yucca Crest escarpment, the average spatially integrated infiltration rate is about $1.2 \mathrm{~mm} / \mathrm{yr}$. Most of this infiltration occurs along the Paintbrush outcrop in the washes north of the repository block.

Based on the above discussion, TSPA-1995 assumes two possible infiltration regimes. At one extreme (the "low" infiltration case), the infiltration rate at the surface is expected to be uniformly distributed between 0.01 and $0.05 \mathrm{~mm} / \mathrm{yr}$-assuming roughly a factor of 2 uncertainty around the mean value of $0.02 \mathrm{~mm} / \mathrm{yr}$. At the other extreme (the "high" infiltration case), the surface infiltration rate is expected to be uniformly distributed between 0.5 and $2.0 \mathrm{~mm} / \mathrm{yr}$-also assuming roughly a factor of 2 uncertainty around the mean value of $1.2 \mathrm{~mm} / \mathrm{yr}$. In order to bound the effect of these ranges of infiltration scenarios, hydrologic simulations have been carried out for six discrete cases corresponding to the limits described above, i.e., at $0.01,0.02,0.05,0.5$, 1.0 and $2.0 \mathrm{~mm} / \mathrm{yr}$.

\section{Matrix and Fracture Properties}

The hydrogeologic database developed by Schenker et al. (1995), which is described in greater detail in Section 2.4, is used as the source for matrix and fracture properties for the hydrogeologic units at Yucca Mountain. Because the Schenker et al. data set includes the latest available information from ongoing site characterization activities, it has been chosen in preference to the "best-guess" hydrologic parameter set used in the LBL-USGS site-scale model (Wittwer et al., 1995).

In order to account for the uncertainty/variability in matrix hydrologic properties, ten random sets of properties have been generated using the summary statistics presented in Chapter 2.4. Figure 7.2-7 shows the values of the sampled variables together with the range and the expected values (arithmetic mean or geometric mean, as appropriate). In the hydrologic simulations, the properties for the hydrogeologic units above the repository horizon (TCw, PTn) are kept fixed at their expected values. As discussed in Section 2.4, residual saturation is treated as a constant for each unit, and fracture properties are treated as constants for all the units. 
The LBL-USGS site-scale model conceptualizes the fractured units at Yucca Mountain as equivalent continua with thermal and hydraulic equilibria between fracture and matrix (Wittwer et al., 1995). The equivalent continuum model (ECM) assumes the existence of enormous disparity in capillary suction between the matrix and the fractures. Thus, during drainage, matrix desaturation does not begin until the fractures are almost completely drained, whereas during imbibition, the fractures remain dry until the matrix is almost completely saturated. In the TOUGH2 implementation of the ECM (Tsang and Pruess, 1989), liquid flow in the fractures is assumed to be initiated only after bulk-liquid saturation exceeds a threshold value corresponding to full saturation of the matrix. This rule can be expressed as follows: if the matrix liquid saturation equals 1.0, then fracture flow may occur (i.e., the fracture liquid saturation is greater than 0.0 ), otherwise the fracture liquid saturation equals 0.0 .

There is growing evidence to suggest that episodic water flow at Yucca Mountain may take place along "fast paths" (Wittwer et al., 1995). Such a situation, which possibly results from nonequilibrium fracture flow, cannot be represented by the equivalent continuum model (ECM). By forcing the fractures to remain dry until the matrix is fully saturated, the ECM formulation artificially inhibits the episodic (and rapid) movement of water along these fast paths. The rigorous approach to incorporating such non-equilibrium flow aspects would require at least the use of a dual-continuum model. An alternative approach would be a relaxation of the fractureflow initiation rule in the ECM in order to allow fracture flow to commence before complete matrix saturation.

With a view to approximating non-equilibrium fracture-matrix flow, Xiang et al. (1995) have proposed an empirical modification to the ECM fracture-flow initiation rule, viz., if the matrix liquid saturation is greater than or equal to $\sigma$, then fracture flow occurs (fracture liquid saturation greater than 0 ), otherwise the fracture liquid saturation equals 0.0 . Here $\sigma(\leq 1)$ is an empirical parameter, hereafter referred to as the "satiated" matrix saturation. This $\sigma$-based formulation forces the fractures to conduct water even before the matrix is fully saturated. However, it does not represent the complete dynamics of non-equilibrium flow because matrix imbibition is neglected. In any case, allowing the fractures to transmit fluids without requiring the matrix to be completely saturated is a more conservative model for fracture flow than the equivalent continuum model, from the standpoint of performance assessment.

The $\sigma$-based formulation is thus a preliminary method to simulate non-equilibrium fracture flow. In the present study, $\sigma$ is treated as a sensitivity parameter, and provides an extra degree of freedom for the analyst to investigate the effects of a relaxed fracture-flow initiation criterion. However, it must be pointed out that this formulation does not include any consideration of matrix imbibition to retard fracture flow. It is intended to be merely a surrogate for a detailed representation of non-equilibrium fracture flow.

Further details of the $\sigma$-based formulation are discussed in Xiang et al. (1995), along with the results from numerical experiments which investigate the sensitivity to $\sigma$. Also presented therein is a comparison between 1-D calculations using a conventional dual-permeability model (Ho, 1995 ) and the empirical $\sigma$-based formulation. Based on these analyses, two values of $\sigma$ (1.0 and 0.95) have been chosen as the two variants for fracture flow initiation in TSPA-1995. Numerical 
experiments with $\sigma$ values lower than 0.95 appear to result in an exaggeration of fracture flow (Xiang et al., 1995). For the purposes of this study, the value of $\sigma=0.95$ is taken to be a reasonable compromise in order to mimic the non-equilibrium flow effects of fracture flow initiation prior to full matrix saturation. Note that the value of 1.0 represents the classical ECM conceptualization, in which no fracture flow occurs until the matrix is fully saturated. A value for $\sigma$ of 0.95 implies the onset of fracture flow as soon as matrix saturation equals 0.95 .

\subsubsection{Abstraction Results and Sensitivity Analyses}

\section{$\underline{\text { Results }}$}

Using the one-dimensional model corresponding to Column 153 in Figure 7.2-4, a total of 120 steady-state TOUGH2 simulations were carried out to develop the hydrologic abstractions. Note that the effects of dimensionality in the development of these abstractions is presented later in this section. As discussed previously, the cases considered here include: (i) ten random realizations of matrix hydraulic properties (Figure 7.2-7), (ii) six infiltration rates, i.e., 0.01, 0.02, $0.05,0.5,1.0$ and $2.0 \mathrm{~mm} / \mathrm{yr}$, and (iii) two fracture flow initiation rules, i.e., $\sigma$ values of 1.0 and 0.95 . Matrix pore velocity, $v_{\text {mat }}$ and fractional fracture flux, $\mathrm{f}_{\mathrm{frac}}$ along Column 153 are taken as the two performance measures. For each of the four hydrostratigraphic units below the potential repository horizon ( $T S w, T S v, C H n v, C H n z$ ), ranges for $\mathrm{v}_{\text {mat }}$ and $\mathrm{f}_{\text {frac }}$ are tabulated as a function of the infiltration rate $\left(\mathrm{q}_{\mathrm{inf}}\right)$ in Table 7.2-3 and Table 7.2-4. These results are also shown in Figure 7.2-8 through Figure 7.2-11.

The minimum and maximum values of $v_{\text {mat }}$ for each infiltration rate are determined from the range of values resulting from simulations using the ten random sets of material properties and the two fracture-flow initiation rules. On the other hand, regarding $f_{\text {frac }}$, it is evident that its maximum value would always correspond to a $\sigma$ value of 0.95 , whereas its minimum value would always correspond to a $\sigma$ value of 1.00 . This argument is based on the following rationale. The ECM assumption regarding fracture-flow initiation only after full matrix saturation (i.e., $\sigma=1.0$ ) tends to minimize fracture flow, whereas using the lower value for $\sigma$ of 0.95 as the fracture-flow initiation rule in the modified ECM formulation provides a more favorable condition for the onset and continuation of fracture flow. The minimum and maximum $f_{\text {frac }}$ for a given infiltration rate are calculated by averaging over the simulations corresponding to the ten sets of random material properties. Given that not all realizations produce fracture flow, an ensemble average is necessary to provide an "expected" and unbiased measure of the fractional fracture flow for a given infiltration rate.

\section{Sensitivity to Dimensionality of Flow}

Wittwer et al. (1995) have investigated possible patterns of moisture flow within Yucca Mountain for assumed average infiltration rates, uniform/variable infiltration distribution and hydrologic characteristics of the major faults. Their simulations suggest that flow below the Paintbrush nonwelded (PTn) unit is mostly vertical, except in the immediate vicinity of the major faults. Although preliminary, these results provide some justification to the assumption of onedimensional vertical flow routinely used in previous TSPA calculations (e.g., Andrews et al., 1994; Wilson et al., 1994). 
To further examine the persistence of vertical one-dimensional flow in the vicinity of the proposed repository block, one- and two-dimensional steady-state flow simulations have been conducted for uniform infiltration rates of $0.01,0.5$, and $1.0 \mathrm{~mm} / \mathrm{yr}$. The two-dimensional model is the cross-section extracted from the LBL-USGS model as shown in Figure 7.2-4, from which Column 153 is extracted as the one-dimensional model. These deterministic calculations use the expected values of the hydrologic properties as tabulated in Table 7.2.1. Figures 7.2-12 and 7.2-13 demonstrate the general agreement between both sets of calculations in predicting liquid saturation in fracture/matrix, fraction of liquid flowing in the fractures, and liquid velocity in the matrix. These results provide further justification for using one-dimensional models of unsaturated flow in the vicinity of the repository block, albeit for steady-state conditions alone.

\section{Representativeness of Column 153}

In TSPA-1995, it is assumed that the ranges of matrix pore velocity and fractional fracture flux as derived for Column 153 (Figure 7.2-4) are representative of the entire repository block. In order to verify this assumption, the response of Column 157-located to the east of the Ghost Dance Fault as shown in Figure 7.2-4-is compared to that of Column 153. Simulations were carried out for two infiltration rates, 0.01 and $1.0 \mathrm{~mm} / \mathrm{yr}$, using the expected values of the matrix hydraulic properties tabulated in Section 2.4. As shown in Figure 7.2-14, matrix pore velocities for Column 153 and Column 157 are in excellent agreement for all four hydrostratigraphic units. Although not shown here, similar results have been obtained in comparisons between Column 153 velocities and those of columns located to the west of the Ghost Dance Fault within the repository block.

\subsubsection{Abstraction Caveats}

In the above sections, a methodology for developing abstractions of the ambient unsaturated-zone hydrology at Yucca Mountain has been described, tested, and implemented. The methodology is customized to the input needs of the total system simulator, RIP, and as such, provides "response functions" for matrix pore velocity and fractional fracture flow. These variables are required inputs to the geosphere-transport module of RIP. Using multiple deterministic simulations, the methodology provides tables of minima and maxima for uniform distributions of the variables of interest as functions of infiltration rate. The distributions account for the uncertainty in material properties, as well as the uncertainty in describing fracture-matrix flow.

The methodology presented herein is a preliminary attempt at rigorously developing and applying abstractions which are based on detailed process-level model calculations. However, several simplifications inherent in these calculations need to be improved in order to further enhance the realism of the unsaturated-zone hydrologic abstractions for future TSPAs. Some of these issues are identified below:

- Although a modified ECM formulation facilitating earlier initiation of fracture flow was used in these analyses, better models are needed to describe non-equilibrium fracturematrix interaction.

- The assumption that ambient hydrologic models are adequate to model radionuclide transport at late time, because thermal effects due to waste emplacement are likely to have 
dissipated, needs further examination. In particular, comparing the onset of unidirectional flow from the repository horizon to the water table predicted by thermohydrologic models with typical waste-package failure-time distributions should provide a sound basis for evaluating this assumption.

- Preliminary model calculations show that flow from the repository horizon to the water table is predominantly one-dimensional in the vertical direction (Wittwer et al., 1995). The actual flow paths are likely to be somewhat more tortuous under the effects of material heterogeneity and/or nonuniform infiltration rate at the surface. Incorporation of the resulting flow-path geometry directly into the TSPA calculations, or indirectly via appropriate abstractions, needs to be included in future analyses.

- The validity of the abstractions depends on the representativeness of the stratigraphy and hydrologic properties. This could be enhanced-especially in the expansion areas-by using more detailed hydrogeologic information (if and when available).

\subsection{DRIFT-SCALE HYDROLOGY}

Besides the model for unsaturated-zone flow at the "mountain-scale", a flow model is required to describe groundwater movement at the "drift-scale". This model predicts spatial variability of fracture flux (or "drips") intersecting potential repository drifts, and quantifies the probability of "drips" and the magnitude of any "drips" that are predicted to occur.

Water saturation in the EBS (backfill/invert) and near-field tuff matrix surrounding the repository drifts is determined from thermohydrologic process-level simulations conducted using FEHM (see Chapter 4). For the high thermal loading case ( $83 \mathrm{MTU} / \mathrm{acre})$, there is an extended dryout period during which no stagnant fluid phase is present adjacent to the waste package. Therefore, no aqueous-phase radionuclide transport to the geosphere is possible through the rock matrix surrounding the waste packages. During this period, the only possible transport of radionuclides from waste packages to the geosphere will be a result of water dripping through fractures onto the packages. Once the rewetting front has returned to the packages (at $\mathrm{T}<100^{\circ} \mathrm{C}$ ), or if the EBS never dries out (low thermal load, $25 \mathrm{MTU} / \mathrm{acre}$ ), then transport to the geosphere is by a combination of both dripping fractures and diffusive matrix flow. Of course, the packages must first suffer corrosion failure before any radionuclides are released. [Note that transport from the packages to the geosphere by advective matrix flow is not considered possible because of the capillary pressure differential between the drift and the surrounding rock.]

The conceptual model for dripping water on the waste packages simulates spatial variability of fracture flow in the near-field rock surrounding the repository drifts. Thus, while the statistical variation in the process-level conceptualization of geosphere fracture flow (discussed in the previous section) is primarily attributable to property uncertainty, the variation in the conceptualization of WP/EBS dripping fracture flow is conceived to arise primarily from property spatial variability. This conceptual difference is appropriate because of the distance scale at which the processes are simulated. For the WP/EBS, effects are modeled at the scale of the package dimensions, whereas in the geosphere the variability in flow at the package level has been upscaled (averaged) to a much greater area. This is done, in part, because of computational constraints, in that it is not possible to simulate small-scale (on the order of the package 
dimensions) heterogeneities over the entire repository within a TSPA model-given the large number of realizations required. Thus, in the geosphere we only consider the average fracture flow at the column scale-which does incorporate uncertainty, as described in the previous section on hydrological process abstractions.

In the WP/EBS fracture-flow conceptualization (see Figure 7.2-2), it is assumed that a given infiltration flux, $q_{i n f}$ can be represented at depth as percolation flux, $q_{\text {perc }}$, log-normally distributed over the area of a given column. The logarithmic $\mathrm{q}_{\mathrm{perc}}$ distribution is defined with a mean equal to the given $\mathrm{q}_{\mathrm{inf}}$ and an assumed standard deviation of 0.5 . Furthermore, from Schenker et al. (1995) - as tabulated in Table 2.4-3 - we have the moments of the saturated matrix conductivity, $\mathrm{K}_{\text {sal }}$, for TSw as: $E\left[\log _{10} \mathrm{~K}_{\text {sat }}\right]=4.07$, and S.D. $\left[\log _{10} \mathrm{~K}_{\text {sat }}\right]=0.9$. (Note that $\mathrm{K}_{\text {sat }}$ is now expressed in $\mathrm{mm} / \mathrm{yr}$.) Suppose there are 10,000 waste packages and that each has a different degree of fracture flow because of variability in the local matrix material properties. Both the $\mathrm{q}_{\text {perc }}$ and $\mathrm{K}_{\text {sat }}$ distributions are sampled 10,000 times to form a distribution for $\left(\mathrm{q}_{\text {pere }}-\mathrm{K}_{\mathrm{sat}}\right)$. For any individual package, if $\left(q_{\text {perc }}-\mathrm{K}_{\text {sal }}\right)>0$, then there is dripping flow on that package, and the value of $\left(\mathrm{q}_{\text {perc }}-\mathrm{K}_{\text {sat }}\right) \equiv \mathrm{q}_{\text {drip }}$ is the dripping flux in $\mathrm{mm} / \mathrm{yr}$. In this way, we develop empirical distributions for the advective dripping flux, $\mathrm{q}_{\text {drip }}$, at various infiltration rates; plus a corresponding fraction (i.e., number, not distribution) of waste packages, $\mathrm{f}_{\text {drip }}$, that experience dripping flow. Figures 7.3-2 and 7.3-4 show the $\mathrm{q}_{\text {drip }}$ distributions for typical "high" and "low" values of $\mathrm{q}_{\text {inf, }}$ and Figures 7.3-1 and 7.3-3 show the corresponding $\mathrm{K}_{\text {sat }}$ distributions. $\left(\mathrm{K}_{\text {sat }}\right.$ would equal the matrix flux in the drift for this simple unit-gradient model, but because of the assumed capillary effect, matrix flow directly on the packages is presumed to be zero.) As an example of the meaning of these CDFs, in Figure 7.3-4, which is for $\mathrm{q}_{\mathrm{inf}}=0.05 \mathrm{~mm} / \mathrm{yr}, 91 \%$ of the packages have a dripping flux less than $10^{-4} \mathrm{~mm} / \mathrm{yr}$, i.e., essentially zero dripping flux.

Because the RIP model does not allow $f_{\text {drip }}$ to be a random variable, we could not use a random distribution to represent $q_{\text {perc }}-K_{\text {sat }}$, i.e., we could not regenerate it for every realization. Therefore, the $q_{\text {perc }}$ and $K_{\text {sat }}$ distributions were sampled $10^{6}$ times for a given value of $q_{\text {inf. }}$ The mean of this sample is an estimate of the expected value, $E\left[q_{\text {drip }}\right]$, of $q_{\text {drip }}$ for the given $q_{\text {inf }}$ and the fraction of waste packages with dripping is an estimate of the expected value, $E\left[f_{\text {drip }}\right]$, of $f_{\text {drip. }}$. This was done for about 10 values of $\mathrm{q}_{\mathrm{inf}}$ over both the low and high $\mathrm{q}_{\mathrm{inf}}$ ranges, and the functional relationships $E\left[q_{\text {drip }}\right]$ versus $q_{\text {inf }}$ and $E\left[f_{\text {drip }}\right]$ versus $q_{\text {inf }}$ were found to be nearly linear for each range. Based on these samples, Figures 7.3-5 and 7.3-6 show the average dripping flow, $E\left[q_{d r i p}\right]$ vs. $q_{\text {inf }}$, that was used in the TSPA-1995 simulations using the Schenker et al. (1995) $\mathrm{K}_{\text {sat }}$ distribution and S.D. $\left[\log _{10} q_{\text {inf }}\right]=0.5$. Figures 7.3-7 and 7.3-8 show the average fraction of packages with drips, $E\left[f_{\text {drip }}\right]$ vs. $q_{\text {inf }}$.

Using $E\left[q_{d r i p}\right]$ for every package results in approximately the same releases as applying the distribution of $\mathrm{q}_{\text {drip }}$ to the packages. To demonstrate this, six values of $\mathrm{q}_{\text {drip }}$ were selected which would represent the range of advective drip rates corresponding to the range of infiltration flux considered in the low- and high-infiltration rate cases (see Figures 7.3-5 and 7.3-6). Using $41 \mathrm{~m}^{2}$ for our "catchment area" (see below), these advective drip rates correspond to advective flow rates, $Q_{\text {drip }}$, of $4 \times 10^{-1}, 4 \times 10^{-2}, 4 \times 10^{-3}, 4 \times 10^{-4}, 4 \times 10^{-5}$, and $4 \times 10^{-6} \mathrm{~m}^{3} / \mathrm{yr}$ for each of the waste packages that sees dripping. RIP was run with each of these advective flow rates (with $f_{\text {drip }}=$ 0.5 , i.e., half of the packages dripping) and a diffusive release rate of $6.1 \times 10^{-5} \mathrm{~m}^{3} / \mathrm{yr}$, and two radionuclides were considered: ${ }^{239} \mathrm{Pu}$, which has a relatively low solubility, and ${ }^{99} \mathrm{Tc}$, which has a relatively high solubility. 
For solubility-limited radionuclides, such as ${ }^{239} \mathrm{Pu}$, Figure 7.3-9 shows that the release rate is proportional to the total flow rate. Thus, averaging the total flow rate over the packages that see dripping will be equivalent to averaging the release rate over these packages, showing that the release rate is not affected by using $E\left[q_{\text {drip }}\right]$ for all packages.

Figure 7.3-10 shows the release rates for ${ }^{99} \mathrm{Tc}$, a radionuclide that is not solubility-limited. The three curves corresponding to the high infiltration rates superimpose. This shows that for high infiltration rates the release rate is bounded by the amount of available ${ }^{99} \mathrm{Tc}$, i.e., it is controlled by the waste-form dissolution rate. Thus, the total flow rate does not matter, and using $E\left[q_{\text {drip }}\right]$ will have little effect. For the three curves corresponding to the low infiltration cases, it can be seen that the curve corresponding to the middle flow rate is generally about equidistant between the other two curves. This suggests that averaging the total flow rates will have an effect close to averaging the release. Therefore, when the release is either flow-rate controlled or dissolutionrate controlled, or in between these two extremes, Figure 7.3-10 suggests that using $E\left[\mathrm{q}_{\text {drip }}\right]$ for all packages is reasonable.

To get the total volumetric flow, $Q_{\text {drip }}$, onto each waste package, the effective "catchment area" is computed as twice the package length times twice the package diameter. Therefore, $\mathrm{Q}_{\text {drip }}=$ $4 \mathrm{~A}_{\text {wp }} q_{d r i p}$, where $A_{\text {wp }}$ is the maximum cross-sectional area of the waste package, perpendicular to flow. Once the first pit goes through both the inner and outer waste-package containers (and also the cladding), it is assumed that all of the waste-form area is exposed to dripping flow. This is the assumption made in the so-called "drips-on-waste-form" model of EBS transport-the default model used for all RIP simulations (see Chapter 9). This is a more conservative (pessimistic) assumption than the diffusive-release model, for which diffusive release is a function of the pitted area. For other models of EBS transport, specifically, the "drips-on-waste-container" model (see Chapters 6 and 9), the drips do not contact the waste directly, but only the waste-package outer surface-pits in the waste container are assumed to be filled with corrosion products that do not allow direct contact of the dripping flux with the waste form. Thus the radionuclides must first diffuse through the corrosion-filled pits in the waste package before they interact with the dripping flow. A sensitivity analysis comparing these two models is presented in Chapter 9.

As discussed in Chapters 8 and 9, without dripping fractures, aqueous-phase radionuclides leave the near-field environment at very low concentrations. This is because diffusive releases are quite low. It shows that, if an effective capillary barrier could be constructed (one that could intercept even dripping fractures), then the repository would reduce releases/doses by several orders of magnitude compared to the drip scenario. (Note: There is still diffusive transport across the EBS when dripping water is present, however, it is negligible when compared to the advective releases. The diffusion model used is discussed in Section 6.5.)

The effect of climate change on dripping flow in the near-field is discussed in Section 7.7. 


\subsection{UNSATURATED-ZONE TRANSPORT}

\subsubsection{Introduction}

At the time of the TSPA-1995 simulations, the Yucca Mountain process-level aqueous-transport model was incomplete (Robinson et al., 1995). Thus, unlike the TSPA-1995 UZ flow model, which is based on abstracted process-level model results, the TSPA transport model is incorporated directly into the RIP TSPA model. It is partly based on the abstractions from the process-level flow model (i.e., the matrix and fracture velocity fields and the partitioning of volumetric flow between fractures and matrix), but also includes a fracture-matrix interaction model (to represent intra-unit fracture connectivity and matrix imbibition) and a radionuclide retardation model (to represent chemical interaction between the matrix and pore water), neither of which is based on process-level transport modeling (although the chemical retardation model is based on LANL experiments on whole tuff samples).

\subsubsection{Unsaturated-Zone Transport Stratigraphy and Model Dimensionality}

For TSPA-1995, transport simulations have been conducted using the stratigraphy from the USGS/LBL unsaturated-zone site-scale model (Wittwer et al., 1995). Because of the intensive computational nature of performing multiple realizations, the numerical grid of the USGS/LBL process-level model must be averaged to a much larger scale for use in the RIP TSPA model. This involves both areal and vertical spatial averaging. The vertical averaging is natural, since although the USGS model has 8 units below and including the repository horizon, the material properties assigned to several units are about the same, and lead to a natural division into four hydrogeologic units below the repository-TSw (Topopah Spring welded-devitrified), TSv (Topopah Spring welded-vitrophyre), CHnv (Calico Hills nonwelded-vitric, and CHnz (Calico Hills nonwelded-zeolitic). These are the hydrogeologic units used within the process-level flow simulations that provide velocity distributions for RIP transport simulations (see Figure 7.2-2). Although this division of units within the site-scale flow model is sufficient for simulating water movement, there is a significant amount of Prow Pass (PP) formation below the CHnz and above the water table, which has different sorption properties than the CHnz. Therefore, for the purposes of radionuclide transport, the CHnz from the USGS/LBL model is subdivided into CHnz and PPn (nonwelded-devitrified) units (see Table 7.4-1).

\subsubsection{RIP Geosphere Pathways}

The RIP TSPA code considers radionuclide transport to be one-dimensional (1-D), i.e., the RIP transport abstraction solves an advection-only or an advection/dispersion equation in 1-D. However, many 1-D aqueous-transport paths may be included in the problem domain to approximate 2-D or 3-D aqueous transport. For the RIP simulations in this report, 3-D aqueous transport in the unsaturated zone is simulated by either six 1-D vertical columns (high thermal load) or ten 1-D vertical columns (low thermal load), covering the area of the potential repository (see Section 3.8 for details regarding pathway geometry). As discussed in Section 7.2, 2-D effects on flow were considered when deriving the velocity and fracture-flow abstractions.

Each of the UZ vertical columns in RIP is represented as a series of "stacked" flow pathways (Figure 7.4-1). As described in Table 7.4-1, each UZ column consists of five pathways of 
differing thickness from column to column: TSw, TSv, CHnv, CHnz, and PPn. All columns empty into one saturated-zone (SZ) pathway (devitrified), which connects with the accessibleenvironment $(\mathrm{AE})$ boundary-the regulatory "fence" at $5 \mathrm{~km}$ downstream of the repository. The SZ pathway runs horizontally in the direction of the regional flow gradient from below the repository to the boundary. For purposes of dose calculations, a biosphere (or dose) pathway is connected to the end of the SZ pathway and converts the concentrations at the accessible environment into dose. The TSPA model does not account for the fact that different UZ columns will be at differing distances from the AE boundary. However, this is a conservative assumption, if the $\mathrm{AE}$ boundary is $5 \mathrm{~km}$ from the outer perimeter of the repository footprint.

The 1-D advection/dispersion (or advection-only) radionuclide mass-transport equation is solved in each individual pathway using finite differences. Input/output of each pathway is determined by its connections to other pathways, and defines the path over which the nuclides travel from the repository to the accessible environment. In summary, each pathway in RIP is similar to a coarse grid block in a process-level simulation. This "grid block" represents an areal average of a certain portion of the repository footprint (either $1 / 6$ or $1 / 10$ ) plus a vertical average over an entire hydrogeologic formation (e.g., the TSw).

\subsubsection{Fracture/Matrix Interaction in the Geosphere}

\section{Process-level conceptual model}

In TSPA-1993, Andrews et al., (1994) considered only matrix transport of radionuclides; however, as shown by the Calico Hills System Study (M\&O, 1995d), fracture flow through the unsaturated zone can significantly reduce travel time to the accessible environment. Thus, in TSPA-1995, both fracture and matrix flow and transport are included.

In order to simulate particle transport in the RIP TSPA model, velocity fields for both fracture and matrix transport are required. The process-level model (and its abstraction to the TSPA model) for these velocity fields is discussed in detail in Section 7.2. A brief summary of how this model affects transport is given here. In this conceptualization of fracture/matrix aqueousphase flow, the TOUGH2 process-level flow model is applied to a representative vertical column from the LBL-USGS model to determine the percent fracture flow and the matrix velocity as a function of depth-for an unsaturated-zone column that has an area (perpendicular to flow) of about $5 \times 10^{5} \mathrm{~m}^{2}$ (i.e., $1 / 6$ of the repository area for the 83 MTU/acre case). The simulations are for ambient conditions only (i.e., not thermally perturbed) and are carried to steady state in order to determine fraction of flow through fractures, $f_{\text {frac }}=Q_{\text {frac }} / Q_{\text {to }}$; matrix interstitial velocity, $v_{\text {mat }}$; and matrix water saturation, $S_{w}$, as functions of a given infiltration flux, $q_{\text {inf }}$. The 1-D simulations have been spot-checked against results from 2-D cross-section simulations to make sure any important component of horizontal velocity is not missed.

From these simulations, which use the equivalent continuum model (ECM), two families of curves $\left(v_{\text {mat }}\right.$ vs. $q_{\text {inf }}$ and $f_{\text {frac }} v s . q_{\text {inf }}$ ) were generated. The range in uncertainty of $v_{\text {mat }}$ or $f_{\text {frac }}$ for any given $\mathrm{q}_{\text {inf }}$ was determined by a range in the following parameters: material properties, including $K_{\text {sat }}, \phi$, and van Genuchten parameters; fracture/matrix coupling as represented by $\sigma$, the "satiated" matrix-water saturation for fracture flow; and vertical spatial variability within a given hydrogeologic unit. For water saturation, only a single curve was determined for average 
$S_{w}$ vs. $q_{i n f}$, rather than a family of curves. This is because it has much weaker variability with material properties compared to the variability in $\mathrm{f}_{\text {frac }}$ and $\mathrm{v}_{\text {mat }}$. The minimum and maximum from each family of curves for $v_{\text {mat }}$ and $f_{\text {frac }}$ are shown in Figures 7.2-8 to 7.2-11 and the raw data are shown in Tables 7.2-3 and 7.2-4. These minimum and maximum curves are used in the TSPA model to describe the entire family (see next section).

\section{TSPA abstracted model}

Based on the above discussion, the infiltration rate, $q_{i n f}$, is the primary independent variable for geosphere transport in the aqueous phase. In particular, during a stochastic simulation, RIP will sample from a $q_{i n f}$ distribution (see below) to determine the $q_{i n f}$ at repository closure (i.e., the initial $q_{\text {inf }}$ ). For this value of $q_{\text {inf }}$, there will be stochastic distributions of $v_{\text {mat }}$ and $f_{\text {frac }}$ (as functions of depth or pathway). These distributions are described by the minimum and maximum values of the given parameter at that $\mathrm{q}_{\mathrm{inf}}$, as illustrated by the minimum/maximum curves on Figures 7.2-8 to 7.2-11. Random uniform sampling between these minimum and maximum values is used to determine a stochastic initial $v_{\text {mat }}$ and $f_{\text {frac }}$ for a given realization (see Figure 7.2-3). During any given simulation (realization), $\mathrm{q}_{\mathrm{inf}}$ may change due to climatic variations, and thus, $f_{\text {frac }}$ and $v_{\text {mat }}$ will be time dependent. (The time dependence of $S_{w}$ is not considered because RIP does not allow time-varying retardation factors-the $S_{w}$ distribution is only used in the retardation factors.)

Let us designate $U(0,1)$ to be the random fraction (uniformly sampled) between the minimum and maximum value of $f_{\text {frac }}$ at any given value of $q_{\text {inf }}$. Then we find the corresponding value of $f_{\text {frac }}$ (designated as $\mathrm{f}$ ) as follows (see Figure 7.2-3):

$$
\frac{f-f_{\min }}{f_{\max }-f_{\min }}=U(0,1)
$$

and the corresponding value of $v_{\text {mat }}$ (designated as $v$ ) as follows:

$$
\frac{\log _{10} v-\log _{10} v_{\min }}{\log _{10} v_{\max }-\log _{10} v_{\min }}=1-U(0,1)
$$

Regardless of climate change (i.e., changing $\mathrm{q}_{\text {inf }}$ ), the initially sampled fraction, $\mathrm{U}(0,1)$, is used throughout the simulation for each new value of $q_{i n f}$, i.e., at all values of time, $t$. This maintains the same distance between the minimum and maximum curves throughout the simulation.

To model geosphere transport in fractures and/or faults, RIP divides the flow on a volume basis between matrix and fracture "flow modes", according to a user-defined percentage, i.e., according to $f_{\text {frre }}$. Then RIP uses a plug-flow solution (i.e., pure advection) for mass transport in each flow mode. Except for the CHnv pathways at low infiltration rates $(0.01-0.05 \mathrm{~mm} / \mathrm{yr})$, all pathways exhibit some degree of transport through fractures (see Table 7.2-3). Velocity in the matrix-flow 
mode, $v_{m a t}$ is given by $v$ from Equation $7.4-2$, and velocity in the fracture-flow mode, $v_{\text {frac }}$, is taken to be

$$
v_{\text {frac }}=\frac{f_{\text {frac }} q_{i n f}}{\phi_{\text {frac }}}
$$

where $\phi_{\text {frac }}$ represents the fracture porosity and is assumed to be equal to 0.001 .

Dispersion between fracture- and matrix-flow modes is simulated by a Markovian process algorithm that randomly transitions particles between fracture and matrix modes (Golder, 1994), with a distribution equal to the natural logarithm of a random uniform sample between 0 and 1 (Figure 7.4-2). The transition rate, $\lambda$, is a user input. For TSPA-1995, the default particletransition rate for the Markovian dispersion process between fracture and matrix is set equal to the inverse of the pathway length. This means that on average a radionuclide particle will travel the length of the pathway (e.g., through the TSw) within a fracture, before transitioning to the matrix-flow mode or vice-versa. For a slug input through a single pathway (i.e., one hydrogeologic unit), this will result in some smearing of the two peaks (fracture and matrix) in the breakthrough curve, but will retain much of the bimodal character of the breakthrough curve. For a series of connected pathways, however, most of the bimodality is lost-not necessarily because of the Markovian process, however, but because of the connections between paths.

Consider, as an example only, four connected pathways (of approximately the same length) with $50 \%$ of the flow through fractures in each pathway (Figure 7.4-3); and suppose an initial pulse input of mass is injected into the beginning of the first pathway (e.g., TSw). The 50\% of the slug that enters the fractures will exit the first pathway much sooner (in general) than the 50\% in the matrix. When this fracture-transported mass enters the beginning of the second pathway (e.g., the TSv), $50 \%$ of it will enter the fracture flow mode of the second pathway and $50 \%$ will enter the matrix flow mode. Thus, only $0.5 \times 0.5=0.25$ or $25 \%$ of the initial part of the slug will pass through the fractures of the second pathway. Thus, for the fourth pathway (e.g:, the $\mathrm{CHnz}$ ), only $(0.5)^{4}$ or $6 \%$ of the initial slug will pass through fractures in the fourth pathway. This means that the initial arrival of nuclides through fractures to the accessible environment will have a much lower mass release than if the fractures in each unit were connected directly with each other. Although this is apparently not a conservative assumption, it does seem more realistic. Similar to a slug input, this same effect will be visible at the beginning of a breakthrough curve resulting from a continuous input. In either case, if the fraction of fracture flow is much less than $50 \%$, the initial arrival of nuclides will be less by the corresponding fraction raised to an exponent equal to the number of connected pathways (assuming the same fracture-flow fraction and the same pathway length for each formation). Thus, fracture flow in TSPA-1995 has less of an impact than might at first be suspected. In order for it to have a much greater effect, it would be necessary to assume a fault pathway with a more direct connection to the accessible environment. (Note: The value of $50 \%$ is only used for illustrative purposes. The actual value is $f_{\text {frac }}$, which is different for each formation.)

For most simulations the matrix/fracture particle transition rate is $\lambda=1 / \mathrm{L}$, where $\mathrm{L}$ is the formation thickness. However, because $\lambda$ is uncertain, a sensitivity case comparing various values of $\lambda$ has been conducted (see Sections 9.2.3 and 9.3.3). 
Geosphere pathways are assumed to be at ambient temperature conditions at all times. The only modification to other ambient conditions during the course of a simulation (i.e., a realization), will be the time-dependent change in infiltration rate and water table height caused by climate change (see Section 7.7). This will in turn cause a change in fracture flux, matrix flux and velocity, and pathway length in the unsaturated zone.

\subsubsection{Comparison of UZ Transport Models in RIP and FEHM}

As outlined in the previous sections, the representation of unsaturated-zone transport implemented in RIP is based primarily on "lumped" descriptive parameters, in particular, the fracture/matrix transition rate. Such an approach utilizes information regarding the flow field from calculations external to RIP (e.g., fractional fracture flow and matrix pore velocity), and then solves the transport problem using an empirical Markovian algorithm within RIP. Li et al. (1995) have recently examined the validity of this hybrid approach in RIP vis-a-vis detailed process modeling of coupled unsaturated flow and transport with FEHM (Zyvoloski et al., 1995).

The basic approach used in the $\mathrm{Li}$ et al. study was to simulate steady-state flow and transient transport with FEHM, and then compare the transport simulations with those from RIP. A onedimensional vertical column, similar to that used by Ho (1995), was utilized for the simulations, with hydrogeologic properties taken from Schenker et al. (1995). For the FEHM model, a saturated boundary condition was applied at the bottom and a constant flux boundary was applied at the top. Solute transport was simulated by injecting a conservative tracer of constant concentration at the top, and monitoring the breakthrough curve at the bottom. The flow calculations were carried out using the dual porosity/dual permeability ( $d p d p)$ option in FEHM. Since RIP does not have the ability to simulate flow, steady-state velocity profiles in both fractures and matrix blocks were abstracted from FEHM and input into RIP. The matrix/fracture transition rate parameter was varied to get a visual match between the breakthrough curves predicted by RIP and FEHM. This process was repeated for multiple infiltration rates and solute diffusion coefficients. Note: The velocity profiles from FEHM, generated during this comparative study, were not used in TSPA-1995 simulations. Velocity profiles for TSPA-1995 came from the TOUGH2 simulations described in Section 7.2.)

Information regarding the models and parameters, together with results for infiltration rates of $0.5,1.0$ and $4.0 \mathrm{~mm} / \mathrm{yr}$, and for matrix diffusion coefficients of $0,1 \times 10^{-12}$ and $1 \times 10^{-10} \mathrm{~m}^{2} / \mathrm{s}$, are discussed in detail by $\mathrm{Li}$ et al. (1995). For reasons of brevity, we present here only the results for an infiltration rate of $4.0 \mathrm{~mm} / \mathrm{yr}$ assuming no matrix diffusion (Figure 7.4-4). The breakthrough curve labelled 'FEHM' represents a composite of the fracture and matrix breakthrough curves weighted by the component porosities. The other curves are RIP predictions (also for the composite medium) corresponding to a range of values for the transition rate parameter, $\lambda$. Note that the general character of the RIP- and FEHM-predicted breakthrough curves are quite similar, and a value of $\lambda \cong 1 / \mathrm{L}$ appears to provide a reasonable match between the two curves. The first arrival time predicted by RIP is much later than that predicted by FEHM, primarily due to the use of a large initial time step size ( $\Delta t=175 \mathrm{yr}$ ), which was necessary to simulate a time period of $10^{6}$ years without violating the constraint on the allowable number of time steps in RIP. 
These results from the $\mathrm{Li}$ et al. (1995) study indicate that properly accounting for the pore velocities, and the partitioning of flow between the fractures and the matrix, in the RIP transport simulations (via abstractions from FEHM, or TOUGH2, flow simulations) helps provide a sound basis in predictions of geosphere transport. Furthermore, these results suggest that the Markovian transport algorithm implemented in RIP provides results which are comparable to those from detailed flow and transport simulations with FEHM.

\subsubsection{Radionuclide Retardation}

In TSPA calculations all rock/water interactions that can serve to retard the transport of radionuclides are modeled with a simple, equilibrium (infinite capacity), distribution-coefficient $\left(\mathrm{K}_{\mathrm{d}}\right)$ model.

Consider a simple equilibrium sorption reaction where species $A_{i}$ in the aqueous phase reacts with species $\bar{A}_{i}$ sorbed onto the rock matrix:

$$
A_{i}-\bar{A}_{i}
$$

The differential material-balance equations (per bulk volume) for $A_{i}$ and $\bar{A}_{i}$ are:

$$
\begin{gathered}
\frac{\partial\left(\phi S_{w} c_{i}\right)}{\partial t}+u_{w} \frac{\partial c_{i}}{\partial x}=R \\
\frac{\partial\left[\bar{c}_{i} \rho_{s}(1-\phi)\right]}{\partial t}=-R
\end{gathered}
$$

where

$$
\begin{aligned}
& c_{i}=\frac{\text { moles of radionuclide } \mathrm{i} \text { in aqueous phase }}{\text { liter of aqueous phase volume }} \\
& \bar{c}_{i}=\frac{\text { moles of radionuclide } \mathrm{i} \text { on solid phase }}{\mathrm{g} \text { of solid phase }} \\
& S_{w}=\frac{\text { liters of aqueous phase volume }}{\text { liter of pore volume }} \\
& \phi=\frac{\text { liters of pore volume }}{\text { liter of bulk volume }} \\
& 1-\phi=\frac{\text { liters of solid volume }}{\text { liter of bulk volume }}
\end{aligned}
$$


$\rho_{s}=\frac{g \text { of solid phase }}{\text { liter of solid phase volume }}$

$u_{w}=\frac{\text { liters of aqueous phase volume }}{\left(\mathrm{dm}^{2} \text { of bulk area }\right) \times \text { time }}=$ Darcy velocity of aqueous phase

$R=\frac{\text { moles of radionuclide } \mathrm{i} \text { in reaction }}{\text { (liter of bulk volume) } \times \text { time }}$

$x=$ decimeters $(\mathrm{dm})$ of bulk length

Combining the above two equations gives the total material balance for species $\mathrm{i}$ :

$$
\frac{\partial}{\partial t}\left[\phi S_{w} c_{i}+\bar{c}_{i} \rho_{s}(1-\phi)\right]+u_{w} \frac{\partial c_{i}}{\partial x}=0
$$

Defining the sorption (or distribution) coefficient, $K_{d}$, as

$$
K_{d} \equiv \frac{\text { moles of radionuclide } \mathrm{i} \text { per } \mathrm{g} \text { of solid phase }}{\text { moles of radionuclide } \mathrm{i} \text { per } \mathrm{ml} \text { of aqueous phase }}=\frac{1000 \bar{c}_{i}}{c_{i}}
$$

and combining with the above equation gives

$$
\frac{\partial}{\partial t}\left[\phi S_{w} c_{i}+\rho_{m}(1-\phi) K_{d} c_{i}\right]+u_{w} \frac{\partial c_{i}}{\partial x}=0
$$

where $\rho_{m}=\rho_{s} / 1000$ and has units of $g / \mathrm{cm}^{3}$. Factoring out $\phi S_{w}$ and rearranging, gives

$$
\left[1+\frac{\rho_{m}(1-\phi)}{\phi S_{w}} K_{d}\right] \frac{\partial c_{i}}{\partial t}+\frac{u_{w}}{\phi S_{w}} \frac{\partial c_{i}}{\partial x}=0
$$

The definition of bulk density, $\rho_{b}$, in a consistent set of units (e.g., $\rho_{b}$ in $g$ per $\mathrm{cm}^{3}$ of bulk volume, $\rho_{w}$ in $\mathrm{g}$ per $\mathrm{cm}^{3}$ of pore volume, $\rho_{\mathrm{m}}$ in $\mathrm{g}$ per $\mathrm{cm}^{3}$ of solid-phase volume, $\phi$ in $\mathrm{cm}^{3}$ of pore volume per $\mathrm{cm}^{3}$ of bulk volume, $1-\phi$ in $\mathrm{cm}^{3}$ of solid-phase volume per $\mathrm{cm}^{3}$ of bulk volume) is

$$
\rho_{b}=(1-\phi) \rho_{m}+\phi \rho_{w}
$$

The "dry" bulk density, $\rho_{b d}$, i.e., the density when $S_{w}=0$, is defined as

$$
\rho_{b d} \equiv \rho_{b}-\phi \rho_{w}=(1-\phi) \rho_{m}
$$

Thus, substituting $\rho_{b d}$ for $\rho_{m}(1-\phi)$ in Equation 7.4-10 gives 


$$
\left[1+\frac{\rho_{b d}}{\phi S_{w}} K_{d}\right] \frac{\partial c_{i}}{\partial t}+\frac{u_{w}}{\phi S_{w}} \frac{\partial c_{i}}{\partial x}=0
$$

With regard to consistency of units, this substitution between Equations 7.4-10 and 7.4-12 is valid because $\phi$ is just a fraction. Thus, although in Equation 7.4-13, $\rho_{b d}$ takes on the numerical value of dry bulk density in units of $\mathrm{g} / \mathrm{cm}^{3}$, it actually has units of

$$
\frac{\mathrm{g} \text { of solid phase }}{\mathrm{cm}^{3} \text { of solid phase volume }} \times \frac{\text { liters of solid phase volume }}{\text { liter of bulk volume }}
$$

It can now be seen that the apparent velocity of radionuclide $A_{i}$ is given by the interstitial velocity in the water phase, $v_{w}=u_{w} / \phi S_{w}$, divided by the retardation coefficient, $R_{d}$, where

$$
R_{d}=1+\frac{\rho_{b d}}{\phi S_{w}} K_{d}
$$

In TSPA-1995, the Schenker et al. (1995) distributions were used for both $\rho_{b d}$ and $\phi$ in the rock matrix of the various hydrogeologic units. Schenker's stochastic distributions for bulk density are based on measurements of both $\rho_{b}$ and $\rho_{b d}$, and values in between where $0<S_{w}<1$. For $S_{w}$ in Equation 7.4-15, the process-level results for matrix water saturation were used $\left(S_{w}\right.$ in Tables 7.2-3 and 7.2-4).

Distribution coefficients represent many possible processes, including ion-exchange, sorption, surface complexation, and precipitation/dissolution. Because $K_{d} s$ are used to model such a wide range of basic phenomenological processes, they must necessarily be modeled as stochastic parameters with a high degree of uncertainty when used in abstracted TSPA models (and even in process-level models). The distributions used for TSPA-1995 are based in part on an expert elicitation workshop conducted for TSPA-1993 (Andrews et. al., 1994), and represent conservative estimates. However, in part because of recent experiments at LANL (Triay et al., 1995c; 1995d; and 1995e), which determined $\mathrm{K}_{d} \mathrm{~s}$ for $\mathrm{Np}, \mathrm{U}, \mathrm{Pu}$, and Se for whole-rock tuff samples, the $K_{d} s$ from TSPA-1993 have been updated (Meijer, 1990; 1992; and 1995). $K_{d} s$ for three different rock types were measured: devitrified tuff, vitric tuff, and zeolitic tuff. Distribution coefficients for these rock types are different in the unsaturated zone compared to the saturated zone, mainly because of ionic strength. For TSPA-1995, the saturated zone was modeled as devitrified; therefore, besides the three types of $\mathrm{K}_{\mathrm{d}}$ distributions in the unsaturated zone, there is one additional set of distributions for the saturated zone. All $\mathrm{K}_{\mathrm{d}}$ distributions are shown in Tables 7.4-2 and 7.4-3.

\subsection{TRANSPORT OF GASEOUS-PHASE RADIONUCLIDES}

For TSPA-1995, geosphere transport of radionuclides in the gaseous phase of the unsaturated zone is not considered. The primary radionuclide to be transported in the gas (air) phase would be ${ }^{14} \mathrm{C}$. However, given the recent recommendations of the NAS (National Research Council, 1995) on protection of the global population, it is clear that the risk from gaseous release of ${ }^{14} \mathrm{C}$ is negligible. However, TSPA-1995 does assume that the ${ }^{14} \mathrm{C}$ released from the inventory is dissolved in the aqueous phase once it reaches the geosphere (i.e., the top of the TSw), and is then transported by the aqueous phase to the accessible environment. Since this is a very 
conservative assumption with respect to computing dose at the accessible environment, Chapter 9 has a sensitivity analysis that computes dose at the accessible environment when ${ }^{14} \mathrm{C}$ is directly released to the atmosphere, i.e., if it never enters the aqueous phase and therefore does not contribute to dose exposure in a water well at the accessible environment.

The other two radionuclides that may be gaseous in the WP/EBS are ${ }^{129} \mathrm{I}$ and ${ }^{36} \mathrm{Cl}$ (Golder, 1993). It is assumed that they leave the waste packages in gaseous form, transport immediately through the EBS, and then dissolve in the aqueous phase in the TSw. Then they are transported through the geosphere as aqueous-phase solutes. Assuming that ${ }^{129} \mathrm{I}$ and ${ }^{36} \mathrm{Cl}$ are released in gaseous form from the inventory is a conservative assumption, and it implies that their transport through the EBS is unaffected by dripping fractures or by a diffusion barrier around the packages. Thus, in the capillary-barrier scenario, ${ }^{129} \mathrm{I}$ controls the peak dose at the accessible environment (see Chapter 9). However, it is debatable whether highly reactive species such as $\mathrm{I}_{2}$ and $\mathrm{Cl}_{2}$ would make it through the WP/EBS environment in the gaseous phase, or whether they would instead be dissolved into the aqueous phase. Thus, we have included a sensitivity case (Chapter 9) that considers aqueous-phase transport of ${ }^{129} \mathrm{I}$ and ${ }^{36} \mathrm{CL}$ through the EBS.

\subsection{SATURATED-ZONE TRANSPORT}

\subsubsection{Saturated-Zone Flux Distribution}

The saturated-zone flux affects the arrival time of radionuclides at the accessible-environment boundary as well as the degree of mixing and dilution in the ground water of the tuff aquifer prior to its extraction and use. Since process-level modeling of saturated-zone flow and transport has not changed appreciably since the completion of TSPA-1993, the same abstraction and basis thereof used in the previous TSPA iteration is also used in the current analyses. The saturatedzone fluxes $\left(q_{s z}\right.$ ) come from simulations by Barr (1993), but are based on limited borehole data. The 2-D simulations of Barr were based on a composite or bulk permeability/flux model, which used a conductivity distribution that represents an average of matrix and fracture permeabilities (similar to an equivalent continuum model). The saturated-zone flux distribution used in TSPA1993 and TSPA-1995 used the entire 2-D distribution of nodal fluxes to represent the possible range of spatially averaged 1-D flux in the saturated zone. Remember that since RIP only considers 1-D transport, that the 2-D flux distribution from the Barr process-level model would have to be averaged to 1-D. Rather than trying to match the breakthrough curve of a 1-D model to some spatially averaged 2-D breakthrough distribution from the composite permeability process-level model, we just used the entire 2-D distribution of steady-state nodal velocities (or fluxes), and sampled from this distribution to determine the 1-D $\mathrm{q}_{\mathrm{sz}}$ for any given realization.

The actual distribution for $\mathrm{q}_{\mathrm{sz}}$ (Darcy velocity in the saturated zone) used in TSPA-1995 is a lognormal distribution with a mean of $2.0 \mathrm{~m} / \mathrm{yr}$, a median of $1.0696 \mathrm{~m} / \mathrm{yr}$, and a standard deviation of 0.4859. Based on this distribution, both TSPA-1993 and TSPA-1995 indicate that the saturated zone is not a significant geosphere barrier compared to the unsaturated zone, as far as time delay of the breakthrough to the accessible environment. The saturated zone's greatest importance lies in its dilution effect. For TSPA-1995, aqueous transport through the saturated zone also assumes longitudinal dispersion, with a dispersivity equal to $10 \%$ of the path length from the base of the repository to the accessible environment (i.e., equal to $500 \mathrm{~m}$ ). Because RIP considers only one-dimensional transport, no lateral dispersion is possible. 


\subsubsection{Dilution and Dose at the Accessible Environment}

After exiting the base of the unsaturated zone, transported contaminants undergo longitudinal dispersion within the saturated zone before reaching the accessible environment at $5 \mathrm{~km}$ from the repository footprint. In order to compute doses at the accessible environment, the radionuclides are assumed to be mixed (diluted) into a volume of groundwater equal to the width of the repository times an arbitrary $50-\mathrm{m}$ mixing depth (or screened interval of a well penetrating the saturated-zone tuff aquifer) times the mean aquifer flux. In particular, dose exposure is computed from mass release rate by the following equation:

$$
D_{i}=\frac{M_{i}}{Q_{m}} D C F_{i}
$$

where

$D_{i}=$ dose for radionuclide $\mathrm{i}(\mathrm{rem} / \mathrm{yr})$,

$\mathrm{M}_{\mathrm{i}}=$ mass rate of release for radionuclide $\mathrm{i}(\mathrm{g} / \mathrm{yr})$,

$\mathrm{Q}_{\mathrm{m}}=$ mixing volumetric flow rate $\left(\mathrm{m}^{3} / \mathrm{yr}\right)$, and

$\mathrm{DCF}_{\mathrm{i}}=$ dose conversion factor for radionuclide $\mathrm{i}\left(\mathrm{rem}-\mathrm{m}^{3} / \mathrm{g}-\mathrm{yr}\right)$.

Note that $M_{i} / Q_{m}$ is the mass concentration of the given nuclide in the media of interest, e.g., the drinking water. $M_{i}$ is just the mass rate of release into the saturated zone, as computed by RIP. The mixing volumetric flow rate, $\mathrm{Q}_{\mathrm{m}}$, is based on the Darcy velocity in the saturated zone and the screened interval of a water well that penetrates the saturated zone. Here we define the screened interval as the depth, $h$, in meters from the top of the saturated zone to the total depth of the well. We make the conservative assumption that the vertical dispersion in the saturated zone between the repository boundary and the water well is such that none of the nuclide mass is dispersed beyond the screened interval. Thus, the mixing volumetric flow rate for the purposes of computing mass concentration is given by

$$
Q_{m}=h W_{r e p} q_{S z}
$$

where

$\mathrm{W}_{\text {rep }}=$ approximate width (m) of repository, perpendicular to the direction of flow in the SZ $\mathrm{q}_{\mathrm{sz}}=$ saturated-zone Darcy velocity $(\mathrm{m} / \mathrm{yr})$.

We assumed a repository width of $4 \mathrm{~km}$ and a screened-interval depth of $50 \mathrm{~m}$. If $\mathrm{q}_{\mathrm{sz}}$ is $2.0 \mathrm{~m} / \mathrm{yr}$ (the mean of the $q_{s z}$ distribution-see above), this gives a $Q_{m}$ equal to $400,000 \mathrm{~m}^{3} / \mathrm{yr}$.

The dose conversion factors in Equation 7.6-1 were selected from the EPA dose conversion factors (EPA, 1988) for ingestion only. These EPA dose conversion factors were converted to an assumed drinking-water exposure scenario. The receptor was assumed to drink 2 liters of water per day. The dose conversion factors are presented in Table 7.6-1. The dose exposure generated over the time period of interest is the maximally-exposed-individual, whole-body dose for a person that obtains all of their drinking water from the contaminated saturated zone. For simplicity and ease of comparison with other dose analyses, this assumption is different than the 
TSPA-1993 evaluation which considered both drinking water and crop irrigation. A comparison of the TSPA-1995 and TSPA-1993 dose conversion factors is included in Table 7.6-1. Generally, the dose conversion factors used in TSPA-1995 are smaller than those used in TSPA-1993. A more detailed analysis of the exposure scenarios will be conducted after the NAS recommendations are evaluated and the regulation for dose has been promulgated.

\subsubsection{Dilution in the Regional Aquifer}

Based on the recent NAS study (National Research Council, 1995), additional dilution of the concentration at the accessible environment (dose reduction) would be expected to occur between the accessible environment and the location where the critical group is assumed to withdraw ground water, based on two processes. These processes are mixing of ground water from two sub-basins in the vicinity of water use (see Figures 2.5-1 and 2.5-2), and by lateral and vertical dispersion over the longer path length. The dilution of the concentration from mixing of groundwater from the two sub-basins in the vicinity of groundwater withdrawal is 3.5. This was determined by dividing the sum of northwestward flow from the Amargosa Desert (20,000 acre-ft/yr) plus southward flow from Yucca Mountain (8,000 acre-ft/yr) by the southward flow from Yucca Mountain (see Table 2.5-1).

The amount of dispersion over the longer path length is largely a function of the regional flow system and the heterogeneity along the migration paths within the flow system. The reduction in concentration of radionuclides over a path length $\mathrm{L}$ in an infinite homogeneous aquifer with a steady-state pore velocity $\left(\mathrm{v}_{\mathrm{x}}\right)$ may be approximated using an advection-diffusion model:

$$
\frac{\partial C}{\partial t}+v_{x} \frac{\partial C}{\partial x}=D_{x} \frac{\partial^{2} C}{\partial x^{2}}+D_{y} \frac{\partial^{2} C}{\partial y^{2}}+D_{z} \frac{\partial^{2} C}{\partial z^{2}}
$$

where $\mathrm{C}$ is the radionuclide concentration, $\mathrm{v}_{\mathrm{x}}$ is the average linear velocity in the $\mathrm{x}$ direction and $D_{x}, D_{y}$, and $D_{z}$ are the dispersion coefficients in the $x, y$, and $z$ directions, respectively. For steady-state transport, the concentration becomes independent of time, and for large time $(t>$ $\left.2 \mathrm{D}_{\mathrm{x}} / \mathrm{v}_{\mathrm{x}}{ }^{2}\right)$, the longitudinal dispersion term may be neglected. Under these conditions, Equation 7.6-3 reduces to the following form:

$$
v_{x} \frac{\partial C}{\partial x}=D_{y} \frac{\partial^{2} C}{\partial y^{2}}+D_{z} \frac{\partial^{2} C}{\partial z^{2}}
$$

This is just the two-dimensional diffusion equation, with an equivalent "time" represented by $x / v_{x}$, the downstream travel time. The general solution of Equation 7.6-4 for an instantaneous point source is:

$$
C(x, y, z)=\frac{\left(2 \dot{M} / v_{x}\right)}{4 \pi \phi \sqrt{D_{y} D_{z}}\left(x / v_{x}\right)} \exp \left\{\frac{y^{2}}{4 D_{y}\left(x / v_{x}\right)}-\frac{z^{2}}{4 D_{z}\left(x / v_{x}\right)}\right\}
$$

where $\phi$ is the porosity and $\dot{M}$ is the mass flux (mass input per unit time). The factor of 2 is included because radionuclides cannot disperse into the upper half-plane above the water table. 
This effect is incorporated through symmetry about the water table by including an extra image source of the same strength at the same position as the original source, resulting in a concentration that is doubled.

Instead of a point source, if we represent the mass flux into the saturated zone as a line source of length $l$ oriented orthogonal to the saturated zone flow direction, then the downstream concentration may be represented by the superposition of Equation 7.6-5 over a series of infinitesimal point sources between $(x, y, z)$ coordinates $(0,-l / 2,0)$ and $(0, l / 2,0)$. Therefore,

$$
C(x, y, z)=(1 / l) \int_{t / 2}^{l / 2} \frac{\left(\dot{M} / v_{x}\right)}{2 \pi \phi \sqrt{D_{y} D_{z}}\left(x / v_{x}\right)} \exp \left\{-\frac{(y-\eta)^{2}}{4 D_{y}\left(x / v_{x}\right)}-\frac{z^{2}}{4 D_{z}\left(x / v_{x}\right)}\right\} d \eta
$$

Integrating Equation 7.6-6 and letting

$$
\begin{aligned}
& D_{y}=\alpha_{y} v_{x}=\beta_{y} x v_{x} \\
& D_{z}=\alpha_{z} v_{x}=\beta_{z} x v_{x}
\end{aligned}
$$

gives the concentration:

$$
C(x, y, z)=\frac{(\dot{M} / l)}{2 \phi v_{x} x \sqrt{\pi \beta_{z}}} \exp \left\{\frac{z^{2}}{4 \beta_{z} x^{2}}\right\}\left\{\operatorname{erf}\left\{\frac{l / 2+y}{2 x \sqrt{\beta_{y}}}\right\}+\operatorname{erf}\left\{\frac{l / 2-y}{2 x \sqrt{\beta_{y}}}\right\}\right\}
$$

The dispersivity model for $\alpha_{y}$ and $\alpha_{z}$ assumed in Equations 7.6-7 is based on the observation in field-scale dispersive transport processes that the effective dispersion coefficients are proportional to the distance traveled and the flow velocity.

The concentrations are at a maximum at the centerline, i.e. $y=0$ and $z=0$. At the centerline, Equation 7.6-8 reduces to

$$
C(x, 0,0)=\frac{(\dot{M} / l)}{q_{S z} x \sqrt{\pi \beta_{z}}} \operatorname{erf}\left\{\frac{l}{4 x \sqrt{\beta_{y}}}\right\}
$$

where $q_{s z}=\phi v_{x}$, is the saturated-zone Darcy velocity. To obtain a dilution factor, note that

and

$$
\begin{gathered}
\dot{M}=C_{u z} q_{u z} A_{r e p} \\
S=\frac{C_{u z}}{C}
\end{gathered}
$$


where $S$ is the dilution factor, $C_{\mathrm{uz}}$ is the radionuclide concentration in the unsaturated-zone flow entering the saturated zone, $q_{u z}$ is the unsaturated-zone Darcy velocity, and $A_{\text {rep }}$ is the "repository" area (actually, the contaminated-flow cross-sectional area entering the saturated zone, assumed to be equal to the waste-package catchment area of $41 \mathrm{~m}^{2}$-see Section 7.3-times 10,000 waste packages, which equals approximately $4 \times 10^{5} \mathrm{~m}^{2}$ ).

Rearranging Equation 7.6-9 and using the definitions in Equation 7.6-10 to solve for the centerline dilution factor gives:

$$
S=\frac{q_{S z} l x \sqrt{\pi \beta_{z}}}{q_{U Z} A_{\text {rep }} \operatorname{erf}\left\{\frac{l}{4 x \sqrt{\beta_{y}}}\right\}}
$$

Estimates of the effects of dispersion on peak (centerline) concentration between the repository and points downstream can be made using Equation 7.6-11 by assuming values for the transverse "dispersivity-scale coefficients", $\beta_{y}$ and $\beta_{z}$. The distances from the repository to the accessible environment and the potential point-of-use at Amargosa Farms are $5 \mathrm{~km}$ and $30 \mathrm{~km}$, respectively. A longitudinal dispersivity-scale coefficient, $\beta_{x}$, of 0.1 was assumed for TSPA-1993 (Andrews et al., 1994). Transverse dispersivity-scale coefficients, $\beta_{y}$ and $\beta_{z}$, are generally a factor of 1.5 to 10 smaller than $\beta_{x}$. Using $\beta_{x}$ equal to 0.1, the longitudinal dispersivity, $\alpha_{x}$, at Amargosa Farms would be 3 kilometers, which seems perhaps too large compared with observed values. Therefore, we conservatively assume that $\beta_{x}$ is 0.01 , resulting in a minimum value for $\beta_{y}$ and $\beta_{z}$ of 0.001 (i.e., assuming they are 10 times smaller than $\beta_{x}$ ). $q_{s z}$ is assumed to be about $2 \mathrm{~m} / \mathrm{yr}$ (see above), the line source length, $l$, is given a value of $4 \mathrm{~km}$ (see Section 7.6-2), and the "repository" (contaminated-flow) area is about $4 \times 10^{5} \mathrm{~m}^{2}$. A table of dilution values are computed for downstream distances of $5 \mathrm{~km}$ and $30 \mathrm{~km}$ and for UZ Darcy velocities of $1.25 \times 10^{-3} \mathrm{~m} / \mathrm{yr}$ and $3.0 \times 10^{-5} \mathrm{~m} / \mathrm{yr}$. (These are the expected values for the high and low $\mathrm{q}_{\mathrm{inf}}$ ranges discussed earlier in this chapter. Note that $\mathrm{q}_{\mathrm{Uz}}=\mathrm{q}_{\mathrm{inf}}$.)

\section{Centerline (Minimum) Dilution Factors}

\begin{tabular}{|c|c|c|}
\hline \multirow{2}{*}{$\begin{array}{c}\mathbf{q}_{\mathrm{Uz}} \\
(\mathbf{m} / \mathbf{y r})\end{array}$} & $\mathbf{2} \mathbf{~ k m}$ & $\mathbf{S}=\mathrm{C}_{\mathrm{Uz}} / \mathbf{C}$ \\
\cline { 2 - 3 } & $4.5 \times 10^{3}$ & $\mathbf{3 0}$ \\
\hline $1.25 \times 10^{-3}$ & $1.9 \times 10^{5}$ & $3.1 \times 10^{4}$ \\
\hline $3.0 \times 10^{-5}$ & $1.3 \times 10^{6}$ \\
\hline
\end{tabular}

The "stirred tank" mixing model discussed in section 7.6 .2 for dilution in the saturated zone between the repository and the accessible environment $(5 \mathrm{~km})$ gives dilution factors $\left(=\mathrm{q}_{\mathrm{sz}} \mathrm{W}_{\mathrm{rep}} \mathrm{h} / \mathrm{q}_{\mathrm{uz}} \mathrm{A}_{\mathrm{rep}}\right)$ of about 800 and $3.3 \times 10^{4}$ for the high and low $\mathrm{q}_{\mathrm{Uz}}$ cases, respectively. Therefore, the advection-diffusion centerline (minimum) dilution values are larger than the mixing-model dilution values by a factor of about 6 at the 5-km AE boundary. However, 
average dilution values for the advection-diffusion model, found by integrating over a 4-kilometer-wide, 50-meter-deep cross-section, are larger by a factor of about 12.

The increased dilution in the advection-diffusion model is largely due to the increased mixing depth (see below) compared with the assumed 50-m depth used in the "stirred tank" mixing model. Although concentrations computed with the advection-diffusion model are sensitive to the choice of dispersion coefficients, the values chosen here are believed to be conservative.

The dilution due to dispersive mixing between the accessible environment $(x=5 \mathrm{~km})$ and the potential point of use at Amargosa Farms $(x=30 \mathrm{~km})$ may be computed from the ratio of the dilution factors for a given value of $\mathrm{q}_{\mathrm{uz}}$, and is found to be about a factor of 7 . Total dilution between the accessible environment and the potential point of use is the product of dilution due to dispersive mixing during transit from the accessible environment to the point of use (Amargosa Farms) $(S=7)$ and the subbasin mixing expected due to inflow from the Amargosa Desert aquifer $(S=3.5$ ). Therefore a dilution factor (dose reduction factor) of at least 25 can be applied to calculated concentrations at the accessible environment to approximate the doses at Amargosa Valley.

The advection-diffusion model assumes that the line source is in an infinite half-space. This assumption is only valid if the dispersive width and depth of the concentration field are small in comparison with the boundaries of the regional aquifer system. The horizontal width of the dispersive plume may be estimated from the ratio of Equation 7.6-8 at $z=0$ to Equation 7.6-9. The value of $y$ for which this ratio is 0.1 may be used as an approximate plume width (roughly equivalent to two standard deviations from the centerline). This ratio is:

$$
\frac{C(x, y, 0)}{C(x, 0,0)}=\frac{\operatorname{erf}\left\{\frac{l / 2+y}{2 x \sqrt{\beta_{y}}}\right\}+\operatorname{erf}\left\{\frac{l / 2-y}{2 x \sqrt{\beta_{y}}}\right\}}{2 \operatorname{erf}\left\{\frac{l}{4 x \sqrt{\beta_{y}}}\right\}}
$$

Similarly, for the mixing depth, we have

$$
h_{w t}(t)=h_{w t}\left(t_{0}\right)+\Delta h_{w t}
$$

where

$$
\Delta h_{w t}=U(0,4) h_{t r i}(t)
$$

Here, $U(0,4)$ is the random number from Equation 7.7-1, and $h_{t r i}(t)$ is a periodic triangular wave with a period of 100,000 years and a peak amplitude of $20 \mathrm{~m}$. Thus, if $U(0,4)=4$, then a maximum water table rise of $80 \mathrm{~m}$ would occur at 50,000 years, whereas if $U(0,4)=0$, there would be no water-table rise. This is illustrated in Figure 7.7-2 for five values of $U(0,4)$. 
Table 7-2.1 TOUGH2 Results Used in the Testing of the Abstraction Methodology

\begin{tabular}{|c|c|c|c|c|c|}
\hline Unit & $\underset{(\mathbf{m m} / \mathbf{y r})}{\mathbf{q}_{\mathrm{inr}}}$ & $\mathbf{v}_{(\mathbf{m})}(\min )$ & $\underset{(\mathrm{m} / \mathrm{s})}{\mathbf{v}_{\mathbf{m a t}}(\max )}$ & $\mathbf{f}_{\text {frac }}(\min )$ & $\mathbf{f}_{\text {frac }}(\max )$ \\
\hline $\mathrm{TSw}$ & $\begin{array}{l}0.1 \\
0.5 \\
1.0\end{array}$ & $\begin{array}{l}2.640 \mathrm{E}-11 \\
8.100 \mathrm{E}-11 \\
1.110 \mathrm{E}-10\end{array}$ & $\begin{array}{l}2.890 \mathrm{E}-11 \\
1.170 \mathrm{E}-10 \\
1.560 \mathrm{E}-10\end{array}$ & $\begin{array}{c}0 \\
0 \\
0.197\end{array}$ & $\begin{array}{c}0 \\
0 \\
0.389\end{array}$ \\
\hline $\mathrm{TSv}$ & $\begin{array}{l}0.1 \\
0.5 \\
1.0\end{array}$ & $\begin{array}{l}6.040 \mathrm{E}-11 \\
1.170 \mathrm{E}-10 \\
3.400 \mathrm{E}-10\end{array}$ & - & $\begin{array}{c}0 \\
0 \\
0.155\end{array}$ & $\begin{array}{c}0 \\
0 \\
0.155\end{array}$ \\
\hline CHnv & $\begin{array}{l}0.1 \\
0.5 \\
1.0\end{array}$ & $\begin{array}{l}2.630 \mathrm{E}-11 \\
9.120 \mathrm{E}-11 \\
1.150 \mathrm{E}-10\end{array}$ & $\begin{array}{l}6.120 \mathrm{E}-11 \\
2.090 \mathrm{E}-10 \\
3.430 \mathrm{E}-10\end{array}$ & $\begin{array}{l}0 \\
0 \\
0\end{array}$ & $\begin{array}{l}0 \\
0 \\
0\end{array}$ \\
\hline CHnz & $\begin{array}{l}0.1 \\
0.5 \\
1.0\end{array}$ & $\begin{array}{l}1.240 \mathrm{E}-11 \\
6.150 \mathrm{E}-11 \\
6.150 \mathrm{E}-11\end{array}$ & $\begin{array}{l}1.840 \mathrm{E}-11 \\
7.940 \mathrm{E}-11 \\
6.900 \mathrm{E}-11\end{array}$ & $\begin{array}{l}0 \\
0 \\
0\end{array}$ & $\begin{array}{l}0 \\
0 \\
0\end{array}$ \\
\hline
\end{tabular}

Note:

$\mathrm{q}_{\text {inf }}$ is applied infiltration rate

$\mathbf{v}_{\operatorname{mat}}(\min )$ and $\mathbf{v}_{\operatorname{mat}}(\max )$ are the minimum and maximum matrix pore velocities

$f_{\text {frac }}(\min )$ and $f_{\text {frac }}(\max )$ are the minimum and maximum fraction of fracture flux 
Table 7.2-2 Comparison of TOUGH2 and RIP Travel Times

\begin{tabular}{|c|c|c|c||}
\hline $\begin{array}{c}\text { Infiltration } \\
(\mathbf{m m} / \mathbf{y r})\end{array}$ & $\begin{array}{c}\text { RIP (min) } \\
(\mathbf{y r})\end{array}$ & $\begin{array}{c}\text { TOUGH2 } \\
(\mathbf{y r})\end{array}$ & $\begin{array}{c}\text { RIP (max) } \\
(\mathbf{y r})\end{array}$ \\
\hline 0.1 & $3.62 \mathrm{E}+05$ & $4.88 \mathrm{E}+05$ & $5.67 \mathrm{E}+05$ \\
\hline 0.5 & $9.17 \mathrm{E}+04$ & $1.29 \mathrm{E}+05$ & $1.43 \mathrm{E}+05$ \\
\hline 1.0 & $5.83 \mathrm{E}+04$ & $7.91 \mathrm{E}+04$ & $1.10 \mathrm{E}+05$ \\
\hline
\end{tabular}

峁 
Table 7.2-3 TOUGH2 Abstractions for the Low-Infiltration Case

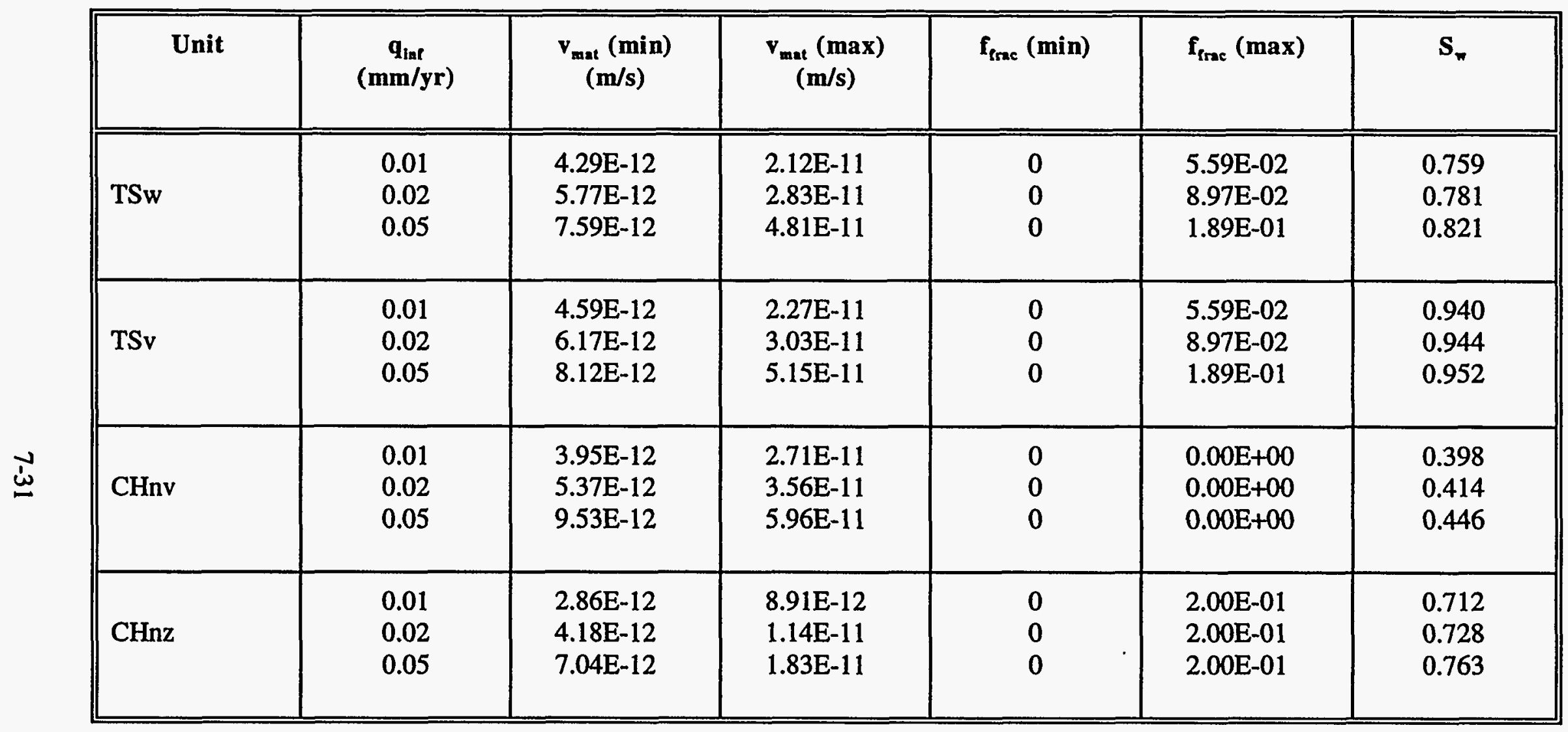


Table 7.2-4 TOUGH2 Abstractions for the High-Infiltration Case

\begin{tabular}{|c|c|c|c|c|c|c|}
\hline Unit & $\underset{(\mathbf{m m} / \mathbf{y r})}{\mathbf{q}_{\mathrm{lnf}}}$ & $\begin{array}{c}\mathbf{v}_{\mathbf{m a t}}(\min ) \\
(\mathbf{m} / \mathbf{s})\end{array}$ & $\underset{(m / s)}{v_{m i t}(\max )}$ & $\mathbf{f}_{\mathrm{frac}}(\mathrm{min})$ & $f_{\text {frac }}(\max )$ & $s_{n}$ \\
\hline TSw & $\begin{array}{c}0.5 \\
1 \\
2\end{array}$ & $\begin{array}{l}8.10 \mathrm{E}-12 \\
8.10 \mathrm{E}-12 \\
7.95 \mathrm{E}-12\end{array}$ & $\begin{array}{l}2.87 \mathrm{E}-10 \\
5.23 \mathrm{E}-10 \\
9.96 \mathrm{E}-10\end{array}$ & $\begin{array}{l}4.32 \mathrm{E}-02 \\
1.14 \mathrm{E}-01 \\
2.24 \mathrm{E}-01\end{array}$ & $\begin{array}{l}2.81 \mathrm{E}-01 \\
3.98 \mathrm{E}-01 \\
5.81 \mathrm{E}-01\end{array}$ & $\begin{array}{l}0.897 \\
0.943 \\
0.979\end{array}$ \\
\hline TSv & $\begin{array}{c}0.5 \\
1 \\
2\end{array}$ & $\begin{array}{l}8.67 \mathrm{E}-12 \\
8.67 \mathrm{E}-12 \\
8.50 \mathrm{E}-12\end{array}$ & $\begin{array}{l}3.07 \mathrm{E}-10 \\
5.59 \mathrm{E}-10 \\
1.07 \mathrm{E}-09\end{array}$ & $\begin{array}{l}4.32 \mathrm{E}-02 \\
1.14 \mathrm{E}-01 \\
2.24 \mathrm{E}-01\end{array}$ & $\begin{array}{l}2.81 \mathrm{E}-01 \\
3.98 \mathrm{E}-01 \\
5.81 \mathrm{E}-01\end{array}$ & $\begin{array}{l}0.984 \\
0.985 \\
0.986\end{array}$ \\
\hline CHnv & $\begin{array}{c}0.5 \\
1 \\
2\end{array}$ & $\begin{array}{l}4.95 \mathrm{E}-11 \\
8.79 \mathrm{E}-11 \\
1.71 \mathrm{E}-10\end{array}$ & $\begin{array}{l}3.36 \mathrm{E}-10 \\
5.89 \mathrm{E}-10 \\
1.03 \mathrm{E}-09\end{array}$ & $\begin{array}{l}0 \\
0 \\
0\end{array}$ & $\begin{array}{l}1.02 \mathrm{E}-02 \\
1.40 \mathrm{E}-02 \\
2.02 \mathrm{E}-02\end{array}$ & $\begin{array}{l}0.548 \\
0.605 \\
0.659\end{array}$ \\
\hline CHnz & $\begin{array}{c}0.5 \\
1 \\
2\end{array}$ & $\begin{array}{l}2.86 \mathrm{E}-11 \\
2.74 \mathrm{E}-11 \\
2.74 \mathrm{E}-11\end{array}$ & $\begin{array}{l}6.85 \mathrm{E}-11 \\
1.23 \mathrm{E}-10 \\
2.01 \mathrm{E}-10\end{array}$ & $\begin{array}{c}0 \\
1.23 \mathrm{E}-01 \\
2.59 \mathrm{E}-01\end{array}$ & $\begin{array}{l}4.27 \mathrm{E}-01 \\
6.24 \mathrm{E}-01 \\
7.26 \mathrm{E}-01\end{array}$ & $\begin{array}{l}0.954 \\
0.970 \\
0.981\end{array}$ \\
\hline
\end{tabular}


Table 7.4-1 Stratigraphy for TSPA-1995

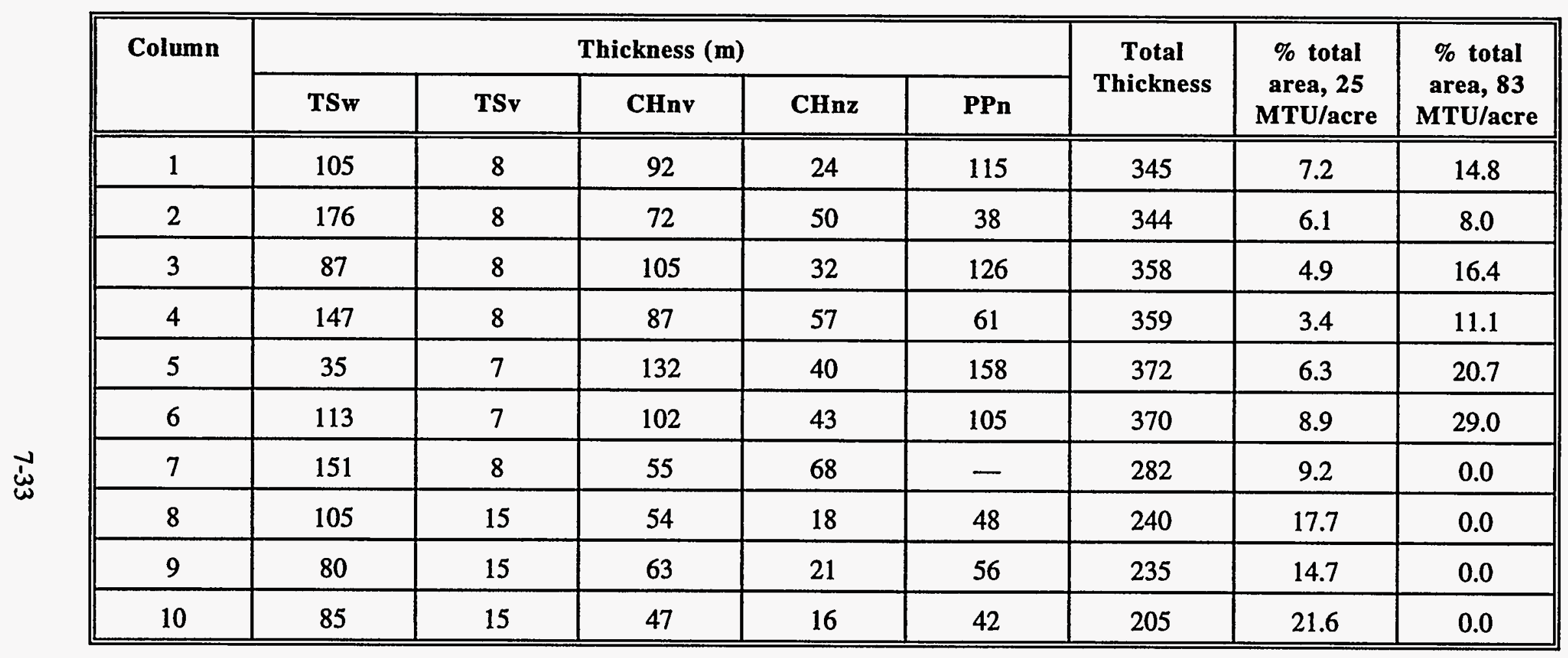


Table 7.4-2 TSPA-1995 Sorption-Coefficient Distributions $\left(\mathrm{K}_{\mathrm{d}}\right.$ in $\mathrm{ml} / \mathrm{g}$ ) for Unsaturated-Zone units (Meijer, 1995)

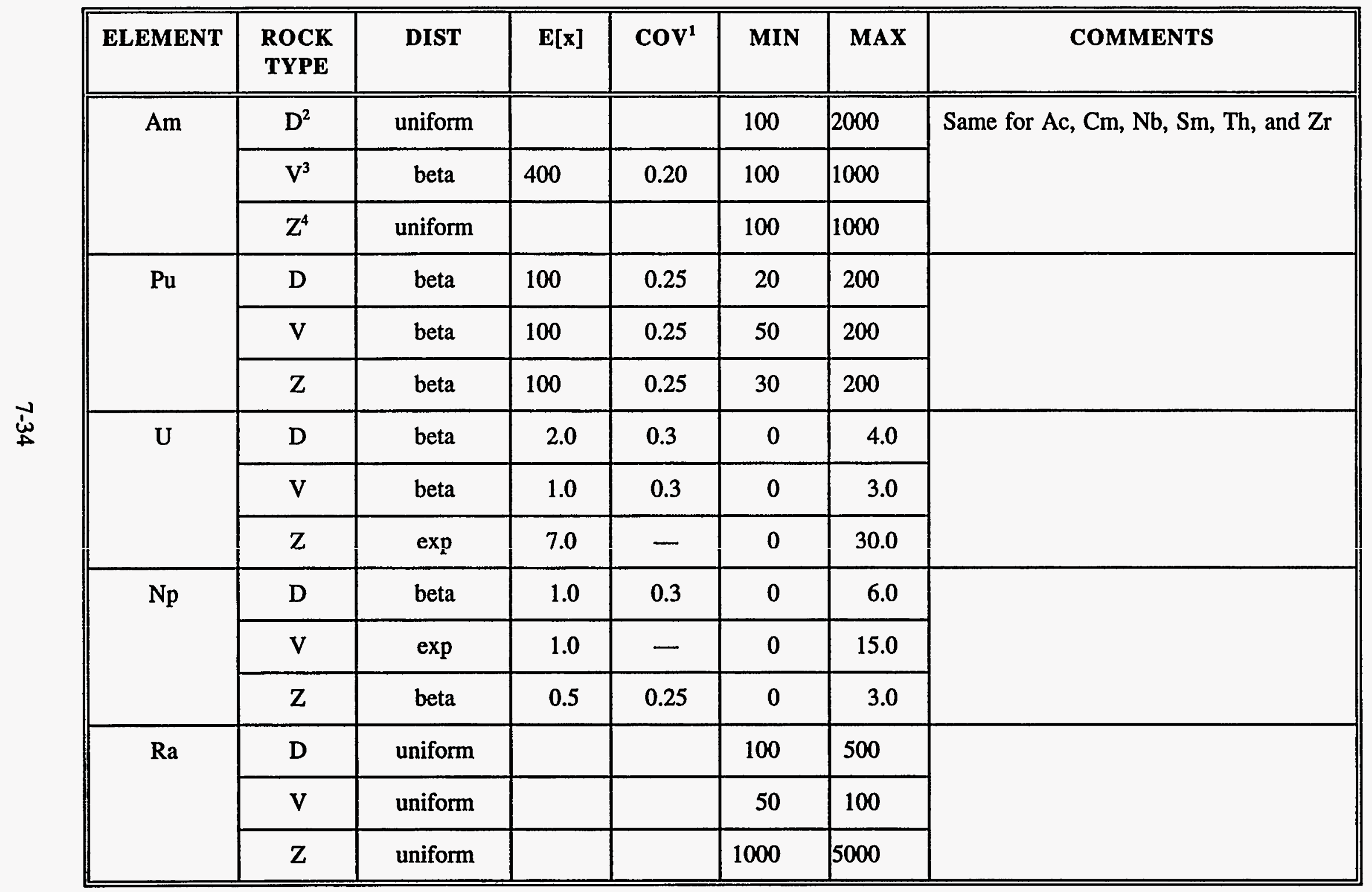


Table 7.4-2 TSPA-1995 Sorption-Coefficient Distributions $\left(\mathrm{K}_{\mathrm{d}}\right.$ in $\left.\mathrm{ml} / \mathrm{g}\right)$ for Unsaturated-Zone units (Meijer, 1995). (Continued)

\begin{tabular}{|c|c|c|c|c|c|c|c|}
\hline ELEMENT & $\begin{array}{l}\text { ROCK } \\
\text { TYPE }\end{array}$ & DIST & $\mathbf{E}[\mathbf{x}]$ & $\operatorname{cov}^{1}$ & MIN & MAX & COMMENTS \\
\hline \multirow[t]{3}{*}{ Cs } & D & uniform & & & 20 & 1000 & \\
\hline & $\mathrm{V}$ & uniform & & & 10 & 100 & \\
\hline & $\mathrm{Z}$ & uniform & & & 500 & 5000 & \\
\hline \multirow[t]{3}{*}{$\mathrm{Sr}$} & D & uniform & & & 10 & 50 & \\
\hline & $\mathrm{V}$ & uniform & & & 0 & 20 & \\
\hline & $\mathrm{Z}$ & uniform & & & 500 & 2000 & \\
\hline \multirow[t]{3}{*}{$\mathrm{Ni}$} & $\mathrm{D}$ & beta & 100 & 0.33 & 0 & 500 & \multirow[t]{3}{*}{ Same for Pd } \\
\hline & $\mathrm{V}$. & beta & 50 & 0.33 & 0 & 100 & \\
\hline & $\mathbf{Z}$ & beta & 100 & 0.33 & 0 & 500 & \\
\hline \multirow[t]{3}{*}{$\mathrm{Pb}$} & D & uniform & & & 100 & 500 & \\
\hline & $\mathrm{V}$ & uniform & & & 100 & 500 & \\
\hline & $\mathrm{z}$ & uniform & & & 100 & 500 & \\
\hline \multirow[t]{3}{*}{$\mathrm{Sn}$} & D & uniform & & & 20 & 200 & \\
\hline & $\mathrm{V}$ & uniform & & & 20 & 200 & \\
\hline & $\mathrm{Z}$ & uniform & & & 100 & 300 & \\
\hline
\end{tabular}


Table 7.4-2 TSPA-1995 Sorption-Coefficient Distributions $\left(\mathrm{K}_{\mathrm{d}} \mathrm{in} \mathrm{ml} / \mathrm{g}\right)$ for Unsaturated-Zone units (Meijer, 1995). (Continued)

\begin{tabular}{|c|c|c|c|c|c|c|c|}
\hline ELEMENT & $\begin{array}{l}\text { ROCK } \\
\text { TYPE }\end{array}$ & DIST & $\mathbf{E}[\mathbf{x}]$ & $\operatorname{cov}^{1}$ & MIN & MAX & COMMENTS \\
\hline \multirow[t]{3}{*}{$\mathrm{Pa}$} & D & uniform & & & 0 & 100 & \\
\hline & $\mathrm{V}$ & uniform & & & 0 & 100 & \\
\hline & Z & uniform & & & 0 & 100 & \\
\hline \multirow[t]{3}{*}{$\mathrm{Se}$} & D & $\exp$ & 3 & & 0 & 30 & \\
\hline & $\mathrm{V}$ & $\exp$ & 3 & & 0 & 20 & \\
\hline & $\mathrm{Z}$ & $\exp$ & 2 & & 0 & 15 & \\
\hline $\mathrm{Cl}, \mathrm{I}, \mathrm{Tc}, \mathrm{C}$ & & & & & 0 & 0 & \\
\hline
\end{tabular}

1 Coefficient of variation: $\mathrm{COV}=\sigma[\mathrm{x}] / \mathrm{E}[\mathrm{x}]$

$2 \quad \mathrm{D}=$ Devitrified tuff

$3 \quad \mathrm{~V}=$ Vitric tuff

$4 \quad \mathrm{Z}=$ Zeolitic tuff 
Table 7.4-3 TSPA-1995 Sorption Coefficient Distributions $\left(\mathrm{K}_{\mathrm{d}}\right.$ in $\left.\mathrm{ml} / \mathrm{g}\right)$ for Saturated-Zone units (Meijer, 1995)

\begin{tabular}{|c|c|c|c|c|c|c|c|}
\hline ELEMENT & $\begin{array}{l}\text { ROCK } \\
\text { TYPE }\end{array}$ & DIST & $\mathbf{E}[\mathbf{x}]$ & $\operatorname{cov}^{1}$ & MIN & MAX & COMMENTS \\
\hline \multirow[t]{3}{*}{$\mathrm{Am}$} & $\mathrm{D}^{2}$ & uniform & & & 100 & 2000 & \multirow[t]{3}{*}{ Same for $\mathrm{Ac}, \mathrm{Cm}, \mathrm{Nb}, \mathrm{Sm}, \mathrm{Th}$, and $\mathrm{Z}$} \\
\hline & $\mathrm{V}^{3}$ & beta & 400 & 0.20 & 100 & 1000 & \\
\hline & $\mathrm{Z}^{4}$ & uniform & & & 100 & 1000 & \\
\hline \multirow[t]{3}{*}{$\mathrm{Pu}$} & D & beta & 100 & 0.15 & 50 & 300 & \\
\hline & $\mathrm{v}$ & beta & 100 & 0.15 & 50 & 300 & \\
\hline & $\mathrm{z}$ & beta & 100 & 0.15 & $30^{\circ}$ & 300 & \\
\hline \multirow[t]{3}{*}{$\mathrm{U}$} & D & beta & 2.0 & 0.30 & 0 & 5.0 & \\
\hline & $\mathrm{v}$ & beta & 1.0 & 0.30 & 0 & 4.0 & \\
\hline & $\mathrm{z}$ & beta & 7.0 & 0.30 & 5 & 20.0 & \\
\hline \multirow[t]{3}{*}{$\mathrm{Np}$} & D & beta & 3.0 & 0.3 & 0 & 10.0 & \\
\hline & $\mathrm{v}$ & $\exp$ & 1.5 & - & 0 & 15.0 & \\
\hline & $\mathrm{z}$ & beta & 4.0 & 0.25 & 0 & 12.0 & \\
\hline \multirow[t]{3}{*}{$\mathrm{Ra}$} & D & uniform & & & 100 & 500 & \\
\hline & $\mathrm{v}$ & uniform & & & 100 & 500 & \\
\hline & $\mathrm{z}$ & uniform & & & 1000 & 5000 & \\
\hline
\end{tabular}


Table 7.4-3 TSPA-1995 Sorption Coefficient Distributions $\left(\mathrm{K}_{\mathrm{d}}\right.$ in $\left.\mathrm{ml} / \mathrm{g}\right)$ for Saturated-Zone units (Meijer, 1995) (Continued)

\begin{tabular}{|c|c|c|c|c|c|c|c|}
\hline ELEMENT & $\begin{array}{l}\text { ROCK } \\
\text { TYPE }\end{array}$ & DIST & $E[x]$ & $\operatorname{cov}^{1}$ & MIN & MAX & COMMENTS \\
\hline \multirow[t]{3}{*}{ Cs } & D & uniform & & & 20 & 1000 & \\
\hline & $\mathrm{V}$ & uniform & & & 10 & 100 & \\
\hline & Z & uniform & & & 500 & 5000 & \\
\hline \multirow[t]{3}{*}{$\mathrm{Sr}$} & D & uniform & & & 10 & 200 & \\
\hline & $\mathrm{V}$ & uniform & & & 20 & 50 & \\
\hline & Z & Log uniform & & & 2000 & 50000 & \\
\hline \multirow[t]{3}{*}{$\mathrm{Ni}$} & D & beta & 100 & 0.33 & 0 & 500 & \multirow[t]{3}{*}{ Same for Pd } \\
\hline & V & beta & 100 & 0.33 & 0 & 200 & \\
\hline & Z & beta & 100 & 0.33 & 0 & 500 & \\
\hline \multirow[t]{3}{*}{$\mathrm{Pb}$} & D & uniform & & & 100 & 500 & \\
\hline & V & uniform & & & 100 & 500 & \\
\hline & $\mathrm{Z}$ & uniform & & & 100 & 500 & \\
\hline \multirow[t]{3}{*}{ Sn } & $\mathrm{D}$ & uniform & & & 20 & 200 & \\
\hline & v & uniform & & & 20 & 200 & \\
\hline & z & uniform & & & 100 & 300 & \\
\hline
\end{tabular}


Table 7.4-3 TSPA-1995 Sorption Coefficient Distributions $\left(\mathrm{K}_{\mathrm{d}}\right.$ in $\left.\mathrm{ml} / \mathrm{g}\right)$ for Saturated-Zone units (Meijer, 1995) (Continued)

\begin{tabular}{|c|c|c|c|c|c|c|c|}
\hline ELEMENT & $\begin{array}{l}\text { ROCK } \\
\text { TYPE }\end{array}$ & DIST & $\mathbf{E}[\mathbf{x}]$ & $\operatorname{cov}^{1}$ & MIN & MAX & COMMENTS \\
\hline \multirow[t]{3}{*}{$\mathrm{Pa}$} & D & uniform & & & 0 & 100 & \\
\hline & V & uniform & & & 0 & 100 & \\
\hline & $\mathbf{Z}$ & uniform & & & 0 & 100 & \\
\hline \multirow[t]{3}{*}{$\mathrm{Se}$} & D & $\exp$ & 3 & & 0 & 30 & \\
\hline & V & $\exp$ & 3 & & 0 & 20 & \\
\hline & $\mathrm{Z}$ & $\exp$ & 2 & & 0 & 15 & \\
\hline $\mathrm{C} 1, \mathrm{I}, \mathrm{Tc}, \mathrm{C}$ & & & & & 0 & 0 & \\
\hline
\end{tabular}

1 Coefficient of variation: $\mathrm{COV}=\sigma[\mathrm{x}] / \mathrm{E}[\mathrm{x}]$ $\mathrm{D}=$ Devitrified tuff

$\mathrm{V}=$ Vitric tuff

$\mathrm{Z}=$ Zeolitic tuff 
Table 7.6-1. Dose Conversion Factors and Specific Activities

\begin{tabular}{|c|c|c|c|}
\hline Isotope & $\begin{array}{c}\text { TSPA } 1995 \\
\text { Dose Conversion } \\
\text { Factor } \\
(\mathbf{r e m} / \mathbf{y r}) /\left(\mathrm{g} / \mathrm{m}^{3}\right)\end{array}$ & $\begin{array}{c}\text { TSPA } 1993 \\
\text { Dose Conversion } \\
\text { Factor } \\
(\mathrm{rem} / \mathrm{yr}) /\left(\mathrm{g} / \mathrm{m}^{3}\right)\end{array}$ & $\begin{array}{l}\text { Specific Activity } \\
\text { (Ci/g) }\end{array}$ \\
\hline${ }^{227} \mathrm{Ac}$ & $7.34 \mathrm{E} 8$ & $2.28 \mathrm{E} 9$ & $7.23 \mathrm{E}-1$ \\
\hline${ }^{241} \mathrm{Am}$ & $9.00 \mathrm{E} 6$ & $2.81 \mathrm{E} 7$ & 3.44E0 \\
\hline${ }^{242 \mathrm{~m}} \mathrm{Am}$ & $2.46 \mathrm{E} 7$ & 7.67E7 & 9.73E0 \\
\hline${ }^{243} \mathrm{Am}$ & $5.21 \mathrm{E} 5$ & $1.63 \mathrm{E} 6$ & $2.00 \mathrm{E}-1$ \\
\hline${ }^{14} \mathrm{C}$ & $6.57 \mathrm{E} 3$ & $1.72 \mathrm{E} 6$ & $4.46 \mathrm{E} 0$ \\
\hline${ }^{36} \mathrm{Cl}$ & $7.19 \mathrm{E} 1$ & - & $3.30 \mathrm{E}-2$ \\
\hline${ }^{244} \mathrm{Cm}$ & $1.17 \mathrm{E} 8$ & $3.65 \mathrm{E} 8$ & $8.09 \mathrm{E} 1$ \\
\hline${ }^{245} \mathrm{Cm}$ & 4.63E5 & $1.44 \mathrm{E} 6$ & $1.72 \mathrm{E}-1$ \\
\hline${ }^{246} \mathrm{Cm}$ & 8.21E5 & 2.57E6 & $3.08 \mathrm{E}-1$ \\
\hline${ }^{135} \mathrm{Cs}$ & 5.85E6 & 1.23E3 & $1.15 \mathrm{E}-3$ \\
\hline${ }^{129} \mathrm{I}$ & $3.52 \mathrm{E} 1$ & $2.05 \mathrm{E} 2$ & $1.77 \mathrm{E}-4$ \\
\hline${ }^{93 \mathrm{~m}} \mathrm{Nb}$ & $1.07 \mathrm{E} 5$ & - & $2.83 \mathrm{E} 2$ \\
\hline${ }^{94} \mathrm{Nb}$ & $9.65 \mathrm{E} 2$ & $2.42 \mathrm{E} 5$ & $1.88 \mathrm{E}-1$ \\
\hline${ }^{59} \mathrm{Ni}$ & $1.14 \mathrm{E} 1$ & - & $7.58 \mathrm{E}-2$ \\
\hline${ }^{63} \mathrm{Ni}$ & $2.57 \mathrm{E} 4$ & - & $6.18 \mathrm{E} 1$ \\
\hline${ }^{237} \mathrm{~Np}$ & $2.25 \mathrm{E} 3$ & $1.31 \mathrm{E} 5$ & $7.06 \mathrm{E}-4$ \\
\hline${ }^{231} \mathrm{~Pa}$ & $3.59 \mathrm{E} 5$ & $1.12 \mathrm{E} 6$ & 4.72E-2 \\
\hline${ }^{210} \mathrm{~Pb}$ & $2.95 \mathrm{E} 8$ & 2.17E9 & $7.64 \mathrm{E} 1$ \\
\hline${ }^{107} \mathrm{Pd}$ & $5.54 \mathrm{E}-2$ & - & $5.15 \mathrm{E}-4$ \\
\hline${ }^{238} \mathrm{Pu}$ & $3.03 \mathrm{E} 6$ & $3.10 \mathrm{E} 6$ & $1.71 \mathrm{E} 1$ \\
\hline${ }^{239} \mathrm{Pu}$ & $1.58 \mathrm{E} 5$ & $1.24 \mathrm{E} 4$ & $6.22 \mathrm{E}-2$ \\
\hline${ }^{240} \mathrm{Pu}$ & $5.80 \mathrm{E} 5$ & $4.56 \mathrm{E} 4$ & $2.28 \mathrm{E}-1$ \\
\hline${ }^{241} \mathrm{Pu}$ & $5.08 \mathrm{E} 6$ & $3.96 \mathrm{E} 5$ & $1.03 \mathrm{E} 2$ \\
\hline${ }^{242} \mathrm{Pu}$ & $9.22 \mathrm{E} 3$ & $7.25 \mathrm{E} 2$ & $3.82 \mathrm{E}-3$ \\
\hline
\end{tabular}


Table 7.6-1. Dose Conversion Factors (Continued)

\begin{tabular}{|c|c|c|c||}
\hline Isotope & $\begin{array}{c}\text { TSPA 1995 } \\
\text { Dose Conversion } \\
\text { Factor } \\
(\mathbf{r e m} / \mathrm{yr}) /\left(\mathrm{g} / \mathrm{m}^{3}\right)\end{array}$ & $\begin{array}{c}\text { TSPA 1993 } \\
\text { Dose Conversion } \\
\text { Factor } \\
(\mathbf{r e m} / \mathbf{y r}) /\left(\mathrm{g} / \mathbf{m}^{3}\right)\end{array}$ & $\begin{array}{c}\text { Specific Activity } \\
\text { (Ci/g) }\end{array}$ \\
\hline \hline${ }^{226} \mathrm{Ra}$ & $9.43 \mathrm{E} 5$ & $8.79 \mathrm{E} 6$ & $9.90 \mathrm{E}-1$ \\
\hline${ }^{228} \mathrm{Ra}$ & $2.82 \mathrm{E} 8$ & - & $2.73 \mathrm{E} 2$ \\
\hline${ }^{79} \mathrm{Se}$ & $4.37 \mathrm{E} 2$ & $1.10 \mathrm{E} 5$ & $6.98 \mathrm{E}-2$ \\
\hline${ }^{151} \mathrm{Sm}$ & $7.34 \mathrm{E} 3$ & - & $2.63 \mathrm{E} 1$ \\
\hline${ }^{126} \mathrm{Sn}$ & $3.99 \mathrm{E} 2$ & $6.08 \mathrm{E} 4$ & $2.84 \mathrm{E}-2$ \\
\hline${ }^{99} \mathrm{Tc}$ & $1.79 \mathrm{E} 1$ & $7.72 \mathrm{E} 2$ & $1.70 \mathrm{E}-2$ \\
\hline${ }^{229} \mathrm{Th}$ & $5.41 \mathrm{E} 5$ & $4.38 \mathrm{E} 5$ & $2.13 \mathrm{E}-1$ \\
\hline${ }^{230} \mathrm{Th}$ & $7.99 \mathrm{E} 3$ & $6.00 \mathrm{E} 3$ & $2.02 \mathrm{E}-2$ \\
\hline${ }^{232} \mathrm{Th}$ & $2.16 \mathrm{E}-1$ & $1.62 \mathrm{E}-1$ & $1.10 \mathrm{E}-7$ \\
\hline${ }^{233} \mathrm{U}$ & $2.02 \mathrm{E} 3$ & $1.36 \mathrm{E} 3$ & $9.69 \mathrm{E}-3$ \\
\hline${ }^{234} \mathrm{U}$ & $1.27 \mathrm{E} 3$ & $4.56 \mathrm{E} 2$ & $6.26 \mathrm{E}-3$ \\
\hline${ }^{235} \mathrm{U}$ & $4.14 \mathrm{E}-1$ & $1.48 \mathrm{E}-1$ & $2.16 \mathrm{E}-6$ \\
\hline${ }^{236} \mathrm{U}$ & $1.25 \mathrm{E} 1$ & $4.48 \mathrm{E} 0$ & $6.48 \mathrm{E}-5$ \\
\hline${ }^{238} \mathrm{U}$ & $6.18 \mathrm{E}-2$ & $3.63 \mathrm{E}-2$ & $3.37 \mathrm{E}-7$ \\
\hline${ }^{93} \mathrm{Zr}$ & $3.00 \mathrm{E} 0$ & - & $2.51 \mathrm{E}-3$ \\
\hline \hline
\end{tabular}

Source: EPA, 1988 (Ingestion only).

Assumed: Receptor drinks 21 /day of water.

- = No dose conversion factor for TSPA 1993 


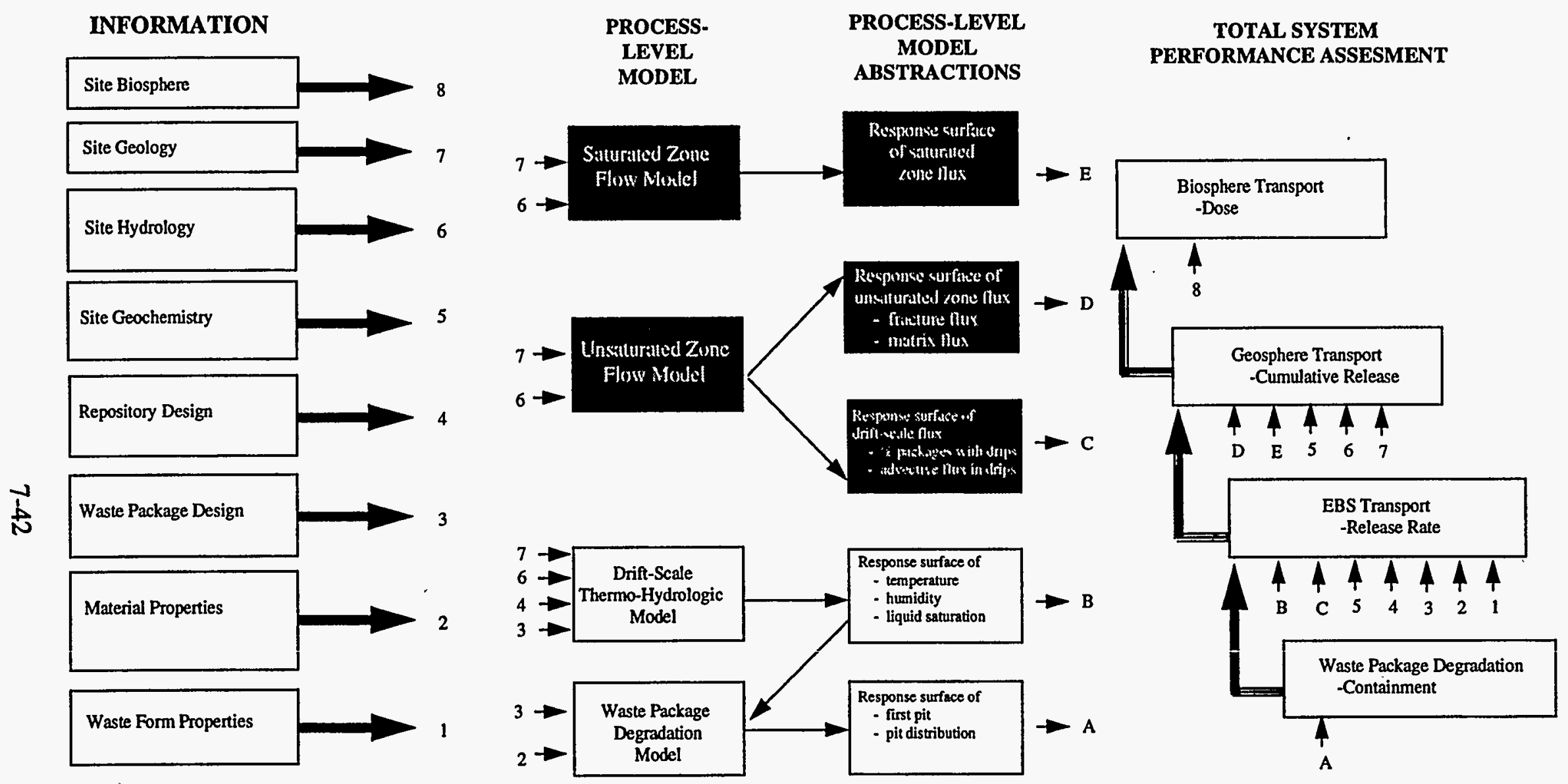

Figure 7.1-1 Information flow schematic for unsaturated zone flow model. 


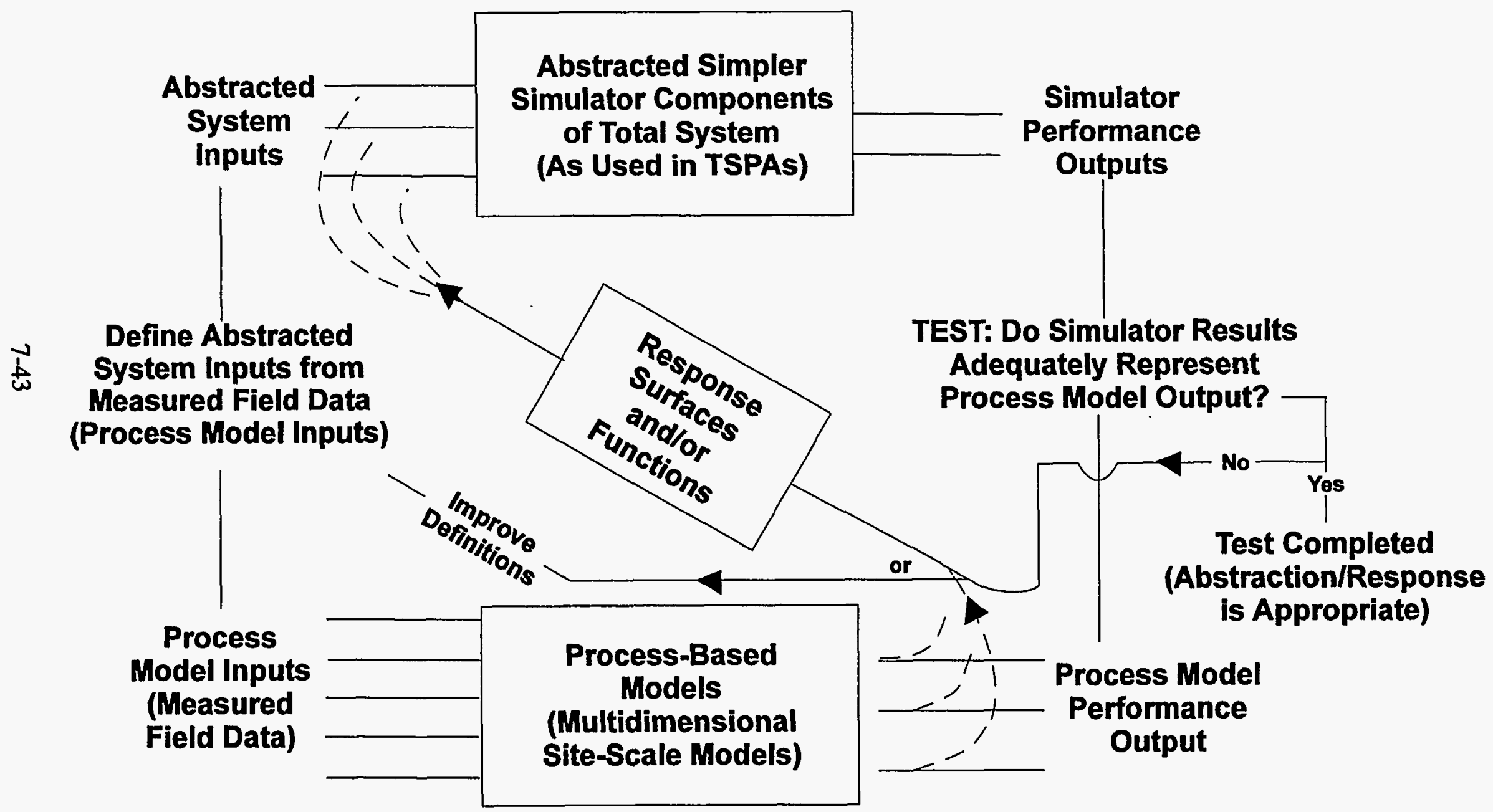

Figure 7.2-1 Illustration of Proposed Testing of Process Model Abstractions/Responses Used in Total System Simulators (after Nelson, 1995). 


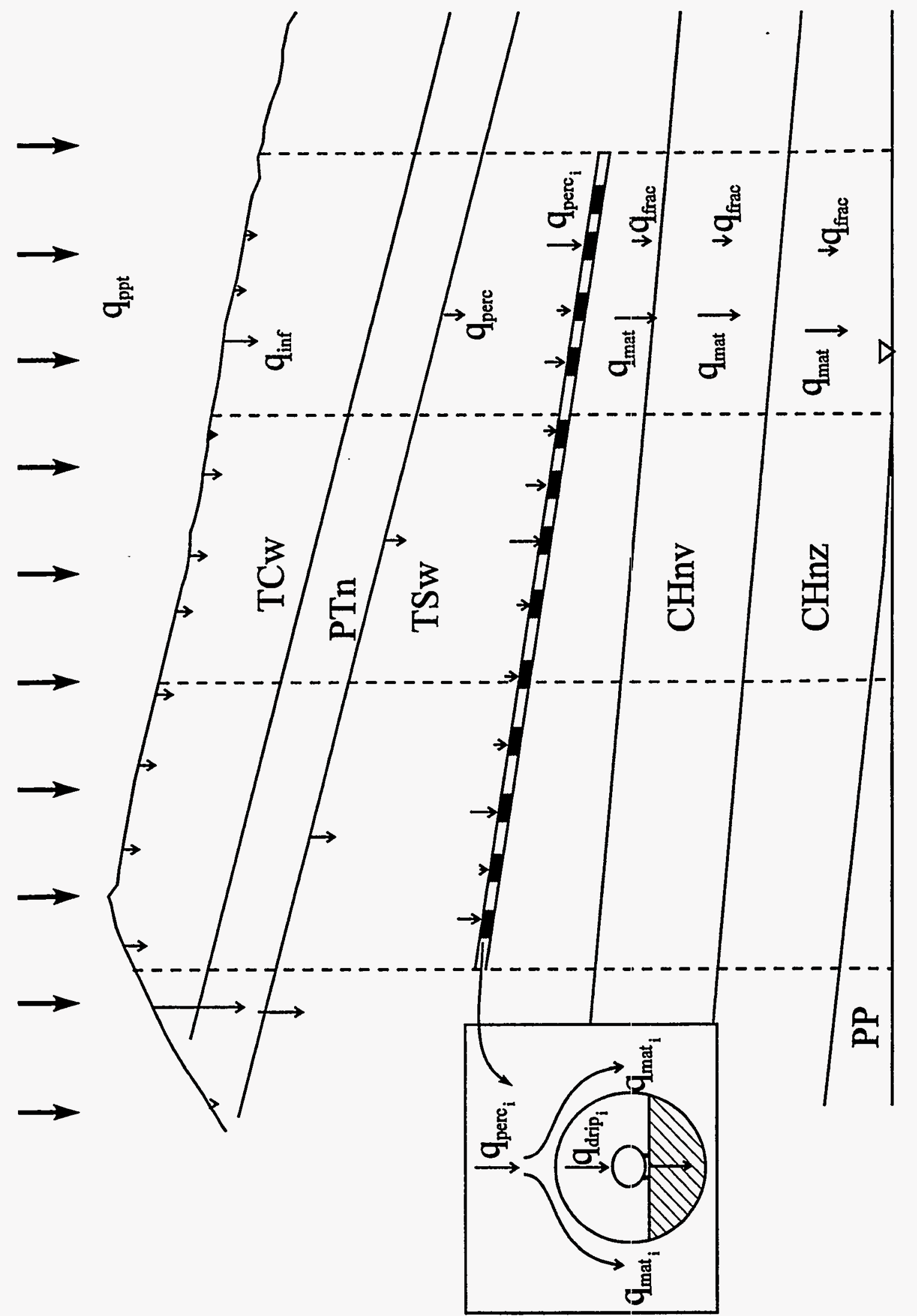

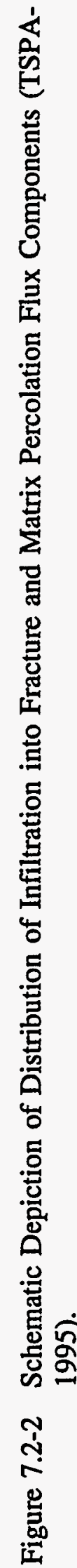




\section{How Much? \\ (Fractional-Fracture-Flow Process-Level Abstraction)}

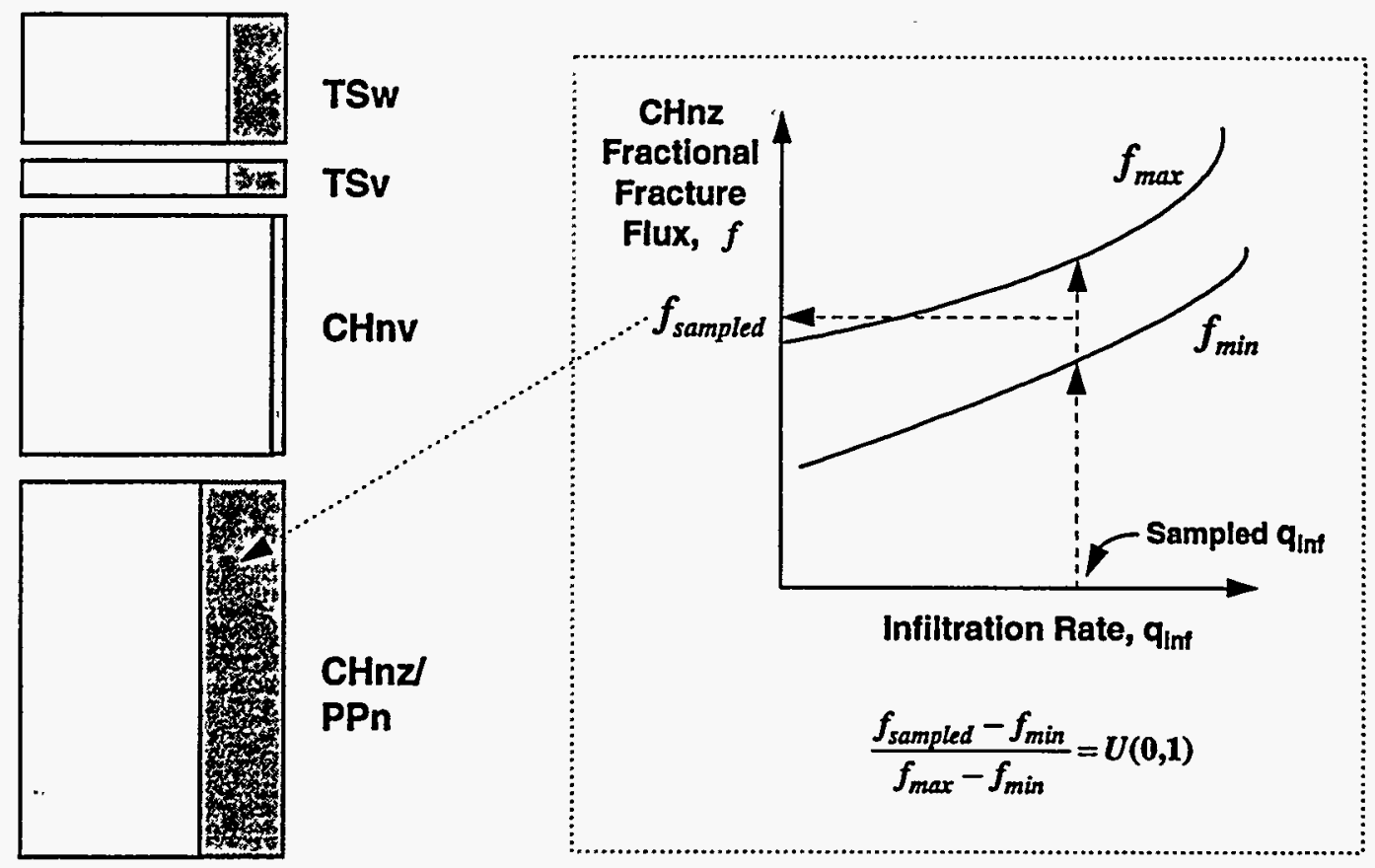

How Fast?

(Matrix-Velocity-Field Process-Level Abstraction)

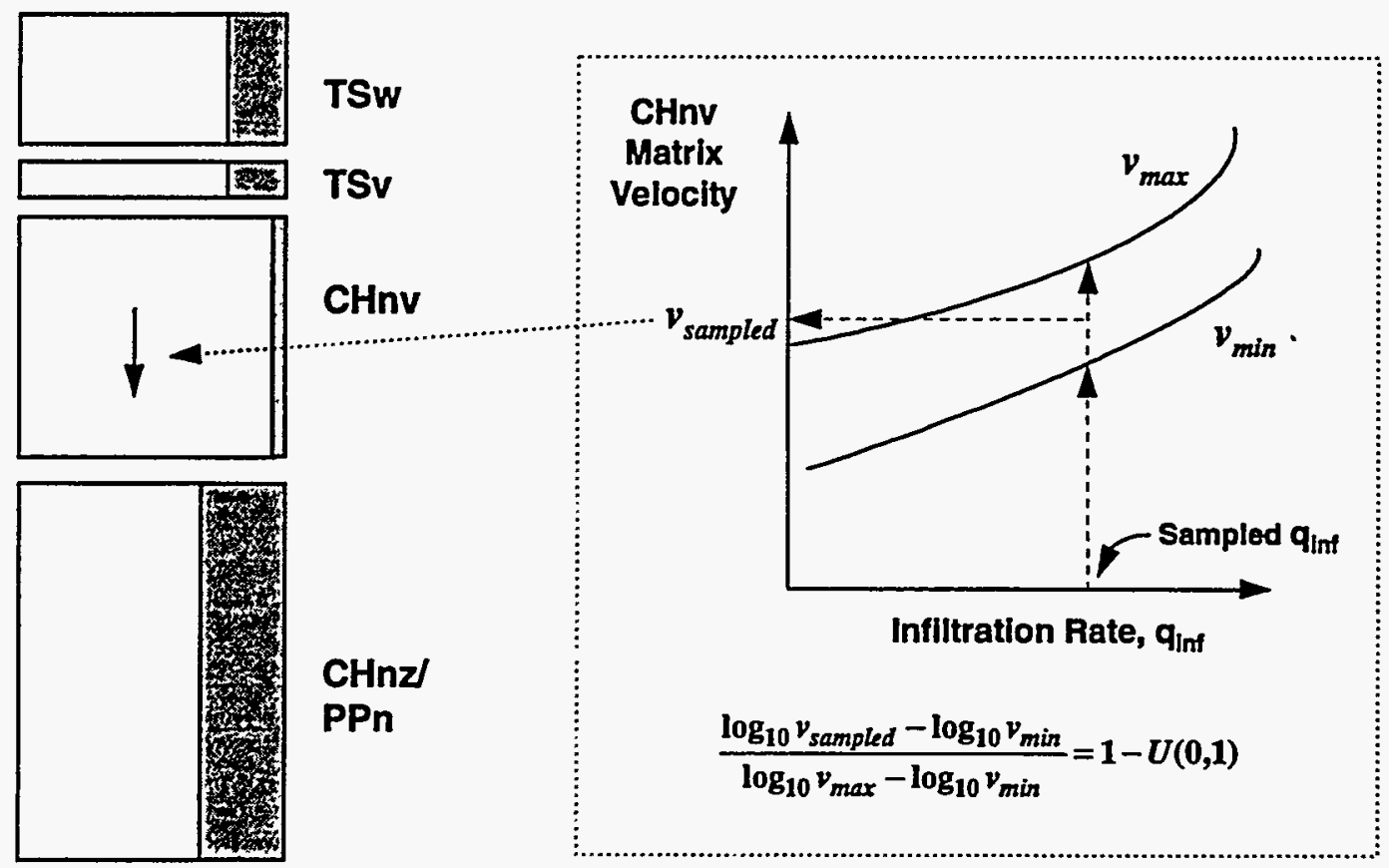

Figure 7.2-3 Schematic of proposed abstraction methodology for determining velocity and fraction of fracture flow as a function of infiltration flux, $\mathrm{q}_{\mathrm{inf}}$. 


\section{LBL/USGS Site Scale Model, 2D Cross Section}

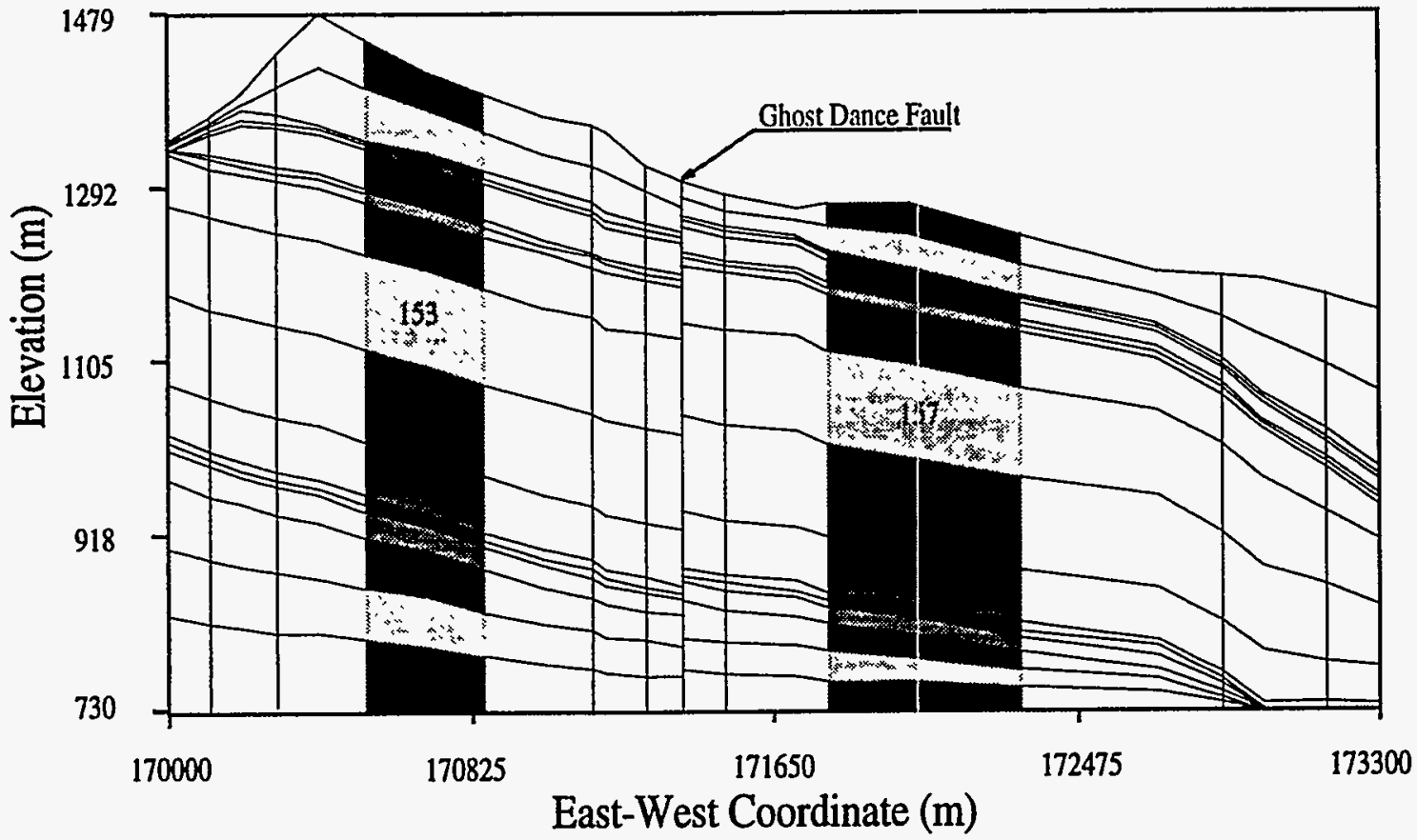

Figure 7.2-4 LBL/USGS Site Scale Model, 2-dimensional cross section.

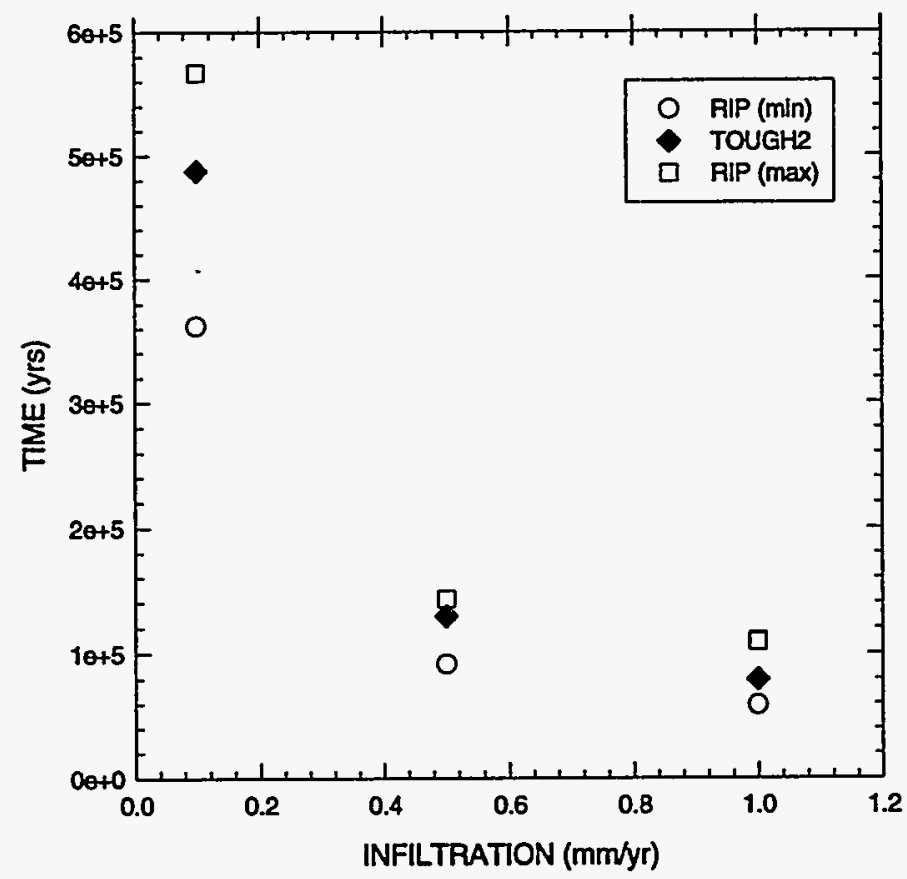

Figure 7.2-5 Comparison of single-point arrival times for TOUGH2 and RIP. 


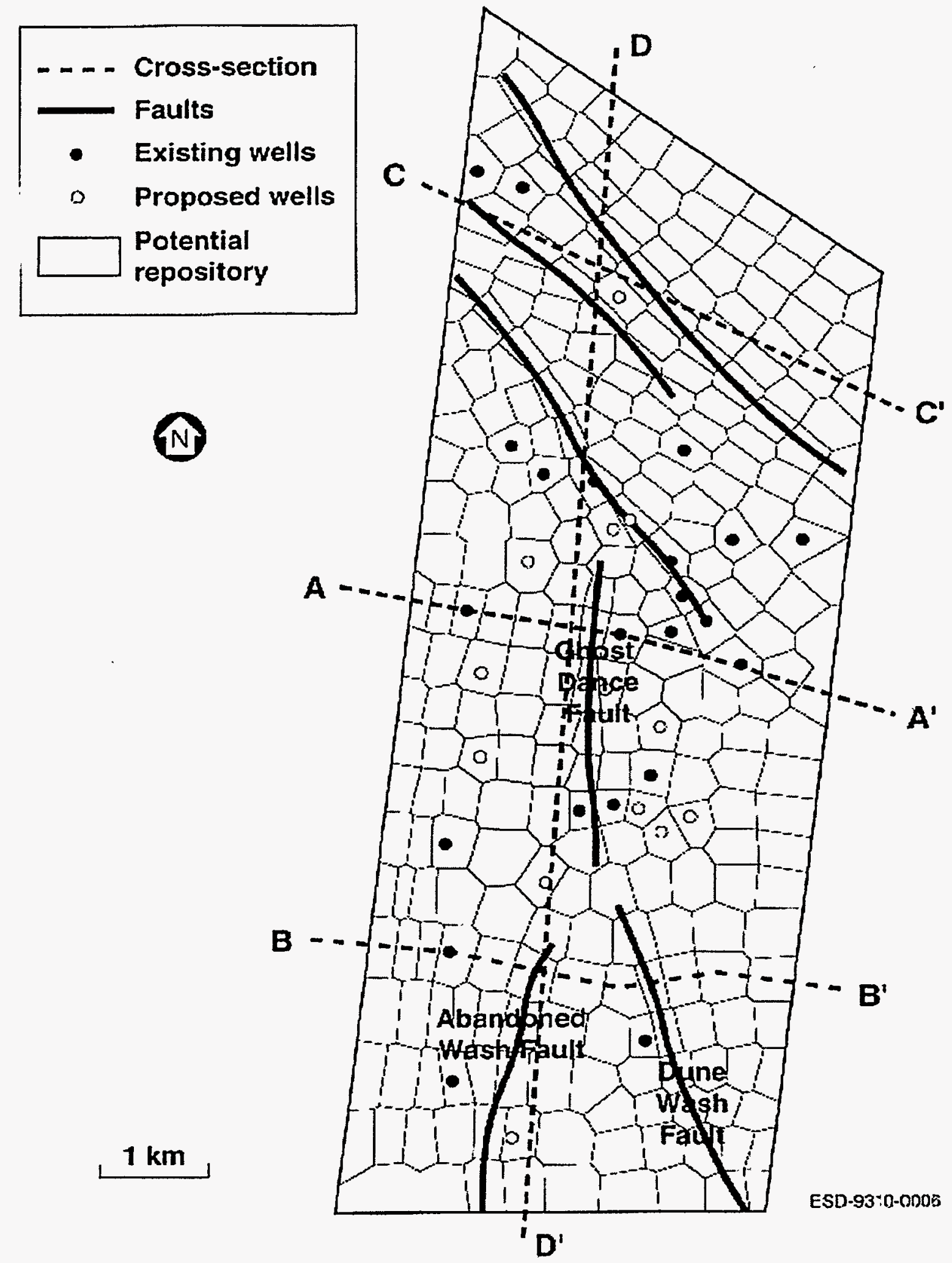

Figure 7.2-6 Plan view of the LBL/USGS Site-Scale Model of the Unsaturated Zone at Yucca Mountain (from Wittwer et al., 1995). 

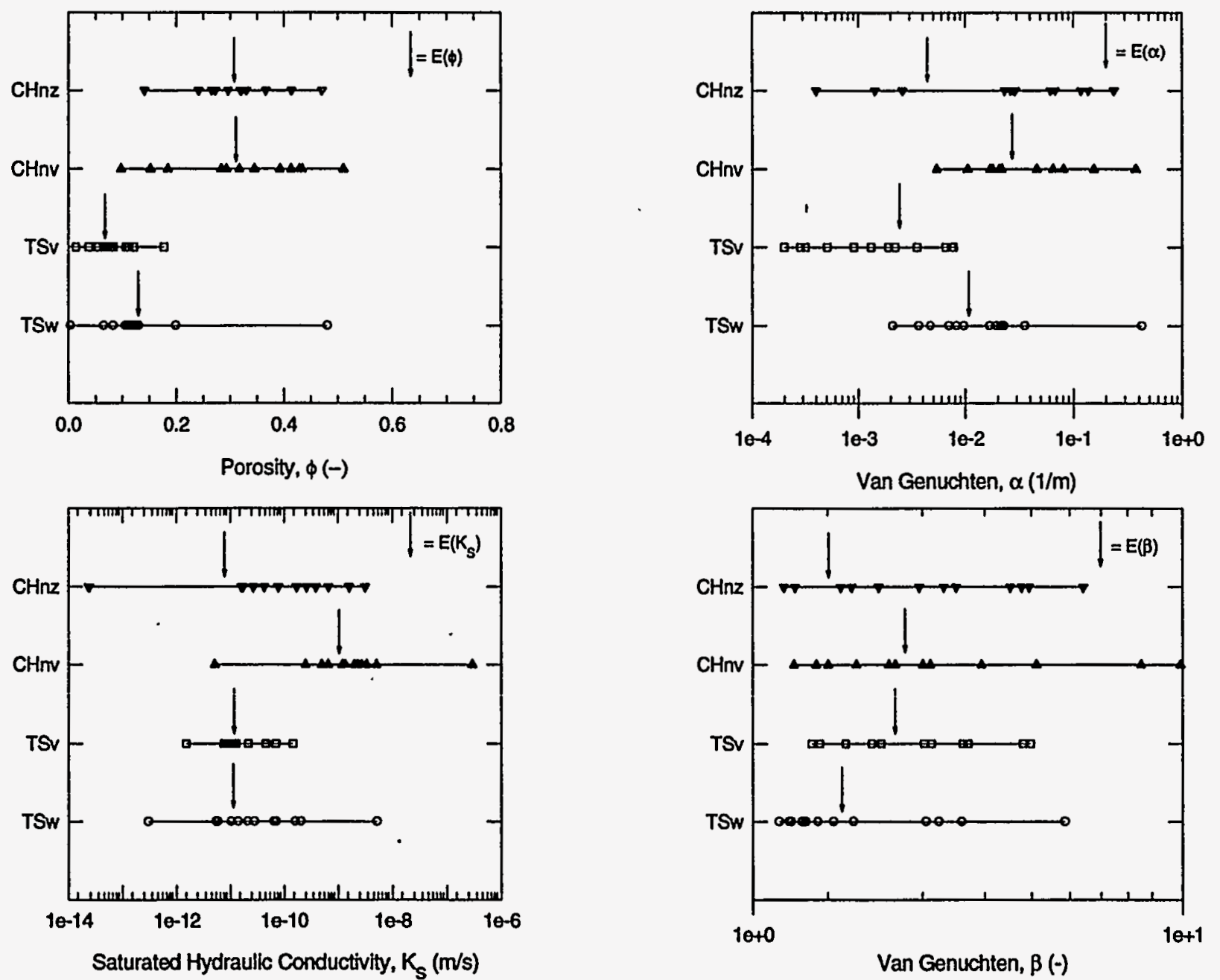

Figure 7.2-7 Range of matrix hydrologic property values sampled randomly from parameter distributions presented in Schenker et al., (1995). 


\section{TSw}
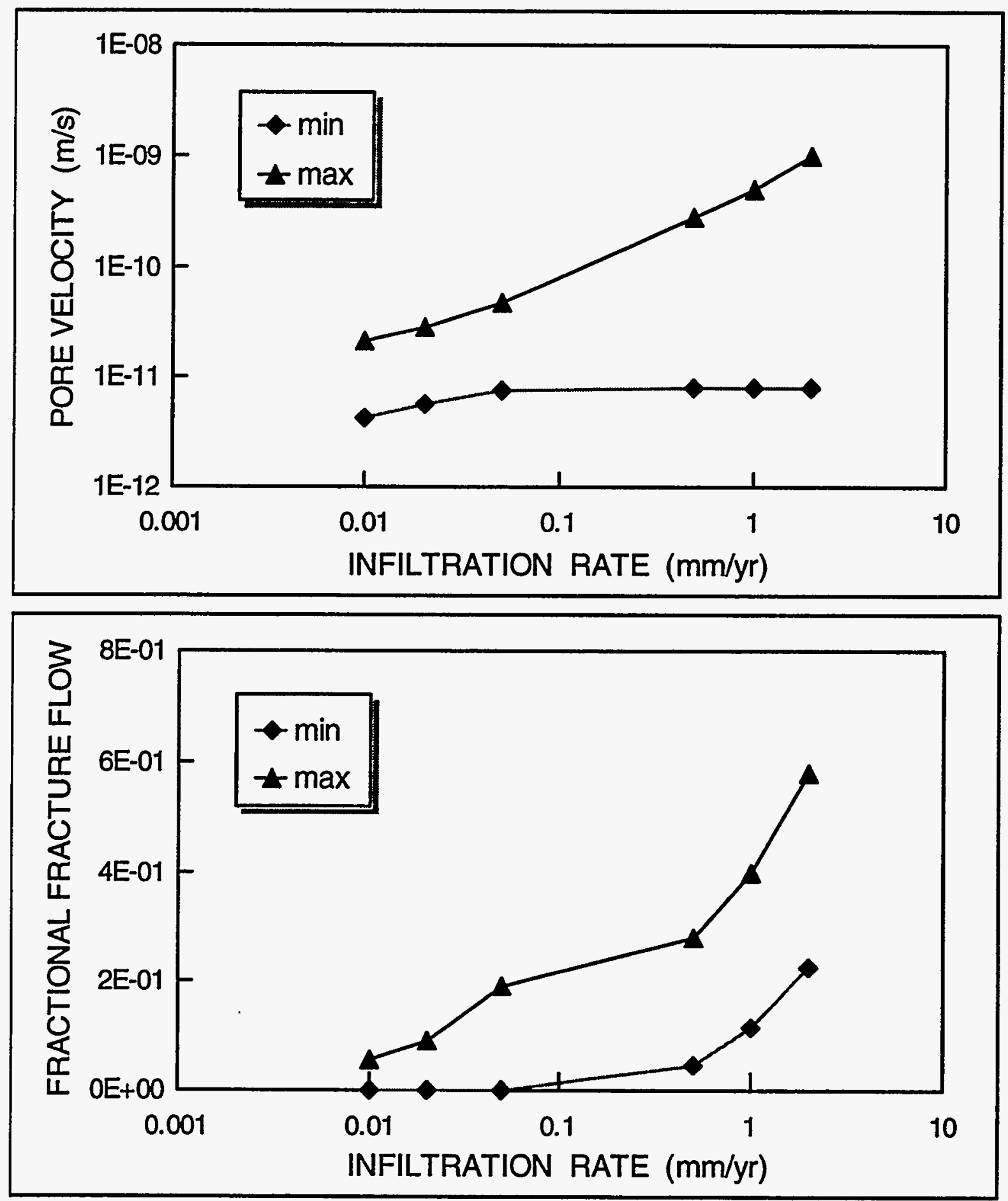

Figure 7.2-8 Ranges of pore velocity and fractional fracture flow for TSw. 


\section{TSv}
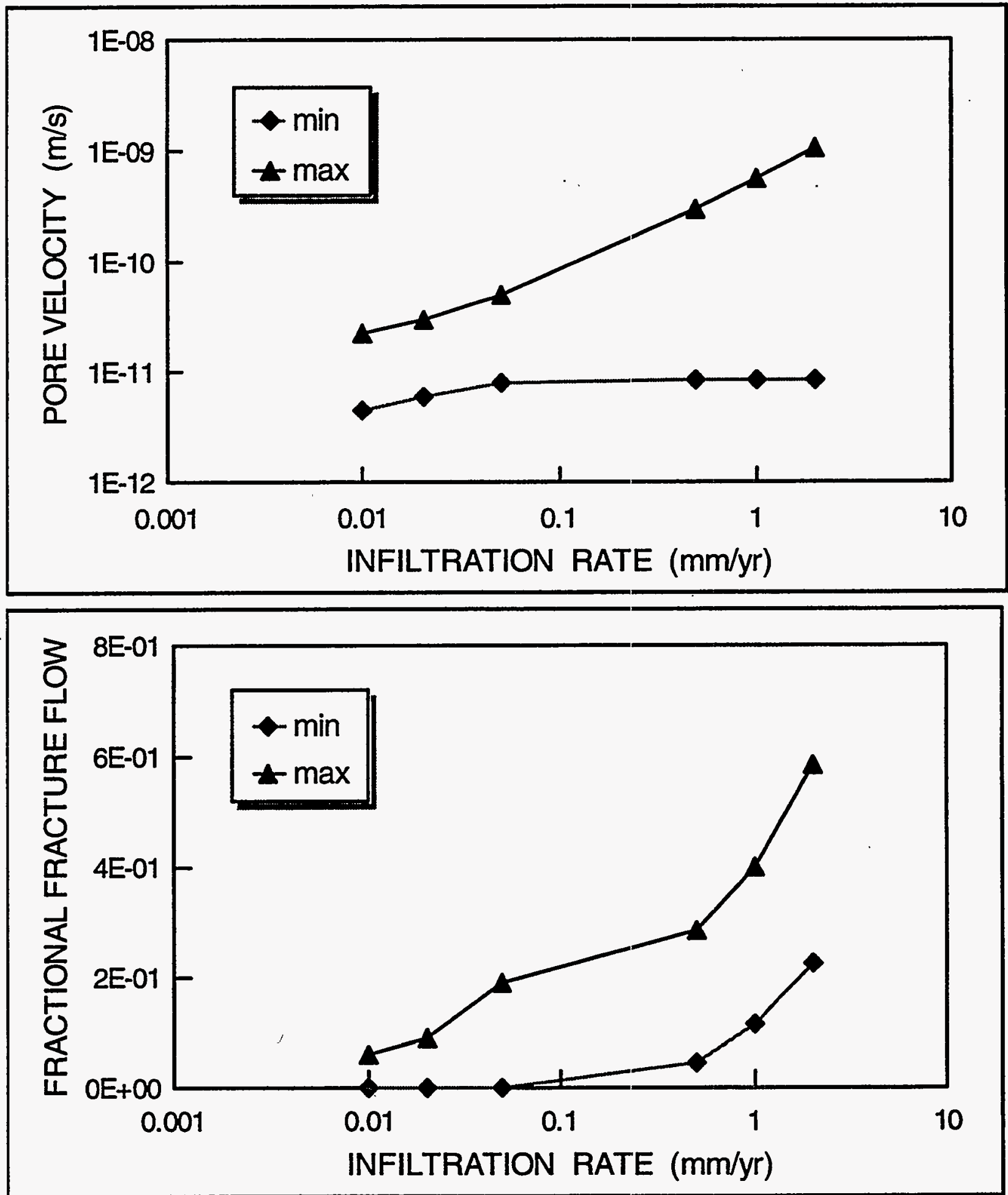

Figure 7.2-9 Ranges of pore velocity and fractional fracture flow for TSv. 


\section{CHnv}
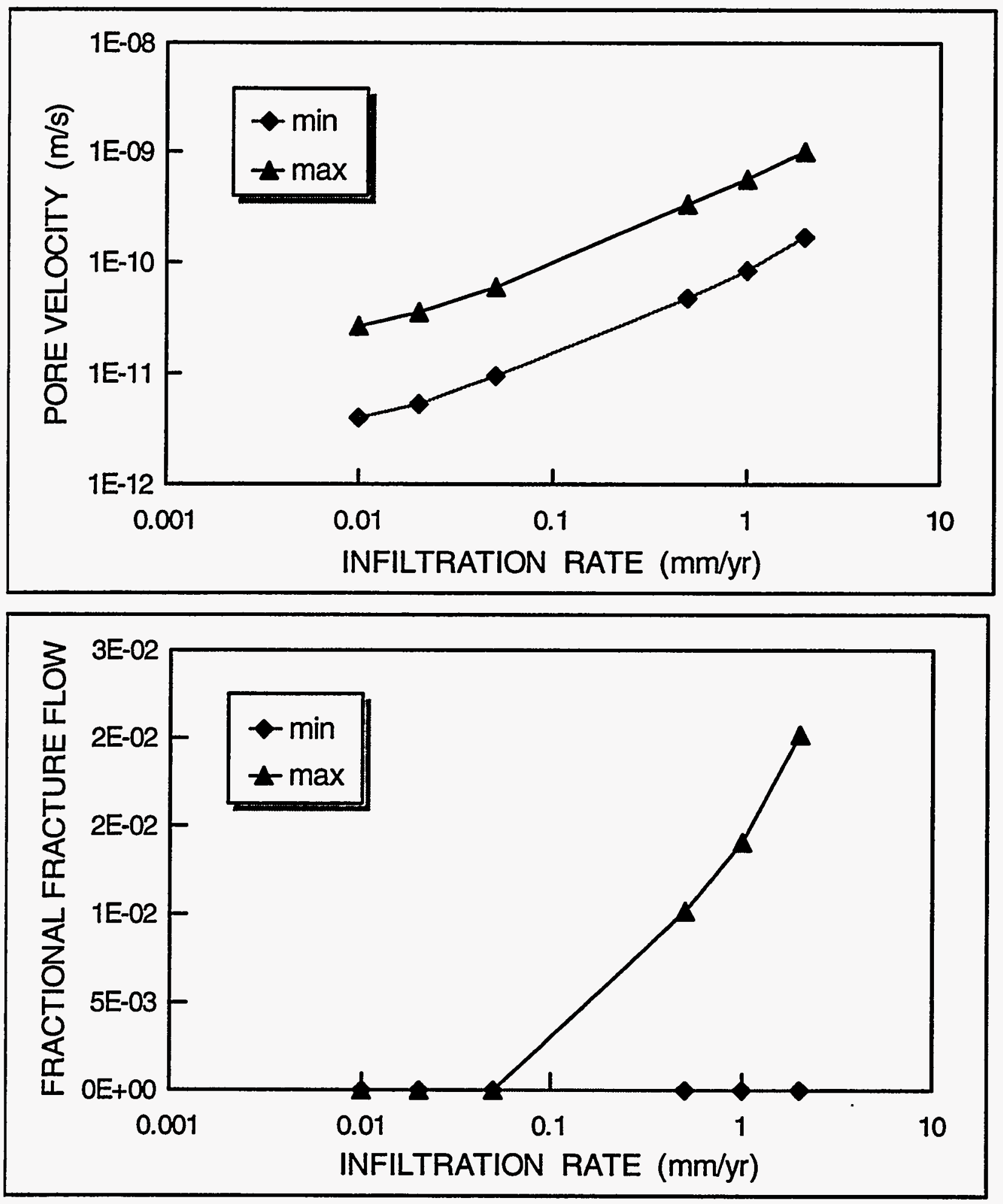

Figure 7.2-10 Ranges of pore velocity and fractional fracture flow for CHnv. 

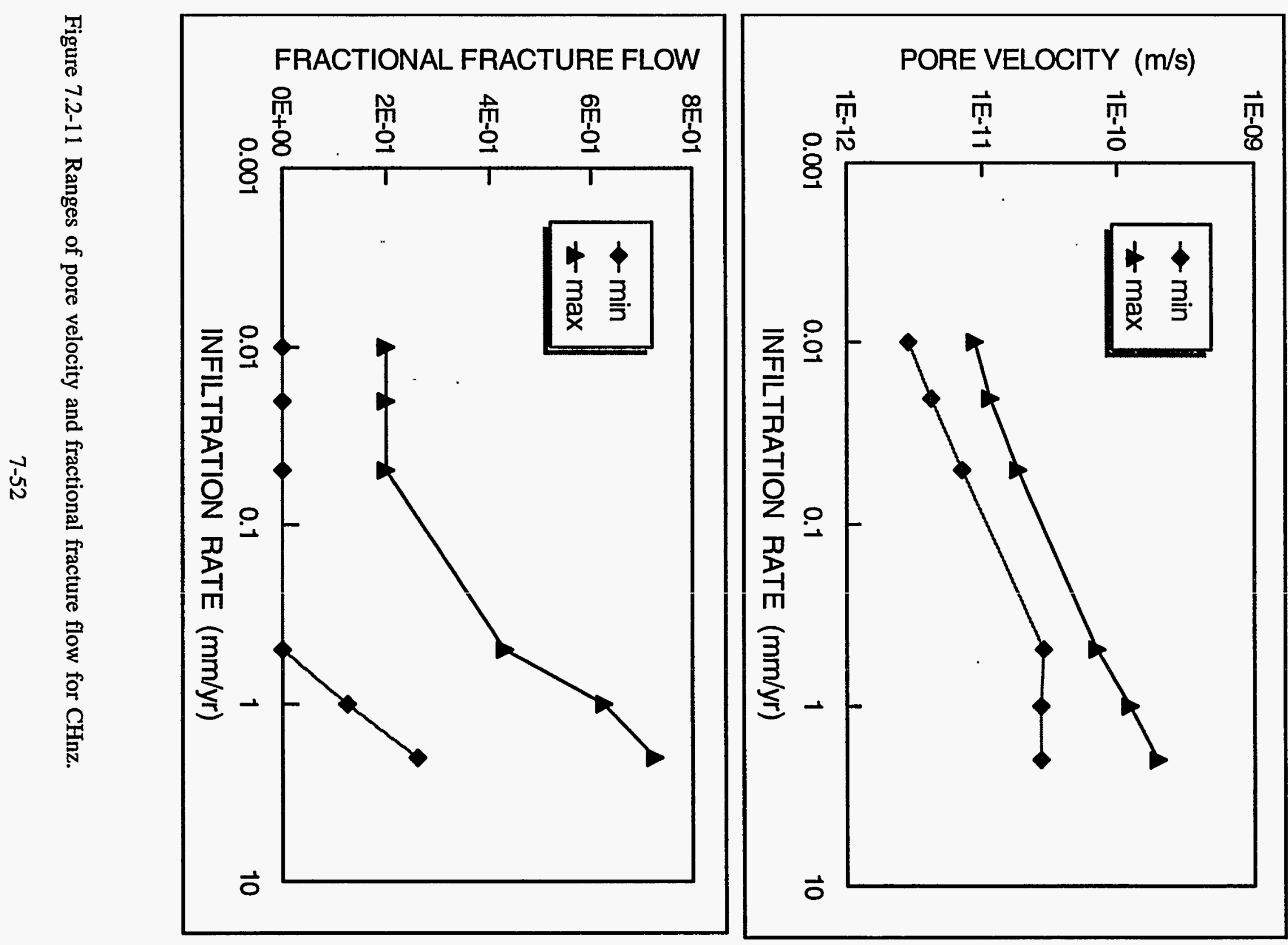

$\frac{\Omega}{\frac{1}{2}}$ 
A)

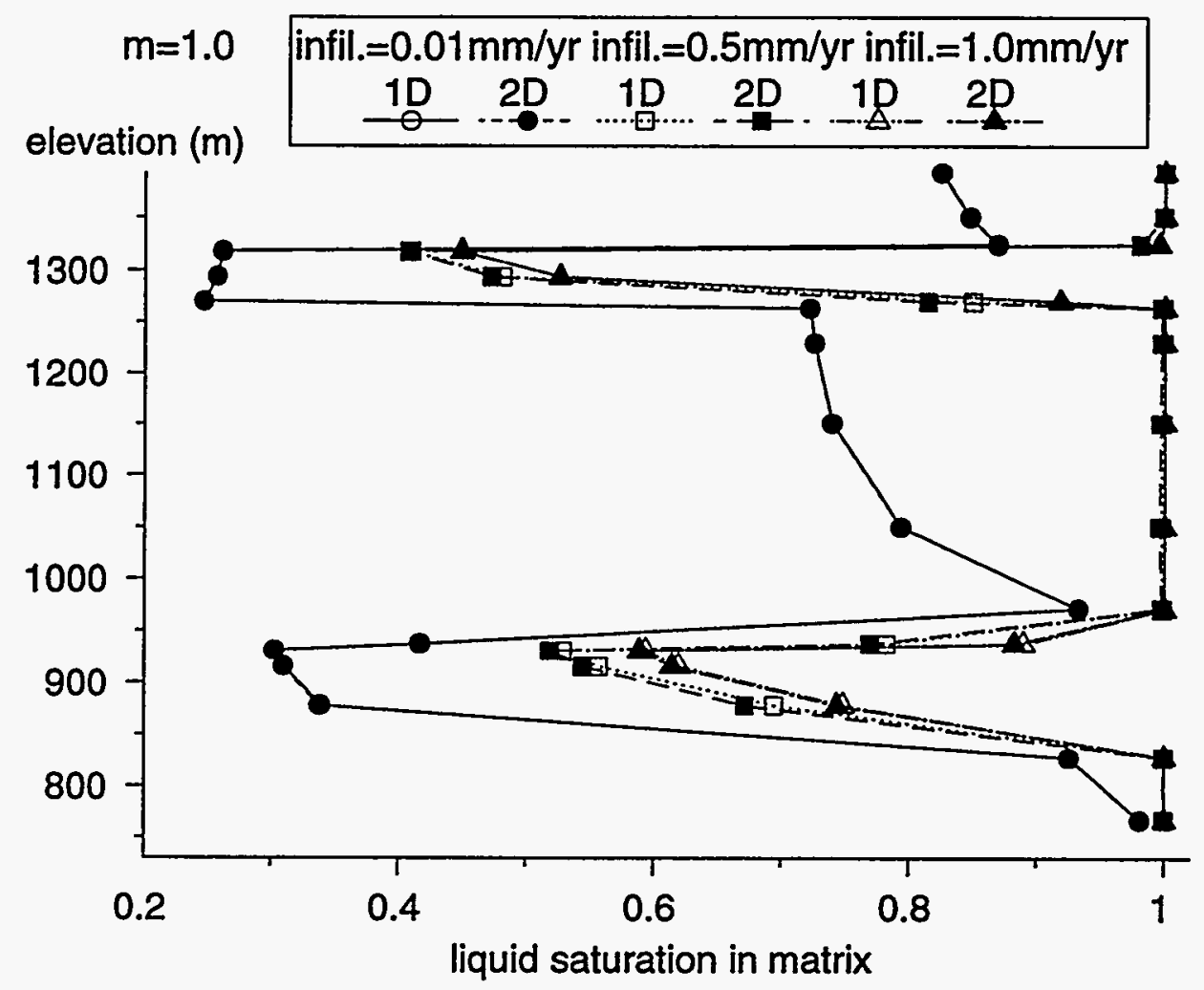

B)

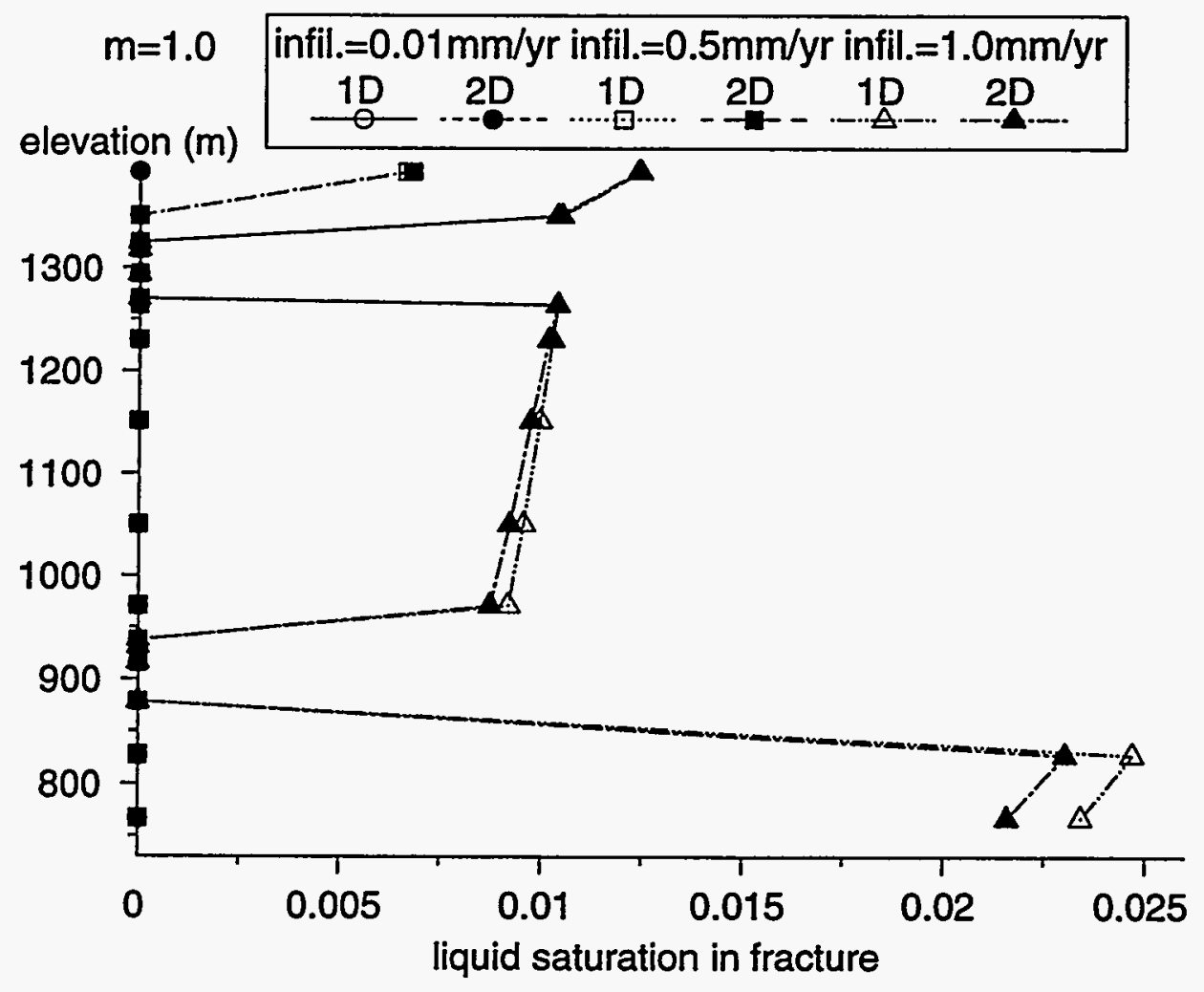

Figure 7.2-12 Liquid saturation distributions along Column 153 of the LBL/USGS site-scale model, for (A) matrix, and (B) fracture. 
A)

$$
\begin{aligned}
& m=1.0 \quad \text { infil. }=0.01 \mathrm{~mm} / \mathrm{yr} \text { infil. }=0.5 \mathrm{~mm} / \mathrm{yr} \text { infil. }=1.0 \mathrm{~mm} / \mathrm{yr} \\
& \begin{array}{lllll}
2 D & 1 D & 2 D & 1 D & 2 D
\end{array}
\end{aligned}
$$

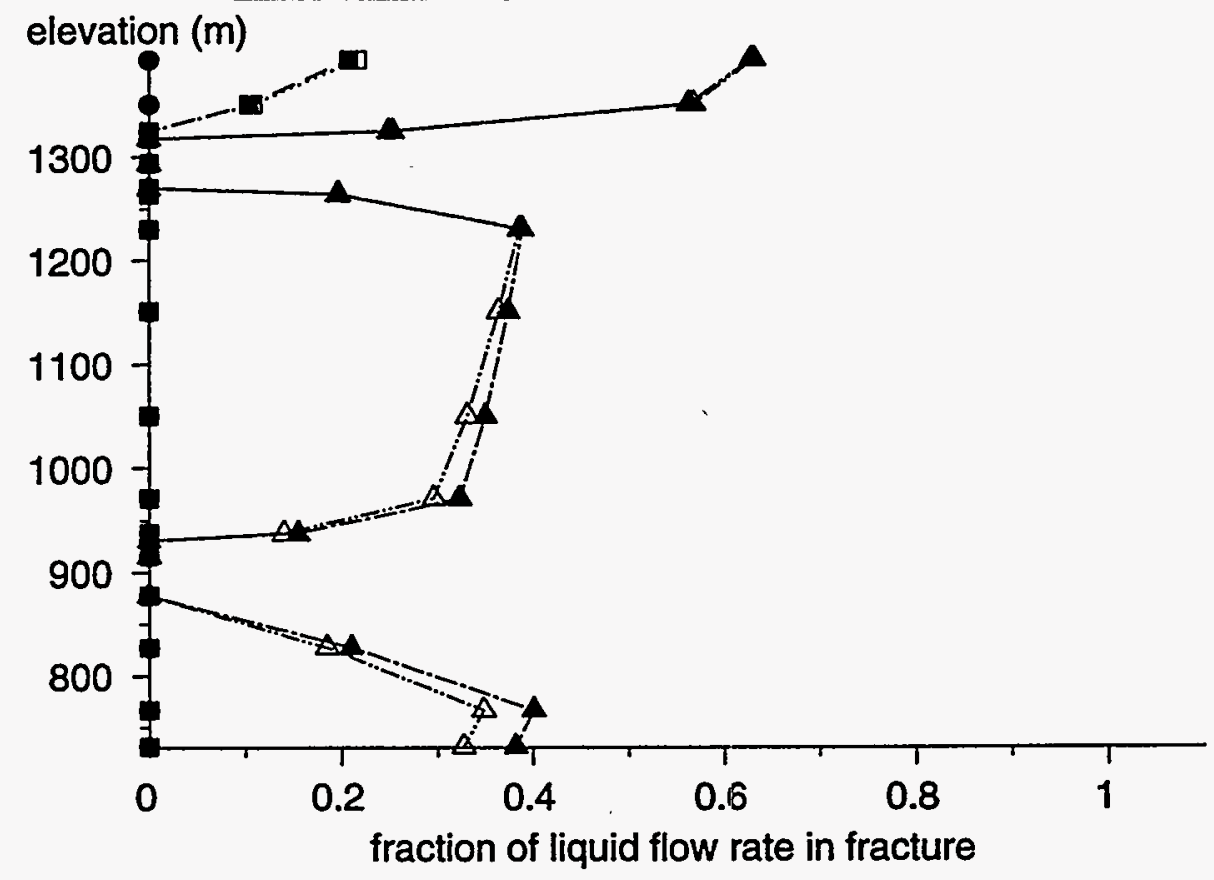

B)

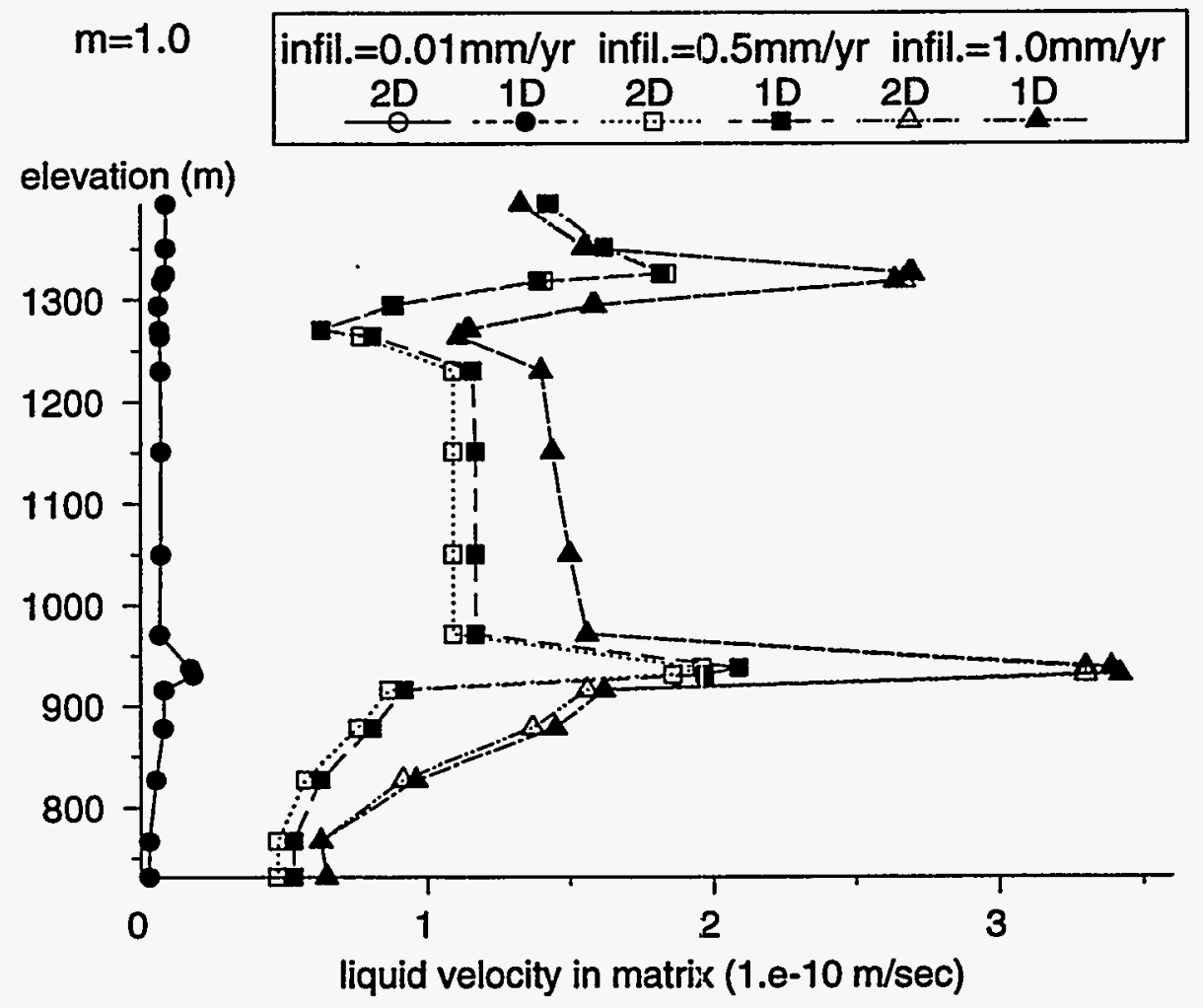

Figure 7.2-13 Liquid flow distribution along Column 153 of the LBL/USGS site-scale model, showing (A) fracture of liquid flow rate in fracture, and (B) pore velocity in matrix. 

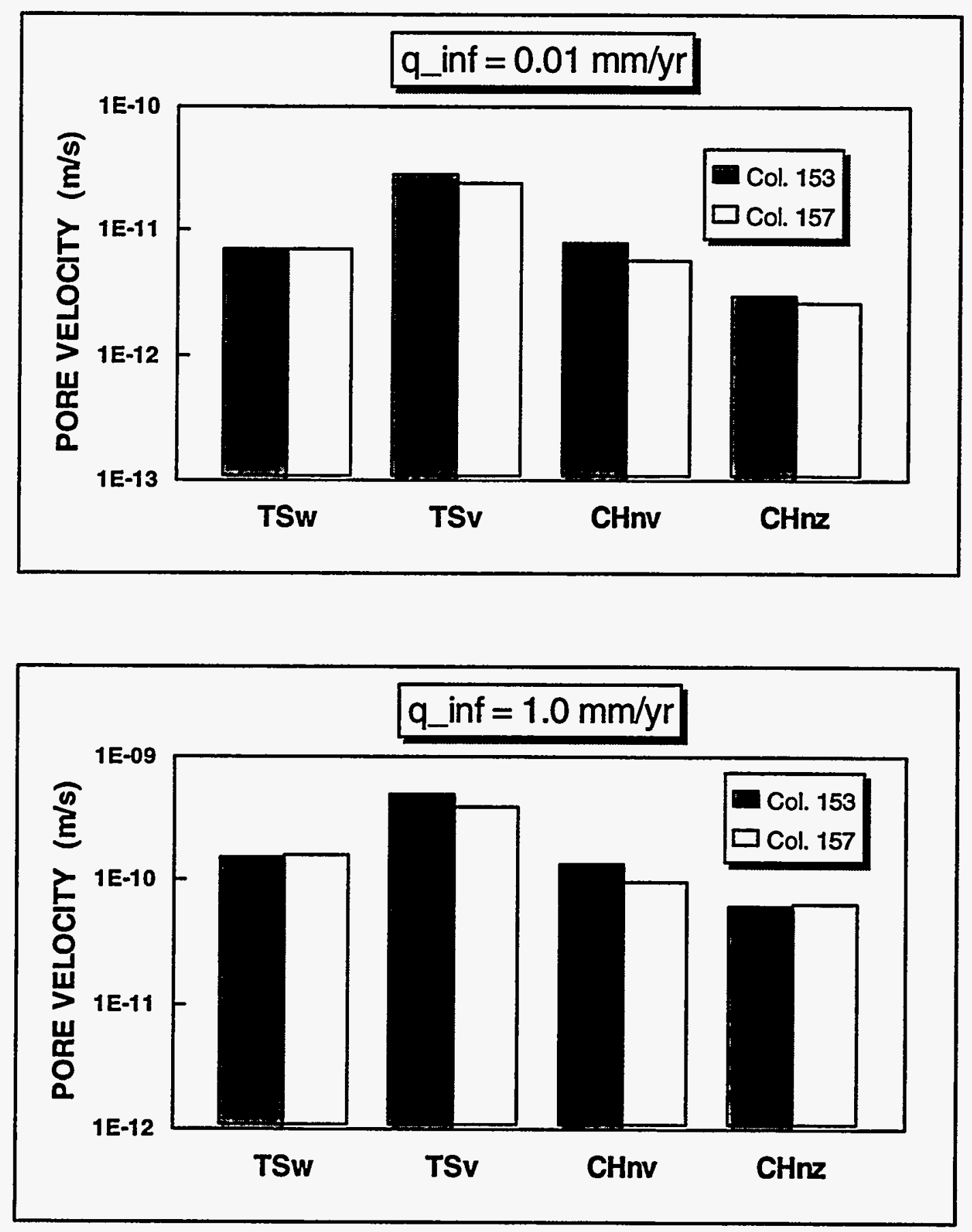

Figure 7.2-14 Comparison of matrix pore velocities for columns 153 and 157 with infiltration of: (i) $0.01 \mathrm{~mm} / \mathrm{yr}$ and (ii) $1.0 \mathrm{~mm} / \mathrm{yr}$. 


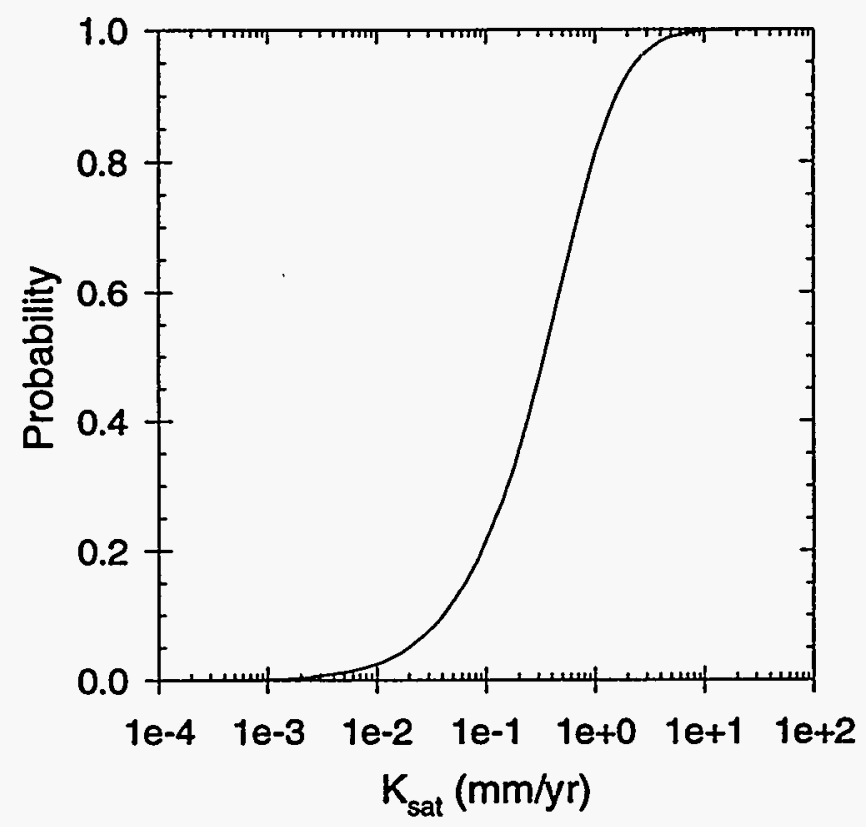

Figure 7.3-1 CDF for $\mathrm{K}_{\text {sat }}$ (in the $\mathrm{TSw}$ ) when $\mathrm{q}_{\mathrm{inf}}$ is $2 \mathrm{~mm} / \mathrm{yr}$.

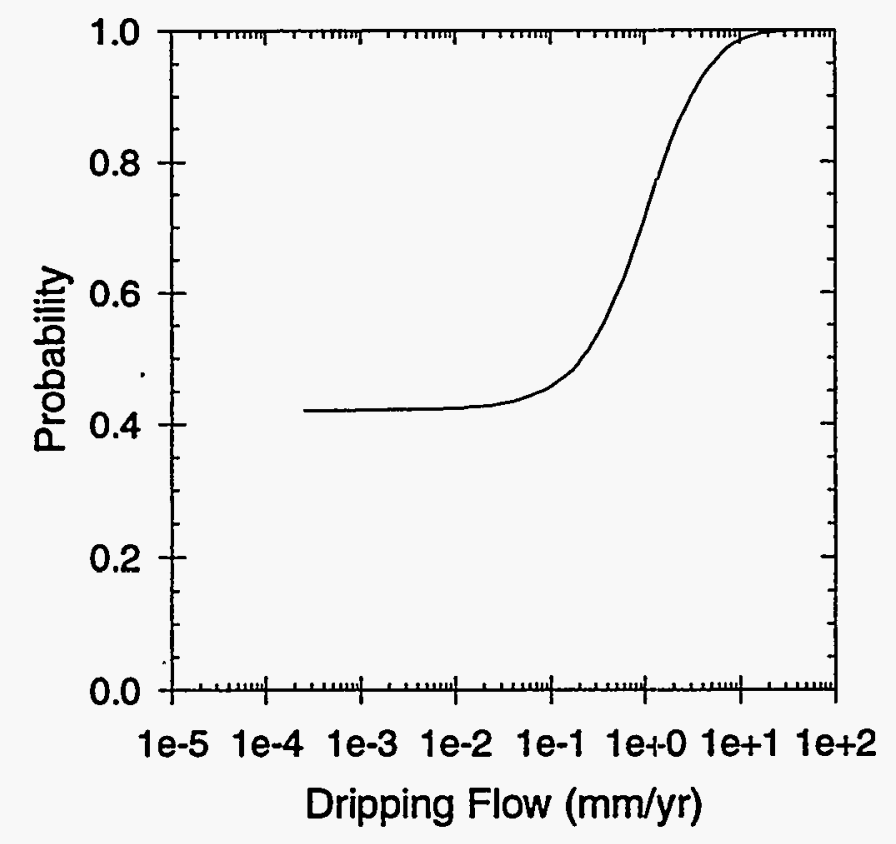

Figure 7.3-2 CDF for dripping flux, $\mathrm{q}_{\text {drip }}$, on waste packages when $\mathrm{q}_{\text {inf }}$ is $2 \mathrm{~mm} / \mathrm{yr}$. 


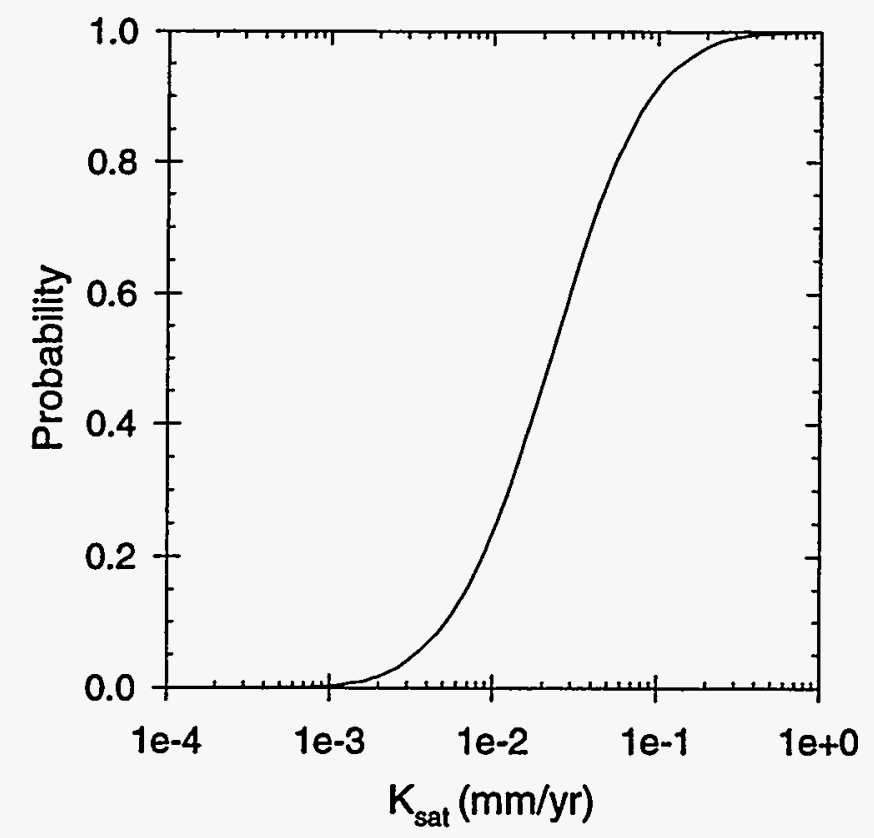

Figure 7.3-3 CDF for $\mathrm{K}_{\text {sat }}$ (in the $\mathrm{TSw}$ ) when $\mathrm{q}_{\text {inf }}$ is $0.05 \mathrm{~mm} / \mathrm{yr}$.

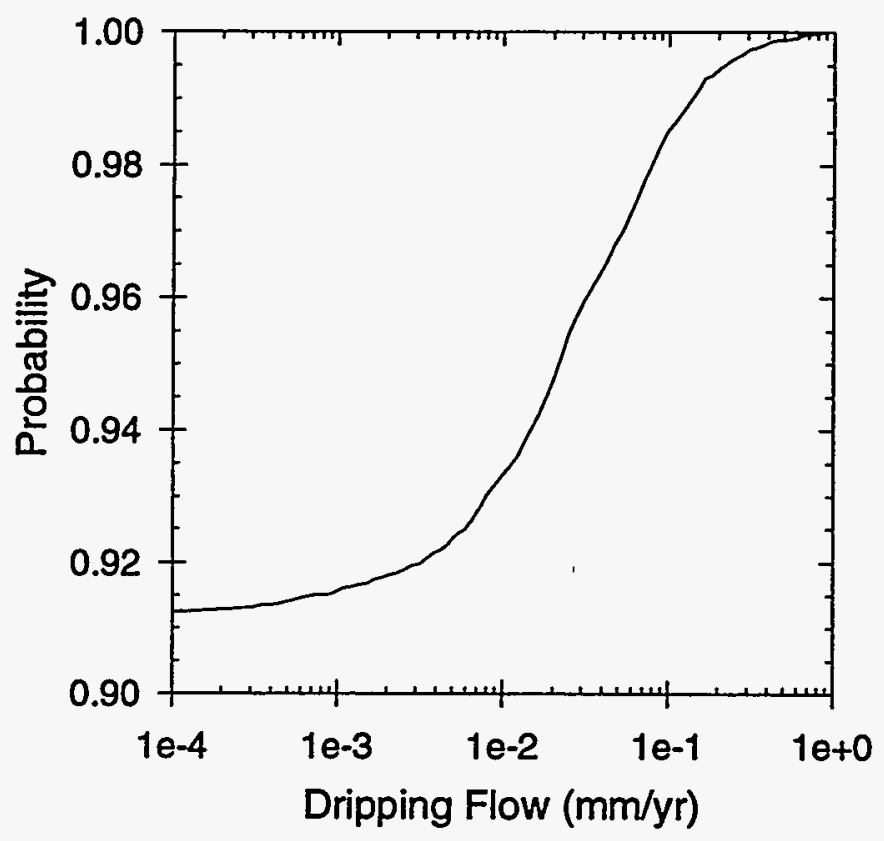

Figure 7.3-4 CDF for dripping flux, $q_{\text {drip }}$, on waste packages when $\mathrm{q}_{\text {inf }}$ is $0.05 \mathrm{~mm} / \mathrm{yr}$. 


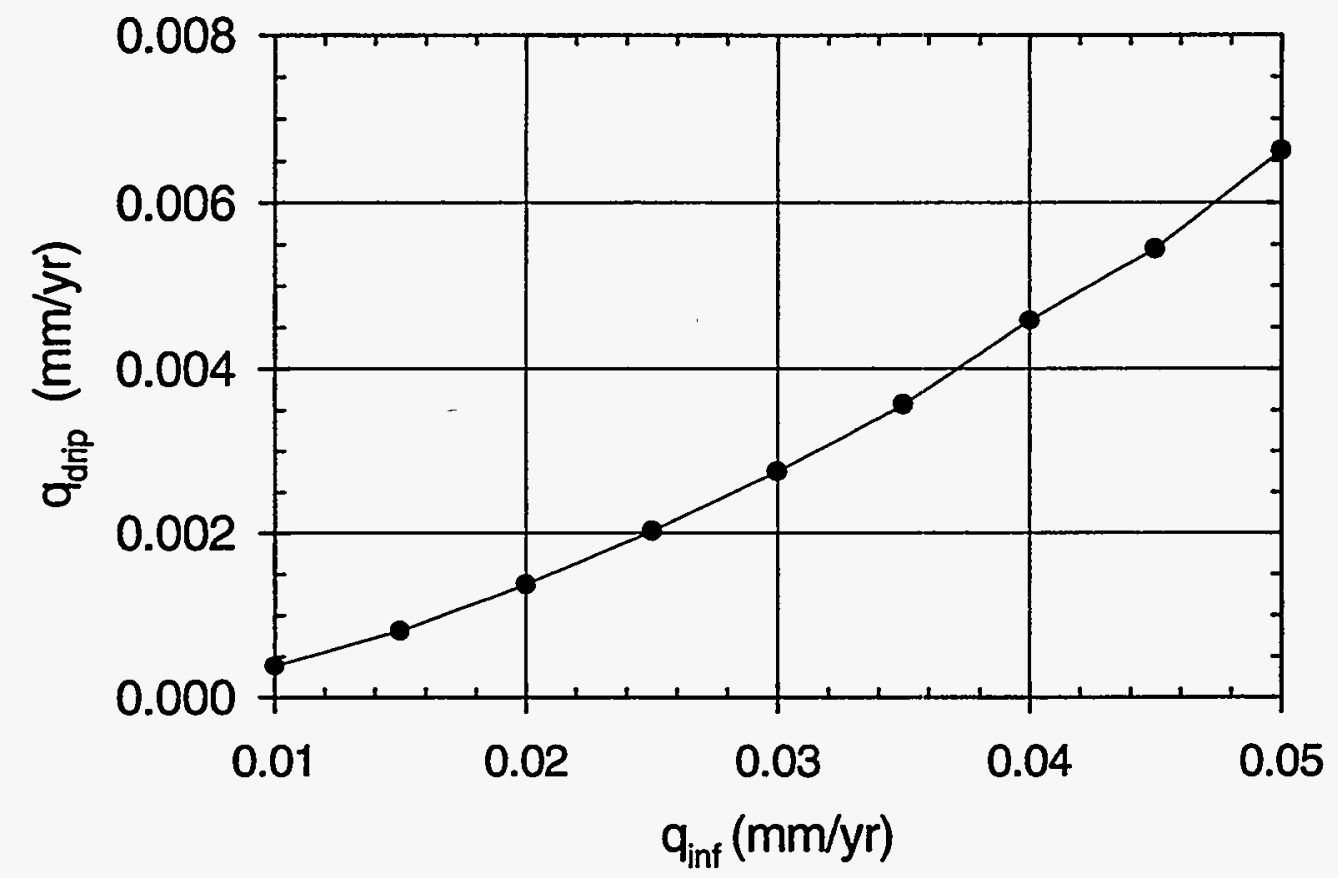

Figure 7.3-5 Average dripping flux (Darcy velocity), $\mathrm{q}_{\mathrm{drip}}$, on waste packages for low unsaturated-zone infiltration rates.

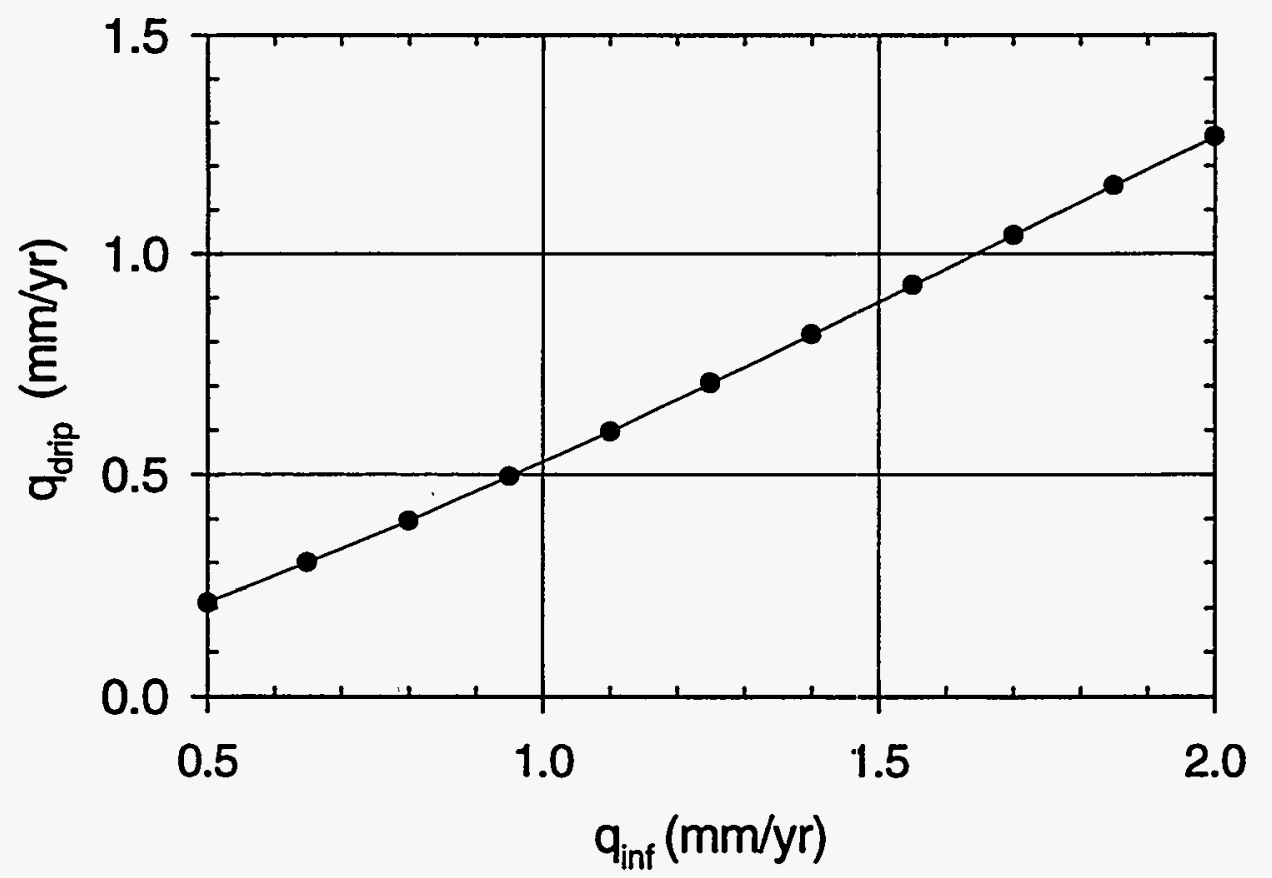

Figure 7.3-6 Average dripping flux (Darcy velocity), $q_{\text {drip }}$, on waste packages for high unsaturated-zone infiltration rates. 


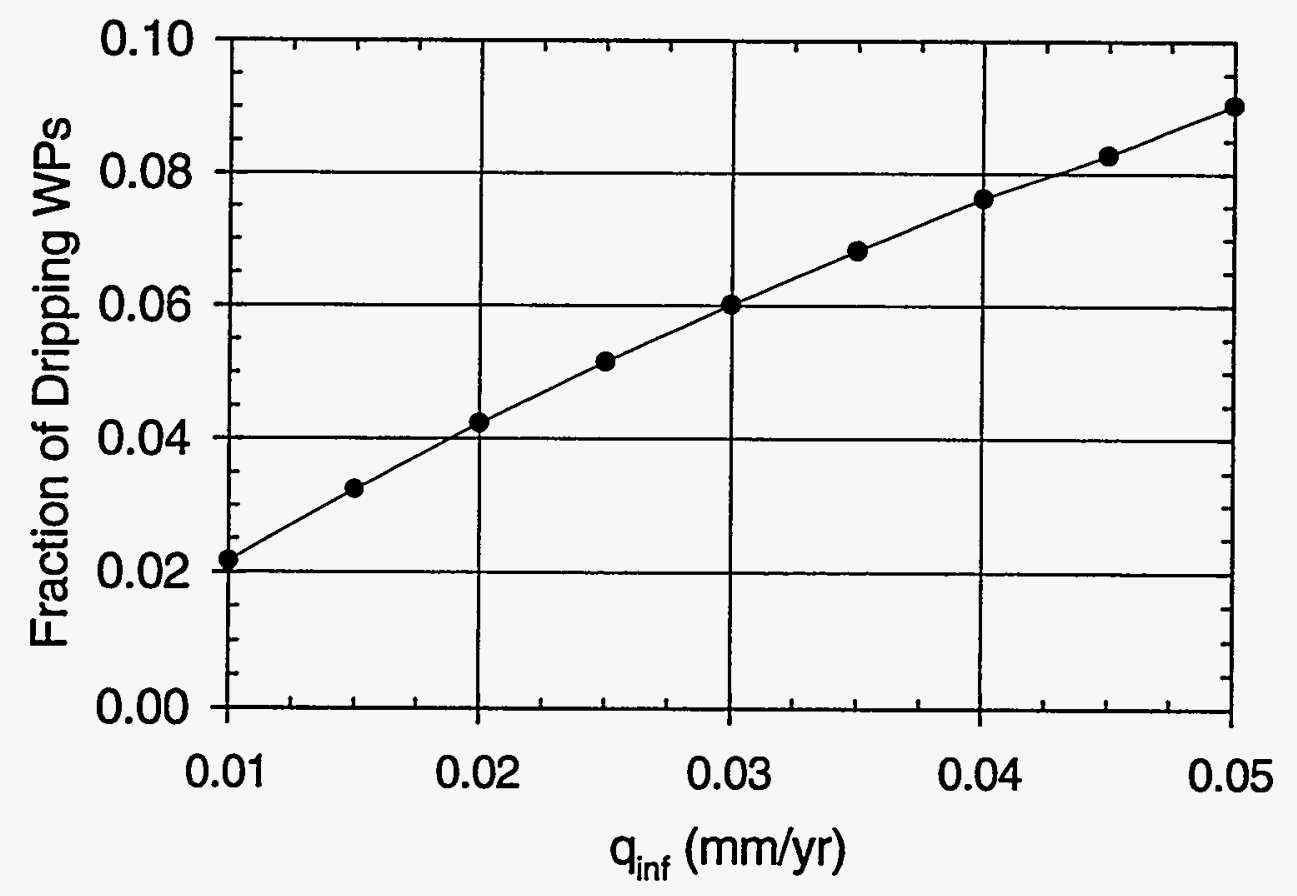

Figure 7.3-7 Average fraction of waste packages with drips, $\mathrm{f}_{\text {drip }}$, for low unsaturated-zone infiltration rates.

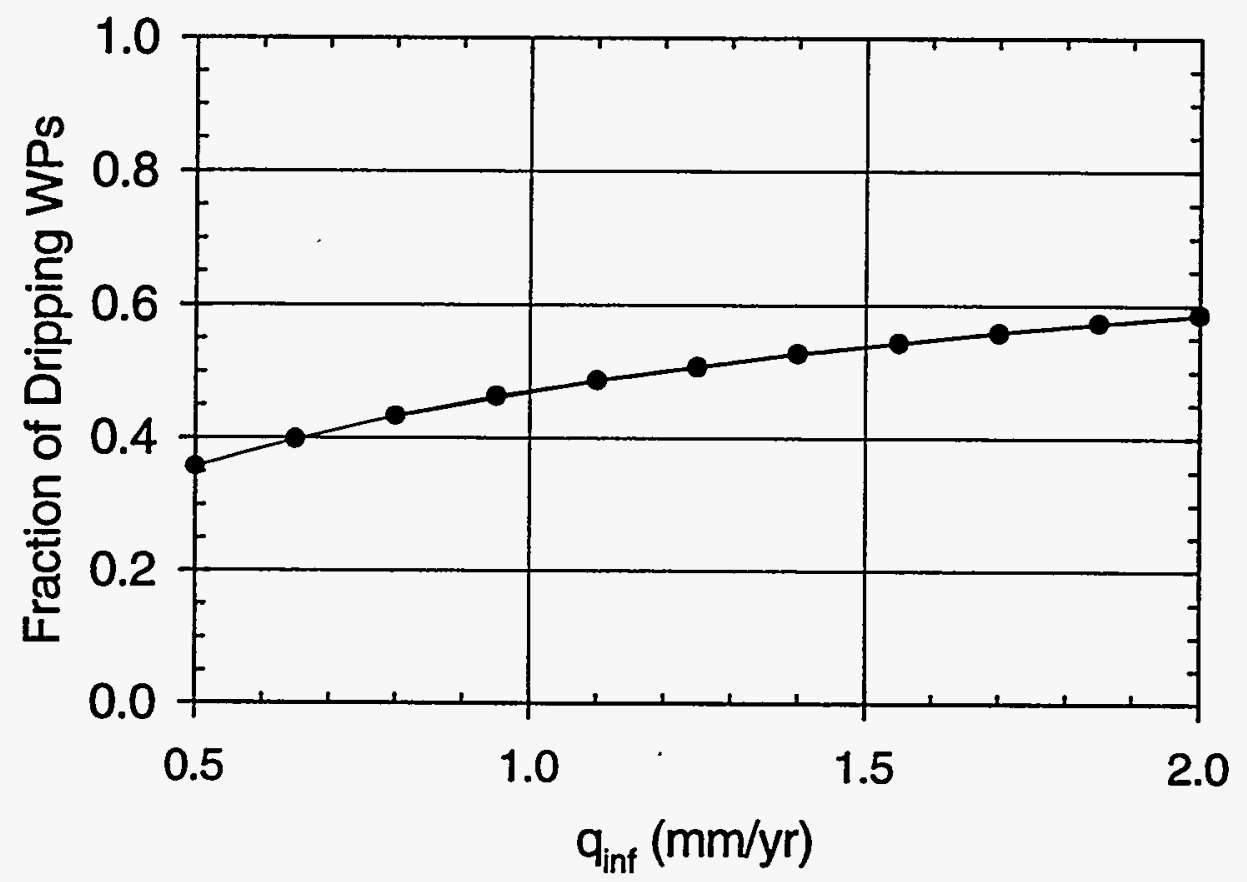

Figure 7.3-8 Average fraction of waste packages with drips, $f_{\text {drip }}$, for high unsaturated-zone infiltration rates. 


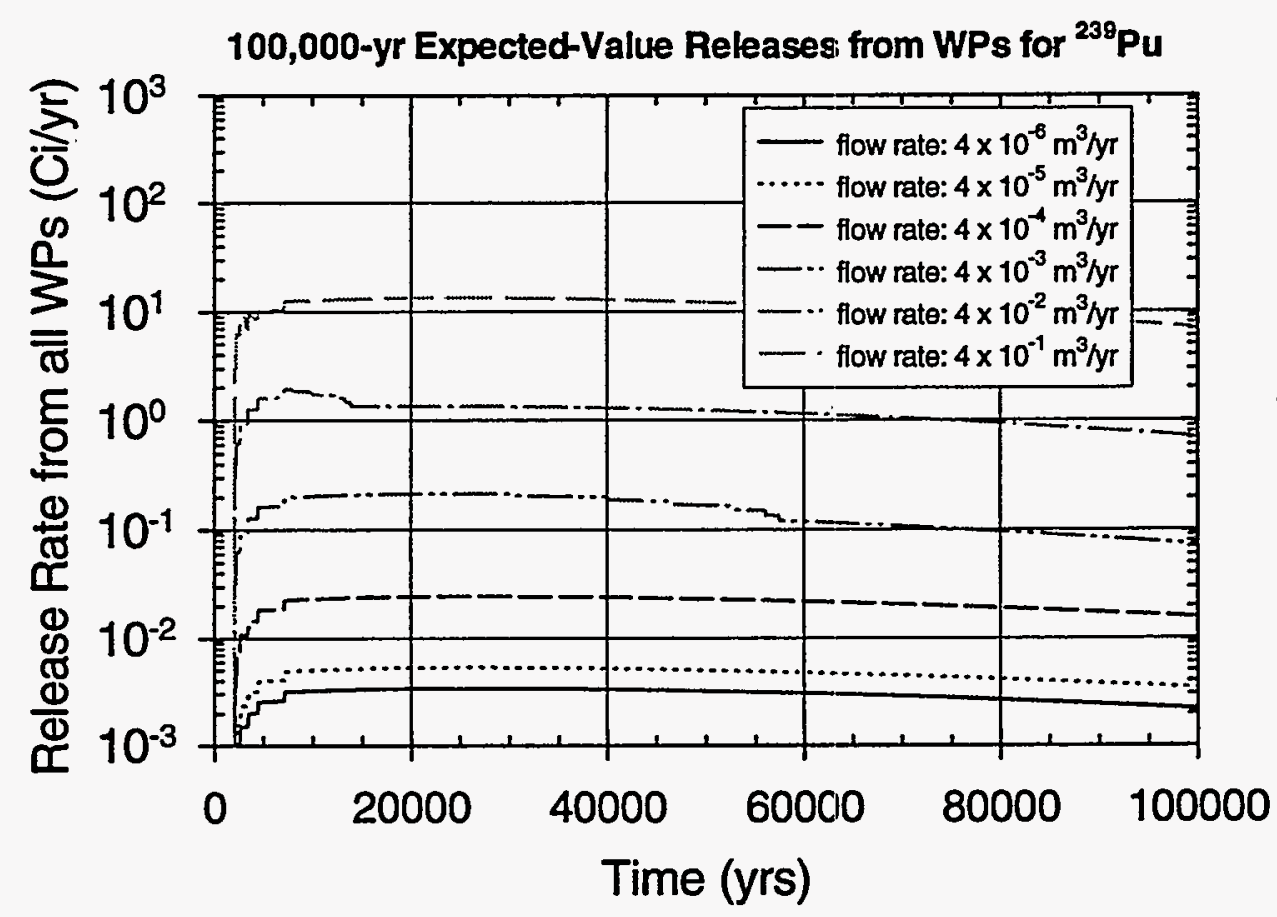

Figure 7.3-9 100,000 -yr expected-value releases for ${ }^{239} \mathrm{Pu}$ from all waste packages, for various values of the dripping flow rate, $Q_{\text {drip }}$.

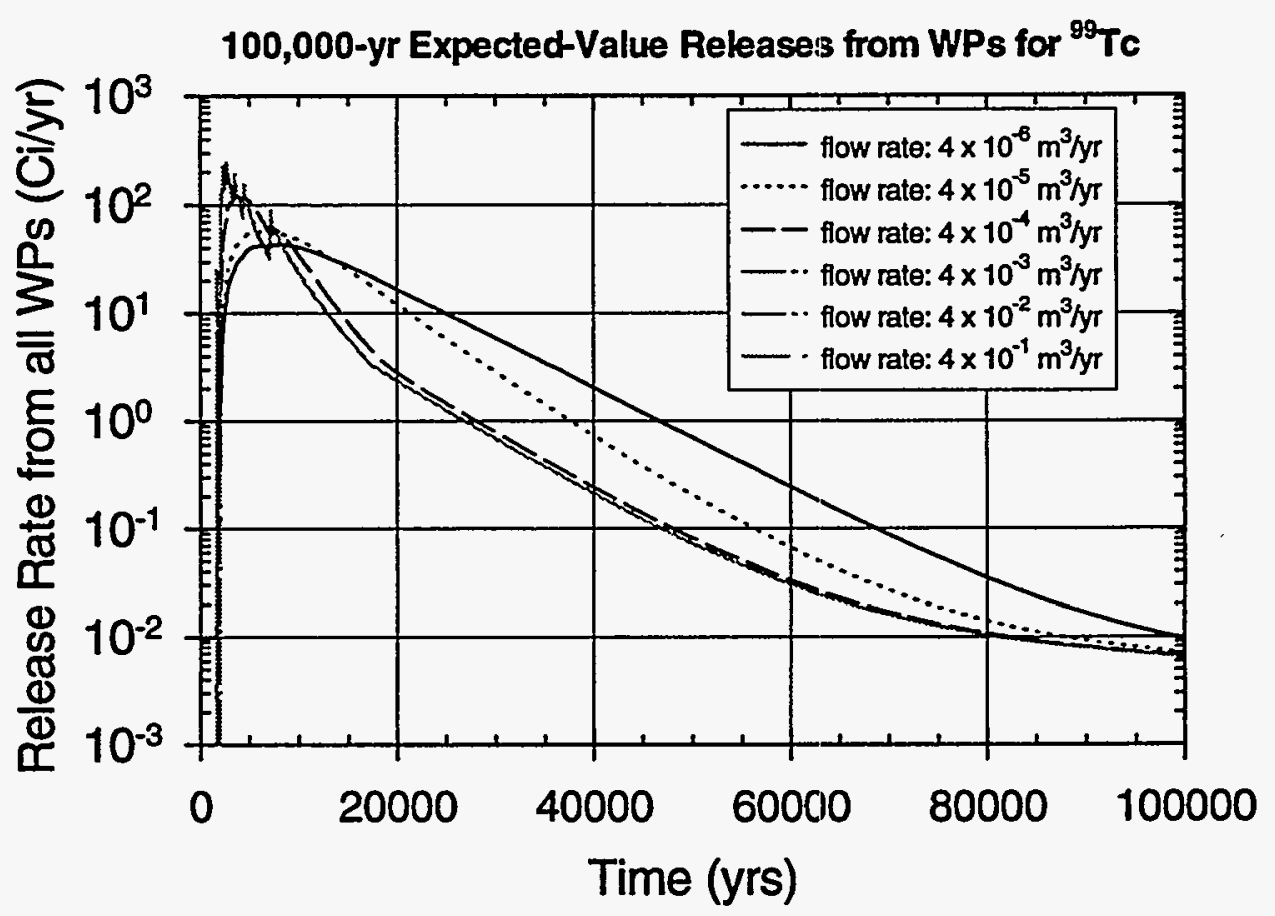

Figure 7.3-10 100,000-yr expected-value releases for ${ }^{99} \mathrm{Tc}$ from all waste packages, for various values of the dripping flow rate, $Q_{\text {drip }}$. 


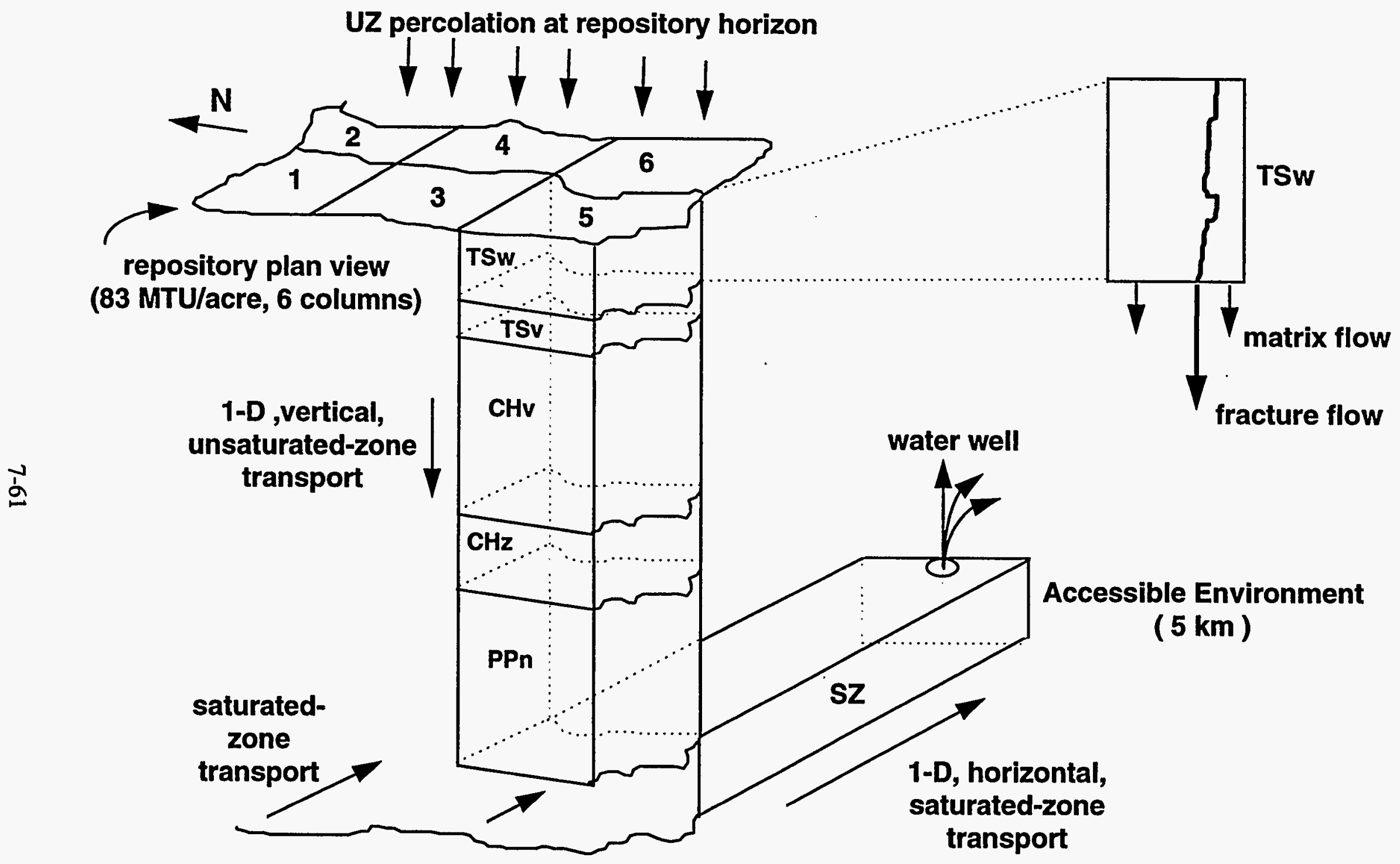

Figure 7.4-1 Schematic of UZ and SZ pathway geometry in RIP TSPA model. 


\section{(Intra-unit Fracture Connectivity: TSPA Abstraction)}

- Average path length in fracture or in matrix before transitioning is equal $1 / \lambda$, where $\lambda$ is the transition rate:

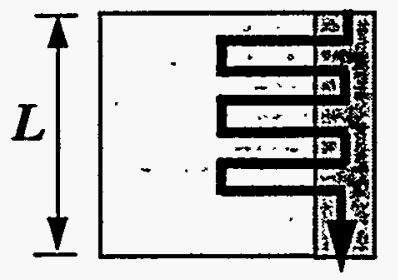

$\lambda=\frac{1}{(0.1) L}$

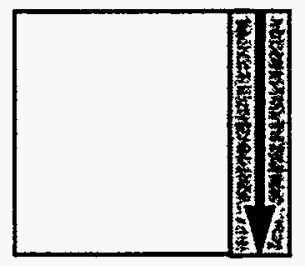

$$
\lambda=\frac{1}{L}
$$

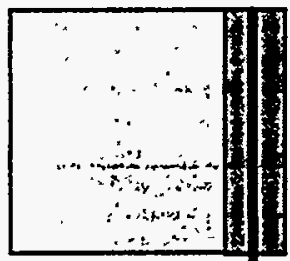

$\lambda=\frac{1}{(\mathbf{1 0 0}) L}$

random travel length in fracture, $l=-\frac{1}{\lambda} \ln [U(0,1)]$

particle transition rate, $\lambda=\frac{1}{l_{\text {avg }}}$

Figure 7.4-2 Schematic of fracture/matrix interaction in RIP: Markovian-particletransitioning process to represent intra-unit fracture connectivity.

\section{(Inter-unit Fracture Connectivity: TSPA Abstraction)}

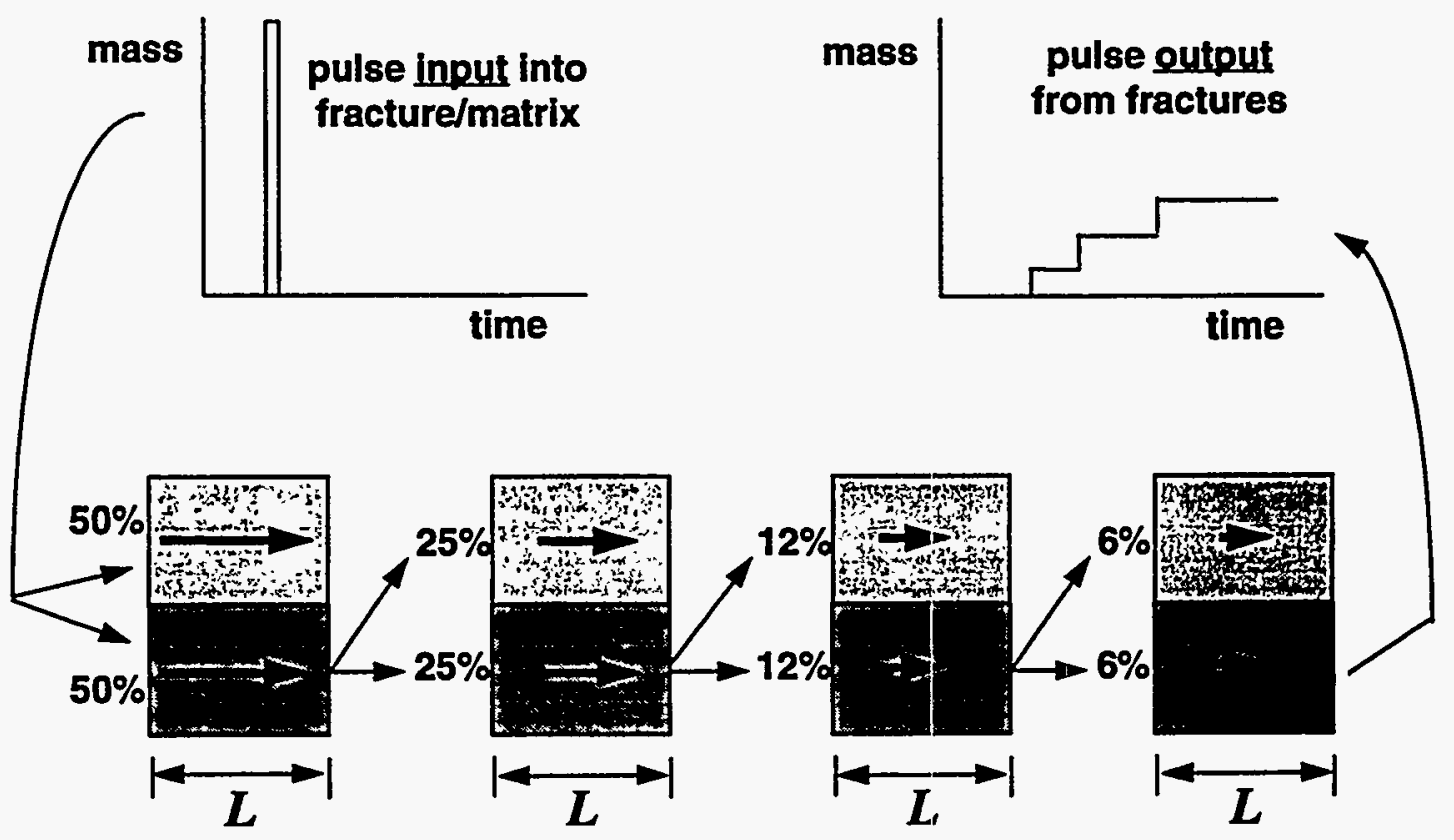

Figure 7.4-3 Schematic of inter-unit fracture and pathway connectivity in RIP. 


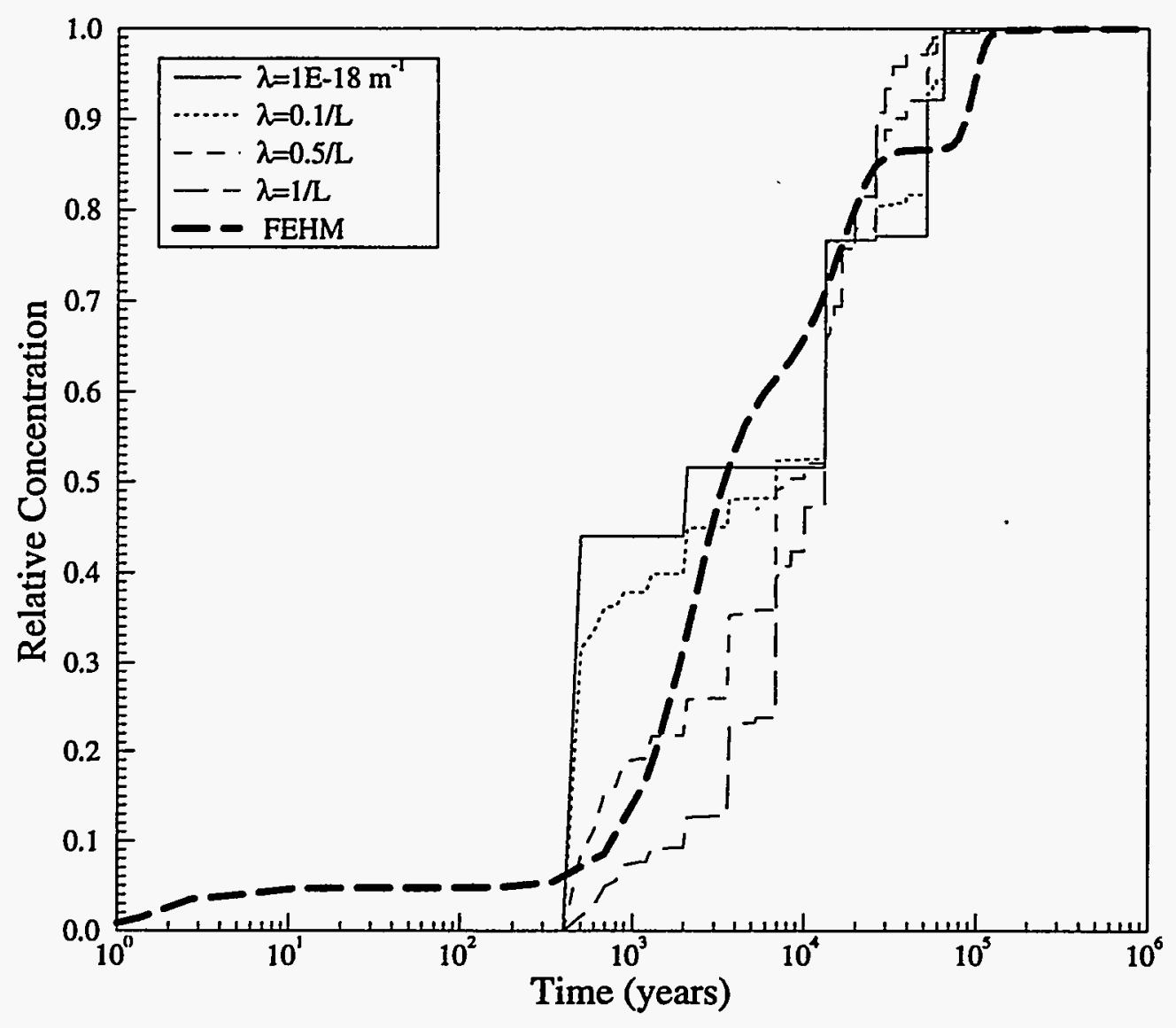

Figure 7.4-4 Comparisons between RIP simulations with different fracture/matrix transition rates and the FEHM simulation for an infiltration rate of $4.0 \mathrm{~mm} / \mathrm{yr}$ and no matrix diffusion (from $\mathrm{Li}$ et al., 1995). 


\section{Climate Change}

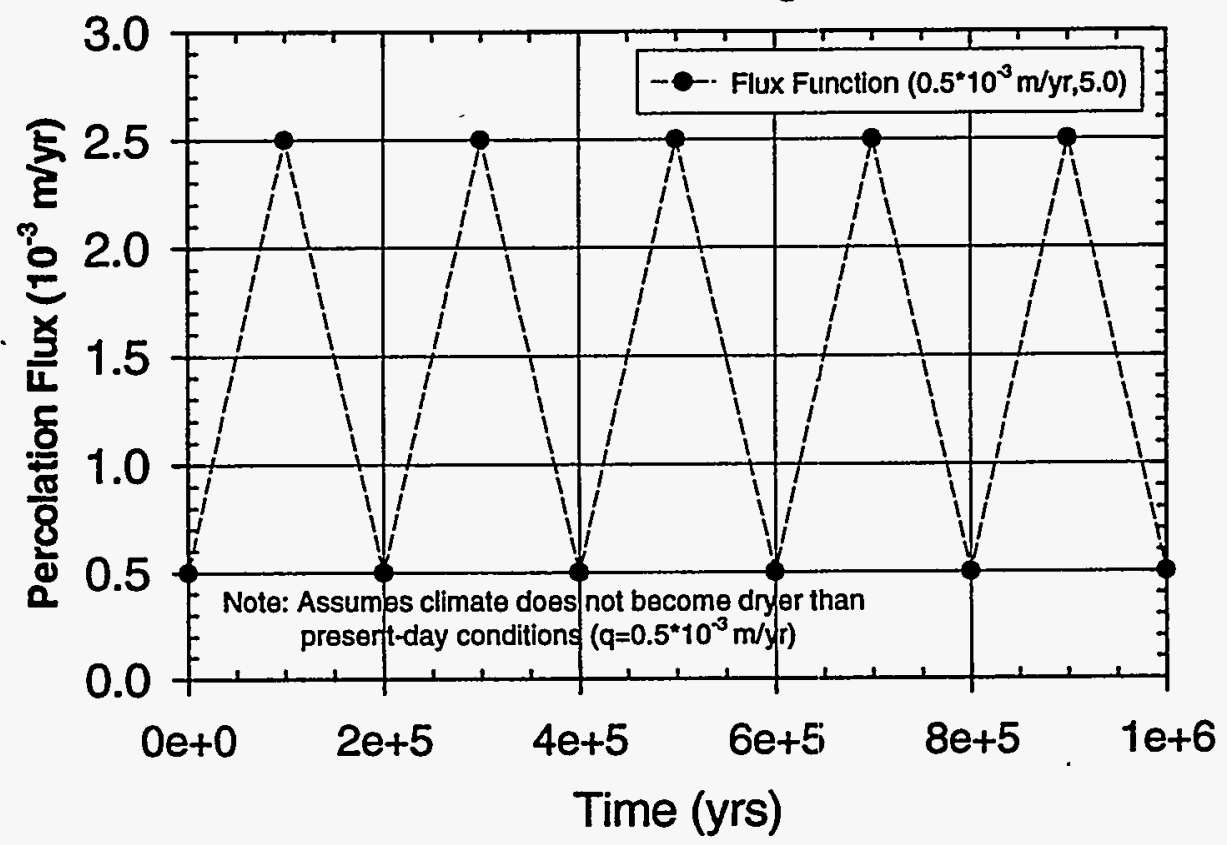

Figure 7.7-1 Effect of climate change on infiltration rate, $q_{\text {inf }}$.

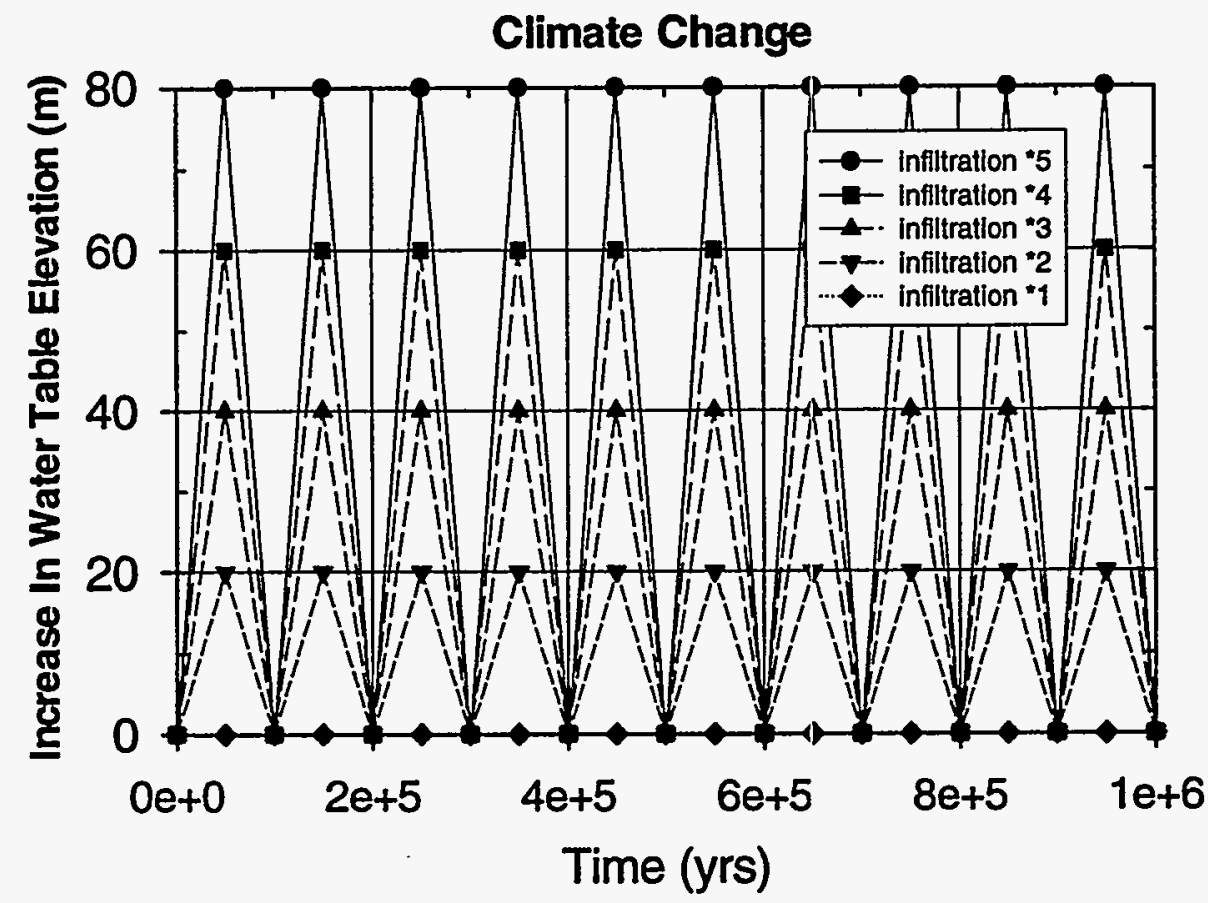

Figure 7.7-2 Effect of climate change on water-table elevation. 


\section{CHAPTER 8}

WASTE PACKAGE/EBS RESULTS 


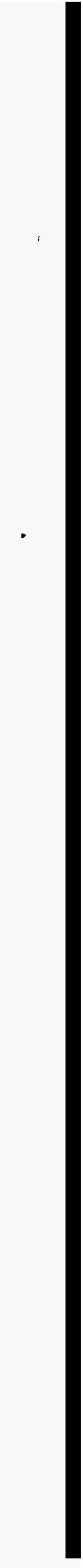




\title{
8. WASTE PACKAGE/ENGINEERED BARRIER SYSTEM RESULTS
}

\author{
Jerry A. McNeish, Joon H. Lee, Joel E. Atkins, Vinod Vallikat
}

\subsection{INTRODUCTION}

Analyses were conducted to evaluate the potential releases from the waste package(WP)/engineered barrier system (EBS). RIP (Golder, 1993), a total system performance assessment code, was used to conduct the performance analyses presented in this chapter. Due to the varying degrees of uncertainties in many of the features of the subsystem components, a sensitivity analysis of the multiple conceptual models was conducted. For example, implementation of the waste package degradation modeling discussed in Chapter 5 led to an evaluation of the impacts of different conceptual models for the initiation of the carbon steel outer barrier corrosion and the cathodic protection of the corrosion resistant (Alloy 825) inner barrier by the outer barrier. This chapter documents and analyzes the sensitivity of the EBS release to the alternate conceptual models. Additional results are also presented to show the effects of using alternate values for various other parameters in the waste package environment. Sensitivity of EBS release to cladding performance and waste form surface area changes were also performed.

As indicated in Figure 8.1-1, the EBS release results are predicated on the abstraction of process model results and laboratory-derived properties, and utilize a range of possible repository and indrift material design options. The NRC release rate requirements are presented for comparison, though a strict compliance evaluation is not conducted. These EBS release results are directly used as input to the geosphere transport analyses which evaluate the cumulative release and peak dose at the accessible environment boundary (see Chapter 9 ).

The chapter presents 1) the major assumptions and key parameter values (Section 8.2), 2) sensitivity analyses of the peak release rate from the EBS as affected by variations in the conceptual model of the subsystem, and 3) the cumulative release from the EBS over 10,000 years using multiple realizations for the distribution of the parameters. Note, that the cases considered in this chapter do not include any effects caused by climate change, because the effect of climate change from 0 to 10,000 years is expected to be negligible.

\subsection{MAJOR ASSUMPTIONS AND KEY PARAMETER VALUES}

This section discusses the major assumptions incorporated into the RIP simulations for the waste package/EBS subsystem performance analyses. The discussion also includes the key parameters used in the simulations.

\subsubsection{Major Assumptions in Waste Package/Engineered Barrier System Performance Analyses}

The major assumptions for the waste package/EBS subsystem incorporated in the performance analyses conducted for TSPA-1995 are discussed below. 
1) In TSPA-1995, the waste disposal containers for both spent fuel and vitrified defense high-level waste were assumed to have a two-layer container design with a $100 \mathrm{~mm}$ thick carbon steel outer layer and a $20 \mathrm{~mm}$ thick Alloy 825 inner layer. This assumption was prompted by the lack of information on the performance of the moderately corrosion resistant barrier materials (Monel 400 and $70 / 30 \mathrm{Cu} / \mathrm{Ni}$ alloy). Details of the waste container design were discussed in Section 3.5.

2) In the analyses, the entire waste form surface was assumed to be covered with a "thin" water film (i.e., uniform thickness of $1.0 \mathrm{~mm}$ ) when the waste container had at least one pit penetration and the surface temperature was less than $100^{\circ} \mathrm{C}$. Alteration of the waste form is assumed to initiate after the first pit penetration. The water film thickness was used in the calculation of the radionuclide concentration at the waste form surface.

3) If a waste container has at least one pit penetration and the waste package surface temperature cools to less than $100^{\circ} \mathrm{C}$, then the waste packages that are dripped on are assumed to release radionuclides both by advection and diffusion. In this EBS release model, the diffusion coefficient in the diffusive release model discussed in Section 6.5 was set to $10^{-7} \mathrm{~cm}^{2} / \mathrm{sec}$. This diffusion coefficient value was obtained from the data developed by Conca and coworkers (Conca, 1990; Conca and Wright, 1992). In the absence of water drips, a diffusive release was assumed, and the diffusion coefficient was calculated using the empirical functional form described in Section 6.5.

4) The releases of ${ }^{14} \mathrm{C},{ }^{36} \mathrm{Cl}$, and ${ }^{129} \mathrm{I}$ from the EBS were assumed to be gaseous. As discussed in detail in Chapters 7 and 9, the gaseous elements are assumed to escape unimpeded from the EBS, and then be dissolved and transported into the geosphere in the aqueous phase. However, there is some uncertainty in the dominant release behavior of ${ }^{129} \mathrm{I}$ from the waste package and EBS. Because of the abundance of Cs (about 10 to 1 in the molar ratio), it has been suggested that all the iodine released from the spent fuel $\mathrm{UO}_{2}$ matrix and grains would form CsI salt which is believed to be the most thermodynamically stable form and is readily soluble in water (Van Konynenburg, 1995; Malinauskas, 1995). This argument supports the contention that aqueous, not gaseous release is the dominant EBS release mechanism for ${ }^{129} \mathrm{I}$. It has also been pointed out that, in some conditions, iodine can escape from the aqueous solution into the air (Gray, $1995 \mathrm{~b}$ ). While the nominal EBS case assumed gaseous release, the ${ }^{129} \mathrm{~T}$ release mode is uncertain and a sensitivity study of the ${ }^{129} \mathrm{~T}$ release rate to its release mode from the EBS was conducted. The results are discussed in Section 8.3.

5) In all TSPA-1995 simulations, an invert composed of gravel was assumed to underlie the waste packages.

\subsubsection{Key Parameter Values}

The key parameter values used in the RIP simulations of the EBS release rate are presented in Tables 8.2-1 to 8.2-5 along with the TSPA-1993 (Andrews, et al., 1994) parameter values for comparison. The waste package parameters used for the RIP implementation are given in Table 8.2-1. Generally, the parameters used in TSPA-1995 are similar to those in TSPA-1993 (Andrews, et al., 1994). The waste burnup values are slightly lower in TSPA-1995 
(36,666 megawatt days/metric ton heavy metal (MWd/MTHM) combined) than for TSPA-1993 (39,075 MWd/MTHM combined) (Andrews, et al., 1994). The TSPA-1995 inventory is compared with the TSPA-1993 (Andrews, et al., 1994) inventory in Table 8.2-2. The gap fraction inventory used in TSPA-1995 is the same as in TSPA-1993 (Andrews, et al., 1994) (Table 8.2-3).

The summary of the exposure parameters used in the RIP implementation for TSPA-1995 are presented in Table 8.2-4 and compared with those in TSPA-1993 (Andrews, et al., 1994). The nominal surface area for the spent fuel used in TSPA-1995 is about 5 times larger than the value used in TSPA-1993 (Andrews, et al., 1994). Discussions of the spent fuel surface area are given in Section 6.2. Comparison of the transport parameter values used in TSPA-1993 (Andrews, et al., 1994) and TSPA-1995 are summarized in Table 8.2-5. In both TSPA-1993 and TSPA-1995, the diffusion coefficient in unsaturated geologic media was derived from the data developed by Conca (Engel, 1995) for a wide variety of geologic materials with varying degrees of water saturation. Details of the data and diffusion coefficient model were discussed in Section 6.5. The repository infiltration rate used in TSPA-1995 was selected from two distributions: 1) 0.01$0.05 \mathrm{~mm} / \mathrm{yr}$ (uniformly distributed); and 2) $0.5-2.0 \mathrm{~mm} / \mathrm{yr}$ (uniformly distributed). The geometric factor for diffusion in TSPA-1995 was embedded in the diffusive release model discussed in Section 6.5.

\subsection{EBS PEAK RELEASE RATE}

\subsubsection{Introduction}

Currently, a potential repository for the permanent disposal of the nation's high-level radioactive wastes including spent nuclear fuel (SF) and vitrified defense high-level waste (DHLW) is subject to the post-closure subsystem regulatory requirements of the U.S. Nuclear Regulatory Commission (NRC). The NRC sub-system performance measures that are relevant to the evaluation of the engineered barrier system (EBS) of the Yucca Mountain site are specified in 10 CFR Part 60 . These include the substantially complete containment requirement (10 CFR 60.113(a)(1)(ii)(A)) and the EBS controlled release rate requirement (10 CFR 60.113(a)(1)(ii)(B)). Waste package performance analyses relevant to the substantially complete containment requirement were presented in Chapter 5. To facilitate discussions in the following section of the analyses of the EBS release rates, the NRC regulatory requirements for the EBS controlled release rate are restated below:

The release rate of any radionuclide from the engineered barrier system following the containment period shall not exceed one part in 10,000 per year of the inventory of that radionuclide calculated to be present at 1,000 years following permanent closure, or such other fraction of the inventory as may be approved by the Commission: provided, that this requirement does not apply to any radionuclide which is released at a rate less than $0.1 \%$ of the calculated total release rate limit. The calculated total release rate limit shall be taken to be one part in 100,000 per year of the inventory of radioactive waste, originally emplaced in the underground facility, that remains after 1,000 years of radioactive decay. [10 CFR 60 (a)(1)(ii)(B)] 
Calculated NRC release rate limits of each radionuclide for the spent fuel are tabulated in Table 8.3-1. The 1,000-year inventory of the spent fuel in the table was determined using the ORIGEN2 code (Croff, 1983) based on the fuel characteristics discussed in Section 3.7. Taking the 1,000-year inventory of a radionuclide and multiplying by $10^{-5}$ yields the NRC maximum EBS release rate limit for that radionuclide. Any radionuclide with a calculated maximum release rate of less than $0.1 \%$ of the total release rate limit of $1.24: \times 10^{3} \mathrm{Ci} / \mathrm{yr}$ (i.e. $1.24 \mathrm{Ci} / \mathrm{yr}$ ) need not be considered.

A sensitivity analysis was conducted using a suite of different conceptual models relevant to waste package and EBS parameters and designs to evaluate the corresponding EBS release rates. The analysis included the effect of: 1) different corrosion initiation threshholds for the waste disposal container; 2) alternative thermal loading; 3) repository level percolation rate; 4) cathodic protection of the inner barrier (Alloy 825) by the carbon steel outer barrier; 5) EBS release models; 6) cladding failure; 7) ${ }^{129} \mathrm{I}$ release mode; and 8) alternative thermal-hydrologic models. The EBS release rates for the cases listed above were simulated with the "expected" values of the input parameters, i.e. the simulations were for a single realization.

Table 8.3-2 summarizes the nominal cases studied in the EBS release sensivity analyses for TSPA-1995. Presented in Table 8.3-3 is the summary of the major cases in terms of the time for the first pit penetration and the number of waste packages with their first pit penetration which were obtained from waste package performance analyses discussed in Chapter 5 . The table shows that the case for 83 MTU/acre, with no backfill, high infiltration rate and using the RH switch for corrosion initiation of the carbon steel outer barrier (labelled as "83/N/H") is most conservative (i.e., has earliest first pit penetration and most waste packages with at least one pit penetration) among those listed in the table. In the following sections, results of the sensitivity analyses for the EBS peak release rates are presented.

\subsubsection{Selection of Radionuclides of Concern}

As discussed in the previous section, those radionuclides with the calculated maximum release rate greater than $0.1 \%$ of the total NRC release limit need to be considered. Radionuclides with a calculated maximum release rate smaller than the NRC limit for the radionuclide are excluded. To select radionuclides to be considered in this study, the EBS release rates of all 39 radionuclides in the TSPA 1995 inventory were calculated for a period of 10,000 years for the most conservative case with the largest release rates, which is also the case with the highest waste package degradation ( $83 \mathrm{MTU} / \mathrm{acre}$, no backfill, high infiltration rate, and RH switch for corrosion initiation of the outer barrier (see Section 5.7.6 and Table 8.3-3)). For the radionuclides which did not have any release in 10,000 years, the calculations were conducted for up to 100,000 years. The results are presented in Table 8.3-4. As shown in column 3 of the table, the radionuclides which have a maximum release rate exceeding $0.1 \%$ of the NRC total release rate limit (i.e., $1.24 \mathrm{Ci} / \mathrm{yr}$ ) are ${ }^{241} \mathrm{Am},{ }^{243} \mathrm{Am},{ }^{14} \mathrm{C},{ }^{135} \mathrm{Cs},{ }^{59} \mathrm{Ni},{ }^{237} \mathrm{~Np},{ }^{210} \mathrm{~Pb},{ }^{107} \mathrm{Pd},{ }^{226} \mathrm{Ra},{ }^{79} \mathrm{Se}$, and ${ }^{99} \mathrm{Tc}$. Among them, the maximum release rates of ${ }^{241} \mathrm{Am}$ and ${ }^{243} \mathrm{Am}$ are less than the NRC limit (column 2), thus they were excluded from further analyses. These radionuclides were also not included in the recent EBS release sensitivity study (M\&O, 1994a).

The radionuclides considered for further analysis are given in Table 8.3-5. As shown in Table 8.3-5, the maximum release rates of the radionuclides in TSPA-1995 are 3 to 6 times higher than 
those in the additional sensitivity study to TSPA-1993 (M\&O, 1994a) that is due mainly to the release by advective transport incorporated in this year's iteration. Assuming no areal infiltration, TSPA-1993 (Andrews, et al., 1994) and the additional EBS release sensitivity study (M\&O, 1994a) found that diffusive transport through the gravel backfill from "failed" waste packages dominated the advective transport component. Although the dominant transport modes considered are different in TSPA-1995 due to the presence of areal infiltration, the radionuclides to be included in TSPA-1995 are the same as those considered in TSPA-1993 (Andrews, et al., 1994) and the additional EBS study (M\&O, 1994a), except ${ }^{107} \mathrm{Pd}$. The higher release rate of ${ }^{107} \mathrm{Pd}$ in TSPA-1995 may be the result of a high water dripping rate assumed in the high infiltration rate case, and may need further consideration to be included in future sensitivity studies, but is not evaluated further at this time. Additionally, the times for the maximum release rate for the radionuclides with a substantial gap fraction $\left({ }^{14} \mathrm{C},{ }^{135} \mathrm{Cs},{ }^{79} \mathrm{Se}\right.$ and $\left.{ }^{99} \mathrm{Tc}\right)$ and high solubility in water (also the gap fraction radionuclides and ${ }^{59} \mathrm{Ni}$ ) are close to those for the same nuclides in the TSPA-1993 additional sensitivity study (M\&O, 1994a). The time for the maximum release rate of ${ }^{237} \mathrm{~Np}(16,600$ years) is much later than the previous study (7,000 years), and the release rates of ${ }^{210} \mathrm{~Pb}$ and ${ }^{226} \mathrm{Ra}$ which are the principal daughters of the uranium decay chain still increase at 100,000 years, whereas in the previous study, they had maximum release rates at 60,000 and 20,000 years respectively.

In the following sections, a short-hand notation is employed to designate the cases to be simulated and help to facilitate the discussions of the results and their analyses. For example, in the notation of " $83 / \mathrm{no} / \mathrm{loq} / \mathrm{RH}$ ", the first group ("83") designates the thermal load, i.e., $83 \mathrm{MTU} / \mathrm{acre}$, and the second group designates the backfill presence, i.e., "no" indicates the no backfill case and "yes" indicates the with backfill case. The third group ("loq") designates the infiltration rate used in the analysis, either from the low infiltration range ("loq") or from the high infiltration range ("hiq"). The fourth group ("RH") indicates the criteria used for corrosion initiation of the carbon steel outer barrier, either relative humidity only criteria ("RH") or relative humidity and temperature criteria ("RH\&T").

\subsubsection{Effects of Alternative Waste Container Corrosion Initiation Conceptual Models}

As discussed in Chapter 5, there is uncertainty in the initiation threshold for the corrosion of the carbon steel outer barrier on the waste packages in the potential repository. The outer barrier corrosion may initiate if relative humidity is above a threshhold level, or if both relative humidity and temperature reach threshhold levels. The relative humidity level at which corrosion occurs is also uncertain. The impacts of the different switches (RH only or $\mathrm{RH}$ and temperature) for the initiation of the carbon steel outer barrier corrosion on the waste container corrosion degradation were discussed in Sections 5.7.5 and 5.7.6. Another major uncertainty associated with the waste package performance is the extent of cathodic protection of the corrosion resistant (Alloy 825) inner barrier by the carbon steel outer barrier. Using the measure for the cathodic protection provided from expert elicitation, the impacts on the waste container performance were also addressed in Section 5.7.8.

In this section, the sensitivities of the EBS release rates to the alternative waste container corrosion initiation conceptual models are presented for each radionuclide discussed in the previous section. The first sensitivity case evaluates the impact of the model for initiation of the outer barrier corrosion. The analysis assumes either 1) the outer barrier initiates corrosion only 
after both the temperature has dropped below $100{ }^{\circ} \mathrm{C}$ and the relative humidity has reached a threshhold level between 65 and 75 percent (RH\&T) or 2) the outer barrier initiates corrosion as soon as relative humidity reaches the threshhold level regardless of the temperature at that time (RH only). The results for the release rate histories of the eight radionuclides $\left({ }^{14} \mathrm{C},{ }^{99} \mathrm{Tc},{ }^{79} \mathrm{Se}\right.$, ${ }^{135} \mathrm{Cs},{ }^{59} \mathrm{Ni},{ }^{237} \mathrm{~Np},{ }^{210} \mathrm{~Pb}$, and ${ }^{226} \mathrm{Ra}$ ), are presented respectively in Figures $8.3-1 \mathrm{a}$ to $8.3-1 \mathrm{~h}$ for the case of 83 MTU/acre thermal load without backfill and with the high or low infiltration rates. The NRC limit for each radionuclide is also indicated in the figure caption. As shown in the figures, using $\mathrm{RH}$ and $\mathrm{T}$ as the criteria for corrosion initiation simply delays the initial releases about 400 years and does not significantly affect the release behavior of the radionuclides. A fraction of the ${ }^{14} \mathrm{C}$ is present in the gap, and the release of ${ }^{14} \mathrm{C}$ from the EBS is assumed to be gaseous. In Figure 8.3-1a, the initial spikes are due to the gap fraction release. The other release spikes in Figure 8.3-1a are indicative of when waste package groups fail. The release rates are not significantly affected by the corrosion initiation assumptions or the infiltration rates. However, the infiltration rate is the major parameter affecting the release rates of other radionuclides.

The results for the sensitivity of the EBS release rates to the cathodic protection of the corrosion resistant inner barrier by the carbon steel outer barrier are shown in Figures 8.3-2a to 8.3-2h for the eight radionuclides for the case of 83 MTU/acre thermal loading without backfill and with a high infiltration rate. The cathodic protection was implemented for the case with both RH and $T$ criteria for the outer barrier corrosion initiation. As discussed in Chapter 5, the cathodic protection model assumed that 75 percent of the initial outer barrier thickness had to be degraded before the inner barrier pitting could begin. Because most of the waste packages for the cathodic protection case did not have pit penetrations until after 10,000 years (see Section 5.7.8), the release rate calculations were extended to 100,000 years. For the case evaluated, the cathodic protection significantly delayed the initiation of EBS release beyond 10,000 years, to a starting time of approximately 15,000 years. However, all the radionuclides, except ${ }^{14} \mathrm{C}$, exceed their NRC limit at this time. For ${ }^{14} \mathrm{C}$, although it is released as a gas from the EBS, the release rate is lower than the NRC limit. This is due to its (relatively) short half-life $(5,730$ years) and the lower near-field temperature at that time which produces lower waste form alteration rates.

\subsubsection{Effects of Alternative Thermal Loading and Repository Level Percolation Rate}

The sensitivity of the EBS release rate to thermal load was evaluated by comparing the results from the $25 \mathrm{MTU} / \mathrm{acre}$ cases with the corresponding $83 \mathrm{MTU} / \mathrm{acre}$ cases. The details of the alternative thermal loading cases are described in Chapter 4 . The results are presented in Figures 8.3-3a to 8.3-3h. The figures also present the effects from using different infiltration rates.

In general, the releases for the $83 \mathrm{MTU} / \mathrm{acre}$ cases begin earlier than those from the corresponding $25 \mathrm{MTU} /$ acre cases regardless of the infiltration rates. This is as expected based on the waste package degradation histories for the cases discussed in Section 5.7.7. The release rates for the $83 \mathrm{MTU} / \mathrm{acre}$ cases are also generally higher than the corresponding $25 \mathrm{MTU} / \mathrm{acre}$ cases. The higher release rate is primarily due to the higher near-field temperature conditions in the $83 \mathrm{MTU} / \mathrm{acre}$ cases which leads to greater waste form alteration rates. Again, except for ${ }^{14} \mathrm{C}$, the infiltration rate has a more significant impact on the release rate than does thermal load. In the case of ${ }^{14} \mathrm{C}$, because of its relatively short half-life, the time for the waste package degradation is also a major parameter affecting its EBS release rate. All the radionuclides, except 
${ }^{237} \mathrm{~Np}$, exceed their NRC limit in the high infiltration rate case regardless of the thermal loading. In the $25 \mathrm{MTU} / \mathrm{acre}$ case with the high infiltration rate, the release rate of ${ }^{237} \mathrm{~Np}$ which is a solubility limited species is below the NRC limit.

\subsubsection{Alternative EBS Release Conceptual Models: Effects of Backfill and Capillary Barrier}

This section combines an evaluation of the sensitivity of the EBS release rate to the presence of a backfill and the sensitivity of the EBS release rate to the EBS release conceptual models. The effects of a backfill were considered by comparing the alternative no-backfill and backfill cases: 1) the no-backfill case assumes an air-filled drift and a gravel invert underneath the waste package; and 2) the backfill case assumes gravel is placed around the waste package.

Three EBS release conceptual models were considered: 1) advection-dominant transport from a "failed" waste package under dripping fractures; 2) advective transport controlled by diffusion through a "failed" waste package under dripping fractures; and 3) diffusion dominant transport from a "failed" waste package in the presence of a capillary barrier. A brief description of each EBS release conceptual model is given below (see also Section 6.5).

As discussed in Section 8.2, when a waste container has at least one pit penetration, and the surface temperature is below $100{ }^{\circ} \mathrm{C}$, the entire surface of the waste form inside the "failed" waste package is assumed to be covered with a "thin" film of water, followed by alteration of the waste form, and mobilization of the radionuclides contained in the waste form. In addition, the number of waste packages under dripping fractures are estimated as a function of the distribution of the percolation flux and the saturated matrix conductivity of the near-field rock surrounding the repository drifts (discussed in Section 7.3).

In the first EBS release conceptual model, if a "failed" waste package is predicted to be under dripping fractures, the entire waste form is conservatively assumed to be exposed to the (dripping) advective flux, and the radionuclides are released by advection. The diffusive release from the "failed" waste package under dripping fractures is also calculated with the model (and the diffusion coefficient set to $10^{-7} \mathrm{~cm}^{2} / \mathrm{sec}$ ) presented in Section 6.5 . In this case, the total release from the "failed" waste package is the sum of advective and diffusive release, and the advective release component is always dominant. For a "failed" waste package that is not subjected to dripping water, the radionuclides are assumed to be released by diffusion only, and the diffusion coefficient is determined as a function of the liquid saturation level of the gravel invert underneath the waste package.

The second EBS release conceptual model considers an alternative approach to advective release from a "failed" waste package under dripping fractures and takes into account the performance of the "failed" waste container as a potentially important barrier to radionuclide release. Because the pits (or holes) of the "failed" waste container are filled with fine, "gel"-like corrosion products, it is assumed the pits filled with corrosion products prevent the dripping water from flowing directly into the waste package and contacting the waste form inside. Instead, the dripping water is diverted around the waste container. Thus, in this conceptual model, radionuclides are transported through the corrosion product-filled holes by diffusion, and once outside the waste container, they are released by advection. This alternative model incorporates 
more realism into EBS release because it assumes any advective release from a waste container failed by pitting corrosion depends on the number of pit penetrations at that time. As in the first EBS release conceptual model, for a "failed" waste package that is not subjected to dripping fractures, radionuclides are released by diffusion only, and the diffusion coefficient is calculated from the liquid saturation level of the gravel invert.

The third EBS release conceptual model is similar to the presence of a Richard's (or capillary) barrier wherein, if it performs with $100 \%$ efficiency in diverting any dripping water away from the waste package, no advective flow or dripping are allowed to occur through the waste packages. In this case, the dominant radionuclide release mechanism is diffusion which is strongly dependent upon the liquid saturation level in the gravel invert.

The effects of backfill for the eight radionuclides were calculated using the $83 \mathrm{MTU} / \mathrm{acre}$ thermal load case, with the high or low infiltration rate, and using the RH switch for the corrosion initiation of the carbon steel outer barrier. The results are shown in Figures 8.3-4a to 8.3-4h, in which the effects of backfill are compared for the cases with and without backfill. For all eight radionuclides, there is not a significant difference in the EBS release rates. This is consistent with the results for the waste package degradation discussed in Chapter 5, in which no significant difference was observed in the presence or absence of backfill.

The results using the alternative advective release model (EBS release conceptual model 2) are presented in Figures 8.3-5a to 8.3-5h. The results shown in the figures are for the cases of the $83 \mathrm{MTU} /$ acre thermal loading, with no backfill, with the low or high infiltration rate, and using the RH switch or the RH and temperature switch for the initiation of the carbon steel outer barrier corrosion. The case for the 83 MTU/acre thermal loading, with no backfill, with the high infiltration rate, and using the RH switch for the corrosion initiation yielded the highest EBS peak release rates for all eight radionuclides. These results can be compared with Figures 8.3-4a to 8.3-4h to evaluate the sensitivity of EBS release rate to the two different EBS release models.

When calculated with the conservative advective release model (EBS release conceptual model 1), the case labelled as "83/no/hiq/RH" as shown in Figures $8.3-4 \mathrm{a}$ to $8.3-4 \mathrm{~h}$ in the figures yielded the most conservative release rates from the EBS for all eight radionuclides. For the same case (83/no/hiq/RH) but with the alternative advective release model (Figures $8.3-5 \mathrm{a}$ to $8.3-5 \mathrm{~h}$ ), the release rates of all the radionuclides, except for ${ }^{14} \mathrm{C}$ which is released in gas and ${ }^{210} \mathrm{~Pb}$ which is the principal decay daughter of uranium, are below $\left({ }^{135} \mathrm{Cs},{ }^{59} \mathrm{Ni}\right.$ and $\left.{ }^{237} \mathrm{~Np}\right)$ or slightly above $\left({ }^{99} \mathrm{Tc}\right.$ and ${ }^{79} \mathrm{Se}$ ) their NRC limit. The shapes of the release rate curves mimic the pitting time histories (see Section 5.7).

Sensitivity of the EBS peak release rate to the presence of the capillary barrier is presented in Figures 8.3-6a to 8.3-6h. The calculations were made for the case of the $83 \mathrm{MTU} / \mathrm{acre}$ thermal loading, with the high infiltration rate, with backfill, and using the $\mathrm{RH}$ for the initiation of the outer barrier corrosion. The results for the no backfill cases with the $83 \mathrm{MTU} / \mathrm{acre}$ and $25 \mathrm{MTU} / \mathrm{acre}$ thermal loading are also presented for comparison.

As expected, the release of ${ }^{14} \mathrm{C}$ is not affected by the presence of the capillary barrier. In general, the release rates of all the radionuclides (except ${ }^{14} \mathrm{C}$ ) are about 5 to 7 orders of magnitude lower in the presence of the capillary barrier compared to the release rates for the corresponding cases 
without a capillary barrier as shown in Figures 8.3-3a to 8.3-3h and 8.3-4a to 8.3-4h. Unlike the other sensitivity results discussed, the releases from the lower thermal load case for all the radionuclides (except ${ }^{14} \mathrm{C}$ ) begin about 5,000 years earlier than for the higher thermal loading case, but the release rates are still lower than the higher thermal loading. The results are in contrast to the waste package degradation histories for the corresponding thermal loading cases, in which the waste package degradation for the high thermal load case was more severe and started earlier than for the low thermal load case. This difference in the release rate result is caused by the higher saturation of the gravel invert underneath the waste package in the lower thermal load case, which gives higher values for the diffusion coefficient in the invert and thus higher diffusive releases. The breakthrough curves for the release rates in the higher thermal load case are very sharp, and the release rates are higher than for the lower thermal load case. This is probably due mostly to a buildup of the radionuclides inside the waste package as the waste form alters at a greater rate because of the higher near-field temperature in the high thermal load case, providing for a high concentration gradient across the gravel invert.

\subsubsection{Effects of Cladding Failure}

The sensitivity of the EBS release rate to the spent fuel cladding failure was evaluated by varying the fraction of the waste form available for release. This was a simplified approach to simulate cladding failure and was implemented in RIP by only allowing failure of the cladding for a selected percentage of the waste packages. Simulations were conducted with 1, 10, and $100 \%$ availability of the spent fuel waste form. Another set of simulations were performed with the same percentages of the spent fuel waste form availability, but with the surface area of the spent fuel within the failed cladding increased by a factor of 100 . The multiplication factor used reflects the volume increases of the oxidized spent fuel in the failed cladding and was conservatively estimated from a recent report by Gray and Wilson (1995) and information provided by Gray (1995a). A detailed discussion of the spent fuel surface area is given Section 6.2.

The EBS release results for the cases with the different cladding failure fraction, but without the surface area increase are given in Figures 8.3-7a to 8.3-7h. The calculations are for the case of the $83 \mathrm{MTU} /$ acre thermal loading, with no backfill, with the high infiltration rate, and using the $\mathrm{RH}$ switch for the initiation of the outer barrier corrosion. All the radionuclides including ${ }^{14} \mathrm{C}$ showed the decreased release rates with the reduction in the cladding failure from $100 \%$ to $1 \%$, i.e. the reduction of the fraction of spent fuel available for release. This was expected because the decrease in the cladding failure was achieved in the simulations by reducing the inventory available for release. However, all the radionuclides, except ${ }^{59} \mathrm{Ni}$ and ${ }^{237} \mathrm{~Np}$, exceed their $\mathrm{NRC}$ limit even with only 1 percent cladding failure, using the conservative advective release model (EBS release conceptual model 1).

Additional sensitivity analyses assumed that all the spent fuel inside the failed cladding (1\% and $10 \%$ failure) is oxidized completely to $\mathrm{U}_{3} \mathrm{O}_{8}$, causing an increase in the surface area by a factor of 100 . Comparison of the results to the $100 \%$ cladding failure without the surface area increase is given in Figures 8.3-8a to 8.3-8h. The simulations were run for the case of the 83 MTU/acre thermal loading, with no backfill, with the high infiltration rate, and using the RH switch for the initiation of the outer barrier corrosion. The surface area increase was expected to lead to an increase in the peak release rates for the radionuclides. However, as shown in the figures, the effect was not significant. The fact that the radionuclides considered (except ${ }^{59} \mathrm{Ni},{ }^{237} \mathrm{~Np}$ and ${ }^{210} \mathrm{~Pb}$ ) 
are highly soluble and have a significant gap fraction inventory may have lessened the effects. For ${ }^{237} \mathrm{~Np}$ the release rates are the same for all three cases.

\subsubsection{Effects of Alternative Thermal-Hy drologic Model}

The effect of the alternative thermal-hydrologic model (LLNL model) (Buscheck, 1995; Buscheck, Nitao and Ramspott, 1995), on the release rate from the EBS was evaluated by comparing the results from a corresponding, but not identical, case. Details of the alternate thermal-hydrologic model were given in Section 4.2. As discussed in Section 5.7.10, with the temperature and humidity profiles calculated with the alternate thermal-hydrologic model, the waste package simulation results showed that there was insignificant waste package degradation for the LLNL model cases with the $80 \mathrm{MTU} /$ acre case with or without backfill and the $24 \mathrm{MTU} /$ acre case with backfill. Only the 24 MTU/acre case with no backfill and no infiltration had significant waste package degradation. Thus, the sensitivity analyses for the alternate thermal-hydrologic model were only conducted for the LLNL model case of the 2.4 MTU/acre thermal loading, with no backfill, and with no infiltration, and a roughly equivalent case, i.e. the case with $25 \mathrm{MTU} / \mathrm{acre}$ thermal loading, no backfill, and the presence of a capillary barrier effect. The comparisons are made in Figures 8.3-9a to 8.3-9h. The results for the alternate thermal-hydrologic model (LLNL model) are indicated in the figures with the designation "LLNL-24/no/no/cap. barrier."

Except for ${ }^{14} \mathrm{C}$, diffusion in the aqueous phase is the dominant release mechanism for the radionuclides for these two cases. As shown in the figures, the release rates of all the radionuclides are two orders of magnitude higher in the current thermal-hydrologic model than in the LLNL model results. The predictions for the temperature and the liquid saturation level in the gravel invert by the alternate LLNL model are lower than the current model, which leads to lower diffusive flux.

\subsubsection{Sensitivity of ${ }^{129}$ I Release Rate to Its Release Mode}

Although the peak release rate $(0.96 \mathrm{Ci} / \mathrm{yr})$ of ${ }^{129} \mathrm{~T}$ from the EBS (given in Table $8.3-4$ ) is less than the total NRC release limit (1.24 Ci/yr) in Table 8.3-1, its release mode (gaseous or aqueous) from the EBS has a significant impact on the release rate at the accessible environment, which is discussed in detail in Chapter 9. In addition, as discussed in Section 8.2.1, its dominant release mode is uncertain. Because of the impact to the accessible environment release rate and the uncertainty in its release mode, simulations were run for the sensitivity of the ${ }^{129} \mathrm{I}$ release mode to its release rate from the EBS. The results shown in Figure 8.3-10 are for the case of 83 MTU/acre, with no backfill, high infiltration rate, and using the $\mathrm{RH}$ switch for the corrosion initiation. The initial release spikes in the figure are due to the release of the ${ }^{129} \mathrm{I}$ gap fraction. The other peaks in the release history occur as each waste package group fails. While, in the high infiltration rate case, the release rate of ${ }^{129} \mathrm{I}$ from the EBS in the aqueous phase is not much different from the gaseous release rate, the aqueous phase peak release rate in the low infiltration rate case is about two orders of magnitude lower than the gas phase release cases. The impact of ${ }^{129} \mathrm{I}$ release mode on the release to the accessible environment is further discussed in Chapter 9. 


\subsubsection{Most Important Model Parameters}

Additional analyses were conducted to identify key model parameters which have a large impact on important performance measures such as peak release rate from the EBS. Using Latin Hypercube Sampling to sample the parameter values, one hundred realizations were simulated with RIP for two cases. These cases were the $25 \mathrm{MTU} /$ acre and $83 \mathrm{MTU} / \mathrm{acre}$ thermal loads, both with no backfill and high infiltration. Once the realizations were simulated, stepwise linear regression was used to determine which parameters could be used to explain the EBS peak release rate. In Tables 8.3-6 and and 8.3-7, the parameters are listed in order of importance along with the percent of the variability which the parameters explain up to that point.

Since the structure of the relationship between the model parameters and the EBS peak release is not known, the stepwise linear regression was done on three transformations of the data. The first transformation was rank regression. The peak release rates were assigned integer values from 1 through 100, corresponding to their rank among the simulations. Each of the model parameters was also assigned an integer value for each realization corresponding to the rank of the value of the parameter at that observation. The ranks of the model parameters are then used to explain the ranks of the peak release rate. Rank regression was used because it is a robust method which is useful when the underlying relationship is not understood.

There are intuitive reasons to believe that the EBS peak release rate should be explained well by a multiplicative model. Thus, for both the second and the third transformation, the natural $\log$ of the peak EBS release rate was treated as the dependent variable. For the second transformation, the model parameters were used to explain the natural log of the EBS peak release rate. For the third transformation, the natural logs of the model parameters were used to explain the natural log of the EBS peak release rate. The results for all three of these transformations are shown in Tables 8.3-6 and 8.3-7.

For both the rank regression and log-log transformation, a small number of parameters explain most of the variability. This supports the idea that the log-log transformations might be appropriate. For both of these transformations, and for both thermal loads, ${ }^{99} \mathrm{Tc}$ solubility, the infiltration rate, and the spent fuel dissolution rate are the three most important parameters. This is consistent with the current understanding of EBS processes. Spent fuel dissolution rate is important, because the spent fuel has to dissolve before it may be transported out of the EBS. ${ }^{99} \mathrm{Tc}$ solubility in particular is important because ${ }^{99} \mathrm{Tc}$ is a highly soluble, abundant radionuclide. Thus, once mobilized from the spent fuel waste form, it's solubility determines the amount of ${ }^{99} \mathrm{Tc}$ available for transport. The two cases analyzed in this section both assumed the advection dominant EBS release model (EBS release conceptual model 1), thus, infiltration rate is also important for determining the EBS peak release rates.

\subsection{CUMULATIVE EBS RELEASE AT 10,000 YEARS}

\subsubsection{Introduction}

Cumulative releases of radionuclides from the EBS provide for an additional comparison of EBS performance, as a supplement to the analysis of peak EBS release rates discussed in the previous section. In this section, cumulative releases of some of the radionuclides considered for the EBS 
release rate were calculated, and the results were normalized to the EPA release limits to the accessible environment (AE) specified in 40 CFR Part 191. Although the EPA normalized cumulative release limits are not directly applicable to the releases from the waste package and EBS, the normalized release calculation provides another useful approach to compare the EBS release behavior of radionuclides.

The cumulative releases from the EBS at 10,000 years are presented in this section only to evaluate the effect of alternative thermal loading and infiltration rates on the release. Alternative waste package degradation conceptual models, backfill, and cladding failure have been sufficiently discussed in previous sections. 100 realizations were simulated for each case. The cumulative normalized releases are presented only for release from the EBS in this section.

\subsubsection{Effects of Alternative Thermal Load}

The complementary cumulative distribution function (CCD)F) results from the $83 \mathrm{MTU} /$ acre case without backfill and with high infiltration are presented in Figure 8.4-1 for the total release as well as for ${ }^{14} \mathrm{C},{ }^{129} \mathrm{I},{ }^{99} \mathrm{Tc},{ }^{237} \mathrm{~Np}$, and ${ }^{59} \mathrm{Ni}$. The total release from the EBS is contributed primarily by ${ }^{14} \mathrm{C}$ and ${ }^{237} \mathrm{~Np}$. The uniform release of two gases, ${ }^{14} \mathrm{C}$, and ${ }^{129} \mathrm{I}$, independent of the other uncertainty in the subsystem is demonstrated by the nearly vertical normalized release curves. The ${ }^{59} \mathrm{Ni}$ release also shows little variability over the 100 realizations. The alteration-limited radionuclide, ${ }^{99} \mathrm{Tc}$, has approximately 3 orders of magnitude variability in the release due to significant variability in dissolution of the waste form, whereas the solubility-limited radionuclide, ${ }^{237} \mathrm{~Np}$, has less variability.

As a comparison with Figure 8.4-1, the CCDF results from the 25 MTU/acre case without backfill and with high infiltration are presented in Figure 8.4-2 for the total release as well as for selected radionuclides, ${ }^{14} \mathrm{C},{ }^{129} \mathrm{I},{ }^{99} \mathrm{Tc},{ }^{237} \mathrm{~Np}$, and ${ }^{59} \mathrm{Ni}$. As in the high thermal loading case, the total release from the EBS is contributed primarily by ${ }^{14} \mathrm{C}$ and ${ }^{237} \mathrm{~Np}$. However, the total releases are over a half of an order of magnitude lower than for the $83 \mathrm{MTU} / \mathrm{acre}$ case. The difference in the releases between the two thermal loading cases is attributable to the previously described differences in waste container degradation and waste form alteration/dissolution rates. The higher thermal load case has higher dissolution rates of the waste form and generally greater degradation of the waste container, leading to earlier and higher releases.

\subsubsection{Effects of Infiltration on EBS Release}

As an evaluation of the effect of infiltration on the cumulative release from the EBS at 10,000 years, the two thermal load cases (83 MTU/acre and $25 \mathrm{MTU} / \mathrm{acre}$ ) with no backfill were simulated with both the high and low infiltration rates. The CCDF results for total normalized release from the EBS at 10,000 years are presented in Figure 8.4-3, in which both the high and low infiltration cases for the $83 \mathrm{MTU} / \mathrm{acre}$ case are shown to produce greater release than the $25 \mathrm{MTU} / \mathrm{acre}$ cases. Also, the releases are greater from the high infiltration cases for a given thermal load than from the low infiltration case. These trends were observed in the waste container degradation analyses presented in Chapter 5, where the 83 MTU/acre case had earlier waste container failure and greater waste container degradation, and can be further explained by the higher dissolution rate of the waste form at higher temperatures in the high thermal load case. 
CCDF results for individual radionuclides $\left({ }^{14} \mathrm{C},{ }^{99} \mathrm{Tc},{ }^{129} \mathrm{I},{ }^{237} \mathrm{~Np}\right.$, and $\left.{ }^{59} \mathrm{Ni}\right)$ for the same cases as in Figure 8.4-3, are presented in Figures 8.4-4 to 8.4-8. For the radionuclides with gaseous release $\left({ }^{14} \mathrm{C}\right.$ and $\left.{ }^{129} \mathrm{I}\right)$, the results presented in 8.4-4 and 8.4-6 are similar to the total release, but the variability between the high and low infiltration case for a given thermal load is not as great. ${ }^{99} \mathrm{Tc}$ release behavior is more variable than was the gaseous radionuclide release perhaps due to more variable diffusive release rate for ${ }^{99} \mathrm{Tc}$ (Figure 8.4-5). Also, an important difference in the release behavior related to infiltration is observed in the results presented in Figure 8.4-5. The high infiltration cases (both $83 \mathrm{MTU} / \mathrm{acre}$ and $25 \mathrm{MTU} / \mathrm{acre}$ ) produce the highest normalized releases because ${ }^{99} \mathrm{Tc}$ release is strongly dependent on the dissolution rate of the waste form and the infiltration rate. The low infiltration cases have a greater variability. The release results for ${ }^{237} \mathrm{~Np}$ as seen in Figure 8.4-7 are similar to ${ }^{99} \mathrm{Tc}$, except there is a greater overall range of normalized releases, from approximately $10^{-4}$ to $5 \times 10^{-1}$ at the 50 th percentile probability. For the cases evaluated in this section, the greatest normalized releases are produced by ${ }^{237} \mathrm{~Np}$. For the cumulative normalized release of ${ }^{59} \mathrm{Ni}$ presented in Figure 8.4-8, the releases for a particular thermal load with high infiltration are higher and have less variability than for the low infiltration case. Again, both of the high infiltration cases have higher releases than the lower infiltration cases, showing the importance of the percolation flux through the repository.

\subsection{SUMMARY AND CONCLUSIONS FROM EBS PERFORMANCE ANALYSES}

The analyses of the waste package/EBS performance presented in Chapter 8 evaluated the release of radionuclides from the EBS in relation to the NRC peak release rate standard. The analyses considered the effects on the EBS peak release rate of alternative corrosion initiation models, two alternative thermal loads, two different infiltration rate ranges, backfill conditions, cladding performance, alternative thermal-hydrologic models, and alternative EBS release models. Eight radionuclides were selected for the analysis based on the maximum release rate that exceeded $0.1 \%$ of the NRC total release rate limit. These radionuclides, ${ }^{14} \mathrm{C},{ }^{135} \mathrm{Cs},{ }^{59} \mathrm{Ni},{ }^{237} \mathrm{~Np},{ }^{210} \mathrm{~Pb},{ }^{226} \mathrm{Ra},{ }^{79} \mathrm{Se}$, and ${ }^{99} \mathrm{Tc}$, were included in the evaluations which attempted to demonstrate the importance of the various parameters and conceptual models listed above.

The evaluations, which were based on thermo-hydrologic modeling results presented in Chapter 4 , demonstrated the significance of the rate of percolation or dripping on the waste containers. Generally, the influence of infiltration was more significant than the alternate waste degradation conceptual models (i.e., Temperature and RH vs. RH only) in terms of causing radionuclides to exceed their NRC release rate limit.

The higher thermal load cases produced higher releases than the corresponding lower thermal load case. This is consistent with earlier waste container failure and higher degradation in the higher thermal load case. In the case when a capillary barrier was assumed, the releases for the low thermal load case began earlier, but the peak release rate remained lower than the peak release rate for the high thermal load case.

Also demonstrated in the analyses are the effects of the alternative advective release model controlled by diffusion through the waste container on the EBS release rate, i.e., diffusive release through the perforations in "failed" waste container and advective release from the outside contacting the dripping water. Compared to the case with the conservative advective release model that yielded the highest release rate ( $83 \mathrm{MTU} / \mathrm{acre}$, no backfill and high infiltration), the alternative 
advective model yielded the release rates for most nuclides within their NRC limit, except for ${ }^{14} \mathrm{C}$ and ${ }^{210} \mathrm{~Pb}$. The implication is that the "partially failed" waste containers by pitting corrosion should still be able to perform as a potentially important barrier to radionuclide release, and EBS transport models that incorporate more realism should be considered in future EBS performance analyses.

Multiple realization simulations to analyze the effects of thermal loading and infiltration produced similar results to the peak release rate analyses. Generally, the higher thermal load produces greater release, and higher infiltration produced significantly higher release than the low infiltration cases. The strong influence of repository percolation rate points to the high importance of the repository flux as it relates to the radionuclide release. 
Table 8.2-1.. Comparison of TSPA-1995 Container Parameters with TSPA-1993 Container Parameters

\begin{tabular}{||l|l|l||}
\hline RIP Package Information & TSPA-1993 $^{\text {1) }}$ & TSPA-1995 \\
\hline \hline \multirow{2}{*}{ Number of packages } & Spent Fuel: 6468 & Spent Fuel: 6468 \\
& DHLW: 3829 & DHLW: 3829 \\
\hline Waste burnup (MWd/MTHM) ${ }^{2)}$ & $42,300-$ PWR & $39,651-$ PWR \\
& $32,250-$ BWR & $31,186-$ BWR \\
& $39,075-$ combined & $36,666-$ combined \\
\hline Mass waste/pkg = MTHM in & 9.74 MTHM/pkg for & 9.74 MTHM/pkg for \\
repository/\# of waste containers & PWR/BWR & PWR/BWR \\
& 1.828 MTHM/pkg- & 1.828 MTHM/pkg- \\
& DHLW & DHLW \\
\hline
\end{tabular}

1) Andrews, et al. (1994)

2) $\mathrm{MWd} / \mathrm{MTHM}=$ megawatt days/metric tons of heavy metal 
Table 8.2-2.. Comparison of Selected Radionuclide Inventory in TSPA-1995 with TSPA-1993 Inventory

\begin{tabular}{|c|c|c|}
\hline INVENTORY & $\begin{array}{c}\text { TSPA-1993 }{ }^{1), 2)} \\
\text { (Ci/container) }\end{array}$ & $\begin{array}{c}\text { TSPA-1995 }{ }^{\text {3) }} \\
\text { (Ci/container) }\end{array}$ \\
\hline \hline${ }^{243} \mathrm{Am}$ & $2.74 \mathrm{E}+02$ & $2.48 \mathrm{E}+02$ \\
\hline${ }^{14} \mathrm{C}$ & $1.44 \mathrm{E}+01$ & $1.38 \mathrm{E}+01$ \\
\hline${ }^{135} \mathrm{Cs}$ & $5.52 \mathrm{E}+00$ & $5.13 \mathrm{E}+00$ \\
\hline${ }^{129} \mathrm{~T}$ & $3.62 \mathrm{E}+00$ & $3.43 \mathrm{E}-01$ \\
\hline${ }^{237} \mathrm{~Np}$ & $4.74 \mathrm{E}+00$ & $4.35 \mathrm{E}+00$ \\
\hline${ }^{239} \mathrm{Pu}$ & $3.65 \mathrm{E}+00$ & $3.56 \mathrm{E}+03$ \\
\hline${ }^{79} \mathrm{Se}$ & $4.67 \mathrm{E}+00$ & $4.41 \mathrm{E}+00$ \\
\hline${ }^{126} \mathrm{Sn}$ & $9.01 \mathrm{E}+00$ & $8.50 \mathrm{E}+00$ \\
\hline${ }^{99} \mathrm{Tc}$ & $1.47 \mathrm{E}+00$ & $1.40 \mathrm{E}+02$ \\
\hline${ }^{234} \mathrm{U}$ & $1.39 \mathrm{E}+00$ & $1.34 \mathrm{E}+01$ \\
\hline
\end{tabular}

1) Andrews, et al. (1994)

2) TSPA-1993 inventory is for 30-year-old fuel. $\mathrm{Ci} /$ container $=\mathrm{Ci} / \mathrm{MTHM} \times 9.2$ MTHM/container.

3) TSPA-1995 inventory is for 30-year-old fuel. Ci/container = Ci/MTHM x 7.94 MTHM/container. 
Table 8.2-3. Comparison of TSPA-1995 Gap Fraction with TSPA-1993 Gap Fraction

\begin{tabular}{|c|c|c||}
\hline INVENTORY & $\begin{array}{c}\text { TSPA-1993 }{ }^{\text {1) }} \\
\text { Gap Fraction }\end{array}$ & $\begin{array}{c}\text { TSPA-1995 } \\
\text { Gap Fraction }\end{array}$ \\
\hline \hline${ }^{243} \mathrm{Am}$ & 0.0 & 0.0 \\
\hline${ }^{14} \mathrm{C}$ & $\begin{array}{c}0.0125 \rightarrow 0.0575: \\
\text { Uniform }\end{array}$ & $0.0125 \rightarrow 0.0575:$ Uniform \\
\hline${ }^{135} \mathrm{Cs}$ & 0.02 & 0.02 \\
\hline${ }^{129} \mathrm{I}$ & 0.02 & 0.02 \\
\hline${ }^{237} \mathrm{~Np}$ & 0.0 & 0.0 \\
\hline${ }^{239} \mathrm{Pu}$ & 0.0 & 0.0 \\
\hline${ }^{79} \mathrm{Se}$ & 0.02 & 0.02 \\
\hline${ }^{126} \mathrm{Sn}$ & 0.0 & 0.0 \\
\hline${ }^{99} \mathrm{Tc}$ & 0.02 & 0.02 \\
\hline${ }^{234} \mathrm{U}$ & 0.0 & 0.0 \\
\hline
\end{tabular}

1) Andrews, et al. (1994) 
Table 8.2-4. Comparison of TSPA-1995 Exposure Parameters with TSPA-1993 Exposure Parameters

\begin{tabular}{|c|c|c|}
\hline RIP Model Parameter & $\begin{array}{l}\text { TSPA-1993 RIP } \\
\text { Base Case }\end{array}$ & $\begin{array}{l}\text { TSPA-1995 RIP } \\
\text { Nominal Case }\end{array}$ \\
\hline $\begin{array}{ll}\text { (1) } & \begin{array}{l}\text { Fraction of } \\
\text { containers } \\
\text { with moist } \\
\text { continuous } \\
\text { conditions }\end{array} \\
& \text { Fraction of waste } \\
\text { (2) } & \text { wetted } \\
\text { (3) } & \text { ECA }^{2)} \\
\text { (4) } & \begin{array}{l}\text { Diffusion } \\
\text { coefficient }\end{array}\end{array}$ & $\begin{array}{l}\text { (1) Dependent on flux, } \\
\text { temperature, saturation } \\
\text { (2) } 1.0 \\
\text { (3) } 8.5-46.5 \mathrm{~m}^{2} \\
\text { (4) Conca curve }\end{array}$ & $\begin{array}{l}\text { (1) Dependent on flux, } \\
\text { temperature, } \\
\text { saturation } \\
\text { (2) If temperature is } \\
<100 \text { degrees } C \text {, } \\
\text { fraction is } 1.0 \text {. } \\
\text { Otherwise, it's } 0.0 \text {. } \\
\text { (3) } 40.94 \mathrm{~m}^{2} \\
\text { (4) Conca curve }\end{array}$ \\
\hline $\begin{array}{l}\text { (1) Fraction of containers } \\
\text { with dripping fractures } \\
\text { (2) Fraction of waste } \\
\text { wetted } \\
\text { (3) ECA } \\
\text { (4) EDC }\end{array}$ & $\mathrm{N} / \mathrm{A}$ & $\begin{array}{l}\text { (1) Dependent on flux, } \\
\text { and saturated } \\
\text { hydraulic } \\
\text { conductivity } \\
\text { (2) If temperature is } \\
<100 \text { degrees C, } \\
\text { fraction is } 1.0 \text {. } \\
\text { Otherwise, it's } 0.0 \text {. } \\
\text { (3) } 40.94 \mathrm{~m}^{2} \\
\text { (4) } 3.15 \mathrm{e}-4 \mathrm{~m}^{2} / \mathrm{yr}\end{array}$ \\
\hline Air alteration rate & 0 & 0 \\
\hline $\begin{array}{l}\text { Matrix dissolution rate } \\
\left(\mathrm{g} / \mathrm{m}^{2} / \mathrm{yr}\right)\end{array}$ & Temperature dependent & Temperature dependent \\
\hline $\begin{array}{l}\text { Surface area of matrix } \\
\left(\mathrm{m}^{2} / \mathrm{g}\right) \\
\text { (combined with matrix } \\
\text { dissolution rate) }\end{array}$ & $\begin{array}{l}\text { 1. Surface Area of Spent } \\
\text { Fuel (ASF)/(1.10062E7) } \mathrm{m}^{2} / \mathrm{g} \\
\text { where Spent fuel surface area } \\
=78-107 \mathrm{~m}^{2} \text { (uniform) } \\
\text { 2. Surface Area of DHLW } \\
\left(\text { AHL) } /(7.012 \mathrm{E} 6) \mathrm{m}^{2} / \mathrm{g} \text { where }\right. \\
\text { AHL }=200-600 \mathrm{~m}^{2}\end{array}$ & $\begin{array}{l}\text { 1. Surface Area of Spent } \\
\text { Fuel (ASF) } /(1.10062 \mathrm{E} 7) \\
\mathrm{m}^{2} / \mathrm{g} \text { where Spent fuel } \\
\text { surface area }=500 \mathrm{~m}^{2} \\
\text { 2. Surface Area of } \\
\text { DHLW (AHL) } /(7.012 \mathrm{E} 6) \\
\mathrm{m}^{2} / \mathrm{g} \text { where AHL }=200 \text { - } \\
600 \mathrm{~m}^{2}\end{array}$ \\
\hline
\end{tabular}


Table 8.2-4. Comparison of TSPA-1995 Exposure Parameters with TSPA-1993 Exposure Parameters (Continued)

\begin{tabular}{||c|l|l||}
\hline RIP Model Parameter & \multicolumn{1}{|c|}{$\begin{array}{c}\text { TSPA-1993 RIP } \\
\text { Base Case } 1)\end{array}$} & \multicolumn{1}{|c|}{$\begin{array}{c}\text { TSPA-1995 RIP } \\
\text { Nominal Case }\end{array}$} \\
\hline $\begin{array}{l}\text { Water volume contacting } \\
\text { matrix }\left(\mathrm{m}^{3}\right)\end{array}$ & $\begin{array}{l}\text { Water volume contacting } \\
\text { matrix: ASF*DWATER : } \\
\text { DWATER }=0.001 \mathrm{~m} \\
\text { (thickness of water film } \\
\text { contacting waste form } \\
\text { matrix) }\end{array}$ & $\begin{array}{l}\text { Water volume contacting } \\
\text { matrix: ASF*DWATER } \\
\text { : DWATER }=0.001 \mathrm{~m} \\
\text { (thickness of water film } \\
\text { contacting waste form } \\
\text { matrix) }\end{array}$ \\
\hline
\end{tabular}

1) Andrews, et al. (1994)

2) $\mathrm{ECA}=$ effective catchment area 
Table 8.2-5. Comparison of TSPA-1995 Transport Parameters with TSPA-1993 Transport Parameters

\begin{tabular}{|c|c|c|}
\hline $\begin{array}{c}\text { RIP } \\
\text { Model Parameter }\end{array}$ & $\begin{array}{c}\text { TSPA-1993 } \\
\text { RIP } \\
\text { Base Case }^{1)} \\
\end{array}$ & $\begin{array}{l}\text { TSPA-1995 RIP } \\
\text { Nominal Case }\end{array}$ \\
\hline $\begin{array}{l}\text { Diffusion coefficient } \\
\left(\mathrm{m}^{2} / \mathrm{yr}\right)\end{array}$ & $\begin{array}{l}\text { Curve fit to Conca } \\
\text { data }\end{array}$ & $\begin{array}{l}\text { Curve fit to Conca } \\
\text { data (see Section 6.5) }\end{array}$ \\
\hline $\begin{array}{l}\text { Repository infiltration } \\
\text { rate }(\mathrm{m} / \mathrm{yr})\end{array}$ & VTOUGH results & $\begin{array}{l}\text { Selected from two } \\
\text { ranges: } \\
0.01-0.05 \mathrm{~mm} / \mathrm{yr} \text { and } \\
0.5-2.0 \mathrm{~mm} / \mathrm{yr}\end{array}$ \\
\hline $\begin{array}{l}\text { Geometric factor for } \\
\text { diffusion }(\mathrm{m})\end{array}$ & $\begin{array}{l}28.05 * N *(f s): \\
N=\text { porosity of } \\
\text { backfill }=0.1-0.3 ; \\
f_{s}=1, \text { if liquid } \\
\text { saturation }>0.08\end{array}$ & See Section 6.5 \\
\hline $\begin{array}{l}\text { Delay pathway (only } \\
\text { in moist continuous) }\end{array}$ & $\begin{array}{l}\text { In-drift emplacement: } \\
0.5 \mathrm{~m} \text { crushed tuff } \\
\text { zone }\end{array}$ & $\begin{array}{l}\text { Implemented in } \\
\text { diffusive release } \\
\text { component of } \\
\text { geometric factor for } \\
\text { diffusion (see } \\
\text { Section } 6.5 \text { ) }\end{array}$ \\
\hline
\end{tabular}

1) Andrews, et al. (1994) 
Table 8.3-1. Calculation of the NRC Release Limit

\begin{tabular}{||c|c|c|c||}
\hline Radionuclide & $\begin{array}{c}1,000-Y e a r \\
\text { Inventory } \\
\text { (Ci/MTU) }\end{array}$ & $\begin{array}{c}\text { 1,000-Year Inventory } \\
\text { for 63,000 MTU } \\
\text { (Ci) }\end{array}$ & $\begin{array}{c}\text { NRC Limit } \\
\text { (Ci/yr) }\end{array}$ \\
\hline \hline${ }^{227} \mathrm{Ac}$ & $3.88 \mathrm{E}-04$ & $2.45 \mathrm{E}+01$ & $2.45 \mathrm{E}-04$ \\
\hline${ }^{241} \mathrm{Am}$ & $1.06 \mathrm{E}+03$ & $6.69 \mathrm{E}+07$ & $6.69 \mathrm{E}+02$ \\
\hline${ }^{242 \mathrm{M}} \mathrm{Am}$ & $2.66 \mathrm{E}-01$ & $1.68 \mathrm{E}+04$ & $1.68 \mathrm{E}-01$ \\
\hline${ }^{243} \mathrm{Am}$ & $2.33 \mathrm{E}+01$ & $1.47 \mathrm{E}+06$ & $1.47 \mathrm{E}+01$ \\
\hline${ }^{14} \mathrm{C}$ & $1.26 \mathrm{E}+00$ & $7.96 \mathrm{E}+04$ & $7.96 \mathrm{E}-01$ \\
\hline${ }^{36} \mathrm{Cl}$ & $1.13 \mathrm{E}-02$ & $7.13 \mathrm{E}+02$ & $7.13 \mathrm{E}-03$ \\
\hline${ }^{244} \mathrm{Cm}$ & $6.65 \mathrm{E}-11$ & $4.19 \mathrm{E}-06$ & $4.19 \mathrm{E}-11$ \\
\hline${ }^{245} \mathrm{Cm}$ & $3.19 \mathrm{E}-01$ & $2.01 \mathrm{E}+04$ & $2.01 \mathrm{E}-01$ \\
\hline${ }^{246} \mathrm{Cm}$ & $6.19 \mathrm{E}-02$ & $3.90 \mathrm{E}+03$ & $3.90 \mathrm{E}-02$ \\
\hline${ }^{135} \mathrm{Cs}$ & $5.26 \mathrm{E}-01$ & $3.31 \mathrm{E}+04$ & $3.31 \mathrm{E}-01$ \\
\hline${ }^{129} \mathrm{I}$ & $3.52 \mathrm{E}-02$ & $2.22 \mathrm{E}+03$ & $2.22 \mathrm{E}-02$ \\
\hline${ }^{93 \mathrm{M}} \mathrm{Nb}$ & $2.32 \mathrm{E}+00$ & $1.46 \mathrm{E}+05$ & $1.46 \mathrm{E}+00$ \\
\hline${ }^{94} \mathrm{Nb}$ & $8.19 \mathrm{E}-01$ & $5.16 \mathrm{E}+04$ & $5.16 \mathrm{E}-01$ \\
\hline${ }^{59} \mathrm{Ni}$ & $2.40 \mathrm{E}+00$ & $1.51 \mathrm{E}+05$ & $1.51 \mathrm{E}+00$ \\
\hline${ }^{63} \mathrm{Ni}$ & $2.13 \mathrm{E}-01$ & $1.34 \mathrm{E}+04$ & $1.34 \mathrm{E}-01$ \\
\hline${ }^{237} \mathrm{~Np}$ & $1.24 \mathrm{E}+00$ & $7.82 \mathrm{E}+04$ & $7.82 \mathrm{E}-01$ \\
\hline${ }^{231} \mathrm{~Pa}$ & $3.88 \mathrm{E}-04$ & $2.44 \mathrm{E}+01$ & $2.44 \mathrm{E}-04$ \\
\hline${ }^{210} \mathrm{~Pb}$ & $3.75 \mathrm{E}-03$ & $2.36 \mathrm{E}+02$ & $2.36 \mathrm{E}-03$ \\
\hline${ }^{107} \mathrm{Pd}$ & $1.29 \mathrm{E}-01$ & $8.12 \mathrm{E}+03$ & $8.12 \mathrm{E}-02$ \\
\hline${ }^{238} \mathrm{Pu}$ & $1.97 \mathrm{E}+00$ & $1.24 \mathrm{E}+05$ & $1.24 \mathrm{E}+00$ \\
\hline${ }^{239} \mathrm{Pu}$ & $3.56 \mathrm{E}+02$ & $2.24 \mathrm{E}+07$ & $2.24 \mathrm{E}+02$ \\
\hline${ }^{241} \mathrm{Pu}$ & $4.90 \mathrm{E}+02$ & $3.09 \mathrm{E}+07$ & $3.09 \mathrm{E}+02$ \\
\hline${ }^{242} \mathrm{Ru}$ & $3.19 \mathrm{E}-01$ & $2.01 \mathrm{E}+04$ & $2.01 \mathrm{E}-01$ \\
\hline & $2.06 \mathrm{E}+00$ & $1.30 \mathrm{E}+05$ & $1.30 \mathrm{E}+00$ \\
\hline & $2.36 \mathrm{E}-03$ & $2.37 \mathrm{E}-03$ \\
\hline & & & \\
\hline & & & \\
\hline
\end{tabular}


Table 8.3-1. Calculation of the NRC Release Limit (Continued)

\begin{tabular}{||c|c|c|c||}
\hline Radionuclide & $\begin{array}{c}1,000-Y e a r \\
\text { Inventory } \\
\text { (Ci/MTU) }\end{array}$ & $\begin{array}{c}1,000-\text { Year Inventory } \\
\text { for 63,000 MTU } \\
\text { (Ci) }\end{array}$ & $\begin{array}{c}\text { NRC Limit } \\
\text { (Ci/yr) }\end{array}$ \\
\hline${ }^{228} \mathrm{Ra}$ & $1.42 \mathrm{E}-08$ & $8.93 \mathrm{E}-04$ & $8.93 \mathrm{E}-09$ \\
\hline${ }^{79} \mathrm{Se}$ & $4.48 \mathrm{E}-01$ & $2.82 \mathrm{E}+04$ & $2.82 \mathrm{E}-01$ \\
\hline${ }^{151} \mathrm{Sm}$ & $2.06 \mathrm{E}-01$ & $1.30 \mathrm{E}+04$ & $1.30 \mathrm{E}-01$ \\
\hline${ }^{126} \mathrm{Sn}$ & $8.66 \mathrm{E}-01$ & $5.46 \mathrm{E}+04$ & $5.46 \mathrm{E}-01$ \\
\hline${ }^{99} \mathrm{Tc}$ & $1.43 \mathrm{E}+01$ & $9.03 \mathrm{E}+05$ & $9.03 \mathrm{E}+00$ \\
\hline${ }^{229} \mathrm{Th}$ & $1.60 \mathrm{E}-04$ & $1.01 \mathrm{E}+01$ & $1.01 \mathrm{E}-04$ \\
\hline${ }^{230} \mathrm{Th}$ & $2.10 \mathrm{E}-02$ & $1.32 \mathrm{E}+03$ & $1.32 \mathrm{E}-02$ \\
\hline${ }^{232} \mathrm{Th}$ & $1.42 \mathrm{E}-08$ & $8.93 \mathrm{E}-04$ & $8.93 \mathrm{E}-09$ \\
\hline${ }^{233} \mathrm{U}$ & $4.05 \mathrm{E}-03$ & $2.55 \mathrm{E}+02$ & $2.55 \mathrm{E}-03$ \\
\hline${ }^{234} \mathrm{U}$ & $2.52 \mathrm{E}+00$ & $1.58 \mathrm{E}+05$ & $1.58 \mathrm{E}+00$ \\
\hline${ }^{235} \mathrm{U}$ & $1.76 \mathrm{E}-02$ & $1.11 \mathrm{E}+03$ & $1.11 \mathrm{E}-02$ \\
\hline${ }^{236} \mathrm{U}$ & $2.94 \mathrm{E}-01$ & $1.85 \mathrm{E}+04$ & $1.85 \mathrm{E}-01$ \\
\hline${ }^{238} \mathrm{U}$ & $3.16 \mathrm{E}-01$ & $1.99 \mathrm{E}+04$ & $1.99 \mathrm{E}-01$ \\
\hline${ }^{93} \mathrm{Zr}$ & $2.44 \mathrm{E}+00$ & $1.54 \mathrm{E}+05$ & $1.54 \mathrm{E}+00$ \\
\hline \hline Total & $1.97 \mathrm{E}+03$ & $1.24 \mathrm{E}+08$ & $1.24 \mathrm{E}+03$ \\
\hline
\end{tabular}


Table 8.3-2. Summary of Analysis Variations for Major Cases Evaluated in TSPA-1995

\begin{tabular}{|c|c|c|c|}
\hline $\begin{array}{l}\text { Thermo- } \\
\text { hydrologic } \\
\text { Modeling }\end{array}$ & $\begin{array}{l}\text { Areal Power } \\
\text { Loading } \\
\text { (MTU/acre) }\end{array}$ & $\begin{array}{c}\text { Backfill } \\
\text { Configuration }\end{array}$ & Infiltration $^{3)}$ \\
\hline \multirow[t]{8}{*}{ FEHM ${ }^{1)}$} & \multirow[t]{4}{*}{25} & \multirow[t]{2}{*}{ No } & Low \\
\hline & & & High \\
\hline & & \multirow[t]{2}{*}{ Yes } & Low \\
\hline & & & High \\
\hline & \multirow[t]{4}{*}{83} & \multirow[t]{2}{*}{ No } & Low \\
\hline & & & High \\
\hline & & \multirow[t]{2}{*}{ Yes } & Low \\
\hline & & & High \\
\hline \multirow[t]{4}{*}{ TOUGH ${ }^{2)}$} & \multirow[t]{2}{*}{24} & No & 0 \\
\hline & & Yes & 0 \\
\hline & \multirow[t]{2}{*}{80} & No & 0 \\
\hline & & Yes & 0 \\
\hline
\end{tabular}

1) FEHM modeling by S. Lingineni (see Chapter 4).

2) TOUGH modeling by T. Buscheck provided for comparison purposes (Buscheck, et al., 1995).

3) Low infiltration range: 0.01 to $0.05 \mathrm{~mm} / \mathrm{yr}$; High infiltration range: 0.5 to $2.0 \mathrm{~mm} / \mathrm{yr}$ 
Table 8.3-3. Waste Package Degradation Information for Major Cases as Implemented in RIP Simulations

\begin{tabular}{|c|c|c|c|c|c|c|c|c|}
\hline \multirow{3}{*}{ Case } & \multirow{2}{*}{\multicolumn{2}{|c|}{$\begin{array}{c}\text { \# of Packages with } \\
\text { at Least } 1 \text { Pit } \\
\text { Penetration in } \\
100,000 \text { years }{ }^{1)} \\
\end{array}$}} & \multicolumn{6}{|c|}{ Time to First Pit Penetration for Each Waste Package Group (years) } \\
\hline & & & \multirow{2}{*}{$\frac{1}{\overline{\text { mean }}}$} & \multirow{2}{*}{$\begin{array}{c}2 \\
\text { mean }\end{array}$} & \multirow{2}{*}{$\frac{3}{\overline{\text { mean }}}$} & \multirow{2}{*}{$\begin{array}{c}4 \\
\text { mean }\end{array}$} & \multirow{2}{*}{$\begin{array}{c}5 \\
\text { mean }\end{array}$} & \multirow{2}{*}{$\frac{6}{\text { mean }}$} \\
\hline & $\begin{array}{c}\text { Spent } \\
\text { Fuel }{ }^{2)} \\
\end{array}$ & DHLW ${ }^{3)}$ & & & & & & \\
\hline $25 / \mathrm{N} / \mathrm{L}$ & 1116 & 564 & 1797 & 2434 & 3247 & 3961 & 7741 & 47119 \\
\hline $25 / \mathrm{N} / \mathrm{H}$ & 2184 & 1098 & 2813 & 4130 & 5330 & 10266 & 29182 & 69958 \\
\hline $25 / \mathrm{Y} / \mathrm{L}$ & 840 & 420 & 2831 & 4276 & 6694 & 17600 & 45275 & 79242 \\
\hline $25 / \mathrm{Y} / \mathrm{H}$ & 2088 & 1050 & 2353 & 3853 & 5383 & 7551 & 15613 & 59021 \\
\hline $83 / \mathrm{N} / \mathrm{L}$ & 5658 & 2850 & 1435 & 1978 & 2362 & 2797 & 3954 & 11844 \\
\hline $83 / \mathrm{N} / \mathrm{H}$ & 6000 & 3030 & 1348 & 1845 & 2179 & 2848 & 4408 & 16517 \\
\hline $83 / \mathrm{Y} / \mathrm{L}$ & 5064 & 2556 & 1790 & 2476 & 2906 & 3459 & 4560 & 11611 \\
\hline $83 / \mathrm{Y} / \mathrm{H}$ & 5358 & 2700 & 1651 & 2217 & 2695 & 3481 & 4406 & 7178 \\
\hline
\end{tabular}

1) Packages which pitted after 100,000 years and before $1,000,000$ years were assumed to fail log-uniformly over that period of time.

2) Total number of spent fuel packages $=6468$.

3) Total number of DHLW packages $=3829$. 
Table 8.3-4. Comparison of NRC Release Rate Limit with an Expected Value Case for up to 100,000 years (83 MTU/acre, no backfill, and high infiltration rate. RH criteria for corrosion initiation ${ }^{1)}$ )

\begin{tabular}{|c|c|c|c|c|}
\hline \multirow{2}{*}{$\begin{array}{l}\text { Radio- } \\
\text { nuclide }\end{array}$} & \multirow{2}{*}{$\begin{array}{c}\text { NRC } \\
\text { Limit } \\
\text { (Ci/yr) }\end{array}$} & \multicolumn{3}{|c|}{83 MTU/acre, No Backfill and High Infiltration Rate Case } \\
\hline & & $\begin{array}{c}\text { Max. Release } \\
\text { Rate } \\
(\mathbf{C i} / \mathbf{y r}) \\
\end{array}$ & $\begin{array}{c}\text { Time for Max. } \\
\text { Release Rate } \\
\text { (years) }\end{array}$ & $\begin{array}{c}\text { Max. Release Rate/ } \\
\text { NRC Limit }\end{array}$ \\
\hline${ }^{227} \mathrm{Ac}$ & $2.45 \mathrm{E}-04$ & $1.54 \mathrm{E}-02$ & 16,600 & $6.28 \mathrm{E}+01$ \\
\hline${ }^{241} \mathrm{Am}$ & $6.69 \mathrm{E}+02$ & $8.92 \mathrm{E}+00$ & 2,200 & 1.33E-02 \\
\hline${ }^{242 \mathrm{M}} \mathrm{Am}$ & $1.68 \mathrm{E}-01$ & $5.38 \mathrm{E}-05$ & 2,200 & $3.20 \mathrm{E}-04$ \\
\hline${ }^{243} \mathrm{Am}$ & $1.47 \mathrm{E}+01$ & $2.11 \mathrm{E}+00$ & 16,600 & $1.43 \mathrm{E}-01$ \\
\hline${ }^{14} \mathrm{C}$ & $7.96 \mathrm{E}-01$ & $3.11 \mathrm{E}+01$ & 2,200 & $3.91 \mathrm{E}+01$ \\
\hline${ }^{36} \mathrm{Cl}$ & 7.13E-03 & 2.93E-01 & 2,200 & 4.11E+01 \\
\hline${ }^{244} \mathrm{Cm}$ & 4.19E-11 & $--{ }^{2)}$ & -- & -- \\
\hline${ }^{245} \mathrm{Cm}$ & $2.01 \mathrm{E}-01$ & $4.09 \mathrm{E}-08$ & 7,100 & 2.03E-07 \\
\hline${ }^{246} \mathrm{Cm}$ & $3.90 \mathrm{E}-02$ & $3.56 \mathrm{E}-05$ & 7,200 & 9.13E-04 \\
\hline${ }^{135} \mathrm{Cs}$ & 3.31E-01 & $7.39 \mathrm{E}+00$ & 2,200 & $2.23 \mathrm{E}+01$ \\
\hline${ }^{129} \mathrm{I}$ & $2.22 \mathrm{E}-02$ & $9.60 \mathrm{E}-01$ & 2,200 & 4.32E+01 \\
\hline${ }^{93 \mathrm{M}} \mathrm{Nb}$ & $1.46 \mathrm{E}+00$ & - & - & -- \\
\hline${ }^{94} \mathrm{Nb}$ & 5.16E-01 & 3.31E-02 & 16,600 & $6.41 \mathrm{E}-02$ \\
\hline${ }^{59} \mathrm{Ni}$ & $1.51 \mathrm{E}+00$ & $3.12 \mathrm{E}+01$ & 2,200 & $2.07 \mathrm{E}+01$ \\
\hline${ }^{63} \mathrm{Ni}$ & $1.34 \mathrm{E}-01$ & $8.96 \mathrm{E}-04$ & 2,100 & $6.69 \mathrm{E}-03$ \\
\hline${ }^{237} \mathrm{~Np}$ & 7.82E-01 & $2.10 \mathrm{E}+00$ & 16,600 & $2.68 \mathrm{E}+00$ \\
\hline${ }^{231} \mathrm{~Pa}$ & 2.44E-04 & $1.86 \mathrm{E}-02$ & 16,600 & $7.62 \mathrm{E}+01$ \\
\hline${ }^{210} \mathrm{~Pb}$ & 2.36E-03 & $1.26 \mathrm{E}+01$ & $100,000+{ }^{3)}$ & $5.34 \mathrm{E}+03$ \\
\hline${ }^{107} \mathrm{Pd}$ & 8.12E-02 & $1.69 \mathrm{E}+00$ & 2,200 & $2.08 \mathrm{E}+01$ \\
\hline${ }^{238} \mathrm{Pu}$ & $1.24 \mathrm{E}+00$ & 4.05E-06 & 2,100 & 3.27E-07 \\
\hline${ }^{239} \mathrm{Pu}$ & $2.24 \mathrm{E}+02$ & 7.19E-01 & 16,700 & $3.21 \mathrm{E}-03$ \\
\hline${ }^{240} \mathrm{Pu}$ & $3.09 \mathrm{E}+02$ & 5.39E-01 & 4,500 & $1.74 \mathrm{E}-03$ \\
\hline${ }^{241} \mathrm{Pu}$ & $2.01 \mathrm{E}-01$ & - & - & -- \\
\hline
\end{tabular}


Table 8.3-4. Comparison of NRC Release Rate Limit with an Expected Value case for up to 100,000 years (83 MTU/acre, no backfill, and high infiltration rate. RH switch for corrosion initiation. ${ }^{1)}$ ) (Continued)

\begin{tabular}{|c|c|c|c|c|}
\hline \multirow{2}{*}{$\begin{array}{l}\text { Radio- } \\
\text { nuclide }\end{array}$} & \multirow{2}{*}{$\begin{array}{l}\text { NRC } \\
\text { Limit } \\
\text { (Ci/yr) }\end{array}$} & \multicolumn{3}{|c|}{83 MTU/acre, No Backfill and High Infiltration Rate Case } \\
\hline & & $\begin{array}{c}\text { Max. Release } \\
\text { Rate } \\
(\mathbf{C i} / \mathrm{yr}) \\
\end{array}$ & $\begin{array}{c}\text { Time for Max. } \\
\text { Release Rate } \\
\text { (years) }\end{array}$ & $\begin{array}{c}\text { Max. Release Rate/ } \\
\text { NRC Limit } \\
\end{array}$ \\
\hline${ }^{242} \mathrm{Pu}$ & $1.30 \mathrm{E}+00$ & 2.32E-02 & $100,000+$ & $1.78 \mathrm{E}-02$ \\
\hline${ }^{226} \mathrm{Ra}$ & 2.37E-03 & $1.69 \mathrm{E}+01$ & $100,000+$ & $7.13 \mathrm{E}+03$ \\
\hline${ }^{228} \mathrm{Ra}$ & 8.93E-09 & $1.51 \mathrm{E}-03$ & $100,000+$ & $1.68 \mathrm{E}+05$ \\
\hline${ }^{79} \mathrm{Se}$ & $2.82 \mathrm{E}-01$ & $6.21 \mathrm{E}+00$ & 2,200 & $2.20 \mathrm{E}+01$ \\
\hline${ }^{151} \mathrm{Sm}$ & $1.30 \mathrm{E}-01$ & 7.32E-04 & 2,100 & 5.63E-03 \\
\hline${ }^{126} \mathrm{Sn}$ & $5.46 \mathrm{E}-01$ & $1.62 \mathrm{E}-02$ & 16,600 & 2.97E-02 \\
\hline${ }^{99} \mathrm{Tc}$ & $9.03 \mathrm{E}+00$ & $2.00 \mathrm{E}+02$ & 2,200 & $2.21 \mathrm{E}+01$ \\
\hline${ }^{229} \mathrm{Th}$ & $1.01 \mathrm{E}-04$ & $1.62 \mathrm{E}-03$ & $100,000+$ & $1.60 \mathrm{E}+01$ \\
\hline${ }^{230} \mathrm{Th}$ & $1.32 \mathrm{E}-02$ & $5.05 \mathrm{E}-03$ & 166,600 & $3.82 \mathrm{E}+01$ \\
\hline${ }^{232} \mathrm{Th}$ & 8.93E-09 & 2.32E-08 & $100,000+$ & $2.60 \mathrm{E}+00$ \\
\hline${ }^{233} \mathrm{U}$ & $2.55 \mathrm{E}-03$ & 3.82E-04 & $100,000+$ & $1.50 \mathrm{E}-01$ \\
\hline${ }^{234} \mathrm{U}$ & $1.58 \mathrm{E}+00$ & $7.29 \mathrm{E}-03$ & 16,600 & $4.61 \mathrm{E}-03$ \\
\hline${ }^{235} \mathrm{U}$ & $1.11 \mathrm{E}-02$ & $2.22 \mathrm{E}-05$ & 35,100 & $2.00 \mathrm{E}-03$ \\
\hline${ }^{236} \mathrm{U}$ & $1.85 \mathrm{E}-01$ & 3.35E-04 & 28,000 & $1.81 \mathrm{E}-03$ \\
\hline${ }^{238} \mathrm{U}$ & $1.99 \mathrm{E}-01$ & 3.33E-04 & 16,600 & 1.67E-03 \\
\hline${ }^{93} \mathrm{Zr}$ & $1.54 \mathrm{E}+00$ & 2.63E-04 & 16,600 & $1.71 \mathrm{E}-04$ \\
\hline
\end{tabular}

1) This case yielded the most conservative results (the largest release rates).

2) -- Indicates that the maximum release rate was very small and is not reported.

3) $100,000+$ indicates that the release rate was increasing at the end of the simulation. 
Table 8.3-5. Radionuclides Considered for the Comparison with the NRC EBS Release Rate Limit in TSPA-1995 ${ }^{1)}$ and TSPA-19932)

\begin{tabular}{||c|c|c|c|c||}
\hline \multirow{2}{*}{$\begin{array}{c}\text { Radio- } \\
\text { Nuclide }\end{array}$} & $\begin{array}{c}\text { Maximum } \\
\text { Release Rate } \\
\text { (Ci/yr) }\end{array}$ & $\begin{array}{c}\text { Time for Max. } \\
\text { Release Rate } \\
\text { (years) }\end{array}$ & $\begin{array}{c}\text { Maximum } \\
\text { Release Rate } \\
\text { (Ci/yr) }\end{array}$ & $\begin{array}{c}\text { Time for Max. } \\
\text { Release Rate } \\
\text { (years) }\end{array}$ \\
\hline \hline${ }^{14} \mathrm{C}$ & $3.11 \mathrm{E}+01$ & 2,200 & $6.20 \mathrm{E}+00$ & 1,000 \\
\hline${ }^{135} \mathrm{Cs}$ & $7.39 \mathrm{E}+00$ & 2,200 & $1.90 \mathrm{E}+00$ & 1,500 \\
\hline${ }^{59} \mathrm{Ni}$ & $3.12 \mathrm{E}+01$ & 2,200 & $6.30 \mathrm{E}+00$ & 2,000 \\
\hline${ }^{237} \mathrm{~Np}$ & $2.10 \mathrm{E}+00$ & 16,600 & $3.90 \mathrm{E}+00$ & 7,000 \\
\hline${ }^{210} \mathrm{~Pb}$ & $1.26 \mathrm{E}+01$ & $100,000+{ }^{3)}$ & $1.90 \mathrm{E}+00$ & 60,000 \\
\hline${ }^{107} \mathrm{Pd}$ & $1.69 \mathrm{E}+00$ & 2,200 & $-\ldots+-{ }^{4)}$ & $-\ldots{ }^{4)}$ \\
\hline${ }^{226} \mathrm{Ra}$ & $1.69 \mathrm{E}+01$ & $100,000+^{3)}$ & $1.30 \mathrm{E}+00$ & 20,000 \\
\hline${ }^{79} \mathrm{Se}$ & $6.21 \mathrm{E}+00$ & 2,200 & $1.60 \mathrm{E}+00$ & 2,000 \\
\hline${ }^{99} \mathrm{Tc}$ & $2.00 \mathrm{E}+02$ & 2,200 & $6.00 \mathrm{E}+01$ & 1,500 \\
\hline
\end{tabular}

1) Nuclides were selected based on the case that yielded the most conservative results: 83 MTU/acre with no backfill, high infiltration rate, and using the $\mathrm{RH}$ criteria for corrosion initiation of the outer barrier. The waste container design assumed a 10-cm thick carbon steel outer barrier and a 2 -cm thick Alloy 825 inner barrier.

2) Nuclides were selected based on the "reference" design that yielded the most conservative results: $57 \mathrm{~kW} /$ acre, a $10-\mathrm{cm}$ thick (carbon steel) outer barrier, a $0.95-\mathrm{cm}$ (Alloy 825) inner barrier, using water saturation as the corrosion initiation for aqueous corrosion, and using Westinghouse model for aqueous corrosion rate (Andrews, et al., 1994).

3) $100,000+$ indicates that the release rate was increasing at the end of the simulation.

4) Not included. 
Table 8.3-6. Regression Statistics for 10,000 Year EBS Peak Release Rate for the Case of 25 MTU/acre, no Backfill, High Infiltration Rate

\begin{tabular}{|c|c|c|c|c|c|c|}
\hline \multirow[t]{2}{*}{ Parameter } & \multicolumn{2}{|c|}{ 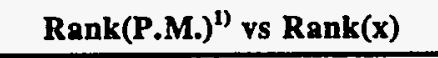 } & \multicolumn{2}{|c|}{$\ln \left(P . M_{.}\right)$vs $x$} & \multicolumn{2}{|c|}{$\ln ($ P.M.) v8 $\ln (x)$} \\
\hline & $\begin{array}{c}\text { Rank } \\
\text { Importance }\end{array}$ & $\begin{array}{c}\% \text { of } \\
\text { Variance } \\
\text { Explained }^{2)}\end{array}$ & $\begin{array}{c}\text { Rank } \\
\text { Importance }\end{array}$ & $\begin{array}{c}\% \text { of } \\
\text { Variance } \\
\text { Explained }\end{array}$ & $\begin{array}{c}\text { Rank } \\
\text { Importance }\end{array}$ & $\begin{array}{c}\% \text { of } \\
\text { Variance } \\
\text { Explained }^{2)}\end{array}$ \\
\hline Solubility Cs & 4 & 73 & & & & \\
\hline Solubility Ni & & & 3 & 32 & & \\
\hline Solubility Np & 5 & 74 & 4 & 34 & 4 & 80 \\
\hline Solubility $\mathrm{Pb}$ & & & & & 5 & 80 \\
\hline \multicolumn{7}{|l|}{ Solubility Se } \\
\hline Solubility Tc & 1 & 51 & & & 1 & 51 \\
\hline \multicolumn{7}{|l|}{$\begin{array}{l}\text { Waste Package } \\
\mathrm{f}_{\text {drip }}{ }^{3)}\end{array}$} \\
\hline \multicolumn{7}{|l|}{$q_{\text {drip }}{ }^{4)}$} \\
\hline $\mathrm{q}_{\mathrm{inf}}(\mathrm{UZ})^{5)}$ & 2 & 62 & 2 & 28 & 3 & 79 \\
\hline \multicolumn{7}{|l|}{$\begin{array}{l}\text { Surface Area of } \\
\text { DHLW }\end{array}$} \\
\hline $\begin{array}{l}\text { Eff. Diff. } \\
\text { Coeff. }\end{array}$ & & & 5 & 37 & & \\
\hline \multicolumn{7}{|l|}{$\begin{array}{l}\text { Glass Diss. } \\
\text { Rate }\end{array}$} \\
\hline SF Diss. Rate & 3 & 73 & 1 & 18 & 2 & 65 \\
\hline
\end{tabular}

1) P.M. = the performance measure (in this case EBS peak release rate)

2) \% of variance explained by parameters ranked less than or equal to the given parameter, e.g., for parameter with rank 3 , the number listed is the \% variance explained by the parameters ranked 1,2 , and 3 , together.

3) Fraction of waste packages with drips.

4) $q_{\text {drip }}=$ flux of dripping fractures

5) $\mathrm{q}_{\mathrm{inf}}(\mathrm{UZ})=$ percolation rate in unsaturated zone 
Table 8.3-7. Regression Statistics for 10,000 Year EBS Peak Release Rate for the Case of 83MTU/acre, no Backfill, High Infiltration Rate

\begin{tabular}{|c|c|c|c|c|c|c|}
\hline \multirow[b]{2}{*}{ Parameter } & \multicolumn{2}{|c|}{$\operatorname{Rank}(\text { P.M. })^{1)}$ vs $\operatorname{Rank}(x)$} & \multicolumn{2}{|c|}{$\ln \left(P_{. M}\right.$.) $)$ vs $x$} & \multicolumn{2}{|c|}{$\ln ($ P.M. $)$ v8 $\ln (x)$} \\
\hline & $\underset{\text { Rank }}{\text { Importance }}$ & $\begin{array}{c}\begin{array}{c}\% \text { of } \\
\text { Variance } \\
\text { Explained }\end{array} \\
\end{array}$ & $\begin{array}{c}\text { Rank } \\
\text { Importance }\end{array}$ & $\begin{array}{c}\begin{array}{c}\% \text { of } \\
\text { Variance } \\
\text { Explained }^{2)}\end{array} \\
\end{array}$ & $\begin{array}{c}\text { Rank } \\
\text { Importance }\end{array}$ & $\begin{array}{c}\% \text { of } \\
\text { Variance } \\
\text { Explained } \\
\end{array}$ \\
\hline Solubility Cs & & & 5 & 46 & & \\
\hline Solubility $\mathrm{Ni}$ & 5 & 91 & & & 5 & 89 \\
\hline \multicolumn{7}{|l|}{ Solubility Np } \\
\hline \multicolumn{7}{|l|}{ Solubility $\mathrm{Pb}$} \\
\hline \multicolumn{7}{|l|}{ Solubility Se } \\
\hline Solubility Tc & 1 & 60 & 3 & 41 & 1 & 51 \\
\hline \multicolumn{7}{|l|}{$\begin{array}{l}\text { Waste Package } \\
\mathrm{f}_{\text {drip }}{ }^{3}\end{array}$} \\
\hline \multicolumn{7}{|l|}{$\mathrm{q}_{\text {drip }}{ }^{4)}$} \\
\hline $\mathrm{q}_{\mathrm{inf}}(\mathrm{UZ})^{5)}$ & 3 & 91 & 2 & 33 & 3 & 87 \\
\hline $\begin{array}{l}\text { Surf. Area of } \\
\text { DHLW }\end{array}$ & 4 & 91 & 4 & 45 & 4 & 88 \\
\hline \multicolumn{7}{|l|}{ Eff. Diff. Coef. } \\
\hline \multicolumn{7}{|l|}{$\begin{array}{l}\text { Glass Diss. } \\
\text { Rate }\end{array}$} \\
\hline SF Diss. Rate & 2 & 80 & 1 & 25 & 2 & 76 \\
\hline
\end{tabular}

1) P.M. = the performance measure (in this case EBS peak release rate)

2) $\%$ of variance explained by parameters ranked less than or equal to the given parameter, e.g., for parameter with rank 3 , the number listed is the \% variance explained by the parameters ranked 1,2 , and 3 , together.

3) fraction of waste packages with drips.

4) $\mathrm{q}_{\text {drip }}=$ flux of dripping fractures

5) $\mathrm{q}_{\mathrm{inf}}(\mathrm{UZ})=$ percolation rate in unsaturated zone 

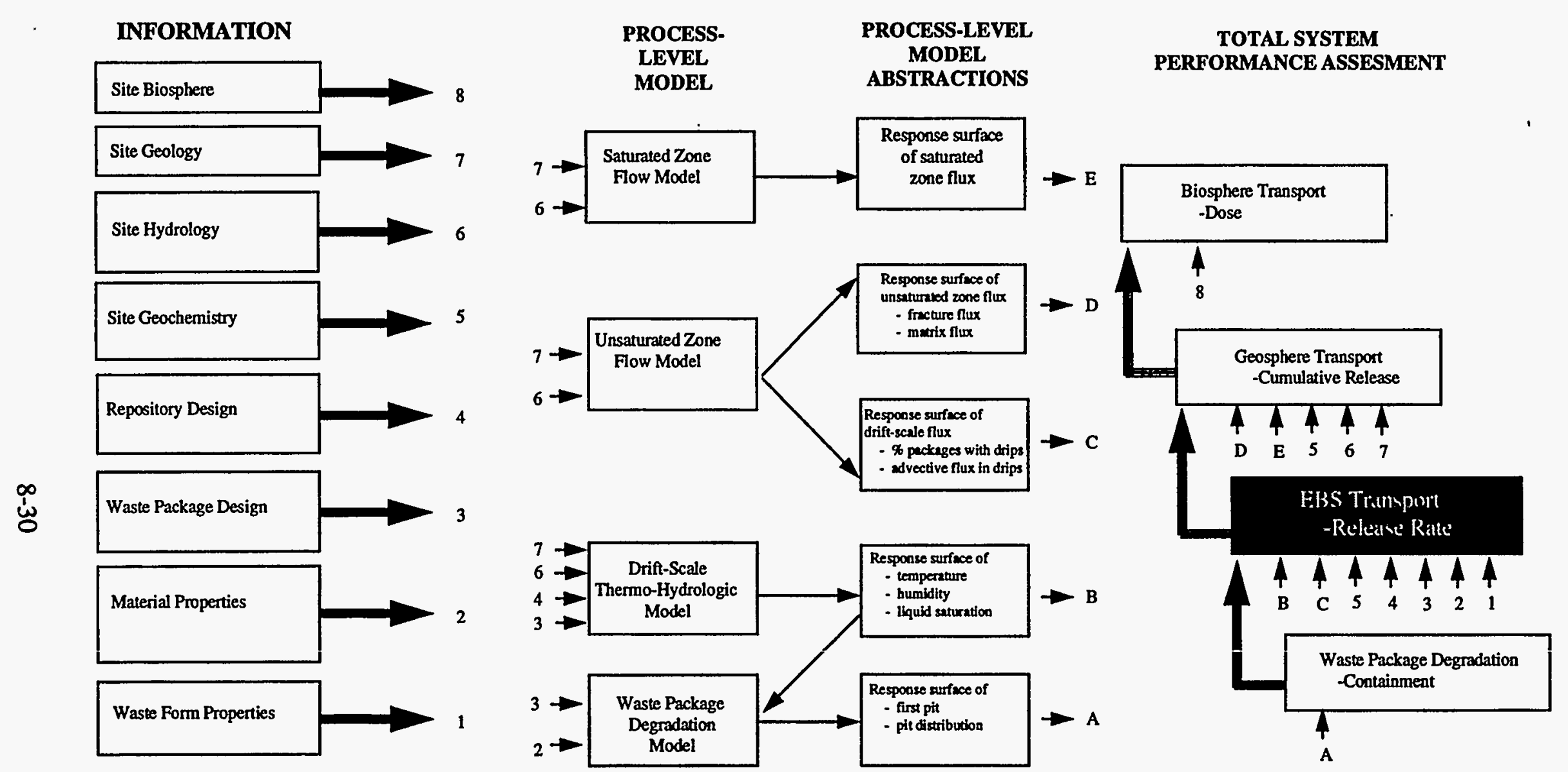

Figure 8.1-1 Relationship of Chapter 8 to the Overall Information Flow Diagram for TSPA 1995 (Figure 1.4-6) 


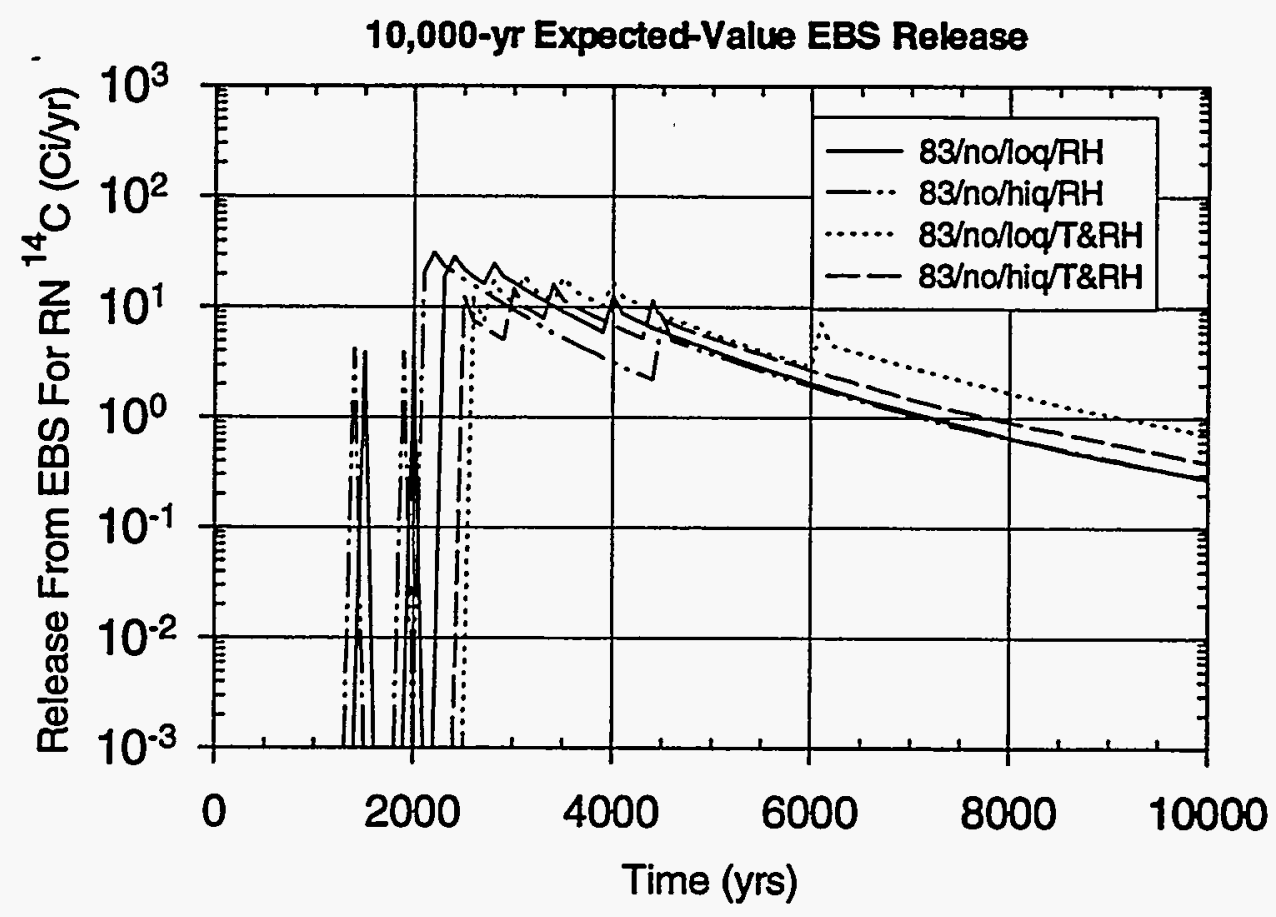

Figure 8.3-1a Sensitivity of the EBS release rate for ${ }^{14} \mathrm{C}$ to the initiation of the carbon steel outer barrier corrosion (NRC limit $=0.796 \mathrm{Ci} / \mathrm{yr}$ ).

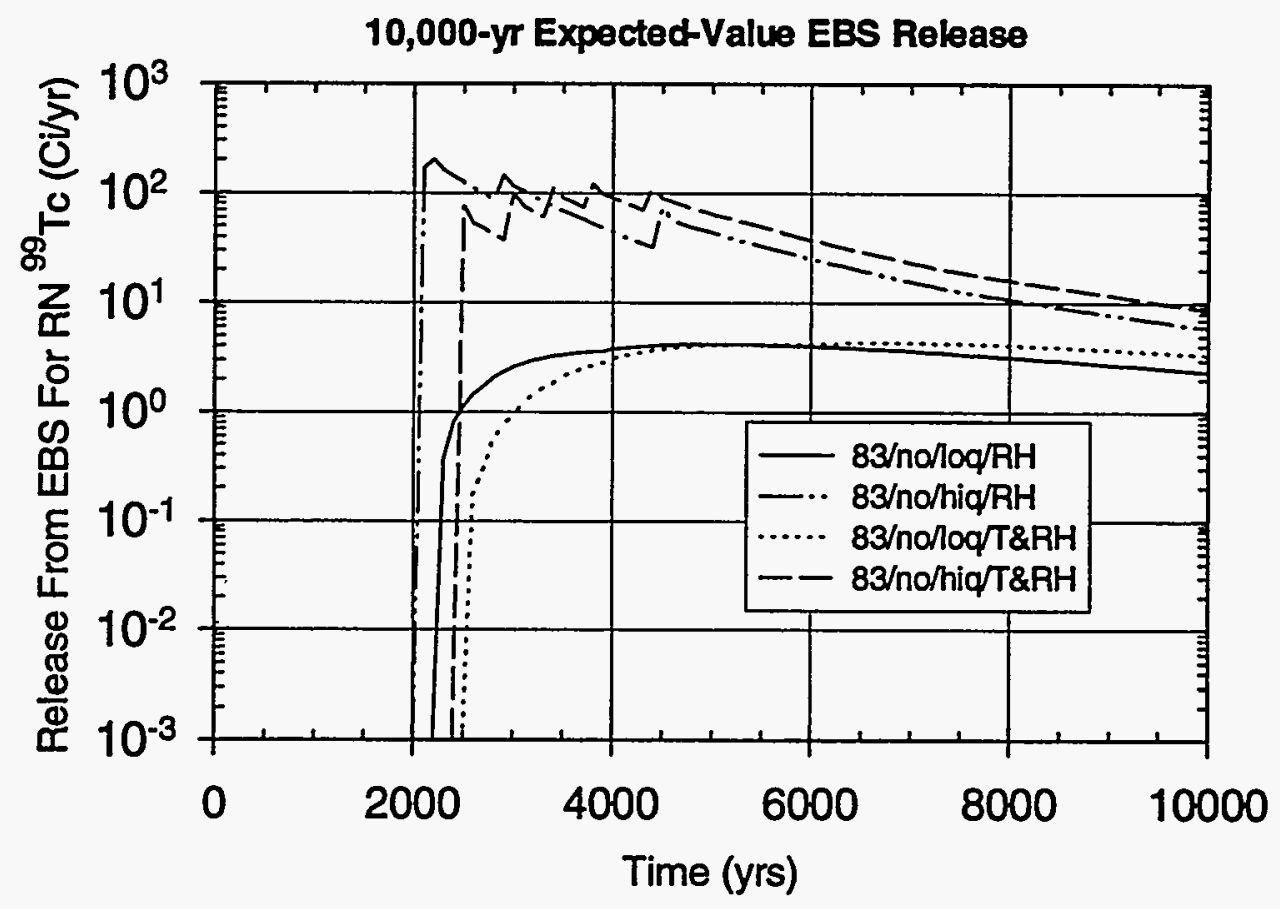

Figure 8.3-1b Sensitivity of the EBS release rate for ${ }^{99} \mathrm{Tc}$ to the initiation of the carbon steel outer barrier corrosion (NRC limit $=9.03 \mathrm{Ci} / \mathrm{yr}$ ). 


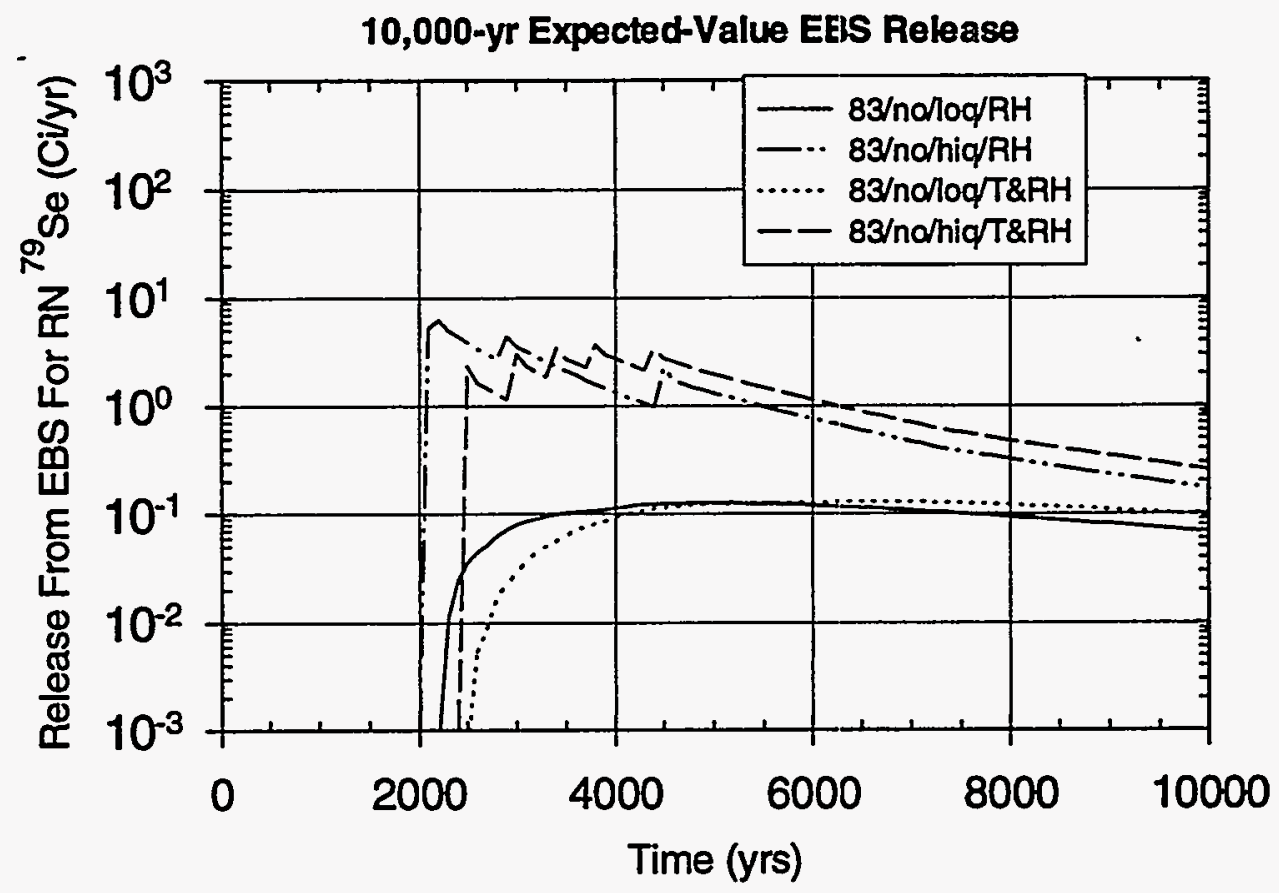

Figure 8.3-1c Sensitivity of the EBS release rate for ${ }^{79} \mathrm{Se}$ to the initiation of the carbon steel outer barrier corrosion (NRC limit $=0.282 \mathrm{Ci} / \mathrm{yr}$ ).

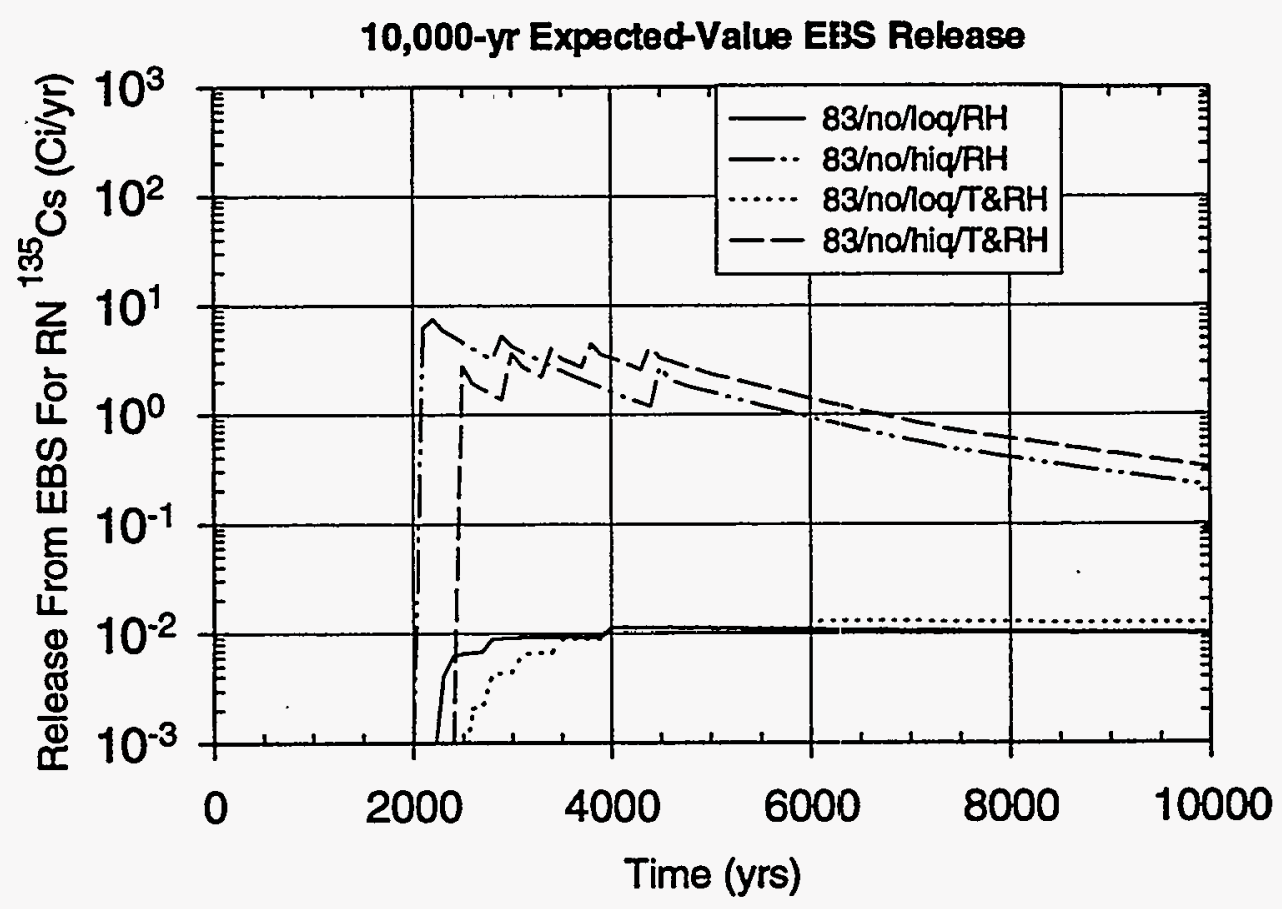

Figure 8.3-1d Sensitivity of the EBS release rate for ${ }^{135} \mathrm{Cs}$ to the initiation of the carbon steel outer barrier corrosion (NRC limit $=0.331 \mathrm{Ci} / \mathrm{yr}$ ). 


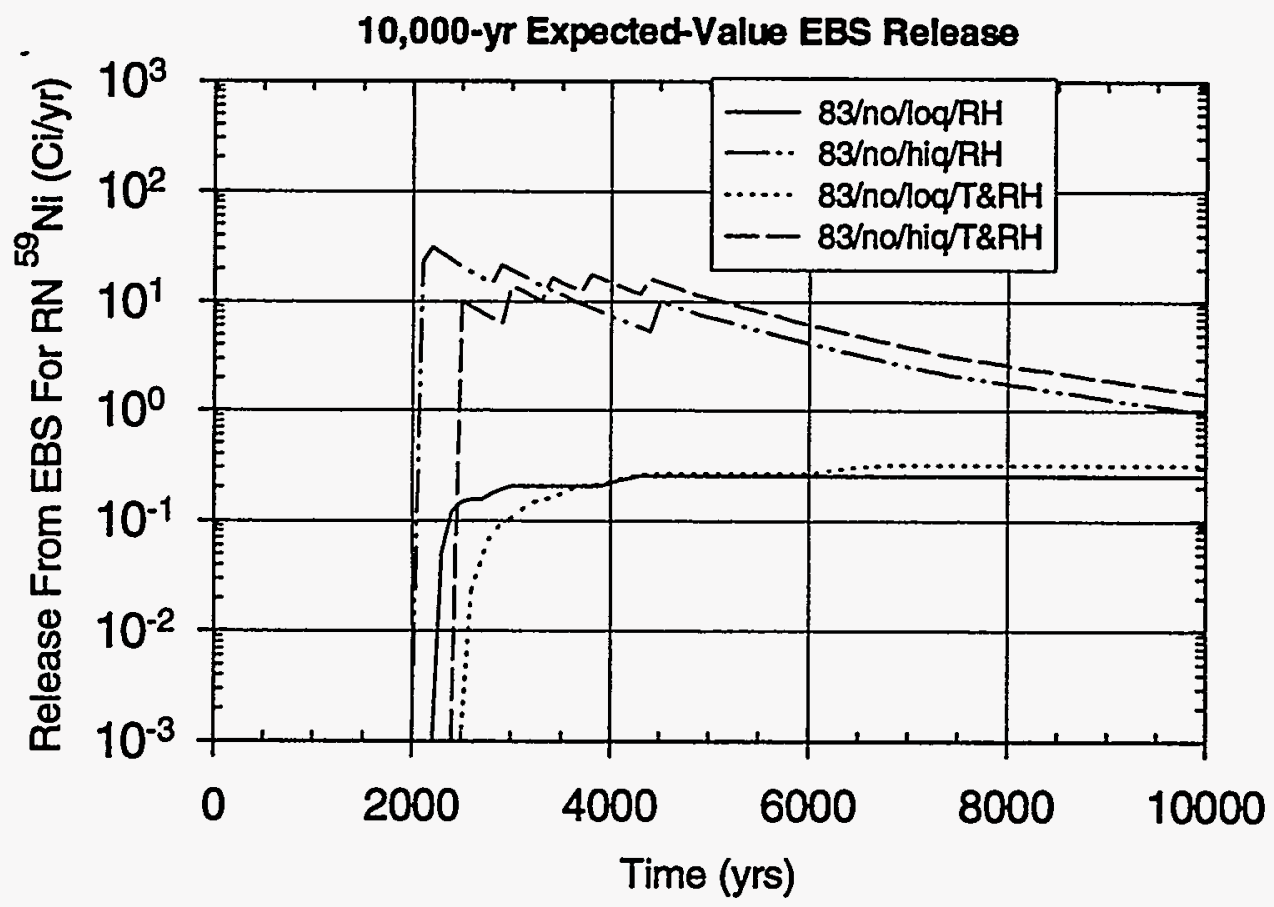

Figure 8.3-1e Sensitivity of the EBS release rate for ${ }^{59} \mathrm{Ni}$ to the initiation of the carbon steel outer barrier corrosion ( $\mathrm{NRC}$ limit $=1.51 \mathrm{Ci} / \mathrm{yr}$ ).

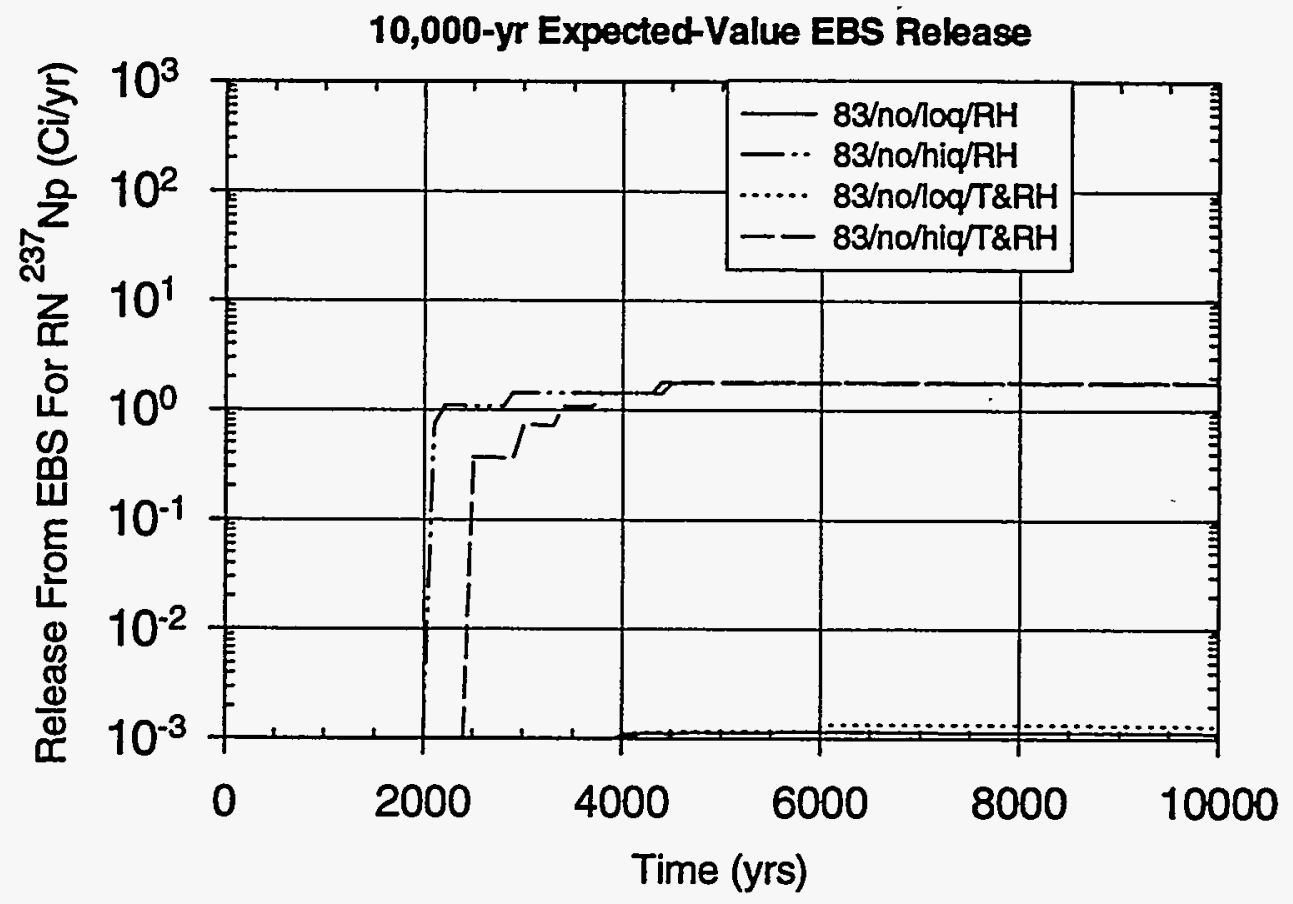

Figure 8.3-1f Sensitivity of the EBS release rate for ${ }^{237} \mathrm{~Np}$ to the initiation of the carbon steel outer barrier corrosion (NRC limit $=0.782 \mathrm{Ci} / \mathrm{yr}$ ). 


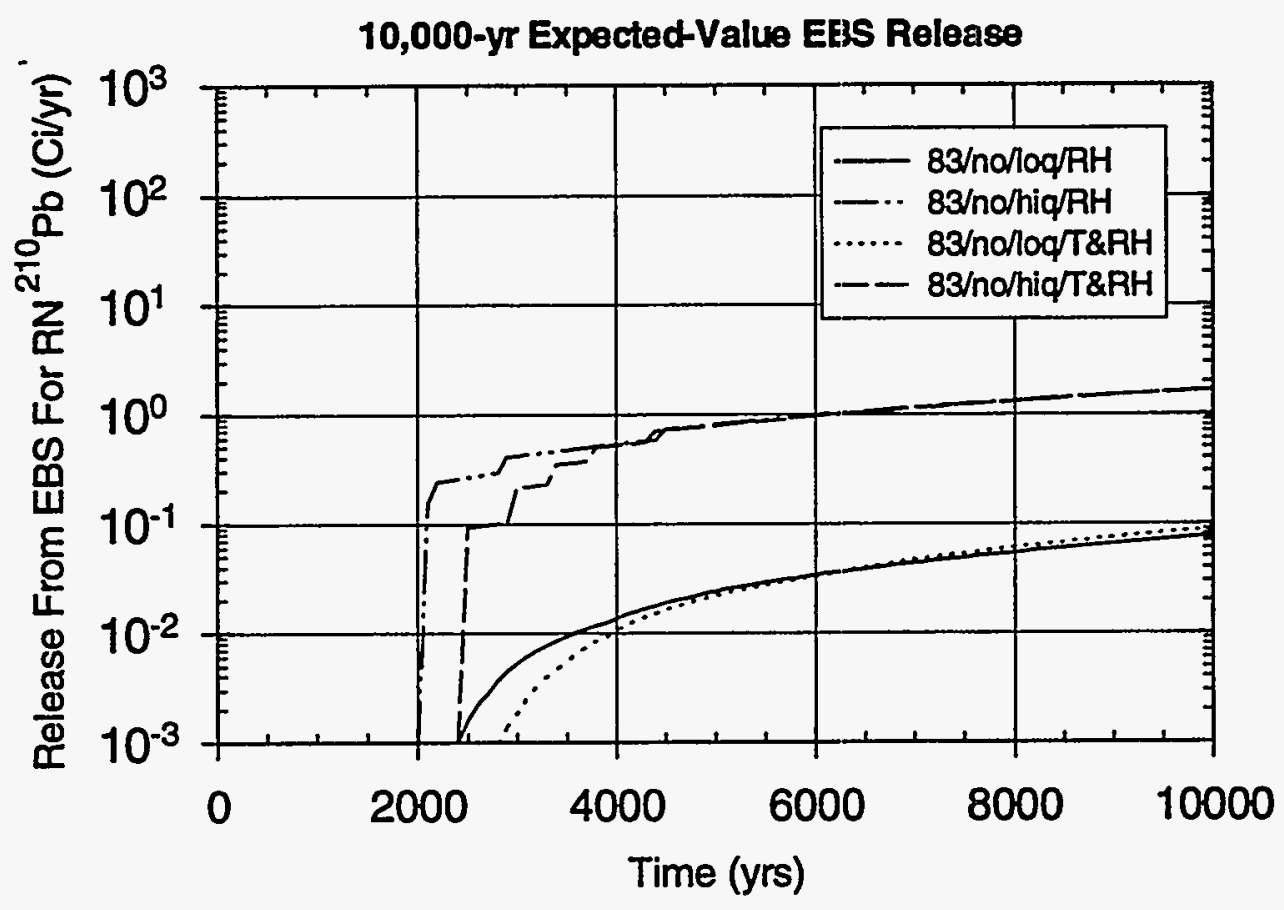

Figure $8.3-1 \mathrm{~g}$ Sensitivity of the EBS release rate for ${ }^{210} \mathrm{~Pb}$ to the initiation of the carbon steel outer barrier corrosion (NRC limit $=0.00236 \mathrm{Ci} / \mathrm{yr}$ ).

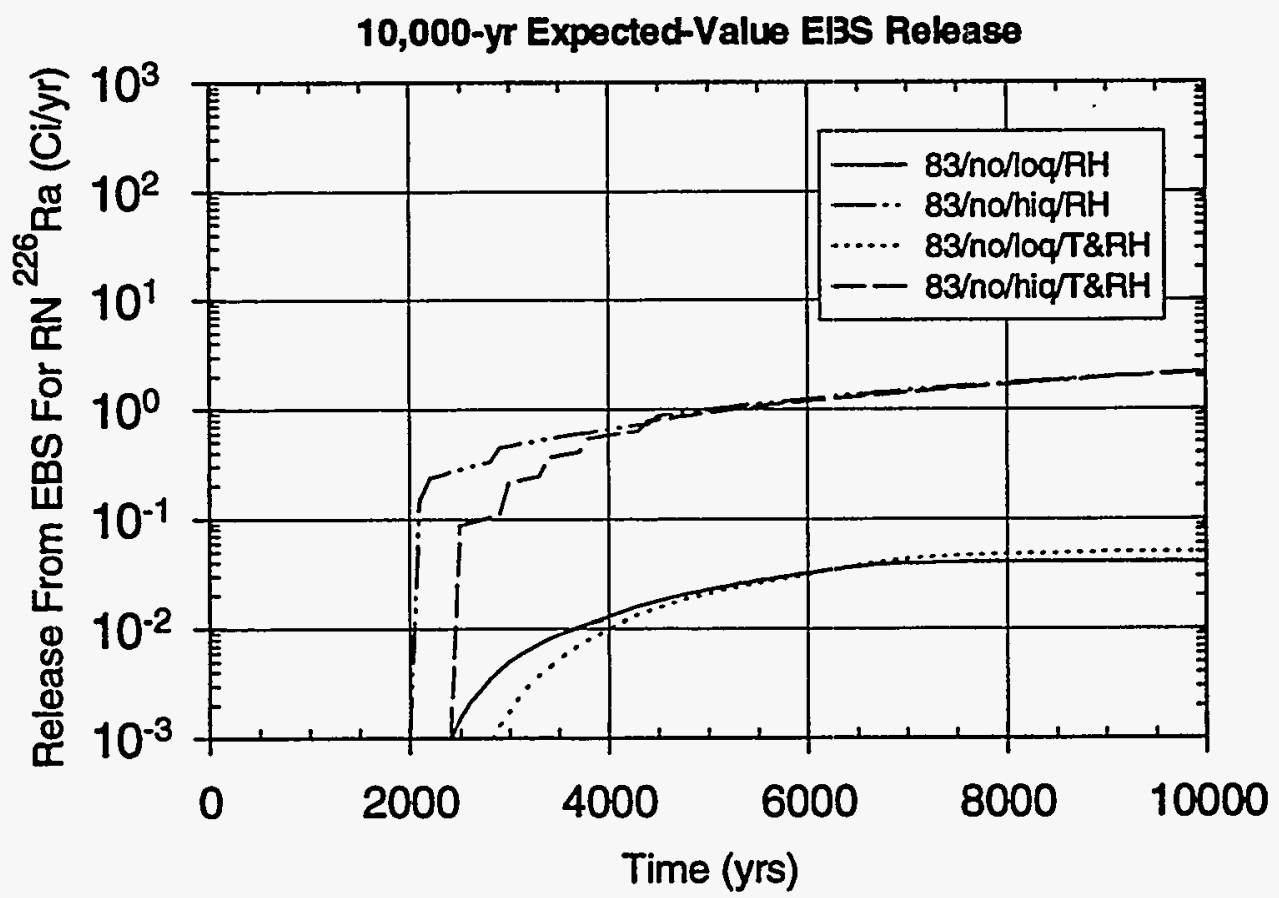

Figure 8.3-1h Sensitivity of the EBS release rate for ${ }^{226} \mathrm{Ra}$ to the initiation of the carbon steel outer barrier corrosion (NRC limit $=0.00237 \mathrm{Ci} / \mathrm{yr}$ ). 


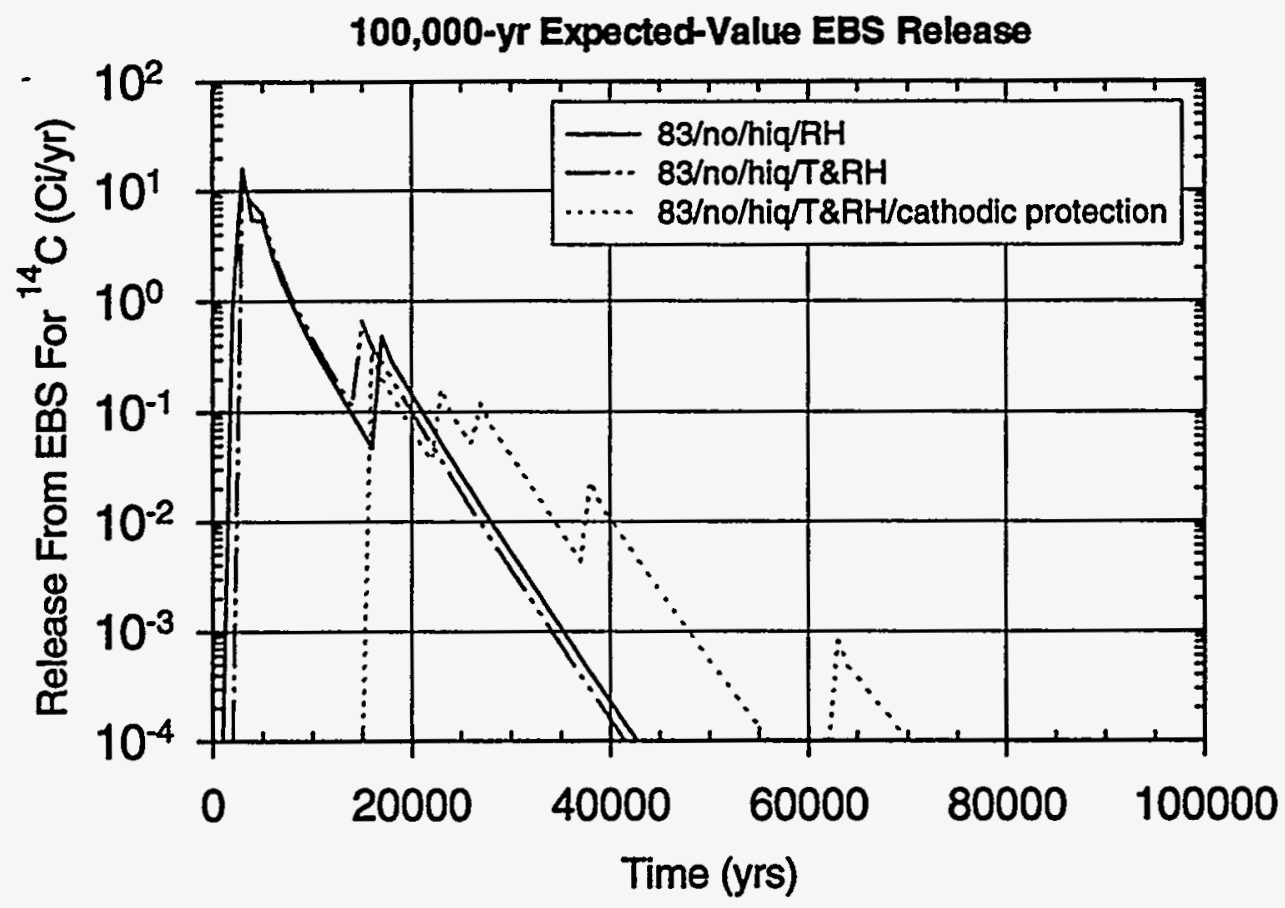

Figure 8.3-2a Sensitivity of the EBS release rate for ${ }^{14} \mathrm{C}$ to cathodic protection (NRC limit = $0.796 \mathrm{Ci} / \mathrm{yr})$.

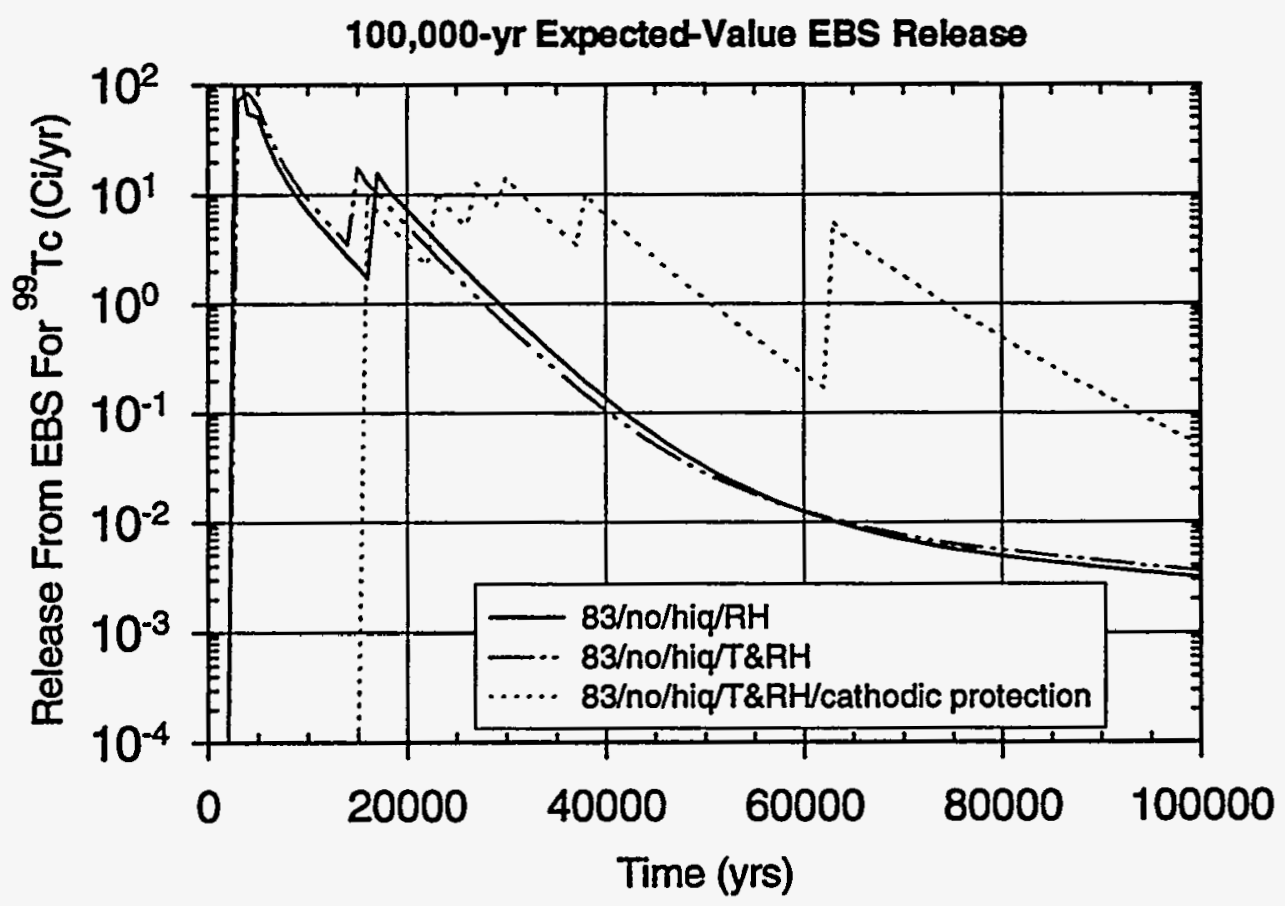

Figure 8.3-2b Sensitivity of the EBS release rate for ${ }^{99} \mathrm{Tc}$ to cathodic protection (NRC limit = $9.03 \mathrm{Ci} / \mathrm{yr})$. 


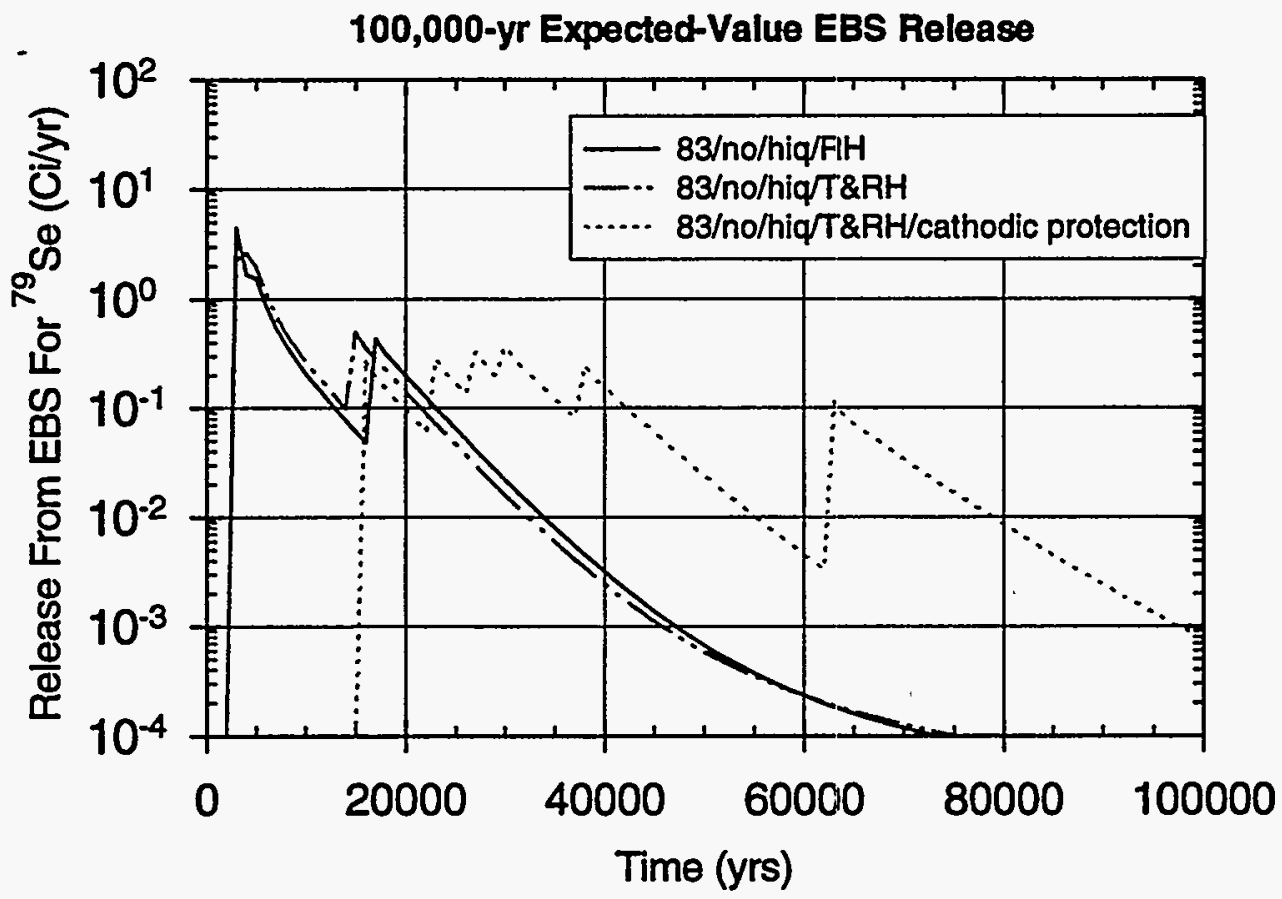

Figure 8.3-2c Sensitivity of the EBS release rate for ${ }^{79} \mathrm{Se}$ to cathodic protection (NRC limit = $0.282 \mathrm{Ci} / \mathrm{yr})$.

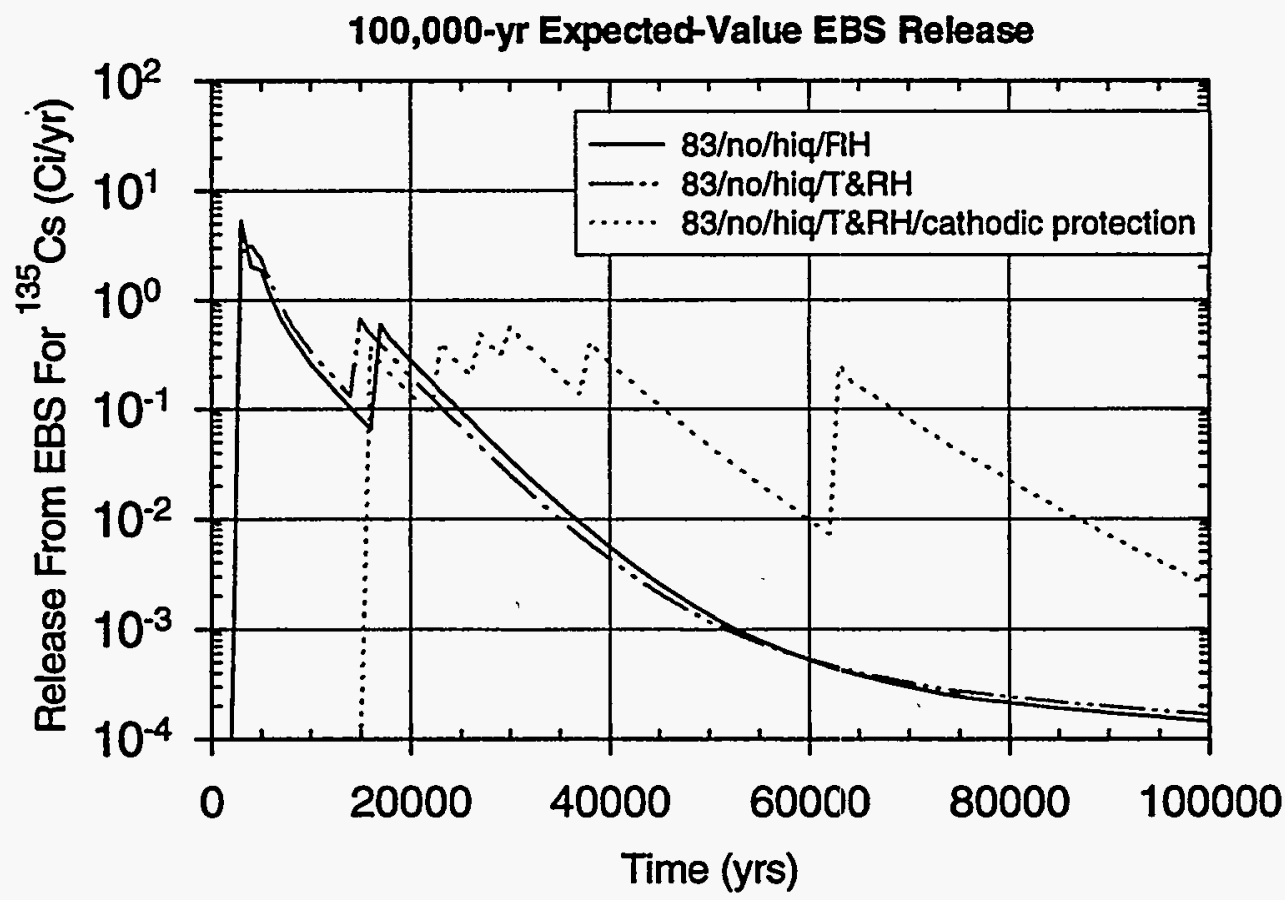

Figure 8.3-2d Sensitivity of the EBS release rate for ${ }^{135} \mathrm{Cs}$ to cathodic protection (NRC limit = $0.331 \mathrm{Ci} / \mathrm{yr}$ ). 


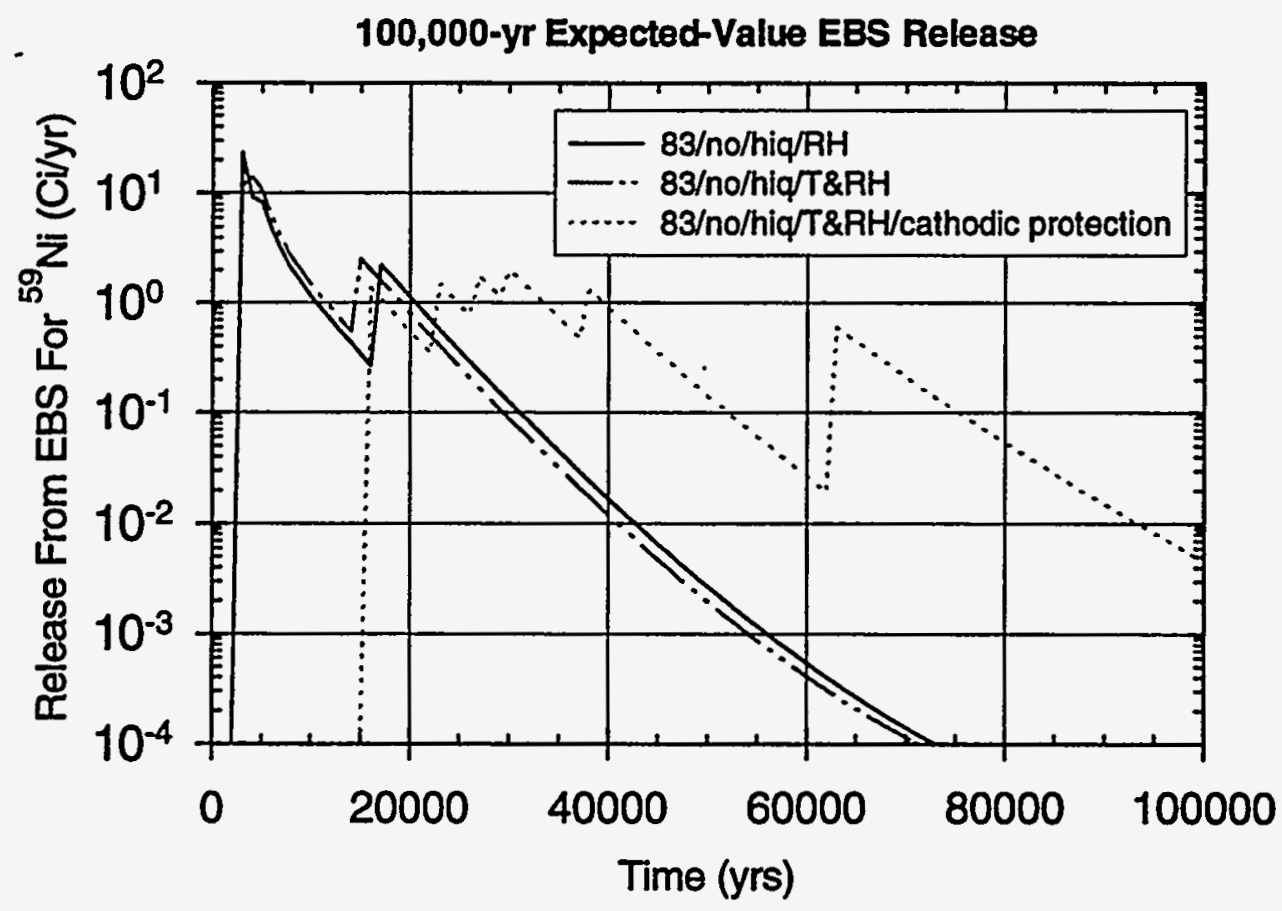

Figure 8.3-2e Sensitivity of the EBS release rate for ${ }^{59} \mathrm{Ni}$ to cathodic protection (NRC limit = $1.51 \mathrm{Ci} / \mathrm{yr})$.

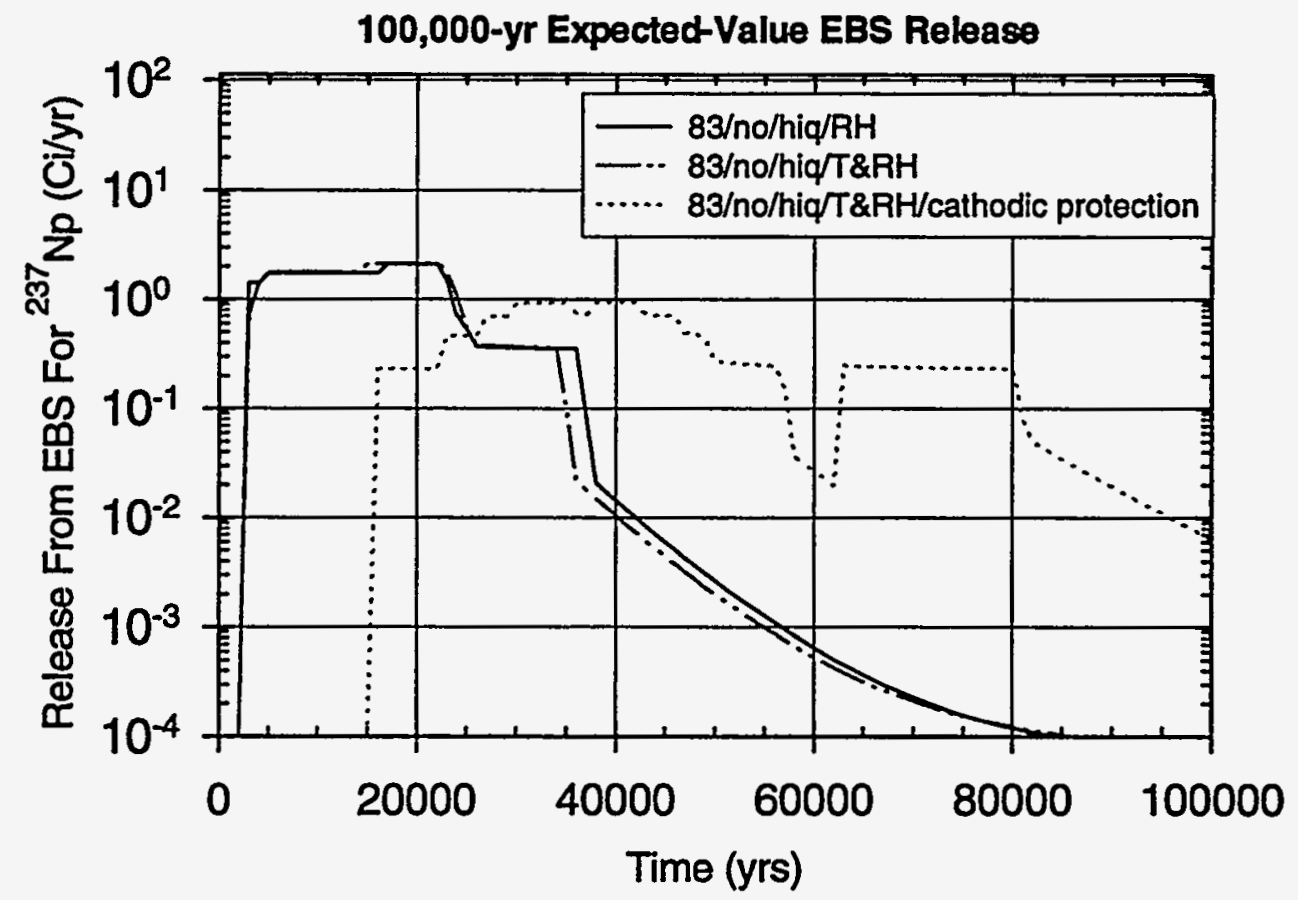

Figure 8.3-2f Sensitivity of the EBS release rate for ${ }^{237} \mathrm{~Np}$ to cathodic protection (NRC limit = $0.782 \mathrm{Ci} / \mathrm{yr}$ ). 


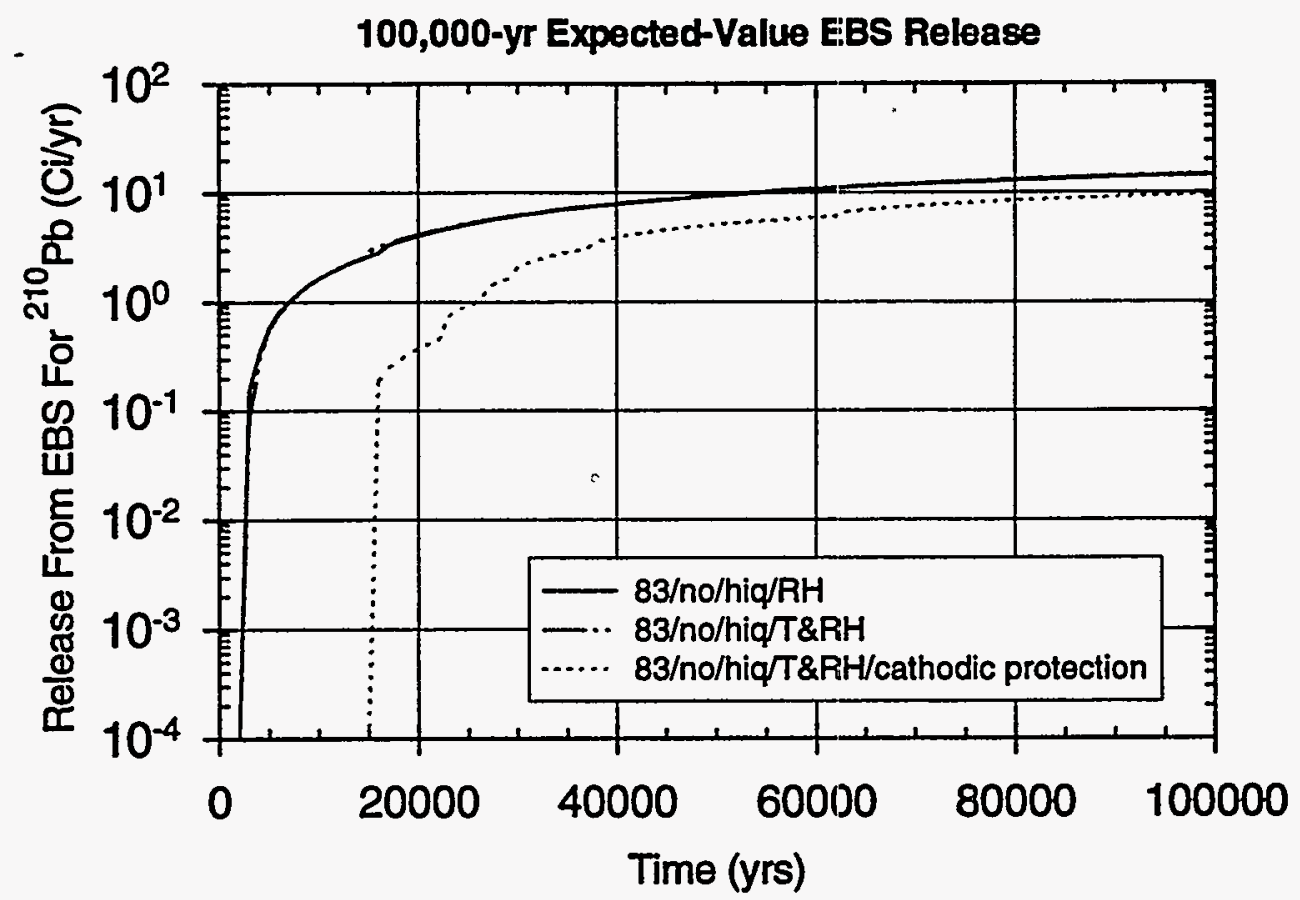

Figure $8.3-2 \mathrm{~g}$ Sensitivity of the EBS release rate for ${ }^{210} \mathrm{~Pb}$ to cathodic protection (NRC limit = $0.00236 \mathrm{Ci} / \mathrm{yr})$.

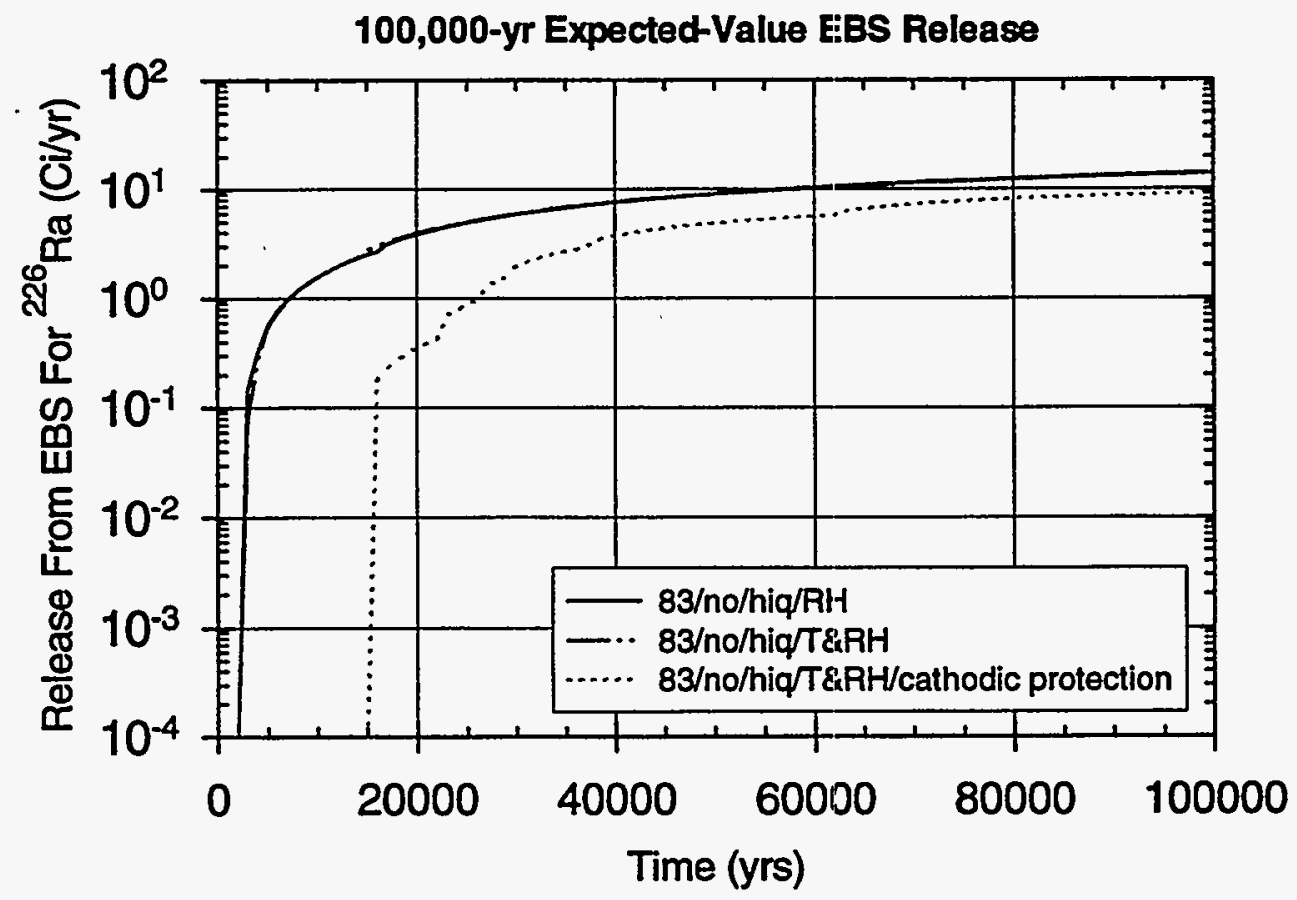

Figure 8.3-2h Sensitivity of the EBS release rate for ${ }^{226} \mathrm{Ra}$ to cathodic protection (NRC limit = $0.00237 \mathrm{Ci} / \mathrm{yr})$. 


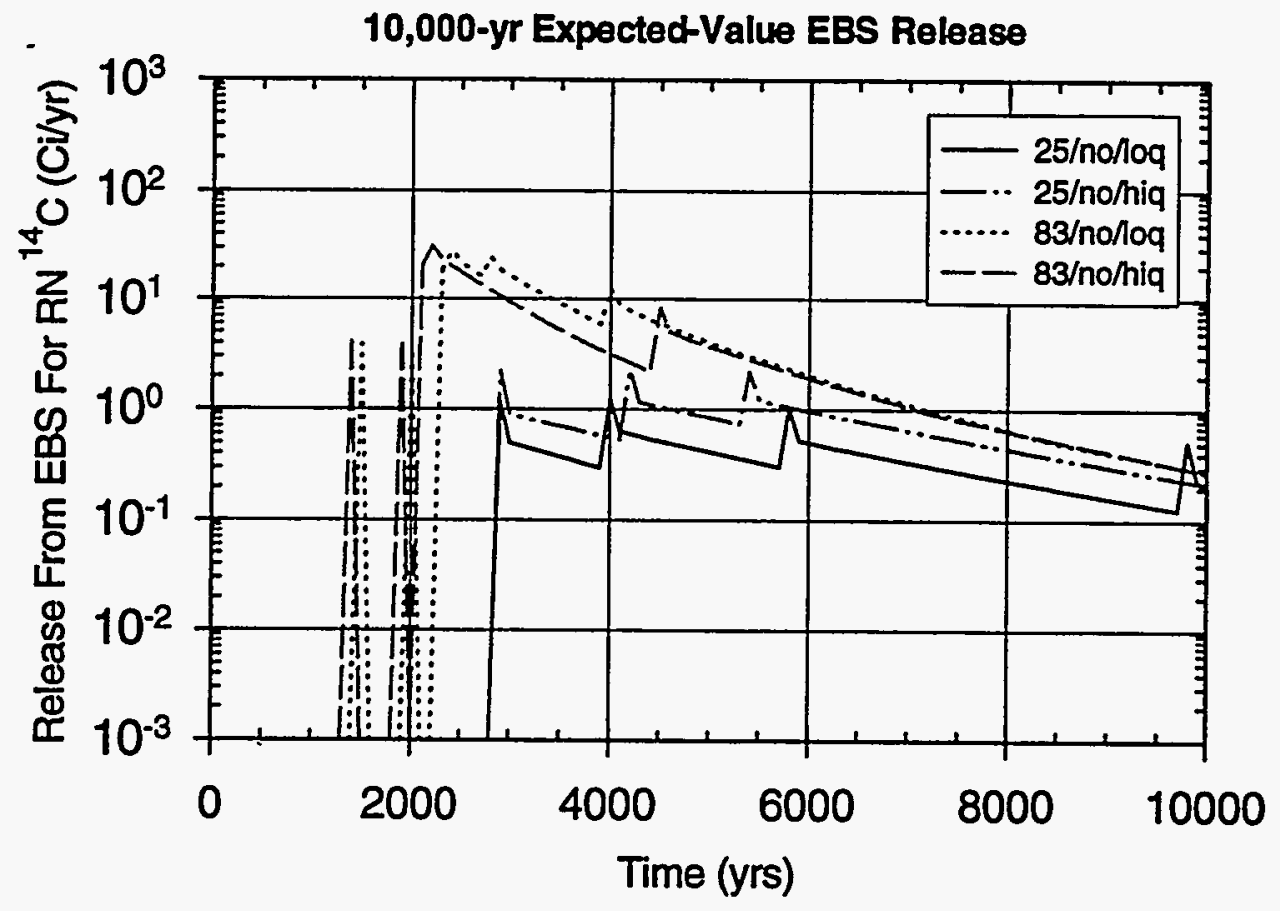

Figure 8.3-3a Sensitivity of the EBS release rate for ${ }^{14} \mathrm{C}$ to thermal loading and infiltration rate $(\mathrm{NRC}$ limit $=0.796 \mathrm{Ci} / \mathrm{yr})$.

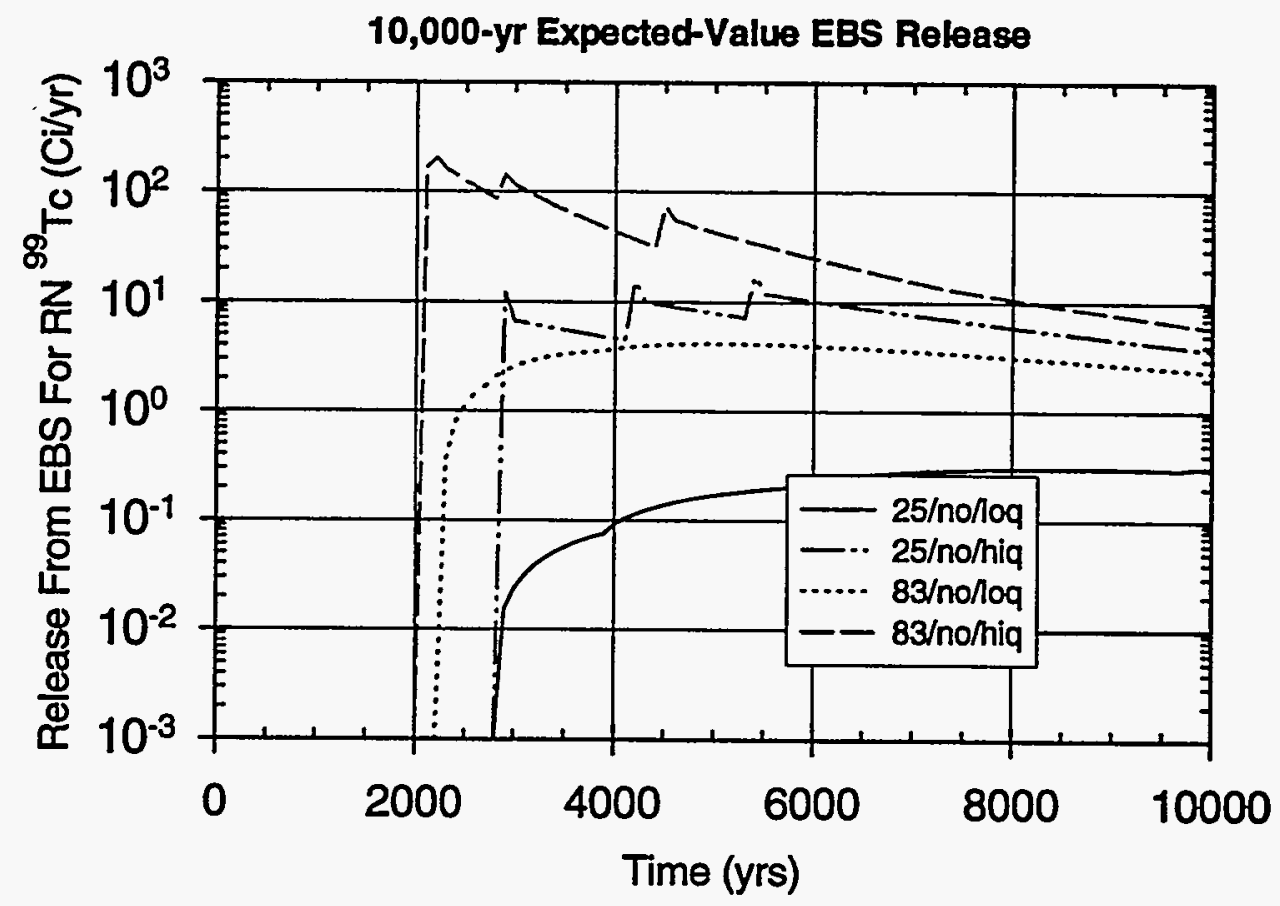

Figure 8.3-3b Sensitivity of the EBS release rate for ${ }^{99} \mathrm{Tc}$ to thermal loading and infiltration rate (NRC limit $=9.03 \mathrm{Ci} / \mathrm{yr})$. 


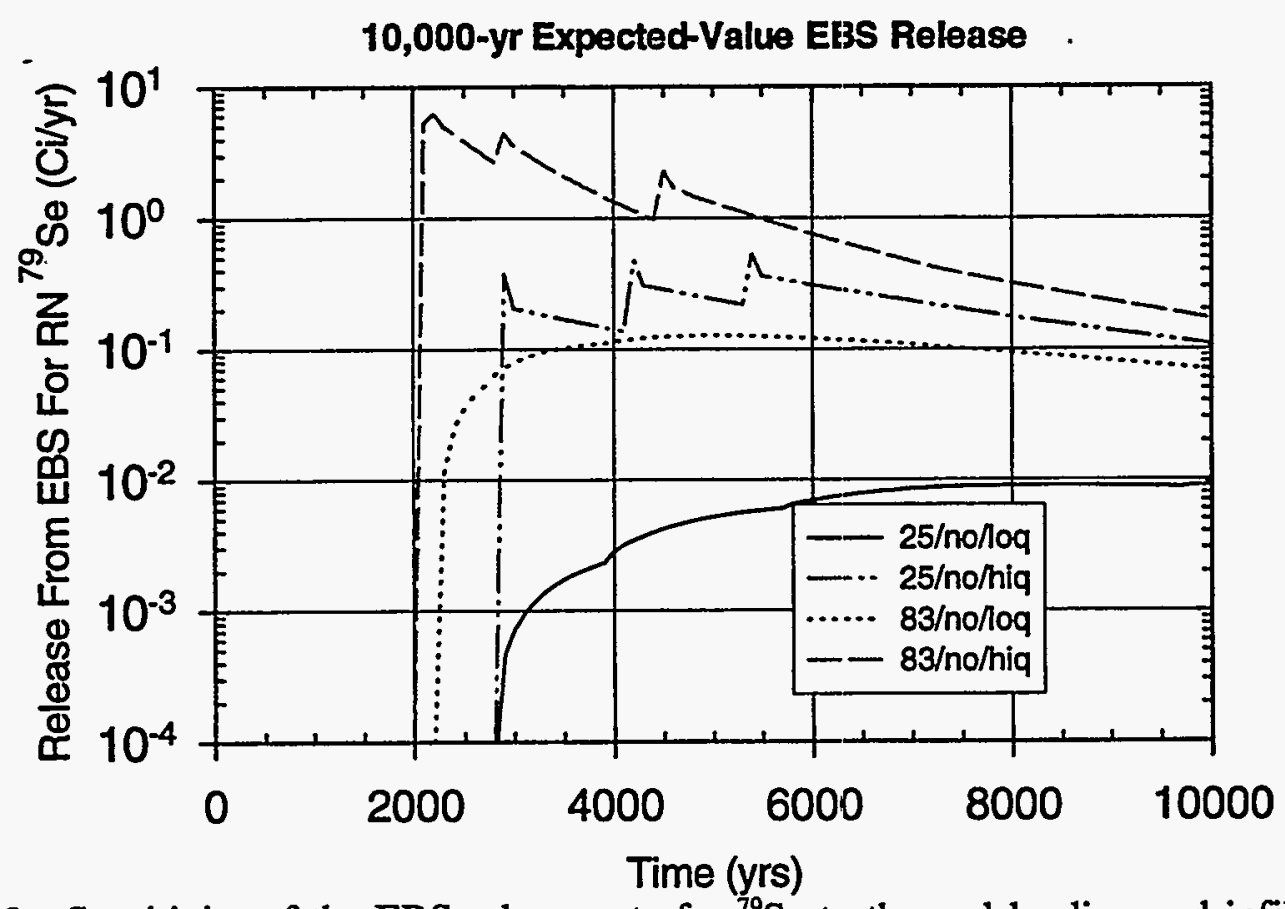

Figure 8.3-3c Sensitivity of the EBS release rate for ${ }^{79} \mathrm{Se}$ to thermal loading and infiltration rate $(\mathrm{NRC}$ limit $=0.282 \mathrm{Ci} / \mathrm{yr})$.

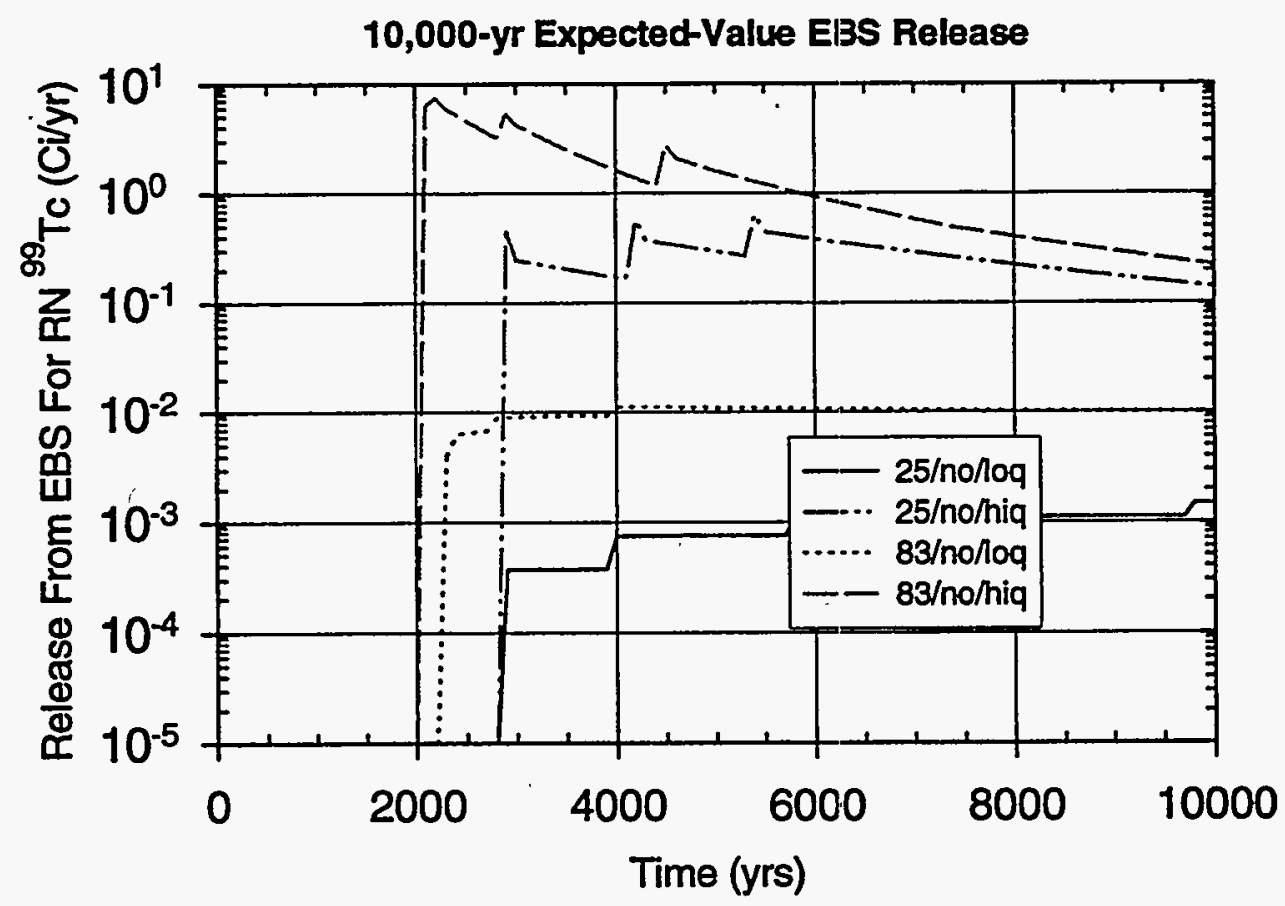

Figure 8.3-3d Sensitivity of the EBS release rate for ${ }^{135} \mathrm{Cs}$ to thermal loading and infiltration rate $(\mathrm{NRC}$ limit $=0.331 \mathrm{Ci} / \mathrm{yr})$. 


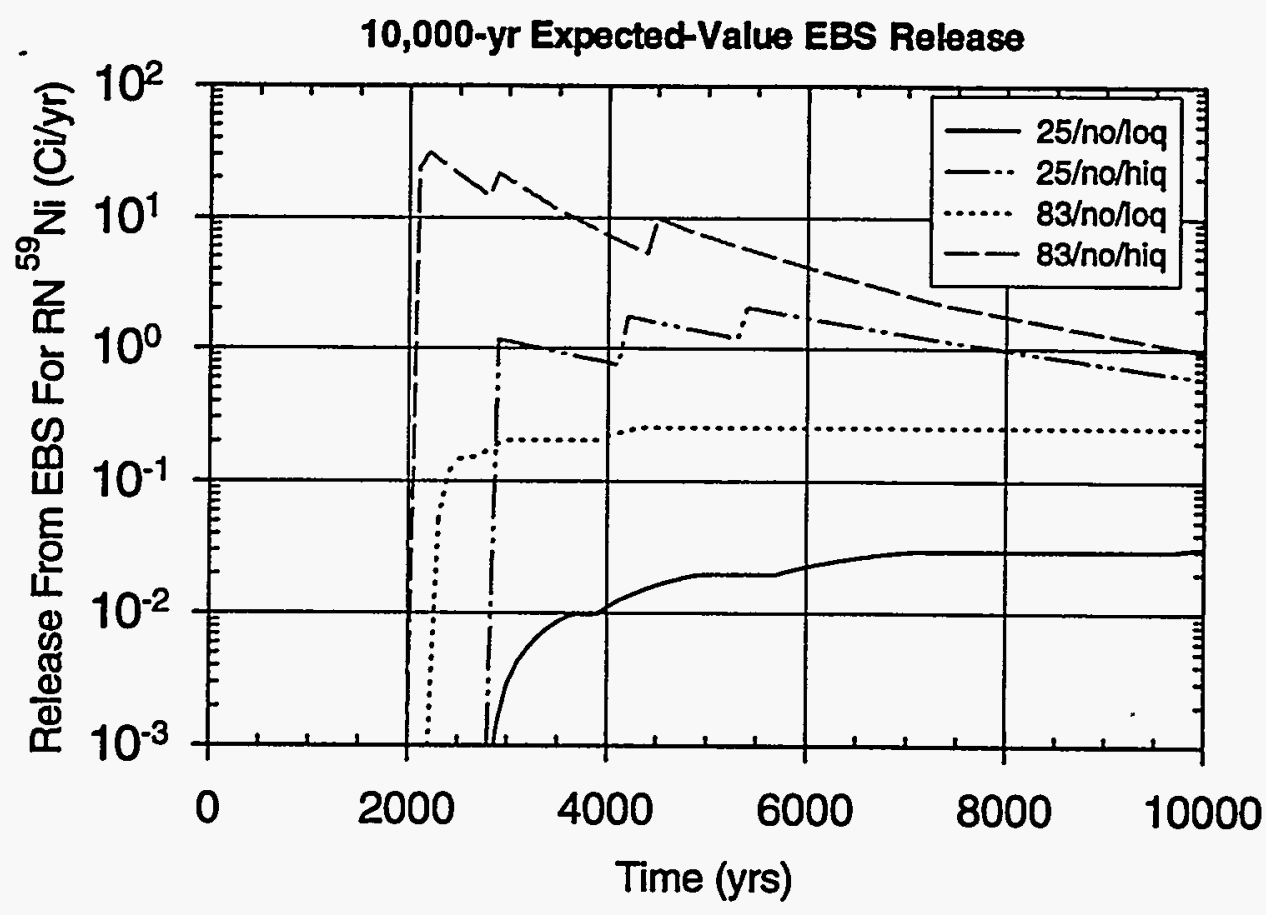

Figure 8.3-3e Sensitivity of the EBS release rate for ${ }^{59} \mathrm{Ni}$ to thermal loading and infiltration rate $(\mathrm{NRC}$ limit $=1.51 \mathrm{Ci} / \mathrm{yr})$.

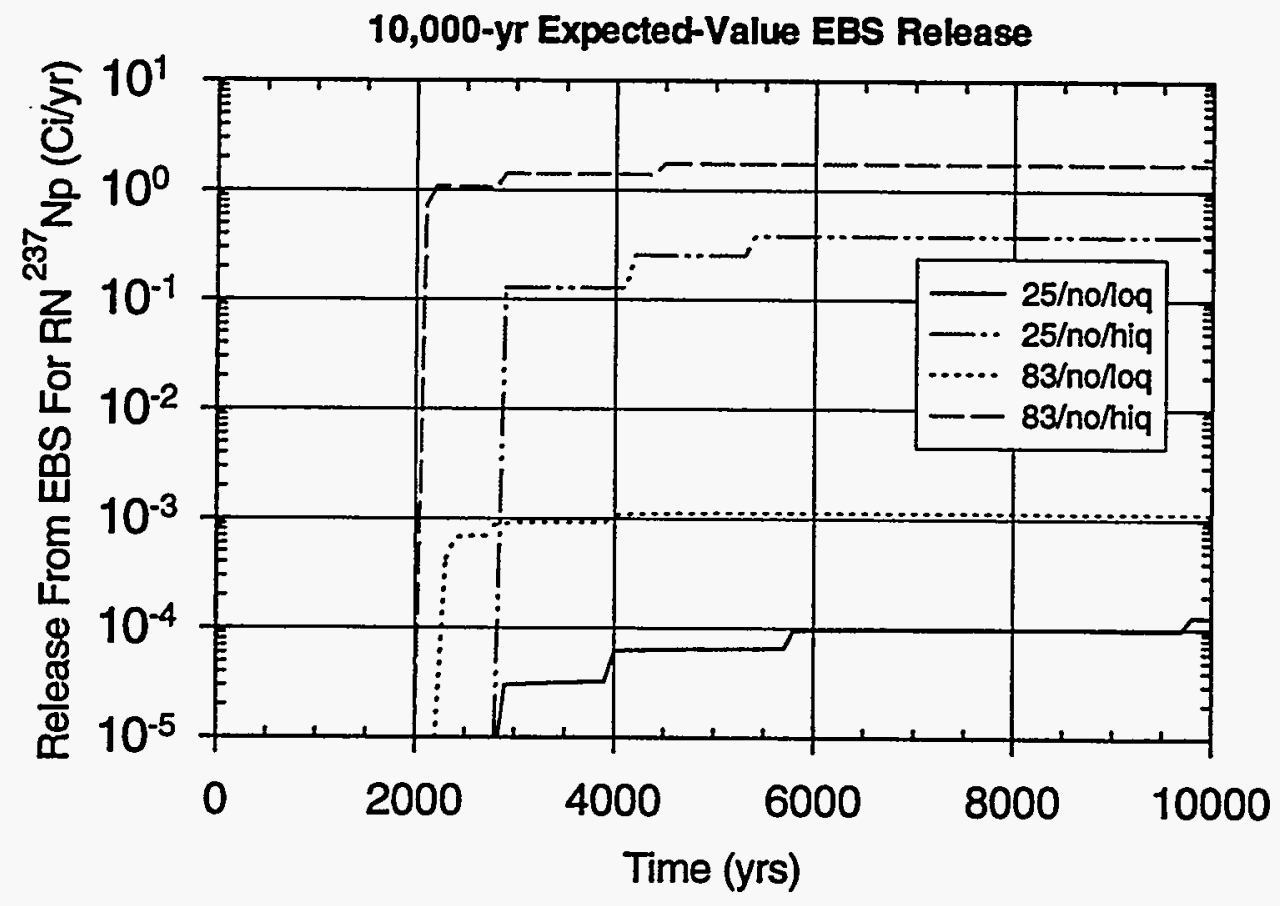

Figure 8.3-3f Sensitivity of the EBS release rate for ${ }^{237} \mathrm{~Np}$ to thermal loading and infiltration rate $(\mathrm{NRC}$ limit $=0.782 \mathrm{Ci} / \mathrm{yr})$. 


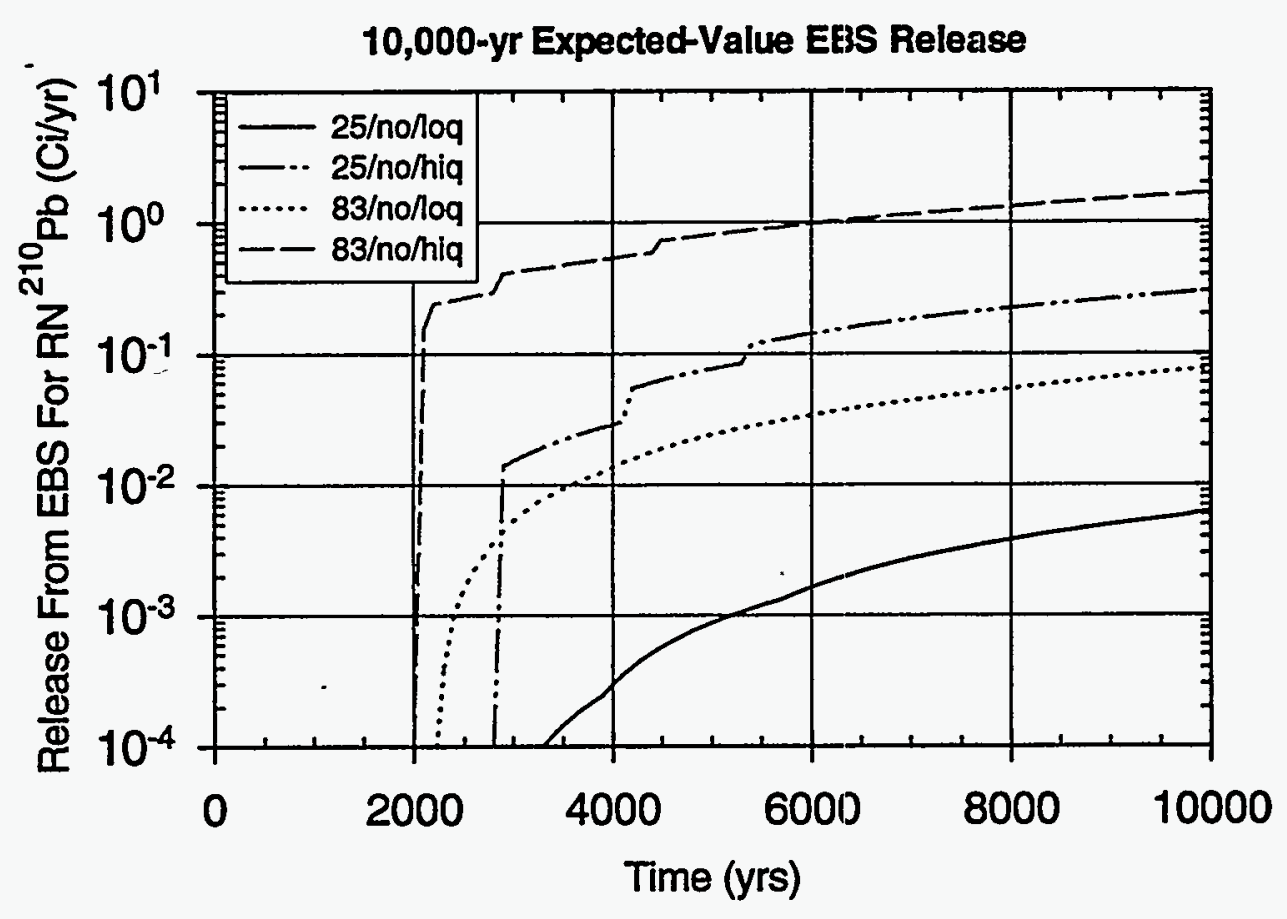

Figure 8.3-3g Sensitivity of the EBS release rate for ${ }^{210} \mathrm{~Pb}$ to thermal loading and infiltration rate (NRC limit $=0.00236 \mathrm{Ci} / \mathrm{yr})$.

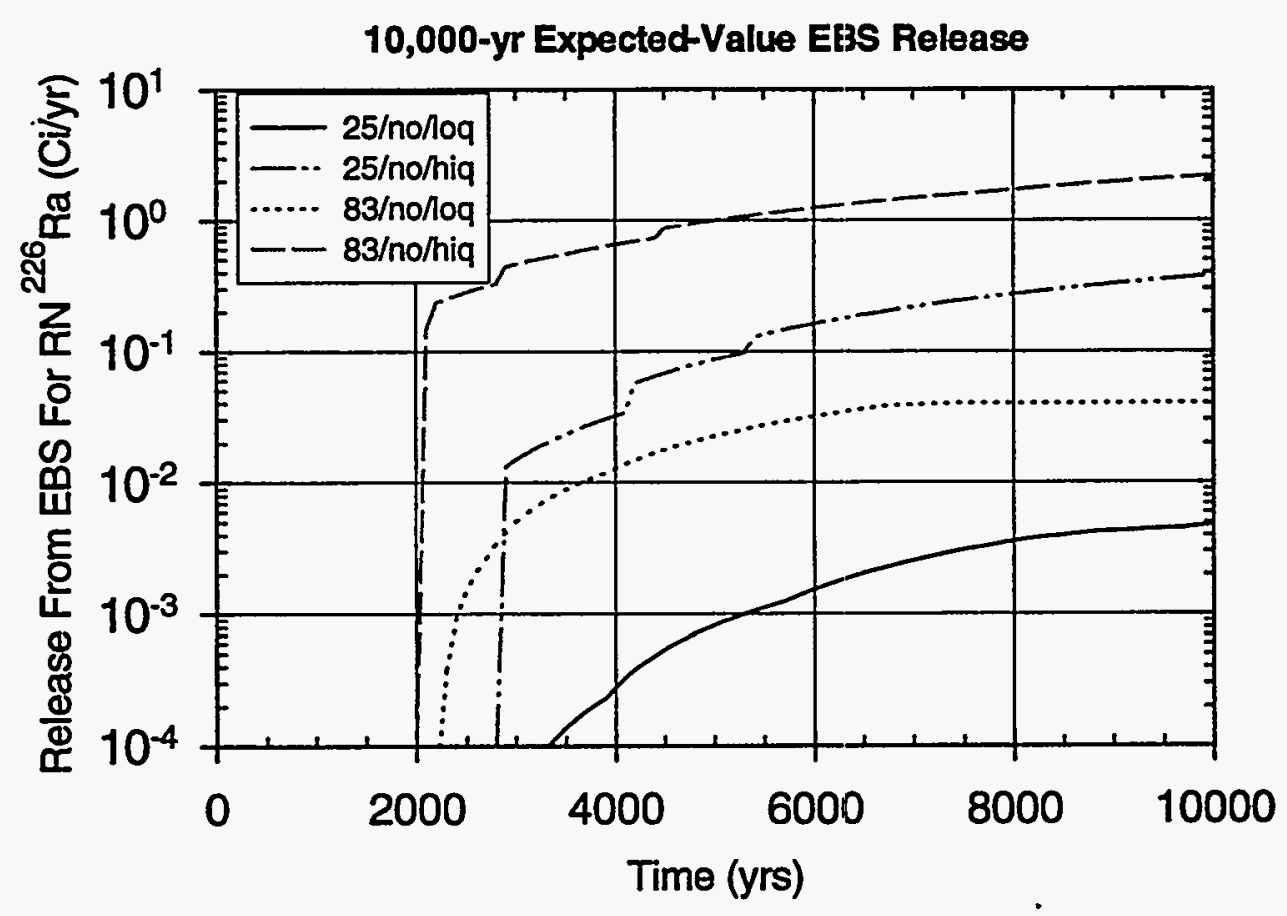

Figure 8.3-3h Sensitivity of the EBS release rate for ${ }^{226} \mathrm{Ra}$ to thermal loading and infiltration rate (NRC limit $=0.00237 \mathrm{Ci} / \mathrm{yr})$. 


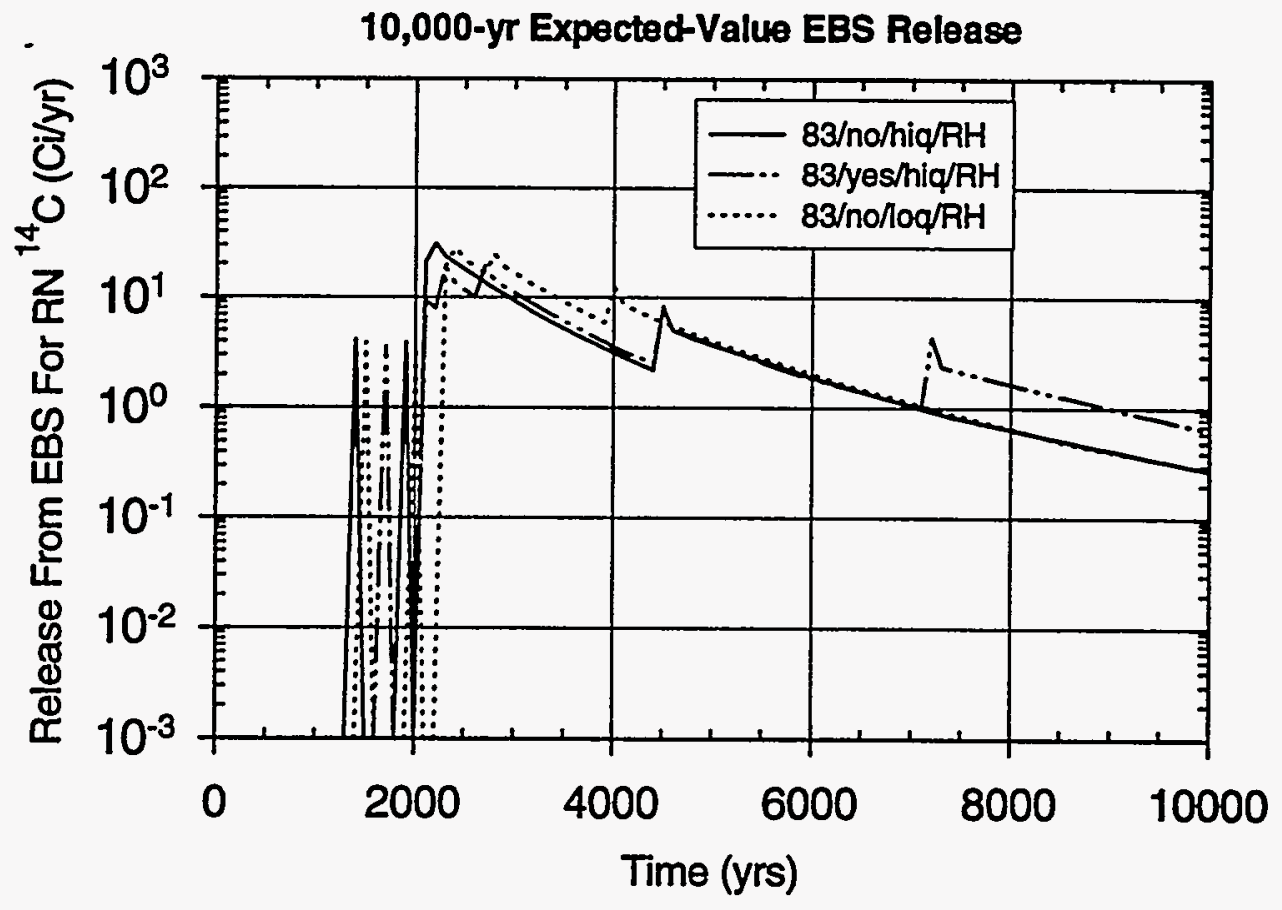

Figure 8.3-4a Sensitivity of the EBS release rate for ${ }^{14} \mathrm{C}$ to the presence of backfill (NRC limit $=0.796 \mathrm{Ci} / \mathrm{yr})$.

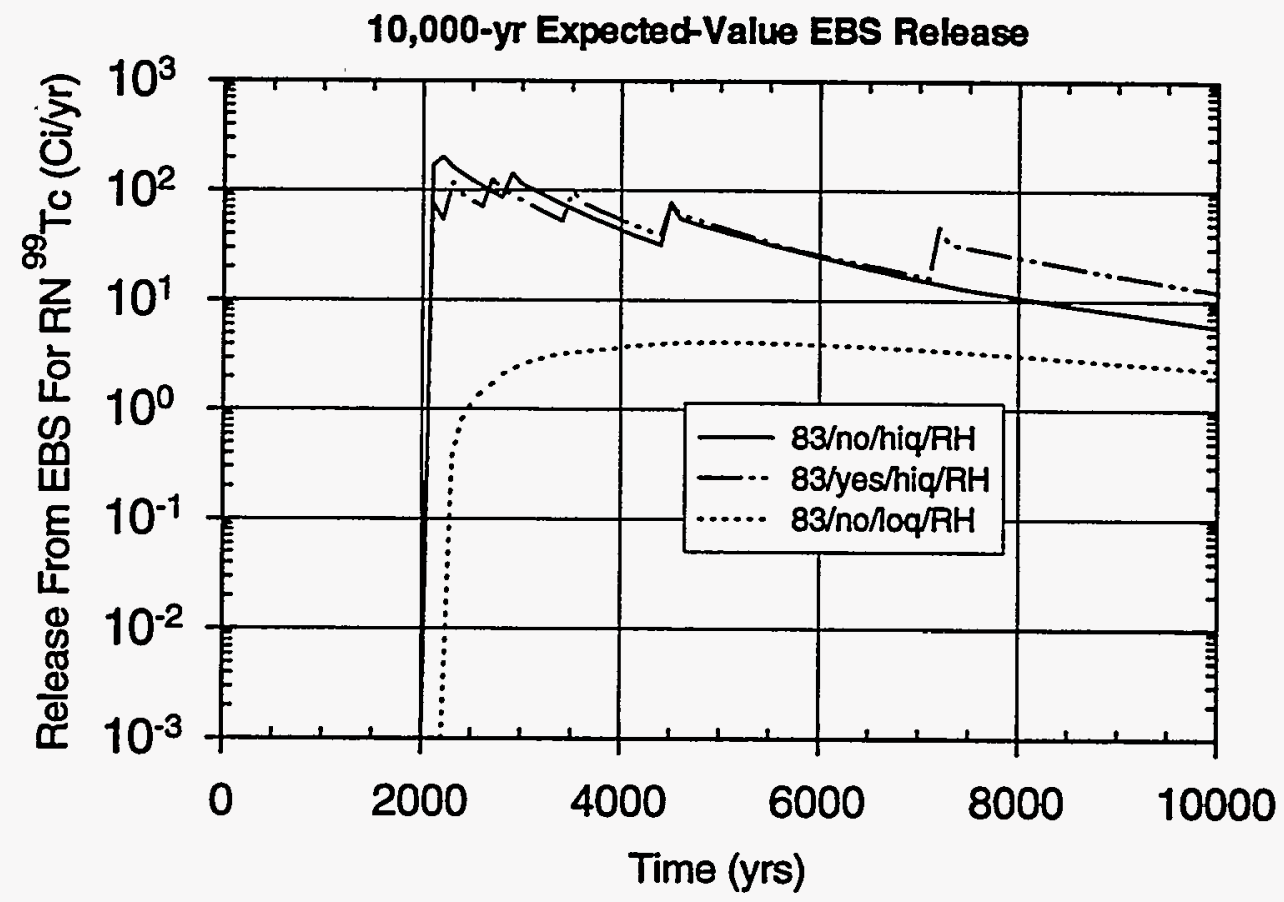

Figure 8.3-4b Sensitivity of the EBS release rate for ${ }^{99} \mathrm{Tc}$ to the presence of backfill (NRC limit $=9.03 \mathrm{Ci} / \mathrm{yr})$. 
10,000-yr Expected-Value EESS Release

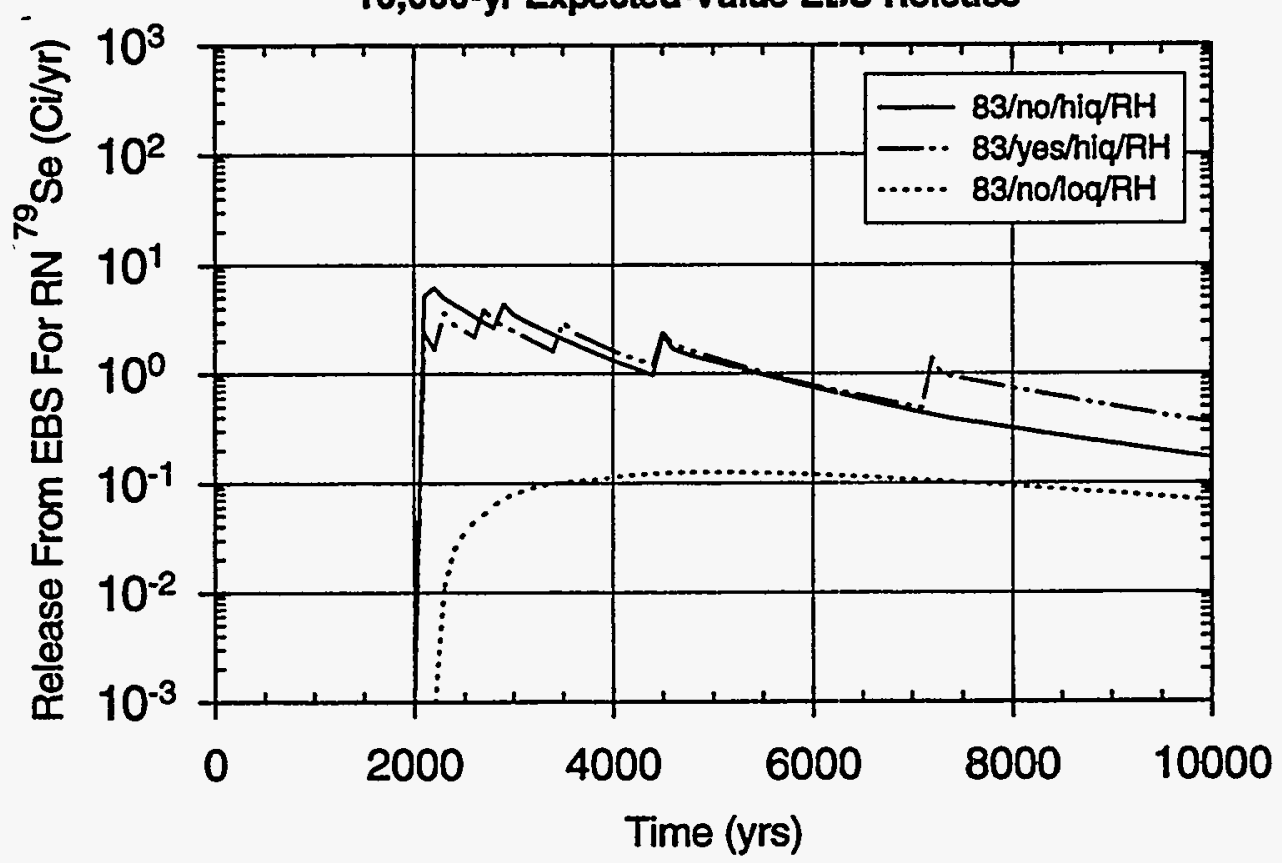

Figure 8.3-4c Sensitivity of the EBS release rate for ${ }^{79} \mathrm{Se}$ to the presence of backfill (NRC limit $=0.282 \mathrm{Ci} / \mathrm{yr})$.

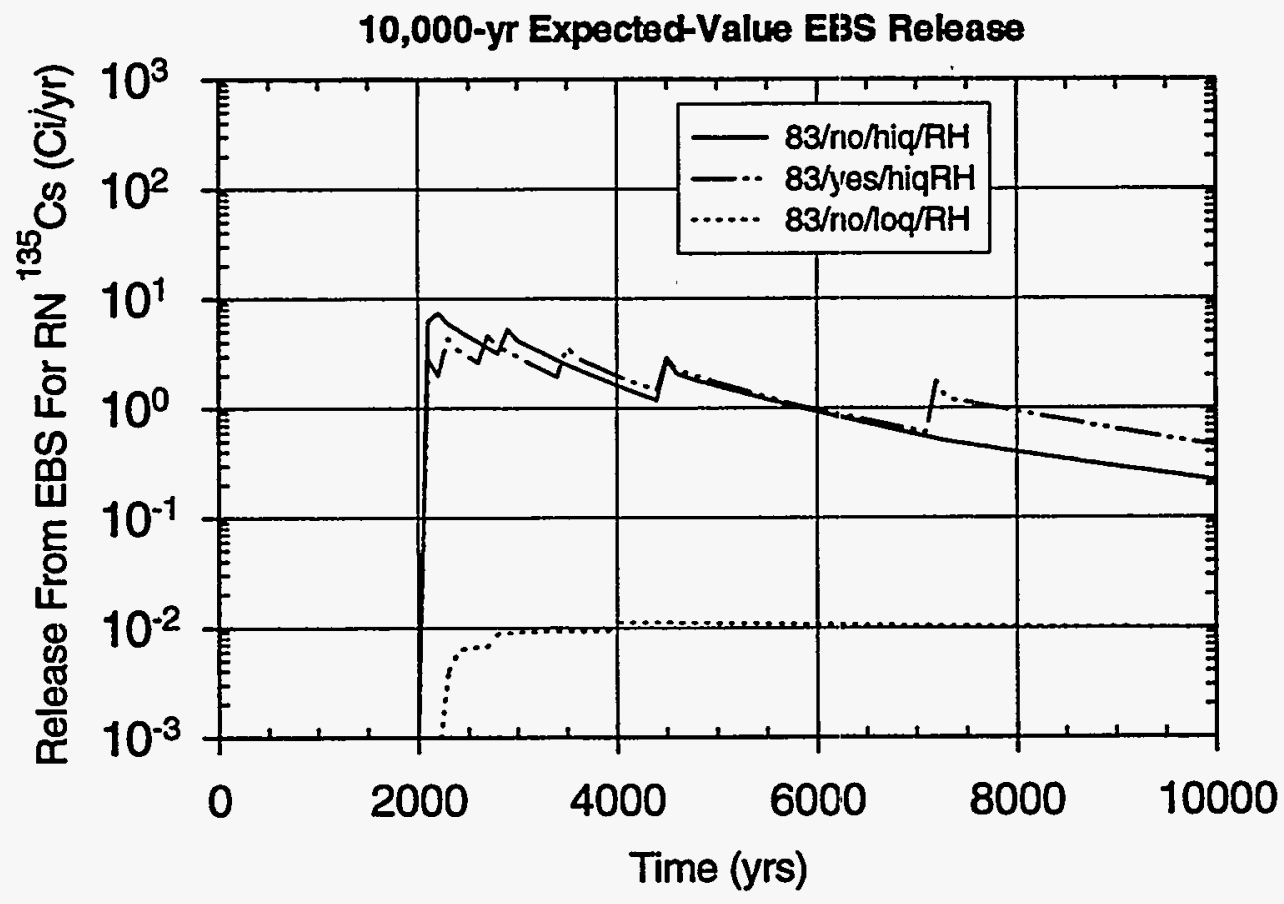

Figure 8.3-4d Sensitivity of the EBS release rate for ${ }^{135} \mathrm{Cs}$ to the presence of backfill (NRC limit $=0.331 \mathrm{Ci} / \mathrm{yr})$. 


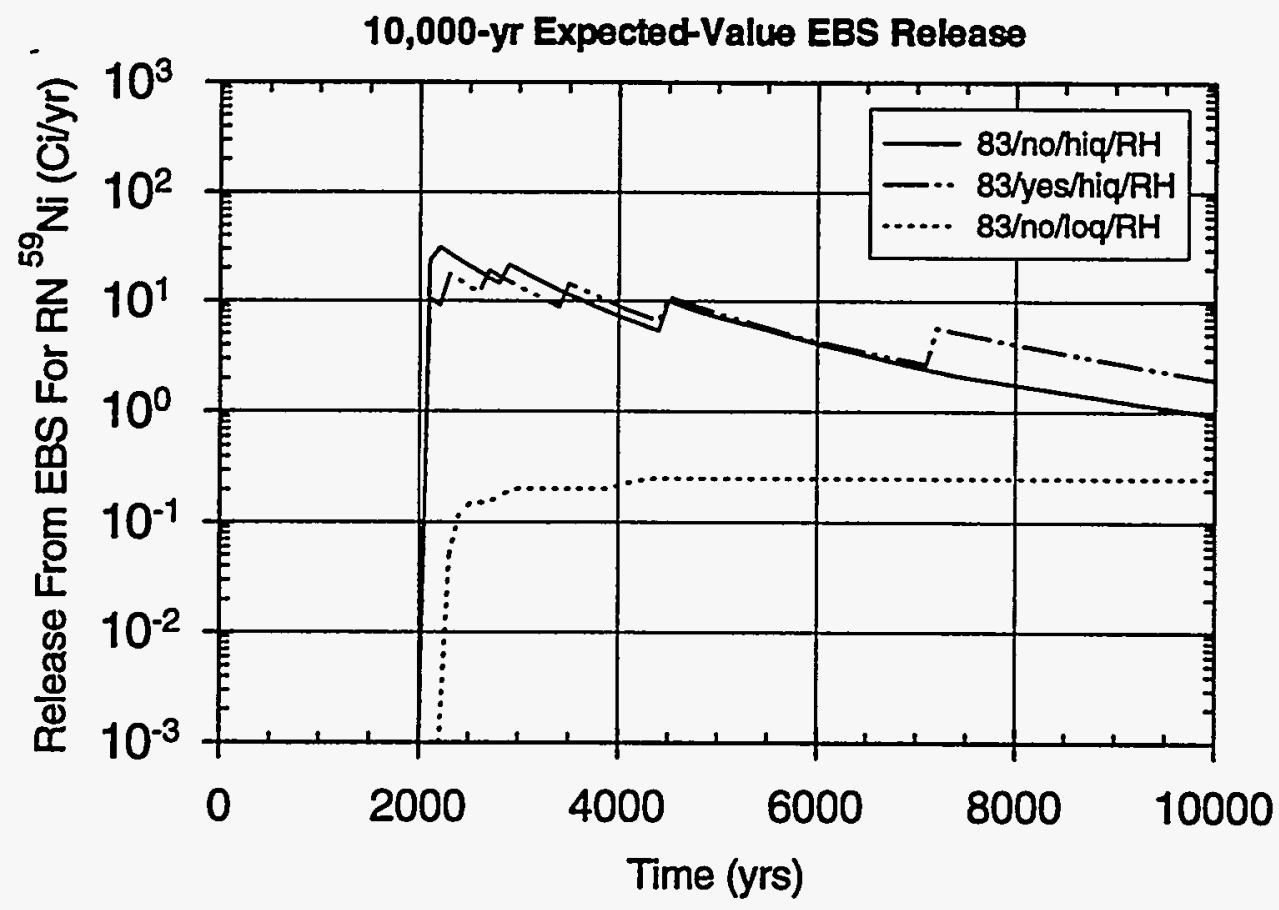

Figure 8.3-4e Sensitivity of the EBS release rate for ${ }^{59} \mathrm{Ni}$ to the presence of backfill (NRC limit $=1.51 \mathrm{Ci} / \mathrm{yr}$ ).

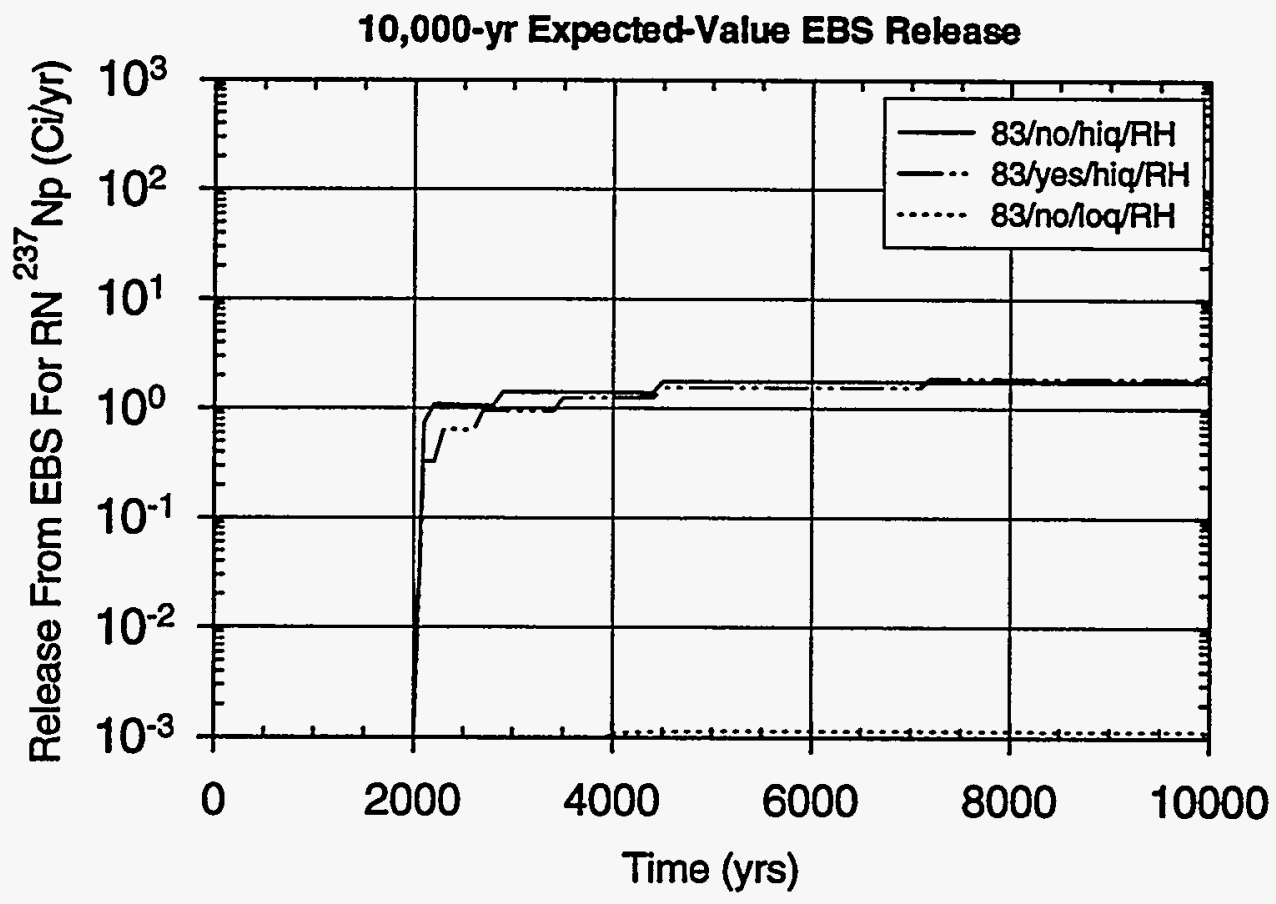

Figure 8.3-4f Sensitivity of the EBS release rate for ${ }^{237} \mathrm{~Np}$ to the presence of backfill (NRC limit $=0.782 \mathrm{Ci} / \mathrm{yr})$. 


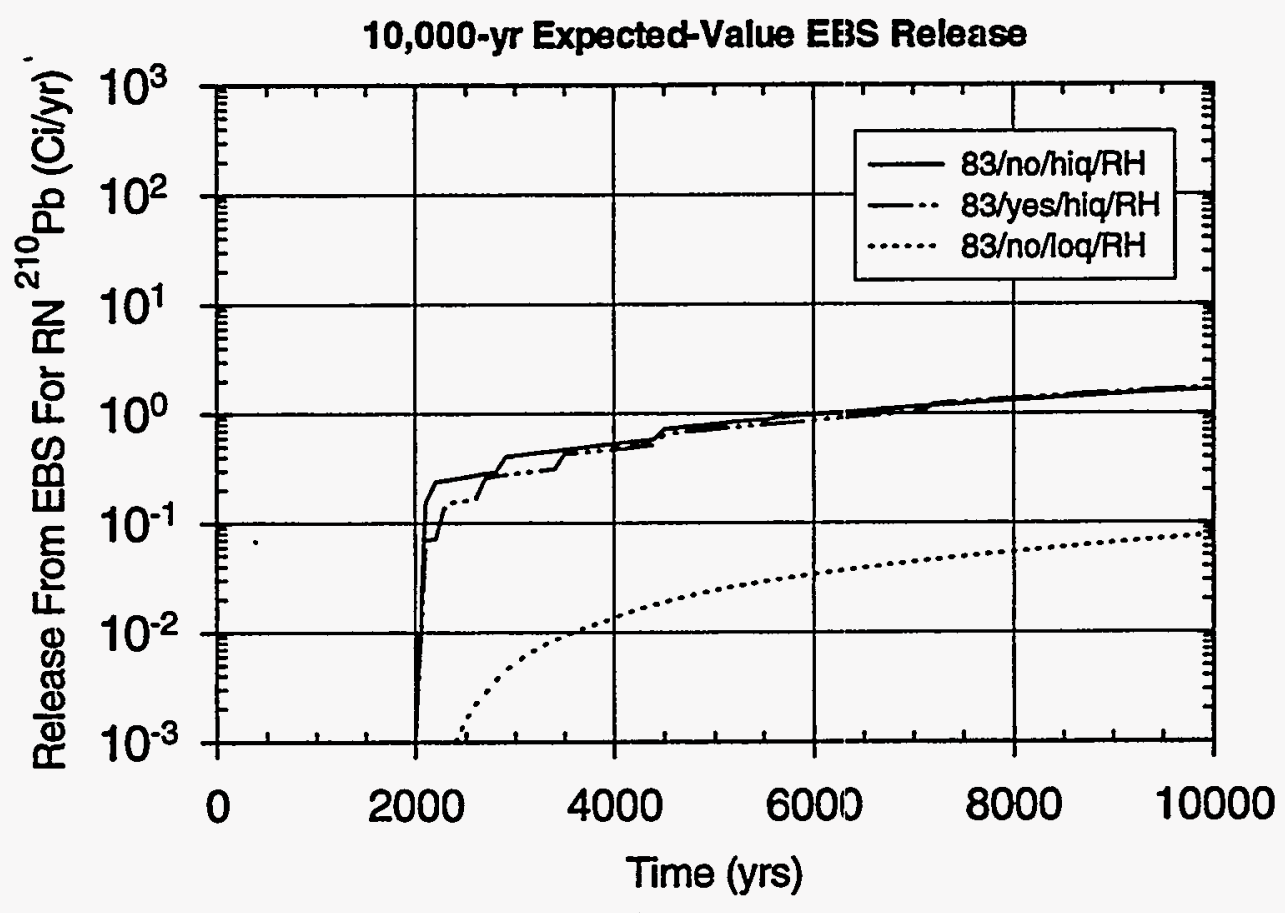

Figure $8.3-4 \mathrm{~g}$ Sensitivity of the EBS release rate for ${ }^{210} \mathrm{~Pb}$ to the presence of backfill (NRC limit $=0.00236 \mathrm{Ci} / \mathrm{yr}$ ).

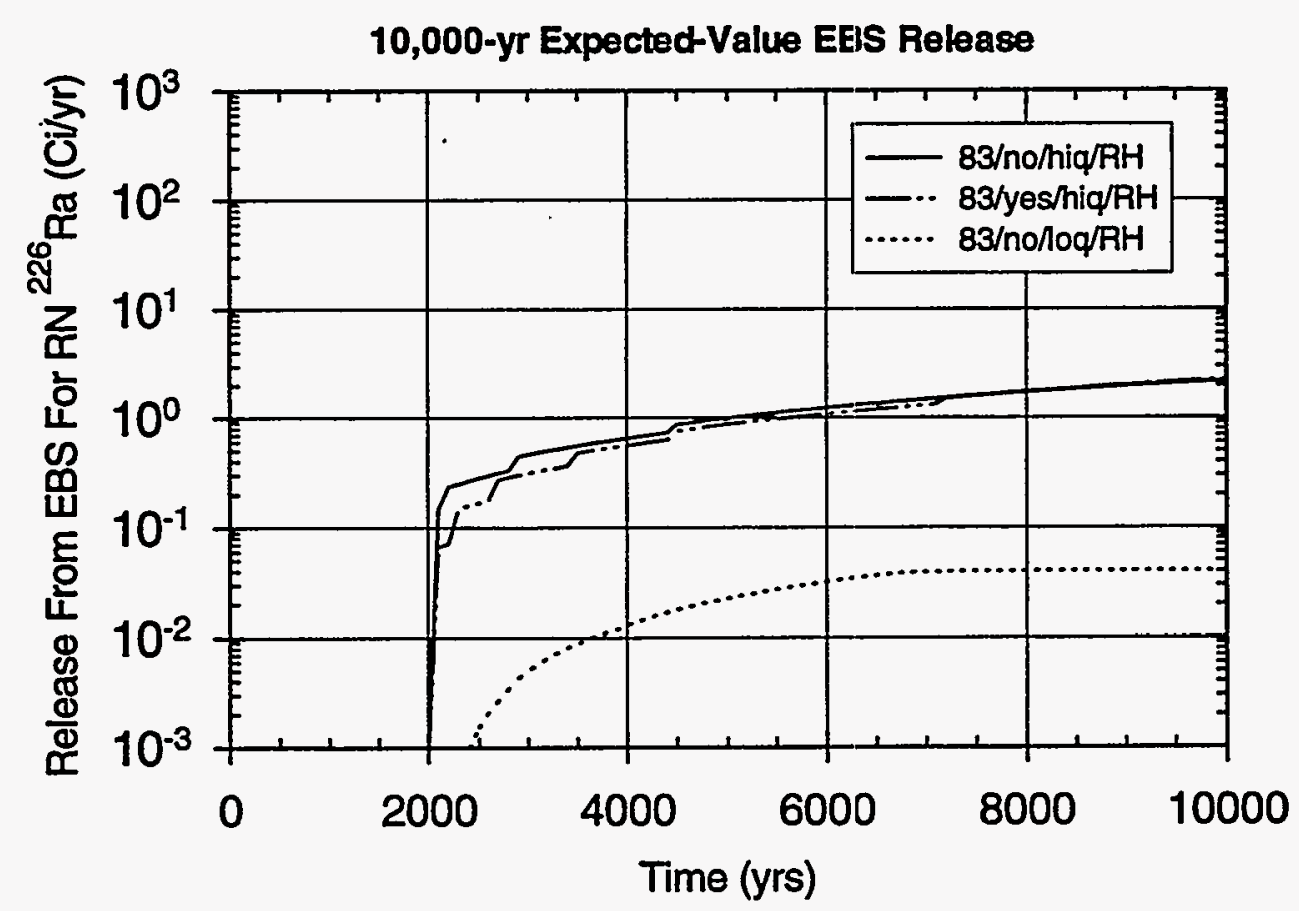

Figure 8.3-4h Sensitivity of the EBS release rate for ${ }^{226} \mathrm{Ra}$ to the presence of backfill (NRC limit $=0.00237 \mathrm{Ci} / \mathrm{yr})$. 


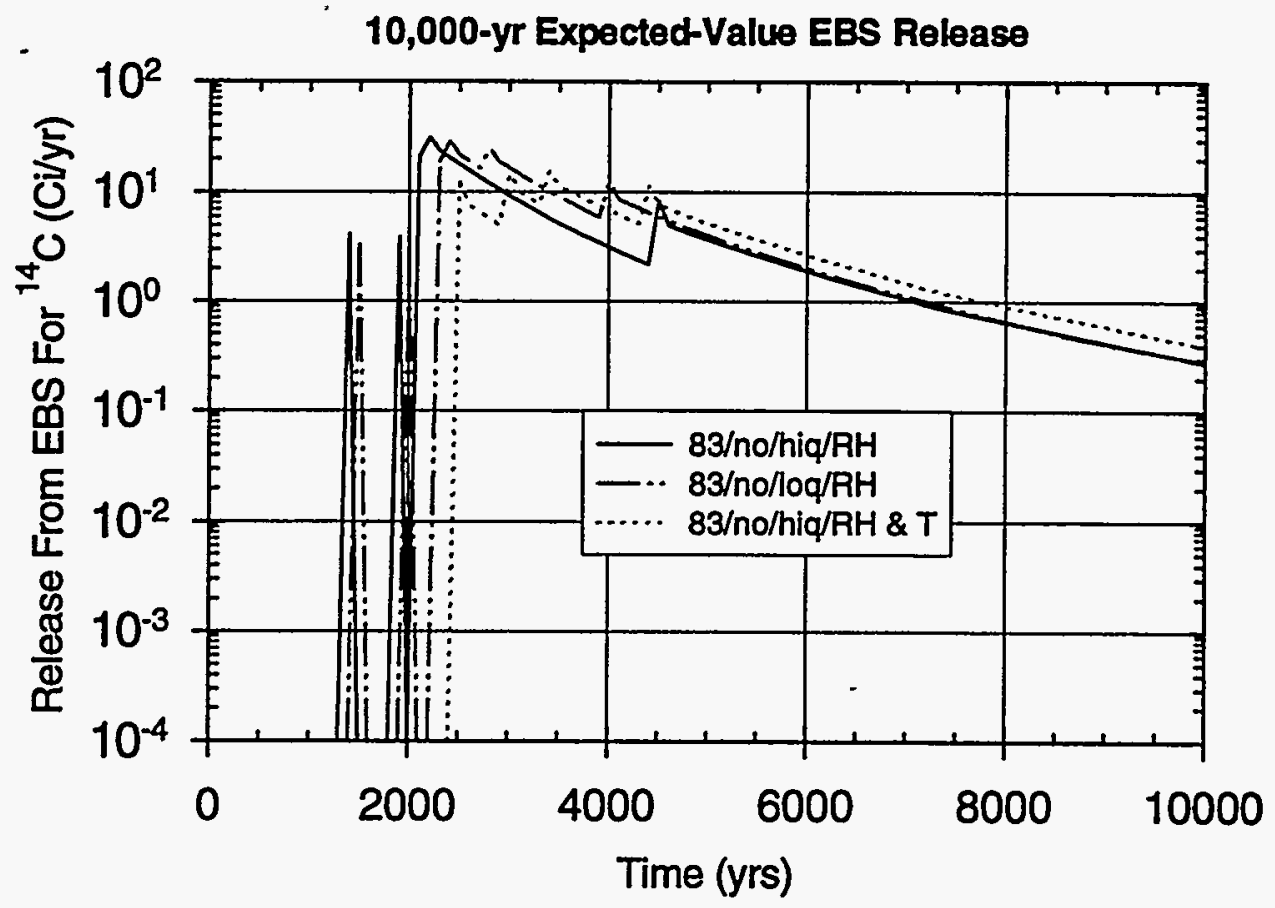

Figure 8.3-5a Sensitivity of the EBS release rate for ${ }^{14} \mathrm{C}$ to the alternative advective release model (NRC limit $=0.796 \mathrm{Ci} / \mathrm{yr})$.

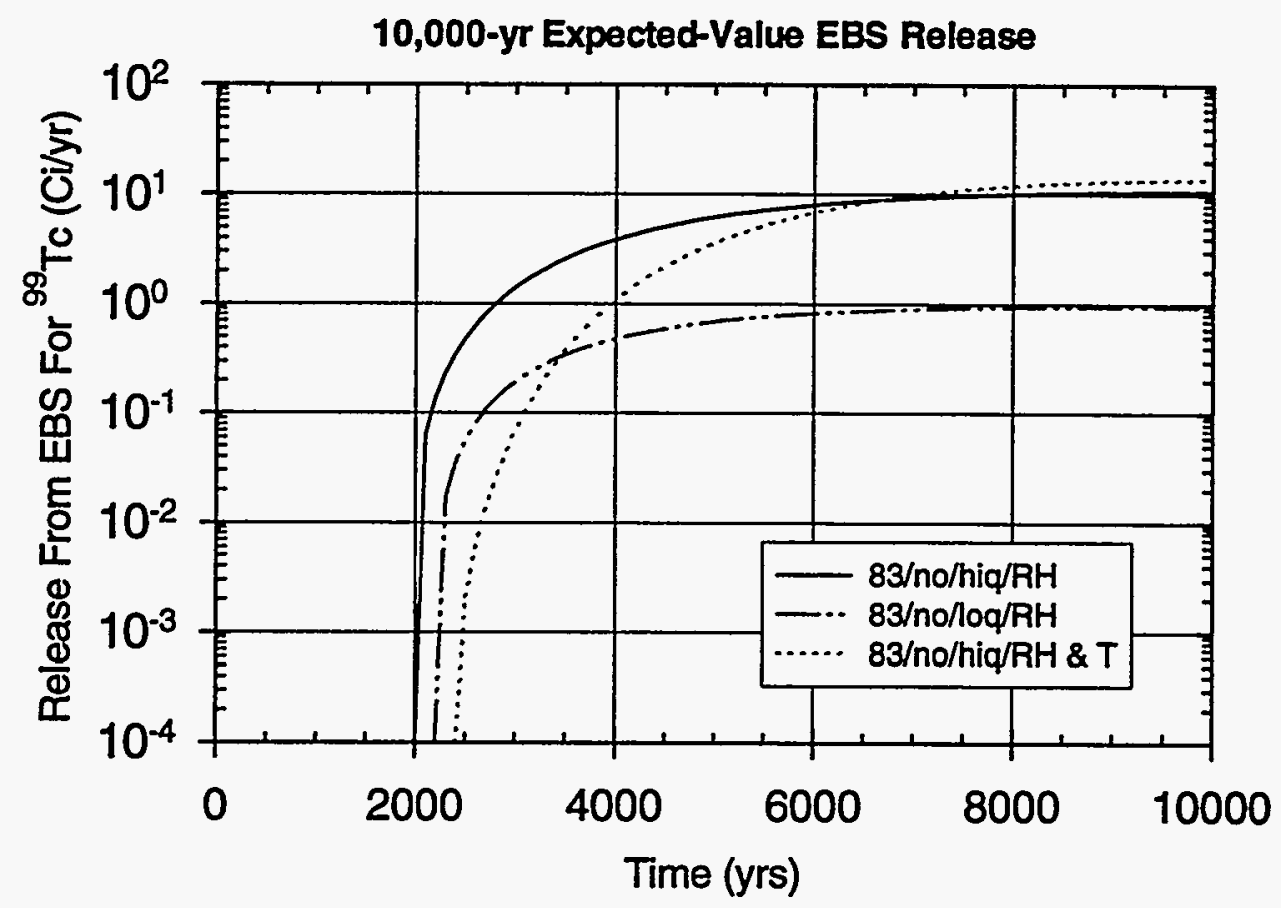

Figure 8.3-5b Sensitivity of the EBS release rate for ${ }^{99} \mathrm{Tc}$ to the alternative advective release model $($ NRC limit $=9.03 \mathrm{Ci} / \mathrm{yr})$. 


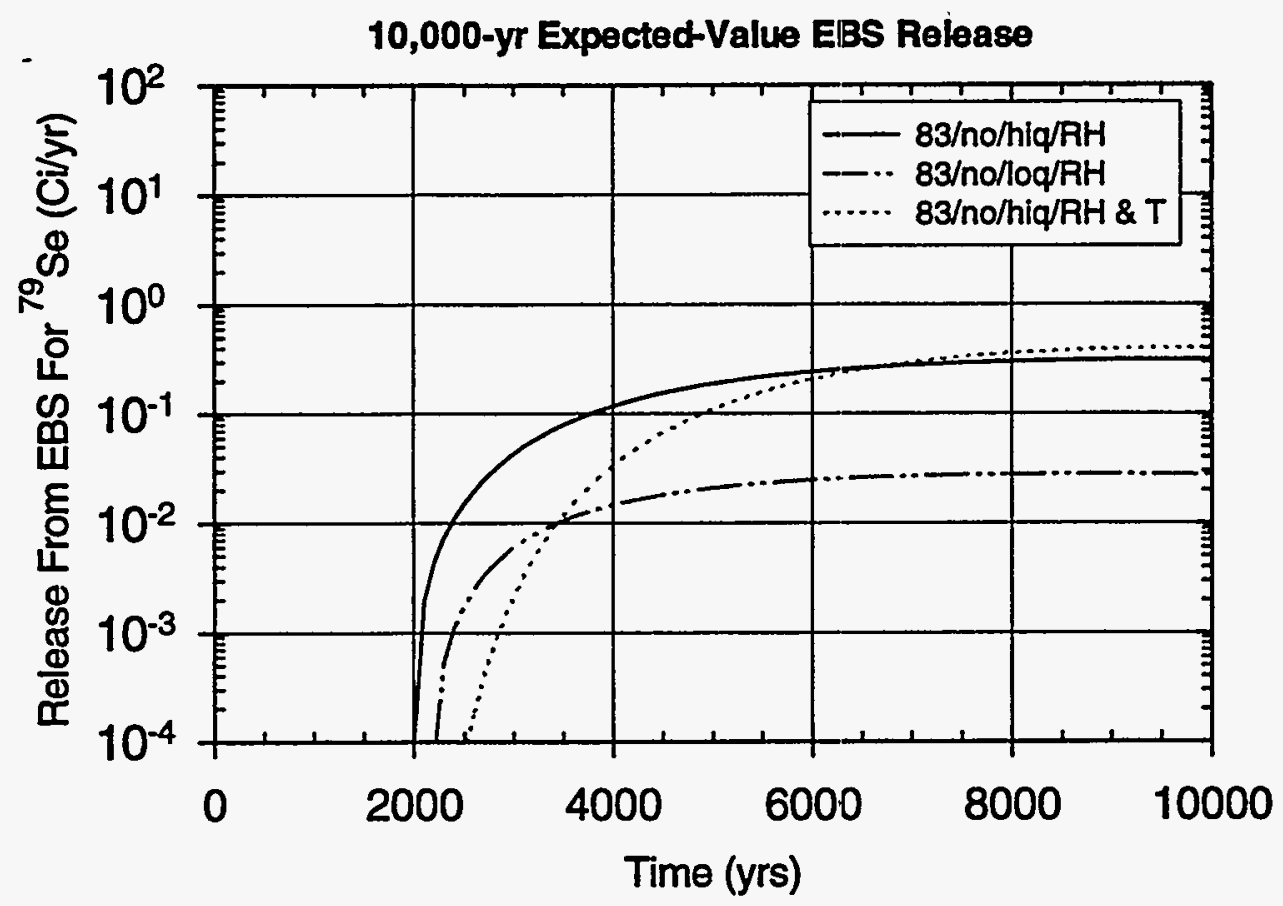

Figure 8.3-5c Sensitivity of the EBS release rate for ${ }^{79} \mathrm{Se}$ to the alternative advective release model (NRC limit $=0.282 \mathrm{Ci} / \mathrm{yr})$.

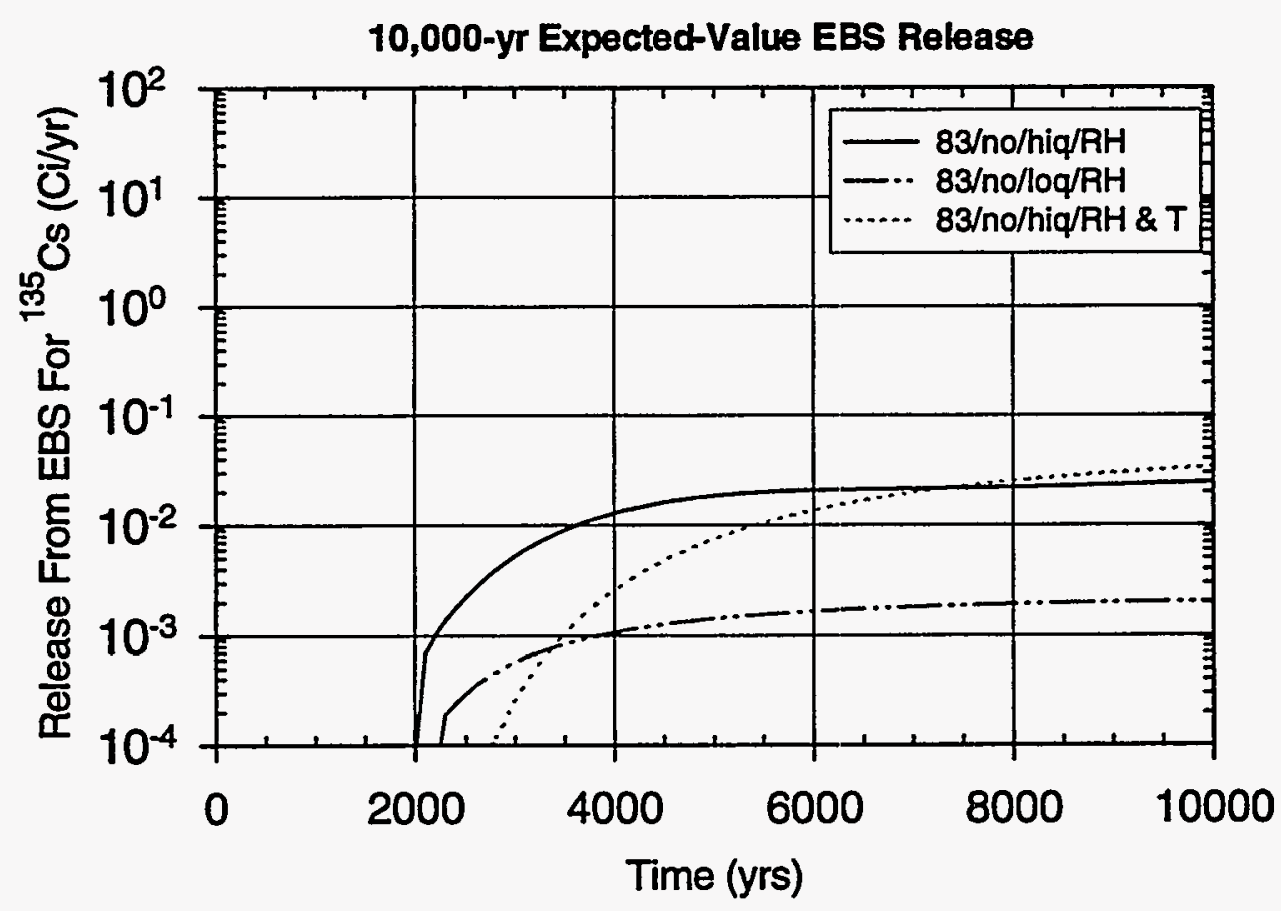

Figure 8.3-5d Sensitivity of the EBS release rate for ${ }^{135} \mathrm{Cs}$ to the alternative advective release model (NRC limit $=0.331 \mathrm{Ci} / \mathrm{yr})$. 


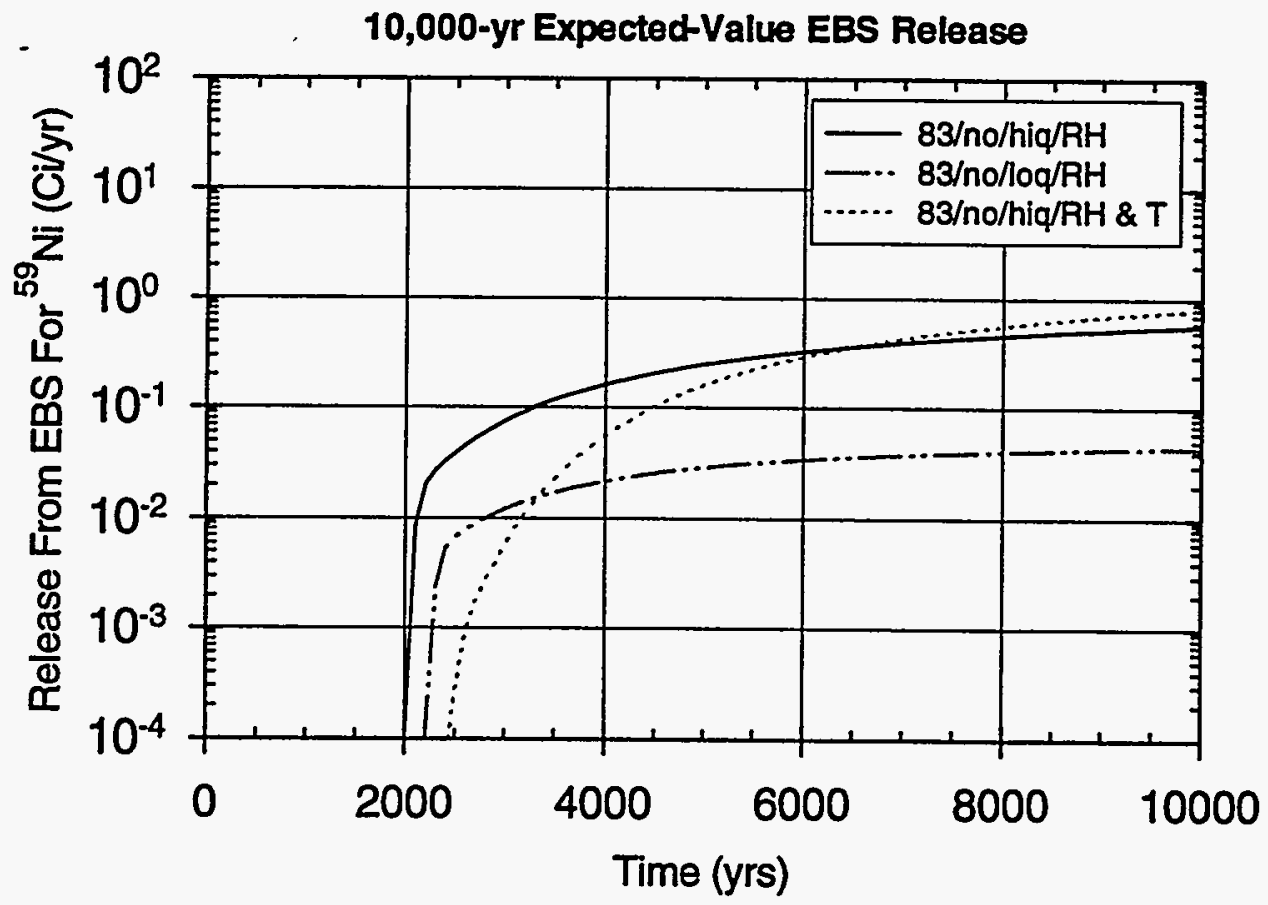

Figure 8.3-5e Sensitivity of the EBS release rate for ${ }^{59} \mathrm{Ni}$ to the alternative advective release model (NRC limit $=1.51 \mathrm{Ci} / \mathrm{yr})$.

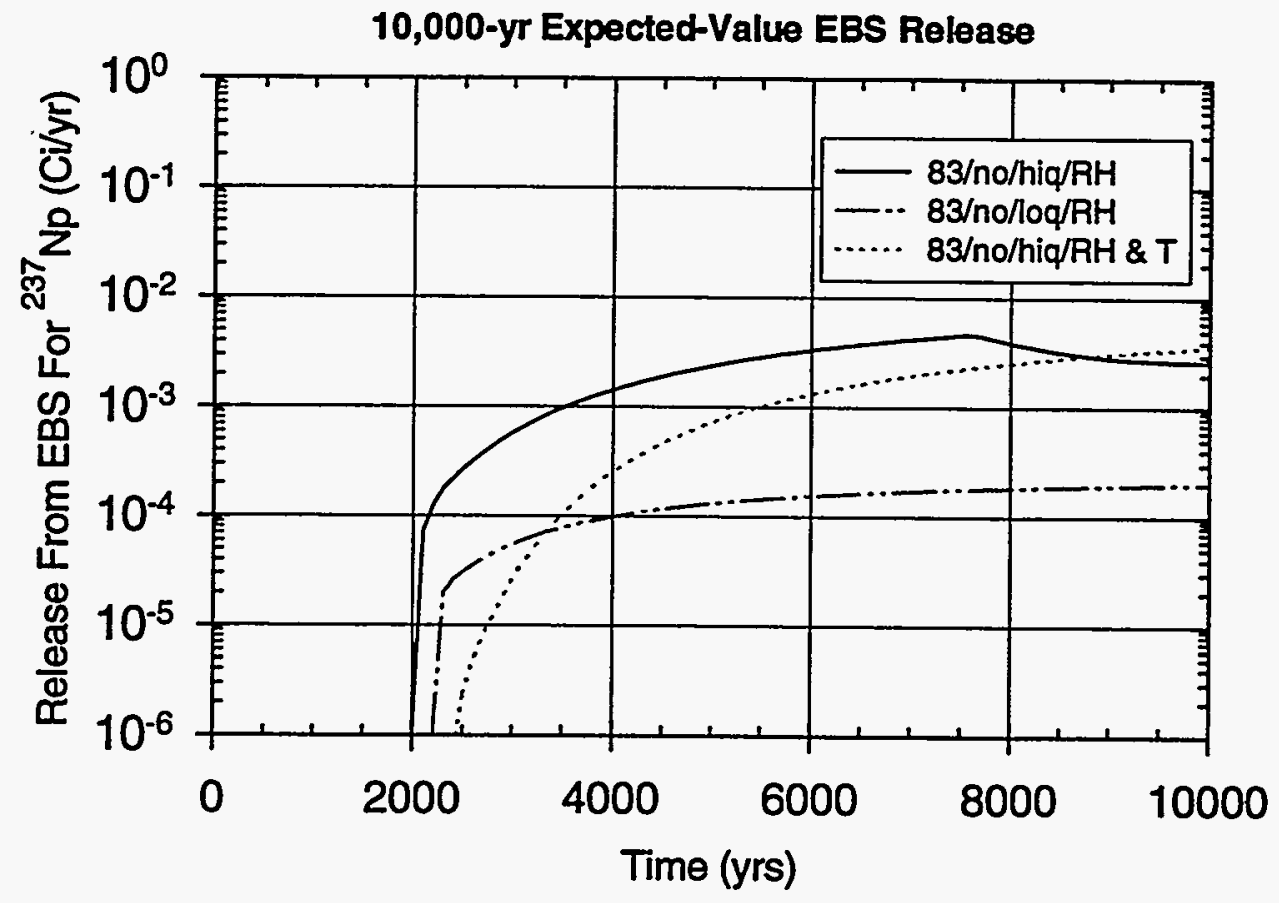

Figure 8.3-5f Sensitivity of the EBS release rate for ${ }^{237} \mathrm{~Np}$ to the alternative advective release model (NRC limit $=0.782 \mathrm{Ci} / \mathrm{yr})$. 


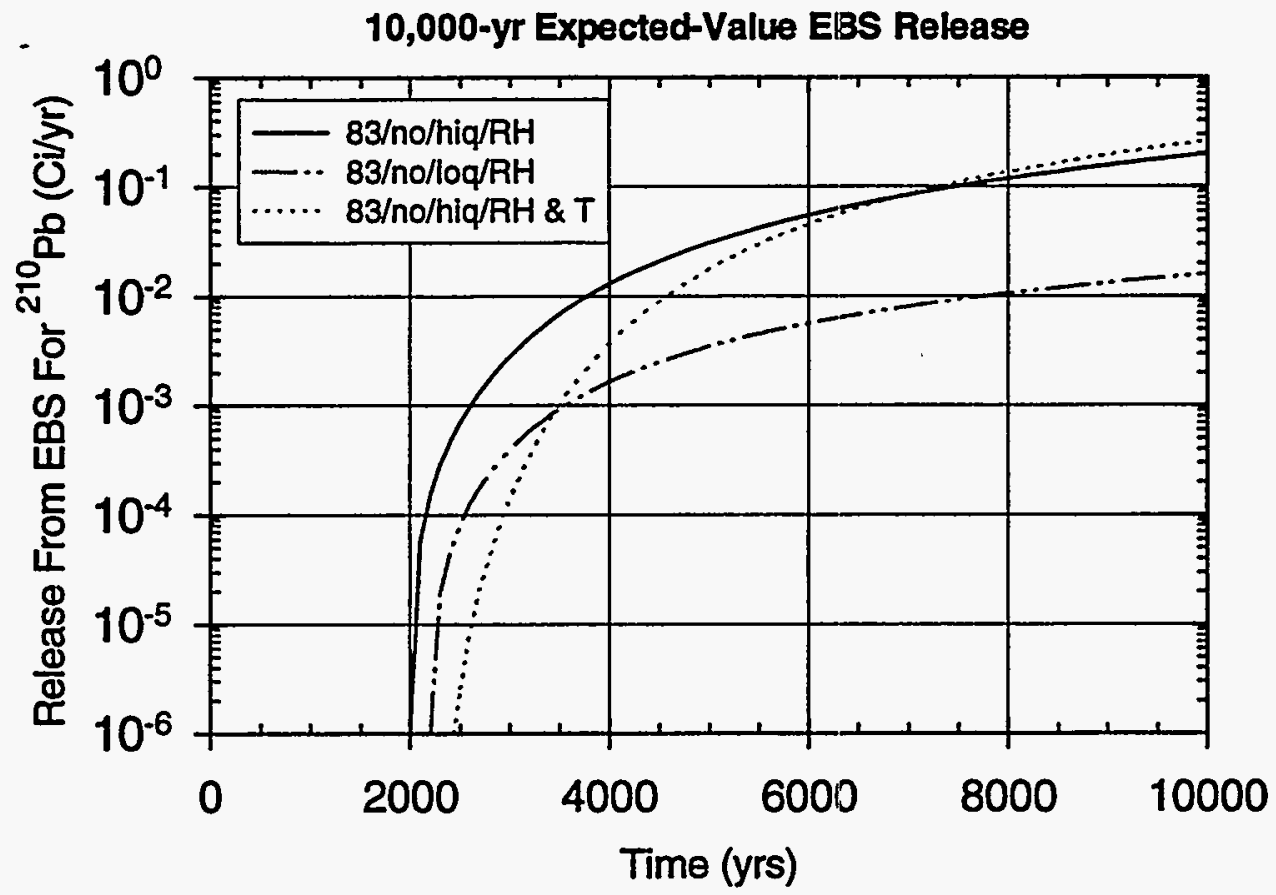

Figure 8.3-5g Sensitivity of the EBS release rate for ${ }^{210} \mathrm{~Pb}$ to the alternative advective release model (NRC limit $=0.00236 \mathrm{Ci} / \mathrm{yr})$.

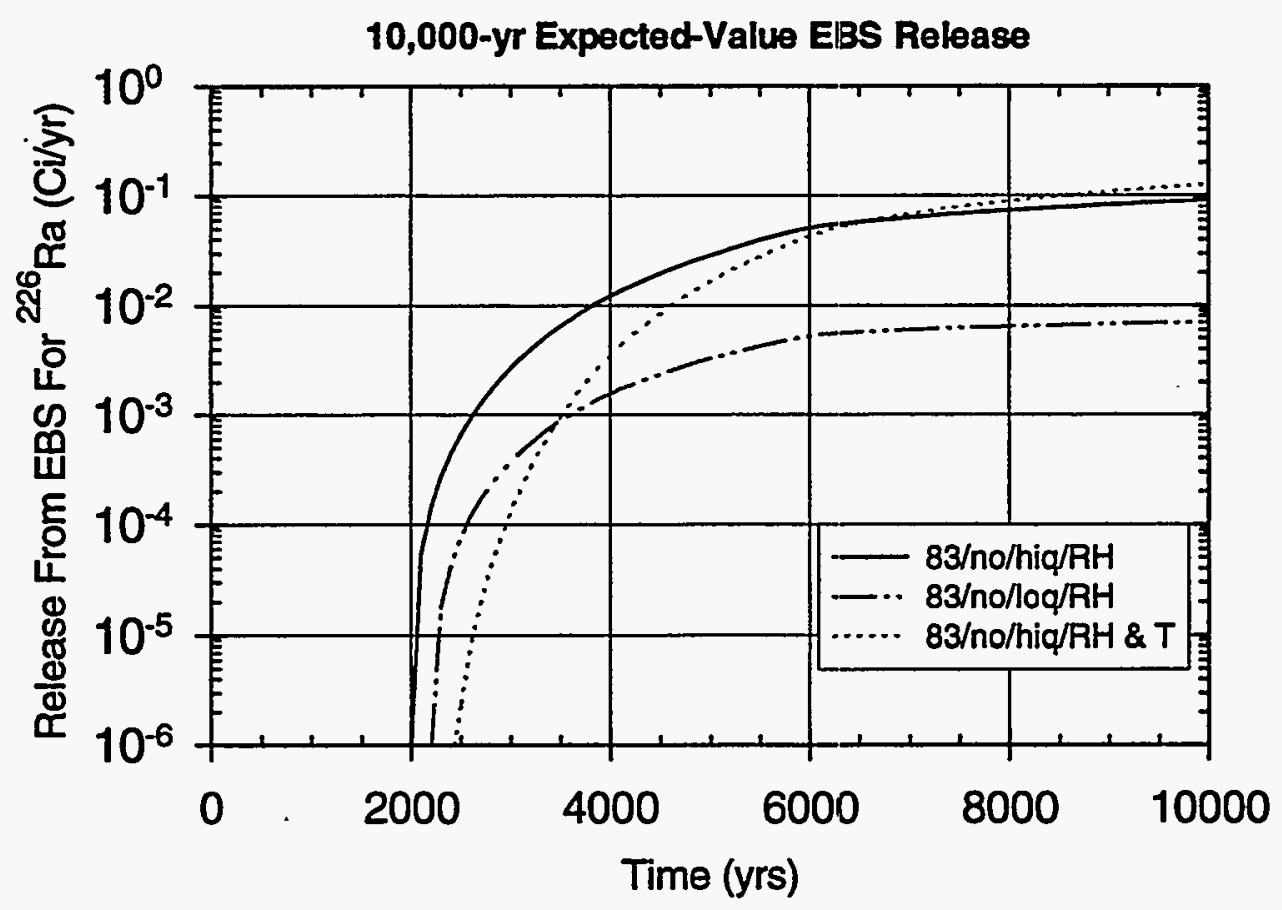

Figure 8.3-5h Sensitivity of the EBS release rate for ${ }^{226} \mathrm{Ra}$ to the alternative advective release model (NRC limit $=0.00237 \mathrm{Ci} / \mathrm{yr}$ ). 


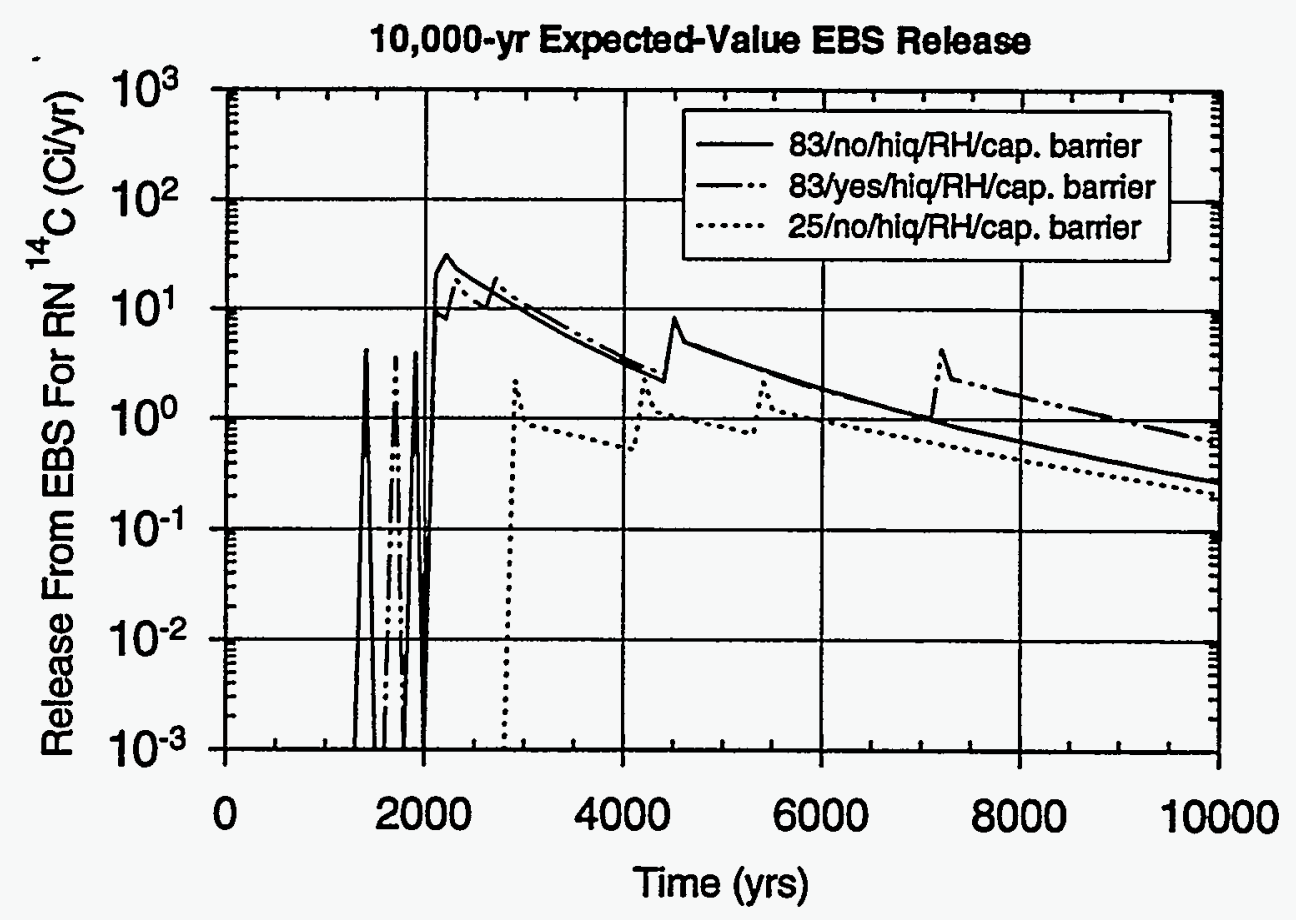

Figure 8.3-6a Sensitivity of the EBS release rate for ${ }^{14} \mathrm{C}$ to the presence of a capillary barrier (NRC limit $=0.796 \mathrm{Ci} / \mathrm{yr})$.

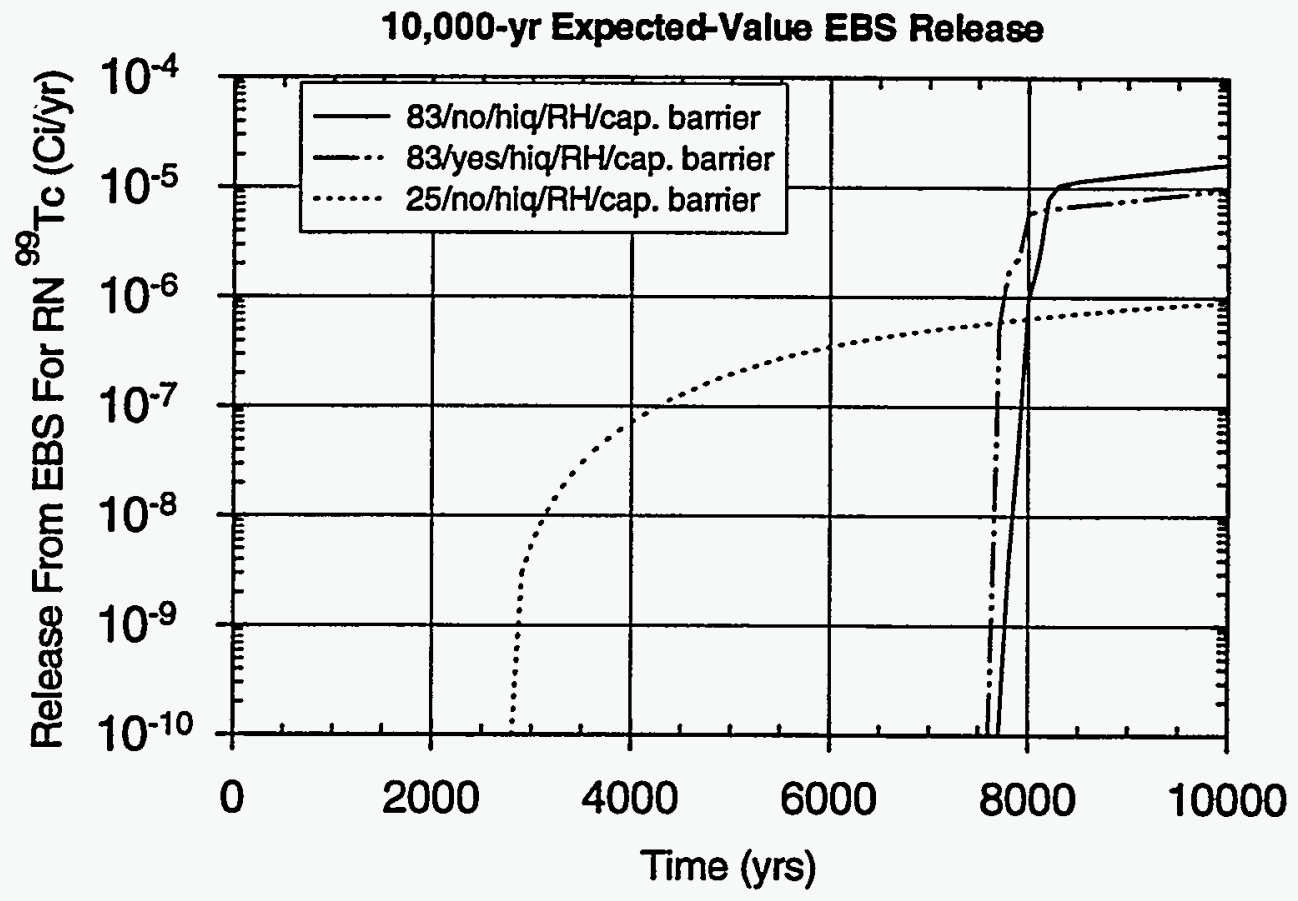

Figure 8.3-6b Sensitivity of the EBS release rate for ${ }^{99} \mathrm{Tc}$ to the presence of a capillary barrier $(\mathrm{NRC}$ limit $=9.03 \mathrm{Ci} / \mathrm{yr})$. 


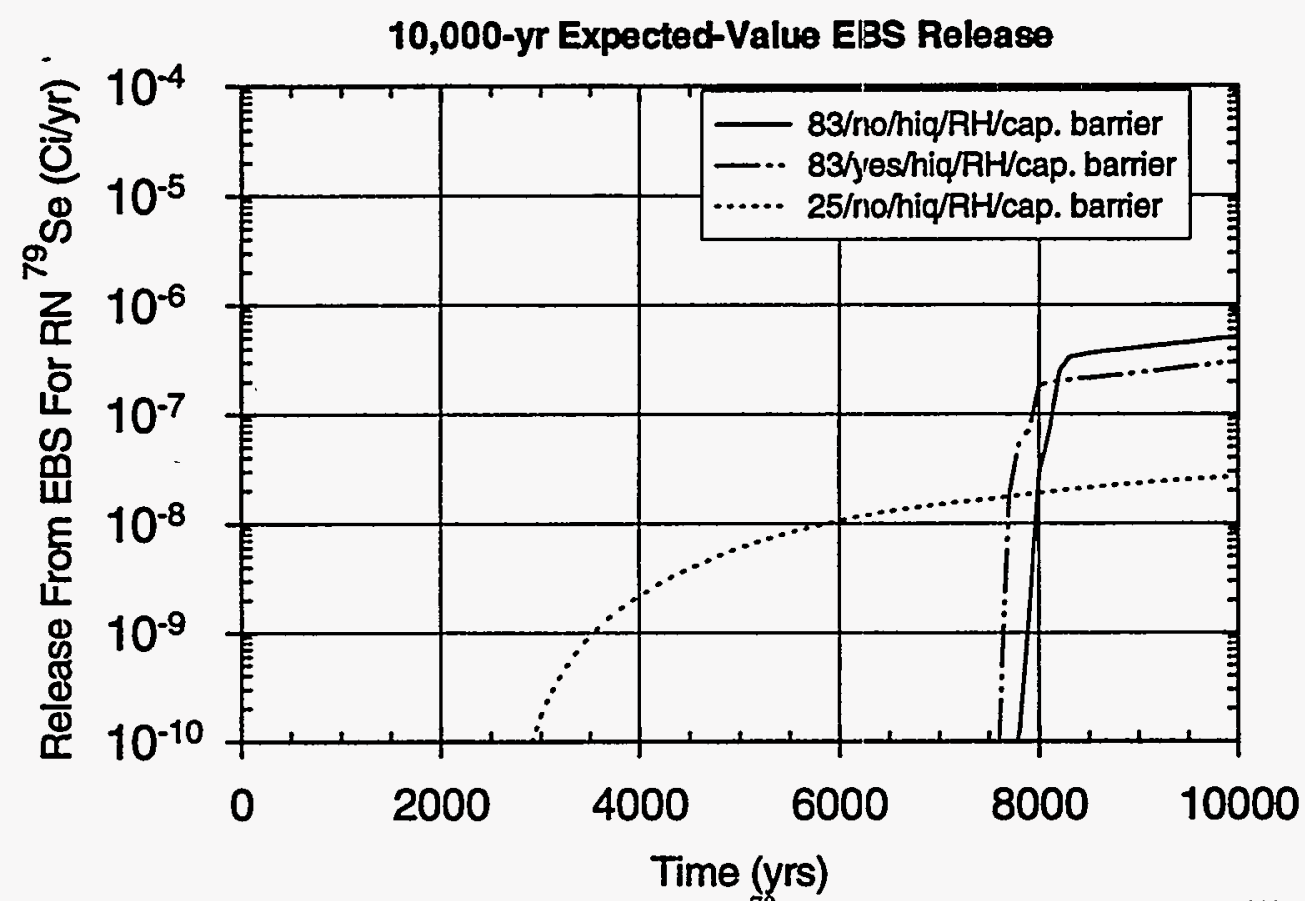

Figure 8.3-6c Sensitivity of the EBS release rate for ${ }^{79} \mathrm{Se}$ to the presence of a capillary barrier $(\mathrm{NRC}$ limit $=0.282 \mathrm{Ci} / \mathrm{yr})$.

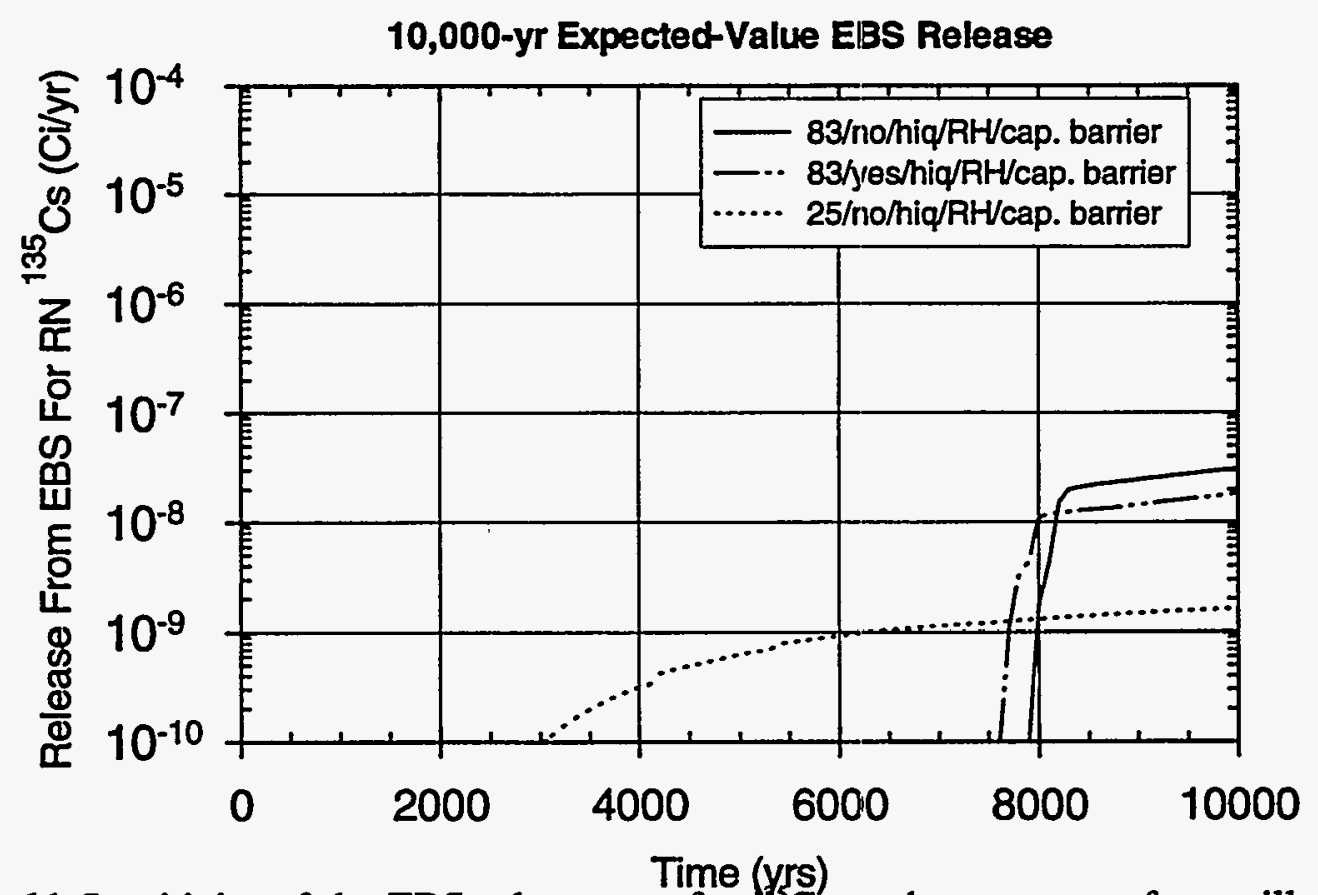

Figure 8.3-6d Sensitivity of the EBS release rate for ${ }^{135}$ to the presence of a capillary barrier (NRC limit $=0.331 \mathrm{Ci} / \mathrm{yr})$. 


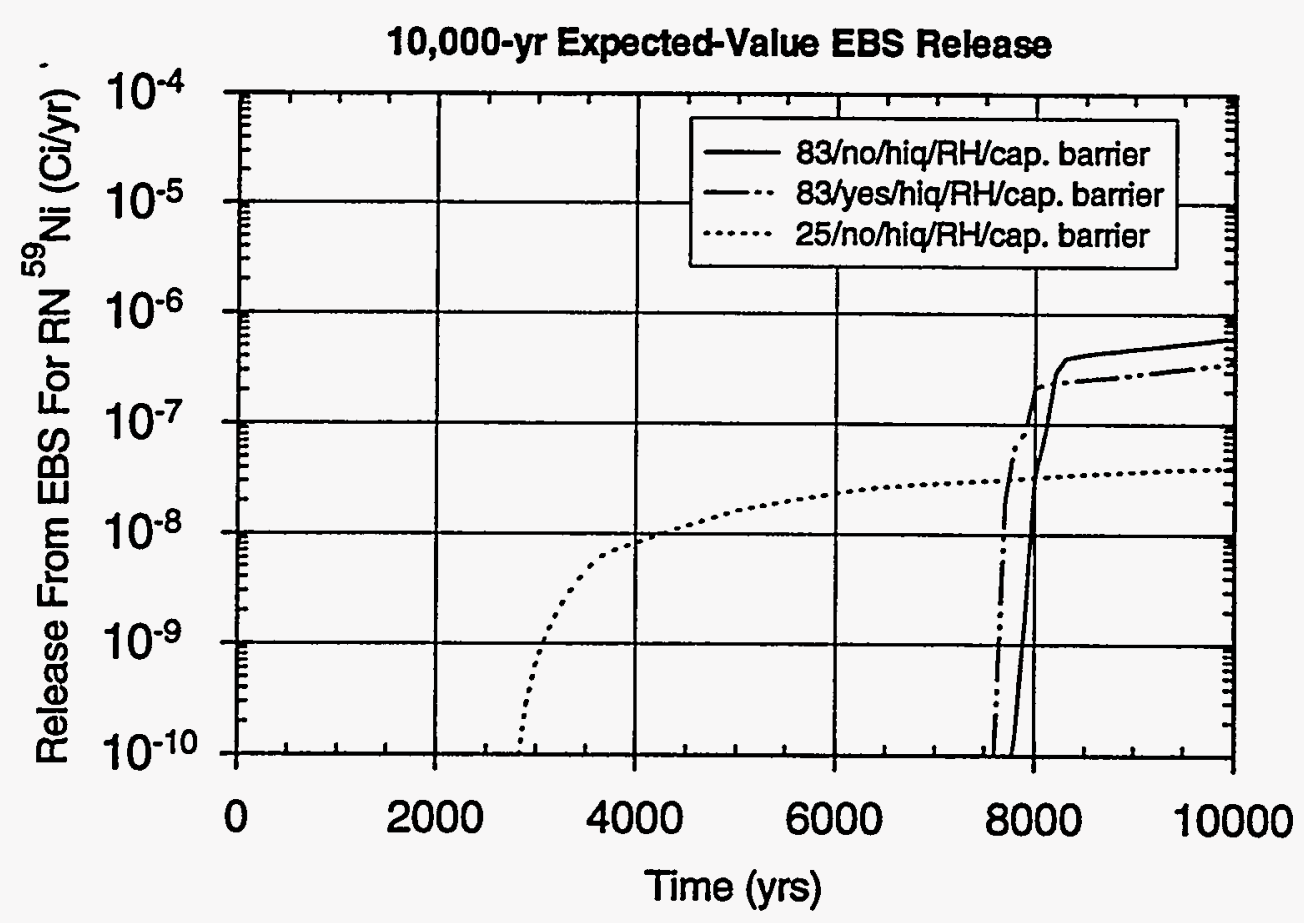

Figure 8.3-6e Sensitivity of the EBS release rate for ${ }^{59} \mathrm{Ni}$ to the presence of a capillary barrier (NRC limit $=1.51 \mathrm{Ci} / \mathrm{yr})$.

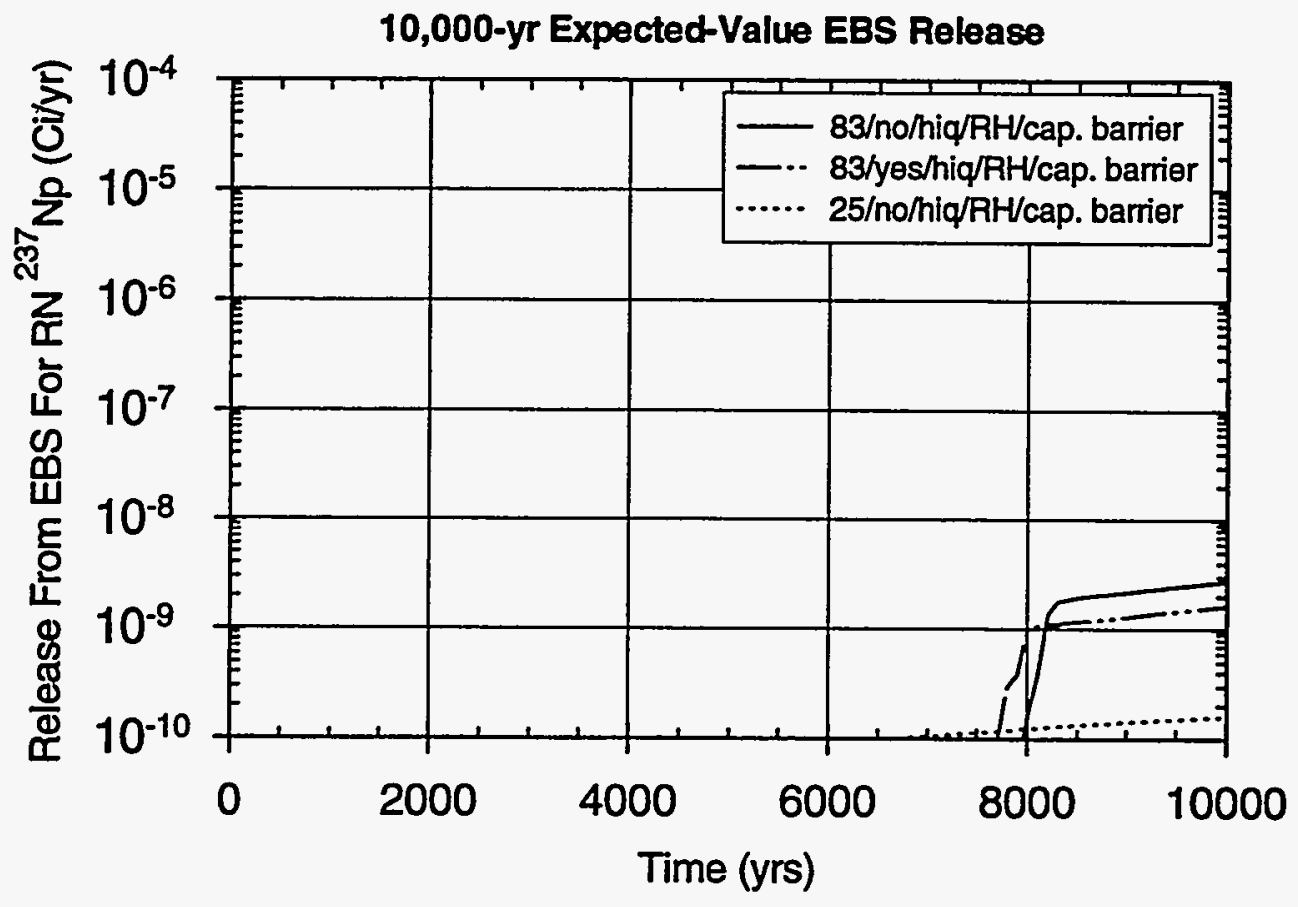

Figure 8.3-6f Sensitivity of the EBS release rate for ${ }^{237} \mathrm{~Np}$ to the presence of capillary barrier (NRC limit $=0.782 \mathrm{Ci} / \mathrm{yr}$ ). 


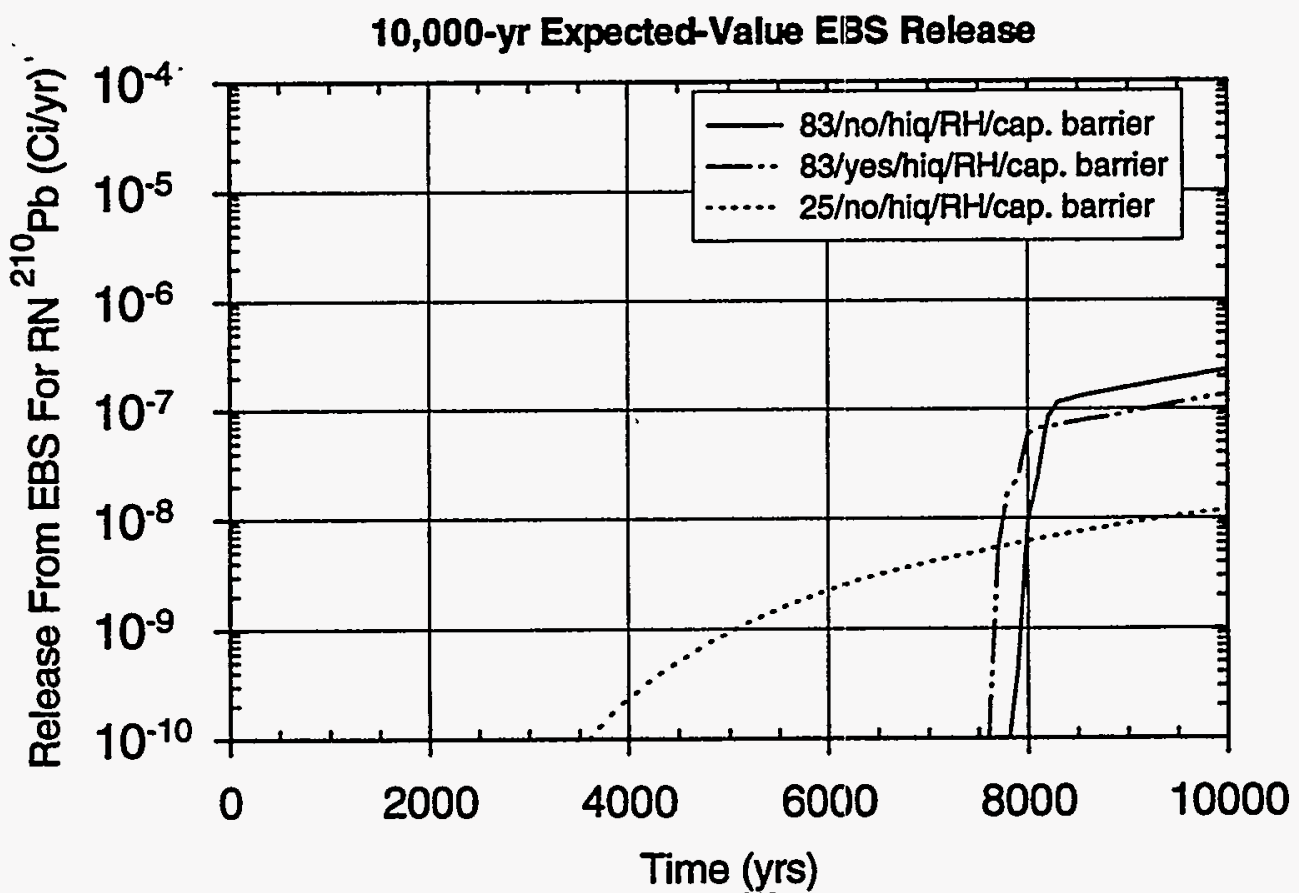

Figure $8.3-6 \mathrm{~g}$ Sensitivity of the EBS release rate for ${ }^{210} \mathrm{~Pb}$ to the presence of a capillary barrier (NRC limit $=0.00236 \mathrm{Ci} / \mathrm{yr}$ ).

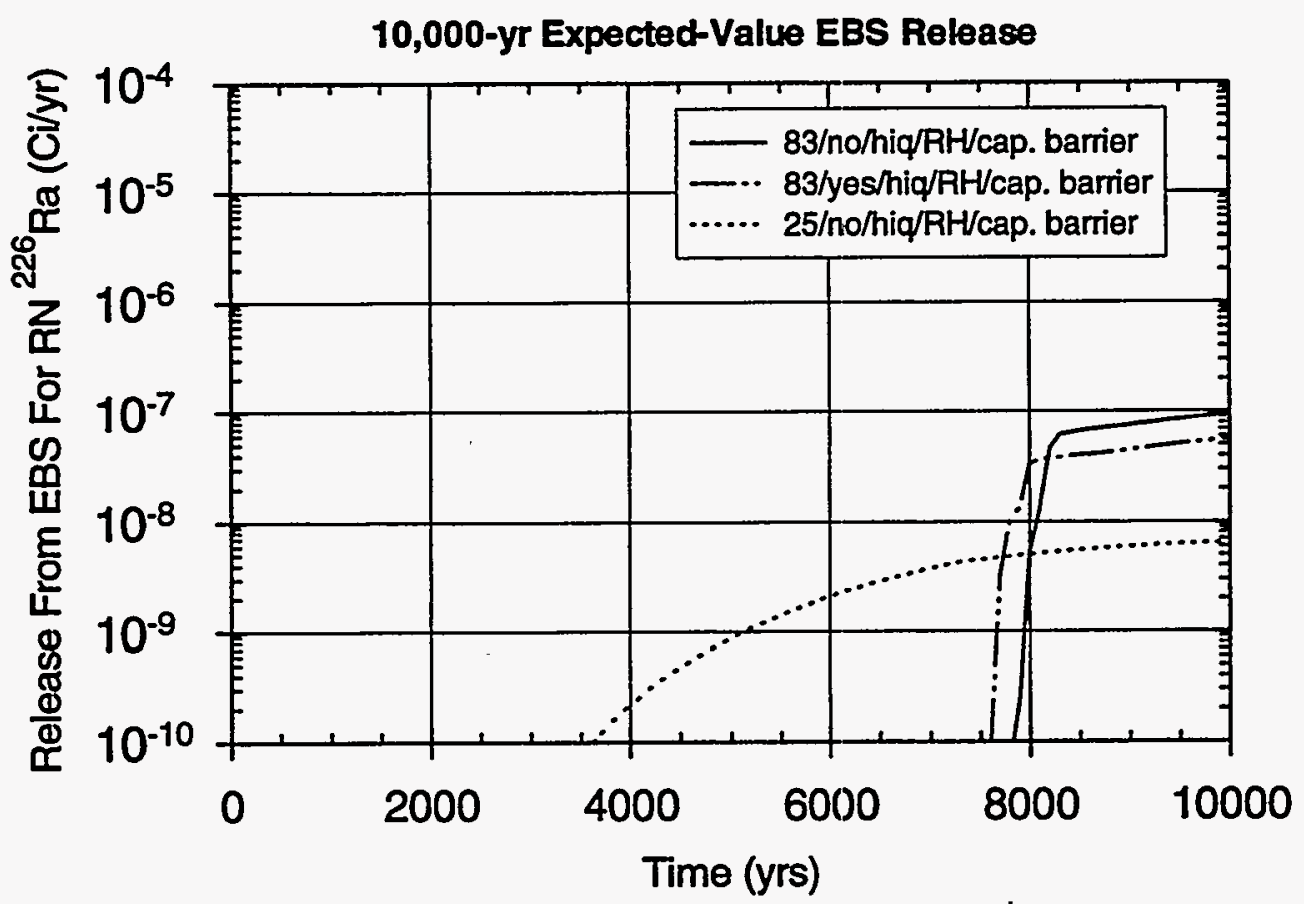

Figure 8.3-6h Sensitivity of the EBS release rate for ${ }^{226} \mathrm{Ra}$ to the presence of a capillary barrier (NRC limit $=0.00237 \mathrm{Ci} / \mathrm{yr})$. 


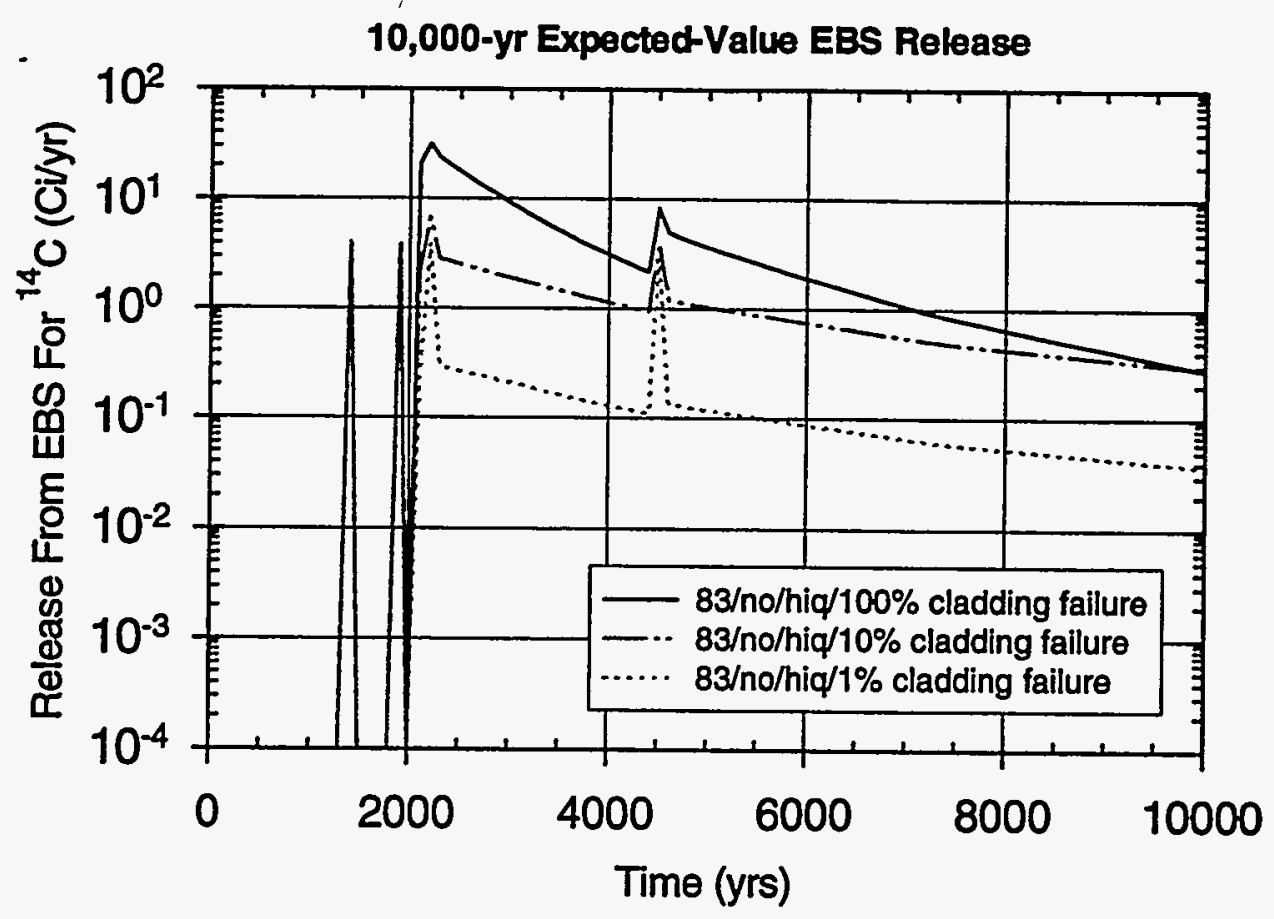

Figure 8.3-7a Sensitivity of the EBS release rate for ${ }^{14} \mathrm{C}$ to cladding failure (NRC limit = $0.796 \mathrm{Ci} / \mathrm{yr})$.

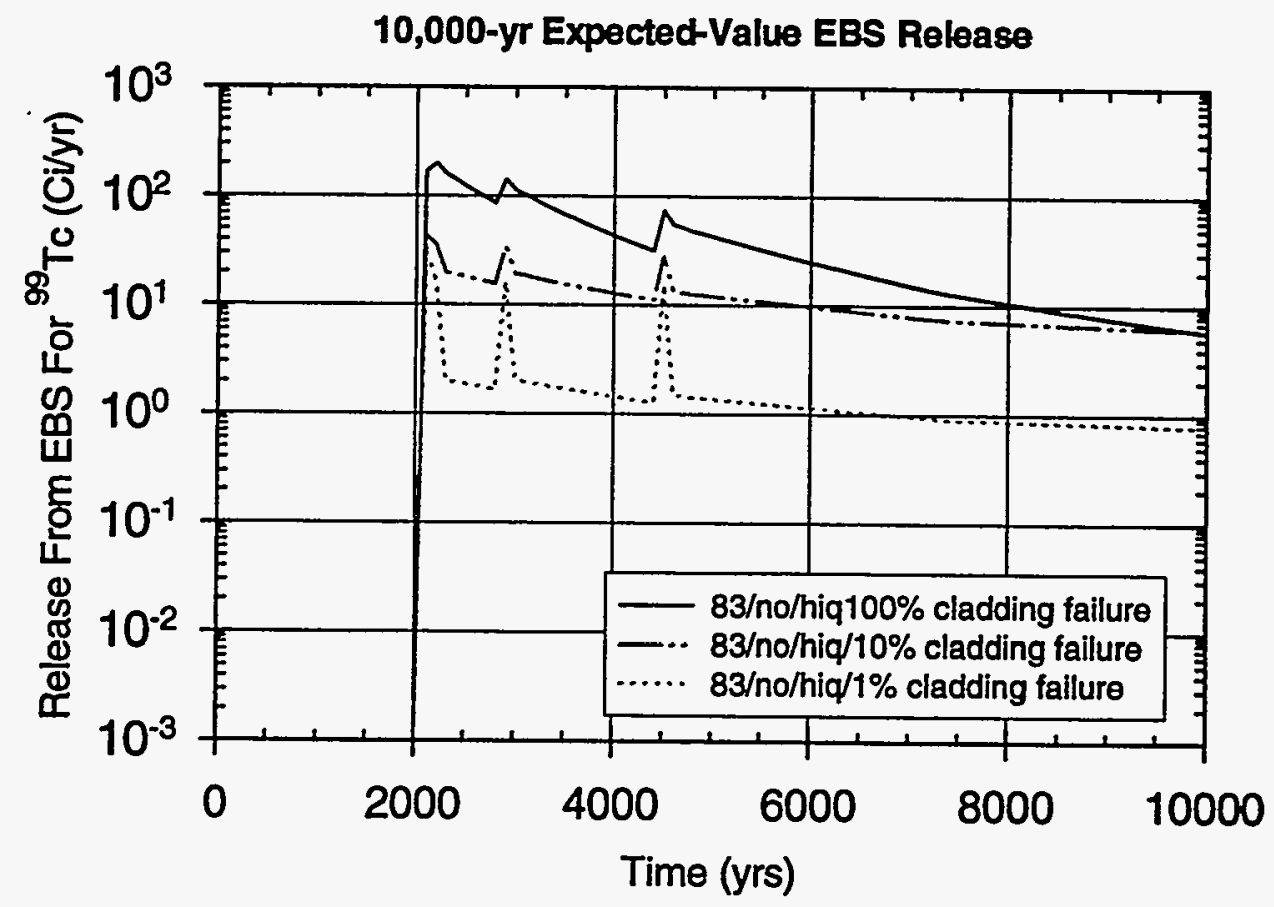

Figure 8.3-7b Sensitivity of the EBS release rate for ${ }^{99} \mathrm{Tc}$ to cladding failure (NRC limit = $9.03 \mathrm{Ci} / \mathrm{yr})$. 


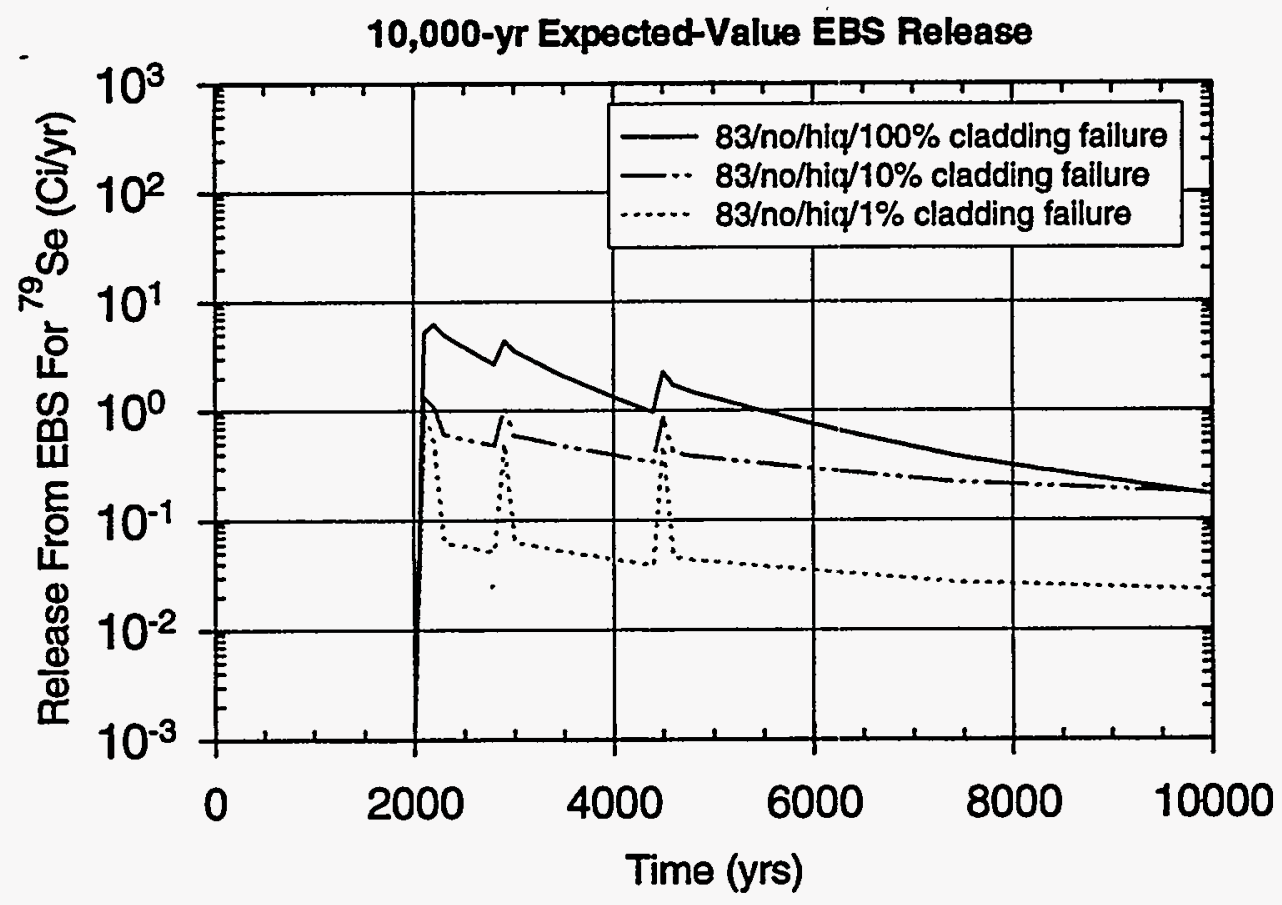

Figure 8.3-7c Sensitivity of the EBS release rate for ${ }^{79}$ Se to cladding failure (NRC limit = $0.282 \mathrm{Ci} / \mathrm{yr}$ ).

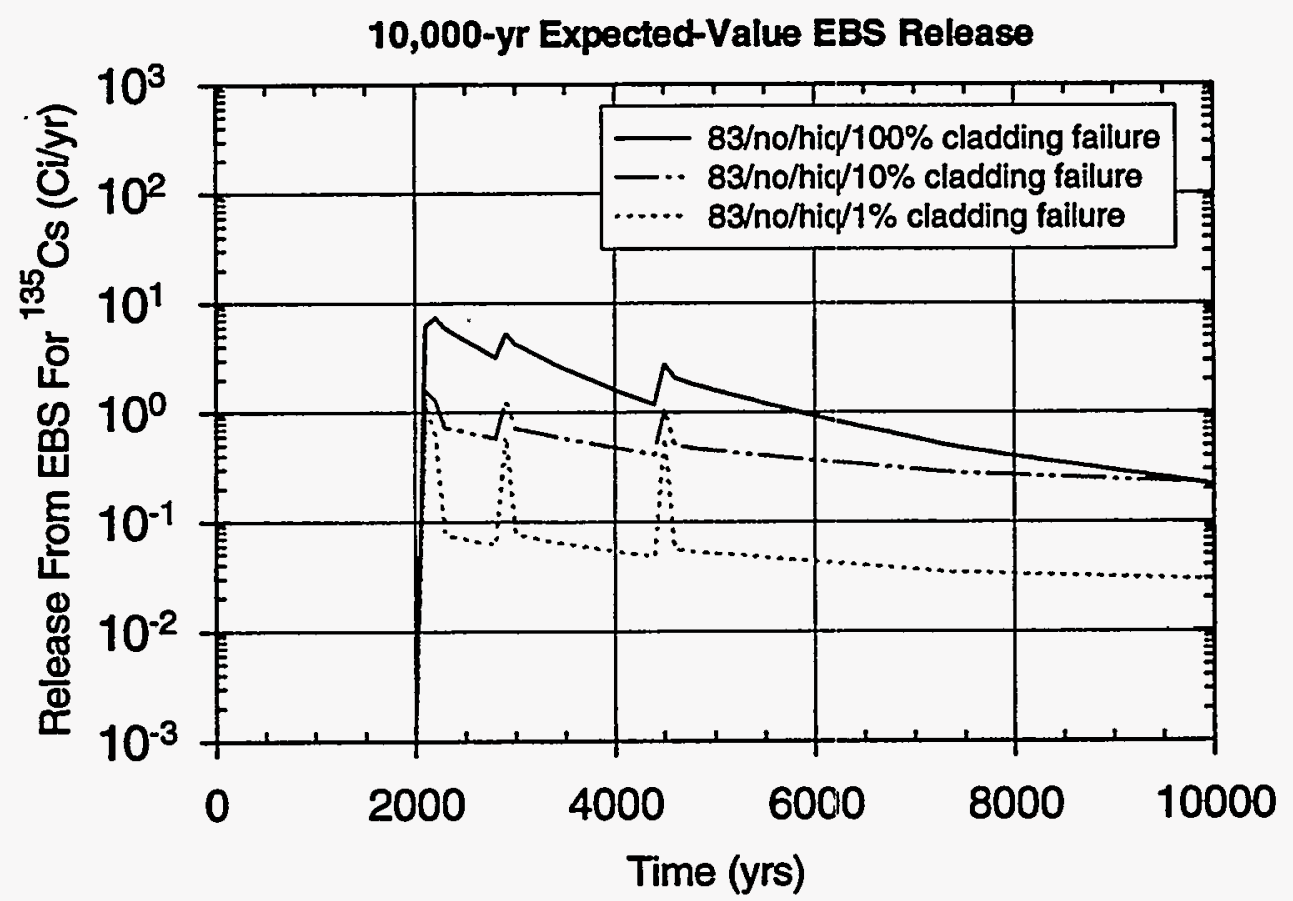

Figure 8.3-7d Sensitivity of the EBS release rate for ${ }^{135} \mathrm{Cs}$ to cladding failure (NRC limit = $0.331 \mathrm{Ci} / \mathrm{yr}$ ). 


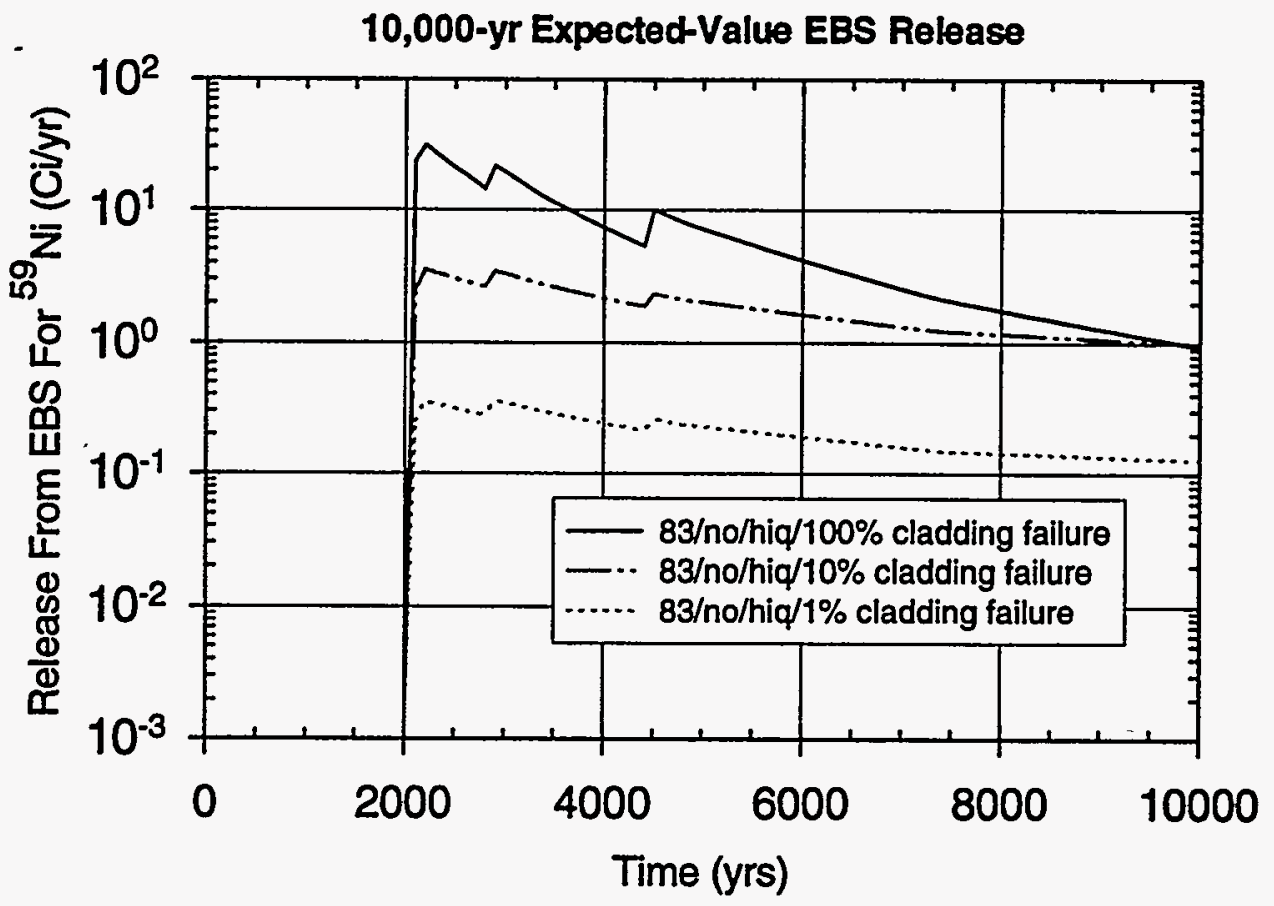

Figure 8.3-7e Sensitivity of the EBS release rate for ${ }^{59} \mathrm{Ni}$ to cladding failure (NRC limit = $1.51 \mathrm{Ci} / \mathrm{yr})$.

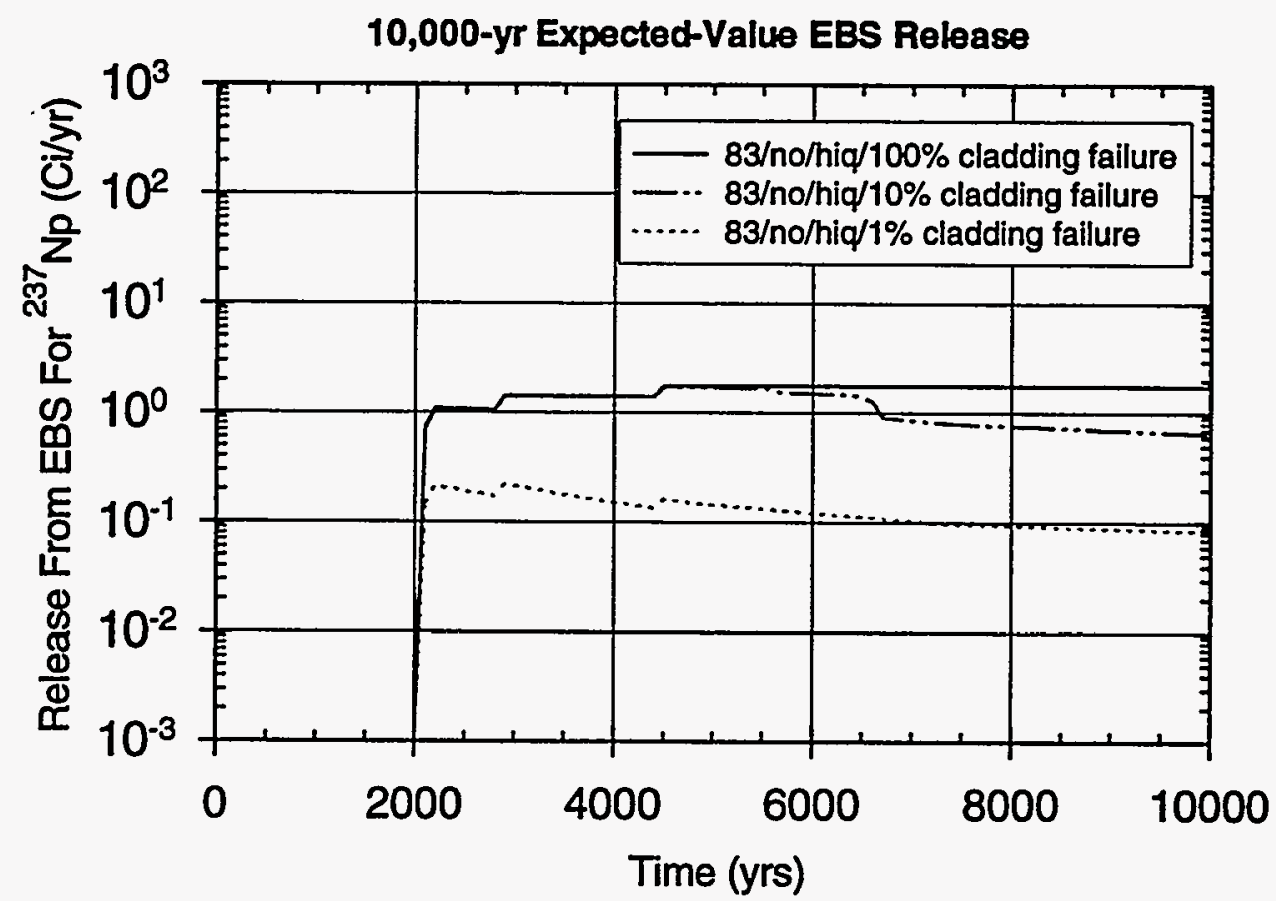

Figure 8.3-7f Sensitivity of the EBS release rate for ${ }^{237} \mathrm{~Np}$ to cladding failure (NRC limit = $0.782 \mathrm{Ci} / \mathrm{yr})$. 


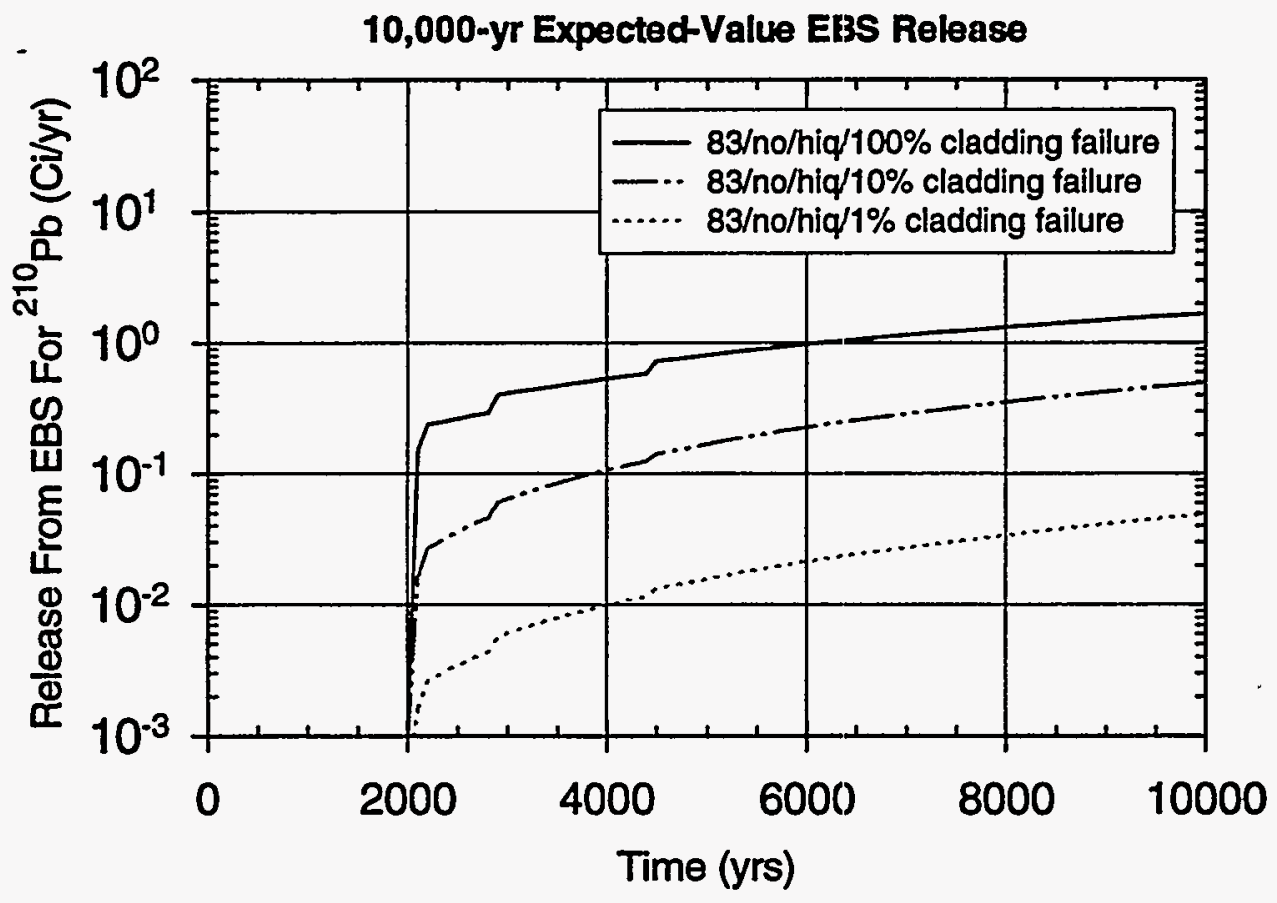

Figure $8.3-7 \mathrm{~g}$ Sensitivity of the EBS release rate for ${ }^{210} \mathrm{~Pb}$ to cladding failure (NRC limit = $0.00236 \mathrm{Ci} / \mathrm{yr})$.

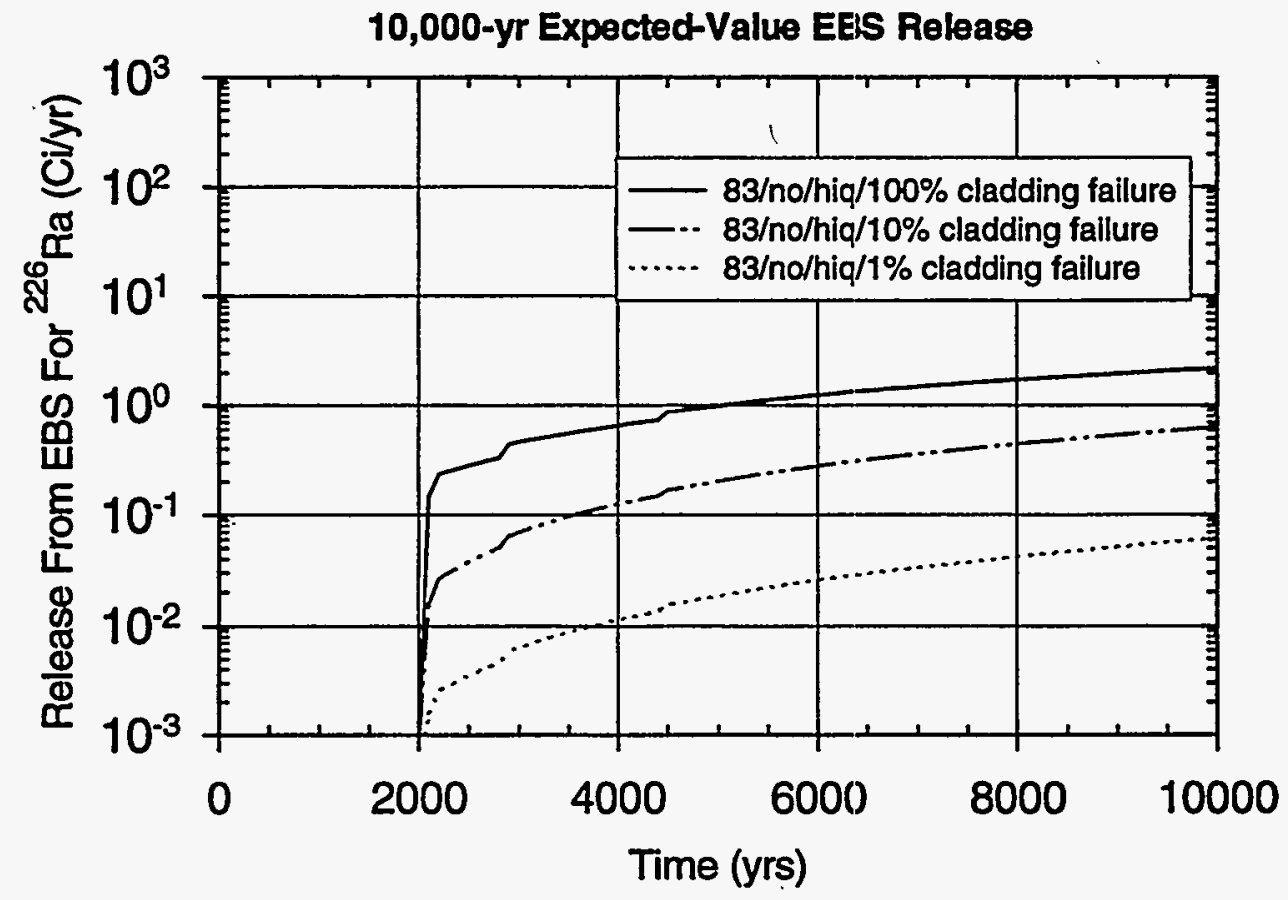

Figure 8.3-7h Sensitivity of the EBS release rate for ${ }^{226} \mathrm{Ra}$ to cladding failure (NRC limit = $0.00237 \mathrm{Ci} / \mathrm{yr})$. 


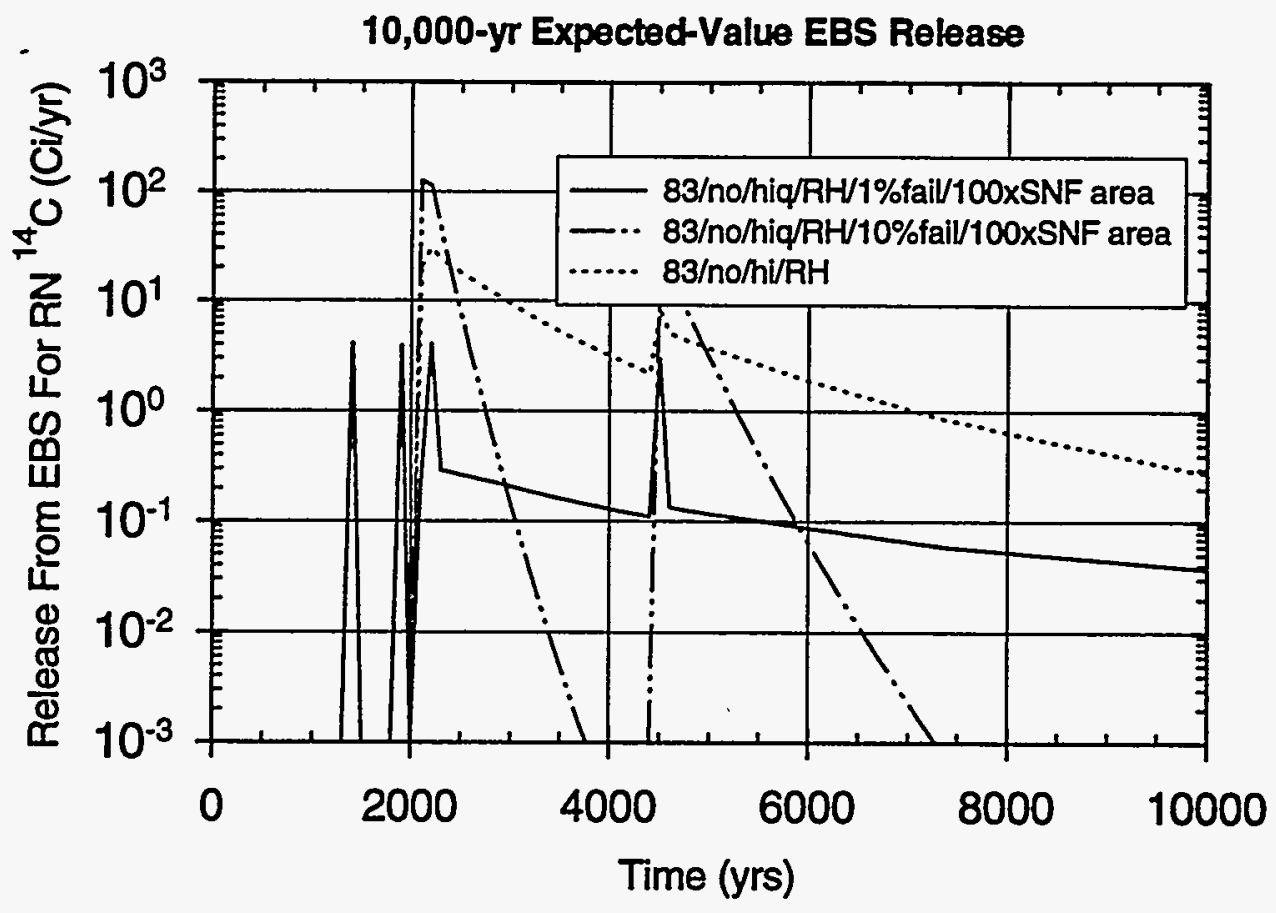

Figure 8.3-8a Sensitivity of the EBS release rate for ${ }^{14} \mathrm{C}$ to cladding failure with the spent fuel surface area increased by a factor of 100 (NRC limit $=0.796 \mathrm{Ci} / \mathrm{yr}$ ).

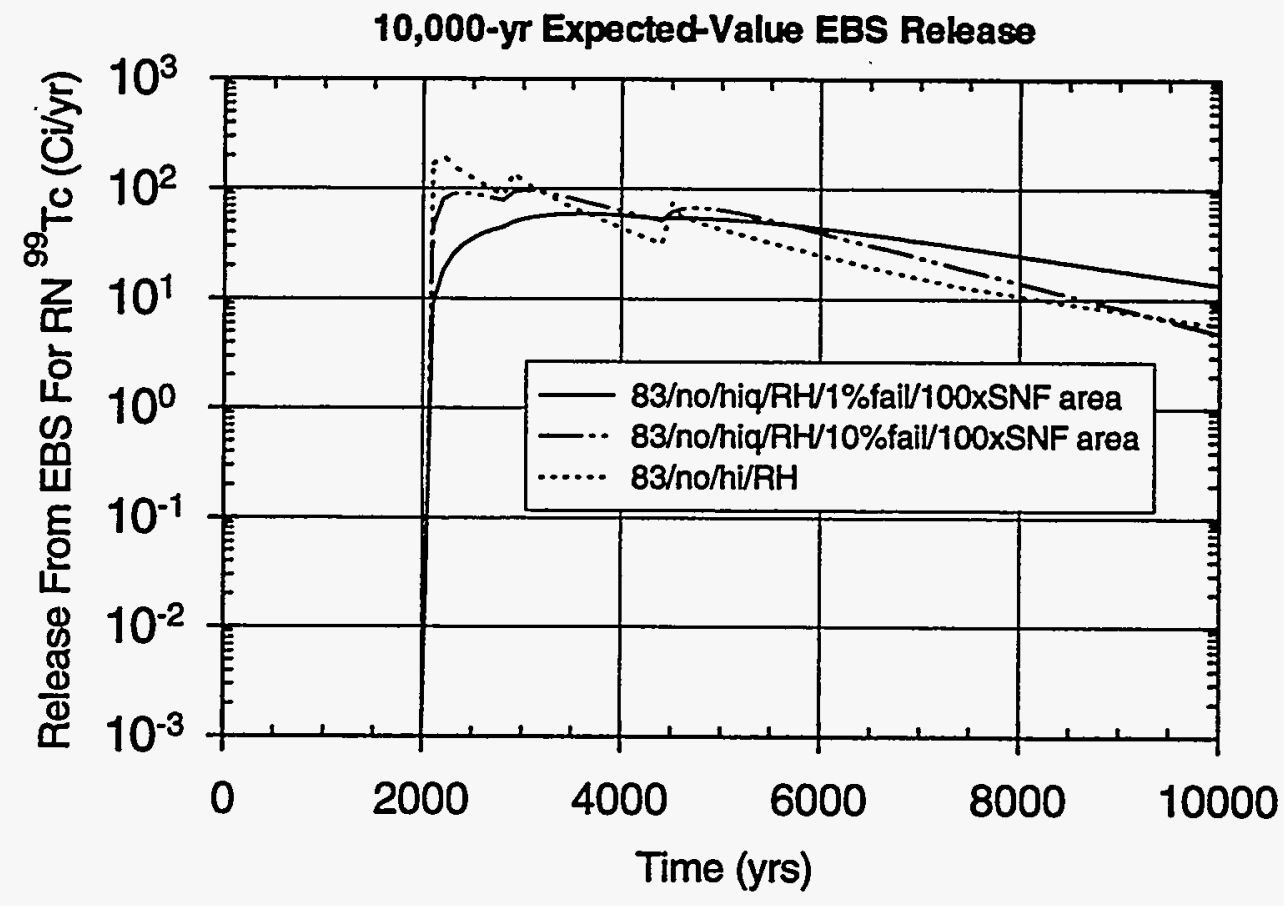

Figure 8.3-8b Sensitivity of the EBS release rate for ${ }^{99} \mathrm{Tc}$ to cladding failure with the spent fuel surface area increased by a factor of $100(\mathrm{NRC}$ limit $=9.03 \mathrm{Ci} / \mathrm{yr})$. 


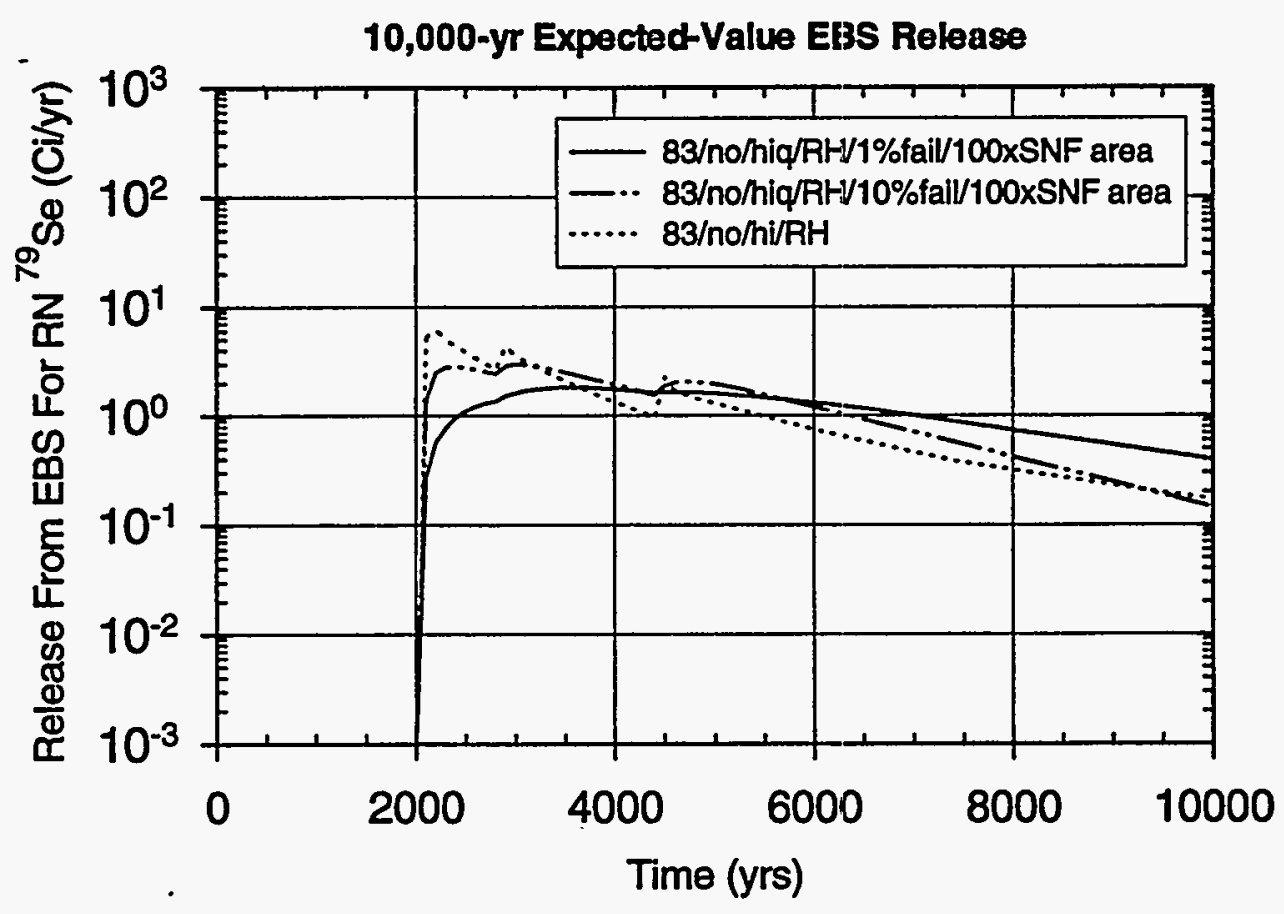

Figure 8.3-8c Sensitivity of the EBS release rate for ${ }^{79} \mathrm{Se}$ to cladding failure with the spent fuel surface area increased by a factor of 100 (NRC limit $=0.282 \mathrm{Ci} / \mathrm{yr}$ ).

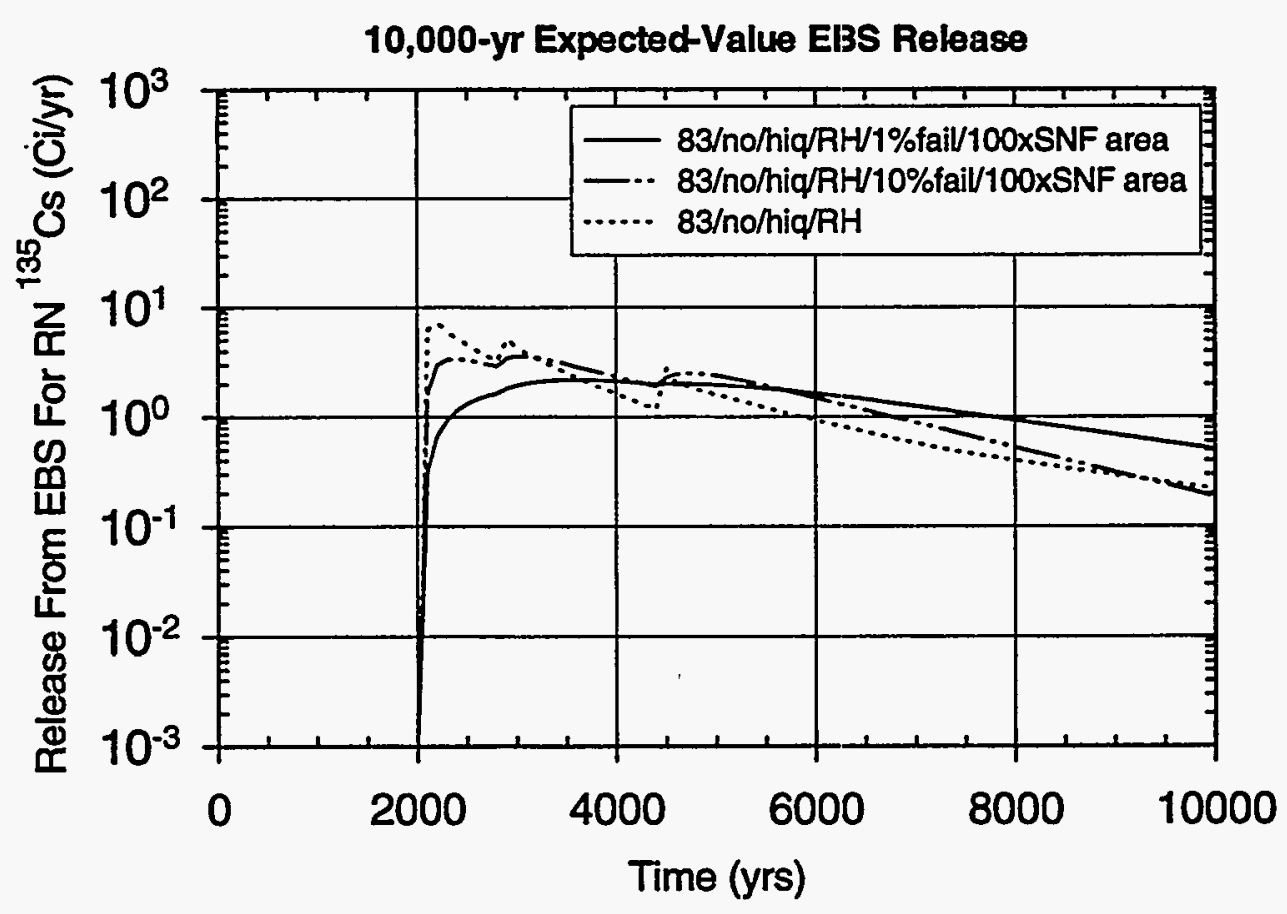

Figure 8.3-8d Sensitivity of the EBS release rate for ${ }^{135} \mathrm{Cs}$ to cladding failure with the spent fuel surface area increased by a factor of $100(\mathrm{NRC}$ limit $=0.331 \mathrm{Ci} / \mathrm{yr})$. 


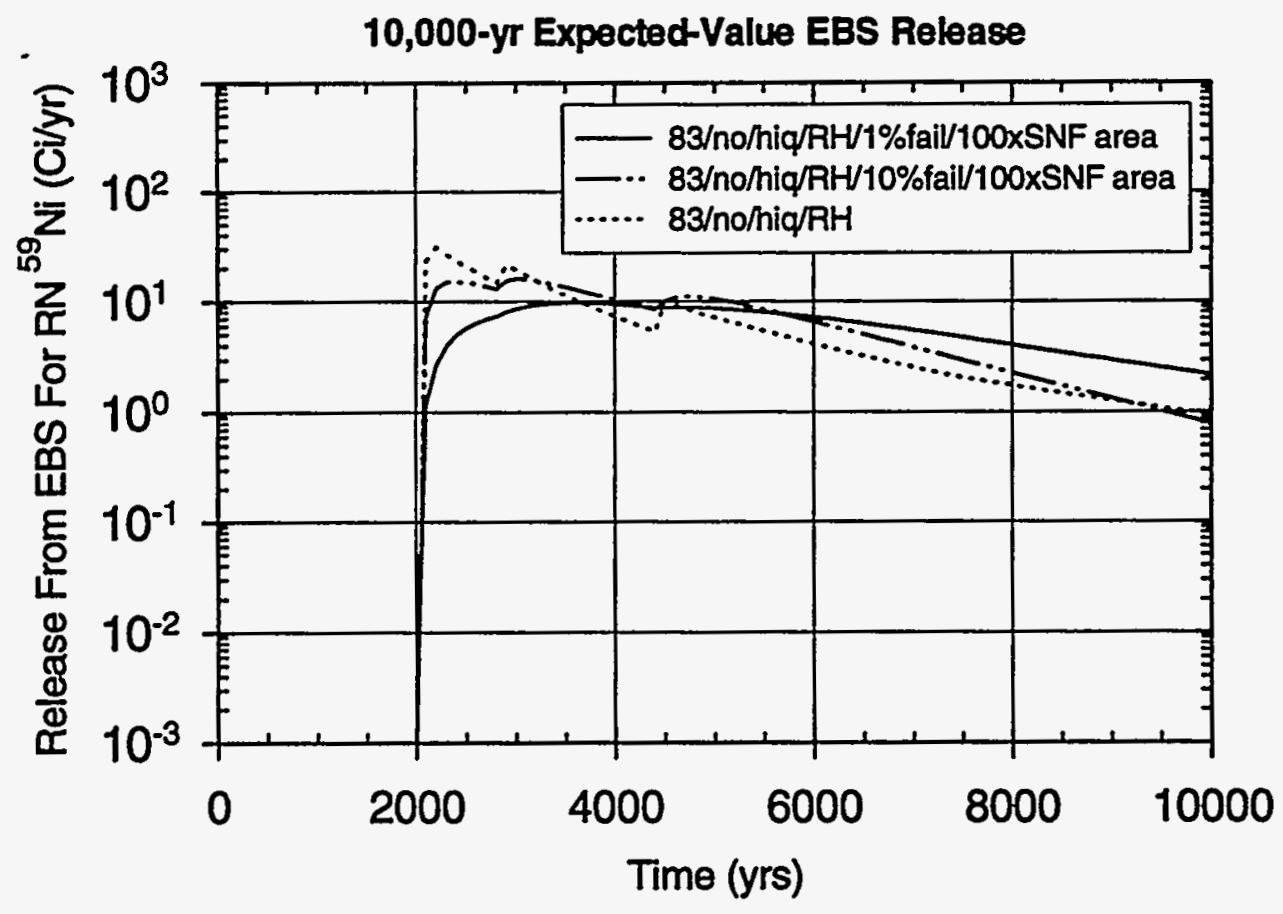

Figure 8.3-8e Sensitivity of the EBS release rate for ${ }^{59} \mathrm{Ni}$ to cladding failure with the spent fuel surface area increased by a factor of 100 (NRC limit $=1.51 \mathrm{Ci} / \mathrm{yr})$.

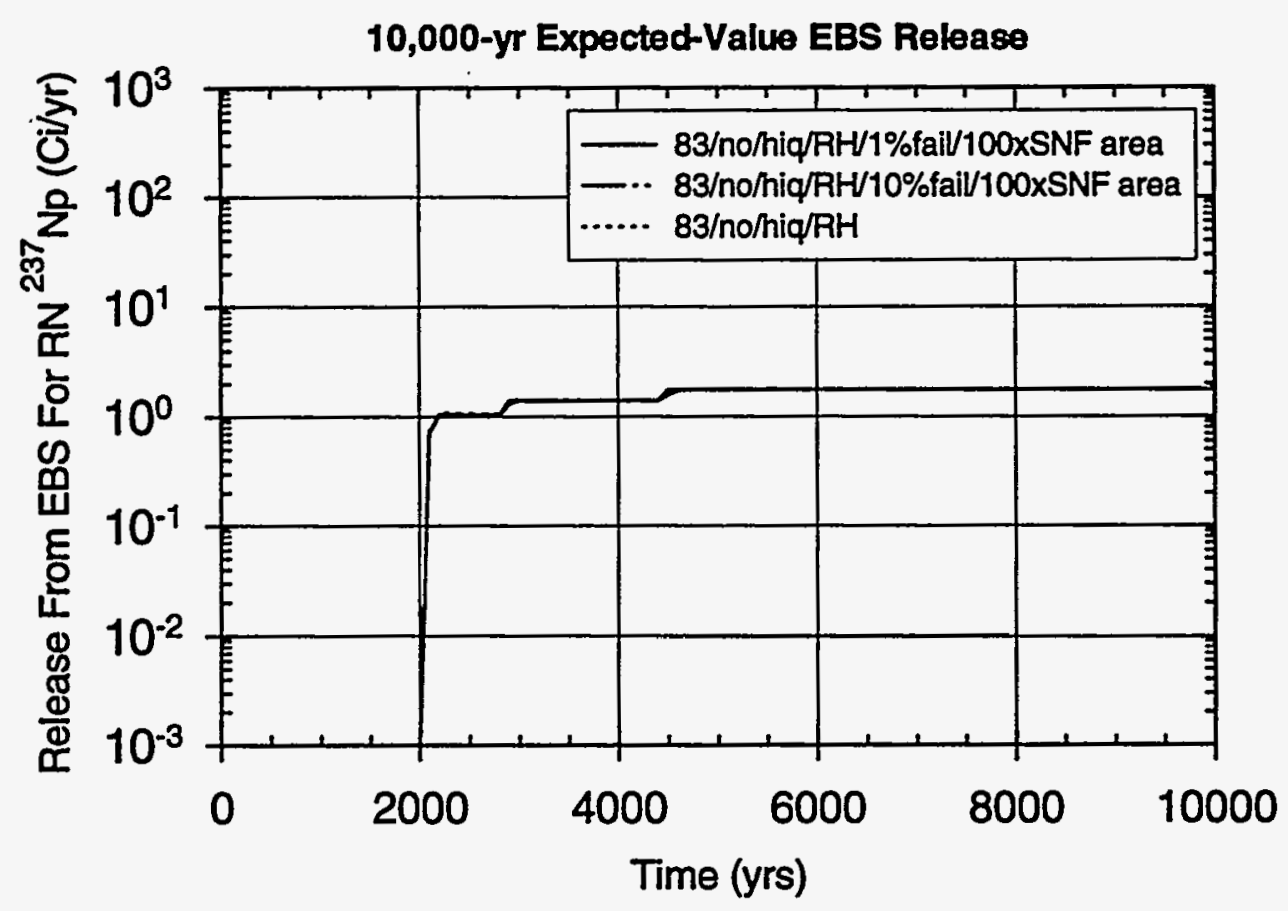

Figure 8.3-8f Sensitivity of the EBS release rate for ${ }^{237} \mathrm{~Np}$ to cladding failure with the spent fuel surface area increased by a factor of 100 (NRC limit $=0.782 \mathrm{Ci} / \mathrm{yr}$ ). 


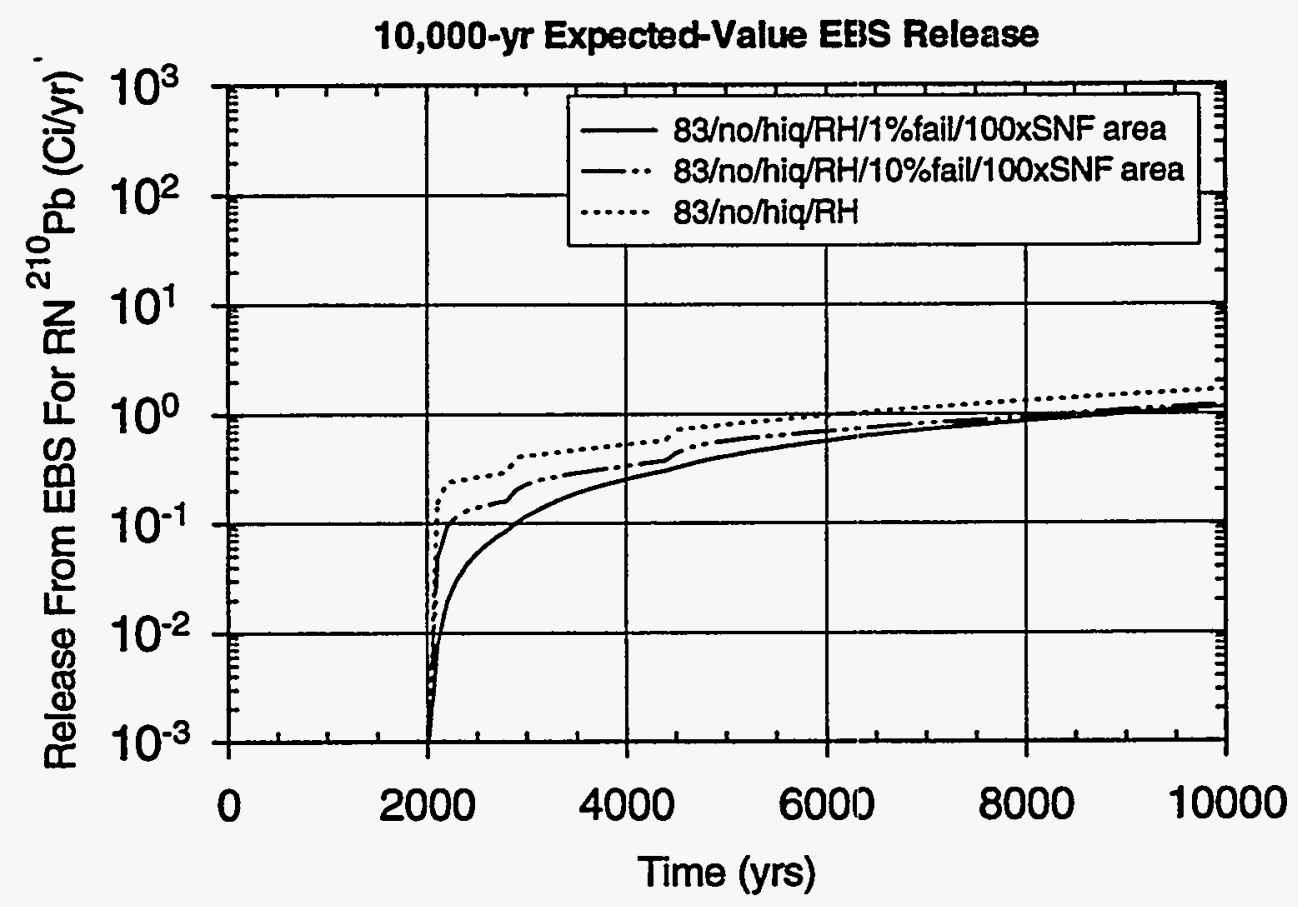

Figure 8.3-8g Sensitivity of the EBS release rate for ${ }^{210} \mathrm{~Pb}$ to cladding failure with the spent fuel surface area increased by a factor of 100 (NRC limit $=0.00236 \mathrm{Ci} / \mathrm{yr}$ ).

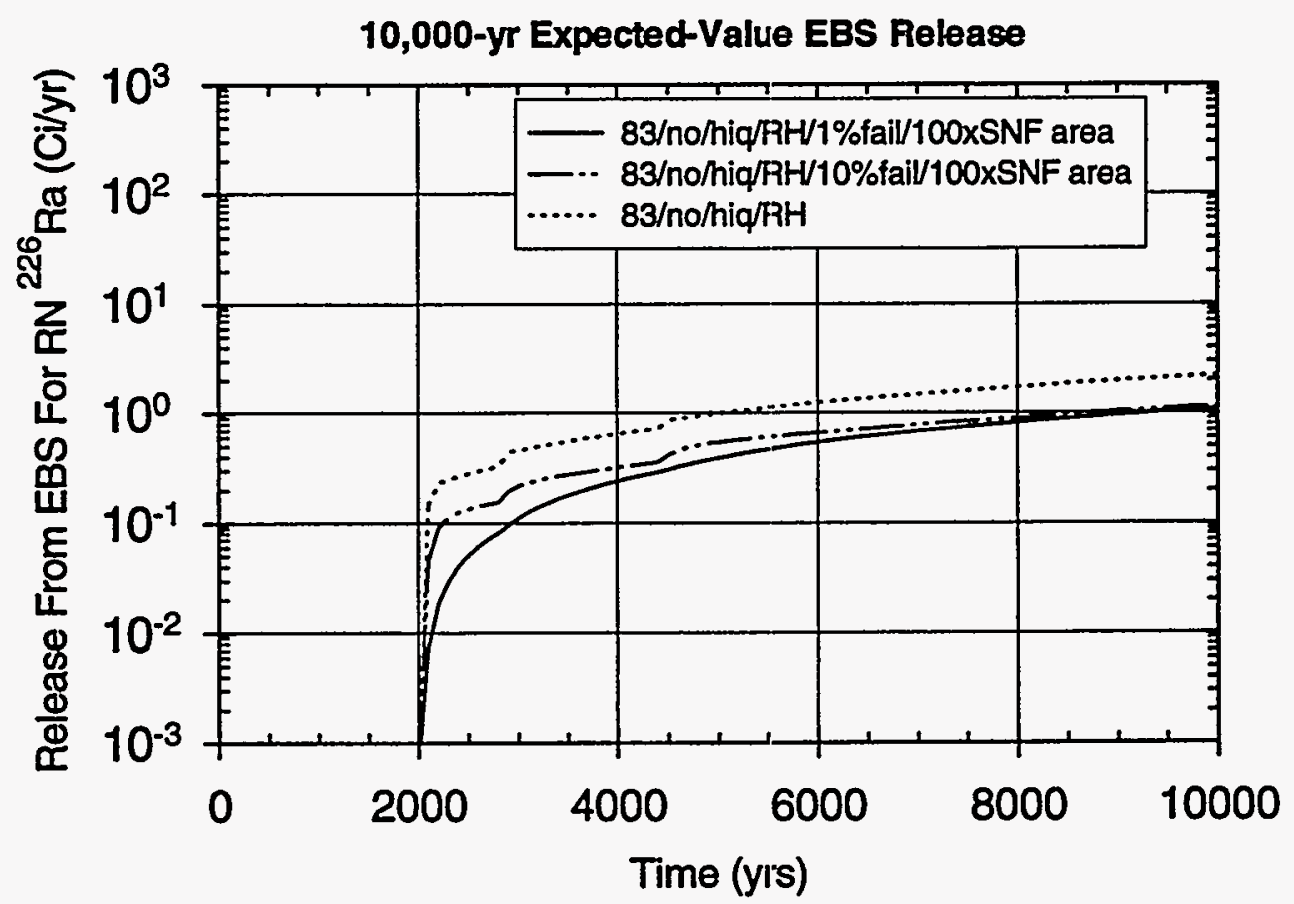

Figure 8.3-8h Sensitivity of the EBS release rate for ${ }^{226} \mathrm{Ra}$ to cladding failure with the spent fuel surface area increased by a factor of 100 (NRC limit $=0.00237 \mathrm{Ci} / \mathrm{yr}$ ). 


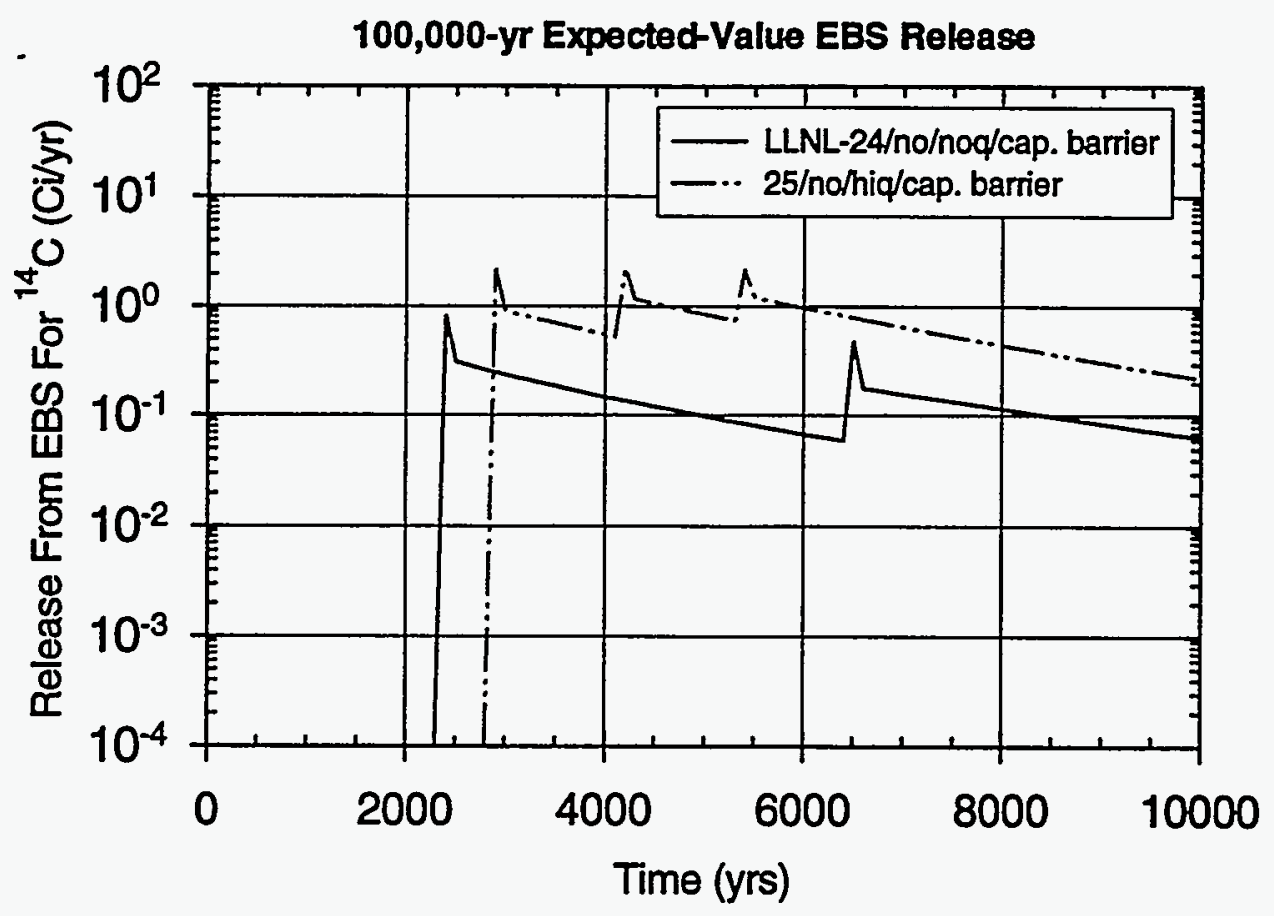

Figure 8.3-9a Sensitivity of the EBS release rate for ${ }^{14} \mathrm{C}$ to the thermal-hydrologic model $(\mathrm{NRC}$ limit $=0.796 \mathrm{Ci} / \mathrm{yr})$.

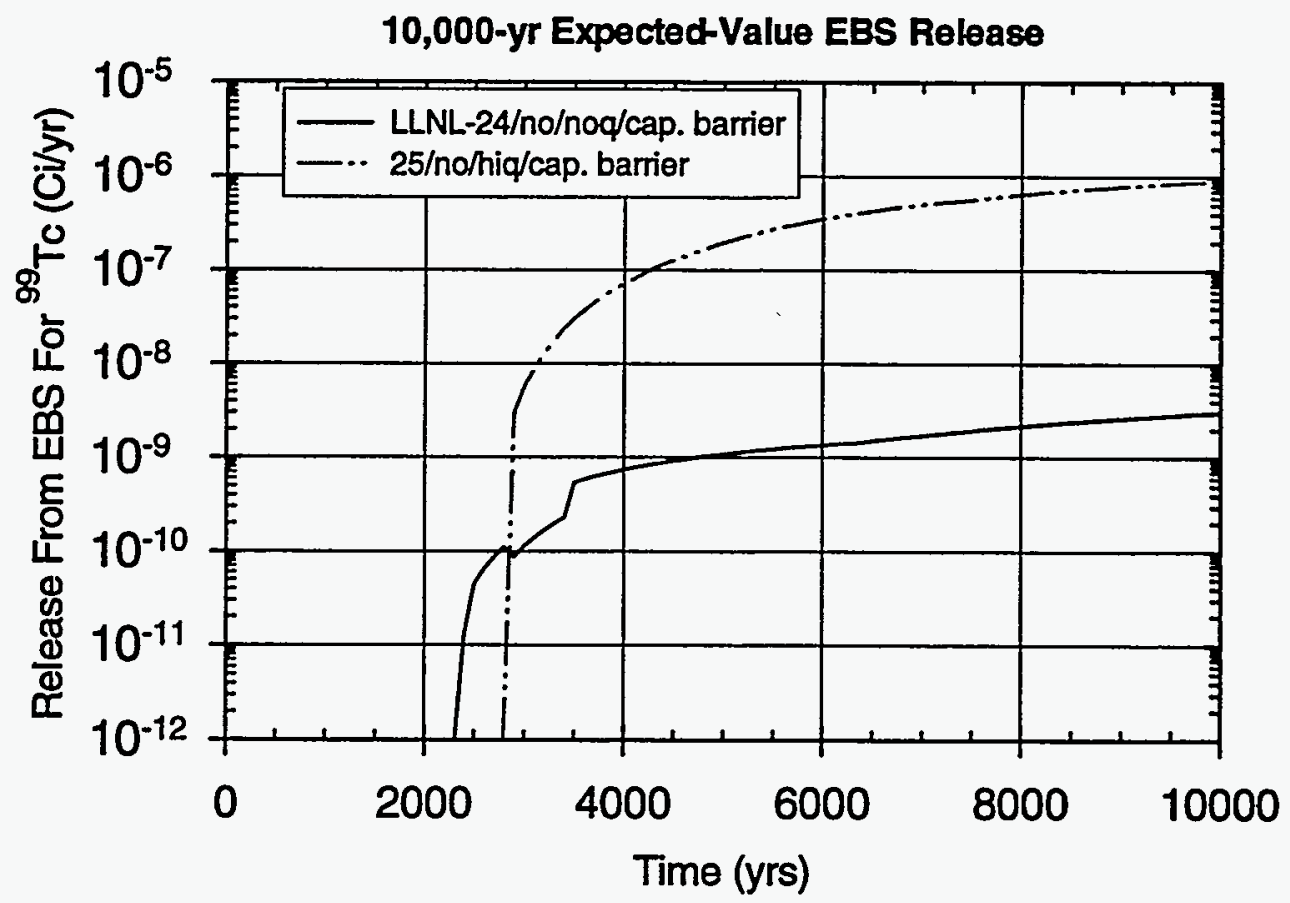

Figure 8.3-9b Sensitivity of the EBS release rate for ${ }^{99} \mathrm{Tc}$ to the thermal-hydrologic model $(\mathrm{NRC}$ limit $=9.03 \mathrm{Ci} / \mathrm{yr})$. 


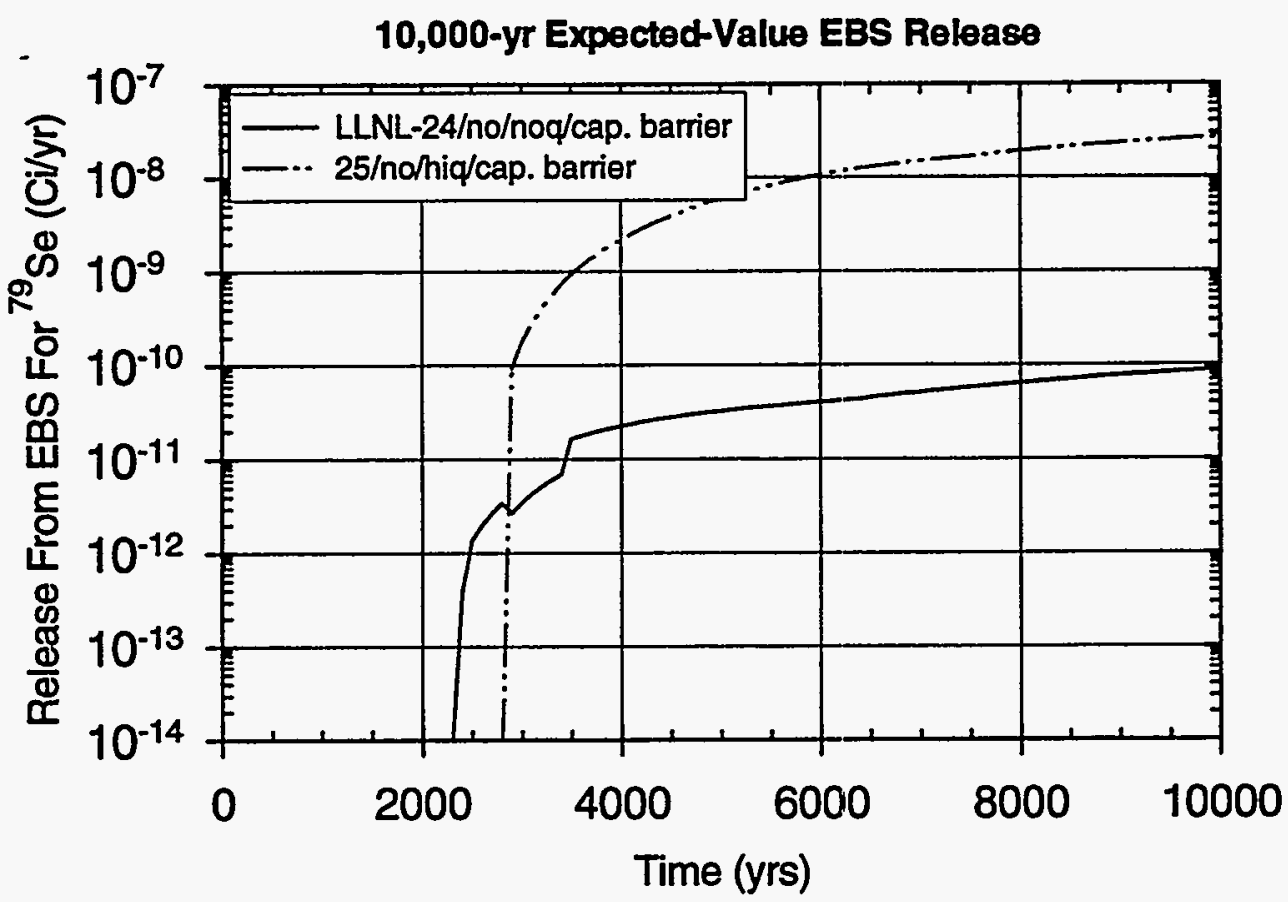

Figure 8.3-9c Sensitivity of the EBS release rate for ${ }^{79} \mathrm{Se}$ to the thermal-hydrologic model (NRC limit $=0.282 \mathrm{Ci} / \mathrm{yr}$ ).

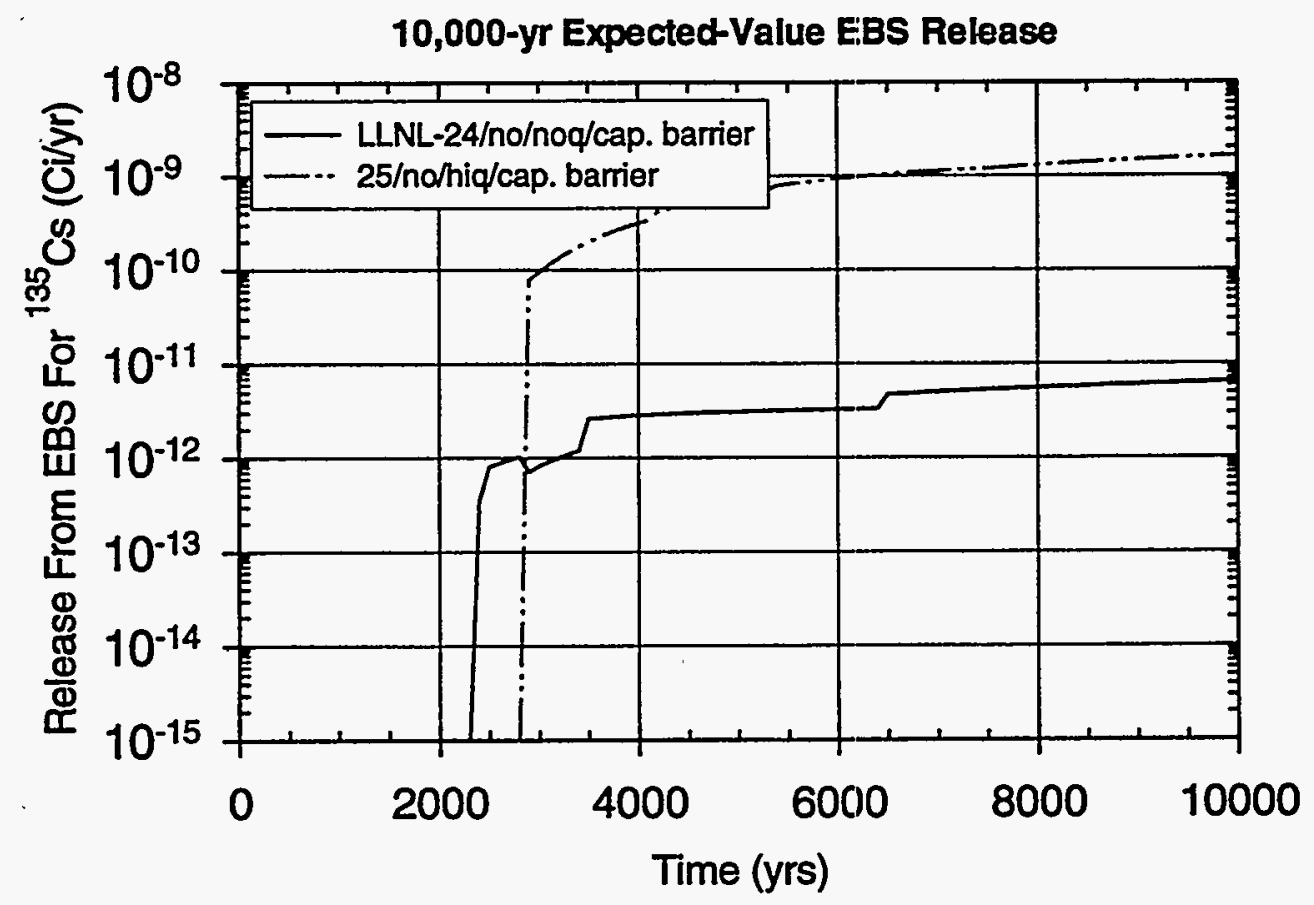

Figure 8.3-9d Sensitivity of the EBS release rate for ${ }^{135} \mathrm{Cs}$ to the thermal-hydrologic model (NRC limit $=0.331 \mathrm{Ci} / \mathrm{yr}$ ). 


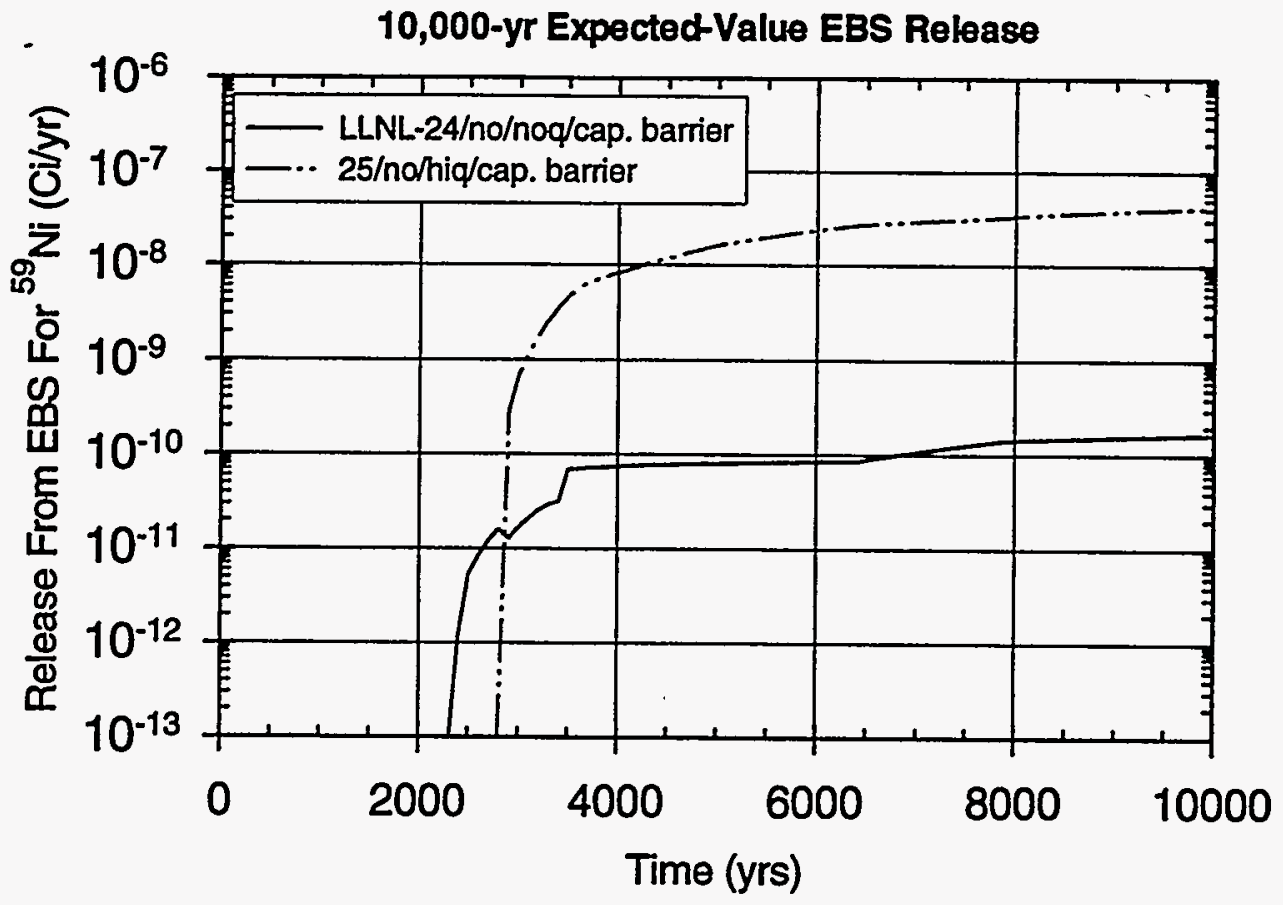

Figure 8.3-9e Sensitivity of the EBS release rate for ${ }^{59} \mathrm{Ni}$ to the thermal-hydrologic model $(\mathrm{NRC}$ limit $=1.51 \mathrm{Ci} / \mathrm{yr})$.

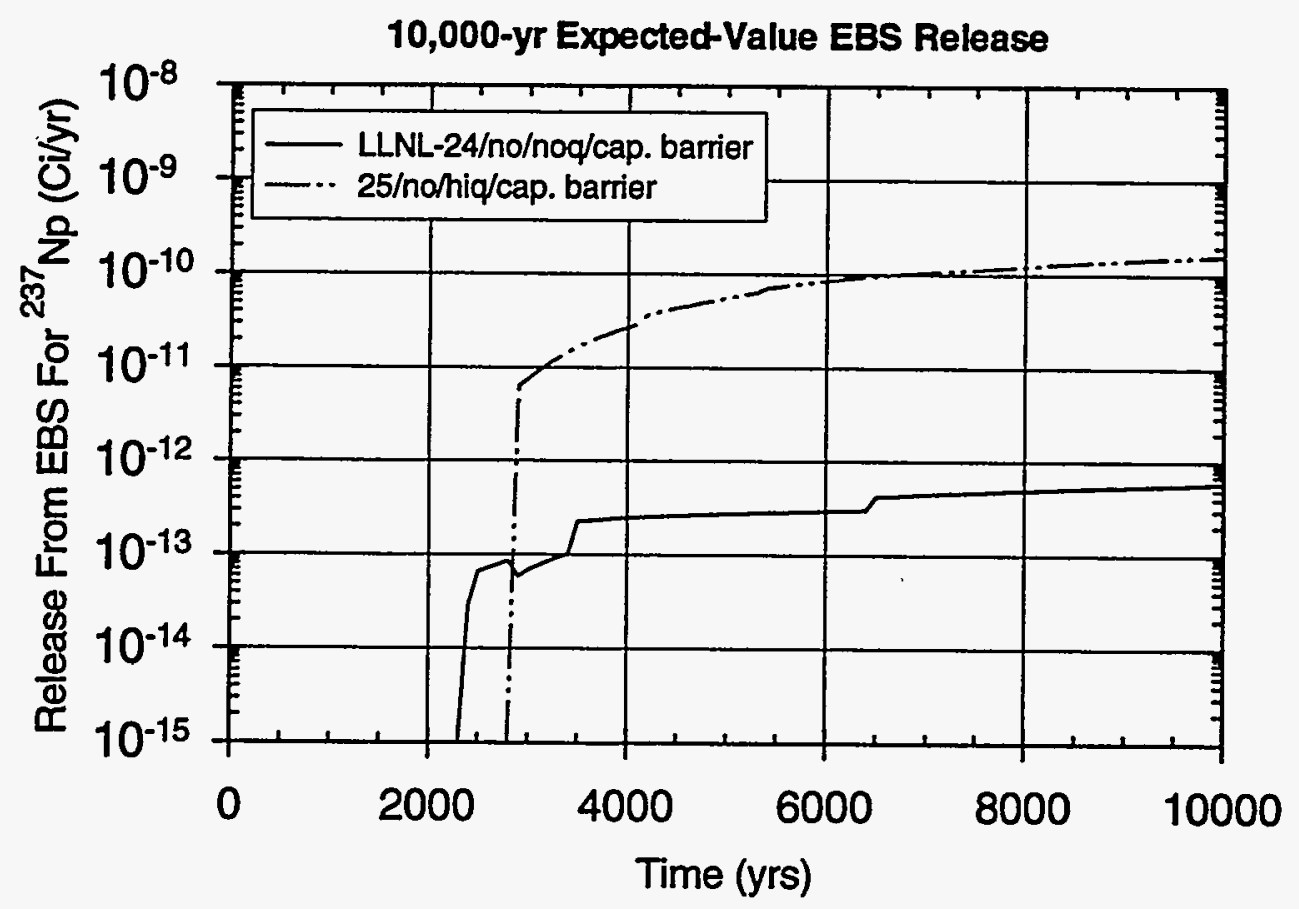

Figure 8.3-9f Sensitivity of the EBS release rate for ${ }^{237} \mathrm{~Np}$ to the thermal-hydrologic model $(\mathrm{NRC}$ limit $=0.782 \mathrm{Ci} / \mathrm{yr})$. 


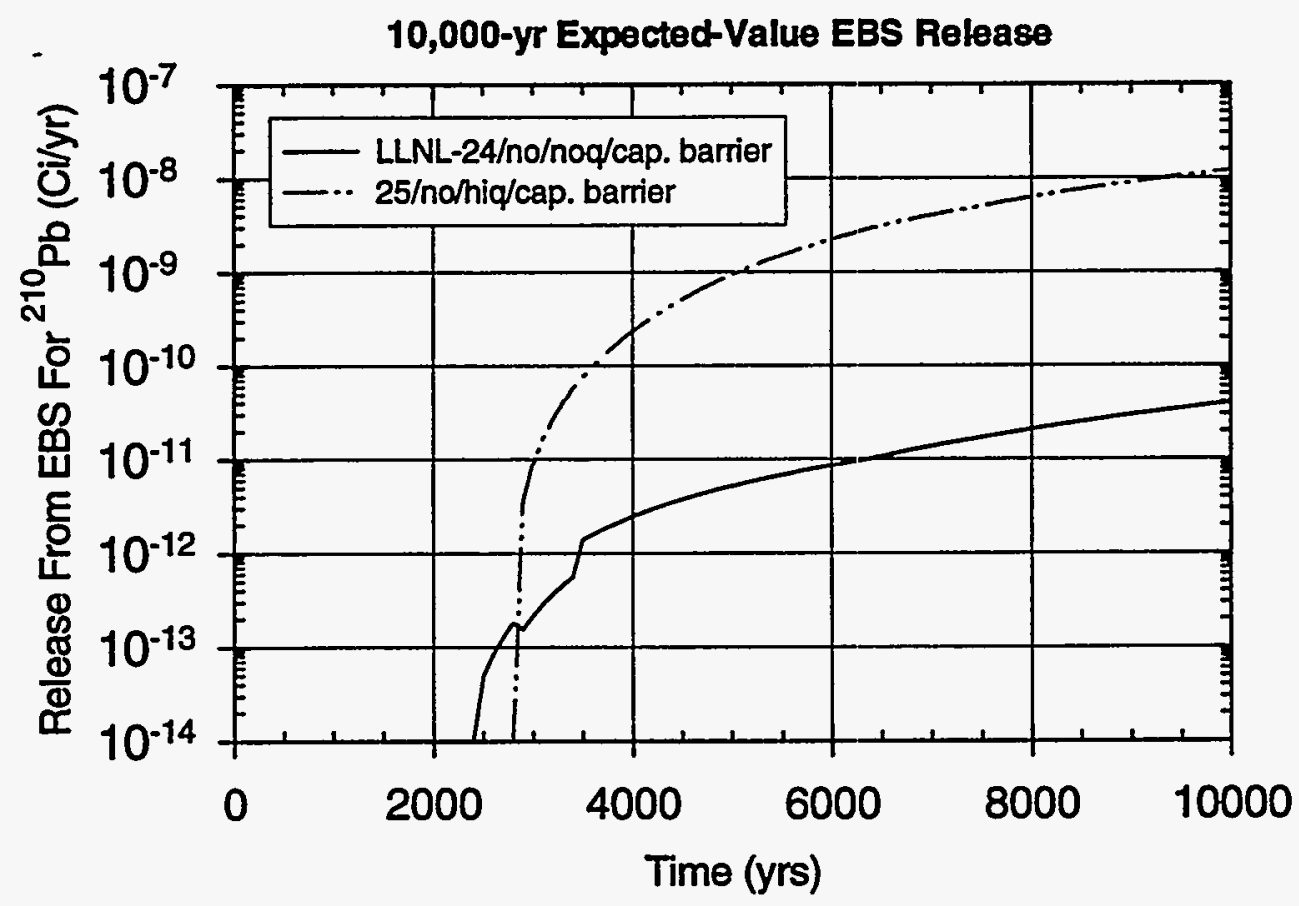

Figure $8.3-9 \mathrm{~g}$ Sensitivity of the EBS release rate for ${ }^{210} \mathrm{~Pb}$ to the thermal-hydrologic model (NRC limit $=0.00236 \mathrm{Ci} / \mathrm{yr}$ ).

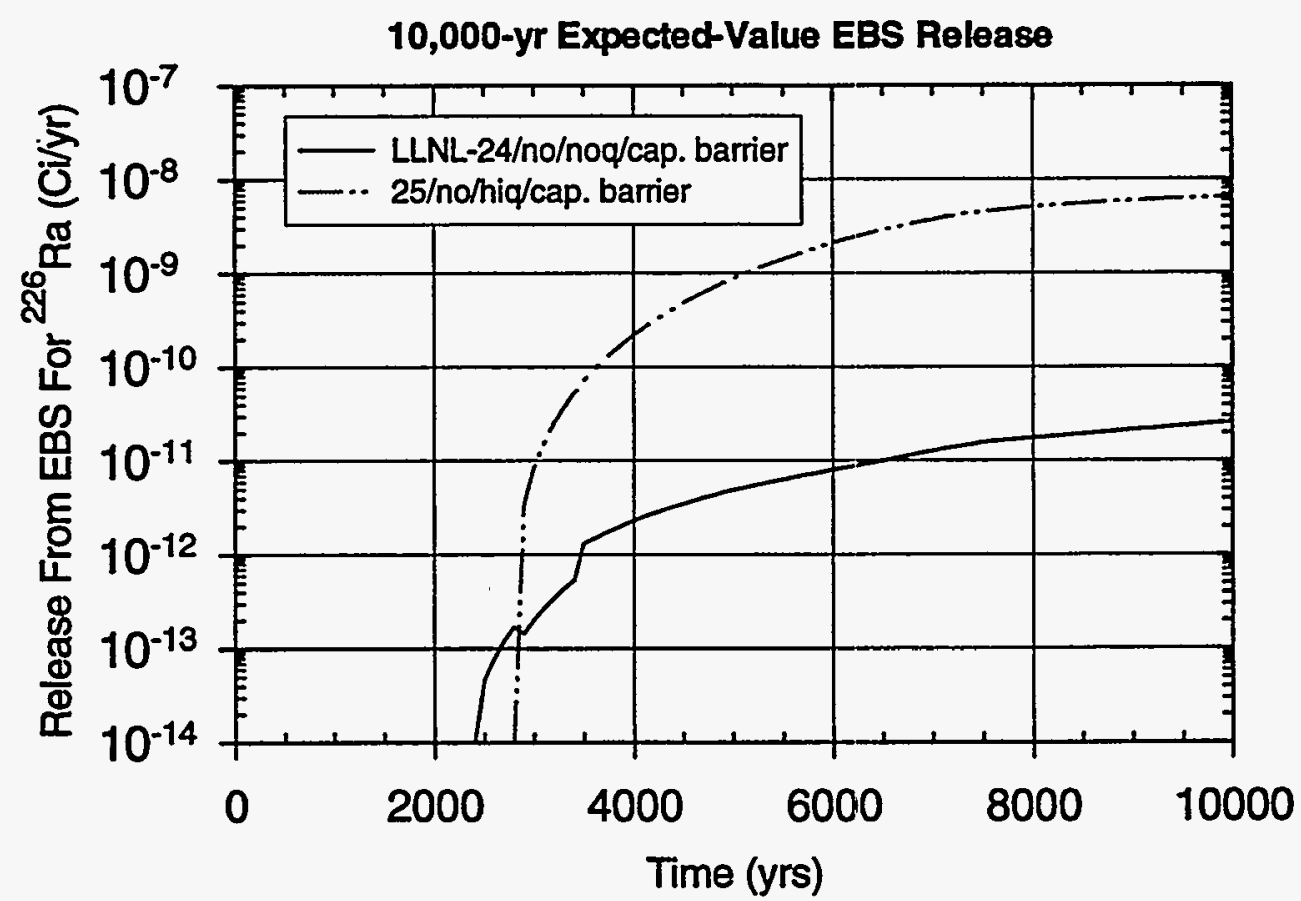

Figure 8.3-9h Sensitivity of the EBS release rate for ${ }^{226} \mathrm{Ra}$ to the thermal-hydrologic model (NRC limit $=0.00237 \mathrm{Ci} / \mathrm{yr}$ ). 


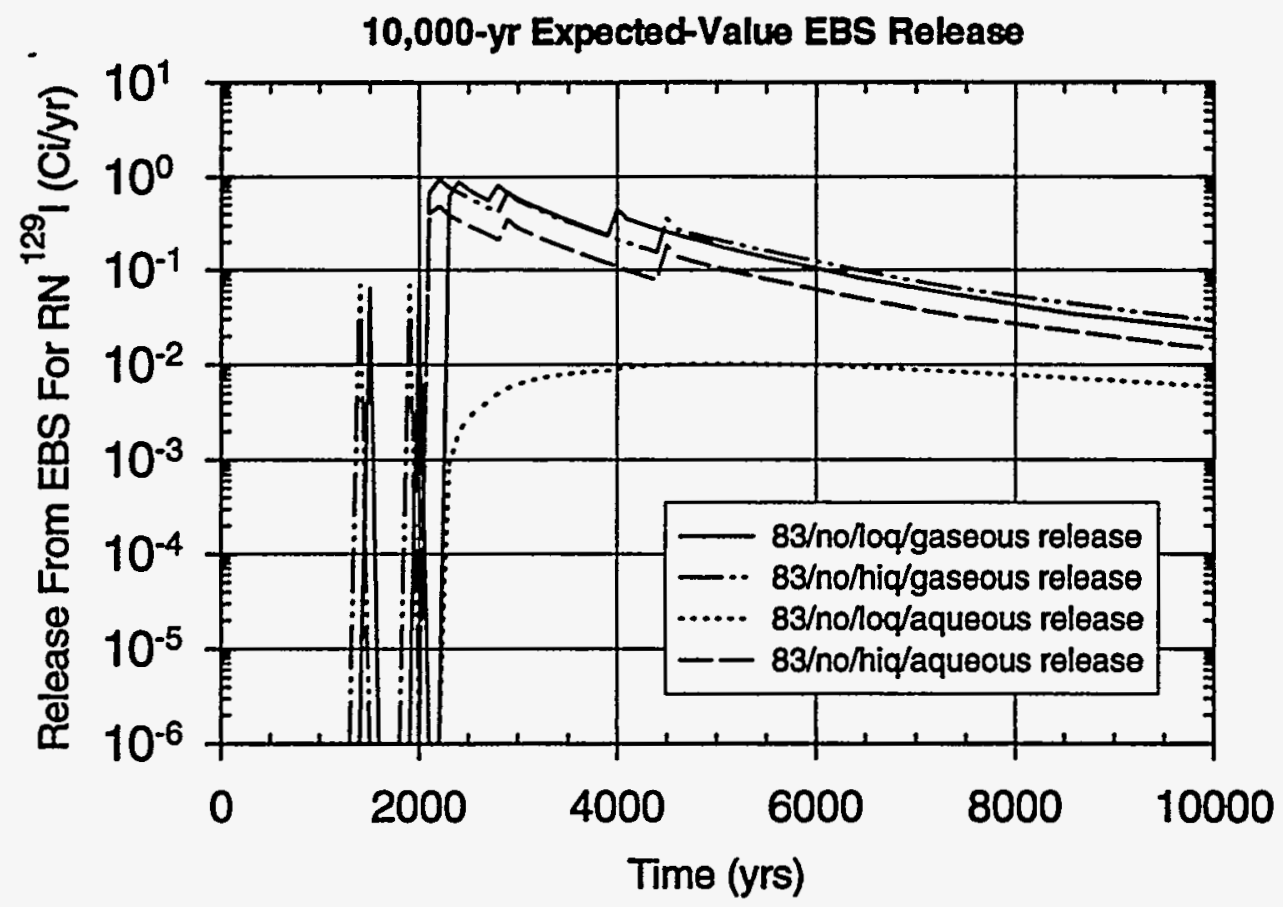

Figure 8.3-10 Sensitivity of the EBS release rate for ${ }^{129} \mathrm{I}$ to its release mode from the EBS (NRC limit $=0.022 \mathrm{Ci} / \mathrm{yr})$.

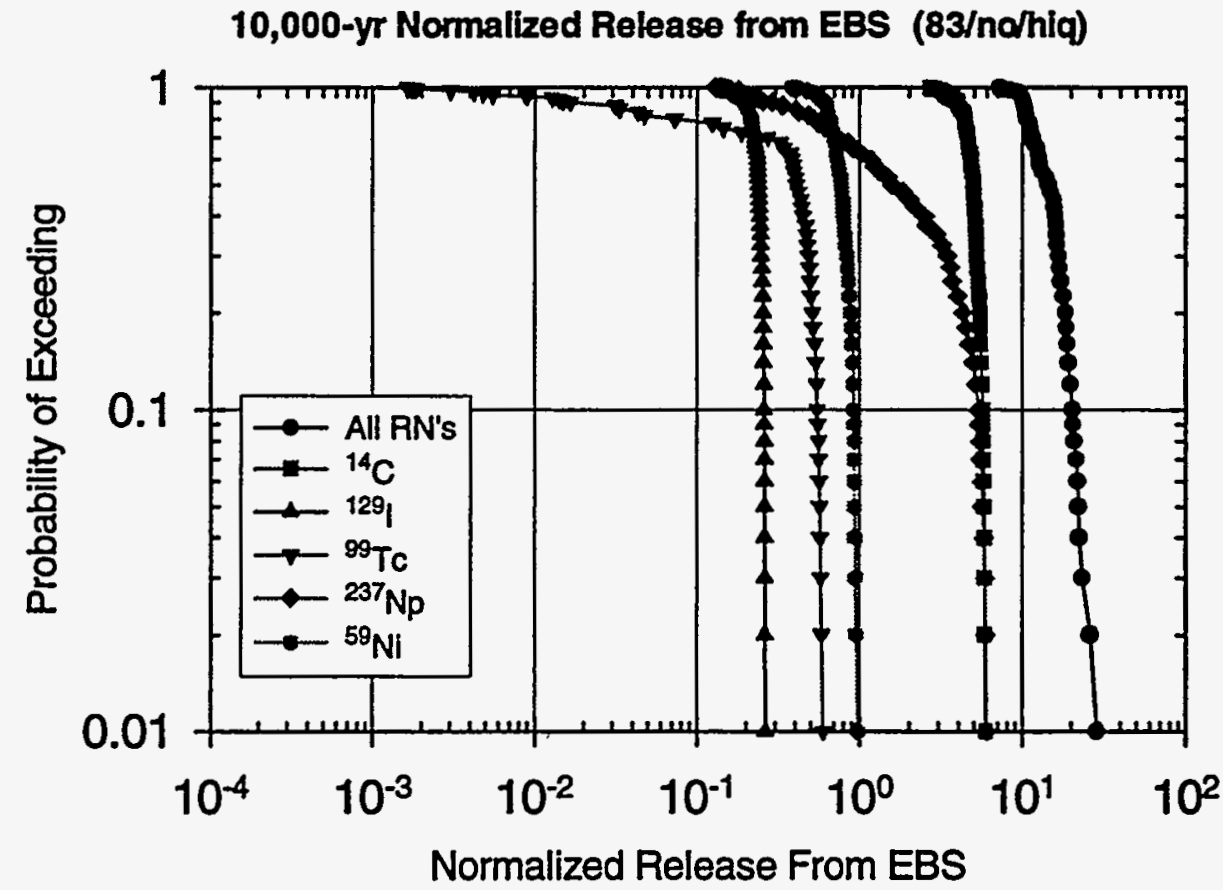

Figure 8.4-1 CCDF's of normalized cumulative release from the EBS (normalized to the 10 CFR 191.13 limit): 83 MTU/acre, no backfill, high infiltration rate, R.H. switch for the corrosion initiation. 


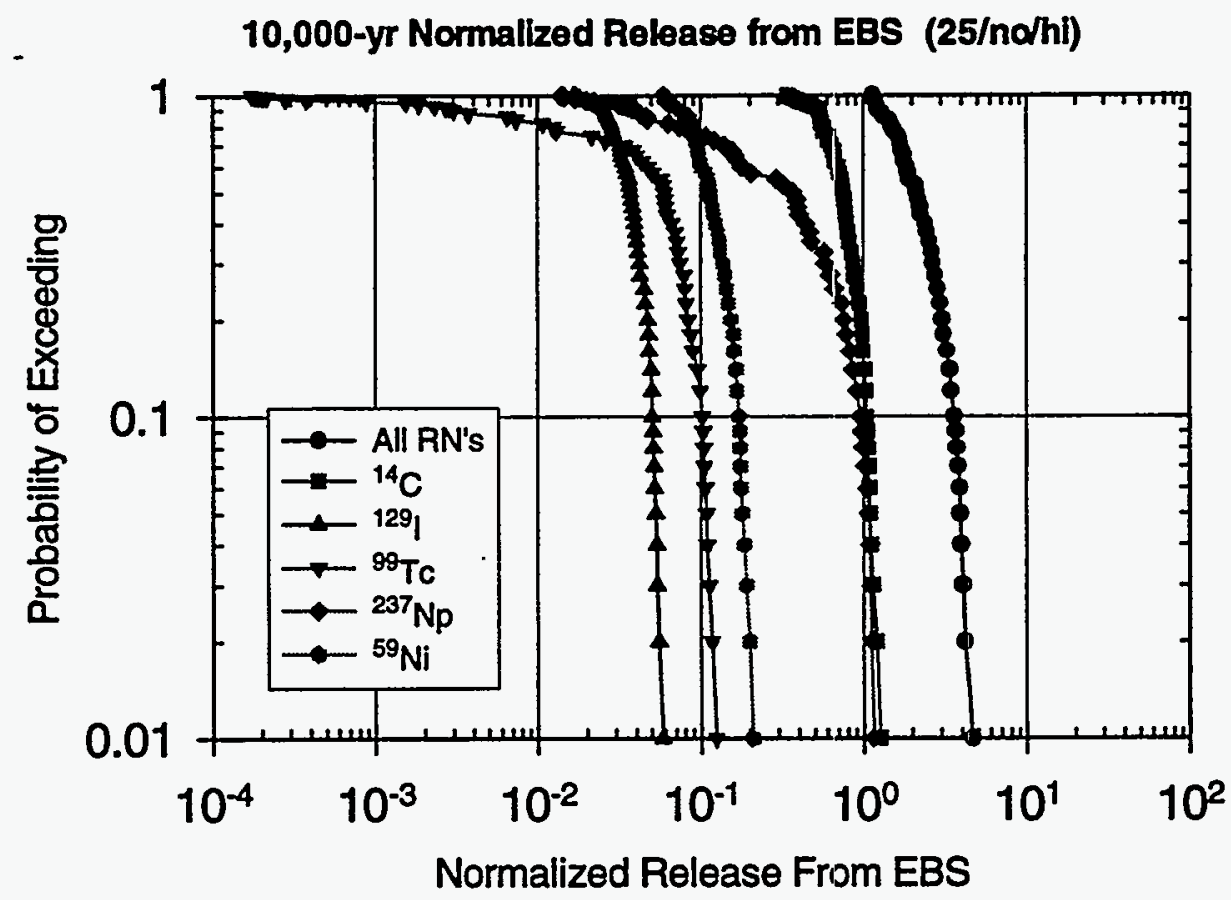

Figure 8.4-2 CCDF's of normalized cumulative release from the EBS (normalized to the 10 CFR 191.13 limit): 25 MTU/acre, no backfil., high infiltration rate, R.H. switch for the corrosion initiation.

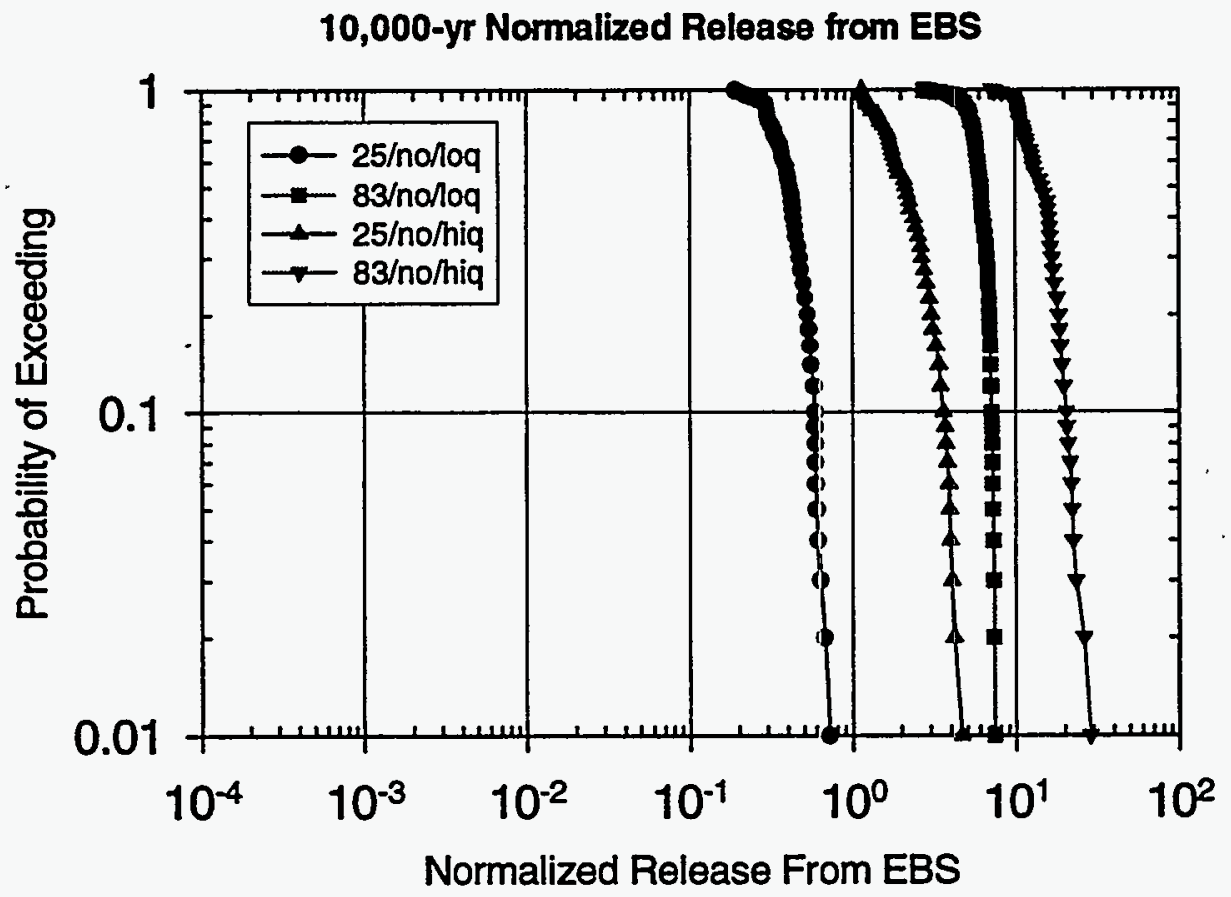

Figure 8.4-3 CCDF's of normalized cumulative release for all the radionuclides from the EBS (normalized to the 10 CFR 191.13 limit): 25 or 83 MTU/acre, no backfill, high or low infiltration rate, R.H. switch for corrosion initiation. 


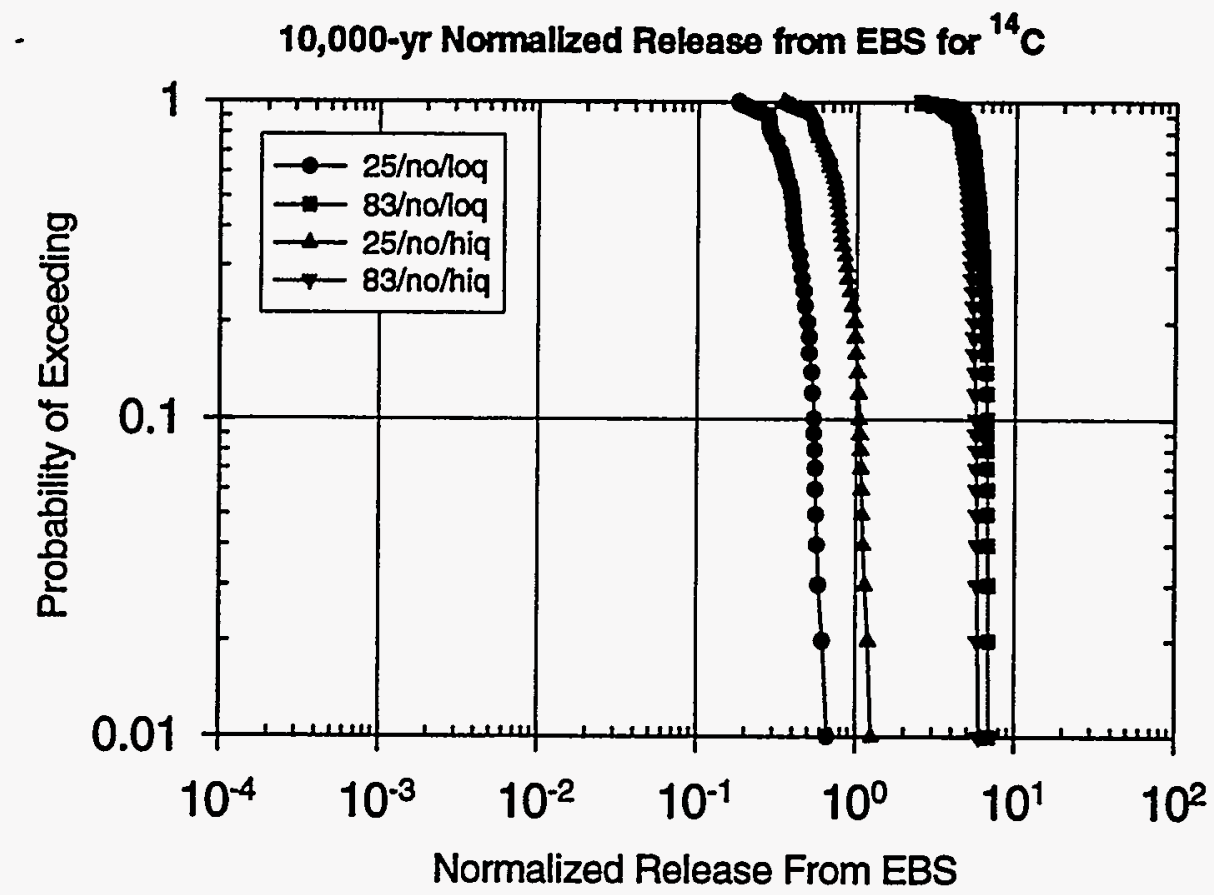

Figure 8.4-4 CCDF's of normalized cumulative release for ${ }^{14} \mathrm{C}$ from the EBS (normalized to the 10 CFR 191.13 limit): 25 or 83 MTU/acre, no backfill, high or low infiltration rate, R.H. switch for the corrosion initiation.

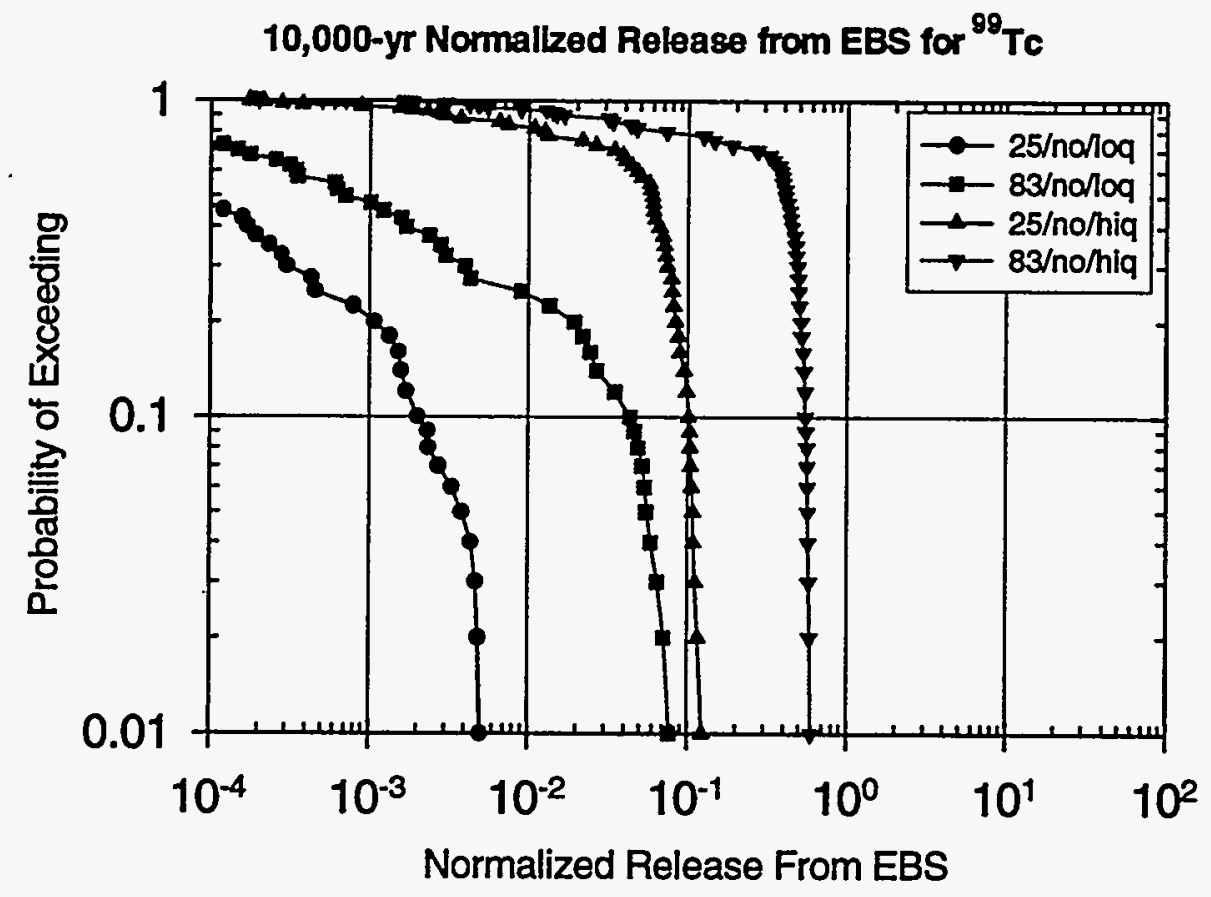

Figure 8.4-5 CCDF's of normalized cumulative release for ${ }^{99} \mathrm{Tc}$ from the EBS (normalized to the 10 CFR 191.13 limit): 25 MTU/acre or 83 MTU/acre, no backfill, high or low infiltration rate, R.H. switch for the corrosion initiation. 


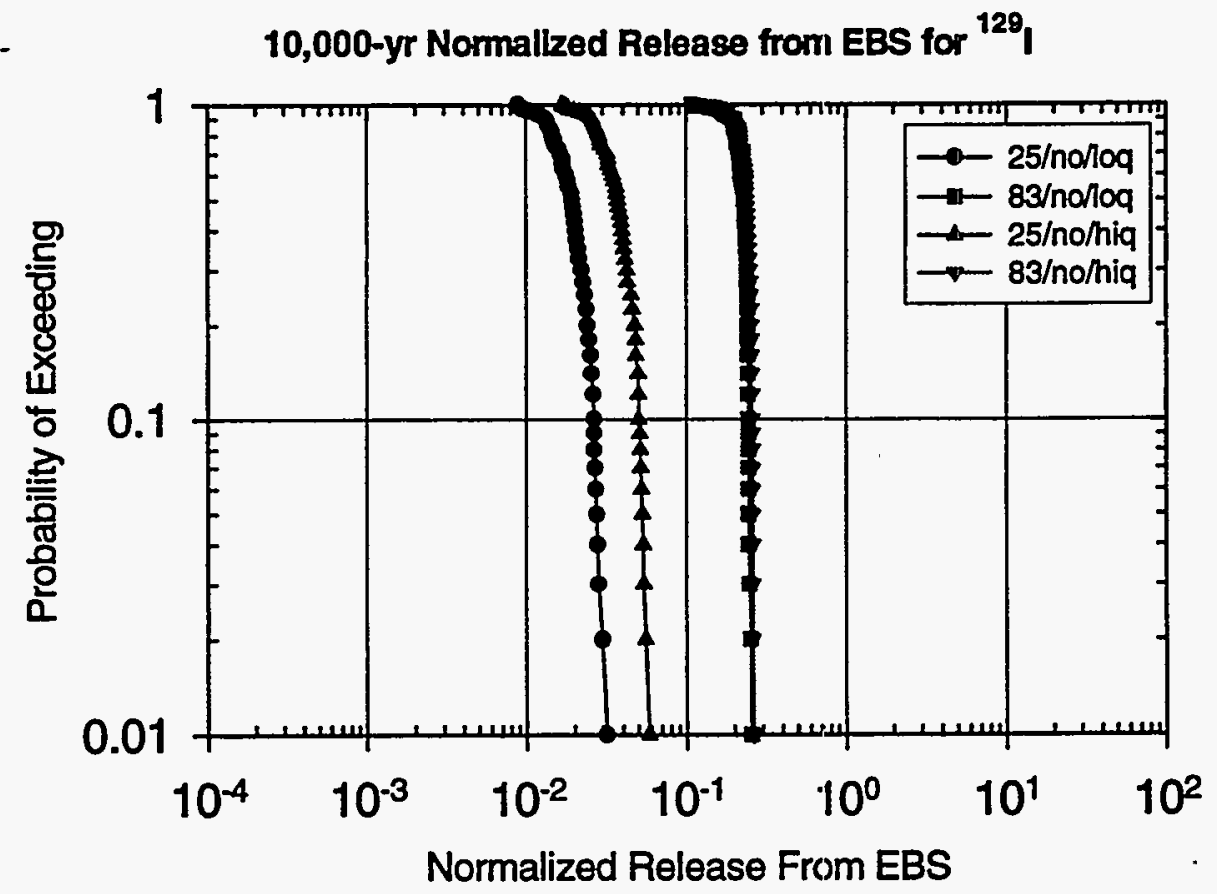

Figure 8.4-6 CCDF's of normalized cumulative release for ${ }^{129} \mathrm{I}$ from the EBS (normalized to the 10 CFR 191.13 limit): 25 or 83 MTU/acre, no backfill, high or low infiltration rate, R.H. switch for the corrosion initiation.

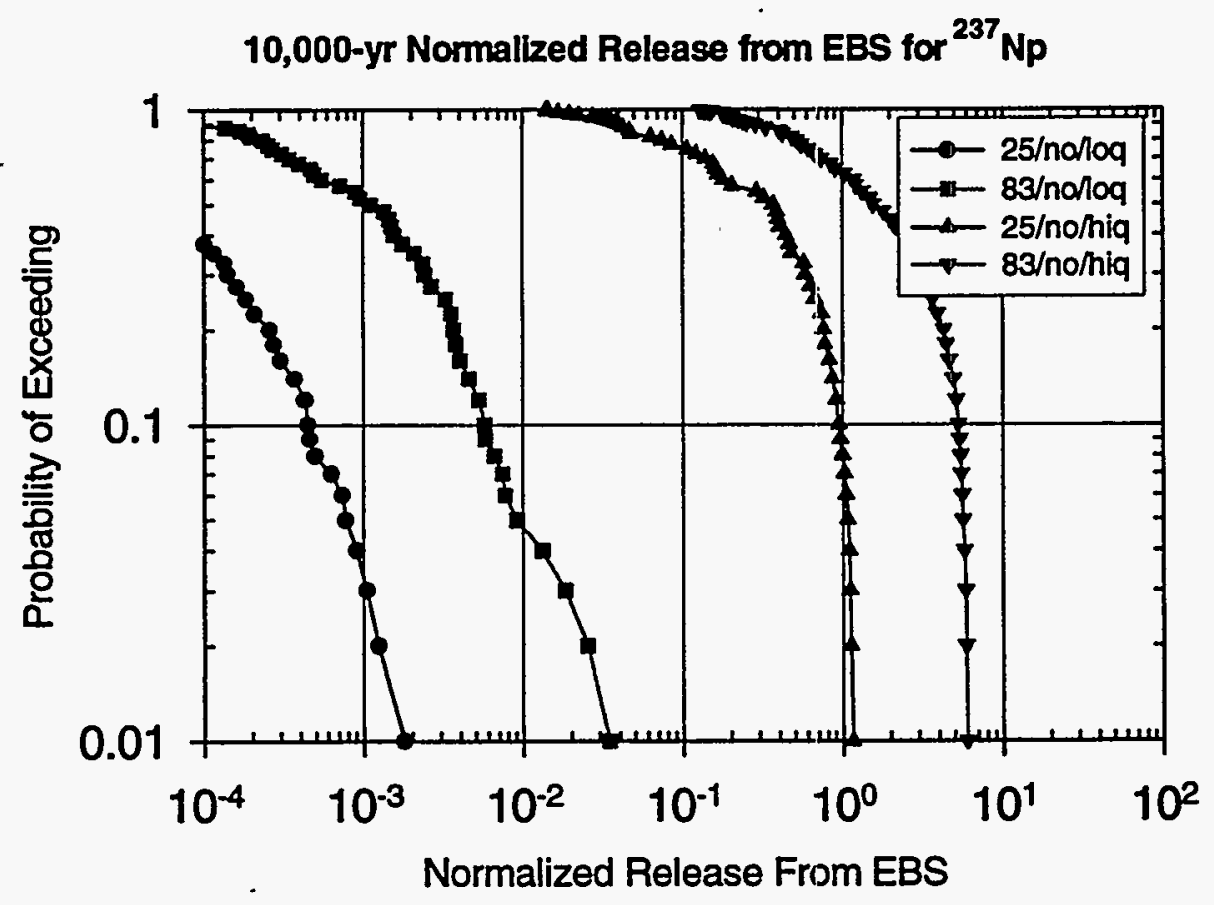

Figure 8.4-7 CCDF's of normalized cumulative release for ${ }^{237} \mathrm{~Np}$ from the EBS (normalized to the 10 CFR 191.13 limit): 25 or 83 MTU/acre, no backfill, high or low infiltration rate, R.H. switch for the corrosion initiation. 


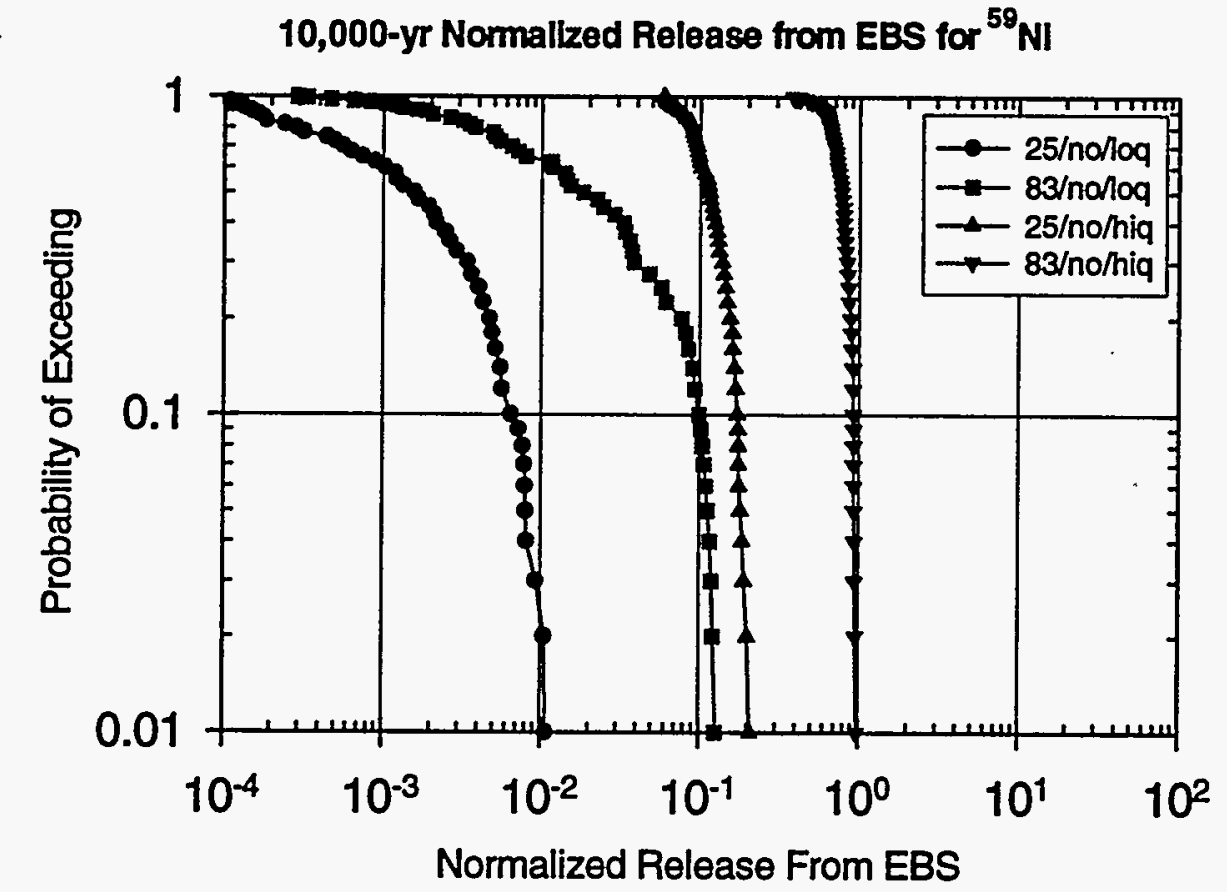

Figure 8.4-8 CCDF's of normalized cumulative release for ${ }^{59} \mathrm{Ni}$ from the EBS (normalized to the 10 CFR 191.13 limit): 25 MTU/acre or 83 MTU/acre, no backfill, high or low infiltration rate, R.H. switch for the corrosion initiation. 


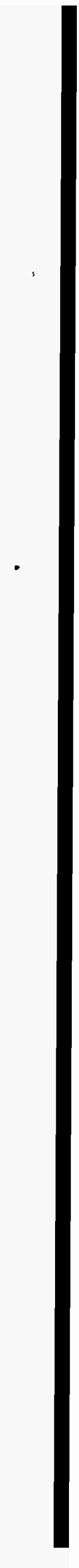


CHAPTER 9

NATURAL BARRIER RELEASE AND DOSE 
$\mid$ 


\section{NATURAL-BARRIER RELEASE AND DOSE}

\section{S. David Sevougian, Jerry A. McNeish, Q. Laura Wang, Joel E. Atkins, Vinod Vallikat}

\subsection{INTRODUCTION}

This chapter presents the predicted radionuclide release and radiation dose at the accessibleenvironment boundary, $5 \mathrm{~km}$ from the repository footprint boundary. As shown in Figure 9.1-1, these results represent the culmination of the TSPA-1995 Information Flow Diagram.

Inherent in the analyses in this chapter is the uncertain or stochastic nature of the predictions. This statistical behavior is captured by plots of the complementary cumulative distribution function (CCDF) of a particular performance measure over the time period of interest, either 10,000 or $1,000,000$ years. Note: $\mathrm{CCDF}=1-\mathrm{CDF}$, where CDF is the cumulative distribution function.) The performance measure for radionuclide release (in Curies) is the total (i.e., the sum of all radionuclides) cumulative release over 10,000 years, normalized to the Table 1 values in $40 \mathrm{CFR}$ Part 191. The performance measure for radiation dose (in rem/yr) is the total (i.e., the sum of all radionuclides) peak dose to a person at the accessible environment using the tuff aquifer for his or her drinking water (2 liters/day), calculated over both 10,000 years and $1,000,000$ years. (The treatment and effect of radionuclides that are transported in the gaseous phase, i.e., ${ }^{14} \mathrm{C}$, rather than the aqueous phase, is discussed in Section 7.5.) The 1,000,000-year time frame for peak dose is the one suggested in the recent report by the National Research Council (1995). [Note: the peak doses calculated in this chapter should not be compared to the average dose a member of the "critical" population may be exposed to over the time period of interest. As discussed in Chapter 10, the average dose is expected to be some orders of magnitude less than the peak dose to the maximally-exposed individual.]

The expected value of a statistical distribution is one of the most important parameters used to characterize the behavior of the distribution. Thus, besides showing CCDFs that represent the entire range of the various parameter distributions, expected-value time histories ("breakthrough curves") are also given in this chapter for the five or six radionuclides with the highest release rates or doses at the accessible environment. An expected-value release-rate history is the breakthrough curve for rate-of-release of radioactivity ( $\mathrm{Ci} / \mathrm{yr}$ ) at the accessible environment for a single realization that uses the expected values for all stochastic parameters. Similarly, an expected-value dose history is the breakthrough curve for dose exposure (rem/yr) at the accessible environment for a single realization that uses the expected values for all stochastic parameters. For the 10,000-year time period, expected-value time histories for both release rate and dose are evaluated, whereas for $1,000,000$ years primarily only dose time histories are evaluated.

The effect of model and parameter uncertainty on predicted results is evaluated by a number of sensitivity analyses. Alternative repository designs and alternative scenarios for natural-system behavior are considered, including (1) low and high water-infiltration rates through the unsaturated zone $(0.01-0.05 \mathrm{~mm} / \mathrm{yr}$ and $0.5-2.0 \mathrm{~mm} / \mathrm{yr})$; (2) low and high thermal load (25 MTU/acre and $83 \mathrm{MTU} / \mathrm{acre}$ ); (3) alternative thermohydrologic models for the near-field environment (the model discussed in Chapter 4 vs. the Buscheck et al. model); (4) three wastepackage-degradation (corrosion-initiation) models (relative-humidity controlled, temperature and 
relative-humidity controlled, and temperature and relative-humidity controlled with cathodic protection); (5) five conceptual models of EBS transport and water movement (drips directly on waste form, drips on waste package but not on waste form, no drips or capillary-barrier effect, no drips and aqueous EBS transport of ${ }^{129} \mathrm{I}$ and ${ }^{36} \mathrm{Cl}$, and no drips and aqueous EBS transport of ${ }^{129} \mathrm{I}$ and ${ }^{36} \mathrm{Cl}$ plus ${ }^{14} \mathrm{C}$ transport directly to atmosphere--the "diffusion-only" model); (6) fracture/matrix interaction in the geosphere (the effect of intra-unit fracture connectivity within a given hydrogeologic unit); and (7) climate change (with and without water table rise).

In addition to CCDFs and expected-value time histories, evaluation of repository performance using linear regression analysis provides an explanation for the degree of the variance in the performance measures (total peak dose or cumulative release) that can be explained by one or more of the model parameters. Thus, in this chapter, stepwise linear regression is used to determine the sensitivity of the performance measures (either cumulative release or peak dose) to the uncertain model parameters for the two time periods of interest, 10,000 and $1,000,000$ years.

This chapter is organized according to the time period of interest, and then by the sensitivity analyses discussed above. Section 9.2 discusses 10,000-year repository performance, while Section 9.3 discusses 1,000,000-year repository performance. Section 9.4 deals with subsystem performance, e.g., 1,000,000-year releases from the EBS compared to 1,000,000-year releases from the various natural barriers. All results in Chapter 9 are generated using the RIP TSPA model (Golder, 1994).

\section{$9.2 \quad 10,000$-YEAR REPOSITORY PERFORMANCE}

This section presents expected-value release-rate and radiation dose histories for various radionuclides over 10,000 years. Total cumulative release CCDFs over all nuclides and totalpeak-dose CCDFs over all nuclides for the 10,000-year time frame are also presented. Each point on the total cumulative release CCDF is the integrated release of radioactivity (integral over 10,000 years and over all nuclides) for a particular realization of the stochastic parameters, normalized by the Table-1 release limits in 40 CFR Part 191. Thus, the cumulative release CCDFs originally had units of Curies, but have been nondimensionalized by the Table-1 release limits. Each point on the total-peak-dose CCDF represents the maximum dose exposure (rem/yr) over the entire time of the simulation for that particular realization. This peak dose may occur at any time during the 10,000-year time span, and represents a sum over all nuclides at that particular time. Unless otherwise noted, all CCDFs represent the result of 100 realizations of the stochastic parameters.

\subsubsection{Alternative Thermal Loads, Thermohydrologic Models, and Infiltration Scenarios}

As discussed in Chapter 4 (Lingineni et al.), process-level simulations for the near-field repository environment included two alternative thermal loads ( $25 \mathrm{MTU} / \mathrm{acre}$ or $83 \mathrm{MTU} / \mathrm{acre}$ ), combined with two backfill scenarios (no backfill, i.e., air surrounding the waste packages, or gravel backfill) and two infiltration rate scenarios ("high" $=0.3 \mathrm{~mm} / \mathrm{yr}$ or "low" $=0.05 \mathrm{~mm} / \mathrm{yr}$ ). Thus, the process-level thermohydrologic simulations produced $2^{3}$ scenarios for near-field repository performance, which are abstracted into the RIP TSPA model. These scenarios are 
designated in the figures for this chapter as: $83 /$ yes/hiq, 83/yes/loq, 83/no/hiq, 83/no/loq, $25 /$ yes/hiq, 25/yes/loq, 25/no/hiq, and 25/no/loq, where

$$
\begin{aligned}
& 83 \equiv 83 \mathrm{MTU} / \mathrm{acre}, \\
& 25 \equiv 25 \mathrm{MTU} / \mathrm{acre}, \\
& \text { yes } \equiv \text { gravel backfill, } \\
& \text { no } \equiv \text { no backfill, } \\
& \text { hiq } \equiv \text { infiltration rate }\left(\mathrm{q}_{\mathrm{inf}}\right) \text { uniformly sampled in the range } 0.5 \text { to } 2.0 \mathrm{~mm} / \mathrm{yr} \text {, and } \\
& \text { loq } \equiv \text { infiltration rate }\left(\mathrm{q}_{\mathrm{inf}}\right) \text { uniformly sampled in the range } 0.01 \text { to } 0.05 \mathrm{~mm} / \mathrm{yr} \text {. }
\end{aligned}
$$

For all eight of these cases, the near-field performance was combined with the geosphere TSPA model to produce 10,000-year simulations of the performance of the combined EBS and natural barrier system. Because the four scenarios with low infiltration rate do not produce any releases to the accessible environment over 10,000 years, there are no plots for these in Section 9.2. (All eight scenarios are applicable for the 1,000,000-year performance discussed in Section 9.3.)

The figures in this section also include the designation "clime", which means that they were generated with the model for infiltration-rate variation introduced in Section 7.7. However, the results in Section 9.2 do not include the model for changes in water-table elevation, also described in Section 7.7. (Climate change has little effect over 10,000 years.)

Besides the process-level simulations presented in Chapter 4, near-field thermohydrologic simulations by Buscheck et al. (1995) were also evaluated for their effect on releases/doses at the accessible environment. The Buscheck et al. thermal modeling results for $80 \mathrm{MTU} / \mathrm{acre}$ did not produce significant waste package failure in 100,000 years. For example, the $80 \mathrm{MTU} / \mathrm{acre}$, no-backfill case resulted in over 99 percent of the packages being intact (i.e., no pits completely through the package) up to 100,000 years, while the 80 MTU/acre, backfill case had 100 percent intact packages up to 100,000 years (see Chapter 5). For the Buscheck et al. low thermal load (24 MTU/acre), the no-backfill case had over 99 percent of the packages intact at 100,000 years, while the backfill case had 90 percent of the packages intact. Over the shorter time-frame of 10,000 years, there were no package failures (see Chapter 5), and therefore no releases to the accessible environment, for the following three cases: (1) Buscheck et al. 80 MTU/acre with backfill; (2) Buscheck et al. 24 MTU/acre with backfill; and (3) Buscheck et al. 80 MTU/acre without backfill. Thus, in Section 9.2.1, for the Buscheck et al. thermohydrologic model, the only case for which 10,000-year releases and doses to the geosphere are presented is $24 \mathrm{MTU} / \mathrm{acre}$ without backfill. These results are discussed at the end of this section.

\section{Release to Accessible Environment (AE)}

The 10,000-year, expected-value, release-rate histories for alternative thermal loads, assuming the high-infiltration range, varying infiltration due to climate change, and the thermohydrologic model of Chapter 4 (Lingineni et al.), are presented in Figures 9.2-1 to 9.2-4 for the most important radionuclides during the 10,000 -year time frame $-{ }^{99} \mathrm{Tc},{ }^{14} \mathrm{C},{ }^{129} \mathrm{I}$, and ${ }^{36} \mathrm{Cl}$. All of these are nonsorbing nuclides, i.e., $\mathrm{K}_{\mathrm{d}}=0$ in the geosphere, and they dominate both the release-rate history curves and the normalized-release CCDFs over 10,000 years (as well as doses-see below). (The most important sorbing radionuclide, ${ }^{237} \mathrm{~Np}$, is also shown on these plots, for 
comparison,-and has much lower releases and doses than the sorbing nuclides during the first 10,000 years.)

The 83 MTU/acre, no-backfill case (Figure 9.2-1) compared to the 25 MTU/acre no-backfill case (Figure 9.2-2) shows the 83 MTU/acre releases begin approximately 1000 years earlier and reach release-rate peaks about 5 times greater than the $25 \mathrm{MTU} / \mathrm{acre}$ case. The step-like nature of the release-rate curves for the 83 MTU/acre case is probably a result of time and spatial discretization within the RIP model. In particular, the column with the fastest travel time breaks through first with its release dispersed over the length of the time step, followed by the second fastest column, etc. The earlier initial breakthrough for the $83 \mathrm{MTU} / \mathrm{acre}$ case is due to earlier and greater waste-package failures because of its higher temperature history compared to the $25 \mathrm{MTU} / \mathrm{acre}$ case. (Higher temperature causes a higher pit-growth rate, and this is the main controlling factor for waste-package failure-cf. Figures 4.2-8, 4.2-12, and 5.5-1.)

The release-rate history curves for the cases with gravel backfill (Figures 9.2-3 and 9.2-4) have a similar shape to those without backfill. However, for the gravel backfill cases, the difference in initial breakthrough time between the $83 \mathrm{MTU} /$ acre case (Figure 9.2-3) and the $25 \mathrm{MTU} / \mathrm{acre}$ case (Figure 9.2-4) is not significant. The no-backfill cases were simulated in the process-level, thermohydrologic analyses (Chapter 4) using a drift filled only with air, and an invert under the waste packages. The backfill case was simulated with gravel in the drift around the waste packages. The temperature, relative humidity, and saturation histories from these process-level results were then incorporated in the TSPA model, where they affect waste-package degradation (corrosion) and diffusion through the EBS. An important conclusion in comparing the predicted releases from the backfill versus no backfill scenarios is that there is very little difference in the release rate curves between the two cases, e.g., compare Figure 9.2-1 with Figure 9.2-3. The difference is even smaller over long time frames (see Section 9.3). This is because the thermohydrologic modeling in Chapter 4 resulted in very similar temperature and relativehumidity histories for the no-backfill and backfill scenarios.

The 10,000-year total cumulative release CCDFs for 100 realizations, normalized to the 40-CFRPart-191 Table-1 release limits are shown in Figures 9.2-5 to 9.2-8. (The release limits are indicated by the shaded area in the figures.) Figure 9.2-5 compares the two thermal loading scenarios assuming no backfill, while Figure 9.2-6 compares the two thermal loading scenarios assuming a gravel backfill. (Again, these cases use results from the thermohydrologic model described in Chapter 4.) Although the expected-value release-rate history curves for the $83 \mathrm{MTU} / \mathrm{acre}$ cases showed higher release-rate peaks than the $25 \mathrm{MTU} / \mathrm{acre}$ cases, the integrated release from the two cases is approximately the same at most values of the sampled parameter distributions. (At the high end of the cumulative release CCDFs, the $83 \mathrm{MTU} / \mathrm{acre}$ load produces slightly higher normalized releases.) One thing to be realized when integrating the release-rate history curves is that, although ${ }^{99} \mathrm{Tc}$ has the greatest releases to the accessible environment in $\mathrm{Ci} / \mathrm{yr}$ on the expected-value plots, ${ }^{14} \mathrm{C}$ dominates the normalized cumulative release $\mathrm{CCDFs}$ because it has a much lower release-limit factor than ${ }^{99} \mathrm{Tc}\left(100\right.$ for ${ }^{14} \mathrm{C}$ vs. 10,000 for $\left.{ }^{99} \mathrm{Tc}\right)$ in the 40-CFR-Part-191 Table 1. That is, since ${ }^{99} \mathrm{Tc}$ release rates are only about 10 times higher than those of the ${ }^{14} \mathrm{C}$, when they are each divided by their respective release-limit factor, ${ }^{99} \mathrm{Tc}$ will be 10 times lower than ${ }^{14} \mathrm{C}$. The other nuclides on the history curves, ${ }^{129} \mathrm{I}$ and ${ }^{36} \mathrm{Cl}$, have releaselimit factors equal to ${ }^{14} \mathrm{C}$, so their integrated releases are unimportant. 
Figure 9.2-7-shows the difference between backfill and no backfill CCDFs for the 83 MTU/acre case, while Figure 9.2-8 shows the same comparison for the $25 \mathrm{MTU} / \mathrm{acre}$ case. As can be seen from these two figures, gravel backfill makes very little difference in the cumulative releases over a 10,000-year time span, at least according to the process-level thermohydrologic model of Chapter 4. However, it is important to note that we have used the same conceptual model for advective transport through the EBS for both the backfill and no-backfill thermohydrologic models, i.e., both of these two cases (backfill and no-backfill) had the same number of dripping fractures on the waste packages in the TSPA model according to the value of the infiltration rate (see Chapter 7). If EBS transport were assumed to be different in these two cases (e.g., if drips on the waste-package were assumed for the no-backfill scenario, but not assumed for the backfill scenario), then the results could be very different, as discussed in Section 9.2.3.

\section{Peak Dose at Accessible Environment}

The 10,000-year expected-value dose histories for the alternative thermal loads, assuming a climate change model (but no water table rise) and the thermohydrologic model of Chapter 4, are presented in Figures 9.2-9 to 9.2-12. Most of the conclusions regarding release rate, discussed above, are applicable to dose also. In particular, for no backfill the 83 MTU/acre cases show an earlier initial breakthrough and greater peak dose for individual radionuclides compared to the $25 \mathrm{MTU} / a c r e$ case. One important difference between release rate histories and dose histories is that ${ }^{129} \mathrm{I}$ is just as important as ${ }^{99} \mathrm{Tc}$ on the dose histories, whereas for release rate ${ }^{99} \mathrm{Tc}$ was the predominant nuclide. This is because ${ }^{129} \mathrm{I}$ has a higher dose-conversion-factor-to-specificactivity ratio than ${ }^{99} \mathrm{Tc}$. In particular, from Table 7.6-1, the dose conversion factor (DCF) for ${ }^{129} \mathrm{I}$ is $35.2(\mathrm{rem} / \mathrm{yr}) /\left(\mathrm{g} / \mathrm{m}^{3}\right)$ and for ${ }^{99} \mathrm{Tc}$ it is $17.9(\mathrm{rem} / \mathrm{yr}) /\left(\mathrm{g} / \mathrm{m}^{3}\right)$. The specific activity of ${ }^{129} \mathrm{I}$ is $1.77 \times 10^{-4} \mathrm{Ci} / \mathrm{g}$ and for ${ }^{99} \mathrm{Tc}$ it is $0.017 \mathrm{Ci} / \mathrm{g}$. Taking the ratio of $\mathrm{DCF}$ to specific activity gives the dose conversion factor in units of $(\mathrm{rem} / \mathrm{yr}) /\left(\mathrm{Ci} / \mathrm{m}^{3}\right)$. This conversion factor is $1.99 \times 10^{5}(\mathrm{rem} / \mathrm{yr}) /\left(\mathrm{Ci} / \mathrm{m}^{3}\right)$ for ${ }^{129} \mathrm{I}$ and $1.05 \times 10^{3}(\mathrm{rem} / \mathrm{yr}) /\left(\mathrm{Ci} / \mathrm{m}^{3}\right)$ for ${ }^{99} \mathrm{Tc}$. This is a ratio of 189 , which explains why the ${ }^{99} \mathrm{Tc} /{ }^{129} \mathrm{I}$ dose ratio is about 1 while the release-rate ratio is about 200 (cf. Figures 9.2-1 and 9.2-9). (To get actual dose in rem/yr from release rate in $\mathrm{Ci} / \mathrm{yr}$ also requires the volumetric fluid-flow rate in $\mathrm{m}^{3} / \mathrm{yr}$.)

The 10,000-year total-peak-dose CCDFs are shown in Figures 9.2-13 to 9.2-16. Figure 9.2-13 compares the two thermal loading scenarios when there is no backfill, while Figure 9.2-14 compares the two thermal loading scenarios when there is a gravel backfill. For both backfill scenarios, the $25 \mathrm{MTU} / \mathrm{acre}$ peak doses are slightly lower than the $83 \mathrm{MTU} / \mathrm{acre}$ peak doses because of the high peak for ${ }^{99} \mathrm{Tc}$ and ${ }^{129} \mathrm{I}$ between 9,000 and 10,000 years in the $83 \mathrm{MTU} /$ acre cases, as indicated on the expected-value history plots. As with releases, there is very little difference on the total-peak-dose CCDFs between backfill and no-backfill scenarios (Figures 9.2-15 and 9.2-16), but again this conclusion is dependent on using the same model for EBS advective transport for both backfill and no-backfill.

\section{Buscheck's Thermohydrologic Model}

The last sensitivity case in this section examines 10,000-year predicted releases and doses at the accessible environment that result from coupling the RIP TSPA model to near-field simulations from the Buscheck et al. (1995) thermohydrologic model. 
Figure 9.2-17 compares the CCDF of total release for the Buscheck et al. 24 MTU/acre model (without backfill) with the CCDF of total release for the Lingineni et al. $25 \mathrm{MTU} / \mathrm{acre}$ model (without backfill) that was described in Chapter 4. Figure 9.2-18 compares the comparable peak dose CCDFs. Overall, as expected from the temperature history (Figure 4.2-21), the use of the Buscheck et al. model results in lower releases and lower doses at the accessible environment because the slightly higher temperature for the Lingineni model results in higher corrosion and dissolution rates. The expected-value history curves for releases and doses (Figures 9.2-19 and 9.2-20) show the same behavior. For example, if we compare Figure 9.2-20 with Figure 9.2-10, it is clear that the total peak dose at the accessible environment over the 10,000-year time span (which results mainly from ${ }^{99} \mathrm{Tc}$ and ${ }^{129} \mathrm{I}$ ) is about 2 times higher for the Lingineni et al. $25 \mathrm{MTU} /$ acre model, which is confirmed on the CCDF plot (Figure 9.2-18) by comparing the two CCDF curves at a probability of 0.5. Similar differences are found on the release-rate histories (Figure 9.2-19 vs. Figure 9.2-2). (As noted previously, ${ }^{14} \mathrm{C}$ dominates the normalized cumulative release CCDFs because it has a much lower 40-CFR-Part-191 release-limit factor than ${ }^{99} \mathrm{Tc}$.)

\subsubsection{Alternative Waste-Package Degradation Models}

Because of the considerable uncertainty about corrosion-initiation processes and corrosion rates, several conceptual models of waste-package degradation have been examined in previous chapters of this report (Chapters 5 and 8). The impact of these various conceptualizations on total peak dose and cumulative release at the accessible environment is presented in this section.

All other results in Section 9.2 have used the corrosion-initiation model that begins corrosion when the relative humidity (R.H.) rises above $65 \%$. In this section, we look at two other corrosion initiation models and their effect on doses at the accessible environment. The first model assumes that two criteria must be met to initiate corrosion: the relative humidity must be above $65 \%$ and the temperature must be below $100^{\circ} \mathrm{C}$. The other sensitivity case is for a model that includes cathodic protection plus initiation of corrosion when both R.H. $>65 \%$ and $\mathrm{T}<$ $100^{\circ} \mathrm{C}$.

For the $25 \mathrm{MTU} / \mathrm{acre}$ thermal load (with the Lingineni et al. thermohydrologic model), the temperature is always below $100^{\circ} \mathrm{C}$ by the time the R.H. rises above $65 \%$. Therefore, the $25 \mathrm{MTU} / a c r e$ case is not useful for checking the sensitivity of doses at the accessible environment to the corrosion-initiation models. Instead, we look at the $83 \mathrm{MTU} / \mathrm{acre}$ thermal load (without backfill and with high $\mathrm{q}_{\text {inf }}$ ), for which the relative humidity reaches 65 percent before the temperature drops below $100^{\circ} \mathrm{C}$. Thus, if corrosion initiation is delayed until both the temperature and relative humidity conditions are satisfied, it is suspected that the releases will be less than if the corrosion is initiated immediately upon reaching R.H. $=65 \%$, i.e., the dose at the accessible environment should be less than for the cases previously discussed in this chapter.

100-realization, total peak dose and cumulative release CCDFs are shown for the R.H.-only corrosion-initiation model and the combined R.H. \& T initiation model in Figures 9.2-21 and 9.2-22, respectively. No releases are shown for the cathodic protection model because no nuclides reached the accessible environment in 10,000 years when using this model. The two models that are shown do not exhibit major differences in releases or doses, with the R.H.\&T model only showing a reduction in release and dose by about a factor of 2 to 5 compared the R.H.-only model during the 10,000-year time span. Clearly, however, the cathodic-protection 
scenario offers dramatic dose reduction if the time frame of interest is 10,000 years. This should be compared to the minimal reduction exhibited during a 1,000,000-year time frame (Section 9.3.2).

\subsubsection{Alternative Conceptual Models for EBS Transport}

This section compares 10,000-year performance for five different conceptual models of water movement and radionuclide transport in the repository drifts: (1) fractures dripping directly onto the waste-form, i.e., directly on the spent fuel and DHLW glass; (2) fractures dripping on the corroding metal waste containers, but not directly on the waste form; (3) no dripping fractures (the so-called capillary-barrier effect); (4) no dripping fractures and also aqueous (rather than gaseous) transport of ${ }^{129} \mathrm{I}$ and ${ }^{36} \mathrm{Cl}$; and (5) no dripping fractures and also aqueous transport of ${ }^{129} \mathrm{I}$ and ${ }^{36} \mathrm{Cl}$ plus direct shunting of ${ }^{14} \mathrm{C}$ to the atmosphere (i.e., ${ }^{14} \mathrm{C}$ does not travel to the accessible environment in the aqueous phase, so it has no effect on dose). The first four of these models have been discussed in more detail in Chapter 6, and EBS releases for these four models were presented in Chapter 8.

The first model, or "drips-on-waste-form" model is the most conservative, i.e., the most pessimistic about repository performance. This model is used for all the simulations in Chapter 9, with the exception of a few discussed in this section. In the "drips-on-waste-form" model, as soon as the first pit completely penetrates the inner waste container, it is assumed that the advective flow from drift-scale dripping fractures goes through the pit, interacts with the waste form, and then advectively transports the radionuclides away from the waste form, through the EBS, and into the geosphere at the same volumetric flow rate as the dripping flow onto the waste form. This model also allows diffusive mass-transfer through the aqueous phase occupying the invert and backfill, but this mode of transport is insignificant compared to the advective transport.

In the second, or "drips-on-waste-container" model, the pits in the waste containers are assumed to always be filled with corrosion products, so that drips cannot directly contact the waste form, but can only contact the outer surface of the waste container. These corrosion-filled pits act as a mass-transfer barrier, such that mass-transfer occurs only by diffusion through the pits. This effectively lowers the radionuclide concentration encountered by drips at the waste-container surface, compared to the concentration the drips would have encountered at the waste-form surface if the corrosion products did not act as a barrier to advection. Once the radionuclides diffuse through the pits, they are swept away in the dripping water by advection, and they also diffuse through the invert and backfill, although the diffusive transport is again insignificant compared to the advection.

The third EBS transport model is the "no-drip", or capillary-barrier-effect model. This model assumes that the dripping fractures never interact with the waste form, waste package, or EBS, so that the aqueous-phase radionuclides (but not gas-phase nuclides) can only enter the geosphere by diffusion through the corroded waste container and then through the invert and/or backfill. Thus there is no advective release of aqueous-phase radionuclides through the EBS. This transport model could result from placing a Richard's (or capillary) barrier above the waste containers, consisting of two materials of disparate capillary properties, which "soaks up" drips from fractures and redistributes the dripping flow as slow matrix flow through the upper layer (the layer with greater capillary suction). The no-drip model might also result from ordinary 
single-layer,.coarse-gravel backfill. In this conceptualization, the dripping water is slow enough that when it contacts the gravel surface, it spreads out and equilibrates with the vapor phase, and is no longer concentrated enough to continue as advective flow.

In the previous three models, and in all other sections of this chapter, it was assumed that all radionuclides moved through the EBS by aqueous-phase transport except ${ }^{129} \mathrm{I},{ }^{36} \mathrm{Cl}$, and ${ }^{14} \mathrm{C}$, which are assumed to be gas-phase species. Thus, the capillary-barrier model is ineffective in retarding the movement of these three gas-phase radionuclides, and they become the biggest contributors to dose for the no-drip or capillary-barrier EBS transport model (see figures below). However, because of the high reactivity of gaseous $\mathrm{I}_{2}$ and $\mathrm{Cl}_{2}$, it seems quite possible that they may easily be dissolved and reduced in the aqueous phase before they are able to traverse the entire EBS. In that case, their only mode of transport across the EBS would be diffusion through the aqueous phase, just like all the other aqueous-phase radionuclides whose advective EBS transport is stopped by the capillary barrier. Thus, the capillary-barrier effect combined with aqueous EBS transport of ${ }^{129} \mathrm{I}$ and ${ }^{36} \mathrm{Cl}$ is the fourth conceptual model of EBS transport to be examined. In this model, only ${ }^{14} \mathrm{C}$ is transported across the EBS in the gas phase.

The fifth and final EBS transport model is called the "diffusion-only" model. In the previous models, ${ }^{14} \mathrm{C}$ was assumed to transport across the EBS in the gas phase and then enter the aqueous phase in the geosphere (i.e., in the TSw formation), from whence it transports through the unsaturated and saturated zones to a water well at the accessible environment. In reality, most of the ${ }^{14} \mathrm{C}$ may be rapidly transported directly to the atmosphere by movement through the gas phase in the unsaturated zone. This phenomenon has the effect of eliminating the dose exposure to ${ }^{14} \mathrm{C}$ at the accessible environment, i.e., by water ingestion at the accessible environment. As described here, this is not really a new model of EBS transport, but a different model of geosphere transport. However, it is convenient to include it as a comparison case in this section. It is called the "diffusion-only" model, since all radionuclides that reach the accessible environment (i.e., the water well) can only traverse the EBS by diffusion through the aqueous phase.

The 83 MTU/acre case with high infiltration was used as the nominal case for the analyses in this section. We only considered the high-infiltration scenario $\left(\mathrm{q}_{\mathrm{inf}}=0.5-2.0 \mathrm{~mm} / \mathrm{yr}\right)$ because, as discussed in the previous section, the low-infiltration scenario $\left(q_{\text {inf }}=0.01-0.05 \mathrm{~mm} / \mathrm{yr}\right)$ does not produce any releases at the accessible environment in 10,000 years.

The 10,000-year expected-value dose histories for the most conservative EBS-transport model (used in all other sections of this chapter), the "drips-on-waste-form" model, have already been shown in Figure 9.2-11. For the second, or "drips-on-waste-container" model, the expected-value dose histories are presented in Figure 9.2-23. As expected, the only major difference between these two figures is in the doses for the aqueous-phase radionuclides, ${ }^{99} \mathrm{Tc}$ and ${ }^{237} \mathrm{~Np} .{ }^{99} \mathrm{Tc}$ dose at the accessible environment at 10,000 years is reduced by about a factor of 10 for the "dripson-waste-container" model compared to the "drips-on-waste-form" model. This will imply that the 10,000-year total peak dose will be reduced by about a factor of 2 , since ${ }^{129} \mathrm{I}$ and ${ }^{99} \mathrm{Tc}$ contributed equally to the total peak dose on Figure 9.2-11. ${ }^{237} \mathrm{~Np}$ for the "drips-on-wastecontainer" model is lowered to values less than $10^{-8} \mathrm{rem} / \mathrm{yr}$. 
Figures 9.2-11 and 9.2-23 may be compared to Figure 9.2-24, which shows the radionuclides with the greatest dose at the accessible environment in the capillary-barrier ("no-drip") scenario. It is apparent that no nuclides that are transported through the EBS via the aqueous phase (e.g., ${ }^{99} \mathrm{Tc}$ ) are able to reach the accessible environment during the 10,000-year time frame (at least at doses above $10^{-8} \mathrm{rem} / \mathrm{yr}$ ) for the capillary-barrier scenario. This is because, without dripping fractures (which are intercepted by the capillary barrier), the only mechanism for release from the EBS is diffusion, which has a very low transport rate. The only nuclides able to escape the EBS are those nuclides $\left({ }^{129} \mathrm{I},{ }^{36} \mathrm{Cl}\right.$, and $\left.{ }^{14} \mathrm{C}\right)$ that are transported as gas-phase nuclides through the EBS.

As mentioned above, because of the high reactivity of $\mathrm{I}_{2}$ gas and $\mathrm{Cl}_{2}$ gas, it seems possible that they may dissolve into the aqueous phase before they traverse the entire EBS. Figure 9.2-25 shows this scenario (i.e., a capillary barrier and aqueous EBS transport of ${ }^{129} \mathrm{I}$ and ${ }^{36} \mathrm{Cl}$ ), and demonstrates that only ${ }^{14} \mathrm{C}$ is able to reach the accessible environment in significant quantities over 10,000 years.

The final EBS transport model is the "diffusion-only" model. In this model ${ }^{14} \mathrm{C}$ is assumed to go directly to the atmosphere, and therefore does not contribute to peak dose in a water well at the accessible environment. This case is not accompanied by a figure because the dose at the accessible environment is not measurable after 10,000 years, i.e., diffusive transport of all other radionuclides across the EBS is too slow for them to appear at the accessible environment within 10,000 years.

100-realization, total-peak-dose CCDFs for the first four transport models are presented in Figure 9.2-26. As seen in the expected-value dose histories, the total peak dose is reduced by about 50\% for the "drips-on-waste-container" and "capillary-barrier" EBS transport models, compared to the "drips-on-waste-form" model, because of the reduction in ${ }^{99} \mathrm{Tc}$. It is not reduced anymore than this because of the contribution from gaseous ${ }^{129} \mathrm{I}$. The fourth model, which combines the "capillary barrier" with aqueous EBS transport of ${ }^{129} \mathrm{I}$ and ${ }^{36} \mathrm{Cl}$, reduces the peak doses by about an additional factor of 10 for the entire range of the CCDF. The reason for this is evident in Figure 9.2-11, which shows that the peak doses due to ${ }^{99} \mathrm{Tc}$ and ${ }^{129} \mathrm{I}$ are both about 10 times greater than the ${ }^{14} \mathrm{C}$ peak dose. Thus, the "drips-on-waste-container" and "capillary-barrier" scenarios both remove the ${ }^{99} \mathrm{Tc}$ peak dose, which halves the CCDF value, while the ${ }^{129} \mathrm{I}^{36} \mathrm{Cl}$ capillary barrier removes both ${ }^{99} \mathrm{Tc}$ and ${ }^{129} \mathrm{I}$, leaving only ${ }^{14} \mathrm{C}$-at a dose exposure 10 times less than ${ }^{129} \mathrm{I}$. The final model, which eliminates ${ }^{14} \mathrm{C}$ as a contributor to peak dose at the accessible environment, has no releases at the accessible environment in 10,000 years.

In contrast to the dose CCDFs, the cumulative release CCDFs almost overlay one another (Figure 9.2-27). The reason for this is related to the 40-CFR-Part-191 release-limit factors, and can be seen by examining Figure 9.2-3. First of all, ${ }^{99} \mathrm{Tc}$, even though it has the highest $\mathrm{Ci} / \mathrm{yr}$ of all nuclides, is unimportant on the CCDF because its Table-1 release-limit factor is 100 times the factor for ${ }^{129} \mathrm{I}$ and ${ }^{14} \mathrm{C}$. Secondly, ${ }^{129} \mathrm{I}$ is released at a 10 -times lower rate than ${ }^{14} \mathrm{C}$, so the values in the normalized release CCDFs in the first four EBS transport scenarios are due almost entirely to ${ }^{14} \mathrm{C}$ release-which remains the same in these four scenarios. [Note: Although ${ }^{129} \mathrm{I}$ release-rate is a factor of 10 lower than ${ }^{14} \mathrm{C}$ release rate, its dose is factor of 10 higher because the ratio of its dose conversion factor (DCF) to its specific activity is much greater than ${ }^{14} \mathrm{C}$. From Table 7.6-1, the DCF for ${ }^{129} \mathrm{I}$ is $35.2(\mathrm{rem} / \mathrm{yr}) /\left(\mathrm{g} / \mathrm{m}^{3}\right)$ and for ${ }^{14} \mathrm{C}$ it is $6570(\mathrm{rem} / \mathrm{yr}) /\left(\mathrm{g} / \mathrm{m}^{3}\right)$. The specific 
activity of ${ }^{129} \mathrm{~T}$ is $1.77 \times 10^{-4} \mathrm{Ci} / \mathrm{g}$ and for ${ }^{14} \mathrm{C}$ it is $4.46 \mathrm{Ci} / \mathrm{g}$. Taking the ratio of $\mathrm{DCF}$ to specific activity gives the dose conversion factor in units of $(\mathrm{rem} / \mathrm{yr}) /\left(\mathrm{Ci} / \mathrm{m}^{3}\right)$. This conversion factor is $1.99 \times 10^{5}(\mathrm{rem} / \mathrm{yr}) /\left(\mathrm{Ci} / \mathrm{m}^{3}\right)$ for ${ }^{129} \mathrm{~T}$ and $1.47 \times 10^{3}(\mathrm{rem} / \mathrm{yr}) /\left(\mathrm{Ci} / \mathrm{m}^{3}\right)$ for ${ }^{14} \mathrm{C}$. This is a ratio of 135 , which explains the reversal in the ${ }^{129} \mathrm{I} /{ }^{14} \mathrm{C}$ dose ratio compared to the release-rate ratio. (To get actual dose in rem/yr from release rate in $\mathrm{Ci} / \mathrm{yr}$ also requires the volumetric fluid-flow rate in $\mathrm{m}^{3} / \mathrm{yr}$.)]

\subsubsection{Fracture/Matrix Interaction in the Geosphere}

\section{Intra-unit Fracture Connectivity}

The effect of modifying the RIP fracture/matrix interaction term $(\lambda)$ in the unsaturated zone is evaluated in this section. This term is also called the Poisson transition ratio (Golder, 1994) and represents the inverse of the average (and random) travel length for a particle in one of the two flow modes, fracture or matrix (see Section 7.4.4). Thus, it may be thought of as representing intra-unit fracture connectivity, i.e., average fracture length within a particular hydrogeologic unit. This parameter describes the rate of a Markov process that randomly transitions radionuclides between fracture and matrix flow modes within a RIP pathway, and results in a dispersion of the bimodal behavior of the fracture/matrix breakthrough curve. For all other sensitivity cases in Section 9.2, except those in this section, we used a value of $\lambda$ equal to $1 / \mathrm{h}$, where $h$ is the pathway length. This value of $\lambda$ implies that on average a particle will travel the thickness of the particular hydrogeologic unit before transitioning from fracture to matrix. This is a conservative assumption that favors flow in fractures. (The saturated-zone pathway was modeled with one flow mode that had the average or bulk properties of the fractures and matrix in the saturated zone, so $\lambda$ is not a parameter for saturated-zone transport.)

For the $\lambda$ sensitivity analysis, the nominal case is taken to be $83 \mathrm{MTU} / \mathrm{acre}$, with backfill, and high infiltration rate $(0.5-2.0 \mathrm{~mm} / \mathrm{yr})$. As mentioned, the nominal case used $\lambda=1 / \mathrm{h}$, where $\mathrm{h}$ is the formation (hydrogeologic unit) thickness. The two sensitivity cases are for $\lambda=1 /(0.1 \mathrm{~h})$, i.e., particles only travel $10 \%$ of the formation thickness on average before switching from fracture to matrix within the given formation, and $\lambda=1 /(100 \mathrm{~h})$, i.e., particles travel 100 times the formation thickness on average before transitioning from fracture to matrix (or, equivalently, if 100 particles are released into the fractures at the top of a unit, 99 of them are expected to remain in the fractures for the entire distance of travel through the unit). The former case $[\lambda=$ $1 /(0.1 \mathrm{~h})]$ represents short fracture lengths within a unit with disconnects between them, while the latter $[\lambda=1 /(100 \mathrm{~h})]$ represents faults traversing an entire formation. One should keep in mind the discussion in Section 7.4.4 about the fact that even though there may be fracture flow within a unit, connected fractures or faults that transect multiple units are not considered. Thus, fracture flow from one unit is divided up into fracture and matrix flow when it reaches the next lowest unit, according to the value of $f_{\text {frac }}$.

The 100-realization total-peak-dose CCDFs and cumulative release CCDFs for the three cases are shown in Figures 9.2-28 and 9.2-29, respectively. Both peak doses and cumulative releases are about 10 times higher for the $\lambda=1 /(100 \mathrm{~h})$ case compared to the $\lambda=1 / \mathrm{h}$ case, because of the larger amount of mass travelling through the highly connected fracture system within each unit. In contrast, both peak doses and cumulative releases are very low for the $\lambda=1 /(0.1 \mathrm{~h})$ case, being at least a factor of $10^{3}$ lower than the $\lambda=1 / \mathrm{h}$ case. This is to be expected, because in this $\lambda$ 
$=1 /(0.1 \mathrm{~h})$ scenario, the fractures are highly disconnected and much of the nuclide mass travels within the slow matrix-flow regime.

\section{Matrix Flow (Zero Fracture Flow)}

The upper bounding case for the $\lambda$ parameter is when there is only matrix flow in the unsaturated zone, i.e., zero fracture flow $\left(\mathrm{f}_{\mathrm{frac}}=0\right.$, see Chapter 7$)$. When the matrix-flow-only model was examined for 10,000-year performance, there were zero releases at the accessible environment for all realizations of the stochastic variables.

\subsubsection{Most Important Model Parameters}

The objective in this section is to identify the parameters in the TSPA model that are most important to repository performance. This information can help focus field and laboratory experiments on reducing uncertainty in these parameters. Two complimentary methods are used to define the most important parameters. First, scatter plots of both 10,000-year cumulative normalized release and 10,000-year total peak dose, as a function of various stochastic parameters, are shown for 100 realizations. The scatter plots give a quick visual check of the data to easily spot linear trends (i.e., clear dependencies of the results on given parameters), in either normal space or log space.

A more sophisticated analysis is stepwise linear regression, which fits the results (release or dose) to subsets of model parameters. From this analysis, we extract sensitivity coefficients to define the dependence of the results on the parameters, and then we rank the parameters according to their order of importance. The sensitivity coefficient used is the percent of the variance of the result which can be explained by, or attributed to, a particular parameter (or group of parameters). By "result", we mean "performance measure", such as 10,000-year total peak dose.

Each RIP simulation was based upon approximately 260 stochastic variables. Because only 100 realizations were run for each case, it was not possible to regress on all of these variables. Thus, based on expert judgement, 25 parameters were selected as potentially the most important. Stepwise linear regression was then used to select the five most important parameters for two different performance measures: 10,000-year normalized cumulative release and 10,000-year total peak dose. The scenario tested was 83 MTU/acre thermal load, high $\mathrm{q}_{\mathrm{inf}}$ range, with backfill, and climate change.

Stepwise linear regression was performed for three transformations of the data. First, rank regression was tried, since it is a robust method when the underlying model is unknown or complex. (Rank regression is where the rank of the dependent variable is fitted with the ranks of the independent variables. For example, the 100 peak doses from the 100 realizations are assigned a rank based on their numerical value, with 1 being assigned to the lowest result and 100 being assigned to the highest result. Then the values of each independent parameter are ranked 1 to 100 . These ranks are then used for the regression.) Since many of the model dependencies are known to be multiplicative, we used the natural log of the performance measurement (P.M.) as the dependent variable for two additional regressions (other than the rank regression). These are: (1) $\ln ($ P.M.) vs. $\ln (\mathrm{x})$ and (2) $\ln ($ P.M.) vs. $x$, where $x$ is a subset of the 25 stochastic parameters that were expected to be the most important. For each transformation, 
the five most important independent variables were recorded in Tables 9.2-1 and 9.2-2, as well as the amount of the variability they explain. The regression analysis was accomplished with S-Plus (Statistical Sciences, 1993), an interactive statistical language developed at AT\&T Bell Laboratories.

One point to note is that for TSPA-1995 some of the stochastic distributions for parameters have been eliminated and replaced with sensitivity analyses which are conducted for only three or four values of the given parameter. Thus, the analysis in this section will not include such parameters in the importance rankings, even though they could be more important than the ranked parameters. An example is the fracture/matrix particle transition parameter, $\lambda$.

The regression analysis will focus on the $\ln (P . M$.$) vs. \ln (x)$ and $\ln (P . M)$ vs. $x$ regressions, which are more physically meaningful than the rank regression. The two performance measures, 10,000-year cumulative release (Table 9.2-1) and 10,000-year total peak dose (Table 9.2-2), show exactly the same rankings for the top three variables for each type of regression. In particular, the top three variables for the $\ln (\mathrm{P} . \mathrm{M}$.) vs. $\ln (\mathrm{x})$ regression are the matrix velocity in the CHnv $\left(v_{\text {mat }}-\mathrm{CHnv}\right)$, the unsaturated zone Darcy flux or infiltration flux $\left(\mathrm{q}_{\mathrm{inf}}\right)$, and the climate change modifier $\left(\mathrm{U}_{\mathrm{cli}}(1,3)\right)$; for the $\ln (\mathrm{P} . \mathrm{M})$ vs. $\mathrm{x}$ regression they are the infiltration flux $\left(\mathrm{q}_{\mathrm{inf}}\right)$, the fraction of fracture flow in the CHnv $\left(\mathrm{f}_{\mathrm{frac}}-\mathrm{CHnv}\right)$, and the climate change modifier $\left(\mathrm{U}_{\text {cli }}(1,3)\right) .\left[U_{c l i}(1,3)\right.$ $=1+U_{c l i}(0,4) / 2$, where $U_{c l i}(0,4)$ was defined in Section 7.7.] In general, the $\ln (\mathrm{P} . \mathrm{M}$.) vs. $\ln (\mathrm{x})$ regression provides a slightly better fit than the $\ln (P . M)$ vs. $x$ regression, as indicated by the fact that the top $1,2,3$, etc. parameters explain more of the variance. For example, ranked parameter \#2 in the $\ln (P . M$.$) vs. \ln (x)$ regression is $q_{i n f}$, which in combination with $v_{\text {mat }}-C H n v$ explains $68 \%$ of the variance of the 10,000 -year releases, whereas, ranked parameter \#2 in the $\ln (\mathrm{P} . \mathrm{M})$ vs. $\mathrm{x}$ regression is $\mathrm{f}_{\mathrm{frac}}-\mathrm{CHnv}$, which together with $\mathrm{q}_{\mathrm{inf}}$ only explains $63 \%$ of the variance. Here we should note that many of the variables are collinear in either log space or linear space, due to the abstractions used in the geosphere (see Chapter 7). For example, $f_{\text {frac }}$ is proportional to $\log _{10} q_{\text {inf }}$, and $\log _{10} v_{\text {mat }}$ is proportional to $\log _{10} q_{\text {inf }}$. This explains why different variables show up using the two different transformations.

A confirmation of the linear regression analysis for the two performance measures can be seen in the scatter plots in Figures 9.2-30 to 9.2-36 (for the 10,000-year release P.M.) and Figures 9.2-37 to 9.2-43 (for the 10,000-year peak dose P.M.). These figures represent scatter plots of all the parameters that showed up with rank 5 or less in any of the three different regressions. The strongest linear trend is for the top 2 parameters, $v_{\text {mat }}-C H n v$ and $q_{\text {inf }}$, with a less obvious linear trend for $\mathrm{f}_{\text {frac }}-\mathrm{CHnv}$. Any parameters with a ranking lower than 2 do not show an obvious trend. This is because their relationship is masked by collinearity in the model. However, if the remaining residual (i.e., the difference in the fitted value and the observed value) is plotted for each parameter and subset of parameters against the next lower ranked parameter, a linear trend is visible. For example, if the residual left after fitting ranked parameters 1 and 2 is plotted versus ranked parameter 3 , a clear linear trend will be visible.

The rankings of the two most important variables in Tables 9.2-1 and 9.2-2 were not unexpected. In TSPA-1993 (Andrews et al., 1994) it was found that the UZ infiltration flux $\left(\mathrm{q}_{\mathrm{inf}}\right)$ had a very strong influence on doses and releases over 10,000 years. This is again true in TSPA-1995. In particular, the peak concentrations of the radionuclides never reach the accessible environment during 10,000 years and variability in $q_{\text {inf }}$ simply translates to a shifting in time of the initial 
portion of the breakthrough curve. However, since this is the steeply rising portion of the breakthrough curve(s) regardless of the value of $q_{\text {inf }}$ (for $q_{\text {inf }}=0.5-2.0 \mathrm{~mm} / \mathrm{yr}$ ), there is a very strong dependence on $\mathrm{q}_{\mathrm{inf}}$. The strong dependence on either $\mathrm{v}_{\mathrm{mat}}-\mathrm{CHnv}$ or $\mathrm{f}_{\mathrm{frac}}-\mathrm{CHnv}$ is also not unexpected because the $\mathrm{CHnv}$ is the formation with the highest value of saturated matrix conductivity, $\mathrm{K}_{\text {sat }}$, and therefore the lowest value of $\mathrm{f}_{\text {frac }}$. Therefore, it tends to control connected fracture flow throughout the mountain, as noted in the Calico Hills System Study (M\&O, 1995d); and without fracture flow, no releases can reach the accessible environment in 10,000 years.

\subsubsection{Summary of 10,000-year Performance}

The following are general conclusions concerning 10,000-year repository performance, based on the sensitivity analyses in Section 9.2:

(1) 10,000-year total peak dose, due mainly to ${ }^{99} \mathrm{Tc}$ and ${ }^{129} \mathrm{I}$, is most sensitive to the following model parameters: matrix velocity in the CHnv and percolation flux in the unsaturated zone;

(2) Over 10,000 years there are zero releases to the accessible environment for the following cases: (i) low infiltration range $(0.01-0.05 \mathrm{~mm} / \mathrm{yr})$, (ii) cathodic protection of the wastepackage, (iii) Buscheck et al. 80 MTU/acre thermal load with and without backfill and $24 \mathrm{MTU} / a c r e$ thermal load with backfill, and (iv) matrix-flow-only (zero fracture flow) in the unsaturated zone;

(3) Depending on the conceptual model of intra-unit fracture connectivity, fracture/matrix interaction can significantly affect peak dose and cumulative release;

(4) Depending on the conceptual model for radionuclide transport across the EBS (viz., if ${ }^{129} \mathrm{I}$ and ${ }^{36} \mathrm{Cl}$ are assumed to be in the aqueous phase and/or ${ }^{14} \mathrm{C}$ is supposed not to contribute to peak dose since it is dispersed in the atmosphere), a "capillary barrier" that prevents drips (i.e., advective flow) from contacting the waste packages can reduce 10,000-year peak doses at the accessible environment by at least a factor of 20 or more (and up to many orders-of-magnitude if only diffusive releases are possible through the EBS).

\section{$9.3 \quad 1,000,000-Y E A R$ REPOSITORY PERFORMANCE}

In their recent report to Congress, the National Research Council (1995) has concluded that "...there is no scientific basis for limiting the time period of the individual-risk standard to 10,000 years... (and) that compliance assessment be conducted for the time when the greatest risk occurs, within the limits imposed by long-term predictability of both the geologic environment and the distribution of local and global populations." Based on geologic considerations, they also state that "the ultimate restriction on time scale ... is on the order of $1,000,000$ years at Yucca Mountain." For these reasons, we have conducted performance assessments of dose and peak dose over a 1,000,000-year time frame, which are presented in this section as a number of sensitivity cases (see Section 9.1) that examine the effect of various system parameters and various repository designs. 


\subsubsection{Altepnative Thermal Loads, Thermohydrologic Mlodels, and Infiltration Scenarios}

The effect of alternative thermal loads (25 MTU/acre vs. 83 MTU/acre) and alternative thermohydrologic conceptual models (Lingineni et al. vs. Buscheck et al.) are presented in this section. Chapter 4 discusses the differences between the two thermohydrologic conceptualizations. They are also discussed in Section 9.2.1 regarding their incorporation into the RIP TSPA simulations.

\section{Peak Dose at Accessible Environment}

The expected-value dose histories (for the radionuclides with the highest doses) for the two different thermal loads, using the Lingineni et al. thermohydrologic model, are presented in Figures 9.3-1 to 9.3-4. The "part a" figures are for 1,000,000 years, and the "part b" figures are a blow-up of the "part a" figures over 100,000 years. These four figures are for the high infiltration case $\left(\mathrm{q}_{\mathrm{inf}}=0.5-2.0 \mathrm{~mm} / \mathrm{yr}\right) .{ }^{237} \mathrm{~Np}$ and ${ }^{229} \mathrm{Th}$ at late times, and ${ }^{99} \mathrm{Tc}$ and ${ }^{129} \mathrm{I}$ at early times, produce the highest dose exposure at the accessible environment for both the $83 \mathrm{MTU} / \mathrm{acre}$ case and the 25 MTU/acre case. For identical backfill, infiltration, and climate conditions, the $83 \mathrm{MTU} / \mathrm{acre}$ cases results in slightly higher dose exposure than the $25 \mathrm{MTU}$ cases at times beyond 80,000 years for the highest-releasing sorbing radionuclides, ${ }^{237} \mathrm{~Np},{ }^{229} \mathrm{Th}$, and ${ }^{233} \mathrm{U}$. At times earlier than 80,000 years, these retarded ions $\left({ }^{237} \mathrm{~Np}\right.$, ${ }^{229} \mathrm{Th}$, and ${ }^{233} \mathrm{U}$ ) have generally lower doses for the $83 \mathrm{MTU} / \mathrm{acre}$ case compared to the $25 \mathrm{MTU} / \mathrm{acre}$ case. However, the time before 80,000 years can be considered just an inconsequential "leading edge" of the breakthrough curve, and when the main peak of radionuclides comes out (beginning at about 200,000 years), the higher thermal load gives slightly higher doses.

The $25 \mathrm{MTU} / \mathrm{acre}$ case is affected more by climate change than the $83 \mathrm{MTU} / \mathrm{acre}$ case, with the 100,000 -year periodic variation of $q_{\text {inf }}$ clearly visible for ${ }^{237} \mathrm{~Np},{ }^{229} \mathrm{Th}$, and ${ }^{233} \mathrm{U}$. The apparent reason for these differences can be found in Table 8.3-3, which shows the waste-package failure history for the various cases. For the $83 \mathrm{MTU} /$ acre thermal load, most of the packages fail very early during the 1,000,000-year time span, whereas for the $25 \mathrm{MTU} / \mathrm{acre}$ thermal load, the failures are much more spread out in time. For sorbing nuclides, this allows the climate effect (due to cyclical variations in the drip rate) to be visible for the low thermal load, but not for the high thermal load (where the nuclides come out essentially as a pulse). Although the cyclic peaks on the $25 \mathrm{MTU} / \mathrm{acre}{ }^{237} \mathrm{~Np}$ curve are approximately the same magnitude as the values of the $83 \mathrm{MTU} / \mathrm{acre}{ }^{237} \mathrm{~Np}$ curve at the corresponding times, the average of the $25 \mathrm{MTU} / \mathrm{acre}{ }^{237} \mathrm{~Np}$ curve (or the integral) is slightly lower. The explanation for the lower average ${ }^{237} \mathrm{~Np}$ dose for $25 \mathrm{MTU} / \mathrm{acre}$ is the higher temperature history for the $83 \mathrm{MTU} / \mathrm{acre}$ case, as discussed below.

For the unretarded nuclides, ${ }^{99} \mathrm{Tc}$ and ${ }^{129} \mathrm{I}$, the situation is similar, namely, the $83 \mathrm{MTU} / \mathrm{acre}$ case yields higher peak doses when the peak of the breakthrough curve reaches the accessible environment. At this time $(-100,000$ years), the higher thermal load gives approximately 3 times higher ${ }^{99} \mathrm{Tc}$ and ${ }^{129} \mathrm{I}$ peaks than the $25 \mathrm{MTU} / \mathrm{acre}$ case. Overall, the total dose (summation of all the nuclides, sorbing and nonsorbing) is greater for the high thermal load case at most times, as illustrated by Figure 9.3-5.

The difference in peak doses for ${ }^{99} \mathrm{Tc}$ and ${ }^{129} \mathrm{I}$ at early times for the two different thermal loads is caused by differences in waste package degradation. Both of these nuclides are parent nuclides 
(part of the original inventory) that are released directly from the waste package and are dissolution rate-limited. In particular, as fast as the waste-form can produce them (by dissolution), these two ions are transported immediately across the EBS. For ${ }^{99} \mathrm{Tc}$ this is a result of rapid release due to advective (dripping) flow, while for ${ }^{129} \mathrm{I}$ it is a result of rapid release by gaseous transport through the EBS. The $83 \mathrm{MTU} / \mathrm{acre}$ case has about 3 times the number of failed packages (first pit breakthrough) at any given time compared to the $25 \mathrm{MTU} / \mathrm{acre}$ case, primarily because of the different temperature history (see Chapter 6). The higher temperature history in the $83 \mathrm{MTU} / \mathrm{acre}$ case also results in a higher dissolution rate for the waste-form and a higher solubility for some of the nuclides. This combination of factors results in higher doses to the accessible environment for the nonretarded nuclides for the $83 \mathrm{MTU} / \mathrm{acre}$ case, and is also the likely cause of the higher doses for the retarded nuclides, ${ }^{237} \mathrm{~Np},{ }^{229} \mathrm{Th}$, and ${ }^{233} \mathrm{U}$.

For the low infiltration cases $\left(\mathrm{q}_{\mathrm{inf}}=0.01-0.05 \mathrm{~mm} / \mathrm{yr}\right.$ ), the expected-value dose histories for the unretarded nuclides ${ }^{129} \mathrm{I},{ }^{99} \mathrm{Tc}$, and ${ }^{36} \mathrm{Cl}$ are about 2-3 times greater for the $83 \mathrm{MTU} / \mathrm{acre}$ case than for the 25 MTU/acre case (Figures 9.3-6 to 9.3-9). As with the high infiltration scenario, this difference can be attributed to differences in waste package degradation. On the other hand, for the sorbing nuclides ${ }^{237} \mathrm{~Np},{ }^{229} \mathrm{Th}$, and ${ }^{233} \mathrm{U}$, the expected-value dose history for the $83 \mathrm{MTU} /$ acre case is lower than for the $25 \mathrm{MTU} / \mathrm{acre}$ case. The reason for this is unclear, but is likely related to the differences in the waste-package-failure histories for the two thermal loads (see Table 8.3-3). Regardless, for both thermal loads, these sorbing nuclides are released at such low concentrations (maximum of $0.01 \mathrm{mrem} / \mathrm{yr}$ for the $25 \mathrm{MTU} / \mathrm{acre}$ case) that they are of little interest.

One interesting comparison is to examine the differences between the high and low infiltration scenarios, i.e., Figures 9.3-1 to 9.3-4 vs. Figures 9.3-6 to 9.3-9. Direct comparisons for the 83 MTU/acre case with backfill are shown in Figures 9.3-10, 9.3-11, and 9.3-12. First of all, the long-lived, sorbing nuclides, such as ${ }^{237} \mathrm{~Np}$ and ${ }^{229} \mathrm{Th}$, do not have significant releases for low UZ infiltration fluxes over the 1,000,000-year time frame. Second, the periods of highest releases (and doses) for nonsorbing nuclides, such as ${ }^{129} \mathrm{I}$ and ${ }^{99} \mathrm{Tc}$, are spread out over a much broader time interval for the low- $q_{\text {inf }}$ case compared to the high- $q_{i n f}$ case, and have a much lower peak. For example, consider ${ }^{99} \mathrm{Tc}$, the highest-dose nonsorbing nuclide that both travels through the geosphere in the aqueous phase and is released from the WP/EBS in the aqueous phase. The primary portion of its breakthrough curve in the high- $q_{\text {inf }}$ case (Figures 9.3-3a and 9.3-10) is much narrower (spanning only about 100,000 years), and has a much higher peak (about $20 \mathrm{mrem} / \mathrm{yr}$ ), than for the low- $\mathrm{q}_{\mathrm{inf}}$ case (Figures 9.3-8 and 9.3-10), where it reaches an approximate peak of only about $0.1 \mathrm{mrem} / \mathrm{yr}$ or less over a broad time frame of about 600,000 years. Doses this low $(0.1 \mathrm{mrem} / \mathrm{yr})$ are expected to be well within any regulatory bounds that may be set for a high-level nuclear waste repository. The other nonsorbing nuclide of interest, ${ }^{129} \mathrm{I}$, travels through the geosphere in the aqueous phase, but is released from the WP/EBS in the gas phase. Similariy to ${ }^{99} \mathrm{Tc}$, it sustains doses near the peak dose for much longer time in the low- $q_{\mathrm{inf}}$ case compared to the high- $q_{\mathrm{inf}}$ case (Figure 9.3-11), but its peak is not reduced as much as ${ }^{99}$ Tc. Specifically, it has a peak dose exposure of about $2 \mathrm{mrem} / \mathrm{yr}$ for the low- $\mathrm{q}_{\mathrm{inf}}$ case compared to $20 \mathrm{mrem} / \mathrm{yr}$ for the high- $\mathrm{q}_{\mathrm{inf}}$ case. This is a reduction by a factor of 10 , compared to a reduction of a factor of 200 for ${ }^{99} \mathrm{Tc}$. As discussed below, the reason ${ }^{129} \mathrm{I}$ is reduced much less than ${ }^{99} \mathrm{Tc}$ is related to dripping water in the drift and to the longer half-life of ${ }^{129} \mathrm{I}$ compared to ${ }^{99} \mathrm{Tc}$. 
The cause of higher, narrower dose histories in the high- $\mathrm{q}_{\mathrm{inf}}$ scenario (i.e., doses not sustained at peak levels for a very long time), compared to the broad, low dose histories in the low- $\mathrm{q}_{\text {inf }}$ scenario (i.e., doses sustained near peak levels for a long time), is due to the interaction of the mass source term with the $\mathrm{UZ}$ flux, $\mathrm{q}_{\mathrm{inf}}$. The best way to explain this is to look at the release of ${ }^{129} \mathrm{I}$, which has a long half-life and is unaffected by dripping fractures on the waste packages, i.e., since ${ }^{129} \mathrm{~T}$ crosses the EBS in the gas phase, the ${ }^{129} \mathrm{~T}$ release into the geosphere is only a function of the dissolution rate and not a function of the number of packages with dripping flow. Thus, the total release of ${ }^{129} \mathrm{I}$ from the waste packages is almost the same for the low and high infiltration cases. The slight differences in waste-package releases between high and low infiltration (see Figure 8.3-10) are due to slightly different waste-package degradation histories caused by somewhat different temperature and relative-humidity histories derived from the thermohydrologic analyses (Chapter 4). (Once the ${ }^{129} \mathrm{I}$ passes across the EBS, it is assumed to dissolve from the gas phase into the aqueous phase.)

In the high-infiltration case, fluid flow in the unsaturated zone is able to transport ${ }^{129} \mathrm{I}$ mass about as rapidly as it comes out of the waste packages. However, in the low-infiltration case, the fluid cannot transport mass rapidly enough and it begins to accumulate at the beginning of the first pathway, i.e., at the top of the TSw unit. This results in a longer, slower release that is spread out in time compared to the high-infiltration case. For aqueous-phase, high-solubility nuclides like ${ }^{99} \mathrm{Tc}$, the same phenomenon occurs but, in addition, the low-infiltration ${ }^{99} \mathrm{Tc}$ total releases and peak doses are reduced much more than ${ }^{129} \mathrm{I}$ or ${ }^{36} \mathrm{Cl}$ because the fraction of packages with drips is much lower for the low- $\mathrm{q}_{\mathrm{inf}}$ case than the high- $\mathrm{q}_{\text {inf }}$ case (Figures 7.3-7 and 7.3-8). (It is primarily the number of packages with drips rather than the dripping flow rate, $Q_{\text {drip }}$, that is the cause of the reduction in release because, as shown by Figure 7.3.10, the dripping flow rate for both the high- $\mathrm{q}_{\mathrm{inf}}$ case and the low- $\mathrm{q}_{\mathrm{inf}}$ case is high enough to transport nearly all of the highsolubility radionuclide mass out of the waste packages. For $q_{\text {inf }}$ equal to $1.25 \mathrm{~mm} / \mathrm{yr}, Q_{\text {drip }}$ equals $0.03 \mathrm{~m}^{3} / \mathrm{yr}$, and for $q_{\text {inf }}$ equal to $0.03 \mathrm{~mm} / \mathrm{yr}, Q_{\text {drip }}$ equals $1.23 \times 10^{-4} \mathrm{~m}^{3} / \mathrm{yr}$-see Figures $7.3-5$ and 7.3-6- where $Q_{\text {drip }}$ is discussed in Chapter 7 and is the volumetric flow rate per package, equal to the catchment area times $\mathrm{q}_{\mathrm{drip}}$.) In comparing ${ }^{99} \mathrm{Tc}$ and ${ }^{129} \mathrm{I}$ doses for the two infiltration ranges, there is also a greater reduction of ${ }^{99} \mathrm{Tc}$ because of its shorter half-life compared to ${ }^{129} \mathrm{I}$.

As discussed in the RIP Theory Manual (Golder, 1994), it would be more physically realistic if mass flow through the pathways influenced the mass transfer out of the waste packages. However, they are decoupled in RIP Version 3.21c. Thus, for the low- $\mathrm{q}_{\mathrm{inf}}$ case, the rate of mass transfer out of the packages is overestimated. "Nevertheless, accumulating mass at the beginning of the first pathway (as opposed to at the waste package itself) produces similar results in terms of mass transport through the entire system." (Golder, 1994.)

The expected-value for low $\mathrm{q}_{\mathrm{inf}}$ equals $0.03 \mathrm{~mm} / \mathrm{yr}$, while the expected value for high $\mathrm{q}_{\mathrm{inf}}$ equals $1.25 \mathrm{~mm} / \mathrm{yr}$. This $\mathrm{q}_{\mathrm{inf}}$ ratio of 40 seems to appear in the first arrival of ${ }^{237} \mathrm{~Np}$, which first reaches the accessible environment at about 15,000 years in the high- $\mathrm{q}_{\text {inf }}$ case (Figure 9.3-3b) and at about 550,000 years in the low- $\mathrm{q}_{\text {inf }}$ case (Figure 9.3-8) - a ratio of 36. The fact that these two ratios are nearly identical is rather fortuitous because the first arrival is not a strict linear function of $\mathrm{q}_{\mathrm{inf}}$ but is related to the amount of fracture flow determined through process-level modeling abstractions. The arrival-time ratio for the nonsorbing nuclide ${ }^{129} \mathrm{I}$ appears to be about 10 . Numerical dispersion in RIP can also mask exact travel times that would be computed with a process-level model. One thing to be noted here is the effect of timestep size, $\Delta t$, in RIP. For 
example, if we compare Figures 9.2-11 $(\Delta t=100 \mathrm{yr})$ and 9.3-3b $(\Delta t=1000 \mathrm{yr})$, we see that the first arrivals occur earlier for $\Delta t=100 \mathrm{yr}$, which is the more accurate prediction. For example, the first breakthrough of ${ }^{129} \mathrm{I}$ for $\Delta t=100 \mathrm{yr}$ is at 6100 years, whereas, it is at 12,000 years for $\Delta t=1000$ yr.

100-realization CCDFs of the 1,000,000-year total peak dose for the alternative thermal load cases are presented in Figures 9.3-13 to 9.3-15. Figure 9.3-13 shows the 83 MTU/acre case, with and without backfill, at the high and low infiltration ranges, while Figure 9.3-14 shows the $25 \mathrm{MTU} / a c r e$ case, with and without backfill, at the high and low infiltration ranges. These two figures demonstrate that backfill (as included in the Lingineni et al. process-level, thermohydrologic model and the resulting near-field temperature, relative humidity, and water saturation histories) has little effect on the results. These figures also illustrate that if the low- $q_{\text {inf }}$ scenario is operable over the $1,000,000$ years postclosure, then the corresponding peak doses will be about 250 times less than the high- $\mathrm{q}_{\mathrm{inf}}$ scenario for the $83 \mathrm{MTU} / \mathrm{acre}$ thermal load and about 500 times less for the $25 \mathrm{MTU} / \mathrm{acre}$ thermal load. The much higher doses over the high- $\mathrm{q}_{\mathrm{inf}}$ range points to the importance of defining and perhaps controlling advective flux through the repository. This issue is discussed in Section 9.3.3, which analyzes the effect of various models of radionuclide transport in the EBS. As a last comparison, Figure 9.3-15 compares the two thermal loading scenarios for the case with backfill, for high and low $q_{\text {inf }}$. For both infiltration ranges there is little difference between the thermal loading scenarios, with the high thermal load yielding at most only about twice the peak dose.

One final difference to notice is that the total-peak-dose CCDFs for the high- $q_{\text {inf }}$ case are primarily a result of the ${ }^{237} \mathrm{~Np}$ peak, whereas for low $\mathrm{q}_{\mathrm{inf}}$, they are primarily due to ${ }^{129} \mathrm{I}$. This was illustrated by the expected-value dose histories in Figures 9.3-1 and 9.3-6.

\section{$\underline{\text { Release at Accessible Environment }}$}

Figure 9.3-16 shows normalized cumulative release CCDFs at the accessible environment for the different thermal loading scenarios with backfill, at low and high $\mathrm{q}_{\text {inf. }}$ It may be compared to the corresponding peak dose CCDFs in Figure 9.3-15. In contrast to the peak dose CCDFs, which have a rather large coefficient of variation (C.V. = S.D. $[\mathrm{x}] / \mathrm{E}[\mathrm{x}]$ ) arising from the distribution of saturated-zone fluid flux and its effect on dilution (see Chapter 7), the cumulative release CCDFs have a C.V. nearly equal to 0 because they are unaffected by dilution or almost any other parameter over the long time frame of $1,000,000$ years. For both infiltration ranges, the $83 \mathrm{MTU} /$ acre thermal load results in normalized cumulative releases about 1.5 times higher than the $25 \mathrm{MTU} / \mathrm{acre}$ load. This behavior is substantiated by the expected-value release histories for high $\mathrm{q}_{\mathrm{inf}}$ (Figures 9.3-17 and 9.3-18) and for low $\mathrm{q}_{\text {inf }}$ (Figures 9.3-19 and 9.3-20). One interesting difference between the release histories and the dose histories is that although ${ }^{99} \mathrm{Tc}$ dominates the release rate (but not the normalized release because of its high release-limit factor) at low $q_{\text {inf }}$, it is ${ }^{129} \mathrm{I}$ that is more important for the doses (Figures 9.3-8 and 9.3-9) because of its higher dose conversion factor to specific activity ratio (see Section 9.2.1). Also, for the high- $\mathrm{q}_{\mathrm{inf}}$ scenario, ${ }^{237} \mathrm{~Np}$ peak dose is about 30 times higher than ${ }^{99} \mathrm{Tc}$ peak dose (Figure 9.3-3a), whereas for release rate the reverse is true (Figure 9.3-17): ${ }^{237} \mathrm{~Np}$ peak release rate is about 100 times lower than

${ }^{99} \mathrm{Tc}$ peak release rate. 
Buscheck's Thermal Hydrologic Model

As discussed in Section 9.2.1, the only Buscheck thermohydrologic model that showed releases and doses to the geosphere over 10,000 years was the 24 MTU/acre without backfill. However, over 1,000,000 years, all of the Buscheck cases mentioned in Section 9.2.1 have significant releases to the accessible environment.

Figures 9.3-21 to 9.3-24 show the 1,000,000-year expected-value dose histories for high infiltration (1.25 mm/yr) for the two Buscheck thermal loads (80 and 24 MTU/acre) with and without backfill, and Figures 9.3-25 to 9.3-28 show the 1,000,000-year expected-value dose histories for low infiltration $(0.03 \mathrm{~mm} / \mathrm{yr}$ ) for the two thermal loads ( 80 and $24 \mathrm{MTU} / \mathrm{acre}$ ) with and without backfill. These various cases may be compared to the previously presented Lingineni cases (Figures 9.3-1 to 9.3-4 and 9.3-6 to 9.3-9). Although Buscheck's process-level thermohydrologic simulations assumed zero infiltration, while Lingineni's simulations assumed either $\mathrm{q}_{\text {inf }}=0.05 \mathrm{~mm} / \mathrm{yr}$ ("low) or $0.3 \mathrm{~mm} / \mathrm{yr}$ ("high"), the following analyses couple the Buscheck near-field results to the dripping-fracture model in RIP, and to the different infiltration ranges in the far-field. Of course, it would be better to have had dripping fractures in the process-level model simulations, but one could argue that including dripping fractures in the nearfield simulations is less important that including them in the transport model for EBS releases. This is demonstrated by comparing total-peak-dose CCDFs in this section with those of Section 9.3.4. This comparison will show that large changes in relative humidity and temperature in the near field (as evident in the Buscheck versus Lingineni thermohydrologic models-see Chapter 4) has much less of an effect on repository performance (i.e., on peak dose at the accessible environment) than the radionuclide transport model in the EBS, i.e., advective transport caused by dripping fractures (see Section 9.3.4). Furthermore, once the temperature and saturation fields return to ambient conditions, both near-field models are the same, and this occurs well before $1,000,000$ years.

Our initial comparison of peak doses from the Buscheck model versus the Lingineni model considers the four high-infiltration scenarios:

(1) High thermal load (83 vs. $80 \mathrm{MTU} / \mathrm{acre}$ ), high infiltration (1.25 mm/yr), no backfill. The Buscheck model (Figure 9.3-21) shows later initial breakthrough times (70,000 - 90,000 years) for sorbing and nonsorbing nuclides compared to the breakthrough times $(15,000-20,000)$ for the Lingineni model (Figure 9.3-1a). The Lingineni model has about 3 times higher ${ }^{237} \mathrm{~Np}$ peak dose and about a 10 times higher ${ }^{129} \mathrm{I}$ dose (see Figures 9.3-29 and 9.3-30). The ${ }^{129} \mathrm{I}$ peak is much narrower and earlier in the Lingineni model. All of these effects result from the much later and more spread-out package failure times for the Buscheck model (see Chapter 5), which are a result of lower relative humidity compared to the Lingineni model. This conclusion also applies to all of the comparisons discussed below.

(2) Low thermal load ( 25 vs. 24 MTU/acre), high infiltration (1.25 mm/yr), no backfill. This was the only Buscheck case that produced releases over 10,000 years. Thus, the 1,000,000-year Buscheck dose histories (Figure 9.3-22) are quite similar to the Lingineni dose histories (Figure 9.3-2a). The ${ }^{237} \mathrm{~Np}$ peak for the Lingineni thermohydrologic model is only about 1.5 times higher than for the Buscheck model and the ${ }^{129} \mathrm{I}$ and ${ }^{99} \mathrm{Tc}$ peaks are only about 3 times higher. Similarly to the Lingineni model, the low-thermal load Buscheck model shows the cyclical climate 
variation to- a greater degree than the Buscheck high thermal-loading scenario, which, as mentioned earlier, probably results from the more spread out (in time) waste-package failures for the low thermal load.

(3) High thermal load (83 vs. $80 \mathrm{MTU} / \mathrm{acre})$, high infiltration $(1.25 \mathrm{~mm} / \mathrm{yr})$, with backfill. This comparison is about the same as case (1), which had no backfill. About the only difference is that the Buscheck model (Figure 9.3-23) with backfill has initial breakthrough times about 50,000 years later than Buscheck without backfill (Figure 9.3-23). The comparable Lingineni results are in Figure 9.3-3a.

(4) Low thermal load (25 vs. $24 \mathrm{MTU} / \mathrm{acre}$ ), high infiltration $(1.25 \mathrm{~mm} / \mathrm{yr}$ ), with backfill. Here we compare Figure 9.3-24 for the Buscheck thermohydrologic model with Figure 9.3-4a for the Lingineni model. The comparison is very similar to the cases with high thermal load without backfill.

For the four low infiltration scenarios, the main differences between the Lingineni et al. and Buscheck et al. models is that for high thermal load ( 83 or 80 MTU/acre), the Lingineni et al. model (see Figures 9.3-6 and 9.3-8 compared to 9.3-25 and 9.3-27) gives about 3 times higher ${ }^{129}$ I peak dose (see Figure 9.3-31), whereas for the low thermal load (see Figures 9.3-7a and 9.3-9a compared to 9.3-26 and 9.3-28) the Lingineni et al. model only gives slightly higher ${ }^{129} \mathrm{I}$ peak dose. As with the high- $\mathrm{q}_{\mathrm{inf}}$ cases, the low- $\mathrm{q}_{\mathrm{inf}}$ Buscheck cases show considerably retarded initial breakthrough times compared to the low- $q_{\text {inf }}$ Lingineni cases, except again for the lowthermal-load/no-backfill scenario.

Finally, Figures 9.3-32 to 9.3-35 illustrate the 100-realization, total-peak-dose CCDFs that compare the Buscheck and Lingineni thermohydrologic models for low and high $\mathrm{q}_{\mathrm{inf}}$. Figures 9.3-32 and 9.3-33 are for high thermal load, without and with backfill, respectively; and Figures 9.3-34 and 9.3-35 are for low thermal load, without and with backfill, respectively. Two general conclusions can be drawn. First, the high thermal load shows a greater difference between the two models over the $1,000,000$-year time frame, but the difference is not very significant. In particular, the high-thermal-load Lingineni model only gives about 2 to 3 times greater peak doses over the entire sampled range of stochastic variables than the Buscheck model. So, although the Buscheck model delayed the appearance of the peak dose at the accessible environment by tens- to hundreds-of-thousands of years, it did not reduce the peak very much over the long time span of 1,000,000 years. Second, as with the Lingineni thermohydrologic model, backfill makes very little difference in the total peak dose for the Buscheck thermohydrologic model.

\section{Broader Infiltration Range}

A final sensitivity analysis was conducted to merge the high $(0.5-2.0 \mathrm{~mm} / \mathrm{yr})$ and low (0.01-0.05 mm/yr) infiltration range into one range $(0.01-2.0 \mathrm{~mm} / \mathrm{yr})$ and to show the shape of the CCDF for 1,000,000-year total peak dose over this entire range, and more importantly, to determine the most important model parameters for this case (see Section 9.3.7). Over the broader range, we use log-uniform sampling, whereas over the separate low and high ranges we used uniform sampling. Without log-uniform sampling, the low infiltrations would rarely be sampled in a 100 -realization simulation. 
Figure 9.3-36 shows the expected-value dose history for the broader infiltration range, for the $83 \mathrm{MTU} / \mathrm{acre}$ loading case with backfill. If we compare Figure 9.3-36a to Figures 9.3-3a (high range) and 9.3-8 (low range), Figure 9.3-36a shows behavior intermediate between these two extremes, however, it is more similar to the low-range in the sense that the peak dose over the $1,000,000$-year time frame is due to ${ }^{129} \mathrm{I}$ rather than ${ }^{237} \mathrm{~Np}$.

The 100-realization total-peak-dose CCDF over the broader infiltration $\left(\mathrm{q}_{\mathrm{inf}}\right)$ range is shown in Figure 9.3-37, along with the CCDFs for the high and low $\mathrm{q}_{\text {inf }}$ ranges. The curves show behavior similar to the expected-value dose histories, i.e., the broader-range curve is intermediate between the other two. From the high probability end of the broad-range CCDF (i.e., at the lower end of the $q_{\text {inf }}$ range) to the low probability end of the broad-range CCDF (i.e., a the higher end of the $q_{i n f}$ range) there is a transitioning from ${ }^{129} \mathrm{~T}$ as the peak dose contributor to ${ }^{237} \mathrm{~Np}$ as the peak dose contributor.

\subsubsection{Alternative Waste Package Degradation Models}

As discussed in Section 9.2.4, because of the uncertainty about corrosion-initiation processes and corrosion rates, several alternative conceptual models have been implemented in the RIP TSPA model to examine their effect on releases and doses at the accessible environment. All other results in Section 9.3 use the corrosion-initiation model that assumes corrosion initiates when the relative humidity (R.H.) rises above $65 \%$. In this section, we also look at the $1,000,000$-year peak doses that result from other two corrosion models discussed in Section 9.2.4.

100-realization, total-peak-dose CCDFs for 1,000,000 years are shown in Figure 9.3-38 for the three alternative waste-package-degradation models. The peak dose for the R.H. and R.H.\&T corrosion-initiation models are nearly identical, when using the Lingineni thermohydrologic model and corresponding temperature and relative humidities for the $83 \mathrm{MTU} /$ acre load without backfill at the high $\mathrm{q}_{\text {inf }}$ range. This is similar to the 10,000 -year peak doses, which were also nearly the same for the two models. In contrast, the effect of cathodic protection over $1,000,000$ years is quite different than for 10,000 years. Over 10,000 years, cathodic protection prevented any releases at the accessible environment, but over $1,000,000$ years the cathodic protection $\mathrm{CCDF}$ is almost the same as the two CCDFs without cathodic protection. The expected-value dose histories for cathodic protection (Figure 9.3-39), show only a slight delay in the initial breakthrough of the various radionuclides compared to the case without cathodic protection (Figure 9.3-1a). However, it is enough of a delay to eliminate any releases over the initial 10,000 years.

\subsubsection{Alternative Conceptual Models for EBS Transport}

This section compares 1,000,000-year performance for five different conceptual models of water movement and radionuclide transport in the repository drifts: (1) fractures dripping directly onto the waste-form, i.e., directly on the spent fuel and DHLW glass; (2) fractures dripping on the corroding metal waste containers, but not directly on the waste form; (3) no dripping fractures (the so-called capillary-barrier effect); (4) no dripping fractures and aqueous (rather than gaseous) transport of ${ }^{129} \mathrm{I}$ and ${ }^{36} \mathrm{Cl}$; and (5) no dripping fractures and aqueous transport of ${ }^{129} \mathrm{I}$ and ${ }^{36} \mathrm{Cl}$ plus direct shunting of ${ }^{14} \mathrm{C}$ to the atmosphere (i.e., ${ }^{14} \mathrm{C}$ does not travel to the accessible environment 
in the aqueous phase, and so has no effect on dose). A detailed explanation of the five EBStransport models was presented in Section 9.2.3.

The 83 MTU/acre case with high infiltration, backfill, and climate change (cyclical $\mathrm{q}_{\text {inf }}$, but no water-table rise) was used as the nominal case for the analyses. We only consider the high infiltration scenario $\left(\mathrm{q}_{\mathrm{inf}}=0.5-2.0 \mathrm{~mm} / \mathrm{yr}\right)$ because according to Figures $9.3-13$ and 9.3-14, the total peak doses for the low infiltration scenario $\left(q_{\text {inf }}=0.01-0.05 \mathrm{~mm} / \mathrm{yr}\right)$ are probably below any level of concern.

The 1,000,000-year expected-value dose histories for the most conservative EBS-transport model (used in all other parts of Section 9.3), the "drips-on-waste-form" model, have previously been shown in Figure 9.3-3a. For the second, or "drips-on-waste-container" model, the expected-value dose histories are presented in Figure 9.3-40. Except for ${ }^{129} \mathrm{I}$, which is released through the gas phase, all other nuclides show a significant dose reduction at the accessible environment for the "drips-on-waste-container" model. The sorbing radionuclides (in particular, ${ }^{237} \mathrm{~Np}$ ) are reduced much more than the nonsorbing aqueous-phase nuclides, such as ${ }^{99} \mathrm{Tc}$. For ${ }^{237} \mathrm{~Np}$, the peak dose is reduced by about a factor of 25 over the 1,000,000-year time span, whereas for ${ }^{99} \mathrm{Tc}$ the reduction is only about a factor of 2 . However, an important change in the 1,000,000-year behavior for the "drips-on-waste-container" model compared to the "drips-on-waste-form" model is that the nonsorbing nuclides ${ }^{129} \mathrm{I}$ and ${ }^{99} \mathrm{Tc}$ are now the most important dose contributors over the $1,000,000$ years, rather than ${ }^{237} \mathrm{~Np}$.

Figures 9.3-3a and 9.3-40 should be compared to Figure 9.3-41, which shows the most important radionuclides to reach the accessible environment in the "no-drip" (capillary-barrier-effect) scenario. Nuclides that are transported through the EBS via the aqueous phase are unable to reach the accessible environment during the 1,000,000-year time frame at doses above $10^{-7} \mathrm{rem} / \mathrm{yr}$, because without dripping fractures (which are intercepted by the capillary barrier), the only mechanism for release from the EBS is by diffusion, which has a very low transport rate (see Figure 9.3-43). The only nuclides able to escape the EBS are those nuclides $\left({ }^{129} \mathrm{I},{ }^{36} \mathrm{Cl}\right.$, and ${ }^{14} \mathrm{C}$ ) that are transported as gas-phase nuclides through the EBS. Thus, the peak dose over $1,000,000$ years for the capillary-barrier scenario is due almost entirely to ${ }^{129} \mathrm{I}$.

As discussed in Section 9.2.3, because of the high reactivity of $\mathrm{I}_{2}$ gas and $\mathrm{Cl}_{2}$ gas, it seems quite possible that they may dissolve into the aqueous phase before they are able to traverse the entire EBS. Figure 9.3-42 shows this scenario (i.e., a capillary barrier and aqueous EBS transport of ${ }^{129} \mathrm{I}$ and ${ }^{36} \mathrm{Cl}$ ), and demonstrates that peak dose over the $1,000,000$ years will occur at an early time and be strictly due to ${ }^{14} \mathrm{C}$ dissolved in the aqueous phase. However, as also discussed in Section 9.2.3, it is quite likely that ${ }^{14} \mathrm{C}$ will not dissolve in the aqueous phase after transport across the EBS, but will travel upward, directly to the atmosphere. This case is shown in Figure 9.3-43, and represents the case where the releases and doses at the accessible environment (i.e., from a water well $5 \mathrm{~km}$ downgradient from the repository) result entirely from aqueous-phase radionuclides that were transported across the WP/EBS strictly by aqueous diffusion. The doses are extremely low, on the order of $10^{-9} \mathrm{rem} / \mathrm{yr}$.

Figures 9.3-44 and 9.3-45 demonstrate the low mass-transfer rate across a capillary barrier for aqueous-phase nuclides. These figures compare ${ }^{237} \mathrm{~Np}$ and ${ }^{99} \mathrm{Tc}$ doses at the accessible 
environment over 1,000,000 years for three scenarios: drips-on-waste-form, drips-on-wastecontainer, and capillary barrier.

100-realization, total-peak-dose CCDFs for the five EBS transport models are presented in Figure 9.3-46, on two different $x$-axis scales. (The $x$-axis scale in Figure 9.3-46a is the one used for all other CCDFs in this section, while the extended scale in Figure 9.3-46b is necessary to show the very low doses for the fifth EBS transport model.) As seen in the expected-value dose histories, the total peak dose is reduced by about a factor of about 25 for the "drips-on-waste-container" compared to the "drips-on-waste-form" model, because of the significant reduction in ${ }^{237} \mathrm{~Np}$ dose. It is not reduced much more than this for the no-drip (or capillary-barrier-effect) model because of the contribution from gaseous ${ }^{129} \mathrm{I}$. The fourth model, which combines the "capillary barrier" with aqueous EBS transport of ${ }^{129} \mathrm{I}$ and ${ }^{36} \mathrm{Cl}$, reduces the peak doses by about an additional factor of about 200 for the entire range of the CCDF. The final model, which eliminates ${ }^{14} \mathrm{C}$ as a contributor to peak dose at the accessible environment, leaving only diffusively transported aqueous-phase nuclides across the EBS, results in an additional reduction by a factor of more than $10^{4}$ in peak dose over the million-year time frame, compared to the fourth model.

\subsubsection{Fracture/Matrix Interaction in the Geosphere}

\section{Intra-unit Fracture Connectivity}

The fracture/matrix interaction term $(\lambda)$, or intra-unit fracture connectivity, has been discussed in detail in Sections 7.4.4 and 9.2.4. As with 10,000-year repository performance, for 1,000,000year performance we likewise examine three possible scenarios: (1) the nominal case, $\lambda=1 / \mathrm{h}$, which has been used for all other plots in Section 9.3, except the sensitivity cases discussed here; (2) the low-connectivity case, $\lambda=1 /(0.1 \mathrm{~h})$, for which particles only travel $10 \%$ of the formation thickness on average before switching from fracture to matrix within the given formation; and (3) the high-connectivity case, $\lambda=1 /(100 \mathrm{~h})$, for which particles travel 100 times the formation thickness on average before transitioning from fracture to matrix (i.e., 99 particles out of 100 will traverse the entire formation within a given flow mode, both fracture and matrix flow modes).

In comparing the expected-value dose histories for the $\lambda=1 / 100 \mathrm{~h}$ case (Figure 9.3-47) to the $\lambda$ $=1 / \mathrm{h}$ case (Figure 9.3-3), there is little difference between the doses for the nonsorbing ions ${ }^{99} \mathrm{Tc}$ and ${ }^{129} \mathrm{I}$, although they do reach their approximate peaks at slightly earlier times for the $\lambda=$ $1 / 100$ h case (at about 20,000 years versus 30,000 years). For the sorbing ions, e.g., ${ }^{237} \mathrm{~Np}$, there seems to be a little more of an effect, whereby at any given time up to 200,000 years, the ${ }^{237} \mathrm{~Np}$ peak dose is higher in the $\lambda=1 / 100 \mathrm{~h}$ case. After that, it is slightly lower, since the source term has been more rapidly depleted. The $\lambda=1 / 0.1 \mathrm{~h}$ case (Figure $9.3-48$ ), for which matrix flow is much more important, shows a more dramatic effect than the $\lambda=1 / 100 \mathrm{~h}$ case, when compared to the $1 / \mathrm{h}$ case. In particular, although the peak dose over a $1,000,000$-year time span is still about the same as the other two cases, it takes much longer to reach this peak dose, i.e., there is a significant delay in the breakthrough curve due to the particles spending more time within the slow flowing matrix water. For example, for the $\lambda=1 / 0.1 \mathrm{~h}$ case it takes about 275,000 years for the ${ }^{237} \mathrm{~Np}$ peak dose to rise about $100 \mathrm{mrem} / \mathrm{yr}$, compared to 85,000 years for the $\lambda=1 / \mathrm{h}$ case, and 53,000 years for the $\lambda=1 / 100 \mathrm{~h}$ case. 


\section{Zero Fracture Flow and Matrix Diffusion}

At one extreme of fracture/matrix interaction in the unsaturated zone is the case of zero flow in fractures ("matrix-flow-only"). Figure 9.3-49 shows expected-value dose histories for this matrixflow-only case, which was the only model used in TSPA-1993 (Andrews et al., 1994). It indicates a further delay in initial breakthrough times for all radionuclides compared to the $\lambda=$ $1 / 0.1 \mathrm{~h}$ case, but much more so for the sorbing nuclides than the nonsorbing nuclides. Also, for this case ${ }^{237} \mathrm{~Np}$ peak dose does not reach the $100 \mathrm{mrem} / \mathrm{yr}$ level until 525,000 years, compared to 275,000 years for the $\lambda=1 / 0.1 \mathrm{~h}$ case. Furthermore, the matrix-only case shows a slight reduction in peak dose for ${ }^{237} \mathrm{~Np},{ }^{129} \mathrm{I}$, and ${ }^{99} \mathrm{Tc}$ - by about a factor of 3 over the $1,000,000$-year time frame-compared to the three fracture-flow scenarios discussed above. A comparison of the three different $\lambda$ scenarios to the matrix-only scenario is shown in Figure 9.3-50 for ${ }^{99} \mathrm{Tc}$ and 9.3-51 for ${ }^{237} \mathrm{~Np}$

Finally, the 100-realization total-peak-dose CCDFs for the three different values of $\lambda$ compared to matrix-flow-only are shown in Figure 9.3-52. As already seen for the expected-value cases, there is little difference in the total-peak-dose CCDF during the 1,000,000-year time span amongst the three values of $\lambda$, although the highly fractured case $(\lambda=1 / 100 \mathrm{~h})$ does show about 2 times the peak dose over a probability range from about 0.2 to 0.7 . Also, as pointed out above, but which is not apparent in the CCDFs, the peak dose for the $\lambda=1 / 0.1 \mathrm{~h}$ case occurs much later in time than the other two cases.

Matrix diffusion refers to the diffusion of solutes from fluid-filled fractures into the surrounding rock matrix because of the concentration gradient that exists between the fracture and matrix when high concentrations of nuclides are rapidly transported through fractures. This phenomenon manifests as a retardation of the travel time of the diffusing solutes compared to the case of nondiffusing solutes (e.g., impenetrable fracture coatings). In the extreme case of equilibrium matrix diffusion (Golder, 1993), the solutes in fractures would travel at the same velocity as solutes in the matrix, and the effect would be the same as having matrix-flow-only, i.e., zero fracture flow. Thus, although we have not modeled matrix diffusion, per se, in TSPA-1995, Figures 9.3-49 and 9.3-52 show its maximum effect on the model.

\subsubsection{Climate Change}

The effect of climate change was evaluated by comparing a case with no climate change to two possible climate-change models. The first climate-change scenario involved a change in infiltration rate only. The periodic time-variation in $\mathrm{q}_{\mathrm{inf}}$ for this model has been described in detail in Section 7.7, and is based on a 100,000-year cycle. The second climate-change scenario included both the infiltration-rate modifier and a rising and falling water table. The effect of the changing water-table height was to shorten the path length from the repository to the water table during the rising water table, and to gradually return the path length to its original length during the falling water-table condition (i.e., during the second half of the climate-change cycle). The periods of infiltration-rate increase and water-table rise are assumed to be synchronous, when in reality one might expect some delay in the water-table rise.

To demonstrate the effect of climate change, the 83 MTU/acre case with backfill and high infiltration is analyzed. The expected-value dose history for $1,000,000$ years with no climate 
change $\left(\mathrm{q}_{\mathrm{inf}}=1.25 \mathrm{~mm} / \mathrm{yr}\right.$ ) is presented in Figures $9.3-53 \mathrm{a}$ and $\mathrm{b}$. The case with periodically increasing $\mathrm{q}_{\mathrm{inf}}$ but no water-table rise has already been presented in Figures 9.3-3a and $\mathrm{b}$, and the case with both periodically increasing $q_{\text {inf }}$ and water-table rise is presented in Figures 9.3-54a and b. The scenario of cyclical increase in $\mathrm{q}_{\mathrm{inf}}$ but no water-table rise (Figure 9.3-3a), when compared to the no climate-change scenario (Figure 9.3-53a), results in a slightly increased peak dose from ${ }^{129} \mathrm{I}$ and ${ }^{99} \mathrm{Tc}$ and slightly narrows the shape of their history curves because of the higher transport rate away from the WP/EBS (cf. the discussion of source term vs. flow rate in Section 9.3.1). The tail of the ${ }^{99} \mathrm{Tc}$ dose history curve in the cyclical- $q_{\mathrm{inf}}$ scenario also has a cyclical nature in response to the increasing and decreasing infiltration. The sorbing ions, ${ }^{237} \mathrm{~Np}$, ${ }^{229} \mathrm{Th}$, and ${ }^{233} \mathrm{U}$, also reach an earlier, higher, peak dose for the cyclical- $q_{\text {inf }}$ scenario than for the no climate-change scenario, which results in a slightly clecreased peak dose at late times compared to the no climate-change scenario. Again, this indicates that the source term for the cyclical- $q_{\text {inf }}$ scenario may be more depleted by the increases in infiltration which occur every 50,000 years. In contrast to the nonsorbing nuclide, ${ }^{99} \mathrm{Tc}$, the dose histories of the sorbing nuclides do not exhibit cyclical release for the 83 MTU/acre case, although as pointed in Section 9.3.1, they do have a cyclical nature for low thermal load. The difference is related to the different waste-package-degradation histories for the two thermal loads.

A cyclical water-table-rise plus cyclical- $q_{\text {inf }}$, scenario (Figure 9.3-54) results in quite jagged dose peaks compared to the changing- $q_{i n}$-only scenario, especially for the sorbing nuclides. The 100,000 -year period of the peaks corresponds to the 100,000 -year period for the maximum increase in $\mathrm{q}_{\mathrm{inf}}$ and simultaneous maximum rise in the water table. Due to the pathway length shortening which occurs during the period of increasing infiltration (i.e., first 50,000 years of the climate cycle), there is a rapid discharge of mass from the PPn into the saturated zone which is quickly transported to the accessible environment. This leads to the positive spike in the dose history curve. As the infiltration decreases, water-table level drops and pathway length increases, and the amount of mass being discharged to the saturated zone is decreased, leading to a negative spike in the dose history-below the level of the infiltration-change-only scenario.

A comparison of the three different climate scenarios for ${ }^{99} \mathrm{Tc}$ and ${ }^{237} \mathrm{~Np}$ is shown in Figures 9.3-55 and 9.3-56, respectively, for the expected-value high-infiltration case. As discussed above, for ${ }^{99} \mathrm{Tc}$ the higher the infiltration rate is, the narrower and higher the history curve is, so the climate change with water table rise produces the highest peaks with the bulk of the ${ }^{99} \mathrm{Tc}$ coming out of the system slightly earlier than for the other two scenarios. For ${ }^{237} \mathrm{~Np}$, the effect is similar but is just spread out over a much longer time frame.

For the low-infiltration case, expected-value dose histories at 1,000,000 years are presented for the three cases in Figures 9.3-57, 9.3-6, and 9.3-58. We again used the 83 MTU/acre thermal load, but this time without backfill. The results are sirnilar to the high-infiltration cases previously presented. The peak dose is higher and arrives earlier for the two climate-change cases. The dose curve is again quite jagged for the case which includes water table change. The decrease at late times for the two climate-change scenarios is again more pronounced than for the no climate-change scenario because of the depletion of the source term. A comparison of the three different climate-change scenarios for ${ }^{99} \mathrm{Tc}$ and ${ }^{237} \mathrm{~Np}$ at low infiltration is shown in Figures 9.3-59 and 9.3-60. The behavior shown on these figures is similar to the behavior in Figures 9.3-55a and 9.3-56a. One point of interest is that no ${ }^{237} \mathrm{~Np}$ reaches the accessible 
environment for the no climate-change scenario; however, the other two cases have such low ${ }^{237} \mathrm{~Np}$ peak doses that they would likely be inconsequential compared to any regulatory limits.

As a final evaluation of the effect of climate change on dose, the 100-realization, total-peak-dose CCDFs are presented in Figure 9.3-61 for the $83 \mathrm{MTU} /$ acre case for the low and high infiltration cases. These figures confirm the results which were seen for the expected-value cases, for example, the climate-change scenario with both increasing $\mathrm{q}_{\mathrm{inf}}$ and rising water table has higher peak doses than the other two cases.

\subsubsection{Alternative Solubility Models for $\mathrm{Np}, \mathrm{Pu}$, and Am}

In this section, results calculated using the distributions of solubility-limited aqueous radionuclide concentrations for $\mathrm{Np}, \mathrm{Pu}$, and $\mathrm{Am}$ (Section 6.3.2) are compared with results calculated using the temperature- and $\mathrm{pH}$-dependent functions for $\mathrm{Np}, \mathrm{Pu}$, and $\mathrm{Am}$ solubility controls in J-13-like water, derived in Section 6.3.3. For both of these cases, the $\mathrm{pH}$ has been set to a value of 7 . Although the derived functions incorporate $\mathrm{pH}$-dependence explicitly, the near-field $\mathrm{pH}$ evolution is uncertain to the extent that adequate constraints do not exist for making a pH choice other than a random selection from a distribution. As such, this comparison emphasizes differences between using implicit temperature effects (i.e., the random selections from the elicited distribution) versus explicit incorporation of time-dependent thermal effects on the aqueous concentrations of $\mathrm{Np}, \mathrm{Pu}$, and Am in J-13-like water. (Direct comparisons are shown in Figures 6.3-21, 6.3-22, and 6.3-23 for the derived functions for $\mathrm{Np}, \mathrm{Pu}$, and $\mathrm{Am}$ solubility limits, respectively, versus the concentration ranges of their corresponding elicited distributions.)

100-realization, total-peak-dose CCDFs for $1,000,000$ years are shown for the two solubility models in Figure 9.3-62. The different solubility models produce nearly identical peak doses $\left({ }^{237} \mathrm{~Np}\right)$ at the accessible environment over the 1,000,000-year time frame. This is not unexpected if we review the linear regression analysis in Section 9.3.7, which shows very little dependency of the results on $\mathrm{Np}$ solubility, at least for the range of $\mathrm{Np}$ solubility in the elicited distribution (see Chapter 6). (The contribution to total peak dose from $\mathrm{Am}$ and $\mathrm{Pu}$ is negligible.)

\subsubsection{Most Important Model Parameters}

The objective in this section is to find the most important model parameters in the TSPA model over a 1,000,000-year time frame, using 1,000,000-year total peak dose as a performance measure. Thus, scatter plots of 1,000,000-year total peak dose versus given model parameters are presented to demonstrate visually any linear trends in the results. Also, three stepwise linearregression analyses are performed, as described in Section 9.2.5. These analyses determine the percent of variability of the results which can be explained by sets of one or more model parameters. In the present section we two different scenarios are analyzed: $83 \mathrm{MTU} / a c r e$ thermal load, backfill, and climate change (cyclical $\mathrm{q}_{\mathrm{inf}}$ only) over the high $\mathrm{q}_{\mathrm{inf}}$ range and $83 \mathrm{MTU} / \mathrm{acre}$ thermal load, backfill, and climate change (cyclical $\mathrm{q}_{\mathrm{inf}}$ only) over the low $\mathrm{q}_{\mathrm{inf}}$ range. Similarly to Section 9.2 .5 , for each type of regression the five most important independent parameters were recorded (Tables 9.3-1 and 9.3-2), as well as the amount of the variability they explain. 
For both the low- $q_{\text {inf }}$ and high- $q_{\text {inf }}$ scenarios, the $\ln (P . M$.$) vs. \ln (x)$ fit is much better than the $\ln (\mathrm{P} . \mathrm{M})$ vs. $x$ fit. For example, for low $\mathrm{q}_{\mathrm{inf}}$, the $\ln (\mathrm{P} . \mathrm{M}$.) vs. $\ln (\mathrm{x})$ fit explains $89 \%$ of the variance using ranked parameter $\# 1$, while the $\ln (P . M)$ vs. $x$ fit only explains $49 \%$ of the variance (Table 9.3-2). Also, both fits are much better for the low- $q_{\mathrm{inf}}$ case than the high- $\mathrm{q}_{\mathrm{inf}}$ case, e.g., the $\ln ($ P.M.) vs. $\ln (\mathrm{x})$ fit explains $97 \%$ of the variance using ranked parameters \#1 and \#2 for low $\mathrm{q}_{\mathrm{inf}}$ (Table 9.3-2), but only $85 \%$ of the variance for high $\mathrm{q}_{\text {inf }}$ when using ranked parameters \#1 through \#5 (Table 9.3-1).

The most important difference between the analysis in Section 9.2.5 for 10,000-year performance and the analysis in this section for 1,000,000-year performance is that over the $1,000,000$-year time frame, dilution in the saturated zone (i.e., $\mathrm{q}_{\mathrm{sz}}$ ) is the most important parameter, whereas over the 10,000 -year time span a UZ parameter $\left(v_{\text {mat }}-\mathrm{CHnv}\right.$ ) was the most important. An explanation of this difference is that the breakthrough of the dose peak has generally occurred within the $1,000,000$-year time period (i.e., the engineered and natural barriers are not predicted to isolate the bulk of the waste from the accessible environment over that time period), so that the only model parameter of importance is how much the waste mass has been diluted (or how much it has decayed); whereas, for 10,000 years only the leading edge of the breakthrough curve has arrived at the accessible environment, so a change in an important UZ parameter can significantly shift this steeply rising portion of the breakthrough curve (see Section 9.2.5).

Over $1,000,000$ years for the low- $q_{\text {inf }}$ scenario, $q_{s z}$ is the overwhelming parameter of importance, explaining $89 \%$ of the variance by itself (in the $\ln \left(\mathrm{P} . \mathrm{M}\right.$.) vs. $\ln (\mathrm{x})$ regression). For the high $\mathrm{q}_{\mathrm{inf}}$ scenario, $\mathrm{q}_{s z}$ is also the most important , but explains only about $48 \%$ of the variability (in the $\ln (P . M$.$) vs. \ln (\mathrm{x})$ regression). $\mathrm{q}_{\mathrm{sz}}$ explains more of the variance in the low- $\mathrm{q}_{\mathrm{inf}}$ case because of its greater effect on dilution at low values of the UZ flux. The strong effect of $\mathrm{q}_{\mathrm{sz}}$ is clearly visible on the scatter plots for both $\mathrm{q}_{\mathrm{inf}}$ scenarios, Figures 9.3-63 and 9.3-70.

As with 10,000-year performance, the UZ flux $\left(\mathrm{q}_{\text {inf }}\right)$ also influences the results, although much less so in the low- $q_{\text {inf }}$ case, where a linear trend on the scatter plot (Figure 9.3-75) is not really discernible. Thus, beyond the first ranked variable $\left(\mathrm{q}_{\mathrm{sz}}\right)$, no visual linear trends are discernible on the scatter plots for the low- $\mathrm{q}_{\mathrm{inf}}$ case (Figures 9.3-75 to 9.3-80). However, for the high- $\mathrm{q}_{\text {inf }}$ case (Figures 9.3-63 to 9.3-69), a visual linear trend is also apparent for ranked parameter \#2 ( $\mathrm{q}_{\mathrm{inf}}$ in Figure 9.3-64). Beyond that, one would have to fit the residuals to the parameters in order to discern a linear trend, as described in Section 9.2.5.

As discussed in Section 9.2.5, for TSPA-1995 some of the stochastic distributions for parameters have been eliminated and replaced by sensitivity analyses, which are conducted for only three or four values of the given parameter. Thus, the analyses in Sections 9.2.5 and 9.3.7 do not include such parameters in the importance rankings, even though they could be more important than the ranked parameters. An example of this is the fracture/matrix particle transition parameter, $\lambda$. A more important example is $q_{i n f}$, which is equivalent in TSPA-1995 to the mean $\mathrm{UZ}$ percolation flux at repository depth. In particular, $\mathrm{q}_{\mathrm{inf}}$ has been separated into two ranges, or sensitivity cases. Within each range, we have included $\mathrm{q}_{\text {inf }}$ in the stepwise linear regression, but its importance has been much reduced compared to if we had constructed 100-realization CCDFs over the entire $q_{i n f}$ range from $0.01-2.0 \mathrm{~mm} / \mathrm{yr}$, as shown in Figure 9.3-37. Thus, $\mathrm{q}_{\mathrm{sz}}$ is the \#1 ranked parameter. However, if stepwise linear regression is performed on the results represented by the middle curve in Figure $9.3-37$, then $\mathrm{q}_{\text {inf }}$ becomes the \#1 ranked parameter and 
$\mathrm{q}_{\mathrm{sz}}$ becomes.the \#2 ranked parameter. This is shown in Table 9.3-3, and demonstrates the clear importance of defining the percolation flux in the unsaturated zone. Of course, it is actually the ratio of $\mathrm{q}_{\mathrm{inf}}$ (i.e., $\mathrm{q}_{\mathrm{uz}}$ ) to $\mathrm{q}_{\mathrm{sz}}$ that determines dilution in the saturated zone, so this again points out that over the $1,000,000$-year time frame, it is primarily dilution that controls peak dose at the accessible environment.

\subsubsection{Summary of 1,000,000-year Performance}

The following general conclusions can be drawn about 1,000,000-year repository performance from the sensitivity analyses in Section 9.3:

(1) 1,000,000-year total peak dose, due mainly to ${ }^{129} \mathrm{~T}$ over the low infiltration range $\left(q_{\text {inf }}=0.01\right.$ $-0.05 \mathrm{~mm} / \mathrm{yr}$ ) and to ${ }^{237} \mathrm{~Np}$ over the high infiltration range $\left(\mathrm{q}_{\mathrm{inf}}=0.5-2.0 \mathrm{~mm} / \mathrm{yr}\right.$ ), is most sensitive to the following model parameters: (i) dilution in the saturated zone (or equivalently, the saturated-zone bulk Darcy flux, $\mathrm{q}_{\mathrm{sz}}$ ), and (ii) percolation flux in the unsaturated zone (where the mean UZ percolation flux equals the infiltration flux, $\mathrm{q}_{\mathrm{inf}}$ );

(2) 1,000,000-year total peak dose may be greatly reduced by a barrier that intercepts dripping water on the waste packages (the capillary-barrier effect), i.e., diffusion-only (no advection) through the WP/EBS produce extremely low doses at the accessible environment;

(3) Low intra-unit fracture connectivity in the unsaturated zone (i.e., high Poisson transition rate in the RIP model) can delay peak doses significantly, but can only slightly reduce the peak dose that occurs during the 1,000,000-year time frame after repository closure (a similar conclusion applies to matrix diffusion);

(4) Alternative thermal loads, alternative thermohydrologic models for the near-field, and alternative corrosion-initiation models (including cathodic protection) do not have a very large effect on the peak dose that occurs during the 1,000,000-year time span (a factor of three is about the largest effect);

(5) Over 1,000,000 years, climate change with water table rise can increase peak dose at the accessible environment by a factor of about 2 to 10 compared to no change in climate; climate change without water table rise (varying infiltration rate only) falls in between these two extremes.

\subsection{SUBSYSTEM PERFORMANCE}

Another important aspect of the TSPA analysis is to determine the ability of various parts of the system, both engineered and natural, to contain or retard the transport of the waste. To evaluate the containment capability of these various subsystems, cumulative (but not normalized) expected-value releases were calculated for a particular case (83 MTU/acre, with backfill, "high" $\mathrm{q}_{\mathrm{inf}}=1.25 \mathrm{~mm} / \mathrm{yr}$ initially, and cyclical $\mathrm{q}_{\mathrm{inf}}$ due to climate change) at various times $(10,000$, 100,000 , and $1,000,000$ years) at the following locations:

1. From the engineered barrier system (EBS),

2. From the base of the repository-level formation (TSw), 
3. From the base of the unsaturated zone (PPn), and

4. At the accessible environment (AE).

Results are presented in Table 9.4-1 and in Figures 9.4-1 to 9.4-5 for total release, ${ }^{99} \mathrm{Tc}$ release, ${ }^{129} \mathrm{I}$ release, ${ }^{237} \mathrm{~Np}$ release, and ${ }^{229} \mathrm{Th}$ release (assuming radionuclide decay throughout the simulations). Generally, the saturated zone does not act as a significant containment barrier as evidenced by the releases at the base of the unsaturated zone and at the accessible environment being nearly identical. For the total release (Figure 9.4-1), the TSw barrier provides nearly an order-of-magnitude reduction in the radioactivity released from the EBS at $10^{6}$ years. An additional 7 times decrease in radioactivity released at $10^{6}$ years is provided by the combination of the other natural barriers (TSv, CHnv, and CHnz).

For the cumulative release of the nonsorbing nuclides ${ }^{99} \mathrm{Tc}$ and ${ }^{129} \mathrm{I}$ (Figures 9.4-2 and 9.4-3), the containment provided by the various subsystems, and combinations thereof, is about the same at times greater than approximately 100,000 years. This is because the nonsorbing nuclides have a relatively rapid travel time, so most of their mass has already passed through the entire system (i.e., all subsystems) after 100,000 years have transpired, whereas between 10,000 and 100,000 years much of their mass is still travelling within the UZ.

For ${ }^{237} \mathrm{~Np}$ release (Figure 9.4-4), the individual natural barriers, and combinations thereof (primarily the UZ), provide additional reduction of radioactivity compared to the EBS, up to and slightly beyond 1,000,000 years. This is supported by Figure 9.3-17, which shows that there is still a significant amount of ${ }^{237} \mathrm{~Np}$ in the system at 1,000,000 years. ${ }^{229} \mathrm{Th}$ releases (Figure 9.4-5) provide a look at the impact of radioactive in-growth of a sorbing species, where the number of curies released from the EBS is actually less than the release at the other three locations (TSw, $\mathrm{PPn}$, and $\mathrm{AE}$ ) after $1,000,000$ years because there is a source of ${ }^{229} \mathrm{Th}$ production within the unsaturated zone (i.e., decay of ${ }^{237} \mathrm{~Np}$ ). This is proven by Figure $9.4-6$, which is the same as Figure 9.4-5, except with decay turned off. In this no-decay case, each of the successive barriers acts to reduce ${ }^{229} \mathrm{Th}$ releases further. 
Table 9.2-1 - Regression statistics for 10,000-year normalized cumulative release, 83 MTU/acre, high- $\mathrm{q}_{\mathrm{inf}}$ range $(0.5-2.0 \mathrm{~mm} / \mathrm{year})$, with backfill and climate change (no water-table rise)

\begin{tabular}{|c|c|c|c|c|c|c|}
\hline \multirow[b]{2}{*}{ Parameter } & \multicolumn{2}{|c|}{ rank (P.M.) ${ }^{1}$ vs. rank (x) } & \multicolumn{2}{|c|}{ In (P.M.) vs. $x$} & \multicolumn{2}{|c|}{ In (P.M.) vs. In (x) } \\
\hline & $\begin{array}{c}\text { Rank } \\
\text { Importance }\end{array}$ & $\begin{array}{c}\% \text { of } \\
\text { variance } \\
\text { explained }{ }^{2}\end{array}$ & $\begin{array}{c}\text { Rank } \\
\text { Importance }\end{array}$ & $\begin{array}{c}\% \text { of } \\
\text { variance } \\
\text { explained }{ }^{2}\end{array}$ & $\begin{array}{c}\text { Rank } \\
\text { Importance }\end{array}$ & $\begin{array}{c}\% \text { of } \\
\text { variance } \\
\text { explained }{ }^{2}\end{array}$ \\
\hline $\mathrm{U}_{\mathrm{cli}}(1,3)$ & 4 & 87 & 3 & 68 & 3 & 72 \\
\hline \multicolumn{7}{|l|}{$\mathrm{Np} \mathrm{K}_{\mathrm{d}}(\mathrm{TSw}, \mathrm{PPn})$} \\
\hline \multicolumn{7}{|l|}{$\mathrm{Np} \mathrm{K}_{\mathrm{d}}(\mathrm{SZ})$} \\
\hline Np K $\mathrm{K}_{\mathrm{d}}$ (TSv, CHnv) & & & 5 & 70 & 5 & 76 \\
\hline \multicolumn{7}{|l|}{$\mathrm{Np} \mathrm{K}_{\mathrm{d}}(\mathrm{CHnz})$} \\
\hline \multicolumn{7}{|l|}{$\phi_{\text {TSW }}$} \\
\hline \multicolumn{7}{|l|}{$\phi_{T S V}$} \\
\hline \multicolumn{7}{|l|}{$\phi_{\mathrm{CHnv}}$} \\
\hline \multicolumn{7}{|l|}{$\phi_{\mathrm{CHnz}}$} \\
\hline $\mathbf{q}_{\mathbf{s z}}$ & 3 & 84 & 4 & 69 & 4 & 75 \\
\hline \multicolumn{7}{|l|}{ Sol Np } \\
\hline \multicolumn{7}{|l|}{ Sol Tc } \\
\hline \multicolumn{7}{|l|}{ Sol Th } \\
\hline \multicolumn{7}{|l|}{$W P f_{\text {drip }}{ }^{3}$} \\
\hline \multicolumn{7}{|l|}{$q_{\text {darip }}$} \\
\hline$f_{\text {frac }} \mathrm{CHnv}$ & 2 & 80 & 2 & 63 & & \\
\hline$v_{m \mu} \mathrm{CHnv}$ & 1 & 60 & & & 1 & 50 \\
\hline $\mathrm{f}_{\mathrm{fnc}} \mathrm{CHnz}$ & 5 & 89 & & & & \\
\hline \multicolumn{7}{|l|}{$\mathrm{v}_{\mathrm{mu}} \mathrm{CHnz}$} \\
\hline $\mathrm{q}_{\operatorname{lnf}}(\mathrm{UZ})$ & . & & 1 & 45 & 2 & 68 \\
\hline \multicolumn{7}{|l|}{$A_{w p}(D H L W)$} \\
\hline \multicolumn{7}{|l|}{$f_{\text {frac }}$ TSv } \\
\hline \multicolumn{7}{|l|}{$v_{m a x} T S v$} \\
\hline \multicolumn{7}{|l|}{$\mathrm{f}_{\mathrm{frac}} \mathrm{TSw}$} \\
\hline$v_{\text {mul }} T S w$ & & & & & & \\
\hline
\end{tabular}

' P.M. = performance measure

${ }^{2} \%$ of variance explained by parameters ranked less than or equal to the given parameter, e.g., for parameter with rank 3, the \% variance listed is for parameters ranked 1,2 , and 3 .

${ }^{3}$ fraction of waste packages with drips 
Table 9.2-2 - Regression statistics for 10,000-year total peak dose, 83 MTU/acre, high- $\mathrm{q}_{\text {inf }}$ range (0.5-2.0 $\mathrm{mm} /$ year), with backfill and climate change (no water-table rise)

\begin{tabular}{|c|c|c|c|c|c|c|}
\hline \multirow[b]{2}{*}{ Parameter } & \multicolumn{2}{|c|}{$\operatorname{rank}(P . M .)^{1}$ vs. rank (x) } & \multicolumn{2}{|c|}{ In (P.M.) vs. $x$} & \multicolumn{2}{|c|}{ In (P.M.) vs. $\ln (x)$} \\
\hline & $\begin{array}{c}\text { Rank } \\
\text { Importance }\end{array}$ & $\begin{array}{c}\text { \% of } \\
\text { variance } \\
\text { explained }\end{array}$ & $\begin{array}{c}\text { Rank } \\
\text { Importance }\end{array}$ & $\begin{array}{c}\% \text { of } \\
\text { variance } \\
\text { explained }{ }^{2}\end{array}$ & $\begin{array}{c}\text { Rank } \\
\text { Importance }\end{array}$ & $\begin{array}{c}\% \text { of } \\
\text { variance } \\
\text { explained }^{2}\end{array}$ \\
\hline $\mathrm{U}_{\mathrm{eti}}(1,3)$ & 3 & 81 & 3 & 67 & 3 & 71 \\
\hline \multicolumn{7}{|l|}{$N p K_{d}(T S w, P P n)$} \\
\hline \multicolumn{7}{|l|}{$N p K_{d}(S Z)$} \\
\hline Np K (TSv, CHnv) & & & & & 4 & 72 \\
\hline \multicolumn{7}{|l|}{$\mathrm{Np} \mathrm{K}_{d}(\mathrm{CHnz})$} \\
\hline \multicolumn{7}{|l|}{$\oint_{\mathrm{TSw}}$} \\
\hline \multicolumn{7}{|l|}{$\oint_{\text {TSV }}$} \\
\hline \multicolumn{7}{|l|}{$\oint_{\text {CHnv }}$} \\
\hline \multicolumn{7}{|l|}{$\phi_{\mathrm{CH} \text { HX }}$} \\
\hline \multicolumn{7}{|l|}{$\mathrm{q}_{s z}$} \\
\hline \multicolumn{7}{|l|}{ Sol $N p$} \\
\hline \multicolumn{7}{|l|}{ Sol Tc } \\
\hline \multicolumn{7}{|l|}{ Sol Th } \\
\hline \multicolumn{7}{|l|}{$W P f_{\text {drip }}{ }^{3}$} \\
\hline \multicolumn{7}{|l|}{$q_{\text {drip }}$} \\
\hline $\mathrm{f}_{\mathrm{fmc}} \mathrm{CHnv}$ & 2 & 78 & 2 & 62 & & \\
\hline $\mathrm{v}_{\mathrm{mut}} \mathrm{CHnv}$ & 1 & 58 & & & 1 & 48 \\
\hline $\mathrm{f}_{\mathrm{trac}} \mathrm{CHnz}$ & 4 & 84 & 4 & 69 & & \\
\hline \multicolumn{7}{|l|}{$\mathrm{v}_{\mathrm{max}} \mathrm{CHnz}$} \\
\hline $\mathrm{q}_{\mathrm{int}}(\mathrm{UZ})$ & & & 1 & 45 & 2 & 67 \\
\hline \multicolumn{7}{|l|}{$A_{\text {wp }}(D H L W)$} \\
\hline$f_{f r x c} T S v$ & & & 5 & 71 & & \\
\hline$v_{m x} T S v$ & 5 & 87 & & & & \\
\hline $\mathrm{f}_{\text {finc }} \mathrm{TSw}$ & & & & & 5 & 73 \\
\hline $\mathrm{V}_{\text {maxt }} \mathrm{TSw}$ & & & & & & \\
\hline
\end{tabular}

1 P.M. = performance measure

$2 \%$ of variance explained by parameters ranked less than or equal to the given parameter, e.g., for parameter with rank 3 , the $\%$ variance listed is for parameters ranked 1,2 , and 3 .

3 fraction of waste packages with drips 
Table 9.3-1.. Regression statistics for 1,000,000-year total peak dose, 83 MTU/acre, high- $q_{\text {inf }}$ range $(0.5-2.0 \mathrm{~mm} / \mathrm{yr}$ ), with backfill and climate change (no water-table rise)

\begin{tabular}{|c|c|c|c|c|c|c|}
\hline \multirow[b]{2}{*}{ Parameter } & \multicolumn{2}{|c|}{$\operatorname{rank}\left(\mathbf{P} . M_{.}\right)^{1} \mathbf{v s} . \operatorname{rank}(\mathrm{x})$} & \multicolumn{2}{|c|}{$\ln (\mathbf{P . M}$.$) vs. x$} & \multicolumn{2}{|c|}{$\ln ($ P.M.) vs. $\ln (x)$} \\
\hline & $\begin{array}{c}\text { Rank } \\
\text { Importance }\end{array}$ & $\begin{array}{c}\% \text { of } \\
\text { variance } \\
\text { explained }^{2}\end{array}$ & $\begin{array}{c}\text { Rank } \\
\text { Importance }\end{array}$ & $\begin{array}{c}\% \text { of } \\
\text { variance } \\
\text { explained }^{2}\end{array}$ & $\begin{array}{c}\text { Rank } \\
\text { Importance }\end{array}$ & $\begin{array}{c}\% \text { of } \\
\text { variance } \\
\text { explained }\end{array}$ \\
\hline $\mathrm{U}_{\mathrm{cll}}(1,3)$ & 4 & 82 & 3 & 53 & 4 & 81 \\
\hline \multicolumn{7}{|l|}{ Np K $\mathrm{K}_{\mathrm{d}}(\mathrm{TSw}, \mathrm{PPn})$} \\
\hline \multicolumn{7}{|l|}{$\mathrm{Np} \mathrm{K}_{\mathrm{d}}(\mathrm{SZ})$} \\
\hline \multicolumn{7}{|l|}{$\mathrm{Np} \mathrm{K}_{\mathrm{d}}(\mathrm{TSv}, \mathrm{CHnv})$} \\
\hline \multicolumn{7}{|l|}{$\mathrm{Np} \mathrm{K}_{\mathrm{d}}(\mathrm{CHnz})$} \\
\hline \multicolumn{7}{|l|}{$\phi_{\text {TSw }}$} \\
\hline \multicolumn{7}{|l|}{$\phi_{\text {TsV }}$} \\
\hline \multicolumn{7}{|l|}{$\phi_{\text {CHav }}$} \\
\hline \multicolumn{7}{|l|}{$\phi_{\mathrm{CH} \mathrm{H}}$} \\
\hline $\mathrm{q}_{52}$ & 1 & 55 & 1 & 23 & 1 & 48 \\
\hline \multicolumn{7}{|l|}{ Sol Np } \\
\hline \multicolumn{7}{|l|}{ Sol Tc } \\
\hline \multicolumn{7}{|l|}{ Sol Th } \\
\hline \multicolumn{7}{|l|}{$W P f_{d d p}{ }^{3}$} \\
\hline \multicolumn{7}{|l|}{$q_{\text {arro }}$} \\
\hline \multicolumn{7}{|l|}{$\mathrm{f}_{\mathrm{fixc}} \mathrm{CHnv}$} \\
\hline \multicolumn{7}{|l|}{$v_{m u t} \mathrm{CHnv}$} \\
\hline \multicolumn{7}{|l|}{$\mathrm{f}_{\mathrm{frxc}} \mathrm{CHnz}$} \\
\hline \multicolumn{7}{|l|}{$v_{m u} \mathrm{CHnz}$} \\
\hline $\mathrm{q}_{\operatorname{linf}}(\mathrm{UZ})$ & 2 & 70 & 2 & 45 & 2 & 65 \\
\hline \multicolumn{7}{|l|}{$A_{\text {wp }}(\mathrm{DHLW})$} \\
\hline $\mathrm{f}_{\text {frec }} \mathrm{TSv}$ & 5 & 84 & 5 & 62 & & \\
\hline $\mathrm{v}_{\mathrm{mu}} \mathrm{TSV}$ & & & & & 5 & 85 \\
\hline$f_{\text {frac }} T S w$ & & & & & 3 & 75 \\
\hline$v_{m u} T S w$ & 3 & 78 & 4 & 60 & & \\
\hline
\end{tabular}

P.M. = performance measure

$2 \%$ of variance explained by parameters ranked less than or equal to the given parameter, e.g., for parameter with rank 3, the \% variance listed is for parameters ranked 1,2 , and 3.

3 fraction of waste packages with drips 
Table 9.3-2 - Regression statistics for 1,000,000-year total peak dose, 83 MTU/acre, low- $q_{\text {inf }}$ range (0.01-0.05 mm/yr), with backfill and climate change (no water-table rise)

\begin{tabular}{|c|c|c|c|c|c|c|}
\hline \multirow[b]{2}{*}{ Parameter } & \multicolumn{2}{|c|}{$\operatorname{rank}\left(\right.$ P.M.) ${ }^{\prime}$ vs. $\operatorname{rank}(x)$} & \multicolumn{2}{|c|}{ In (P.M.) vs. $x$} & \multicolumn{2}{|c|}{ ln (P.M.) vs. $\ln (x)$} \\
\hline & $\begin{array}{c}\text { Rank } \\
\text { Importance }\end{array}$ & $\begin{array}{c}\% \text { of } \\
\text { variance } \\
\text { explained }^{2}\end{array}$ & $\begin{array}{c}\text { Rank } \\
\text { Importance }\end{array}$ & $\begin{array}{c}\% \text { of } \\
\text { variance } \\
\text { explained }{ }^{2}\end{array}$ & $\begin{array}{c}\text { Rank } \\
\text { Importance }\end{array}$ & $\begin{array}{c}\% \text { of } \\
\text { variance } \\
\text { explained }{ }^{2}\end{array}$ \\
\hline $\mathrm{U}_{\mathrm{cli}}(1,3)$ & & & 3 & 57 & & \\
\hline \multicolumn{7}{|l|}{$\mathrm{Np} \mathrm{K}_{\mathrm{d}}(\mathrm{TSw}, \mathrm{PPn})$} \\
\hline \multicolumn{7}{|l|}{$N p K_{d}(S Z)$} \\
\hline Np $K_{d}$ (TSv, CHnv) & & & 4 & 60 & & \\
\hline \multicolumn{7}{|l|}{$\mathrm{Np} \mathrm{K}_{\mathrm{d}}$ (CHnz) } \\
\hline \multicolumn{7}{|l|}{$\phi_{\text {TSw }}$} \\
\hline \multicolumn{7}{|l|}{$\phi_{\mathrm{TSV}}$} \\
\hline \multicolumn{7}{|l|}{$\phi_{\text {CHinv }}$} \\
\hline \multicolumn{7}{|l|}{$\phi_{\mathrm{CHnz}}$} \\
\hline $\mathbf{q}_{s z}$ & 1 & 89 & 1 & 49 & 1 & 89 \\
\hline \multicolumn{7}{|l|}{ Sol Np } \\
\hline Sol Tc & & & & & . & \\
\hline \multicolumn{7}{|l|}{ Sol Th } \\
\hline \multicolumn{7}{|l|}{$W P f_{d r i p}{ }^{3}$} \\
\hline \multicolumn{7}{|l|}{$\mathbf{q}_{\text {drip }}$} \\
\hline \multicolumn{7}{|l|}{$\mathrm{f}_{\text {frac }} \mathrm{CHnv}$} \\
\hline \multicolumn{7}{|l|}{$\mathrm{v}_{\max } \mathrm{CHnv}$} \\
\hline $\mathrm{f}_{\text {frac }} \mathrm{CHnz}$ & & & 5 & 62 & & \\
\hline $\mathrm{v}_{\mathrm{mux}} \mathrm{CHnz}$ & 2 & 95 & & & 2 & 97 \\
\hline $\mathrm{q}_{\text {ins }}(\mathrm{UZ})$ & & & 2 & 55 & & \\
\hline$A_{w_{p}}(D H L W)$ & $:$ & & & & & \\
\hline \multicolumn{7}{|l|}{$f_{\text {frac }}$ TSv } \\
\hline \multicolumn{7}{|l|}{$v_{\max }$ TSV } \\
\hline \multicolumn{7}{|l|}{$f_{\text {frac }}$ TSw } \\
\hline $\mathrm{v}_{\mathrm{mul}} \mathrm{TSw}$ & 3 & 97 & & & 3 & 98 \\
\hline
\end{tabular}

1 P.M. = performance measure

$2 \%$ of variance explained by parameters ranked less than or equal to the given parameter, e.g., for parameter with rank 3 , the $\%$ variance listed is for parameters ranked 1,2 , and 3 .

3 fraction of waste packages with drips 
Table 9.3-3 . Regression statistics for 1,000,000-year total peak dose, 83 MTU/acre, entire$\mathrm{q}_{\mathrm{inf}}$ range (0.01-2.0 mm/yr), with backfill and climate change (no water-table rise)

\begin{tabular}{|c|c|c|c|c|c|c|}
\hline \multirow[b]{2}{*}{ Parameter } & \multicolumn{2}{|c|}{$\operatorname{rank}(\mathbf{P . M} .)^{1}$ vs. $\operatorname{rank}(\mathrm{x})$} & \multicolumn{2}{|c|}{ In (P.M.) vs. $x$} & \multicolumn{2}{|c|}{ In (P.M.) vs. $\ln (x)$} \\
\hline & $\begin{array}{c}\text { Rank } \\
\text { Importance }\end{array}$ & $\begin{array}{c}\% \text { of } \\
\text { variance } \\
\text { explained }\end{array}$ & $\begin{array}{c}\text { Rank } \\
\text { Importance }\end{array}$ & $\begin{array}{c}\% \text { of } \\
\text { variance } \\
\text { explained }{ }^{2}\end{array}$ & $\begin{array}{c}\text { Rank } \\
\text { Importance }\end{array}$ & $\begin{array}{c}\% \text { of } \\
\text { variance } \\
\text { explained }^{2}\end{array}$ \\
\hline $\mathrm{U}_{\mathrm{cl}}(1,3)$ & 4 & 86 & 3 & 78 & 5 & 88 \\
\hline \multicolumn{7}{|l|}{$\mathrm{Np} \mathrm{K}_{\mathrm{d}}(\mathrm{TSw}, \mathrm{PPn})$} \\
\hline \multicolumn{7}{|l|}{$N p K_{d}(S Z)$} \\
\hline Np K (TSv, CHnv) & & & 4 & 80 & & \\
\hline \multicolumn{7}{|l|}{$\mathrm{Np} \mathrm{K}_{\mathrm{d}}(\mathrm{CHnz})$} \\
\hline \multicolumn{7}{|l|}{$\phi_{\text {TSW }}$} \\
\hline \multicolumn{7}{|l|}{$\phi_{\text {TSV }}$} \\
\hline \multicolumn{7}{|l|}{$\phi_{\mathrm{CHnv}}$} \\
\hline \multicolumn{7}{|l|}{$\phi_{\mathrm{CHnz}}$} \\
\hline $\mathrm{q}_{s z}$ & 2 & 81 & 2 & 75 & 2 & 74 \\
\hline Sol Np & 5 & 87 & & & & \\
\hline \multicolumn{7}{|l|}{ Sol Tc } \\
\hline \multicolumn{7}{|l|}{ Sol Th } \\
\hline$W P f_{\text {drip }}{ }^{3}$ & & & & & 3 & 83 \\
\hline \multicolumn{7}{|l|}{$\mathrm{q}_{\text {drip }}$} \\
\hline \multicolumn{7}{|l|}{$\mathrm{f}_{\text {frac }} \mathrm{CHnv}$} \\
\hline \multicolumn{7}{|l|}{$\mathrm{v}_{\mathrm{mu}} \mathrm{CHnv}$} \\
\hline \multicolumn{7}{|l|}{$\mathrm{f}_{\mathrm{fne}} \mathrm{CHnz}$} \\
\hline \multicolumn{7}{|l|}{$v_{\text {mut }} \mathrm{CHnz}$} \\
\hline $\mathrm{q}_{\mathrm{inf}}(\mathrm{UZ})$ & 1 & 46 & 1 & 64 & 1 & 50 \\
\hline \multicolumn{7}{|l|}{$A_{\text {wp }}$ (DHLW) } \\
\hline \multicolumn{7}{|l|}{$\mathrm{f}_{\text {frec }} \mathrm{TSv}$} \\
\hline \multicolumn{7}{|l|}{$v_{m e r} T S v$} \\
\hline $\mathrm{f}_{\text {frac }} \mathrm{TSw}$ & & & 5 & 81 & & \\
\hline$v_{m u}$ TSw & 3 & 85 & & & 4 & 86 \\
\hline
\end{tabular}

P.M. = performance measure

$2 \%$ of variance explained by parameters ranked less than or equal to the given parameter, e.g., for parameter with rank 3 , the $\%$ variance listed is for parameters ranked 1,2 , and 3 .

3 fraction of waste packages with drips 
Table 9.4-1 . Cumulative releases from various subsystems: Expected-value releases at various times for $83 \mathrm{MTU} /$ acre thermal load, with backfill, $\mathrm{q}_{\mathrm{inf}}=1.25 \mathrm{~mm} / \mathrm{yr}$, and climate change (no water-table rise)

\begin{tabular}{|l|l|c|c|c|c||}
\hline \hline $\begin{array}{c}\text { Year of } \\
\text { Release } \\
\text { (yrs) }\end{array}$ & \multicolumn{1}{|c|}{ RN } & $\begin{array}{c}\text { Release from } \\
\text { EBS } \\
\text { (Ci) }\end{array}$ & $\begin{array}{c}\text { Release from } \\
\text { TSw } \\
\text { (Ci) }\end{array}$ & $\begin{array}{c}\text { Release to SZ } \\
\text { (Ci) }\end{array}$ & $\begin{array}{c}\text { Release to } \\
\text { AE } \\
\text { (Ci) }\end{array}$ \\
\hline \hline 10,000 & Total & $5.00 \times 10^{5}$ & $8.38 \times 10^{4}$ & $2.47 \times 10^{2}$ & $1.20 \times 10^{2}$ \\
\hline & ${ }^{129} \mathrm{I}$ & $1.59 \times 10^{3}$ & $2.97 \times 10^{2}$ & 1.15 & $5.62 \times 10^{-1}$ \\
\hline & ${ }^{237} \mathrm{~Np}$ & $1.52 \times 10^{4}$ & $1.94 \times 10^{3}$ & $4.74 \times 10^{-4}$ & $7.86 \times 10^{-5}$ \\
\hline & ${ }^{99} \mathrm{Tc}$ & $3.26 \times 10^{5}$ & $6.09 \times 10^{4}$ & $2.34 \times 10^{2}$ & $1.14 \times 10^{2}$ \\
\hline & ${ }^{229} \mathrm{Th}$ & 2.51 & $3.68 \times 10^{-1}$ & $1.29 \times 10^{-5}$ & $3.59 \times 10^{-7}$ \\
\hline 100,000 & Total & $2.32 \times 10^{6}$ & $6.94 \times 10^{5}$ & $3.07 \times 10^{5}$ & $3.07 \times 10^{5}$ \\
\hline & ${ }^{129} \mathrm{I}$ & $1.84 \times 10^{3}$ & $1.82 \times 10^{3}$ & $1.72 \times 10^{3}$ & $1.72 \times 10^{3}$ \\
\hline & ${ }^{237} \mathrm{~Np}$ & $3.89 \times 10^{4}$ & $7.67 \times 10^{3}$ & $4.66 \times 10^{2}$ & $3.89 \times 10^{2}$ \\
\hline & ${ }^{99} \mathrm{Tc}$ & $3.76 \times 10^{5}$ & $3.44 \times 10^{5}$ & $3.04 \times 10^{5}$ & $3.03 \times 10^{5}$ \\
\hline \hline & ${ }^{229} \mathrm{Th}$ & $2.13 \times 10^{2}$ & $3.41 \times 10^{2}$ & $4.06 \times 10^{1}$ & $1.90 \times 10^{1}$ \\
\hline $1,000,000$ & Total & $1.99 \times 10^{7}$. & $2.54 \times 10^{6}$ & $3.75 \times 10^{5}$ & $3.65 \times 10^{5}$ \\
\hline & ${ }^{129} \mathrm{I}$ & $1.84 \times 10^{3}$ & $1.84 \times 10^{3}$ & $1.84 \times 10^{3}$ & $1.84 \times 10^{3}$ \\
\hline & ${ }^{237} \mathrm{~Np}$ & $3.89 \times 10^{4}$ & $3.23 \times 10^{4}$ & $2.60 \times 10^{4}$ & $2.58 \times 10^{4}$ \\
\hline & ${ }^{99} \mathrm{Tc}$ & $3.77 \times 10^{5}$ & $3.46 \times 10^{5}$ & $3.17 \times 10^{5}$ & $3.15 \times 10^{5}$ \\
\hline & ${ }^{229} \mathrm{Th}$ & $1.54 \times 10^{3}$ & $2.14 \times 10^{4}$ & $1.39 \times 10^{4}$ & $6.57 \times 10^{3}$ \\
\hline & & & & \\
\hline
\end{tabular}




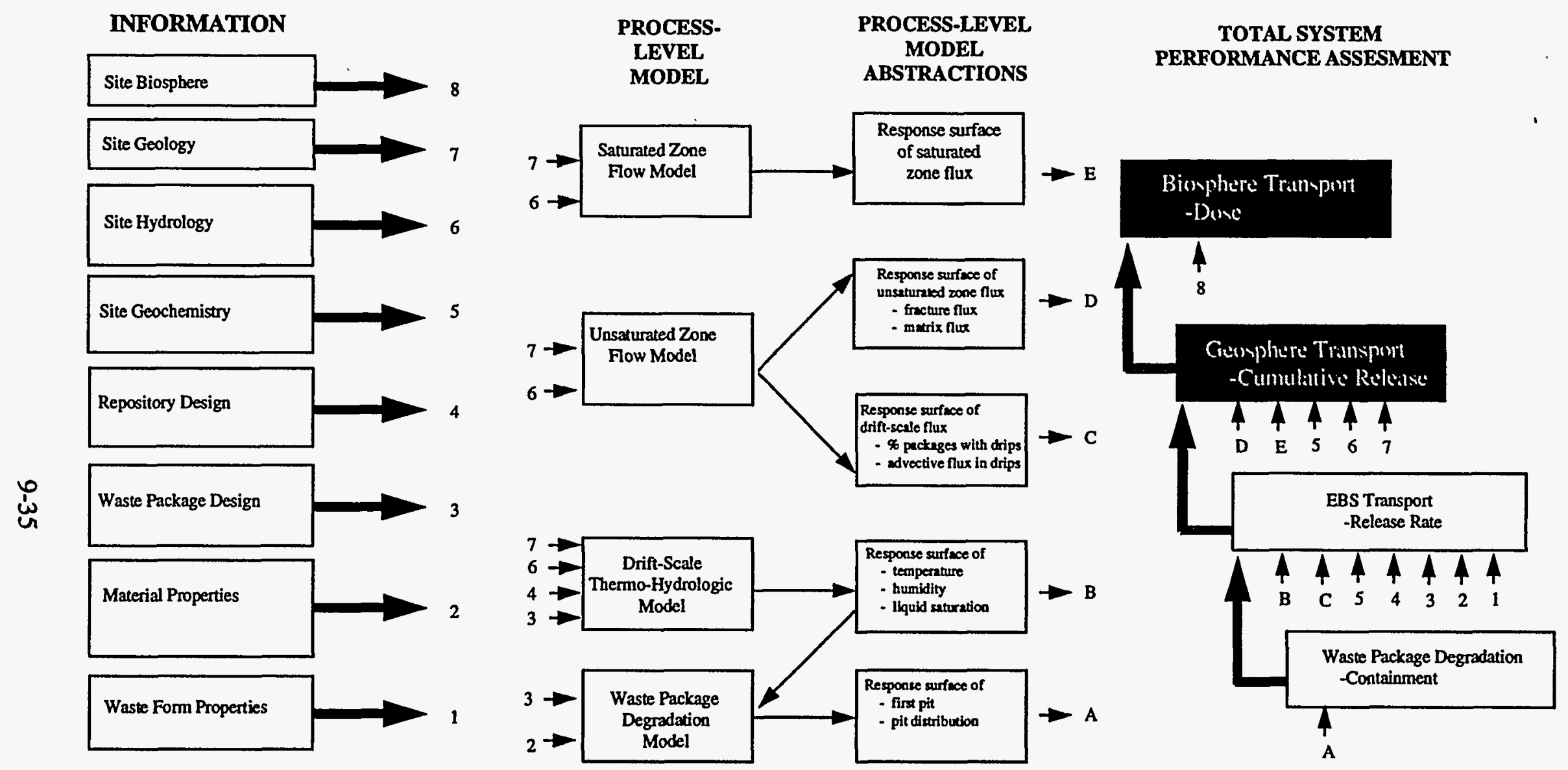

Figure 9.1-1 Relationship of Chapter 9 to the Overall Information Flow Diagram for TSPA 1995 (Figure 1.4-6). 


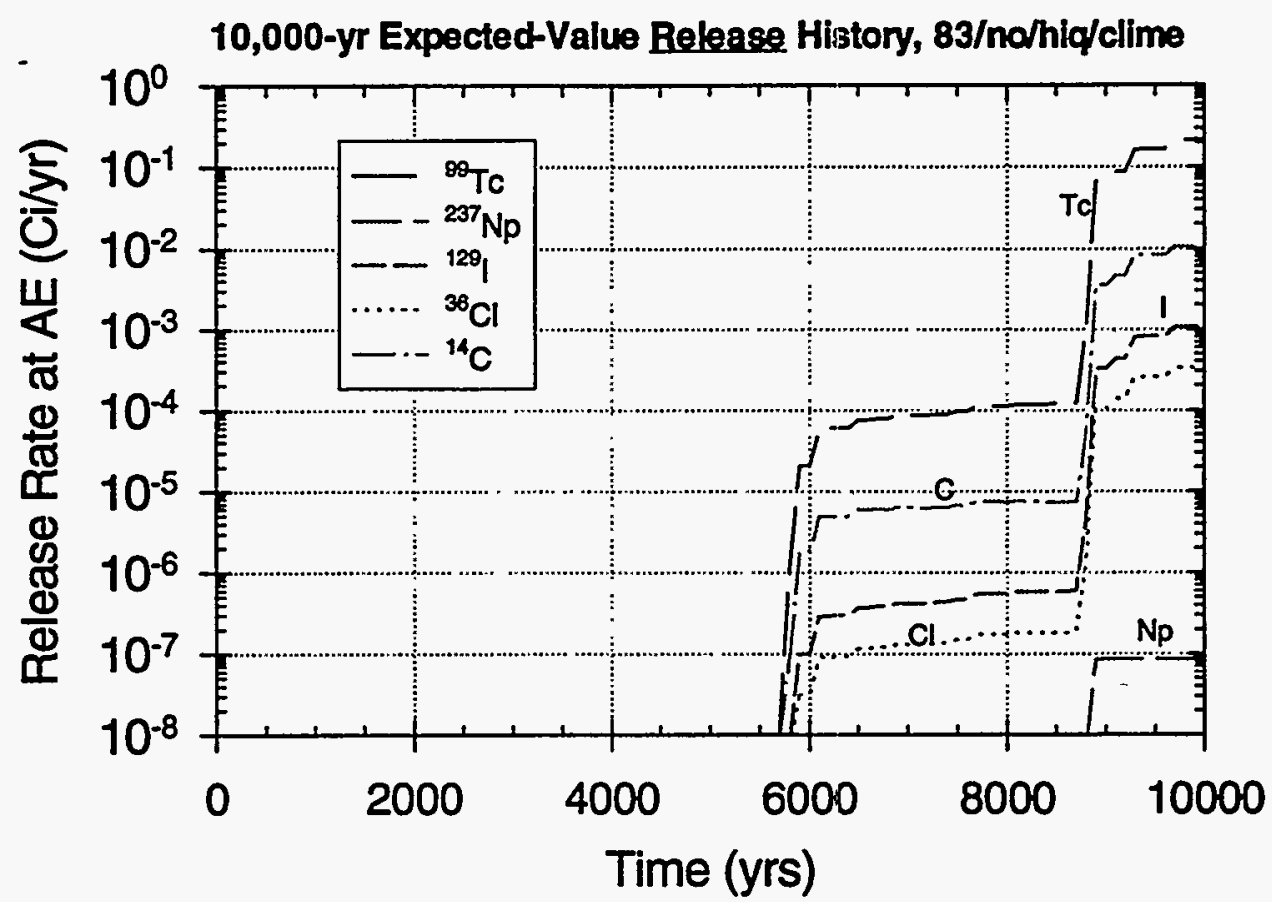

Figure 9.2-1 Expected-value release-rate history: 10,000 years, 83 MTU/acre, no backfill, high infiltration $\left(\mathrm{q}_{\text {inf }}=1.25 \mathrm{~mm} / \mathrm{yr}\right)$.

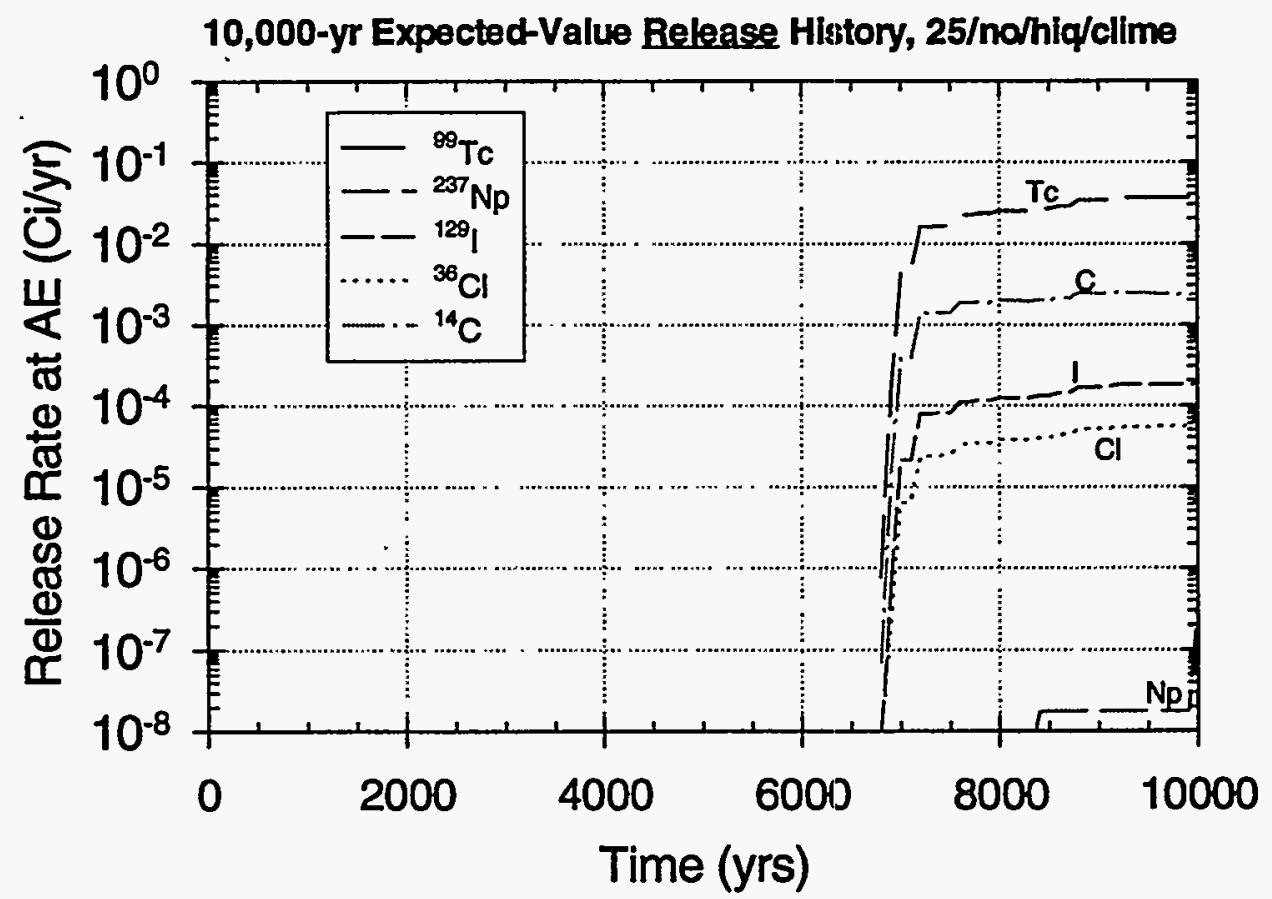

Figure 9.2-2 Expected-value release-rate history: 10,000 years, 25 MTU/acre, no backfill, high infiltration $\left(\mathrm{q}_{\text {inf }}=1.25 \mathrm{~mm} / \mathrm{yr}\right)$. 


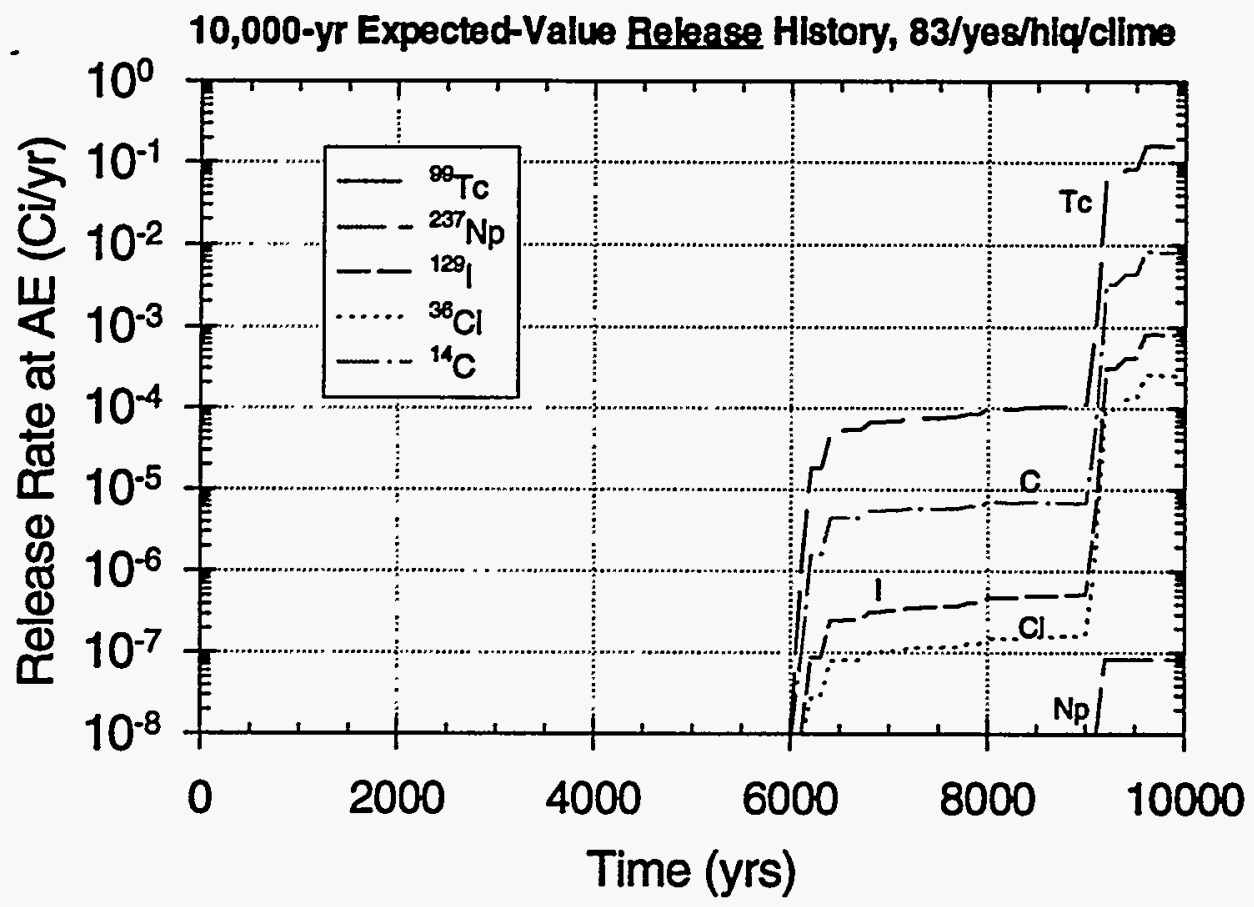

Figure 9.2-3 Expected-value release-rate history: 10,000 years, 83 MTU/acre, backfill ("yes"), high infiltration $\left(\mathrm{q}_{\text {inf }}=1.25 \mathrm{~mm} / \mathrm{yr}\right)$.

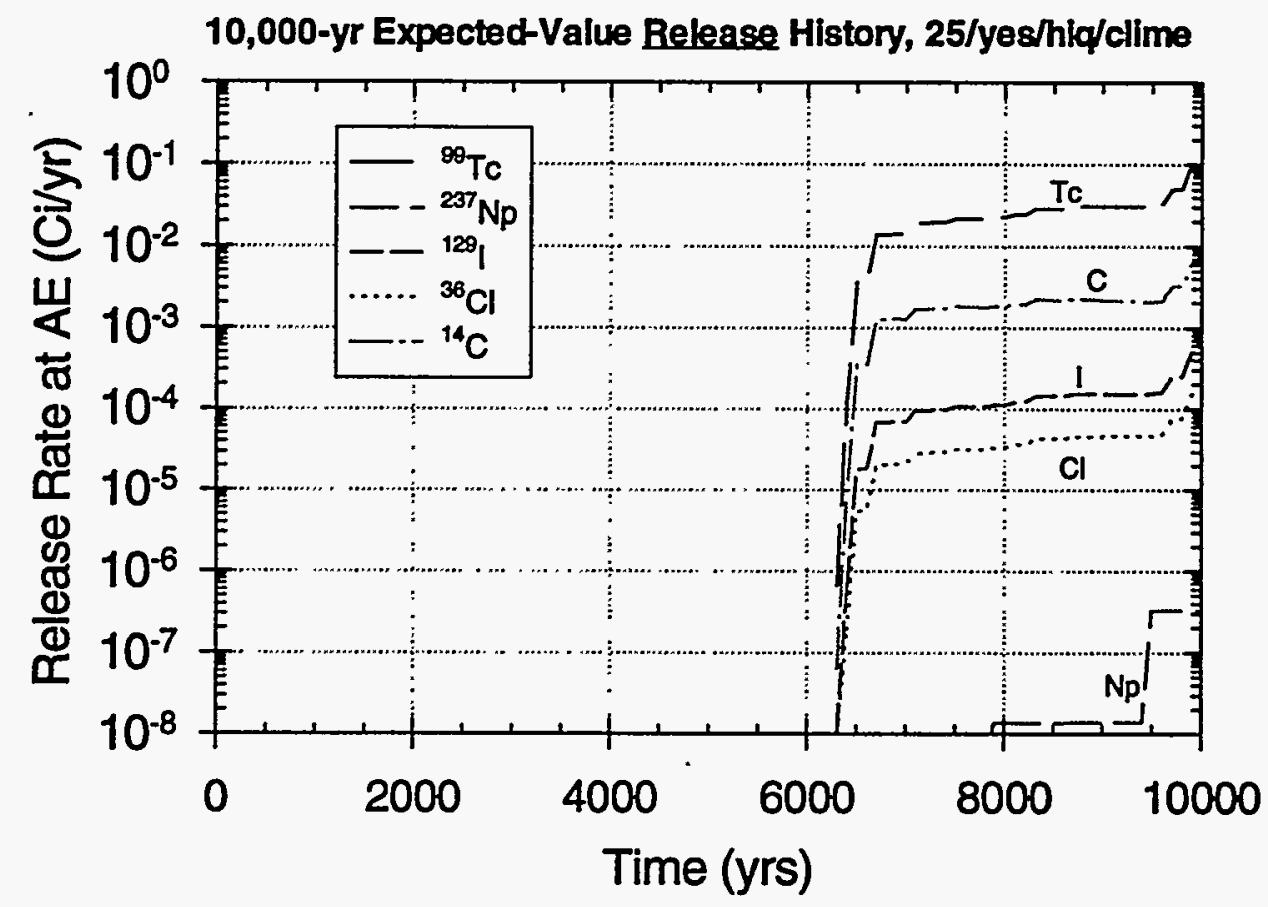

Figure 9:2-4 Expected-value release-rate history: 10,000 years, 25 MTU/acre, backfill ("yes"), high infiltration $\left(\mathrm{q}_{\text {inf }}=1.25 \mathrm{~mm} / \mathrm{yr}\right)$. 


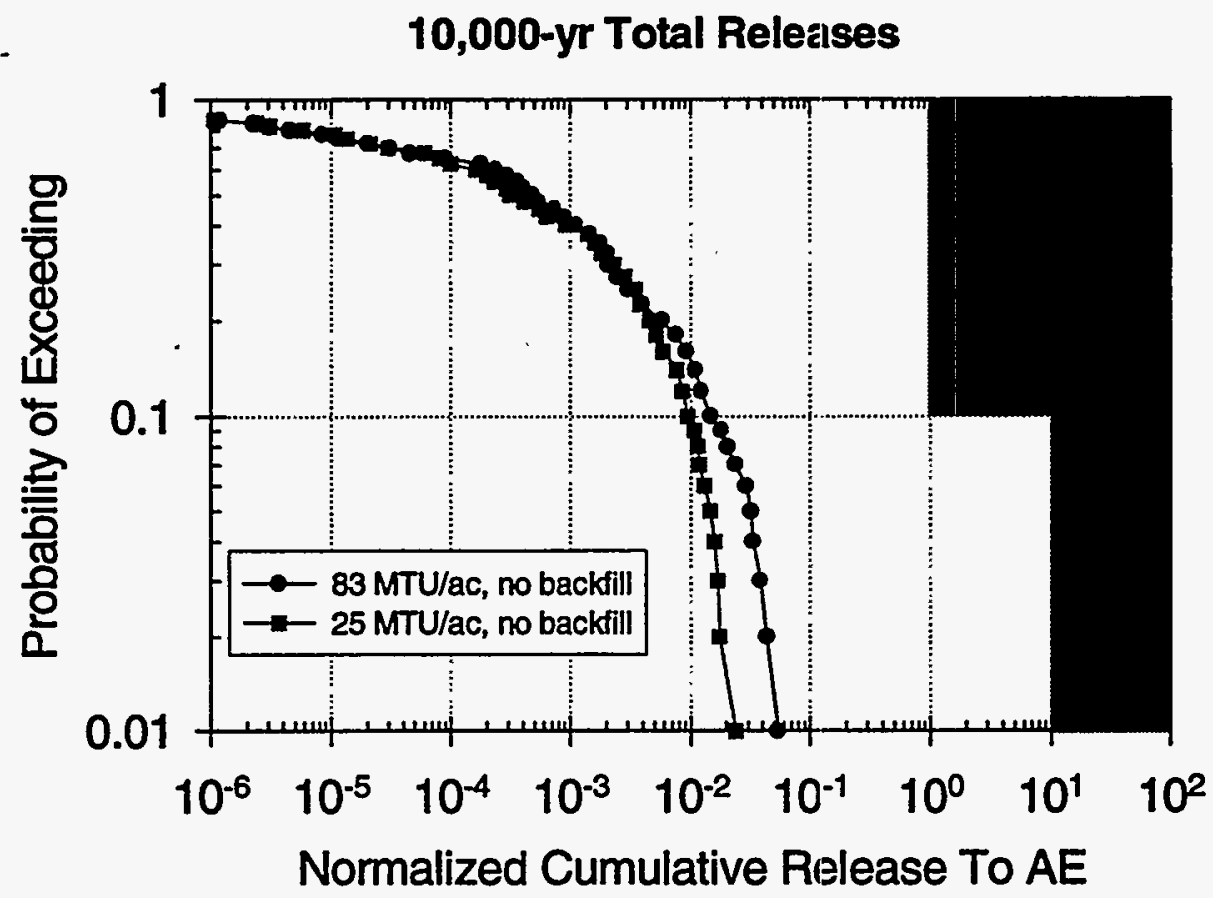

Figure 9.2-5 CCDF of Total Normalized Cumulative Release: 10,000 years, 83 MTU/acre and $25 \mathrm{MTU} / \mathrm{acre}$, no backfill, high infiltration range.

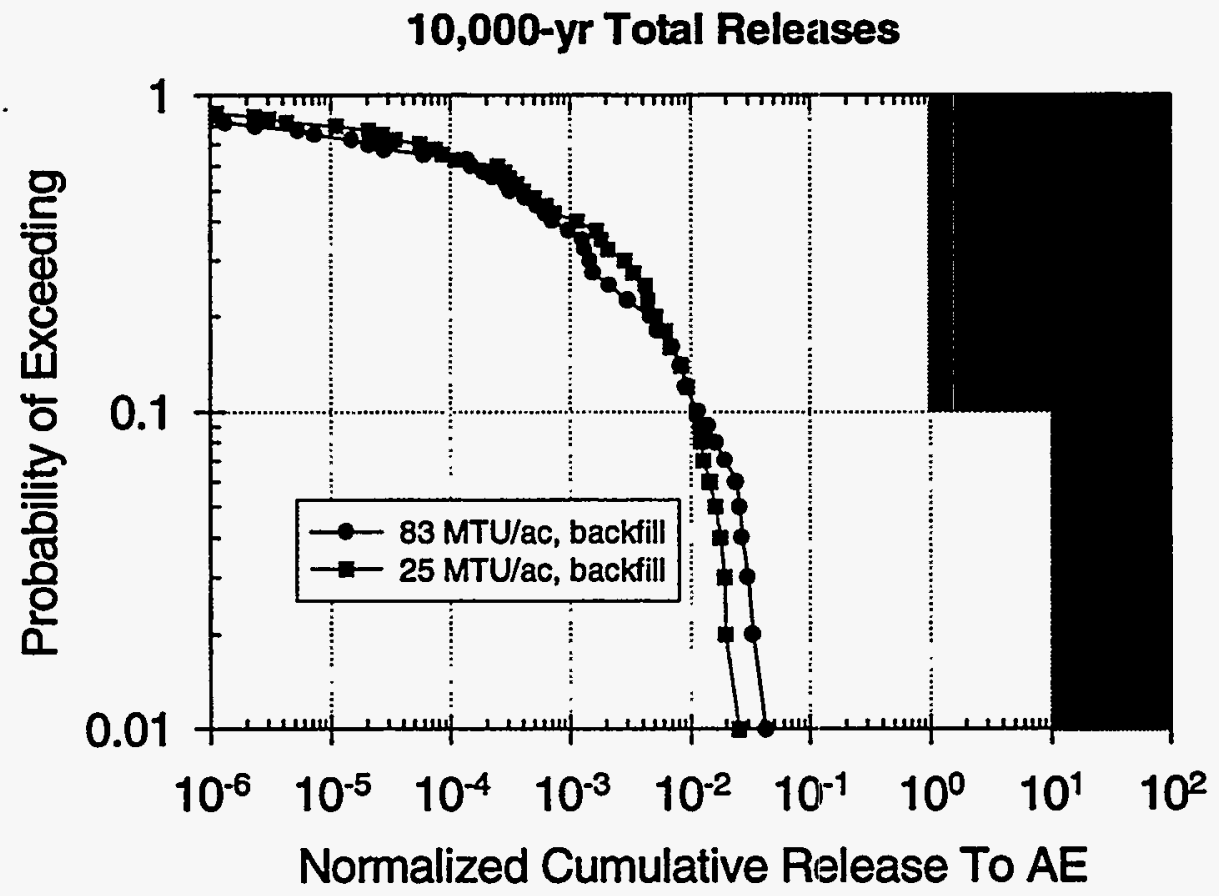

Figure 9.2-6 CCDF of Total Normalized Cumulative Release: 10,000 years, 83 MTU/acre and 25 MTU/acre, backfill, high infiltration range. 


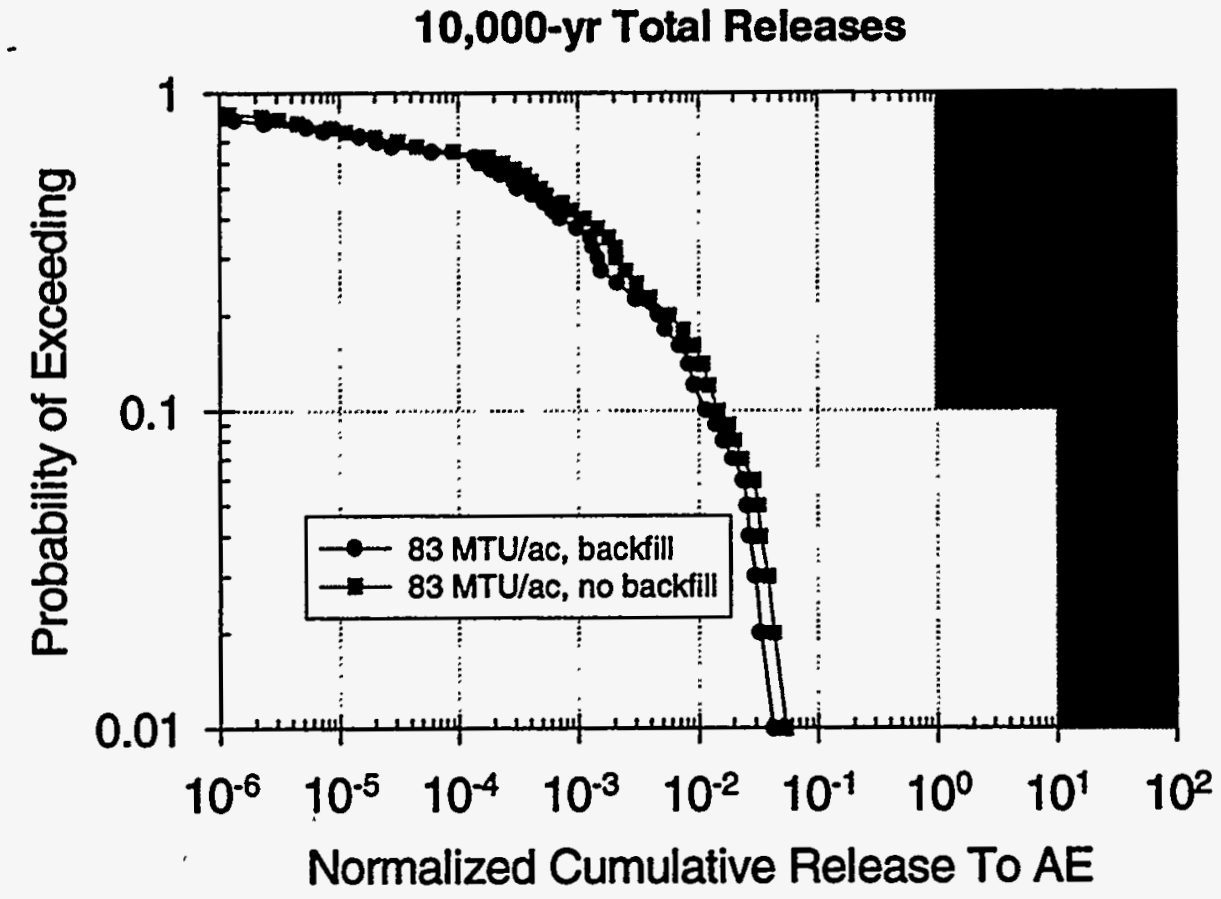

Figure 9.2-7 CCDF of Total Normalized Cumulative Release: 10,000 years, 83 MTU/acre, with and without backfill, high infiltration range.

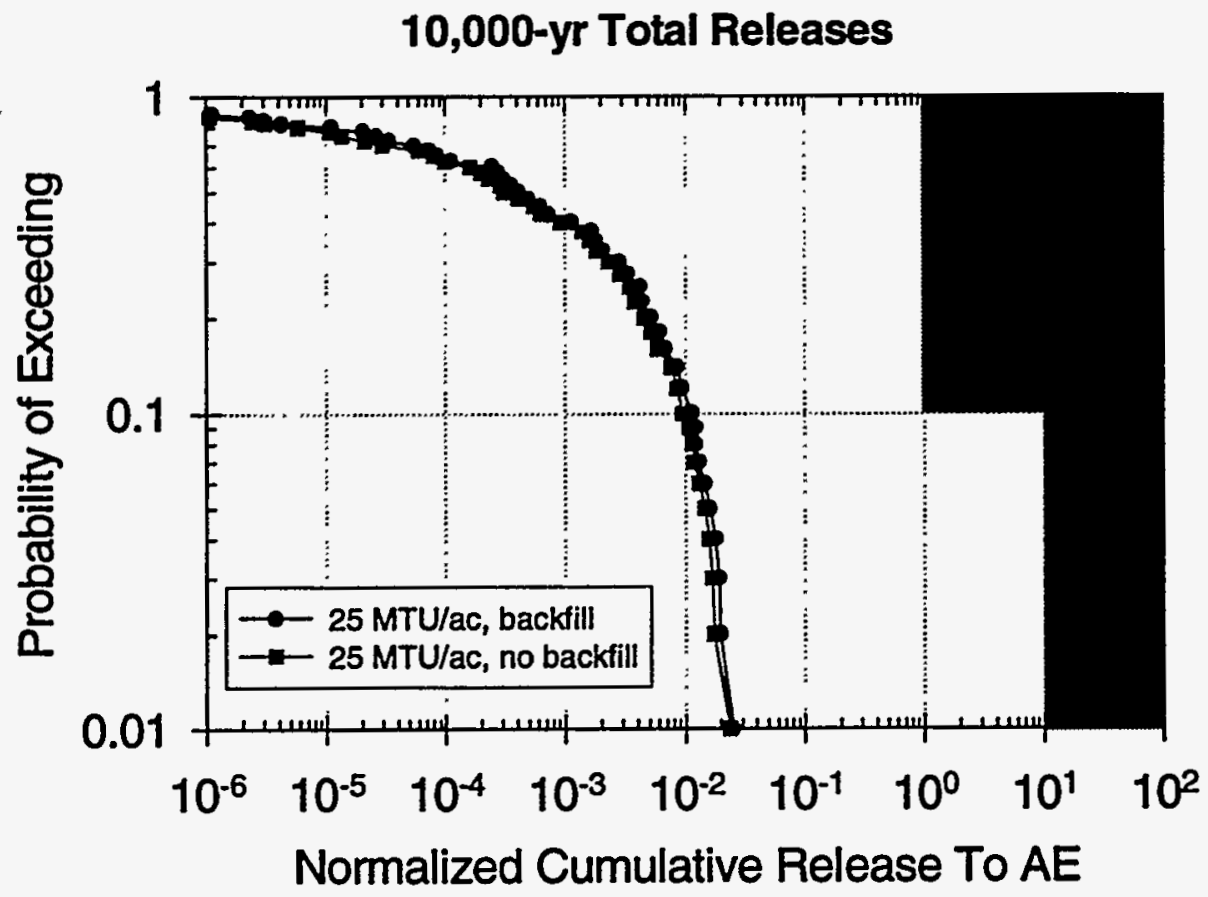

Figure 9.2-8 CCDF of Total Normalized Cumulative Release: 10,000 years, 25 MTU/acre, with and without backfill, high infiltration range. 


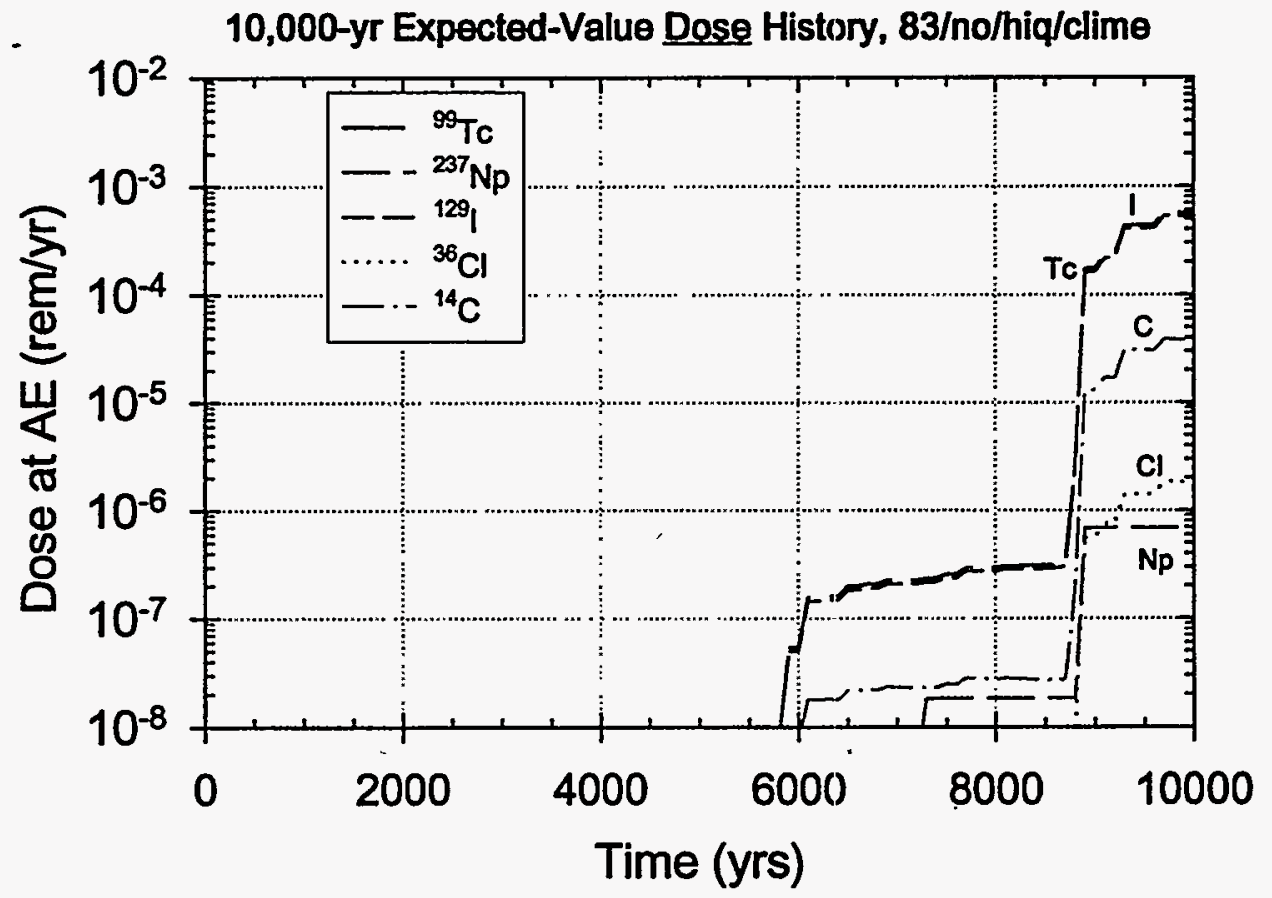

Figure 9.2-9 Expected-value dose history: 10,000 years, 83 MTU/acre, no backfill, high infiltration $\left(\mathrm{q}_{\mathrm{inf}}=1.25 \mathrm{~mm} / \mathrm{yr}\right)$.

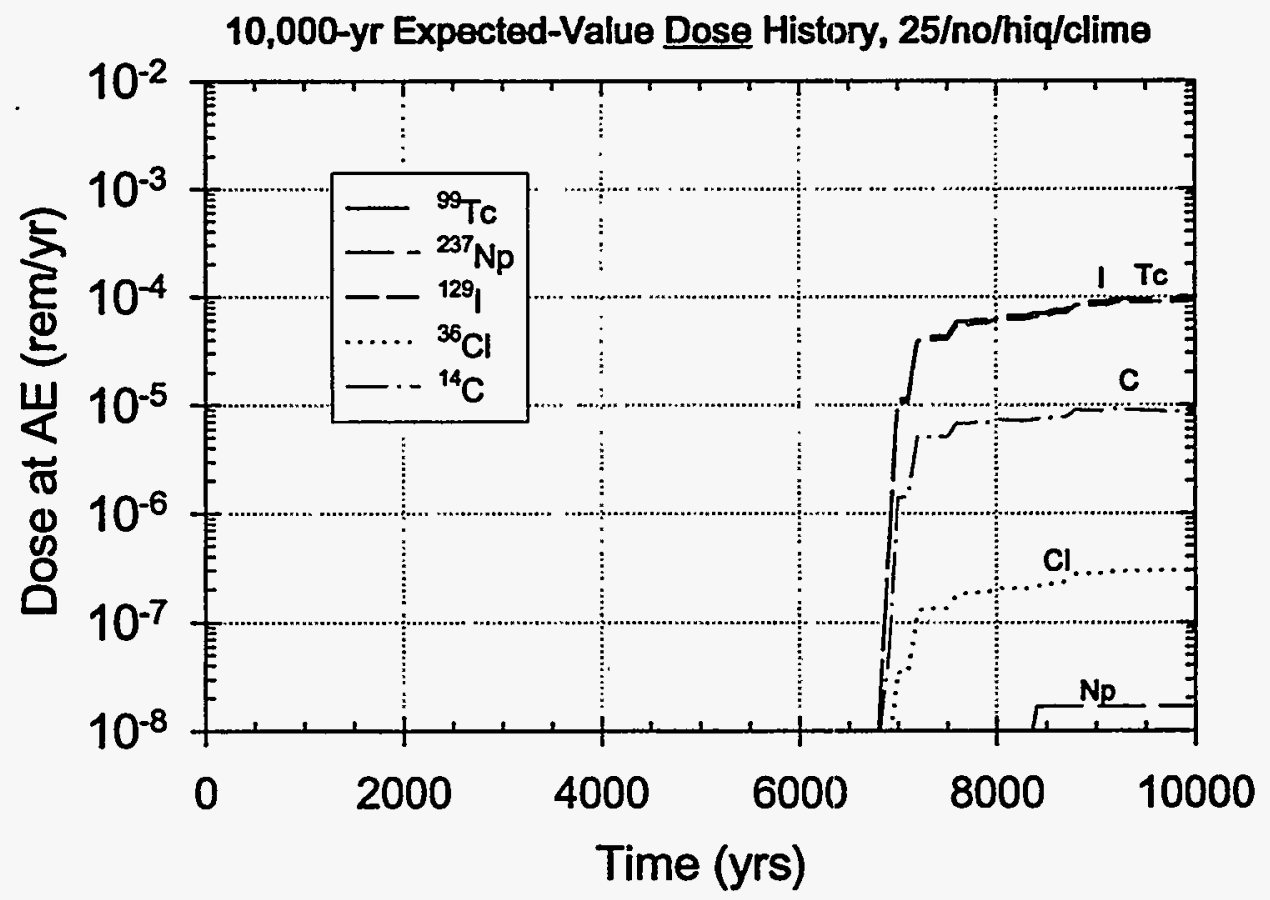

Figure 9.2-10 Expected-value dose history: 10,000 years, 25 MTU/acre, no backfill, high infiltration $\left(\mathrm{q}_{\mathrm{inf}}=1.25 \mathrm{~mm} / \mathrm{yr}\right)$. 


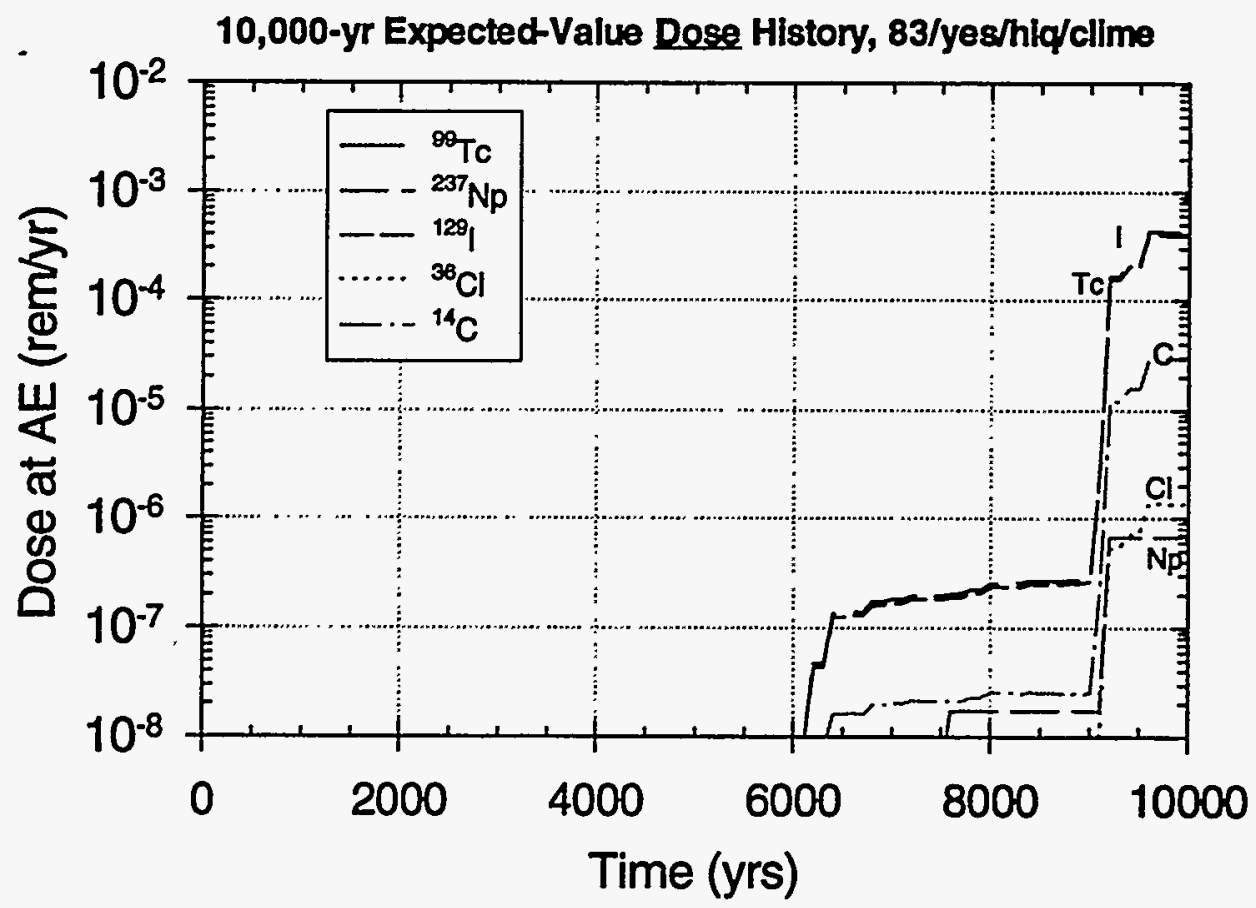

Figure 9.2-11 Expected-value dose history: 10,000 years, 83 MTU/acre, backfill ("yes"), high infiltration $\left(\mathrm{q}_{\mathrm{inf}}=1.25 \mathrm{~mm} / \mathrm{yr}\right)$.

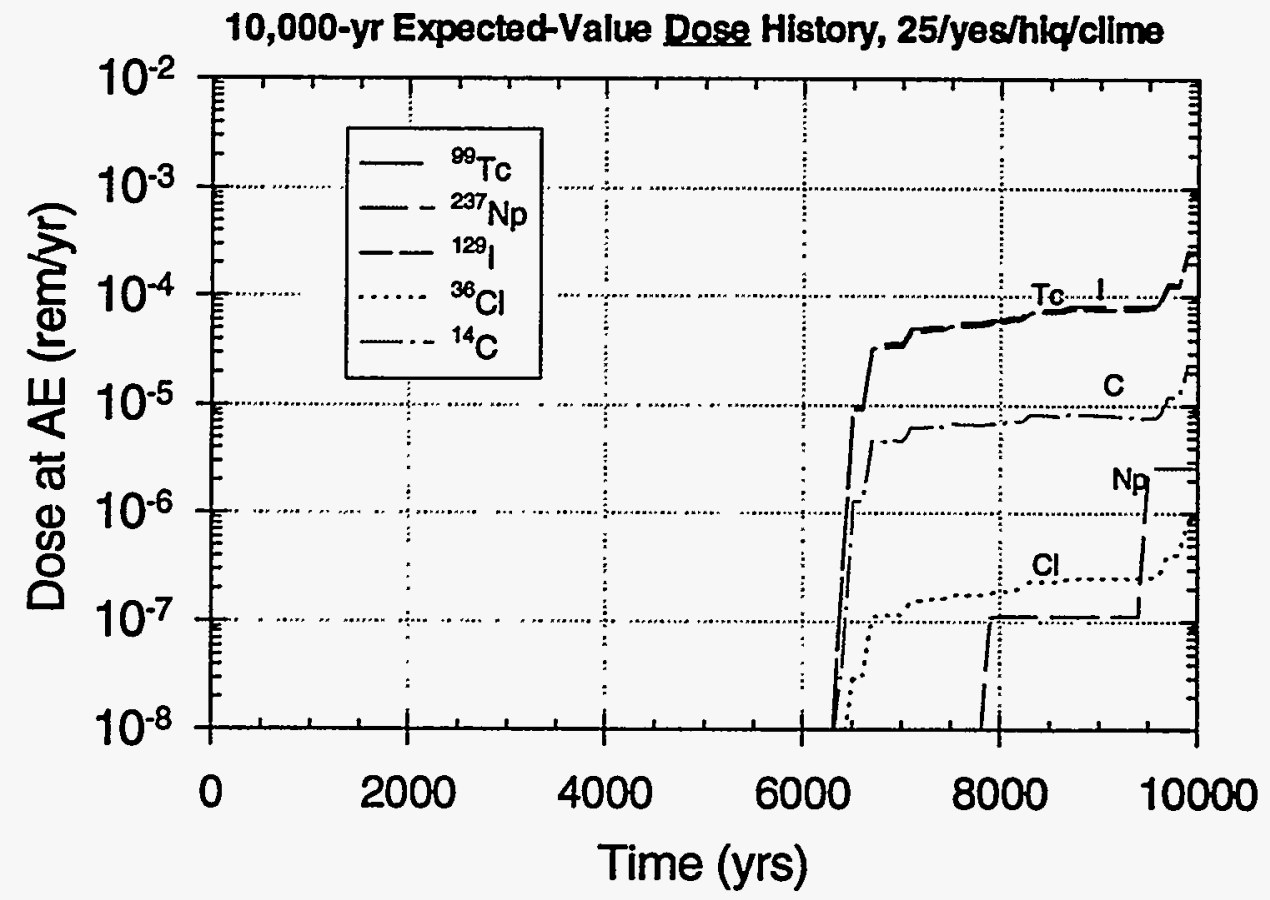

Figure 9.2-12 Expected-value dose history: 10,000 years, 25 MTU/acre, backfill ("yes"), high infiltration $\left(\mathrm{q}_{\mathrm{inf}}=1.25 \mathrm{~mm} / \mathrm{yr}\right)$. 


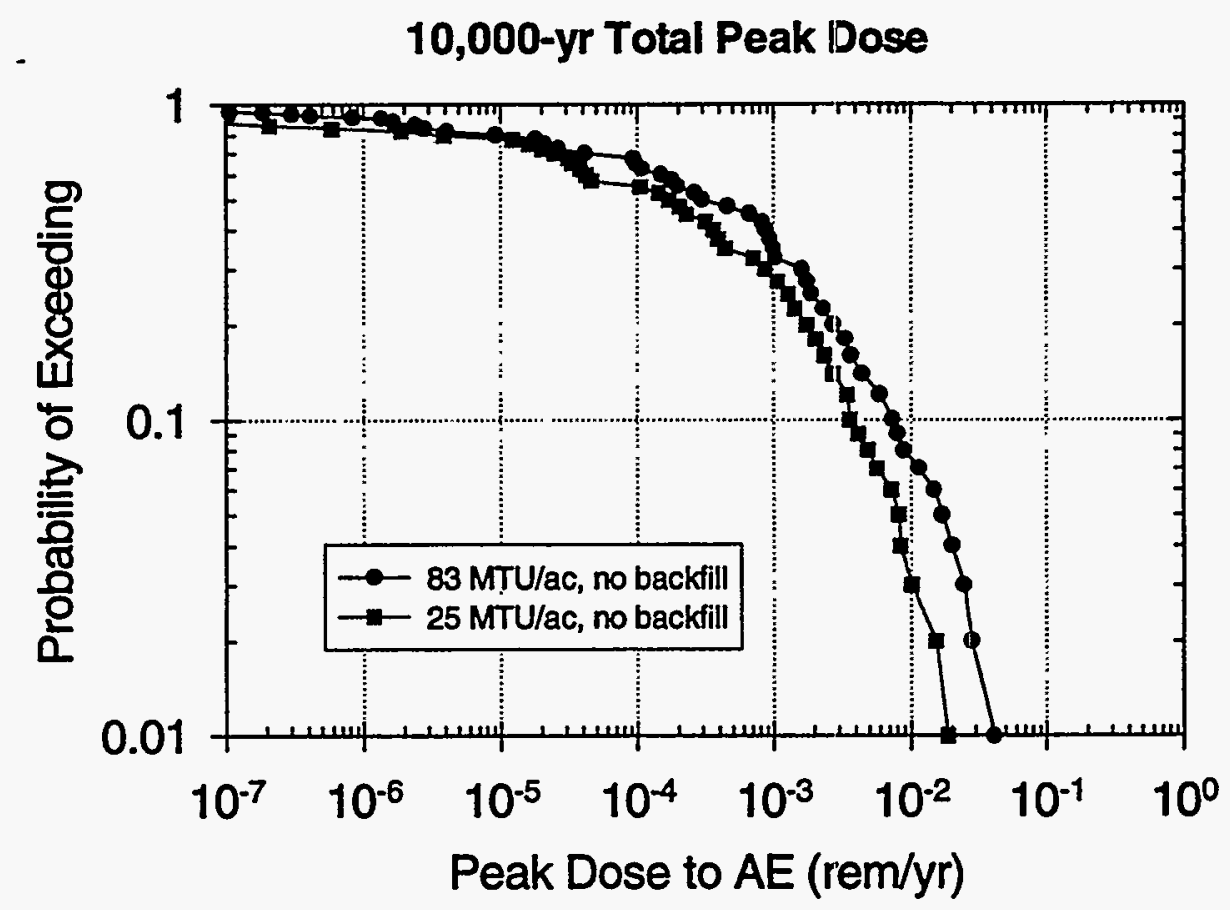

Figure 9.2-13 CCDF of Total Peak Dose: 10,000 years, 83 MTU/acre and 25 MTU/acre, no backfill, high infiltration range.

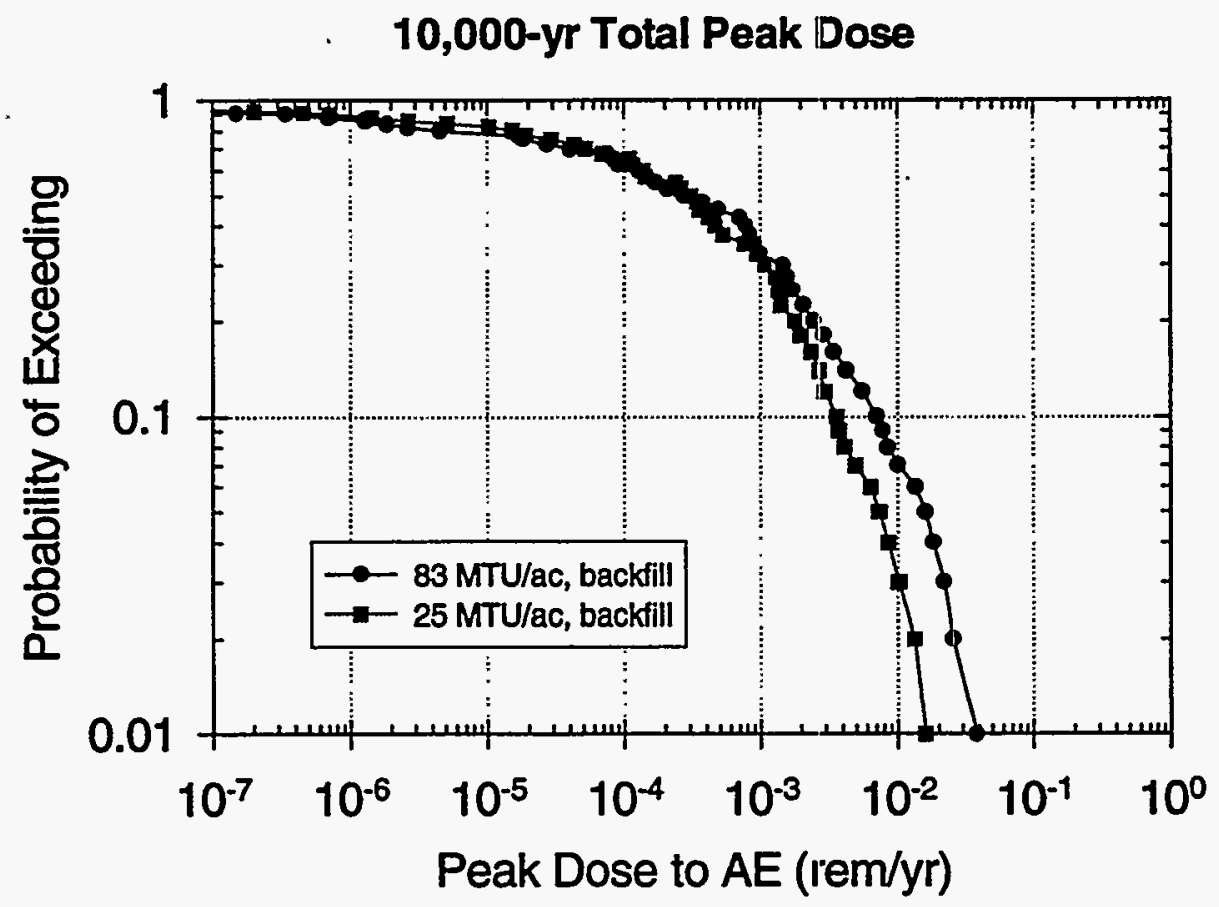

Figure 9.2-14 CCDF of Total Peak Dose: 10,000 years, 83 MTU/acre and 25 MTU/acre, backfill, high infiltration range. 


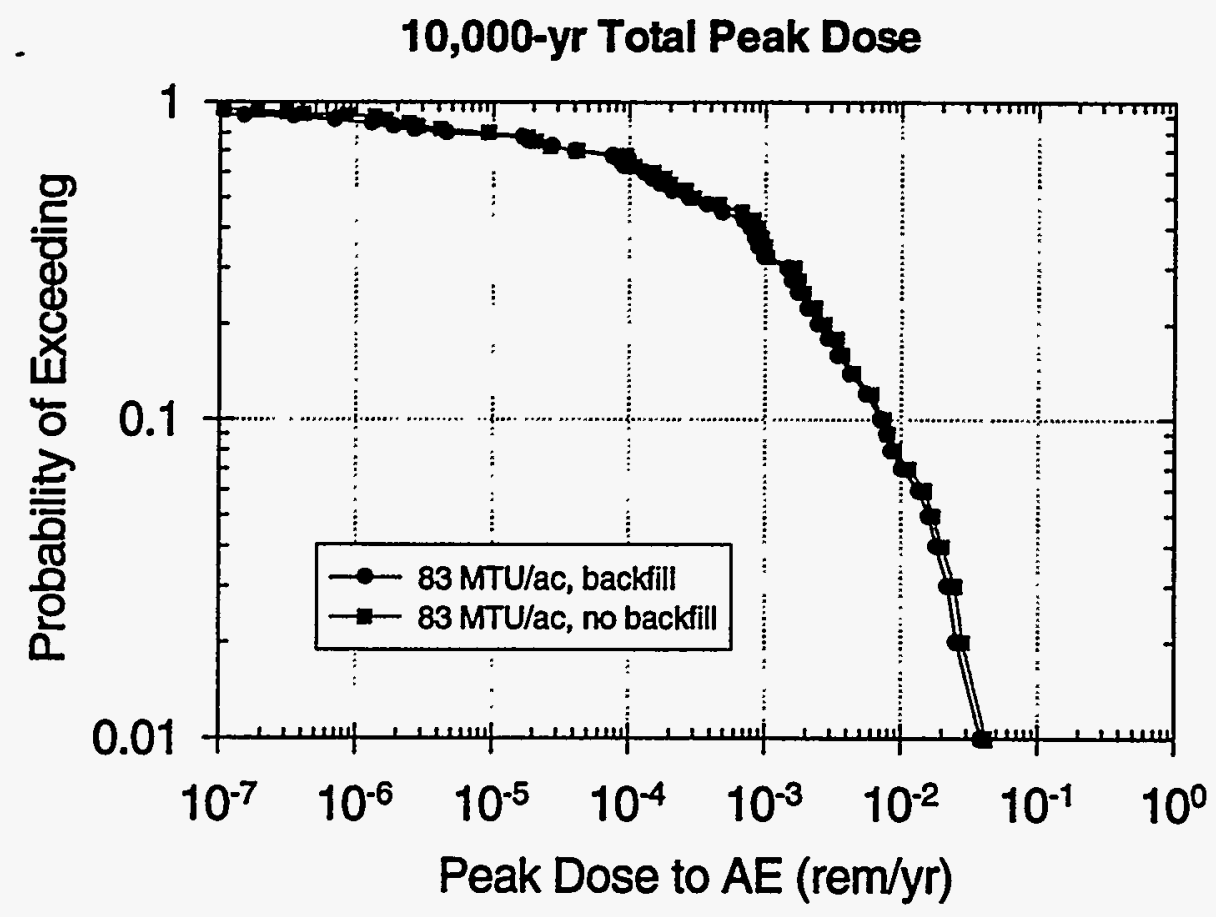

Figure 9.2-15 CCDF of Total Peak Dose: 10,000 years, 83 MTU/acre, with and without backfill, high infiltration range.

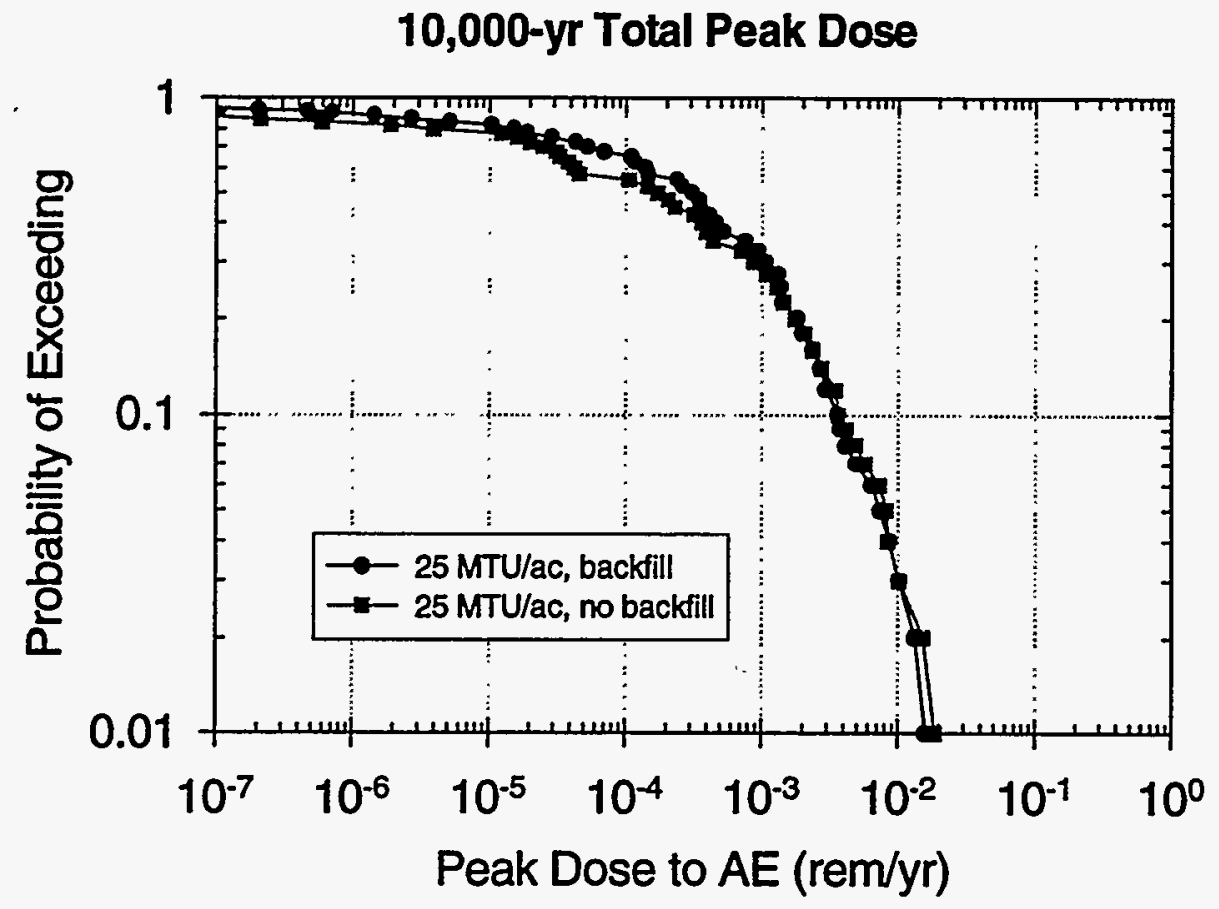

Figure 9.2-16 CCDF of Total Peak Dose: 10,000 years, 25 MTU/acre, with and without backfill, high infiltration range.

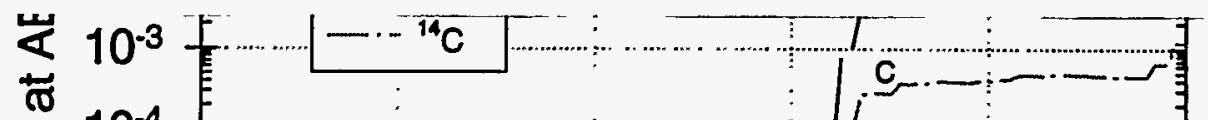




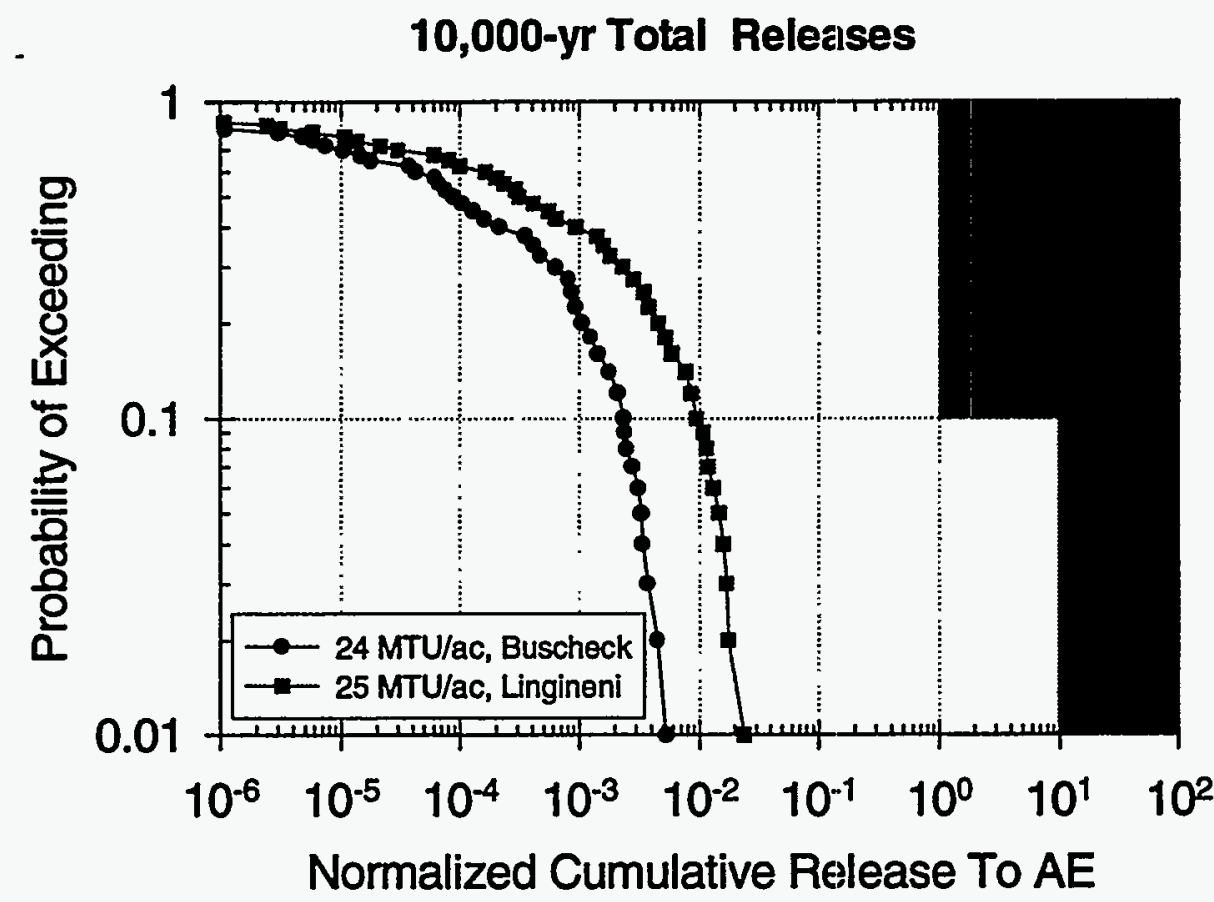

Figure 9.2-17 CCDF of Total Normalized Cumulative Release: 10,000 years, Buscheck 24 MTU/acre and Lingineni 25 MTU/acre, no backfill, high infiltration range.

10,000-yr Total Peak Dose

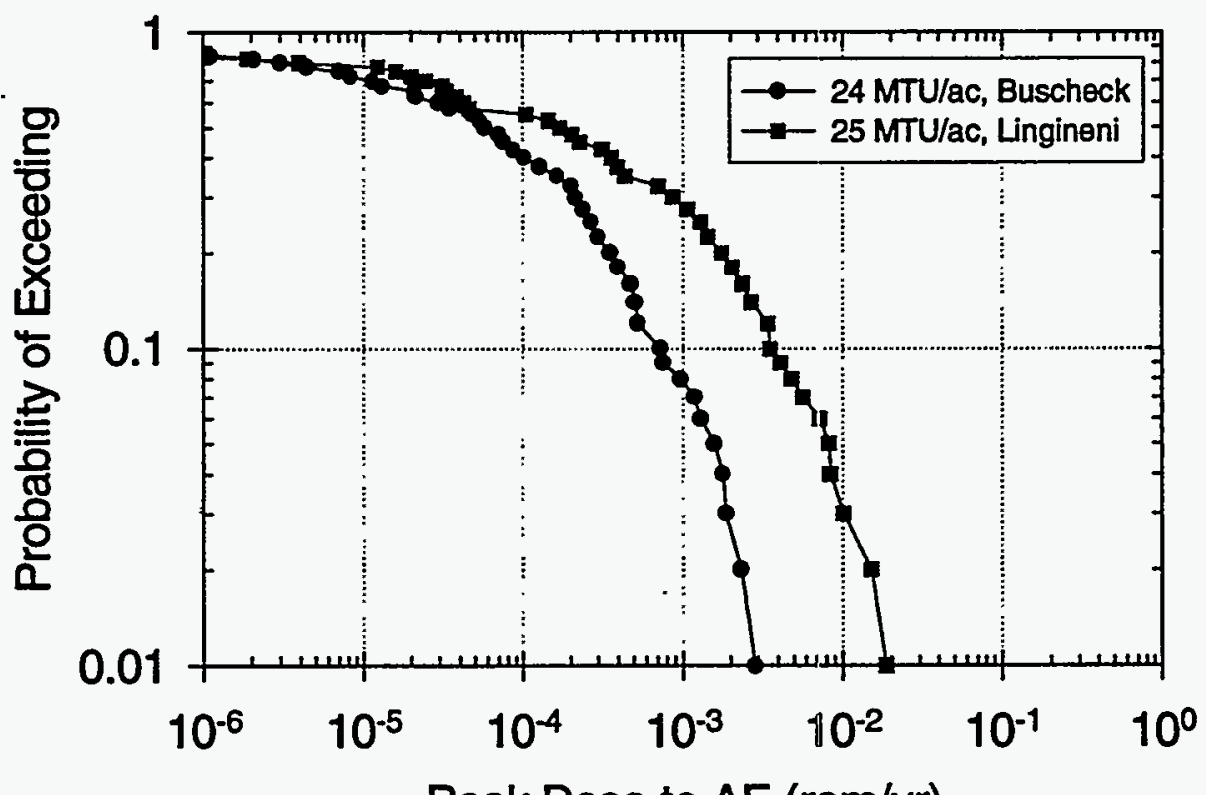

10,000-yr Total Peak Dose

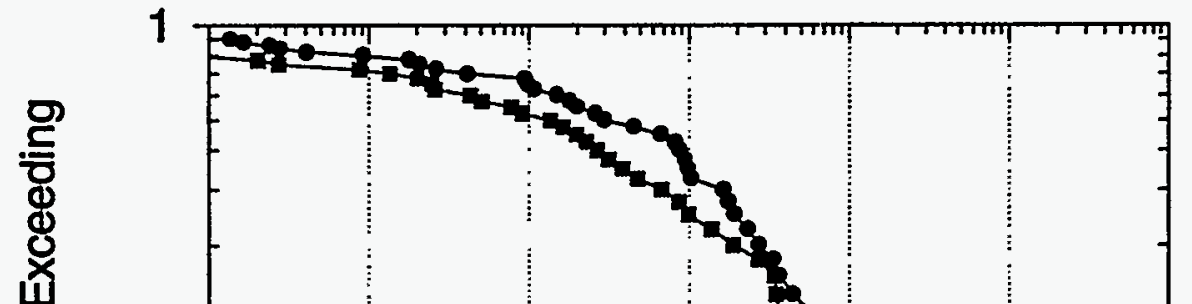




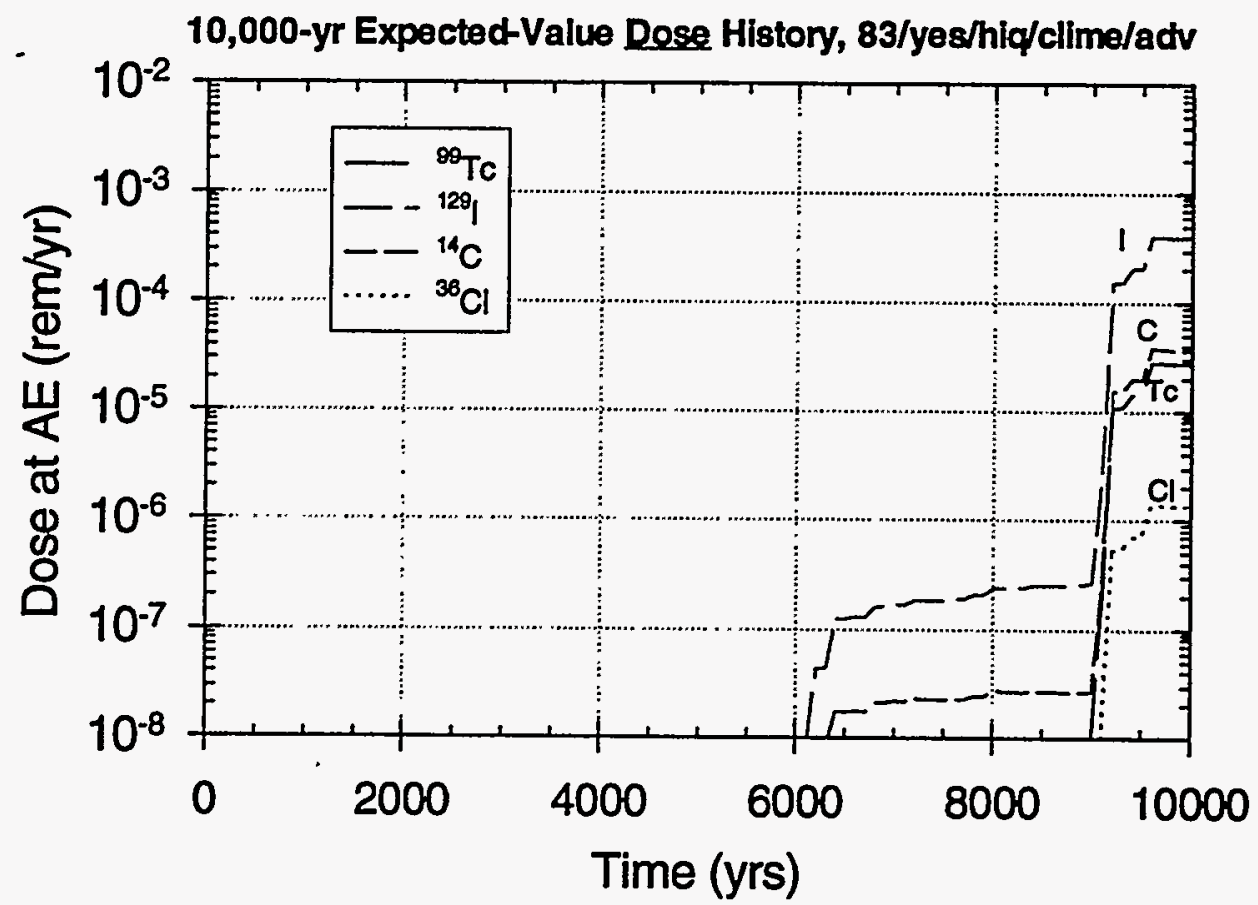

Figure 9.2-23 Expected-value dose history: 10,000 years, "drips-on-waste-container" EBS transport model, $83 \mathrm{MTU} / \mathrm{acre}$, backfill, high infiltration $\left(\mathrm{q}_{\mathrm{inf}}=1.25 \mathrm{~mm} / \mathrm{yr}\right)$.

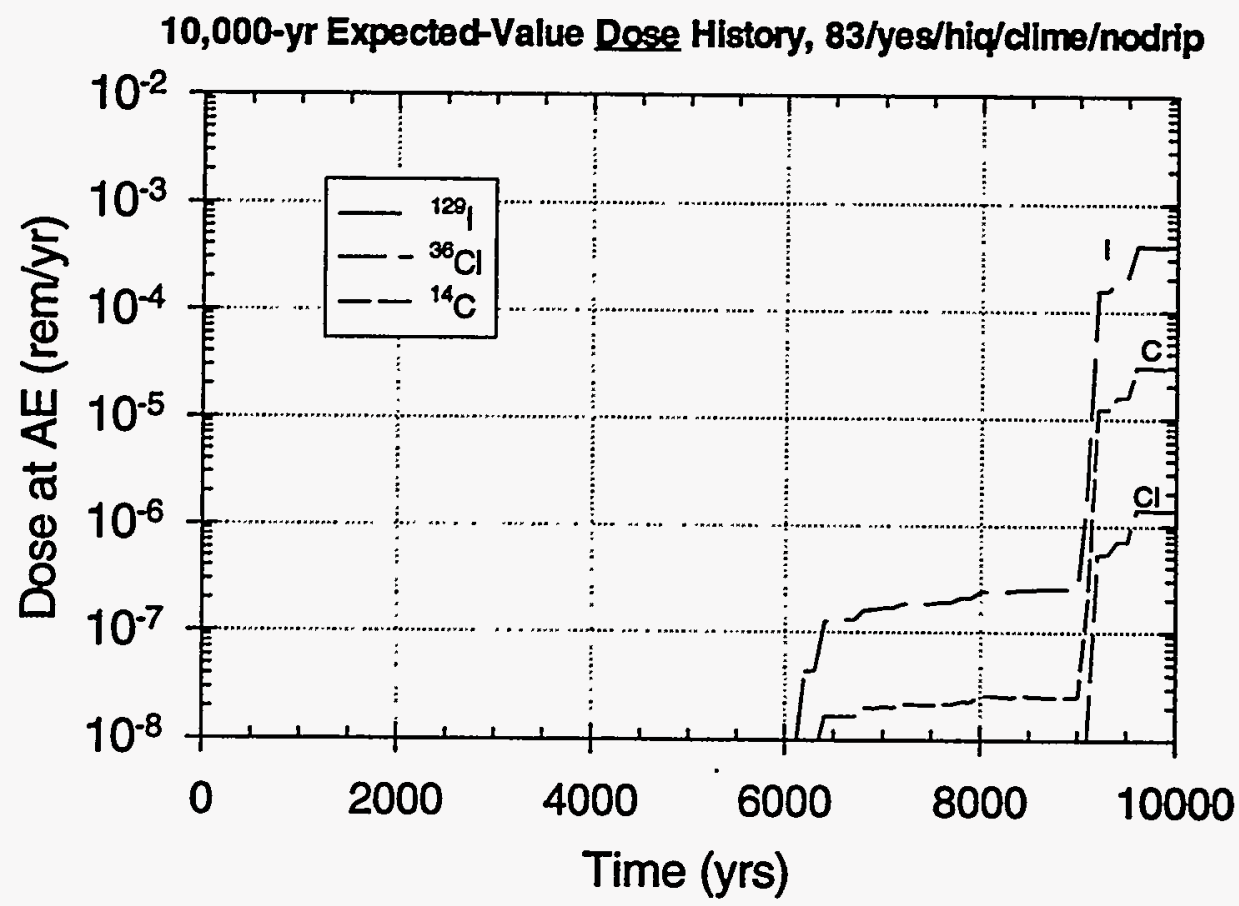

Figure 9.2-24 Expected-value dose history: 10,000 years, capillary-barrier-effect ("no drips") EBS transport model, $83 \mathrm{MTU} / \mathrm{acre}$, backfill, high infiltration $\left(\mathrm{q}_{\text {inf }}=1.25\right.$ $\mathrm{mm} / \mathrm{yr})$. 


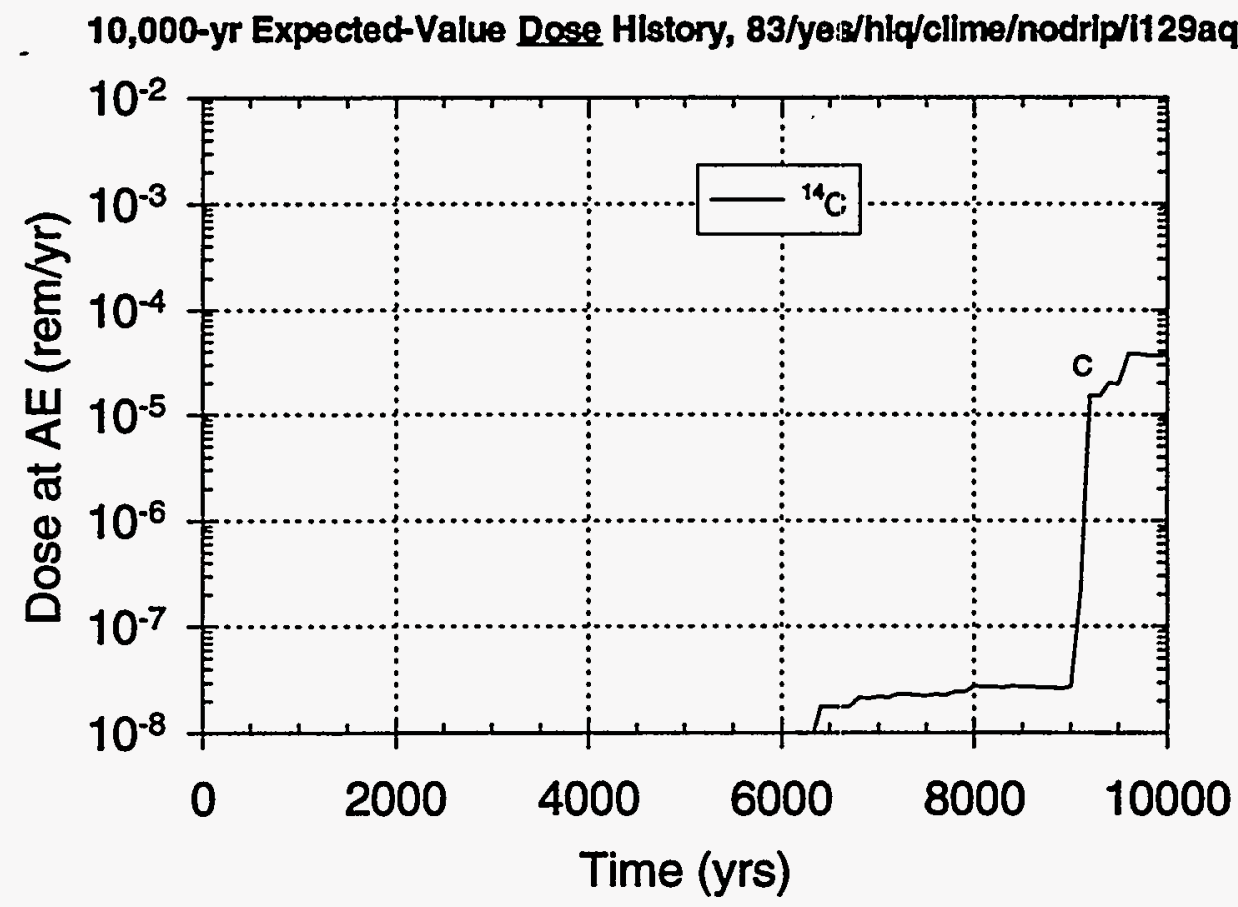

Figure 9.2-25 Expected-value dose history: 10,000 years, capillary-barrier-effect ("no drips") EBS transport model with ${ }^{129} \mathrm{I}$ and ${ }^{36} \mathrm{Cl}$ transported through EBS in the aqueous phase, $83 \mathrm{MTU} / \mathrm{acre}$, backfill, high infiltration $\left(\mathrm{q}_{\text {inf }}=1.25 \mathrm{~mm} / \mathrm{yr}\right)$.

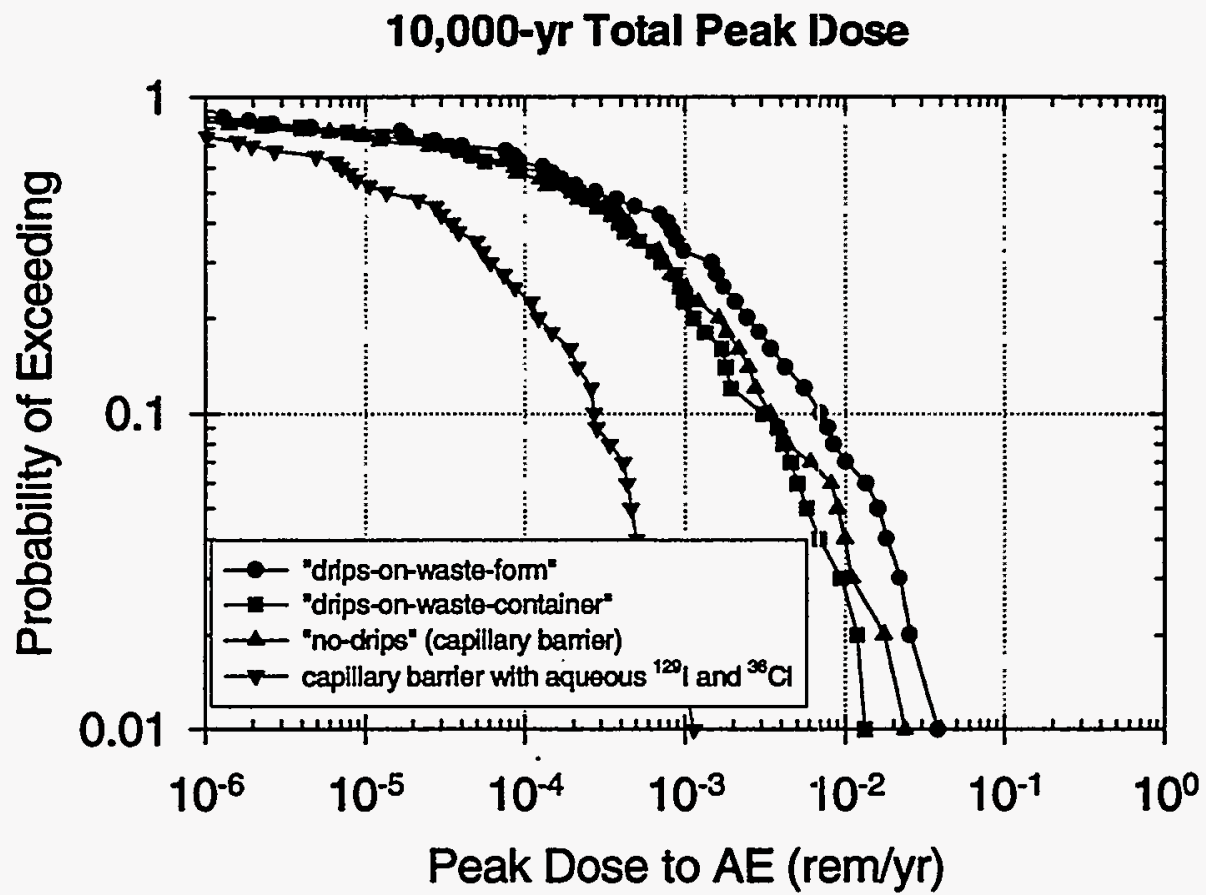

Figure 9.2-26 Comparison of EBS transport models. CCDF of Total Peak Dose: 10,000 years, 83 MTU/acre, backfill, high infiltration range. 


\section{0,000-yr Total Releases}

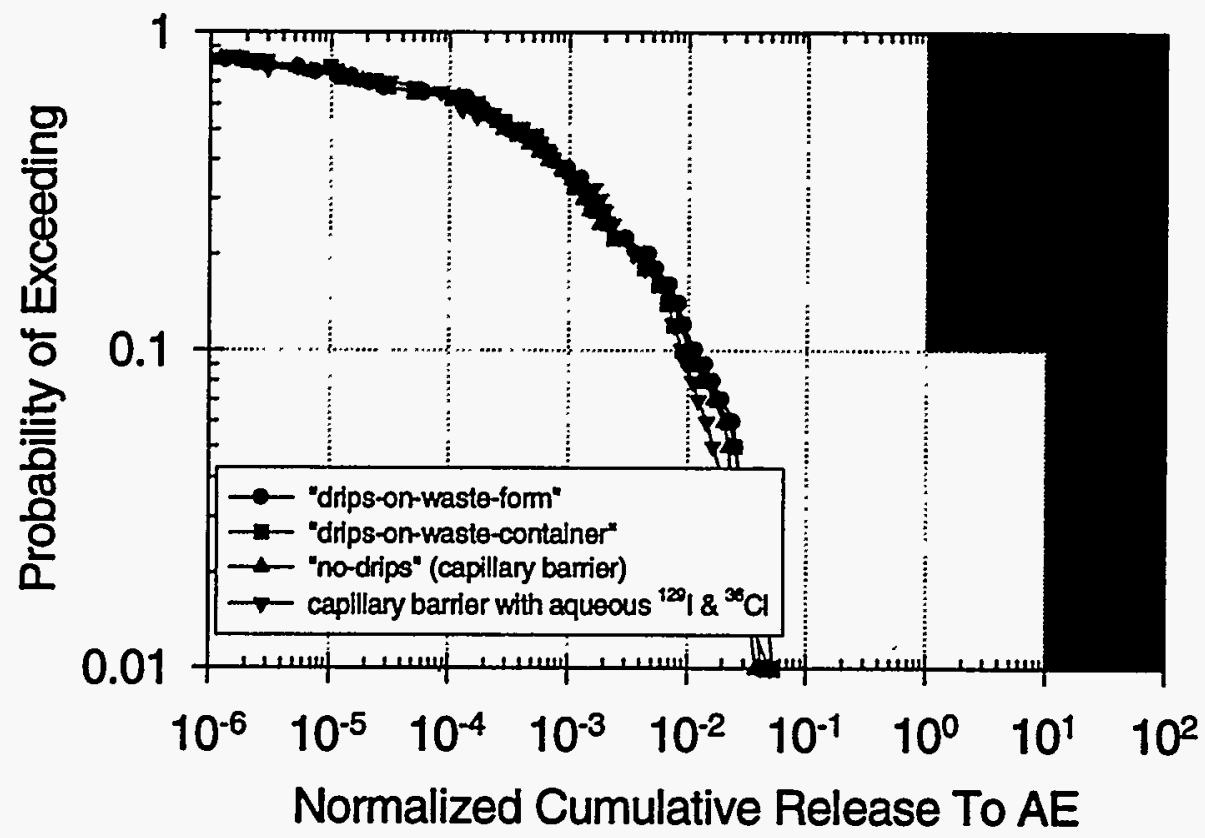

Figure 9.2-27 Comparison of EBS transport models. CCDF of Total Normalized Cumulative Release: 10,000 years, 83 MTU/acre, backfill, high infiltration range.

10,000-yr Total Peak Dose

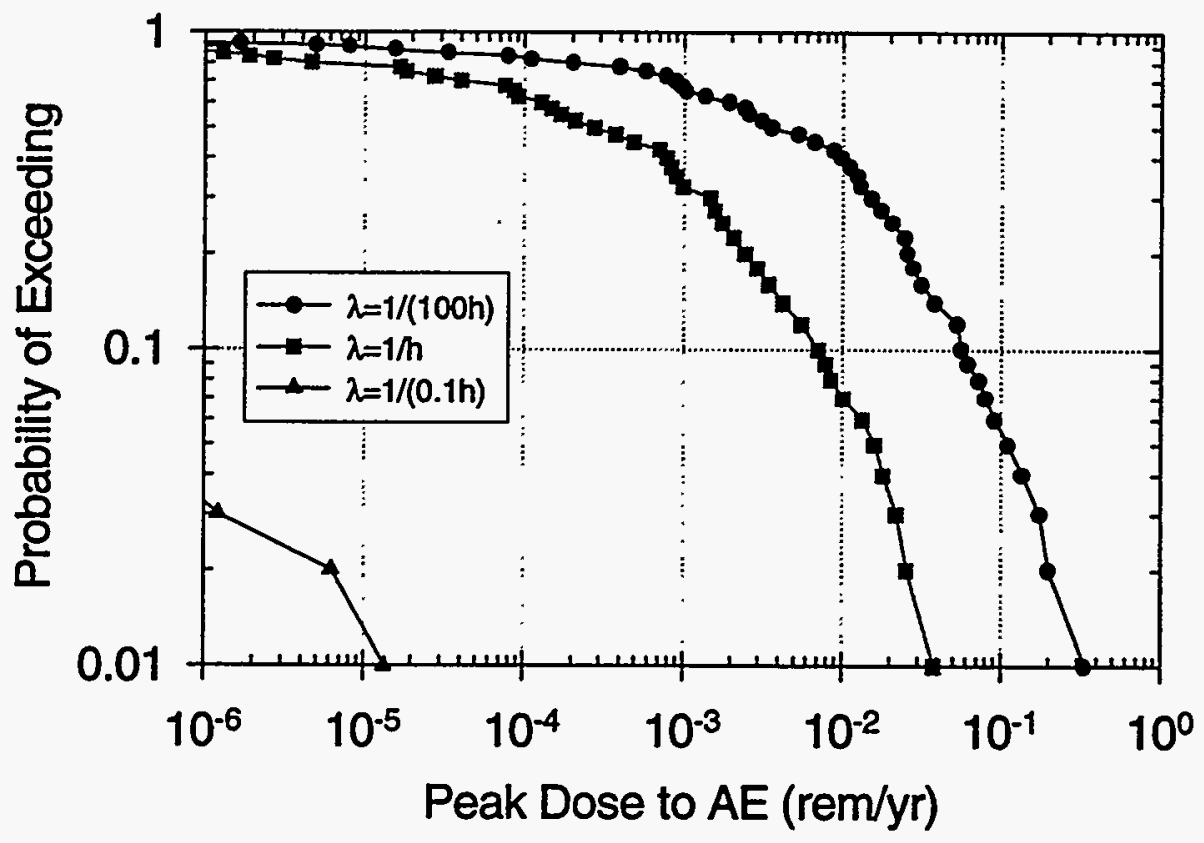

Figure 9.2-28 Comparison of intra-unit fracture connectivity parameter: $\lambda=1 /(0.1 \mathrm{~h})$ vs. $\lambda=1 / \mathrm{h}$ vs. $\lambda=1 /(100 \mathrm{~h})$, where $\mathrm{h}=$ pathway length in each unit. CCDF of Total Peak Dose: 10,000 years, 83 MTU/acre, backfill, high infiltration range. 


\section{0,000-yr Total Releases}

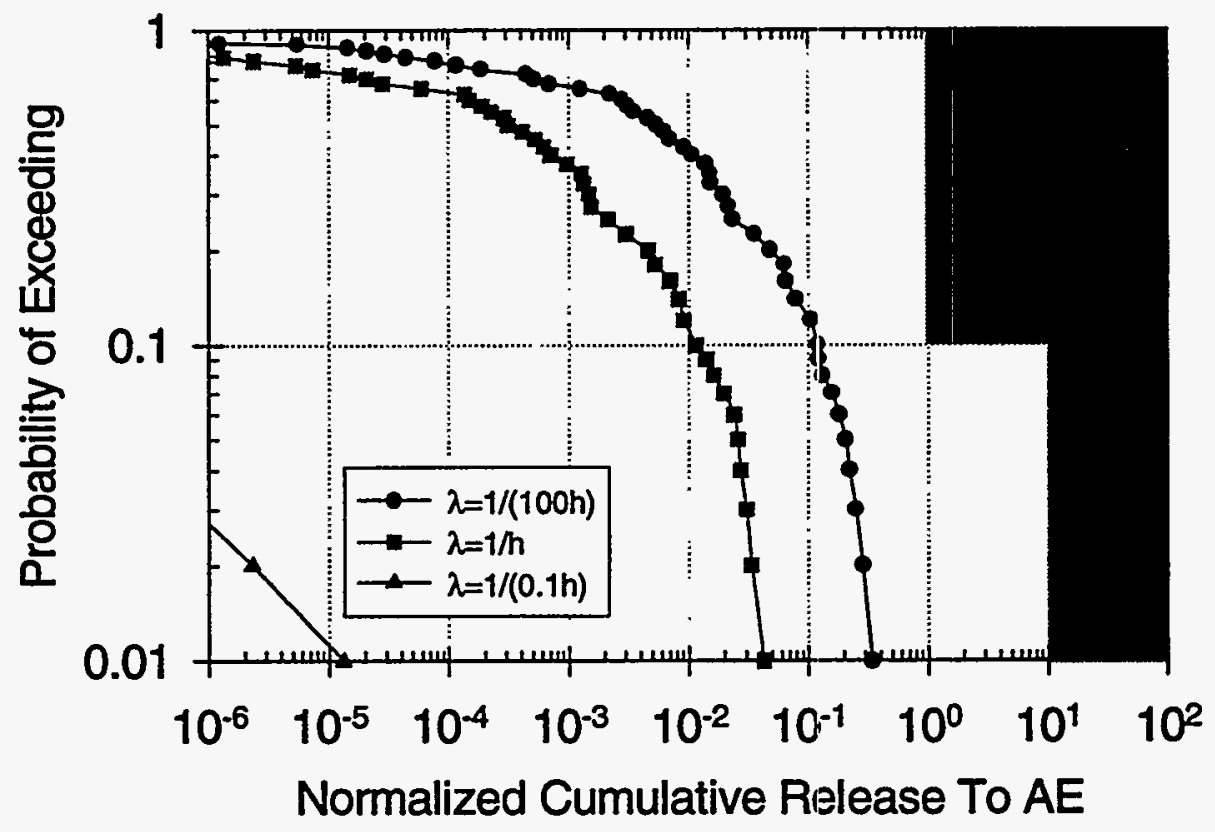

Figure 9.2-29 Comparison of intra-unit fracture connectivity parameter: $\lambda=1 /(0.1 \mathrm{~h})$ vs. $\lambda=1 / \mathrm{h}$ vs. $\lambda=1 /(100 \mathrm{~h})$, where $\mathrm{h}=$ pathway length in each unit. CCDF of Total Normalized Cumulative Release: 10,000 years, 83 MTU/acre, backfill, high infiltration range. 


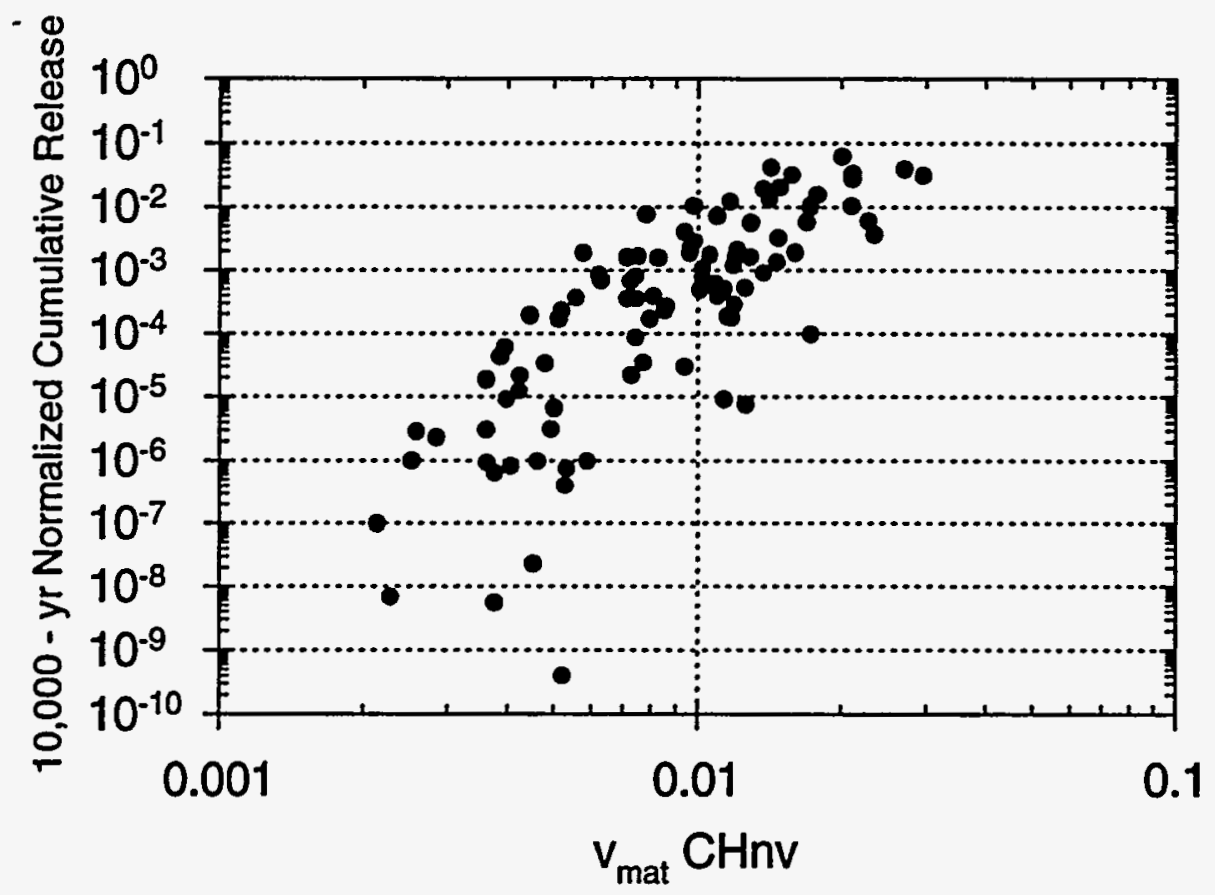

Figure 9.2-30 Scatter plot of 10,000-year total normalized cumulative release versus matrix velocity $(\mathrm{m} / \mathrm{yr})$ in the $\mathrm{CHnv}$ for $83 \mathrm{MTU} / \mathrm{acre}$, backfill, high infiltration $\left(\mathrm{q}_{\mathrm{inf}}=\right.$ $1.25 \mathrm{~mm} / \mathrm{yr})$.

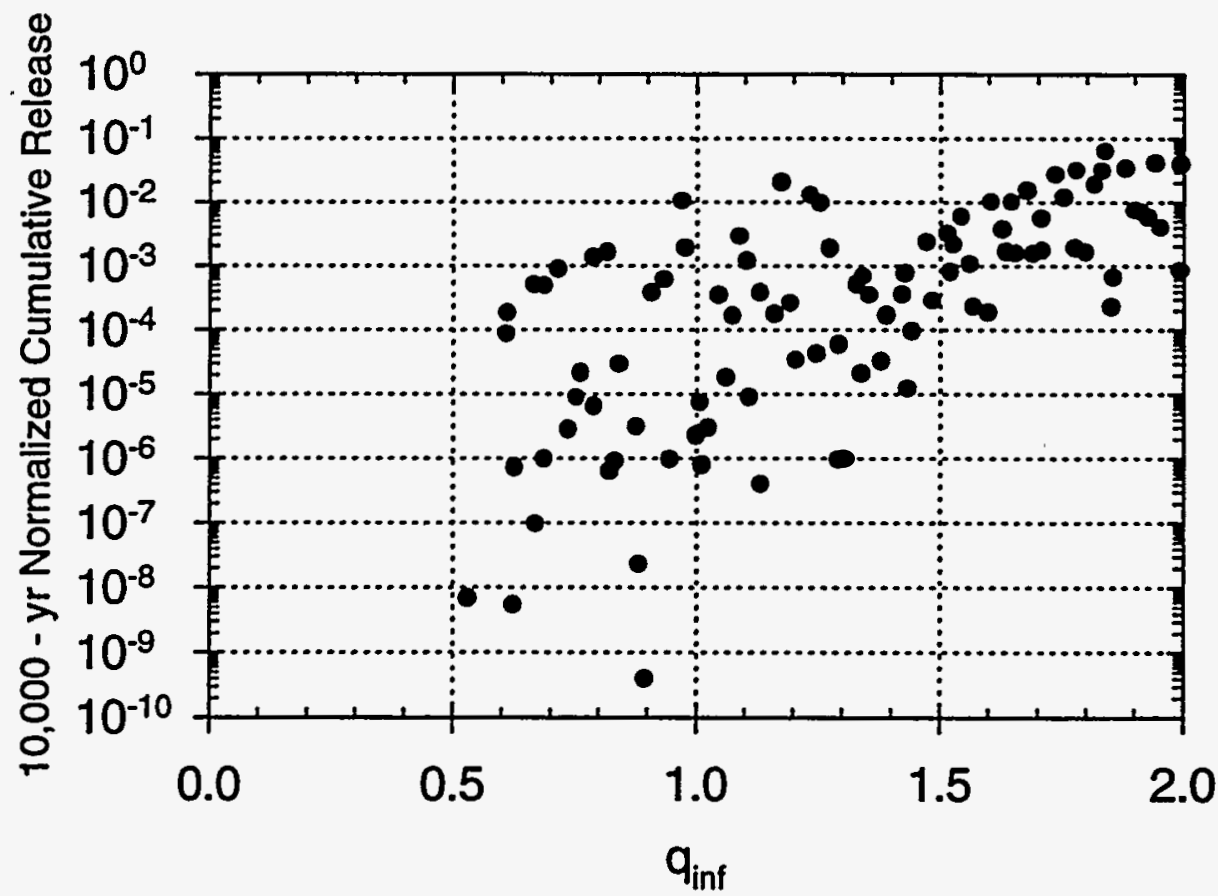

Figure 9.2-31 Scatter plot of 10,000-year total normalized cumulative release versus UZ percolation flux $(\mathrm{mm} / \mathrm{yr})$ for $83 \mathrm{MTU} / \mathrm{acre}$, backfill, high infiltration $\left(\mathrm{q}_{\mathrm{inf}}=1.25\right.$ $\mathrm{mm} / \mathrm{yr}$ ). 


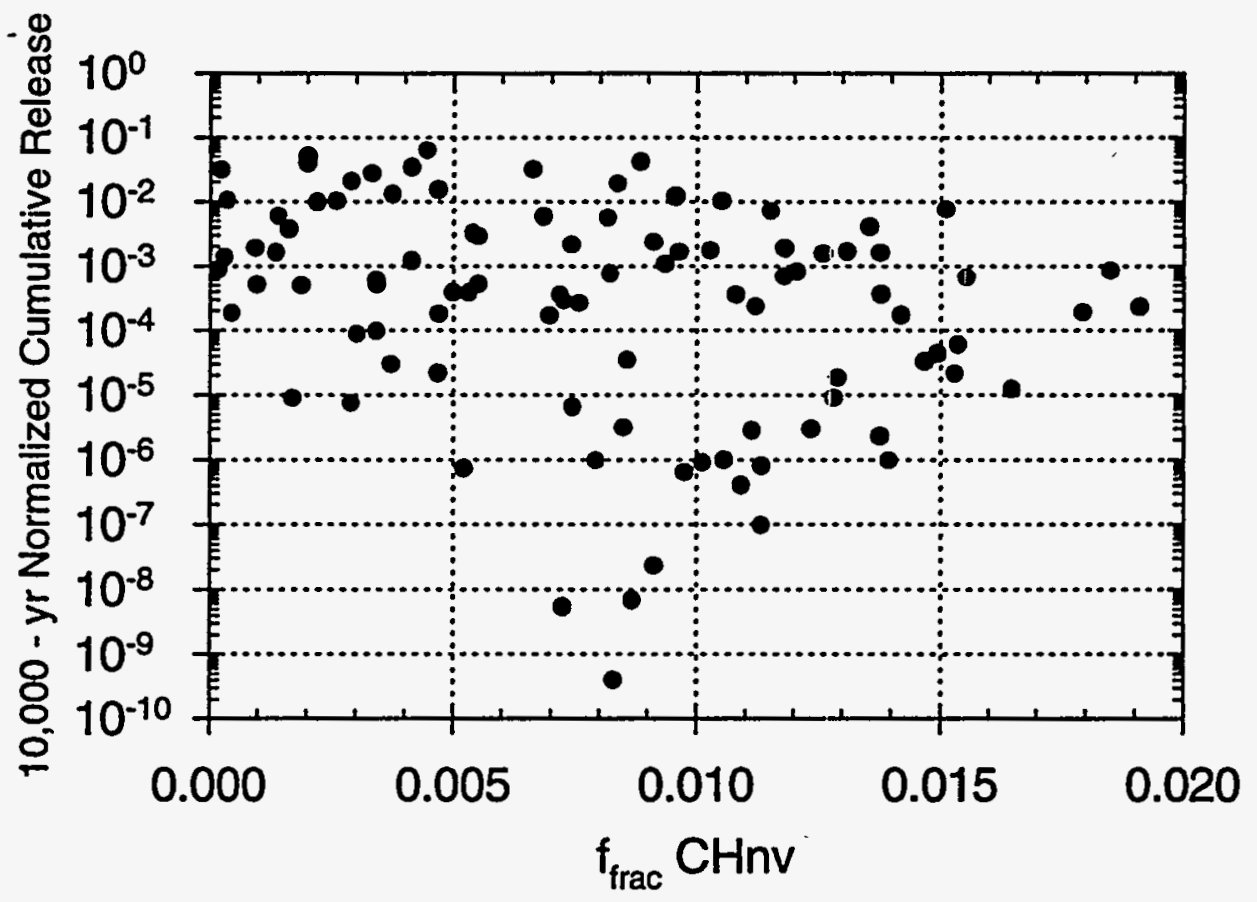

Figure 9.2-32 Scatter plot of 10,000-year total normalized cumulative release versus fraction of fracture flow in the CHnv for $83 \mathrm{MTU} / \mathrm{acre}$, backfill, high infiltration $\left(\mathrm{q}_{\mathrm{inf}}=\right.$ $1.25 \mathrm{~mm} / \mathrm{yr}$ ).

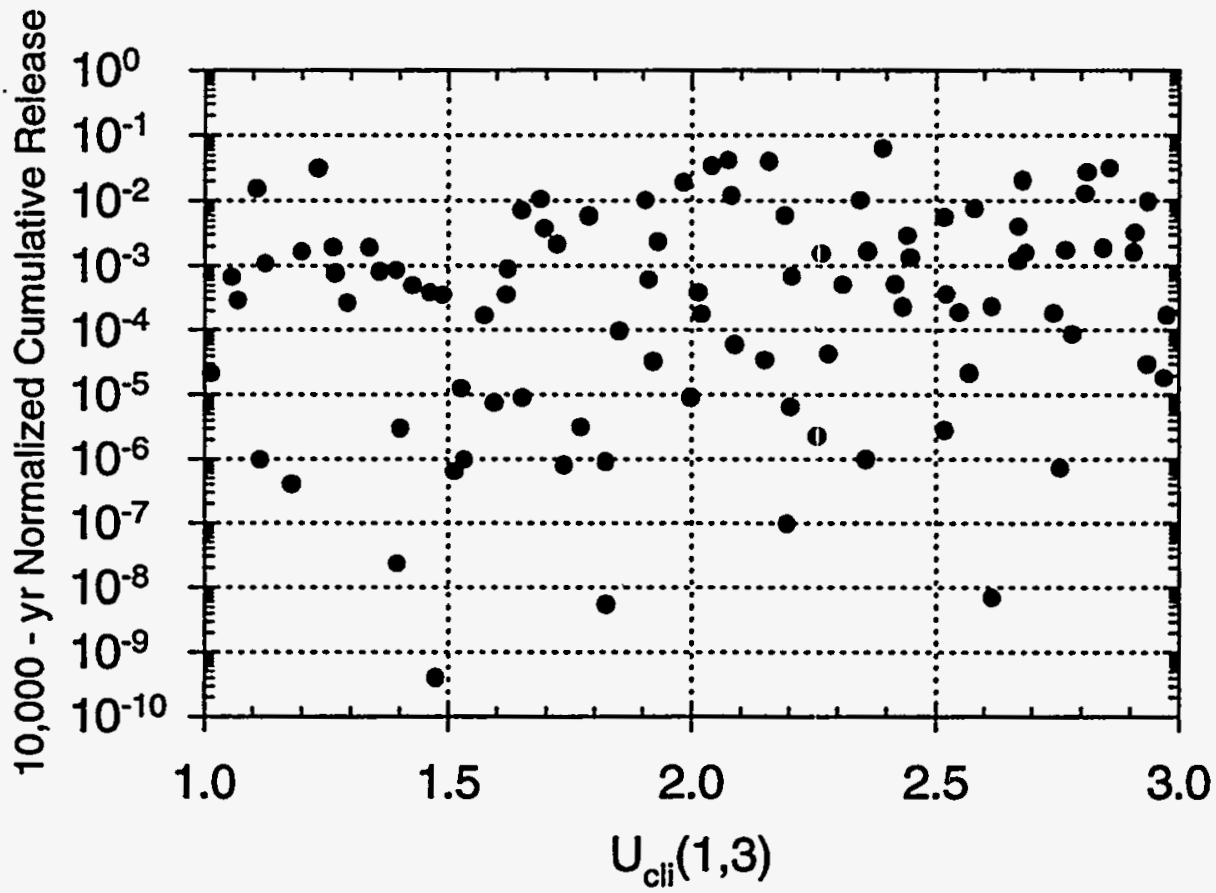

Figure 9.2-33 Scatter plot of 10,000-year total normalized cumulative release versus climatechange modifier for $83 \mathrm{MTU} / \mathrm{acre}$, backfill, high infiltration $\left(\mathrm{q}_{\mathrm{inf}}=1.25\right.$ $\mathrm{mm} / \mathrm{yr}$ ). 


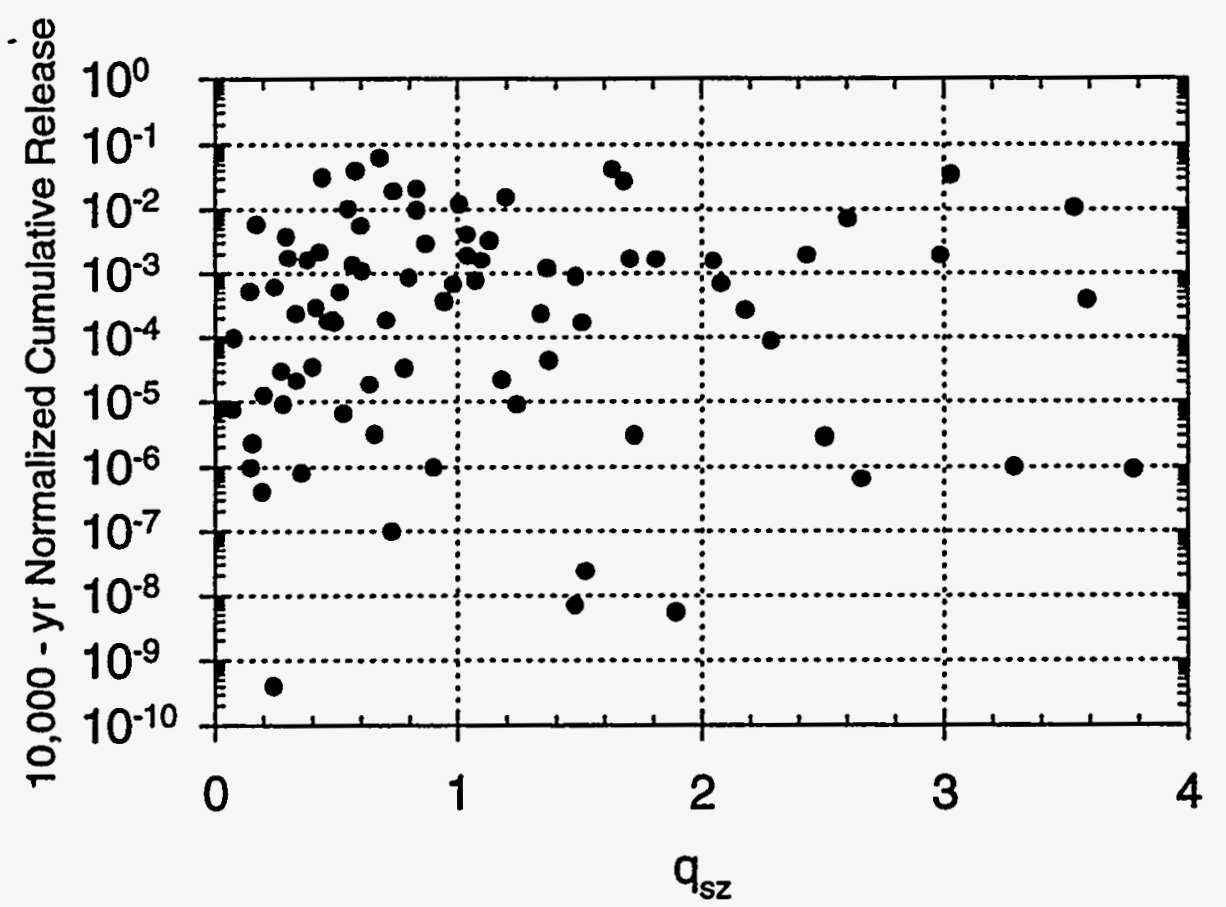

Figure 9.2-34 Scatter plot of 10,000-year total normalized cumulative release versus saturated-zone Darcy velocity (m/yr) for 83 MTU/acre, backfill, high infiltration $\left(\mathrm{q}_{\mathrm{inf}}=1.25 \mathrm{~mm} / \mathrm{yr}\right)$.

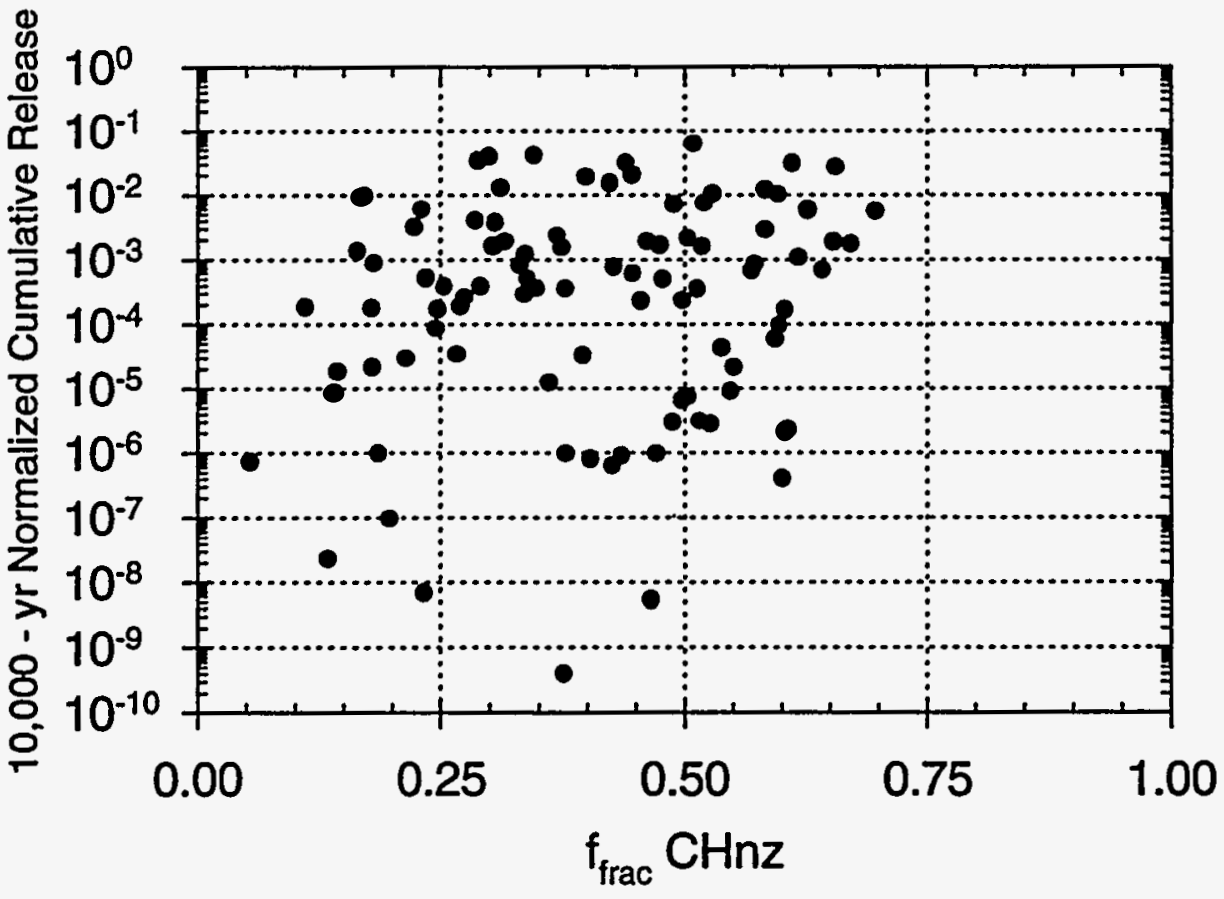

Figure 9.2-35 Scatter plot of 10,000-year total normalized cumulative release versus fraction of fracture flow in the $\mathrm{CHnz}$ for $83 \mathrm{MTU} / \mathrm{acre}$, backfill, high infiltration $\left(\mathrm{q}_{\mathrm{inf}}=\right.$ $1.25 \mathrm{~mm} / \mathrm{yr})$. 


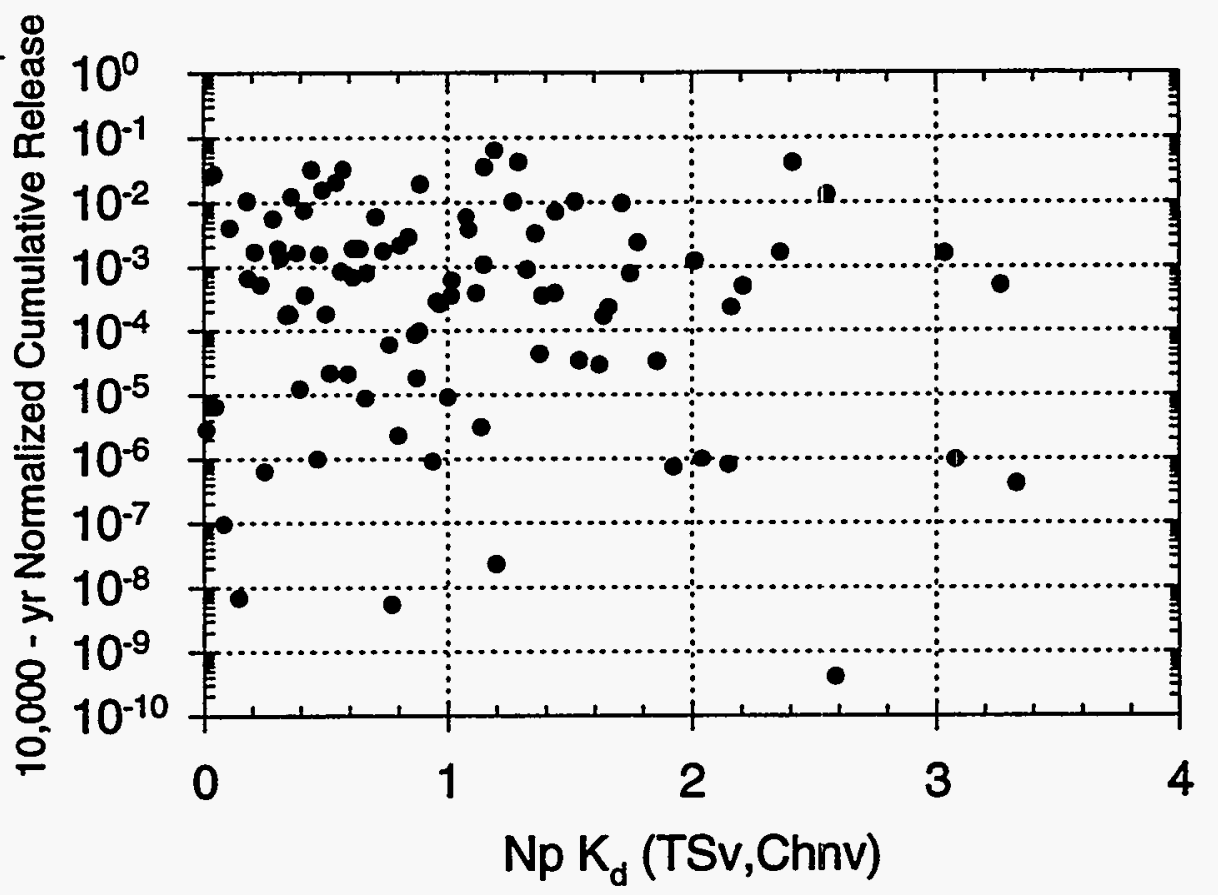

Figure 9.2-36 Scatter plot of 10,000-year total normalized cumulative release versus Np sorption coefficient in the vitric tuff for $83 \mathrm{MTU} /$ acre, backfill, high infiltration $\left(\mathrm{q}_{\text {inf }}=1.25 \mathrm{~mm} / \mathrm{yr}\right)$.

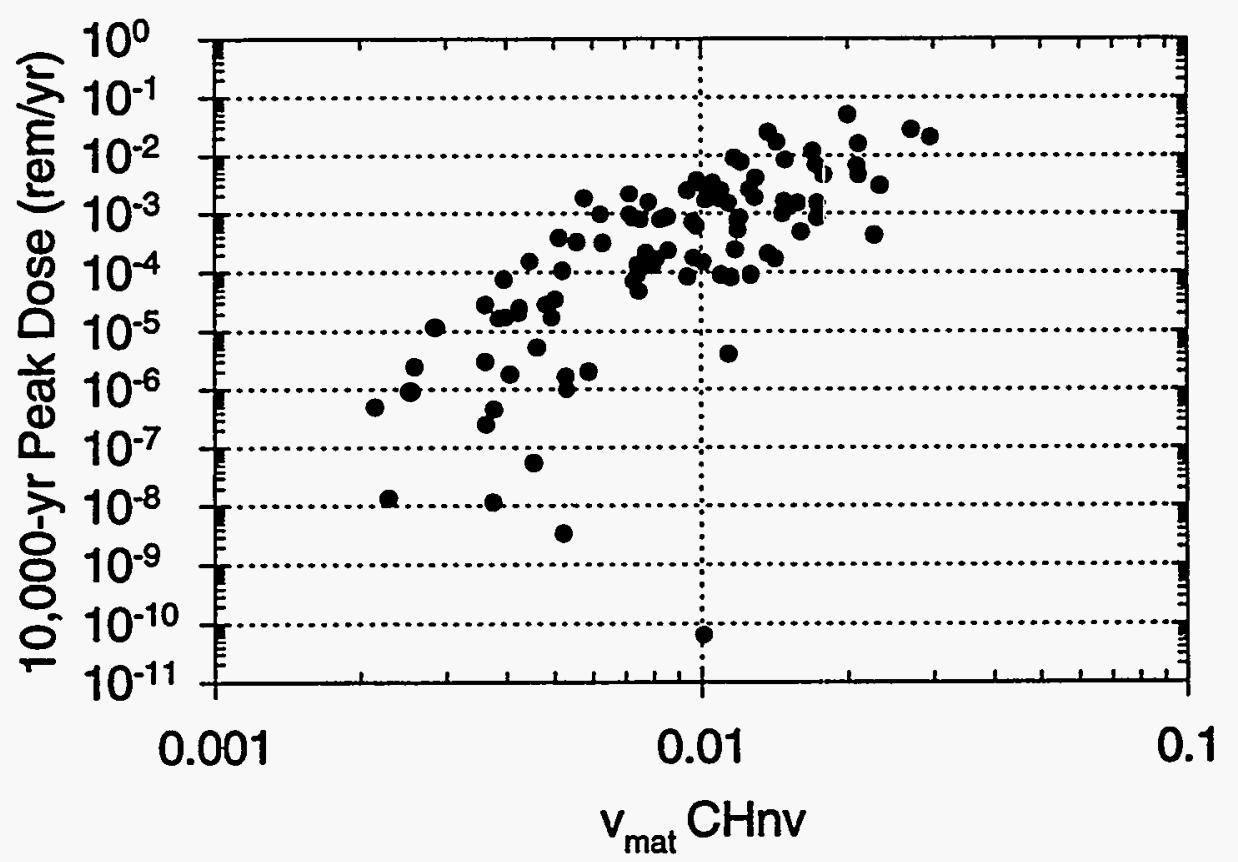

Figure 9.2-37 Scatter plot of 10,000-year total peak dose versus matrix velocity $(\mathrm{m} / \mathrm{yr})$ in the CHnv for $83 \mathrm{MTU} / \mathrm{acre}$, backfill, high infiltration $\left(\mathrm{q}_{\mathrm{inf}}=1.25 \mathrm{~mm} / \mathrm{yr}\right)$. 


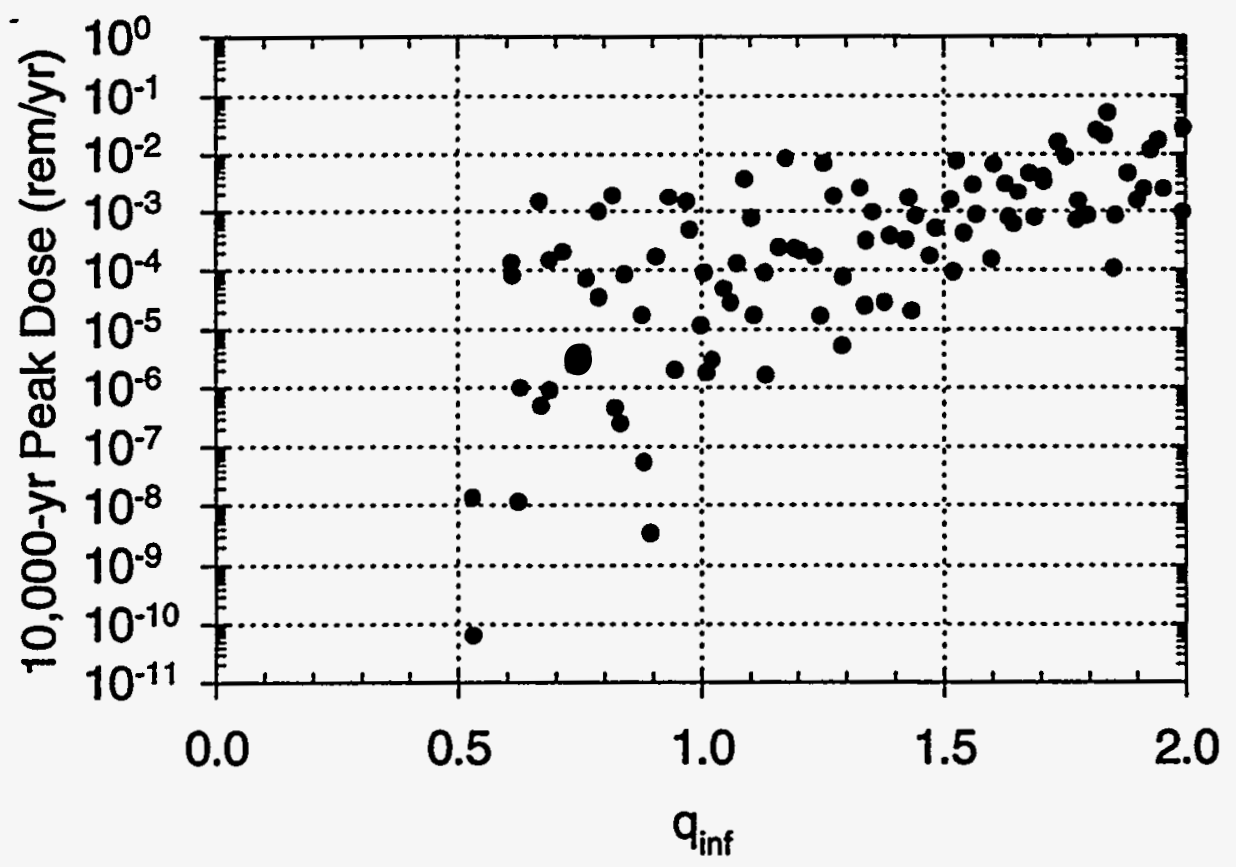

Figure 9.2-38 Scatter plot of 10,000-year total peak dose versus UZ percolation flux (mm/yr) for $83 \mathrm{MTU} / \mathrm{acre}$, backfill, high infiltration $\left(\mathrm{q}_{\mathrm{inf}}=1.25 \mathrm{~mm} / \mathrm{yr}\right)$.

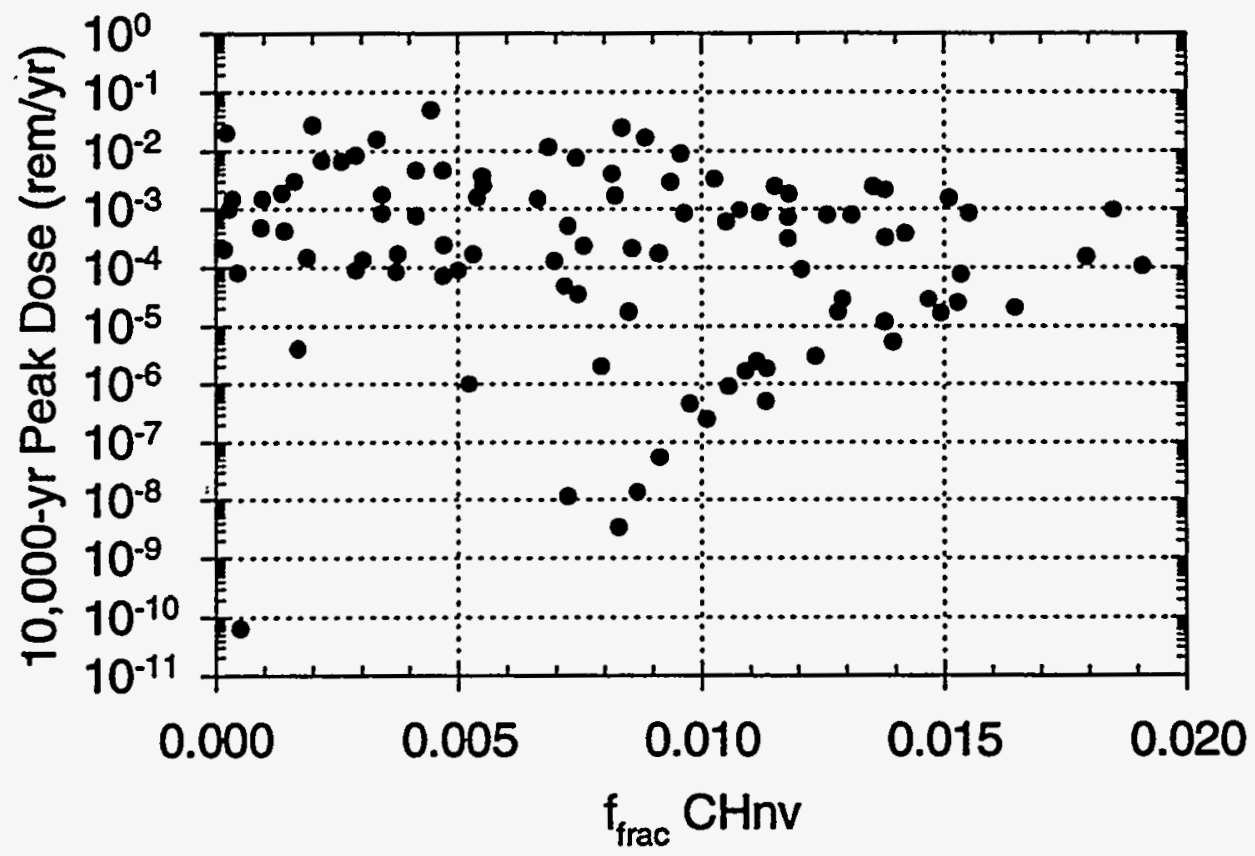

Figure 9.2-39 Scatter plot of 10,000-year total peak dose versus fraction of fracture flow in the CHnv for $83 \mathrm{MTU} / \mathrm{acre}$, backfill, high infiltration $\left(\mathrm{q}_{\mathrm{inf}}=1.25 \mathrm{~mm} / \mathrm{yr}\right)$. 


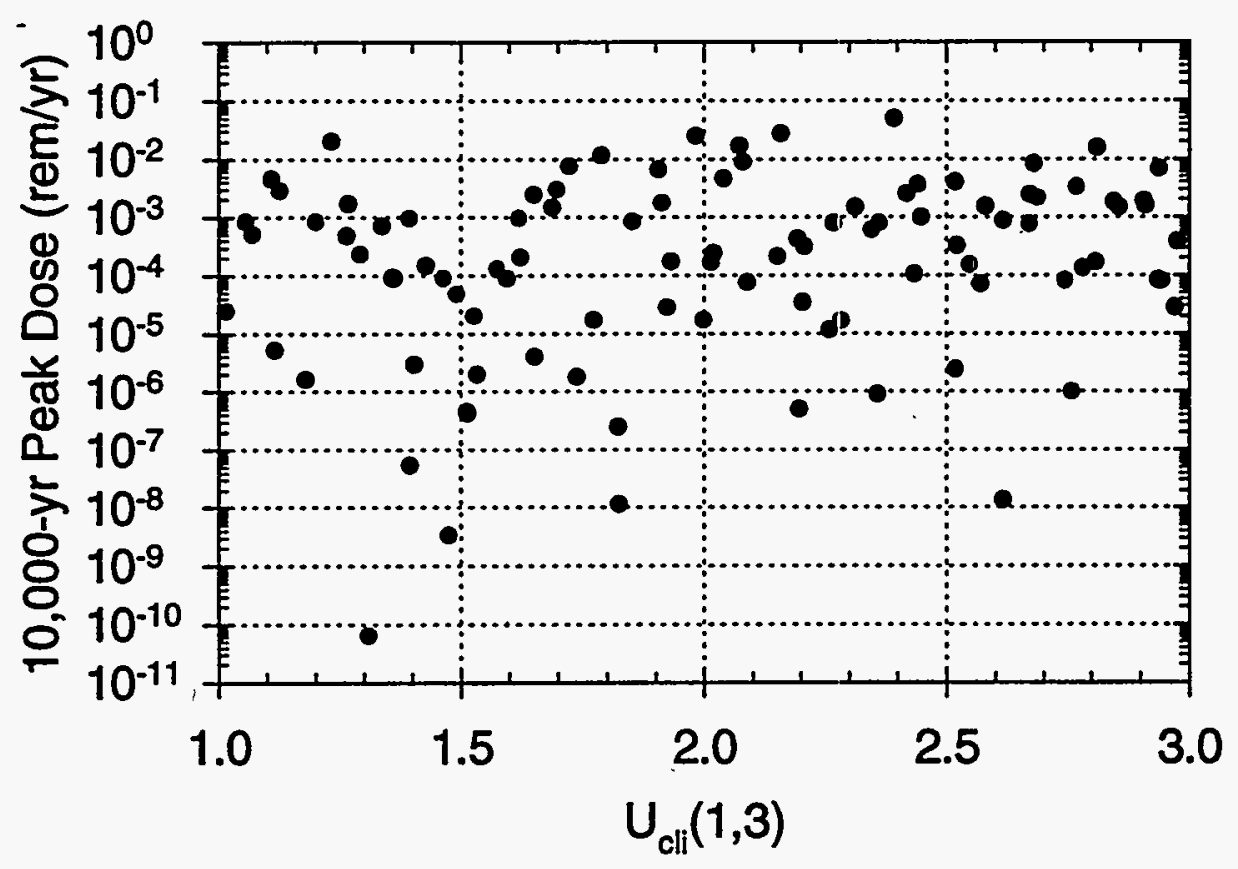

Figure 9.2-40 Scatter plot of 10,000-year total peak dose versus climate-change modifier for $83 \mathrm{MTU} / \mathrm{acre}$, backfill, high infiltration $\left(\mathrm{q}_{\mathrm{inf}}=1.25 \mathrm{~mm} / \mathrm{yr}\right)$.

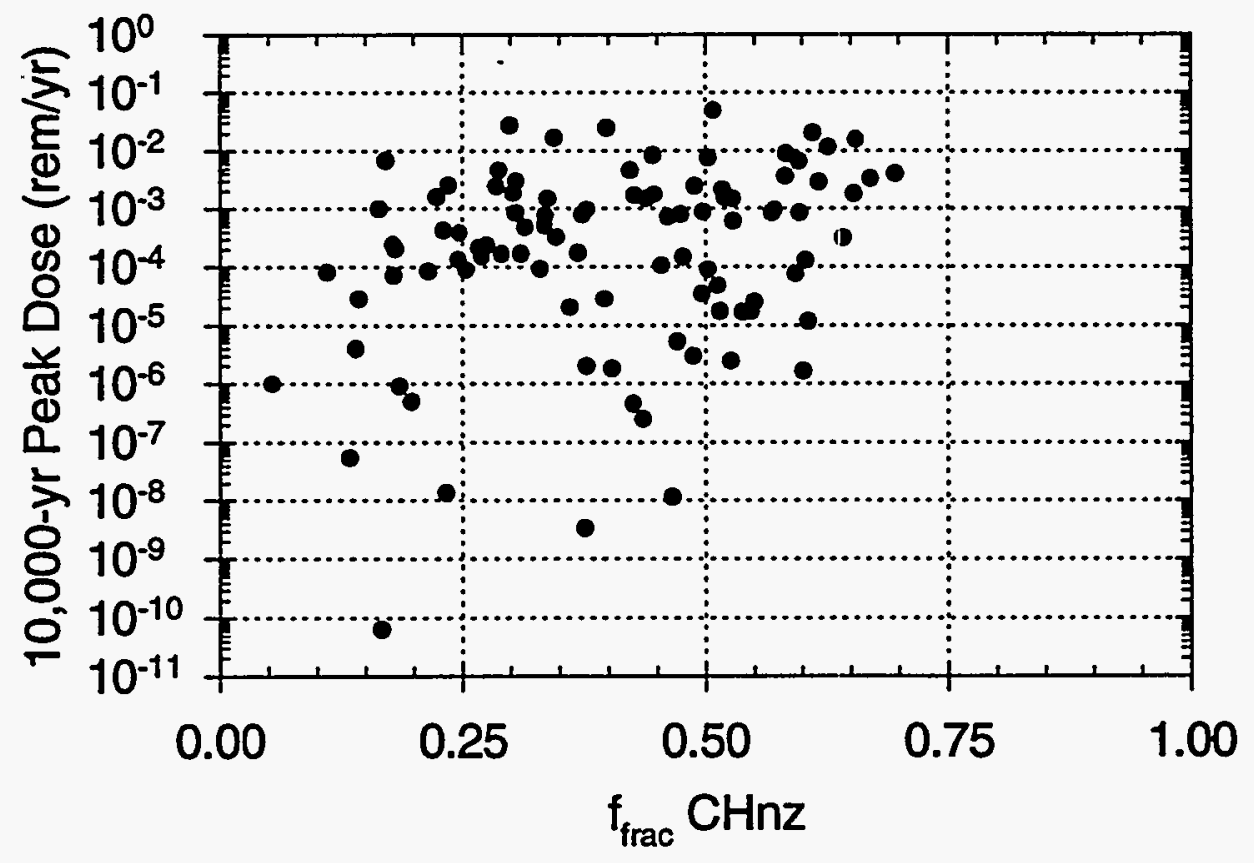

Figure 9.2-41 Scatter plot of 10,000-year total peak dose versus fraction of fracture flow in the CHnz for $83 \mathrm{MTU} / \mathrm{acre}$, backfill, high infiltration $\left(\mathrm{q}_{\mathrm{inf}}=1.25 \mathrm{~mm} / \mathrm{yr}\right)$. 


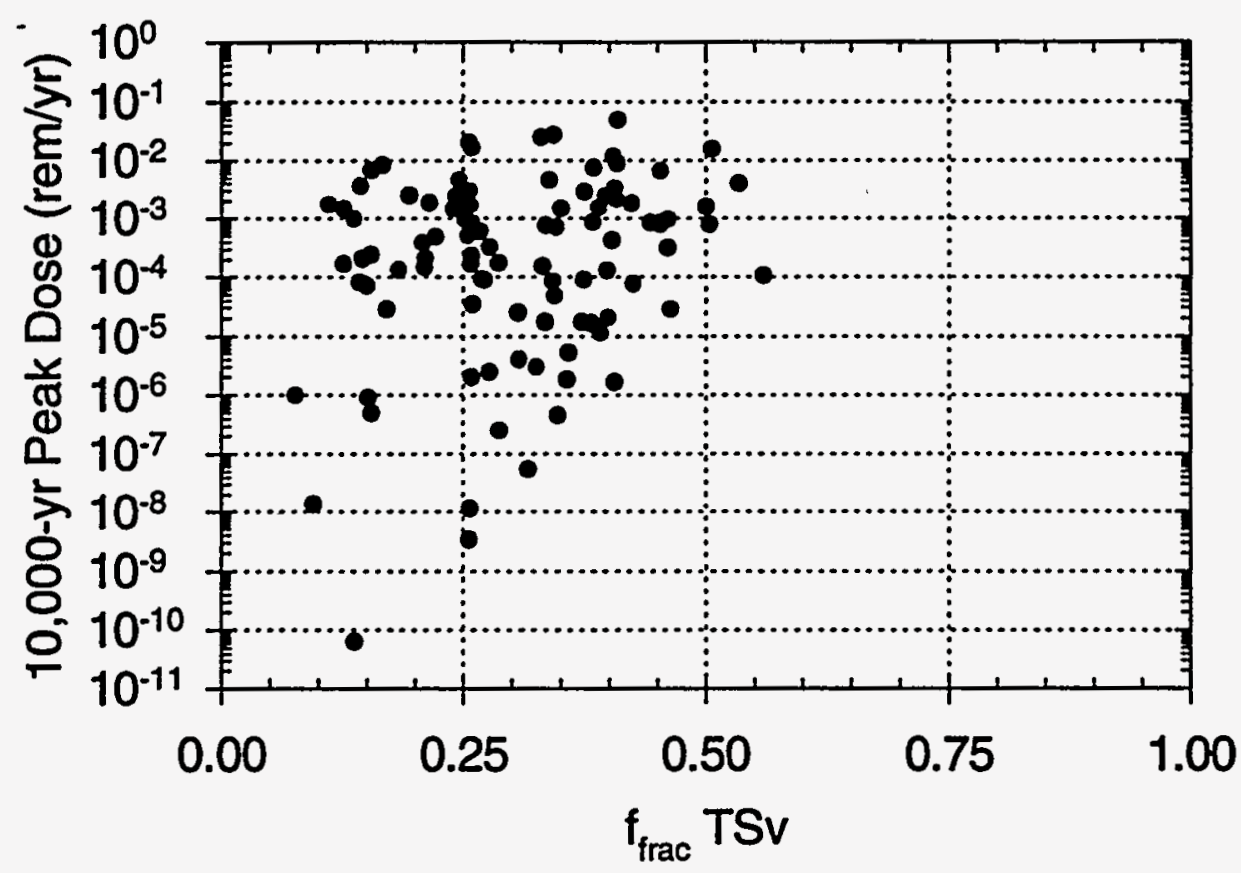

Figure 9.2-42 Scatter plot of 10,000-year total peak dose versus fraction of fracture flow in the TSv for $83 \mathrm{MTU} / \mathrm{acre}$, backfill, high infiltration $\left(\mathrm{q}_{\mathrm{inf}}=1.25 \mathrm{~mm} / \mathrm{yr}\right)$.

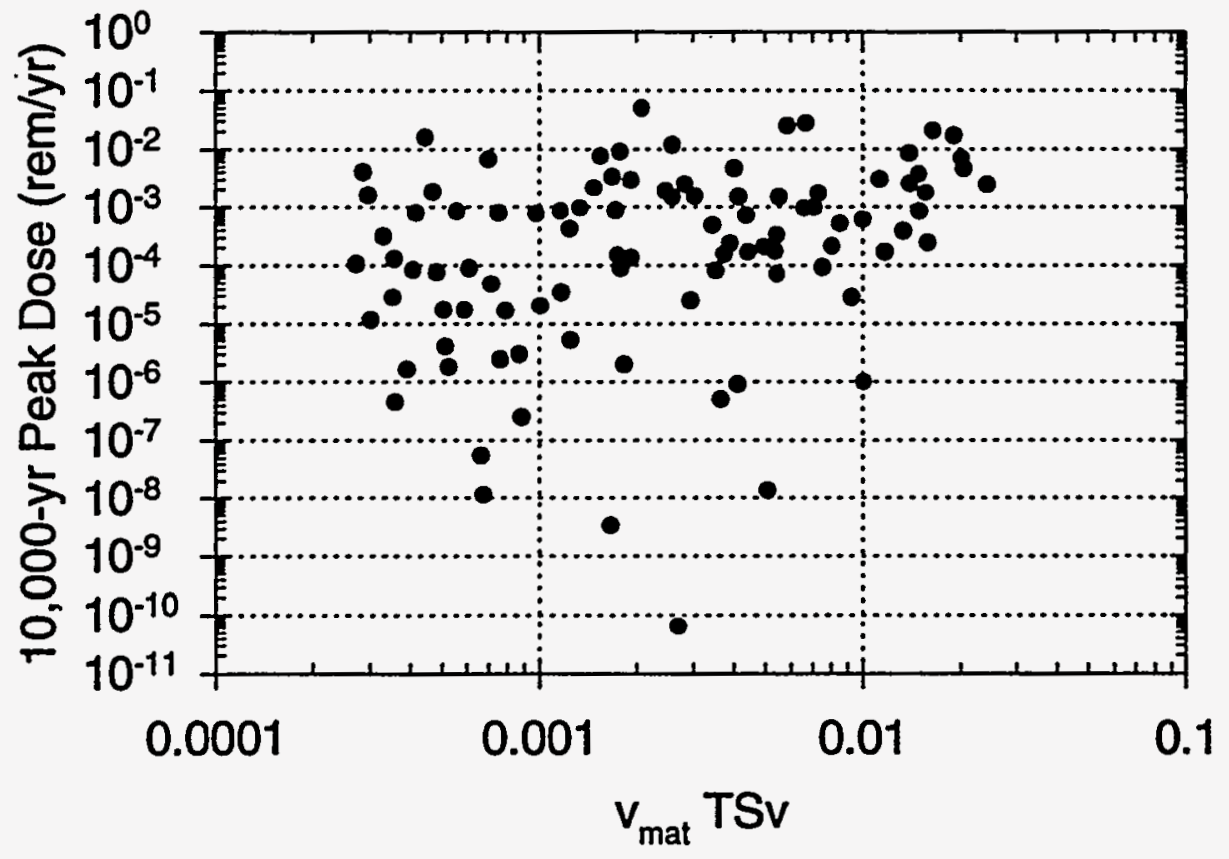

Figure 9.2-43 Scatter plot of 10,000-year total peak dose versus matrix velocity $(\mathrm{m} / \mathrm{yr})$ in the TSv for $83 \mathrm{MTU} / \mathrm{acre}$, backfill, high infiltration $\left(\mathrm{q}_{\mathrm{inf}}=1.25 \mathrm{~mm} / \mathrm{yr}\right)$. 


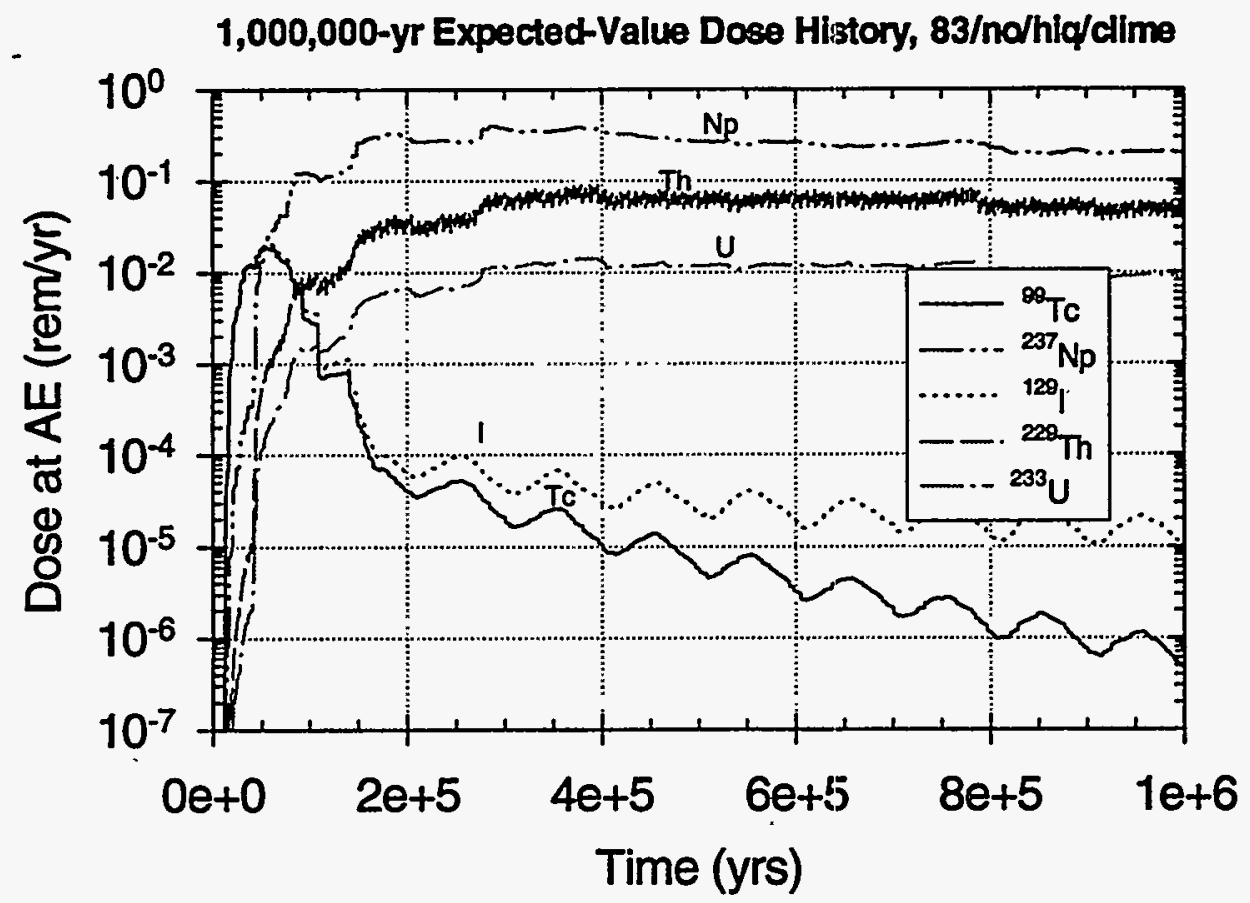

Figure 9.3-1a Expected-value dose history: 1,000,000 years, 83 MTU/acre, no backfill, high infiltration (initial $\mathrm{q}_{\mathrm{inf}}=1.25 \mathrm{~mm} / \mathrm{yr}$ ), cyclical- $\mathrm{q}_{\mathrm{inf}}$ climate model.

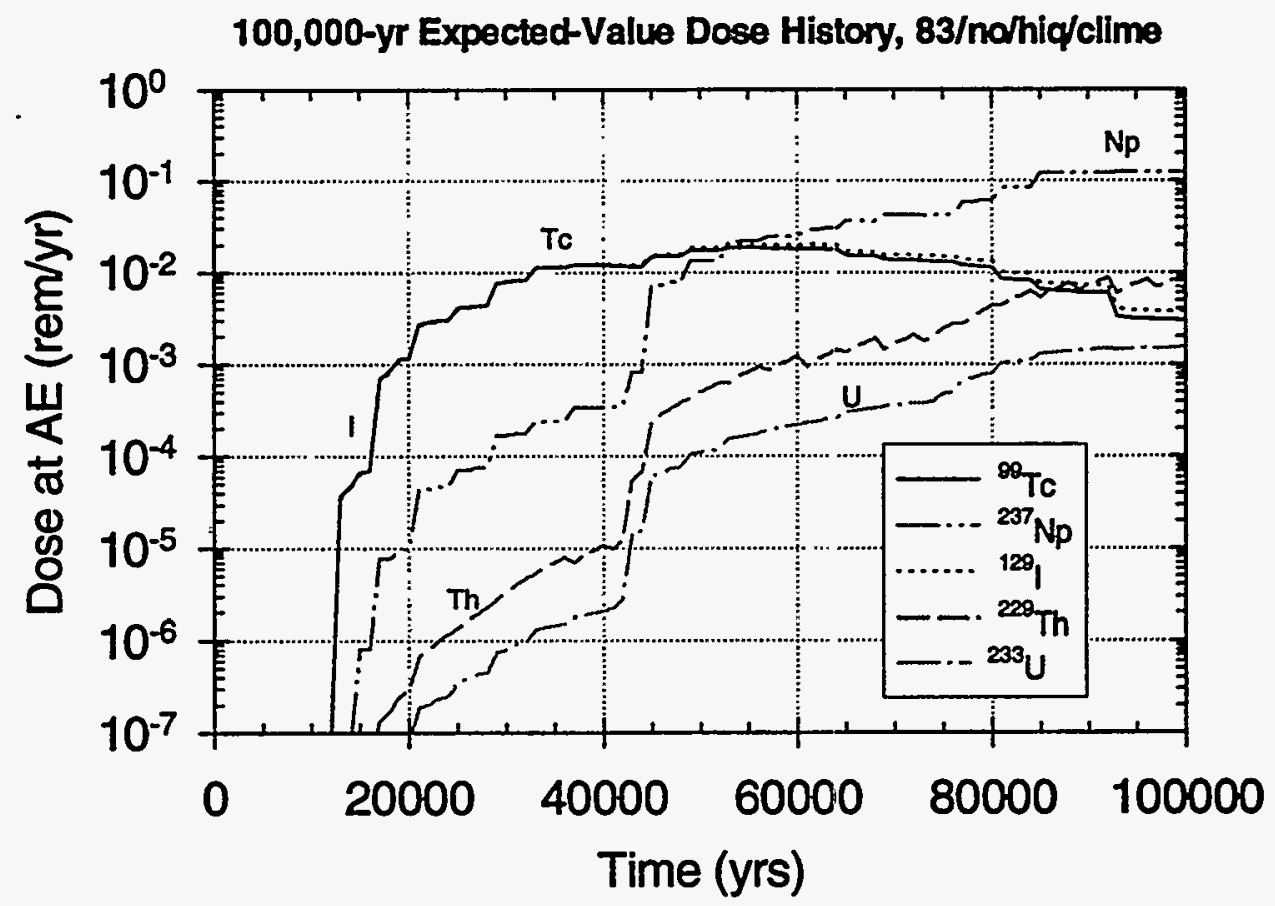

Figure 9.3-1b Expected-value dose history: 100,000 years, 83 MTU/acre, no backfill, high infiltration (initial $\mathrm{q}_{\mathrm{inf}}=1.25 \mathrm{~mm} / \mathrm{yr}$ ), cyclical- $\mathrm{q}_{\mathrm{inf}}$ climate model. 


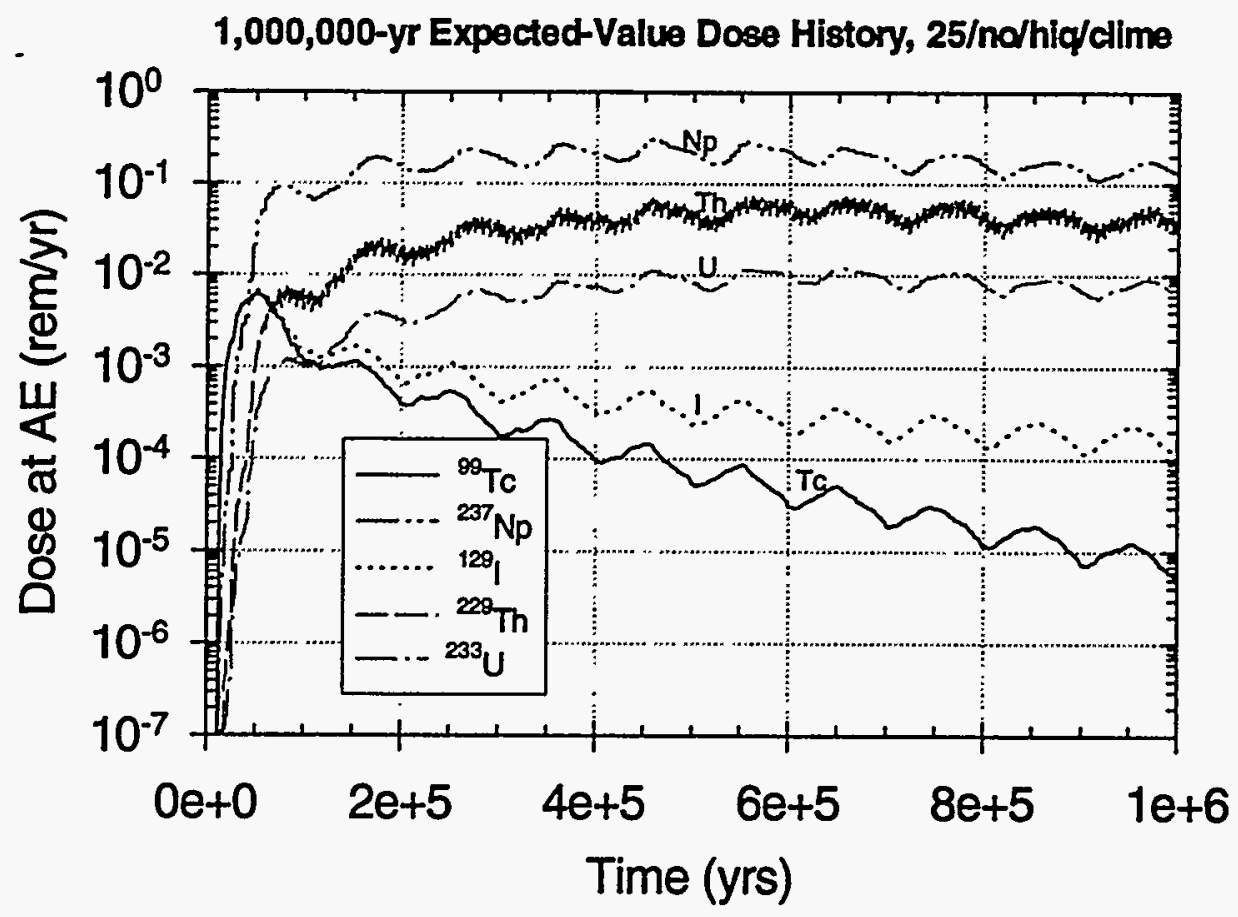

Figure 9.3-2a Expected-value dose history: 1,000,000 years, 25 MTU/acre, no backfill, high infiltration (initial $\mathrm{q}_{\mathrm{inf}}=1.25 \mathrm{~mm} / \mathrm{yr}$ ), cyclical- $\mathrm{q}_{\text {inf }}$ climate model.

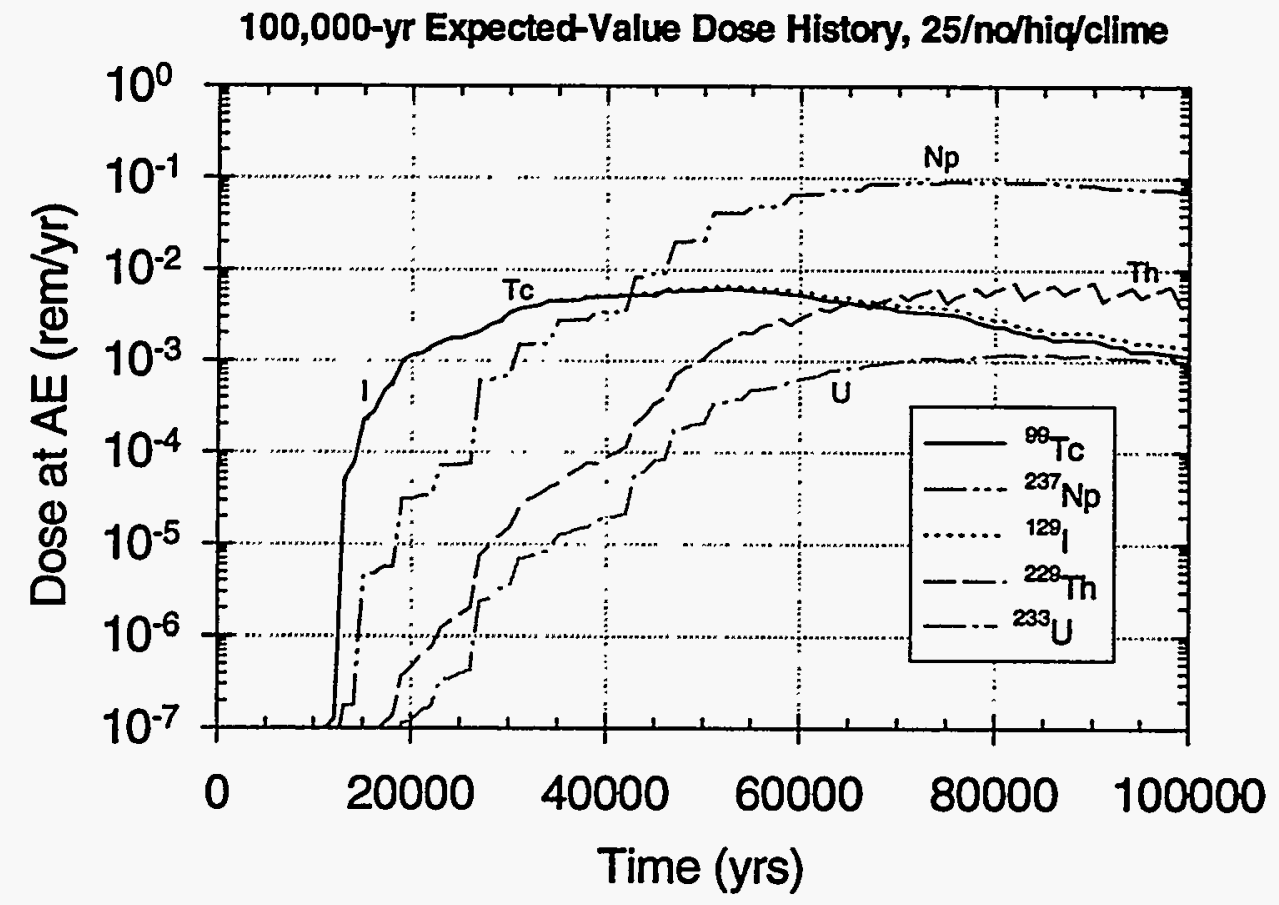

Figure 9.3-2b Expected-value dose history: 100,000 years, 25 MTU/acre, no backfill, high infiltration (initial $\mathrm{q}_{\mathrm{inf}}=1.25 \mathrm{~mm} / \mathrm{yr}$ ), cyclical- $\mathrm{q}_{\mathrm{inf}}$ climate model. 


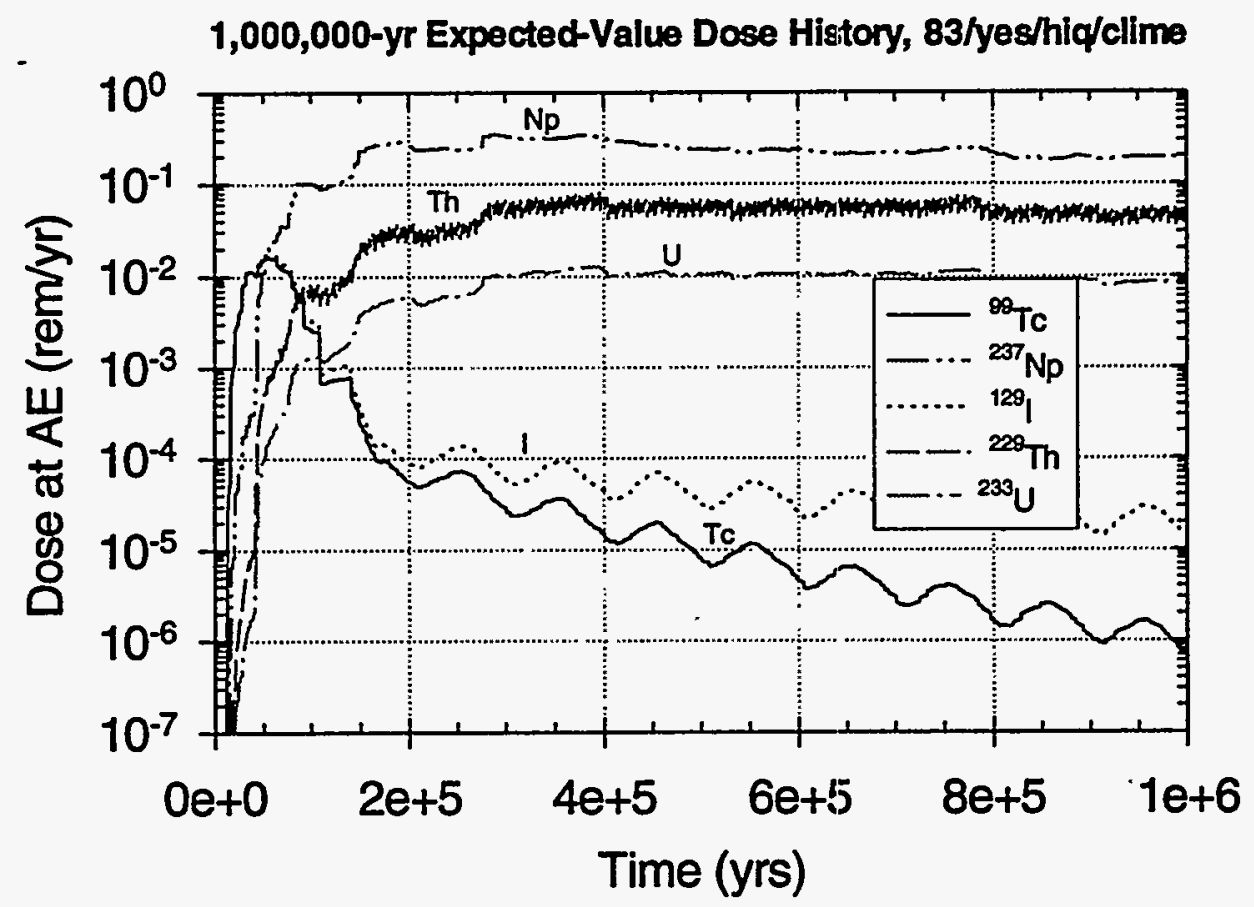

Figure 9.3-3a Expected-value dose history: 1,000,000 years, 83 MTU/acre, backfill, high infiltration (initial $\mathrm{q}_{\mathrm{inf}}=1.25 \mathrm{~mm} / \mathrm{yr}$ ), cyclical- $\mathrm{q}_{\mathrm{inf}}$ climate model.

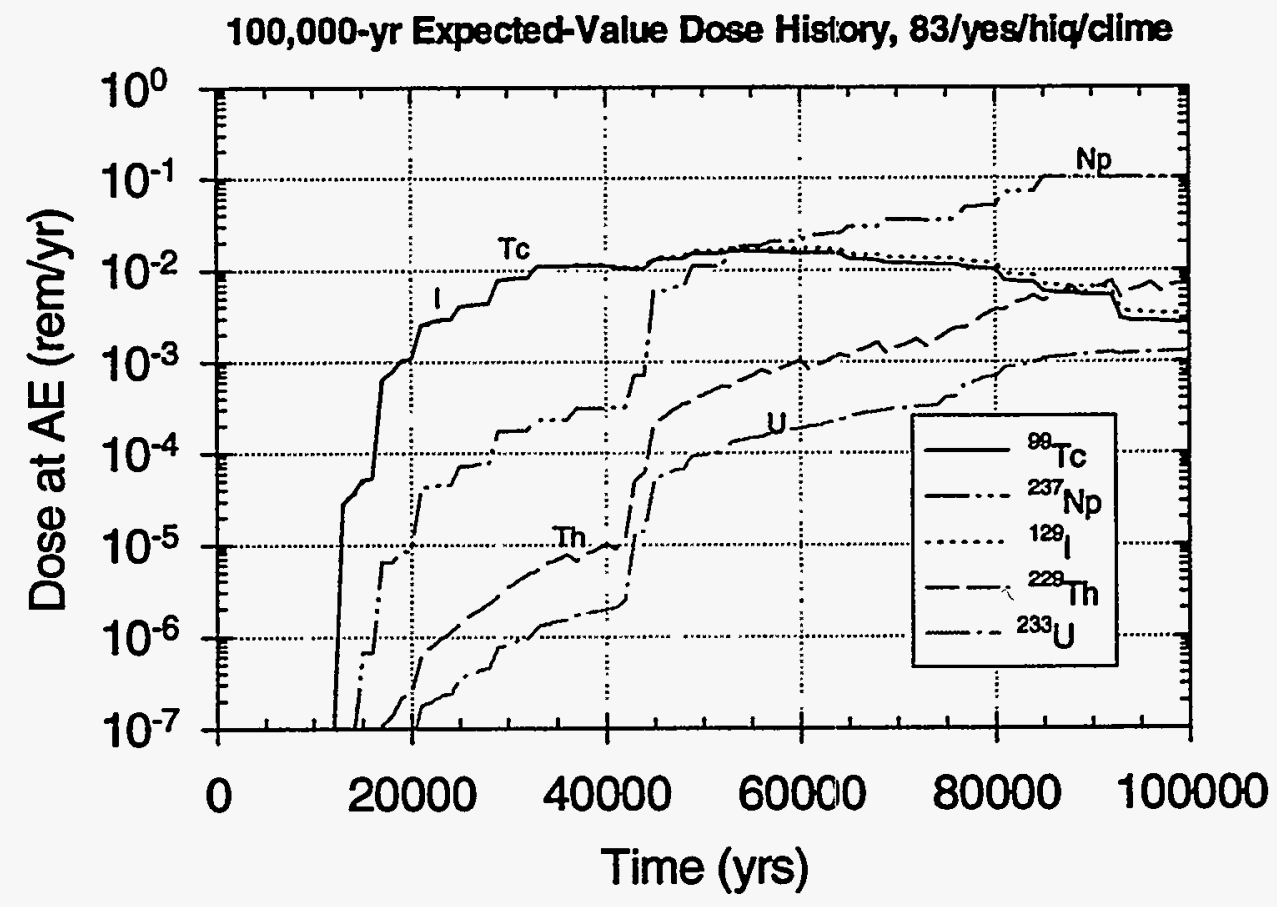

Figure 9.3-3b Expected-value dose history: 100,000 years, 83 MTU/acre, backfill, high infiltration (initial $\mathrm{q}_{\text {inf }}=1.25 \mathrm{~mm} / \mathrm{yr}$ ), cyclical- $\mathrm{q}_{\text {inf }}$ climate model. 


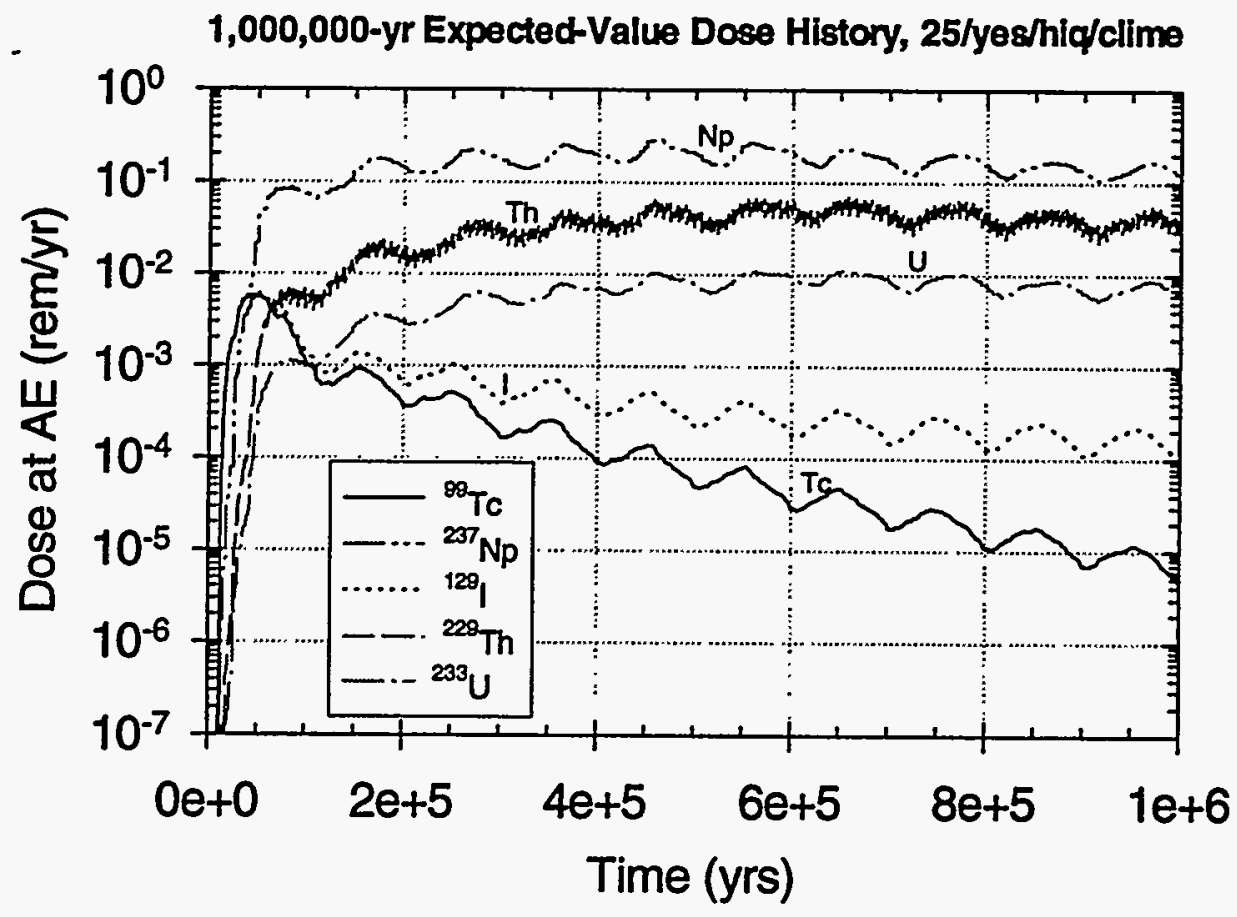

Figure 9.3-4a Expected-value dose history: 1,000,000 years, 25 MTU/acre, backfill, high infiltration (initial $\mathrm{q}_{\mathrm{inf}}=1.25 \mathrm{~mm} / \mathrm{yr}$ ), cyclical- $\mathrm{q}_{\mathrm{inf}}$ climate model.

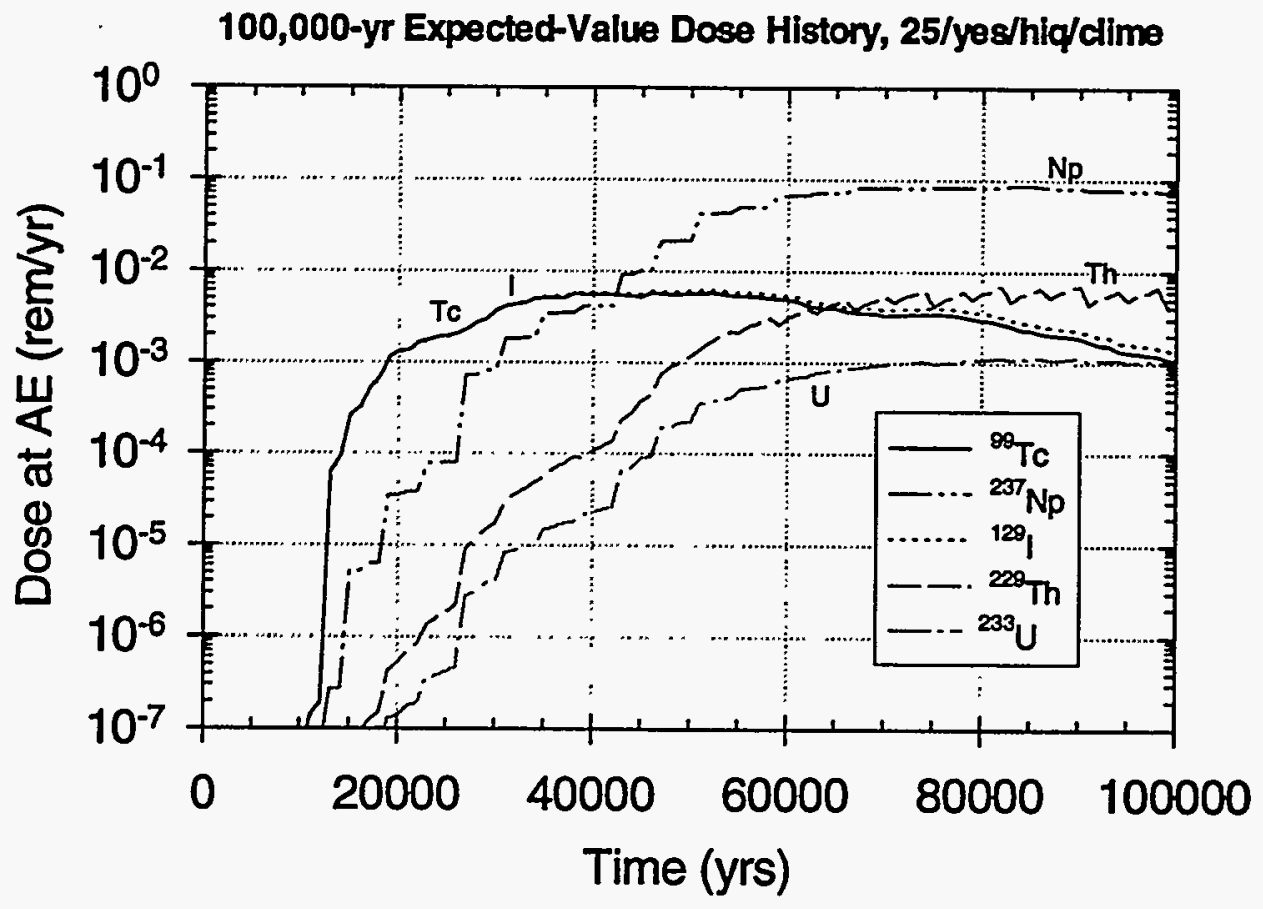

Figure 9.3-4b Expected-value dose history: 100,000 years, 25 MTU/acre, backfill, high infiltration (initial $\mathrm{q}_{\mathrm{inf}}=1.25 \mathrm{~mm} / \mathrm{yr}$ ), cyclical- $\mathrm{q}_{\mathrm{inf}}$ climate model. 


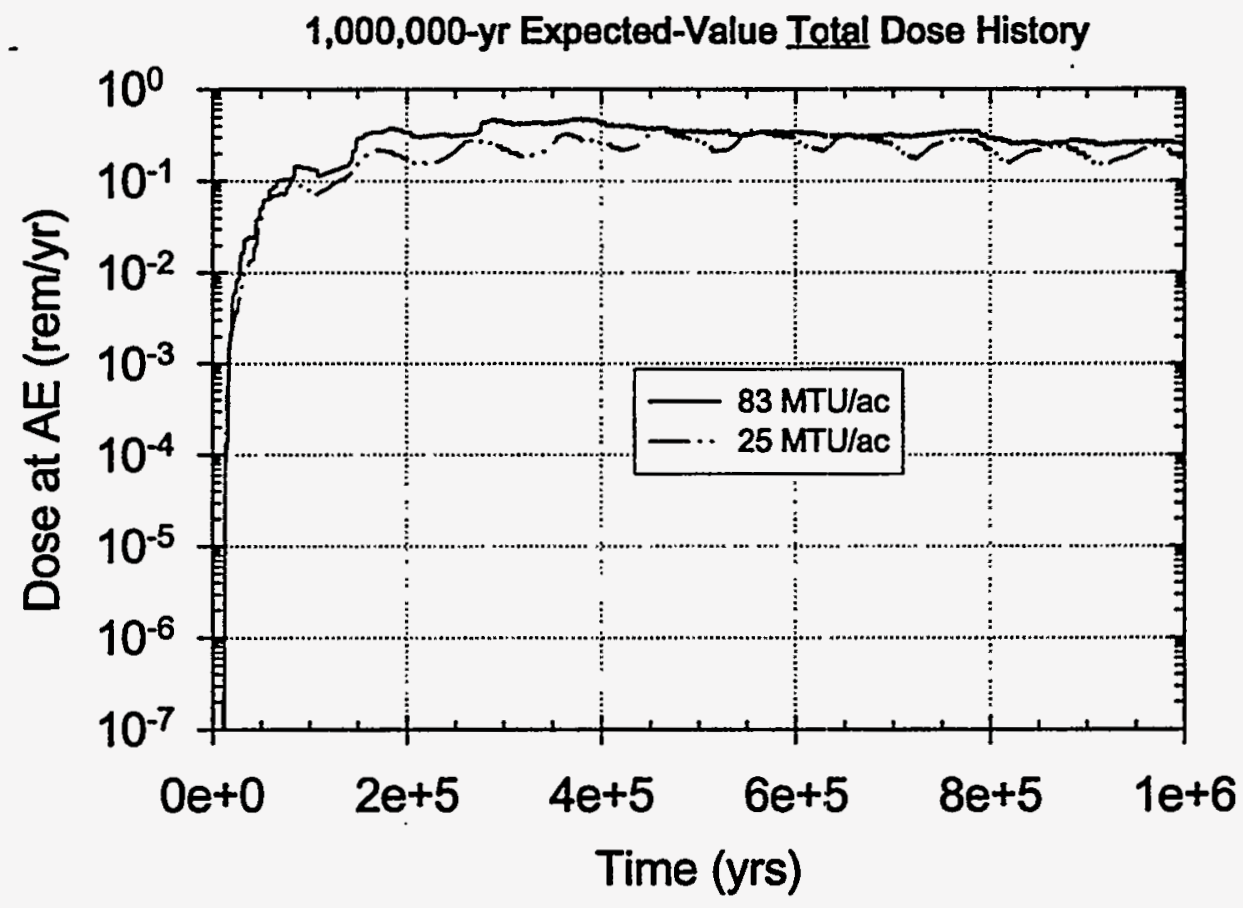

Figure 9.3-5 Expected-value total dose history: 1,000,000 years, 83 MTU/acre versus 25 MTU/acre, no backfill, high infiltration (initial $\mathrm{q}_{\mathrm{inf}}=1.25 \mathrm{~mm} / \mathrm{yr}$ ), cyclical- $\mathrm{q}_{\mathrm{inf}}$ climate model.

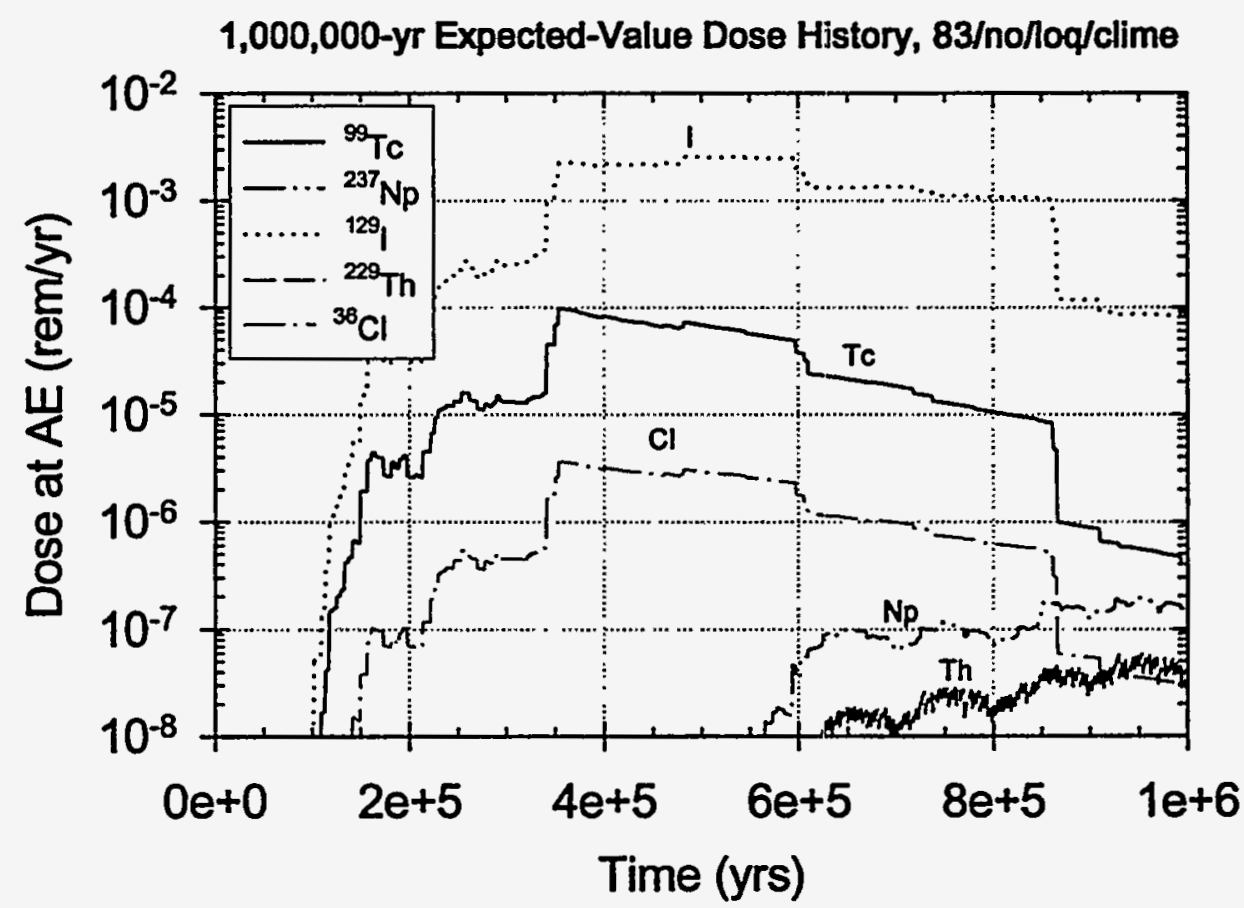

Figure 9.3-6 Expected-value dose history: 1,000,000 years, 83 MTU/acre, no backfill, low infiltration (initial $\mathrm{q}_{\mathrm{inf}}=0.03 \mathrm{~mm} / \mathrm{yr}$ ), cyclical- $\mathrm{q}_{\mathrm{inf}}$ climate model. 


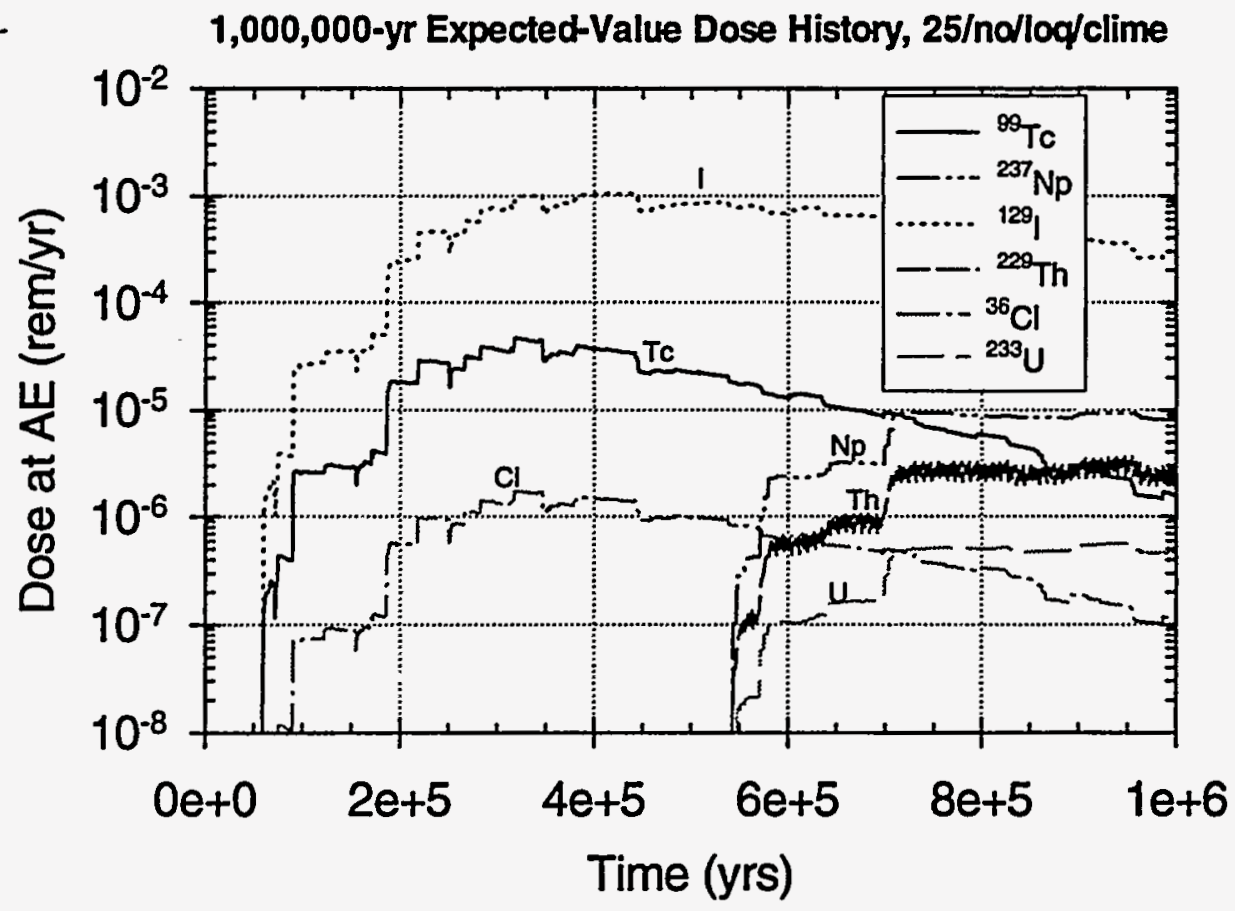

Figure 9.3-7a Expected-value dose history: 1,000,000 years, 25 MTU/acre, no backfill, low infiltration (initial $\mathrm{q}_{\mathrm{inf}}=0.03 \mathrm{~mm} / \mathrm{yr}$ ), cyclical- $\mathrm{q}_{\mathrm{inf}}$ climate model.

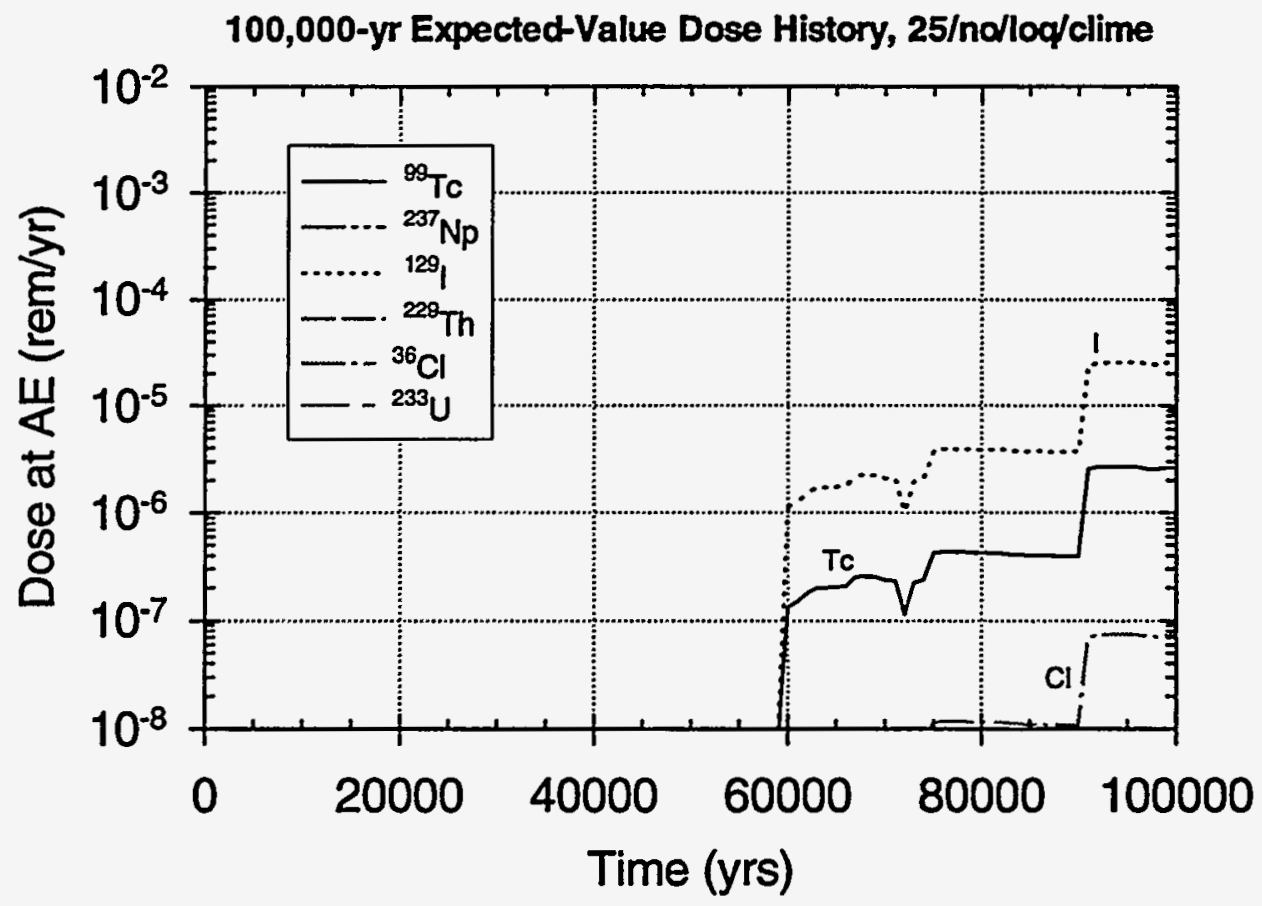

Figure 9.3-7b Expected-value dose history: 100,000 years, 25 MTU/acre, no backfill, low infiltration (initial $\mathrm{q}_{\mathrm{inf}}=0.03 \mathrm{~mm} / \mathrm{yr}$ ), cyclical- $\mathrm{q}_{\mathrm{inf}}$ climate model. 


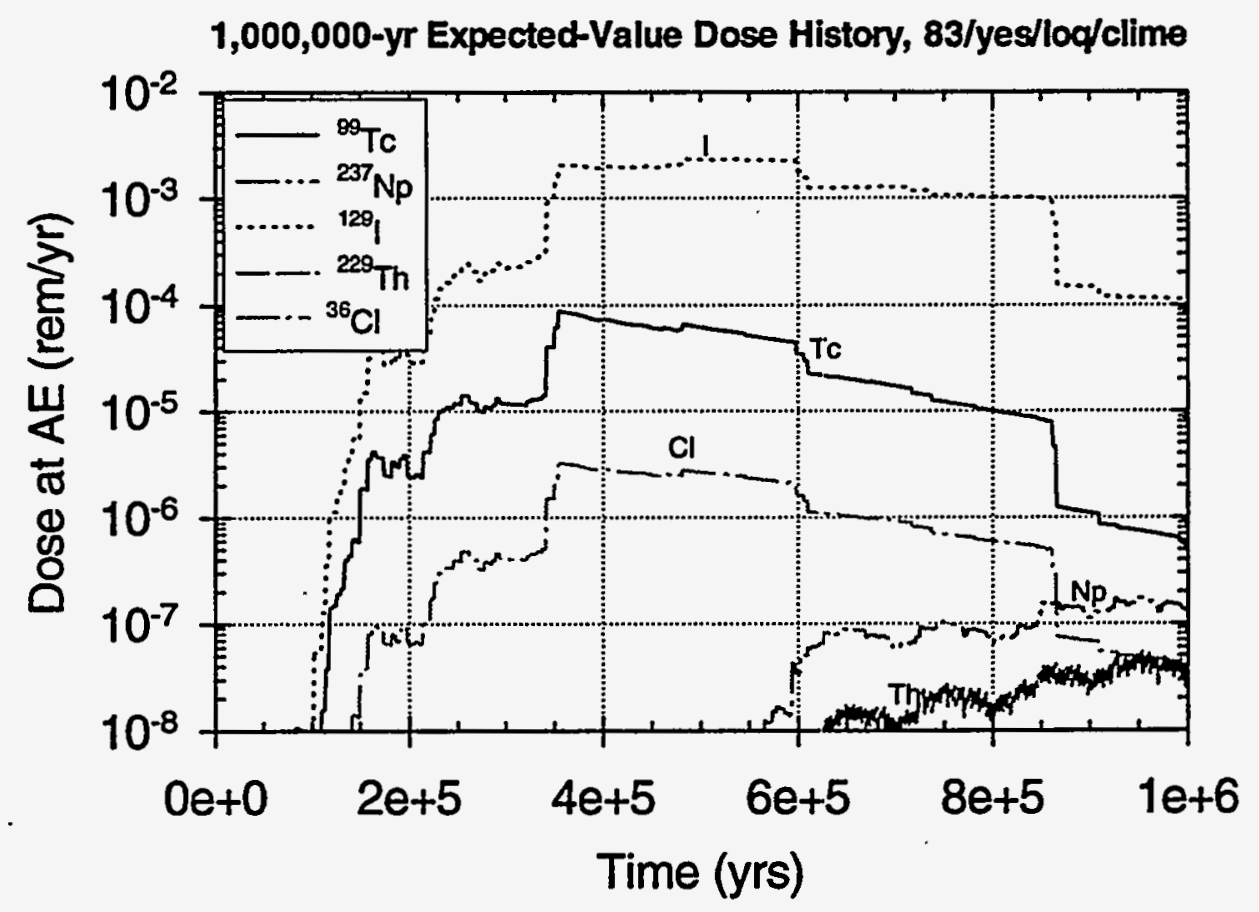

Figure 9.3-8 Expected-value dose history: 1,000,000 years, 83 MTU/acre, backfill, low infiltration (initial $\mathrm{q}_{\mathrm{inf}}=0.03 \mathrm{~mm} / \mathrm{yr}$ ), cyclical- $\mathrm{q}_{\mathrm{inf}}$ climate model. 


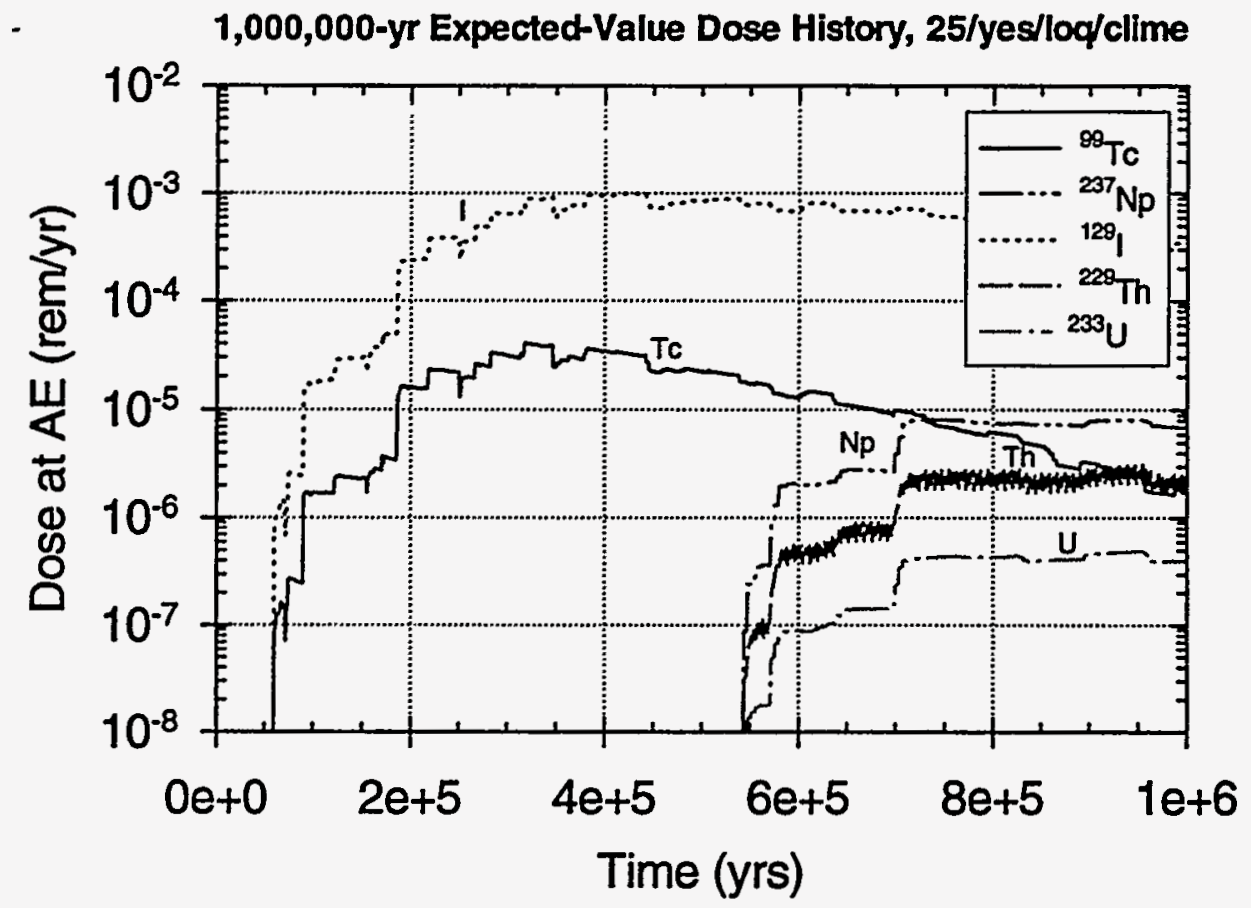

Figure 9.3-9a Expected-value dose history: 1,000,000 years, 25 MTU/acre, backfill, low infiltration (initial $\mathrm{q}_{\mathrm{inf}}=0.03 \mathrm{~mm} / \mathrm{yr}$ ), cyclical- $\mathrm{q}_{\mathrm{inf}}$ climate model.

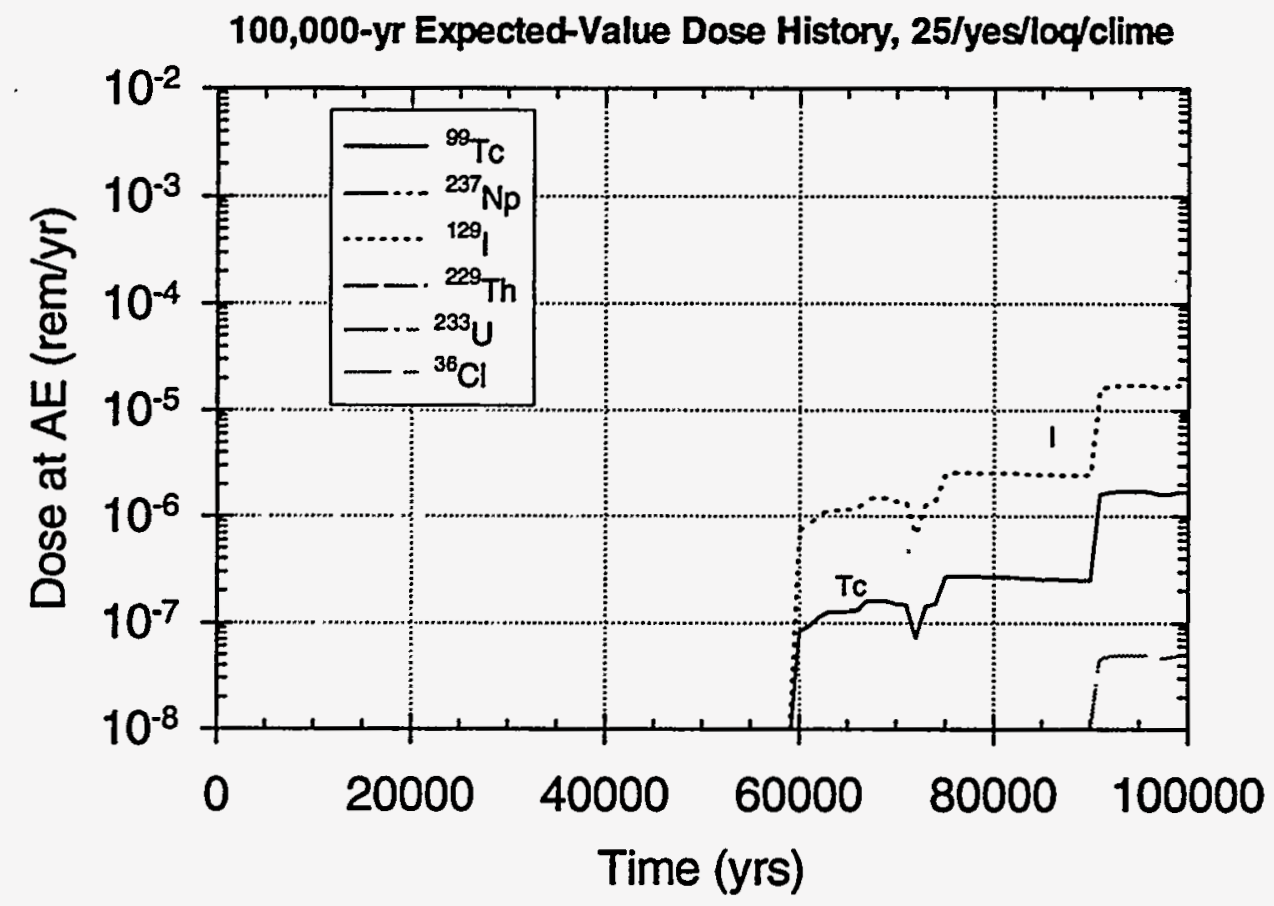

Figure 9.3-9b Expected-value dose history: 100,000 years, 25 MTU/acre, backfill, low infiltration (initial $\mathrm{q}_{\mathrm{inf}}=0.03 \mathrm{~mm} / \mathrm{yr}$ ), cyclical- $\mathrm{q}_{\mathrm{inf}}$ climate model. 


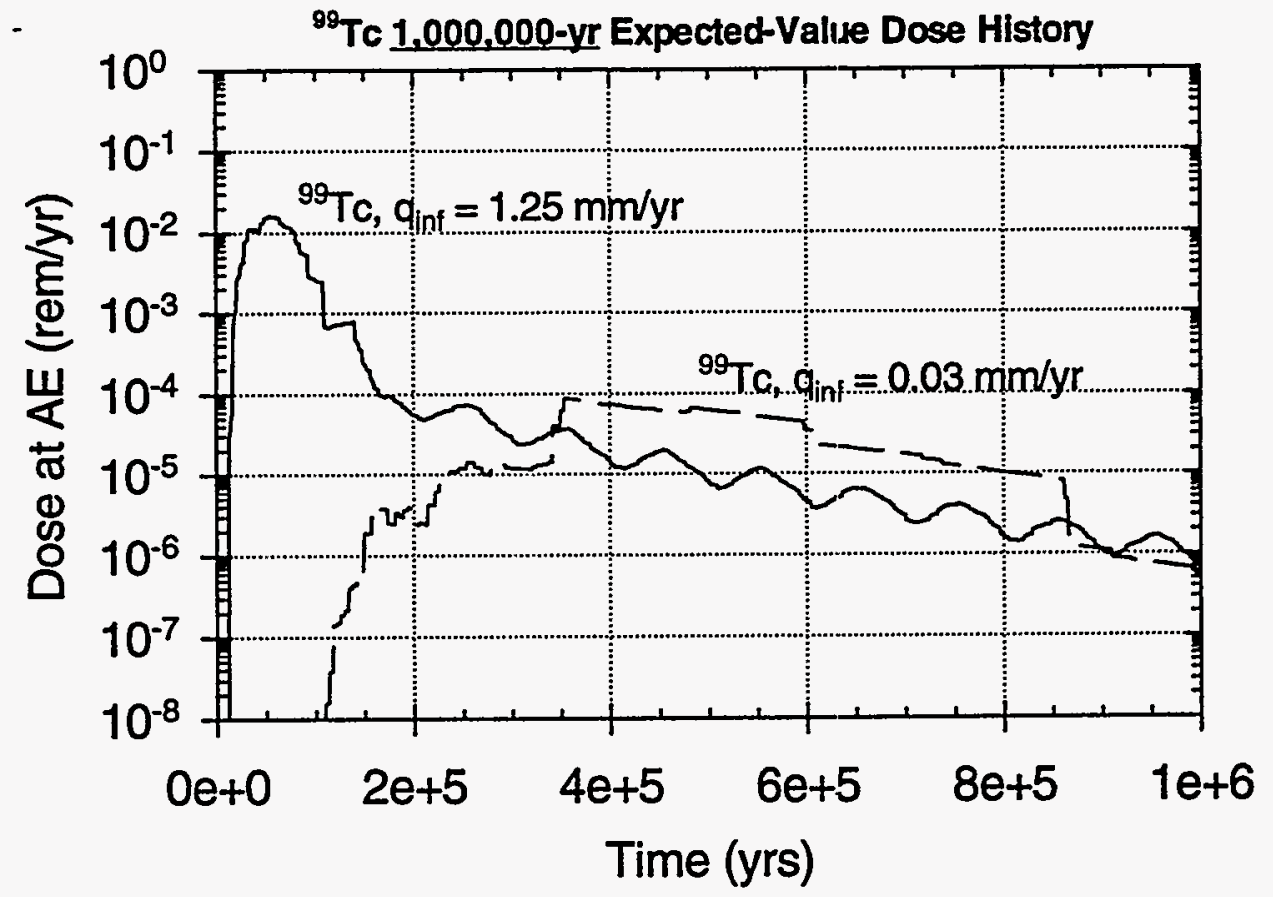

Figure 9.3-10 Expected-value dose history for ${ }^{99} \mathrm{Tc}$. 1,000,000 years, infiltration rate comparison: "high" ( $\left.\mathrm{q}_{\mathrm{inf}}=1.25 \mathrm{~mm} / \mathrm{yr}\right)$ versus "low" $\left(\mathrm{q}_{\mathrm{inf}}=0.03 \mathrm{~mm} / \mathrm{yr}\right)$ infiltration, $83 \mathrm{MTU} / \mathrm{acre}$, backfill, cyclical- $q_{\mathrm{inf}}$ climate model.

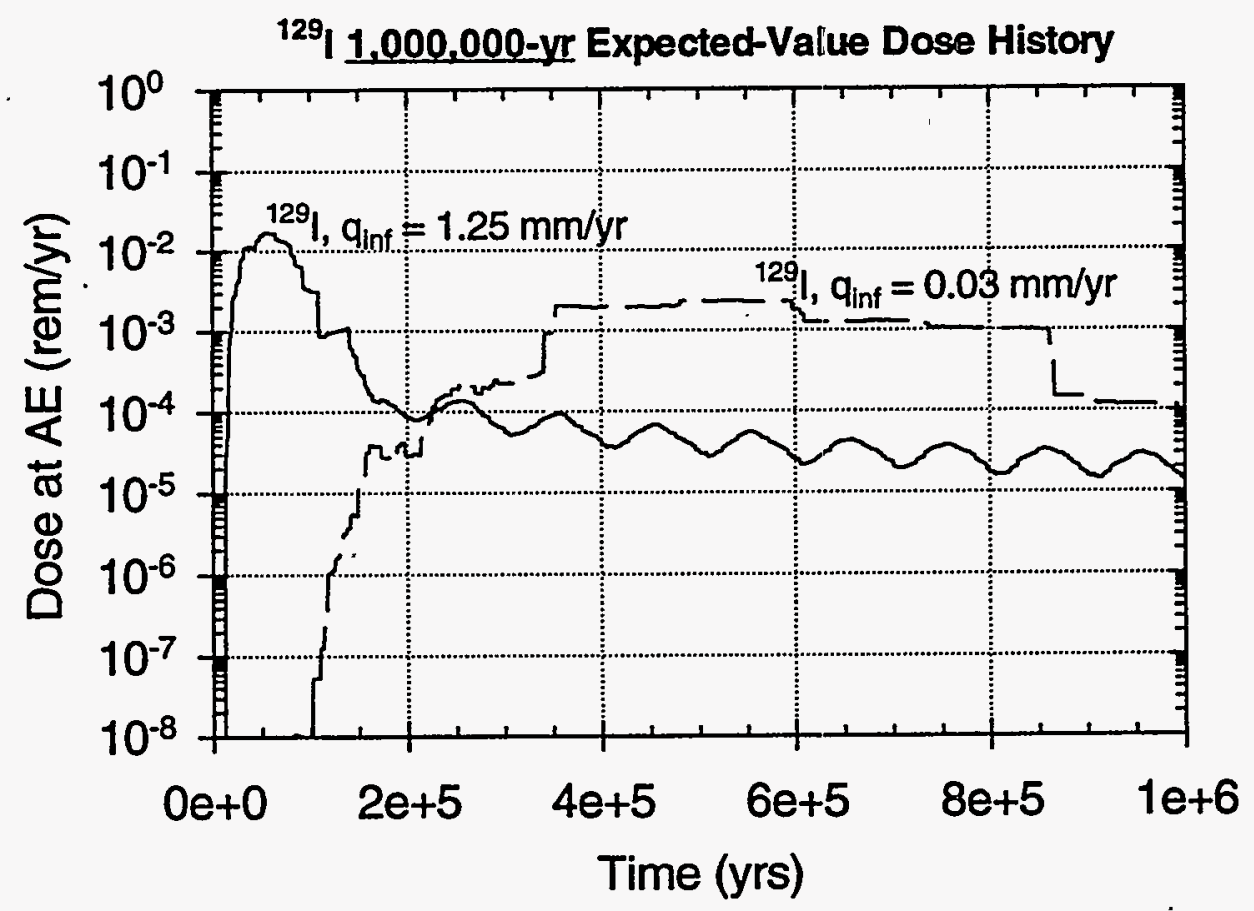

Figure 9.3-11 Expected-value dose history for ${ }^{129} \mathrm{~T}$. 1,000,000 years, infiltration rate comparison: "high" ( $\left.\mathrm{q}_{\mathrm{inf}}=1.25 \mathrm{~mm} / \mathrm{yr}\right)$ versus "low" $\left(\mathrm{q}_{\mathrm{inf}}=0.03 \mathrm{~mm} / \mathrm{yr}\right)$ infiltration, 83 MTU/acre, backfill, cyclical- $\mathrm{q}_{\text {inf }}$ climate model. 


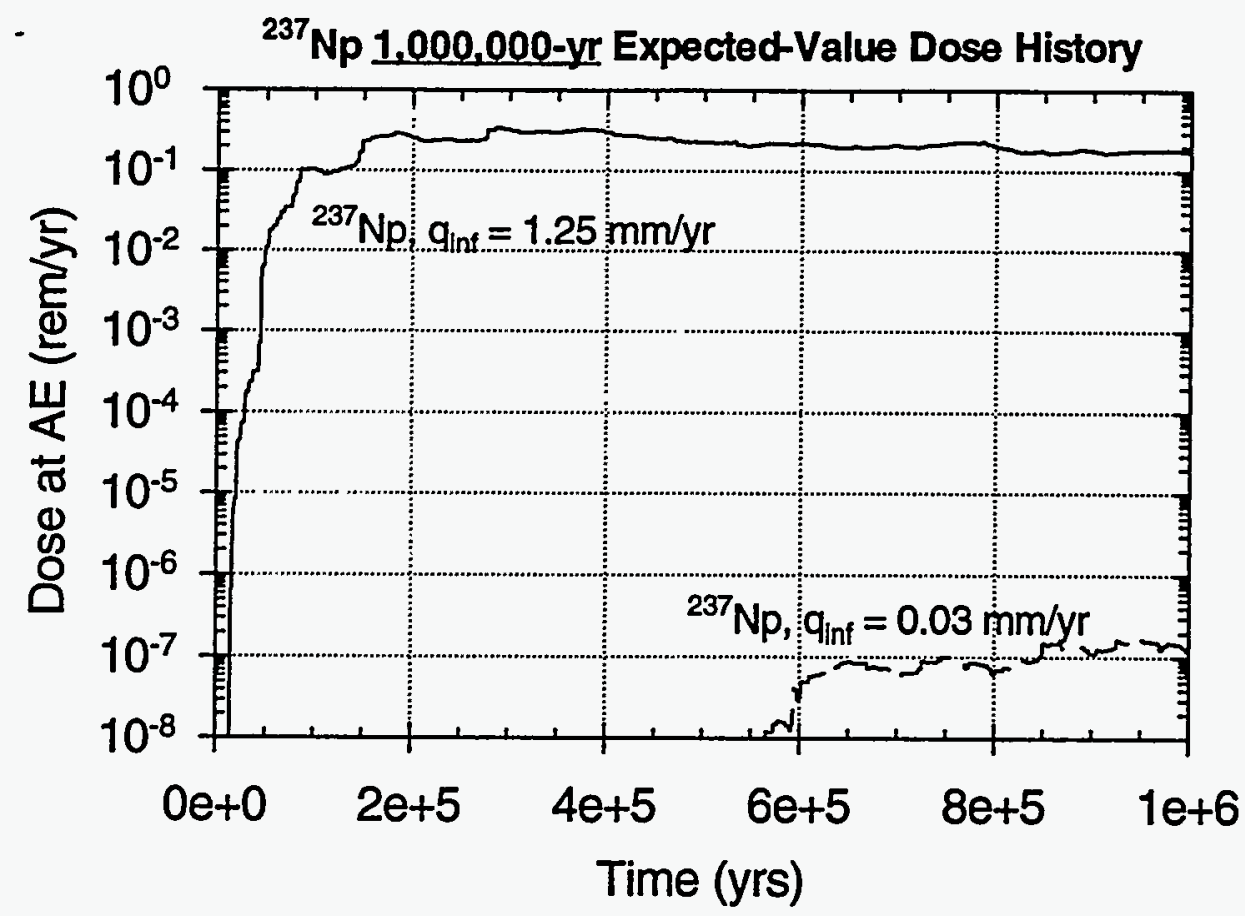

Figure 9.3-12 Expected-value dose history for ${ }^{237} \mathrm{~Np}$. 1,000,000 years, infiltration rate comparison: "high" ( $\left.q_{\text {inf }}=1.25 \mathrm{~mm} / \mathrm{yr}\right)$ versus "low" $\left(\mathrm{q}_{\mathrm{inf}}=0.03 \mathrm{~mm} / \mathrm{yr}\right)$ infiltration, $83 \mathrm{MTU} / \mathrm{acre}$, backfill, cyclical- $\mathrm{q}_{\mathrm{inf}}$ climate model.

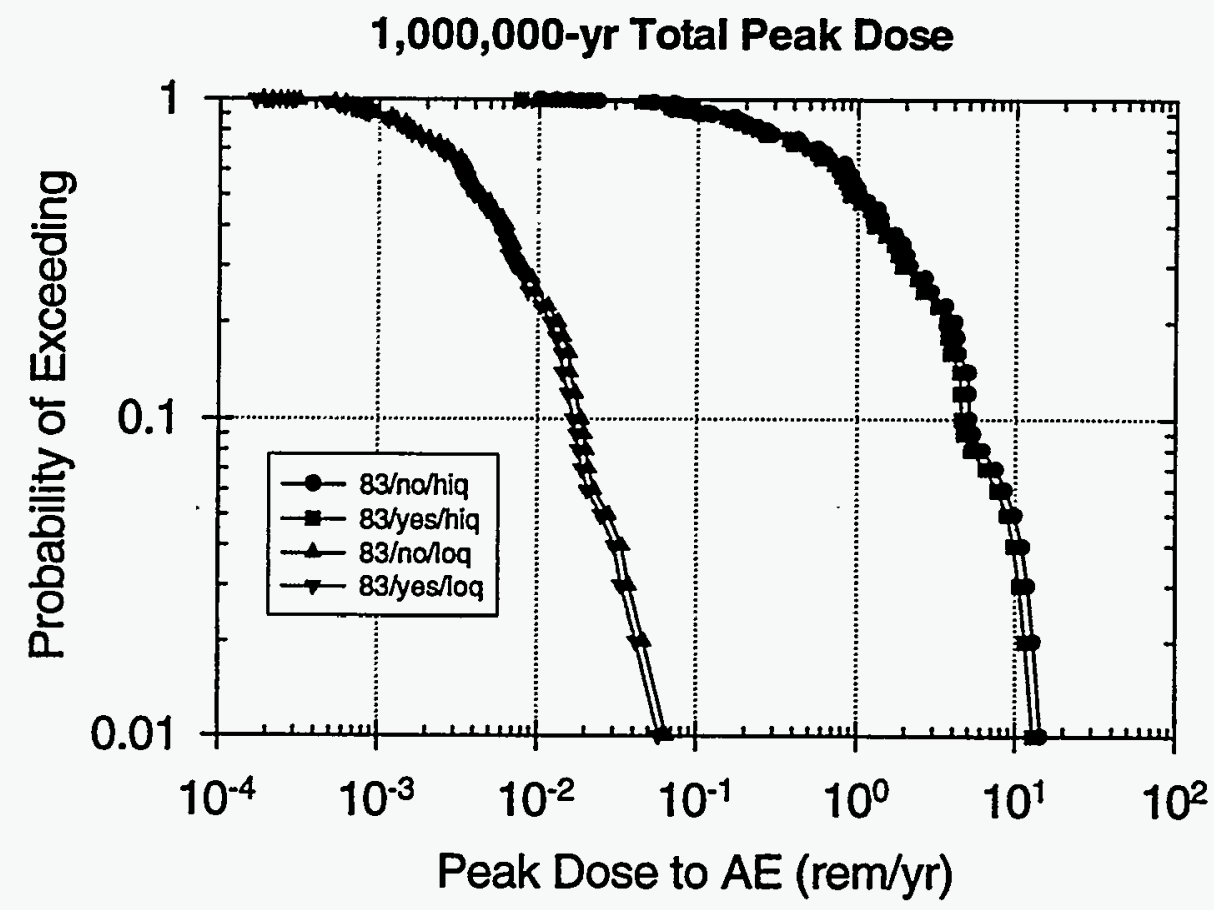

Figure 9.3-13 CCDF of Total Peak Dose: 1,000,000 years, 83 MTU/acre, with ("yes") and without ("no") backfill, high and low infiltration $\left(\mathrm{q}_{\text {inf }}\right)$ ranges, cyclical- $\mathrm{q}_{\text {inf }}$ climate model. 


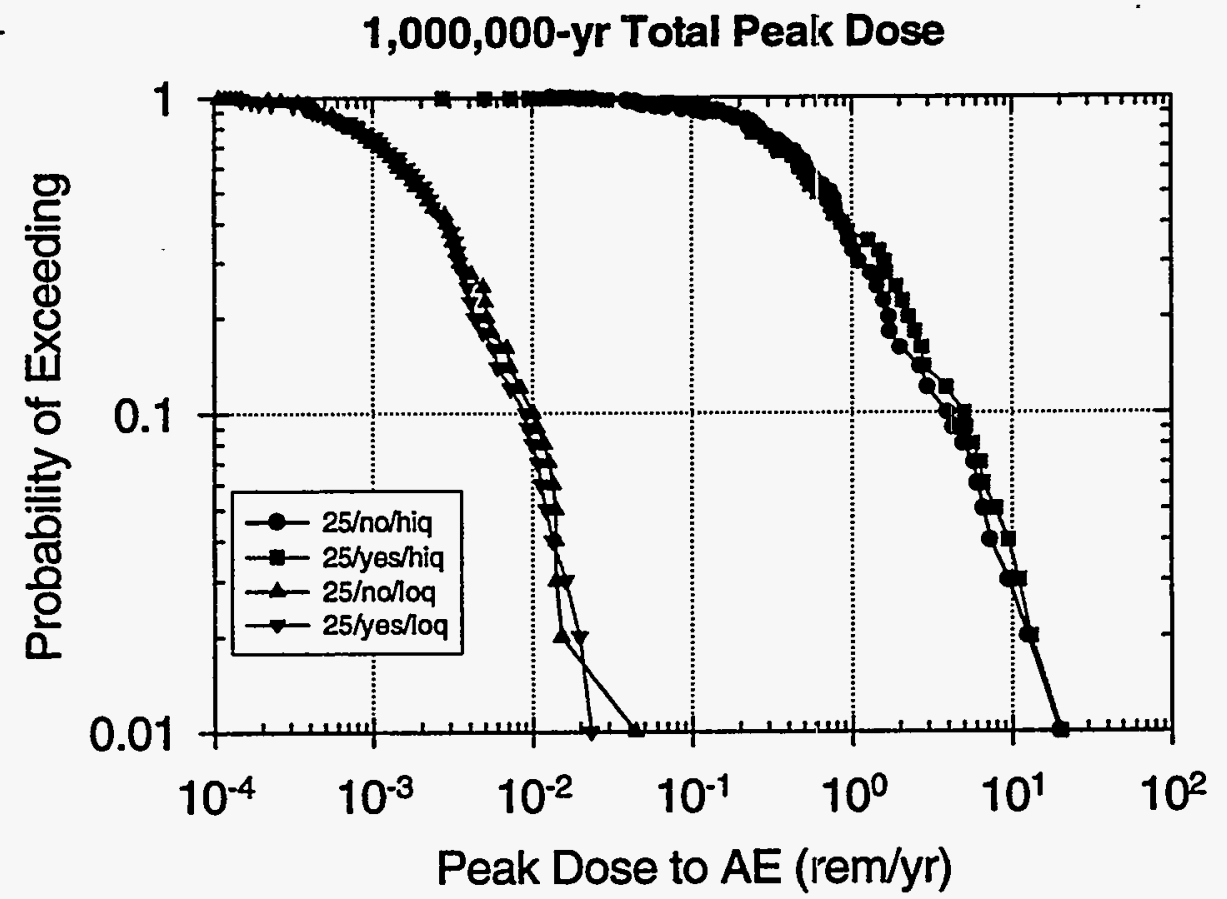

Figure 9.3-14 CCDF of Total Peak Dose: 1,000,000 years, 25 MTU/acre, with ("yes") and without ("no") backfill, high and low infiltration $\left(\mathrm{q}_{\mathrm{inf}}\right)$ ranges, cyclical- $\mathrm{q}_{\mathrm{inf}}$ climate model.

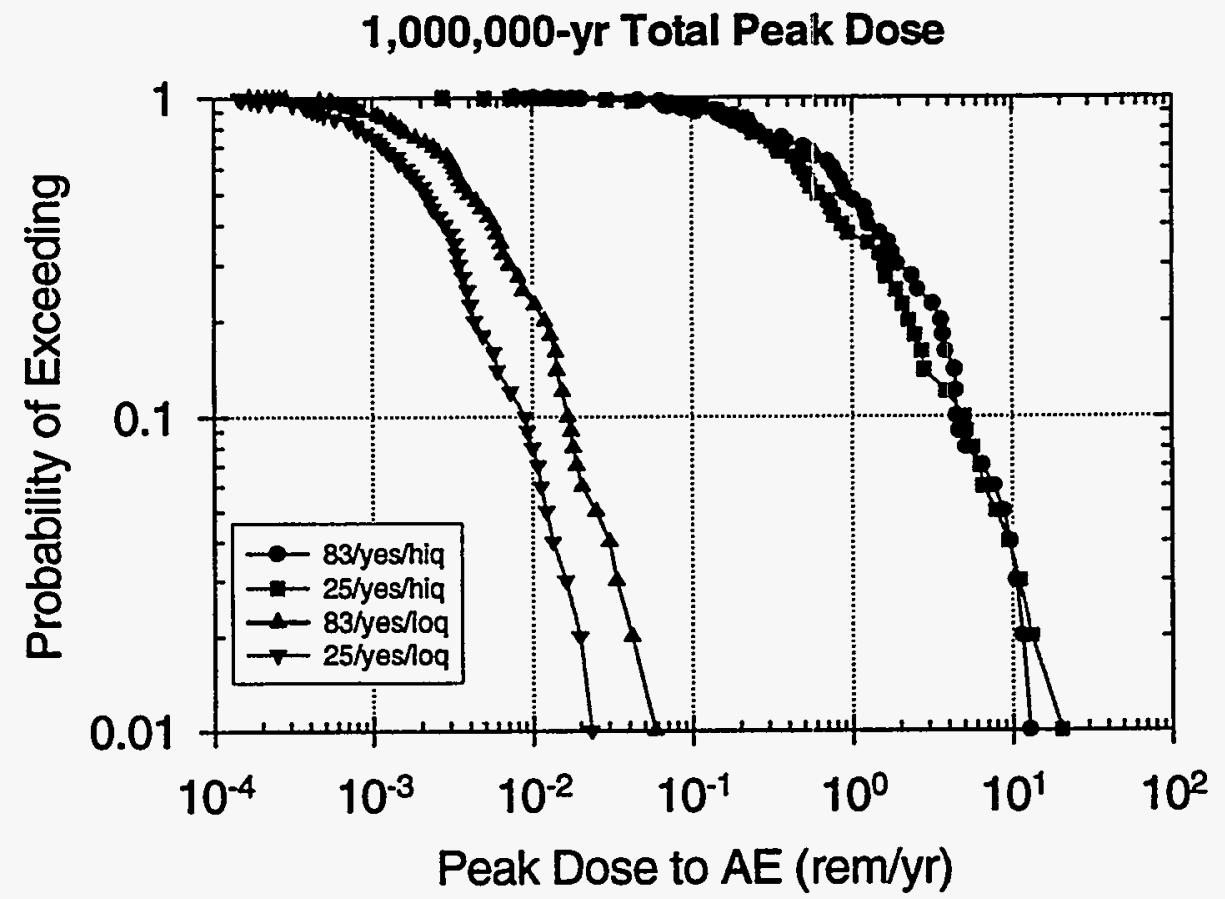

Figure 9.3-15 CCDF of Total Peak Dose: 1,000,000 years, 83 MTU/acre and 25 MTU/acre, with ("yes") backfill, high and low infiltration $\left(\mathrm{q}_{\mathrm{inf}}\right)$ ranges, cyclical- $\mathrm{q}_{\mathrm{inf}}$ climate model. 


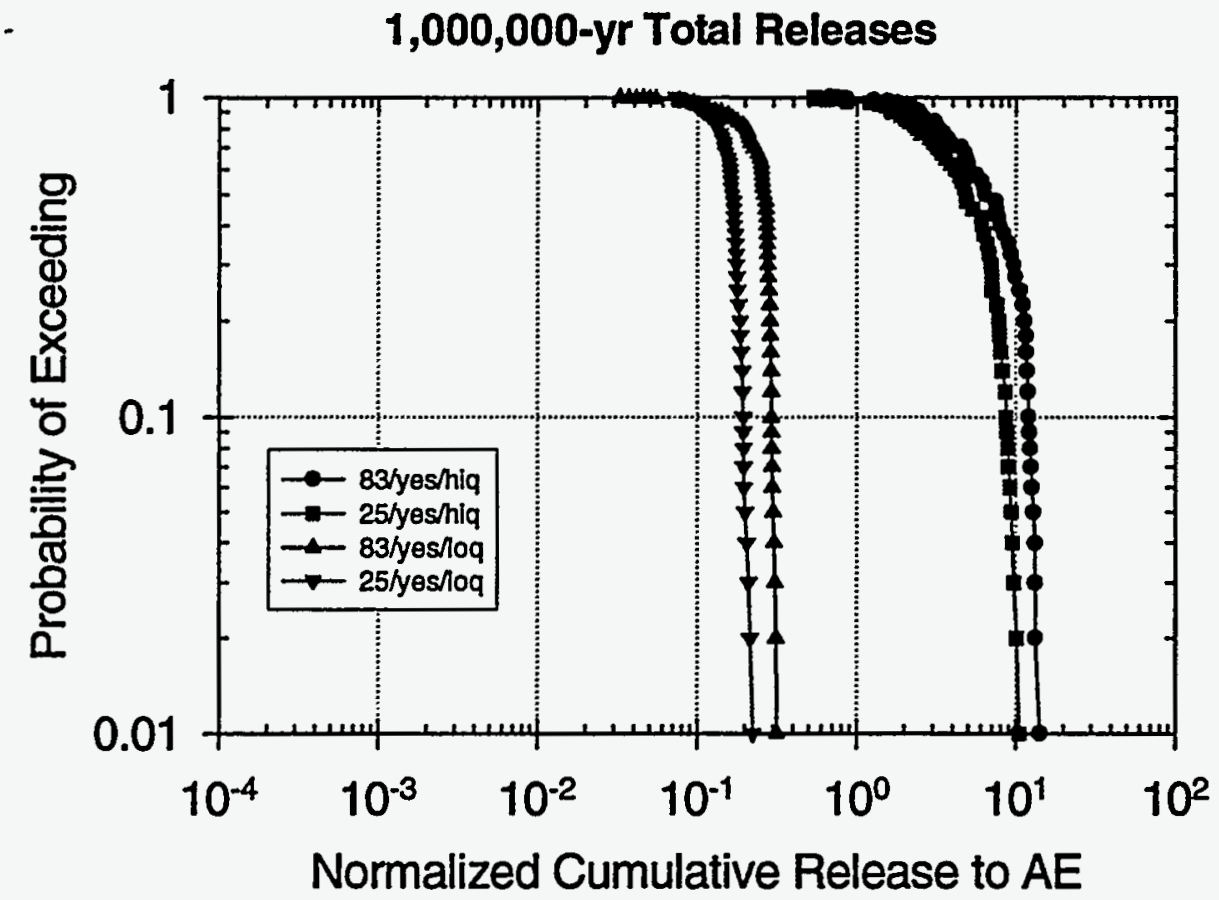

Figure 9.3-16 CCDF of Total Normalized Cumulative Release: 1,000,000 years, 83 MTU/acre and $25 \mathrm{MTU} / \mathrm{acre}$, with ("yes") backfill, high and low infiltration $\left(\mathrm{q}_{\mathrm{inf}}\right)$ ranges, cyclical- $\mathrm{q}_{\text {inf }}$ climate model.

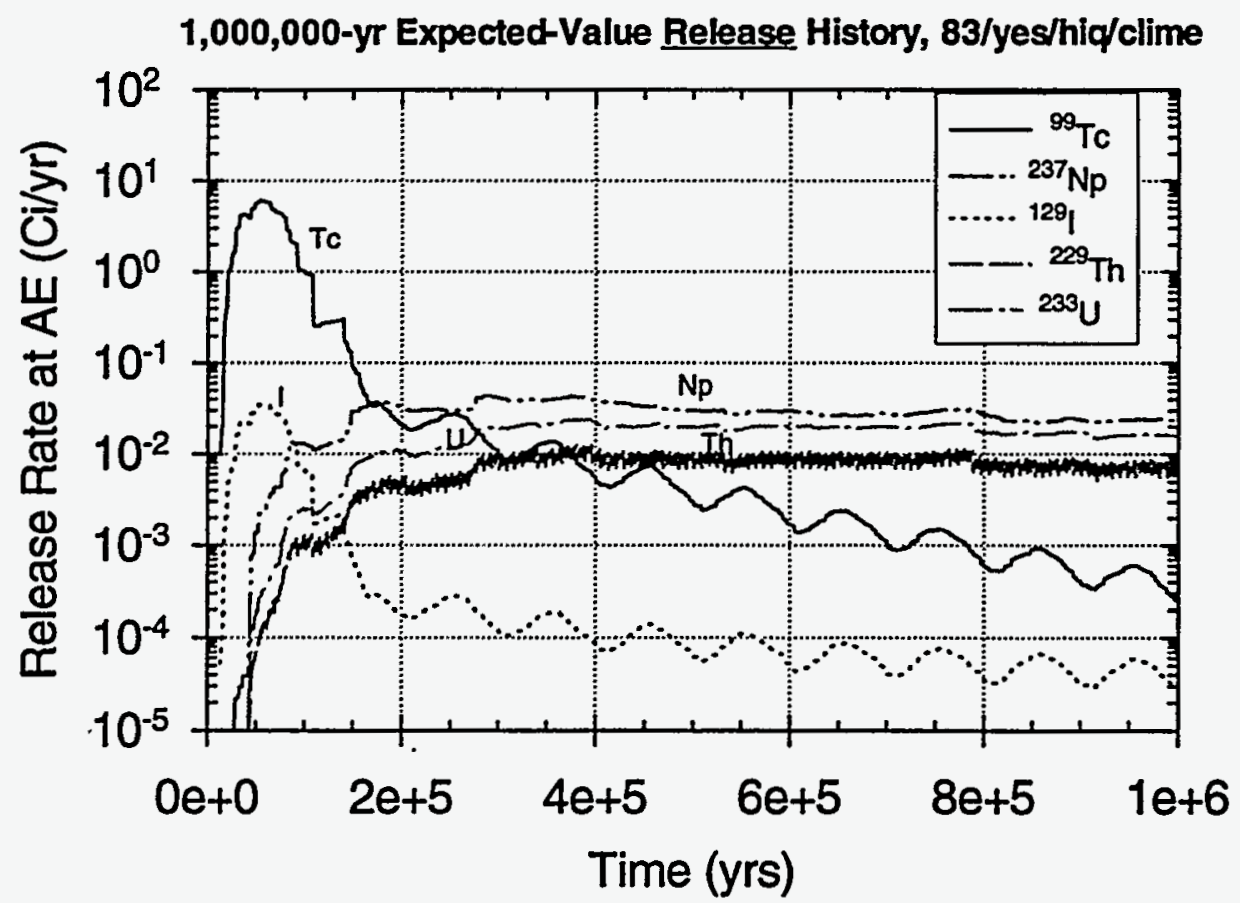

Figure 9.3-17 Expected-value release-rate history: 1,000,000 years, 83 MTU/acre, backfill, high infiltration (initial $\mathrm{q}_{\mathrm{inf}}=1.25 \mathrm{~mm} / \mathrm{yr}$ ), cyclical- $\mathrm{q}_{\mathrm{inf}}$ climate model. 

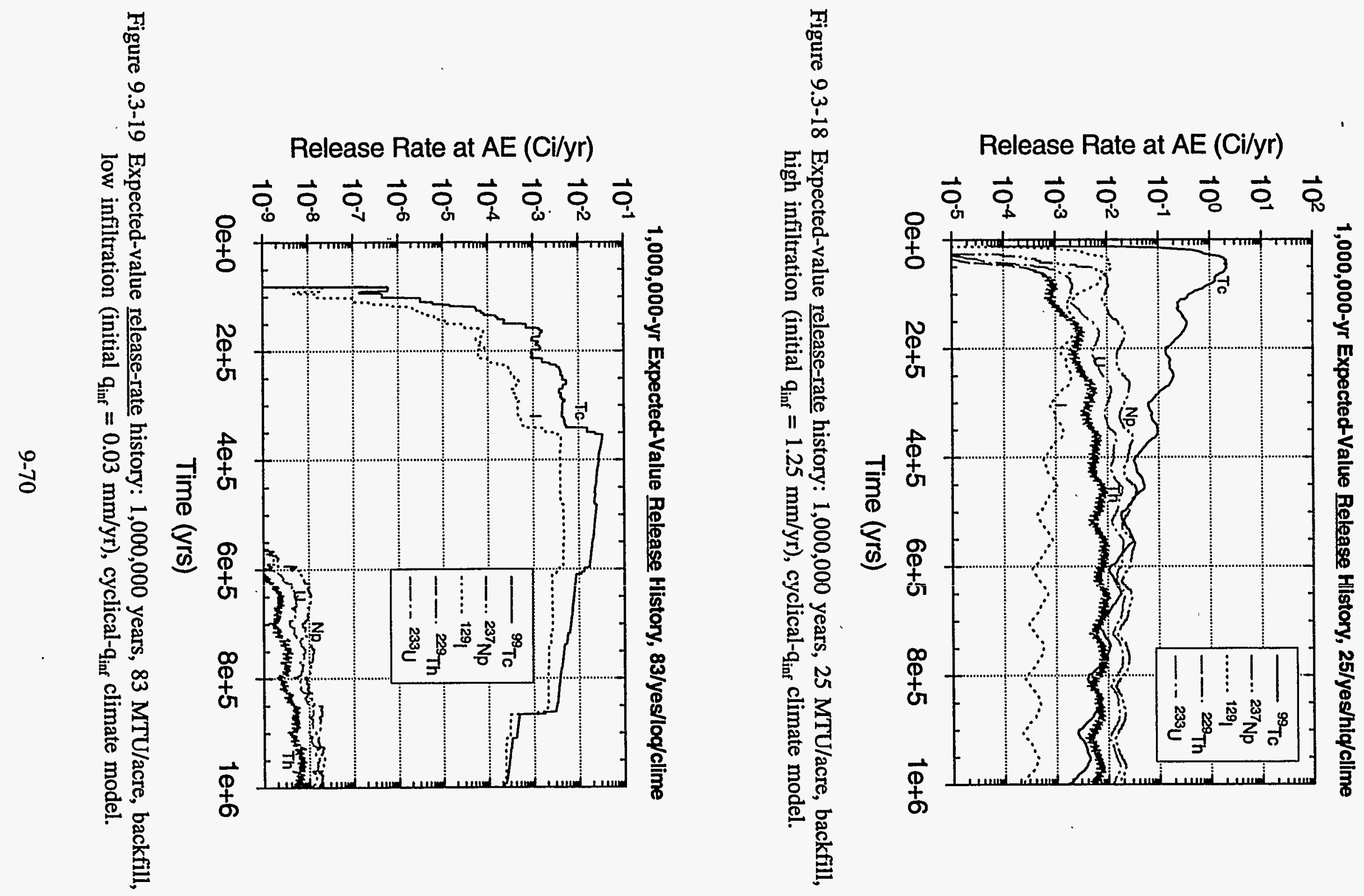


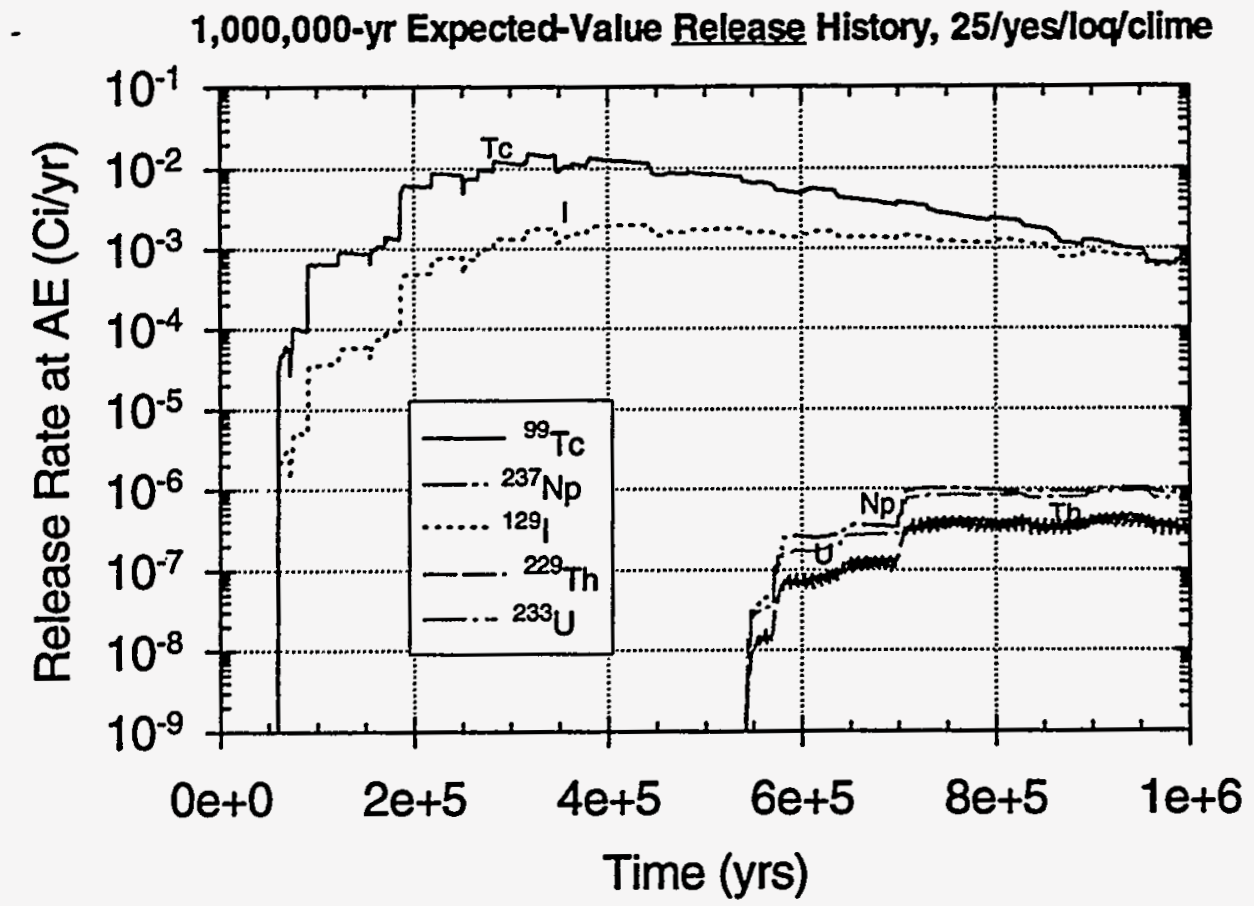

Figure 9.3-20 Expected-value release-rate history: 1,000,000 years, 25 MTU/acre, backfill, low infiltration (initial $\mathrm{q}_{\mathrm{inf}}=0.03 \mathrm{~mm} / \mathrm{yr}$ ), cyclical- $\mathrm{q}_{\mathrm{inf}}$ climate model.

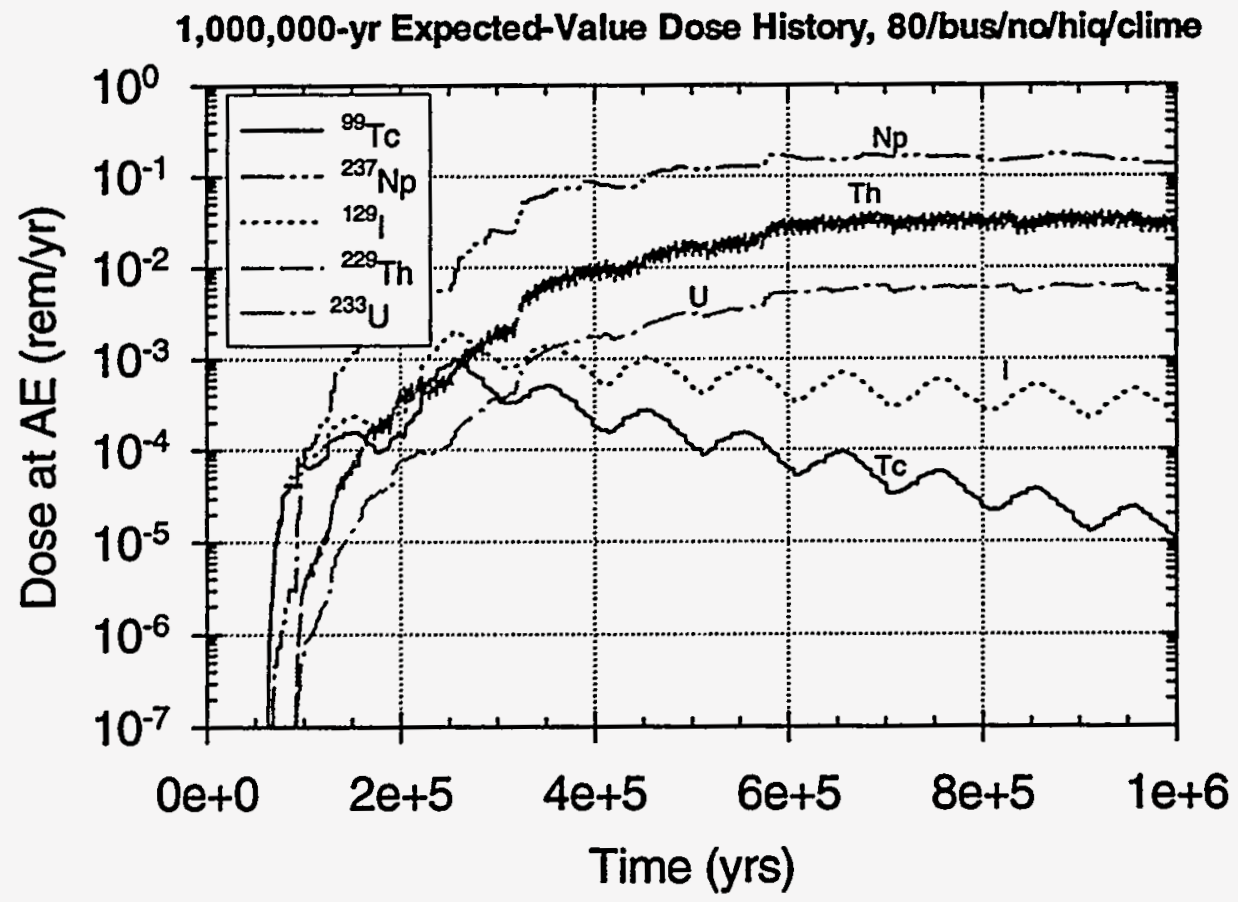

Figure 9.3-21 Expected-value dose history: 1,000,000 years, Buscheck 80 MTU/acre, no backfill, high infiltration (initial $\mathrm{q}_{\mathrm{inf}}=1.25 \mathrm{~mm} / \mathrm{yr}$ ), cyclical- $\mathrm{q}_{\mathrm{inf}}$ climate model. 


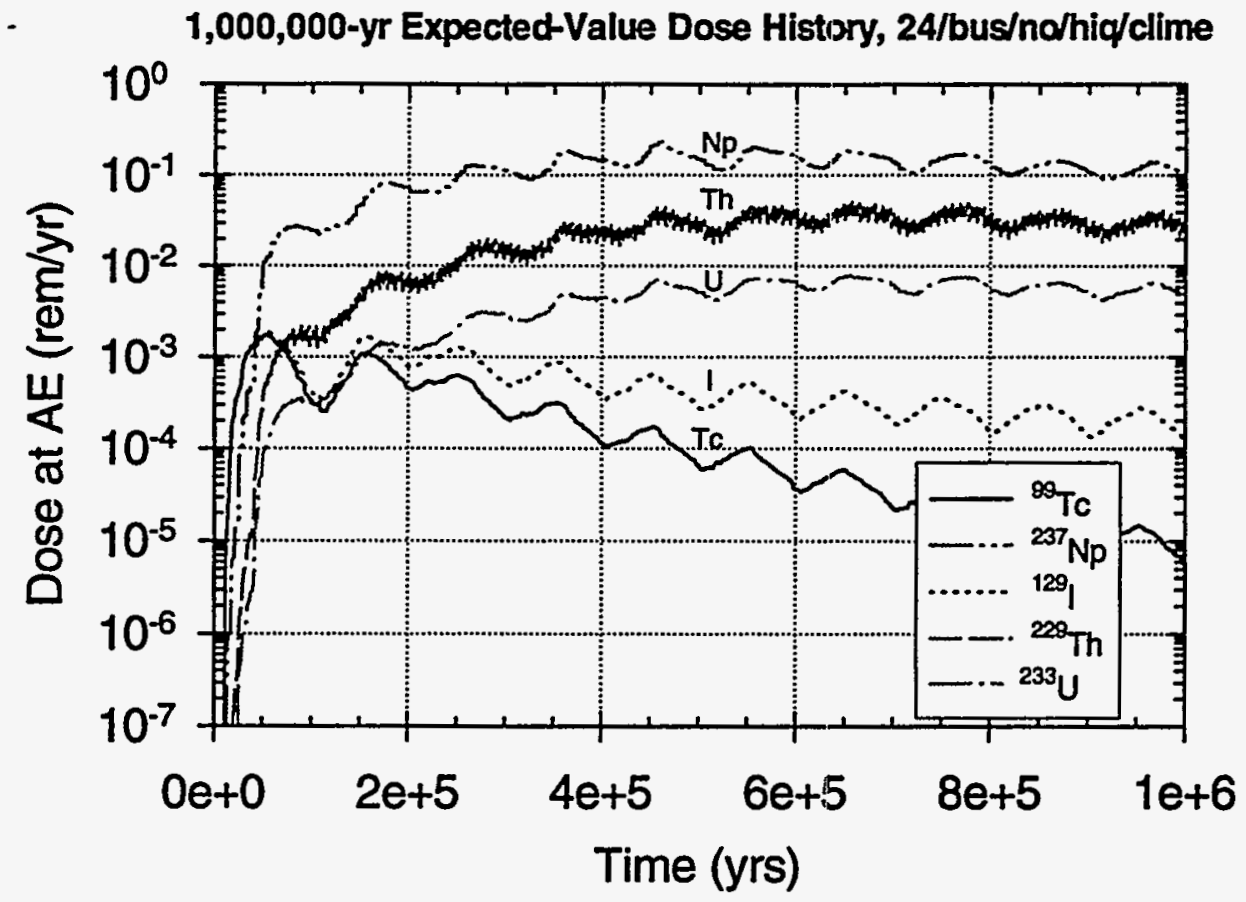

Figure 9.3-22 Expected-value dose history: 1,000,000 years, Buscheck 24 MTU/acre, no backfill, high infiltration (initial $\mathrm{q}_{\mathrm{inf}}=1.25 \mathrm{~mm} / \mathrm{yr}$ ), cyclical- $\mathrm{q}_{\mathrm{inf}}$ climate model.

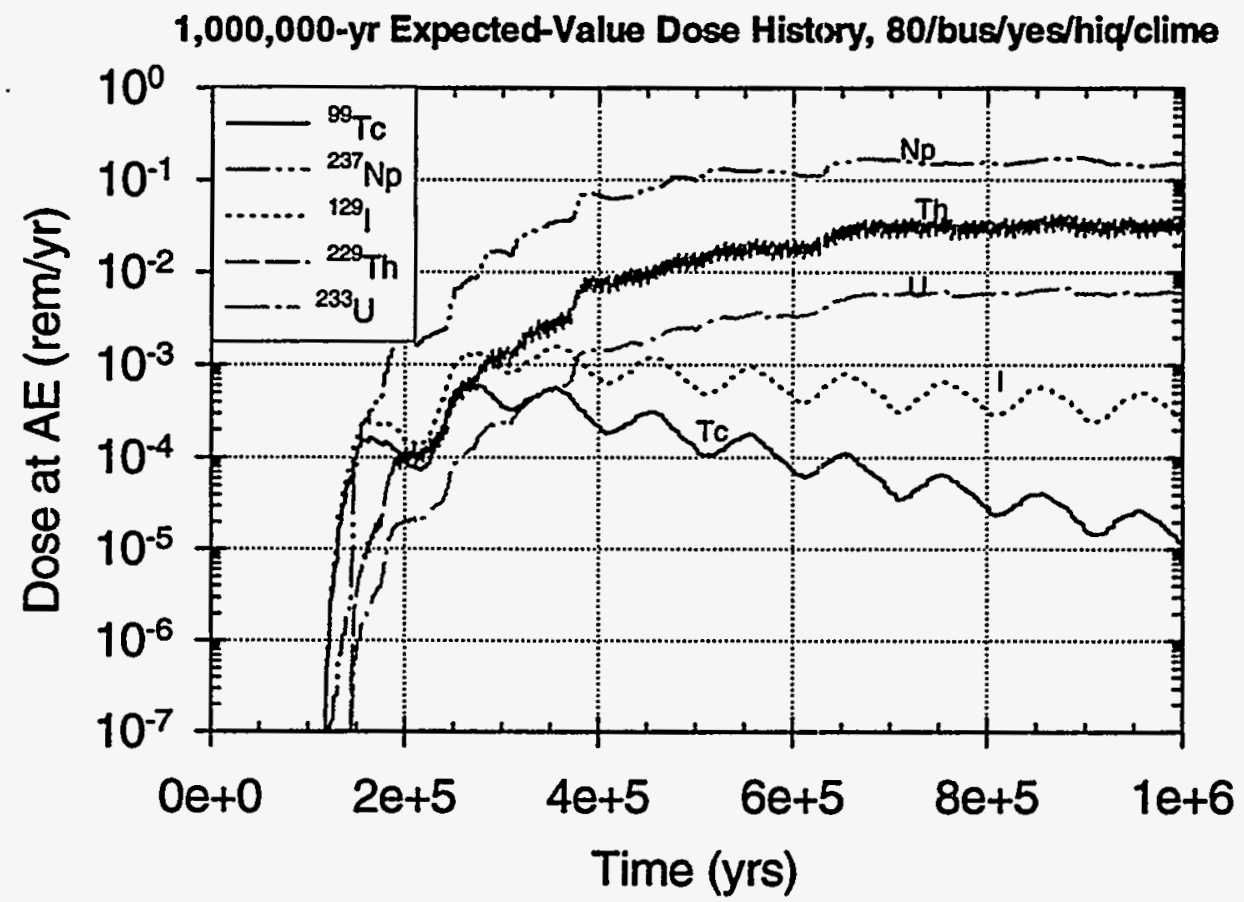

Figure 9.3-23 Expected-value dose history: 1,000,000 years, Buscheck 80 MTU/acre, backfill, high infiltration (initial $\mathrm{q}_{\text {inf }}=1.25 \mathrm{~mm} / \mathrm{yr}$ ), cyclical- $\mathrm{q}_{\text {inf }}$ climate model. 


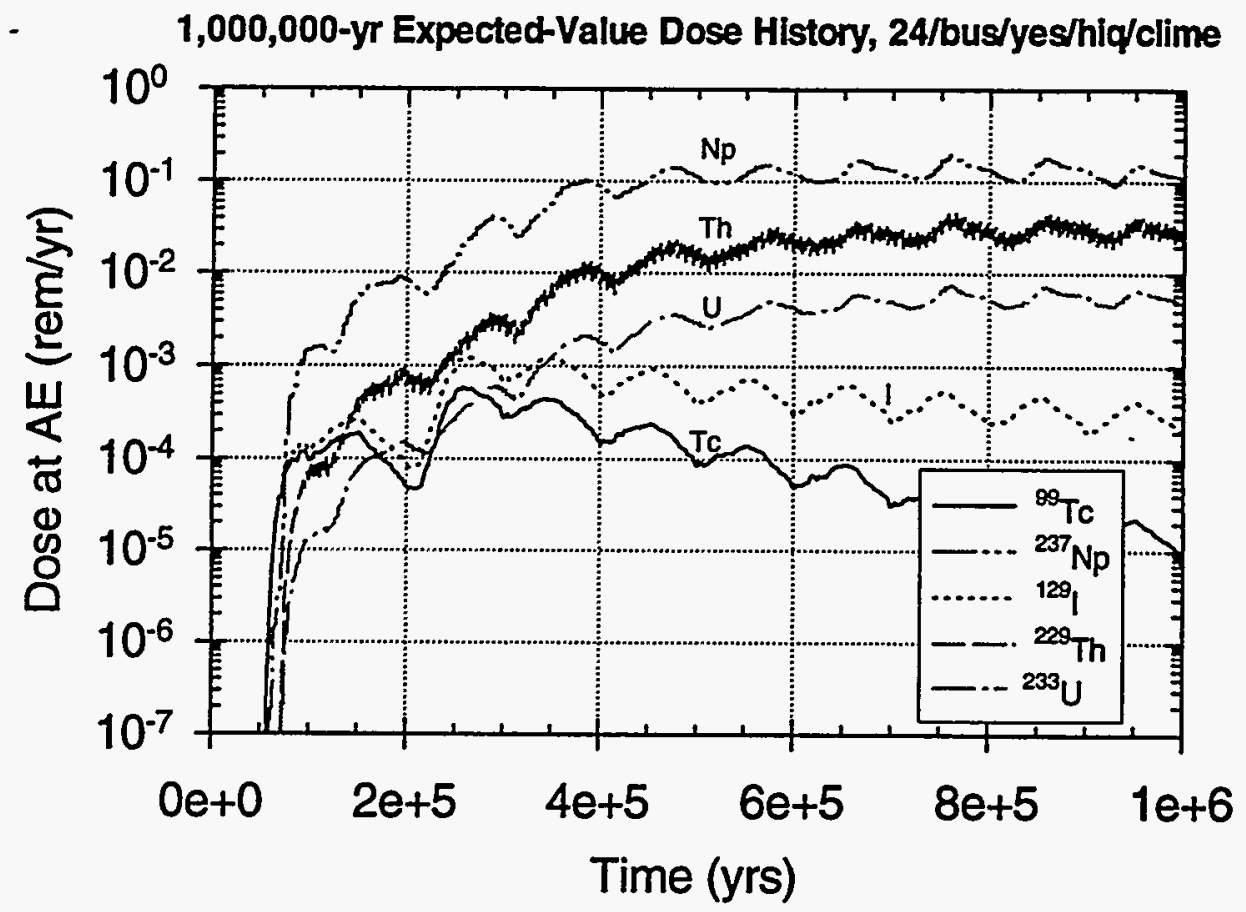

Figure 9.3-24 Expected-value dose history: 1,000,000 years, Buscheck 24 MTU/acre, backfill, high infiltration (initial $\mathrm{q}_{\mathrm{inf}}=1.25 \mathrm{~mm} / \mathrm{yr}$ ), cyclical- $\mathrm{q}_{\mathrm{inf}}$ climate model.

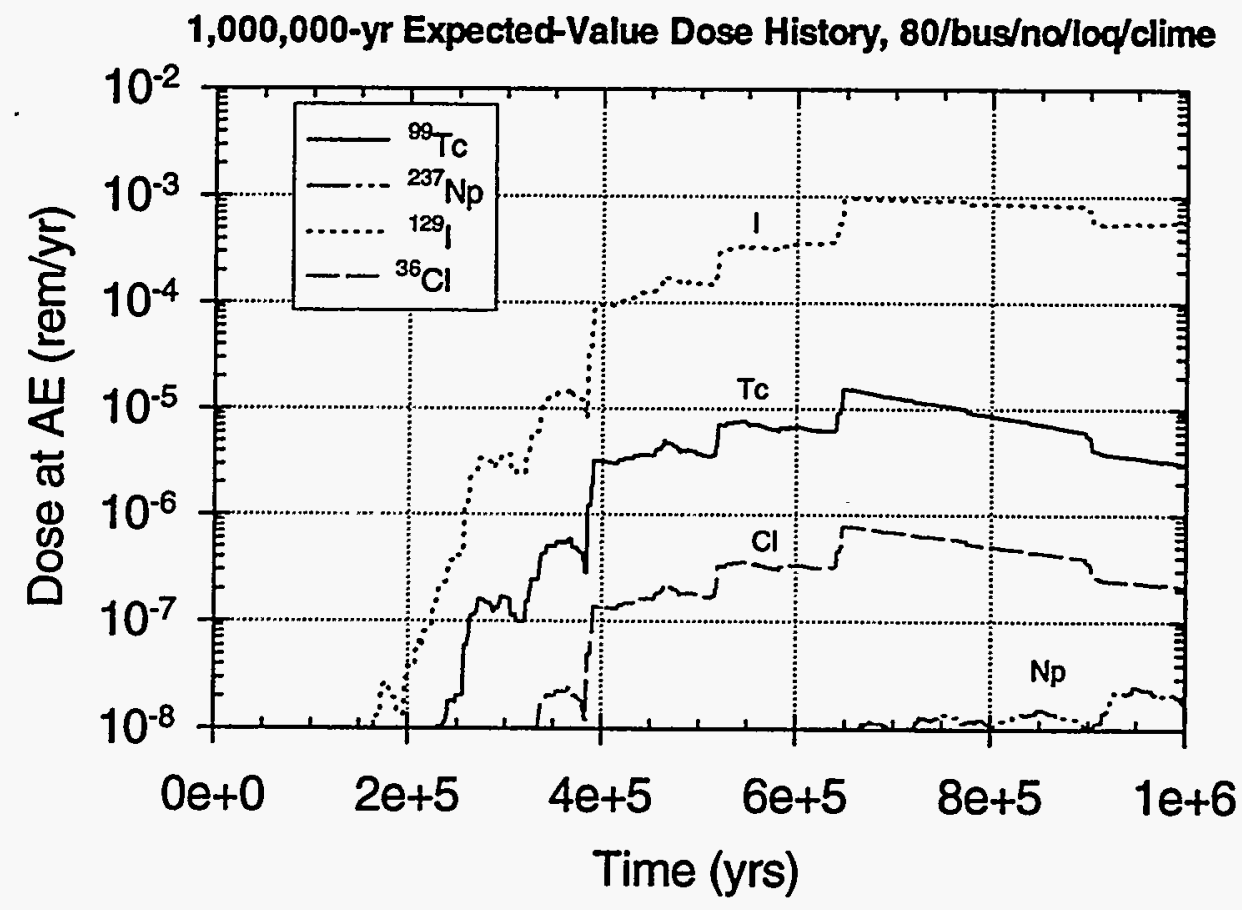

Figure 9.3-25 Expected-value dose history: 1,000,000 years, Buscheck 80 MTU/acre, no backfill, low infiltration (initial $\mathrm{q}_{\text {inf }}=0.03 \mathrm{~mm} / \mathrm{yr}$ ), cyclical- $\mathrm{q}_{\text {inf }}$ climate model. 


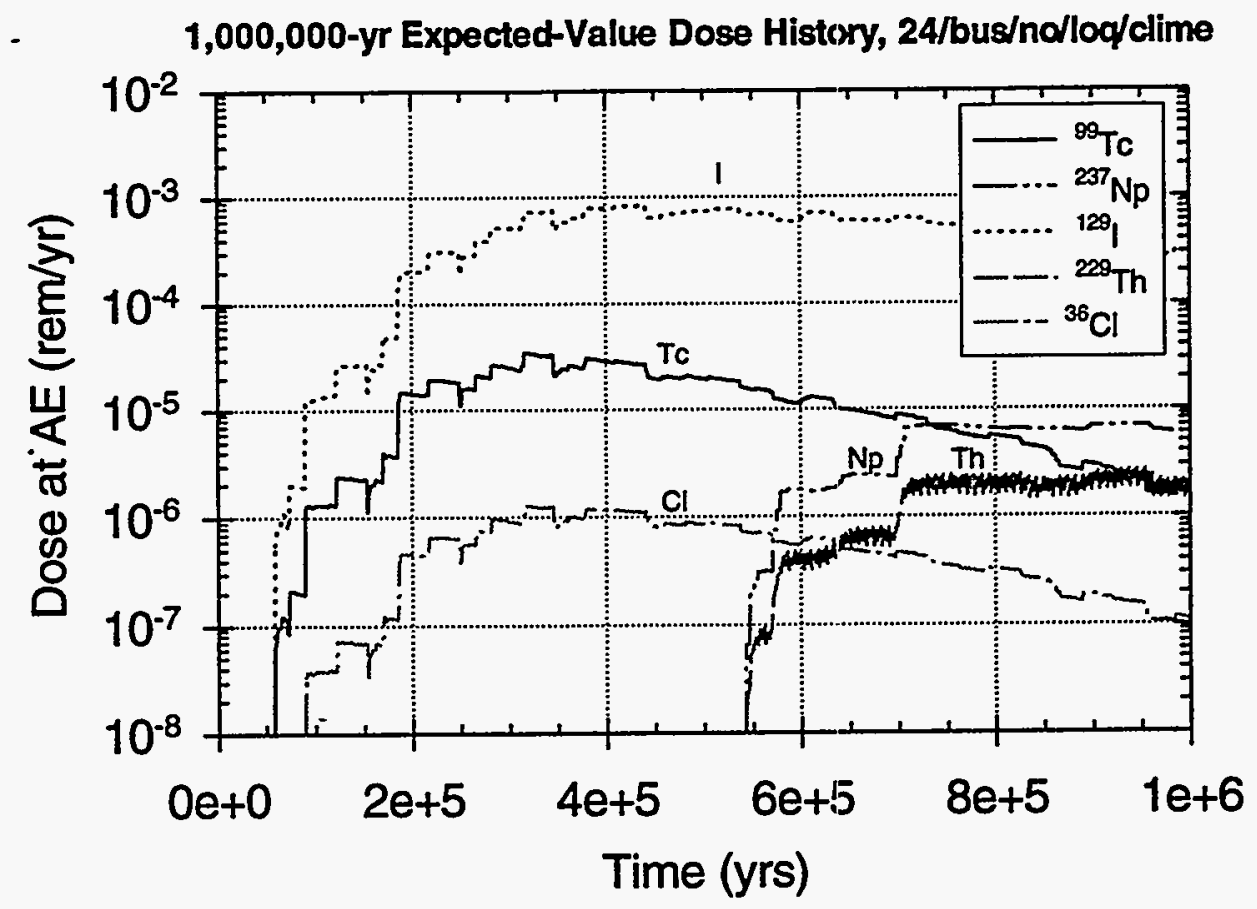

Figure 9.3-26 Expected-value dose history: 1,000,000 years, Buscheck 24 MTU/acre, no backfill, low infiltration (initial $\mathrm{q}_{\mathrm{inf}}=0.03 \mathrm{~mm} / \mathrm{yr}$ ), cyclical- $\mathrm{q}_{\mathrm{inf}}$ climate model.

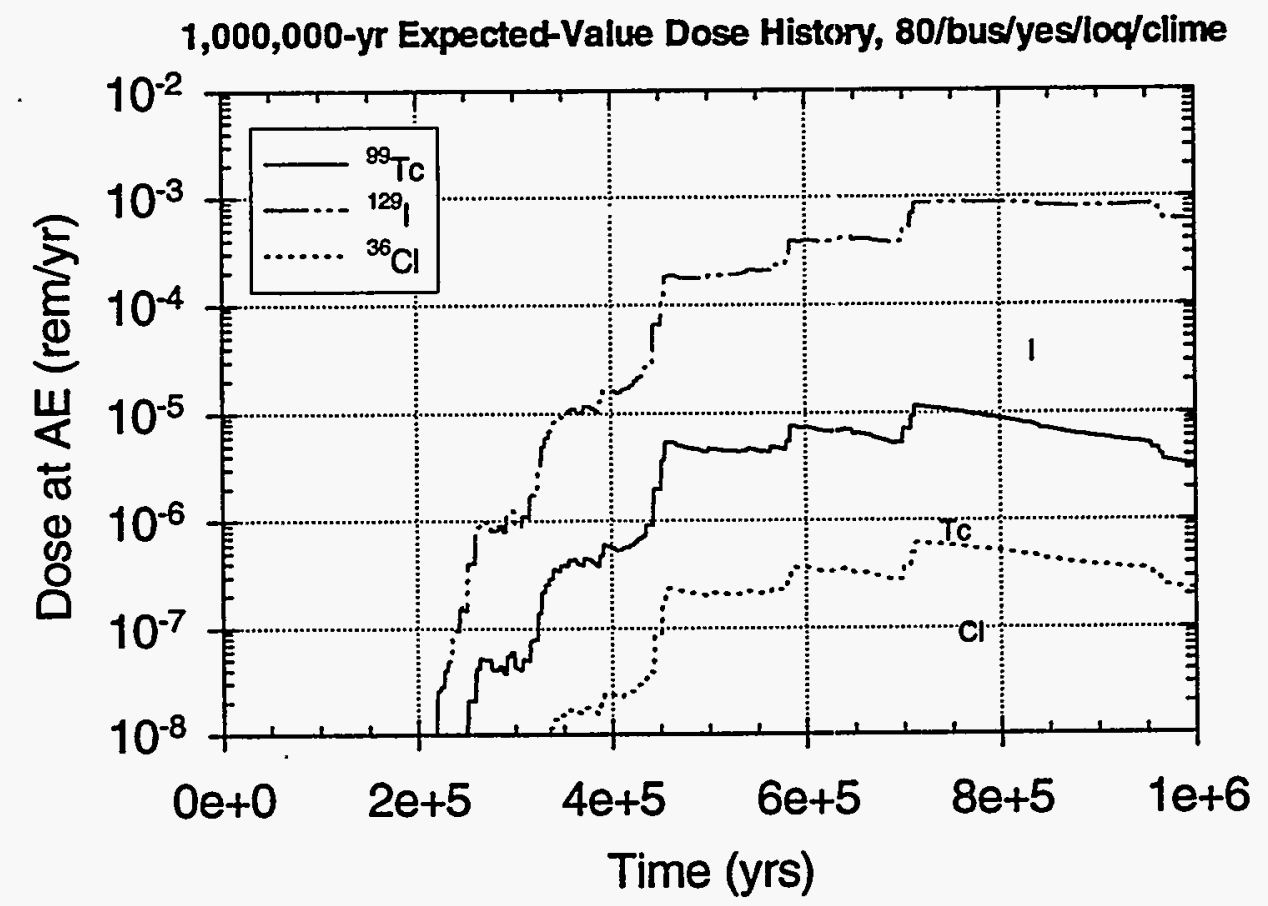

Figure 9.3-27 Expected-value dose history: 1,000,000 years, Buscheck 80 MTU/acre, backfill, low infiltration (initial $\mathrm{q}_{\mathrm{inf}}=0.03 \mathrm{~mm} / \mathrm{yr}$ ), cyclical- $\mathrm{q}_{\mathrm{inf}}$ climate model. 


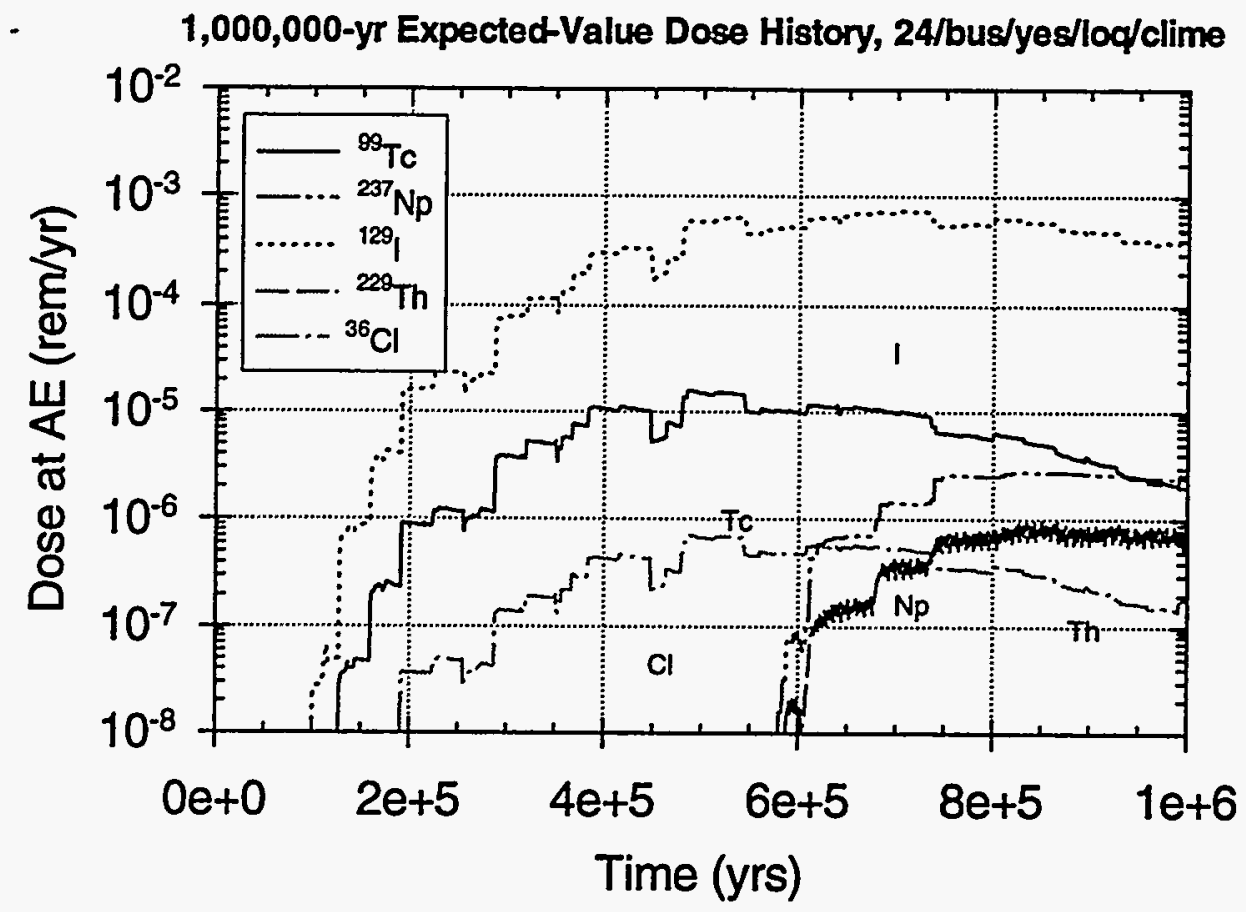

Figure 9.3-28 Expected-value dose history: 1,000,000 years, Buscheck 24 MTU/acre, backfill, low infiltration (initial $\mathrm{q}_{\text {inf }}=0.03 \mathrm{~mm} / \mathrm{yr}$ ), cyclical- $\mathrm{q}_{\text {inf }}$ climate model.

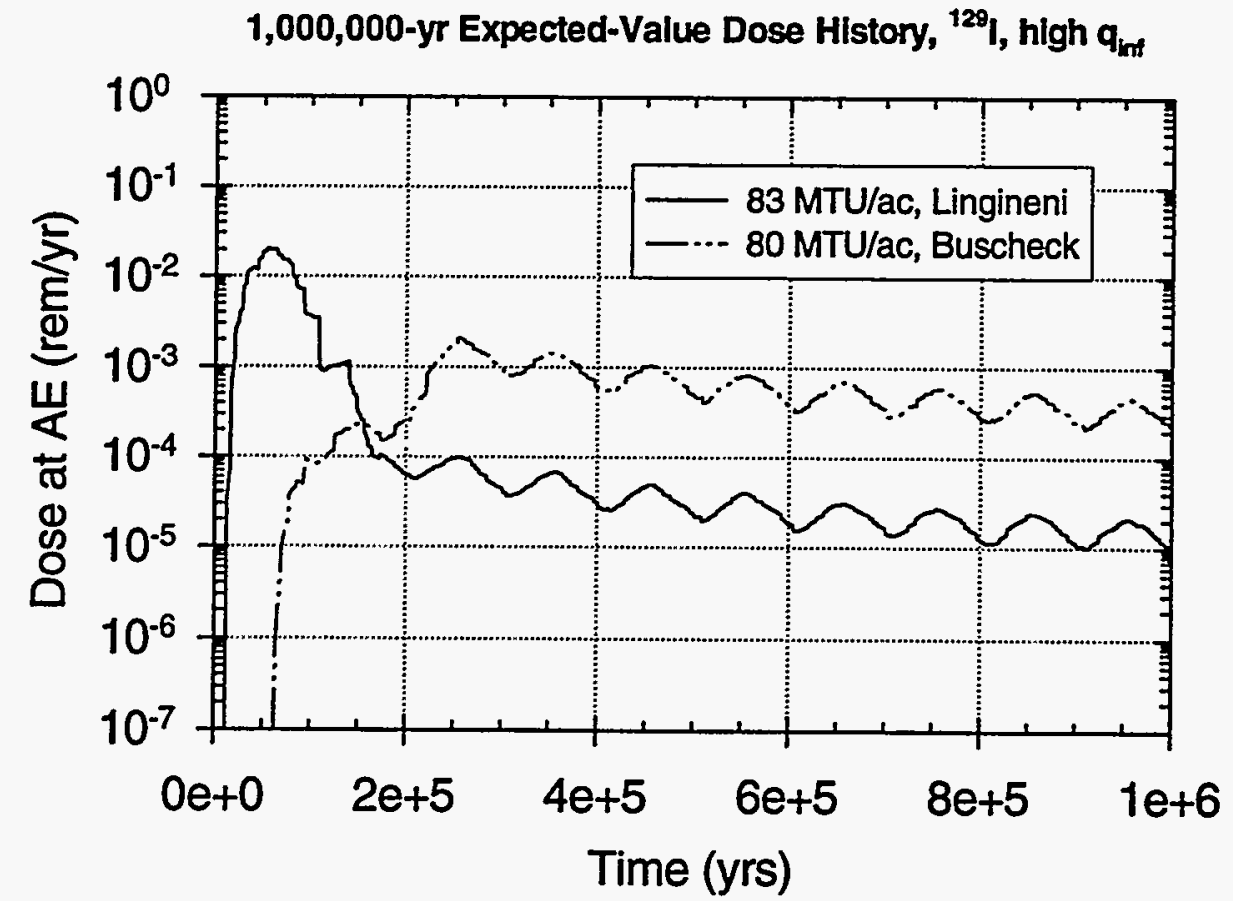

Figure 9.3-29 Expected-value dose history for ${ }^{129}$. 1,000,000 years, comparison of thermohydrologic models: Lingineni $83 \mathrm{MTU} / \mathrm{acre}$ and Buscheck 80 MTU/acre, high infiltration rate $\left(\mathrm{q}_{\mathrm{inf}}=1.25 \mathrm{~mm} / \mathrm{yr}\right)$, no backfill, cyclical- $\mathrm{q}_{\mathrm{inf}}$ climate model. 


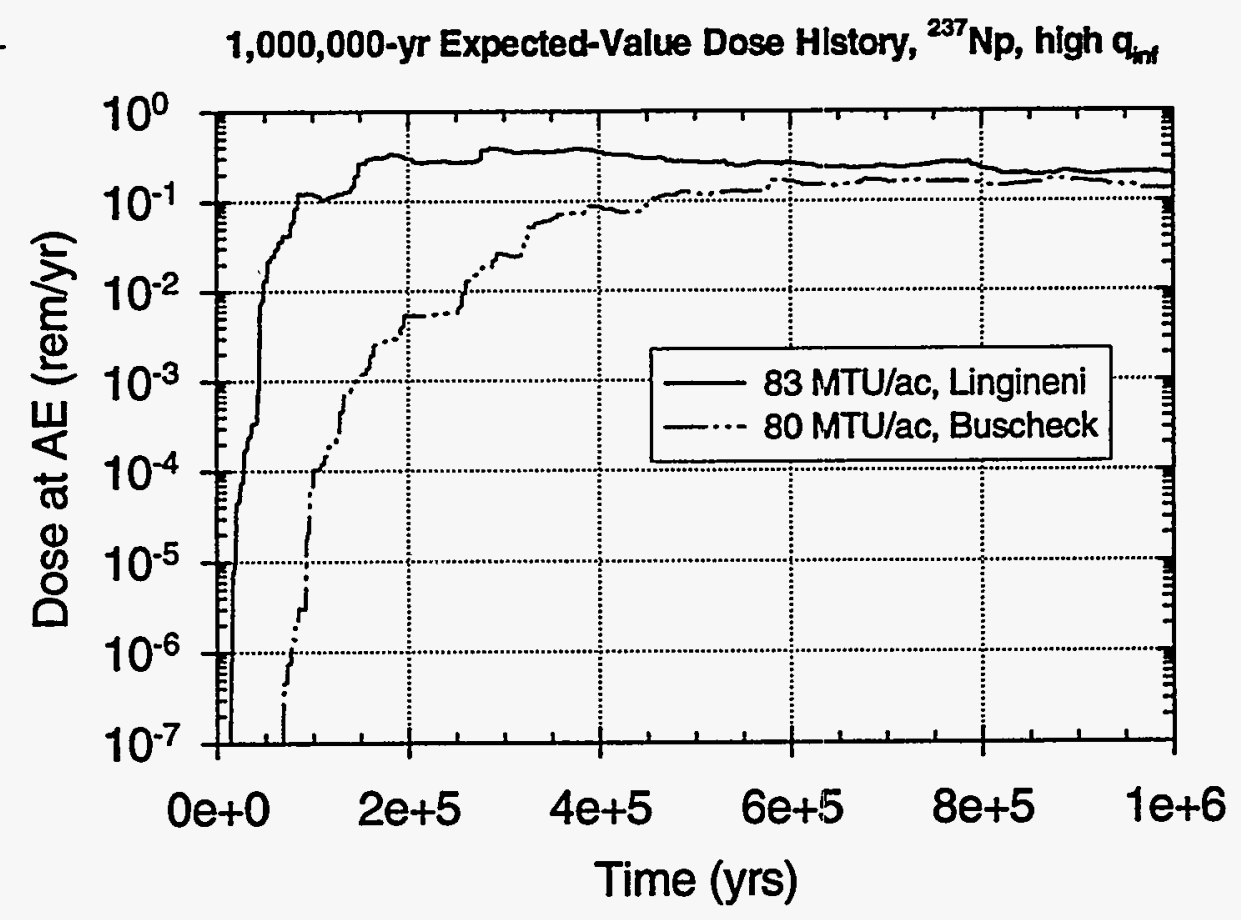

Figure 9.3-30 Expected-value dose history for ${ }^{237} \mathrm{~Np} . \quad 1,000,000$ years, comparison of thermohydrologic models: Lingineni $83 \mathrm{MTU} / \mathrm{acre}$ and Buscheck 80 MTU/acre, high infiltration rate $\left(\mathrm{q}_{\mathrm{inf}}=1.25 \mathrm{~mm} / \mathrm{yr}\right)$, no backfill, cyclical- $\mathrm{q}_{\mathrm{inf}}$ climate model.

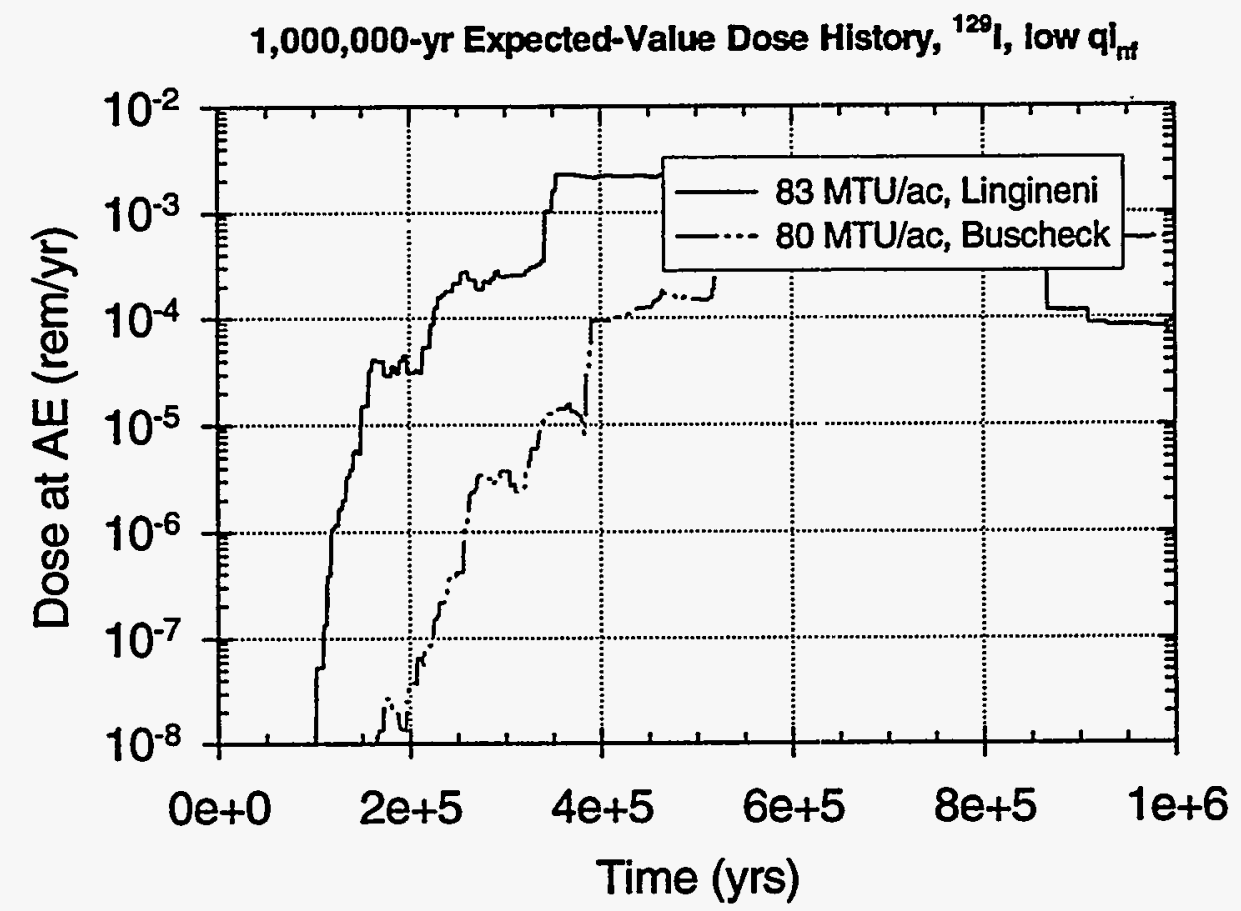

Figure 9.3-31 Expected-value dose history for ${ }^{129} \mathrm{~T}$. 1,000,000 years, comparison of thermohydrologic models: Lingineni 83 MTU/acre and Buscheck 80 MTU/acre, low infiltration rate $\left(\mathrm{q}_{\text {inf }}=0.03 \mathrm{~mm} / \mathrm{yr}\right)$, no backfill, cyclical- $\mathrm{q}_{\mathrm{inf}}$ climate model. 


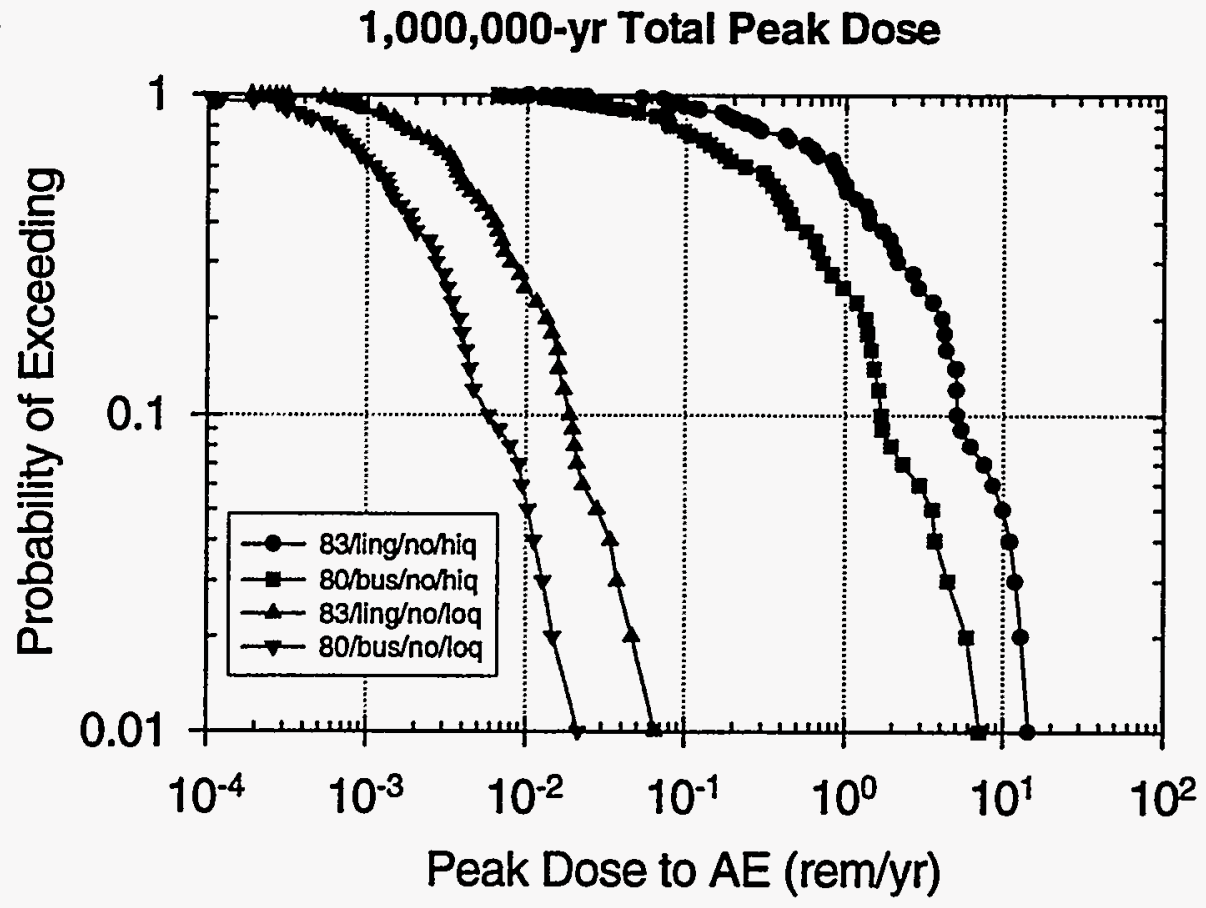

Figure 9.3-32 CCDF of Total Peak Dose: 1,000,000 years, Lingineni 83 MTU/acre and Buscheck $80 \mathrm{MTU} / \mathrm{acre}$, no backfill, high and low infiltration $\left(\mathrm{q}_{\mathrm{inf}}\right)$ ranges, cyclical- $\mathrm{q}_{\text {inf }}$ climate model.

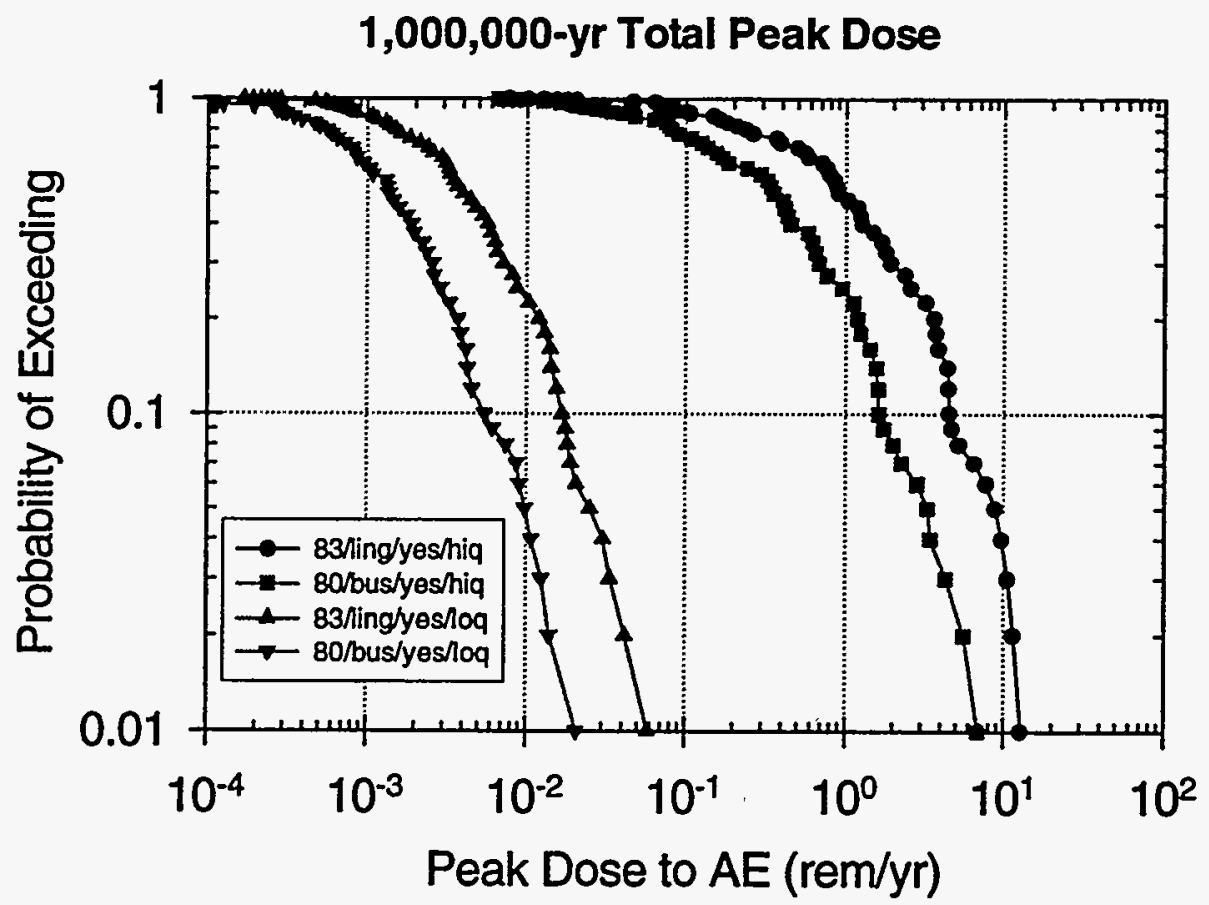

Figure 9.3-33 CCDF of Total Peak Dose: 1,000,000 years, Lingineni 83 MTU/acre and Buscheck $80 \mathrm{MTU} / \mathrm{acre}$, backfill, high and low infiltration $\left(\mathrm{q}_{\text {inf }}\right)$ ranges, cyclical- $\mathrm{q}_{\text {inf }}$ climate model. 


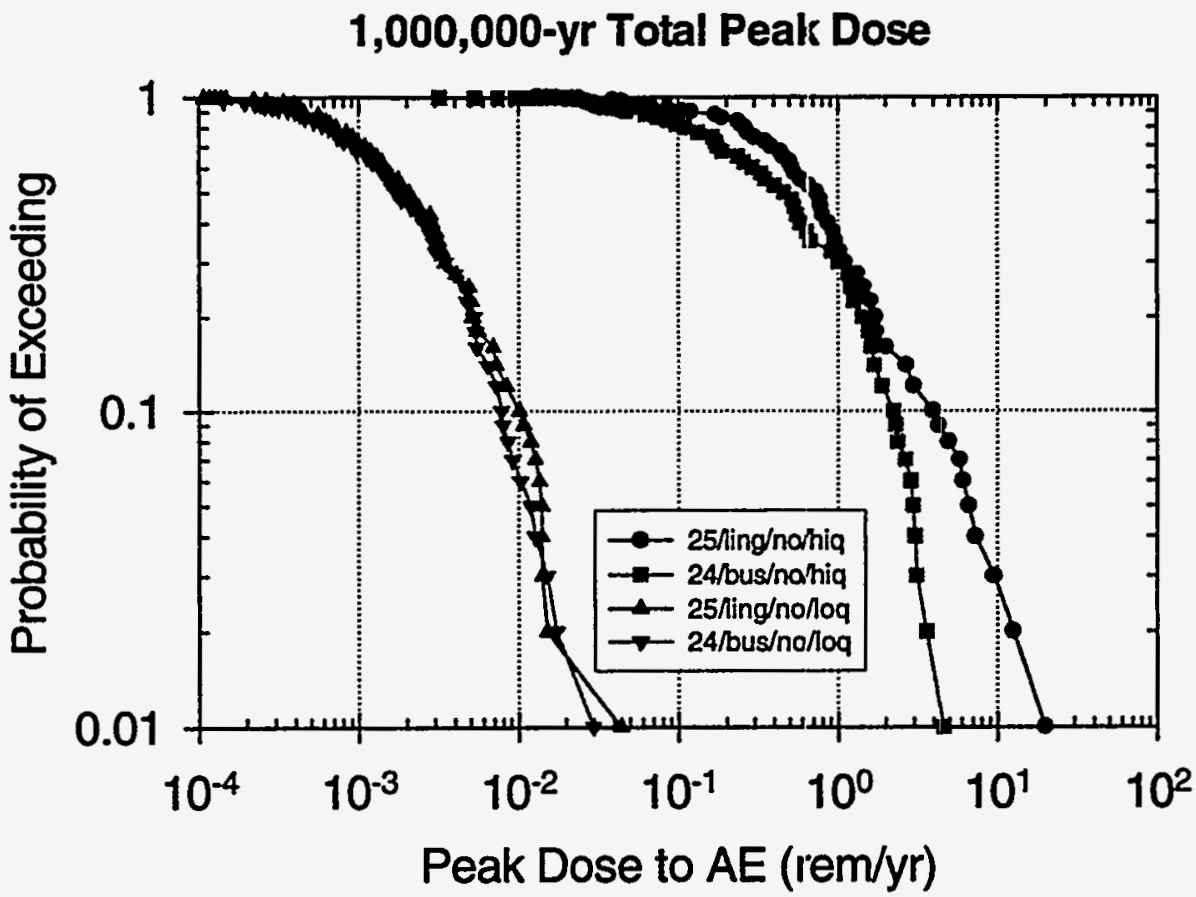

Figure 9.3-34 CCDF of Total Peak Dose: 1,000,000 years, Lingineni 25 MTU/acre and Buscheck $24 \mathrm{MTU} / \mathrm{acre}$, no backfill, high and low infiltration $\left(\mathrm{q}_{\mathrm{inf}}\right)$ ranges, cyclical- $\mathrm{q}_{\mathrm{inf}}$ climate model.

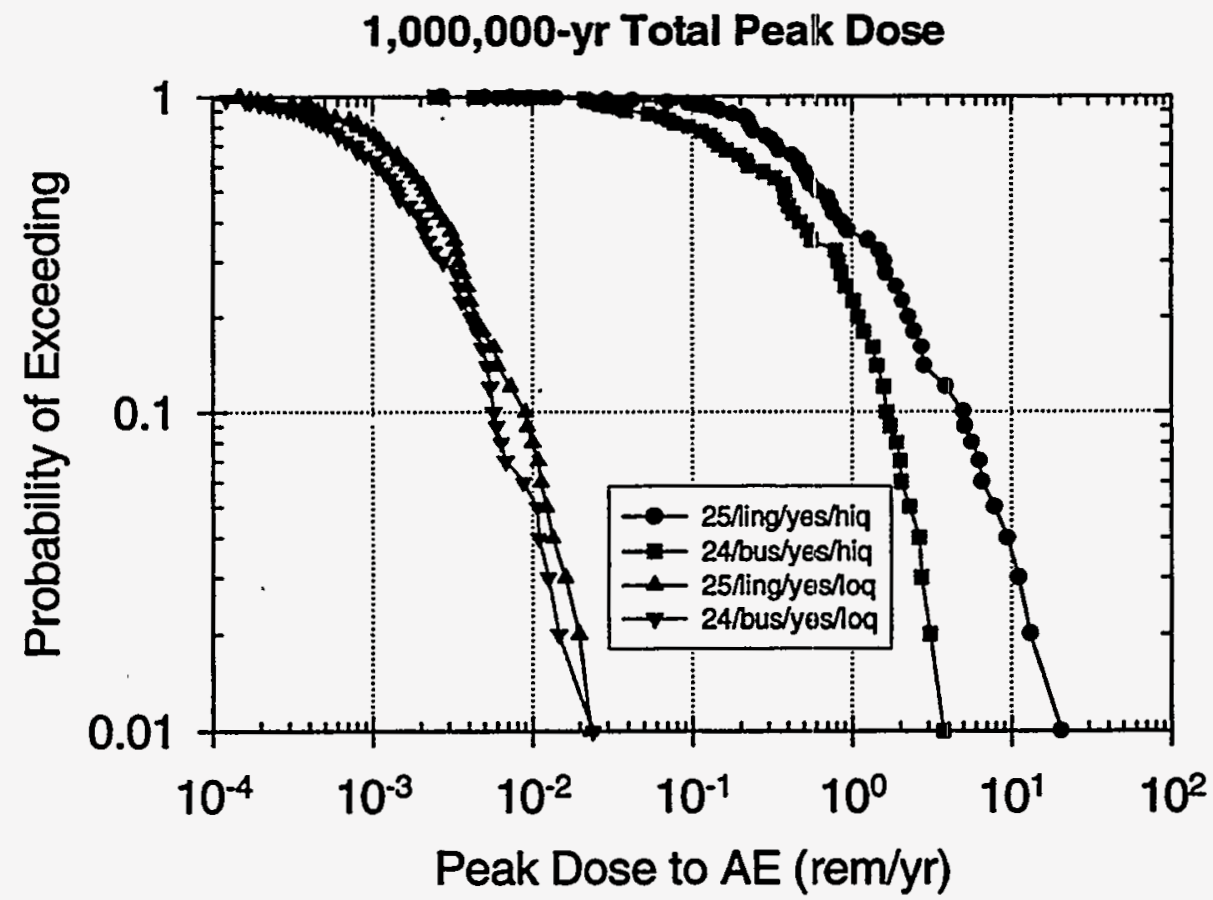

Figure 9.3-35 CCDF of Total Peak Dose: 1,000,000 years, Lingineni $25 \mathrm{MTU} / \mathrm{acre}$ and Buscheck $24 \mathrm{MTU} / \mathrm{acre}$, backfill, high and low infiltration $\left(\mathrm{q}_{\text {inf }}\right)$ ranges, cyclical- $\mathrm{q}_{\text {inf }}$ climate model. 

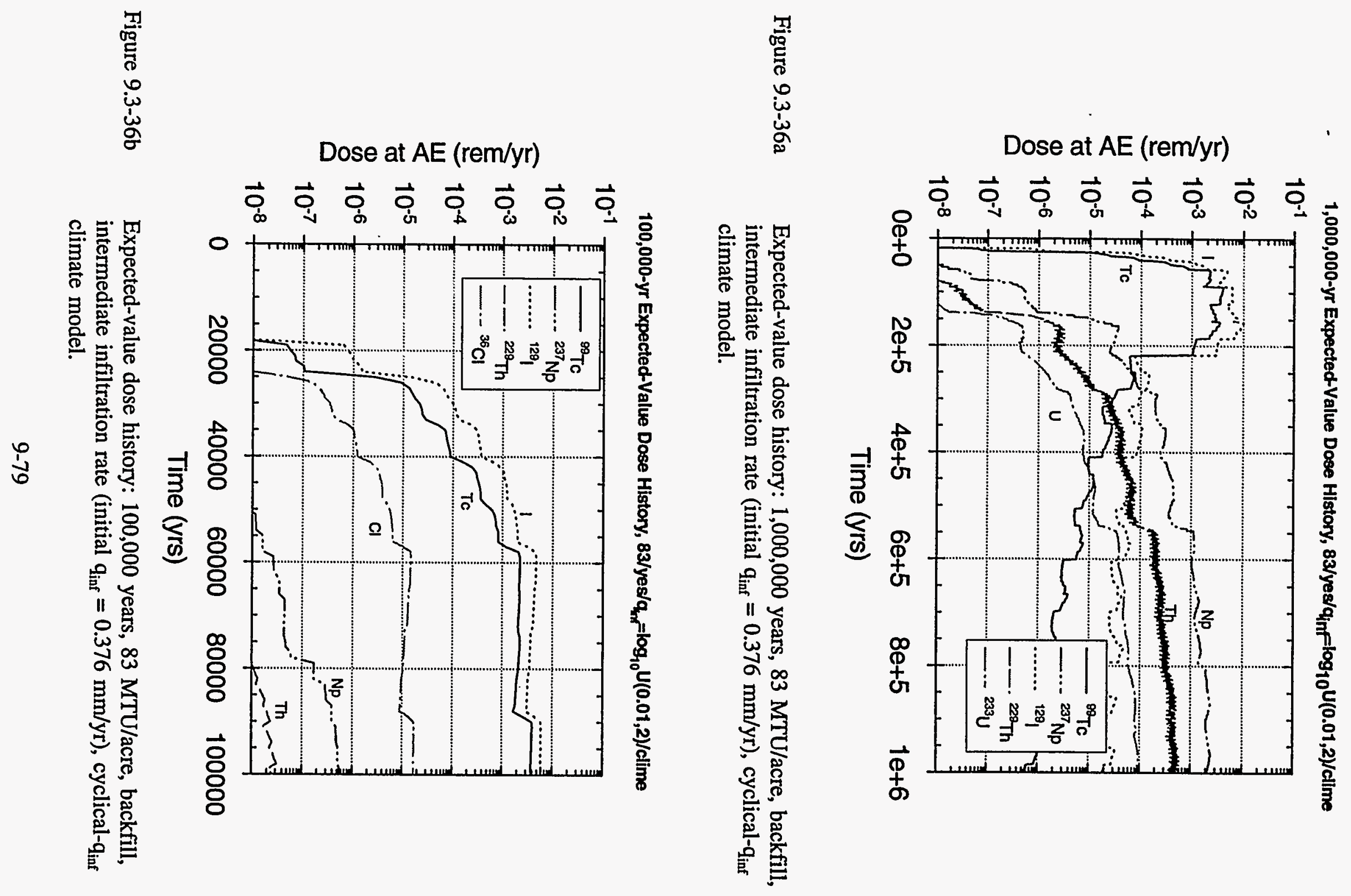


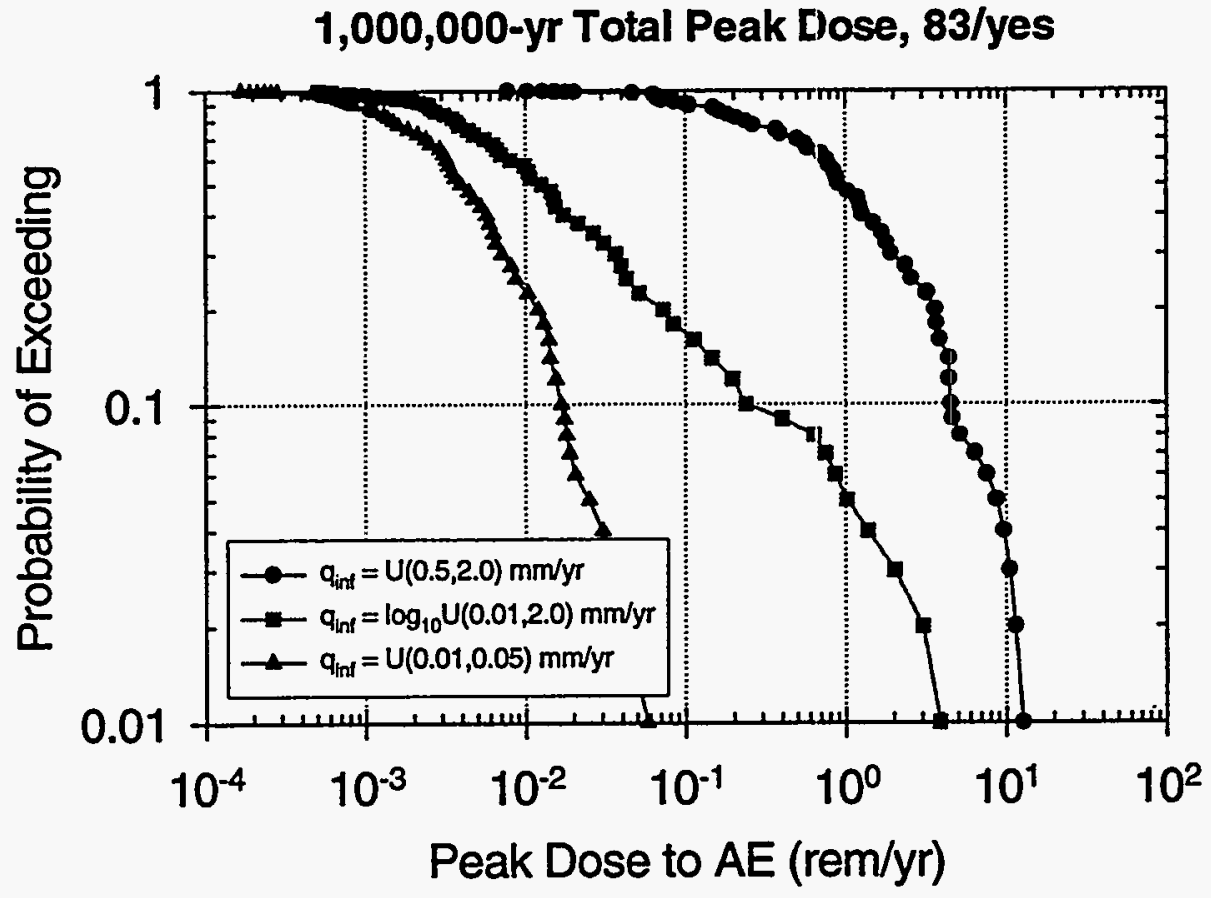

Figure 9.3-37 CCDF of Total Peak Dose: 1,000,000 years, 83 MTU/acre, backfill, high infiltration range $\left(q_{\text {inf }}=0.5-2.0 \mathrm{~mm} / \mathrm{yr}\right)$, low infiltration range $\left(\mathrm{q}_{\mathrm{inf}}=0.01-0.05\right.$ $\mathrm{mm} / \mathrm{yr})$, and entire infiltration range $\left(\mathrm{q}_{\mathrm{inf}}=0.01-2.0 \mathrm{~mm} / \mathrm{yr}\right)$, cyclical- $\mathrm{q}_{\mathrm{inf}}$

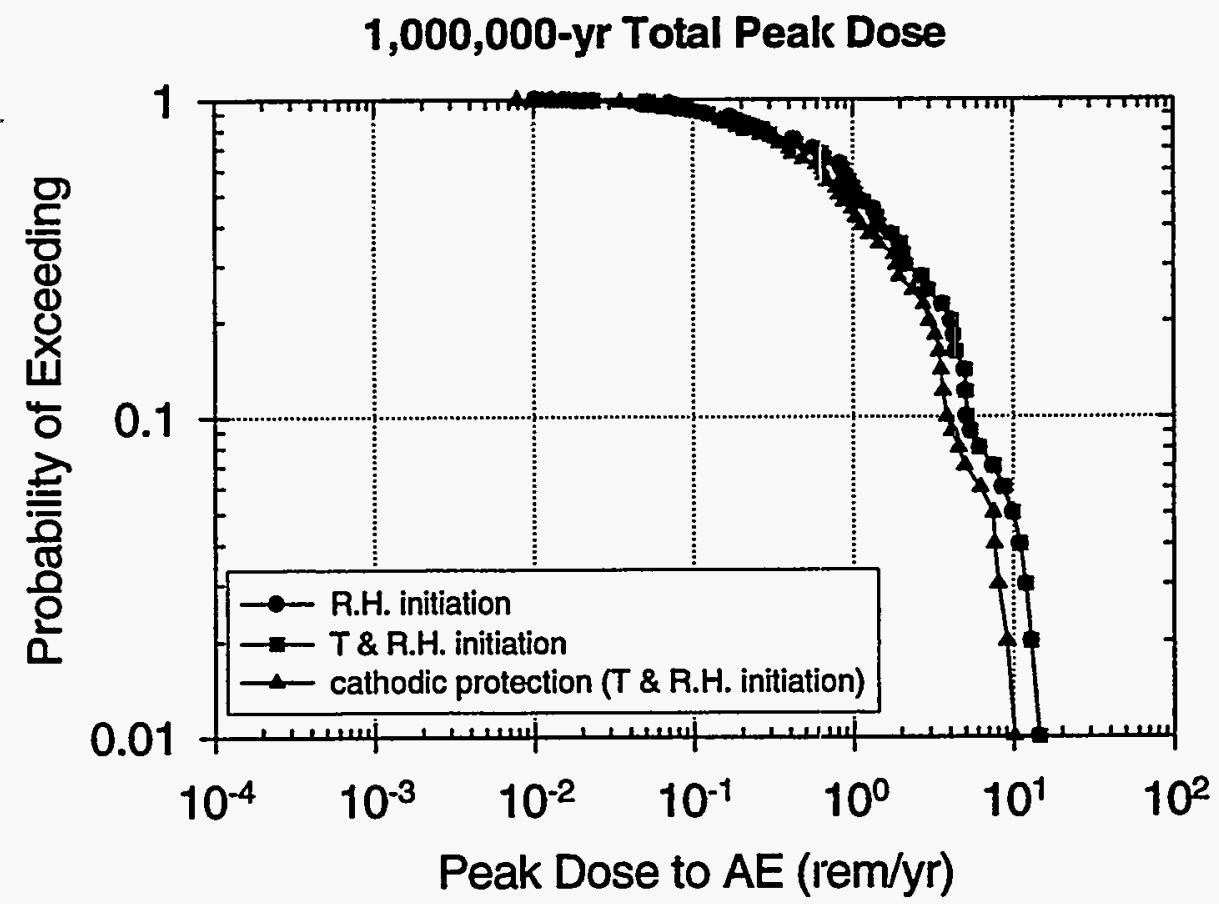

Figure 9.3-38 Effect of alternative corrosion-initiation models: Relative humidity only vs. temperature and relative humidity vs. temperature, relative humidity, and cathodic protection. CCDF of Total Peak Dose: 1,000,000 years, 83 MTU/acre, no backfill, high infiltration range, cyclical- $q_{\text {inf }}$ climate model. 


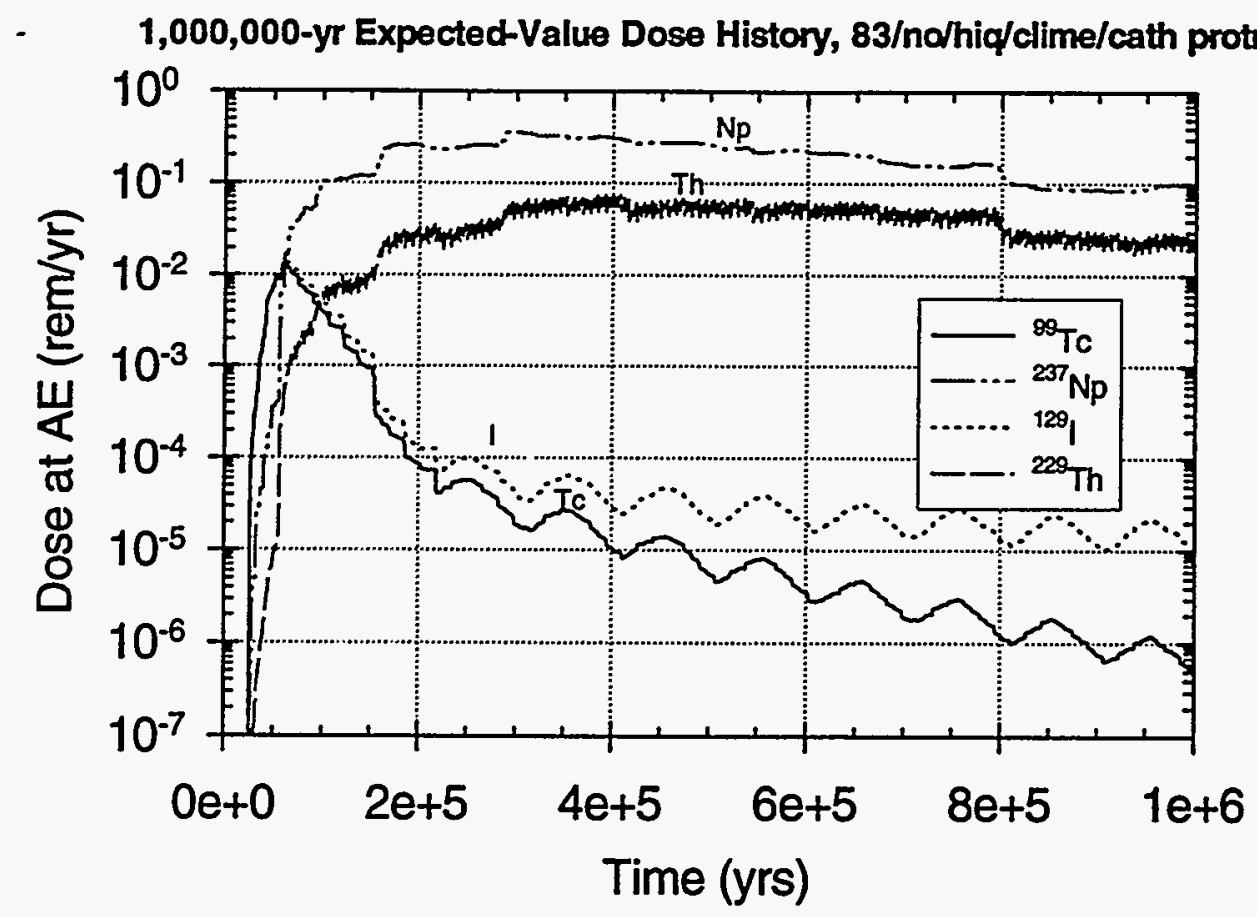

Figure 9.3-39 Expected-value dose history: 1,000,000 years, cathodic protection (with temperature and relative humidity corrosion-initiation), $83 \mathrm{MTU} / \mathrm{acre}$, no backfill, high infiltration (initial $\mathrm{q}_{\mathrm{inf}}=1.25 \mathrm{~mm} / \mathrm{yr}$ ), cyclical- $\mathrm{q}_{\mathrm{inf}}$ climate model.

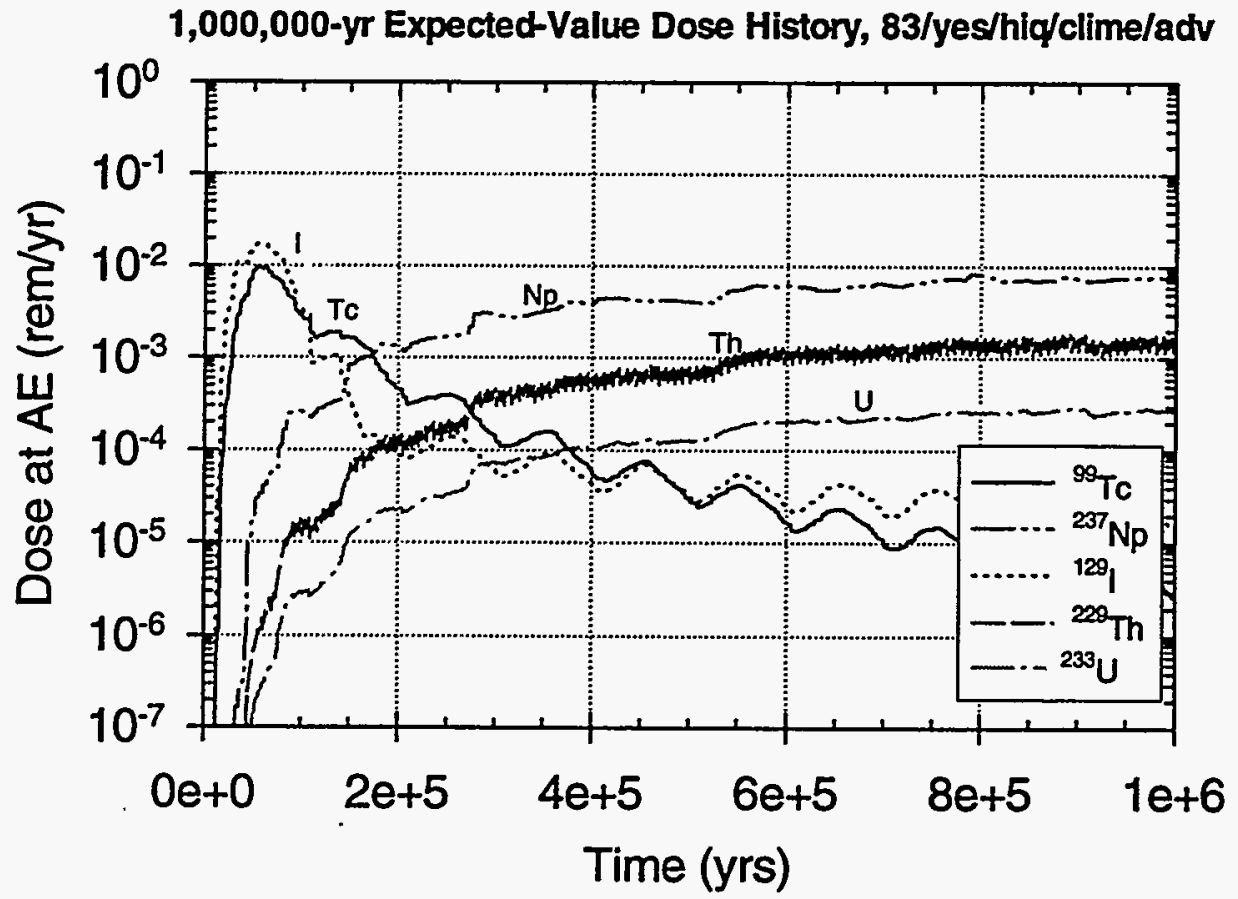

Figure 9.3-40 Expected-value dose history: 1,000,000 years, "drips-on-waste-container" EBS transport model, $83 \mathrm{MTU} / \mathrm{acre}$, backfill, high infiltration (initial $\mathrm{q}_{\mathrm{inf}}=1.25 \mathrm{~mm} / \mathrm{yr}$ ), cyclical- $\mathrm{q}_{\text {inf }}$ climate model. 


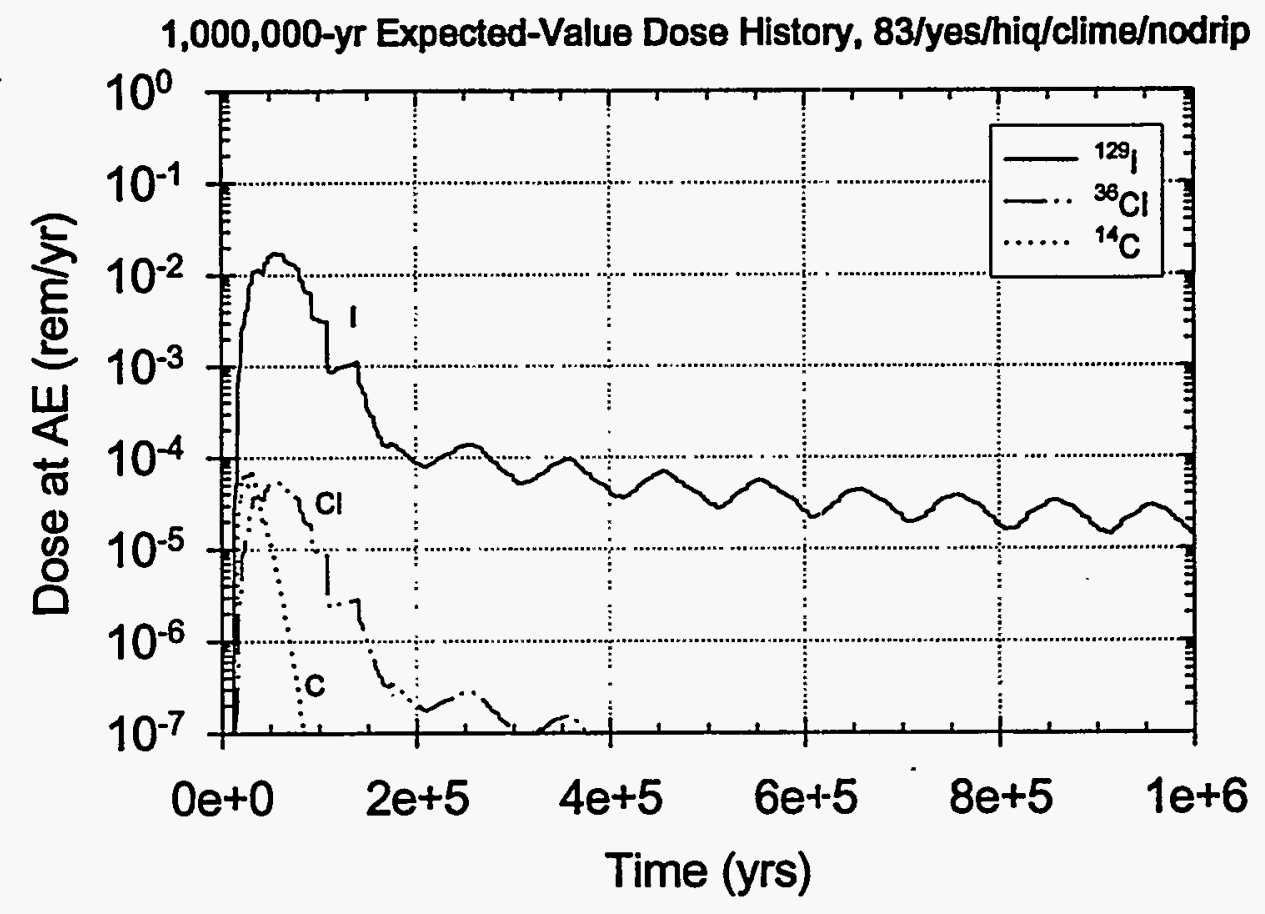

Figure 9.3-41 Expected-value dose history: 1,000,000 years, capillary-barrier-effect ("no drips") EBS transport model, $83 \mathrm{MTU} / \mathrm{acre}$, backfill, high infiltration (initial $\mathrm{q}_{\mathrm{inf}}=1.25$ $\mathrm{mm} / \mathrm{yr})$, cyclical- $\mathrm{q}_{\mathrm{inf}}$ climate model.

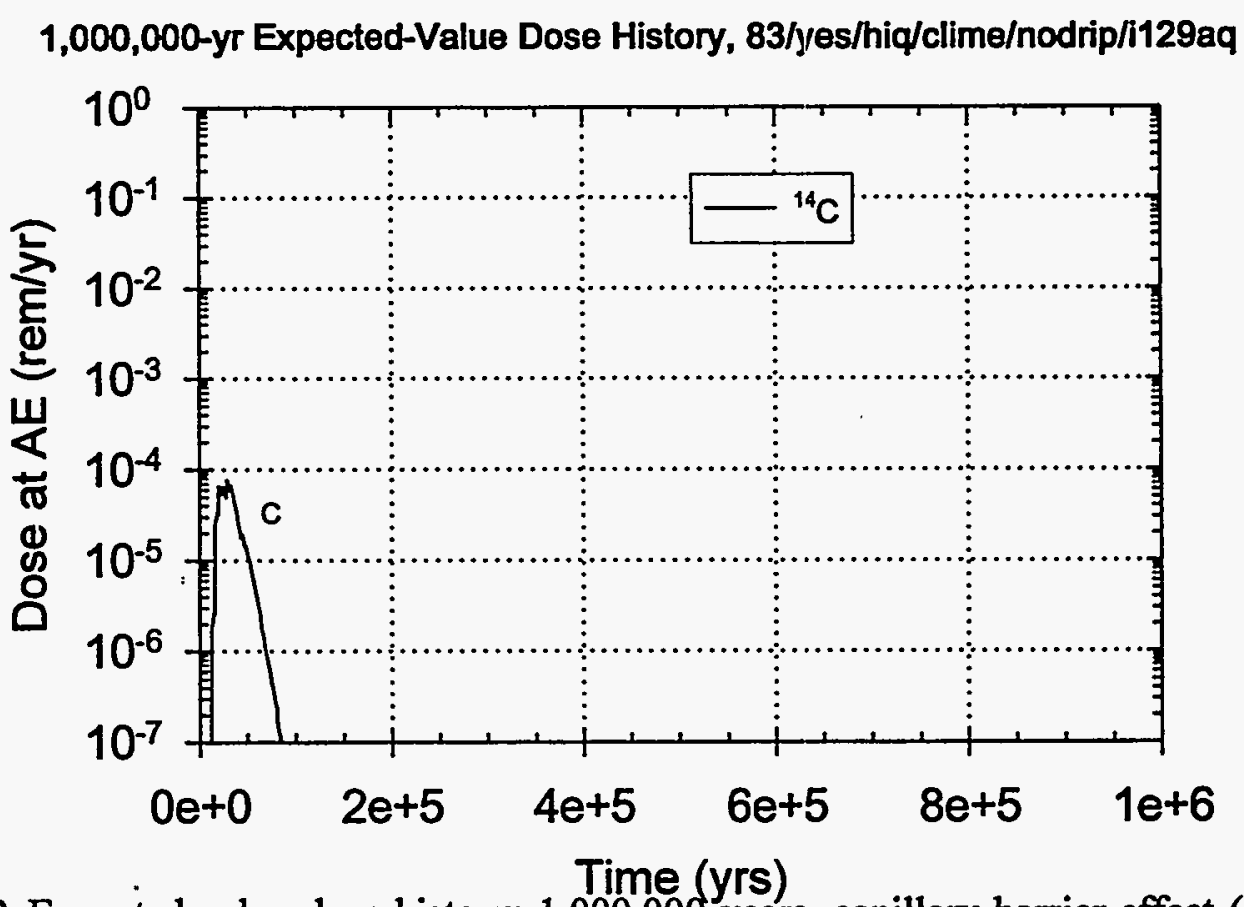

Figure 9.3-42 Expected-value dose history: 1,000,000 years, capillary-barrier-effect ("no drips") EBS transport model with ${ }^{129} \mathrm{I}$ and ${ }^{36} \mathrm{Cl}$ transported through EBS in the aqueous phase, $83 \mathrm{MTU} / \mathrm{acre}$, backfill, high infiltration (initial $\mathrm{q}_{\mathrm{inf}}=1.25 \mathrm{~mm} / \mathrm{yr}$ ), cyclical$\mathrm{q}_{\text {inf }}$ climate model. 


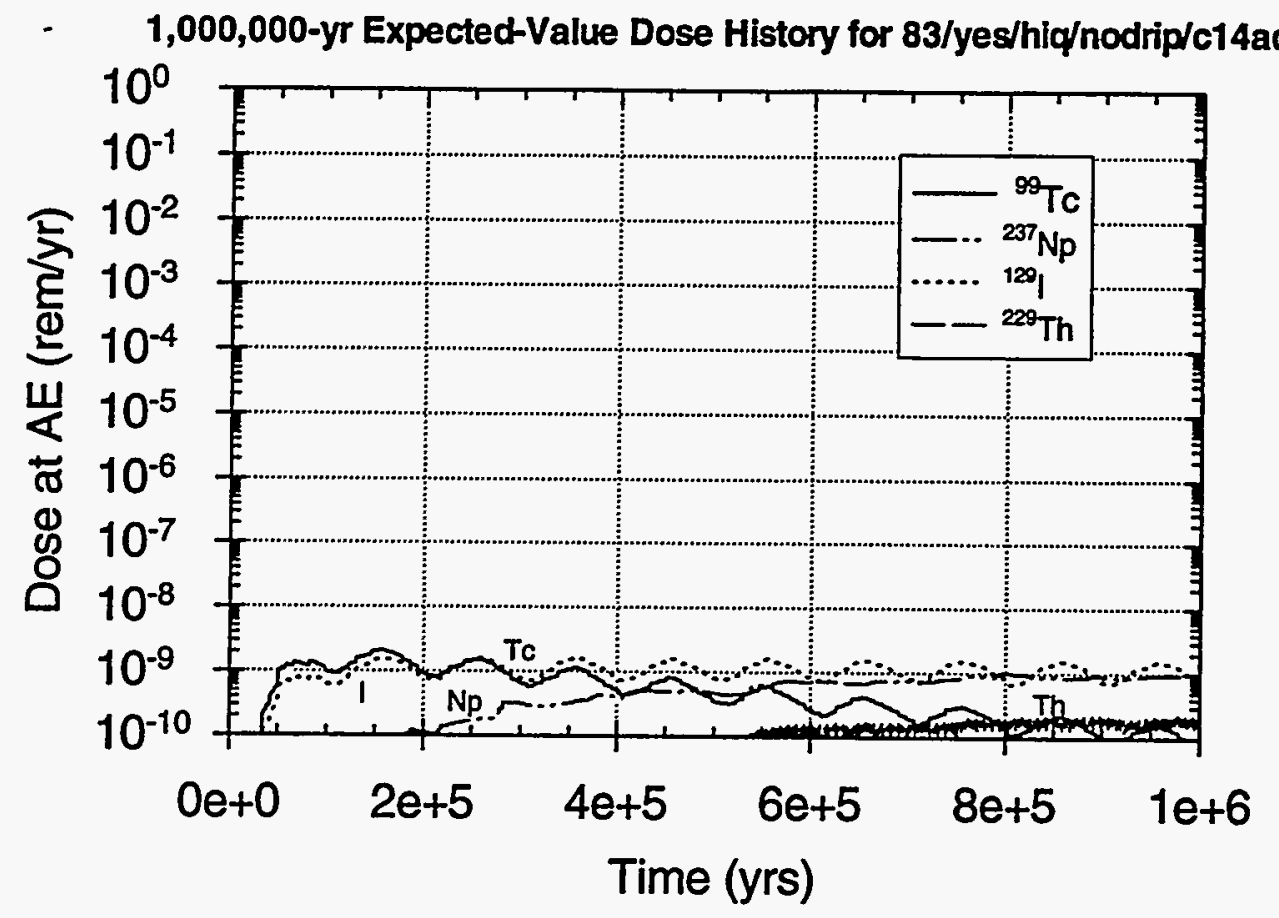

Figure 9.3-43 Expected-value dose history: 1,000,000 years, "diffusion-only" EBS transport model, $83 \mathrm{MTU} / \mathrm{acre}$, backfill, high infiltration (initial $\mathrm{q}_{\mathrm{inf}}=1.25 \mathrm{~mm} / \mathrm{yr}$ ), cyclical- $q_{\text {inf }}$ climate model.

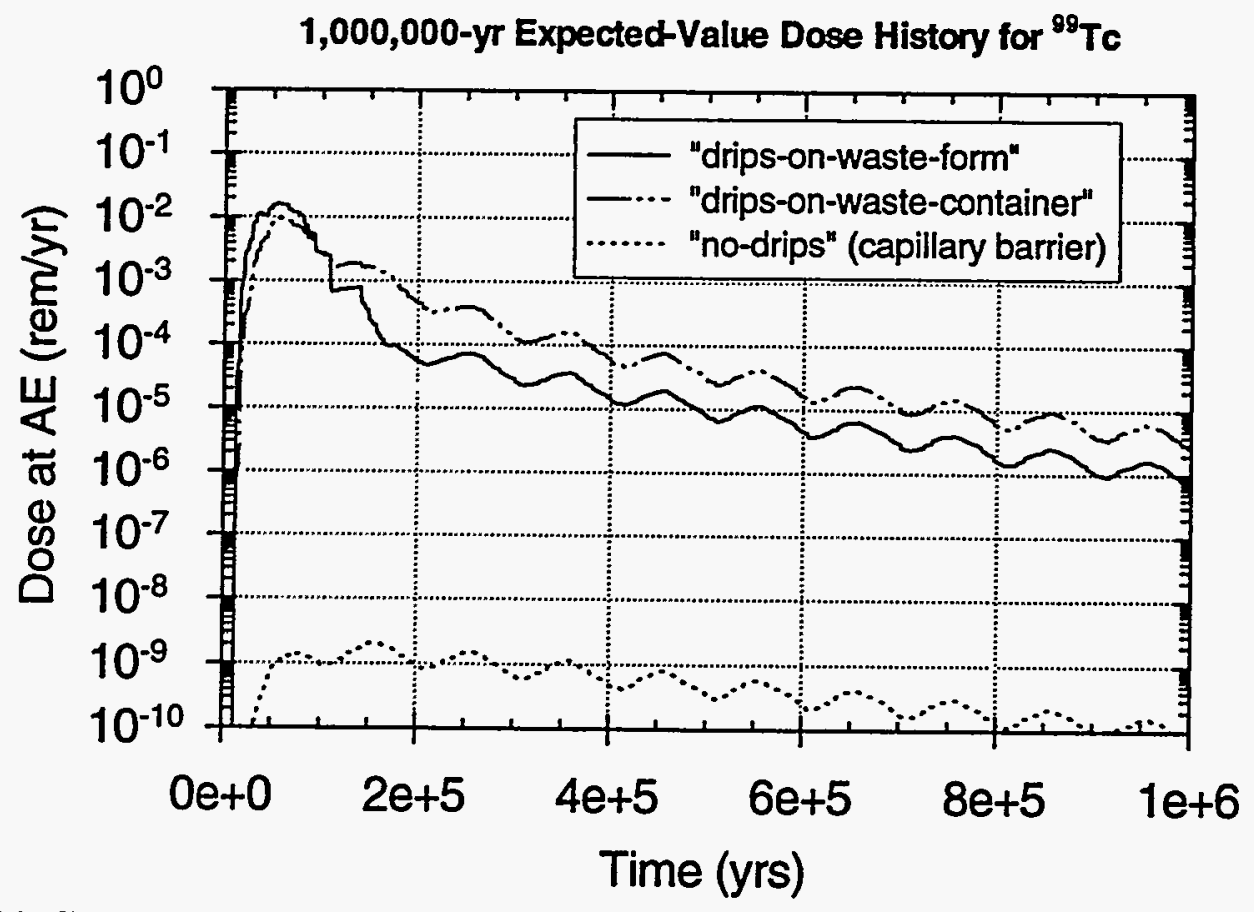

Figure 9.3-44 Comparison of EBS transport models. Expected-value dose history for ${ }^{99} \mathrm{Tc}$ : $1,000,000$ years, "drips-on-waste-form" model vs. "drips-on-waste-container" model vs. "no-drip" model, $83 \mathrm{MTU} / \mathrm{acre}$, high infiltration (initial $\mathrm{q}_{\mathrm{inf}}=1.25$ $\mathrm{mm} / \mathrm{yr}$ ), cyclical-q $\mathrm{q}_{\mathrm{inf}}$ climate model. 


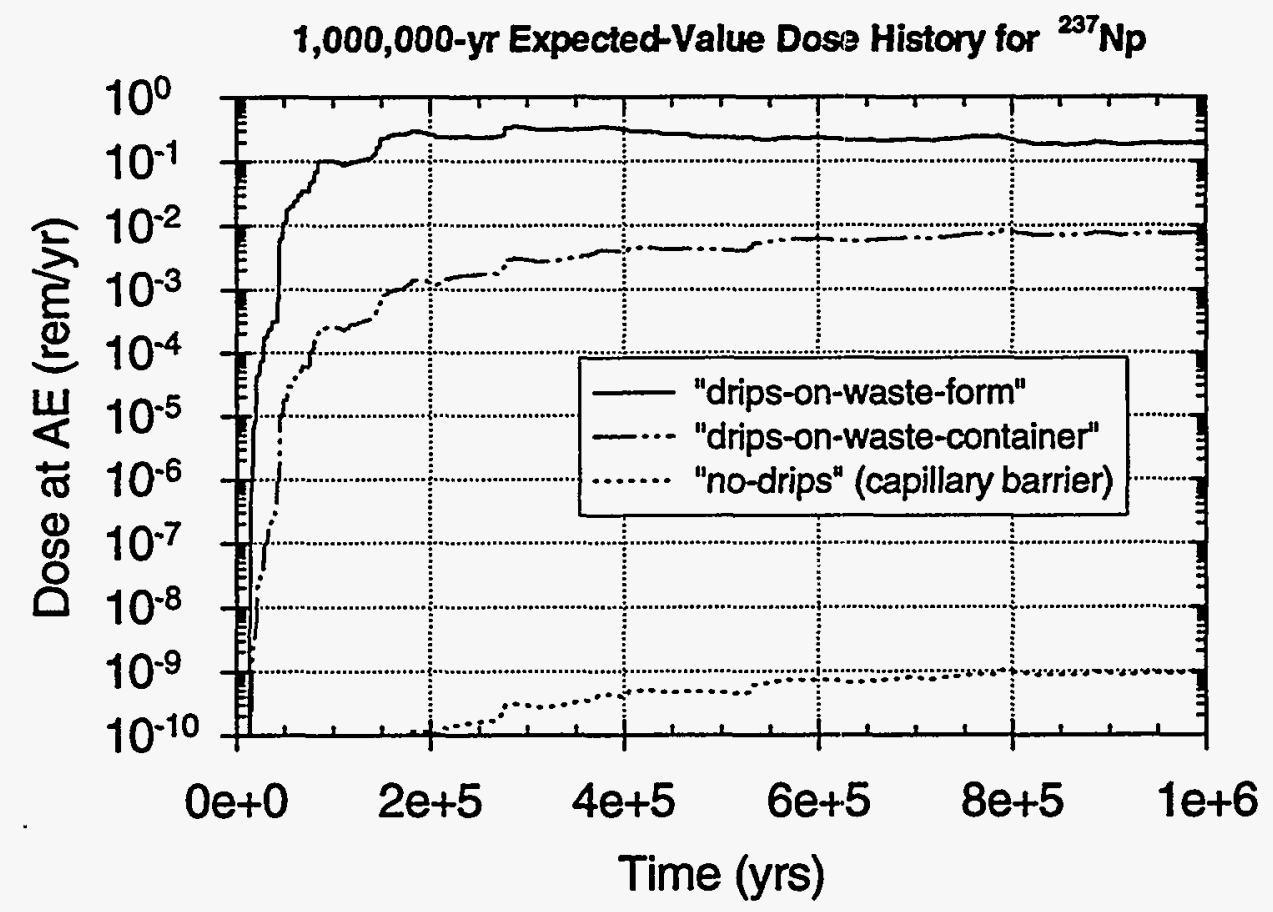

Figure 9.3-45 Comparison of EBS transport models. Expected-value dose history for ${ }^{237} \mathrm{~Np}$ : $1,000,000$ years, "drips-on-waste-form" model vs. "drips-on-waste-container" model vs. "no-drip" model, $83 \mathrm{MTU} / \mathrm{acre}$, high infiltration (initial $\mathrm{q}_{\mathrm{inf}}=1.25$ $\mathrm{mm} / \mathrm{yr}$ ), cyclical- $\mathrm{q}_{\mathrm{inf}}$ climate model. 


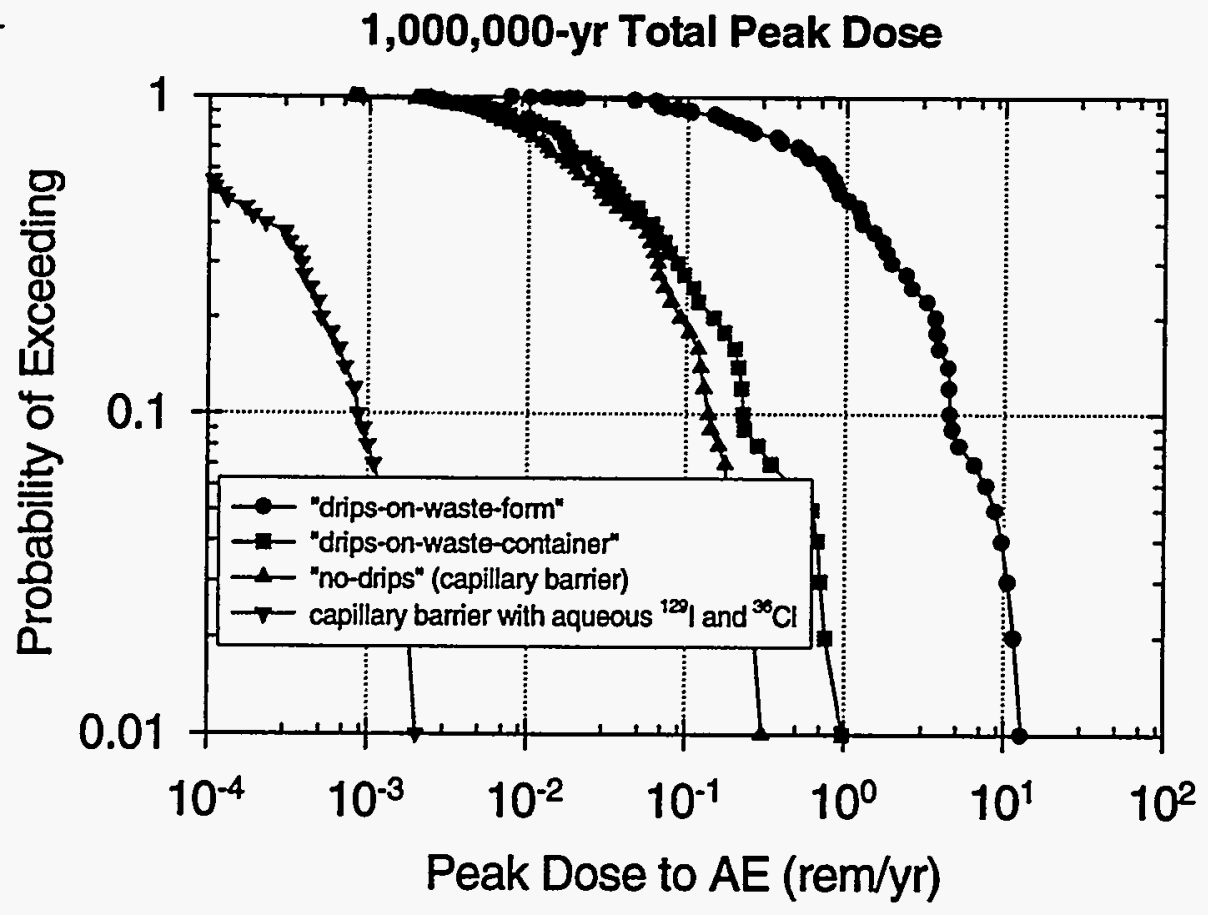

Figure 9.3-46a

Comparison of EBS transport models. CCDF of Total Peak Dose: $1,000,000$ years, $83 \mathrm{MTU} / \mathrm{acre}$, high infiltration range, cyclical- $\mathrm{q}_{\text {inf }}$ climate model.

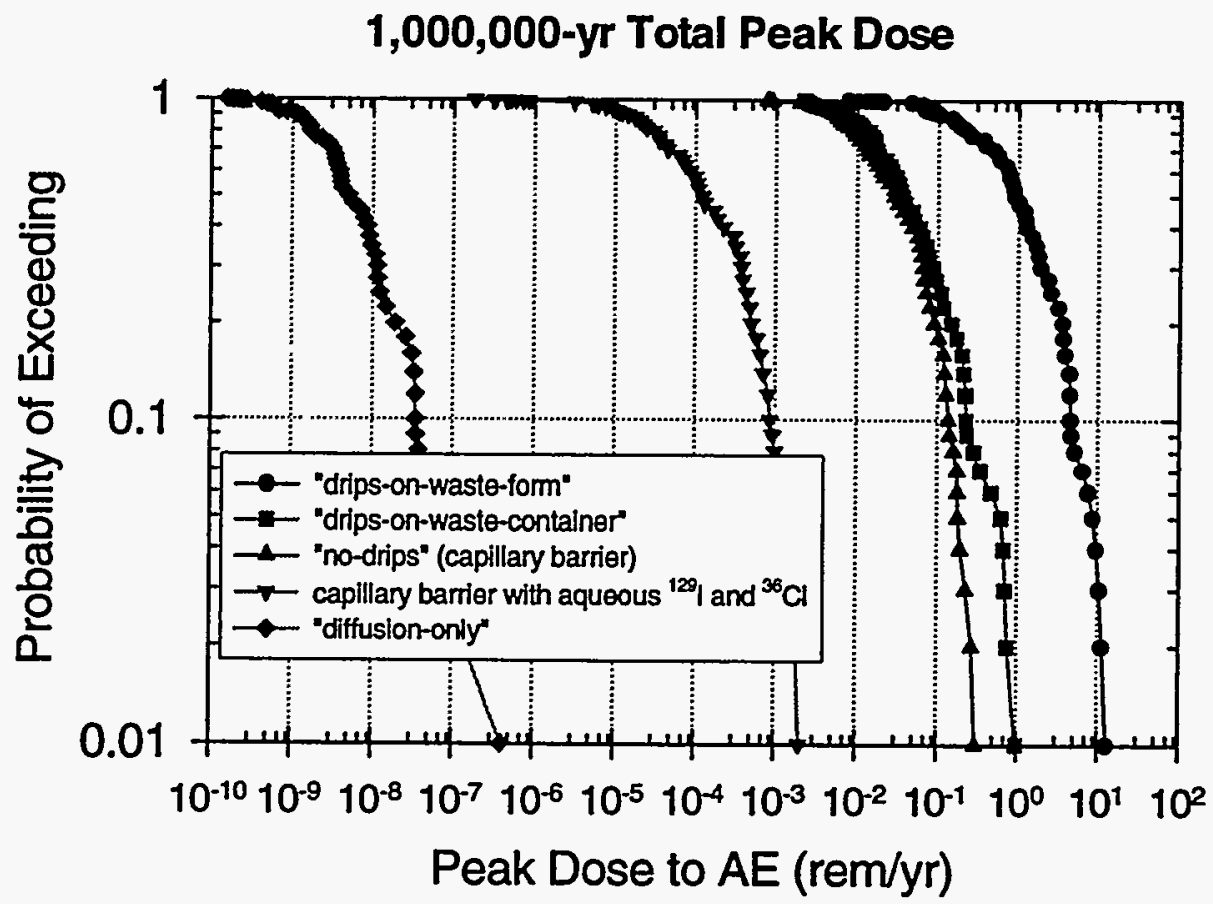

Figure 9.3-46b

Comparison of EBS transport models. CCDF of Total Peak Dose: 1,000,000 years, $83 \mathrm{MTU} / \mathrm{acre}$, high infiltration range, cyclical- $\mathrm{q}_{\mathrm{inf}}$ climate model. 


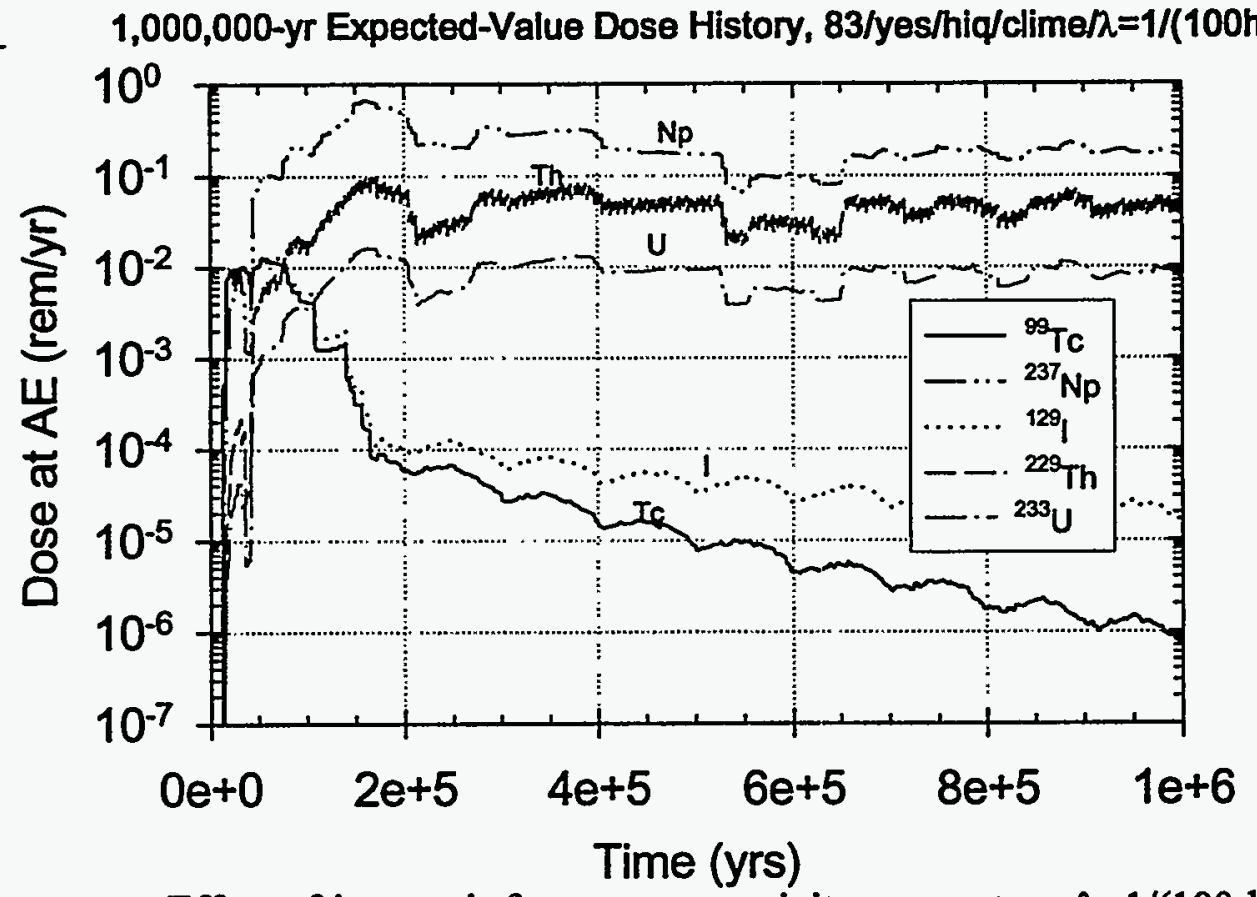

Figure 9.3-47a Effect of intra-unit fracture connectivity parameter: $\lambda=1 /(100 \mathrm{~h})$, where $h=$ pathway length in each unit. Expected-value dose history: 1,000,000 years, $83 \mathrm{MTU} /$ acre, backfill, high infiltration (initial $\mathrm{q}_{\mathrm{inf}}=1.25 \mathrm{~mm} / \mathrm{yr}$ ), cyclical$\mathrm{q}_{\text {inf }}$ climate model.

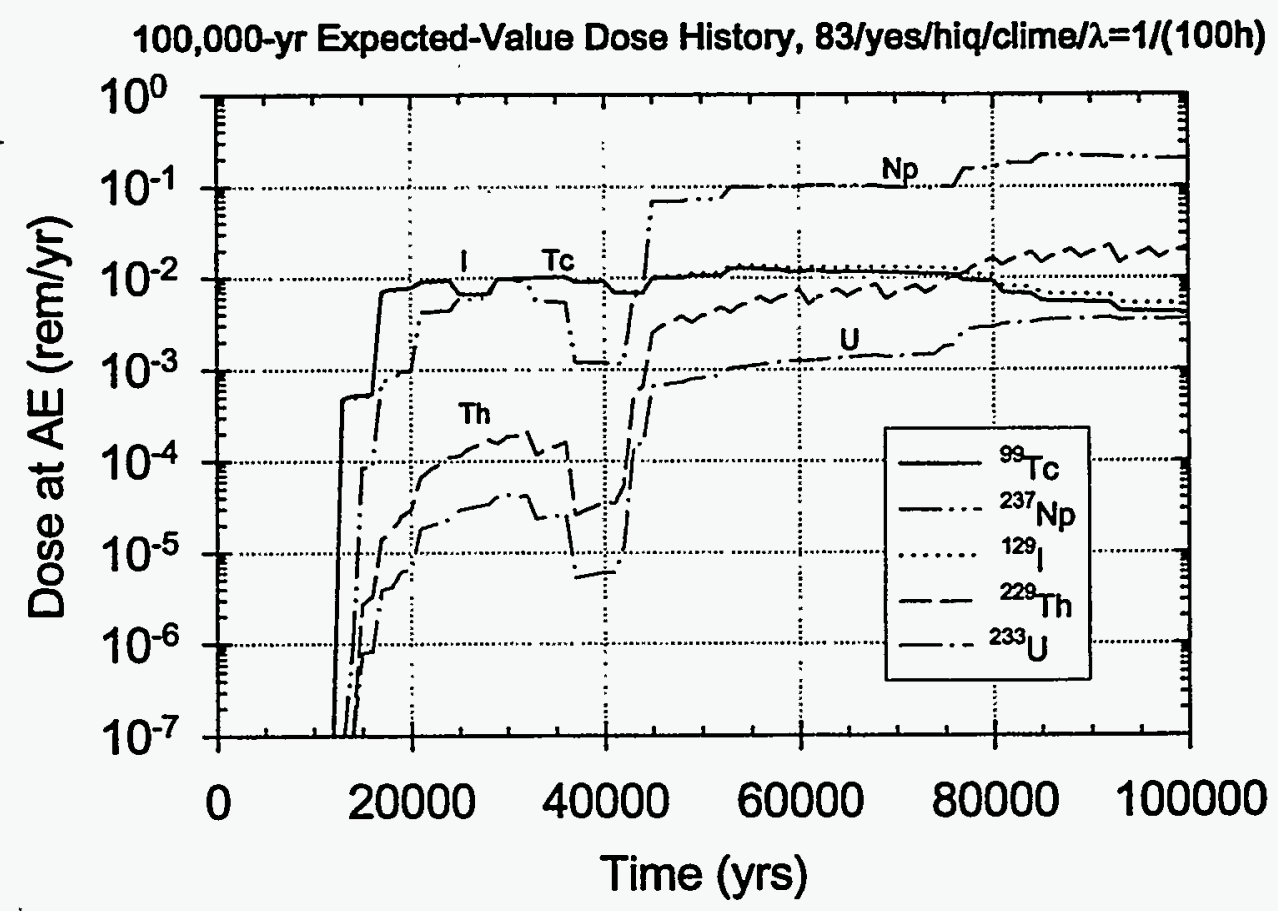

Figure 9.3-47b Effect of intra-unit fracture connectivity parameter: $\lambda=1 /(100 \mathrm{~h})$, where $\mathrm{h}=$ pathway length in each unit. Expected-value dose history: 100,000 years, $83 \mathrm{MTU} /$ acre, backfill, high infiltration (initial $\mathrm{q}_{\mathrm{inf}}=1.25 \mathrm{~mm} / \mathrm{yr}$ ), cyclical$\mathrm{q}_{\text {inf }}$ climate model. 


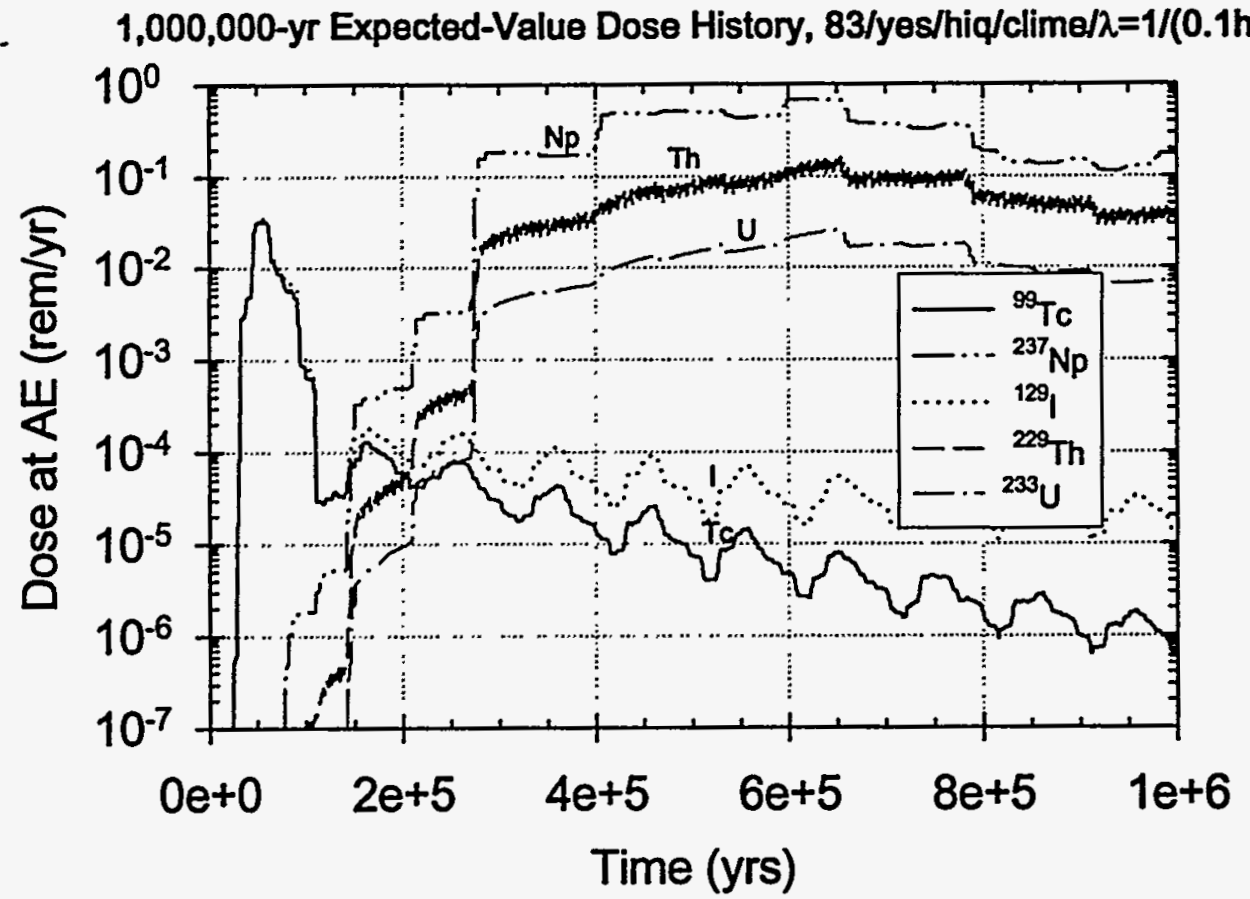

Figure 9.3-48a Effect of intra-unit fracture connectivity parameter: $\lambda=1 /(0.1 \mathrm{~h})$, where $h=$ pathway length in each unit. Expected-value dose history: 1,000,000 years, $83 \mathrm{MTU} / a c r e$, backfill, high infiltration (initial $\mathrm{q}_{\mathrm{inf}}=1.25 \mathrm{~mm} / \mathrm{yr}$ ), cyclical$\mathrm{q}_{\text {inf }}$ climate model.

00,000-yr Expected-Value Dose History, 83/yes/hiq/clime/ $2=1 /(0.1 \mathrm{~h})$

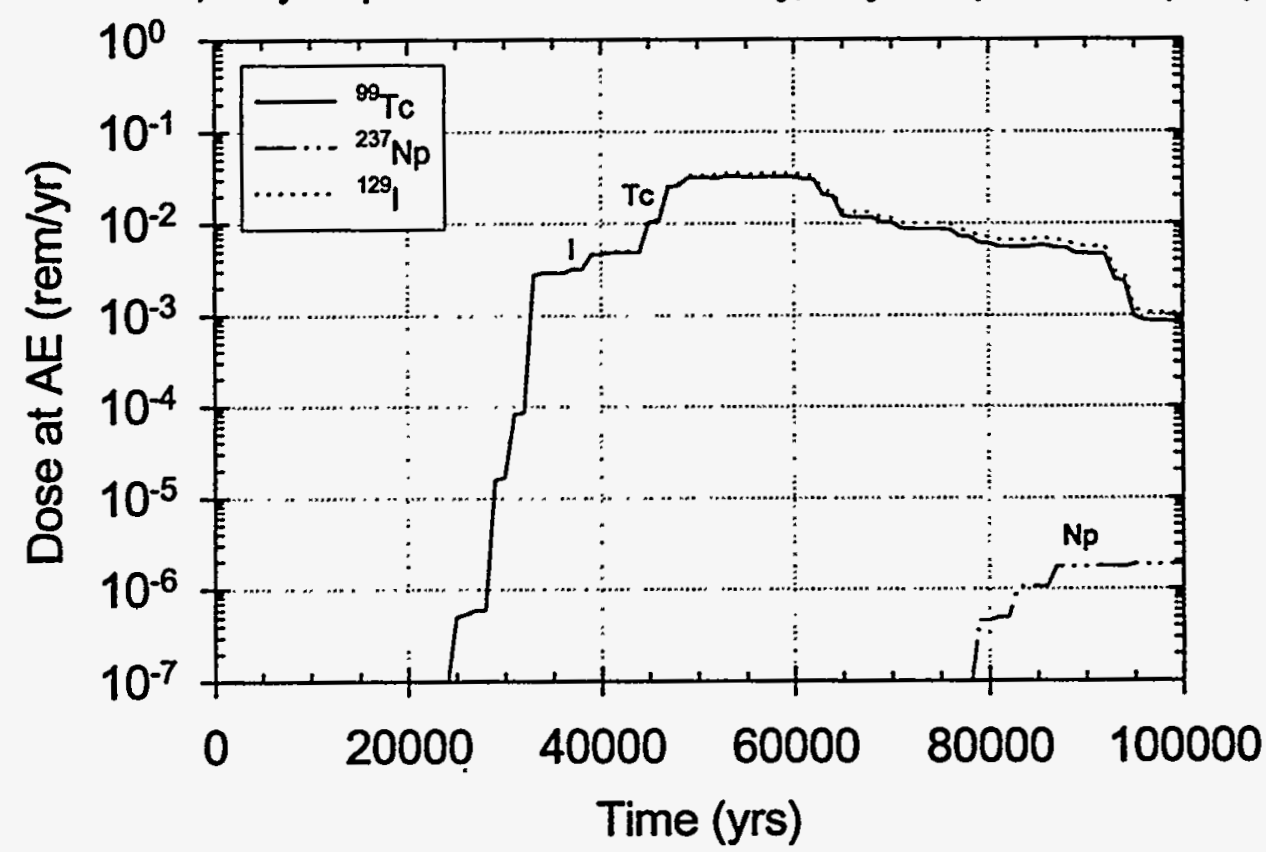

Figure 9.3-48b Effect of intra-unit fracture connectivity parameter: $\lambda=1 /(0.1 \mathrm{~h})$, where $h=$ pathway length in each unit. Expected-value dose history: 100,000 years, $83 \mathrm{MTU} /$ acre, backfill, high infiltration (initial $\mathrm{q}_{\mathrm{inf}}=1.25 \mathrm{~mm} / \mathrm{yr}$ ), cyclical$\mathrm{q}_{\text {inf }}$ climate model. 


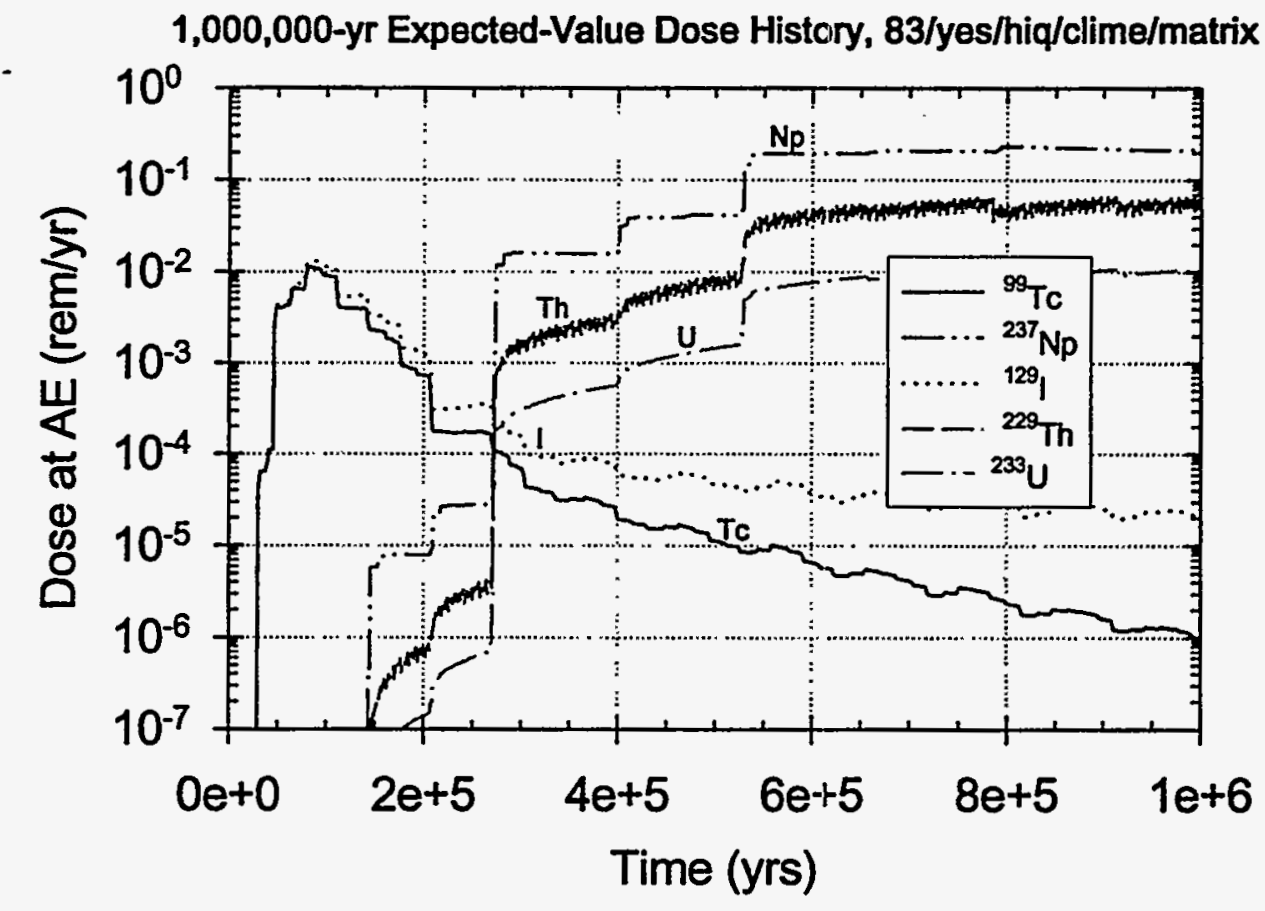

Figure 9.3-49 Effect of matrix-only flow (no fracture flow). Expected-value dose history: $1,000,000$ years, $83 \mathrm{MTU} / \mathrm{acre}$, backfill, high infiltration (initial $\mathrm{q}_{\mathrm{inf}}=1.25 \mathrm{~mm} / \mathrm{yr}$ ), cyclical- $\mathrm{q}_{\mathrm{inf}}$ climate model.

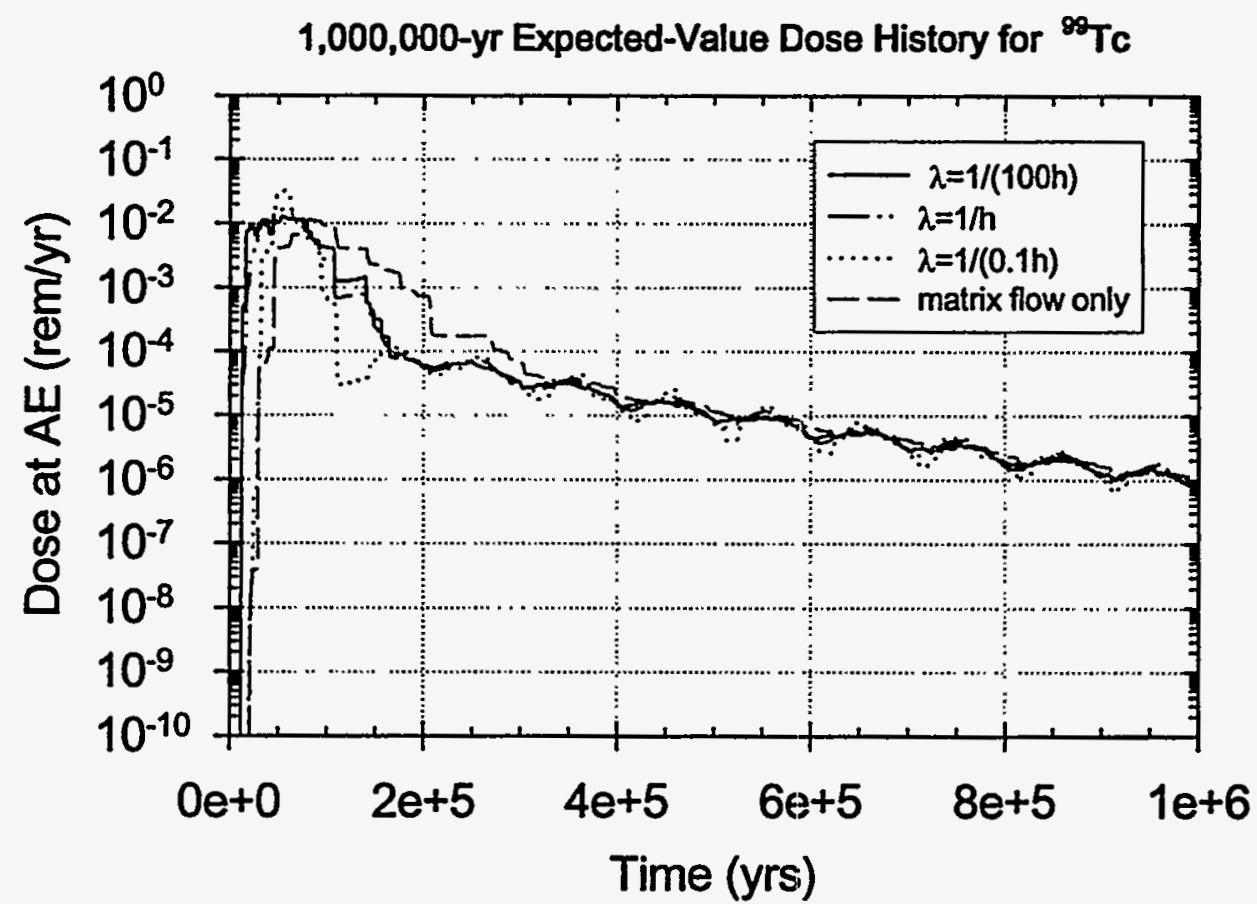

Figure 9.3-50 Comparison of intra-unit fracture connectivity parameter: $\lambda=1 /(100 \mathrm{~h})$ vs. $\lambda=1 / \mathrm{h}$ vs. $\lambda=1 /(0.1 \mathrm{~h})$ vs. matrix-flow-only, where $h=$ pathway length in each unit. Expected-value dose history for ${ }^{99} \mathrm{Tc}: 1,000,000$ years, $83 \mathrm{MTU} / \mathrm{acre}$, backfill, high infiltration (initial $\mathrm{q}_{\mathrm{inf}}=1.25 \mathrm{~mm} / \mathrm{yr}$ ), cyclical- $\mathrm{q}_{\mathrm{inf}}$ climate model. 


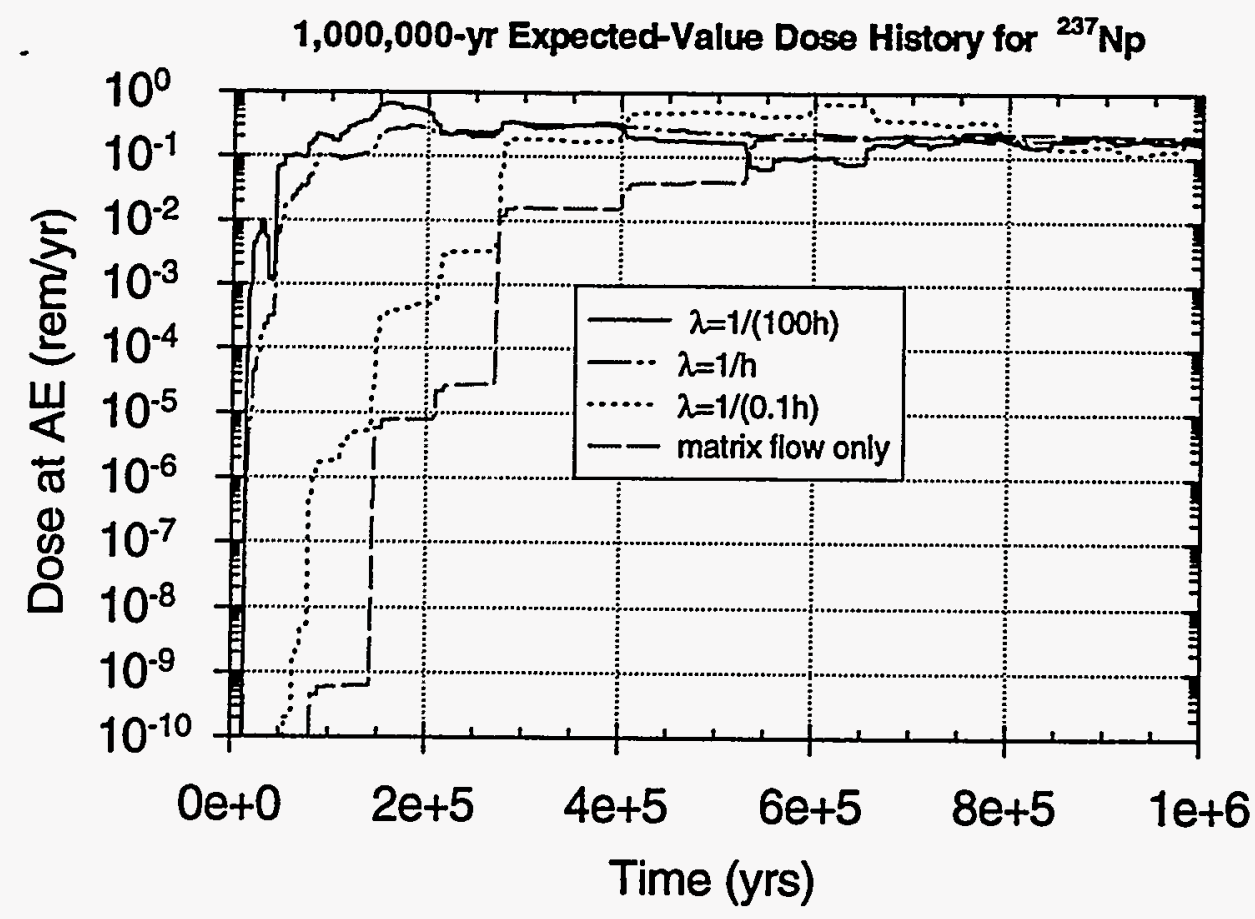

Figure 9.3-51 Comparison of intra-unit fracture connectivity parameter: $\lambda=1 /(100 \mathrm{~h})$ vs. $\lambda=1 / \mathrm{h}$ vs. $\lambda=1 /(0.1 \mathrm{~h})$ vs. matrix-flow-only, where $h=$ pathway length in each unit. Expected-value dose history for ${ }^{237} \mathrm{~Np}: 1,000,000$ years, $83 \mathrm{MTU} / \mathrm{acre}$, backfill, high infiltration (initial $\mathrm{q}_{\mathrm{inf}}=1.25 \mathrm{~mm} / \mathrm{yr}$ ), cyclical- $\mathrm{q}_{\mathrm{inf}}$ climate model.

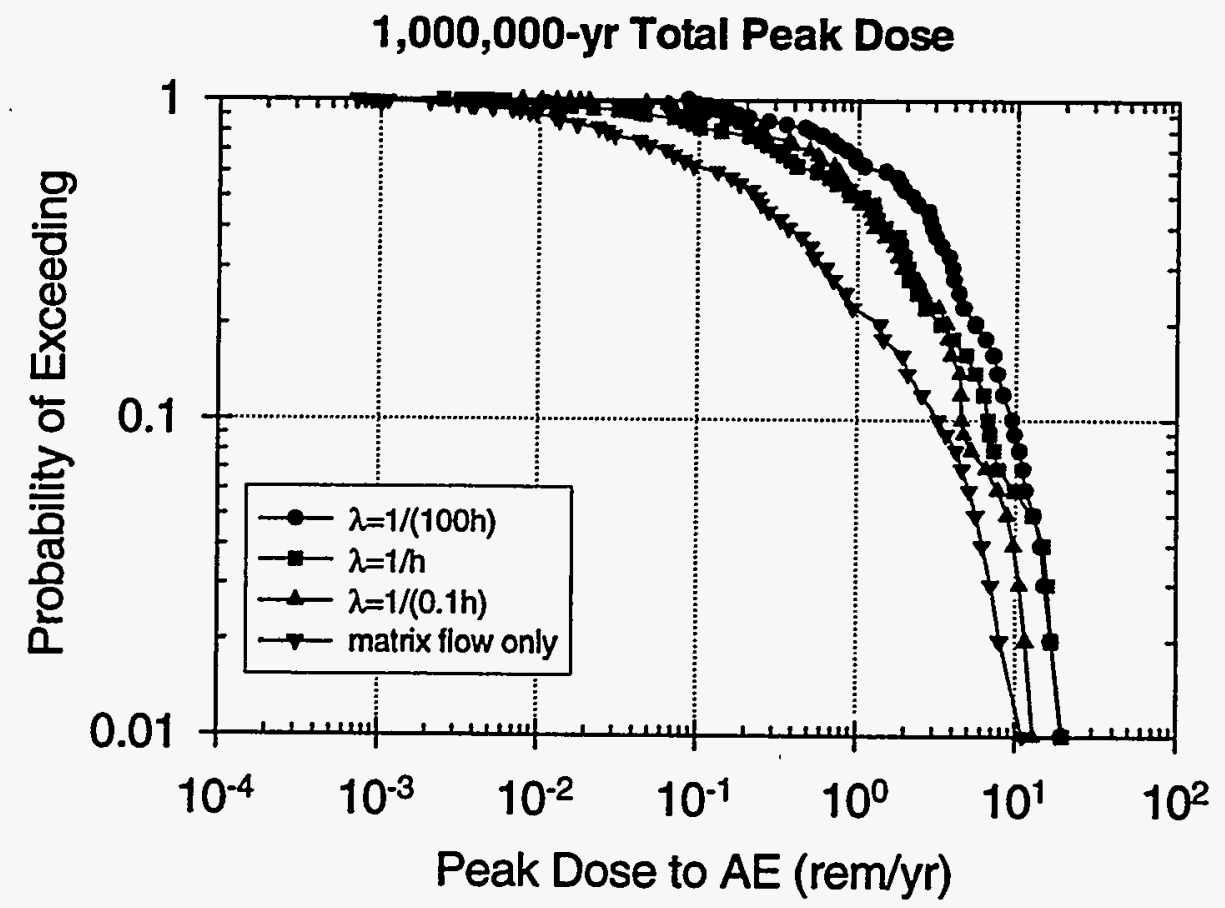

Figure 9.3-52 Comparison of intra-unit fracture connectivity parameter: $\lambda=1 /(100 \mathrm{~h})$ vs. $\lambda=1 / \mathrm{h}$ vs. $\lambda=1 /(0.1 \mathrm{~h})$ vs. matrix-flow-only (no fractures), where $\mathrm{h}=$ pathway length in each unit. CCDF of Total Peak Dose: 1,000,000 years, 83 MTU/acre, backfill, high infiltration range, cyclical- $\mathrm{q}_{\mathrm{inf}}$ climate model. 


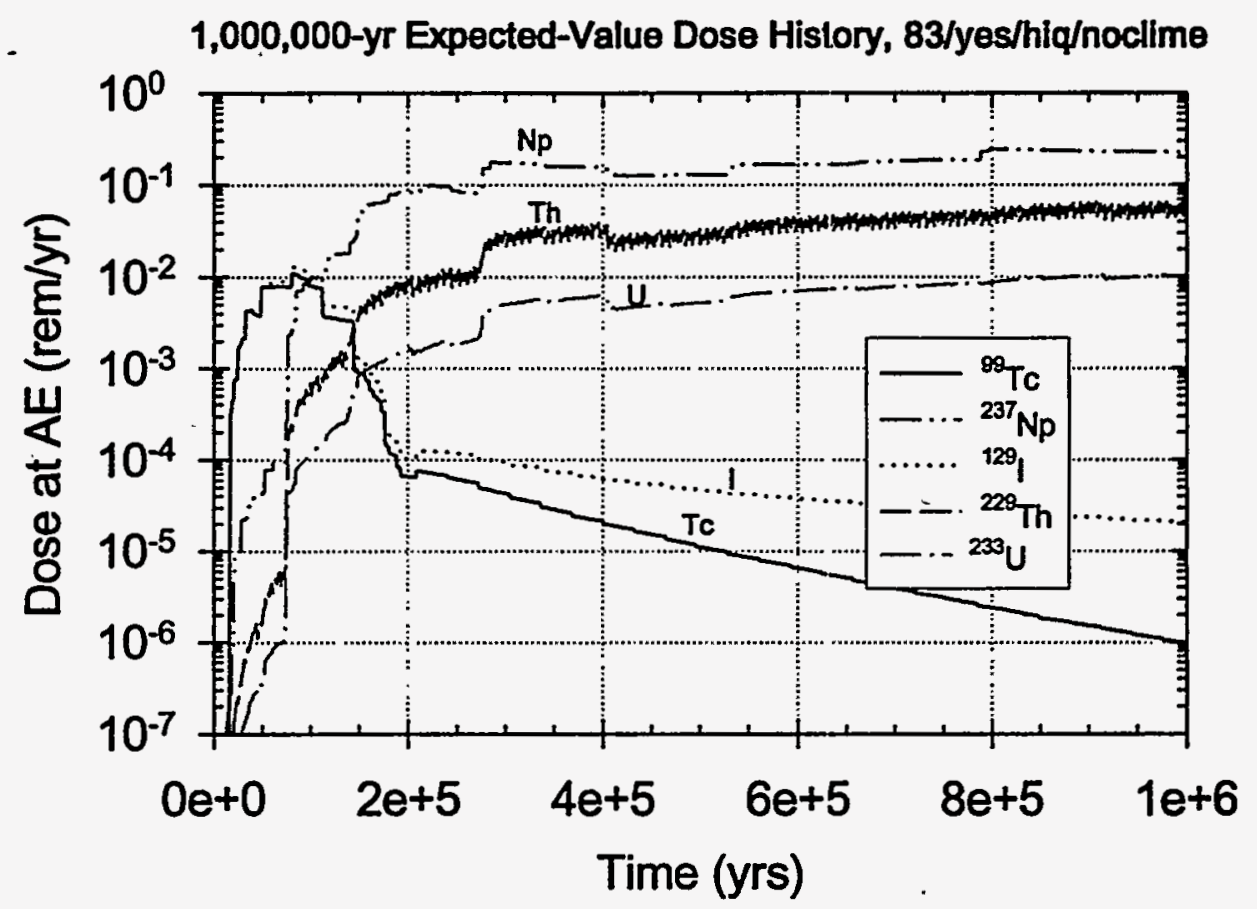

Figure 9.3-53a No climate-change model. Expected-value dose history: $1,000,000$ years, $83 \mathrm{MTU} / \mathrm{acre}$, backfill, high infiltration $\left(\mathrm{q}_{\mathrm{inf}}=1.25 \mathrm{~mm} / \mathrm{yr}\right)$.

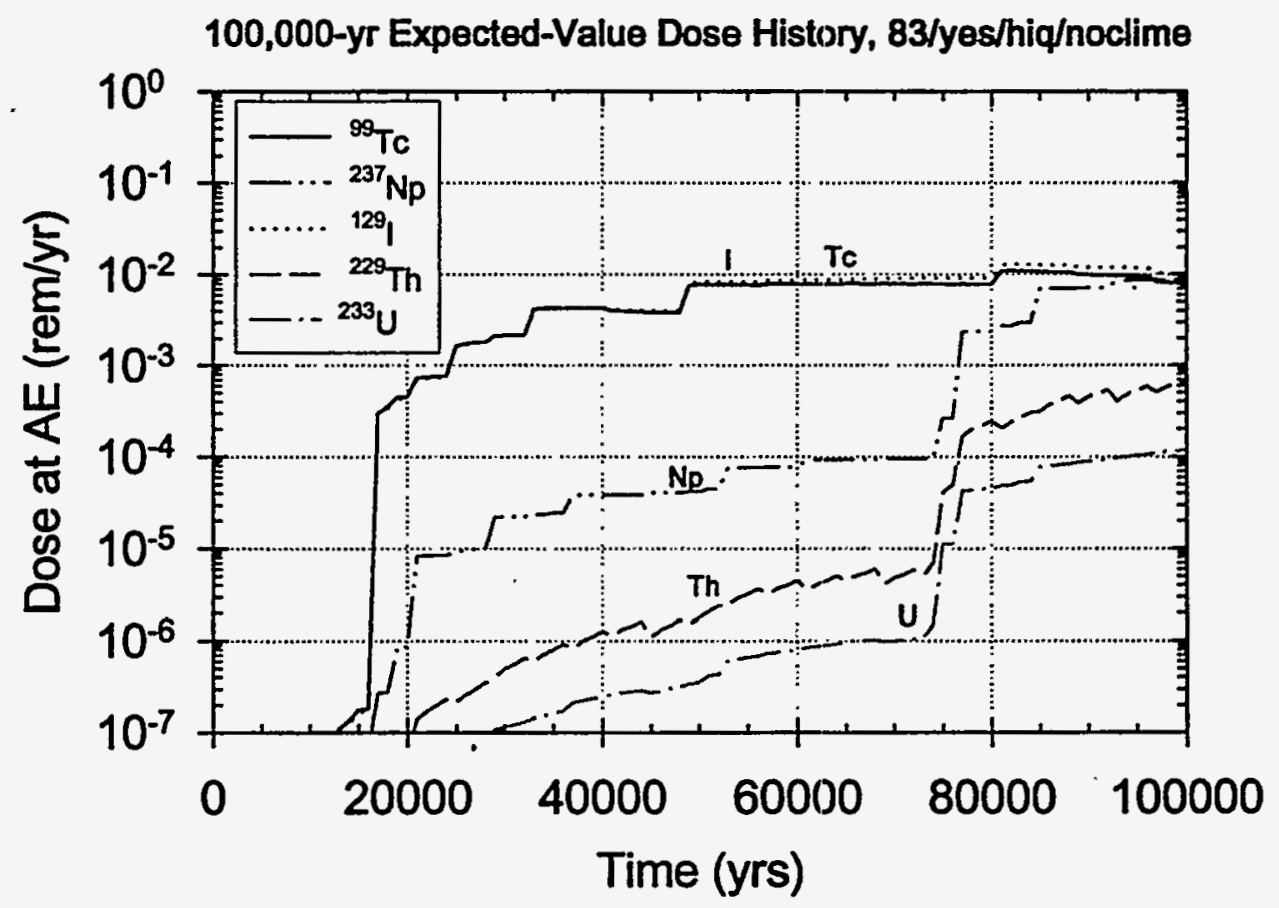

Figure 9.3-53b No climate-change model. Expected-value dose history: 100,000 years, $83 \mathrm{MTU} / \mathrm{acre}$, backfill, high infiltration $\left(\mathrm{q}_{\mathrm{inf}}=1.25 \mathrm{~mm} / \mathrm{yr}\right)$. 


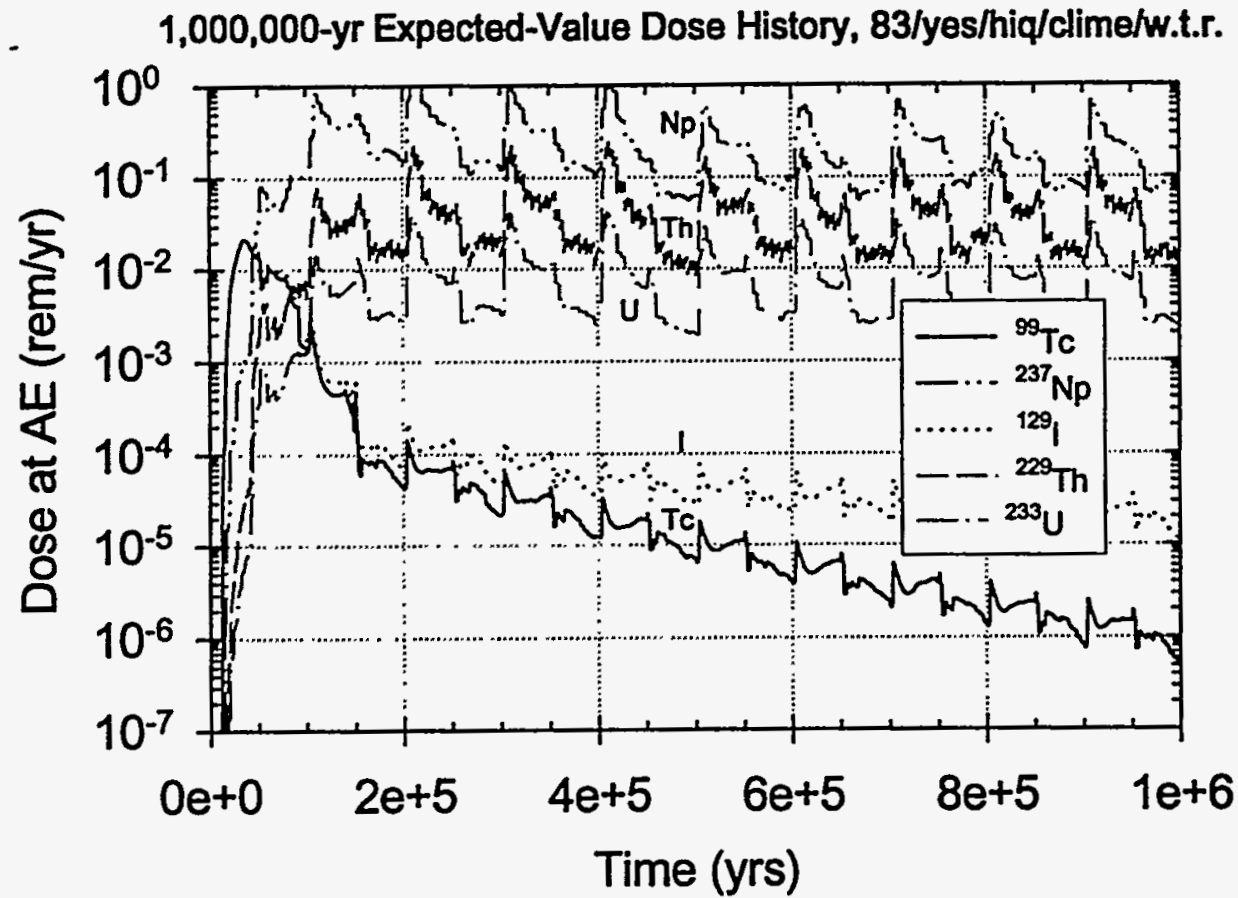

Figure 9.3-54a Climate-change model with cyclical $\mathrm{q}_{\mathrm{inf}}$ and cyclical water table rise. Expected-value dose history: 1,000,000 years, 83 MTU/acre, backfill, high infiltration (initial $\mathrm{q}_{\mathrm{inf}}=1.25 \mathrm{~mm} / \mathrm{yr}$ ).

100,000-yr Expected-Value Dose History, 83/yes/hiq/clime/w.t.r.

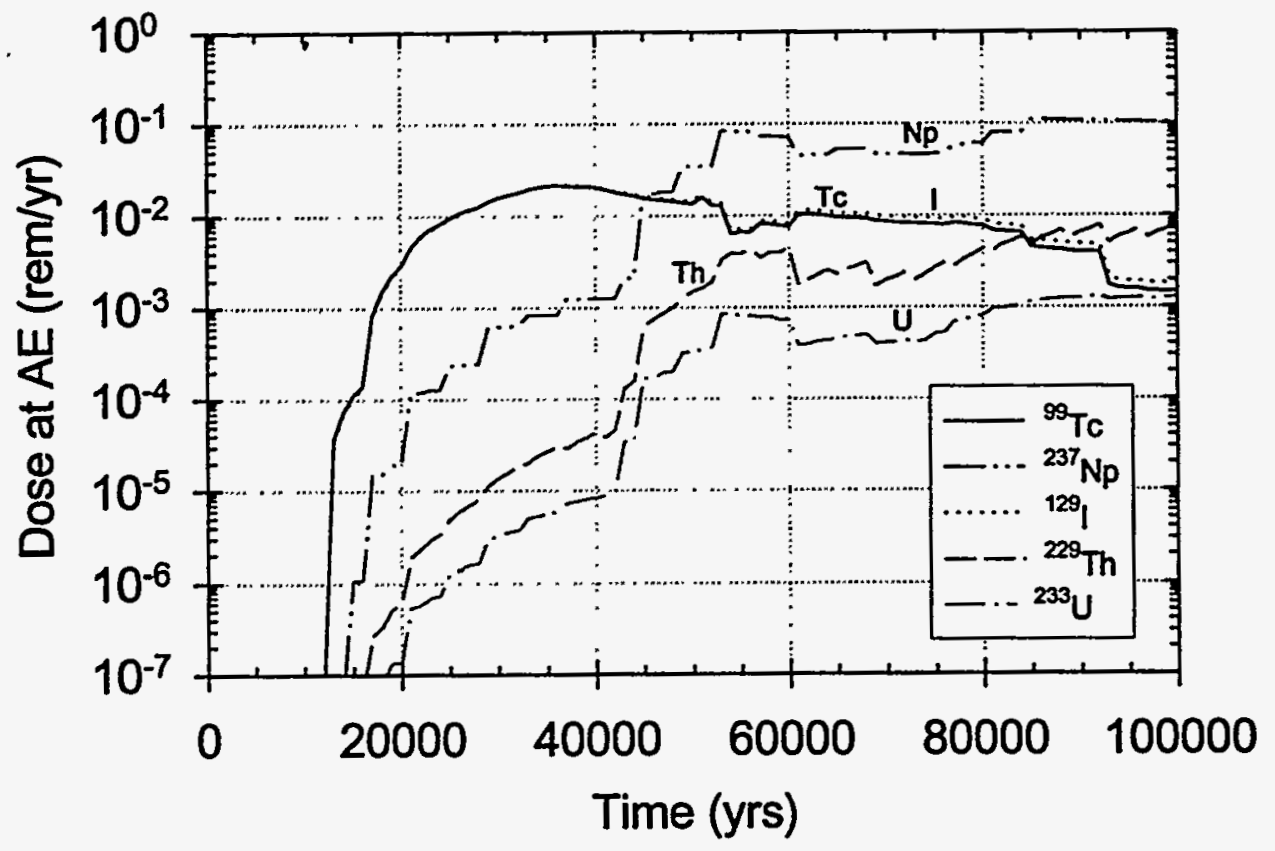

Figure 9.3-54b Climate-change model with cyclical $\mathrm{q}_{\mathrm{inf}}$ and cyclical water table rise. Expected-value dose history: 100,000 years, 83 MTU/acre, backfill, high infiltration (initial $\mathrm{q}_{\mathrm{inf}}=1.25 \mathrm{~mm} / \mathrm{yr}$ ). 


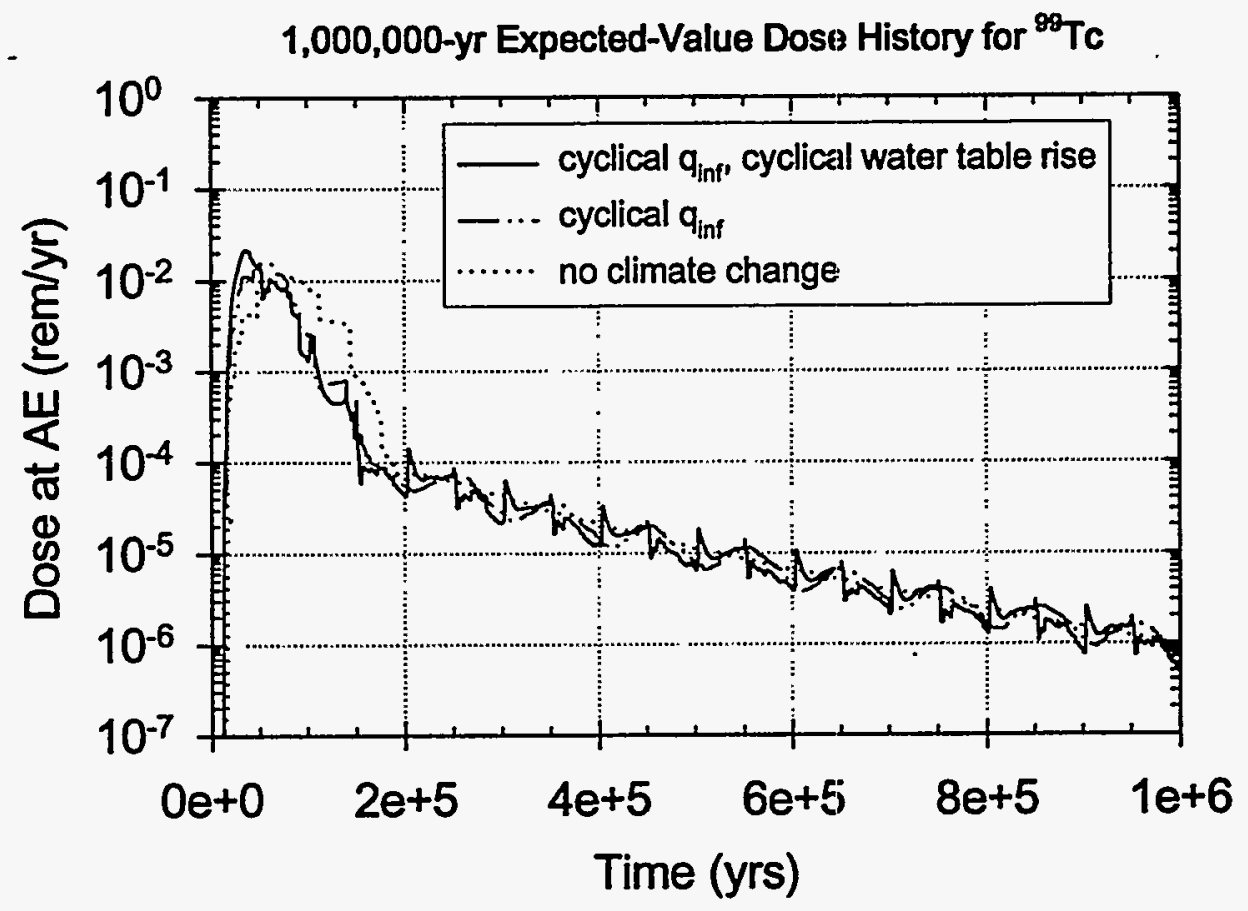

Figure 9.3-55a

Effect of climate on ${ }^{99} \mathrm{Tc}$ dose: Climate change with and without water table rise vs. no climate change. Expected-value dose history: 1,000,000 years, $83 \mathrm{MTU} / \mathrm{acre}$, backfill, high infiltration (initial $\mathrm{q}_{\mathrm{inf}}=$ $1.25 \mathrm{~mm} / \mathrm{yr})$.

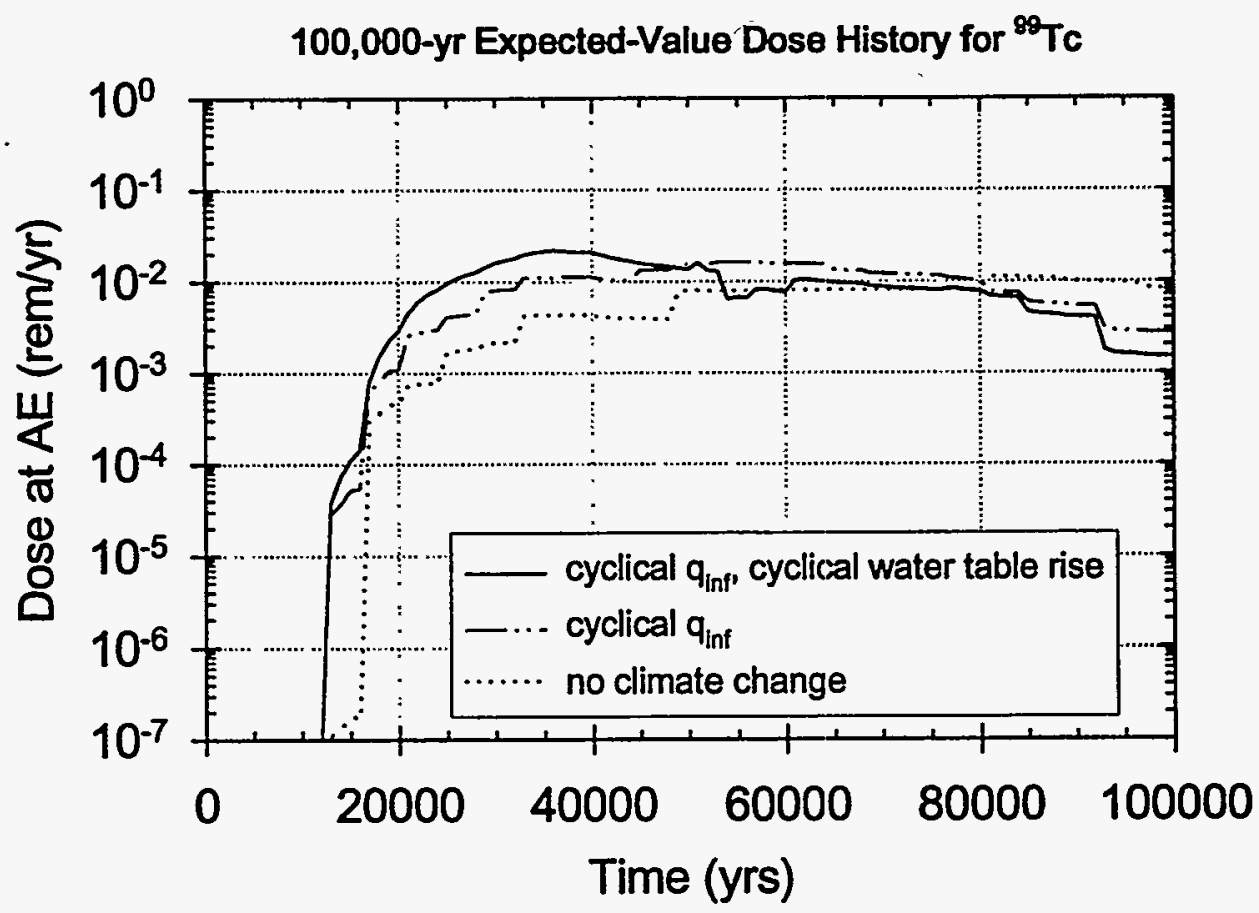

Figure 9.3-55b

Effect of climate on ${ }^{99} \mathrm{Tc}$ dose: Climate change with and without water table rise vs. no climate change. Expected-value dose history: 100,000 years, $83 \mathrm{MTU} / \mathrm{acre}$, backfill, high infiltration (initial $\mathrm{q}_{\mathrm{inf}}=1.25 \mathrm{~mm} / \mathrm{yr}$ ). 


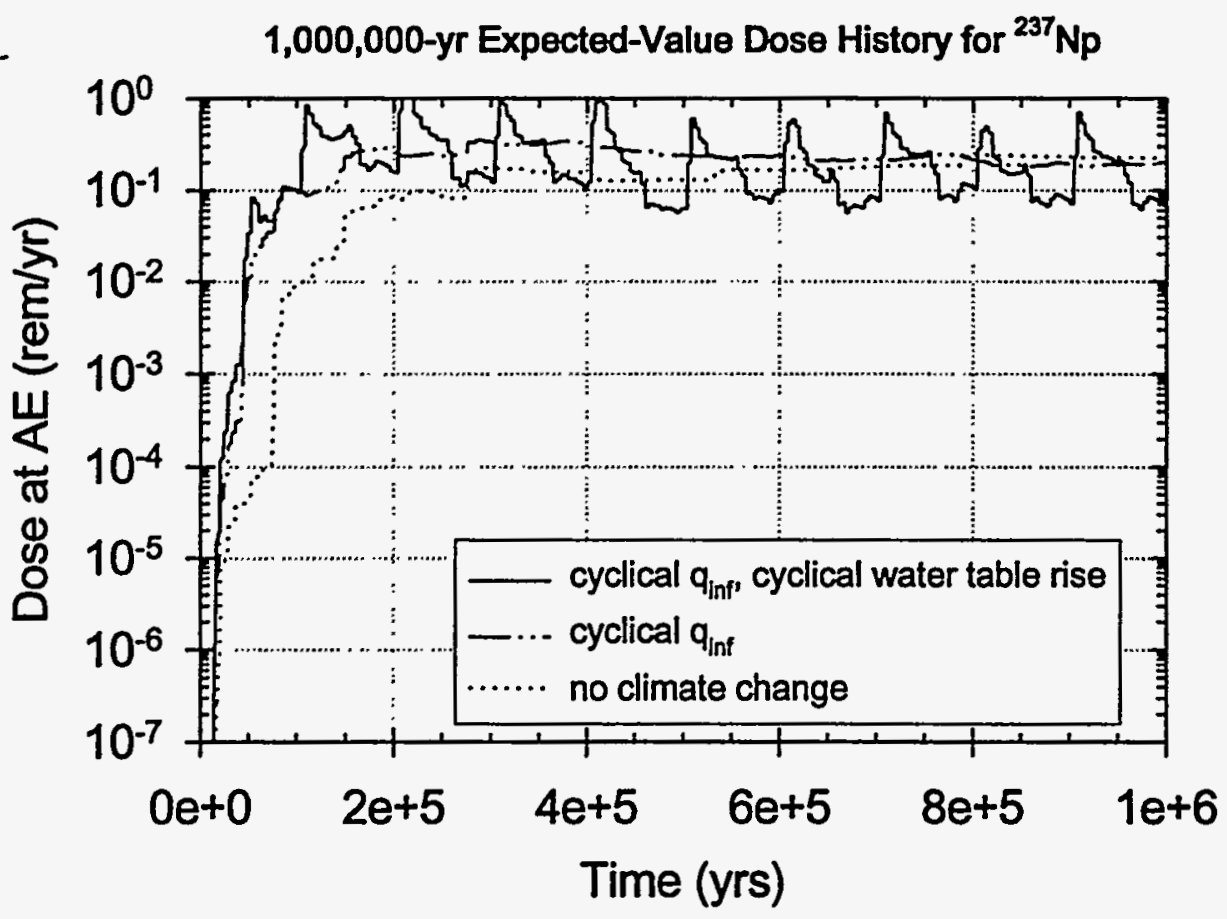

Figure 9.3-56a Effect of climate on ${ }^{237} \mathrm{~Np}$ dose: Climate change with and without water table rise vs. no climate change. Expected-value dose history: $1,000,000$ years, $83 \mathrm{MTU} / \mathrm{acre}$, backfill, high infiltration (initial $\mathrm{q}_{\mathrm{inf}}=$ $1.25 \mathrm{~mm} / \mathrm{yr})$.

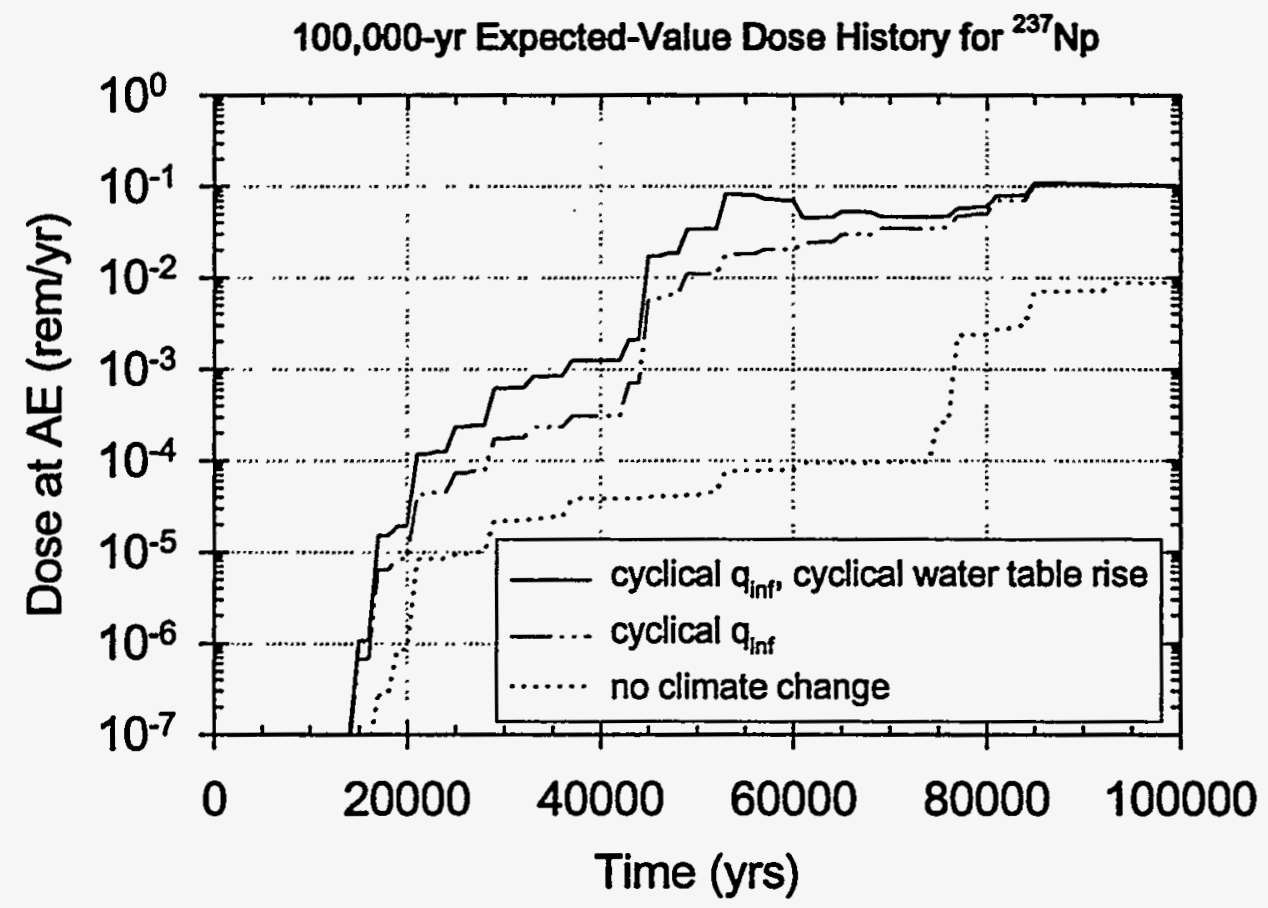

Figure 9.3-56b Effect of climate on ${ }^{237} \mathrm{~Np}$ dose: Climate change with and without water table rise vs. no climate change. Expected-value dose history: 100,000 years, $83 \mathrm{MTU} / \mathrm{acre}$, backfill, high infiltration (initial $\mathrm{q}_{\mathrm{inf}}=1.25 \mathrm{~mm} / \mathrm{yr}$ ). 


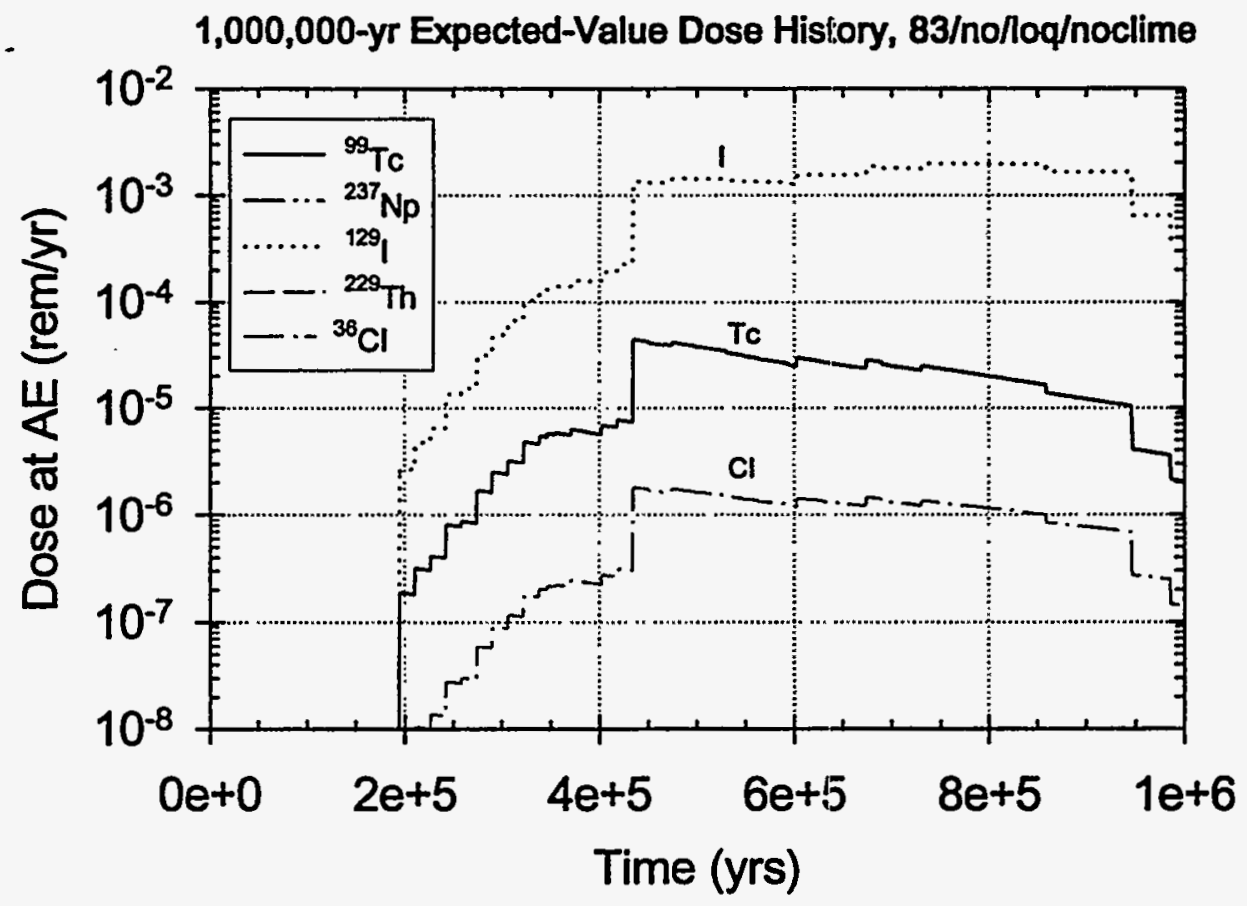

Figure 9.3-57 No climate-change model. Expected-value dose history: 1,000,000 years, 83 MTU/acre, no backfill, low infiltration ( $q_{\text {inf }}=0.03 \mathrm{~mm} / \mathrm{yr}$ ).

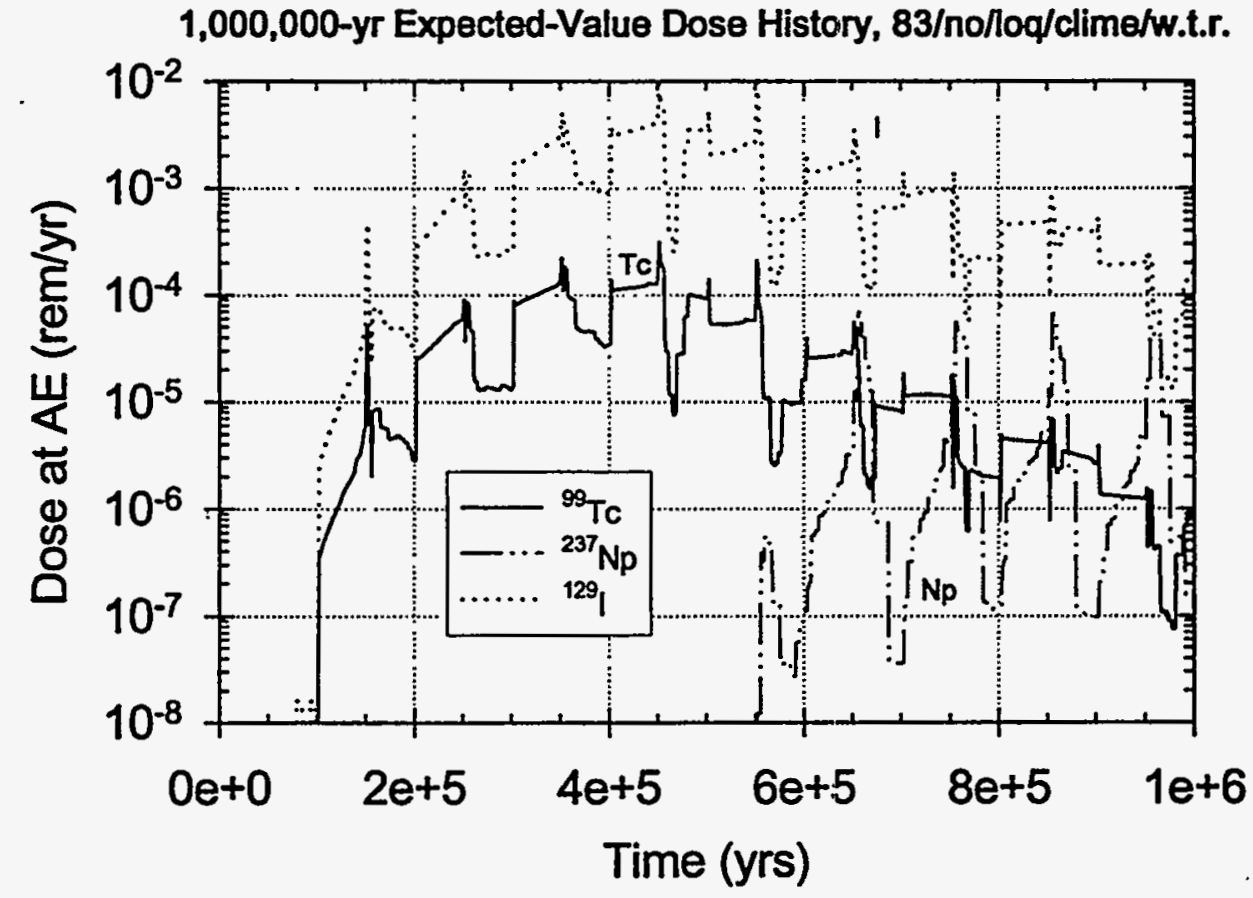

Figure 9.3-58 Climate-change model with cyclical $\mathrm{q}_{\mathrm{inf}}$ and cyclical water table rise. Expected-value dose history: 1,000,000 years, $83 \mathrm{MTU} / \mathrm{acre}$, no backfill, low infiltration (initial $\mathrm{q}_{\mathrm{inf}}=0.03 \mathrm{~mm} / \mathrm{yr}$ ). 


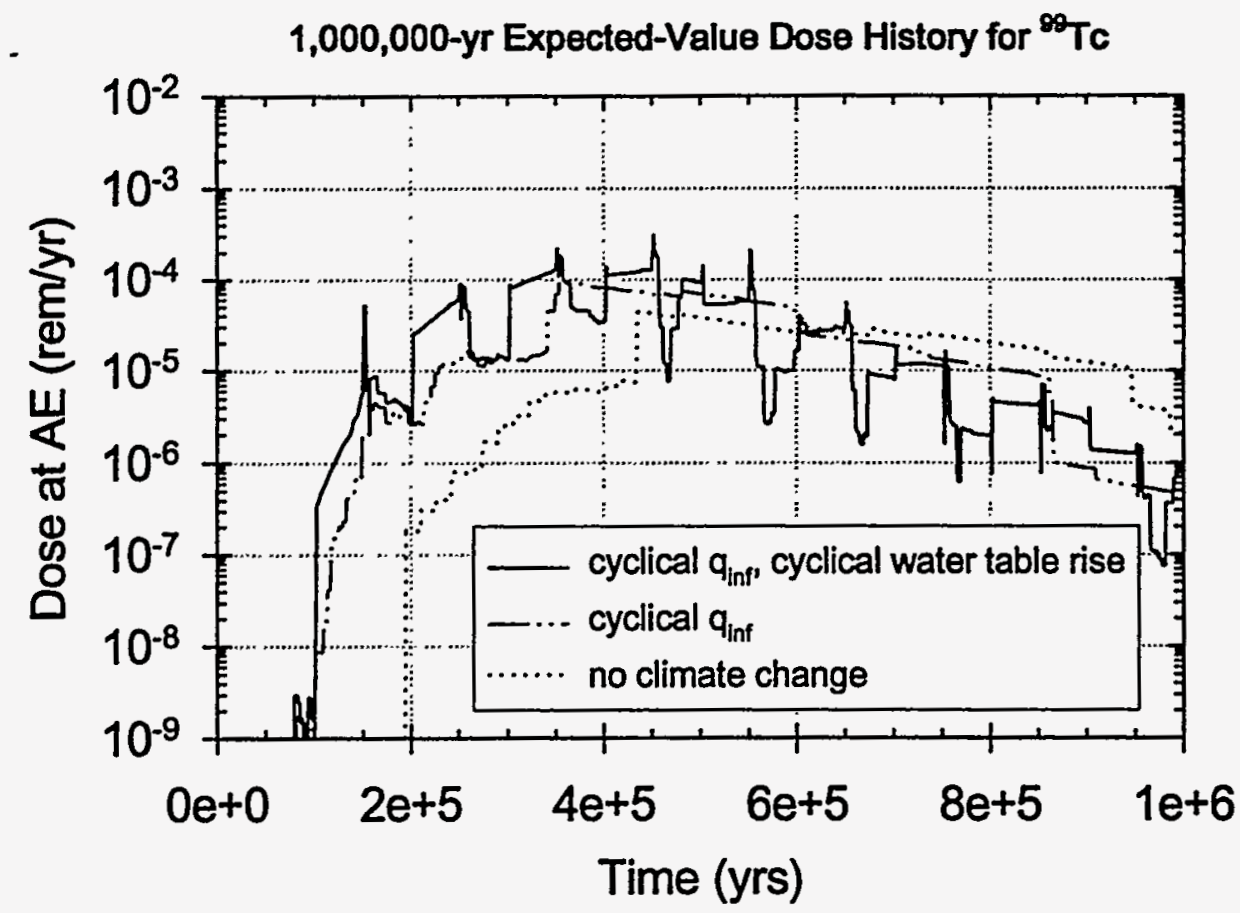

Figure 9.3-59 Effect of climate on ${ }^{99} \mathrm{Tc}$ dose: Climate change with and without water table rise vs. no climate change. Expected-value dose history: 1,000,000 years, 83 MTU/acre, no backfill, low infiltration (initial $q_{\text {inf }}=0.03 \mathrm{~mm} / \mathrm{yr}$ ).

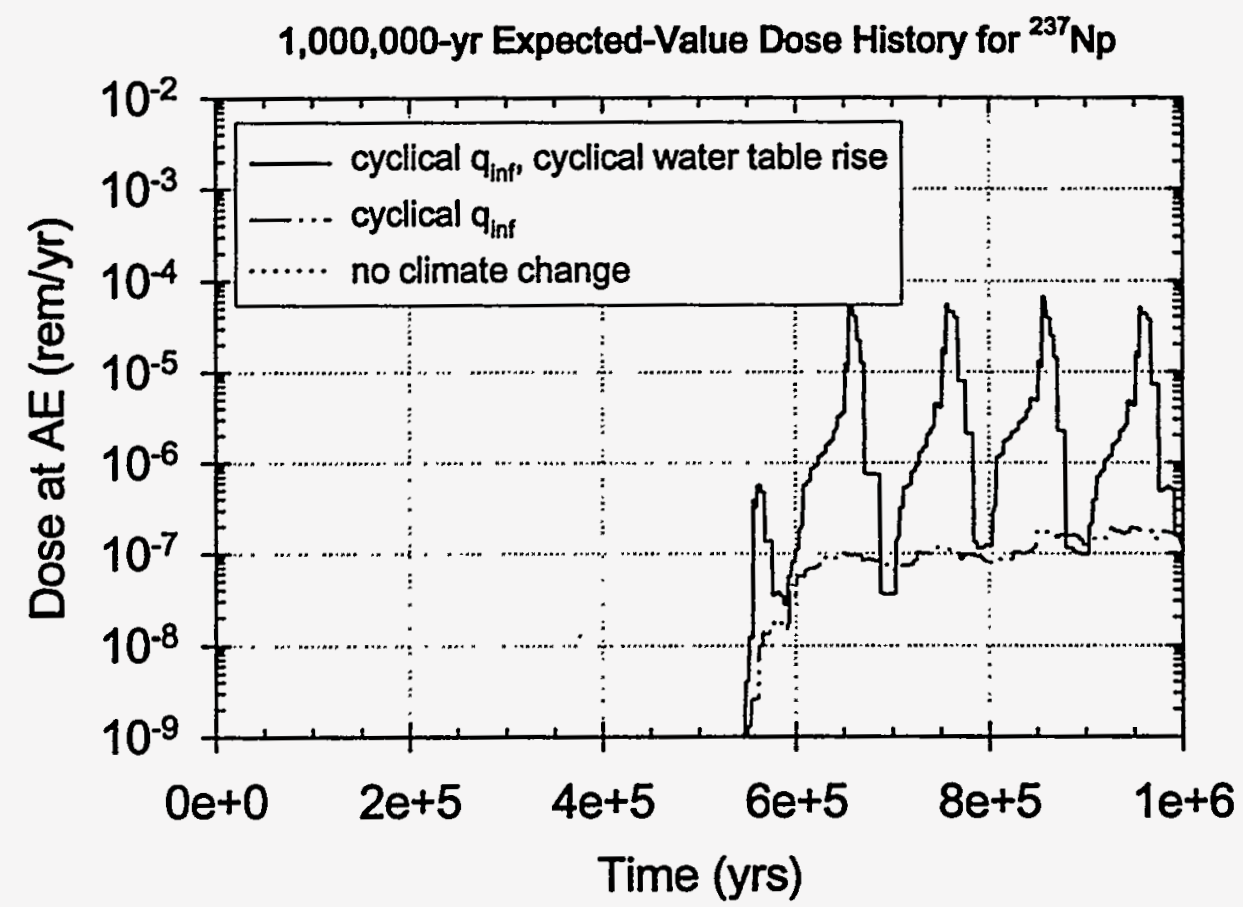

Figure 9.3-60 Effect of climate on ${ }^{237} \mathrm{~Np}$ dose: Climate change with and without water table rise vs. no climate change. Expected-value dose history: $1,000,000$ years, 83 MTU/acre, no backfill, low infiltration (initial $\mathrm{q}_{\text {inf }}=0.03 \mathrm{~mm} / \mathrm{yr}$ ). 


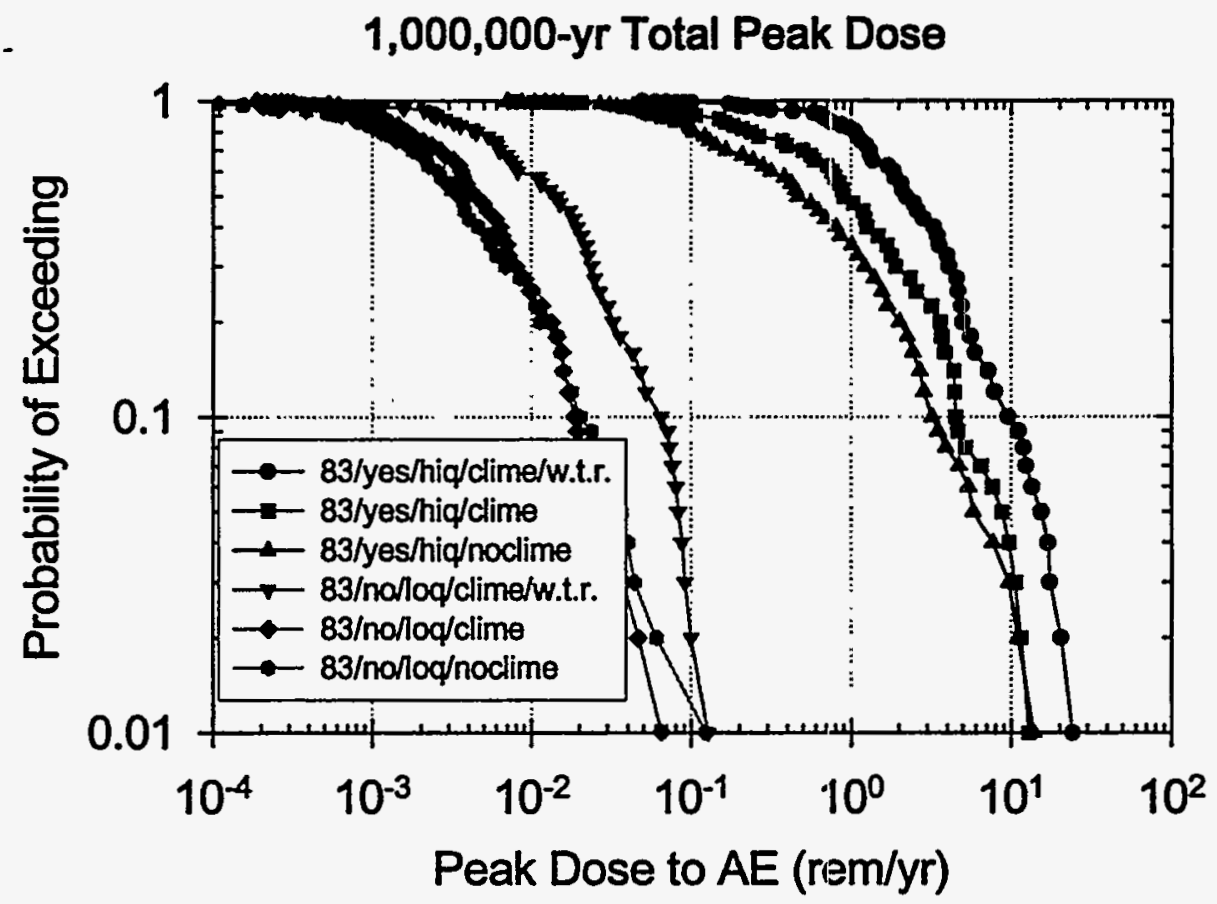

Figure 9.3-61 Effect of climate on total dose: Climate change with and without water table rise ("w.t.r.") vs. no climate change. CCDF of Total Peak Dose: 1,000,000 years, $83 \mathrm{MTU} / \mathrm{acre}$, with and without backfill, high and low infiltration ranges.

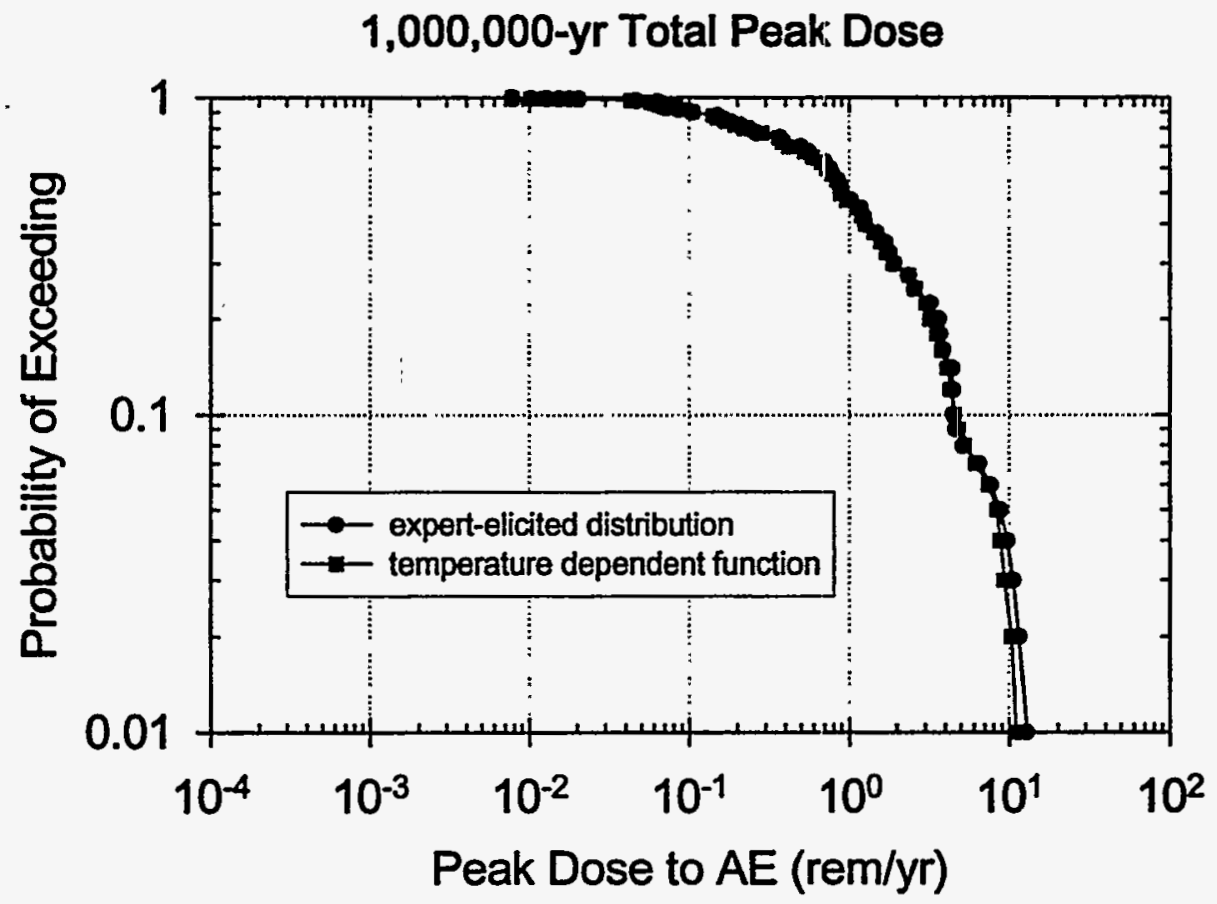

Figure 9.3-62 Effect of alternative models for $\mathrm{Np}, \mathrm{Pu}$, and Am solubility: LANL expertelicited model vs. Sassani temperature-dependent model. CCDF of Total Peak Dose: 1,000,000 years, 83 MTU/acre, backfill, high infiltration range. 


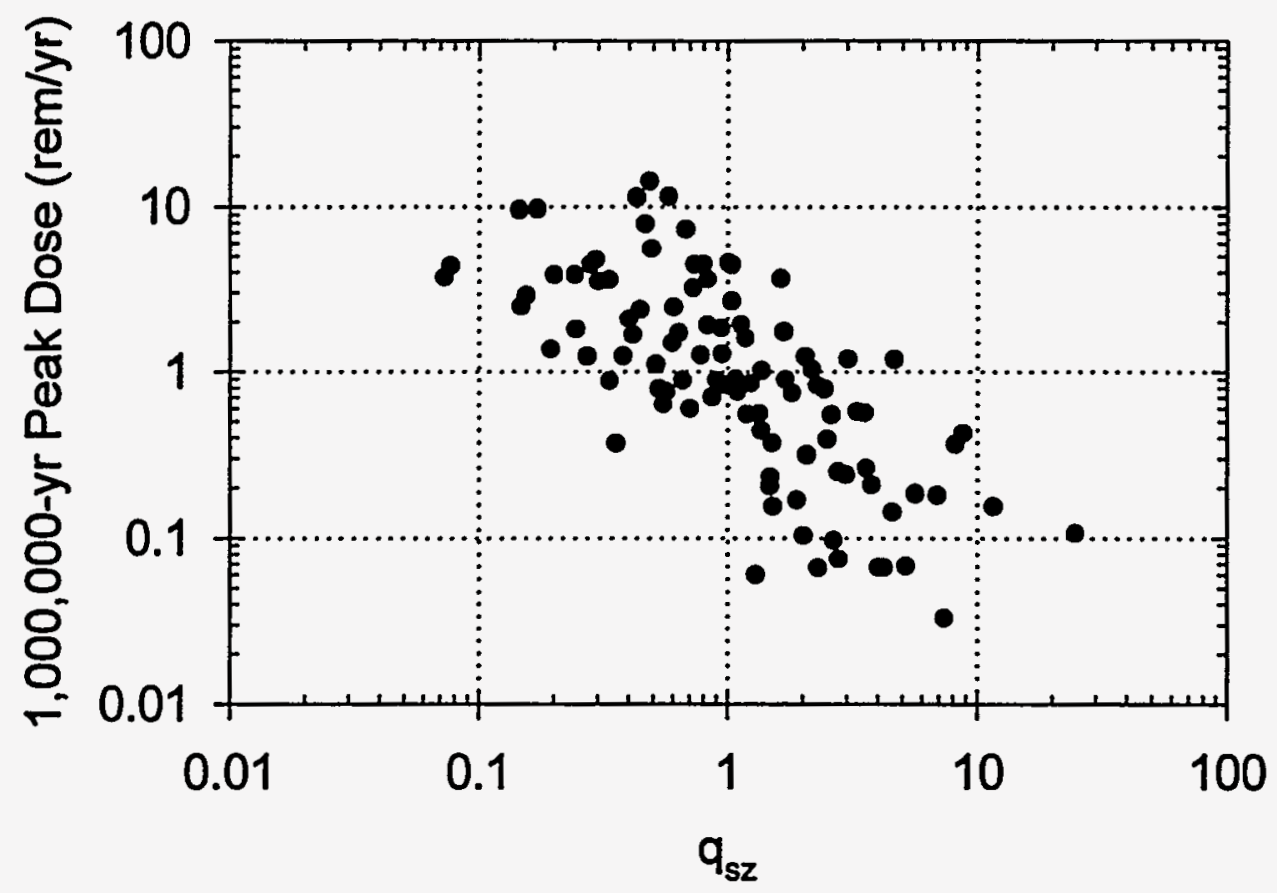

Figure 9.3-63 Scatter plot of 1,000,000-yr total peak dose versus saturated zone Darcy velocity $\left(\mathrm{m} / \mathrm{yr}\right.$ ) for $83 \mathrm{MTU} / \mathrm{acre}$, backfill, high infiltration (initial $\mathrm{q}_{\mathrm{inf}}=1.25$ $\mathrm{mm} / \mathrm{yr}$ ), cyclical- $\mathrm{q}_{\mathrm{inf}}$ climate model.

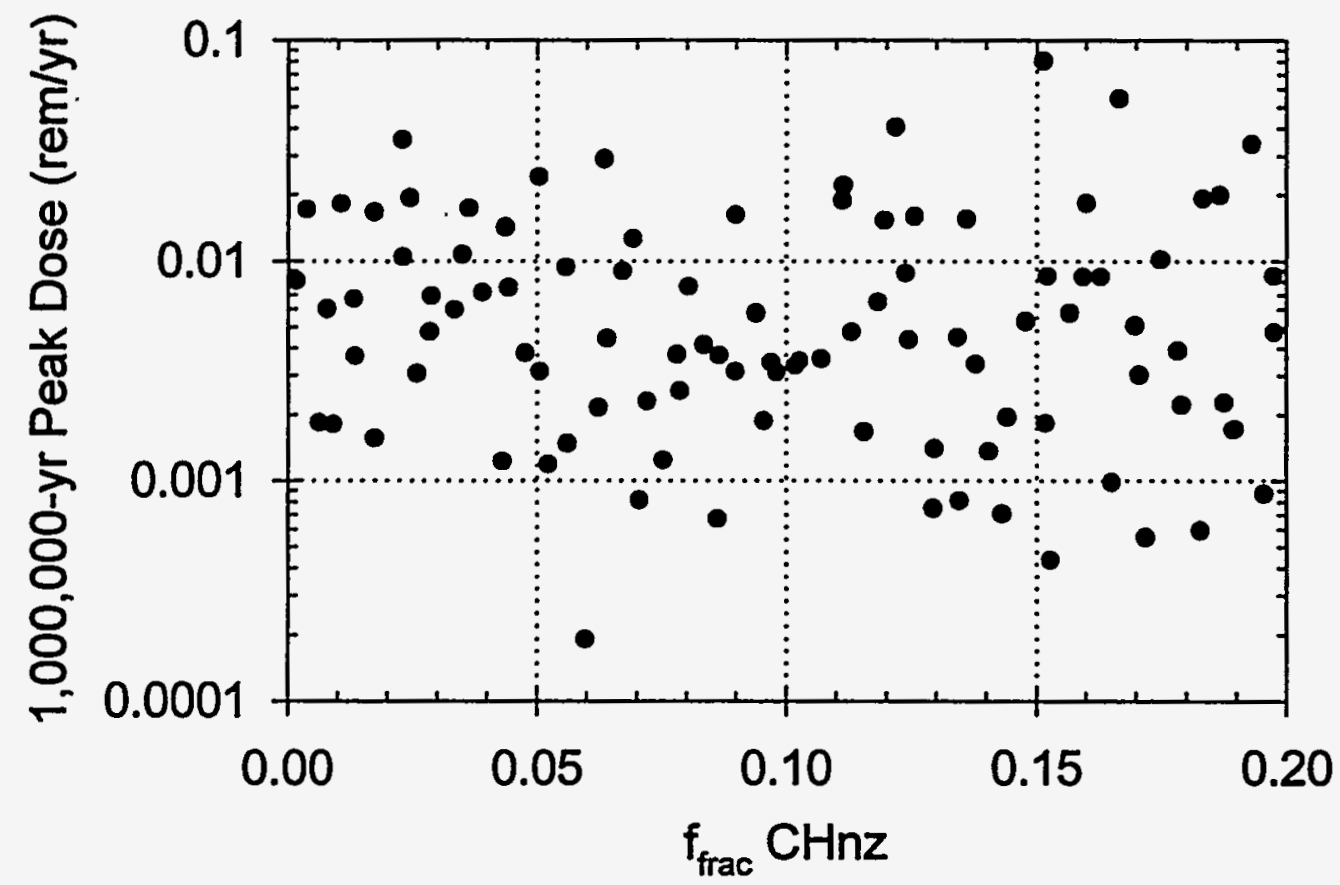

Figure 9.3-64 Scatter plot of 1,000,000-yr total peak dose versus UZ percolation flux (mm/yr) for $83 \mathrm{MTU} / \mathrm{acre}$, backfill, high infiltration (initial $\mathrm{q}_{\mathrm{inf}}=1.25 \mathrm{~mm} / \mathrm{yr}$ ), cyclical$\mathrm{q}_{\text {inf }}$ climate model. 


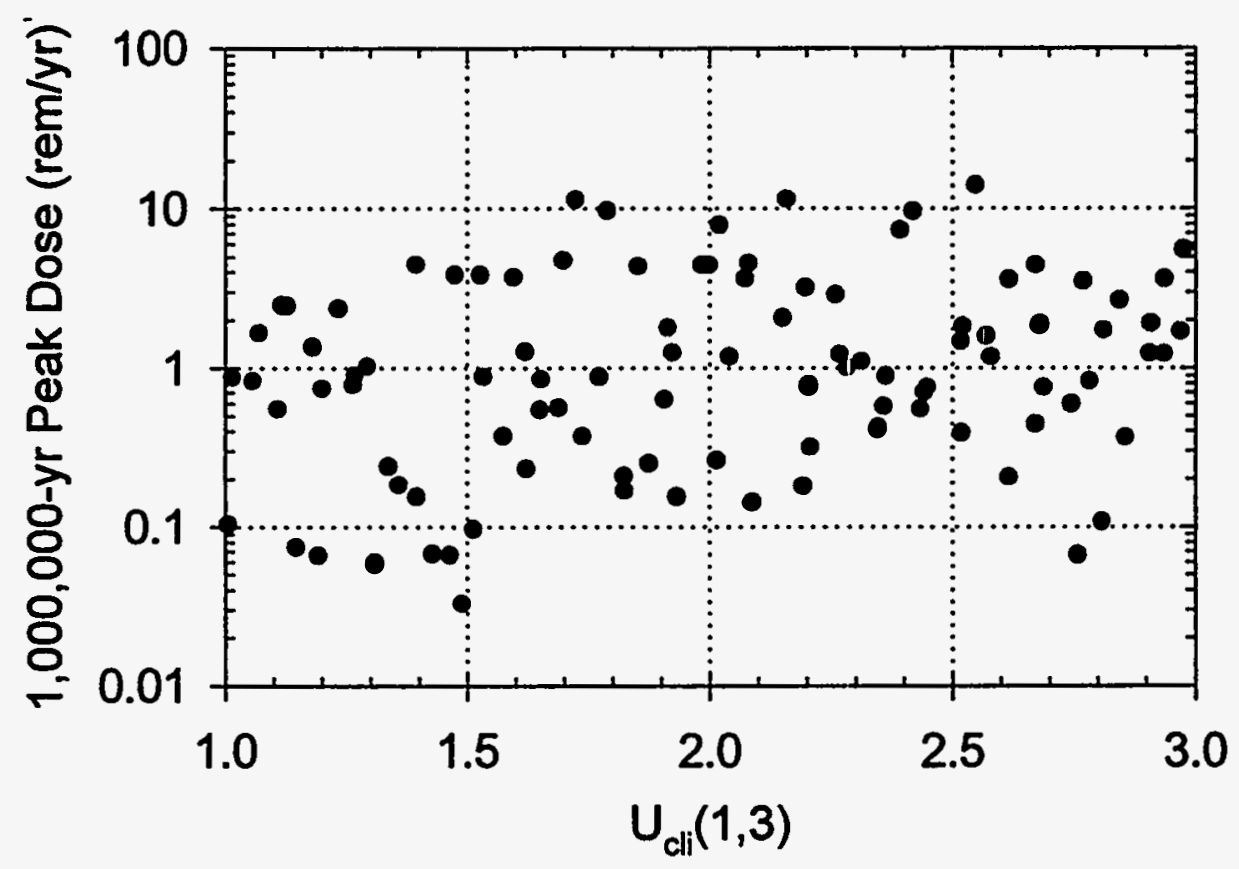

Figure 9.3-65 Scatter plot of 1,000,000-yr total peak dose versus climate change modifier for $83 \mathrm{MTU} / \mathrm{acre}$, backfill, high infiltration (initial $\mathrm{q}_{\mathrm{inf}}=1.25 \mathrm{~mm} / \mathrm{yr}$ ), cyclical- $\mathrm{q}_{\mathrm{inf}}$ climate model.

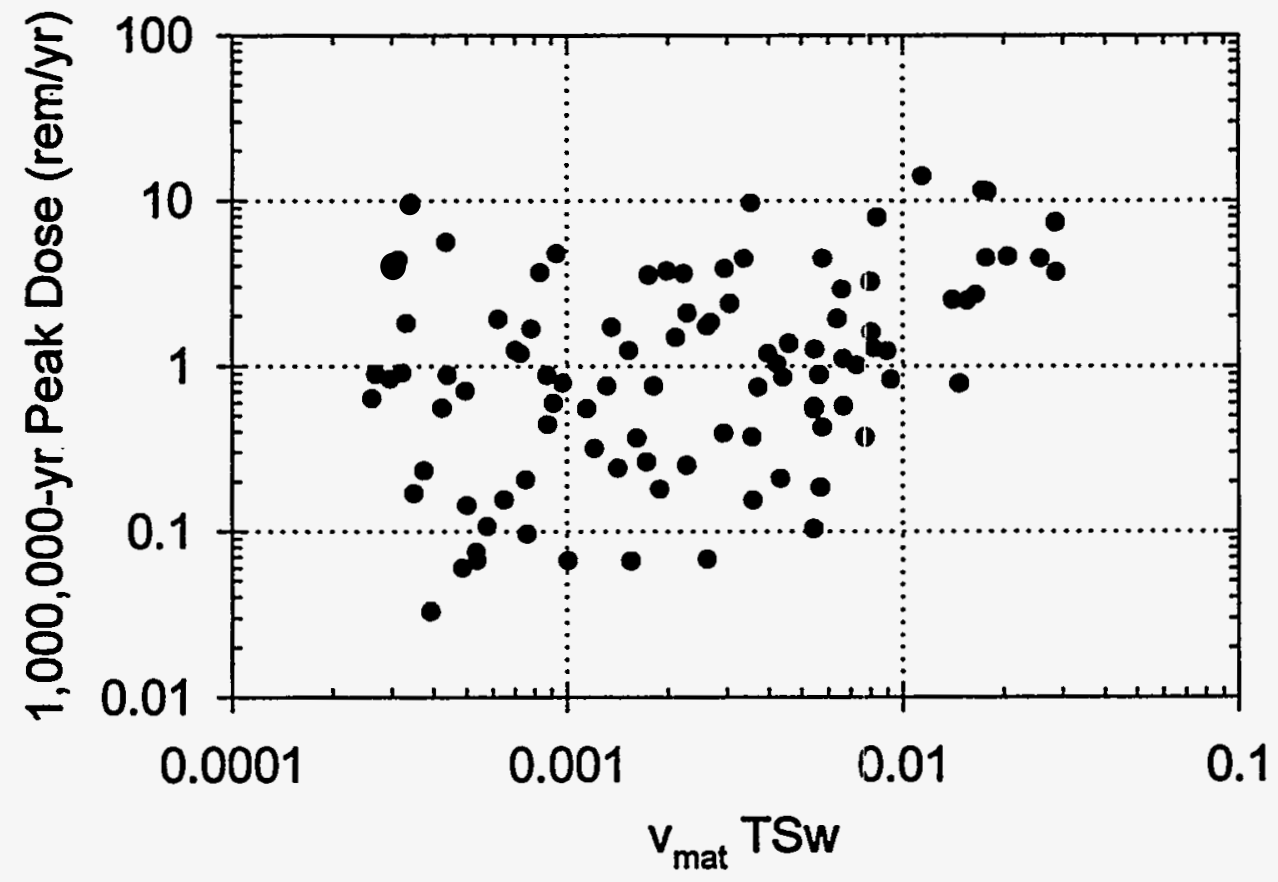

Figure 9.3-66 Scatter plot of 1,000,000-yr total peak dose versus matrix velocity $(\mathrm{m} / \mathrm{yr})$ in the TSw for $83 \mathrm{MTU} / \mathrm{acre}$, backfill, high infiltration (initial $\mathrm{q}_{\mathrm{inf}}=1.25 \mathrm{~mm} / \mathrm{yr}$ ), cyclical- $\mathrm{q}_{\mathrm{inf}}$ climate model. 

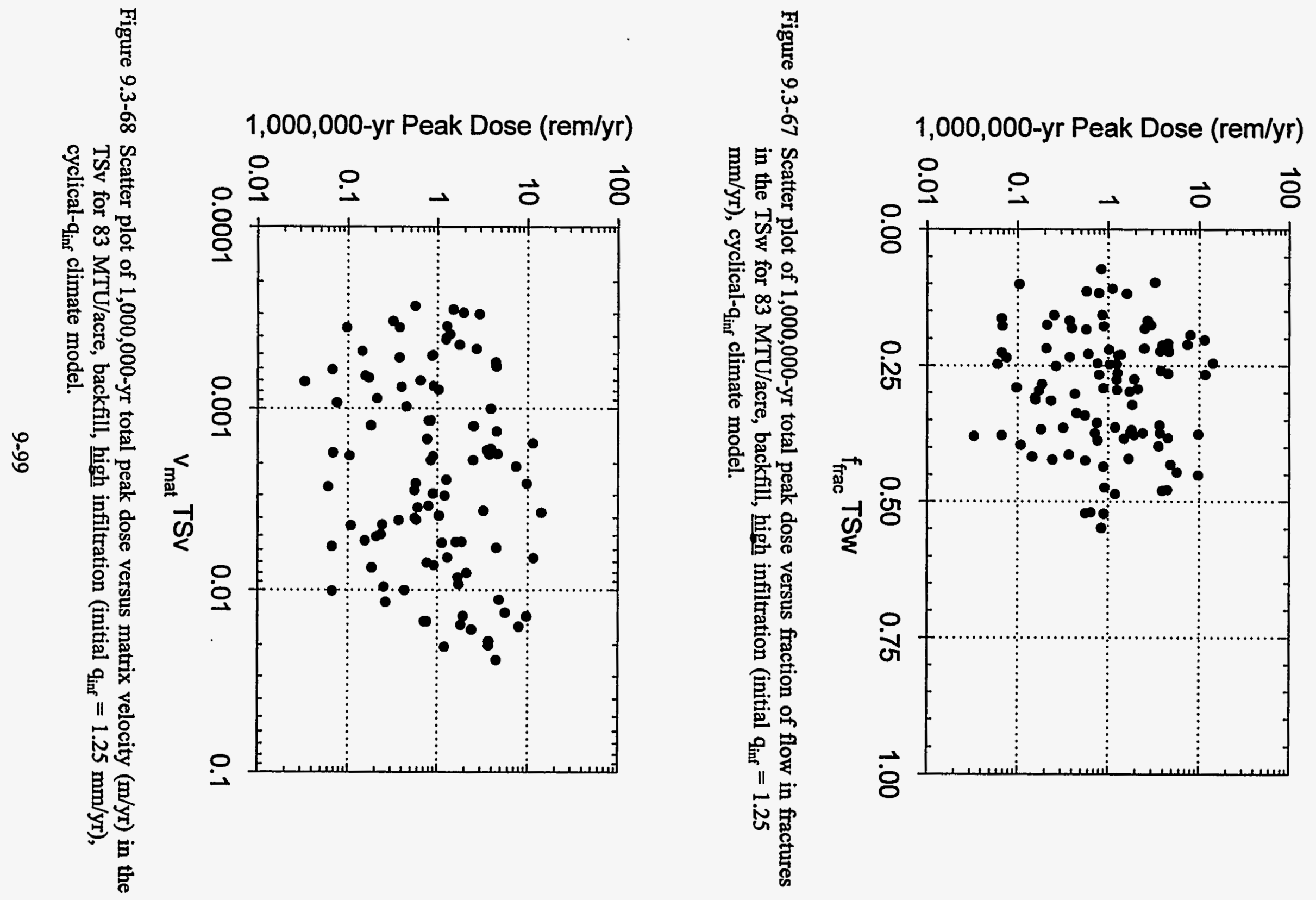


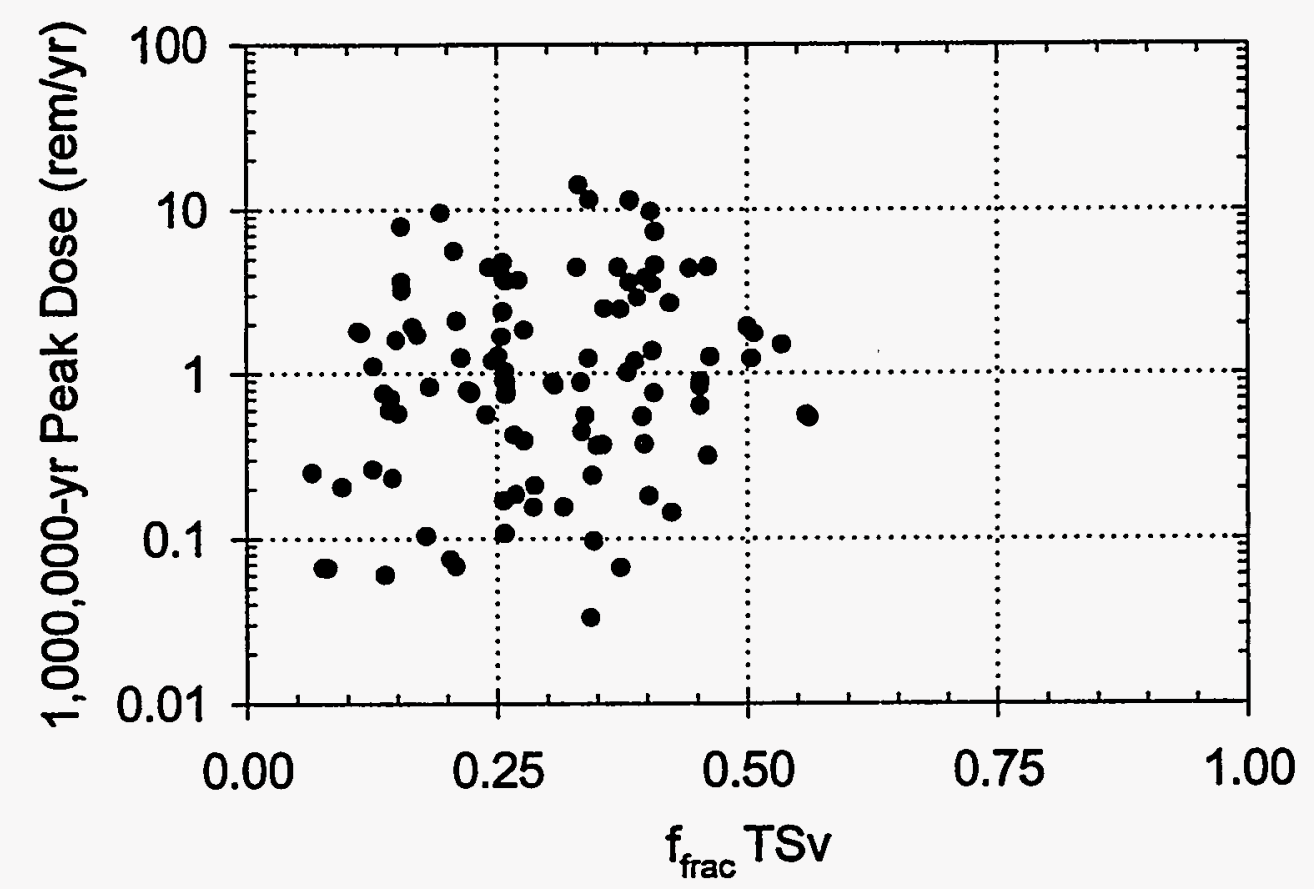

Figure 9.3-69 Scatter plot of 1,000,000-yr total peak dose versus fraction of flow in fractures in the TSv for 83 MTU/acre, backfill, high infiltration (initial $\mathrm{q}_{\mathrm{inf}}=1.25$ $\mathrm{mm} / \mathrm{yr})$, cyclical- $\mathrm{q}_{\mathrm{inf}}$ climate model.

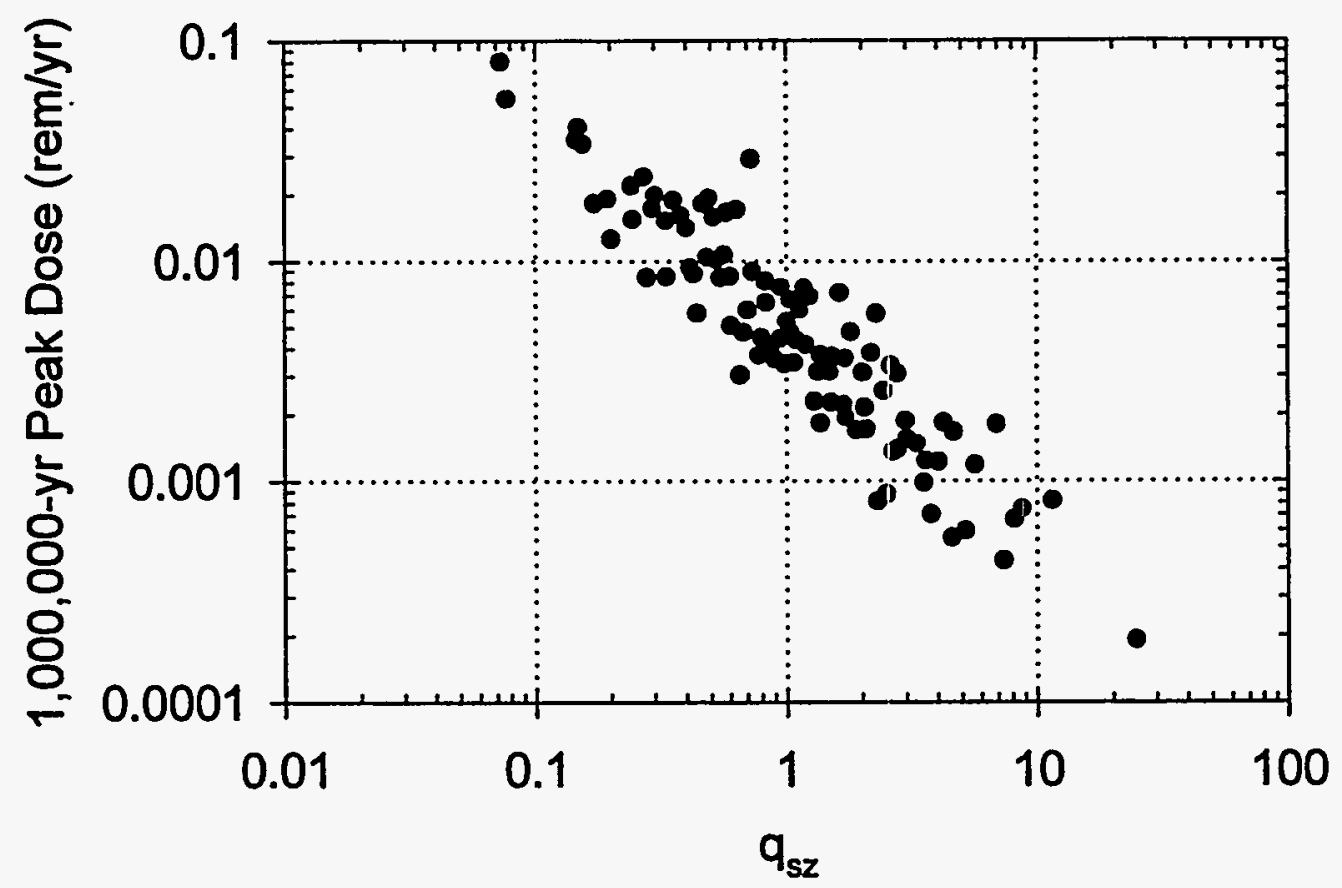

Figure 9.3-70 Scatter plot of 1,000,000-yr total peak dose versus saturated zone Darcy velocity $\left(\mathrm{m} / \mathrm{yr}\right.$ ) for $83 \mathrm{MTU} / \mathrm{acre}$, backfill, low infiltration (initial $\mathrm{q}_{\mathrm{inf}}=\mathbf{0 . 0 3}$ $\mathrm{mm} / \mathrm{yr})$, cyclical- $\mathrm{q}_{\mathrm{inf}}$ climate model. 


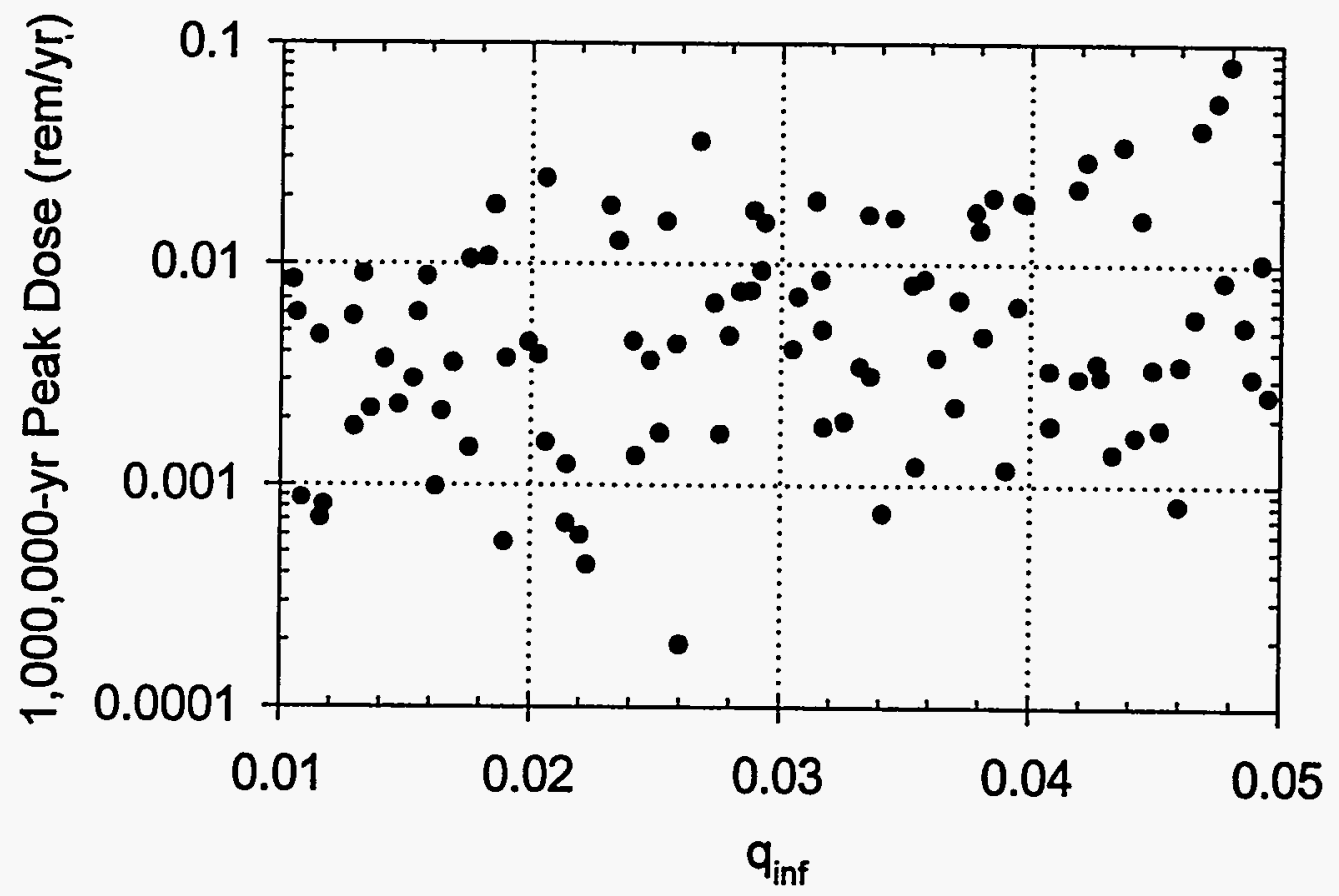

Figure 9.3-71 Scatter plot of 1,000,000-yr total peak dose versus UZ percolation flux (mm/yr) for $83 \mathrm{MTU} / \mathrm{acre}$, backfill, low infiltration (initial $\mathrm{q}_{\mathrm{inf}}=0.03 \mathrm{~mm} / \mathrm{yr}$ ), cyclical$\mathrm{q}_{\mathrm{inf}}$ climate model.

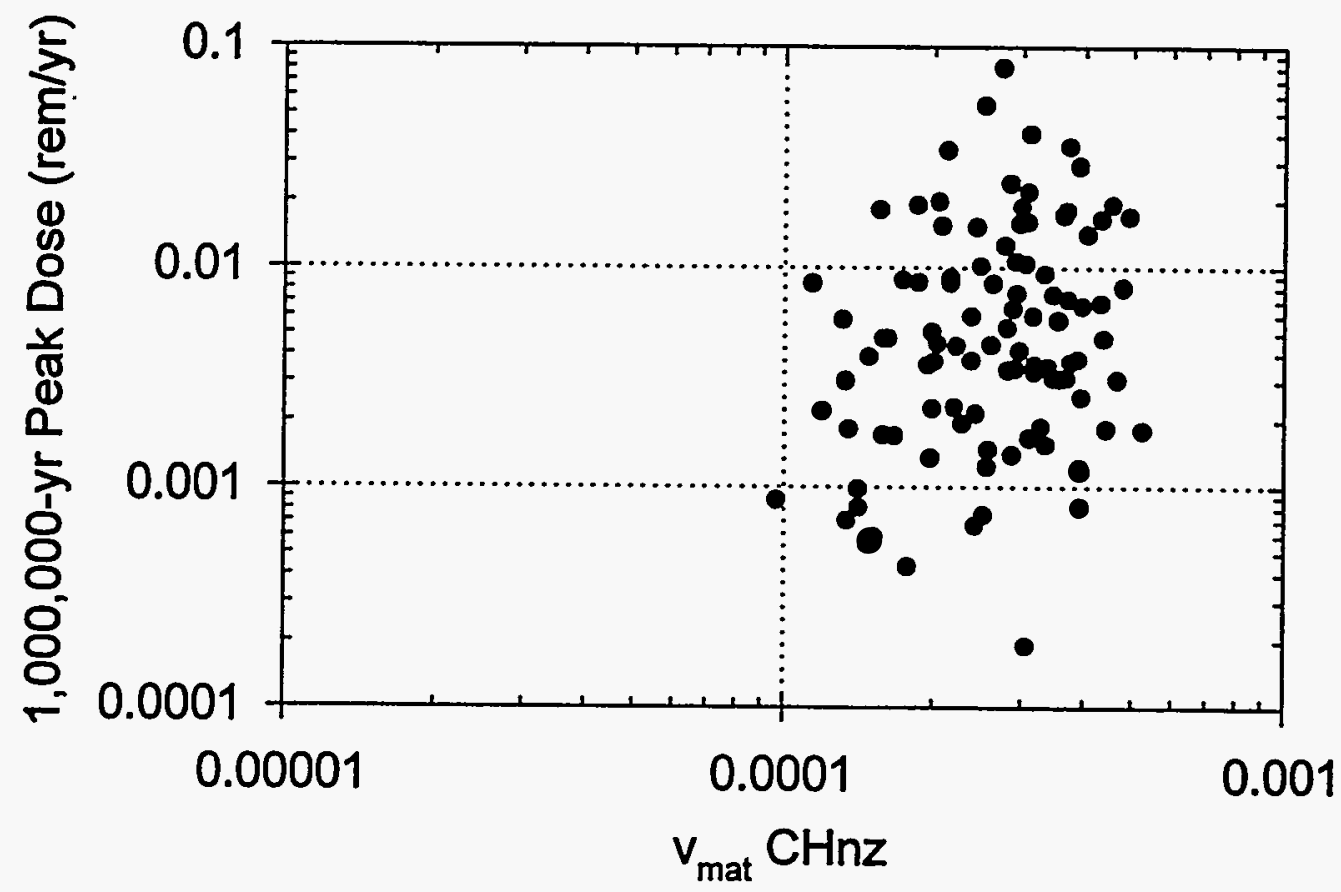

Figure 9.3-72 Scatter plot of 1,000,000-yr total peak dose versus matrix velocity $(\mathrm{m} / \mathrm{yr})$ in the CHnz for $83 \mathrm{MTU} / \mathrm{acre}$, backfill, low infiltration (initial $\mathrm{q}_{\mathrm{inf}}=0.03 \mathrm{~mm} / \mathrm{yr}$ ), cyclical- $\mathrm{q}_{\mathrm{inf}}$ climate model. 


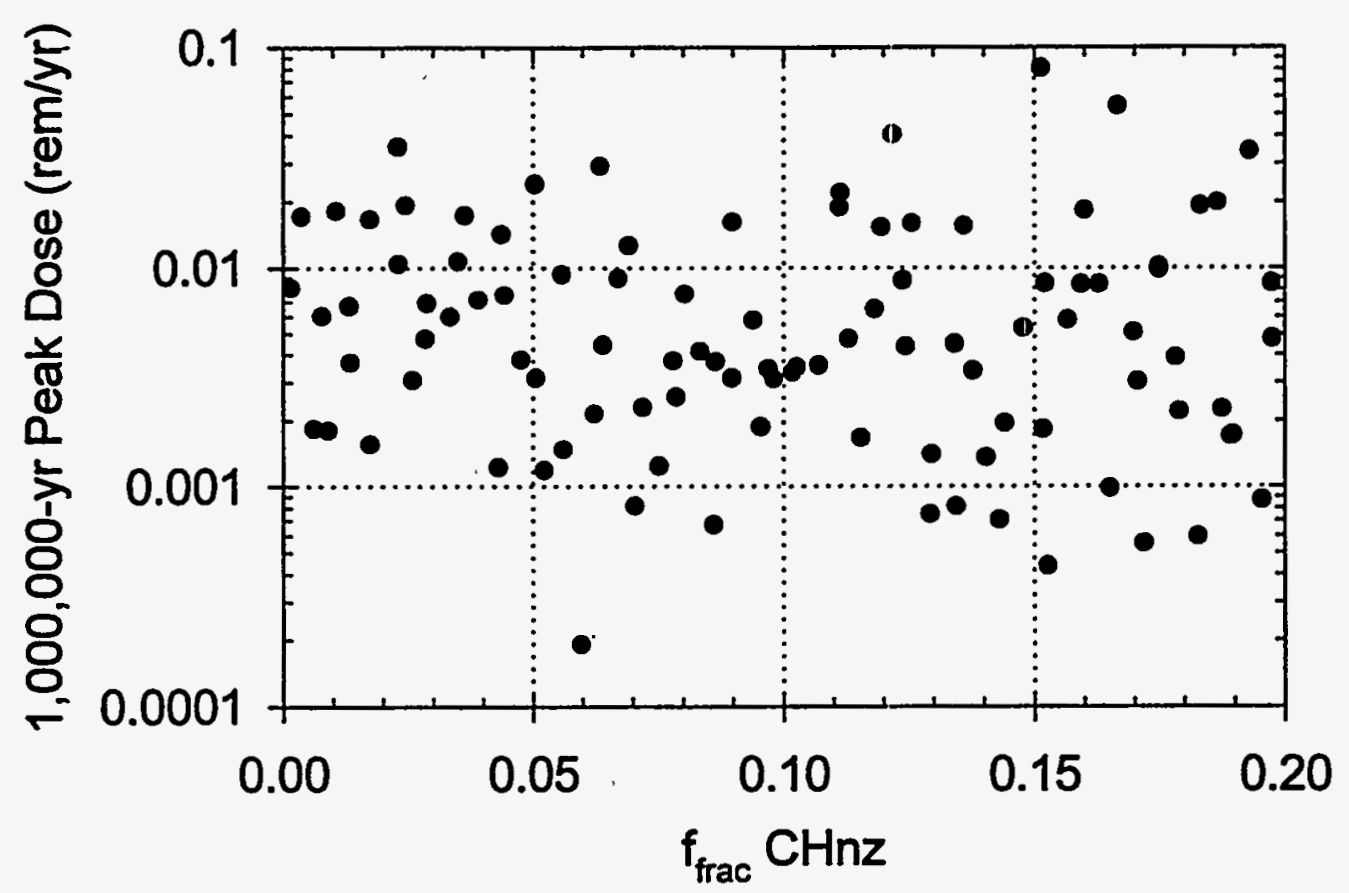

Figure 9.3-73 Scatter plot of 1,000,000-yr total peak dose versus fraction of flow in fractures in the CHnz for $83 \mathrm{MTU} / \mathrm{acre}$, backfill, low infiltration (initial $\mathrm{q}_{\mathrm{inf}}=0.03$ $\mathrm{mm} / \mathrm{yr})$, cyclical- $\mathrm{q}_{\mathrm{inf}}$ climate model.

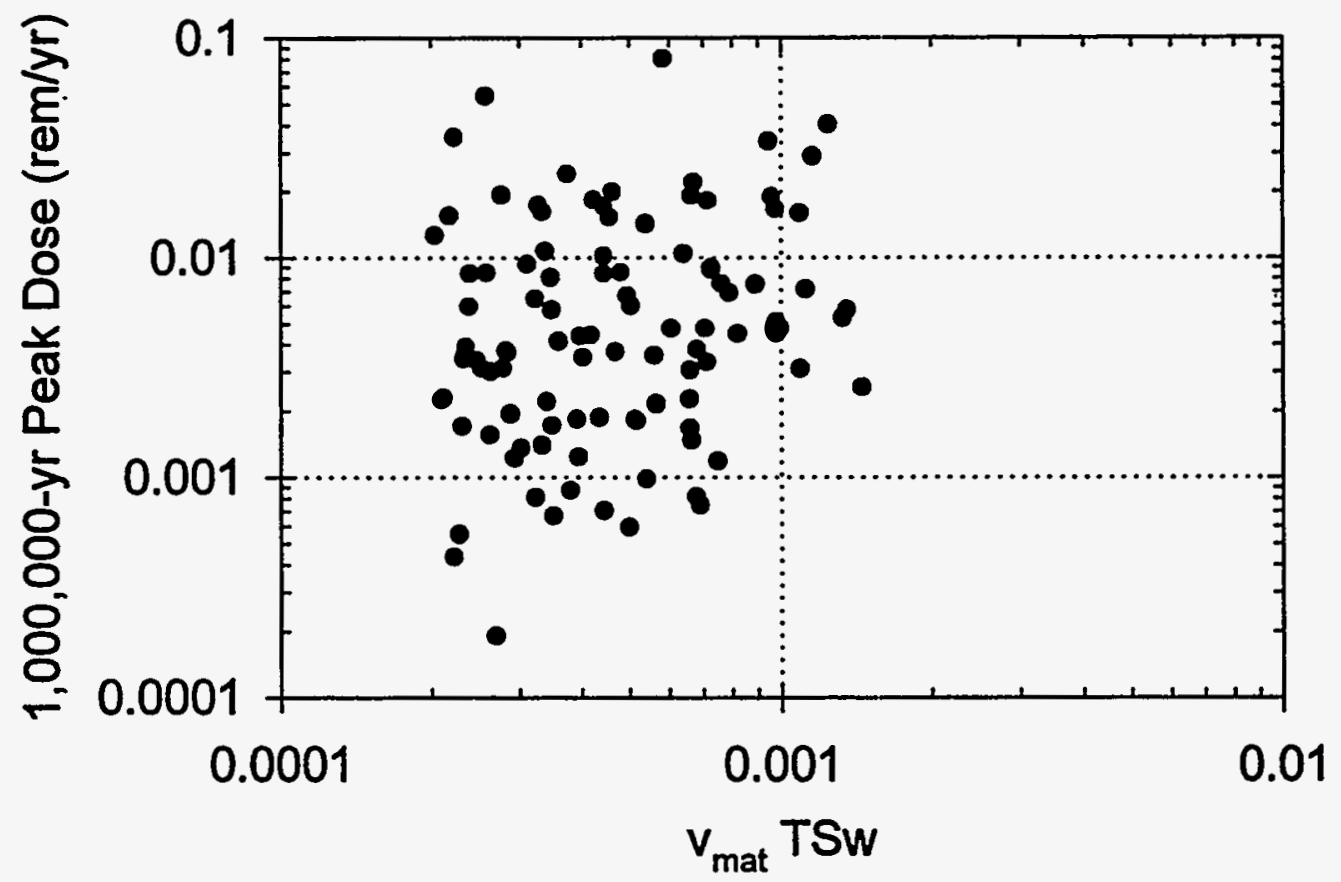

Figure 9.3-74 Scatter plot of 1,000,000-yr total peak dose versus matrix velocity $(\mathrm{m} / \mathrm{yr})$ in the TSw for $83 \mathrm{MTU} / \mathrm{acre}$, backfill, low infiltration (initial $\mathrm{q}_{\mathrm{inf}}=0.03 \mathrm{~mm} / \mathrm{yr}$ ), cyclical- $\mathrm{q}_{\mathrm{inf}}$ climate model. 


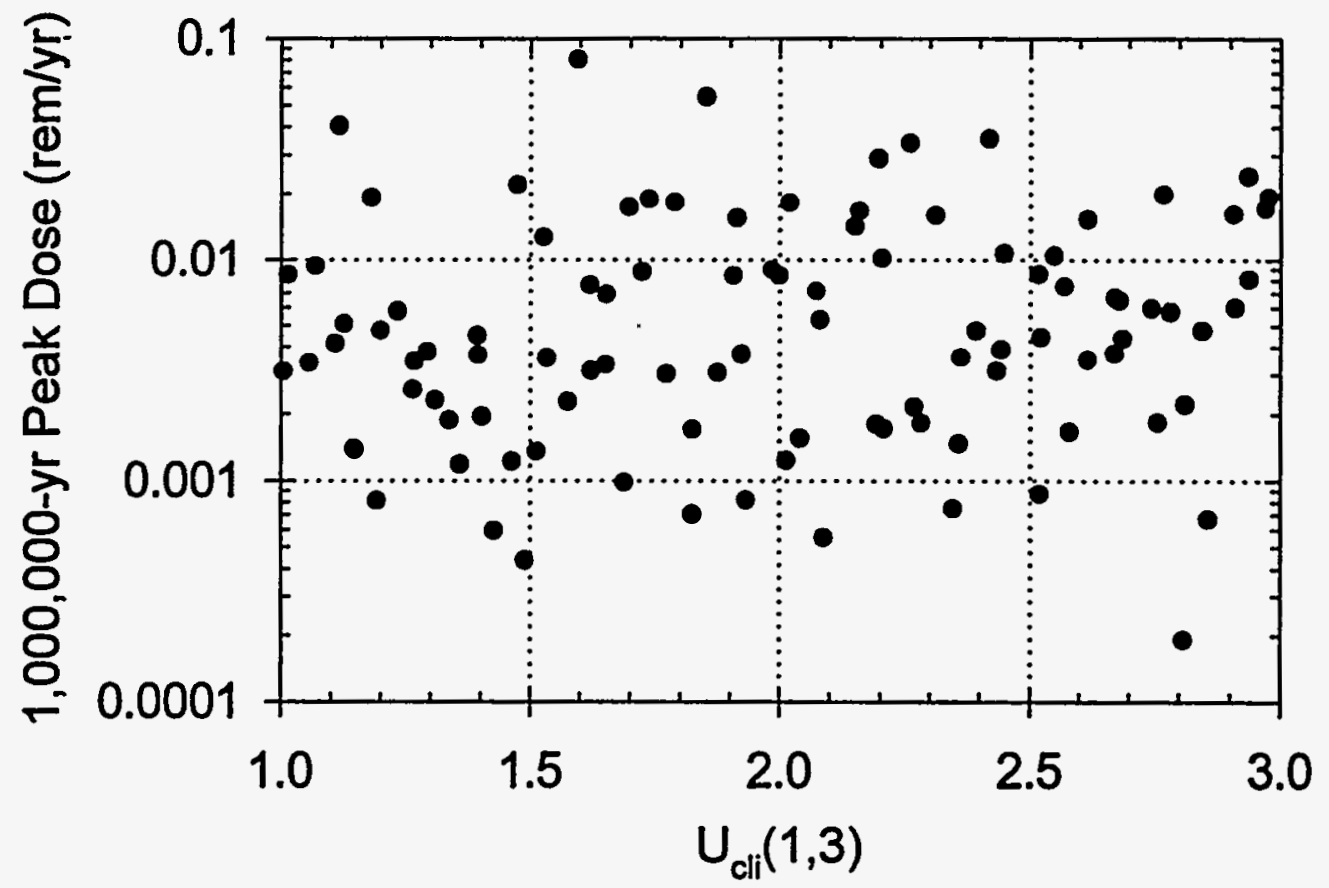

Figure 9.3-75 Scatter plot of 1,000,000-yr total peak dose versus climate change modifier for $83 \mathrm{MTU} / \mathrm{acre}$, backfill, low infiltration (initial $\mathrm{q}_{\mathrm{inf}}=0.03 \mathrm{~mm} / \mathrm{yr}$ ), cyclical- $\mathrm{q}_{\mathrm{inf}}$ climate model.

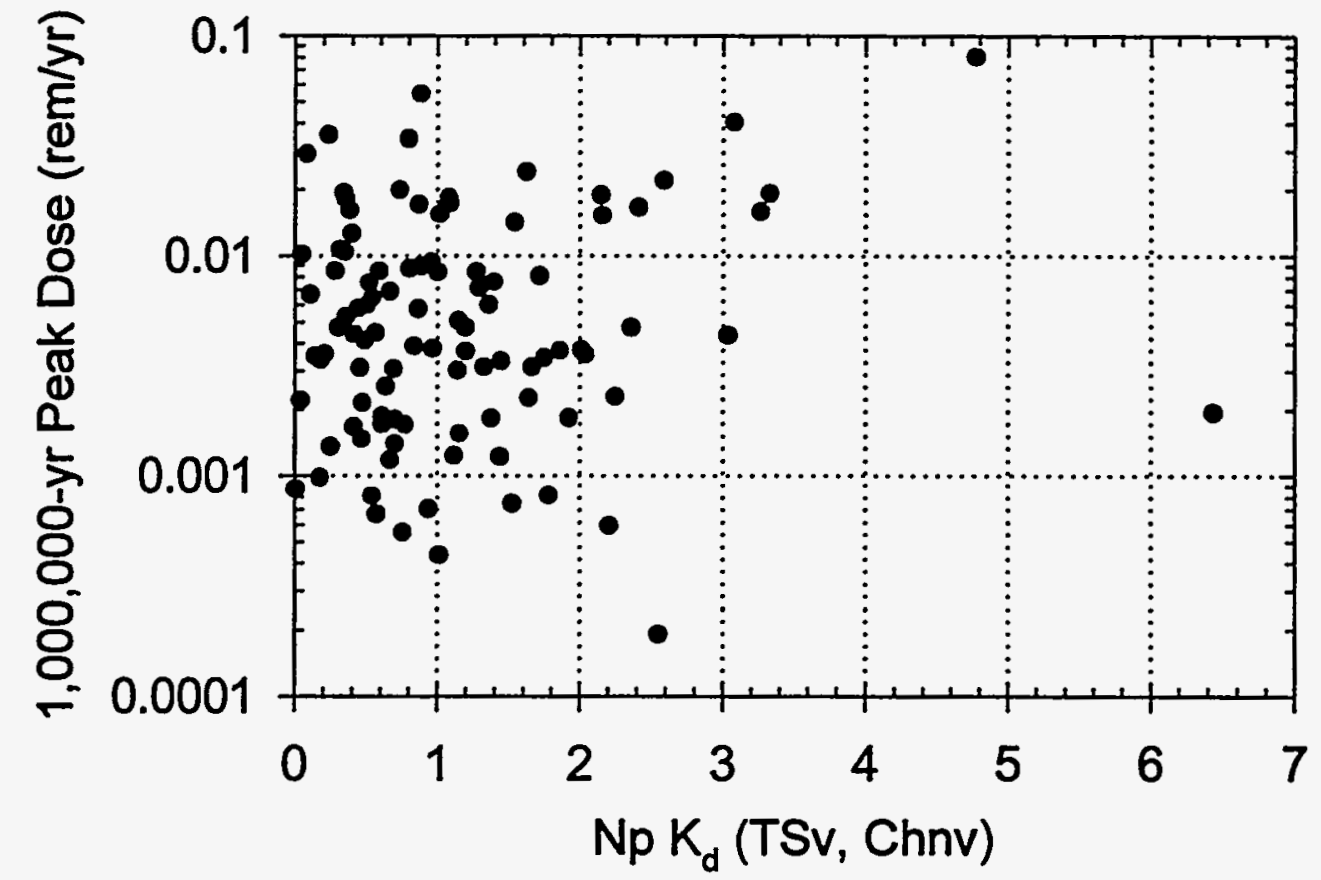

Figure 9.3-76 Scatter plot of 1,000,000-yr total peak dose versus Np sorption coefficient in the vitric tuff for $83 \mathrm{MTU} / \mathrm{acre}$, backfill, low infiltration (initial $\mathrm{q}_{\mathrm{inf}}=0.03$ $\mathrm{mm} / \mathrm{yr}$ ), cyclical- $\mathrm{q}_{\mathrm{inf}}$ climate model. 
83YH Subsystem Releases: Total

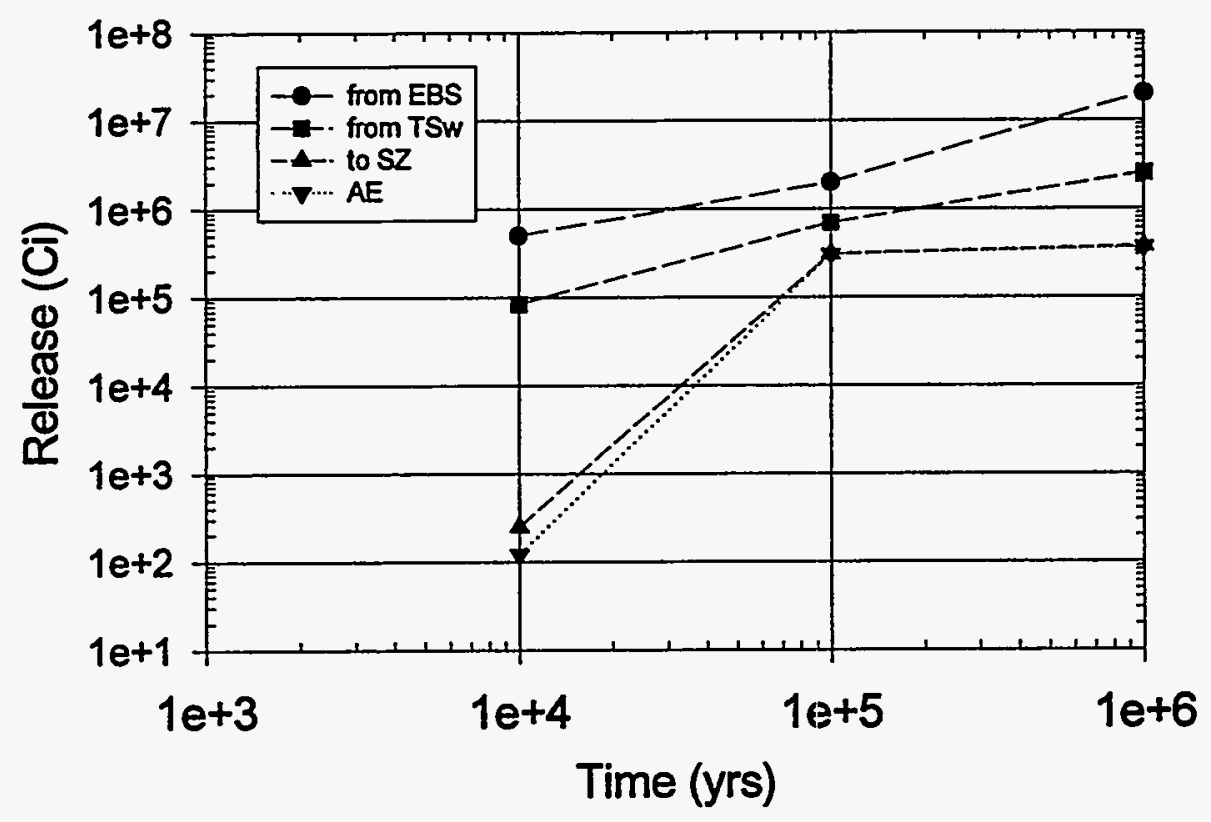

Figure 9.4-1. Subsystem Total Release. Expected-value release at 10,000, 100,000 and $1,000,000$ years for 83 MTU/acre, backfill, high infiltration $\left(\mathrm{q}_{\mathrm{inf}}=1.25 \mathrm{~mm} / \mathrm{yr}\right)$, no climate change, with decay.

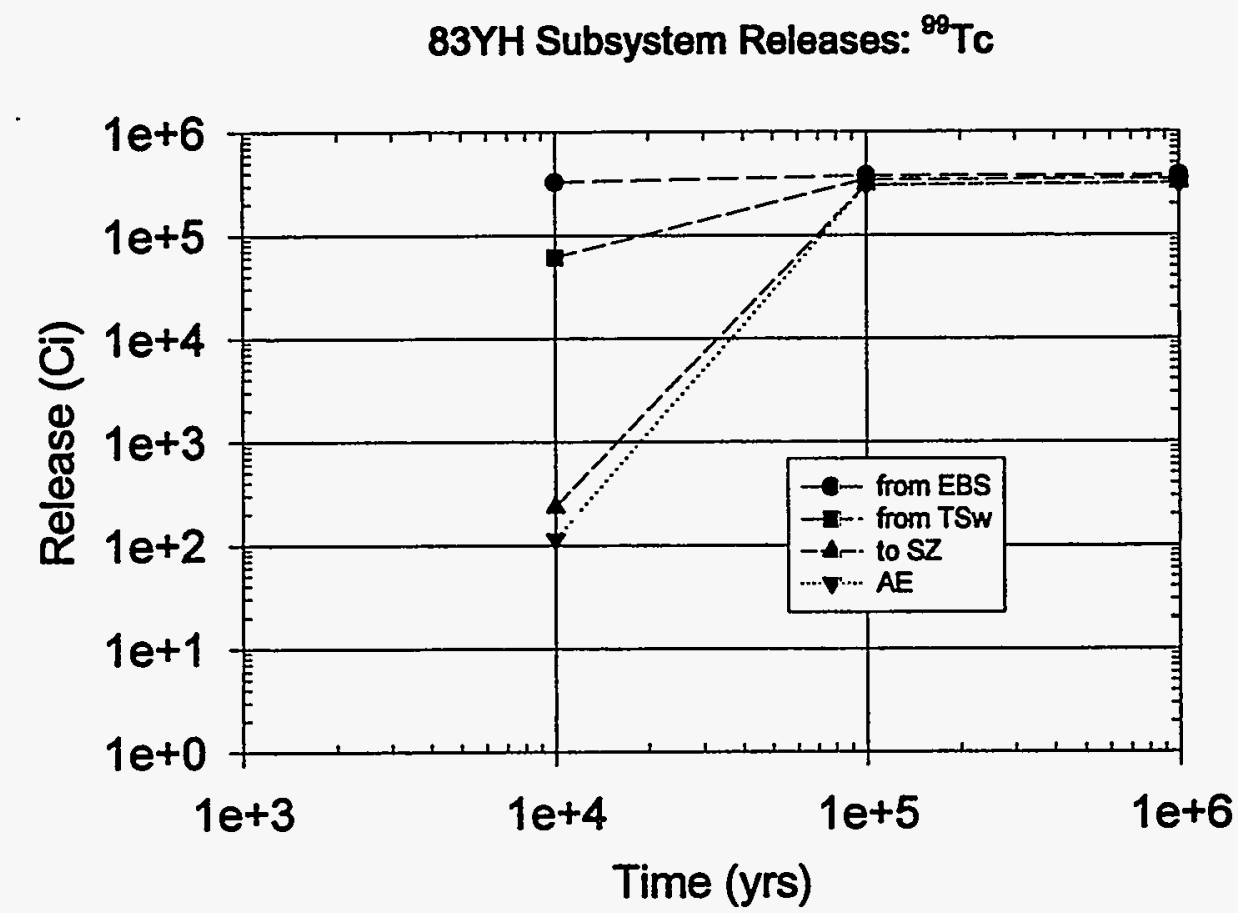

Figure 9.4-2. Subsystem ${ }^{99}$ Tc Release. Expected-value release at 10,000, 100,000 and $1,000,000$ years for 83 MTU/acre, backfill, high infiltration $\left(\mathrm{q}_{\mathrm{inf}}=1.25 \mathrm{~mm} / \mathrm{yr}\right)$, no climate change, with decay. 


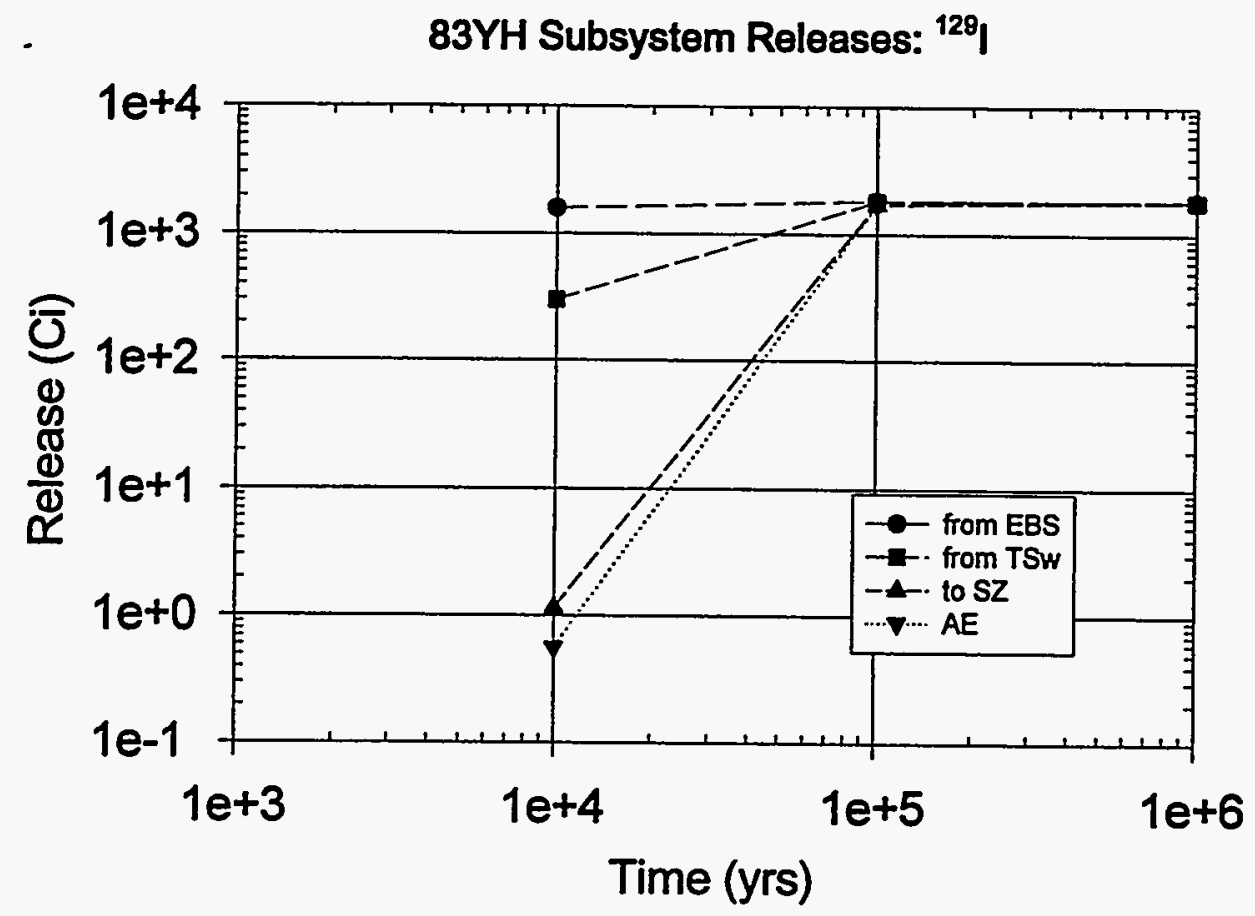

Figure 9.4-3. Subsystem ${ }^{129}$ I. Expected-value release at $10,000,100,000$ and $1,000,000$ years for $83 \mathrm{MTU} /$ acre, backfill, high infiltration $\left(\mathrm{q}_{\mathrm{inf}}=1.25 \mathrm{~mm} / \mathrm{yr}\right)$, no climate change, with decay.

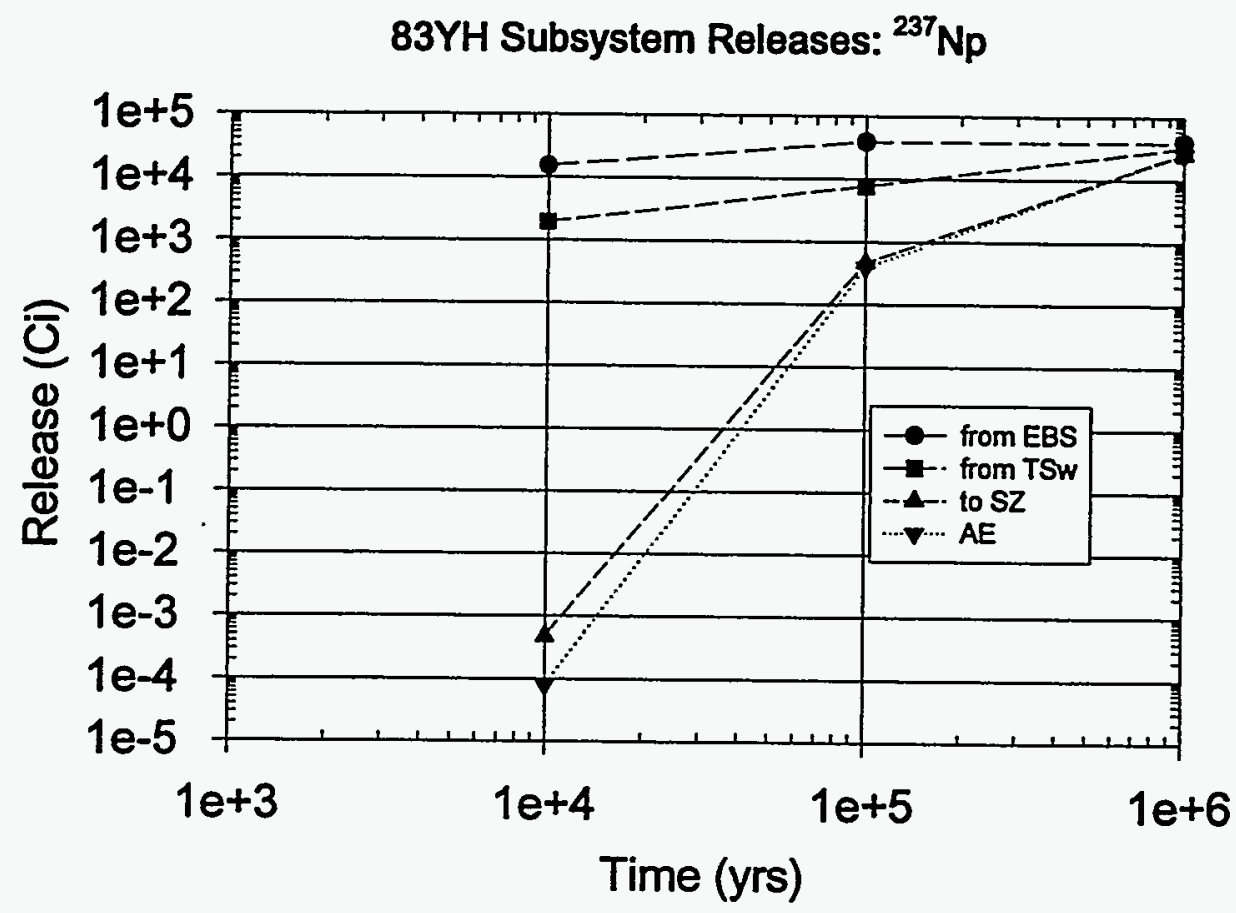

Figure 9.4-4. Subsystem ${ }^{237} \mathrm{~Np}$. Expected-value release at 10,000, 100,000 and 1,000,000 years for $83 \mathrm{MTU} /$ acre, backfill, high infiltration $\left(\mathrm{q}_{\mathrm{inf}}=1.25 \mathrm{~mm} / \mathrm{yr}\right)$, no climate change, with decay. 


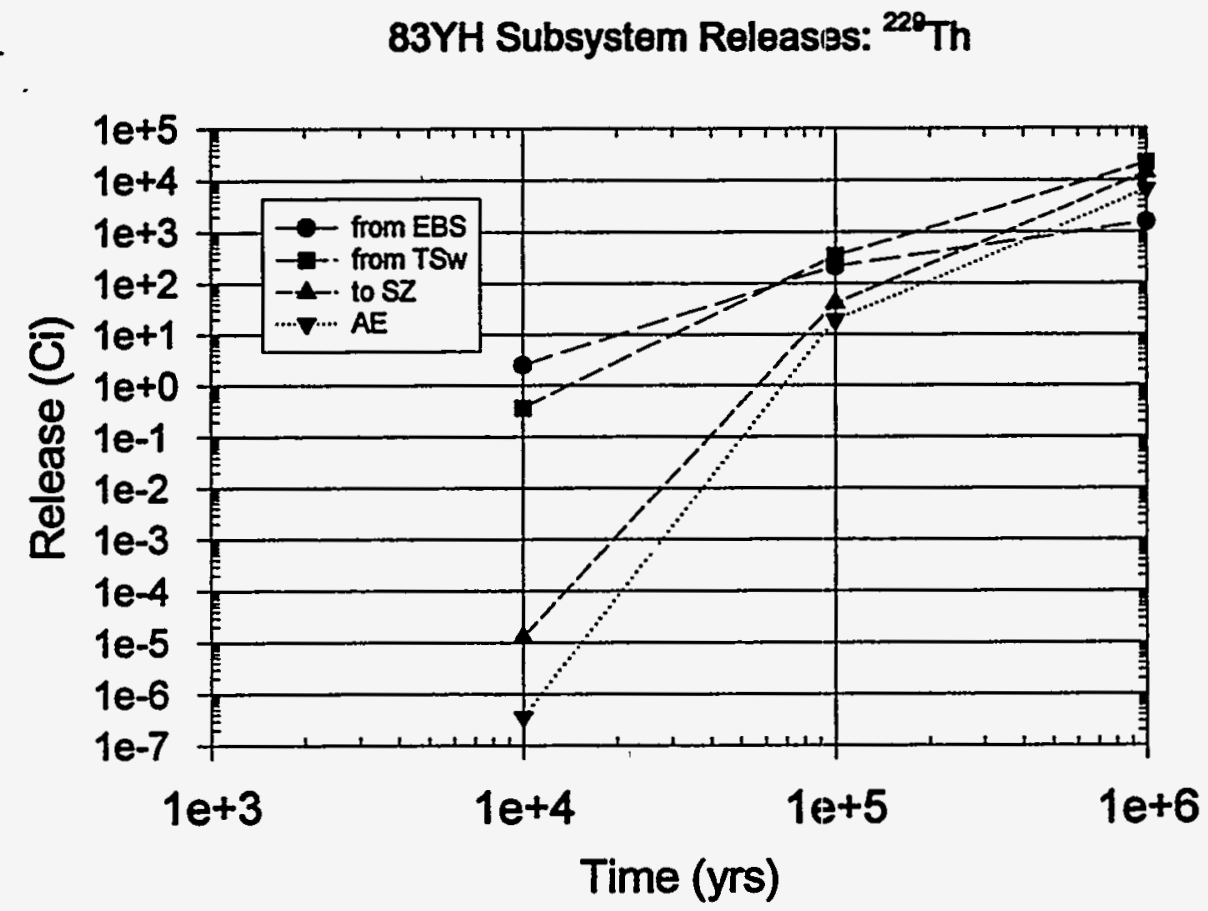

Figure 9.4-5. Subsystem ${ }^{229} \mathrm{Th}$. Expected-value release at $10,000,100,000$ and $1,000,000$ years for $83 \mathrm{MTU} / \mathrm{acre}$, backfill, high infiltration $\left(\mathrm{q}_{\mathrm{inf}}=1.25 \mathrm{~mm} / \mathrm{yr}\right)$, no climate change, with decay.

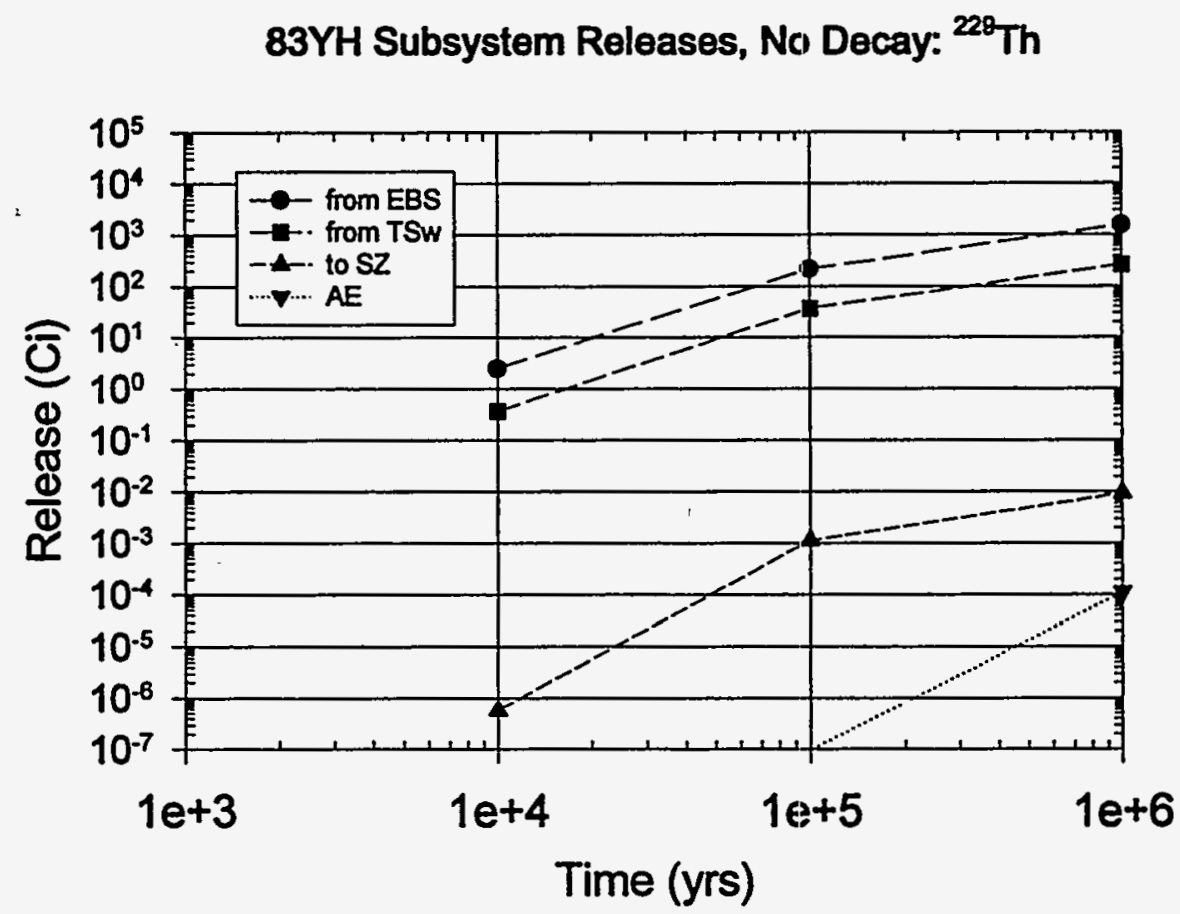

Figure 9.4-6. Subsystem ${ }^{229}$ Th. Expected-value release at $10,000,100,000$ and $1,000,000$ years for $83 \mathrm{MTU} / \mathrm{acre}$, backfill, high infiltration ( $\mathrm{q}_{\mathrm{inf}}=1.25 \mathrm{~mm} / \mathrm{yr}$ ), no climate change, no decay. 


\section{CHAPTER 10}

SUMMARY AND CONCLUSIONS

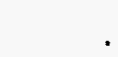




\title{
10. CONCLUSIONS AND RECOMMENDATIONS
}

\author{
Robert W. Andrews and James O. Duguid
}

\subsection{CAVEATS}

This report documents a total system performance assessment of the Yucca Mountain potential repository, including the conceptual and parameter assumptions used. The report describes the results and their significance with respect to predicted postclosure performance, in terms of (1) the waste package lifetime (substantially complete containment); (2) the radionuclide release from the engineered barrier system; (3) the cumulative radionuclide release at the accessible environment over 10,000 years; and (4) the maximum radiation dose in 10,000 and 1,000,000 years to an individual located at the accessible environment boundary. The results and conclusions derived in this study must be tempered by the assumptions that are made in the course of the analyses. It is important to stress that the representativeness of the results, and therefore the robustness of the conclusions, are based on the assumptions used.

In the present discussion, the term robust has a very specific connotation to imply that changes in the considered conceptual model or parameter distribution will not significantly change the results or conclusions of the analyses. One can almost always consider "worst-case" scenarios for virtually every model or parameter distribution that would extend the envelope of the considered values to highly unlikely extremes and have significant effects on the predicted performance. That is not the philosophy incorporated in the present document nor will it be the approach taken in subsequent performance assessment iterations leading up to the evaluation of the suitability and licensability of the Yucca Mountain potential repository site. However, the robustness of the assumptions incorporated in the analyses are in many instances synergistic, with the effect of one model or parameter on the predicted performance being dependent on assumptions made regarding another totally unrelated component of the system. This is not unexpected, given the complexity of the system being simulated, the dependence of numerous factors on the overall response of the total system, and the range of alternative conceptual models possible at the present stage of scientific investigations. Even given this caution, however, it is possible to make reasonable conclusions and recommendations based on the current analyses, while at the same time acknowledging the need for complete substantiation and documentation of the process-level models ultimately to be used as the basis for abstractions used in performance assessment analyses.

The present analyses focus attention on models and parameters that earlier performance assessment analyses have determined to be significant. In particular, the emphasis is on evaluating the impact of alternative models of the near-field thermohydrologic environment in the vicinity of the waste package, alternative assumptions regarding the initiation and rate of degradation of the waste package materials, alternative assumptions regarding the efficiency of capillary barriers if placed in the drifts, alternative conceptual representations of advective flow in the drifts and percolation flux in the unsaturated zone, and alternative conceptual models of transport in the unsaturated zone. 
In addition to the above conceptual assumptions, alternative thermal loading designs and backfill emplacement options are examined. These design options are not exhaustive of the range of designs that have been or are being considered. For example, alternative waste package designs (in terms of both the use of filler materials and alternative waste package materials) have been proposed that are not considered in the present analyses. It is impossible to evaluate every alternative design because each alternative often requires additional information that may not be available. Performance assessment analyses, which strive to be reasonably conservative representations of the range of behavior of the natural and engineered components of the overall system, lag slightly behind the most current scientific and engineering understanding because of the time required for the analyses. However, because performance assessments require evidence (i.e., data).with which to support the development of representative or "valid" conceptual models and parameters, they often point to the need for additional information to properly evaluate the alternative designs being considered.

Performance assessment is an iterative process. The analyses strive to use the most current understanding of the site and designs that can be substantiated, which implies that work in progress cannot be directly incorporated in the current iteration. The process-level models used for the abstraction of results into TSPA are "frozen" some months before the completion of the performance assessment. In the present iteration, this has necessitated using process-level understanding of unsaturated- and saturated-zone flow and transport that is currently undergoing revision. The delay in developing and documenting process-level models was identified as a significant issue in TSPA-1993 (Andrews, et al., 1994) and it remains so with the current iteration. With the exception of a preliminary version of the unsaturated-zone flow model (Wittwer et al., 1995), which does not address many important heterogeneity and scaling issues, there are still no documented models that have been substantiated adequately enough to be used with confidence in performance assessments. It is therefore recommended to (1) focus the data collection program primarily on observations and testing in the Exploratory Studies Facility (and the collection of "perishable" data) and (2) emphasize data interpretation/synthesis and processlevel model development, substantiation, testing and review.

Although the models and parameter values used in the current TSPA iteration can be directly traced back to reasonable (and representative) assumptions, they have not all come directly from the process-level models because these models do not exist in all cases. This is not to imply that the process-level models, even when complete, will explain all alternative reasonable explanations for the observations made, nor to imply that the completion of the process-level models is all that performance assessment requires. There will be a number of issues associated with model and parameter variability and heterogeneity and scaling that will not be resolved within the context of the process models as currently envisioned. These issues will have to be "resolved" by sensitivity analyses using simplified TSPA models.

Performance assessment is often expected to "drive" the scientific investigation and design programs. This expectation is inspired by the belief that the priority of each investigation should be driven by the significance of that component of the system to the overall predicted performance. Those processes or parameters that significantly affect the predicted performance should be given increased focus, while those that contribute marginally to the overall performance should be deemphasized. While such an approach makes sense, its application has been limited because the degree to which performance assessment can "drive" the rest of the scientific and 
design programs is, with few exceptions, directly related to the conceptual understanding existing at the time the analyses are performed. For different conceptual assumptions, one might reach very different conclusions of the significance, or lack thereof, of particular aspects of the investigation program. That is to say, the conclusions drawn are necessarily predicated on the assumptions included in the analyses. Because a number of assumptions in TSPA-1995 are not directly tied to substantiated conceptual models, care must be taken in "over-interpreting" the results or "over-utilizing" the results in the allocation of priorities. However, it is believed that a performance assessment-based prioritization approach can be used successfully in combination with technical judgment to provide a firm technical basis for the allocation of scientific investigation and engineering design priorities. This prioritization should be iterative and flexible, because priorities may change as understanding advances and performance assessment predictions become more refined and focused.

\subsection{SIGNIFICANT CONCLUSIONS}

Five different measures of performance were evaluated in TSPA-1995. The waste package failure distribution (if failure is defined by the penetration of the first pit through the corrosionresistant inner package material) may be considered to represent the substantially complete containment requirement of NRC and is presented in Chapter 5. The peak release rate from the engineered barrier system, which may be compared to the NRC requirement, has been presented in Chapter 8. The total system performance is quantified with respect to three measures, namely, the cumulative release of radionuclides at the accessible environment over 10,000 years normalized to the Table 1 values in the remanded EPA environmental standard (40 CFR Part 191), and the peak radiation dose over both 10,000 and $1,000,000$ years incurred by an individual located at the accessible environment boundary who uses water from the tuff aquifer as a sole source of drinking water. Because the conclusions are slightly different for the various scales (in space and time), each performance measure is discussed separately below.

\subsubsection{Substantially Complete Containment}

Because the initiation and rate of aqueous corrosion (by both humid air and liquid water) are dependent on the thermohydrologic environment, the determination of when the first pit penetrates the corrosion-resistant barrier is dependent on the thermal load. However, this dependency is more complicated than it may appear at first glance. One may initially assume that higher thermal loads would lead to lower humidities for longer times and therefore delay the onset of aqueous corrosion and extend the duration of the containment period. While the first part of this statement is true, the effect on containment is also significantly influenced by the temperature of the waste package surface, with higher temperatures yielding higher corrosion rates (this being especially significant for the assumed pitting corrosion model for the corrosionresistant material). Therefore, from some of the results presented in Chapter 5, the rate of container degradation does not appear to be directly correlated with the thermal load.

The preceding conclusion must be tempered by the assumed thermohydrologic model and the assumed spacing of waste packages within the repository drifts. For example, the assumptions made in the drift-scale thermohydrologic analyses conducted by Buscheck (1995) (namely the lower thermal conductivity of the backfill, the lack of any applied infiltration rate, and the relative humidity reduction caused by temperature gradients between the waste package and drift 
walls) generate significantly lower humidities for significantly longer periods for the higher thermal loads, and result in no waste package failures in the first 10,000 years for the higher thermal load case. Although the validity of each of these assumptions needs to be substantiated, the potential benefits in extending the waste package lifetime are apparent.

In addition to the effect of the thermohydrologic regime affecting waste package lifetimes, the conceptual model for corrosion also impacts the calculated failure distribution. In TSPA-1993 (Andrews, et al., 1994), the apparent benefits of cathodic protection of the Alloy 825 inner corrosion-resistant barrier were mentioned but not evaluated. The need for the development of a defensible model to incorporate this process in future performance assessments was stated as a high priority. Although no model of cathodic protection is currently available, sensitivity analyses incorporating what is believed to be a reasonable first-order approximation have been performed. As expected, incorporating cathodic protection significantly extends the lifetime of the waste packages. The eathodic protection has a two-fold effect. First, it directly extends the package lifetime by delaying the onset of pitting corrosion of the corrosion-resistant material. Second, this primary effect has an important multiplicative effect by causing a lower temperature during pitting of the corrosion-resistant layer, and therefore significantly reducing the pitting corrosion rate of this material. Because of its possibly large effect on containment, the cathodic protection model needs to be confirmed using literature- and laboratory-derived information.

The pitting-corrosion model for the corrosion-resistant layer was identified as being overly conservative in TSPA-1993 (Andrews, et al., 1994). In the absence of any cathodic protection considerations, the corrosion-resistant material did not substantially extend the containment time. Based on the assumptions made in TSPA-1993 (Andrews, et al., 1994), an additional centimeter of corrosion-allowance material would have been better than utilizing the corrosion-resistant material at all. Thus, a more definitive model of pitting of corrosion-resistant materials was identified in TSPA-1993 (Andrews, et al., 1994) as an important information need. Although no experimentally-based improved model for pitting of corrosion-resistant materials is available, sensitivity analyses are performed using an assumed model in which pitting growth rates are time dependent (with a decreasing rate with time). This revised model has a significant effect on the predicted failure distribution, confirming that the validity of this model is an important activity.

While the conceptual representations of drift-scale thermal hydrology and the corrosion degradation models significantly affect the waste package "failure" distribution over the first 10,000 years (and, therefore, also affect 10,000-year total system performance measures, such as the cumulative release at the accessible environment or peak dose at the accessible environment), these models have generally less significance when the performance measure is extended to longer times (i.e., 1,000,000 years). This observation was also made in TSPA-1993 (Andrews et al., 1994 and Wilson et al., 1994) and in the sensitivity analyses conducted to develop the environmental standards for Yucca Mountain (Duguid et al., 1994). However, these models do have some effect at longer times by limiting the total inventory that is accessible for release and transport because some waste packages are predicted to never fail. Also, if diffusive releases dominate or if it is assumed that the advective flux through the EBS is dependent on the percent of package surface penetrated by pits, the corrosion degradation models can have an effect even on long-term doses. However, all conceptualizations of these models for TSPA-1995 generate the bulk of package failures early enough during the $1,000,000$ year time span that the results are 
fairly insensitive to the particular conceptualization (no more than a factor of 3 difference in peak dose among these various conceptualizations).

\subsubsection{Peak Release Rate from the Engineered Barrier System}

Once the waste package has been degraded for modeling purposes, to the extent that the initial pit has penetrated the corrosion-resistant material, alteration/dissolution and advective/diffusive release processes can occur resulting in transport of dissolved radionuclides to the geosphere. For the current conceptualization of diffusive release, the diffusion coefficient is a function of the liquid saturation in the drift materials, and the area through which diffusion can occur is dependent on the distribution of pits through the waste package. Both the saturation and the area are functions of time. For this conceptualization of diffusion, diffusive releases are very small. Therefore, the substantiation of the probability and quantity of drift-scale advective flux (i.e., drip rate) becomes an important performance issue. The drift-scale advective flux is a function of the percolation flux distribution as discussed in the conceptual representation presented in Chapter 7. It is not directly evaluated in the site-scale unsaturated zone flow model (Wittwer et al., 1995) because the distribution of flux over a drift-scale of roughly $100 \mathrm{~m}^{2}$ is not quantifiable in this model. It is controlled by small-scale heterogeneity and variability, which is not incorporated in the site-scale model, although it may be discernible by unperturbed observations and testing in the ESF.

In those cases where advection dominates the EBS release, the infiltration-rate distribution has a significant effect. The conceptual representation of how dripping water contacts the waste package is also important. In the cases where the dripping water is assumed to be distributed evenly over the package surface (perhaps due to spreading associated with an emplaced backfill), the advective release becomes dependent on the percent of the waste package surface area degraded as a function of time. Therefore, all the uncertainties in the waste package degradation conceptual model described above become significant. In the cases where the dripping water, if it is predicted to be present, is concentrated at a particular spot on the waste package surface, all of the advective flux flows through the waste package and EBS releases are conservatively high. The emplacement of a Richard's (or capillary) barrier, is assumed to perform with $100 \%$ efficiency in diverting any dripping water away from the waste package, significantly reduces the advective releases from the EBS.

The above observations point to the continued need to define, with some degree of confidence, the potential existence and distribution of localized flux that might intersect the potential repository drifts. It is important to point out that these flux values are small. Even if an average percolation flux of $1 \mathrm{~mm} / \mathrm{yr}$ and an interception area of $100 \mathrm{~m}^{2}$ is considered, the volumetric flow rate would be only $0.1 \mathrm{~m}^{3} / \mathrm{yr}(100 \mathrm{l} / \mathrm{yr}$ or $0.3 / \mathrm{day}$ or $0.2 \mathrm{ml} / \mathrm{min}$ or approximately 1 drip every 15 seconds), which may be difficult to directly measure in the presence of any ventilation.

An additional issue of importance in the evaluation of peak EBS release rates is the form of the radionuclide when the waste form is altered. For many cases presented in Chapter 8, after dissolution from the waste form, some radionuclides (namely, ${ }^{14} \mathrm{C},{ }^{36} \mathrm{Cl}$ and ${ }^{129} \mathrm{I}$ ) are assumed to be immediately transported to the host rock in the gaseous phase, where there is presumed to be sufficient water available into which these radionuclides would dissolve and subsequently be transported in the aqueous phase to the accessible environment. Sensitivity analyses are 
performed to evaluate the alternative assumption that these radionuclides are immediately dissolved into whatever water may exist on the waste-form surface and then transported through the EBS by aqueous advective/diffusive processes, rather than by gas-phase transport. These different assumptions not only affect the predicted peak EBS release rates (especially in the cases of low or no advective flux through the EBS), but also the peak doses at the accessible environment.

For the assumptions made regarding the performance of the cladding and the dissolution of the waste form, the dissolution rate itself does not significantly affect the peak EBS release rate. This is probably a result of the observation that the dissolution rate significantly controls the release of the high-solubility radionuclides, but these radionuclides $\left({ }^{135} \mathrm{Cs}\right.$, ${ }^{79} \mathrm{Cs}$, and $\left.{ }^{99} \mathrm{Tc}\right)$ are also presumed to be present in the gap fraction. Therefore, a certain percentage of the inventory for these radionuclides (assumed to be $2 \%$ in the analyses presented in Chapter 8 ) is available for transport from the waste form surface to the edge of the EBS as soon as the cladding fails.

\subsubsection{Cumulative Release of Radionuclides at the Accessible Environment - 10,000 Years}

When considering a 10,000-year total system performance measure, there are many EBS and natural barrier system factors that affect the predicted results. The results presented in Chapters 8 and 9 indicate that under certain conceptual assumptions the engineered barriers by themselves can provide complete containment of the radionuclides for the entire 10,000-year time period. Similarly, for cases when the percolation flux distribution is at the lower end of the possible range of likely values, the natural barrier by itself can provide complete isolation of the radionuclides from the accessible environment for the entire 10,000-year time period. This is, of course, the definition of redundant barriers.

For cases when the most conservative estimates of both EBS and natural barrier performance are considered, i.e., those cases which produce some non-zero integrated release to the accessible environment over 10,000 years, several factors are important. The predominant factor is the percolation flux distribution, which not only affects the likelihood of there being advective flux (i.e., dripping) through the EBS, but also affects the magnitude of the advective release from the EBS, the distribution of radionuclide transport between the fractures and matrix in the unsaturated zone, and the average matrix velocity through the unsaturated zone. That is, for conservative assumptions regarding the waste package degradation model, the percolation flux distribution controls the 10,000-year cumulative release. This is the same conclusion reached in TSPA-1991 (Barnard et al., 1992) and TSPA-1993 (Wilson et al., 1994 and Andrews et al., 1994). It is worthwhile to point out that the radionuclides of interest over the 10,000-year time period are highly soluble with little or no sorption, such as ${ }^{99} \mathrm{Tc},{ }^{129} \mathrm{I}$, and ${ }^{14} \mathrm{C}$. Slightly sorbed radionuclides such as ${ }^{237} \mathrm{~Np}$ can be released in small quantities over 10,000 years in cases of high percolation flux. For the parameter distributions used in the present analyses (that may be subject to change upon evaluation of the controlling phase of the radionuclide), highly sorbed and low solubility radionuclides such as plutonium, americium and curium, are not transported appreciable distances through the EBS or host rock in 10,000 years. 


\subsubsection{Peak Radiation Dose to Maximally Exposed Individual at the Accessible Environment $-10,000$ Years}

Similar conclusions regarding the significance of particular conceptual models and parameters reached for the 10,000-year cumulative release total system performance measure are also germane to the 10,000-year peak radiation dose prediction. If the EBS and/or natural system perform in such a way as to preclude, either individually or collectively, any release of radionuclides to the accessible environment in 10,000 years, then there would clearly not be any dose consequences in the accessible environment over this time frame.

For those cases when radionuclides do arrive at the accessible environment boundary within 10,000 years (as noted above, this is primarily a function of the percolation flux distribution), the factors which delay, disperse or dilute the radionuclides have the greatest effect on the calculated peak dose, for given assumptions about the biosphere. Delaying the arrival of radionuclides at the accessible environment can be an issue over 10,000 years because it affects the arrival time of the leading edge of the breakthrough curve. In addition to the percolation flux, delay can be enhanced by sorption and matrix-diffusion mechanisms in the geosphere. For example, the non-zero retardation of neptunium can be sufficient to delay the arrival of this radionuclide until after the 10,000-year time period. In addition, utilizing an enhanced matrix diffusion or decreasing the mean fracture flow path length can reduce the average radionuclide travel time.

Dispersive effects have two impacts on the arrival of radionuclides at the accessible environment. On one hand, increased dispersion, especially when it occurs in the geosphere, can cause an earlier arrival of the breakthrough curve. Significant dispersion in the unsaturated zone could cause some radionuclides to arrive before 10,000 years, whereas a "plug flow" assumption would result in the initial arrival after this time. On the other hand, increased dispersion tends to lower the magnitude of the peak height. Over a 10,000-year time period, these issues are competing with one another in their combined effect on peak concentrations or peak doses. Because there are very few instances when the actual predicted peak arrival time is less than 10,000 years for any radionuclide (it generally occurs in the time frame of tens to hundreds of thousands of years, depending on the nuclide and the flow and transport conceptualization), the dispersive effect on initial arrival time is more significant, i.e., by shifting the initial arrival to an earlier time, increased dispersion leads to an increased peak dose during the 10,000-year time period. As discussed below, the opposite is true for longer time periods of interest.

Dilution of radionuclides in the saturated zone is an important process in the determination of peak concentrations and ultimately peak doses. It is important to note that dilution is not a factor in the evaluation of cumulative release. For all dose calculations presented in Chapter 9, it is assumed that the dilution in the saturated zone occurs within a volumetric flow equal to the cross-sectional width of the repository (taken to be $4000 \mathrm{~m}$ and kept the same for both low and high thermal loads for consistency even though the cross-sectional width is greater for lower thermal loads) times an assumed mixing depth of $50 \mathrm{~m}$ (which may be considered to be the slotted interval of the individual's well) times the uncertain Darcy flux within the tuff aquifer. Higher Darcy fluxes generate the potential for greater dilution and therefore lower peak doses at the accessible environment. Therefore, as noted in TSPA-1993 (Andrews, et al., 1994 and Wilson, et al., 1994), the local Darcy flux distribution within the saturated zone in the vicinity of the potential Yucca Mountain site is an important parameter for concentration-, dose-, or risk-based performance measures. 


\subsubsection{Peak Radiation Dose to Maximally Exposed Individual at the Accessible Environment $-1,000,000$ Years}

While the predicted peak radiation dose over a 10,000-year time period is dependent on numerous factors, in extending the time to $1,000,000$ years only a few factors dominate the predicted response. In general, factors which tend to delay the arrival of the peak concentration at the accessible environment are found to be less significant. This is a direct result of the extremely long time period considered and the long half-lives of some of the key radionuclides that always contribute to the predicted peak dose (notably ${ }^{99} \mathrm{Tc}$ with a 200,000 -year half-life, ${ }^{237} \mathrm{~Np}$ with a 2,000,000-year half-life, and ${ }^{129} \mathrm{I}$ with a 20,000,000-year half-life). Even for the low end of the assumed percolation-flux distribution and even assuming a nonconservative conceptual representation of fracture-matrix flow and transport, the above radionuclides are either not sorbed at all or are only slightly sorbed $\left({ }^{237} \mathrm{~Np}\right.$ ) and they break through within $1,000,000$ years. In addition, even with the most nonconservative waste package degradation model assumptions, a certain fraction of waste packages would be degraded within the 1,000,000-year period. Thus, although a combination of waste package performance and site performance can contribute to containing and isolating radioactive wastes within the Yucca Mountain area for some tens- to even hundreds-of-thousands of years, it is unlikely that such barriers can be reasonably shown to delay the above radionuclides sufficiently to preclude their release over a 1,000,000-year time period.

While delay itself does not contribute appreciably to the prediction of long-term doses, dispersion and dilution are still significant processes. Dispersion in this case is the result of both geosphere and EBS processes. Dispersion tends to spread out the release of the radionuclides over time and therefore reduce the peak concentration and peak dose. Geosphere dispersion is enhanced by increased matrix diffusion or decreased the mean fracture-flow length (in cases where fracture transport is active) or increased vertical, lateral and/or longitudinal dispersion in the saturated zone. As noted in Chapter 7, the dispersive effects in the saturated zone are enhanced with increasing distance between the repository and the assumed user of the tuff aquifer. This effect has significant ramifications with respect to the definition of where the average member of the critical population proposed in the recent NAS recommendations resides. If the critical group is located in the Amargosa Valley, some $25 \mathrm{~km}$ down gradient from the present "accessible environment" as defined in 40 CFR Part 191, the increased geosphere dispersion may be expected to reduce the peak concentration and peak dose by several orders-of-magnitude.]

Besides dispersion in the geosphere, dispersive-type effects within the engineered barrier system are extremely important in reducing the predicted peak concentration and dose at the accessible environment. Spreading of releases from the EBS can occur as a result of either a wide distribution of waste-package failure times; an extremely low alteration/dissolution rate, or diffusion-dominated releases through the package and EBS. The first two factors are generally insufficient to significantly decrease the peak release rate over the range of parameter values considered in this TSPA iteration. However, diffusion-dominated releases from the EBS can significantly reduce the peak release rate. Such diffusion-dominated releases occur when either a very low percolation flux distribution is assumed (in which case only a small percent of the packages experience advective release) or an efficient capillary barrier in the backfill is considered. In both cases, the diffusion through the waste package and other EBS materials is a highly nonlinear function of the in-drift liquid saturation (generally very low for all thermal loads, except when advective flow into the drift 
occurs), as well as the effective surface area through which diffusion occurs (which is controlled by the waste package degradation model).

Confidently demonstrating that diffusive release is the dominant transport mechanism in the EBS would be key to reducing the predicted long-term dose to individuals or critical groups. It is not at all coincidental that virtually every other high-level radioactive waste disposal program around the world that has published results of total system performance has incorporated a diffusive barrier in their engineered barrier design (see Neall et al., 1995). In other countries the diffusive barrier is a bentonite or bentonite-sand mixture, because these programs have focussed on crystalline host rocks within the saturated zone. A potential diffusive barrier in the unsaturated zone such as Yucca Mountain is crushed rock with low capillary suction.

Besides the spreading out (in time) of the release of radionuclides from the source term, the predicted peak dose at the accessible environment boundary over the 1,000,000-year time period is also significantly affected by dilution in the saturated zone. This dilution can occur naturally by the mixing of different ground-water sources along the flow path between the repository and the user of the tuff aquifer (or other ground-water sources that are supplied by the tuff aquifer), or anthropogenically by the user tapping alternative sources of water for consumption (i.e., by slotting the well over different isolated aquifers). Although alternative dilution scenarios are discussed in Chapter 7, analyses of the exact effect of these scenarios on repository performance are beyond the scope of the present document. Assuming that the EPA accepts the NAS recommendations for protecting individuals of critical groups as an appropriate environmental standard for Yucca Mountain, additional analyses of regional ground-water flow patterns should be conducted. It is relevant to point out that dilution by saturated-zone mixing is not important for the cumulative release performance measure and is less significant at shorter distances between the potential repository and the defined location of the critical group.

\subsection{PRIORITIZATION OF SITE CHARACTERIZATION AND DESIGN ACTIVITIES}

As discussed in Sections 10.1 and 10.2, it is difficult to confidently and unambiguously identify the most significant elements of the Yucca Mountain site characterization and design programs that contribute to the predictions of total system performance. This is primarily a result of the lack of definitive process-level models with which to abstract the necessary response surfaces for input to the total system performance assessment. In many instances, the lack of a representative processlevel models allows for various reasonable approximations to be made, the results of which are significantly different. That is to say that the conceptual assumption does make a difference on the predicted performance. In this Section, the key conceptual assumptions made in the course of this TSPA iteration are discussed. Identification of the significant assumptions assists in defining the key site characterization and design activities for improving the process-level models. The types of information expected for the various process-level models are discussed in Section 10.6.

In addition to the lack of definitive process-level models, as described in Section 10.2, the importance of particular models or parameters is also a function of the performance measure considered. For the substantially complete containment criterion, definition of the relevant corrosion degradation models as well as the initiation and rate parameters for these models should be considered a high priority information need. For the peak EBS release rate, the existence and magnitude of percolation flux which passes through the EBS is of highest priority (assuming the 
gaseous radionuclides are highly soluble where the waste form contacts water). The 10,000-year cumulative release or peak dose predictions are affected principally by the corrosion degradation model and the unsaturated zone aqueous flux model for fracture-matrix transport. The $1,000,000$-year peak dose is primarily controlled by the relative magnitude of advective and diffusive releases through the EBS (which in turn is affected by the distribution of percolation flux which intersects the repository drifts), the advective flux in the unsaturated-zone (if this flux is at the low end of the considered distribution), and the degree of dispersion and mixing in the saturated zone aquifer between the repository footprint and the user of the tuff aquifer. These key issues are highlighted in the discussion below.

The predominant site characterization issue remains the distribution of percolation flux in the unsaturated zone. In the conceptualizations embodied in the analyses presented in Chapters 8 and 9, the percolation flux distribution controls (1) the likelihood and magnitude of advective flux through the EBS, (2) the EBS diffusion coefficient in the cases where there are some "drips" into the EBS, (3) the fraction of volumetric flow in fractures and (4) the matrix velocity. It is important to point out that this parameter is not measurable. It is inferred from a number of observations that must be synthesized and explained by the site-scale unsaturated zone flow model. However, it is expected that different conceptual assumptions will be possible to explain the varying observations. Also, the scale of the model does not allow the spatial refinement required to address heterogeneity and scaling issues of importance to define the distribution of flux over each of the 10,000 waste packages. Therefore, it is recommended that an unsaturated-zone flow model at the scale of individual drifts be developed and tested. This testing should consist of both representativeness/reasonableness of the model (perhaps by comparison with the distribution of any advective seeps or the distribution of ground-water residence times observed along the ESF axis) and the significance of alternative models on surrogates of performance (such as the likelihood and magnitude of seepage fluxes intersecting the drifts). It bears noting that the distribution of flux may be affected over some time period by the imposed thermal regime. Therefore, the same alternative conceptualization used to evaluate flow in the vicinity of the drifts should be used in the substantiation of the thermohydrologic response.

The representation of fracture-matrix coupling, while significantly affecting the predicted total system performance over 10,000 and 100,000 years, generally has a less significant effect over the 1,000,000-year time period unless the percolation flux is at the lower end of the expected distribution range. Therefore, the need for detailed characterization of fracture-matrix transport issues in the geosphere is dependent on whether the EPA accepts the NAS recommendation of a peak concentration, dose, or risk performance standard.

The representation of saturated-zone flow and transport is generally insignificant to the predicted performance over a 10,000-year time period, but can be very significant in the prediction of $1,000,000$-year peak individual doses, especially if the individual of concern is located in areas of current water consumption such as the Amargosa Valley. Although it is generally recognized that the saturated zone contributes little in the way of delay (unless the potential for modifications in geochemistry is considered which could cause significant changes in the oxidation potential and therefore solubility of some of the key radionuclides), it can significantly affect the dispersive spreading and mixing of any radionuclides released to the saturated zone and therefore reduce the peak concentrations several orders of magnitude. Better understanding of the regional saturatedzone flow system in general and the mixing of different ground-water sources, including recharge 
of the alluvial aquifer along the Amargosa Valley in particular, is required to better approximate the degree of dilution expected.

In addition to identifying the key site-related processes affecting post-closure, it is also important to discuss some processes that are generally less significant using current conceptual understanding. Principal among these, as alluded to in Section 10.2, is the role of transport in the unsaturated zone. The key radionuclides reaching the accessible environment and impacting dose calculations over either long or short time periods are not sorbed at all or are only slightly sorbed. While the role of matrix diffusion over short time periods can be significant, it is generally insignificant over the 1,000,000-year time period. These results indicate that the conceptual model of unsaturated zone transport does not warrant significant additional investigation, except as it helps to confirm the understanding of the natural ground-water tracers observed in the unsaturated-zone waters. This is a direct result of the fact that delay in the 1,000,000-year time frame is not possible within the unsaturated zone except under the most nonconservative of expected percolation flux distributions.

Repository and drift designs (in particular the emplacement of backfill materials) impact the predicted performance in two important ways. On one hand, the hydrologic and thermal characteristics of the EBS materials can significantly affect the prediction of relative humidity in the vicinity of the waste packages, as well as the distribution of advective flux in the drift itself in the presence of drips. The former will impact the waste package degradation for long periods of time (although generally not as much as $1,000,000$ years). The latter will affect the release of radionuclides from the EBS. In addition to these direct effects, the potential performance benefits of an efficient capillary barrier are apparent over long time periods, in that it forces the EBS releases to occur through diffusion only, which is orders of magnitude less than the advective flux even at the low percolation flux distribution range. The design issue of significance then is the ability to emplace backfill within the drifts (recognizing that this would be emplaced after the presumed 100 -year retrieval period) and the ability to engineer the backfill to specifications to enhance the overall system performance (either by reducing the thermal conductivity in order to reduce the humidity or by engineering a capillary barrier). If preliminary scoping analyses indicate that engineering a capillary barrier is not feasible, then even greater emphasis must be placed on confidently predicting the drift-scale hydrologic flow regime and precluding the possible intersection of advective drips with the waste packages.

The focus of the role of the in-drift materials discussed above is in how these materials affect the in-drift thermal hydrology. Although not examined in this TSPA iteration, an additional role of the EBS materials is their effect on the near-field geochemical environment. An important parameter which affects the long term dose calculations is the solubility of neptunium. This parameter is not identified as important in the sensitivity analyses for the simple reason that its values are constrained at the high end of the solubility range representing oxidizing conditions. However, within representative solubility values, the peak dose has been shown to be almost linearly dependent on the solubility of neptunium (see Duguid et al., 1994). Studies described in Chapter 6 indicate the potential that the current estimates of neptunium solubility may be metastable and the stable phase may be some seven to ten orders of magnitude less soluble. This solubility is dependent on the geochemical and thermal alteration of the liquid phase into which the neptunium dissolves. Assuming that long-term doses are the performance measure of interest, delineating the expected neptunium solubility remains an important information need. 
One of the elements in the selection of candidate materials and fabrication techniques for application to alternative waste package designs has been the predictability of the material's degradation behavior. In fact this has been noted as one of the advantages associated with the tentative selection of the mild steel corrosion-allowance material (the other being that it may provide significant cathodic protection of the corrosion-resistant material). Some designs have been proposed without considering whether applicable predictive models exist to describe the performance of the material over the range of likely environments. For example, although there is some indication that corrosion-resistant materials should perform very well in delaying the penetration of pits created by corrosion, the models available to substantiate this belief are very uncertain. In addition, there do not appear to exist representative models to allow confident prediction of the potential benefits of cathodic protection. It is recommended that any proposed change in waste package design (which may be for a variety of reasons unrelated to performance, such as cost or fabricability) be accompanied with representative model(s) and their bases for making predictions of material degradation. For example, if a particular material is proposed for guarding against potential microbiologically-influenced corrosion, the basis for the material selection should include the mechanistic model used to support the decision. Analog information should also be used where possible.

The waste package degradation processes, models and parameters could be considered unimportant to the long-term (i.e., 1,000,000 year) performance of the repository system. This assumption, however, must be tempered with the observation that the rate of package degradation over time is an important aspect of the long-term isolation of the wastes, because it allows for the spreading of the release over time. Therefore, the long-term degradation of the waste package can still be a significant issue. However, confidently predicting the long-term (i..e, 1,000,000 year time period) behavior of engineered materials is difficult to validate.

\subsection{SUMMARY OF CONCEPTUAL ASSUMPTIONS NOT EV ALUATED}

Although this TSPA iteration includes a significant amount of sensitivity and uncertainty analyses, it does not test every key assumption or combination of assumptions, because of (1) limitations on the ability of the mathematical models to address certain issues without overly burdening the computational resources (i.e., there is always a trade-off between detail possible and time requirements), (2) limitations on available information (i.e., it is possible to conduct additional sensitivity analyses but the representativeness would be questioned), (3) a belief or expectation that the alternative representations are less likely than those examined and, finally, (4) a lack of time. The tested assumptions are believed to be the most important, although this is not demonstrable without conducting the additional analyses. That is, it is possible that some key issue that is significant to performance is either masked by other assumptions made in the analyses or is not observable because that process or model has not been included in the assessment. This section briefly discusses some of the analyses not performed.

The near-field thermohydrologic environment is based on two alternate models using twodimensional representations of the drift and emplaced materials. Three-dimensional effects should be examined to determine if they affect the predicted humidities in the vicinity of the waste package. The impact of uncertain hydrologic and thermal properties of the backfill/invert material and potential effects of heterogeneity on the predicted drift-scale response should be evaluated. The possible incorporation of repository edge effects is discussed in Section 4.3. Finally, the linking of 
representative drift-scale thermohydrologic analyses with the considered model for the distribution of "drips" into the drifts should be considered.

The primary failure mode considered for waste package material degradation is aqueous corrosion (i.e., by water and humid air). Alternative modes of failure (e.g., defective containers, mechanical container failure due to rock fall) should be examined and demonstrated to be insignificant before confidently using the single failure mode.

The EBS release model considered in the present analyses does not rely on an explicit determination of the flow regime in the drift. It simply assumes that the water intersecting the drifts as "drips" is either evenly distributed over the waste package or is concentrated on the first pits through the waste package. More explicit evaluation of the in-drift hydrology would appear to be useful (albeit adding an additional level of assumptions), especially given the importance of diffusive versus advective releases from the EBS on the long-term dose prediction.

The EBS model at present does not consider any geochemical effects, whether beneficial or deleterious. Such effects are likely to occur due to the presence of introduced materials in the drifts and should be considered in subsequent iterations of TSPA.

The unsaturated zone flow model used in the abstraction of flux distributions, although developed from an early version of the site-scale flow model (Wittwer et al., 1995), was extended to try to account for the potential for non-equilibrium fracture-matrix flow. The results of this model are compared to a dual-permeability formulation, but should also be compared to the unsaturated zone transport model currently under development. In addition, the duration and magnitude of thermal perturbations to the unsaturated zone flow field should be evaluated.

The saturated zone flow model used in the present analyses is a very simple mixing model. As alternative biosphere locations are considered, conducting more representative regional- and or sitescale saturated-zone flow and transport models (with the transport aimed at addressing mixing and dispersion effects) should be considered.

The biosphere transport model used in the present analyses is simply based on dose conversion factors published by EPA. Although it would be desirable to have the regulatory agency define the appropriate biosphere for analyses, it would be useful to construct alternative biospheres to evaluate the sensitivity of the predicted long-term dose to various biosphere assumptions.

\subsection{POTENTIAL IMPACTS OF ALTERNATIVE ENVIRONMENTAL STANDARDS}

The Energy Policy Act of 1992 mandated that the Environmental Protection Agency (EPA) standard (40 CFR Part 191) no longer apply to a repository at Yucca Mountain, and that the National Academy of Sciences (NAS) make recommendations for the development of a new Yucca Mountain specific standard. The NAS formed the Committee on Technical Bases for Yucca Mountain Standards in the spring of 1993 and released their recommendations in August of 1995. The recommendations of the NAS that affect the total system performance assessment (TSPA) calculations and the effects of these recommendations on the presentation of dose calculations in TSPA-1995 are summarized below. 
The Committee on Technical Bases for Yucca Mountain Standards recommended that the environmental standards for a repository be based on the risk of fatal cancer to an average member of a critical group (NAS, 1995). They stated that compliance assessment of this risk should be at the time when the greatest risk occurs within the limits of the long-term stability of the geologic environment. They suggested that a risk limit in the range of $10^{-6}$ to $10^{-5}$ excess cancer fatalities per year would be appropriate and that the geologic environment in the vicinity of Yucca Mountain would be expected to remain stable for at least $1,000,000$ years. In terms of radiation dose, this risk limit range translates to a range of 2 to $20 \mathrm{mrem} / \mathrm{yr}$ to the average member of the critical group, using accepted dose conversion factors.

The critical group is defined according to the International Commission on Radiological Protection (ICRP) as a relatively homogeneous group of people whose location and habits are such that they receive the highest dose from the expected repository releases (ICRP, 1985a and ICRP, 1985b). The dose within the entire population is a distribution of which the critical group represents the extreme (i.e., those members of the population expected to receive the highest dose). "In the case of Yucca Mountain, these individuals presumably would live in the near vicinity of the site and would potentially be exposed to radiation through the use of contaminated ground water" (NAS, 1995). The critical group under this assumption would be using ground water and be located down gradient from the repository site. The critical-group dose is defined as the dose received by an average member of the critical group.

The ICRP definition of the critical group requires that:

- The persons calculated to receive the highest dose based on cautious, but reasonable, assumptions be included in the group.

- The group be homogeneous in dose; there should be a relatively small difference between those individuals receiving the highest and lowest doses (ICRP, 1991). The ICRP Publication 46 (ICRP, 1985b) suggests that if the ratio of calculated average dose to the regulatory limit is less than 0.1 , then the group should be considered homogeneous if the distribution of individual doses lies substantially within a range of a factor of ten, or a factor of three on either side of the average. For ratios greater than 0.1 a smaller range is required for homogeneity.

- The size of the group is recommended by the ICRP to be a few tens of persons. The group should not be a single person and homogeneity requires that the group not be too large.

Based on the ICRP guidance the NAS recommended that the critical group be:

"Representative of those individuals in the population who, based on cautious, but reasonable, assumptions, have the highest risk resulting from repository releases. The group should be small enough to be relatively homogeneous with respect to diet and other aspects of behavior that affect risks. The critical group includes the individuals at maximum risk and is homogeneous with respect to risk. A group be considered homogeneous if the distribution of individual risk within the group lies within a total range of a factor of ten and the ratio of the mean of the individual risks in the group to the standard is less than or equal to one-ténth. If the ratio of the mean group risk to the standard is greater than or equal to 
one, the range of the risk within the group must be within a factor of 3 for the group to be considered homogeneous. For groups with ratios of mean group risk to standard between one-tenth and one, homogeneity requires a range of risk interpolated between these limits."

In the present and near future, these persons are presumed to live in the vicinity of the repository in the direction that migration of the ground-water plume of radionuclides would take in the far future (NAS, 1995). In order to develop an exposure scenario, assumptions about lifestyle, location, eating habits, and other factors will have to be made. The ICRP recommends use of the present knowledge with cautious, but reasonable, assumptions in making projections into the future. These assumptions are part of the exposure scenario that would be used as the basis to determine whether the repository would meet a performance standard based on risk to an average member of the critical group. In developing this scenario the NAS states that there is no scientific basis to make projections of the nature of future human societies to within reasonable limits of certainty. The NAS also states that there are scenarios that include the use of contaminated ground water that are likely to lead to exposure, and that if the ground water either is not used or is treated, exposure is not likely to occur. This implies that there are natural factors and physical processes such as topography, hydrogeology, soil type, climate, and location that should be included in developing scenarios for determination of the critical group and exposure to an average member of that group. The scenarios and/or the method of constructing them is a policy decision and is expected to be a major part of the rule-making process if the EPA decides to accept the NAS recommendations to develop a risk based standard for Yucca Mountain.

The NAS considered two approaches to illustrate the development of exposure scenarios that the EPA might use to initiate the rule making process (NAS, 1995). The majority of the NAS Committee believed that a probabilistic approach based on physical characteristics of the site and their influence on population distribution could be used to develop the exposure scenario. The second, and more widely used method of scenario development, is to assume that a subsistence farmer is present at the time of peak concentration and that this person/family represents the most exposed member of the critical group. This latter approach appears to be simpler to explain to the public and is more consistent with the recommendations of the IAEA (NAS, 1995, Appendix D).

Prior to the release of the NAS recommendations, the dose calculations performed in TSPA-1995 were based on dose to the maximally exposed individual at the accessible environment. These results were based on the assumption of a subsistence farmer located 5,000 meters down gradient from the repository. The NAS recommendations alter these assumptions in two important ways.

First, the artificial boundary at 5,000 meters is no longer assumed. The approach of using present conditions to develop an exposure scenario would likely lead to consideration of locations farther from the repository (i.e., at farming communities in the Amargosa Valley). The increased distance to the assumed location(s) of the future exposure or future well locations would allow for significantly more radionuclide dilution and dispersion and the potential mixing of different groundwater sources (see Chapter 7). Retardation over the longer transport path and radioactive decay over the longer transport time would be expected, but would not significantly change the concentration because of the long half-lives of the radionuclides involved (i.e., only the time of the assumed exposure would change). Consequently the only reduction in dose would be from the dispersion (which decreases radionuclide concentration in the ground water that is being used in the exposure scenario). 
The second dose reduction factor is caused by considering the average member of a critical group instead of the maximally exposed individual. The reduction in dose between the maximally exposed individual and an average member of the critical group would be no more than one order of magnitude if the maximally exposed individual is assumed to be a member of the critical group (i.e., the range of dose within the critical group should be no more than one order of magnitude as recommended by ICRP). The assumptions made to define the maximally exposed individual, i.e., the definition of the subsistence farmer, could change based on studies of the life styles of the current population of the Amargosa Valley. These changes would have to be defined during the EPA rule making and would further reduce the dose to an average member of the critical group.

\subsection{RECOMMENDED DEVELOPMENT, SUBSTANTIATION, DOCUMENTATION AND TESTING OF PROCESS LEVEL MODELS TO BE USED IN FUTURE TOTAL SYSTEM PERFORMANCE ASSESSMENTS}

The following discussion summarizes the initial expectations for the level of detail required in the process level models being developed and tested by different organizations that will be used as the foundation for future Total System Performance Assessments.

Performance assessments attempt to predict, with reasonable levels of conservatism, the long-term behavior of the repository system and all potentially significant features, events and processes that may impact the ability of the site and engineered barriers to contain and isolate the radioactive wastes. Because long-term predictions are required in these assessments, models are used. These models attempt to incorporate all the relevant processes affecting the containment and isolation of the waste. The goal is to have the models be as realistic as possible, but failing that, to ensure that they conservatively capture the important characteristics in order to bound the prediction of the performance.

The basis of the process level models as the foundation of performance assessment predictions must be demonstrated. Developing the confidence required in these process models relies on the testing, and data acquisition, data interpretation, data synthesis and conceptual model development conducted by the site, design, and research organizations. The model documents to be prepared by the site, design, and research organizations should summarize this understanding and the level of confidence in using the developed models for making predictions.

It warrants noting that the performance assessment analyses may not use a process model explicitly, but some abstracted representation based on the detailed process model. This abstracted/simplified model has to be compared with the more detailed process model and the results have to be shown to be reasonable or conservative. Therefore, the detailed process models are required as the justification for the abstractions used in the performance assessment models. As a result, both the developing organizations (i.e., the suppliers) and the implementing organizations (i.e., the customers) have distinct roles and responsibilities that must be performed to successfully develop defensible site suitability and ultimately licensing documents.

The primary models of importance to performance assessment have been tentatively prioritized with respect to their significance to overall system performance as shown in Table 10.6-1. The primary focus (Priority 1 models) is on the conceptual understanding of the hydrologic regime in the vicinity of the waste packages as it significantly impacts the initiation and rate of corrosion degradation, the 
mobilization of the radionuclides from the waste form, and the release of radionuclides from the waste package and EBS, i.e., the source term for geosphere transport. Of subsequent importance (Priority 2 models) are issues related to the mobilization and release of radionuclides from the EBS. Priority 3 models generally relate to the understanding of transport in the geosphere as well as the key externally initiated scenarios. Dissolution is included here because it is believed to be reasonably, albeit very conservatively bounded at present. Priority 4 model refers to models which will either be conservatively bounded in future TSPAs or for which direct testing and substantiation are not possible (i.e., assumptions will always be required, the technical basis for which might be always extremely limited).

It is important to point out that the fundamental justification of the process level models is the responsibility of the appropriate developing organization. These models should be supported by available information that independently corroborates the model predictions of the observed processes being considered. Alternative models and parameters that could be invoked to reproduce the observations equally well should be clearly discussed and evaluated by the developing organization. That is, it is the responsibility of the developing organization to place reasonable bounds on the model and the corresponding parameters included in the model. Some examples of relevant observations for the higher priority process models are presented in Table 10.6-2.

It is the responsibility of performance assessment to evaluate the significance of the inherent uncertainty in both the models and parameters and of the effects of this uncertainty on predicted performance. Performance assessment should take the best-estimate models and parameter values and conduct sensitivity analyses with respect to various measures of performance and/or surrogate measures of performance. An example surrogate might be the transport of an unretarded or partially retarded dissolved species from the repository horizon to the water table, assuming the release occurs instantly (i.e., time $=0$ ) and at a constant rate or an instantaneous pulse. In other cases, the sensitivity of the uncertainty with respect to overall system performance should be evaluated. The following list (Table 10.6-3) details the performance measures or surrogate performance measures which might be the outcome of the sensitivity analyses performed by performance assessment using the process models and the inherent uncertainty and variability in these models and the corresponding parameters.

The inherent complexity of probabilistic total system performance assessments, as well as current computational constraints, precludes a direct incorporation of most of the underlying process models into the performance assessment process. The approach taken in this and related studies is to first perform detailed calculations using the process models, and then abstract/simplify the results for input into TSPA codes. Because of limitations on computer and time resources, only a limited number of detailed process model evaluations are typically carried out - thus preventing the consideration of all alternate conceptual models and sources of parameter uncertainty/variability.

For each of the detailed process models, it is expected that there will be a corresponding model report. Each of the model documents is expected to contain the following basic elements':

'These elements apply whether considering physical-chemical processes occurring in the natural geologic setting or physical-chemical processes occurring in the engineered portions of the system. 
1. - Goals and objectives of model.

2. Processes considered in the model and processes excluded (and technical basis).

3. Conceptual representation and alternatives of the processes considered in the model.

4. Software employed in the analysis of the model (if applicable) and numerical solution technique.

5. Temporal and spatial scale considered in the model (and technical basis).

6. Boundary conditions applied to the model domain (and technical basis).

7. Initial conditions applied to the model domain (and technical basis).

8. Physical-chemical properties within the model domain (and technical basis).

9. Effect of scale on the physical-chemical properties within the model domain.

10. Independent physical-chemical observations which will be used in model testing/calibration.

11. Comparison of model predictions with independent physical-chemical observations.

12. Sensitivity analyses of comparison of model predictions with independent observations

13. Uncertainty analyses of comparison of model predictions with independent observations

14. Alternative models that could explain observations

15. Applicability of model and alternatives to making long-term predictions (i.e., outside the spatial and temporal scales of the independent observations)

16. Relevant natural analogs to support long-term model predictions of the processes included in the model

17. Possible effect of other processes not included in the model (qualitative)

18. Summary and Conclusions

The following discussions focus on some of the higher priority models:

Site-scale UZ Hydrologic Model. The model should include a description of hydrogeologic units and an explanation of the observed hydrologic property differences. Once the hydrogeologic units have been specified, the geometry must be defined, including a comparison of the "observed" and "as modeled" structural contours and isopachs. All relevant hydrogeologic properties for each hydrogeologic unit should be specified. The actual distribution of the values should be shown in order to define the "representativeness" of the values assumed in the analyses. The spatial variability of the "observed" values should be presented. The development of equivalent "blockaverage" properties from measurements made at the core scale should be discussed. Alternate representations of fracture-matrix coupling should be "tested" with the model. All boundary conditions (both location and type) must be justified or their significance evaluated by sensitivity analyses. In particular, justification of the infiltration rates assumed in the model is required. For each assumed conceptual model and parameter distribution, comparisons should be made between the simulated/predicted flow system (i.e., the results of the model) and relevant direct observations of the flow system. Finally, the uncertainty associated with the model and the derived results should be discussed.

Drift-scale thermohydrologic model. This model should be based on the general hydrogeologic conceptual description and associated parameters (including a discussion of the uncertainty/variability in the model and associated parameters and the effects of scaling of smallscale measurements to the larger-scale discretization) used in the site-scale UZ model. This model 
description should include the conceptual design(s) being analyzed. This model should discuss the representativeness of laboratory or literature derived thermohydrologic parameters to the scale of the model developed. This model description should include the boundary conditions and their uncertainty/variability, in particular the prescribed aqueous flux. This model should be compared with observations made in similar geohydrologic settings (for example, the G-tunnel experiments). This model should be used as a basis for planning in-situ experiments conducted from ESF test alcoves, with the calibration measures being defined. This model documentation should discuss the possible effects of thermochemistry and thermomechanics on the thermohydrologic regime. The document should discuss natural analogs which may be used to support the conceptual representation.

Waste Package Degradation Model. This model document should describe the materials selected in the current design options and discuss the general advantages and disadvantages of each material selected. This model should include the environments under which degradation is likely to occur. This model should describe the range of possible degradation modes ${ }^{2}$. This model should describe the fabrication of the different materials to form the waste package and any zones of mechanical/chemical weakness due to the fabrication process. This model should present the physical/chemical phenomenology behind the significant degradation modes. This model should present the parametric relationship between the rates of degradation (assumed to be principally some form of corrosion such as pitting corrosion or stress corrosion cracking) and the environmental parameters such as geochemistry, man-made materials, temperature, and hydrology. This model should also discuss the changes in the environmental parameters caused by the degradation process itself. The data with which the parametric model has been constructed should be described and their representativeness discussed. The ability to extrapolate short-term accelerated tests to the long-term predictions required should be discussed. Comparison of model predictions with analog materials under similar environmental conditions should be presented.

Waste Package-scale Thermochemical Models (including Radionuclide Solubility). The mobility of the radionuclides that have been dissolved from the waste form is dependent on the aqueous solubility of the radionuclides and the ability of the radionuclides to sorb onto colloidal particles. Both of these processes are dependent on the geochemical environment in the vicinity of the waste packages and the changes in that geochemistry due to the degradation of the package and the thermal hydrologic environment and the presence of man-made materials. Models of the very near field (waste package scale) geochemistry are therefore required. These models should describe the fundamental thermodynamic relationships incorporated in the model as well as the potential role of non-equilibrium thermodynamics on the anticipated geochemistry. The uncertainty in the model as well as the basic thermodynamic database used in the model should be presented. Comparisons of the model predictions with direct observations of reaction rates should be presented. Comparisons should also be made with direct observations of radionuclide solubilities from both oversaturation and undersaturation. The stable and metastable phases in any solubility measurements should be presented as well as the role of colloidal or organic enhancement in the total mobile phase of the radionuclides. The uncertainty in the laboratory measurements as well as the model approximation of the laboratory measurements should be presented. Comparisons on model predictions with analog

${ }^{2}$ Models are required for each potentially significant degradation mode. 
solubility and or mobility observations should be presented to enhance the confidence in the predictions based on the model.

Drift-Scale Transport Model. Radionuclides which are mobilized from the dissolution of the waste form may be transported through the waste package and the EBS by either advective or diffusive processes. The magnitudes of both the advective and diffusive components of transport are a function of the drift-scale thermal hydrology described above. In addition to the thermohydrologic regime, the diffusion through the partially saturated materials in the drift needs to be substantiated. This may include both laboratory observations, appropriate in-situ tests and, if available, analog observations. Also, the potential for the drift-scale thermochemical regime to affect the retardation potential of the drift materials should be addressed and quantified. The uncertainty in the conceptual representation of drift-scale transport should be discussed qualitatively and, if possible, quantitatively. The variability in advective and diffusive transport should be discussed qualitatively. The effects of colloids on transport enhancement should be addressed.

Site-Scale Unsaturated Zone Transport Model. Radionuclides that are released from the EBS will be transported in the geosphere to the accessible environment, or will be decayed during transport along the flow path given a sufficiently low advective-dispersive velocity. The UZ transport model needs to incorporate all the aspects (and the corresponding uncertainty and variability) of the UZ flow model and, in addition, the transport process models and parameters including dispersion, matrix diffusion, and matrix and fracture sorption. The developed model should discuss the model domain considered and the relevance of the applied boundary conditions for both flow of water and gas and the transport of dissolved species. The uncertainty in the boundary conditions for both flow and transport should be discussed and quantitatively evaluated. The observations used to enhance the confidence in the developed model include the in-situ observations of ground-water ages. The representativeness and uncertainty in these observations should be described. The calibration of the model with these observations should be presented and alternative models and parameters that can be reasonable prescribed that also explain the observations should be discussed. If alternative models than those used to represent the hydrologic conditions in the UZ flow model are required to explain the geochemical observations, these should be clearly discussed. The representativeness of laboratory derived batch experiments to in-situ conditions should be substantiated. Effects of scale on representative transport properties (in particular for fracture-matrix transport and matrix diffusion) should be defined and substantiated by in-situ observations where possible. The effects of colloids on transport enhancement should be addressed.

Repository-Scale Unsaturated Zone Thermo-Hydrology Model. In addition to the drift-scale thermohydrology model identified above, the long-term transient thermohydrologic response of the groundwater flow regime in the unsaturated hydrogeologic units must also be defined. It is acknowledged that evaluation of repository-scale (about $10^{9} \mathrm{~m}^{3}$ ) thermo-hydrology will only be possible during the performance confirmation period. Therefore the technical basis for the repository-scale process will be primarily provided by the short-term, limited areal extent testing done from the ESF. This model should start with the unsaturated zone flow model describing the ambient hydrogeologic conditions. Given that a range of possible hydrologic models are anticipated, at least that same number of thermohydrologic models should be described. It may be possible to use natural analogues of thermal hydrologic perturbations (for example, intruded magma bodies into unsaturated fractured tuffs) to bound the possible effects of the thermal source associated with the spent fuel waste. As 
in other flow. and/or transport processes, the effects of scale, the treatment of heterogeneities, and the technical basis for such approximations should be presented.

Site-Scale Unsaturated Zone Geochemical Model. Similar to describing the ambient hydrology, it is important to define the expected ambient hydrogeochemistry of the unsaturated zone pore waters because it defines the initial condition of any possible perturbation caused by the thermal effects or interactions with repository-induced materials (whether introduced intentionally or unintentionally). The ambient geochemical environment is expected to be spatially variable, due to local heterogeneities in aqueous flow paths as well as the mineralogy along these flow paths. The "observed" ambient geochemistry is expected to be uncertain due to the difficulties in measuring the pore water geochemistry in unsaturated media. Therefore, it is important to qualitatively, and to the extent practical, quantitatively, describe the range in the likely aqueous geochemistry expected at the potential repository depth. This geochemical synthesis should also be used to substantiate the aqueous flow regimes predicted in the unsaturated-zone flow model. The "observed" geochemistry should be compared to the predicted geochemical environments using appropriate geochemical reaction path models.

Drift-Scale Thermo-Chemical Model. The aqueous geochemistry in the vicinity of the waste packages may be significantly altered from the ambient geochemistry as a result of the materials emplaced in the drifts (both intentionally and unintentionally) and the thermal regime imposed due to the emplacement of the waste. The change in the geochemical environment may impact the waste package degradation (i.e., corrosion) and radionuclide transport properties of the in-drift materials. This alteration may extend into the rock itself. Predictions of the drift-scale thermochemical environment require an appropriate thermo-chemical model. This model should be substantiated, to the extent practical, using laboratory information and appropriate natural analogs. The representativeness of the model used to make the near-field geochemical environment predictions should be discussed.

Waste Form Dissolution Model. Once water comes into contact with the waste form, the waste form can be altered and the radionuclides can be dissolved. The rate of alteration and subsequent dissolution is dependent on a number of environmental factors (notably the hydrology, geochemistry and temperature) and the nature of the waste form surfaces exposed to these conditions. Laboratory investigations of possible alteration and dissolution rates given a range of environments have been underway for some years. The applicability of these laboratory-determined rates to expected in-situ conditions has to be postulated and subsequently substantiated. This substantiation may utilize natural analogs of uranium ore deposits in unsaturated media (such as the Pena Blanca site being investigated by NRC). In addition to the laboratory dissolution rates (commonly normalized to the exposed surface area of the test material), the range in possible spent fuel and glass surface areas as a function of environmental conditions should also be defined. As with any laboratory derived parameter, the applicability of this parameter to actual conditions should be discussed and the uncertainty and possible variability described.

Regional and Site-Scale Saturated Zone Flow Models. The ultimate point of release of the aqueous radionuclides is to the saturated zone. Predicting the ambient flow in the saturated zone is important to define the potential ground-water flow paths to the accessible environment. The ambient saturated-zone hydrology is also important because it defines the initial condition for any subsequent modifications due to future climate changes. As with the unsaturated-zone flow model, the regional 
and site-scale saturated-zone flow models should be compared to all relevant potentiometric information during the calibration process as well as geochemical indications of the regional flow directions and rates. Of particular importance is the degree of mixing, including dispersion, of different ground-water flow systems along the likely travel path from the potential repository to the defined location of the critical group. The uncertainty and variability of the developed model should be presented. This may be accomplished by presenting a range of possible flow fields which capture the range of possible hydraulic properties and hydrologic boundary conditions.

Volcanic Direct and Indirect Effects Models. The possibility of future volcanic processes needs to be considered in postclosure performance assessment if the probability of these processes occurring within some reasonable distance of the potential repository is greater than a specified limit (on the order of $10^{-4}$ over $10^{4}$ years). Direct effects of such volcanic processes imply the direct exhumation of a certain percentage of the waste. The direct effects are controlled by the geometric and physical properties of the extrusive magma body. Indirect effects are related to changes in the ambient properties (thermal, hydrologic, geochemical) caused by an intrusive magma body located in the vicinity of the potential repository. While it may be possible to predict the magnitude of such changes by perturbing the ambient process models, it is likely that other indirect effects will be controlled by the physical/chemical attributes of the intruding body itself. One approach to addressing the indirect effects uses natural analogs of similar intrusive bodies in similar geologic and hydrogeologic settings. The uncertainty in the range of indirect effects should be qualitatively defined and substantiated. Note that the consequences of the indirect effects will be evaluated as part of the total system performance assessment.

Climate Change Indirect Effects Model. If the past is any indication of the future, then the climate in the Yucca Mountain area will change over the time period of concern (up to 1,000,000 years). Although climate change does not directly affect repository' performance, the indirect effects of climate change may be significant. These indirect effects may include a change in infiltration rate (with a corresponding change in percolation flux at depth) and a change in the water table elevation. Although it is possible to predict the transient effects associated with given climate changes, it is important to also provide a basis for such predictions. Therefore, it is useful to compare possible past climates with indications of past fluxes or water table elevations in the Yucca Mountain climate. The uncertainty in the predicted effects should be quantified to the extent practical.

General Qbservations. As noted earlier, information from site characterization, and design- related and research activities over the next few years is expected to result in significant progress in the development of process models which are representative of the site. The incorporation of this body of knowledge in future total system performance assessments, albeit in an abstracted/simplified fashion, requires: (a) the testing of the abstraction methodology for some baseline case, and (b) the generation of abstractions which cover the expected range of conditions. A paradigm for the testing of abstractions is shown in Figure 7.2-2 and has been demonstrated for the unsaturated hydrologic system in Section 7.2. In what follows, a generic approach for the development of abstractions is presented.

- $\quad$ Based on the appropriate process model (e.g., UZ flow), identify a set of alternate conceptual models (e.g., ECM, nonequilibrium flow) and the corresponding range of spatial variability/parameter uncertainty (e.g., variations in $\mathrm{K}_{\text {sat }}$ ) and driving forces (e.g., infiltration rates). 
- For several equally probable representations of the physical system (e.g., unsaturated zone), perform detailed calculations using a multi-dimensional process model.

- Map the performance measures of interest (e.g., pore velocity) into a simplified description of the physical system consistent with that implemented in the TSPA code. Also, develop a response surface of the performance measure (e.g., pore velocity) as a function of the driving force (e.g., infiltration rate) that includes the effects of various conceptual and parameter uncertainties.

- Use these response surfaces as an integral component of the probabilistic performance assessments.

Future iterations of TSPA should thus be based on more representative process models of the natural and engineered systems and should rely on abstractions which cover a broader range of parameter and conceptual uncertainties.

\subsection{CONSERVATIVE AND NONCONSERVATIVE FACTORS INFLUENCING THE PREDICTED RESULTS}

A large number of sensitivity and uncertainty analyses have been performed during the course of this iteration of total system performance assessment. These analyses are presented and discussed in Chapters 5, 8 and 9 and are summarized in Section 10.2. Such analyses are always an important component of any performance assessment. They provide an important means to gain insights into those components, processes, models and parameters which most significantly affect the predicted waste containment and isolation over the time periods of interest.

While many useful conclusions have been reached on the basis of the sensitivity analyses performed, it is also instructive to step back a little and examine in a more qualitative fashion the implications of some of the assumptions made in the development of the total system performance assessment. The implications may be in the direction of improving the predicted performance (when the conservative assumptions are relaxed) or in the direction of degrading the predicted performance (when the nonconservative assumptions are tightened).

The following discussion addresses the entire system, i.e., the contribution of both the engineered and natural components and is irrespective of the time period of regulatory concern. It is important to point out that while the relative importance of a particular component, process, model, or parameter may depend strongly on the time period of interest, the absolute importance is generally independent of the time frame considered. This is probably not as true for externally-initiated features, events or processes (such as volcanism or other tectonic processes) which have an increased probability of occurring, for a constant recurrence interval, as the time period of interest is increased.

\subsubsection{Significance of Nonconservative Assumptions}

The question of the significance of nonconservative assumptions may be posed as follows: What components, processes, models, or parameters could, with some reasonable likelihood, be sufficiently different from the assumptions made in the current TSPA iteration, such that the 
predicted releases or doses could be a factor of 100 to 1000 greater than those presented in Chapter. 9 ?

Percolation Flux. The primary factor which could cause a significant increase in the predicted releases or doses at the accessible environment is the unsaturated-zone percolation flux. Significantly greater percolation flux values (on the order of $10 \mathrm{~mm} / \mathrm{yr}$ ) would be expected to increase the percentage of waste packages experiencing advective release from the EBS and the magnitude of that advective release if no hydraulically-engineered barrier (such as a capillary barrier or drip shield) were emplaced in the drifts. At some percolation flux, the limiting factor on the predicted release from the EBS would be the dissolution rate of the waste form itself, which in the present analyses is quite conservative. While increasing the percolation flux also decreases the advective travel time in the unsaturated zone and therefore increases the possible release of key radionuclides to the accessible environment, travel time does not appreciably affect the peak dose because the dominant dose contributor is always ${ }^{237} \mathrm{~Np}$ (at the higher percolation flux values), and it is released eventually anyway.

Dose Conversion Factor. An additional factor that may increase the predicted dose above the values presented in Chapter 9 is the dose conversion factor. This factor, which converts concentrations to doses, has been derived from an EPA reference, but it is possible that revised biosphere modeling of ingestion pathways and bioconcentration factors may affect the conversion factor. It is recommended that the EPA delineate this conversion ratio as part of their rulemaking process assuming they accept the notion of dose- or risk-based total system performance.

Radionuclide Solubility. Given that it is neptunium which generally controls the predicted peak dose at the higher percolation flux values (it may be iodine or technetium at lower percolation flux values), the solubility of this radionuclide plays a significant role. The assumed solubility value of this radionuclide is already considered to be at the realistic-conservative end of the expected range. Therefore, increasing this value substantially is not believed reasonable. In addition, even if the value were increased, one would quickly reach a point where the dissolution rate would control the release of this radionuclide (assuming a significant advective release component through the EBS).

Colloidal Radionuclide Transport. Finally, colloidal transport of radionuclides has not been considered in the present TSPA analyses. Although natural- and/or radio-colloids may be formed in the waste package environment, their stability and mobility is uncertain. For those nuclides which may exist as a colloidal phase and which are also stable and mobile, their transport to the accessible environment may be significantly enhanced if the colloidal matter does not sorb onto the rock. In such a scenario, albeit unlikely, the peak concentration of some key dose-producing radionuclides (especially plutonium) may be significantly increased which would also increase the predicted dose.

Combined Effects on Nonconservative Assumptions. In surn, considering all of the above factors, the maximum increase in the predicted long term dose above the values presented in Chapter 9 is expected to be on the order of 1000 ; with a factor of 10 due to the percolation flux, a factor of 30 due to the dose conversion factor, and a factor of 3 due to colloidal transport. 


\subsubsection{Significance of Conservative Assumptions}

The question of the significance of conservative assumptions may be posed as follows: What components, processes, models, or parameters could, with some reasonable likelihood, be sufficiently different from the assumptions made in the current TSPA iteration, such that the predicted releases or doses could be a factor of 100 to 1000 less than those presented in Chapter 9? In answering this question, virtually every element of the total system is a candidate for discussion. A large number of conservative assumptions have been made that would tend to significantly impact the predicted long term release or dose if the assumptions were relaxed or if the nonconservative end of the parameter space was considered.

Percolation Flux. For example, when considering the lowest percolation fluxes, the peak dose is reduced by about 100 to 1000 , even when the release of ${ }^{129} \mathrm{I}$ from the EBS is in the gaseous phase. Releasing ${ }^{129} \mathrm{I}$ in the aqueous phase reduces the peak dose an additional factor of 100 to 1000 . Low average percolation fluxes have two very positive effects, namely reducing the EBS release rate (because the advective component of the release is reduced) and increasing the travel time (because the propensity for fracture flow and transport is reduced and the matrix velocities are lower).

Waste Package Failure. Limiting the available inventory by either extending the lifetime of a certain fraction of the waste packages or incorporating the potential contribution of cladding has a positive effect on the predicted performance. Therefore, although the time of waste package failure may not be so important in peak dose calculations (even in the most optimal degradation model, some packages have failed by 100,000 years), the fact that only a small fraction of the packages have failed for certain assumptions is still important. This might contribute a factor of 10 to 100 to reducing the peak release and dose.

Saturated-Zone Dilution and Dispersion. An important conservatism that significantly affects the predicted peak dose is the determination of the amount of mixing due to dilution and dispersion in the saturated zone. For the present analyses, the only dispersive mixing is assumed to occur in the vertical plane to a depth of $50 \mathrm{~m}$ below the top of the water table. Transverse dispersion would not be considered significant over the 5-km distance to the accessible environment. Also, longitudinal dispersion has a minimal effect when considering essentially a constant source term. However, if one considers the mixing possible between the repository and the ultimate point of ground-water discharge (whether $30 \mathrm{~km}$ down-gradient in the Amargosa Valley or $80 \mathrm{~km}$ down-gradient at Franklin Lake Playa), then significant reductions (about a factor of 100) in the peak concentrations and doses would result.

Radionuclide Solubility. In those cases where the neptunium release dominates the peak dose, the neptunium solubility plays a key role. It has been suggested that the neptunium solubilities used in the TSPA analyses are based on experiments that represent metastable equilibrium concentrations and that the actual equilibrium concentration may be several orders of magnitude lower. If this were the case, neptunium would be replaced by either technetium or iodine as the peak dose contributor. This would lower the peak dose by an order of magnitude.

Combined Effects of Conservative Assumptions. Combining the above factors (not all of which are multiplicative because different radionuclides are controlling the peak dose depending on the conceptual model and parameter assumptions incorporated) could yield a reduction in the peak dose 
by about a factor of $10^{8}$. This factor is the product of about a factor of 300 due to the percolation flux, a factor of about 300 for the aqueous release of ${ }^{129} \mathrm{I}$, a factor of 10 for cladding effects, and a factor of 100 for saturated zone dispersion and dilution. In this case, the principal radionuclide would be either ${ }^{99} \mathrm{Tc}$ or ${ }^{129} \mathrm{I}$.

It should come as no surprise that the above issues are the key factors in the assessment of the total system performance of the Yucca Mountain potential repository. These are the same factors noted in every other countries' assessment of their potential repository concepts ${ }^{3}$. A more detailed comparison of these studies with the current analyses is beyond the intent of the present discussion.

\subsection{FUTURE TSPA ACTIVITIES}

Virtually every scientific or technical report ends with a section on the knowledge gained during the course of the study and the needs for additional investigations to improve/refine the conclusions reached as a result of the study. In many regards, performance assessment documents are a little different. Although the need for additional investigations to substantiate assumptions made in the analyses is identified, other YMP organizations than performance assessment are responsible for conducting these investigations, which include (1) collecting, interpreting and synthesizing the data, (2) developing substantiating, and testing the process-level models, and (3) documenting all of the above. Based on the anticipated improvement in understanding and its corresponding documentation, performance assessment can then evaluate the significance of the uncertainty which is likely to still remain. While there is certainly much more that performance assessment could do in the way of additional sensitivity analyses of alternative conceptual models of the natural and engineered barrier systems, the highest priority performance assessment activity in the coming year is a detailed technical analysis of the robustness of the process models being developed and documented. In addition, considering that the next full iteration of total system performance assessment will occur in the Fiscal Year 1997-1998 time frame, a significant effort is involved in assuring that the developed and substantiated process models can be appropriately abstracted for use at that time. This will require substantial integration of the various technical disciplines to assure the completeness and representativeness of the analyses conducted at that time.

${ }^{3}$ See Neall et al., (1995) for a comparison of recent total system performance assessments conducted by the high-level radioactive waste disposal programs in Sweden (SKB 91), Finland (TVO 92), Canada (AECL 94), Japan (H-3) and Switzerland (Kristillin-1). 
Table 10.6-1 List of Process Level Models Required by Performance Assessment for Development of Future TSPA Abstractions

\begin{tabular}{|c|l||}
\hline Priority & \multicolumn{1}{|c|}{ Process Model } \\
\hline \hline 1 & Site-scale UZ hydrology model(s) (ambient) \\
3 & Repository-scale UZ thermo-hydrology model(s) \\
3 & Site-scale UZ geochemical model(s) (ambient) \\
1 & Drift-scale thermo-hydrology model(s) \\
3 & Drift-scale thermo-chemical model(s) \\
4 & Drift-scale thermo-mechanical model(s) \\
2 & Drift-scale coupled T-H-C-M model(s) \\
4 & Waste package degradation model(s) \\
3 & Cladding degradation model(s) \\
2 & Waste form dissolution model(s) \\
2 & Waste-package-scale thermo-chemical model(s) (solubility) \\
3 & Drift-scale transport model(s) \\
3 & Site scale UZ transport model(s) \\
3 & Regional and site scale SZ flow model(s) \\
3 & Site scale SZ transport model(s) \\
4 & Biosphere transport model(s) ${ }^{2}$ \\
3 & Tectonics direct and indirect effects model(s) \\
2 & Volcanics direct and indirect effects model(s) \\
\hline
\end{tabular}

1 Potentially higher priority if there is no backfill in the drift.

2 It is recommended that this model be prescribed during EPA rulemaking if a dose- or risk- based performance measure is selected. 
Table 10.6-2 Example Observations Used to Evaluate Representativeness of Process Models

\begin{tabular}{|c|c|c|}
\hline Prioritý & Process Model & Example Comparison to Observations \\
\hline 1 & UZ Hydrology & $\begin{array}{l}\text { In-situ saturations } \\
\text { Air phase flow rates and pressures following } \\
\text { storm events } \\
\text { ESF ventilation humidity and aqueous flux (if } \\
\text { observed) } \\
\text { Ground-water ages in the UZ }\end{array}$ \\
\hline 1 & $\begin{array}{l}\text { Drift-scale thermo- } \\
\text { hydrology }\end{array}$ & $\begin{array}{l}\text { G-tunnel experiments } \\
\text { Laboratory tests } \\
\text { Small-scale (temporal and spatial) tests } \\
\text { conducted from the ESF } \\
\text { Natural analogs }\end{array}$ \\
\hline 2 & Degradation & $\begin{array}{l}\text { Observed pitting corrosion rates in candidate } \\
\text { materials }\end{array}$ \\
\hline 2 & Solubility & $\begin{array}{l}\text { Corrosion of analog materials } \\
\text { Laboratory tests } \\
\text { Natural analogs }\end{array}$ \\
\hline 2 & Drift-scale transport & $\begin{array}{l}\text { Laboratory diffusion experiments } \\
\text { ESF transport experiments } \\
\text { P-tunnel transport: experiments }\end{array}$ \\
\hline 3 & UZ transport & $\begin{array}{l}\text { In-situ saturations } \\
\text { Ground-water ages in the UZ } \\
\text { Gaseous ages in the UZ } \\
\text { In-situ transport experiments }\end{array}$ \\
\hline 3 & $\begin{array}{l}\text { Repository-scale thermo- } \\
\text { hydrology }\end{array}$ & $\begin{array}{l}\text { Natural analogs } \\
\text { Performance confirmation tests }\end{array}$ \\
\hline 3 & UZ geochemical & Ambient observed geochemistry \\
\hline 3 & $\begin{array}{l}\text { Drift-scale thermo- } \\
\text { chemical }\end{array}$ & Laboratory scale tests \\
\hline 3 & Waste form dissolution & $\begin{array}{l}\text { Laboratory tests under range of hydrologic } \\
\text { and geochemical conditions }\end{array}$ \\
\hline 3 & Volcanic effects & $\begin{array}{l}\text { Natural analogs } \\
\text { Natural analogs in the site and region }\end{array}$ \\
\hline 3 & $\begin{array}{l}\text { Regional-site SZ } \\
\text { hydrology }\end{array}$ & $\begin{array}{l}\text { Potentiometric levels } \\
\text { Ground-water ages in the SZ }\end{array}$ \\
\hline 3 & Climate & $\begin{array}{l}\text { Pleistocene playa lake levels } \\
\text { Calcite vein deposits }\end{array}$ \\
\hline
\end{tabular}


Table 10.6-3. Example Evaluation Measures Used to Determine Significance of Process Models

\begin{tabular}{|c|c|c|}
\hline Priority & Process Model & Possible Evaluation Measures \\
\hline 1 & UZ Hydrology & $\begin{array}{l}\text { Percolation flux at repository horizon (variability and uncer- } \\
\text { tainty) } \\
\text { Percent of flux through fractured media at repository hori- } \\
\text { zon (variability and uncertainty) } \\
\text { Travel path length in UZ from repository to water table } \\
\text { (variability and uncertainty) } \\
\text { Transient nature of impact of climate change on percolation } \\
\text { flux (variability and uncertainty) }\end{array}$ \\
\hline 1 & $\begin{array}{l}\text { Drift-scale thermo- } \\
\text { hydrology }\end{array}$ & $\begin{array}{l}\text { Humidity in drift (uncertainty and variability) } \\
\text { Temperature in drift (uncertainty and variability) } \\
\text { Advective flux in drift (uncertainty and variability) } \\
\text { Saturation in drift (uncertainty and variability) }\end{array}$ \\
\hline 2 & Degradation & $\begin{array}{l}\text { Criteria for pit initiation (uncertainty) } \\
\text { Pitting corrosion rate for corrosion allowance materials, } \\
\text { corrosion resistant materials and moderately corrosion resis- } \\
\text { tant materials (uncertainty) } \\
\text { Effect of near-field geochemical environment on pitting } \\
\text { corrosion rates } \\
\text { Effect of near-field thermohydrologic environment on } \\
\text { pitting corrosion rates } \\
\text { Time for first pit to penetrate a waste package (uncertainty } \\
\text { and variability) } \\
\text { Time for } 1000 \text { th pit to penetrate a waste pack- } \\
\text { age(uncertainty and variability) }\end{array}$ \\
\hline 2 & Solubility & $\begin{array}{l}\text { Solubility of radionuclides (uncertainty) } \\
\text { Effect of near-field geochemical environment on solubilities } \\
\text { (uncertainty and variability) } \\
\text { Effect of near-field thermohydrologic environment on solu- } \\
\text { bilities (uncertainty and variability) } \\
\text { Effect of colloids on solubility (uncertainty and variability) }\end{array}$ \\
\hline 2 & Drift-scale transport & EBS release rate normalized to NRC limits \\
\hline 3 & UZ transport & $\begin{array}{l}\text { Travel time of unretarded species from repository to water } \\
\text { table (uncertainty and variability) } \\
\text { Travel time of retarded species from repository to water } \\
\text { table (uncertainty and variability) }\end{array}$ \\
\hline 3 & $\begin{array}{l}\text { Repository-scale } \\
\text { thermo-hyd. }\end{array}$ & $\begin{array}{l}\text { Thermally perturbed travel time of unretarded species from } \\
\text { repository to water table (uncertainty and variability) } \\
\text { Temperature at specified location (TBD) (uncertainty and } \\
\text { variability) }\end{array}$ \\
\hline
\end{tabular}


Table 10.6-3. Example Evaluation Measures Used to Determine Significance of Process Models (Continued)

\begin{tabular}{|c|l|l||}
\hline Priority & \multicolumn{1}{|c|}{ Process Model } & \multicolumn{1}{c|}{ Possible Evaluation Measures } \\
\hline 3 & UZ geochemical & $\begin{array}{l}\text { Retardation coefficients (uncertainty and variability) } \\
\text { Retardation coefficient changes with geochemistry and ther- } \\
\text { mo-hydrology (uncertainty and variability) } \\
\text { Travel time of retarded species from repository to water } \\
\text { table (uncertainty and variability) } \\
\text { ph, Eh, DOC in drifts (uncertainty and variability) and } \\
\text { function of thermo-hydrology } \\
\text { Dissolution rates as functions of T-H-C environments } \\
\text { (uncertainty and variability) } \\
\text { EBS release rate normalized to NRC limits } \\
\text { Evaluation of doses }\end{array}$ \\
\hline
\end{tabular}




\section{CHAPTER 11}

\section{REFERENCES AND ACRONYM LIST}


. 


\section{$\cdot$

Andersson, K., 1988. "SKI Project-90: Chemical Data," SKI TR 91:21, Swedish Nuclear Power Inspectorate, Stockholm, Sweden. (NNA.940303.0040)

Andrews, R. W., T. F. Dale, and J. A. McNeish, 1994. "Total System Performance Assessment-1993: An Evaluation of the Potential Yucca Mountain Repository," B00000000-01717-2200-00099-Rev. 01, Civilian Radioactive Waste Management System, Management and Operating Contractor, Las Vegas, Nevada.

Apted, M. J., A. M. Liebetrau, and D. W. Engel, 1989. "The Analytical Repository SourceTerm (AREST) Model: Analysis of Spent Fuel as a Nuclear Waste Form," Pacific Northwest Laboratory, PNL-6347, Richland, Washington.

Arnold, B. W., S. J. Altman, T. H. Robey, R. W. Barnard, and T. J. Brown, 1995. "Unsaturated-Zone Fast-Path Flow Calculations for Yucca Mountain Groundwater Travel Time Analyses (GWTT-94), SAND95-0857, UC-814. Sandia National Laboratories, Albuquerque, New Mexico.

Atkins, A., and Nickerson, A. K., 1984. "The Diffusion of Ions Through Water-Saturated Cement," Journal of Materials Science, Vol. 19, pp. 3068-3078.

Baes, C. F., Jr., and Mesmer, R. E., 1976. "The Hydrolysis of Cations," John Wiley \& Sons Inc., New York, 489 pp.

Bahney, R. H., 1995. "MPC Internal Temperatures," Interoffice Correspondence to J. H. Lee, IOC.LV.WP.RHB.05/95-164, May 5.

Barnard, R. W., M. L. Wilson, H. A. Dockery, J. H. Gauthier, P. G. Kaplan, R. R. Eaton, F. W. Bingham, and T. H. Robey, 1992. "TSPA 1991: An Initial Total-System Performance Assessment for Yucca Mountain," SAND91-2795, Sandia National Laboratories, Albuquerque, New Mexico, September.

Barner, J. O., 1985, "Characterization of LWR Spent Fuel MCC-Approved Testing Matrial ATM-101", Pacific Northwest Laboratory Report, PNL-5109 Rev. 1, UC-70.

Barr, G. E., 1993. Personal communication.

Bates, J. K., J. C. Hoh, J. W. Emery, E.C. Buck, J. A. Fortner, S. F. Wolf, and T. R. Johnson, 1995. "Reactivity of Plutonium-Containing Glasses for the Immobilization of Surplus Fissile Materials," Proceedings of the Sixth Annual International Conference on High Level Radioactive Waste Management. Las Vegas. Nevada. April 30-May 5. 1995 , American Nuclear Society, Inc., La Grange Park, IL, and American Society of Civil Engineers, New York, New York, pp. 588-593. 
Bates; J. K.,.W. L. Ebert, and T. J. Gerding, 1990. "Vapor Hydration and Subsequent Leaching of Transuranic-Containing SRL and WV Glasses," Proceedings of the International Topical Meeting on High-Level Radioactive Waste Management. Las Vegas. Nevada. April 8-12.1990, American Nuclear Society, La Grange Park, IL, and American Society of Civil Engineers, New York, New York, Vol. 2, pp. 1095-1102.

Bates, J. K., J. P. Bradley, A. Teetsov, C. R. Bradley, and M. Buchholtzten Brink, 1992. "Colloid Formation During Waste Form Reaction: Implications for Nuclear Waste Disposal," Science, Vol. 256, pp. 649-651. (NNA.920416.0050)

Beavers, J. A., and C. L. Durr, 1991. "Immersion Studies on Candidate Container Alloys for the Tuff Repository," NUREG/CR-5598, Cortest Columbus Technologies, Columbus, Ohio.

Beckmann, P., and J. E. O. Mayne, 1960. "Inhibitors of the Corrosion of Iron. I. Effects of the Cation," Journal of Applied Chemistry, Vol. 10, pp. 417-419.

Bennet, P. C., Siegel, D. E., Baedecker, and Hult, M. F., 1993. "Crude Oil in a Shallow Sand and Gravel Aquifer--I. Hydrogeology and Inorganic Geochemistry," Applied Geochemistry, Vol. 8, pp. 529-550.

Benson, L. V., Robinson, J. H., Blankennagel, R. K., and Ogard, A. E., 1983. "Chemical Composition of Ground Water and the Locations of Permeable Zones in the Yucca Mountain Area, Nevada," Open File Report 83-854, U. S. Geological Survey.

Blankennagel, R. K., and J. E. Weir Jr., 1973. "Geohydrology of the Eastern Part of Paihute Mesa, Nevada Test Site, Nye County, Nevada," U.S. Geological Survey Professional Paper 712-B, Washington, D.C., 35 pp.

Boden, P. J., 1994. "Effect of Concentration, Velocity and Temperature," Corrosion (3rd ed.), L. L. Shreir, R. A. Jarmen and G. T. Burstein (ed.), Vol. 1 - Metal/Environment Reactions, pp. 2:3-2:30.

Bourcier, W., 1993. "Draft Input for LLNL PA Calculation, Glass Wasteform," A memo to R. Stout, March 17.

Bourcier, W. L., S. A. Carroll, and B. L. Phillips, 1994. "Constraints on the Affinity Term for Modeling Long-Term Glass Dissolution Rates," Scientific Basis for Nuclear Waste Management XVII. Materials Research Society Symposium Proceedings, Vol. 333, pp. 507-512. A. Barkatt and R. A. Van Konynenburg (eds.), Materials Research Society, Pittsburgh, Pennsylvania.

Brakel, J. V., and Heertjes, P. M., 1974. "Analysis of Diffusion in Macroporous Media in Terms of a Porosity, a Tortuosity and a Constrictivity Factor," International Journal of Heat and Mass Transfer, Vol. 17, pp. 1093-1103. 
Brasher, D. M., and A. D. Mercer, 1968. "Comparative Study of Factors Influencing the Action of Corrosion Inhibitors for Mild Steel in Neutral Solution. I. Sodium Benzoate," British Corrosion Journal, Vol. 3, pp. 121-129.

Brunauer, S., 1961. "Solid Surface and the Solid-Gas Interface," Advances in Chemistry Series, Vol. 33, American Chemical Society, Washington, D.C.

Bruton, C. J., B. L. Phillips, A. Meike, S. Martin, and B. Viani, 1993a. "Cement Minerals at Elevated Temperature: Thermodynamic and Structural Characteristics," Proceedings of the Materials Research Society Meeting, Boston, Massachussets.

Bruton, C. J., A. B. Meike, B. Viani, S. Martin, and B. L. Phillips, 1993b. "Thermodynamic and Structural Characteristics of Cement Minerals at Elevated Temperature," Proceedings of the Topical Meeting on Site Characterization and Model Validation. Eocus '93, September 26-29, 1993, Las Vegas, Nevada, American Nuclear Society, Inc., La Grange Park, Illinois, pp. 150-156.

Buddemeier, R. W., and J. R. Hunt, 1988. "Transport of Colloidal Contaminants in Groundwater," Applied Geochemistry, Vol. 3, No. 5, pp. 535-548. (NNA.930701.0051)

Buesch, D. C., R. W. Spengler, T. C. Moyer, and J. K. Geslin, 1995. "Revised Stratigraphic Nomenclature and Macroscopic Identification of Lithostratigraphic Units of the Paintbrush Group Exposed at Yucca Mountain, Nevada," Open-File Report 94-469, U.S. Geological Survey, Lakewood, Colorado.

Bullen, D., 1992. "Preliminary Data Set for the Golder Associates Waste Package Model," Consultant Report GAI-91-01-001, Golder Associates, Redmond, Washington.

Buscheck, T. A., and J. J. Nitao, 1992. "The Impact of Thermal Loading on the Repository Performance at Yucca Mountain," Proceedings of the Third International High Level Radioactive Waste Management Conference, Las Vegas, Nevada, April 12-16.

Buscheck, T. A., and J. J. Nitao, 1993. "The Analysis of Repository Heat-Driven Hydrothermal Flow at Yucca Mountain," Proceedings of the Fourth International High Level Radioactive Waste Management Conference, Las Vegas, Nevada, April 26-30.

Buscheck, T. A., and J. J. Nitao, 1994. "The Impact of Buoyant Gas-Phase Flow and Heterogeneity on Thermo-Hydrological Behavoir at Yucca Mountain," Proceedings of the Fifth International High-Level Radioactive Waste Management Conference, Las Vegas, Nevada.

Buscheck, T. A., J. J Nitao, and S. F. Saterlie, 1994. "Evaluation of Thermo-Hydrological Performance in Support of Thermal Loading Systems Study," Proceedings of the Fifth International High-Level Radioactive Waste Management Conference, Las Vegas, Nevada.

Buscheck, T. A., 1995, Personal communication to J. H. Lee, August 16 and 17. 
Buscheck, T. A., J. J. Nitao, and L. Ramspott, 1995. "Localized Dry-out: An Approach for Managing the Thermo-hydrological Effects of Decay Heat at Yucca Mountain," presented at the Materials Research Society Symposium on the Scientific Basis for Nuclear Waste Management XIX, 1995 Fall Meeting, Nov. 27 - Dec. 1, Boston, Massachusetts.

Carslaw, H. S., and J. C. Jaeger, 1959. "Conduction of Heat in Solids," 2nd Edition, Oxford University Press, London.

Castet, S., Dandurand, J. L., Schott, J., and Gout, R., 1992. "Experimental Study of Aluminum Hydrolysis and Complexation with Acetate and Sodium Ions in Hydrothermal Solutions," Proceedings of the Seventh.International Symposium on Water-Rock Interaction. Vol. 2, Y. K. Kharaka and A. Maest (eds.), U.S. Geological Survey, Menlo Park, pp. 1013-1016.

Chambre, P. L., W. W-L. Lee, C. L. Kim, and T. H. Pigford, 1986. "Steady-State and Transient Radionuclide Transport Through Penetrations in Nuclear Waste Containers," LBL-21806, Lawrence Berkeley Laboratory, University of California, Berkeley, California.

Chambre, P.L, 1995. "The Steady State Mass Transfer from Perforated Waste Package Containers," Informal Report UCB-NE 4205, Department of Nuclear Engineering, University of California, Berkeley, California.

Chin, B. A., and E. R. Gilbert, 1989. "Prediction of Maximum Allowable Temperatures for Dry Storage of Zircaloy-Clad Spent Fuel in Inert Atmosphere," Nuclear Technology, Vol. 85, pp. 57-65.

Choppin, G. R., 1992. "The Role of Natural Organics in Radionuclide Migration in Natural Aquifer Systems," Radiochimica Acta, Vol. 57, pp. 113-120.

Claassen, H. C., 1985. "Sources and Mechanisms of Recharge for Ground Water in the WestCentral Amargosa Desert, Nevada--A Geochemical Interpretation," Professional Paper 712-F, U.S. Geological Survey.

Clark, D. L., D.E. Hobart, and M. P. Neu, 1995. "Actinide Carbonate Complexes and Their Importance in Actinide Environment Chemistry," Chemical Reviews, Vol. 1995, pp. 25-48.

Coache, R., 1986. "Amargosa Valley Basin 230-1985 Groundwater Pumpage Inventory, Tabular Material on Water Use," State of Nevada, Department of Conservation and Natural Resources, Water Resources Division, Las Vegas, Nevada.

Coburn, S. K., 1978. "Corrosion in Fresh Water," Properties and Selection: Irons and Steels, Metals Handbook, Ninth Edition, American Society for Metals, Metal Parks, Ohio, Vol.1, pp.733-738. 
Codell, R. B., and B. Sagar, 1995. "Approaches to Model Abstraction for Performance Assessment," Proceedings of the Sixth Annual International High Level Radioactive Waste Management Conference Las Vegas, Nevada, pp. 258-260.

Conca, J. L., 1990. "Diffusion Barrier Transport Properties of Unsaturated Paintbrush Tuff Rubble Backfill," Proceedings of the International Topical Meeting on High Level Radioactive Waste Management. Las Vegas. Nevada. April 8-12. 1990, American Nuclear Society, Inc., La Grange Park, IL, and American Society of Civil Engineers, New York, New York, Vol. 1, pp. 394-401.

Conca, J. L., and J. Wright, 1990. "Diffusion Coefficients in Gravel Under Unsaturated Conditions," Water Resources Research, Vol. 26, pp. 1055-1066.

Conca, J. L., and J. Wright, 1992. "Diffusion and Flow in Gravel, Soil, and Whole Rock," Applied Hydrogeology, Vol. 1, pp. 5-24.

Craig, B., and S.L. Pohlman, 1987. "Forms of Corrosion: Introduction," Corrosion Metals Handbook, 9th Edition, American Society for Metals International, Metals Park, Ohio, Volume 13, pp. 79.

Crank, J., 1975. "The Mathematics of Diffusion", 2nd Edition, Oxford University Press, New York, New York.

Croff, A. G., 1983, "ORIGEN2: A Versatile Computer Code for Calculating the Nuclide Compositions and Characteristics of Nuclear Materials," Nuclear Technology, Vol. 62, pp. 335-352.

Crowe, B. M., F. Perry, J. Geissman, L. McFadden, S. Wells, M. Murrell, J. Paths, G. A. Valentine, L. Bowner, and K. Finnegan, 1995. "Status of Volcanism Studies for the Yucca Mountain Site Characterization Project", Los Alamos LA-MS report., Los Alamos, New Mexico.

Czarnecki, J. B., and R. K. Waddel, 1984. "Finite-Element Simulation of Ground-Water Flow in the Vicinity of Yucca Mountain, Nevada-California," USGS-OFR-84-4349. Water Resources Investigations Report, U.S. Geological Survey.

Czarnecki, J. B., 1989. "Characterization of the Subregional Ground-Water Flow System at Yucca Mountain and Vicinity, Nevada-California," Radioactive Waste Management and the Nuclear Fuel Cycle, Vol. 13, No. 1-4, pp. 51-61.

Dettinger, M. D., 1992. "Geohydrology of Areas Being Considered for Exploratory Drilling and Development of the Carbonate-Rock Aquifers in Southern Nevada--Preliminary Assessment," USGS-WRI-90-4077, U.S. Geological Survey, 35 p.

DOE (U.S. Department of Energy), 1995. "Mined Geologic Disposal System License Application Annotated Outline", Revision 0, YMP 94-05, Yucca Mountain Site Characterization Office, Las Vegas, Nevada. 
DOE (U.S. Department of Energy), 1995a. "Engineered Barrier Design Requirements Document," YMP/CM-0024, Rev. 1, Office of Civilian Radioactive Waste Management, Las Vegas, Nevada, October.

DOE (U.S. Department of Energy), 1995b. "In-Situ Thermal Testing Program Strategy," DOE/TMSCO-003, The Yucca Mountain Site Characterization Office, Las Vegas, Nevada.

DOE (U.S. Department of Energy), 1990. "Yucca Mountain Project Reference Information Base," YNP/CC-0002 (Version 04.002), Nevada Operations Office, Las Vegas, Nevada.

DOE (U.S. Department of Energy), 1988. "Site Characterization Plan, Yucca Mountain Site," DOE/RW-0199, Office of Civilian Radioactive Waste Management.

DOE (U.S. Department of Energy), 1987. "Characteristics of Spent Fuel, High-Level Waste, and Other Radioactive Wastes Which May Require Long-Term Isolation," DOE/RW0184, OCRWM, Washington, D.C.

Doering, T. W., 1995. "Dimensions of Waste Package Barriers," CRWMS M\&O Interoffice Correspondence, IOC LV.WP.TWD.5/95.182, May 26.

Dudley, W. W., Jr., and J. D. Larson, 1976. "Effect of Irrigation Pumping on Desert Pupfish Habitats in Ash Meadows, Nye County, Nevada," U.S. Geological Survey Professional Paper 927, U.S. Government Printing Office, Washington, D. C.

Duguid, J. O., R. W. Andrews, E. Brandstetter, T. F. Dale, and M. Reeves, 1994. "Calculations Supporting Evaluation of Potential Environmental Standards for Yucca Mountain," B00000000-01717-2200-00094, CRWMS Management and Operating Contractor, Vienna, Virginia.

Duncan, J. R., and D. J. Spedding, 1973. "The Effect of Relative Humidity on Adsorption of Sulphur Dioxide on to Metal Surfaces," Corrosion Science, Vol. 13, pp. 993-1001.

Dyer, J. R., 1993. "Radionuclide Solubility Working Group (SolWOG) Meeting Report (SCP: N/A)," Department of Energy Letter with Enclosure to LLNL and LANL, August 2.

Ebert, W. L., and J. K. Bates, 1995. "Performance Testing of West Valley Reference 6 Glass," Proceedings of the Sixth Annual International Conference on High Level Radioactive Waste Management. Las Vegas. Nevada, April 30-May 5. 1995, American Nuclear Society, Inc., La Grange Park, Illinois, and American Society of Civil Engineers, New York, New York, pp. 583-587.

Eikenberg, J., and Lichtner, P. C., 1992. "Propagation of Hyperalkaline Cement Pore Waters into the Geologic Barrier Surrounding a Radioactive Waste Repository," Proceedings of the Seventh International Symposium on Water-Rock Interaction. Vol. 1, Y. K. Kharaka and A. Maest (eds.), U.S.Geological Survey, Menlo Park, pp. 377-380. 
Eikenberg, J., 1990. "On the Problem of Silica Solubility at High pH," PSI Report 74 and NAGRA Technical Report NTB 90-36, Switzerland.

Einziger, R. E., 1994. "Preliminary Spent Fuel Oxidation Source Term Model," Proceedings of the Fifth International Conference on High-Level Radioactive Waste Management. Las Vegas. Nevada. May 22-26. 1994, American Nuclear Society, La Grange Park, Illinois, and American Society of Civil Engineers, New York, New York, Vol. 2, pp. 554-559.

Engel, D., 1995. A memo to J.H. Lee, January 30.

EPA (Environmental Protection Agency), 1988. "Limiting Values of Radionuclide Intake and Air Concentration and Dose Conversion Factors for Inhalation, Submersion, and Ingestion, EPA-520/1-88-020, Washington, D.C.

EPRI (Electrical Power Research Institute), 1992. "Source Term in the EPRI Performance Assessment," R. Shaw, presented to Nuclear Waste Technical Review Board, Las Vegas, Nevada, October 15, 1992.

Ervin, E. M., R. R. Luckey and D. J. Burkhardt, 1994. "Summary of Revised Potentiometric Surface Map for Yucca Mountain and Vicinity, Nevada", Proceedings of the Fifth International High Level Radioactive Waste Management Conference Las Vegas, Nevada, May 22-26, 1994.

Fabryka-Martin, J., 1995. "Isotopic Dating of Ground Water at Yucca Mountain", Presentation at Nuclear Waste Technical Review Board on Hydrogeology and Geochemistry, San Francisco, California, June 26-27, 1995.

Farmer, J. C., and R. D. McCright, 1989. "Localized Corrosion and Stress Corrosion Cracking of Candidate Materials for High-Level Radioactive Waste Disposal Containers in U.S.: A Critical Literature Review," Scientific Basis for Nuclear Waste Management XII, W. Lutze and R. C. Ewing (eds.), Proceedings of the Symposium by the Material Research Society, Pittsburg, Pennsylvania, Vol. 127, pp. 359-371.

Farmer, J. C., R. A. Van Konynenburg, R. D. McCright, and D. B. Bullen, 1988. "Survey of Degradation Modes of Candidate Materials for High-Level Radioactive-Waste Disposal Containers. Volume 3: Localized Corrosion and Stress Corrosion Cracking of Austenitic Alloys," UCID-21362 Vol. 3, Lawrence Livermore National Laboratory, Livermore, California

Feng, X., E. C. Buck, C. Mertz, J. K. Bates, and J. C. Cunnane, 1993. "Study on the Colloids Generated from Testing of High-Level Nuclear Waste Glasses," Proceedings of the Symposium on Waste Management. Tucson, Arizona, February 28 - March 4. 1993, Vol. 2, 1015-1021. (NNA.930907.0054) 
Finn, P. A., J. K. Bates, E.C. Buck, D. J. Wronkiewicz, J. C. Hoh, and S. F. Wolf, 1995. "Alteration of Spent Fuel Matrix Under Unsaturated Water Conditions," Proceedings of the Sixth Annual International Conference on High Level Radioactive Waste Management. Las Vegas. Nevada, April 30-May 5.1995, American Nuclear Society, Inc., La Grange Park, Illinois, and American Society of Civil Engineers, New York, New York, pp. 606-608.

Flint, A. L., and L. E. Flint, 1994. "Spatial Distribution of Potential Near Surface Moisture Flux at Yucca Mountain," Proceedings of the Fifth Annual International Conference on High Level Radioactive Waste Management. Las Vegas. Nevada, pp. 2352-2358.

Flint, A. L., 1995. "Shallow Infiltration and the Initiation of Fracture Flow at Yucca Mountain, Nevada," Presented to Nuclear Waste Technical Review Board, San Francisco, California, June.

Fontana, M. G., 1986. "Corrosion Engineering," 3rd Edition, McGraw-Hill, New York.

Freeze, R. A., and J. A. Cherry, 1979. "Groundwater," Prentice-Hall, Englewood Cliffs, New Jersey.

French, R. H., A. Elzeftawy, J. Bird, and B. Elliot, 1984. "Hydrology and Water Resources Overview of the Nevada Nuclear Waste Storage Investigations, Nevada Test Site, Nye County, Nevada," NVO-284, Desert Research Institute, Las Vegas, Nevada.

Fyfe, D., 1994. "The Atmosphere," Corrosion, Vol. 1-Metal/Environment Reactions, 3rd Edition, L. L. Shreir, R. A. Jarman and G. T. Burstein (eds.), Butterworth-Heinemann, pp. 2:31-2:42.

Gauthier, J., 1993. "Expert Elicitation of the Solubility Distributions to be Used in TSPA\#2 Calculations," Draft Report, June 1, 1993.

Gauthier, J. H., 1995, "Proposed Models of Colloid-Facilitated Transport for Total-System Performance Assessment," Proceedings of the Sixth Annual International Conference on High-Level Radioactive Waste Management. Las Vegas. Nevada. April 30-May 5. 1925, American Nuclear Society, Inc., La Grange Park, II, and American Society of Civil Engineers, New York, NY, pp. 448-450.

Gdowski, G. E., and D. B. Bullen, 1988. "Survey of Degradation Modes of Candidate Materials for High-Level Radioactive-Waste Disposal Containers," UCID-21362 Vol. 2, Lawrence Livermore National Laboratory, Livermore, California.

Gelhar, L. W., 1993, "Stochastic Subsurface Hydrology," Prentice-Hall, Englewood Cliffs, New Jersey. 
Glassley, Wฯ 1993. "Coupled Hydro-Geochemical Processes and their Significance for Yucca Mountain Site Characterization," Proceedings of the Topical Meeting on Site Characterization and Model Validation, Focus '93, September 26-29, 1993. Las Vegas. Nevada, American Nuclear Society, Inc., La Grange Park, Illinois, pp. 122-126.

Golder Associates, Inc., 1993. "Application of the RIP (Repository Integration Program) to the Proposed Repository at Yucca Mountain: Conceptual Model and Input Data Set," Golder Associates, Redmond, Washington.

Golder Associates, Inc., 1994. "RIP Performance Assessment and Strategy Evaluation Model: Theory Manual and User's Guide, Version 3.20", Golder Associates, Redmond, Washington.

Golder Associates, Inc., 1994a. "Alternative Conceptualizations for WIPP Performance Assessment Modeling," prepared for the WIPP Technical Assistance Contractor (WTAC), U.S. Department of Energy, November, 1995.

Golder Associates, Inc., 1995a. "Implementation of the SPM-2 Data Set Within RIP," Draft Report prepared for the WIPP Technical Assistance Contractor (WTAC), U.S. Department of Energy, August, 1995.

Golder Associates, Inc., 1995b. "Long-Term Performance Assessment of New York LowLevel Radioactive Waste Disposal Methods," Draft Report prepared for New York State Low-Level Radioactive Waste Siting Commission, 923-D006.003, June 1995.

Golder Associates, Inc., 1995c. "Verification Report for the Repository Integration Program (RIP)," prepared for the WIPP Technical Assistance Contractor (WTAC), U.S. Department of Energy, August, 1995.

Gray, W. J., 1995a. A memo to D. Engel, April 28.

Gray, W. J., 1995b. A personal communication to J. H. Lee, August 21.

Gray, W. J., H. R. Leider, and S. A. Steward, 1992. "Parametric Study of LWR Spent Fuel Dissolution Kinetics," UCRL-JC-110160, Lawrence Livermore National Laboratory, Livermore, California.

Gray, W. J., and C. N. Wilson, 1995. "Spent Fuel Dissolution Studies FY 1991-1994," PNL10450, Pacific Northwest Laboratory, Richland, Washington.

Guttman, H., 1968. "Effects of Atmospheric Factors on the Corrosion of Rolled Zinc," Metal Corrosion in the Atmosphere, ASTM STP 435, American Society for Testing and Materials, pp. 223-239. 
Guttman, H.. and P. J. Sereda, 1968. "Measurement of Atmospheric Factors Affecting the Corrosion of Metals," Corrosion in Natural Enviroments, ASTM STP 558, American Society for Testing and Materials, pp. 33-51.

Halsey, W., 1995. "Recommendations for Modifications of the Waste Package Corrosion Model for TSPA-95," Interoffice Correspondence IOC LV.WP.PG.08/95.261, August 3.

Harrill, J. R., 1986. "Ground-Water Storage Depletion in Pahrump Valley, Nevada-California, 1962-1975," U.S. Geological Survey, Water-Supply Paper 2279.

Harrill, J. R., J. S. Gates, and J. M. Thomas, 1988. "Major Ground Water Flow Systems in the Great Basin of Nevada, Utah and Adjacent States," Department of Interior, U. S. Geological Survey, Reston, Virginia.

Haynie, F. H., J. W. Spence, and J. B. Upham, 1978. "Effects of Air Pollutants on Weathering Steel and Galvanized Steel: A Chamber Study,"Atmospheric Factors Affecting the Corrosion of Engineering Metals, ASTM STP 646, S.K. Coburn (ed.), American Society for Testing and Materials, pp. 30-47.

Haynie, F. H., and J. B. Upham, 1974. "Correlation Between Corrosion Behavior of Steel and Atmospheric Pollution Data," Metal Corrosion in the Atmosphere, ASTM STP 435, American Society for Testing and Materials, pp. 326-359.

Henshall, G. A., W. L. Clarke, and R. D. McCright, 1993. "Modeling Pitting Corrosion Damage of High-Level Readioactive-Waste Containers, with Emphasis on the Stochastic Approach," UCRL-ID-111624, Lawrence Livermore National Laboratory, Livermore, California, January.

Hersch, P., J. B. Hare, A. Robertson, and S. M. Sutherland, 1961a. "An Experimental Survey of Rust Preventives in Water: I. Methods of Testing," Iournal of Applied Chemistry, Vol. 11, pp. 246-250.

Hersch, P., J. B. Hare, A. Robertson, and S. M. Sutherland, 1961b. "An Experimental Survey of Rust Preventives in Water: III. Some General Results," Journal of Applied Chemistry, Vol. 11, pp. 265-271.

Hevesi, J. A., A. L. Flint and J. D. Istok, 1993. "Precipitation Estimates in Mountainous Terrain Using Multivariate Geostatistics, Part II: Isohyetal Maps," Journal of Applied Meteorology, Vol. 31, pp. 677-688.

Ho, C., 1995. "Assessing Alternative Conceptual Models of Fracture Flow," Proceedings of TOUGH Workshop '25, Lawrence Berkeley Laboratory, Berkeley, California, March 20-22. 
Hobart, D. E., D. E. Morris, P. D. Palmer, and T. W. Newton, 1989. "Formation, Characterization and Stability of Plutonium (IV) Colloid: A Progress Report," Proceeding of Nuclear Waste Isolation in the Unsaturated Zone. FOCUS '89, Las Vegas. Nevada. September 17-21, pp. 118-124. (NNA.890815.0254)

Hoxie, D. T., 1989. "A Conceptual Model for the Unsaturated Zone Hydrogeologic System, Yucca Mountain, Nevada," Radioactive Waste Management Nuclear Fuel Cycle, Vol. 13, No. 1-4, pp. 63-76.

ICRP (International Commission on Radiological Protection), 1991. "1990 Recommendations to the International Commission on Radiological Protection," Report ICRP-60. Annals of the ICRP.

ICRP (International Commission on Radiological Protection), 1985a. "Radiation Protection Principles for the Disposal of Solid Radioactive Waste," Report ICRP-46. Annals of the ICRP.

ICRP (International Commission on Radiological Protection), 1985b. "Principles of Monitoring for the Radiation Protection of the Population," Report ICRP-43. Annals of the ICRP.

Janecky, D. R., C. J. Duffy, C. D. Tait, and D. Clark, 1994. "Thermochemical Data on Actinides for Modeling," Letter Report, LANL Milestone 4025.

Jardine, L. J., 1991. "Submission of Data to the SEPDB, LLNL Letter LLYMP9101029 with Attachments to SNL SEPD Administrator," January 22. (NNA.920617.0023)

Johnson, J. W., E. H. Oelkers, and H. C. Helgeson, 1992. "SUPCRT92: A Software Package For Calculating the Standard Molal Thermodynamic Properties of Minerals, Gases, Aqueous Species, And Reactions From 1 To 5000 Bar and 0 To $1000^{\circ} \mathrm{C}$," Computers and Geosciences, Vol. 18, No. 7, pp. 899-947.

Jones, D. A., and R. S. Howryla, 1993. "Electrochemical Sensor to Monitor Atmospheric Corrosion in Repository Environments," Presented at the Yucca Mountain Waste Package Workshop, Las Vegas, Nevada, September 21-23.

Kerrisk, J. F., 1984. "Solubility Limits on Radionuclide Dissolution at a Yucca Mountain Repository," LA-9995-MS, Los Alamos National Laboratory, Los Alamos, New Mexico (NNA.870519.0049)

Kerrisk, J. F., 1987. "Groundwater Chemistry at Yucca Mountain, Nevada, and Vicinity,"LA10929-MS, Los Alamos National Laboratory, Loś Alamos, New Mexico. 
Klavetter, E. A., and R. R. Peters, 1986. "Estimation of Hydrologic Properties of an Unsaturated Fractured Rock Mass," SAND84-2642, Sandia National Laboratories, Albuquerque, New Mexico.

Knauss, K. G., W. L. Bourcier, K. D. McKeegan, C. I. Merzbacher, S. N. Nguyen, F. J. Ryerson, D. K. Smith, H. C. Weed, and L. Newton, 1990. "Dissolution Kinetics of a Simple Analogue Waste Glass As a Function of pH, Time and Temperature," Scientific Basis for Nuclear Waste Management XIII. Materials Research Society Symposium Proceedings, Vol. 176, pp. 371-381, V.M. Oversby and P.W. Brown (eds.), Materials Research Society, Pittsburgh, Pennsylvania.

Knotkova, D., P. Holler, and J. Vickova, 1981. "The Evaluation of the Microclimate Effect on the Characteristics of Environment and Corrosion of Metals," Proceedings of the Eighth International Congress on Metallic Corrosion. September 6-11, Mainz, FRG, Vol. 1, pp. 859-864.

Knotkova-Cermakova, D., J. Vickova, and J. Honzak, 1982. "Atmospheric Corrosion of Weathering Steels," Atmospheric Corrosion of Metals, ASTM STP 767, S. W. Dean, Jr. and E. C. Rhea (eds.), American Society for Testing and Materials, pp. 7-44.

Komp, M. E., 1987. "Atmospheric Corrosion Ratings of Weathering Steels-Calculation and Significance," Materials Performance, pp. 42-44, July.

Kucera, V., and E. Mattsson, 1974. "Electrochemical Technique for Determination of the Instantaneous Rate of Atmospheric Corrosion," Corrosion in Natural Environments, ASTM STP 558, American Society for Testing and Materials, pp. 239-260.

Kwicklis, E.; 1994. "High Level Radioactive Waste Management, Gas Migration within Clay," May 22 - 26, pp. 2071 - 2080, Presented to Nuclear Waste Technical Review Board, Las Vegas, Nevada, October.

LANL (Los Alamos National Laboratory), 1992. "Mountain Site Characterization Project Radionuclide Absorption," Workshop at Los Alamos National Laboratory, (ed.), J. A. Canepa, LA-12325-6, 1992, Los Alamos National Laboratory, Los Alamos, New Mexico.

Larrabee, C. P., 1953. "Corrosion Resistance of High-Strength Low-Alloy Steels As Influenced by Composition and Environment," Corrosion, Vol. 9, pp. 259-271.

Lee, J. H., 1995. "Response to IOC LV.WP.PG.08/95.261 from William Halsey," Interoffice Correspondence IOC LV.PA.JHL.08/95.001, August 7.

Levy, S. S., 1992. "Natural Gels in the Yucca Mountain Area, Nevada, USA, "Applied Clay Science, Vol. 7, pp. 79-85. 
Li, C., V. Vallikat, S. Mishra, and S. D. Sevougian, 1995. "Influence of the Poisson Transition Rate and Matrix Diffusion on Solute Transport in Fractured Media," Letter Report, CRWMS Management and Operating Contractor, Las Vegas, Nevada.

Lingineni, S., M. Reeves, and S. Mishra, 1994. "Hydrothermal Analyses at the Waste Package/ Drift Scale, A Benchmarking Study with FEHM and TOUGH2," BBA000000-01717-0200-00001, Las Vegas Nevada.

Long, A., and S.W. Childs, 1993. "Rainfall and Net Infiltration Probabilities for Future Climate Conditions at Yucca Mountain," in Proceedings of the Fourth Annual High Level Radioactive Waste Management Conference Las Vegas Nevada. April 26-30. 1993, American Nuclear Society Inc., La Grange Park, IL, and American Society of Civil Engineers, New York, NY, pp. 112-121.

Longenbaugh, R., C. A. Rautman, and E. E. Ryder, 1994. "Yucca Mountain Thermal Response: An Evaluation of the Effects of Modeled Geologic Structure and Thermal Property Descriptions". SAND94-2247, Sandia National Laboratories, Albuquerque, New Mexico, September.

Malinauskas, A., 1995. A personal communication to J.H. Lee, August 21.

Manaktala, H., Turner, D., Ahn, T., Colten-Bradley, V., and Bonano, E., 1995, "Implications of Colloids on the Performance of a HLW Repository," Proceedings of the Sixth Annual International Conference on High-Level Radioactive Waste Management. Las Vegas. Nevada. April 30-May 5. 1995, American Nuclear Society Inc., La Grange Park, IL, and American Society of Civil Engineers, New York, NY, pp. 445-447.

Marsh, G. P. and K. J. Taylor, 1988. "An Assessment of Carbon Steel Containers for Radioactive Waste Disposal," Corrosion Science, Vol. 28, pp. 289-320.

Marsh, G. P., K. J. Taylor, and Z. Sooi, 1988. "The Kinetics of Pitting Corrosion of Carbon Steel," SKB Technical Report 88-09, Stockholm, Sweden, February.

Masamura, K., and I. Matsushima, 1983. "Corrosion and Electrochemical Behavior of Steel in $\mathrm{CO}_{2}$ Bearing Water," Transactions of the Iron and Steel Institute of Japan, Vol. 23, No. 8, pp. 676-679.

McCarthy, J. F., and J. M. Zachara, 1989. "Subsurface Transport of Contaminants," Environmental Science and Technology, Vol. 23, No. 5, pp. 496-502. (NNA 830625.0032)

McCoy, K., 1994. "Corrosion Model for Corrosion-Allowance Materials: Thermal Loading and Degradation of Corrosion-Allowance Materials in Humid Air," CRWMS M\&O Interoffice Correspondence, IOC LV.WP.JKM.8/94.201, August 5. 
McCoy, K., 1995. "Cladding Degradation and Fuel Exposure," Interoffice Correspondence to J. H. Lee, IOC.LV.WPD.JKM.3/95.098, March 21.

McCright, R. D. and H. Weiss, 1985. "Corrosion Behavior of Carbon Steels under Tuff Repository Environmental Conditions," Scientific Basis for Nuclear Waste Management VIII. Material Research Society Symposium Proceedings, Vol. 44, pp. 287-294, C. M. Jantzen, J. A. Stone and R. C. Ewing (eds.), Materials Research Society, Pittsburg, Pennsylvania.

McCright, R. D., 1994. "Scientific Investigation Plan: Metallic Barriers Task," W.B.S 1.2.2.5.1, Rev. 2, UCRL-xx-xxxx, Lawrence Livermore National Laboratory, Livermore, California, December.

McCright, R. D., 1995. "Galvanized Effects in Multi-Barrier Waste Package Containers". Personal Communication to J. H. Lee, July 12.

McGuire, R. K., D. B. Bullen, N. Cook, K. J. Coppersmith, J. Kemeny, A. Long, F. J. Pearson, Jr., F. Schwartz, M. Sheridan, and R. R. Youngs, 1990. "Demonstration of a Risk-Based Approach to High-Level Waste Repository Evaluation," EPRI NP-7057, Electric Power Research Institute, Palo Alto, California.

McGuire, R. K., M. J. Apted, D. B. Bullen, S. Childs, N. Cook, K. J. Coppersmith, R. L. Keeney, J. M Kemeny, A. Long, F. J. Pearson, Jr., B. Ross, F. W. Schwartz, M. F. Sheridan, and R. R. Youngs, 1992. Demonstration of a Risk-Based Approach to HighLevel Waste Repository Evaluation: Phase 2, EPRI TR-100384, Electric Power Research Institute, Palo Alto, California.

Means, J. L.; A. S. Maest, and D. A. Crear, 1983. "The Organic Geochemistry of Deep Ground Waters and Radionuclide Partitioning Experiments Under Hydrothermal Conditions," Office of Nuclear Waste Isolation, Battelle Memorial Institute, Technical Report ONWI-448, Distribution Category UC-70, July.

Meijer, A., 1990. "Yucca Mountain Project Far-Field Sorption Studies and Data Needs," LANL Report LA-11671-MS, UC-510, September, 37 p.

Meijer, A., 1992. "A Strategy for the Derivation and Use of Sorption Coefficients in Performance Assessment Calculations for the Yucca Mountain Site," Proceedings of the DOE/Yucca Mountain Site Characterization Project Radionuclide Absorption Workshop at Los Alamos National Laboratory, September 11-12, 1990, J. A. Canepa (ed.), LA-12325-C, Los Alamos National Labortory, Los Alamos, New Mexico.

Meijer, A., 1995. Memo to S. D. Sevougian, June 7, 1995.

Meike, A., 1995. "A Discussion of Some Specific Needs for Historical Analogs within the Introduced Materials Task," LLNL Milestone MOL 128 Draft Report, June. 
Meike, A., and Wittwer, C., 1993, "Formation of Colloids from Introduced Materials in the Post-Emplacement Environment: A Report on the State of Understanding," Proceedings of the Topical Meeting on Site Characterization and Model Validation. Focus '93, September 26-29, 1993, Las Vegas, NV, Amer. Nuc. Soc., Inc., La Grange Park, Illinois, p. 95-102.

Meike, A., C. J. Bruton, M. Onofrei, and B. Viani, 1994. "Progress in Understanding the Structure and Thermodynamics of Calcium Silicate Hydrates," Proceedings of the Fifth Annual International Conference on High Level Radioactive Waste Management, Las Vegas, Nevada, pp. 2590-2596.

Mercer, A. D., I. R. Jenkins, and J. E. Rhoades-Brown, 1968. "Comparative Study of Factors Influencing the Action of Corrosion Inhibitors for Mild Steel in Neutral Solution. III. Sodium Nitrite," British Corrosion Journal, Vol. 3, pp. 136-144.

Mifflin, M. D., and J. W. Hess, 1979. "Regional Carbonate Flow Systems in Nevada," W. Back and D. A. Stephenson (Guest-Editors), Contemporary Hydrogeology, The Goerge Burke Maxey Memorial Volume, Journal of Hydrology, Vol. 43, pp. 217-237.

Miller, D. G., 1982. "Estimation of Tracer Diffusion Coefficients of Ions in Aqueous Solution," UCRL-53319, Lawrence Livermore National Laboratory, Livermore, California.

Miller, I., R. Kossik and M. Cunnane, 1992. "A New Methodology for Repository Site Suitability Evaluation," Proceedings of the Third International Conference for High Level Radioactive Waste Management. Las Vegas, Nevada, April 12-16. 1992.

Minai, Y., G. R. Choppin, and D. H. Sisson, 1992. "Humic Material in Well Water from the Nevada Test Site," Radiochimica Acta, Vol. 56, pp. 195-199. (NNA. 930607.0076)

M\&O (Civilian Radioactive Waste Management System, Management and Operating Contractor [CRWMS M\&O]), 1993a. "A Comparative Application of the Repository Integration Program (RIP) to Total System Performance Assessment-1991," B00000000AA-09-00010-00, Las Vegas, Nevada.

M\&O (Civilian Radioactive Waste Management System, Management and Operating Contractor [CRWMS M\&O]), 1993b. "Repository Subsurface Layout Options and ESF Interface," B0000000-01717-5705-00009, Rev. 00, Las Vegas, Nevada, December .

M\&O (Civilian Radioactive Waste Management System, Management and Operating Contractor [CRWMS M\&O]), 1993c. "Characteristics Database: LWR Radiological PC Database," A00000000-02268-1200-20002, V1.0, VA-M04-20002.021.C014, Vienna, Virginia 
M\&O (Civilian Radioactive Waste Management System, Management and Operating Contractor [CRWMS M\&O]), 1994a. "Additional Sensitivity Analyses Extending the Total System Performance Assessment (TSPA)-1993 Results," B00000000-01717-020000122, Rev. 00, CRWMS M\&O, Las Vegas, Nevada.

M\&O (Civilian Radioactive Waste Management System, Management and Operating Contractor [CRWMS M\&O]), 1994b. "Initial Summary Report for Repository/Waste Package Advance Conceptual Design," B00000000-01717-5705-00015, Rev. 01, Las Vegas, Nevada.

M\&O (Civilian Radioactive Waste Management System, Management and Operating Contractor [CRWMS M\&O]), 1994c. "Generic Repository Layouts for Various Thermal Loadings," B00000000-01717-5705-00002, Rev. 00, Las Vegas, Nevada, August.

M\&O (Civilian Radioactive Waste Management System, Management \& Operating Contractor [CRWMS M\&O]), 1995a. "Thermomechanical Analyses," B00000000-01717-570500013, Rev. 00, Las Vegas, Nevada.

M\&O (Civilian Radioactive Waste Management System, Management and Operating Contractor [CRWMS M\&O]), 1995b. "Estimation of the Extent of the Disturbed Zone Around a Repository Drift Caused by Excavation and Thermal Loading," Las Vegas, Nevada, letter report transmitted to DOE via transmittal LV.RL.SEL.06/30-138 on June 30.

M\&O (Civilian Radioactive Waste Management System, Management and Operating Contractor [CRWMS M\&O]), 1995c. "Controlled Design Assumption Document," B0000000001717-4600-00032, Rev. 01, Las Vegas, Nevada, April 28.

M\&O (Civilian Radioactive Waste Management System, Management and Operating Contractor [CRWMS M\&O]), 1995d. "Systems Study of Options for Characterizing the Calico Hills Nonwelded Hydrogeologic Unit at Yucca Mountain, Nevada," B00000000-017175705-00021, Rev. 01., Las Vegas, Nevada.

M\&O (Civilian Radioactive Waste Management System, Management and Operating Contractor [CRWMS M\&O]), 1995e. "White Paper: Proposed Thermal Loading Strategy," A00000000-01717-1710-00001, Rev. 00, Las Vegas, Nevada.

M\&O (Civilian Radioactive Waste Management System, Management and Operating Contractor [CRWMS M\&O]), 1995f. "Emplacement Mode Evaluation Report," BCA00000001717-5705-00002, Rev. 00, Las Vegas, Nevada, May.

Montazer, P., and W. E. Wilson, 1984. "Conceptual Hydrologic Model of Flow in the Unsaturated Zone, Yucca Mountain, Nevada," Water-Resources Investigation Report 844345, U.S. Geological Survey, Lakewood, Colorado. 
Murphy, W..M., 1991. "Performance Assessment Perspectives with Reference to the Proposed Repository at Yucca Mountain, Nevada," Proceedings from the Technical Workshop on Near-Field Performance Assessment for High-Level Waste Held in Madrid. October 1517. 1990, SKB Technical Report 91-59, P. Sellen, M. Apted, and J. Gago (eds)., Swedish Nuclear Fuel and Waste Management Co., Stockholm, Sweden, pp. 11-22.

Murphy, W. M., 1993. "Geochemical Models for Gas-Water-Rock Interactions in a Proposed Nuclear Waste Repository at Yucca Mountain," Proceedings of the Topical Meeting. on Site Characterization and Model Validation. Focus '93. September 26-29. 1993. Las Vegas. Nevada, American Nuclear Society, Inc., La Grange Park, Illinois, pp. 115-121.

NAS, (National Research Council), 1983. "A Study of the Isolation System for Geological Disposal of Radio Active Waste," Board on Radioactive Waste Management - Waste Isolation Panel, National Academy Press, Washington, D.C.

NAS, (National Research Council), 1995. "Technical Bases for Yucca Mountain Standards," National Academy of Science, Washington, D.C.

Neall, F., P. Smith, T. Sumerling, and H. Umeki, 1995. "Putting HLW Performance Assessment Results in Perspective," NAGRA Bulletin, No. 25, pp 47-55.

Nelson, R. W., 1995. "Testing of Abstractions Used in Total System Performance Assessments," Proceedings of the Sixth Annual International Conference on High Level Radioactive Waste Management. Las Vegas, Nevada, pp. 255-257.

Nevada Bureau of Mines and Geology and the Nevada Department of Minerals, 1993. "Major Mines of Nevada," University of Nevada-Reno, MacKay School of Mines, Special Publication P-4.

Nichols, W. D., and J. P. Akers, 1985. "Water-Level Declines in the Amargosa Valley Area," Nye County, Nevada, 1962-84, USGS-WRI-85-4273.

Nitao, J. J., 1989. "V-TOUGH - An Enhanced Version of the TOUGH Code for the Thermal and Hydrologic Simulation of Large-Scale Problems in Nuclear Waste Isolation," UCID21954, Lawrence Livermore National Laboratory, Livermore, California.

Nitao, J. J., 1988. "Numerical Modeling of the Thermal and Hydrological Environment Around a Nuclear Waste Package Using the Effective Continum Approximation: Horizontal Emplacement," UCID-21444, Lawrence Livermore National Laboratory, Livermore, California. 
Nitsche H., R. C. Gatti, E. M. Standifer, S. C. Lee, A. Muller, T. Prussin, R. S. Deinhammer, H. Maurer, K. Becraft, S. Leung, and S. A. Carpenter, 1993. "Measured Solubilites and Speciations of Neptunium, Plutonium and Americium in a Typical Groundwater (J-13) from the Yucca Mountain Region," Milestone Report 3010-WBS 1.2.3.4.1.3.1. LA-12562MS UC-802, Los Alamos National Laboratory, Los Alamos, New Mexico, 127 pp.

Nitsche H., K. Roberts, T. Pussin, A. Muller, K. Becraft, D. Keeney, S. A. Carpenter, and R. C. - Gatti, 1994. "Measured Solubilities and Speciations from Oversaturation Experiments of Neptunium, Plutonium, and Americium in UE-25p \#.1 Well Water from the Yucca Mountain Region," Milestone Report 3329-WBS 1.2.3.4.1.3.1. LA-12563-MS UC-802, Los Alamos National Laboratory, Los Alamos, New Mexico, 95 pp.

Nitsche H., Roberts, K., Becraft, K., Pussin, T., Keeney, D., Carpenter, S. A., and Hobart, D. E., 1995, "Comparison of Solubilities and Speciations from Oversaturation and Undersaturation Experiments of Neptunium, Plutonium, and Americium in UE-25p \#1 Well Water at $60^{\circ} \mathrm{C}$ from the Yucca Mountain Region," Milestone Report 3412, WBS 1.2.3.4.1.3.1, LA-LBL-TIP-94-001, January, 1995, Lawrence Berkeley Laboratory, Berkeley, California, 85p.

NRC (U. S. Nuclear Regulatory Commission), 1981. Estimates of Internal Dose Equivalent to 22 Target Organs for Radionuclides Occurring in Routine Releases from Fuel-cycle Facilities, Vol. III., Dunning D. Killough G., Bernard S., Pleasant J., and Walsh P., NUREG/CR-150 Vol. 3, (ORNL/GUREG/TM-190/V3, US NRG, Washington, D.C.

NRC (U. S. Nuclear Regulatory Commission), 1993. "Disposal of High-Level Radioactive Wastes in Geologic Repositories," Part 60, Title 10, Chapter 1, Code of Federal Regulations, Washington, D.C.

NRC (U. S. Nuclear Regulatory Commission), 1995. "Iterative Performance Assessment: Phase II", Draft report. Washington, D.C.

Nuttall, H. E., R. Jain, and Y. Fertelli, 1991. "Radiocolloid Transport in Saturated and Unsaturated Fractures," Proceedings of the Second Annual International Conference on High Level Radioactive Waste Management, Las Vegas, Nevada. April 28-May 3, Vol. 1, pp. 189-196. (NNA.930625.0031)

Ogard, A. E., and J. F. Kerrisk, 1984. "Groundwater Chemistry Along Flow Paths Between a Proposed Repository Site and the Accessible Environment," LA-10188-MS, UC-70, Los Alamos National Laboratory, Los Alamos, New Mexico.

Ogard, A. E., 1987. "Importance of Radionuclide Transport by Particulates Entrained in Flowing Groundwaters," Groundwater Chemistry at Yucca Mountain, Nevada, and Vicinity," J. F. Kerrisk, LA-10929-MS, Los Alamos National Laboratory, Los Alamos, New Mexico, pp. 114-118. (NNA.83067.0078) 
Ortiz, T. S.,.R. L. Williams, F. B. Nimick, B. C. Whittet, and D. L. South, 1985. "A ThreeDimensional Model of Reference Thermal/Mechanical and Hydrological Stratigraphy at Yucca Mountain, Southern Nevada," SAND84-1076, Sandia National Laboratories, Albuquerque, New Mexico.

Pei-Lin., T., M. D. Siegel, C. D. Updegraf, K. K. Wahi, and R. V. Guzowski, 1985. "Repository Site Data Report for Unsatruated Tuff, Yucca Mountain, Nevada," NUREG/CR-4410, U.S. Nuclear Regulatory Commission, Washington, D.C. (HQS.880517.1853)

Penrose, W. R., W. L. Polzer, E. H. Essington, D. M. Nelson, and K. A. Orlandini, 1990. "Mobility of Plutonium and Americium Through a Shallow Aquifer in a Semiarid Region," Environmental Science_and Technolegy, Vol. 24, pp. 228-234. (NNA.830607.0058)

Pereira D., O. Nobre, and E. Almeida, 1993. "Atmospheric Corrosion of Mild Steel: What Can We Do?," Progress in the Understanding and Prevention of Corrosion, J. M. Costa and A. D. Mercer (eds.), Vol. 1, pp. 66-75.

Peters, C. A., Yang, I. C., Higgins, J. D., and Burger, P. A., 1992. "A Preliminary Study of the Chemistry of Pore Water Extracted from Tuff by One-Dimensional Compression," Proceedings of the Seventh International Symposium on Water-Rock Interaction. Vol. 1, pp. 741-745, Y. K. Kharaka and A. Maest (eds.), U.S. Geological Survey, Menlo Park, California.

Phipps, P. B., and D. W. Rice, 1979. "The Role of Water in Atmospheric Corrosion," Corrosion Chemistry, G. R. Brubaker, and P. B. Phipps (eds.), ACS Symposium Series 89, American Chemical Society, pp. 235-261.

Pigford, T. H., 1993. "The Engineered Barrier System: Performance Issues," Scientific Basis for Nuclear Waste Management XVI. Materials Research Society Symposium Proceedings, Vol. 294, pp. 657-662, C.G. Interrante and R.T. Pabalan (eds.), Materials Research Society, Pittsburgh, Pennsylvania.

Pourbaix, M., 1966. "Atlas of Electrochemical Equilibrium in Aqueous Solutions," Pergamon Press, 644 pp.

Prowell, G., 1994. Personal communication to J. H. Lee, December 28.

Pruess, K., 1987. "TOUGH User's Guide," NUREG/CR-4645, Nuclear Regulatory Commission, Washington, D.C.

Pruess, K., 1991. "TOUGH2 - A General -Purpose Numerical Simulator for Multiphase Fluid and Heat Flow," Lawrence Berekely Laboratory, LBL-29400. 
Pruess, K., and Y. W. Tsang, 1993. "Modeling of Strongly Heat-Driven Flow Processes at a Potential High-Level Nuclear Waste Repository at Yucca Mountain," Proceedings of the Fourth International High Level Radioactive Waste Management Conference Las Vegas. Nevada, April 26-30.

Pruess, K., and Y. W. Tsang, 1994. "Thermal Modeling for a Potential High-Level Nuclear Waste Repository at Yucca Mountain, Nevada," LBL-35381, Lawrence Berkeley Laboratory, Berkeley, California.

Pruess, K., Y. W. Tsang, and J. S. Y Wang, 1985. "Modeling of Strongly Heat-Driven Flow in Partially Saturated Fractured Porous Media," Memoirs, International Association of Hydrogeologists, XXVII, pp. 486-497.

Pryor, M. J., and M. Cohen, 1953. "The Inhibition of the Corrosion of Iron by Some Anodic Inhibitors," Journal of the Electrochemical Society, Vol. 100, No. 5, pp. 203-215.

Pyke, R., and M. Cohen, 1948. "Rate of Breakdown and Mechanism of Nitrite Inhibition of Steel Corrosion," Transaction of Electrochemical Society, Vol. 93, No. 3, pp. 63-78.

Ramsay, J. D., 1988. "The Role of Colloids in the Release of Radionuclides from Nuclear Waste", Radiochimica Acta, Vol. 44/45, pp. 165-170. (NNA.930701.0050)

Reeves, M., N. A. Baker, and J. O Duguid, 1994." "Review and Selection of Unsaturated Flow Models," B00000000-01425-2200-00001, Rev. 00, CRWMS M\&O, Las Vegas, Nevada.

Robinson, B. A., A. V. Wolfsberg, G. A.Zyvoloski, and C. W. Gable, 1995. "An Unsaturated Zone Flow and Transport Model of Yucca Mountain," Draft Report, Milestone 3468, Los Alamos National Laboratory, Los Alamos, New Mexico.

Ruijini, G., S. C. Srivastava, and M. B. Ives, 1989. "Pitting Corrosion Behavior of UNS No. 8904 Stainless Steel in a Chloride/Sulfate Solution," Corrosion, Vol. 45, No. 11, pp. 874-882.

Rush, F. E., 1970. "Regional Ground-Water Systems in the Nevada Test Site Area, Nye, Lincoln, and Clark Counties, Nevada," Department of Conservation and Natural Resources Water Resources Reconnaissance Report 54, State of Nevada, 25 pp

Rush, F. B., B. R. Scott, A. S. Van Denburgh, and B. J. Vasey, 1971. "State of Nevada Water Resources and Interbasin Flows," Nevada Division Water Research Map, 1:750,000, State of Nevada.

Ryder, E. E., 1993. "Comparison of Predicted Far-field Temperatures for Discrete and Smeared Heat Sources", Proceedings of the Fourth International High-Level Radioactive Waste Management Conference, Las Vegas, Nevada. 
SAIC (Science Applications International Incorporated), 1986. "Preliminary Socioeconomic Profile of Nye County, Nevada: Community Services," DOE/NV/10270-3, Las Vegas, Nevada.

Santanam, L., S. Raghavan, and B. A. Chin, 1992. "Zircaloy Cladding Rupture During Repository Storage," Nuclear Technology, Vol. 97, pp. 316-322.

Sassani, D. C., 1992. "Petrologic and Thermodynamic Investigation of the Aqueous Transport of Platinum-Group Elements During Alteration of Mafic Intrusive Rocks," Ph.D. Dissertation, Washington University, St. Louis, Missouri, University Microfilms, 1100 p.

Saterlie, S. F., 1994. "Integration of Thermal Calculations," TRW IOC LV.SEA.SFS.12/94-134, TRW Environmental Safety Systems, Las Vegas, Nevada.

Scanlon, B. R., 1995. "Review of Unsaturated Zone Studies in Arid Sites and Implications for Contaminant Transport," Presented to Nuclear Waste Technical Review Board, San Francisco, California, June.

Schenker, A. R., D. C. Guerin, T. H. Robey, C. A. Rautman, and R. W. Barnard, 1995. "Stochastic Hydrogeologic Units and Hydrogeologic Properties Development for Total System Performance Assessments," SAND94-0244, Sandia National Laboratories, Albuquerque, New Mexico.

Scott, R. B., and J. Bonk, 1984. "Preliminary Geologic Map of Yucca Mountain with Geologic Sections, Nye County, Nevada," Open-file Report 84-494, U.S. Geological Survey, Las Vegas, Nevada.

Siegel, M. D., D. B. Ward, W. C. Cheng, C. Bryant, C. S. Chocas, and C. G. Reynolds, 1993. "Preliminary Characterization of Materials for Reactive Transport Model Validation Experiment," High Level Radioactive Waste Management. Proceedings of the Fourth Annual International Conference, Las Vegas. Nevada. April 26-30, American Nuclear Society, La Grange Park, Illinois. (NNA.870519.0076)

Sinnock, S., 1995. "The Many Barriers of Yucca Mountain," Proceedings of the Sixth International High Level Radioactive Waste Management Conference, Las Vegas. Nevada, pp. 281-283.

SNL (Sandia National Laboratories), 1987. "Nevada Nuclear Waste Storage Investigations Project, Site Characterization Plan Conceptual Design Report," SAND84-2641, Sandia National Laboratories, Albuquerque, New Mexico, September.

Southwell, C. R., and A. L. Alexander, 1970. "Corrosion of Metals in Tropical Waters. Structural Ferrous Metals," Materials Protection, pp. 14-23, January. 
Southwell, C. R., and J. D. Bultman, 1982. "Atmospheric Corrosion Testing in the Tropics," Atmospheric Corrosion, W. H. Ailor (ed.), Wiley-Interscience, pp. 943-967.

Southwell, C. R., J. D. Bultman, and A. L. Alexander, 1976. "Corrosion of Metals in Tropical Environments - Final Report of 16-Year Exposures," Materials Performance, pp. 9-26, July.

Stahl, D., 1993. "Waste Package Corrosion Inputs," CRWMS M\&O Interoffice Correspondence, IOC LV.WP.DS.06/93.107, June 21.

Stahl, D., 1995. "Demonstrating Compliance with the Controlled Release Requirements," Presentation at the DOE/NRC Technical Exchange on EBS Release Rates and Waste Form Testing, June 28-29, Las Vegas, Nevada.

Statistical Sciences, 1993. "A Gentle Introduction to S-PLUS for Windows, Version 3.2," StatSci, a Division of MathSoft, Inc., Seattle, Washington.

Steward, S. A., and W. J. Gray, 1994. "Comparison of Uranium Dissolution Rates from Spent Fuel and Uranium Dioxide," Proceedings of the Fifth International Conference on HighLevel Radioactive Waste Management. Las Vegas, Nevada. May 22-26. 1994, American Nuclear Society, La Grange Park, Illinois, and American Society of Civil Engineers, New York, New York, Vol. 4, pp. 2602-2608.

Stumm, W., and Morgan, J. J., 1981, Aquatic Chemistry, 2nd edition, John Wiley \& Sons Inc., New York, 780 p.

Strum, M. J., H. Weiss, J. C. Farmer, and D. B. Bullen, 1988. "Survey of Degradation Modes of Candidate Materials for High-Level Radioactive-Waste Disposal Containers. Vol. 7: Weldability of Austenitic Alloys," UCID-21362, Lawrence Livermore National Laboratory, Livermore, CA, June.

Strutt, J. E., J. R. Nichols, and B. Barbier, 1985. "The Prediction of Corrosion by Statistical Analysis of Corrosion Profiles," Corrosion Science, Vol. 25, pp. 305-315.

Szklarska-Smialowska, Z., 1986. "Pitting Corrosion of Metals", National Association of Corrosion Engineers, Houston, Texas.

Taylor, P., R. J. Lemire, and D. D. Wood, 1993. "The Influence of Moisture on Air Oxidation of $\mathrm{UO}_{2}$ : Calculations and Observations," Nuclear Technology, Vol. 104, pp. 164-170.

Taylor, P., D. D. Wood, A. M. Duclos, and D. G. Owen, 1989. "Formation of Uranium Trioxide Hydrates on $\mathrm{UO}_{2}$ Fuel in Air-Steam Mixtures Near $200^{\circ} \mathrm{C}$, " Journal of Nuclear Materials, Vol. 168, pp. 70-75. 
Thompson, J. L., 1989. "Actinide Behavior on Crushed Rock Columns," Journal of Radioanalytical and Nuclear Chemistry, Vol. 130, No. 2, pp. 353-364. (NNA.920131.0401)

Townsend, H. E., and J. C. Zoccola, 1982. "Eight-Year Atmospheric Corrosion Performance of Weathering Steel in Industrial, Rural and Marine Environments," Atmospheric Corrosion of Metals, ASTM STP 767, S.W. Dean, Jr. and E.C. Rhea (eds.), American Society for Testing and Materials, pp. 45-59.

Tri, N. Q., V. D. Huy, L. V. Cuong, and P. Th. San, 1993. "Atmospheric Corrosion Testing in Vietnam," Progress in the Understanding and Prevention of Corrosion, J.M. Costa and A.D. Mercer (eds.), Vol. 1, pp. 105-114.

Triay, I. R., D. E. Hobart, A. J. Mitchell, T. W. Newton, M. A. Ott, P. D. Palmer, R. S. Rundberg, and J. L. Thompson, 1991. "Size Determinations of Plutonium Colloids Using Autocorrelation Photon Spectroscopy," Radiochimica Acta. Vol. 52/53, pp. 127131.(NNA.930607.0060)

Triay, I. R., C.R. Cotter, M.H. Huddleston, D.E. Leonard, S.C. Weaver, S.J. Chipera, D.L. Bish, A. Meijer, and J.A. Canepa, 1995a. "Neptunium Transport through Yucca Mountain Tuffs I: Batch Sorption Results," Milestone \#3349, Los Alamos National Laboratory, Los Alamos, New Mexico.

Triay, I. R., C.R. Cotter, S.M. Kraus, M.H. Huddleston, S.J. Chipera, and D.L. Bish, 1995b. "Report on Radionuclide Sorption in Yucca Mountain Tuffs with J-13 Well Water: Neptunium, Uranium and Plutonium," Milestone \# 3338, Los Alamos National Laboratory, Los Alamos, New Mexico.

Triay, I. R., A. Furlano, S.C. Weaver, S.J. Chipera, and D.L. Bish, 1995c. "Report on the Study of Kinetic Effects using crushed Tuff Columns: Neptunium in Sodium Bicarbonate Waters," Milestone \# 3041, Los Alamos National Laboratory, Los Alamos, New Mexico.

- Triay, I., Simmons, A., Levy, S., Nelson, S., Nuttal, H., Robinson, B., Steinkampf, W., and Viani, B., 1995a, "Colloid-Facilitated Radionuclide Transport at Yucca Mountain", Los Alamos National Laboratory Report LA-12779-MS, UC-802, April, 1995.

Triay, I., Degueldre, C., Wistrom, A., Cotter, C., and Lemons, W., 1995b, "Progress Report on Colloid-Facilitated Transport at Yucca Mountain," Milestone Report 3383, Draft \#2, (LA00000000128.001).

Tsang, Y. W., and K. Pruess, 1989. "Preliminary Studies of Gas Phase Flow Effects and Moisture Migration at Yucca Mountain, Nevada," LBL-28819, Lawrence Berkeley Laboratory, Berkeley, California. 
Tsang, Y. W., and K. Pruess, 1990. "Further Modeling Studies of Gas Phase Flow Effects and Moisture Migration at Yucca Mountain, Nevada," LB.L-29127, Lawrence Berkeley Laboratory, Berkeley, California.

van Genuchten, M. Th., 1980. "A Closed-Form Equation for Predicting the Hydraulic Conductivity of Unsaturated Soils," Soil Science Society American Journal, Vol. 44, pp. 892-898.

van Genuchten, M. Th., and D. R. Nielsen, 1985. "On Describing and Predicting the Hydraulic Properties of Unsaturated Soils," Annales Geophysicae, Vol. 3, No. 5, pp. 615-628.

Van Konynenburg, R. A., C. Smith, H. Culham, and C. Otto, Jr., 1986. "Behavior of Carbon14 in Waste Packages for Spent Fuel in a Repository in Tuff," Scientific Basis for Nuclear Waste Management VIII, J. Jantzen, J. Stone, and R. Ewing (eds.), pp. 405-412.

Van Konynenburg, R. A., C. F. Smith, H. W. Culham, and H. D. Smith, 1987. "Carbon-14 in Waste Packages for Spent Fuel in a Tuff Repository," Scientific Basis for Nuclear Waste Management X, J.K. Bates and W.B. Seefeld, (eds.), Vol. 84, Materials Research Society, Pittsburgh, Pennsylvania.

Van Konynenburg, R. A., R. D. McCright, A. K. Roy, and D. A. Jones, 1995. "Engineered Materials Characterization Report for the Yucca Mountain Site Characterization Project: Volume 1. Introduction, History, and Current Candidates," UCRL-ID-119564, Vol. 1, Lawrence Livermore National Laboratory, Livermore,-California, August.

Van Konynenburg, R. A., 1995. Personal communication to J.H. Lee, August 21.

Vernon, W. H., 1933. "The Role of the Corrosion Product in the Atmospheric Corrosion of Iron," Transactions of the Electrochemical Society, Vol. 64, pp. 31-41.

Vilks, P., 1994. "The Role of Colloids and Suspended Particles in Radionuclide Transport in the Canadian Concept for Nuclear Fuel Waste Disposal," AECL-10280, Whiteshell Laboratory, Atomic Energy of Canada, Ltd., Pinawa, Manitoba.

Vinsome, P. K., and J. Westerveld, 1980. "A Simple Method for Predicting Cap and Base Rock Heat Losses in Thermal Reservoir Simulators," Journal of Canadian Petroleum Technology, pp. 87-90, July-September.

Waddel, R. K., 1982. "Two-Dimensional, Steady-State Model of Ground-Water Flow, Nevada Test Site and Vicinity," USGS-WRI-82-4085, U.S. Geological Survey, 72 pp.

Waddel, R. K, J. H. Robison, and R. K. Blankennagel, 1984. "Hydrology of Yucca Mountain and Vicinity," Nevada-California--Investigative Results Through Mid-1983, USGS-WRI84-4267, U.S. Geological Survey. 
Walker, G. E., and T. E. Eakin, 1963. "Geology and Ground Water of Amargosa Desert," Nevada-California, Department of Conservation and Natural Resources, Ground-Water Resources Reconnaissance Series Report 14, State of Nevada, Carson City, Nevada.

Wan, J., and J. L. Wilson, 1994, "Colloid Transport in Unsaturated Porous Media," Water Resources Research, v. 30(4), pp. 857-864.

Wang, J. S., and T. N. Narasimhan, 1993. "Processes, Mechanisms, Parameters and Modeling Approaches for Partially Saturated Flow in Soil and Rock Media," SAND88-7054, Sandia National Laboratories, Albuquerque, New Mexico.

Wanner, H., and Forest, I., 1992, "Chemical Thermodynamics of Uranium Vol. 1", NorthHolland Elsevier Science Publishers, The Netherlands.

Was, G. S., R. Christensen, C. Park, and R. W. Smith, 1985. "Statistical Patterns of Fuel Failure in Stainless Steel Clad Light Water Reactor Fuel Rods," Nuclear Technology, Vol. 71, pp. 445-457.

Wasywich, K. M., W. H. Hocking, D. W. Shoesmith, and P. Taylor, 1993. "Differences in Oxidation Behavior of Used CANDU Fuel During Prolonged Storage in MoistureSaturated Air and Dry Air at $150{ }^{\circ} \mathrm{C}$," Nuclear Technology, Vol. 104, pp. 309-329.

Wei, F. I., 1991. "Atmospheric Corrosion of Carbon Steels and Weathering Steels in Taiwan," British Corrosion Journal, Vol. 26, No. 3, pp. 209-214.

West, K. A., 1988. "Nevada Nuclear Waste Storage Investigations Exploratory Shaft Facility Fluids and Materials Evaluation," LA-11398-MS, November 1988.

Westinghouse Electrical Co., 1982. "Conceptual Waste Package Designs for Disposal of Nuclear Waste in Tuff," Report AESD-TME-3138, Appendix B, pp. 353-380, September.

Wilson, C. N., 1987, "Results from Cycles 1 and 2 of NNWSI Series 2 Dissolution Tests", HEDL-TME85-22, May, 1985.

Wilson, C. N., 1990, "Results from the NNWSI Series 3 Spent Fuel Dissolution Tests", Pacific Northwest Laboratory Report PNL-7170, June 1990.

Wilson, M. L., J. H. Gauthier, R. W. Barnard, G. E. Barr, H. A. Dockery, E. Dunn, R. R. Eaton, D. C. Guerin, N. Lu, M. J. Martinez, R. Nilson, C. A. Rautman, T. H. Robey, B. Ross, E. E. Ryder, A. R. Schenker, S. A. Shannon, L. H. Skinner, W. G. Halsey, J. Gansemer, L. C. Lewis, A. D. Lamont, I. R. Triay, A. Meijer, and D. E. Morris, 1994. "Total System Performance Assessment for Yucca Mountain - SNL Second Iteration (TSPA-1993)," SAND93-2675, Sandia National Laboratories, Albuquerque, New Mexico. 
Winograd, I. J., and I. Friedman, 1972. "Deuterium as a Tracer of Regional Ground-Water Flow, Southern Great Basin, Nevada-California," Geological Society America Bulletin, Vol. 83, No. 12, pp. 3691-3708.

Winograd, I. J., and W. Thordarson, 1975. "Hydrogeologic and Hydrochemical Framework, South-Central Great Basin, Nevada-California, with Special Reference to the Nevada Test Site," U.S. Geological Survey Professional Paper 712-C, U.S. Government Printing Office, Washington, D.C., pp. Cl-C126.

Wittwer, C., G. Chen, G. S. Bodvarsson, M. Chornack, A. Flint, L. Flint, E. Kwicklis, and R. Spengler, 1995. "Development of the LBL-USGS Three-Dimensional Site-Scale Groundwater Flow Model of Yucca Mountain, Nevada," LBL-37356/UC-814, Lawrence Berkeley Laboratory, Berkeley, California.

Xiang, Y., S. Mishra, and B. Dunlap, 1995. Hydrologic Sensitivity Analyses for the Unsaturated Zone at Yucca Mountain. Nevada, B00000000-01717-2200-00099, Rev. 00, Civilian Radioactive Waste Management System, Management and Operating Contractor, Las Vegas, Nevada.

Yang, I. C., A. K. Turner, T. M. Sayre, and P. Montazer, 1988. "Triaxial-Compression Extraction of Pore Water from Unsaturated Tuff, Yucca Mountain, Nevada," USGS Water-Resources Investigations Report 88-4189, U.S. Geological Survey.

Yang, I. C., G. S. Davis, and T. M. Sayre, 1990. "Comparison of Pore-Water Extraction by Triaxial Compression and High-speed Centrifugation Methods," Proceedings of Conference on Minimizing Risk to the Hydrology Environment," American Institute of Hydrology, pp. 250-259.

Younker, J. L., W. B. Andrews, G. A. Fasano, C. C. Herrington, S. R. Mattson, R. C. Murray, L. B. Ballou, M. A. Revelli, A. R. Ducharme, L. E. Shephard, W. W. Dudley, D. T. Hoxie, R. J. Herbst, E. A. Patera, B. R. Judd, J. A. Docka, and L. D. Rickertsen, 1992. "Report of Early Site Suitability Evaluation of the Potential Repository Site at Yucca Mountain, Nevada," SAIC-91/8000, Technical and Nanagement Support Services, Science Applications International Corporation, Las Vegas, NV.

Younker, J. L., 1995. :"Waste Containment and Isolation Strategy for the Yucca Mountain Site," Presentation at the Nuclear Waste Technical Review Board Meeting, October 1718, Arlington, Virginia.

Zyvoloski, G., Z. Dash, and S. Kelkar, 1995. "FEHM 1.0, Finite Element Heat and Mass Transfer Code," LA-12062-MS, Rev.1, Los Alamos National Laboratory, Los Alamos, New Mexico. 


\section{CODES AND REGULATIONS}

40 CFR Part 191, "Environmental Standards for the Management and Disposal of Spent Nuclear Fuel, High-level and Transuranic Radioactive Wastes," Federal Register, Vol. 50, No. 182, September 19, 1985, pp. 38066-38089. 


\section{ACRONYM LIST}

AE

APD

AECL

AML

BWR

CAM

CCDF

CDA

CFR

CIDP

$\mathrm{CHn}$

$\mathrm{CHv}$

$\mathrm{CHz}$

CRM

1-D

2-D

3-D

DF

DHLW

DOE

EBS

ECM

EPA

EPRI

ESF

FEHM

FEP

GAI

GWd

HLW

IAEA

ICRP

LBL

LANL

LLNL
Accessible Environment

Areal Power Density

Atomic Energy of Canada Limited

Areal Mass Loading

Boiling Water Reactor

Corrosion Allowance Material

Complementary Cumulative Distribution Function

Controlled Design Assumption

Code of Federal Regulations

Center In Drift On Pedestal

Calico Hills nonwelded

Calico Hills nonwelded-vitric (also Chnv)

Calico Hills nonwelded-zeolitic (also Chnz)

Corrision Resistant Material

One-dimensional

Two-dimensional

Three-dimensional

Degree of Freedom

Defense High-Level Waste

Department of Energy

Engineered Barrier System

Equivalent Continuum Model

Environmental Protection Agency

Electric Power Research Institute

Exploratory Studies (Shaft) Facility

Finite Element Heat and Mass Transfer

Features, Events, and Processes

Golder Associates, Inc.

Giga Watt days

High-Level Waste

International Atomic Energy Agency

International Commission on Radiation Protection

Lawrence Berkeley Laboratory

Los Alamos National Laboratory

Lawrence Livermore National Laboratory 


$\begin{array}{ll}\text { MCRM } & \text { Moderately Corrosion Resistant Material } \\ \text { MIC } & \text { Microbiologically Influenced Corrosion } \\ \text { M\&O } & \text { Management \& Operating Contractor } \\ \text { MGDS } & \text { Mined Geologic Disposal System } \\ \text { MPC } & \text { Multi-Purpose Canister } \\ \text { MTHM } & \text { Metric Tons Heavy Metal } \\ \text { MTU } & \text { Metric Tons of Uranium } \\ \text { MWd } & \text { Mega Watt days } \\ \text { NAGRA } & \text { Swiss National Cooperative for the Disposal of Radioactive Waste } \\ \text { NAS } & \text { National Academy of Science } \\ \text { NRC } & \text { Nuclear Regulatory Commission } \\ \text { OCRWM } & \text { Office of Civilian Radioactive Waste Management } \\ \text { PNC } & \text { Power Reactor and Nuclear Fuel Development Corporation (Japan) } \\ \text { PNL } & \text { Pacific Northwest Laboratory } \\ \text { PPn } & \text { Prow Pass nonwelded } \\ \text { PTn } & \text { Paintbrush nonwelded } \\ \text { PWR } & \text { Pressurized Water Reactor } \\ \text { RH } & \text { Relative Humidity } \\ \text { RIP } & \text { Repository Integration Program } \\ \text { RSS } & \text { Residual Sum of Squares } \\ \text { SKB } & \text { Svensk Karnbranslehantering AB (Sweden) } \\ \text { SNF } & \text { Spent Nuclear Fuel } \\ \text { SNL } & \text { Sandia National Laboratory } \\ \text { SZ } & \text { Saturated Zone } \\ \text { SolWoG } & \text { Solubility Working Group } \\ \text { T } & \text { Temperature } \\ \text { TCw } & \text { Tiva Canyon welded } \\ \text { TSA } & \text { Total System Analyzer } \\ \text { TSPA } & \text { Total System Performance Assessment } \\ \text { TSv } & \text { Topopah Spring welded-vitrophyre } \\ \text { TSW } & \text { Topopah Spring welded } \\ \text { TVO } & \text { Teollisuuden Voima Oy (Finland) } \\ \text { USGS } & \text { U.S. Geological Survey } \\ \text { UZ } & \text { Unsaturated Zone } \\ \text { VG } & \text { Van Genuchten } \\ \text { WIPP } & \text { Waste Isolation Pilot Plant } \\ \text { WP } & \text { Waste Package } \\ \text { Yr } & \text { Year } \\ \end{array}$


